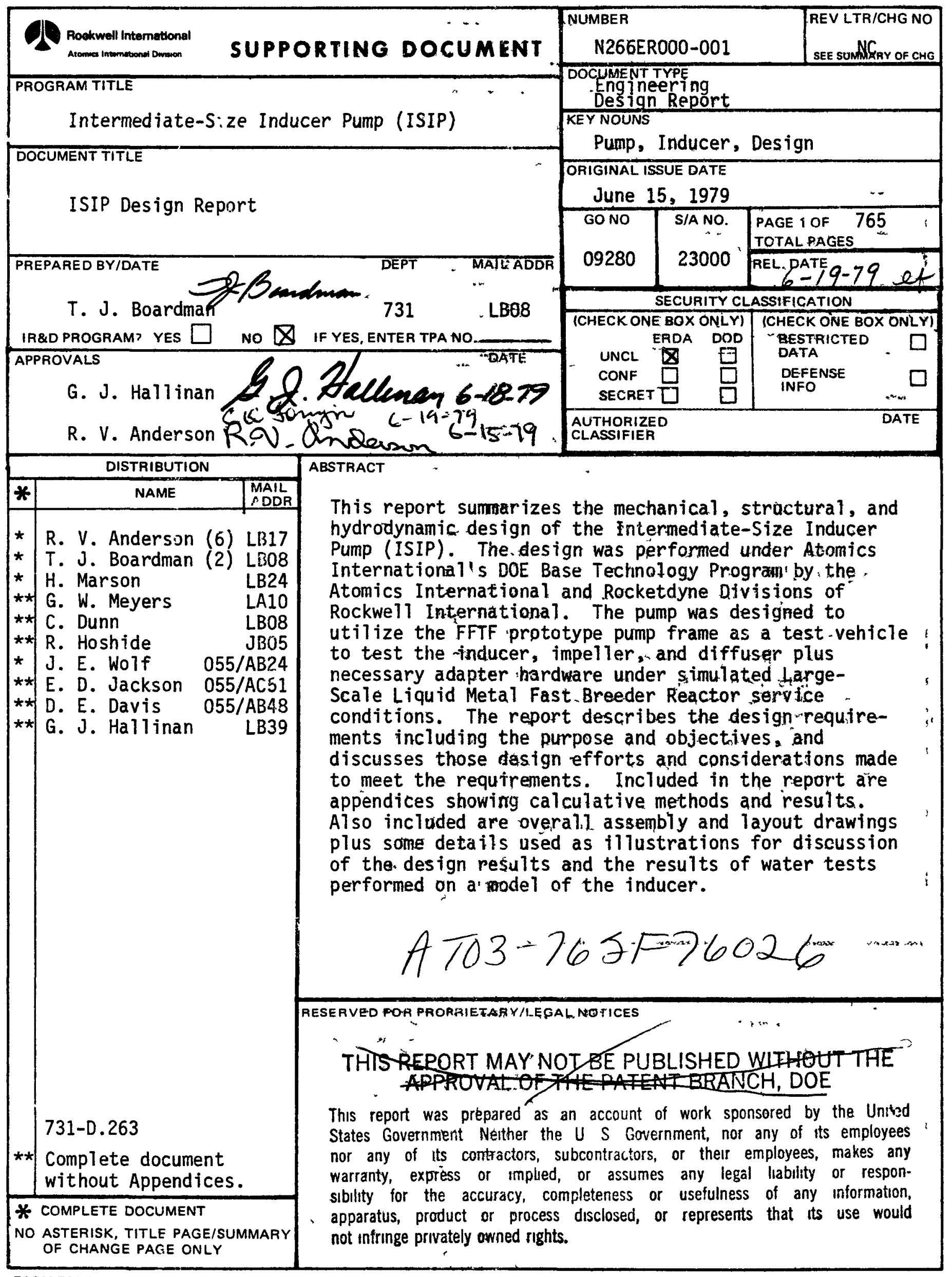




\section{DISCLAIMER}

This report was prepared as an account of work sponsored by an agency of the United States Government. Neither the United States Government nor any agency Thereof, nor any of their employees, makes any warranty, express or implied, or assumes any legal liability or responsibility for the accuracy, completeness, or usefulness of any information, apparatus, product, or process disclosed, or represents that its use would not infringe privately owned rights. Reference herein to any specific commercial product, process, or service by trade name, trademark, manufacturer, or otherwise does not necessarily constitute or imply its endorsement, recommendation, or favoring by the United States Government or any agency thereof. The views and opinions of authors expressed herein do not necessarily state or reflect those of the United States Government or any agency thereof. 


\section{DISCLAIMER}

Portions of this document may be illegible in electronic image products. Images are produced from the best available original document. 
1.1 Purpose.............................. 6

1.2 Objectives.............................. 6

1.3 Technical Background....................... 7

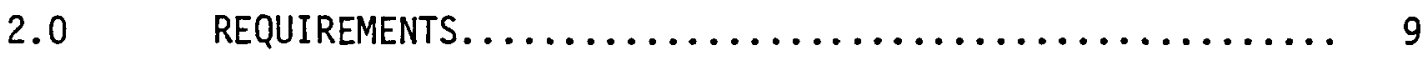

2.1 General................................. 9

2.2 Specifications.......................... 9

2.3 Hydrodynamic Design Requirements.............. 10

2.4 Structural Design Requirements................ 10

2.5 Mechanical Design Requirements................ 12

2.6 Materials and Processes.................... 15

P.0 PRESENT DESIGN.............................. 17

3.1 Description........................... 17

3.2 Mechanical Design....................... 20

3.2.1 Prototype Pump Part Modifications...... 20

3.2.2 Impeller....................... 22

3.2.3 Inducer....................... 25

3.2.4 Diffuser-Asșembiy.................. 27

3.2.5 Tie-Bolt and Shaft Adapter Nut........ 29

3.2.6 Piston Ring GTand................. 31

3.2.7 Rotordynamics.................... 34

3.2.8 Vibration......................... 34

3.2.9 Clearances and Tolerance Stackup....... 35 
CONTENTS (continued)

3.2.9.1 Axial Clearances........... 35

3.2.9.2 Radial Clearances.......... 36

3.3 Hydrodynamic Design................... 39

3.3.1 Impeller..................... 43

3.3 .2 Inducer....................... 48

3.3.3 Impeller/Inducer Assembly........... 51

3.3 .4 Diffuser..................... 52

3.4 Structural Design..................... 53

3.4.1 Steady-State Analysis............ 53

3.4.2 Thermal Transient Analysis.......... 54

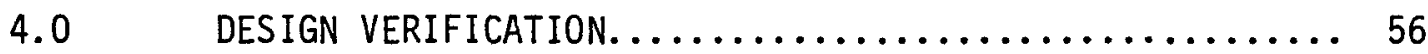

4.1 Reviews............................ 56

4.2 Feature Tests..................... 57

4.3 Assembiy Checks..................... 59

$5.0 \quad$ TEST PLANS............................. 60

$6.0 \quad$ REFERENCES $\ldots \ldots \ldots \ldots \ldots \ldots \ldots \ldots \ldots \ldots \ldots \ldots \ldots \ldots \ldots$ 
CONTENTS (continued)

\section{APPENDICES}

\section{Appendix}

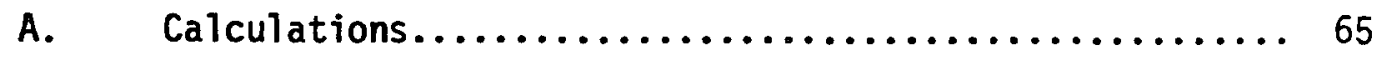

B. Design Specification - Pump, Sodium, Inducer, Intermediate-Size (ISIP)(Impeller/Inducer/Diffuser Retrofit)............................... 84

C. Recirculating Flow Analyses of Intermediate-Size Inducer Pump.

D. Customer Design Review Intermediate-Size Inducer Pump

E. Rotordynamics of the Intermediate-Size Inducer Pump (ISIP)............................. 192

F. Radial Tolerance Stackup - ISIP................. 206

G. Hydrodynamic Design Report................... 243

H. Steady-State Structural Analysis (Pump Internals)..... 276

I. Intermediate-Size Inducer Pump - Structural Analys is and Transient Deformation Studies......... 365

J. Transient Thermal Analysis of ISIP.......................... 499

K. Verification of Thermal Model for ISIP (Inter-

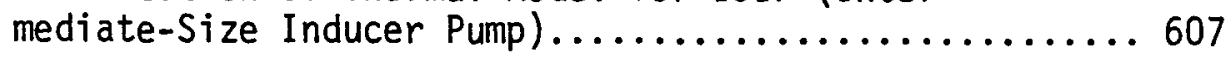

L. Model Inducer Water Tunnel Test Report.............. 685

M. Model Inducer Water Tunnel Test Report - Eccentric

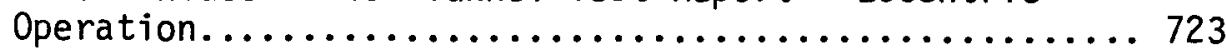

\section{TABLES}

$\underline{\text { Table }}$

1. Hydrodynamic Design Requirements............... 11 


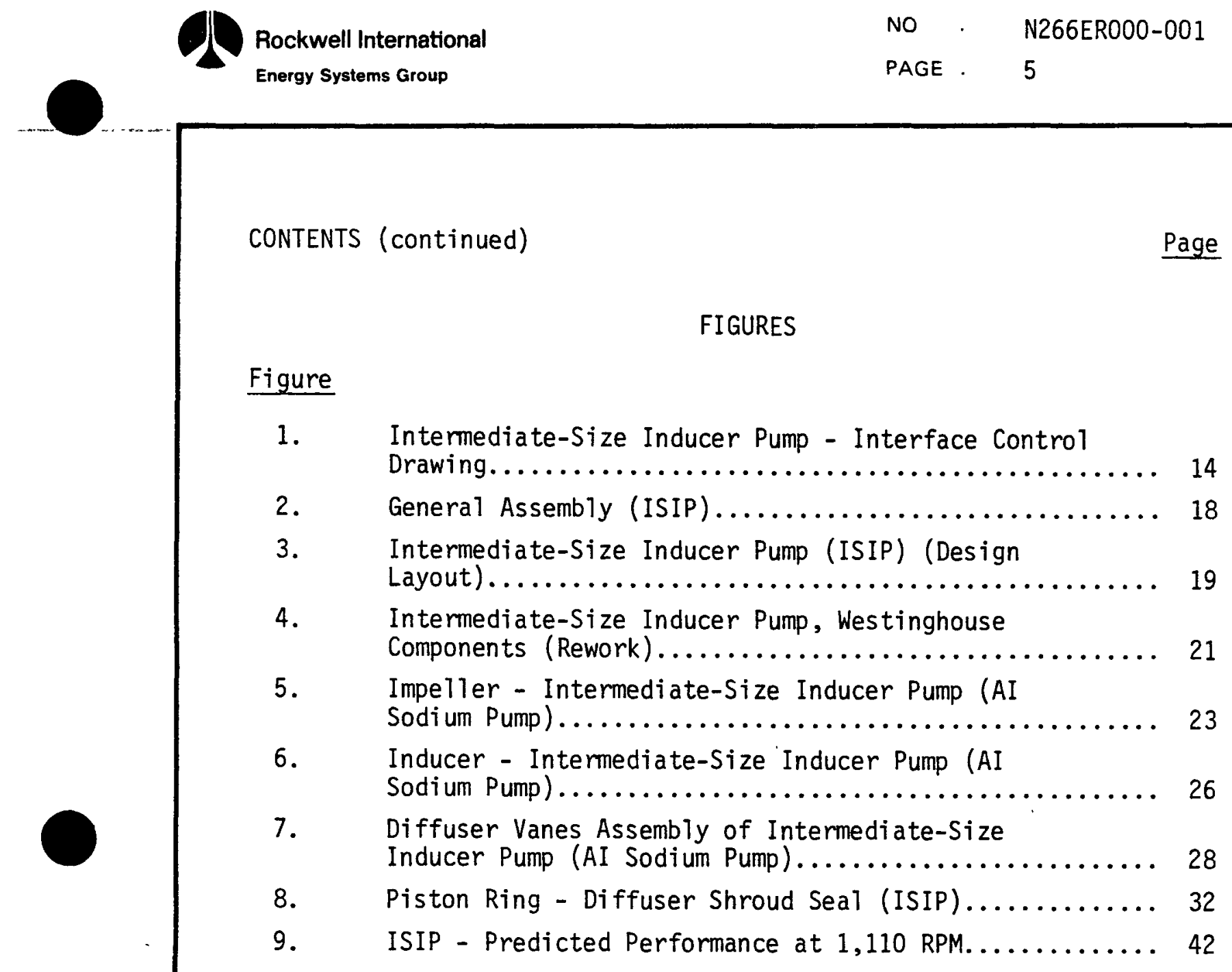




\subsection{INTRODUCTION}

\subsection{PURPOSE}

The Intermediate Size Inducer Pump (ISIP) project was initiated to demonstrate, by test, the applicability of axial flow inducers to centrifugal pumps for primary coolant service in large sodium-cooled reactors. This project is the second step in the DOE inducer pump development program which was started at Atomics International with a smaller, "subscale" inducer pump which was designed, fabricated, and tested in water, and is now undergoing endurance tests in sodium. (1) Achievement of program objectives is based on utilizing the combined engineering capabilities of Atomics International (AI), a division of Energy Systems Group (ESG), where there has been considerable sodium, reactor, and ASME Code design experience, and of the Rocketdyne Division which has developed the hydrodynamic technology needed to produce inducers that can operate at low suction pressure (high suction specific speed) while meeting Liquid Metal Fast Breeder Reactor (LMFBR) life requirements.

\subsection{OBJECTIVES}

The principal project objective, as stated in the Task Proposal/ Agreement, $(2)$ is the demonstration of the inducer technology through the design of an intermediate-size inducer, impeller, and diffuser system; a system which can be sodium-tested using the Fast Flux Test Facility (FFTF) Prototype Primary Pump as a test vehicle. The design task, therefore, includes hydrodynamic and structural design of the impeller, inducer, and diffuser, plus necessary adapter hardware, to operate inside the existing FFTF Prototype Primary Pump in lieu of the present FFTF Prototype Pump impeller. Because the prototype pump is designated as a plant spare for FFTF, it was necessary that the ISIP design not include any requirements for change or modification of existing hardware that might jeopardize the "spare" status. This 
required that the ISIP design be physically and functionally compatible with existing configurations and operating requirements of the prototype pump.

\subsection{TECHNICAL BACKGROUND}

The advantage of using inducers to permit centrifugal pump operation at lower suction pressures was initially used at Rockwell International, by the Rocketdyne Division, in the development of fuel and oxidizer pumps for rocket engines. In this application, the hydrodynamic goals for inducers were the same as for reactor coolant pumps; i.e., reduction of the suction pressure requirements. However, the design problems were significantly different than those faced in designing a pump for reactor coolant service. For rocket engine applications it was necessary to use extremely high speeds (which result in high centrifugal stresses), in order to reduce the size and weight of the pump to proportions suitable for flight service. Design life requirements were short, measured in minutes or hours, as opposed to life requirements, measured in years for reactor coolant service. Also, for rocket engines, the operating temperatures were very low, in the cryogenic range, and thermal cycles were few, whereas sodium-cooled reactors require temperatures in the order of $1000^{\circ} \mathrm{F}$ and equipment must be capable of withstanding a significant number of thermal cycles over the long (20-40 yr) 1 ife.

In the intervening period, between developing inducer pumps for rocket engine application and the present development of similar pumps for reactor coolant service, the Rocketdyne Division developed a commercial line of inducer pumps for use in water jet propulsion systems of hydrofoil craft. The design of those pumps did not have to consider the temperature extremes of cryogenic or reactor service, but had to provide extended life $(5,000$ to $20,000 \mathrm{hr})$ free from disabling damage due to 
cavitation. In addition to meeting the long life requirements, the physical size of the inducers had to be increased from the small, highspeed units used for rocket engines to sizes slightly larger than that being used for ISIP.

The most recent development in sodium inducer pumps is the Subscale Inducer Pump, a small pump specifically designed for operation with low suction pressures (high suction specific speed) in high temperature sodium. This pump was originally built and tested in water and in sodium under DOE contract. It was later modified and further tested in sodium under contract from ANL. (1) As of this date, the Subscale Inducer Pump has successfully completed a 2,000 hr design point endurance test in sodium at $950^{\circ} \mathrm{F}$, with a suction pressure margin of $200 \%$ above the conventionally defined cavitation point ( $3 \%$ reduction in head due to cavitation). The inducer and impeller showed no signs of cavitation as a result of this test. 


\subsection{REQUIREMENTS}

\subsection{GENERAL}

Initial design requirements for the Intermediate-Size Inducer Pump (ISIP) were based principally on those requirements originally used for the Fast Flux Test Facility (FFTF) Prototype Primary Pump, and were contained in pump specification HWS-1551. (3) Since the ISIP design effort covered only those hydrodynamic elements and adapters used to replace the prototype pump impeller, much of the information given in HWS-1551 was not pertinent to this project. It was assumed that the FFTF Prototype Pump met the requirements of HWS-1551 and that as long as the operating conditions for those parts to be used in the ISIP assembly were not changed, or were not outside of the range of specification requirements, no further analyses of prototype pump parts were needed. Also, because the ISIP was to be used only for testing (as opposed to reactor service), some of the requirements, such as design life and thermal transients, were rewritten in terms of test reouirements. These requirements were planned to be identical to those used for Phase $B$ sodium testing of the FFTF Prototype Pump by Energy Technology Engineering Center (ETEC) (then Liquid Metal Engineering Center (LMEC)) in the Sodium Pump Test Facility (SPTF).

\subsection{SPECIFICATIONS}

In order to permit early initiation of the cooperative design effort to be performed by Atomics International and Rocketdyne, a set of technical requirements ${ }^{(4)}$ based on HWS-1551 was developed. The set covered the basic hydrodynamic and structural design requirements, including expected limiting values (upper and lower limits) for those parameters which could not be quantified precisely at the time. Subsequently, a more formal and inclusive design specification was written 
(Appendix B). This specification was revised once as a result of design review comments.

\subsection{HYDRODYNAMIC DESIGN REQUIREMENTS}

Hydrodynamic design requirements, with the exception of suction performance, are basically the same as those used in HWS-1551 for the FFTF Prototype Pump. The principal parameters are shown in Table I, which was extracted from the design specification. Added to the original FFTF Prototype Pump requirements was a requirement for operation at design speed, flow, and temperature, with a net positive suction head (NPSH) of $12.8 \mathrm{ft}$ "without cavitation" as defined in the specification. For both the ISIP and the FFTF Prototype Pump "without cavitation" is defined as operating under this condition; the total head across the pump is not reduced by more than $3 \%$, due to reduced suction pressure from its noncavitating (adequate suction pressure) value. The NPSH at this $3 \%$ head reduction condition is designated as the required net positive suction head (NPSHR).

The fluid properties on which the hydrodynamic design is based are those contained in ANL $7323^{(12)}$ which is the same source document as used for design of the FFTF Prototype Pump. Although later publications of sodium properties may have been available, it was felt that use of these properties, in the design and test evaluation of the ISIP, would provide more consistent comparison between performance characteristics of the ISIP and those of the FFTF Prototype Pump which was tested in the same 7oop.

\subsection{STRUCTURAL DESIGN REQUIREMENTS}

The initial structural design requirements given in Reference 4 were established to provide a basis for design initiation. These criteria 


\section{TABLE I}

HYDRODYNAMIC DESIGN REQUIREMENTS

DESIGN POINT

Flow

Head

Speed

Required NPSH

MAXIMUM FLOW POINT

(2-Loop Operation)

Flow

Head

Speed

Cover Gas Pressure

Submergence

(Overdischarge centeriine)

$$
\begin{aligned}
14,500 \mathrm{gpm} \\
500 \mathrm{ft} \\
1,110 \mathrm{rpm} \\
12.8 \mathrm{ft} \text { (max.) }
\end{aligned}
$$


covered steady state structural design only. The maximum primary membrane stress and the maximum primary membrane plus bending stress were limited to those values which had been previously calculated for the FFTF Prototype Pump impeller ( $7450 \mathrm{psi}$ and $7730 \mathrm{psi}$, respectively). Since the ISIP impeller has a similar configuration, it was felt that having the initial design based on these previously successful values would allow a high probability of success in limiting the stresses during thermal transients to values obtained using Code Case N-47 (1592-10) as guidance. These criteria are given in Reference 3.

Unlike many design approaches which require design for specified thermal transients, requirements for structural design of the ISIP components were based on developing a structurally conservative steady state design. This design would have a high probability of meeting the transient requirements, then analyzing the design to determine which, if any, of the specified test thermal transients could not be met within the structural design criteria. The scope of analysis, (4) was based on limiting the structural analys is effort to elastic, and simplified inelastic, methods to make this determination.

\subsection{MECHANICAL DESIGN REQUIREMENTS}

Using the FFTF Prototype Pump frame as a test vehicle dictated a number of physical and functional interface requirements. The requirements were to be included in the ISIP design specification in order to avoid the risk of damage to the pump frame. Other mechanical design requirements were based on developing the original concept arrangement, as depicted in the early proposal, into a fully detailed assembiy which would be suitable for reactor coolant service.

The following changes from the FFTF Prototype Pump design, in physical interface requirements, were implemented with HEDL concurrence. 
a) Axial Clearance - The prototype pump had 3/4 in. axial clearance above and below the impeller. The ISIP design specification requires $1 / 2$ in. axial clearance above and below the impeller.

b) Radial Clearance - The prototype pump has .100 in. radial clearance at the lower (front) labyrinth seal. The ISIP design specification requires that the design provide .015 in. minimum radial clearance margin against rubbing under the combined effects of eccentricity, thermal distortion, and .025 in. radial movement at the lower labyrinth seal and the inducer blade tips.

Other physical interfaces with the prototype pump frame are defined on the interface control drawing (ICD) (Figure 1), which includes "asbuilt" measurements from the prototype pump components, and on the rework drawing which defines modifications in the prototype pump parts made to accommodate ISIP components.

Functionally, design of the ISIP components was to provide for necessary internal circulation, and to avoid excess loads on the prototype pump components. To alleviate the effects of thermal transients, the ISIP design had to maintain the provision for circulation of $50 \mathrm{gpm}$, up through the hollow lower end of the prototype shaft; to the radial holes above the impeller. The ISIP impeller/inducer design had to provide recirculation capability to maintain the pressure at the lower end of the sodium bearing below $18 \mathrm{psi}$. This requirement was necessary to assure adequate flaw over the lower bearing sill.

The specification requires axial loads to be limited to within $70,0001 \mathrm{~b}$ upward thrust and 40,000 1b downward thrust. That is within the thrust bearing capability - rotor weight considered. These axial 


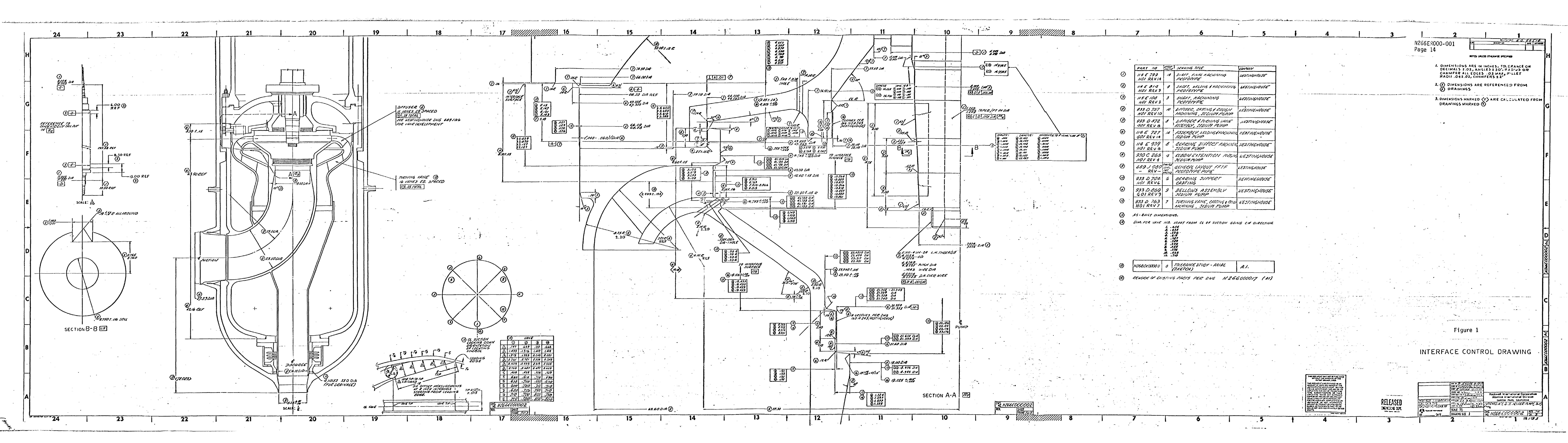


thrust limits must be met under the effect of a $10 \%$ difference in static head between the upper (back) and lower (front) shrouds of the impeller; a requirement based on changes in axial thrust which have been noted on many pumps. This includes water tests of the prototype pump when flow is throttled significantly below the design value.

Other mechanical design requirements included provision of methods of venting and draining the ISIP components (these features were already included in the design of the prototype pump), and provision for attachment of lifting and handling tools. The specification anticipated that some new tools or modification of the existing prototype pump tools might be required. Lifting tools were to conform to the requirements of RDT F8-6T ${ }^{(6)}$ and support stands were to conform to the Uniform Building Code requirements for this region.

\subsection{MATERIALS AND PROCESSES}

Materials and processes required for use on the ISIP were selected to be compatible with those materials presently in the FFTF Prototype Pump. Ali forged parts were to be made from Type 304 forgings, as was the prototype pump. Also, like the prototype pump, the impeller was to be fabricated from CF8, the chemically equivalent cast material to 304 . Unlike the prototype, threaded fasteners in the ISIP were to be made from ASME SA-638, Grade 660, commercially known as A286. This alloy was chosen because of its reduced tendency to gall against stainless steel and its compatibility with the thermal expansion coefficient of stainless steel. This nickel alloy also has the advantage of a higher strength than Type 304. The piston ring which is used to restrict leakage from the impeller discharge to the inducer inlet, was to be made from a precipitation hardened nickel alloy, ASME SA-637, Grade 718, commercially known as Inconel alloy 718. 
The specification also required that the major parts be given a supplemental heat treatment as a part of the fabrication process to develop dimensional stability. The purpose of this requirement was to avoid, or minimize, the effects of material densification during extended exposure to high temperatures. These effects were identified as having contributed to the sodium bearing failure during Phase $A$ testing of the prototype pump. 


\section{0 PRESENT DESIGN}

\subsection{DESCRIPTION}

The final design of the Intermediate-Size Inducer Pump (ISIP) is shown in Figure 2. This figure was taken from general assembly Drawing N266000032 which is the top level drawing showing a11 ISIP components. The drawing includes components from the Fast Flux Test Facility (FFTF) Prototype Pump and those new components provided by Rockwell. The material 1 ist provides entry to the drawing tree. This permits identification of all lower level drawings of subassemblies and individual components. The ISIP general assemb7y drawing was produced by modifying a copy of the original FFTF Prototype Pump general assembly Drawing 114E829. Using lines and cross-hatching over information from the prototype pump assembly drawing which does not apply to the ISIP assembly, permits easy identification of those items which were changed for the ISIP configuration. The "find numbers" (equivalent to the prototype pump piece numbers) in the parts list for the new ISIP components start with No. 400. This permits easy distinction from the original piece numbers which end with No. 216.

Detailed information concerning principal dimensions and fits for the ISIP hydrodynamic components is shown in Figure 3 which was taken from the detail layout Drawing N266R000015. Fits and clearances at interfaces with original prototype pump components shown on the layout, are based on design dimensions for the prototype pump parts. Actual fits and clearances may be slightly different when considering the present "as built" dimensions for the prototype pump parts shown in Figure 1. Differences between design dimensions and "as built" dimensions for prototype pump components are probably a result of previously operating the prototype pump at elevated temperatures during sodium tests at the Sodium Pump Test Facility (SPTF). Following the tests, 


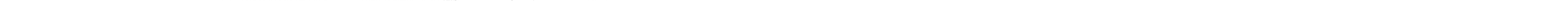



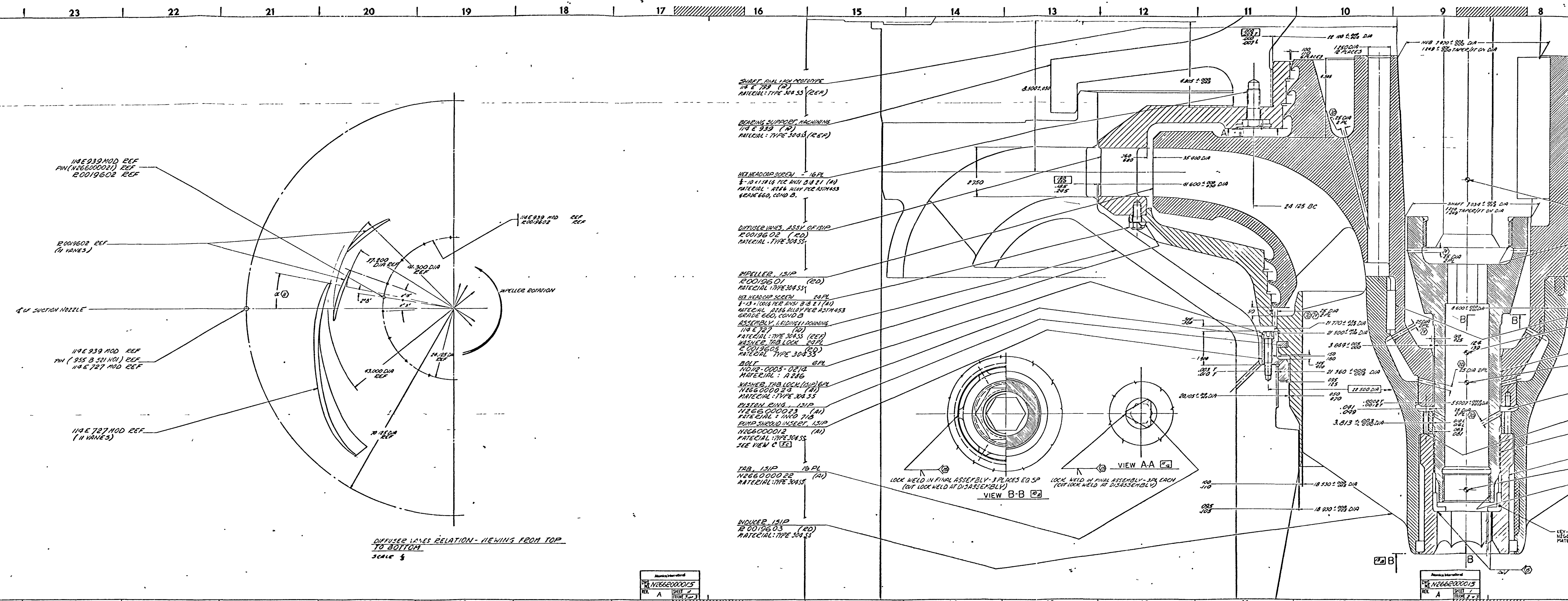
there was evidence of some material densification due to exposure to high temperatures, which could have caused small dimensional changes.

\subsection{MECHANICAL DESIGN}

Basically, mechanical design of the ISIP is very similar to that of the FFTF Prototype Pump. For the ISIP, the prototype impeller and impeller nut are replaced by the ISIP impeller/inducer assembly, the tie-bolt, and the nut adapter. The ISIP diffuser assembly mounts on the lower side of the prototype bearing support flange and functions both as an adapter-diffuser, between the ISIP impeller outlet and the prototype diffuser inlet, and as a support for the inducer tunnel which is part of the diffuser shroud. A shroud insert is installed into the lower labyrinth seal of the prototype static hydraulics. This insert has a hard-surfaced cylindrical bore against which the piston ring, mounted on the ISIP diffuser shroud, rides to restrict leakage toward the inducer inlet while permitting radial and axial motion as needed to accommodate tolerance stackups, and as might occur during thermal transients.

\subsubsection{Protoype Pump Part Modifications}

Mounting of the ISIP diffuser assembly onto the prototype bearing support flange and installation of the shroud insert into the prototype static hydraulics required some modification of the bearing support flange and of the static hydraulics. These modifications are shown in Figure 4, taken from N266000017. All of the modification work, except drilling of the two drain holes in the static hydraulics, were to be performed by the Westinghouse-Sunnyvale plant. Design of the modifications was coordinated with HEDL to assure that the changes would not affect the "spare" status of the prototype parts, and with WestinghouseSunnyvale to assure that the modifications were within the capability of the existing machine tools. 


\subsubsection{Impeller}

The ISIP impeller, Figure 5, was designed to have the same fit with the prototype pump shaft as the prototype impeller., and the same assembly criteria was to be used, i.e., an interference fit to be achieved by advancing the impeller .025 in. further along the shaft taper than its cold set position. This criteria results in a .0026 in. diametral interference fit in the approximately 8 in. mean diameter of the tapered bore ( $1 / 8 \mathrm{in}$. taper on diameter per foot of length). The taper fit and tolerances permit using hot $\left(180^{\circ} \mathrm{F}\right)$ water to heat the impeller before mounting to achieve the design interference. The 121.25 in. diameter holes through the impeller hub are designed to channel the recirculating internal flow from the upper (back) labyrinth, and from the lower end of the sodium bearing, back to the eye of the impeller. The total $669 \mathrm{gpm}$ flow had to be accommodated while maintaining the pressure between the hub and the bearing no more than 18 psi above suction pressure (see Figure 2 of Appendix $C$ ). The pressure criteria was provided by HEDL to assure adequate flow out of the pump hydrostatic bearing pocket, across the lower sill of the pocket.

The impeller design provides additional material at both (upper and lower) ends of the hub and near the tips of the two shrouds for dynamic balancing. Balancing of the impeller and inducer was accomplished under ESG Specification $N 4007,{ }^{(13)}$ which requires the impeller and inducer to be balanced individually; then an assembly check balance performed after the inducer is mounted on the lower end of the impeller hub. Because the impeller is a sand casting, subject to core shifts during the casting process, it was necessary that a liberal amount of material be available for removal during balancing operations.

Alignment for the inducer, which mounts on the lower end of the impelter hub, is provided by the $5.5007 \mathrm{in}$. diameter and $8.600 \mathrm{in}$. 
diameter cylindrical surfaces on the impeller hub, and by the shoulder which is machined perpendicular to the axis of the impeller bore within $.0005 \mathrm{in}$. The $5.5007 \mathrm{in}$. diameter was designed for an interference fit with the inducer bore. After installation in the ISIP, the upper end of the inducer hub is held against the square shoulder on the impeller by the tie-bolt and nut.

Considerable discussion was given to design of the impeller labyrinth seals. The original labyrinth seals on the prototype pump had a series of annular grooves in the stationary member running in close proximity $(0.100)$ to a cylindrical surface on the impeller. The grooves were $1 / 8 \mathrm{in}$. deep and the lands between the grooves had a $1 / 8 \mathrm{in}$. pitch (Ref. 7 ). The nominal radial clearance was .050 in. at the rear (upper) labyrinth, and .100 in. at the front (lower) labyrinth. To minimize leakage through the labyrinth seals, it was decided to combine several features which were not included in the prototype pump. First, a stepped labyrinth design was used to help break up the velocity carryover effect from fluid leaving one stage of the labyrinth before it reached the next stage. Second, the pitch and groove depth between labyrinth stages was drastically increased from a $0.125 \mathrm{in}$. depth to $0.5 \mathrm{in.}$, and from a $0.125 \mathrm{in}$. pitch to $1.25 \mathrm{in.}$ (1.4 in. for the upper labyrinth). Thereby, the path length between lands was increased, and the cross-section area available for velocity dispersion, and associated momentum destruction, was also increased. Third, the form of the land and groove was specially designed to deflect a part of the fluid jet leaving one land down into the pocket, then redirecting it back against the fluid entering that pocket. The intent of this action is to destroy fluid momentum by taking a part of the velocity stream and directing it back against itself. The tooth form of the labyrinth and its effectiveness, particularly for relatively large radial clearances, had been reported in the technical literature referred to in the Engineering responses to the design review report (see Attachment III in Appendix D). Calculations indicated that this labyrinth 
design would be more effective in limiting internal leakages than the more conventional straight labyrinth, under the required radial clearances.

\subsubsection{Inducer}

Mechanical design of the inducer, Figure 6, was concerned principally with the internal surfaces of the bore, where provisions for mounting and for transmitting torque had to be provided. External surfaces of the hub and blade surface coordinates were dictated by hydrodynamic considerations. Blade thicknesses and blade-to-hub fillets were based on compromise between ideal hydrodynamic and structural conditions, with structural given as much dominance as practical, without undue detractions from hydrodynamic performance. Practically, this approach results in the leading edges and outer portions of the blade being controlled almost entirely. by hydrodynamic requirements, while the inner portions, including the root, and trailing edges being controlled mostly by structural requirements (exclusive of the general blade shape).

Internal to the hub, the inducer design includes two internal bores at 5.4995 and 8.601 in. diameters, to match the 5.5007 and 8.600 in. diameters on the impeller hub. This arrangement provides for an interference fit at the smaller diameter, near the axial center of the inducer blades, and a close tolerance clearance fit at the upper (back) end of the inducer to react against transverse moments. These moments could occur if pressure distribution around the inducer is not exactly symmetrical. Like the taper fit between the impeller and the shaft, the fit between the inducer and the impeller is designed to permit the use of hot $\left(180^{\circ} \mathrm{F}\right)$ water. Hot water is used to heat the inducer before mounting it on the impeller, to achieve the design interference. A $5 / 8$ in. square key transmits torque from the impeller hub to drive the inducer during operation. 


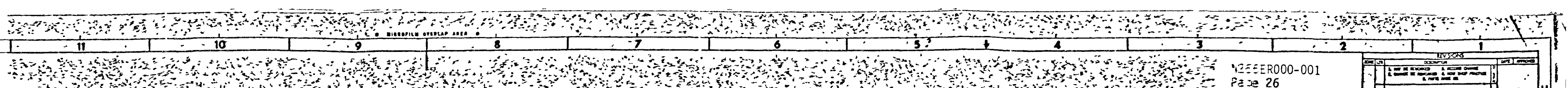

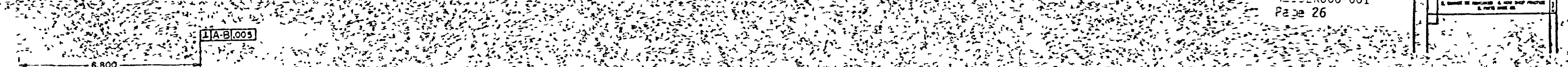
mos

a
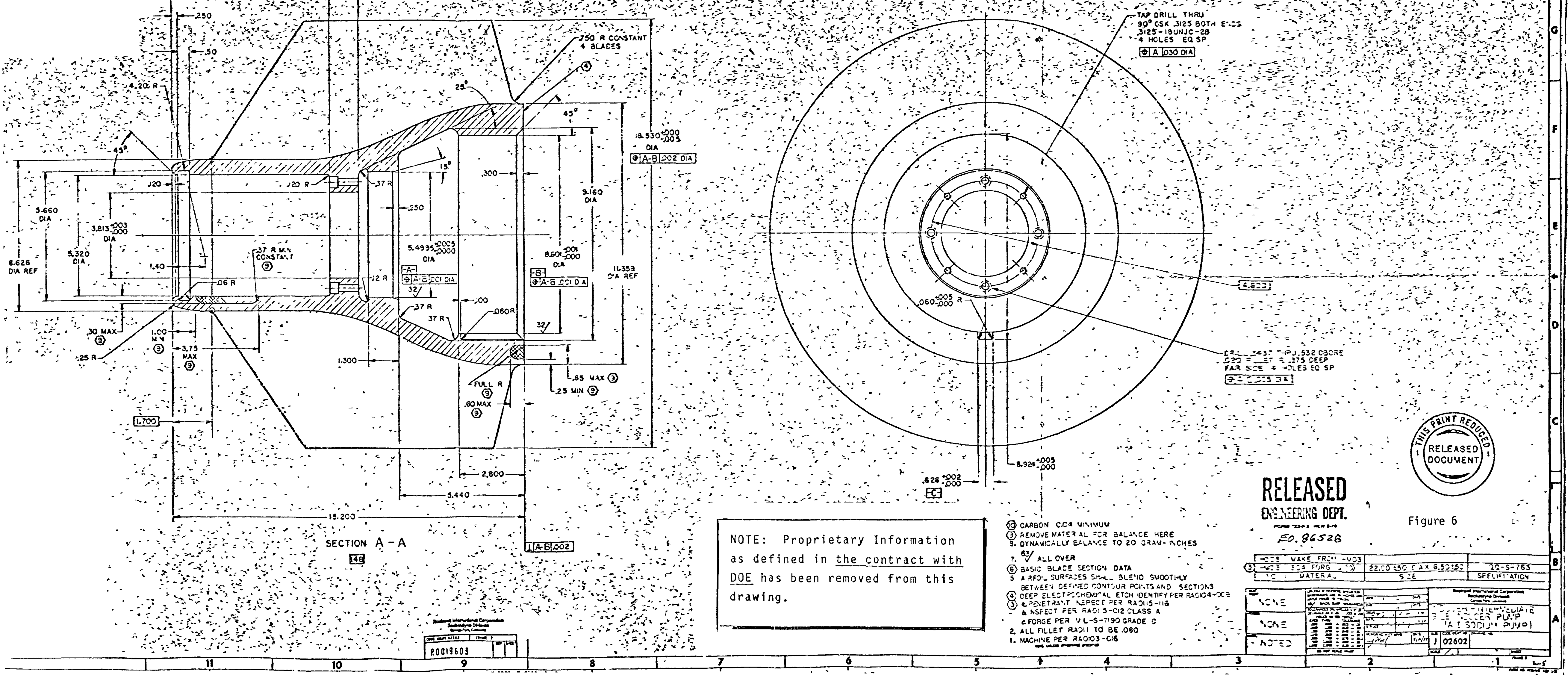
The internal flange of the inducer has four tapped holes and four clearance holes which are aligned with tapped holes in the impeller hub. The four tapped holes permit the use of jacking screws in removing the inducer from the impeller. The clearance holes permit temporary assembly bolts to be installed, holding the two parts together safely for handling during operations, such as during dynamic balancing. A11 eight tapped holes (four in the inducer and four in the impeller) provide connection for the lifting tool used to hoist the impeller/inducer assembly during pump assembly.

\subsubsection{Diffuser Assembly}

The diffuser assembly, Figure 7 , serves a number of purposes in adapting the ISIP impeller and inducer to the existing FFTF Prototype Pump parts. First, the diffuser provides structural support for the stationary vanes designed to guide fluid leaving the ISIP impeller to the existing prototype diffuser. Second, the diffuser assembiy serves as the stationary member of the upper and lower labyrinth seals for the impeller. Third, the assembly provides structural support for the inducer tunnel. The labyrinth seals are designed to operate with close running tolerances (nom. .050 in.), therefore, the diffuser must maintain concentricity at these locations. The lower end of the diffuser shroud forms the inducer tunnel, a cylindrical bore which, like the labyrinth seals, has a .050 in. running clearance and must be maintained concentric with the rotating element. The diffuser tunnel outside diameter, although stationary, has a .050 nominal clearance with the prototype pump parts, and must be maintained concentric with those parts during normal operation.

The diffuser shroud is designed for an interference fit at its mounting on the diffuser vanes, as are the diffuser vanes designed for an interference fit with the upper labyrinth bore in the prototype pump 
bearing flange. Both fits are provided with tapped holes to permit use of jacking bolts during disassembly. The interference fits are designed to be accomplished using dry ice $\left(-110^{\circ} \mathrm{F}\right)$ to chill the male portion of the fit to a temperature approximately $100^{\circ} \mathrm{F}$ below ambient temperature.

Mounting the diffuser to the bearing support flange and the diffuser shroud to the diffuser using interference fits reduced the maximum eccentricity at the lower labyrinth and at the inducer tips from what might have been encountered if these parts were fixed to the diffuser shroud of the prototype pump. The $.050 \mathrm{in}$. radial clearance with the prototype pump outside the inducer tunne1, combined with the $.050 \mathrm{in}$. radial clearance inside the inducer tunnel permits the Hanford Engineering Development Laboratory (HEDL) required transverse motion of the prototype pump parts at the lower labyrinth, even under the most adverse tolerance stackup while still adequate margin against rubbing at the inducer blade tips or the lower labyrinth sea1. (See Paragraph 3.2.9.2 for a detailed discussion of radial clearances.)

\subsubsection{Tie-Bolt and Shaft Adapter Nut}

The tie-bolt serves as an extension to the existing prototype pump shaft and as the principal tension member in holding the impeller/ inducer assembly on the shaft. The upper end of the tie-bolt connects to the $5 \mathrm{in}$. thread at the lower end of the shaft (where the shaft nut is installed in the prototype pump design) and provides a 3.75 in. thread at the lower end of the tie-bolt where the shaft adapter nut is installed to clamp the inducer/impeller assembly onto the shaft taper. The hole through the center of the tie-bolt provides passageway for the calculated $50 \mathrm{gpm}$ flow, up through the shaft to a region above the sodium bearing, to control temperature differences during thermal transients. Provision for flow through the shaft was a feature designed into the prototype pump. Despite the slight increase in flow resistance 
offered by addition of the tie-bolt, the flow rate is not expected to be affected significantly.

In addition to holding the impeller/inducer on the shaft, the tiebolt is also part of the puller tool used to remove the impeller/inducer from the shaft during disassembly. For this application, the tie-bolt is unscrewed from the $5 \mathrm{in}$. thread on the shaft end and the puller tool attached to the $3.75 \mathrm{in}$. thread on the tie bolt. The pull is against the internal shoulder of the impeller hub. Also, during assembly and disassembly, the modified guide plate which is used to clamp the bearing support flange to the shaft assembly, is connected to the shaft assembly through the $2.75 \mathrm{in}$. internal thread at the lower end of the tie-bolt.

Material for the tie-bolt is A286 (ASME SA-638, Grade 660), and is used to minimize the risk of thread galling. The thermal expansion coefficient of this material is comparable to that of Type 304 stainless steel, but is slightly lower. Therefore, as the pump temperature rises during service, it is expected that the tension in the tie-bolt will increase. To compensate for this effect, the tightening torque for the shaft nut adapter is specified as $100 \mathrm{ft} / 1 \mathrm{~b}$, instead of the $450 \mathrm{ft} / 1 \mathrm{~b}$ used in mounting the prototype impeller on the shaft. This torque is expected to provide adequate tension at the minimum operating temperature $\left(400^{\circ} \mathrm{F}\right)$. The impeller/inducer is held in place this way under the influence of axial thrust, while still not causing an overstressed condition due to differential thermal expansion at the maximum temperature of $1050^{\circ} \mathrm{F}$. The 13,300 in. $-1 \mathrm{~b}$ hydrodynamic moment on the inducer is reacted at the 5.5 and $8.6 \mathrm{in}$. diameter turns at the lower end of the impeller hub.

The shaft nut adapter is a sleeve-type nut with an internal hex, which mounts on the $2.75 \mathrm{in}$. thread of the tie-bolt. The lower end of the nut has six lugs, two of which are lock welded to the lower end of 
the inducer hub at assembly (the remaining four lugs are for subsequent assemblies, if required). Lock welding the nut to the inducer hub prevents the nut from turning (relative to the shaft). However, it is not a positive lock against the tie-bolt turning, despite the difference between the $5 \mathrm{in}$. thread pitch and the $3.75 \mathrm{in}$. thread pitch (four threads/in. vs eight threads/in.). Therefore, two "L" shaped locking keys are included in the assembly. The keys are installed into keyways at the lower end of the tie-bolt before the nut is installed. Then they are lock welded to the inside of the nut. Since both the nut and keys are Type 304 stainless steel, the lock weld does not involve dissimilar materials.

\subsubsection{Piston Ring Gland}

The piston ring gland is compromised of a piston ring assembly, Figure 8 , installed in a groove in the ISIP diffuser shroud, and the shroud insert which is installed in the prototype pump static hydraulics, as shown in Figure 3 . The static hydraulics were modified to accept the shroud insert by machining a controlled tolerance recess (23.450 in. diameter) and mounting seat, and providing six 3/4-in. tapped holes for the mounting bolts as shown in Figure 4. Also, two 1/4-in.-diameter drain holes were provided, to drain the groove which would exist between the outside diameter of the shroud insert and the prototype pump shroud. Concentricity of the shroud insert, within the static hydraulics, is maintained by an interference fit between the shroud insert and the lower labyrinth grooves of the prototype pump. Like the diffuser parts, the interference fit is designed to permit the use of dry ice to cool the insert $100^{\circ} \mathrm{F}$ below ambient before installation. Tapped holes are provided in the insert to permit use of jacking bolts at disassembly.

Design of the piston ring gland was based on three basic criteria: 


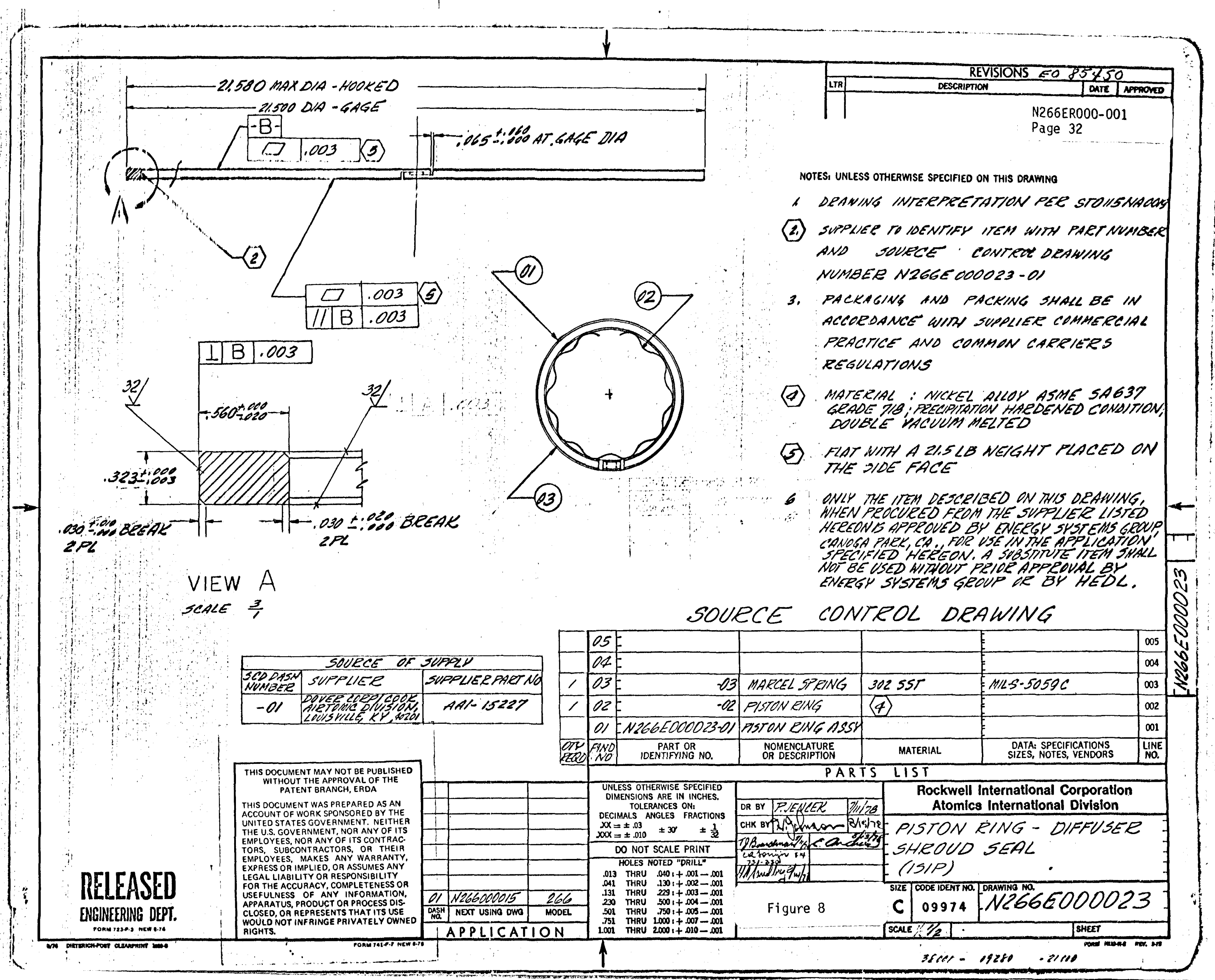


1) Limiting the leakage through the gland. Eighty-five gpm at 177 psi differential pressure was specified.

2) Limiting the axial load against the ISIP diffuser shroud, due to sliding friction, which might occur as a result of relative motion during thermal transients. A friction factor of 0.5 was assumed for this application.

3) Avoiding possible "hangup" which might fracture the ring during assembly for the most adverse misalignment conditions. Since this is a blind assembly under heavy load, failure of the ring during assembly might not be identified.

The ring itself was a purchased item with limiting groove dimensions and lead-in taper dimensions provided to the supplier. The supplier's recommendation to use a centering spring under the piston ring simplified the lead-in taper design aim; to prevent the ring from catching on the shroud insert and breaking during pump assembly. The calculated maximum permissible eccentricity between the ring and inducer shroud is .09 in., considering all adverse tolerances. Also included in the supplier's design is an end-hook arrangement to limit expansion of the ring prior to pump assembly.

To reduce the risk of galling, the base of the shroud insert, where the piston ring seats, has a hard-surface overlay (Stellite). The ring is made from a precipitation hardened material, Inconel 718 , and has chamfered corners.

Conservative estimates of leakage through the piston ring, considering the effective radial gap to be $1 / 2$ the diametral tolerance of the Shroud Insert, and the axial gap to be $1 / 2$ the required flatness of 
the ring, yield a calculated value of $90.9 \mathrm{gpm}$ vs the specified $85 \mathrm{gpm}$. This calculated estimate also considers no fluid friction losses in the gap, only a 0.5 velocity head entrance loss and a 1.0 velocity heat exit loss. The $90.9 \mathrm{gpm}$ estimate was judged sufficiently close to the $85 \mathrm{gpm}$ requirement for acceptance of the ring design (see Appendix $A$ ).

\subsubsection{Rotordynamics}

Rotordynamic analysis of the shaft assembly was performed to assure that substitution of the ISIP impeller/inducer assembly for the original prototype impeller would not result in a critical speed problem during operation. To perform the analysis an analytical "stick" model of the shaft assembly was made. The model was similar to the one in Reference 8 which was used to analyze the prototype rotor assembly. Calculations were also made using a finite element dynamics computer program. Verification of the modeling technique and program operation was done by - first running a model of the prototype shaft in the finite element program - then checking the results against those reported in Reference 8 for the prototype pump. The results of the verification run and the ISIP analysis are reported in Appendix $E$. The two programs (the program used by Atomics International, and the program used by Westinghouse) for prototype pump design showed close agreement for the verification. The critical speed for the ISIP configuration was slightly higher than that predicted for the prototype pump. Since no critical speed problems were encountered during sodium tests of the prototype pump, it was concluded that shaft critical speed problems would be unlikely in the ISIP.

\subsubsection{Vibration}

Previous vibration problems had been encountered during sodium testing of the prototype pump; therefore, this was a concern in the ISIP design. The previous problem had been due to excitation by turbulent 
vortices which were generated by flow through the upper (back) labyrinth. The vortex shedding frequency resonated in the chamber above the impelier and excited a harmonic of the impeller labyrinth seal. Such occurrences are practically impossible to predict. However, the ISIP design includes changes in configuration which were made in an effort to avoid repetition of the problem. The upper (back) labyrinth ring on the impeller has a tapered cross-section, making it less susceptible to excitation by a single frequency. Calculation of the natural frequencies of the inducer blades and of the impeller did not show frequencies in a range where excitation could be anticipated. (Actual measurement of natural frequencies was specified as part of the preassembly data recording requirements.)

\subsubsection{Clearances and Tolerance Stackup}

\subsubsection{Axial Clearances}

The ISIP was designed to use basically the same procedures for axial positioning of the impeller, with respect to the diffuser, as the FFTF Prototype Pump. Mounting details for installation of the impeller onto the existing tapered shaft have the same dimensional relationship, including tolerances, between taper bore in the hub and impeller discharge centerline, as the prototype pump. Because the ISIP diffuser is mounted on the bearing support flange and not in the static hydraulics like the prototype, initial axial positioning of the shaft assembly, which involves alignment between the ISIP diffuser inlet centerline and the impeller discharge centerline, can be set and verified more readily than could be on the prototype pump before installing the upper assembly on the static hydraulics.

The ISIP design provides $1 / 2$ in. axial clearance above and below the impeller, as opposed to the $3 / 4 \mathrm{in}$. provided in the prototype pump. 
The reduction in axial clearance was made to minimize disk friction losses from the impeller shrouds and with HEDL concurrence that $1 / 2$ in. would be acceptable based on the existing shaft, oil bearing, and SP/SC design. The largest differential change in axial length was calculated to be $0.043 \mathrm{in}$., occurring when the pump speed is suddenty reduced from high speed, with all sodium pumped from the shaft tunnel, to low speed, when sodium suddenly flows back up in the shaft tunnel (see Appendix A).

\subsubsection{Radial Clearances}

The nominal radial clearance at the lower labyrinth seal of the FFTF Prototype Pump impeller was 0.100 in. The nominal radial clearance at the lower labyrinth seal of the ISIP impeller is $0.050 \mathrm{in}$. The radial clearance at the ISIP inducer blade tips is also 0.050 in. Both the FFTF and ISIP impellers have a 0.050-in. radial clearance at the upper labyrinth seal. Soon after the start of design, AI requested HEDL approval of the 0.050-in. ISIP impeller lower labyrinth seal radial clearance. At that time, the ISIP inducer tunnel and lower labyrinth seal (both a part of the diffuser shroud) were guided by a seal sleeve in the static hydraulics as shown in Figure A-1 of Appendix $A$. The clearance between the sleeve and the ISIP inducer tunnel was only enough for assembly. In response to the AI request, HEDL stated that at least a $0.065-i n$. radial clearance would be necessary. This necessary clearance was based on a 0.025-in. allowance for stackup of tolerances, a 0.025-in. allowance for thermal distortion (occurring as lateral motion at the top of the Prototype Pump suction elbow), and a 0.015-in. margin against rubbing.

Re-evaluation of the hydrodynamic design showed that the 0.050-in. inducer blade tip radial clearance was the maximum permissible for proper operation of the ISIP. Therefore, to provide a 0.015-in. margin as requested by HEDL, the ISIP was redesigned to provide the configuration shown in Figure $A-2$ of Appendix $A$. This configuration maintains 
the 0.050 -in. rotating clearances at the ISIP impeller lower labyrinth seal and inducer blade tips. The design introduces an additional 0.050-in. stationary radial gap behind the inducer tunnel (part of the diffuser shroud) and the Prototype Pump static hydraulics. Recirculation flow through this gap is restricted by a piston ring seal which can accommodate more than $0.050 \mathrm{in}$. radial motion.

Based on this design (Figure $A-2$ ), the radial tolerance stackup analyses were performed (Appendix F). These analyses showed, that under the most adverse stackup of tolerances at assembly, a 0.012-in. minimum radial clearance would exist at the inducer blade tips, at room temperature (Condition 5, Dimension J). The corresponding minimum stationary radial gap behind the inducer tunnel would be 0.0255 in. (Condition 5 , Dimension 0). These were calculated with the shaft bearing journals against opposite sides of the upper (oil) and lower (sodium) bearings. The condition inciudes the effects of looseness at rabbet fits, perpendicularity, and concentricity for all stationary and rotating parts from the oil bearing to the inducer.

As previously stated, the tolerance stackup analyses assumed contact at opposite sides of the oil and sodium bearings to establish the minimum inducer tip clearance of $0.012 \mathrm{in.}$. In actuality, with the pump operating, the specified minimum sodium bearing film thickness is $0.005 \mathrm{in}$. (this is continuously monitored during operation). Taking account of the amount of rotor overhang, this translates to an increase of $0.0054 \mathrm{in}$. on the calculated minimum radial clearance at the inducer tip, providing a calculated minimum clearance of $0.0174 \mathrm{in}$. $(0.012+$ 0.0054 ) during operation. The minimum calculated stationary radial gap behind the diffuser tunnel is not affected by bearing film thickness and remains at 0.0255 in. 
The minimum calculated clearances were compared to the required clearance values from HEDL. The HEDL allowance for tolerance stackup was $0.025 \mathrm{in.}$, and this tolerance stackup was accounted for by the stackup analyses which were based on design tolerances for each individual part. The HEDL value for thermal distortion (lateral movement at the top of the suction elbow) was 0.025 in., which can be accommodated by the stationary gap of $0.0255 \mathrm{in}$. behind the inducer tunnel. The HEDL value for margin against rubbing, after accounting for tolerance stackup and thermal distortion, was $0.015 \mathrm{in.}$, which is met by the calculated minimum clearance at the inducer tip of $0.0174 \mathrm{in.}$

In addition to considering the foregoing margin requirement provided by HEDL, a more detailed evaluation was made which considers local thermal distortions in addition to the 0.025-in. lateral movement at the top of the suction elbow. Referring to Table 1 of the transient structural analysis and deformation studies (Appendix I), Transient Events E-208 and E-203 cause the greatest reductions in inducer tip clearance (Location $E$ ) and inducer tunnel stationary clearance (Location $F$ ) due to local distortions. The inducer tip clearance at the Location $E$ is the most critical running clearance on the ISIP rotor.

For Transient E-208, local distortions cause the stationary gap behind the inducer tunnel to increase by 0.0131 in., changing the minimum stationary clearance from 0.0255 in. to $0.0386 \mathrm{in}$., which is more than the 0.025-in. lateral motion at the top of the suction elbow. At the same time, the minimum inducer tip clearance is reduced by $0.0037 \mathrm{in.}$ from $0.0174 \mathrm{in}$. to $0.0137 \mathrm{in}$., which is more than twice the 0.0054-in. allowance at the inducer tip for minimum sodium bearing film thickness. It is, therefore, concluded that no rubbing would occur for this transient at the inducer tips. 
For Transient E-203, the minimum stationary gap is reduced by $0.0061 \mathrm{in}$. from $0.0255 \mathrm{in}$. to $0.0194 \mathrm{in}$. A lateral motion of 0.025 in. at the top of the suction elbow could cause a lateral motion of 0.0056 in. (0.025-0.0194) at the inducer tunnel. At the same time, the minimum inducer tip clearance (without lateral motion of the tunnel) is increased by $0.0029 \mathrm{in}$. from $0.0174 \mathrm{in}$. to $0.0203 \mathrm{in}$. Subtracting the $0.0056 \mathrm{in}$. lateral motion of the inducer tunnel from this minimum clearance leaves a minimum clearance of $0.0147 \mathrm{in.}$, which is also more than twice the $0.0054 \mathrm{in}$. allowance at the inducer tip for minimum sodium bearing film thickness. Therefore, it is also concluded that for this transient no rubbing would occur at the inducer tips.

NOTE: $\quad$ The minimum clearances utilized above are based on the worst tolerance stackup as calculated from the dimensions of individual parts in the ISIP assembly. The actual stackup as subsequently measured during Assembly Procedures AP-39-PP-036 and AP-39-PP-043 resulted in a 0.037-in. minimum clearance at the inducer tips (versus a calculated 0.012 in.) and a 0.054-in. minimum clearance behind the inducer tunnel (vs a calculated 0.0255 in.).

\subsection{HYDRODYNAMIC DESIGN}

Hydrodynamic design of the ISIP components was based on meeting the same noncavitating performance requirements as the FFTF Prototype Pump, which were also included in the ISIP design specification (Appendix B). The following is a list of the basic requirements: 
Design Point:

Flow

Head

Speed

Maximum Flow Point:

Flow

Head

Speed
$14,500 \mathrm{gpm}$

$500 \mathrm{ft}$

$1,100 \mathrm{rpm}$

$18,000 \mathrm{gpm}$

$375 \mathrm{ft}$ (minimum)

$1,110 \mathrm{rpm}$

In addition to the above requirements, the ISIP is also designed to have a required net positive suction head (NPSHR) of not more than $12.8 \mathrm{ft}$ when operating at design flow and speed, and to be capable of operating at $200 \%$ margin above the required net positive suction head for 2,000 hours without any visual effect of damage due to cavitation damage. The present margin is defined as:

$$
\% \text { Margin }=\left(\frac{\text { NPSHA }}{\text { NPSHR }}-1\right) 100
$$

where: NPSHR = Required NPSH

$$
\text { NPSHA }=\text { Available NPSH }
$$

Refer to Paragraph 2.3 for definition of NPSHR.

Three hydrodynamic elements are included in the ISIP design: impeller, inducer, and diffuser. These elements are to be installed in the impeller cavity of the prototype pump. An existing hydrodynamic element, the prototype pump diffuser, will remain in the pump and its characteristics will also contribute to the overall hydrodynamic performance. The hydrodynamic design process (not unlike other design efforts) was necessarily an iterative one, especially in the early stages, consisting of assuming or selecting certain parameters or 
configuration features and calculating their impact and compatibility with other features. This report covers basically the final step, or steps of this process.

Initial steps in the hydrodynamic design effort consisted of sizing the impeller (determining its tip diameter) to verify the feasibility of the conceptual design, which included an intermediate (ISIP) diffuser between the impeller discharge and the prototype pump diffuser inlet, and evaluating the internal recirculation flows to predict actual flow rates through each of the various hydrodynamic elements. The diameter of the inducer was limited to about 19 in. by the existing inlet configuration of the prototype pump (see Figure 2 ). The outlet diameter of the ISIP diffuser was limited to about $41.75 \mathrm{in}$. by the inside diameter of the existing prototype diffuser. Calculation of the internal recirculation flows is presented in N266TI000003 (Appendix C). This report shows the internal flows originally calculated for the FFTF Prototype Pump design, and the changes in those flows resulting from the ISIP design. Using these flow rates and the head requirements from the design specification, calculation of the impeller tip diameter was completed. Final, detail hydrodynamic calculations were performed by the Rocketdyne Division using computer programs containing both theoretical and empirical relations developed through design and test of numerous, similar configurations. For detail description of the final hydrodynamic design process and calculated results, see the hydrodynamic design report, Appendix G. This report describes the design criteria and identifies the computer programs used for hydrodynamic analysis. It also includes tables and curves of calculated performance parameters such as overall performance, blade loadings, and internal losses. Figure 9 shows a composite of the expected head, efficiency, and NPSHR characteristics at $1,110 \mathrm{rpm}$. The following subparagraphs discuss the initial calculations used to establish design feasibility prior to submitting the problem for computer analysis. 


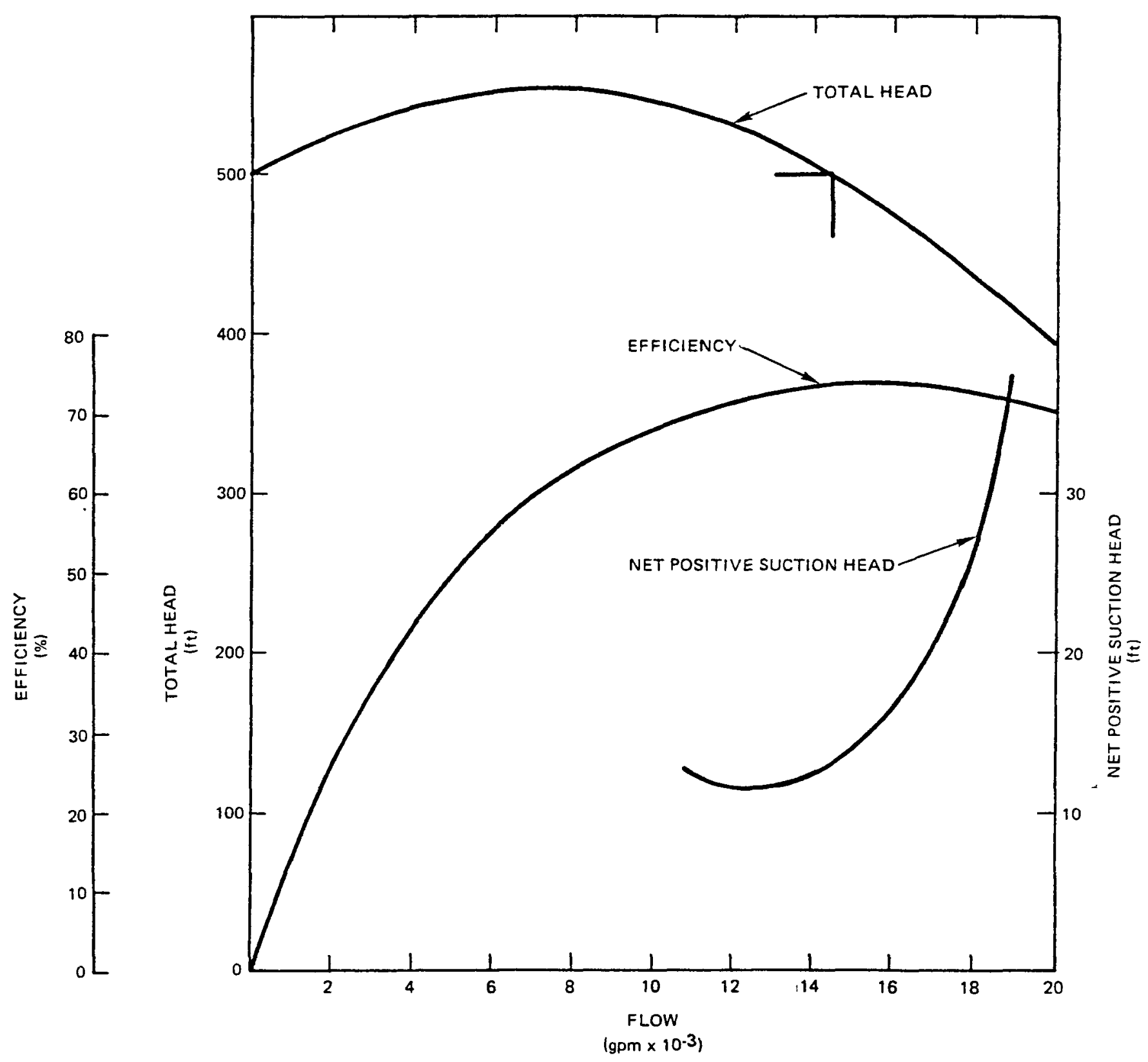

FIGURE 9. ISIP - PREDICTED PERFORMANCE AT 1,110 RPM 


\subsubsection{Impel7er}

The first step in the impeller design effort was to establish a practical impeller discharge diameter and blade trailing edge configuration which would permit reducing the impeller diameter sufficiently, from that of the prototype impeller, to permit installation of a varied intermediate (ISIP) diffuser between the ISIP impeller discharge and the existing prototype diffuser inlet. The ISIP diffuser was needed to extend the permissible range of flow variation toward the low-flow regime, and to provide better control of clearances between the inducer and the inducer tunnel. Radial tolerance stackup and possible transverse movement of the existing inlet structure in the prototype pump would not permit adequate control of clearances.

Based on an assumed head rise efficiency for the pump (not including efficiency losses due to internal recirculation), the required Euler head $\left(H_{e}\right)$, or head rise for the rotating vane system (impeller plus inducer), was calculated. The impeller tip diameter and blade discharge angle, as determined from this head, is not appreciably affected by the head rise through the inducer in the ISIP configuration.

$$
\begin{array}{rlrl}
H_{e}=H / \eta_{h} & \text { where: } & H=\text { net head rise through pump }(\mathrm{ft}) \\
=500 / 0.8 & \eta_{h}= & \text { pump head rise efficiency } \\
H_{e}=625 \mathrm{ft} & & \text { (assumed }=80 \text { percent) } \\
H_{e}= & \text { Euler head of rotating vane } \\
& & \text { system }(\mathrm{ft})
\end{array}
$$

The Euler head is proportional to the product of the impeller tip velocity $\left(\mathrm{U}_{2}\right)$ and the tangential component of the absolute fluid velocity leaving the impeller $\left(\mathrm{C}_{\mathrm{U}_{2}}\right)$. With the selected (through design iteration) 
tip diameter of $35.4 \mathrm{in}$. and the specified rotating speed of $1,100 \mathrm{rpm}$, the tangential fluid velocity component is calculated by use of the EuTer equation:

$$
\begin{aligned}
& H_{e}=C_{u 2} U_{2} / g \quad \text { where: } \quad C_{u 2}=\text { tang. absolute fluid } \\
& \text { vel. }(\mathrm{ft} / \mathrm{sec}) \\
& \mathrm{g}=\text { gravitational constant } \\
& \left(\mathrm{ft} / \mathrm{sec}^{2}\right) \\
& \therefore \quad C_{u 2}=g H / U_{2} \\
& U_{2}=\text { impeller tip velocity } \\
& (\mathrm{ft} / \mathrm{sec}) \\
& =\text { (171.4 based on 35.4-in. } \\
& \text { diameter at } 1,110 \mathrm{rpm} \text { ) } \\
& =32.2(625) / 171.4 \\
& c_{u 2}=117.4 \mathrm{ft} / \mathrm{sec}
\end{aligned}
$$

The prototype pump impeller had a blade tip diameter of 38.6 in. and produced the same net head rise with approximately the same pump head rise efficiency. For this initial calculation, losses were not assumed to vary significantly between the prototype pump and the ISIP pump design; therefore, reduction of the ISIP impeller diameter to $35.4 \mathrm{in}$. required increasing the head coefficient above that used for the prototype pump impeller design. The methods by which the head coefficient for a radial discharge impeller may be increased have been publicized in various texts on impeller design and become apparent by examination of the discharge velocity triangle and the Euler head equation (refer to impeller blade calcuations in Appendix A). These methods principaliy consist of:

1) Increasing the angle of the impeller blade $\left(\beta_{2}\right)$ in the region of the impeller tip (blade trailing edge). 
2) Increasing the number of impeller blades to provide better flow guidance, forcing the angle of the relative flow into better conformance with the blade angle in the tip region.

Both of these techniques were used in the design of the ISIP impeller. The blade discharge angle was increased by about ten degrees (approximately from $20^{\circ}$ to $30^{\circ}$ ), and the number of blades at the discharge was increased from six to 10 . Five of the 10 blades were designed as partial blades to avoid excessive blockage of through flow area in the eye, due to the total vane thickness. The blade width $\left(B_{2}\right)$ at the ISIP impeller discharge was increased from $2.40 \mathrm{in}$. to $2.75 \mathrm{in}$. to match the width at the diffuser inlet (both ISIP and prototype pump diffusers) in an effort to minimize turbulent losses when the fluid travels from one vane system to the next.

Impeller blade calculation results show a blade discharge angle of $31.5^{\circ}$ (Appendix A). The calculation method was based on theoretical considerations as presented in the text of Reference 9 . The method consists of calculating a correction for the discharge velocity triangle based on the exit geometry using the method derived by Stodola. The Stodola correction was put in the form which includes a coefficient, nominally equal to 1.0 for impellers with vane overlap but for which further modification is available based on published theoretical work by Busemann. Considering the tangential component of the absolute discharge velocity $\left(C_{u 2}\right)$, necessary to produce the required Euler head $\left(H_{e}\right)$, the "maximum usable" velocity triangle correction $\left(\Delta \nu{ }_{S A}^{\prime}\right)$ was calculated for various blade discharge angles. These correction values were then compared to calculated corrections $\left(\Delta \nu_{S A}\right)$ predicted from the theoretical methods in the text. Plotting the results of two, the calculations, with the discharge angle as the independent variable, yields a solution at the intersection of the two curves where the 
"maximum usable" correction equals the predicted correction. The solution, although not exact, indicated that the hydrodynamic requirements would result in a practical impeller discharge configuration which could be fabricated, and not be outside the range of experience at Rocketdyne or commercial pump manufacturers.

These initial calculations were based on frictionless flow through the impeller since, at the time, head losses through the pump were lumped under one assumed head-rise efficiency $\left(\eta_{h}\right)$. Also, the Stodola coefficient, as determined by Busemann, is based on blades with a logarithmic spiral (constant blade angle). The foregoing calculations are approximate, but no refinement was attempted, since the quantitative effects of impeller discharge geometry does not readily lend itself to theoretical analysis. Instead, at Rocketdyne, as at other pump designers, empirical data built up from published information and from the design organization's own past experience is normally relied upon. For the ISIP, detail calculations were made using two company developed computer programs developed through design and test evaluation of numerous impellers.

Initial calculation of the inlet angle for the impeller blades was based on accepting the flow leaving the inducer blade system with a minimum amount of entry losses (see Appendix A). Using an inducer EuTer head $\left(H_{e i}\right)$, assumed as $12 \%$ of the total head rise through the rotor, the tangential component of the absolute velocity leaving the inducer $\left(\mathrm{C}_{\mathrm{u} 2 \mathrm{i}}\right)$ can be calculated from the Euler equation. With the tip diameter limited by the existing prototype pump inlet configuration, the inducer exit hub diameter was first determined using company data from inducers with similar hydrodynamic characteristics. The impeller inlet hub diameter was set equal to the inducer hub outlet diameter, thereby establishing the through flow area and permitting calculation of the meridinal approach velocity to the impeller. For initial evaluation, fluid and 
blade velocities at the tip, or outer periphery, are the principal concern because they are usually most critical to the design. Subsequent detail calculations considering radial equilibrium and axial velocity distribution for various steam tubes are performed by the computer program to determine impeller inlet blade angle variation between the tip and the hub.

As can be seen from the blade inlet calculations in Appendix $A$, use of an inducer aids in suppressing cavitation in the impeller, not only by generation of static pressure, but also by providing prewhirl which reduces the relative velocity of the fluid entering the impeller vane system. Proper prediction of this velocity angle and magnitude permits lower entry shock losses for the impeller than would be achievable without an inducer. Results of the calculations show the relative angle of the fluid approaching the blade $\left(\beta_{1}\right)$ as 28 degrees. To minimize entry losses, the impeller leading edge is set at this angle plus a slight positive correction to account for the increase in meridinal velocity $\left(C_{m 1}\right)$ due to vane blockage.

It was previously mentioned that the Busemann value for the Stodola correction coefficient was based on blades assumed to have a constant angle (logarithmic spiral). Comparison of the calculated blade inlet angle of 28 degrees (plus a small positive correction) to the discharge angle of 31.5 degrees shows that this was a reasonably accurate assumption for the ISIP impeller.

Final calculations, as presented in the hydrodynamic design report (Table 1 of Appendix G), predict a. $9 \%$ head margin for the impeller. During conventional development of impeller designs, which include water tests of full-size impellers or scale models, some adjustment in the pump head (either decrease or increase) can be made by decreasing the impeller diameter or underfilling the impeller vane tips. For the ISIP 
impeller, no water testing is scheduled, therefore, pump head may be subject to some error due to the lack of opportunity to "fine tune" the impeller discharge geometry on the basis of test results.

\subsubsection{Inducer}

The inducer is a high specific speed, axial flow runner, characterized by a low head rise, compared to the flow and speed. There is considerably more theoretical and empirical data available for axial flow runners than for radial flow runners, where blade shapes and solidity (length to spacing rates) effects, as applied to the function of generating head, are concerned. However, in addition to the obvious objective of head generation to suppress impeller cavitation, the following two objectives must also be met for inducer applications requiring long life, such as for primary sodium pumps.

1) The inducer itself must operate with low suction pressure (low NPSH) without (gross) cavitation, to the extent that head rise in the inducer or in the following impeller would be impaired.

2) Any local cavitation, which might occur near the low suction pressure limit must be handled in a way that prevents collapse of cavitation bubbles which would cause material damage on the surface of the inducer or the following impeller.

To achieve the above objectives, Rocketdyne makes heavy use of empirical data compiled from the results of testing previous successful designs. In addition to information from previous designs, a thorough knowledge of how the thermodynamic and transport properties of fluids affect the cavitation problem also had to be developed. Finally, 
knowledge of the effects of varying various local details such as clearances, contours, and vane-edge shapes, which might be varied in any one design, had to be developed, specifically in application to the hydrodynamic runner. The procedures for applying this information have largely been put into computer programs to minimize calculative time requirements. Since the problems are seldom straightforward (implicit) many iterations are required for a solution. Also, for any particular design, optimizations, requiring repitition of the iteration process, are also required. (See Appendix G for detail description of the inducer design.)

Achievement of the first objective, performance at low suction pressures, is met through the design of the vane shapes and hub profile. The design must ensure that entry losses are minimized and momentum is imparted to the fluid by the blades in a manner which does not result in pressures low enough to cause cavitation on the low-pressure (suction) side of the blade. Pressure distributions, due to rotational fields and influence of adjacent vanes, are among the design considerations.

The second objective, avoidance of material damage due to local cavitation, involves:

- Predicting transport paths from the point of generation to the point of collapse in the free stream

- Predicting possible bubble formation in local areas, such as the blade leading edges, where there are high fluid accelerations with local static reductions

- Predicting possible bubble formation in clearance areas where there is likely to be high fluid shear rates and flow separation. 
The inducer profile is shown in Figure 6, with some of the features resulting from the design effort required to install an inducer in the existing prototype configuration. For the blade tips, the nominal inlet diameter of $19 \mathrm{in.}$ in the prototype pump was reduced to $18.53 \mathrm{in}$. to provide room for the inducer tunnel (low end of the ISIP diffuser) to extend down into the 19-in. inlet bore of the remachined prototype inlet (see Figure 3 ). The nominal 0.050 -in. radial gap between the inducer blade tips and the bore of the diffuser tunnel was calculated for this blade shape. The purpose of this allowance was to carry any bubbles which might form in flow through the gap, away from the blade surface and into the fluid stream between blades before collapse. The leading edge configuration provides a low loss entry into the vane system, with the blade "rake" imparting slight prewhirl to the fluid before reaching the blade tip leading edge.

The inducer inlet hub diameter was a compromise selection between having optimum hydrodynamic performance and providing adequate area for the 50-gpm through-the-shaft flow to the top of the bearing (see Figures 1 and 2 of Appendix C), plus room for inducer mounting hardware. The increased exit hub diameter provides some increase in head for the hub-side stream tube by virtue of its larger (than the inlet hub) tangential velocity, making a more uniform head profile across the exit radius.

Approximate velocity triangle calculations for the inducer are shown in Appendix A. These figures indicate that the change in blade angle is low, approximately 11 degrees over the length of the blade, making the inducer blades appear somewhat like a constant angle helix. The calculations are approximate, similar to the sizing calculations for the impeller. Actual vane angles and hub profile are performed in detail and optimized with the computer programs, considering local fluid velocities, accelerations, and blade pressure differences. The high 
solidity blading permits low local blade loading and avoids the risk of flow separation within the blade system.

\subsubsection{Impeller/Inducer Assembly}

Two hydrodynamic requirements had been established for the impeller/ inducer assembly; these were regarding limits for the hydrodynamic radial and axial thrust loads which have to be supported by the pump bearing. The radial load requirement was a qualitative one, stating that symmetry should be used where feasible to minimize radial loads. The ISIP impeller and diffuser are designed with polar symmetry. The only existing hydrodynamic asymmetry in the ISIP design is in the existing suction elbow. However, through test experience, it is known that hydrodynamic radial loads will occur due to eccentricities resulting from manufacturing and assembly tolerances, bearing characteristics, and flow phenomena. The radial loads due to flow phenomena are most pronounced at low (throttled) flows when flow angles are markedly different from vane angles. In such cases, an asymmetrical flow and pressure distribution pattern is possible. The estimated maximum radial thrust for the impeller given in Appendix $G$ is $800 \mathrm{lb}$. For the inducer there is an estimated transverse moment (normal to the shaft axis), due to asymmetrical axial pressure gradients of 13,300 in.-1b. If acting in the same line, the combined radial load at the sodium bearing could be 984 ib (see Appendix A).

Control of axial thrust generated by the impeller/inducer assembly is achieved by sizing the labyrinth seals to provide thrust within the specification limits. Inputs for the thrust calculations include momentum change through the assembly (axial components only), radial pressure distribution along the lower (front) and upper (back) shrouds, and the radial pressure distribution between the upper (back) labyrinth and the shaft. For configurations such as the shroud, an assumption 
that the fluid rotates at about half the angular velocity of the impeller is usually adequate; for other configurations, such as between the upper labyrinth and shaft where the rotating surface area is relatively large compared to the stationary area, higher fluid rotational velocities are justified for use in the calculations.

\subsubsection{Diffuser}

With a new pump design, one diffuser would normally be considered adequate for conversion of impeller discharge velocity into pressure. However, for the ISIP, being installed into an existing configuration, there were two considerations as to why the intermediate (ISIP) diffuser was included in the hydrodynamic design: hydrodynamic performance at low (throttled) flow conditions, and structural support at the inducer tunnel.

Performance tests of the Westinghouse Prototype Pump (with its existing diffuser) showed unstable, and high, radial loads when the discharge flow was throttled below about $80 \%$ of its design value at constant speed $(Q / N \cong 11)$. The result was evidenced in the performance of the hydrostatic sodium bearing during which the position of the journal within the bearing would start to vary, both in angle from a fixed reference and offset from the bearing center, until the minimum film thickness would start to decrease below minimum permissible operating value, which was $25 \%$ of the available radial clearance, approximately 0.005 in.. Rocketdyne attributed this instability to flow separation (similar to stalling) in the curved diffusion passageways of the prototype diffuser when the inlet flow angle was changed from its design value by throttling. In an effort to permit a wider range of operation, the ISIP diffuser was designed to provide fluid flow to the prototype diffuser at a nearly constant angle. Not having curved diffusion passageways, the ISIP diffuser is expected to be less sensitive to variations of the inlet flow angle which occur during throttling. 
The structure that supports the lower labyrinth seal of the prototype pump permits too much lateral motion to use for support of the diffuser tunnel.

Proper operation of the inducer requires that the inducer blade tip-to-inducer tunnel bore radial clearance be maintained at .050 in. (nominal) within close tolerance. Therefore, the inducer tunnel was designed as part of the ISIP diffuser shroud which is supported from the pump bearing support structure through the 11 ISIP diffuser vanes. This mechanical arrangement permitted maintaining the blade radial clearance independent of motion at the prototype lower labyrinth. Otherwise, attaching the diffuser tunnel to the stationary member of the prototype lower labyrinth would have required a greater clearance, as evidenced by the 0.100 in. radial clearance for the prototype lower labyrinth as opposed to the $0.050 \mathrm{in}$. radial in the upper labyrinth, which is a part of the bearing support flange (see 2.9.3 for discussion of radial clearances).

The ISIP diffuser has 11 vanes, as has the prototype diffuser. The vanes are installed so the wake from the trailing edge of the ISIP diffuser vanes will feed into the middle of the channels of the prototype diffuser throats. The staggering of vanes was chosen to minimize the potential for boundary layer buildup through the prototype diffuser passageways. Like the ISIP impeller, the width of the ISIP diffuser was maintained equal to the prototype diffuser inlet width (2.75 in.) to minimize flow losses.

\subsection{STRUCTURAL DESIGN}

\subsubsection{Steady-State Analys is}

Analyses of the structural integrity of ISIP components were performed in two parts. The first part was the steady-state structural 
analysis based on steady-state operation at design temperature. At the time of the steady-state analysis, the design temperature was specified as $1050^{\circ} \mathrm{F}$, and the structural design criteria were those given in the technical requirements document (Ref. 4). The work was performed using computer models of the components as shown in the design layout drawing (Figure 3). Other input data included the mechanical loadings due to pressure distributions around the various components. The data were based on results from the hydrodynamic analysis, centrifugal forces due to rotation, and assembly loads resulting from shrink fits. The impellerto-shaft fit was the most intensive in this category. The results are reported in the steady-state stress report of Appendix $H$. The results show that the steady-state design criteria are met. It should be noted that in view of these results, the reported margins are with respect to the design criteria of Reference 4 which also have margin included to allow for additional stresses to be imposed during thermal transients. For hydrodynamic loadings resulting from other than design point operation, the steady-state design criteria could be relaxed some to reduce the margins since all thermal transients are scheduled to be run at design speed and flow. No effort was made to revise the steady-state structural analysis and calculated stress margins after the specified test temperature was reduced from $1050^{\circ} \mathrm{F}$ to $950^{\circ} \mathrm{F}$, since the effect was to increase the allowable stresses by about 15\%, which would have increased the calculated margins above already acceptable values.

\subsubsection{Thermal Transient Analys is}

Structural response of the ISIP during thermal transients was analyzed by first calculating the temperature distribution throughout the lower end of the structure, which would occur during the test thermal transients; then, on the basis of selecting most adverse temperature distributions, calculating the resulting thermal stresses. The calculated temperature distributions were also used to calculate thermal distortions which affect internal fits and running clearances. 
Results of the thermal stress and distortion calculations are given in Appendix I. These are based on the temperature distortions calculated in Appendix $J$. In order to verify the adequacy of the ISIP thermal model, it was first used to calculate temperatures from the previous prototype pump tests, using actual test input temperatures. The calculated temperatures were then compared to temperatures measured during the tests. The results of this verification study is given in Appendix $K$.

In addition to transient structural analysis of the ISIP components, an investigation of the adjacent, existing prototype components was made; particularly of the bearing support flange. The investigation was made to determine whether they would be subjected to more severe transient conditions during ISIP tests, than they had previously withstood successfully during transient tests of the prototype pump, and for which they had been previously analyzed. The results, as shown in Appendix I, show that the prototype pump parts will not be subjected to more severe conditions during ISIP tests than were encountered during prototype pump tests. Therefore, no further structural evaluation was made. 


\subsection{DESIGN VERIFICATION}

Final verification of the ISIP design will be through meeting the hydrodynamic and cavitation performance criteria of the specification, as evidenced by sodium test results and post-test inspection. To gain confidence that the ISIP will meet these ultimate objectives, a number of checks were made during the design and fabrication process. These checks can be divided into three categories: reviews, feature tests, and assembly checks.

\subsection{REVIEWS}

Due to the developmental nature of the ISIP project, the design was subject to continuous review, generally informal, throughout its progress. In addition to this continuous surveillance, three more structured reviews were held, the last of which included customer participation. For the structured reviews, a review board was selected from persons within the Energy Systems Group and the Rocketdyne Division. Those chosen are knowledgeable in specific areas of design, fabrication, and testing, and if possible, have not had part in generating the information to be reviewed.

The initial review was held on December 8, 1977, for the purpose of determining the adequacy of the conceptual design layout drawing and technical requirements. This review was designated as an "Engineering Review" since the board's function was to provide recommendations and questions for consideration as the design progressed. No engineering response to these recommendations and questions was required.

The second review was held on April 10, 1978, and designated as a "Preliminary Design Review." Its purpose was to review the preliminary design, as represented by the design layout drawing, and the pump specification. The review also served to define those items for which 
additional work was required prior to the final. (customer) design review to be held before fabrication.

The third review was held on May 10, 1978 and was designated as a "Customer Design Review." The review board included members from Argonne National Laboratory (ANL), who represented the interests of the customer (DOE), and from Hanford Engineering Development Laboratory (HEDL), who represented the test vehicle owner. The Rockwell members included persons skilled in the areas of materials, structural and thermal analyses, hydrodynamics, mechanical design, test, quality assurance, and manufacturing. The design layout drawing and pump specifications were reviewed along with supporting documentation, including material specifications and analytical reports. The review resulted in a number of action items and recommendations which were subsequentiy resolved with the board members by the Engineering Department. A copy of the completed review report is included as Appendix $D$. The issue shown (Change No. 1) includes a statement, on the cover page, to the effect that all action items were answered satisfactorily, and is signed by the chairman and the administrator of the review board. Final release of the layout drawing, Figure 3 , includes a decal adjacent to the title block with approval signatures by the review board members.

An additional review to be performed is the test readiness review, which will be held approximately one week prior to rotation. The purpose of this review is to verify that both the pump assembly and the test facility are ready for the initiation of testing.

\subsection{FEATURE TESTS}

Feature tests are used to verify that specific design features will perform as expected, prior to the completion of the pump assembly. For the ISIP, one feature test was performed. This was a test series to 
verify that hydrodynamic design of the inducer was adequate. These tests were run on a 6-in. diameter scale model of the inducer in the water tunnel test loop at the Rocketdyne Division, where the inducer was designed and fabricated. The tests consisted of measuring the cavitation performance (variation of inducer head with net positive suction head) of the model inducer in water, and running simulated life tests to assess the capability for long-term operation in sodium at $200 \%$ NPSH margin without cavitation damage. Model tests were run ranging from $80 \%$ to $130 \%$ of the design flow, with NPSH margins from zero percent to $258 \%$. A surface coating of "Magic Marker Type A" ink, as was used for previous model tests of the subscale inducer, was applied to the blades for the simulated life tests. The life tests were evaluated under the assumption that if dye removal occurs as a result of cavitation effects during water tests, there is almost a certainty that cavitation effects will eventually occur during operation in sodium under similar conditions. The converse is also assumed. The tests were run for both concentric and eccentric positioning of the inducer tunnel. Test results, as reported in Appendices $L$ and $M$, show that the inducer has good life expectancy with respect to the design requirements when operating at rated condition $\left(14,500 \mathrm{gpm}, 1,110 \mathrm{rpm}, 950^{\circ} \mathrm{F}\right)$ with $200 \% \mathrm{NPSH}$ margin.

NOTE: Due to the proprietary nature of some information contained in the original issue of Appendices $L$ and $M$, those pages containing proprietary information (i.e., inducer blade surface coordinates, inducer leading edge trim, inducer trailing edge trim, and impeller leading edge trim) have been deleted from the appendices. 


\subsection{ASSEMBLY CHECKS}

Assembly checks verify the design, manufacturing, and often a portion of the assembly procedures with respect to fits, clearances, and tolerances. Those checks are over and above the normal dimensional inspection, and generally relate to functionability. For the ISIP, four assembly checks were included. The first was to verify that the $1-$ in. total axial clearance between the impeller and diffuser shroud was actually provided prior to pump assembly. Measurements made prior to assembly, using the actual parts, showed that 0.999-in. clearance was available. The second assembly check was to verify that the fits and lead-in tapers of the design were adequate to align the diffuser shroud to the static hydraulics, without interference or damage to the thin lower end of the diffuser shroud. That check was also to verify that the piston ring would compress without damage during assembly of the upper internals (SP/SC sodium bearing assembly, oil bearing assembiy, and shaft assembly) to the static hydraulics. The ring cannot be seen as it starts into the static hydraulics, nor is there any "feel" due to the weight of the upper internals (approximately 45 tons). The initial check, using the diffuser assembiy mounted on the bearing support flange, showed no problem with piston ring compression or diffuser shroud alignment.

The third assembly check was the shaft alignmnent check, designed to verify that assembiy of the upper internals had been accomplished satisfactorily within the calculated tolerance stackup limits. Measurements taken of the inducer blade-to-inducer tunnel shroud clearance showed a minimum measured clearance of .037 in. vs a calculated worst condition of .012 in. (Appendix F). Radial eccentricity of the inducer with respect to the axis of the shaft journal bearings was .005 in. vs a calculated maximum value of .007 in., and eccentricity of the diffuser shroud around the inducer was .003 in. vs a calculated maximum value of .0075 in. 


\subsection{TEST PLANS}

Testing of the Intermediate-Size Inducer Pump (ISIP) is to be performed in the Sodium Pump Test Facility (SPTF) at the Energy Technology Engineering Center (ETEC) where sodium tests were run on the Fast Flux Test Facility (FFTF) Prototype Pump. The prototype pump tank, which will also be used for the ISIP, is still installed in the SPTF test loop. Pump assembly and disassembly, also considered a part of testing, is to be performed by ETEC in the Component Handling and Cleaning Facility (CHCF) which is adjacent to the SPTF. Special tools required for assembly will be principally the same tools as used for assembling the prototype pump. Some modifications of the prototype tools and new tools specially designed to fit ISIP components were provided by Atomics International.

As originally planned, testing of the ISIP in SPTF would repeat most of the Phase $B$ tests previously performed on the prototype pump with basically the same instrumentation. In addition to utilizing existing facilities, this approach has the advantage of permitting comparative evaluation of two different types of pumps, one with an inducer and one without, without introducing questions of test setup or facility differences when evaluating the results.

An Approval-in-Principle (AIP) was prepared and submitted to Department of Energy for approval of the tests to be run by ETEC (Ref. 10). Next, a Request for Test (RFT) was prepared (Ref. 11) giving detail requirements for tests to be performed in the ISIP. In addition to the tests previously performed on the FFTF Prototype Pump during Phase B tests at SPTF, the RFT also included an interim disassembly and inspection, to be performed after determining NPSH requirements at various flows. These tests were to be followed by a $2000 \mathrm{hr}$ design point endurance test at $200 \%$ NPSH margin, then a $300 \mathrm{hr}$ off-design 
endurance test to be run at runout loop impedance but reduced pump speed to match the design flow, and finally the series of thermal transient tests which had been run on the FFTF prototype pump.

The NPSH value corresponding to $200 \%$ margin would be based on the measurement NPSH required at design flow and speed $(14,500 \mathrm{gpm}$ and 1,110 rpm) to 1 imit the overall head drop, due to cavitation, to $3 \%$. For the off-design endurance test, the NPSH would remain the same as for the $200 \%$ margin at design condition, but the flow impedance of the test 10op would be decreased to that defined by the runout flow condition $(18,000$ gpm at 1,110 rpm). The pump speed would be decreased to $894 \mathrm{rpm}$ to maintain the $14,500 \mathrm{gpm}$ flow rate. Based on results from water tests of an inducer model, the NPSH margin for this off-design condition is expected to be approximately $89 \%$.

The Request for Test was subsequently revised to delete those tests which, although important for the FFTF Prototype Pump, would add little information concerning the ISIP design. Tests deleted included the onehour NPSH demonstration test which was based on FFTF plant requirements, the 8-hr post NPSH test endurance run which would be covered by the 2000-hr endurance run, two low-rate $\left(0.4^{\circ} \mathrm{F} / \mathrm{sec}\right)$ thermal transients which would retest the prototype pump structure but not the ISIP components, and one up transient which was basically a repeat of a similar transient at lower temperatures. Also deleted was the interim disassembly and inspection. The maximum test temperature was reduced from $1050^{\circ} \mathrm{F}$ to $950^{\circ} \mathrm{F}$ which obviated those tests designed to monitor pump operation from $950^{\circ} \mathrm{F}$ to $1050^{\circ} \mathrm{F}$, and those $1050^{\circ} \mathrm{F}$ tests which were a repeat of the $950^{\circ} \mathrm{F}$ tests. When the test request was originally written, water test results of the ISIP inducer model were not yet available. These results later showed that inducer performance in the specified operating range was expected to be very good (see Appendices $L$ and $M$ ). Test results from the subscale inducer model also indicated that the water test results 
were valid for predicting good suction performance in sodium, as later confirmed by sodium tests of that pump. These test results provided the confidence level needed for the AI recommendation to delete the interim disassembly and inspection from the ISIP test plans. 


\subsection{REFERENCES}

1. ANL Contract 31-109-38-4473, "Subsca7e Inducer Pump Prototype Update"

2. ESG-DOE-13265, "Task Proposal/Agreement," SA033, dated March 15, 1979

3. HWS-1551, Rev. 1, "Specification - LMFBR Low-Capacity Prototype Pump and FFTF Primary Pump," dated January 1974, including Modifications to RDT-E3-2T dated January 1974 and Addenda through IP dated May 24, 1977

4. N266TI000001, "Intermediate-Size Inducer Pump Technical Requirements," dated January 20, 1978

5. HEDL Letter 7850652 dated February 10, 1978 (1906AT), W. J. McShane (HEDL) to Director, FFTF-PO, "HEDL Approval of AI ISI Bearing Drain Methodology and Labyrinth Clearances.

6. RDT F 8-6T, "Hoisting and Rigging of Critical Components and ReTated Equipment"

7. Westinghouse Drawing 160A243, "Standard Labyrinth Seal Grooves"

8. EM4708, "FFTF Primary Pump Rotor Dynamics Ana7ysis," by L. C. McNutt, February 9, 1977 - Westinghouse Electric Corp., Electro-Mechanica? Division, Cheswick, Pa.

9. "Fluid Mechanics of Turbomachinery," by George F. Wislicenas; 2nd Ed., Vol. I, Dovar Publications Inc., N.Y., N.Y., 1965

10. AI Letter 78AT-2187, R. V. Anderson (AI) to Director, DOE-SAN "Intermediate-Size Inducer Pump (ISIP), Revised Request for ApprovalIn-Principle (AIP)," dated March 7, 1978

11. N266RFT000001, "Sodium Testing of Intermediate-Size Inducer Pump in SPTF at ETEC" by J. 0. Pfouts

12. ANL-7323, "Thermophysical Properties of Sodium," by G. H. Golden and J. V. Tokar, Argonne National Laboratory, Argonne, Illinois, August 1967

13. N40007, "Intermediate-Size Inducer Pump (ISIP) Impeller/Inducer Dynamic Balance," October 9, 1978 


\section{APPENDICES}

Appendix

$\underline{\text { Page }}$

A. Calculations............................. 65

B. Design Specification - Pump, Sodium, Inducer, Intermediate-Size (ISIP) (Impelier/Inducer/Diffuser Retrofit)............................ 84

C. Recirculating Flow Analyses of Intermediate-Size

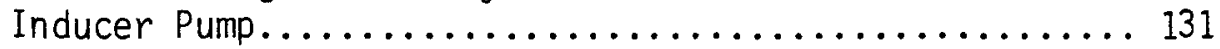

D. Customer Design Review Intermediate-Size Inducer Pump................................... 149

E. Rotordynamics of the Intermediate-Size Inducer Pump (ISIP)............................ 192

F. Radial Tolerance Stackup - ISIP................. 206

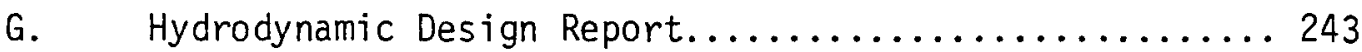

H. Steady-State Structural Analysis (Pump Internals)..... 276

I. Intermediate-Size Inducer Pump - Structural Analysis and Transient Deformation Studies.......... 365

J. Transient Thermal Analysis of ISIP................ 499

K. Verification of Thermal Model for ISIP (Intermediate-Size Inducer Pump).................. 607

L. Model Inducer Water Tunnel Test Report.............. 685

M. Model Inducer Water Tunnel Test Report - Eccentric Operation. 


\section{APPENDIX A}

\section{Page}

CALCULATIONS

Radial Clearances

Piston Ring Leakage Estimate

Impeller Blade Calculations

Inducer Blade Calculations

Radial Loads on Sodium Bearing

Axial Motion of Impeller with Respect to Diffuser 


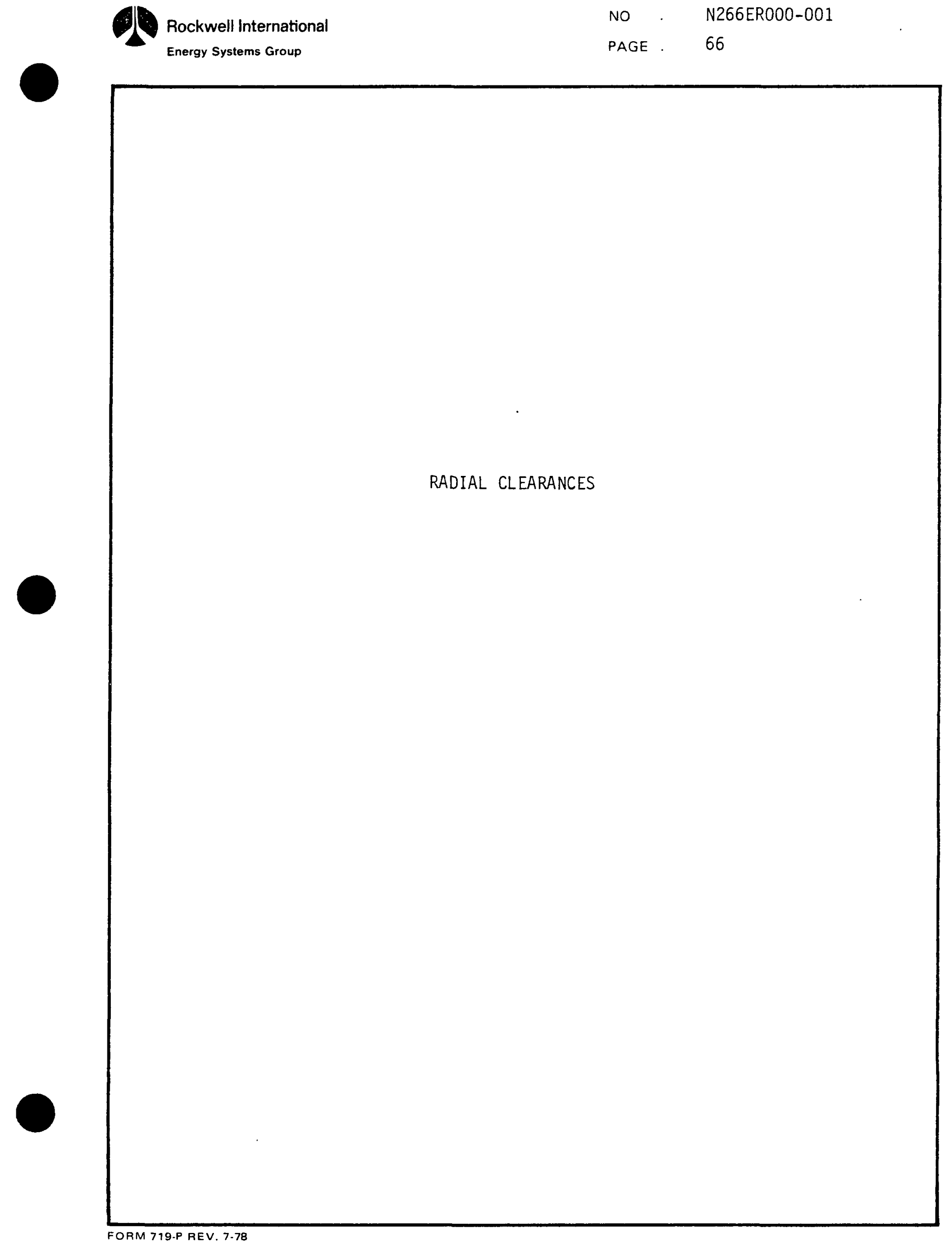




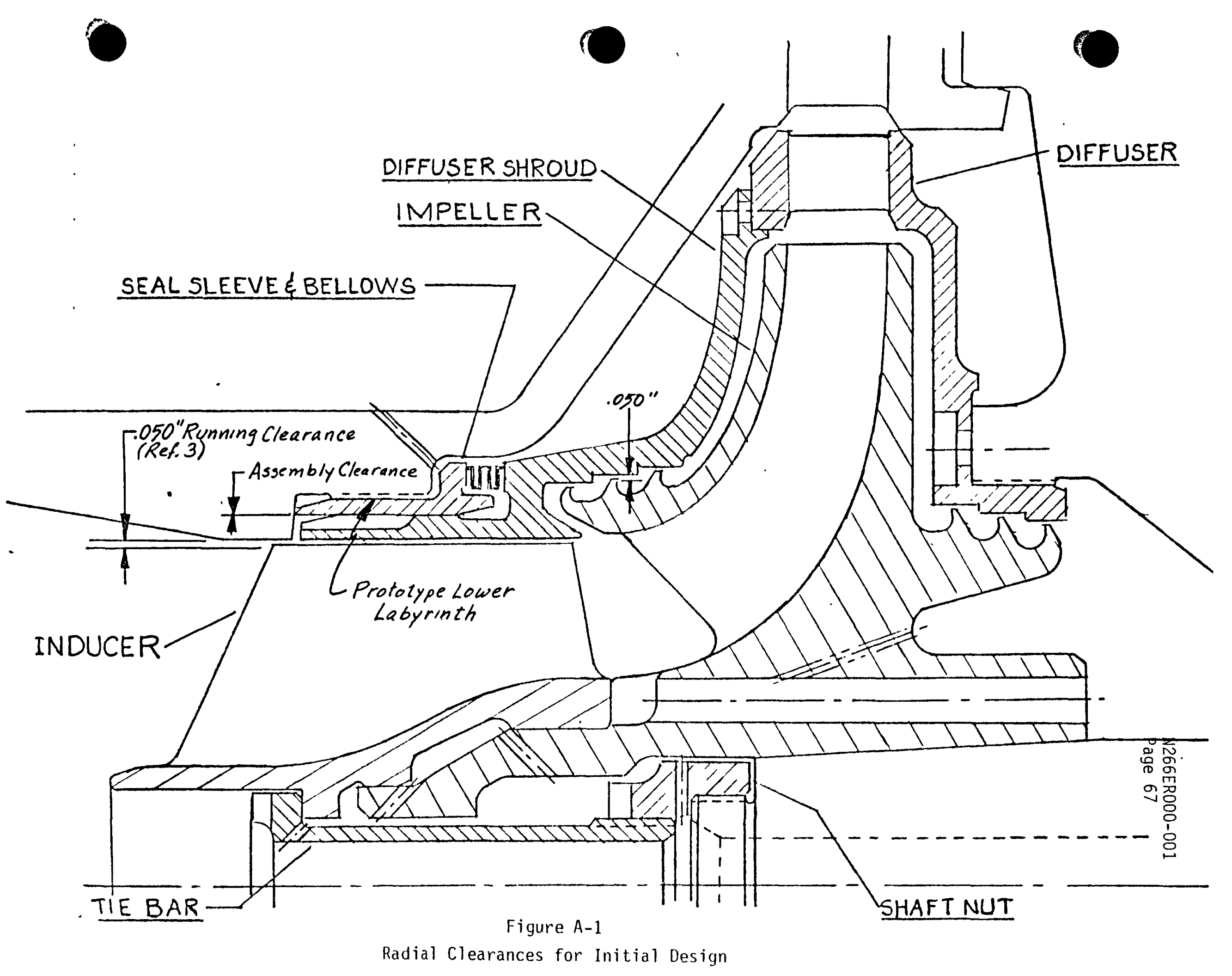




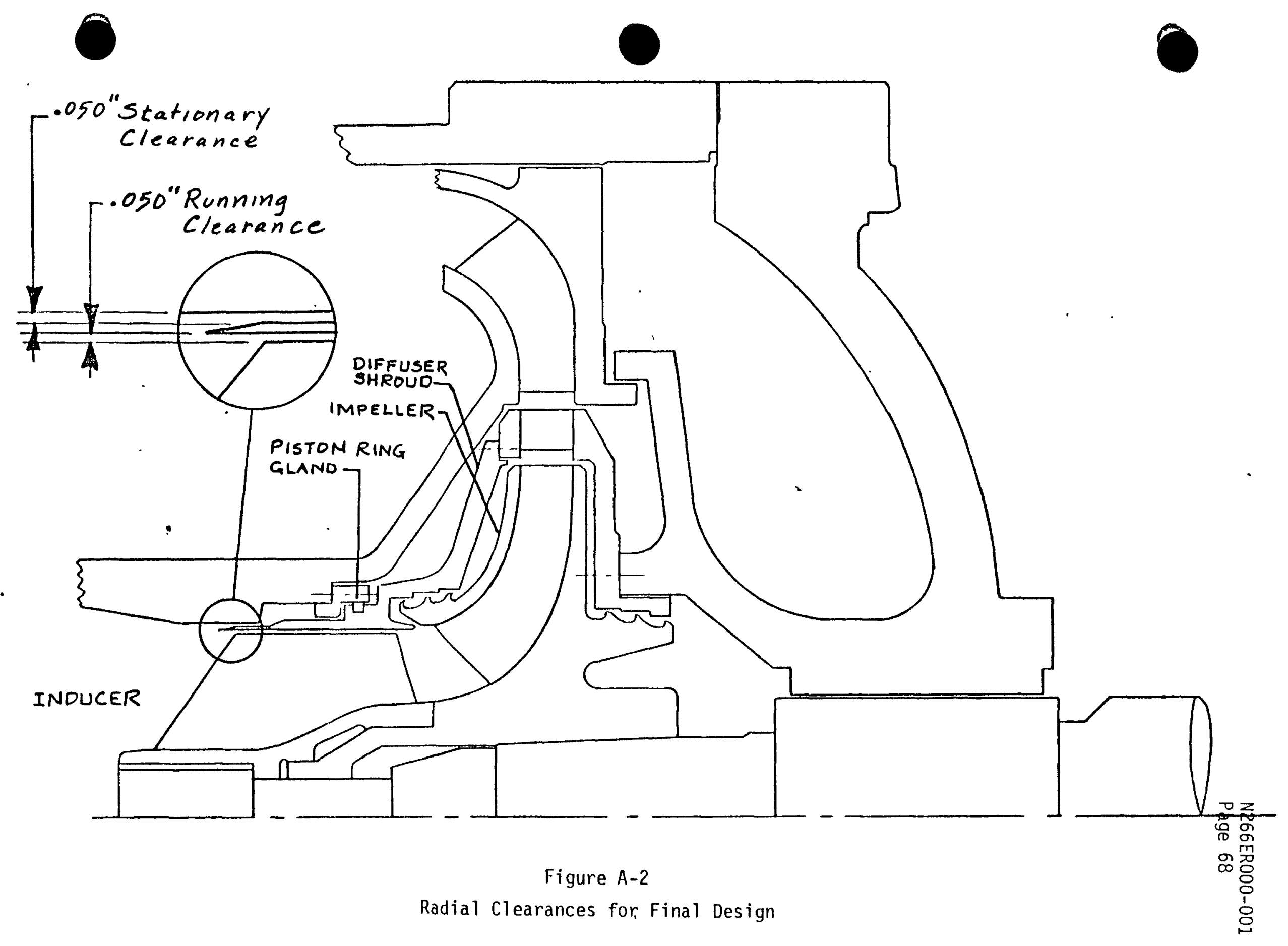




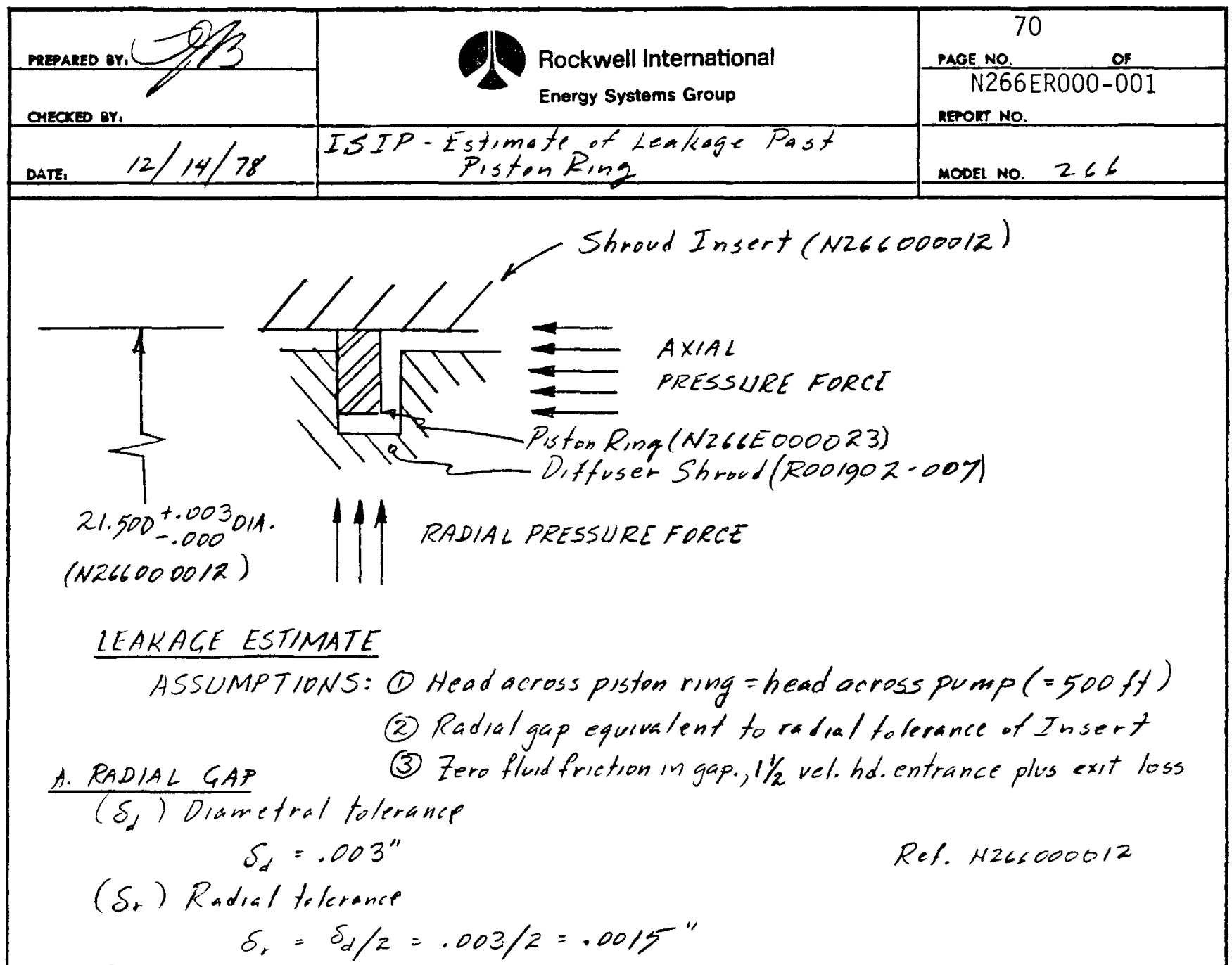

(D) Seal diameter

$$
D=21.500^{\prime \prime} \text { (nom) }
$$

$\left(A_{1}\right)$ Area of radial gap

$$
A_{r}=\pi D \delta_{r}=\pi(21.5 \times .0015)=0.101 \mathrm{in}^{2}
$$

Assumption (2)

$\left(v_{m i}\right)$ Maximum velocity thru gap

$$
\begin{aligned}
& 1.5 \frac{V_{m}^{2}}{2 g}=H \\
& V_{m 1}=\sqrt{2 g H / 1.5}=\sqrt{2(32.2)(500) / 1.5} \\
& V_{m 1}=146 \mathrm{ft} / \mathrm{sec}
\end{aligned}
$$

Assumption (3)

Assumption (1)

$\left(Q_{m}\right)$ Maximum flow thru gap

$$
\begin{aligned}
Q_{m,} & A, V_{m 1} / .321 \text { Where } .321=\text { Conversion factor for } 1 n^{2}, \mathrm{ft} / \mathrm{sec}, \mathrm{gpm} \\
& (.101)(146) / .321 \\
Q_{m i}= & 46.24 \mathrm{gpm}
\end{aligned}
$$

N 152-R-2 REV. B-78 


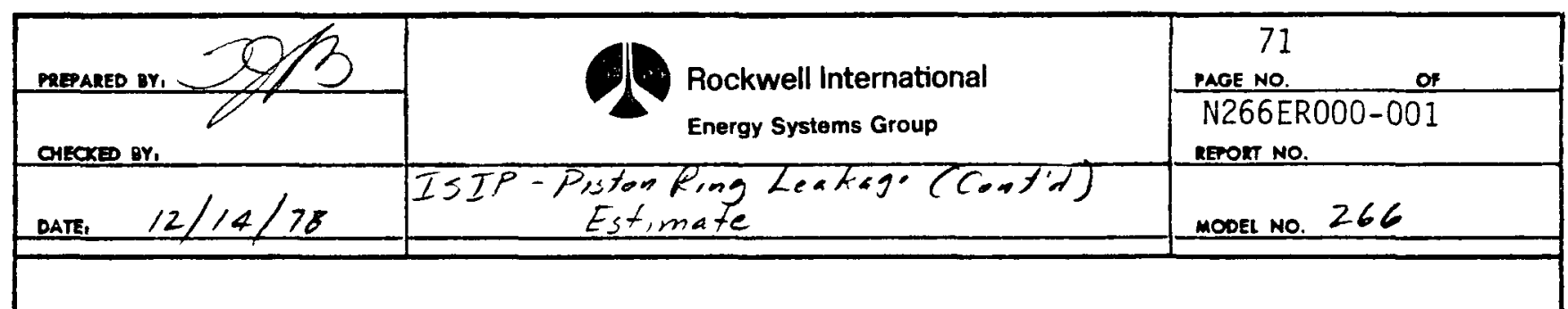

B. $A X I A L G A P$

A SSUMPIIONS: (4) Axial gap equivalent to $1 / 2$ piston ring flat ines

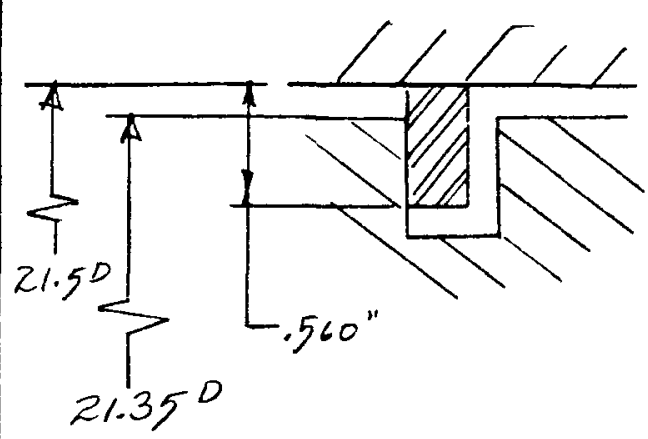

$\left(D_{0}\right)$ Outer diameter of seal

$D_{0}=21.35^{\prime \prime}$

Rot. R0019602

(W) Width of sea

$w=0.560^{\circ}$

Ref. N266E000023

$\left(D_{i}\right)$ Inner diameter of seal

$$
D_{i}=21.35-2(.560)=20.23^{\circ}
$$

$\left(\delta_{a}\right)$ Equivalent axial gop

$$
\delta_{a}=.003 / 2=.0015 "
$$

Assumption (t)

Ref N266E000023

(D) Root mean square dial. (for evaluating $r^{2}$ f ot.)

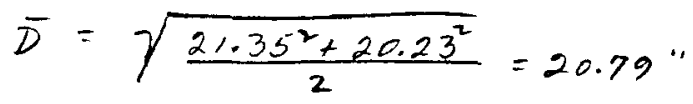

(Aa) Area of axial gop

$$
A_{a}=\pi \bar{D} \delta_{a}=\pi(20.79)(0015): 0979 \mathrm{in}^{2}
$$

$\left(V_{m_{2}}\right)$ Maximum Velocity thrugap

$$
V_{m_{2}}=\sqrt{2 g H / 1.5}=146 \mathrm{ft} / \mathrm{sec}
$$

Assumptions (3) \& (1)

$\left(Q_{m 2}\right)$ Maximum flow thru gap

$$
\begin{aligned}
& Q_{m z}=A_{a} V_{m z} / .321=.0579(146) / .321 \\
& Q_{m z}=44.7 \mathrm{gpm}
\end{aligned}
$$

(Q) Total flow throperstoneing seal

$$
Q=Q_{m,}+Q_{m, 2}=46.24+44.7=90.9 \mathrm{gpm}
$$

Considering the conservative assumptions concerning gap and flow losses, the calculated $90.9 \mathrm{gpm}$ is close enough to the specified $80 \mathrm{gpm}$ to accept the piston ring design

N 152-R-2 REV. 8-78 


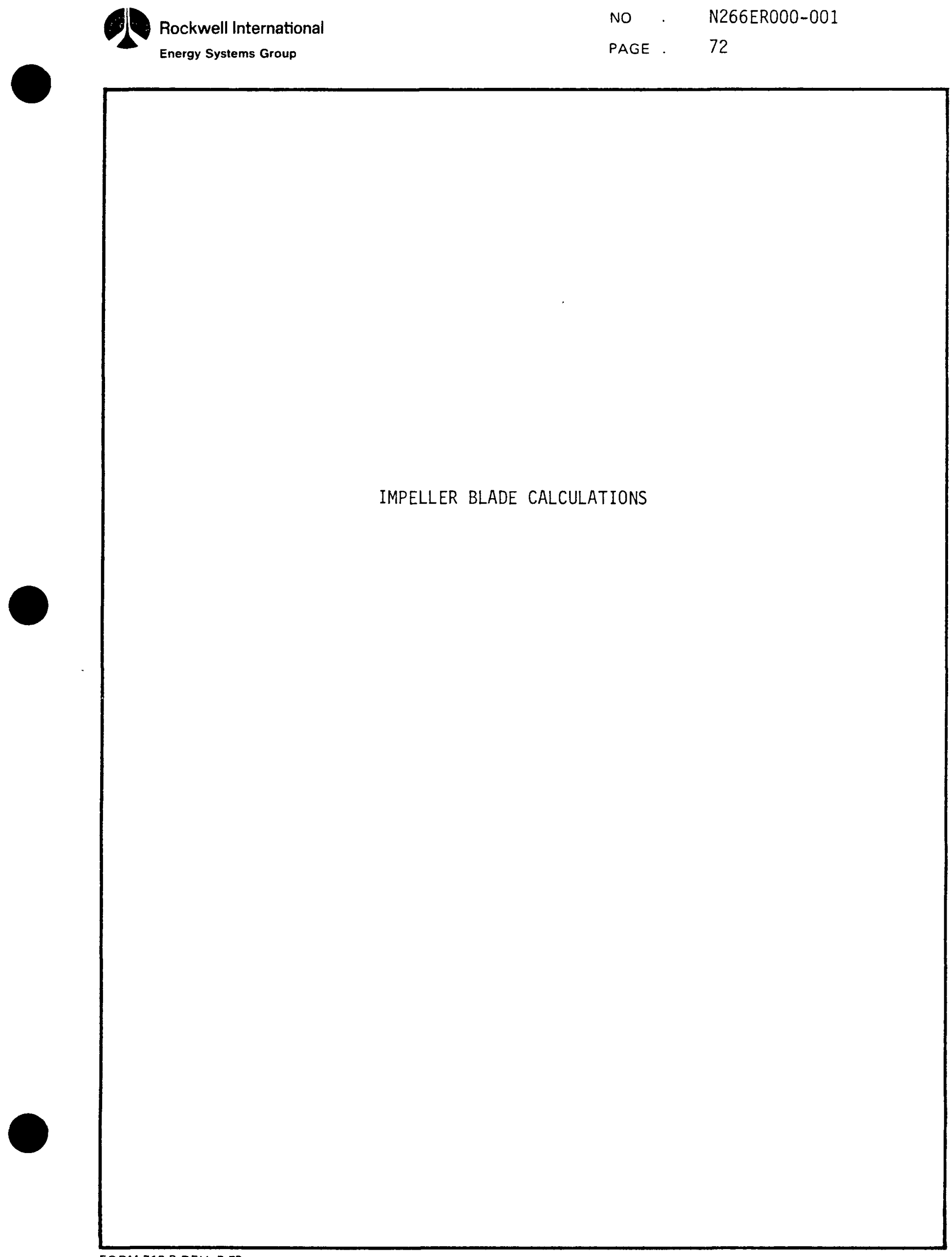

FORM 719.P REV. 7-78 


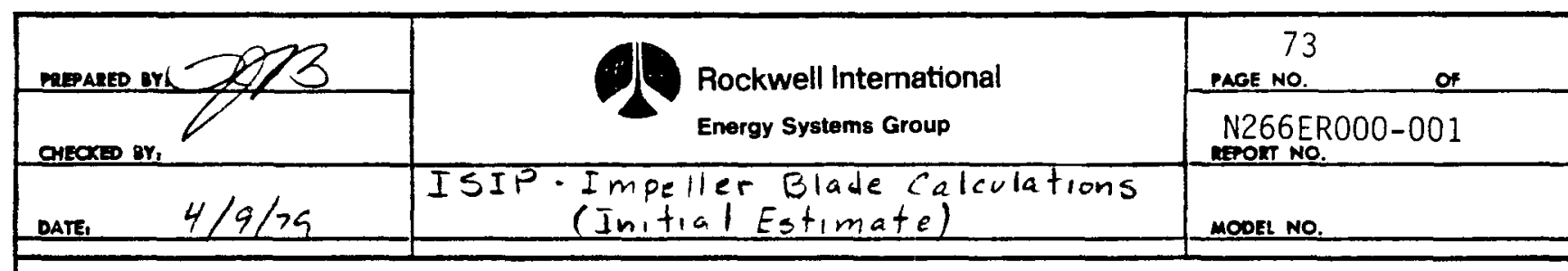

Ref."Fluid Mechanics of Turbo machinery" by G. F. Wislicenas

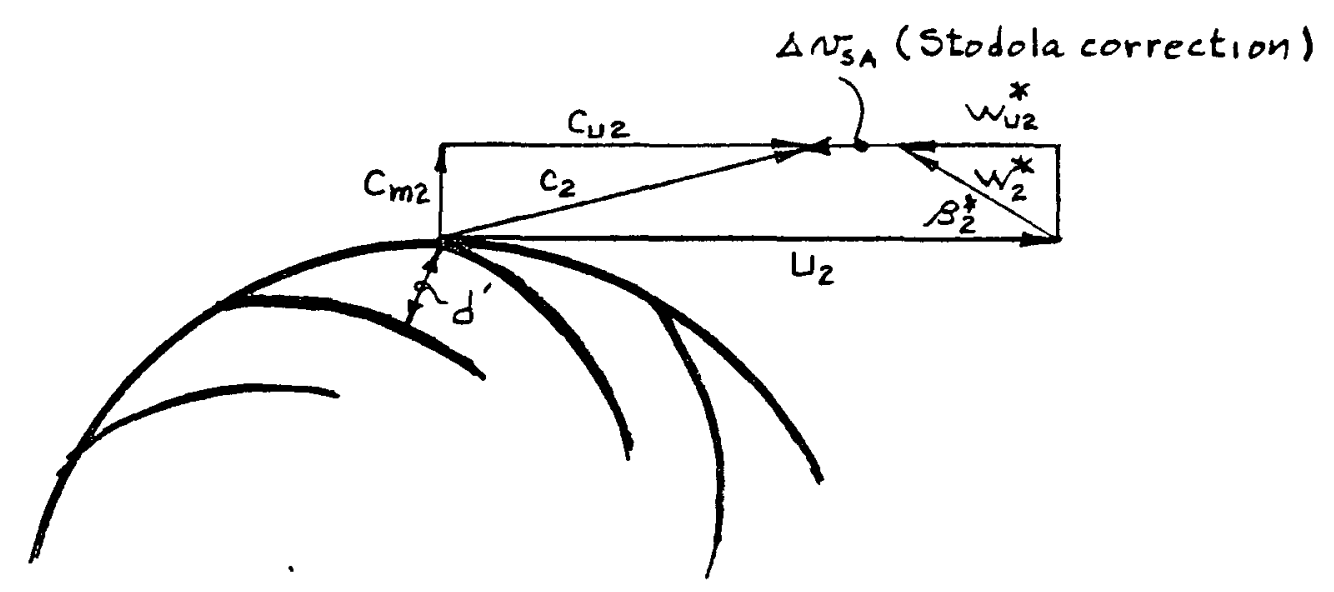

(Q) Impeller flow

$\left(D_{2}\right)$ Impeller tip diameter

$$
\begin{aligned}
& Q=15.917 \mathrm{gpm} \\
& D_{2}=35.4 \mathrm{in} \\
& B_{2}=2.75 \mathrm{in} \\
& N=1110 \mathrm{rpm} \\
& z=10
\end{aligned}
$$

(Sec Appendix )

$\left(B_{2}\right)$ Impeller tip width

(N) Rotating speed

(z) No. of blades

(H) Required head

$\left(\eta_{h}\right)$ Head rise efficiency (assumed) $\eta_{h}=80$ percent

$\left(H_{e}\right)$ Euler head

$$
\begin{aligned}
& H_{e}=H / \eta_{h}=900 / 0.8 \\
& H_{e}=625 \mathrm{ft}
\end{aligned}
$$

$\left(U_{2}\right)$ Impeller tip velocity

$$
\begin{aligned}
& \omega_{2}=\pi D_{2} N / 720=\pi(35.4) / 720 \\
& \omega_{2}=171.4 \mathrm{ft} / \mathrm{sec}
\end{aligned}
$$

$\left(C_{w_{2}}\right)$ Tangential absolute exit velocity (required)

$$
\begin{aligned}
C_{U_{2}} & =g H_{e} / \omega_{2}=32.2(625) / 171.4 \\
C_{L_{2}} & =117.4 \mathrm{ft} / \mathrm{sec} \\
\left(C_{m_{2}}\right) \text { Thru flow velocity }(0.85 \text { vane thickness blocking factor assumed }) & \\
C_{m_{2}} & =0.321 Q / 0.85 \pi D_{2} B_{2}=0.321(15917) / 0.85 \pi(35.4)(2.75) \\
C_{m_{2}} & =19.6 \mathrm{ft} / \mathrm{sec}
\end{aligned}
$$

N 152-R-2 REV. 8-78 


\begin{tabular}{|c|c|c|}
\hline & ell International & $\begin{array}{r}74 \\
\text { PAGE NO }\end{array}$ \\
\hline OHECKP BY & Energy Systems Group & $\begin{array}{l}\text { N266 ER000-001 } \\
\text { repokT No. }\end{array}$ \\
\hline Dare, $\quad 4 / 9 / 75$ & $\begin{array}{c}\text { ISIP- Impeller Blade Caleulations } \\
\text { (Initial Estimate) }\end{array}$ & MOOE NO. \\
\hline
\end{tabular}

BLADE DISCHARGE ANGLE CALCLLATION

(d) Discharge throat height

$$
\begin{array}{ll}
d^{\prime}=\frac{\pi D_{2}}{2} \operatorname{sen} \beta_{2}^{*} & \beta_{2}^{*} \rightarrow \\
d^{\prime}=\frac{\pi(35.4)}{10} \operatorname{sen} \beta_{2}^{*} \text { in } \quad d^{\prime} \rightarrow
\end{array}
$$

Parameters for 10 blade imperiler

$\left(A_{t 2}\right)$ Discharge throat area

$$
A_{t 2}=d^{\prime} B_{2} \quad \mathrm{in}^{2}
$$

$\left(W_{2}^{*}\right)$ Relative discharge velocity (fietitious)

$$
\begin{array}{ll}
w_{2}^{*}=\frac{.321 Q}{3 A_{t 2}} & \text { Ref. Sec.s } 333^{36} \\
E_{9 \cdot}(162)^{36} \\
w_{2}^{*}=321(15917) / 10 \cdot A_{t 2} \mathrm{ft} / \mathrm{sec} & W_{2}^{*} \rightarrow
\end{array}
$$

$\left(W_{v_{2}}^{*}\right)$ Tangential relative discharge velocity

$$
W_{\nu 2}^{*}=W_{2}^{*} \cos \beta_{2}^{*} \quad t t / \sec \quad W_{\nu_{2}}^{*} \rightarrow
$$
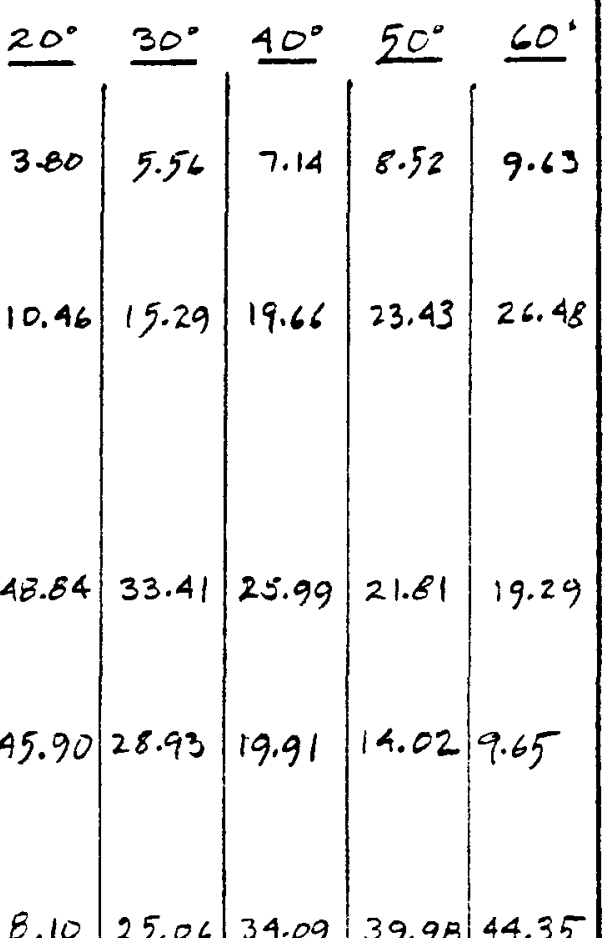

$\left(\Delta N_{S A}^{\prime}\right)$ Maximum usuable Stadola correction

$$
\Delta v_{S A}^{\prime}=\left(U_{2}-c_{u_{2}}\right)-W_{\omega_{2}}^{*} \mathrm{ft} / \mathrm{sec}
$$

8.10

28.93

19.91

$\left(K_{S A}^{\prime}\right)$ Stodola cerrection coefficient (based on Busemann's theoretical results)

$$
\underset{\text { (interpolated) }}{\text { Ref. Fig. } 127} \underset{K_{S A}^{\prime} \rightarrow}{ } \rightarrow
$$

$\left(\Delta N_{S A}\right)$ Predicted Stadola correction

$$
\begin{aligned}
\Delta v_{S A} & =K_{S A}^{\prime} H_{2} \frac{\pi \sin \beta_{2}^{*}}{3} \quad \text { Ref. } E_{q .}(3 \times q) \\
& =\frac{171.4 \pi}{10} K_{S A}^{\prime} \sin \beta_{2}^{*} t t / \sec \quad \Delta v_{S A} \rightarrow
\end{aligned}
$$

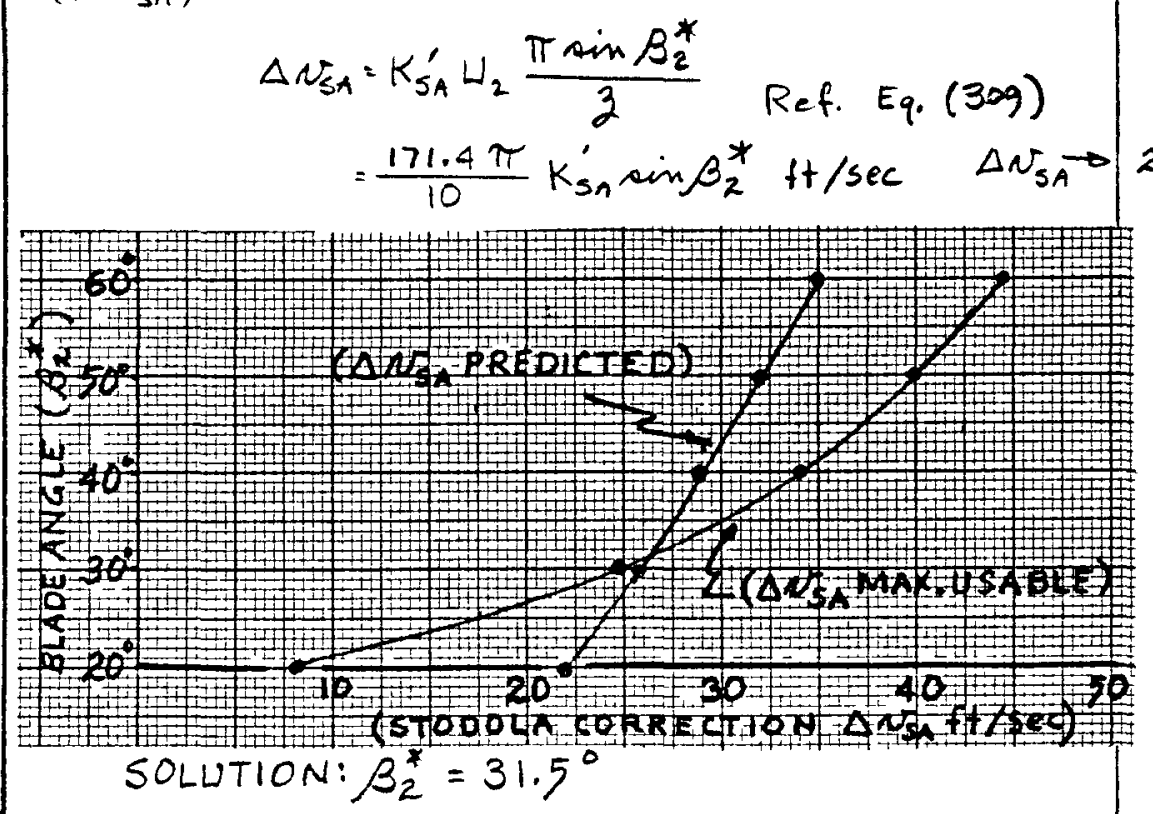




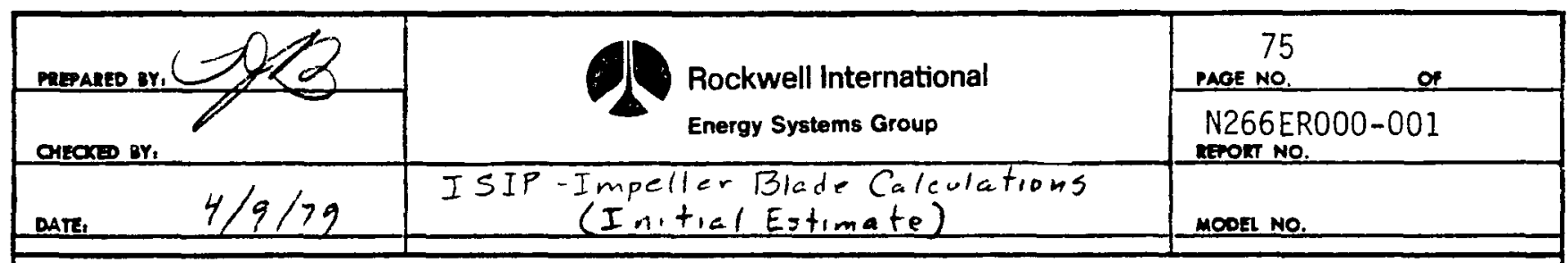

BLADE ANGLE INLET CALCULATIONS

$\left(D_{1}\right)$ Eye diameter

$$
D_{1}=19 \mathrm{in}
$$

Set by existing inlet diameter

$\left(d_{h}\right)$ Hub diameter

$$
d_{h}=11.36 \mathrm{in}
$$

$\left(H_{e i}\right)$ Inducer Euler head

$$
\begin{aligned}
H_{e i} & =.12 \mathrm{He}_{e} \\
& =.12(625) \\
H_{e i} & =75 \mathrm{ft}
\end{aligned}
$$

Based on inducer outlet hub sizing

Expected maximum inducer head for size and speed limit Subscript (i) denotes inducer

$\left(U_{1}\right)$ Impeller inlet tangential velocity

$$
\begin{aligned}
U_{1} & =\pi D_{1} N / 720 \\
& =\pi(19)(1110) / 720 \\
U_{1} & =92 \mathrm{ft} / \mathrm{sec} \\
& \text { NOTE: } U_{1} \simeq U_{2 i} \text { (inducer tip velocity) }
\end{aligned}
$$

$\left(C_{L 1}\right)$ Tangential fluid velocity approaching impeller

$$
\begin{aligned}
C_{U 1} & =C_{\nu 2 i}=g H_{C i} / U_{2 i} \\
& =32.2(75) / 92 \\
C_{U 1} & =26.24 \mathrm{ft} / \mathrm{sec}
\end{aligned}
$$

$\left(C_{m 1}\right)$ Meridional (thru-flow) velocity approaching impeller

$$
\begin{aligned}
C_{m_{1}} & =.321 Q / A_{e} \quad \text { Where } A_{\epsilon}=\text { Eyearea } \\
& =.321(15917) / .785\left(19^{2}-11.36^{2}\right) . \\
C_{m 1} & =28.0 \mathrm{ft} / \mathrm{sec}
\end{aligned}
$$

$\left(B_{1}\right)$ Relative approach angle

$$
\begin{aligned}
\beta_{1} & =\tan ^{-1} c_{m_{1}} /\left(U_{1}-c_{\nu_{1}}\right) \\
& =\tan ^{-1} 28.0 /(92-26.24) \\
\beta_{1} & =23^{\circ}
\end{aligned}
$$

$\left(W_{1}\right)$ Relative approach velocity

$$
\begin{aligned}
w_{1} & =c_{m_{1}} / \sin \beta_{1} \\
& =28 / \sin 23^{\circ} \\
w_{1} & =71.4 \mathrm{ft} / \mathrm{sec}
\end{aligned}
$$

N 152-R-2 REV. 8-78 
INDUCER BLADE CALCULATIONS 


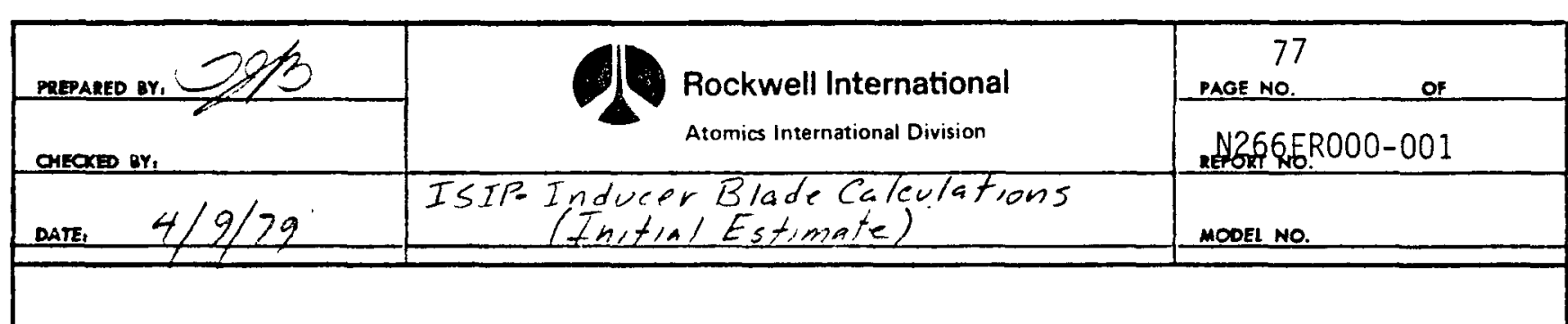

$\left(A_{1}\right)$ Inlet Flow Area

$$
\begin{aligned}
A_{1} & =\left(D_{i}{ }^{2}-D_{h l}^{2}\right) \pi / 4 \\
& =\left(18.63^{2}-6.63^{2}\right) \pi / 4 \\
A_{1} & =238 \mathrm{in}^{2}
\end{aligned}
$$

Where: $A_{1}=$ Inlet Flow Area $\left(\mathrm{in}^{2}\right)$

$D_{i}=$ Inducer Tunnel bore (in)

$D_{h_{1}}=$ Inducer inlet hub $O D(\mathrm{~m})$

( $\left.C_{m 1}\right)$ Axial fluid velocity (approaching inducer)

$$
\begin{aligned}
& C_{m 1}=0.321 Q / A_{1} \quad \text { Where: } Q=\text { Inducer flow }(\mathrm{gpm}) \\
& =0.321(14600 / 238) \\
& C_{m 1}=19.68 \mathrm{ft} / \mathrm{sec} \\
& (=14600 \mathrm{gpm} \text { from App. }) \\
& C_{m i}=A \times 1 a l \text { inset vel. (ff/sec) }
\end{aligned}
$$

$(U$,$) Blade tip velocity at inlet$

$$
\begin{aligned}
U_{1} & =\pi D_{4} \mathrm{~N} / 720 \\
& =\pi(18.53)(1110) / 720 \\
U_{1} & =89.75 \mathrm{ft} / \mathrm{sec}
\end{aligned}
$$

Where:

$$
\begin{aligned}
& U_{1}=\text { Tang, veldt blade tip (fflsed) } \\
& D_{t}=\text { Blade tip dian (in) } \\
& N=\text { Rotating speed (rpm) }
\end{aligned}
$$

$\left(\beta_{1}\right)$ Fluid inlet angle, relative to blade tip

$$
\begin{aligned}
\beta_{1} & =\arctan \left(C_{m_{1}} / \nu_{1}\right) \quad \text { Where: } \beta_{1}=\text { Reloangleatiniet }(\operatorname{deg}) \\
& =\arctan (19.68 / 89.75) \\
\beta_{1} & =12.36^{\circ}
\end{aligned}
$$

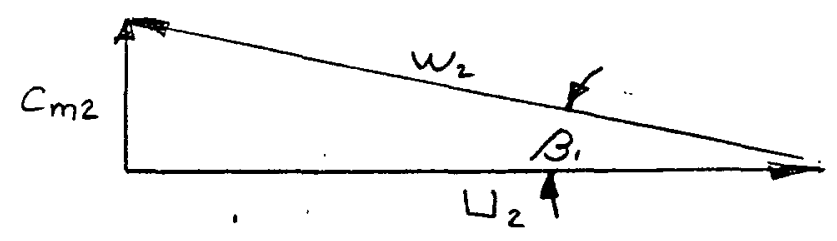

N IS2.R.2 REV. 2.76 


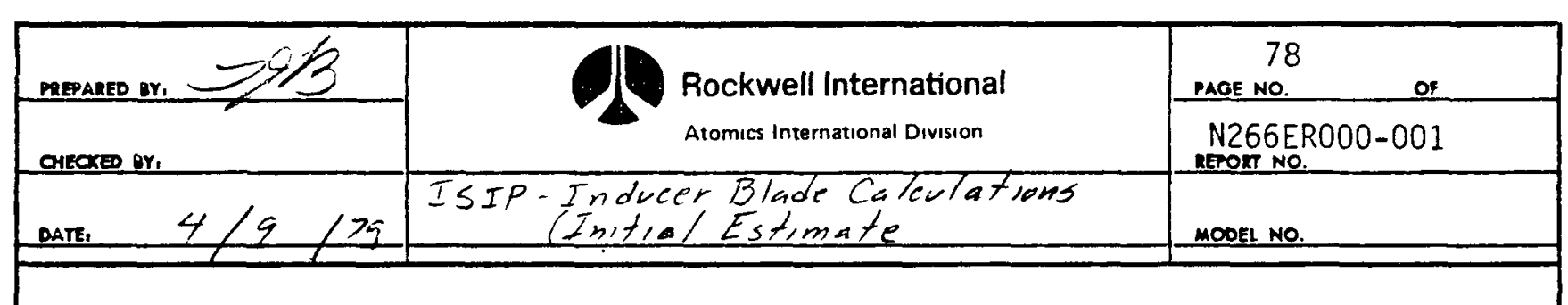

$\left(C_{u 2}\right)$ Tangential fluid velocity at exit

$$
\begin{aligned}
C_{U_{2}} & =g H_{e i} / \nu_{2} \\
& =32.2(75) / 89.75 \\
C_{\nu_{2}} & =26.91
\end{aligned}
$$

Where $C_{u z}=$ Tang, abs.exit vel. (ft/sec)

$H_{e i}=$ Inducer head

$(f t)$

(See imp. inlet calculation)

$U_{2}=$ Blade tip vel o ext (At/sec) $\left(=U_{1}\right)$

NOTE: This value differs slightly from the $26.24 \mathrm{ft} / \mathrm{sec}$ velocity calculated for the impeller inlet velocity triangle due to the slight difference in assumed inducer diameters (18.53 vs $19 \mathrm{in}$ )

$\left(A_{2}\right)$ Exit flow area

$$
\begin{aligned}
A_{2} & =\left(D_{i}^{2}-D_{h 2}^{2}\right) \pi / 4 \\
& =\left(18.63^{2}-11.36^{2}\right) \pi / 4 \\
A_{2} & =171 \mathrm{in}^{2}
\end{aligned}
$$

Where: $A_{2}=$ Exit flow area $\left(\mathrm{in}^{2}\right)$

$D_{h_{2}}=$ Inducer ext hub oD (in)

$\left(C_{m_{2}}\right)$ Axial fluid velocity (leaving inducer)

$$
\begin{aligned}
C_{m 2} & =0.321 Q / A_{2} \quad \text { Where. } C_{m 2}=\text { Ax/alexit well }(\mathrm{ft} / \mathrm{sec}) \\
& =0.321(14600) / 71 \\
C_{m 2} & =27.35
\end{aligned}
$$

$\left(\beta_{2}\right)$ Flue exit angle relative to blade tip

$$
\begin{aligned}
\beta_{2} & \left.=\arctan \left[C_{m z} /\left(U_{2}-C_{\nu 2}\right)\right] \text { Where: } \beta_{2}=\text { Reloangleat exit (deg }\right) \\
& =\arctan [27.35 /(89.75-26.91)] \\
\beta_{2} & =23.52^{\circ}
\end{aligned}
$$

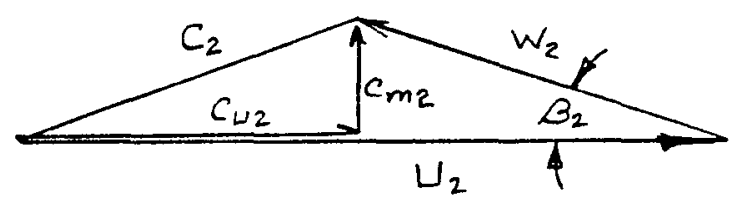

N 152R-2 REV. 2.76 
PAGE

79

RADIAL LOADS ON SODIUM BEARING

FORM 719-P REV. 7.78 


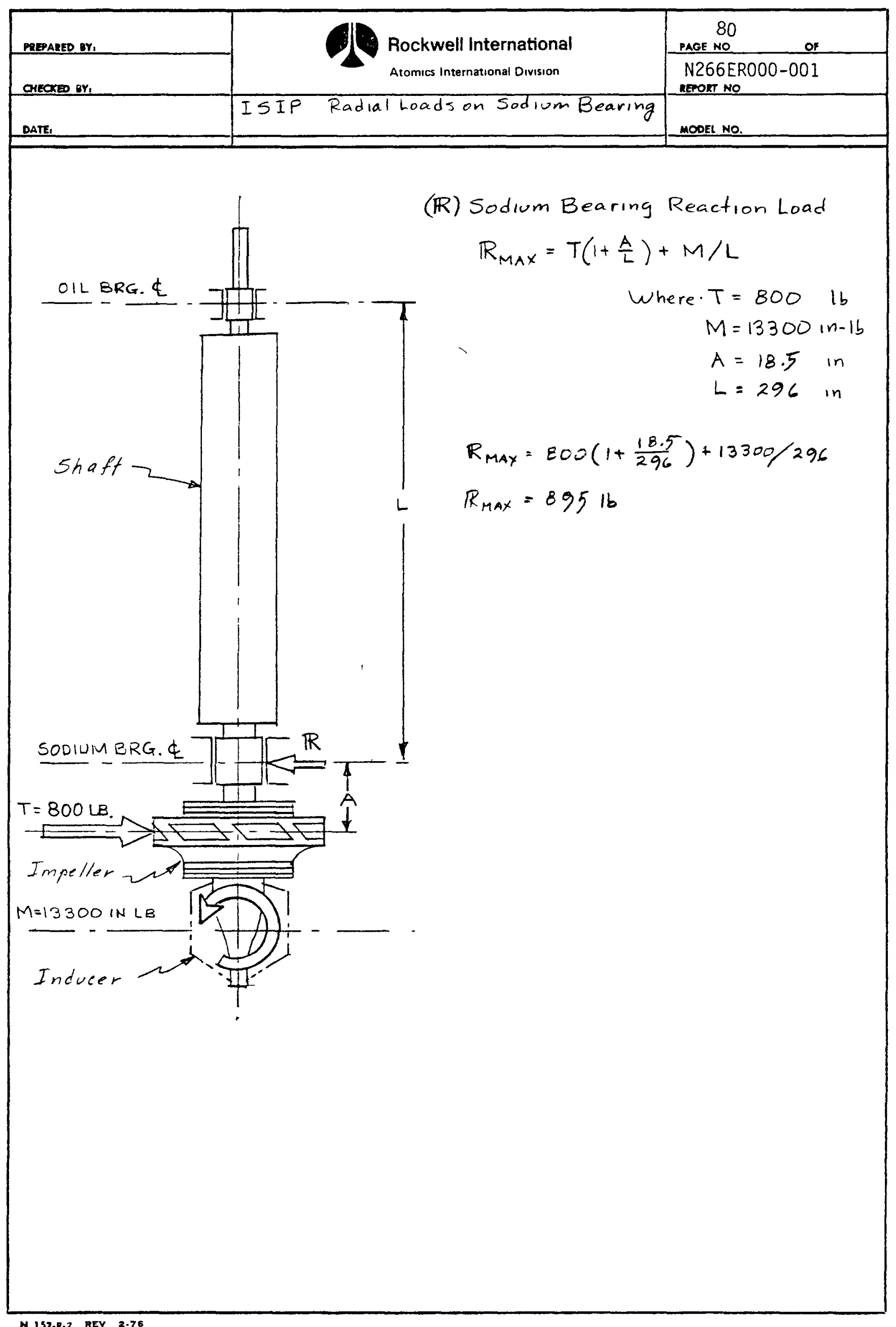

152.R.2 REV 2.76 


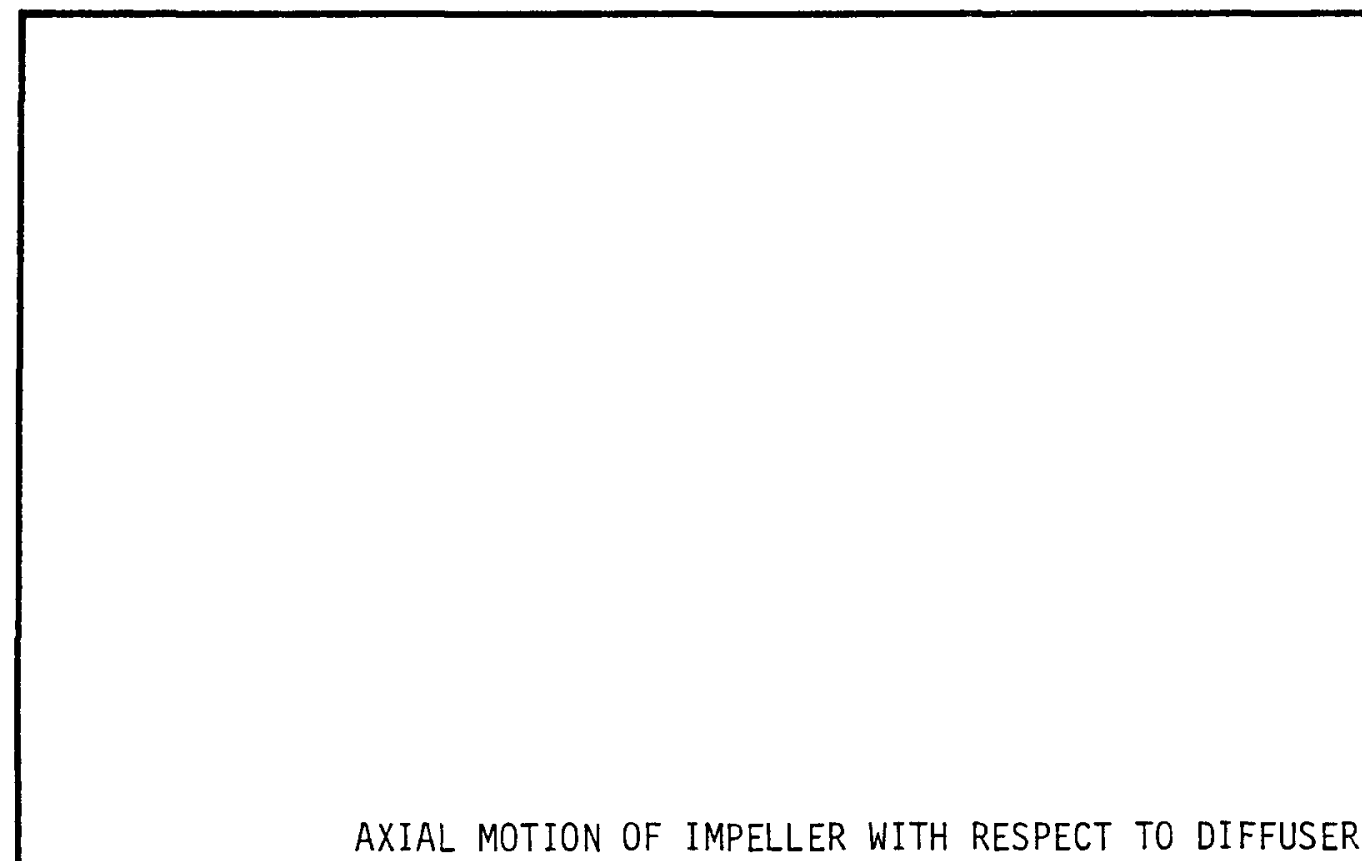




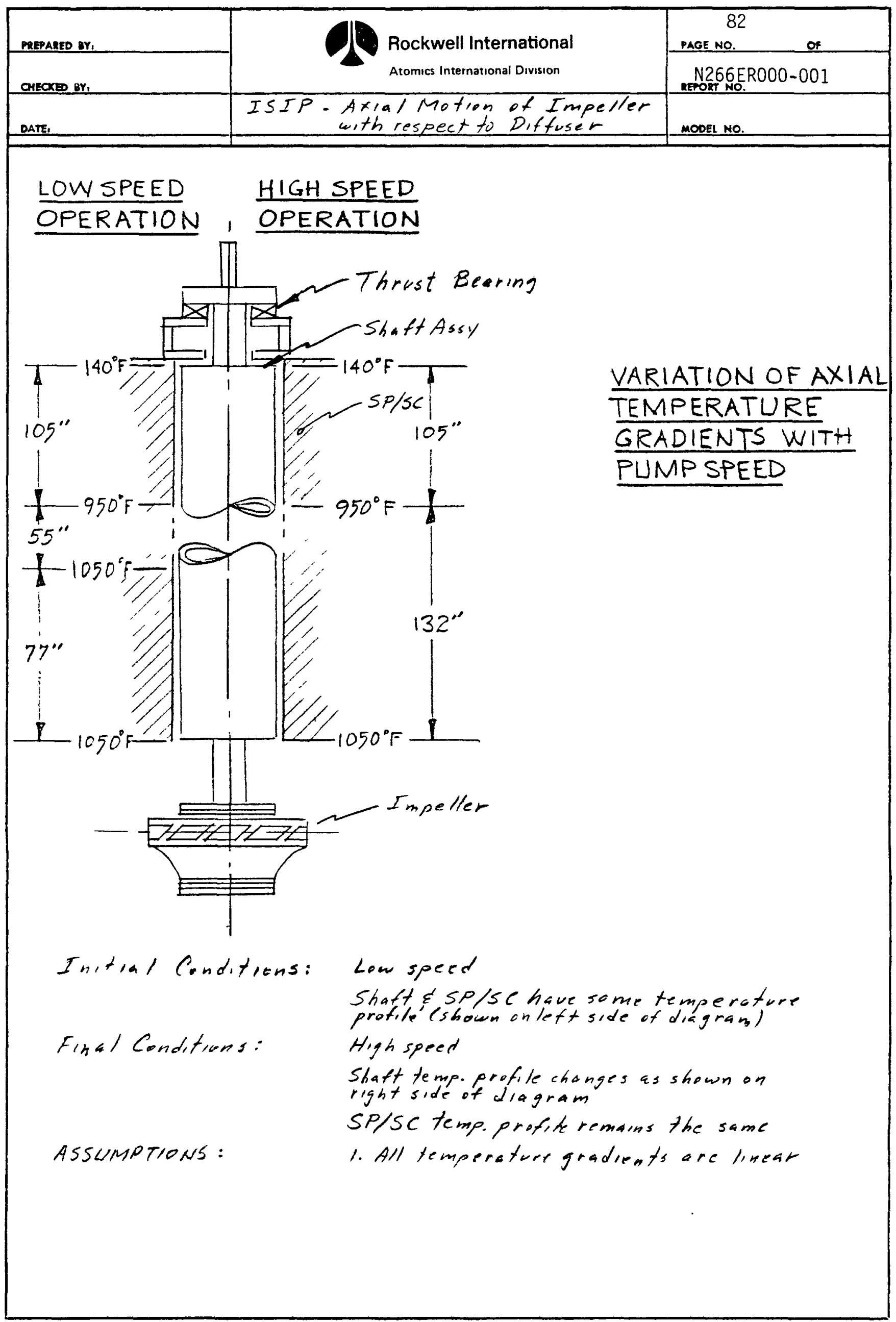

N 152.R.2 REV. 2.76 


\begin{tabular}{|c|c|c|}
\hline PREPARED BY, & Rockwell International & $\begin{array}{l}83 \\
\text { page no. }\end{array}$ \\
\hline CHECXED BY, & Atomics International Division & $\underset{\text { REPORT NO. }}{\text { N266 }}$. \\
\hline DATE, & $\begin{array}{c}\text { ISIP Arial Motiem it Impoller } \\
\text { with resped to Diffusor }\end{array}$ & MODEL NO. \\
\hline
\end{tabular}

1. Top zone (1st 1rs") temperature gradient remains wnehanged.

$\therefore$ no change in length eccurs

2. Midle zene (wext 55 ")

a.) the temperature gradirnt changes from: 950 F-to-105is to:

$$
\begin{aligned}
& 950 F-10-\left[950+\frac{55}{132}(1050-950)\right] \\
= & 9505 \cdot+0 \cdot[950+41.7] \\
= & 550 F \cdot+0.991 .7
\end{aligned}
$$

b) the mean temperature changer from: $\frac{950+1050}{2}=10005\left(-5377^{\circ} \mathrm{C}\right)$ to: $\frac{5 \sin +591.7}{2}=971 \mathrm{~F} \cdot\left(-521.7^{\circ} \mathrm{C}\right)$

c) for this range, the instantaneows coefficient it thermal expansion 15: $\alpha=20.25 \times 10^{-6} \mathrm{H} \mathrm{C}$ Ret. - Nuctear SystemsMaterab Honabook, $V_{c} /$. I

$$
\times \frac{5}{9}=11.25 \times 10^{-6} / . \mathrm{F}
$$

d) the ehange in length, based an the change in mean tempo's is.

$$
\begin{aligned}
& \Delta L_{1}=L_{1} \alpha(\Delta t)=55\left(11.25 \times 10^{-6}\right)(1000-971) \\
& \Delta L_{1}=.0179 \mathrm{in}
\end{aligned}
$$

3. Lower jone (next 77")

a.) the temperaturegradient ehanges from: 1050F-to.1050F (0.0gradient) to:

$$
991.75-t_{0}-1050 F
$$

b.) the mean temperatue changes from: $1050 \mathrm{~F}\left(=565.5^{\circ} \mathrm{C}\right)$

$$
t_{0}: \frac{991.2+1050}{2}=102,17(-549 . \mathrm{c})
$$

c) for thes range, the inotantancews coefficrent of thermal erposusion

is: $\alpha=20.35 \times 10^{\circ} /{ }^{\circ} \mathrm{C}$

$$
\times r / 9=11.31 \times 10^{-6} / . F
$$

d) Hhe change la lergth, based to the change in mean temp's is

$\Delta L_{2}-77\left(11.31 \times 10^{-6}\right)(10 \vee 0-1021)$

$\Delta L_{2}=.0252 \mathrm{im}$

4. Total change in length

$$
\Delta L_{\text {T.t. }}=\Delta L_{1}+\Delta L_{2}=.0179+.0252=.043 \mathrm{in} .
$$


PAGE . 84

\section{APPENDIX B}

DESIGN SPECIFICATION - PUMP, SODIUM, INDUCER, INTERMEDIATE SIZE (ISIP) (IMPELLER/INDUCER/DIFFUSER RETROFIT)

ESG Document N266ST310001 


\begin{tabular}{|c|c|c|c|}
\hline \multirow{2}{*}{\multicolumn{4}{|c|}{$\begin{array}{l}\text { Rockwell International } \\
\text { Atomics International Division }\end{array}$}} \\
\hline & & & \\
\hline \multirow{3}{*}{$\begin{array}{l}\text { PREPAREDBY } \\
\frac{\text { QRTacader }}{\text { D.R. Paradise }} \\
\text { Specs. \& Stds. Engineer }\end{array}$} & \multirow{4}{*}{$\begin{array}{c}\text { DESIGN } \\
\text { SPECIFICATION }\end{array}$} & \multicolumn{2}{|c|}{\begin{tabular}{|l|} 
NUMBER \\
N266ST310001 \\
\end{tabular}} \\
\hline & & \multirow{2}{*}{\multicolumn{2}{|c|}{\begin{tabular}{|l|l|l|} 
REV & B & $\square$ AMEND \\
TYPE & COMPONENT
\end{tabular}}} \\
\hline & & & \\
\hline 5.22 .79 & & $\begin{array}{l}\text { TOTAL } \\
\text { PAGES } 444\end{array}$ & E.o. 912995 \\
\hline
\end{tabular}

TITLE

PUMP, SODIUM, INDUCER, INTERMEDIATE SIZE (ISIP) (IMPELLER/INDUCER/DIFFUSER RETROFIT)

APPROVALS

Rov.

R.V. Anderson

Project Manager

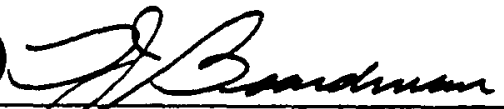

T. Boardman

Project Engineer $\frac{\text { L. K. Nochen } 2 .}{\text { L.R. Woehler, Sr., Manager }}$

Specifications \& Standards

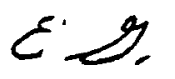

Onchuse

E. Andrews

Quality Assurance
THIS REPORT MAY NOT : PUBLISHED WITHOUT THE APPROVAL OF THE TATENT BRANCH, DOE

This report was prepared as an account of work sponsored by the United States Government. Neither the U. S. Government, nor any of its employees nor any of its contractors, subcontractors, or their emplinees, makes any warranty, express or implied, or assumes any $|\cdot-3|$ liability or responsibility for the accuracy, completen. or 1 ? $\cdot$ ination, apparatus, product or process disclusen, or lusuccins linat in use would not infringe privately owned rights.

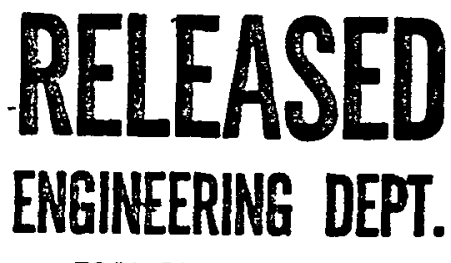

FORM 723-P.3 NEW 8-74 


\begin{tabular}{|c|c|}
\hline REV. & AMEND \\
\hline
\end{tabular}

\section{SUMMARY OF CHANGES}

This summary of Changes delineates the changes which constitute Revision $B$. The outside margins have been marked to indicate where changes, deletions, or additions from the previous issue have been made.

Revision $B$ changes were made to bring this specification in line with Request for Test (N266RFT000001) Rev. C. changes.

\section{Page Paragraph Title-Description of Change}

$3-1 \quad 3.1 .1 .3$

Radial Clearance In the first sentence, following word "clearance" deleted statement "but in no case shall the radial clearance be less than 0.050 inch using the most adverse tolerance stackup." Added new second sentence beginning with "At least... and ending with transient tests."

$3-2 \quad 3.2 .2 .1$

Operating life In the second sentence added word "design" preceding operating and after 4000 hours deleted words "minimum, at conditions described in 4.45 " and substituted words beginning "of which 3000 hours... and ending with $1110 \mathrm{rpm}$."

$3-2 \quad 3.2 .2 .2$

Flow/Speed Ratio (was titled system Resistance)

System resistance was defined in terms of flow/speed ratio instead of specific speed.

3-14 Figure $3-1 \mathrm{~A}$

Pump Main Motor Operation Envelope. System resistance lines were redefined (see paragraph 3.2.2.2 above).

$4-3 \quad 4 \cdot 4 \cdot 5$

Performance Testing Extensive test changes made to first and third paragraphs. Added new second paragraph.

$4-4 \quad 4 \cdot 4 \cdot 5 \cdot 1$

Determination of NPSHR In first sentence $(950 \mathrm{~F})$ was $(1050 \mathrm{~F})$, and deleted $14,000 \mathrm{gpm}$. In subparagraph b, second sentence, added "(Elevation at the lower end of the inducer blade tip)."

$4-4 \quad 4.4 .5 .2$

Determination of Suction Capability at Runout Flow Deleted entire paragraph.

$4-4 \quad 4 \cdot 4 \cdot 5 \cdot 3$

Test Success Criteria Renumbered paragraph to 4.4.5.2.

4-5 Figure 4-1 NPSHR Determination Added explanatory words

"97\% of initial head". 


\begin{tabular}{|l|l|l|l|l|}
\hline \multirow{2}{*}{$\begin{array}{l}\text { Rockwell International } \\
\text { Atomics International Division }\end{array}$} & \multicolumn{3}{|c|}{ PUMBER } \\
\cline { 2 - 5 } & REV & N2665T310001 \\
\hline
\end{tabular}

Page Paragraph Title-Description of Change

4-6 TABLE 4-I Test seguence Deleted previous sequence numbers/test \& descriptions 14, 15, 16, 17, 19 and 23. Added new test

$4-7$ descriptions for sequence numbers 15 and 16 . Deleted from sequence numbers 17 through 19, thermal transients 201,205 and 206 .

4-8 TABLE 4-II Test Thermal Transients Deleted events 201, 205 and 206. 


\begin{tabular}{|c|c|c|}
\hline $\begin{array}{c}\text { REV. } \\
\text { B }\end{array}$ & AMEND. & PAGE NO. \\
\hline
\end{tabular}

\section{TABELE_OF_CONTENTS}

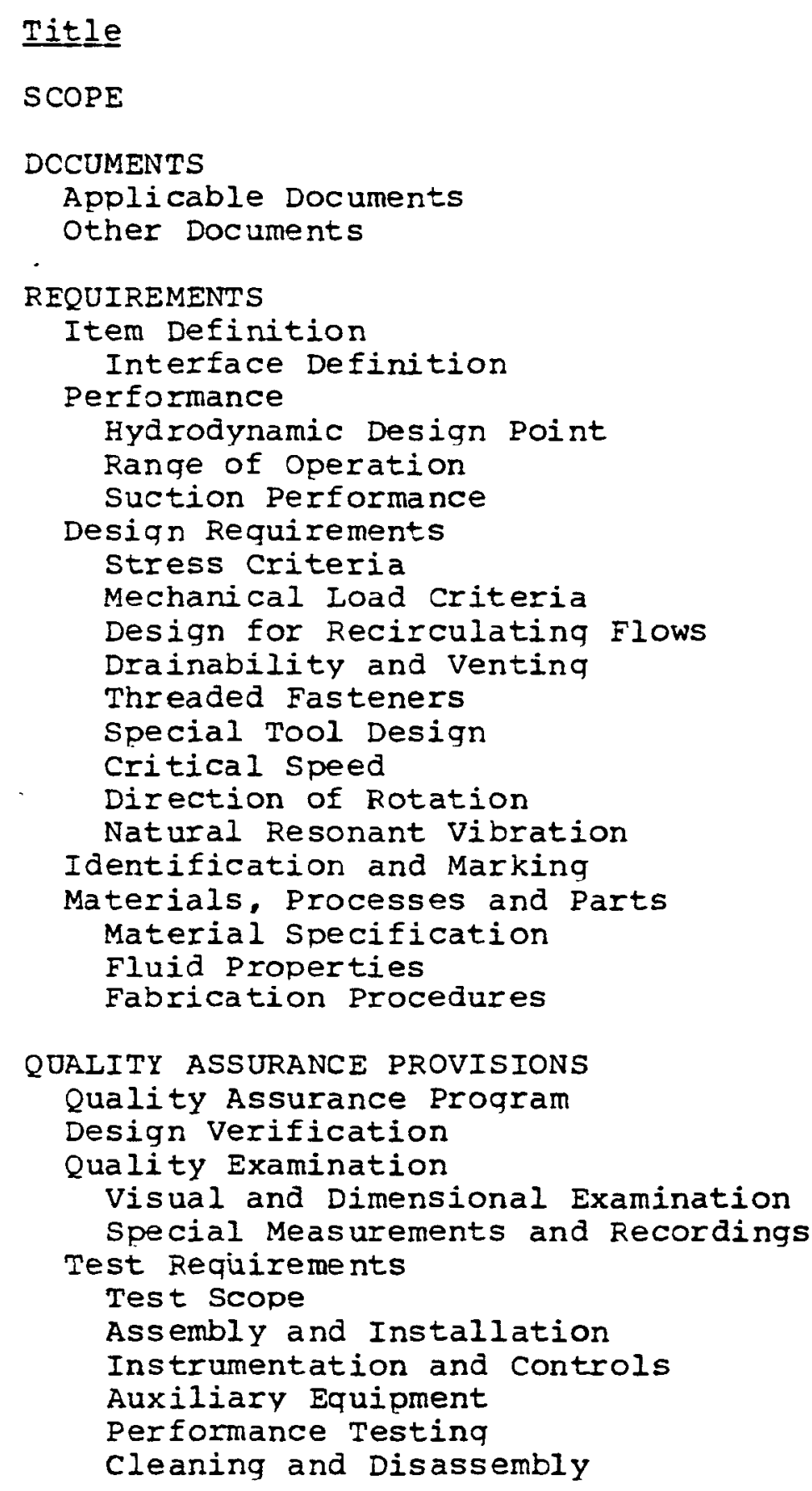

PACKAGING AND PACKING

\begin{tabular}{|c|c|}
\hline ParagIaph & paqe \\
\hline 1. & $1-1$ \\
\hline $\begin{array}{l}2 . \\
2.1 \\
2.2\end{array}$ & $\begin{array}{l}2-1 \\
2-1 \\
2-3\end{array}$ \\
\hline $\begin{array}{l}3 . \\
3.1 \\
3.1 .1 \\
3.2 \\
3.2 .1 \\
3.2 .2 \\
3.2 .3 \\
3.3 \\
3.3 .1 \\
3.3 .2 \\
3.3 .3 \\
3.3 .4 \\
3.3 .5 \\
3.3 .6 \\
3.3 .7 \\
3.3 .8 \\
3.3 .9 \\
3.4 \\
3.5 \\
3.5 .1 \\
3.5 .2 \\
3.5 .3\end{array}$ & $\begin{array}{l}3-1 \\
3-1 \\
3-1 \\
3-2 \\
3-2 \\
3-2 \\
3-3 \\
3-3 \\
3-3 \\
3-4 \\
3-4 \\
3-4 \\
3-5 \\
3-5 \\
3-5 \\
3-5 \\
3-5 \\
3-5 \\
3-6 \\
3-6 \\
3-6 \\
3-6\end{array}$ \\
\hline $\begin{array}{l}4 . \\
4.1 \\
4.2 \\
4.3 \\
4.3 .1 \\
4.3 .2 \\
4.4- \\
4.4 .1 \\
4.4-2 \\
4.4-3 \\
4.4-4 \\
4.4-5 \\
4.4 .6\end{array}$ & $\begin{array}{l}4-1 \\
4-1 \\
4-1 \\
4-1 \\
4-1 \\
4-1 \\
4-2 \\
4-2 \\
4-2 \\
4-2 \\
4-2 \\
4-3 \\
4-4\end{array}$ \\
\hline 5. & \\
\hline
\end{tabular}




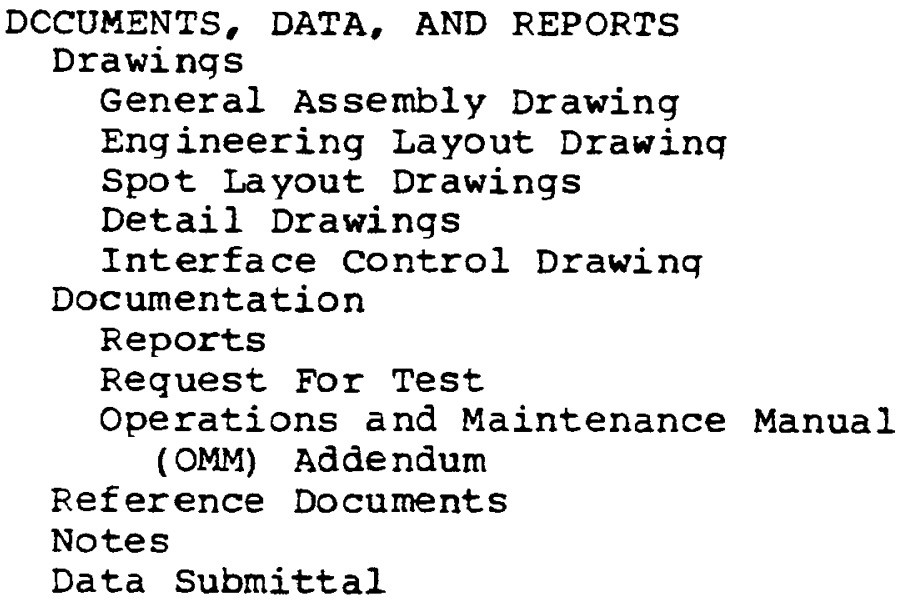

APPENDIX 10 APPENDIX 20

$\begin{array}{ll}6 . & 6-1 \\ 6.1 & 6-1 \\ 6.1-1 & 6-1 \\ 6.1-2 & 6-1 \\ 6.1 .3 & 6-1 \\ 6.1-4 & 6-1 \\ 6.1 .5 & 6-1 \\ 6.2 & 6-2 \\ 6.2 .1 & 6-2 \\ 6.2 .2 & 6-2\end{array}$

6.2 .3

$6-2$

6.3

$6-2$

$6-3$

$6-4$

10-1

20-1

\section{LIST_OFF_FIGURES}

Figure $3-1 \mathrm{~A}$ Figure 3-1B

Figure 3-2

Figure 3-3

Figure 4-1
Inducer Pump Operation Envelope Inducer Pump Pony Motor Operation. Envelope

Suction Performance NPSHR Target Valves for Intermediate Size Inducer Pump (ISIP)

Design Fatique strain Range, $E$. $3045 S$ and 316Ss --- Elastic Analysis NPSHR Determination
$3-14$

$3-14$

$3-15$

3-16

4-5 


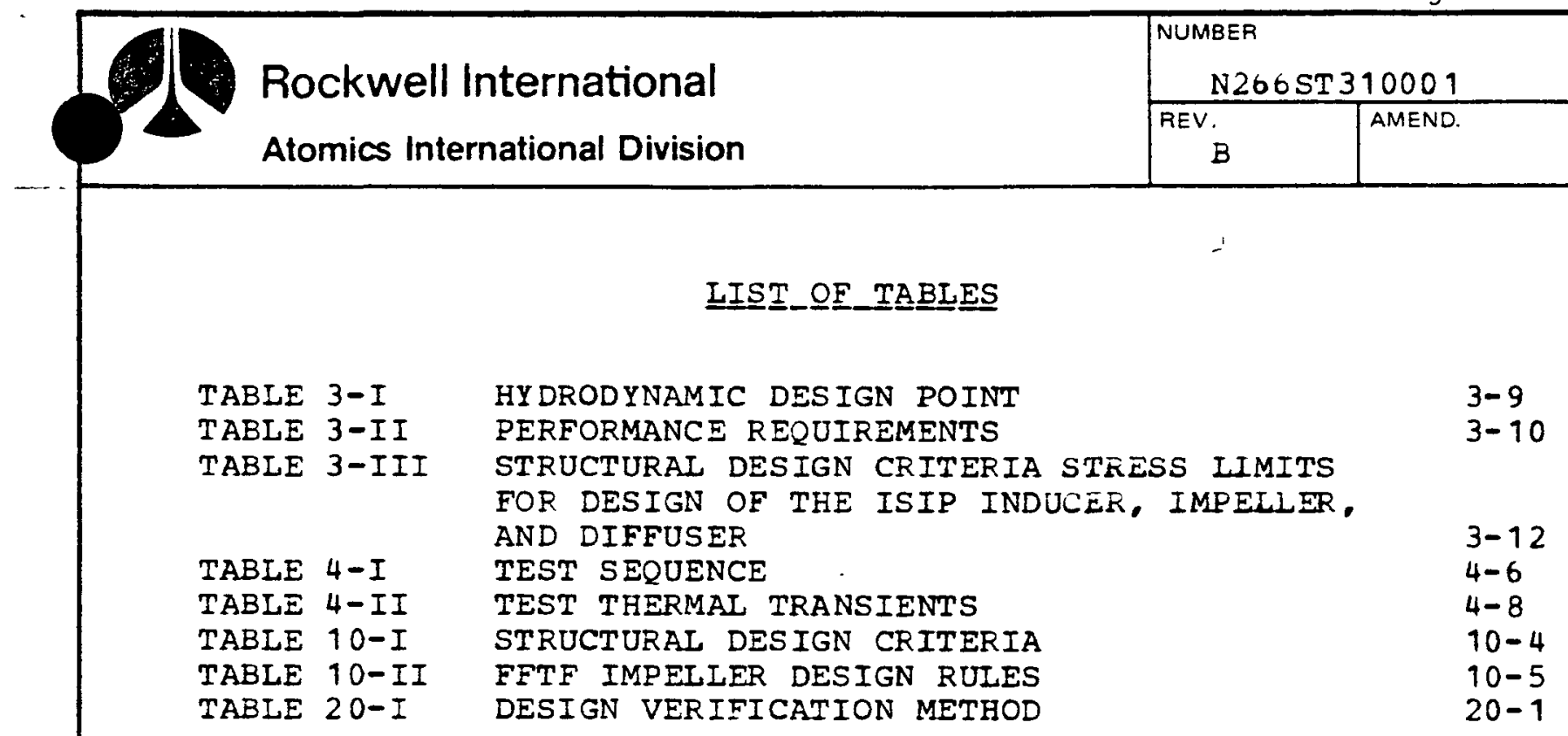


1. S므르 This specification defines the requirements for the Intermediate-Size Inducer Pump, (also referred to herein as the ISIP) which is to be made by reolacing tine impeller of the FFTF Prototype Pump with a new inducer, lmpeller, diffuser, seal, and necessary adapter hardware. suosequent resting requirements of the complete pump assembly are included. 


\begin{tabular}{|l|l|l|l|}
\hline \begin{tabular}{|l|l|} 
Rockwell International \\
Atomics International Division
\end{tabular} & \multicolumn{2}{|c|}{ NUMBER } \\
\cline { 2 - 4 } & REV. & AMEND. & PAGE NO. \\
$2-1$
\end{tabular}

\section{DOQCUMENTS}

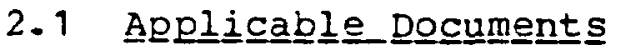

\section{Amerícan_Society_of MechangicaI_Engineers_(ASME)}

ASME Boiler and Pressure Vessel code, 1977 Eaition, including Summer 1977 Addenda

\begin{tabular}{|c|c|c|}
\hline ANSI/ASME & $B P V-I I I-N C A$ & $\begin{array}{l}\text { Division } 1 \text { and Division } 2 \\
\text { Nuclear Power Plant } \\
\text { Components: General } \\
\text { Requirements }\end{array}$ \\
\hline ANSI/ASME & $B P V-I I I-1-N B$ & Class 1 Components \\
\hline ASME & $S A-182$ & $\begin{array}{l}\text { Specification for Forged or } \\
\text { Rolled Alloy-steel Pipe } \\
\text { Flanges, Forged Fittings, and } \\
\text { Valves and Parts for Hiqh } \\
\text { Temperature Service }\end{array}$ \\
\hline ASME & $S A-351$ & $\begin{array}{l}\text { Specification for Austenitic } \\
\text { Steel Castings For High- } \\
\text { Temperature Service }\end{array}$ \\
\hline ASME & $S A-453$ & $\begin{array}{l}\text { Specification For Boltinq } \\
\text { Materials, High Temperature, } \\
50 \text { to } 85 \text { KSI Yield Strenqth, } \\
\text { with Expansion Coefficients } \\
\text { Comparable to Austenitic steel }\end{array}$ \\
\hline ASME & $S A-637$ & $\begin{array}{l}\text { Specification For } \\
\text { Precipitation Haraenina Nickel } \\
\text { Alloy Bars, Forging Stock For } \\
\text { High-Temperature Service }\end{array}$ \\
\hline ASME & $S A-638$ & $\begin{array}{l}\text { Specification For } \\
\text { Precipitation Hardening Iron } \\
\text { Base Superalloy Bars, } \\
\text { Forqinqs, and Forgind stock } \\
\text { for Hiqh-Temperature service }\end{array}$ \\
\hline code case & $N-47(1592-10)$ & $\begin{array}{l}\text { Class } 1 \text { Component Elevated } \\
\text { Temperature Service }\end{array}$ \\
\hline
\end{tabular}




\begin{tabular}{|l|l|l|l|}
\hline Rockwell International & \multicolumn{3}{|l|}{ NUMBER } \\
Atomics International Division & N266ST 310001 \\
\cline { 2 - 5 } & REV & BMEND & PAGE NO \\
\hline
\end{tabular}

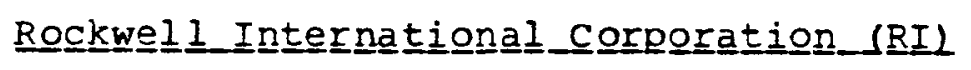

Draㅡㅌing

N266E000002

Specifíicationg

N001A0110001

NO01A0116001

N266RFT 000001

MW1-08061-000
Interface control Drawing (ICD), "Intermediate-Size Inducer Pump"

cleaning and cleanness

Packaging and Packing for Shipping and Storage; dated 27 April 1977

Sodium Testing of intermediate Size Inducer Pump in SPTF at IMEC

General weld Procedure: dated November 1975

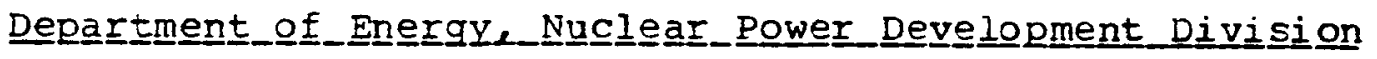
RDT Staㅡ므므므모

RDT $F 2-2$

Quality Assurance Proqram Requirements, Auqust 1973. including Amendments 1 through 4

RDT $F \quad 8-6 T$

Hoisting and Rigging of Critical Components and Related Equipment with Amendments 1 through 3

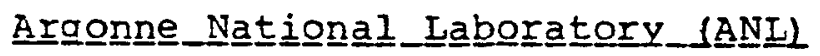

ANI-7273 Thermophysical Properties of Sodium

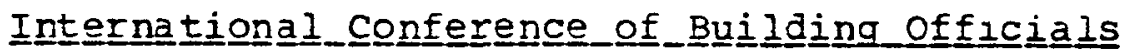

UBC-1976 Edition Uniform Building code 


\begin{tabular}{|l|l|l|l|}
\hline $\begin{array}{l}\text { Rockwell International } \\
\text { Atomics International Division }\end{array}$ & \multicolumn{2}{|l|}{ NUMBER } \\
\cline { 2 - 4 } & NEV. 206 ST 310001 \\
\hline
\end{tabular}

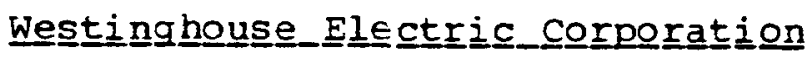

HWS- 1551

LMFBR Low Capacity Prototype Pump -- FFTF Primary Pump, Rev. 1, January 1974 , including addendum $1 \mathrm{P}$ (June 1977)

WDTRS 25.14, Rev. 18 Sodium Testing of the FFTF Prototype Pump

WEMD 114E829, Rev. 12 General Assembly, Prototype Sodium Pump

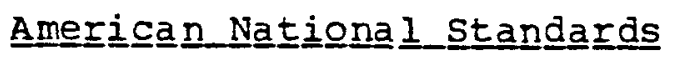

ANSI B46.1-1962 (R1971) Surface Texture

2.2 other Documents (See 6.3 ). 


\section{REQDIREMENTS}

3.1 Item Definition The FFTF Prototype Pump's original construction requirements are defined in document HWS- 1551. The basic pump frame for the ISIP is from the FFTF Prototype Pump. This specification defines the desiqn, fabrication. assembly and test for utilizing this pump frame with a new inducer/impeller/diffuser and necessary adapter hardware in place of the original impeller. For a complete description of the FFTF Prototype Pump, refer to referenced Document a.. (CMM-051-00-005, hereinafter referred to as. OMM).

3.1. 1 Interface Definition The physical interface of the ISIP components are defined by ICD N266E000002. Changes in the interface shall be minimized wherein the pump shall be capable of being restored to its original configuration.

3.1.1.1 Impeller Mounting Mounting of the lnaucer/impeller on the existing taper at the lower end of the pump shaft shall be designed for controlied advance onto the taper such that the stress criteria of Table 3-III are not exceeaed.

3.1.1.2 Axial clearance At least one-half inch axial clearance shall be provided by the design aoove and below all rotating members.

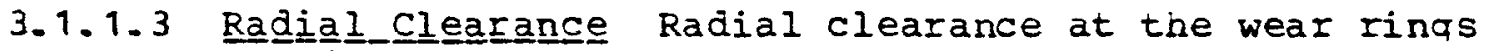
and at the inducer vane tips shall be based on assembly stackup of tolerances for the parts determining the clearance. At least 0.015 inch margin shall be provided aqainst rubbing when the pump is operating with the most adverse radial tolerance stackup and is concurrently subject to distortion resulting from thermal transient tests.

\subsubsection{Toool_Interfaㅡㄹㅗ}

a. The inducer, impeller, adapter diffuser, and other new parts (weiqhing in excess of 10 pounds) designated for installation into the existing pump frame, shall be designed to permut lufeing and handing in accordance with the requirements of RDT F 8-6. In addition, the parts snall be designed to interface with the special assembly tools as part of the assembly procedure described in the specially addended version of the OMM.

b. Tool interface requirements shall be met by designing the parts to interface with existina, 


\begin{tabular}{|l|l|l|l|}
\hline $\begin{array}{l}\text { Rockwell International } \\
\text { Atomics International Division }\end{array}$ & \multicolumn{2}{|l|}{ NUMBER } \\
\cline { 2 - 4 } & REV. $2665 T 310001$ \\
\hline
\end{tabular}

\section{modified, or new special assembly tools (refer to 3. 4.6). \\ c. The bearing support flange (approximate weiqht 10,000 pounds) shall be posicioned and supported from the impeller (or shaft) during upending and installation of the shield plug/support cylinder (SP/SC) over the shaft. During installation, the shaft assembly shall be supporced from the lower end.}

\subsection{Performance}

3.2. 1 Hydrodynamic Design Point The hydraulic desian conditions for which the pump shall be desiqned shall be in accordance with Table 3-I.

3.2.2 Range of operation The range of operation for which the inducer and impeller and associated components shall be desiqned is presented in Table 3-II, which also includes the desiqn point, and is depicted in Fiqures $3-1 \mathrm{~A}$ and $3-1 \mathrm{~B}$.

3.2.2.1 Operating Life The inducer and impeller shall be designed for testing over the operating ranges aepicted in Figures 3-1A, 3-1B and under the suction conditions (NPSHA) given in 3.2.2.3. The design operating test time shall total 4,000 hours, minimum, of which 3000 hours snall be at design temperature and speed, and 1000 hours shall be at temperatures of 400F, 600F and $800 \mathrm{~F}$ at speeds between 500 to $1110 \mathrm{rmm}$.

3.2.2.2 Flow/Speed Ratio The system resistanse (R) curves shown on Figure 3-IA represent coincident curves of constant flow/speed $(Q / N)$ ratio for the pump. The following table defines specified flow/speed ratios correspondirg to the various system resistance designations:

\begin{tabular}{l|l|l|l|l|l|l|l}
$\begin{array}{l}\text { System Resistance } \\
\text { Designation (R) }\end{array}$ & $R-0$ & $R-1$ & $R-2$ & $R-3$ & $R-4$ & $R-5$ & $R-6$ \\
\hline Flow/Speed Ratio ( $Q / N$ & 0.0 & 6.576 & 8.243 & 9.459 & 13.063 & 16.216 & 22.400
\end{tabular}




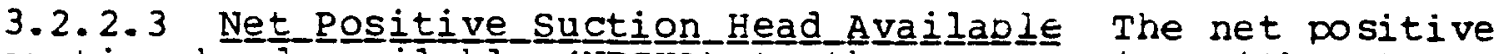
suction head available (NPSHA) to the pump varies with output flow rate at $1050 \mathrm{~F}$ in accordance with the following relationship:

\begin{tabular}{|c|c|c|}
\hline Where: & NPSHA $=$ & $\begin{array}{l}\text { Net Positive Suction Head at pump } \\
\text { inlet nozzle, minus the elevation } \\
\text { difference, in feet, Irom the inducer } \\
\text { inlet elevation down to the inlet } \\
\text { nozzle centerline. }\end{array}$ \\
\hline & $Q=$ & Output volumetric flow rate \\
\hline & (NOTE: & $\begin{array}{l}\text { Inducer inlet flow may be slightly } \\
\text { hiqher than pump outlet flow due to } \\
\text { internal leakage.) }\end{array}$ \\
\hline
\end{tabular}

\subsubsection{Suction Performance}

3.2.3.1 Design Flow NPSH The pump shall be designed to operate with a net positive suction head of 12.8 feet, or less, at desiqn speed, flow and temperature and with less than 3 percent reduction of head due to cavitation (refer to Explanation note 6.4 a).

3.2.3.2 Runout Elow NPSH The pump shall be designed to operate at 18,000 gpm at desian speed and temperature, with less than 3 percent reduction in head due to cavitation, when the suction conditions correspond to minimum submergence (refer to Explanation note $6.4 \mathrm{~b}$ ).

\section{3 Design Reguirements}

3.3. 1 Strress_criteria All parts (excepe instrumentation) shall be designed and analysed to meet the structural desian criteria of Table 3-III.

3.3.1.1 Steady=State_conditions A reduction of the structural design criteria in Table 3-III shall be determined and the reduced criteria used for design under steady-state temperature conditions.

3.3.1.2 Thermal Transients The design shall be analyzed to identify which of the test thermal transients described in Table 4-II may be run without exceeding the structural desian criteria of Table 3-III. The pump shall be analyzed subsequently to determine which thermal cransients, listed in 


\section{Rockwell International}

Atomics International Division

Hhs-1551, the pump could withstand without exceeding the structural desian criteria of Table 3-III.

The foregoing analysis shall be limited to use of elastic and simplified inelastic methods. Those areas where inelastic analysis would be required shall be identifled.

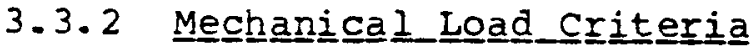

3.3.2.1 Unbalanced_Rotating_Ioads The umpeller and inducer design shall include provisions to permit àyamic balancing of the inducer-impeller assembiy within 3.5 inch-ounces at each balance plane when mounted on a balance spindle.

3.3.2.2 Radial Thruㅗㄴ Loads Desian of the Inaucer, impeller, and diffuser adapter shali be such that polar symetry is maintained.

3.3.2.3 Axial Thrust_Loads The wear ring diameters shall be desiqned to maintain axial thrust between the limies of 70,000 pcunds upward and 40,000 pounds downward over the operating range of the pump. Axial thrust calcularlons shall consider the possibility of at least ten percent dirlerence between the static head at the tip of the lower (front) shroud and static head at the tip of the upper (back) shroud. Balance piston arrangements based on variation of axial clearances shall not be used to balance axial thrust.

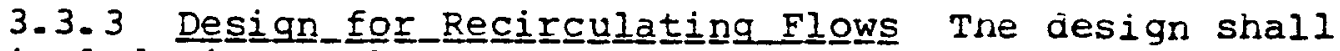

include internal passageways to permit ducting flow from the lower end of the hydrostatic bearing and recircularing flow from the back wear ring of the impeller, to a low pressure region of the inducer/impeller assembly. Flow from the bearing will be $100 \mathrm{gpm}$ at desiqn conditions. To minimize distortion under thermal transient conditions, passaqeways shall be symmetrical about the pump axis. At desiqn operating conditions, passageways shall be sized to maintain the static pressure below the hydrostatic bearing to less than 18 psi above the inducer inlet pressure.

3.3.4 Drainability and Venting All internal parts shall be designed for self draining and venting. Tne use of drain hcles and vent holes at specific locations shall be accentable providing flow through these holes is consiaered in the hydrodynamic design. Concurrent draining and venting through the same holes shall not be permitted.

3.3.5 Threa de d Easteners All internal tnreaded fasteners shall be positively locked to prevent loosening (friction 
locks are not acceptable), and the head of the fastener shall be trapped to prevent entry into the fluid stream in the event of failure of the fastener shank. Unless otherwise specifically required, threads shall be the coarse thread series (UNC) and shall have a nominal diameter of one-half inch or greater. Mating surfaces of internal and external threads shall be of different materials.

3.3.6 Special Tool Design Special tools, or equipment to permit adapting existing special tools to tne ISIP, shall be provided as required to permit handling and assembly of the pump internals. The design, fabrication, and proof testing of all lifting tools shall conform to the requirements of RDT $F$ 806 for tackle. support stands and similar static equipment shall meet the requirements of the uniform Builaing code for this reqion. Tool surfaces designed to contact the stainless steel pump parts shall be corrosion resistant. Stalnless steel, nickel plate, chrome plate or nylon are chemically suitable contact surface materials. The design of the special tools shall permit assembly of the ISIP as described in the OMM (refer to $6.3 a$ ).

3.3.7 Critical Speed The calculated crurlcal speed of the rotating assembly, including the ISIP inaucer and zmpeller. shall not be more than 5 percent below the calculated critical speed for the FFTF Prototype Pump.

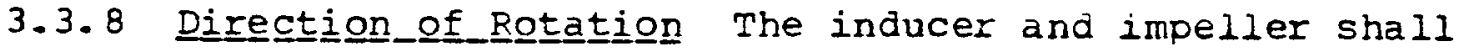
be designed to rotate counterclockwise when viewed from the pump drive end (top).

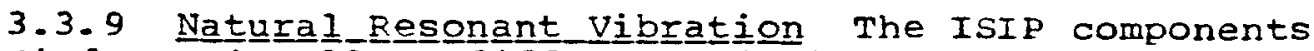
(inducer/impeller, diffuser and diffuser shroud) shall be designed to avoid resonant vibration while under the influence of flow induced pressure pulses (such as the vortex shedding frequency of labyrinth seals) and mechanically induced pressure pulses (such as primary rotating and impeller-todiffuser blade passing frequency).

3.4 I dentifification and Marking Identification and marking of parts shall be according to applicable detail design drawings. 


\begin{tabular}{|c|c|c|c|}
\hline \multirow{2}{*}{$\begin{array}{l}\text { Rockwell International } \\
\text { Atomics International Division }\end{array}$} & \multicolumn{3}{|c|}{ NUMBER } \\
\hline & \begin{tabular}{|l}
$\mathrm{N} 2$ \\
$\mathrm{REV}$ \\
$\mathrm{B}$
\end{tabular} & $\frac{10001}{\text { AMEND. }}$ & $\begin{array}{c}\text { PAGE NO } \\
3-6\end{array}$ \\
\hline
\end{tabular}

\subsection{Mater}

3.5.1 Material 1 Specification Material for the major parts shall conform to the following material specifications:

\author{
Paㅡㅌㅗ \\ 1. Inducer \\ 2. Diffuser \\ 3. Diffuser Adapter
}

4. Impeller

5. Piston Ring

6. Bolting Stock

(Threaded fasteners. shaft keys, etc.)

\section{Material specification}

Forqing, Grade F 304

Austenitzc Stainless steel, conforming to requirements of ASME SA-182; to the requirements of AISI/ASME BPVIII-1-NB, Article NE-2000, and supplemental reguirements to be specifiea by KI.

Casting, Grade CF8 Austenitic Stainless steel, conforming to the requirements of ASME SA-351; to the requirements of ANSI/ASME BPV-III-1-NB, Article No-2000, and to the supplemental requirements to be specified by RI.

Nickel Alloy, ASME SA-637 Grade 718, precipitation hardened condicion, made from double vacuum melted ingot.

(A286 Bolting Stock) Conforming to ASME SA-638. Grade 660, Type 2 or ASME SA-453, Grade 660, Class B.

3.5.2 Fluid Properties The thermophysical properties of sodium to be used for this design and subsequent test evaluation shall be according to ANL-7323.

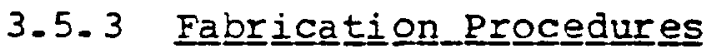

a. Equipment protection Extreme care shall be exercised to protect all surfaces from contamination during fabrication, handling. testing, and storage. Precautions necessary to ensure such protection shall be incorporated in the detailed component or fabrication frocedure. Detailed procedures for cleanness control, in- 
process cleaning, and final cleaning of all carts, components, and assemblies shall be utilized.

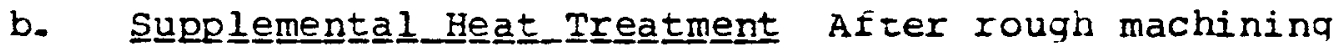
and prior to final machining, the inducer, impeller, diffuser, and adapter shall be aiven a supplemental heat treatment in order to develop dimensional stability.

These heat treated parts shall be subsequently protected from moisture which can promote intergrannular attack or stress corrosion. contaminates to be avoided include oxıdizing aqents (such as nitric acid), halide environments (such as salt air or fluorides from weld fluxes or smoke) and caustic solutions (such as hydroxides).

c. Sufaㅡㄹㅡ Finish The definitions, measurement and designation of surface finishes shall be in accordance with ANSI B46.1.

d. Lock Welds All lock weld (bolt capture) joints shall be in accordance with Mw1-08061-000. Lock welds shall be visually examinea under $5 x$ magnification for evidence of cracks.

e. Special_processes Any nonstandard fabrication processes employed shall be identified and a procedure for their application specified. Examples of nonstandard processes are electrodischarge or electrochemical machining and electron beam welding.

f. Cleanining All cleaning shall be in accordance with the requirements of RI specification N001A0110001. Final cleaned surfaces shall meet the requirements for cleanness Level 3. All cleaning procedures shall be submitted and approved by KI.

9. Iubricant/Coolant A lubricant/coolant may be employed during machining operations provided it does not contaminate any crevice or inacessible area that cannot be subsequently cleaned, and provided the lubricant is removed after completion of all operations. Iubricants used on austenitic stainless steel shall have a sulfur or chloride content of less than 5,000 ppm. 
N266ER000-001

Page 102

Rockwell International

Atomics International Division

NUMBER

N266ST310001

REV.

AMEND.

PAGE NO.

B

3-8

h. Thread Lubricant Thread lubricants shall be used during assembly. The following lubricants, or equivalent shall be specified on assembly drawings.

Type

Never-Seez Pure Nickel

Special, Nuclear Grade

N-5000 Nuclear Grade Fel-Pro
Manufacturer

Never-Seez Compound corporation, Broadview, III.

Fel-Pro Incorporated,

Skokie, Ill.

FORM N 131-H.2 REV. 2.78 


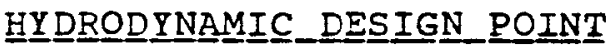

Flow Rate

Total Head Across Pump

Shaft speed

* Mi nimum Submergence (above

impeller discharqe centerline)

* Minimum cover Gas Pressure

(at minimum submergence)

Fluid

Fluid Inlet Temperature

Fluid Density
14,500 qpm

$500 \mathrm{ft}$

$1,110 \mathrm{rpm}$

$4 \mathrm{ft}$

36 ft $\mathrm{Na}$ absolute

(at 1050 F)

Sodium

$1050 \mathrm{~F}$

$50.971 \mathrm{~b} / \mathrm{ft}^{3}$

*Réfer to $3 . \overline{2} \cdot \overline{2}$ for normal operatinq condrtions.

**Resulting NPSH is approximately $41.3 \mathrm{ft}$, referred to inducer

inlet elevation. This value includes pump inlet velocity

head, but does not include internal suction elbow losses. 
TABLE 3-II

PERFORMANCE REQUIREMENTS

1 Design flow rate, gpm

14500

2 Total head at design flow rate, ft.

3 Design speed, rpm

4 Minimum sodium level above impeller

discharge centerline, ft.

5 Minimum cover gas pressure at minimum sodıum level, ft of sodium absolute, 1050F

6 Maximum required NPSH at design flow rate, ft.

Note 1

7 Maximum required NPSH at runout flow rate, ft.

Note 1

8 Flow rate, at pony motor speed, qpm (maximum

1400

9 Total head at shutoff, ft. (maximum)

Note 2

10 Total head (at pony motor speed) ft. (see Note 3)

$5(\max )$

11 Runout flow rate, gpm

18000

12 Runout head, ft. (minimum)

13 Maximum inlet temperature, $F$ (See Note 4)

14 Minimum inlet temperature, $F$

15 Allowable change of free-surface level, ft.

16 Performance rangeability $\mathrm{N}$

17 Maximum shaft horsepower (shp) at design

speed (1100 rpm) and desian flow $(14.500 \mathrm{gpm})$ with $400 F$ sodium

NOTES:

1. The minimum available NPSH at a flow of $18,000 \mathrm{qpm}$ shall be that corresponding to minrmum cover gas 


\begin{tabular}{|l|l|l|l|}
\hline \multirow{2}{*}{$\begin{array}{l}\text { Rockwell International } \\
\text { Atomics International Division }\end{array}$} & \multicolumn{2}{|l|}{ NUMBER } \\
\cline { 2 - 5 } & REV. 266 ST 310001 \\
\hline
\end{tabular}

Fressure occuring concurrently with minimum sodium level. The pump shall not lose more than 3 percent head due to cavitation under these conditions and over the range of operation as specified in 3.2.2.

2. The pump shall have a stable (neqative slope) headcapacity curve between flows of 8,000 to $18,000 \mathrm{gmm}$ at design speed. A runout head of qreater than $375 \mathrm{ft}$. is specified to assure smooth, stable operation at runout.

3. At pony motor operation, the maximum allowable head shall be $5 \mathrm{ft}$. A desiqn objective at pony motor speed is to meet $4 \mathrm{ft}$. head at a low of 1,100 to $1.450 \mathrm{gpm}$.

4. For the maximum outlet temperature, the heat input from the pump shall be taken into account.

5. The pump shall be capable of continuous operation between the boundaries shown on Figure 3-1A. 
Rockwell International Corporation

Atomics International Division

CODE IDENT NO 09974

\begin{tabular}{|c|c|c|c|c|c|c|c|c|}
\hline NUMBER & \multicolumn{5}{|c|}{ REVISION LETTER } & PAGE \\
N266ST310001 & A & $\boldsymbol{B}$ & & & & & & \\
$3-12$
\end{tabular}

TABLE 3-III

STRUCTURAL DESIGN CRITERIA STRESS

IIMITS FOR DESIGN OF THE ISIP INDUCER, IMPEIIER, AND DIFFUSER

A. HIGH TEMPERATURE_CRITERIA_( $\left.\geqq \underline{8} \underline{\underline{0}} \underline{0}{ }^{\circ} F\right)$

Use codé case $\mathrm{N}-47$ (1592-10) (as quidance)

\section{A. 1 Primary_stresess_limits}

A. 1.1 Desigign_Condiitiㅡㅁㅡ

Design Pressure + Dead Load + Design Mechanical

Load (includes seismic)

$$
\begin{aligned}
& P_{M} \leq S_{0} \\
& P_{M}+P_{b} \leq 1.5 S_{0}
\end{aligned}
$$

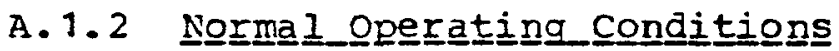

$$
\begin{aligned}
& \text { Pressure + Mechanical Loads + Dead Weight } \\
& \qquad P_{M} \leq S_{M t} \\
& P_{L}+P_{b} \leq k S_{M t} \\
& P_{L}+\frac{P_{L}}{K_{t}} \leq S_{t}
\end{aligned}
$$

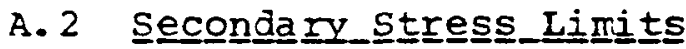

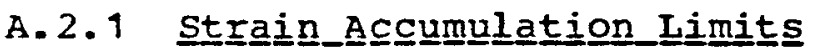

$$
\begin{aligned}
& \text { Average Inelastic Strain } \leq 0.5 \% \text { weld } \\
& 1.0 \% \text { base material } \\
& \text { or } \\
& X+Y \leq S_{a} / S_{y} \\
& S_{a}=1.25 S_{t} \text { (maximum temperature for } 10^{4} \text { hours) } \\
& S_{y}=\text { Yield at average temperature of cycle } \\
& I_{\text {MOX }}+\frac{+}{2}-T_{\text {HIN }}
\end{aligned}
$$


Atomics International Division

CODE IDENT NO 09974

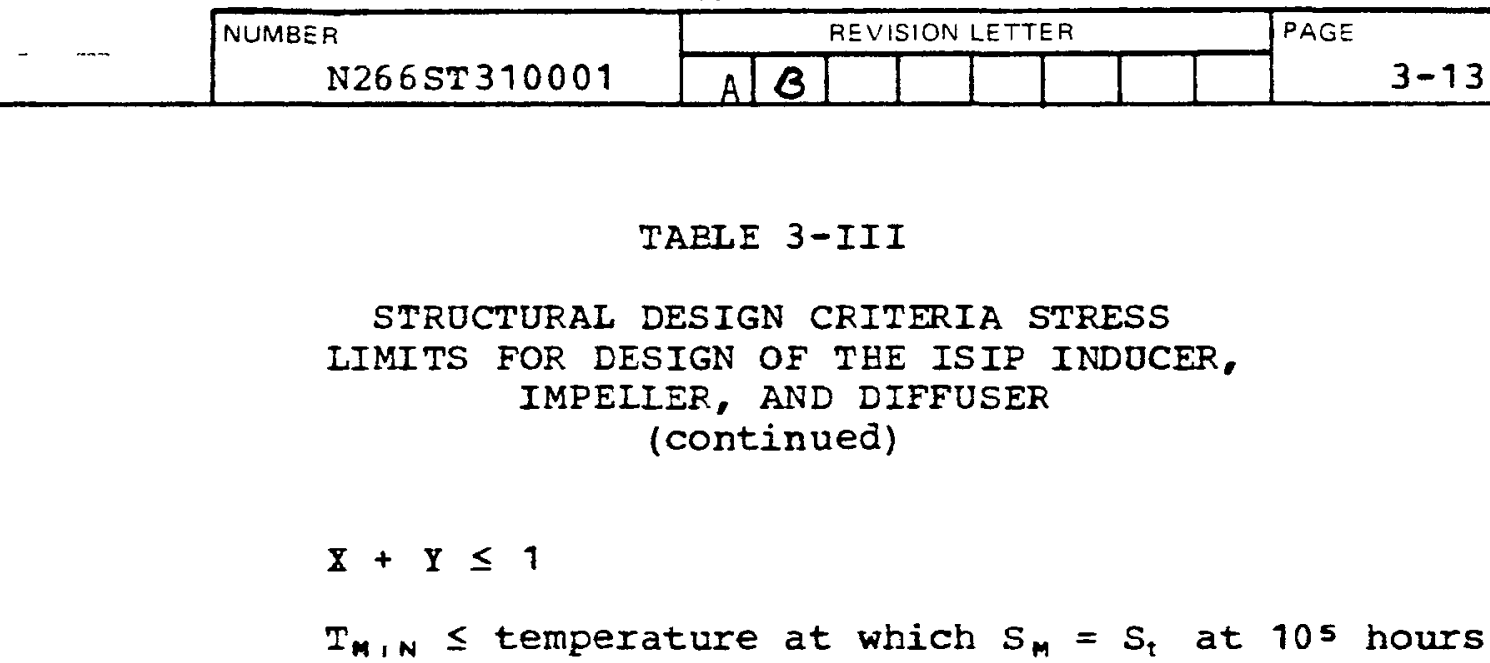

\section{A. 2.2 Creep_Fatiquge_Limits}

$$
\sum \frac{b}{N a}+\sum \frac{t}{T d} \leq 0.6
$$

Figure $3-3$ shall be used as the design fatigue curve for pressure or other high-cycle oscillations.

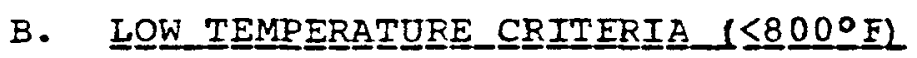

section III, subsection NB (as guidance)

\section{B. 1 Primary_t_secondary streses Limits}

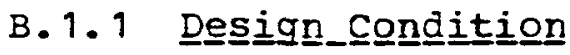

Design Pressure + Design Dead Weight + Design Mechanical Load (include seismic)

$$
\begin{aligned}
& P_{M} \leq S_{M} \\
& P_{L}+P_{b} \leq 1.5 S_{M}
\end{aligned}
$$

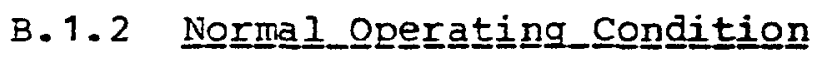

Pressure + Thermal + Mechanical Load + Dead Weight

$$
P_{L}+P_{b}+Q \leq 3 S_{M}
$$


CODE IDENT NO. 09974

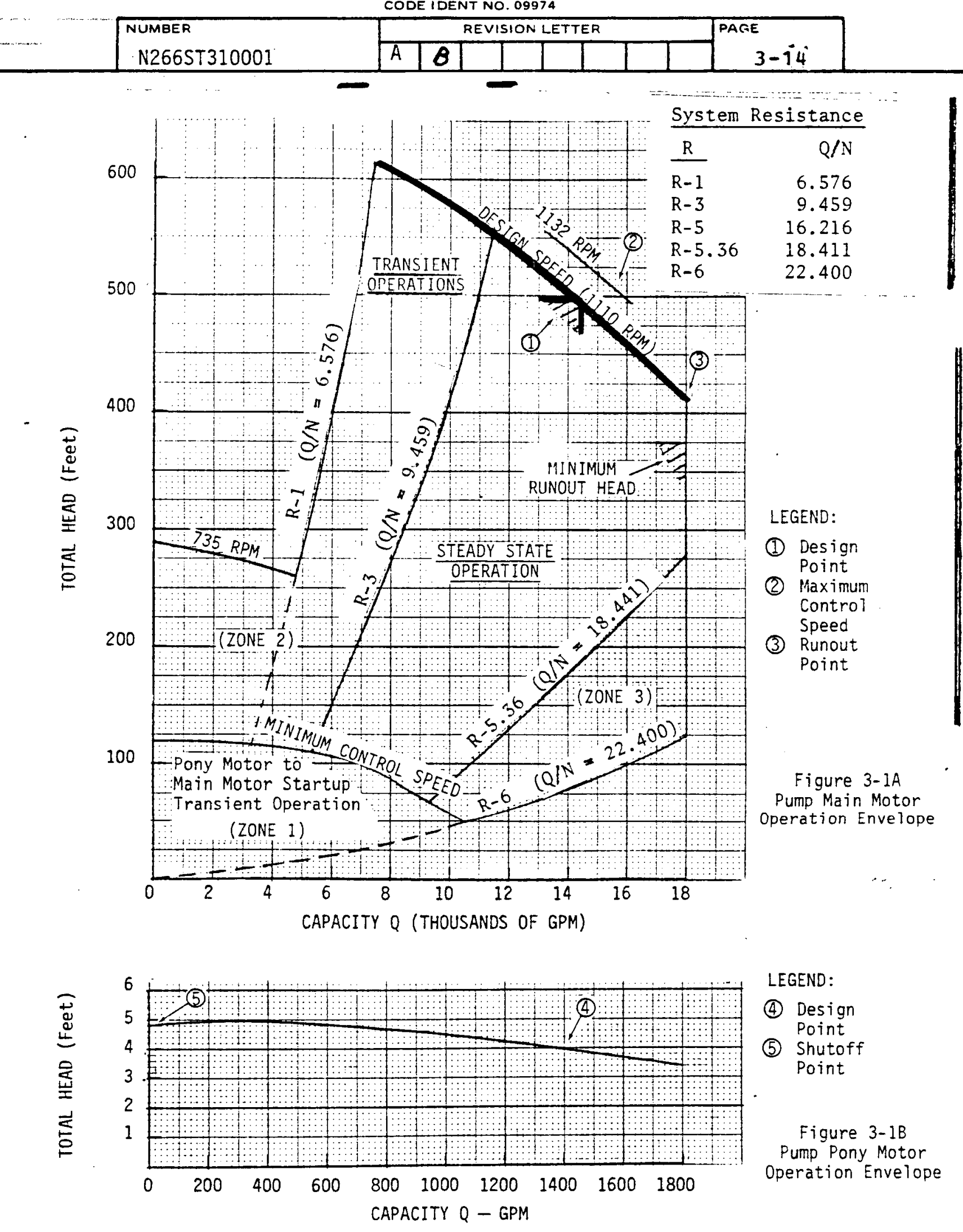

Refer: HWS-1551, Fig. 2 


\section{Rockwell International Corporation N266ER000-001 Atomics International Division \\ Page 109 .}

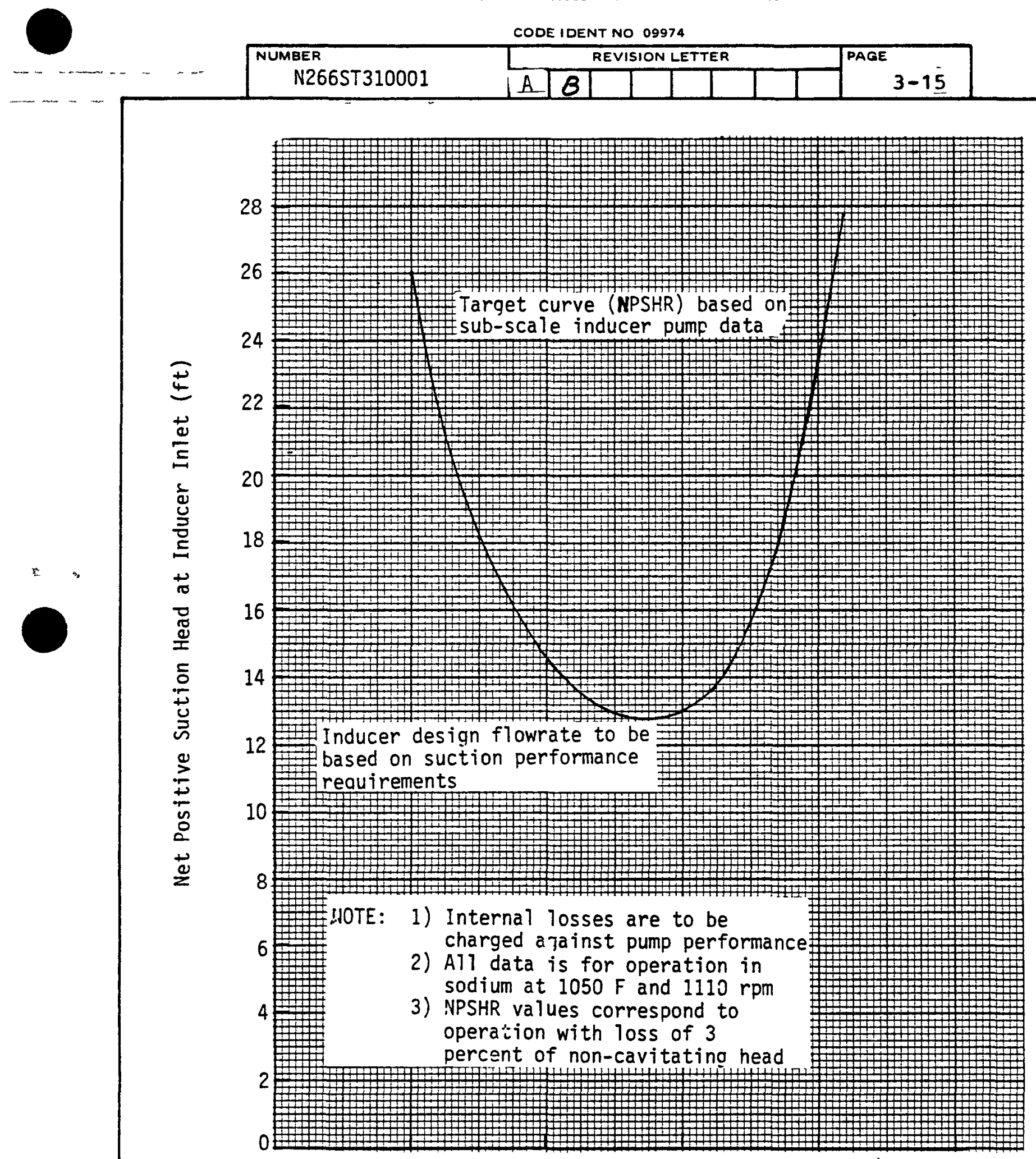

$$
\begin{array}{lcccc}
0.6 & 0.8 & 1.0 & 1.2 & 1.4 \\
\text { Inducer (Actual } & \text { Flowrate)/(Design } & \text { Flowrate) }
\end{array}
$$

Figure 3-2. Suction Performance NPSHR Target Values for Intermediate Size Inducer Pump (ISIP) 
CODE IDENT NO 09974

\begin{tabular}{|l|l|}
\hline$A$ & $B$ \\
\hline
\end{tabular}

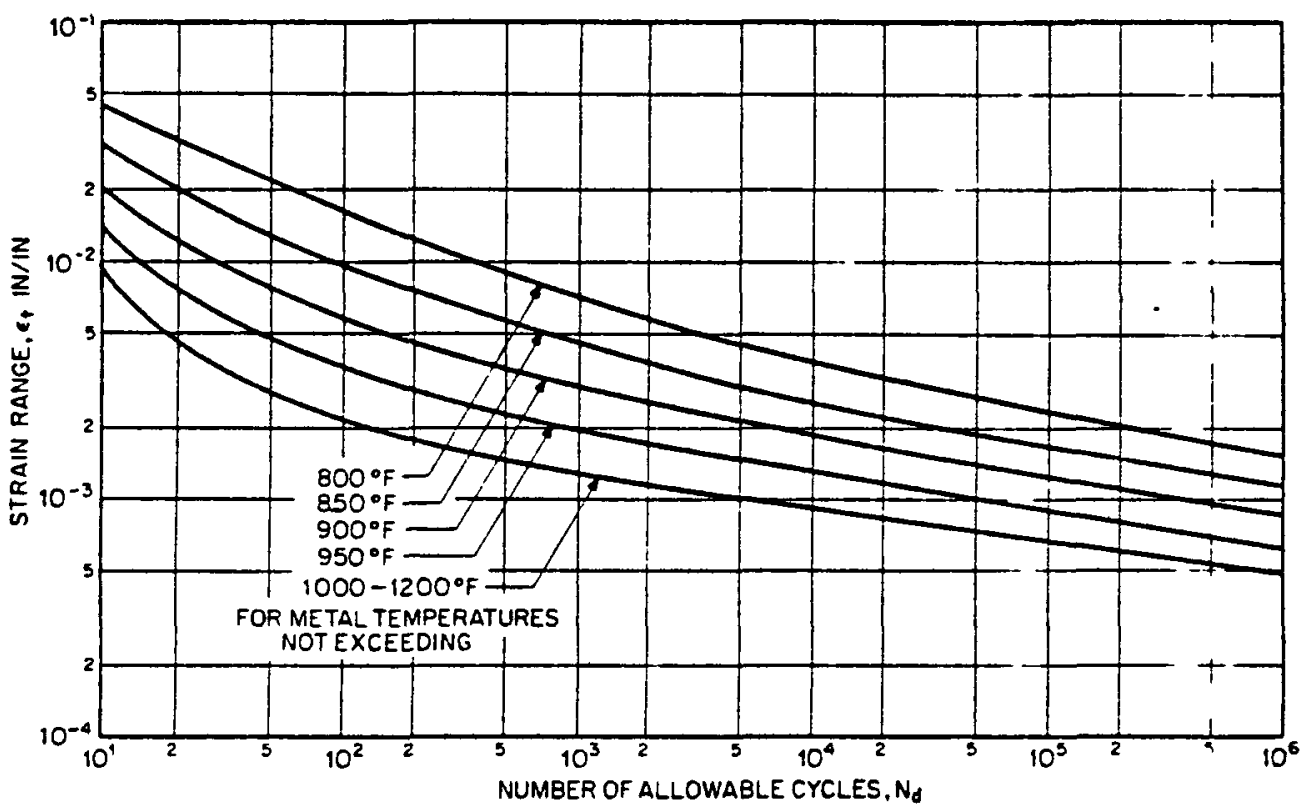

Design fatıgue straın range, $\epsilon_{t}, 304$ SS and 316 SS elastic analysis

Desıgn Fatıgue Strain Range, $\epsilon_{t}$, for 304 SS and 316 SS

(Elastic Analysis)

\begin{tabular}{|c|c|c|c|c|c|}
\hline \multirow{2}{*}{$\begin{array}{c}N_{d} \\
\text { Number } \\
\text { of } \\
\text { Cycles }\end{array}$} & \multicolumn{5}{|c|}{$\epsilon_{t}$, Strain Range (In.//n.) at Temperature } \\
\hline & $800 \mathrm{~F}$ & $850 \mathrm{~F}$ & $900 \mathrm{~F}$ & $950 \mathrm{~F}$ & $10001200 \mathrm{~F}$ \\
\hline $\begin{array}{r}10^{1} \\
2 \times 10^{1} \\
4 \times 10^{1}\end{array}$ & $\begin{array}{l}.0448 \\
.0318 \\
.0231\end{array}$ & $\begin{array}{l}.0303 \\
.020 \\
.0145\end{array}$ & $\begin{array}{l}.0201 \\
.0124 \\
.00867\end{array}$ & $\begin{array}{l}.0107 \\
.0078 \\
.0051\end{array}$ & $\begin{array}{l}.00915 \\
.00472 \\
.00322\end{array}$ \\
\hline $\begin{array}{r}10^{2} \\
2 \times 10^{2} \\
4 \times 10^{2}\end{array}$ & $\begin{array}{l}0168 \\
0125 \\
.00956\end{array}$ & $\begin{array}{l}.00982 \\
.00772 \\
.00612\end{array}$ & $\begin{array}{l}.00587 \\
.00469 \\
.00387\end{array}$ & $\begin{array}{l}.00355 \\
.0028 \\
.0024\end{array}$ & $\begin{array}{l}.00212 \\
.00174 \\
.00152\end{array}$ \\
\hline $\begin{array}{r}10^{3} \\
2 \times 10^{3} \\
4 \times 10^{3}\end{array}$ & $\begin{array}{l}00711 \\
00576 \\
.00476\end{array}$ & $\begin{array}{l}.00462 \\
.00382 \\
.00322\end{array}$ & $\begin{array}{l}.00304 \\
.00257 \\
.00222\end{array}$ & $\begin{array}{l}.00198 \\
.00173 \\
.00153\end{array}$ & $\begin{array}{l}.00129 \\
.00114 \\
.00104\end{array}$ \\
\hline $\begin{array}{r}10^{4} \\
2 \times 10^{4} \\
4 \times 10^{4}\end{array}$ & $\begin{array}{l}.00376 \\
.00316 \\
.00269\end{array}$ & $\begin{array}{l}.00261 \\
.00222 \\
.00202\end{array}$ & $\begin{array}{l}.00186 \\
.00164 \\
.00144\end{array}$ & $\begin{array}{l}.0013 \\
.00116 \\
.00106\end{array}$ & $\begin{array}{l}.000922 \\
.000842 \\
.000762\end{array}$ \\
\hline $\begin{array}{r}10^{5} \\
2 \times 10^{3} \\
4 \times 10^{5}\end{array}$ & $\begin{array}{l}00224 \\
.00196 \\
.00176\end{array}$ & $\begin{array}{l}.00162 \\
.00147 \\
.00131\end{array}$ & $\begin{array}{l}.00122 \\
.00108 \\
000966\end{array}$ & $\begin{array}{l}.000899 \\
.000799 \\
.000719\end{array}$ & $\begin{array}{l}.000662 \\
.000602 \\
.000544\end{array}$ \\
\hline $10^{6}$ & .00151 & .00112 & .000826 & .000619 & .000482 \\
\hline
\end{tabular}

Reference ASME Code Case $\mathrm{N}-47$ (1592-10), Fig .

$\mathrm{T}-1430-1 \mathrm{~A}, 1 \mathrm{~B}$ and Table 1430-1A,1B

Figure 3-3 


\begin{tabular}{|c|c|c}
\hline REV & AMEND & PAGE NO \\
$4-1$
\end{tabular}

\section{QUALITY ASSURANCE_PROVISIONS}

4. 1 Qüality $\overline{\text { Âss }}$ urance Program A quality assurance proqram shall be established and maintained meeting the requirements of RDT F 2-2, Section 1, Section 2 (except 2.5.1), section 3 (except 3.3.5 and 3.9), Section 4 (except 4.12), and section 5 (except $5.3,5.9$ and 5.14 ).

4.2 Design Verification Compliance with the desiqn requirements of section 3 of this specification, shall be demonstrated by analysis and accepted procedures (refer to Table, Appendix 20) and assessed by an indepenaent formal desiqn review.

\section{3 Qualitity Examination}

4.3.1 Visual and Dimensional Examination All fabricated parts shall be subjected to a visual examnation and a dimensional check to verify compliance with drawings and applicable specifications.

\subsubsection{Special Measurements_and Recordings}

4.3.2.1 Inducer/Impelier Surface Measurements Prior to initial assembly and after post-test cleaning, coordinates of the inducer blade surfaces shall be measured and recorded in accordance with inspection requirements to be provided in the addendum to the OMM (refer to 6.2.3). In addztion to measurement of inducer blade, surface coordinates, photoqraphs and cast replicas of the inducer and impeller blade surfaces, including those regions near the leading and tralling edqes, shall be taken before and after the test and malntalned as test records.

4.3.2.2 Natural Resonant Vibration Measurement The natural vibration frequencies of the individual ISIP components (inducer, impeller, diffuser and diffuser shroud) shall be measured and recorded prior to assembly to conform to requirement 3.3 .9 .

4.3.2.3 Fit_and clearance Measurements The assembly fit of the bearing support assembly, diffuser, diffuser shroud, shroud insert and static hydraulics shall be physically checked. The check shall include measurement and recording of minimum and maximum clearances between the shroud lower end (inducer tunnel) and the bore at the suction elbow upper end. In addition, the radial play (looseness) between the bearing support and static hydraulics shall be measured. 


\section{Rockwell International}

\subsection{Test Regui rements}

4.4.1 Test scope Testing is considered to start with the recording of the receipt of inspection data and to continue through assembly, installation, performance testing, removal, cleaning, and post-test inspection. All lnformation regardinq the condition or performance of the pump and its auxiliaries. whether or not the information concerns the inducer, shall be considered as test data.

4.4.2 Assembly and Installation Pump parts shall be received, inspected, and assembled in accordance with the addended $O M M$ by the testing organization. Following assembly of the internals, the internal subassembly shall be installed in the pump tank, then installation of the motor and connection of auxiliaries completed. Assembly and installation shall be performed in accordance with specific procedures in accordance with OMM requirements.

4.4.2.1 Special Tools In addition to the operating equipment, there is a set of special tools used for assembly and disassembly of the pump. These tools are "pump peculiar," desiqned specifically to meet pump requirements. Other general purpose and "facility peculiar" tools are not included.

For complete description of the special tools, refer to the OMM.

4.4.3 Instrumentation and Controls Instrumentation to be used for sodium testing of the ISIP shall be the same, or equivalent to, instrumentation used for testing the frototype FFTF pump during Phase B tests, with the exception of the midshaft bearing and MTI probes which will be deleted. The complete list of instrumentation is described in N266RFT000001.

4.4.3.1 Internal Instrumentation Internal instrumentation, consisting of thermocouples, accelerometers, and proximity probes, and including necessary clips and penetration seals, will be supplied by RI for installation by the ETEC testing organization.

4.4.3.2 External Instrumentation Controls and Eguipment. External instrumentation, controls and auxiliary equipment (4.4) shall be supplied by the ETEC. testing organization.

4.4.4 Auxiliary Equipment Auxiliary equipment requirements, in addition to the liquid rheostat shall include: 
a. The liquid rheostat control cabinet (C201A).

b. An alarm/monitor control cabinet (C999 - sometimes referred to as (C201B) which includes an annunciator panel, lube oil and motor temperature indicators and which functions as an interface junction between the pump and the facllity control system.

c. An oil lubrication system to provide oil circulation, cooling and filtration for the upper. oil lubricated bearings. Includes indicators of temperature, pressure, and level to monitor performance of the oil lubrication system.

4.4.5 Performance Testing After all equipment has been installed and preoperational checkouts completed per the OMM, pump performance tests shall be performed. The performance test shall repeat those selected tests performed during Phase $B$ testing of the prototype pump including a locked rotor impedance test (refer to WDTRS 25.14) in accordance with the Fequest for Test (refer to 6.2.2) and detail test procedures to be prepared by the ETEC test orqanization. The maximum test temperature shall be 950F. The seguence of tests shown in Table 4-I shall be used. Temperature ranges and rates for thermal transient testing shall be as listed in Table 4-II.

For the cavitation performance tests, the suction pressure shall be reduced to the point of 3.0 percent reduction in tctal head across the pump at 14,500, 16,000, and 18,000 qpm.

After cavitation performance testing, a 2,000 hour design pcint endurance test at $950 \mathrm{~F}, 14,500 \mathrm{gpm}$ and full speed shall be conducted with a 200 percent NPSH margin over the value determined for a 3 percent reduction in non-cavitating head. Following the design point endurance test, a 300 hour offdesign endurance test shall be run at $950 \mathrm{~F}, 14,500 \mathrm{gpm}$ and speed of $894 \mathrm{rpm}$ with the same NPSH as was used for the design pcint endurance test.

Percent NP.SH margin shall be calculated using the following equation:

$$
\begin{aligned}
\% M=100(N P S H T / N P S H R & -1) \\
\text { Where: } \% M & =\text { Percent NPSH marqin } \\
\text { NPSHT }= & \begin{aligned}
\text { NPSH to be provided to the pump during the } \\
\text { test }
\end{aligned}
\end{aligned}
$$




\section{NPSHR = NPSH required to limit pump head reduction to $3 \%$ of the non-cavitating head under the same speed, flow and temperature conditions. (test value)}

4.4.5.1 Determination of NPSHR Pump tests to determine the net positive suction head required (NPSHR) to limit the cavitation head loss to 3 vercent, shall be performed at design speed (1110 $\mathrm{rpm})$ and design temperature (950F) at initial measured flow rates of $14,500,16,000$ and 18,000 apm. The tests shall be run with fixed (constant) flow impedance. The NPSHR shall be reported for each initial measured flow by two methods (refer to Figure 4-1):

\section{a. Inlet Nozzle Centerline Elevation as Reference NPSHR shall be determined at the measured flow corresponding to a 3 percent head arop (point (a) of Figure 4-1) below the initial (non-cavitating) head at the initial flow. NPSH shall be referenced to the inlet nozzle centerline (refer to Explanation 6.4c). \\ b. Inducer Inlet Centerline Elevation_a s Reference NPSHR shall be determined at the measured flow corresponding to a 3 percent head drop (Doint (b) of Figure 4-1) at the actual (not initial) flow (refer to Explanation 6.4d). NPSH shall be referenced to the inducer inlet elevation (elevation at the lower end of the inducer blade tip).}

4.4.5.2 Test_success Criteria verification of design shall be by inspection of the impeller and inducer after testing. The criteria for success shall be the absence of visual evidence of material damage (which can be attributed to cavitation) when reviewed with the unaided eye.

4.4.6 cleaning and Disassembly Removal from the pump tank, cleaning and disassembly of the ISIP shall be performed in accordance with the addended OMM using detail procedures prepared by the test orqanization. During removal, the pump internals shall be maintained in an inert atmosphere until cleaned. The alcohol cleaning process shall be used. Following general cleaning, disassembly and spot cleaning (as required) shall be completed. All disassembled parts shall be inspected and inspection data recorded on special data forms provided in the addended OMM. 
TOTAL FLOW RATE (Q)

POINT (a) - NPSHR DETERMINED USING INLET NOZZLE CENTERLINE ELEVATION AS REFERENCE \& $97 \%$ OF THE INITIAL NON-CAVITATING HEAD POINT (b) - NPSHR DETERMINED USING INDUCER INLET CENTERIINE ELEVATION AS REFERENCE \& $97 \%$ OF TEST FLOW NON-CAVITATING HEAD 


\begin{tabular}{|c|c|c|}
\hline $\begin{array}{l}\text { Sequence } \\
\text { Number }\end{array}$ & $\begin{array}{l}\text { Test } \\
\text { Identification } \\
\text { (WDTRS } 25.14 \text { ) }\end{array}$ & Test Description \\
\hline 1. & 7.2 .1 & Pump Assembly and Installation \\
\hline 2. & 7.2 .2 & Auxiliary System Check \\
\hline 3. & $7 \cdot 2 \cdot 3$ & Preheat and Sodium Fill \\
\hline 4. & 7.2 .4 & $\begin{array}{l}\text { Initial Startup and Operation } \\
\text { During Wetting }\end{array}$ \\
\hline 5. & 7.2 .5 .4 & Pony Motor Flow scan \\
\hline 6. & 7.2 .5 .5 & Main Motor (R4) Speed Scan \\
\hline 7. & - & 500 rpm Flow $\operatorname{scan}(1)$ \\
\hline 8. & 7.2 .7 .1 & $700 \mathrm{~F}$ checkout \\
\hline 9. & 7.2 .7 .2 & $\begin{array}{l}750 F \text { Checisout and speed Scan } \varepsilon \\
\text { Endurance Test }\end{array}$ \\
\hline 10. & 7.2 .7 .4 & $800 \mathrm{~F}$ Checkout \\
\hline 11. & 7.2 .7 .5 & $850 F$ Checkout and speed scan \\
\hline 12. & 7.2 .7 .8 & $900 F$ Checkout \\
\hline 13. & 7.2 .8 .1 & $\begin{array}{l}950 F \text { Checkout and Speed Scans } \varepsilon \\
\text { Endurance Test }\end{array}$ \\
\hline 14 & $7.2 .11 . B$ & Cavitation Performance \\
\hline 15. & - & $\begin{array}{l}2000 \text { Hour Design Pt. Endurance } \\
\text { Test at } 200 \% \text { NPSH Margin }\end{array}$ \\
\hline
\end{tabular}

(1) Test needs to be based on results of Pony Motor Flow scan. 


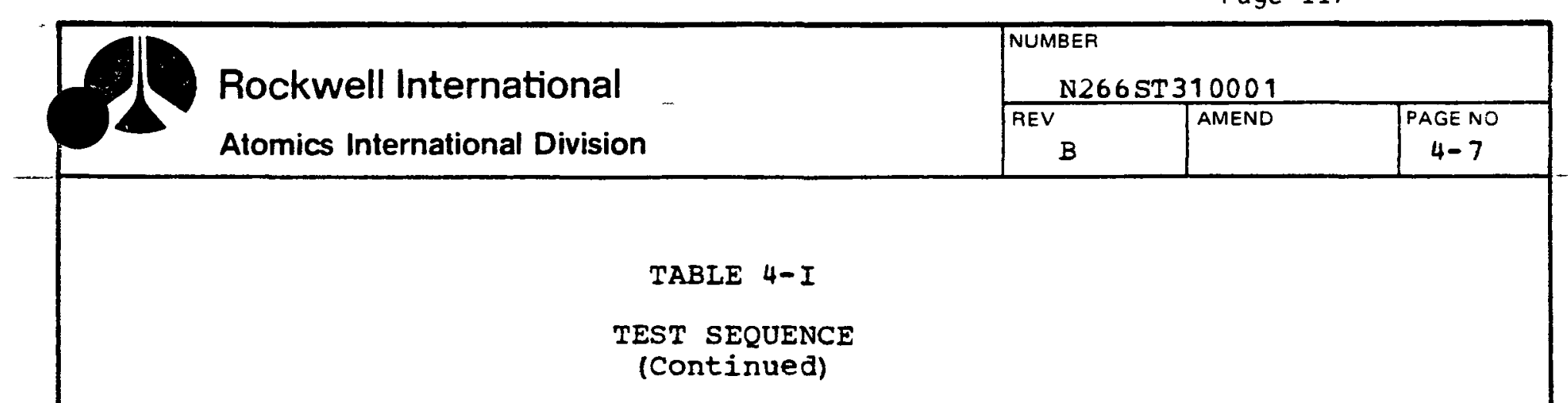

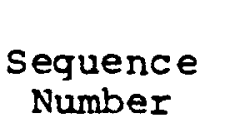

16.

17.

18.

19.
Test Identification (WDTRS 25.14)

7.2 .7 .3

7.2 .7 .6

7.2 .7 .6
Test Descriptzon

3000 Hour Off-Design Endurance Test at Reduced Speed

Low-Temperature Thermal

Transients 202 and 203

Mid-Temperature Thermal

Transient 204

High-Temperature Thermal

Transients 207,208 , and 210 
5. PACKAGING_AND PACKING Finished component castinqs, forgings and machined parts shall be packaged and packed in accordance with the requirements of RI speclfication N001A0116001. Packaging to Level A shall be reguired to maintain a dry arqon purge gas environment during shiprent and storage. Packing to Level $B$ applies using wood packing crates. 
6. DOCOMEENTS_ DATA, AND REPORTS

6.1 Drawings Drawing requirements for the ISIP shall include the following:
a. General Assembly Drawing
b. Engineering Layout Drawing
c. "Spot" Layout Drawings (as required)
d. Detail Drawings
e. Interface control Drawing

6.1.1 General Assembly Drawing The general assembly drawing shall be the top level drawing for the ISIP, through which access to all other drawings can be attalned. This drawing shall be a modified or addended version of the existing Westinghouse Drawing $114 \mathrm{E} 829$ for the FFTF Prototype Pump.

6.1.2 Engineering Layout Drawing The engineering layout drawing shall be a cross-section assembly drawing showing assembled dimensions, tolerances, and clearances for the inducer/impeller and its hydrodynamic surroundings. This drawing shall have sufficient dimensional data and auxiliary views to permit engineering stress and thermal analysis. The layout drawing shall be maintained in an up-to-aate status as new or revised dimensional data is received.

6.1.3 Spot Layout Drawings Spot layout drawings shall be prepared as required to show assembled dimensional information in local regions. These drawings shall be for temporary use in providing up-to-date enqineering information as the desiqn develops and as supplements to the overall layout drawing between update periods.

6.1.4 Detail_Drawings Detail drawings shall be prepared for each new part showing all the requirements for fabricating and inspecting the part.

6.1.5 Interface Control Drawing An interface control drawinq shall show all dimensional and functional interface data required for the design of new parts. The source of all data shall be referenced on the drawing. 


\title{
6.2 Documentation
}

6.2.1 Reports The following reports shall be prepared to record and support the design, analysis, and test effort:
a. Hydrodynamic desian report
b. Steady-state stress analysis report
c. Final design report, including thermal transient analysis
d. Interim test reports
e. Final test report, including post-test inspection
f. Status reports, weekly and monthly, to report project status with relation to established milestones, recent accomplishments, and problem areas.

\begin{abstract}
6.2.2 Reguest for Test A Request for Test snall be prepared in accordance with requirements of the test facllity, describing all those tests to be run and the sequence of testing to be used. In addition, the Request for lest shall define restrictive limits, non-test operation of the pump, and data recording and reporting requirements. The kequest for Test shall contain sufficient detail to permit preparation of test procedures by the testing orqanization. The Request for Test shall include the requirement for determination of locked rotor impedance of the pump.
\end{abstract}

6.2.3 Operations and Maintenance Manual (OMM) Addendum An addendum shall be prepared for the existing OMM (refer to dccument a.) to cover assembly, disassembly, and inspection of those new parts used to construct the ISIP from the existing prototype pump. The addendum shall include graphic material and detail instructions for the use of special tools at least to the extent presently provided in the existing manual.

\subsection{Reference Documents}

a. OMM-051-00-005, Rev. 2, Westinghouse Electric Corporation Electro-Mechanical Division (WARD). "Operation and Maintenance Manual, Liquzd Metal Coolant Pump, Model LMP-1, for the Fast Flux Test Facility (Prototype and Primary) contract E(45-1)2170." 


\section{Rockwell International}

Atomics International Division

NUMBER

N266ST310001

\begin{tabular}{|l|l|}
\hline REV & AMEND \\
\hline
\end{tabular}

B

b. 77. IMEC-DRF-2476, letter from R.E. Fenton (LMEC) to T.A. Mangelsdorf (HEDL), "FFTF Prototype Pump Phase B - Minimum NPSH Demonstratıon at Runout Flow and Pump Cavitation Performance at selected Flowrates," July 19, 1977.

c. Engineering Memorandum 4438, Westinghouse Electric Corporation, E-M Division, "Stress Analysis of the FFTF Impeller, FFTF Primary Pump," S.0. 0360. August 31, 1972, by R.J. Oleyar.

d. FRA-152-3, Draft for RDT F 9-1, "Interim Supplementary structural Criteria for Elevated Temperature," A.L. Snow, November 6, 1970.

\subsection{Notes}

a. Explanation of 3.2.3.1.

The criterion for NPSH is defined as the total (static plus velocity) head available to the pump at the inlet nozzle*, referred to the elevation of the inducer inlet. less the vapor head of the sodium, all expressed in feet of sodlum at desian temperature. Suction performance will be the prinicpal criteria to be usea for evaluating the inducer/impeller assembly relative to a conventional impeller. Target values for the net positive suction head required (NPSHR) to limit the head loss to 3 percent cavitatzon are shown in Figure 3-2.

*Subtract the elevation difference between the inducer inlet and the pump inlet centerline.

b. Explanation of 3.2.3.2.

Minimum submerqence comprises 4 feet above the impeller discharge centerline concurrent with a minimum cover qas pressure of 36 feet absolute of sodium at 1050F. Corresponding conditions for this criterion are defined as having the sum of the submergence and absolute cover gas head equal to 40 feet. 


\section{c. Explanation of 4.4.5.1a. \\ NPSHR, corresponding to method defined in 4.4.5.1a was reported in Reference Document b in 6.3 . \\ d. Explanation of 4.4.5.1b. \\ This NPSFR valve will require determination of an imperical equation to represent the non-cavitating $\mathrm{H}-\mathrm{Q}$ characteristic.}

6.5 Da castings, forgings, and other machined parts), shall be submitted as defined in. Appendix 10 and as specified in the applicable Procurement specification and purchase order. A supplier data list (SDRI) shall be prepared, as applicable, for each procurement specification. 


Rockwell International
Atomics International Division

NUMBER

N266ST 310001

\begin{tabular}{l|l|l}
\hline REV & AMEND & PAGE NO
\end{tabular}

B

$10-1$

\section{APPENDIX 10}

DATA SUBMITTAL REQUIREMENTS 
10. 1 INTRODUCTION This appendix establishes the requirement for data to be submitted to RI. It is comprised of two major elements: a set of general requirements which apply to all data items; a Supplier Data Requirements Ilst (SDRI)* which lists all of the data items required and provides the schedule and submittal requirements.

\subsection{GENERAL_REOUIREMENTS}

\section{2. 1 Document Identification Requirements}

10.2. 1. 1 Title Each document submitted shall bear a title which is descriptive of the contents and whlch distinguishes it from other similar documents.

10.2.1.2 Numbering All documents shall be numbered. The Supplier's document numbering system may be used provided that it prohibits the use of the same number on more than one document. The document number shall appear on each page of the document. The supplier's drawing numbering system shall meet the following minimum requirements:
a. The document number shall not exceed 15 characters. These characters may 2 nclude numbers, letters, and dashes, with the following limitations:
(1) Letters $I, O$, and $Q$ snali not be used.
(2) Letters shall be upper case (capltals).
(3) Numbers shall be whole Arabic (1, 2, 3 . etc.) numerals. Fractional, decimal, and Roman numerals shall not be used.
(4) Blank spaces are not permitted.

Each page of multisheet documents shall be numbered. The first paqe shall indicate the total number of pages.

*SDRI to be provided in applicable procurement document. 
10.2.1.3 Revisions The supplier's document revision system shall include a requirement for advancing the revision letter or number each time the document is revised and reissued.

10.2.1.4 Identification The first page of the document shall show the supplier's name and address (city and state are required, street address is optional), the document title, document number, current revision letter or number, and date.

\subsection{Document_Legibility_and Reproducioility}

10.2.2. 1 Clarity All documents submitted shall be of sufficient clarity such that, when reproduced, lines, numbers, letters, and characters of the reproductions will be clearly legible and readable.

10.2.2.2 Reproducible copies when reproducible copies of drawings are ordered, they shall be direct reading black-onwhite translucents. sepias are not acceptable. Reproducibles shall be of such quality that when microfllmed, copies made from the microfilm meet the requirements of Paragraph 10.2.2. 1 .

\subsubsection{Subtier Documents All documents forwarded from} subtier suppliers shall comply with these same reguirements.

10.2.3 Contractual Due Dates when the due date specified in the SDRI Occurs on Saturday. Sunday, or a noliday, the due date becomes the subsequent working day. Unless otherwise specified, all schedules are expressed in calendar days.

\subsubsection{Prepararation for shipment}

10.2.4.1 Transmittal Letter The supplier shall submit all data under a transmittal letter (or equivalent) which includes the following:
a. RI Purchase order number
b. Purchase order line item number
c. SDRL line item number. (If the document satisfies more than one item number, then all applicable line item numbers will be listed.)
d. Supplier document identification number, title, and revision or date 


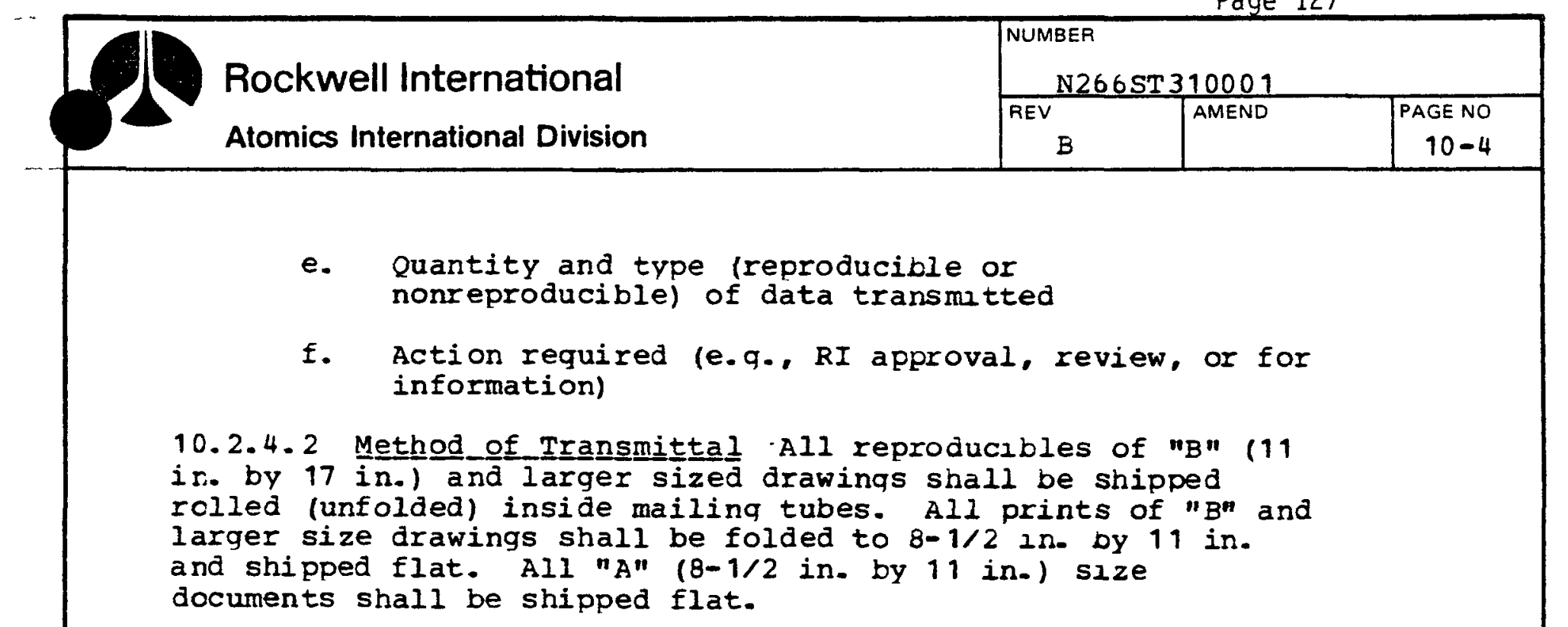


CODE IDENT NO. 09974

\begin{tabular}{|c|c|c|}
\hline \multicolumn{2}{|c|}{ NUMBER N266ST310001 } & REVISION LETTER \\
\hline
\end{tabular}

APPENDIX 20

TABLE 20-I. DESIGN VERIFICATION HETHOD

\begin{tabular}{|c|c|c|c|c|c|c|c|}
\hline \multirow[b]{2}{*}{ Paragraph } & \multirow[b]{2}{*}{ Requirement } & \multicolumn{5}{|c|}{ Verification Method } & \multirow{2}{*}{ Comment } \\
\hline & & Ana lys is & $\begin{array}{l}\text { Drawing } \\
\text { Review }\end{array}$ & Checking & $\begin{array}{l}\text { Tolerance } \\
\text { Stackup }\end{array}$ & Test & \\
\hline 3.1 .1 .1 & Impeller Mounting & & & & & & $\begin{array}{l}\text { Procedure in } \\
\text { OMM Addendum (6) }\end{array}$ \\
\hline 3.1 .1 .2 & Axial Clearance & & & $x$ & $x$ & & \\
\hline 3.1 .1 .3 & Radial Clearance & & & $x$ & $x$ & & \\
\hline $3.1 .1 .4(a)$ & Tool Interfaces & & $x$ & $x$ & & & $\begin{array}{l}\text { RDT F 8-6 } \\
\text { Stress Signoff }\end{array}$ \\
\hline (b) & & & $x$ & $x$ & & & \\
\hline$(c)$ & & & $x$ & $x$ & & & \\
\hline 3.2 .1 & Hydrodynamic Design Point & $x$ & & & & & Analysis (1) \\
\hline 3.2 .2 & Range of Operation & $x \cdot$ & & & & & Analys is (1) \\
\hline 3.2 .2 .1 & Operating Life & $x$ & & & & & $\begin{array}{l}\text { Analys is }(1,3) \\
\text { Report }(2)\end{array}$ \\
\hline 3.2 .3 .1 & Design Flow NPSH & $x$ & & & & $x$ & $\begin{array}{l}\text { Analys is (1) } \\
\text { Test }(4.4 .5 .1)(4)\end{array}$ \\
\hline 3.2 .3 .2 & Runout Flow NPSH & & & & & $x$ & Test $(4.4 .5)(4)$ \\
\hline 3.3 .1 & Stress Criteria & $x$ & & & & & Analysis (3) \\
\hline 3.3 .1 .1 & Steady State Conditions & $x$ & & & & & Analysis (3) \\
\hline 3.3 .1 .2 & Thermal Transients & $\mathbf{x}$ & & & & & Analys is (5) \\
\hline 3.3 .2 .1 & Unbalanced Rotating Loads & & $x$ & $x$ & & & \\
\hline 3.3 .2 .2 & Radial Thrust Loads & $x$ & $x$ & $x$ & & & $\begin{array}{l}\text { (a) Anaiysis (1) } \\
\text { (b) Test Org \& Insp }\end{array}$ \\
\hline 3.3 .2 .3 & Axial Thrust Loads & $x$ & $x$ & $x$ & & & Analysis $(1,3)$ \\
\hline 3.3 .3 & Design for Recirculating Flows & $x$ & $x$ & $x$ & & & Report (2) \\
\hline 3.3 .4 & Drainability and Venting & $x$ & $x$ & $x$ & & & \\
\hline 3.3 .5 & Threaded Fasteners & & $x$ & $x$ & & & \\
\hline 3.3 .6 & Special Tool Design & & $x$ & $x$ & & & OMM Addendum (6) \\
\hline 3.3 .7 & Critical Speed & $x$ & & & & & \\
\hline 3.3 .8 & Direction of Rotation & & $x$ & $x$ & & & \\
\hline 3.3 .9 & Natural Resonant Vibration & $x$ & & & & $x$ & 4.3 .2 .2 \\
\hline 3.4 & Identification and Marking & & $x$ & $x$ & & & Procurement Spec \\
\hline 3.5 .1 & Material Specification & & $x$ & $x$ & & & Procurement Spec's \\
\hline 3.5 .2 & Fluid Properties & $x$ & & & & & Analys is, Reports $(1,4)$ \\
\hline 3.5 .3 & Fabrication Procedures & & $x$ & & & & Procurement Spec's \\
\hline
\end{tabular}

Reference Documents

(1) Hydrodynamic Analys is Report (Est. Complete 4/7/78) by Rocketdyne

(2) Design Report (Est. Complete Dec.) by AI

(3) Structura T Anaiys is Report (Est. Complete $4 / 7 / 78$ ) by Rocketdyne

(4) Final Test Report (Est. Complete Dec. 1980) by AI

(5) Test Transient identification, TI (Est. Complete Sept. 1978) by A

(6) OMM Addendum (Est. Complete Jul. 10, 1978) by AI 
(This page intentionally blank) 
(This page intentionally blank) 


\section{APPENDIX C}

RECIRCULATING FLOW ANALYSES OF

INTERMEDIATE SIZE INDUCER PUMP

ESG Document N266TI000003 


Rockwell international SUPPORTING DOCUMENT
Intermediate = Size Inducer PUMP
DOCUMENT TITLE
Recirculating Flow Analyses of Inte rmediate
Size Inducer Pump (ISIP)

\begin{tabular}{|l|l|}
\hline NUMBER & REV LTR/CHG NO. \\
N266 TIO00003 & SEE SUMMARY OF CHG \\
\hline
\end{tabular}

DOCUMENT TYPE

Technical Information KEYNOUNS Inducer Pump ORIGINAL ISSUE DATE April 20, 1978

\begin{tabular}{|c|c|c|c|c|}
\hline Size inducer Fump (LIF) & & GONO. & S/A NO. & $\begin{array}{l}\text { PAGE } 1 \text { OF } \\
\text { TOTAL PAGES } \quad 17\end{array}$ \\
\hline PREPARED BY/DATE & MAIL ADDR & 09280 & 23000 & $\begin{array}{l}\text { REL.DATE } \\
4-21-78 B A\end{array}$ \\
\hline R. K. Hoshide $\pi$ & & & SECURITY CL & ASSIFICATION \\
\hline IRED PROGRAM? YES $\square$ NO $X$ & JBUS & ICHECKO & $\begin{array}{l}\text { BOX ONLY) } \\
\text { RDA DOD }\end{array}$ & $\begin{array}{l}\text { (CHECK ONE BOX ONLY) } \\
\text { RESTRICTED }\end{array}$ \\
\hline $\begin{array}{l}\text { APPROVALS } \\
\text { L. Stabinsky }\end{array}$ & 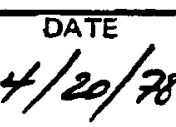 & $\begin{array}{l}\text { UNCL } \\
\text { CONF } \\
\text { SECR }\end{array}$ & $\begin{array}{ll}\square & \square \\
\square & \square\end{array}$ & $\begin{array}{l}\text { DATA } \\
\text { DEFENSE } \\
\text { INFO. }\end{array}$ \\
\hline & & & & \\
\hline
\end{tabular}

\begin{tabular}{|l|lr|}
\hline \multicolumn{3}{|c|}{ DISTRIBUTION } \\
\hline$*$ & \multicolumn{3}{|c|}{ NAME } & $\begin{array}{l}\text { MAIL } \\
\text { ADDR }\end{array}$ \\
\hline$*$ & R. V. Anderson r & LB 17 \\
$*$ & T. J. Boardman(17 & LB 39 \\
$*$ & C. Dunn & LB 39 \\
$*$ & R. K. Hoshide & JB05 \\
$*$ & L. Stabinsky & JB05 \\
\end{tabular}

* complete document

NO ASTERISK, TITLE PAGE/SUMMARY OF CHANGE PAGE ONLY
ABSTRACT

Enclosed is a report which documents the recirculation flow analyses for the Intermediate-Size Inducer Pump (ISIP), from which the primary flowrates through the pump were obtained. The front and rear impeller labyrinth seals, which incorperate stepped pockets with slanted and rounded ribs were checked. These seal design features should minimize the impeller laby rinth seal leakages and also provide excellent shutoff head characteristics.

\section{J.HIS REPORT MAY NOT BE PUBLISHED WITHOUT THE APPROVAL OF THE PATENT BRANCH, ERDA}

This report was prepared as an account of work sponsored by the United States Government. Neither the U. S. Government, nor any of its employees nor any of its cantractors, subeontractors, or their employees, makes any worranty, express or implied, or assumes any legal liability or respon. sibility for the accuracy, completeness or usefutness of any information, apparatus, product or process disclosed or represents that its use would not infringe privately owned rights 


\section{Recirculating Flow Analyses of Intermediate Size} Inducer Pump (ISIP)

Refs: (1) AI Drawing, "Intermediate-Size Inducer Pump Layout, ISIP," Drawing N266R000015, Issue 1, March 16, 1978

(2) Allen, H. G., "Hydraulics Design Report FFTF Primary Pump," Engr. Memo 4476, Westinghouse Electric Corporation, Electro-Mechanical Div., Cheswick, Pennsylvania, January 15, 1973

(3) Crane, "Flow of Fluids Through Valves, Fittings, and Pipe," Technical Paper 410, Crane Company, New York, N.Y., 1976

(4) Internal Letter, "Pump Impeller Labyrinth Seal Study," DDR-712-3012, Isaacson, J., Rocketdyne Division, Rockwel1 International, Canoga Park, California, December 4, 1957

(5) Crewdson, E., "Water-Ring Self-Primary Pumps," Vo1. 170, No. 13, Institution of Mechanical Engineers, Westminster, South Wales, 1956

\section{INTRODUCTION}

Recirculating flows of the ISIP were analyzed, and the calculations are shown in Appendix A. Secondary flow paths were first obtained before the primary flow rates through the pump were obtained. Analyses were also conducted to check the impeller labyrinth seal design and the drain and vent hole leakages.

\section{SUMMARY}

Recirculation flow rates were obtained and are shown in Figures 1 and 2 . From these recirculation flows, the primary flow rates through the pump were obtained and are also shown in Figures 1 and 2.

The impeller labyrinth seal design incorporates good design features which are stepped pockets with slanted and rounded ribs. These features are especially helpful in minimizing the leakage flows for this large clearance seat application. 


\section{DISCUSSION}

The ISIP layout drawing (Reference 1) was used to determine the various recirculation flow paths through the pump. Recirculation flows which remained the same from the previous pump design were obtained from Reference 2 and are shown in Figure 1.

Secondary flow paths were first obtained and are summarized below:

1. $Q_{1}$, leakage between suction nozzle outlet cone and inlet to suction elbow $=160 \mathrm{gpm}$.

2. $Q_{2}$, leakage through inlet static seal $=85 \mathrm{gpm}$.

3. $Q_{3}$, flow through drive shaft $=50 \mathrm{gpm}$.

4. $Q_{4}$, leakage through front impeller labyrinth seal $=648 \mathrm{gpm}$.

5. $Q_{5}$, leakage through rear impeller labyrinth seal $=569 \mathrm{gpm}$.

6. $Q_{6}$, flow through hydrostatic bearing $=200 \mathrm{gpm}$.

7. $Q_{7}$, leakage through the diffuser and radial bearing housing $=131 \mathrm{gpm}$.

8. $Q_{8}$, leakage through discharge bellows static seal $=10 \mathrm{gpm}$.

9. $Q_{9}$, leakage through impeller return holes $=669 \mathrm{gpm}$.

These recirculation flow calculations are shown in the appendix, and the flows are shown in Figures 1 and 2. Friction factors used were obtained from Crane (Reference 3 ).

Impeller labyrinth seal leakage rates were checked using previous Rocketdyne empirical data (Reference 4) and results obtained from E. Jackson (addendum to Reference 5). The seal flow coefficient obtained for both front and rear labyrinth seals was 0.428 which is realistic for the present design. These labyrinth seal designs incorporate the step configuration from Reference 4 and the slanted rounded backs of the ribs from Reference 5 . These features should minimize these leakages and also provide excellent shutoff head characteristics.

The shaft extension does not affect the flow rate through the drive shaft. Only a small decrease (less than $1 / 2 \mathrm{gpm}$ ), which includes the vent/drain holes contribution, is realized and was neglected for this analysis.

From this recirculation flow analysis, the following primary flow rates through the pump were obtained: 
Page: 4

N266ER000-001

Page 135

1. Q disch., discharge flow rate $=14,500 \mathrm{gpm}$.

2. Q inlet, inlet flow rate $=14,500 \mathrm{gpm}$.

3. Q suct. el., suction elbow flow rate $=14,660 \mathrm{gpm}$.

4. $Q$ ind., flow through inducer $=14,695 \mathrm{gpm}$.

5. Q imp., flow through impeller $=15,997 \mathrm{gpm}$.

6. Q trans. diff., flow through transition diffuser $=14,780 \mathrm{gpm}$.

7. Q exist. diff., flow through existing diffuser $=14,841 \mathrm{gpm}$. 


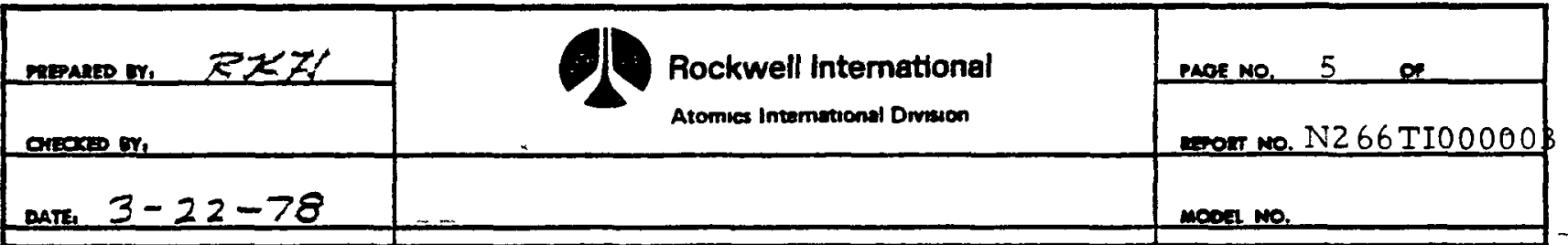

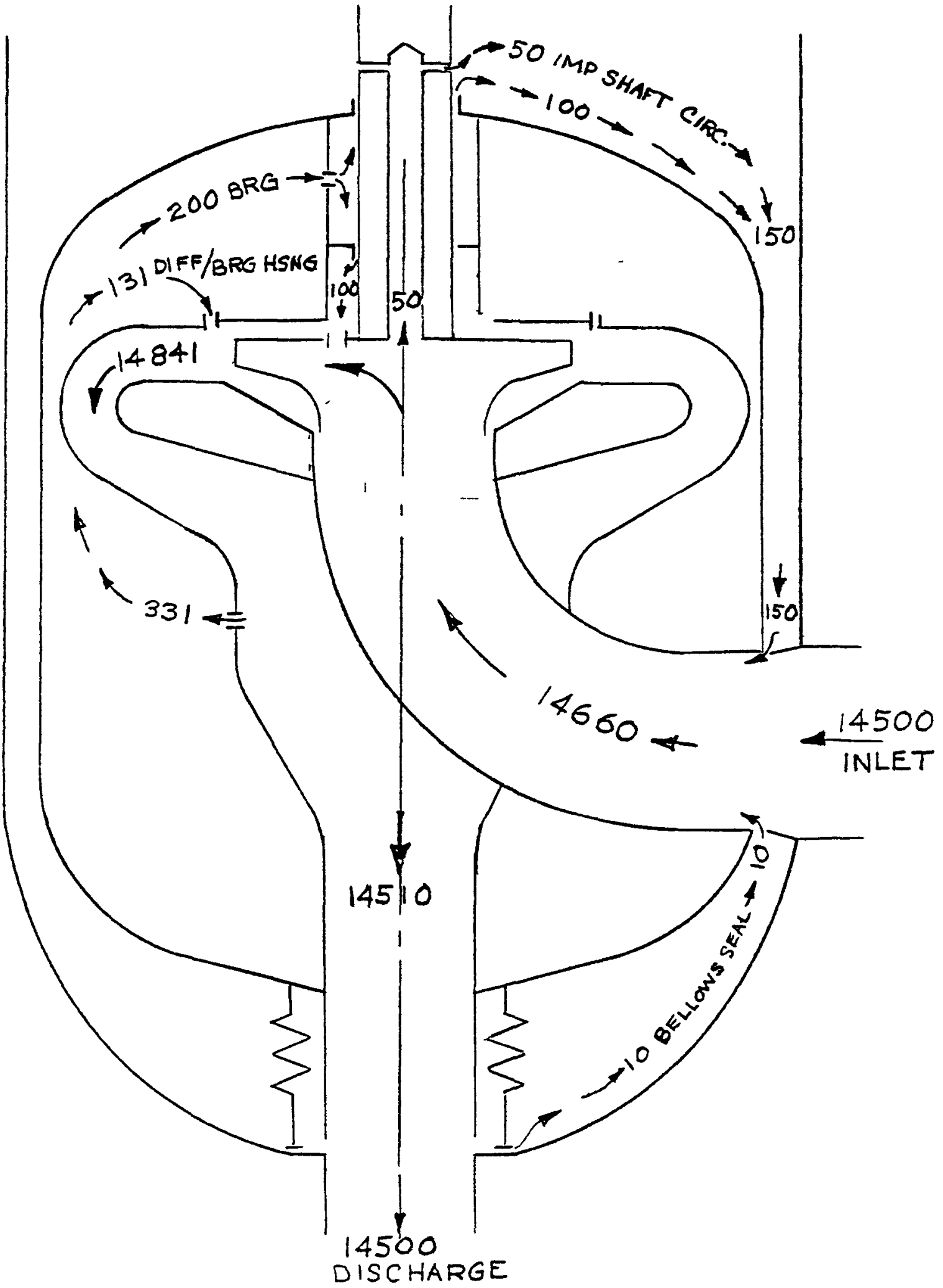

FIG.I WEMD RECIRCULATION FLOWS 


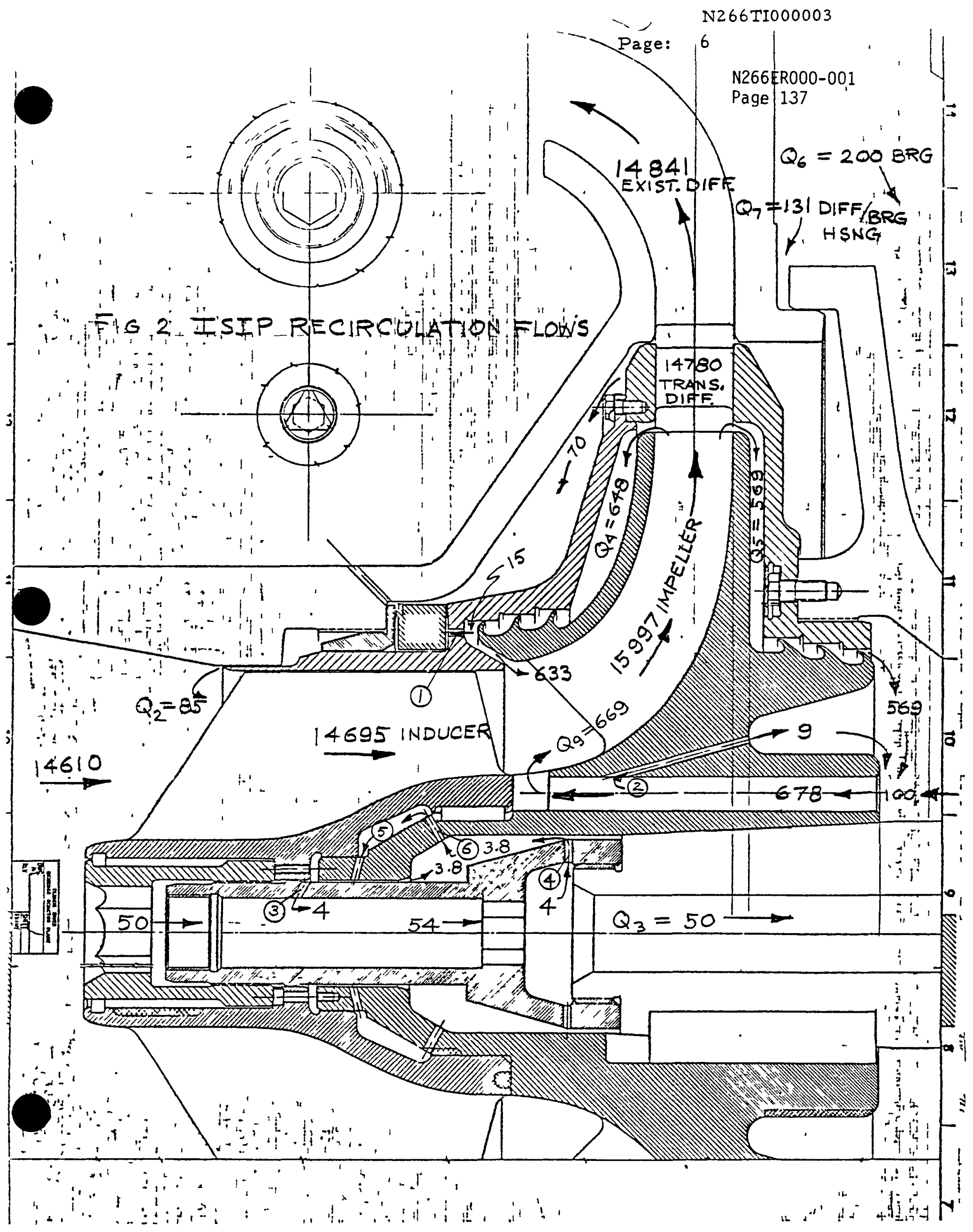




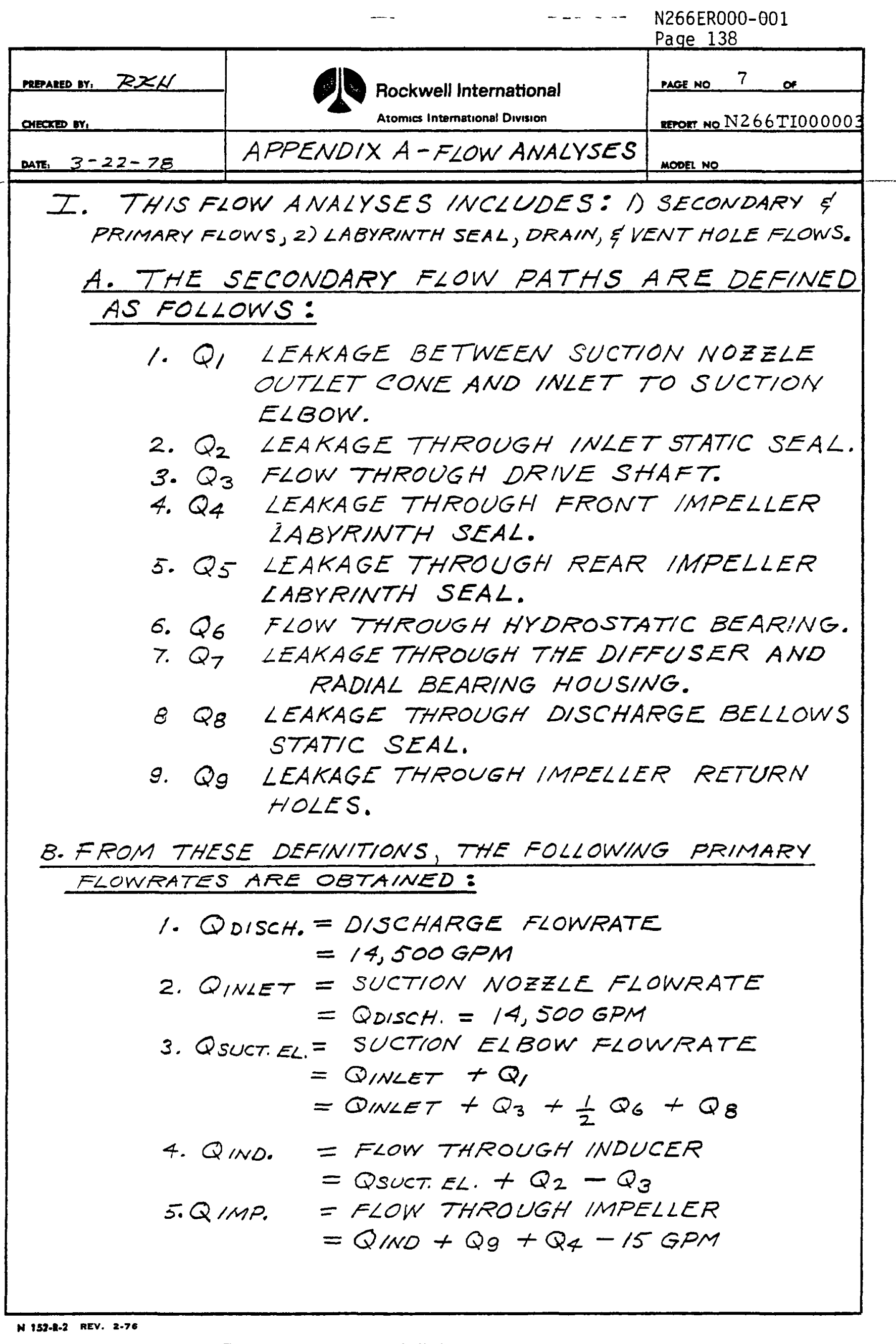


N266ER000-001

Page 139

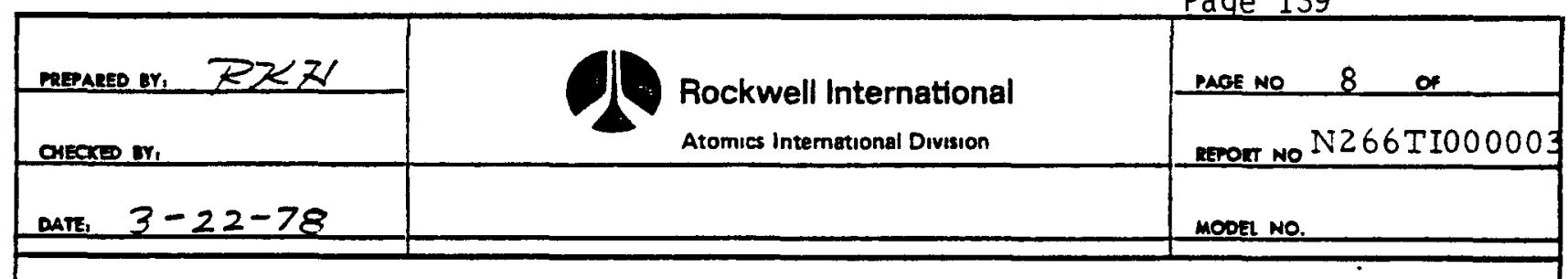

$$
\begin{aligned}
& \text { 6. Q TRANS. DIFF. }= \text { FLOW THROUGH TRANSITION } \\
& \text { DIFFUSER } \\
&= Q_{\text {IMP }}-Q_{4}-Q_{5} \\
& \text { 7. QEXIST. DIFF. }= \text { FLOW THROUGH EXISTING DIFFUSSER } \\
&= Q_{\text {TRANS. DIFF. }}+Q_{7}-Q_{2}+15 \text { GPA } \\
& \text { 8. QDISCH. }=Q_{\text {EXIST. DIFF. }}-Q_{6}-Q_{7}-Q_{8} \\
&= 14,500 \text { GP. }
\end{aligned}
$$

C. THIS SECONDARY FLOW ANALYSES ARE AS FOLLOWS:

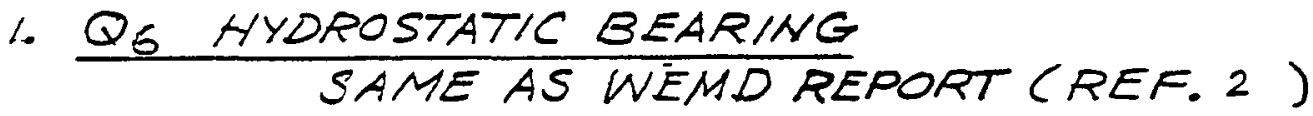

$$
Q_{G}=\underline{\underline{200 G P M}}
$$

2. Q7 DIFFUSER AND RADIAL BEARING HOUSING

$$
Q_{7}=\underline{\underline{13 / G P M}}
$$

3. Q8 DISCHARGE BELLOWS STATIC SEAL

$$
Q_{8}=10 \mathrm{GPM}
$$

4. Q4 FRONT IMPELLER LABYRINTH SEAL

FROM ROCKET DYNE DIV, ROCKWELL INT.

6633 CANOGA AVE, CANOGA PK., CA.

$$
Q_{4}=\underline{\underline{648} \text { GP }}
$$

5. Q5 REAR IMPELLER LABYRINTH SEAL

FROM ROCKETDYNE DIV., ROCKWELL INT. 6633 CANOLA AVE, CANOGA PK, CA.

$$
Q_{5}=\underline{\underline{569 G P M}}
$$

6. Q $\frac{Q_{2} \text { INLET STATIC SEAL }}{\text { GIVEN: MEAN SEAL D IA }}$

$$
\begin{aligned}
& \text { FACE WIDTH }=\frac{1}{8} \mathrm{IN} \\
& \text { CLEARANCE }=0 \text { TO } 3 \text { MILS, SAY } 1.5 \mathrm{M} / L S
\end{aligned}
$$

PER SEAL:

$$
\begin{aligned}
A R E A & =\pi(M E A N D / A) C \angle E A R A N C E \\
& =\pi(23.2)(.0015)=0.109 / N^{2}
\end{aligned}
$$

N 152-R-2 REV 2.76 
N266ER000-001

Page 140

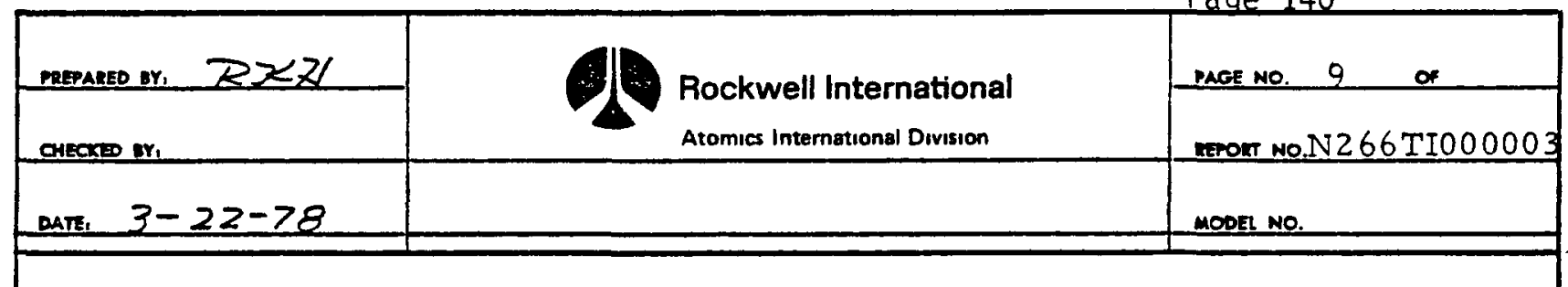

LET: HEAD LOSS ( $\left.H_{2}\right)$ THROUGH GAP EQUAL TO:

$$
H_{2}=1.5 \frac{V^{2}}{29}+f \frac{L}{D} \frac{V^{2}}{29}
$$

- WHERE: $V=V E L$ THROUGH GAP

$$
\begin{aligned}
f= & \text { FRICTION FACTOR } \\
= & 0.037 \text { FOR VERY SMALL } \\
& \text { CLEARANCES } \\
L= & \text { LENGTH } \\
= & \frac{1}{8} \mathrm{NN} . \\
D= & \text { EQUIVALENT DIR } \\
= & \text { TWICE THE CLEARANCE } \\
= & 2(0.0 O I 5)=0.003 / N . \\
g= & \text { ACCELERATION DUE TO GRAVITY } \\
= & 32.174 \text { FT/ SEC }
\end{aligned}
$$

SUBSTITUTING :

$$
H_{2}=1.5 \frac{5 V^{2}}{29}+.0 \frac{37\left(\frac{1}{8}\right)}{(.003)} \frac{V^{2}}{29}
$$

SOLVING FOR $V$ :

$$
\begin{aligned}
V & =\left(\frac{29 H_{2}}{3.04}\right)^{\frac{1}{2}} \\
\text { LET: } H_{2} & =500 \mathrm{FT} \text { (MAX.) } \\
V & =\left(\frac{2.500}{3.04}\right)^{\frac{1}{2}}=103 \mathrm{FT} / \mathrm{SEC} \\
V & =\frac{Q 144}{A 448.83}
\end{aligned}
$$

WHERE:

$$
\begin{aligned}
Q & =\text { FLOWRATE THROUGH SEAL } \\
A & =\text { AVE. LEAKAGE AREA }=0.109 \mathrm{NN}^{2} \\
\therefore Q & =\frac{V A 48.83}{144}=\frac{103(0.109) 448.83}{144} \\
& =35 \mathrm{GPM}
\end{aligned}
$$

FOR BOTH FACES:

$$
Q=2(35)=70 \text { GP }
$$

ADDITIONAL LEAKAGE THROUGH THE 2 EA $\frac{1}{4} \mathrm{IN}$. DRAIN HOLES MUST BE ACCOUNTED FOR

N 152-R-2 REV. 2-76 


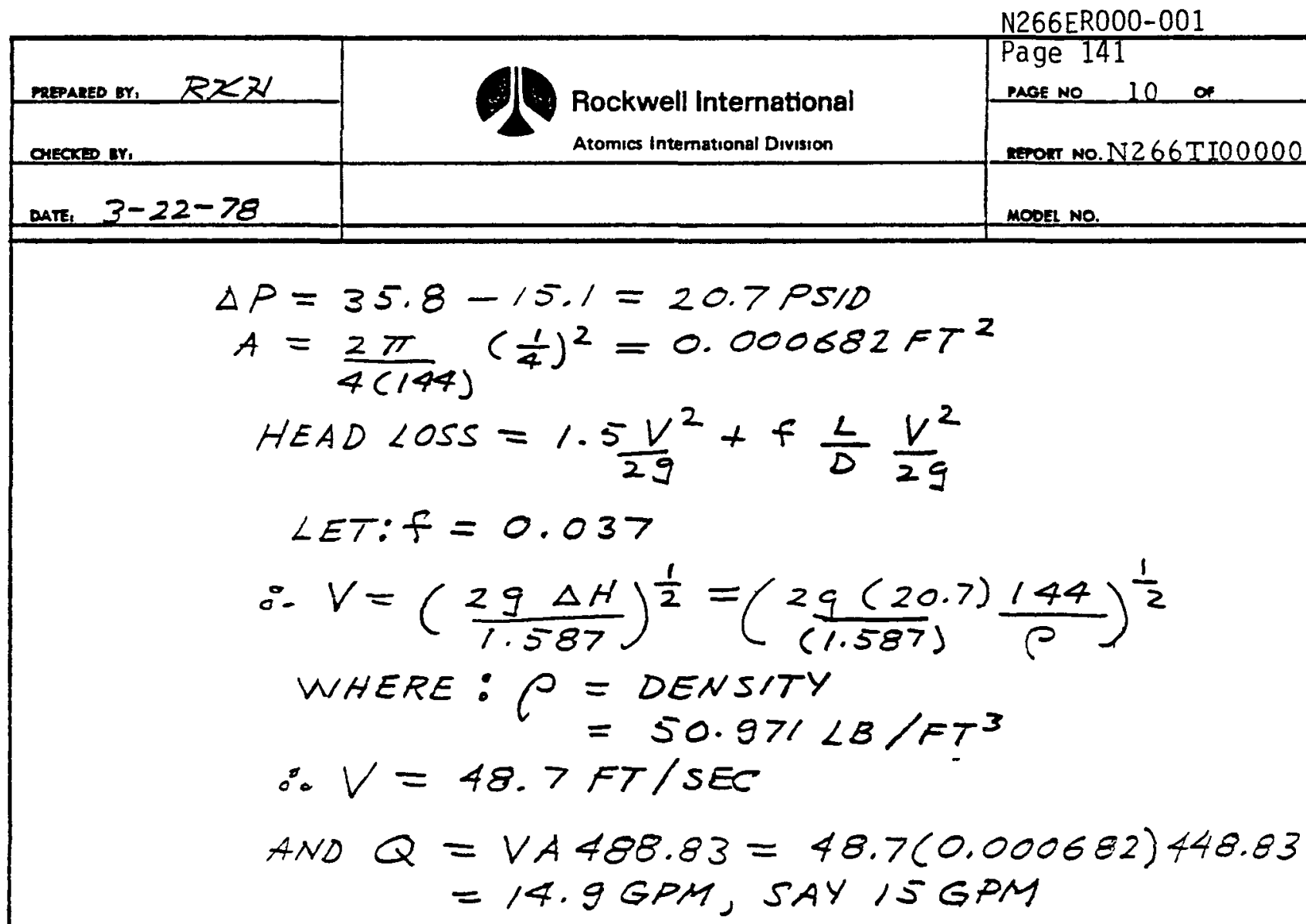

$\therefore$ TOTAL INLET STATIC SEAL LEAKAGE IS:

$$
Q_{2}=70+15=85 \mathrm{GPM}-
$$

CHECK ON REYNOLDS NO. (RE)

$$
\begin{aligned}
R e=P \frac{V d}{\mu} & \\
\text { WHERE: } \sigma & =\text { DI., FT } \\
\mu & =V I S C O S I T Y \\
& =0.522 / \angle B / F T H R
\end{aligned}
$$

SUBSTITUTING:

$$
\begin{aligned}
& R_{C}=\frac{50.971(48.7) \frac{.25}{12}}{0.5221}(3600)=3.5 \times 10^{5} \\
& \angle E T: \frac{e}{d}=\frac{0.0001}{\frac{1}{4}}=0.0004 \\
& \text { FROM CRANE }(\text { REF. } 3) \\
& \quad f=0.0173 \\
& \therefore \Delta H=1.5 \frac{V^{2}}{29}+(0.0173) \frac{.59}{\frac{1}{4}} \frac{V^{2}}{29} \\
& V=\left(\frac{29 \Delta H}{1.54}\right)^{\frac{1}{2}}=\left(\frac{\left.29(20.7) \frac{144}{1.54}\right)^{\frac{1}{2}}=49.4 \mathrm{FT} / \mathrm{SEC}}{50.971}\right) \mathrm{GPM} \\
& Q=49.4(0.000682) 448.83=15 \mathrm{GP} \\
& \therefore Q_{2}=70+15=85 \mathrm{GPM}
\end{aligned}
$$

N 152-R-2 REV. 2-76 
N266ER000-001

Page 142

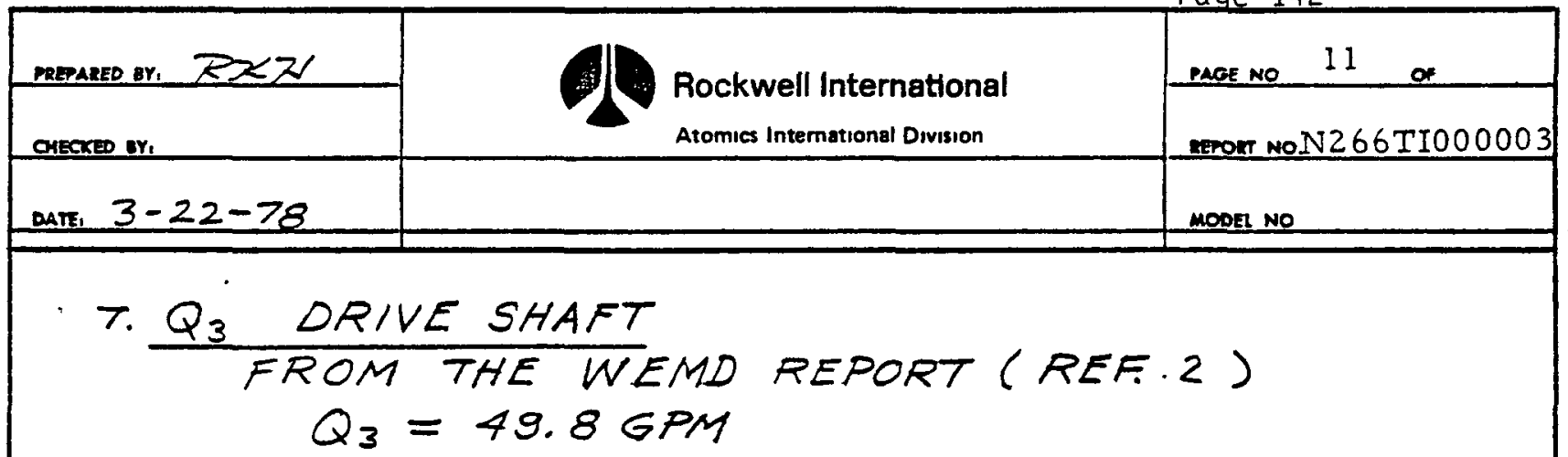

BECAUSE THE ISIP DESIGN HAS AN ADDITIONAL SHAFT EXTENSION, THE ADDITIONAL PRESSURE LOSS AND ACCOMPANYING DECREASE IN FLOWRATE WAS CHECKED AS FOLLOWS:

$$
\begin{aligned}
& \angle E T: d=1.95 \mathrm{NN} \text {. (DISTANCE ACROSS FLATS) } \\
& \therefore A=\frac{\pi}{4(144)}(1.95)^{2}=0.0207 F^{2} \text {. } \\
& \angle E T: Q=49.8 \mathrm{GPM} \\
& \therefore V=\frac{Q}{A 448.83}=\frac{49.8}{(0.0207) 448.83} \\
& =5.36 \mathrm{FT} / \mathrm{SEC} \\
& R_{e}=\frac{50.971(5.36) \frac{1.95}{12}(3600)}{0.5221} \\
& =3.07 \times 10^{5} \\
& \frac{e}{d}=\frac{0.001}{1.95}=0.0005 \\
& \text { FROM CRiME } \\
& f=0.0182 \\
& \Delta H=1.5\left(\frac{5.36)^{2}}{29}+\frac{0.0182(13.9)(5.36)^{2}}{1.95(29)}\right. \\
& =0.73 \mathrm{FT} \\
& Q=K \sqrt{\Delta H}, O R: K=\frac{Q}{\sqrt{\Delta H}} \text {. } \\
& \text { FROM WElD (REF. } 2 \text { ) } \\
& K=\frac{49.8}{\sqrt{49.84}}=7.054 \\
& \therefore Q_{3}=7.054 \sqrt{49.84-.73}=49.44 \mathrm{GPM} \\
& \text { DECREASE IN FLOW }=49.8-49.44 \\
& =0.36 G P M \text { (NEGLIGIBLE) } \\
& \therefore \angle E T Q_{3}=50 G P M
\end{aligned}
$$

N 152-R-2 AEV. 2.76 
N266ER000-001

Page 143

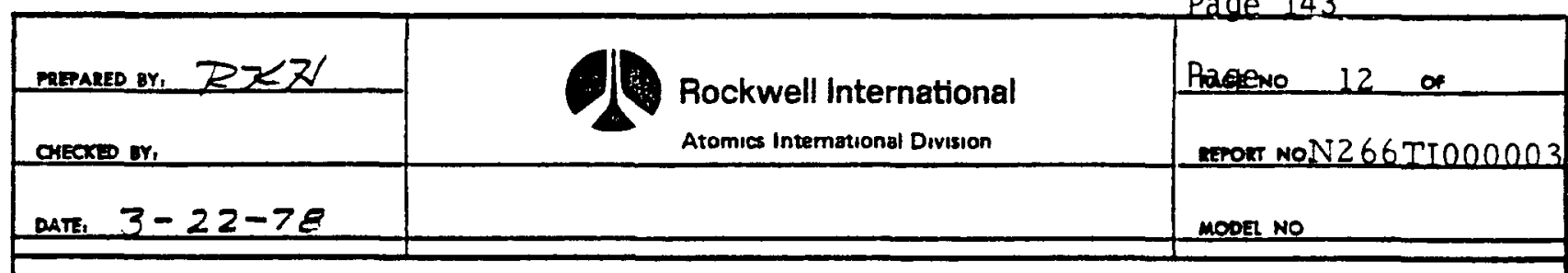

8. Q, SUCTION NOZZLE OUTLET CONE AND INLET TO SUCTION ELBOW

$$
\begin{aligned}
Q_{1} & =Q_{3}+\frac{1}{2} Q_{6}+Q_{8} \\
& =50+\frac{1}{2}(200)+10 \\
& =160 \text { GP }
\end{aligned}
$$

9. Qq IMPELLER RETURN HOLES

$$
\begin{aligned}
Q_{9} & =Q_{5}+\frac{1}{2} Q_{6} \\
& =569+\frac{1}{2}(200) \\
& =669 \text { GP }
\end{aligned}
$$

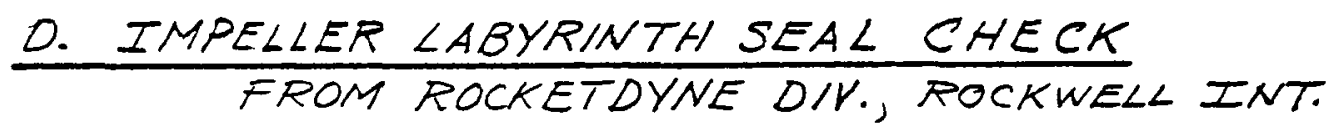

$$
\begin{aligned}
& Q_{4}=648 \mathrm{GPM} \\
& Q_{5}=569 \mathrm{GPM} \\
& \triangle P A=\text { DELTA PRESSURE (STATIC) ACROSS FRONT } \\
& \angle A B Y R I N T H \text { SEAL } \\
& =129.7-35.8=93.8 \text { PS } 1 D \\
& \triangle P_{5}=\text { DELTA PRESSURE (STATIC) ACROSS REAR } \\
& \angle A B Y R I N T H S E A L \\
& =126.9-39.7=87.2 \text { PS10 } \\
& \text { FRONT SEAL AVE. OrA. }=22.5 \mathrm{IN} \text {. } \\
& \text { REAR SEAL AVE. DIs. }=20.45 \mathrm{IN} \text {. } \\
& \text { DIAMETRAL CL. }=0.100 \text { TO } 0.110 \mathrm{lN} \text {. } \\
& \text { AVE DIAMETRAL CL }=0.105 \mathrm{IN} \text {. } \\
& \text { FRONT CASING IA. }=22.5+0.105=22.605 \mathrm{IN} \text {. } \\
& \text { REAR CASING IA. }=20.45+0.105=20.555 \mathrm{NN} \text {. } \\
& \text { FRONT SEAL CL. AREA }=\left(22.605^{2}-22.5^{2}\right) \frac{\pi}{4(144)} \\
& =0.02583 F T^{24(144)} \\
& \text { REAR SEAL CL. AREA }=\left(20.605^{2}-22.5^{2}\right) \frac{\pi}{4(144)} \\
& =0.02348 \mathrm{FT}^{2}
\end{aligned}
$$

N 152.R.2 REV 2.76 


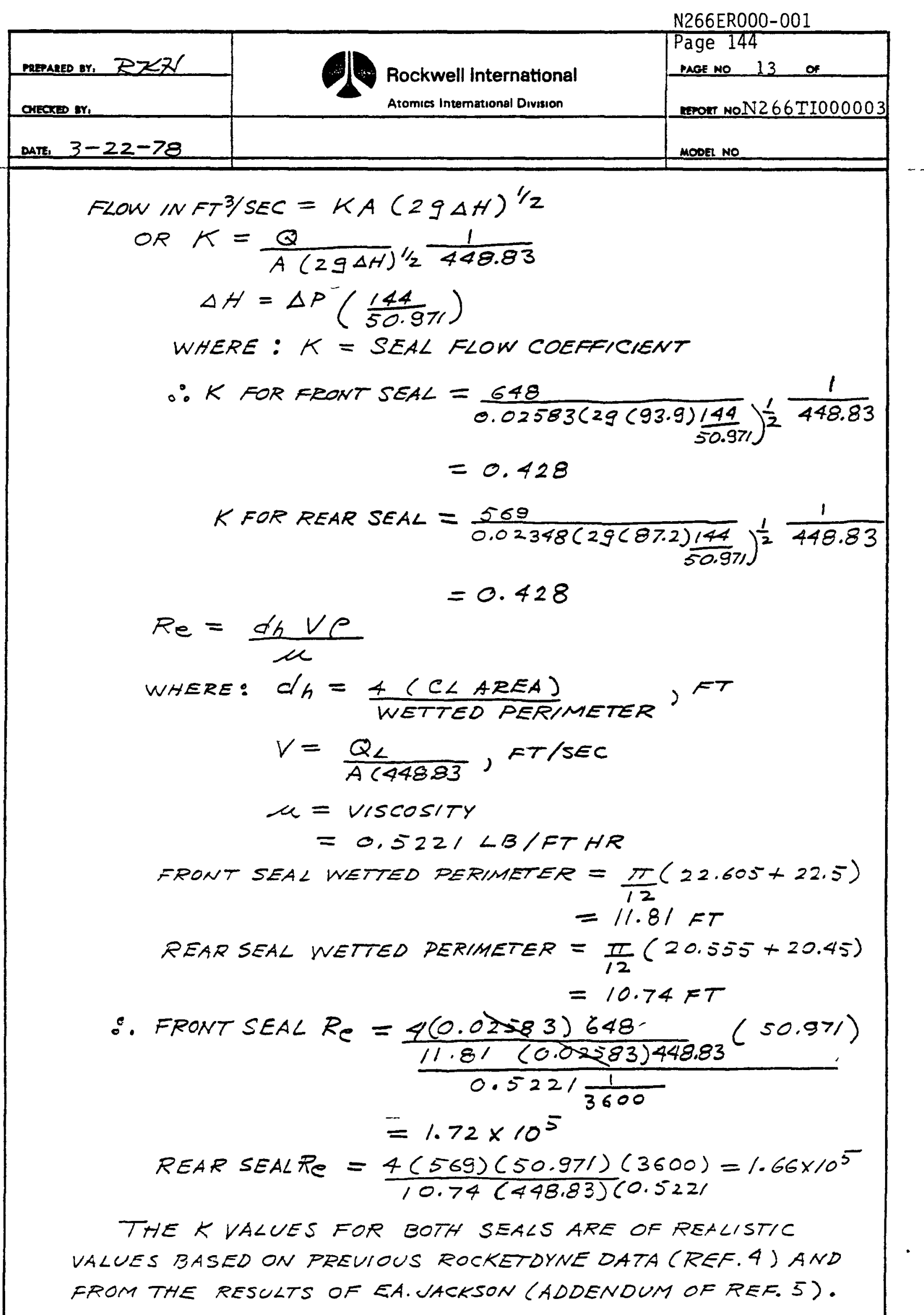

A 132-R-2 REV 2.76 


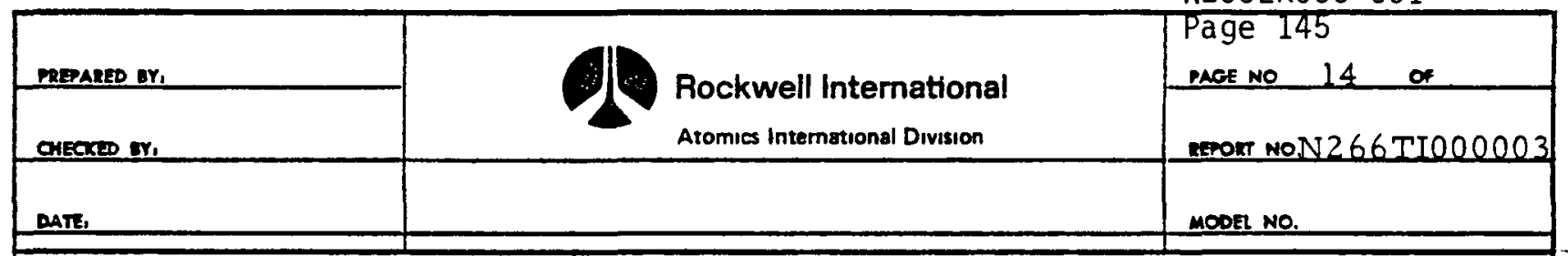

THE LABYRINTH SEAL CONFIGURATION INCORPERATES FEATURES FROM BOTH REFERENCES, NAMELY:

1. STEP CONFIGURATION FROM REF 4.

2. ROUNDEO BACKS OF SLOPED RIBS FROM REF. 5

THE STEP CONFIGURATION RESULTS IN LOW LEAKAGE FLOWS COMPAREO TO NON-STEPPED CONFIGURATIONS (REFA).

THE ROUNDED EACK ALSO RESULTS IN LOW LEAKAGE FLOWS ESPECIALLY FOR SEALS WITH LARGE PLEARANIEES (AS IN OUR DESIGM). THIS POUNDED BACK DESIGN ALSO PROUIDES FOR EXCELLENT SHUT-OFF HEAD CHARACTERISTICS WHERE HIGH PUMPHEAD IS MAINTAINED, (REF. 5 ).

E. DRAIN AND VENT HOLE CHECK

VARIOUS DRAIN AND VENT HOLES LOCATED MAY ALLOW LEAKAGE FLOWS WITHIN THE PUMP. THESE HOLES ARE IDENTIFIED BY CIRCLED NUMBERS (SEE FIG. 2 )

(1) INDUCER AND IMPELLER (FRONT SHROUD) HOUSING DRAIN HOLES $=15$ GPM (SEE PG A4)

(2) IMPELLER DRAIN HOLES( $2 E A_{1}, \frac{1}{4}$ IN DIA.)

$$
\begin{aligned}
& \Delta H=\frac{U_{2}^{2}-C_{1}^{2}}{2 g} \\
& C_{2}=\frac{\pi D_{2} N}{720}=\pi \frac{(13.8) \pi}{720}=66.8 \mathrm{FT} / \mathrm{sEC} \\
& L_{1}=\frac{\pi D_{1} N}{720}=\pi \frac{(11.2)}{720} 110=54.2 \mathrm{FT} / \mathrm{sEC} \\
& \Delta H=\frac{66.8^{2}-54.2^{2}}{29}=23.6 \mathrm{FT} \\
& \Delta H=\frac{1.5 V^{2}}{29}+f \frac{L}{0} \frac{V^{2}}{29} \\
& =\frac{1.5 V^{2}}{2 g}+0.0173 \frac{(4.8)}{0.25} \frac{V^{2}}{29} \\
& V=\left(\frac{29 \Delta H}{1.83}\right)^{\frac{1}{2}}=\left(\frac{2 g(23.6)}{1.83}\right)^{\frac{1}{2}}=28.8 \mathrm{FT} / \mathrm{sEC} \\
& Q=V A 448.83=28.8(0.000682) 448.83 \\
& =9 \text { GPM. }
\end{aligned}
$$




\begin{tabular}{|c|c|c|}
\hline MREPALED BY, $R Z K$ & arwall Intarnational & $\begin{array}{ll}\text { Page } 148 \\
\text { PAGE No } 17 \text { of }\end{array}$ \\
\hline OAECADD W $\mathrm{Y}_{1}$ & Atomics international Division & MEN MON266T1000003 \\
\hline DAII $3-22-78$ & & mopg \\
\hline
\end{tabular}

G. PRIMARY FLOWRATES THROUGH PUMP

FROM PAPA $B$, PAGES AI AND AZ, THE FOLLOWING FLOWRATES ARE OBTAINED:

\% QOSSCH $=14,500$ GPM

2. QINLET $=14,500$ GPM

3. Q SUCT. EL. $=$ Q/NLET $+Q_{1}$

$$
=14,500+160=14,660 \text { GPM }
$$

4. QIND. $=$ Qsuct.EL. $+Q_{2}-Q_{3}$

$=14,660+85-50$

$=14,695$ GPM

5. QIMP. $=Q_{1 N D}+Q_{9}+Q_{4}-15$

$$
\begin{aligned}
& =14695+669+.648-15 \\
& =15,997 \text { GPM }
\end{aligned}
$$

6. QTRANS DIFF. $=Q_{\text {IMP }}-Q_{4}-Q_{5}$

$=15,997-648-569$

$=14,780 \mathrm{GPM}$

7. QEXIST. DIFF: $=Q_{\text {TRANS DIFF }}+Q_{7}-Q_{2}+15$

$=14,780+131-85+15$

$=\underline{14,841 \mathrm{GPM}}$

8. $Q_{D / S C H}=Q_{E \times 15 T . D_{F}}-Q_{6}-Q_{7}-Q_{8}$

$=14,841-200-131-10$

$=14,500 \mathrm{GPM}$ 


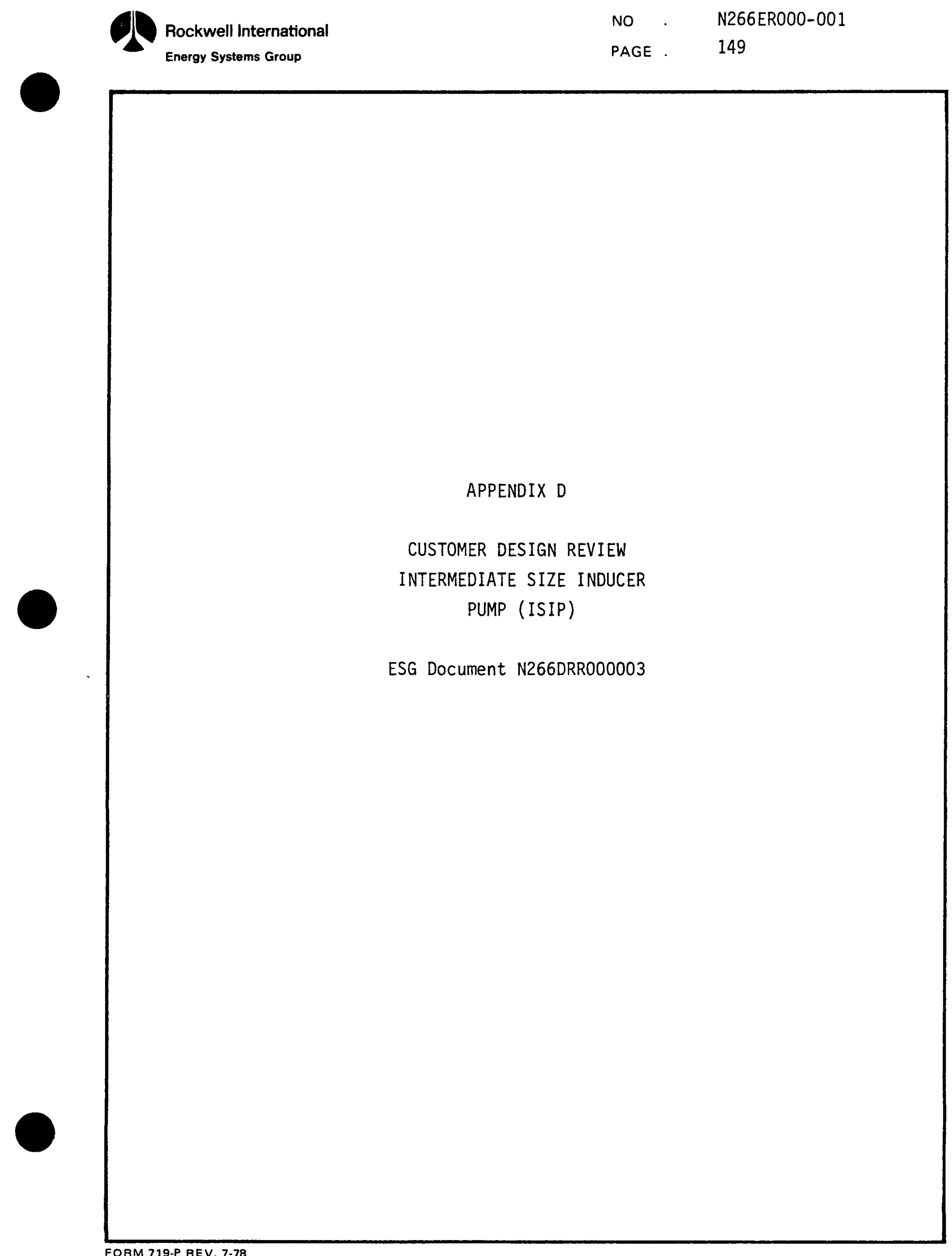




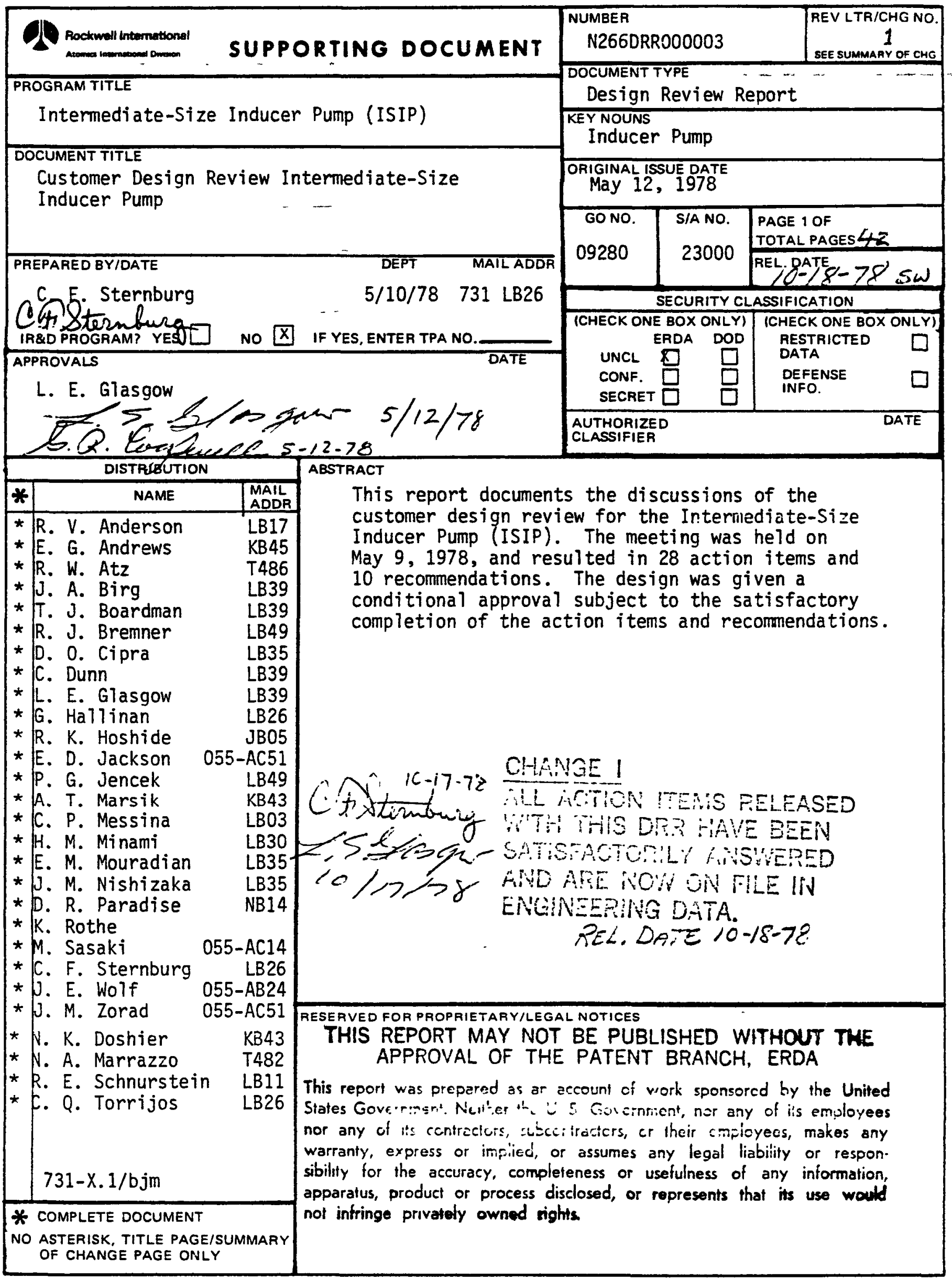




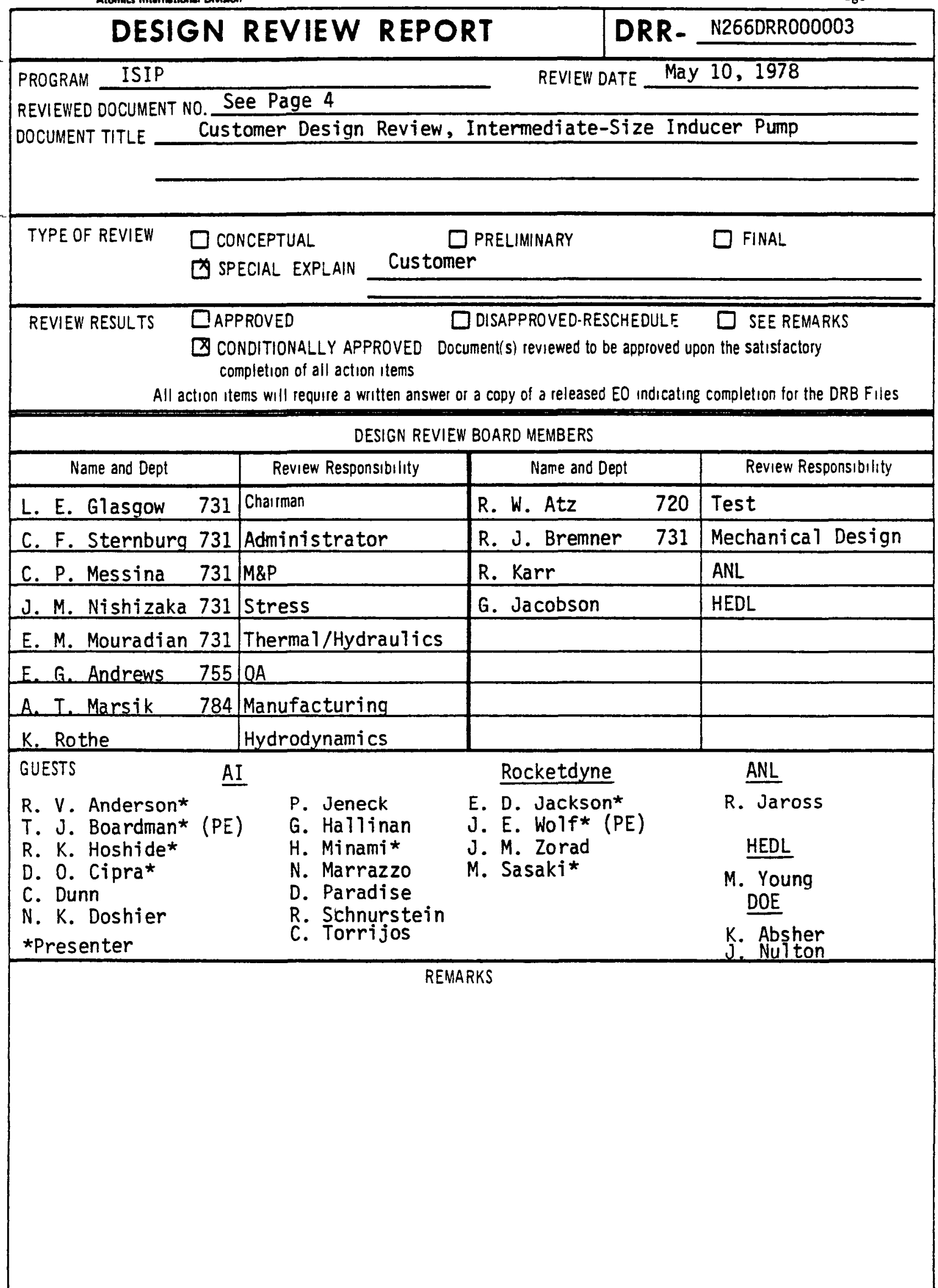


Atomics Internetional Divruon

Page 3

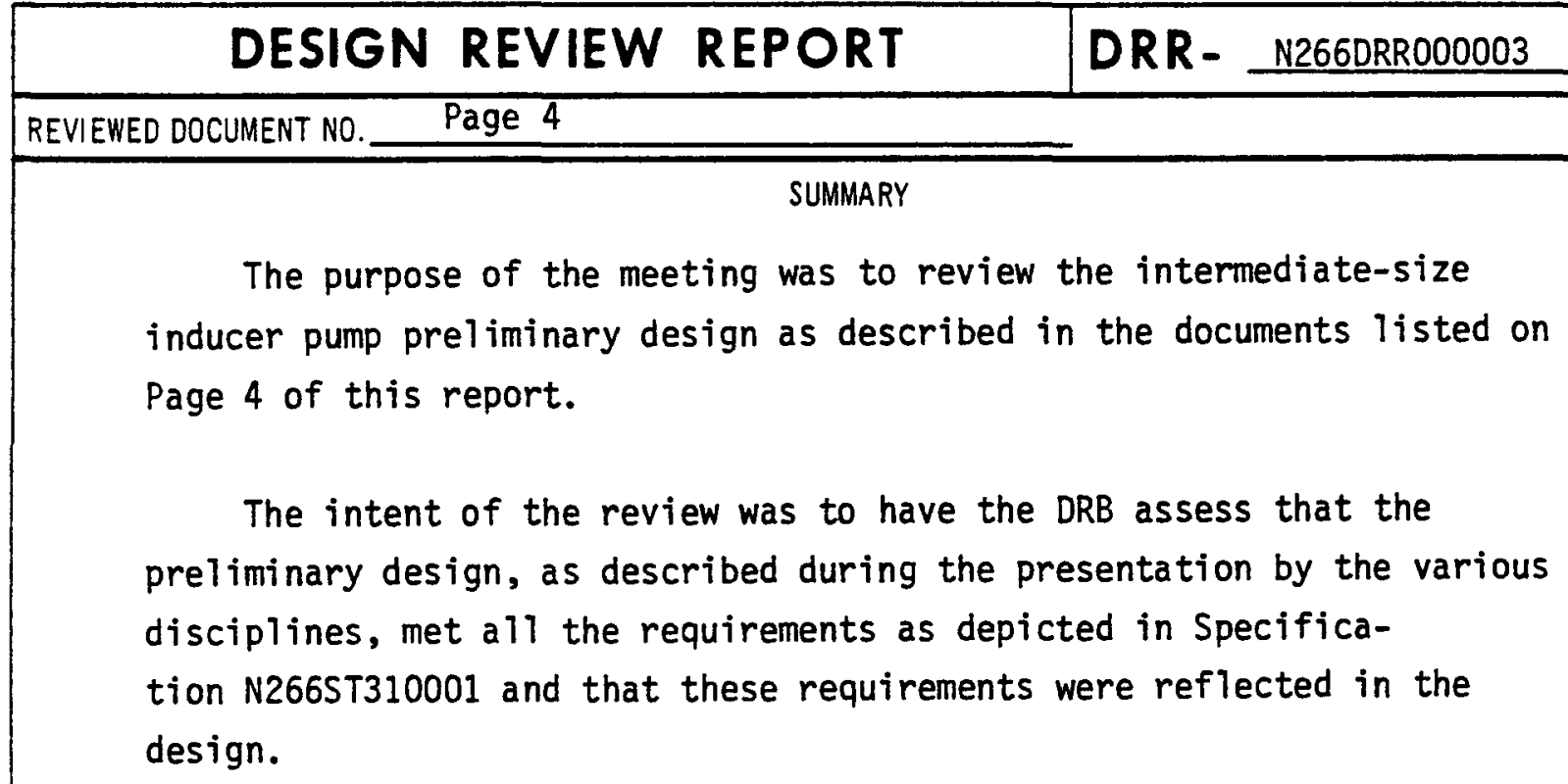

The Chairman requested that written comments be submitted by the Board Members on the critique of the data package, as indicated on the IL sent to the DRB.

The design review meeting was opened on May 9, 1978, by the Chairman, and after a brief introductory statement, the meeting was turned over to the responsible engineers for their presentations. During the course of the presentations, questions and concerns that were not satisfactorily resolved at the meeting resulted in action items. Those written comments by the DRB that did not result in action items are listed as recommendations.

The meeting was concluded by granting "Conditional Approval" to the design, subject to the satisfactory completion of the action items and recommendations.

All action items shall be resolved within 30 days from the date of the design review. Responses to the recommendations are due within 15 days of the design review. Responses to the action items and recommendations shall be forwarded to the Board Chairman and the Administrator by IL. Procedures of EMP 5-3, Design Reviews, apply. 


\begin{tabular}{|c|c|}
\hline DESIGN REVIEW REP ORT & DRR - \\
\hline REVIEWED DOCUMENT NO. \\
\hline SUMMARYRRO00003 \\
CUSTOMER DESIGN REVIEW \\
INTERMEDIATE-SIZE INDUCER PUMP \\
DATA PCKAGE
\end{tabular}

Review Items

N266R000015 Design Layout Drawing

N266ST310001 Pump Specification

Supporting Documents

N266E000002 Interface Control Drawings

N266SK00017 Rework Sketch for Static Hydraulics and Bearing Support Flange

N266T1000002 Pump Shaft Rotodynamics

N266TI000003 Recirculating Flow Analyses

N266B0160001 Specification, CF8 Castings

N266B0160002 Specification, 304 Forging

R/H 8113-3630 Hydrodynamic Design Report

Steady-State Stress Analysis Summary Assembly Outline Procedure 


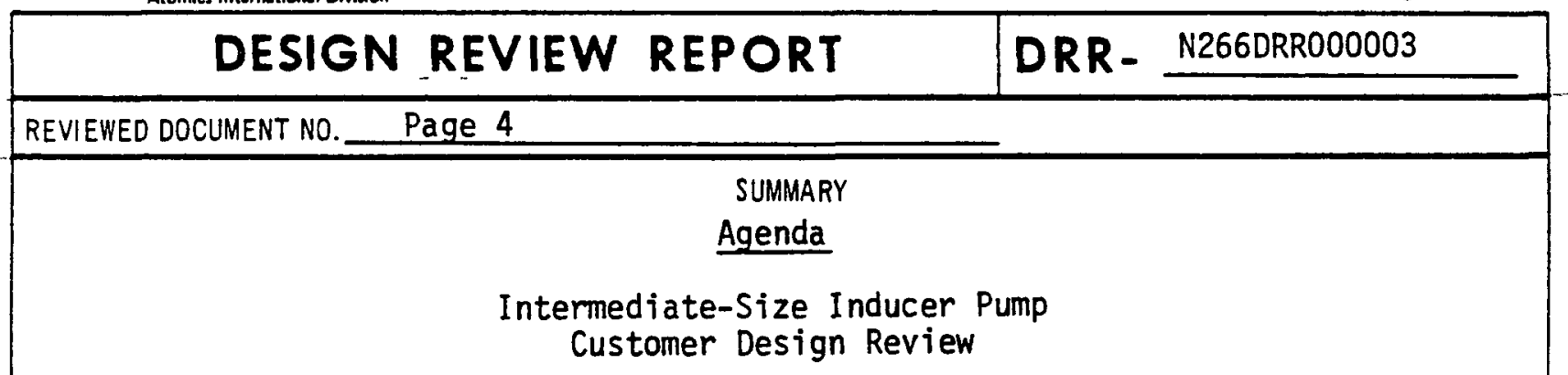

Place: $\quad$ Conference Room 1

Time: $\quad 8: 10$ a.m., May 9, 1978

Attendees: AI, Rocketdyne, ANL, and HEDL

\begin{tabular}{|c|c|c|c|}
\hline & & & $\begin{array}{l}\text { Approximate } \\
\text { Time } \\
\end{array}$ \\
\hline I. & Introduction & L. Glasgow & $8: 55$ a.m. \\
\hline II. & Project Description and Goals & R. V. Anderson & $8: 20$ a.m. \\
\hline III. & Design Approach & T. J. Boardman & $8: 30$ a.m. \\
\hline IV. & $\begin{array}{l}\text { Description of Hydrodynamics } \\
\text { Components }\end{array}$ & J. Wolf & $8: 55$ a.m. \\
\hline v. & Hydrodynamic Design Description & E. D. Jackson & $9: 15$ a.m. \\
\hline VI. & $\begin{array}{l}\text { Systems Analysis Recirculation } \\
\text { Flow Analysis }\end{array}$ & R. K. Hoshide & $10: 00$ a.m. \\
\hline VII. & Stress Analysis & H. Minami & $10: 20$ a.m. \\
\hline VIII. & Stress Analysis Rotordynamics & D. O. Cipra & $10: 30$ a.m. \\
\hline$I X$. & Stress Analysis Steady State & M. Sasaki & $10: 45$ a.m. \\
\hline$x$. & DRB Review of Documentation & Board & $11: 15$ a.m. \\
\hline $\mathrm{XI}$. & $\begin{array}{l}\text { Review of Board Poll and Con- } \\
\text { tingent Sign-Off }\end{array}$ & & \\
\hline
\end{tabular}




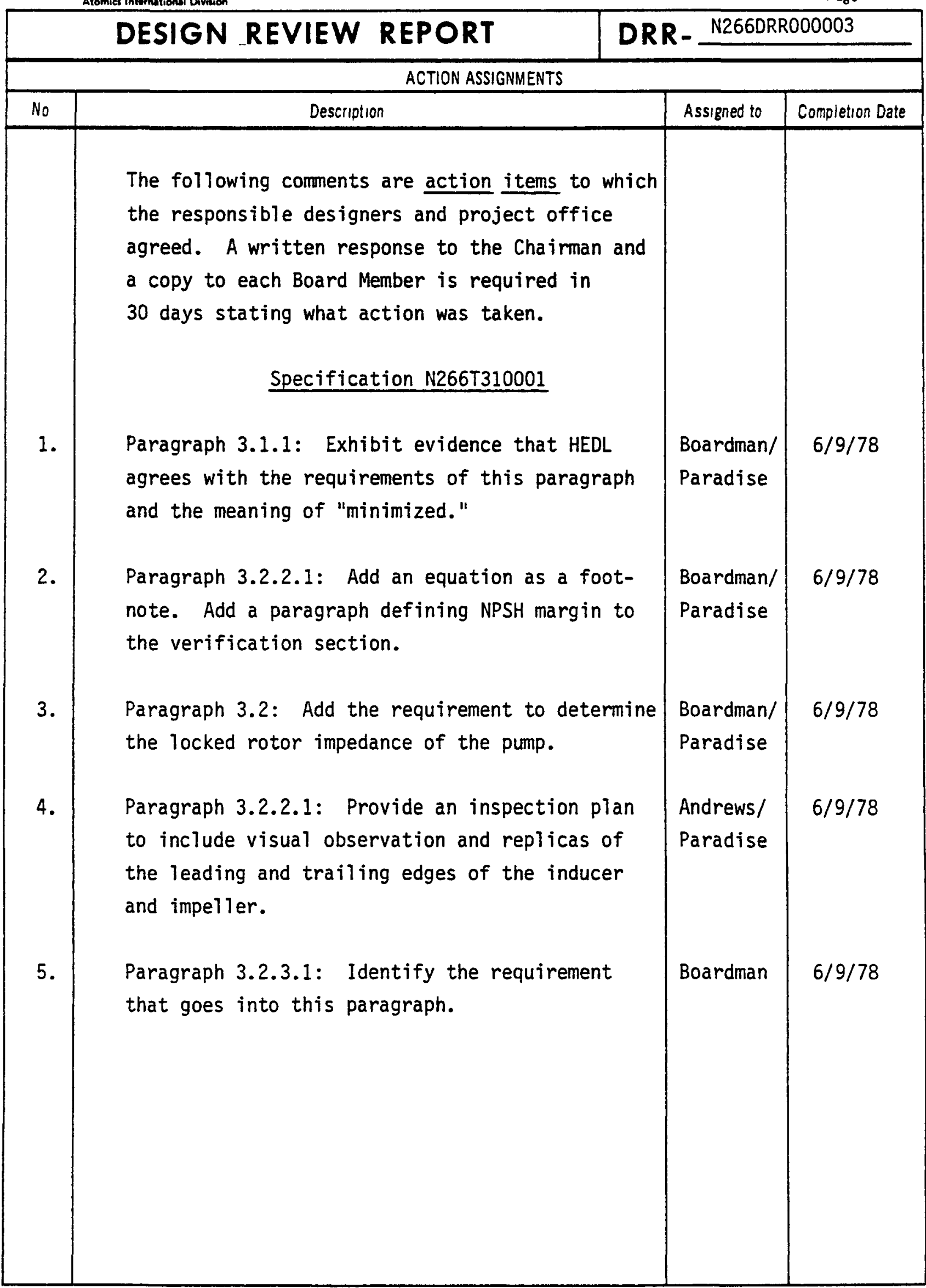




\begin{tabular}{|c|c|c|c|}
\hline \multicolumn{2}{|r|}{ DESIGN REVIEW REPORT } & \multicolumn{2}{|c|}{ DRR - N266DRR000003 } \\
\hline \multicolumn{4}{|c|}{ ACTION ASSIGNMENTS } \\
\hline No. & Description & Assigned to & Completion Date \\
\hline 6. & $\begin{array}{l}\text { Paragraph 3.3.1: Add a parenthetical quantity } \\
\text { stating that the stress report shall be signed } \\
\text { by the manager of the stress group. }\end{array}$ & Paradise & $6 / 9 / 78$ \\
\hline 7. & $\begin{array}{l}\text { Paragraph 3.3.2: Add a paragraph to specify } \\
\text { the requirements for vibration stiffness of the } \\
\text { AI diffuser and inducer tunnel. }\end{array}$ & $\begin{array}{l}\text { Boardman/ } \\
\text { Paradise }\end{array}$ & $6 / 9 / 78$ \\
\hline 8. & $\begin{array}{l}\text { Compare the structural design requirements of } \\
\text { the FFTF pump with those of the ISIP. }\end{array}$ & Boardman & $6 / 9 / 78$ \\
\hline 9. & $\begin{array}{l}\text { Paragraph } 3.5 .1 \text {, Part 5: Replace "bellows } \\
\text { seal" with "piston ring" which fits into the } \\
\text { bellows seal area. Modify the specification to } \\
\text { remove "bellows." }\end{array}$ & $\begin{array}{l}\text { Boardman/ } \\
\text { Paradise }\end{array}$ & $6 / 9 / 78$ \\
\hline 10. & Examine the impact of material dilation. & $\begin{array}{l}\text { Friske/ } \\
\text { Nishizaka }\end{array}$ & $6 / 9 / 78$ \\
\hline 11. & $\begin{array}{l}\text { Paragraph } 3.5 .3 \mathrm{~b}: \text { Remove the word "maximum" } \\
\text { from the first sentence. }\end{array}$ & Paradise & $6 / 9 / 78$ \\
\hline 12. & $\begin{array}{l}\text { Paragraph } 3.5 .3 \mathrm{~b}: \text { Separate this paragraph into } \\
\text { a heat treatment paragraph and a sensitization } \\
\text { protection paragraph. }\end{array}$ & $\begin{array}{l}\text { Friske/ } \\
\text { Paradise }\end{array}$ & $6 / 9 / 78$ \\
\hline 13. & Paragraph 3.5.3e: Remove the first sentence. & Paradise & $6 / 9 / 78$ \\
\hline 14. & $\begin{array}{l}\text { Paragraph } 3.5 .3 e: \text { Lock welding should be to } \\
\text { the Code requirements. }\end{array}$ & $\begin{array}{l}\text { Friske/ } \\
\text { Paradise }\end{array}$ & $6 / 9 / 78$ \\
\hline
\end{tabular}




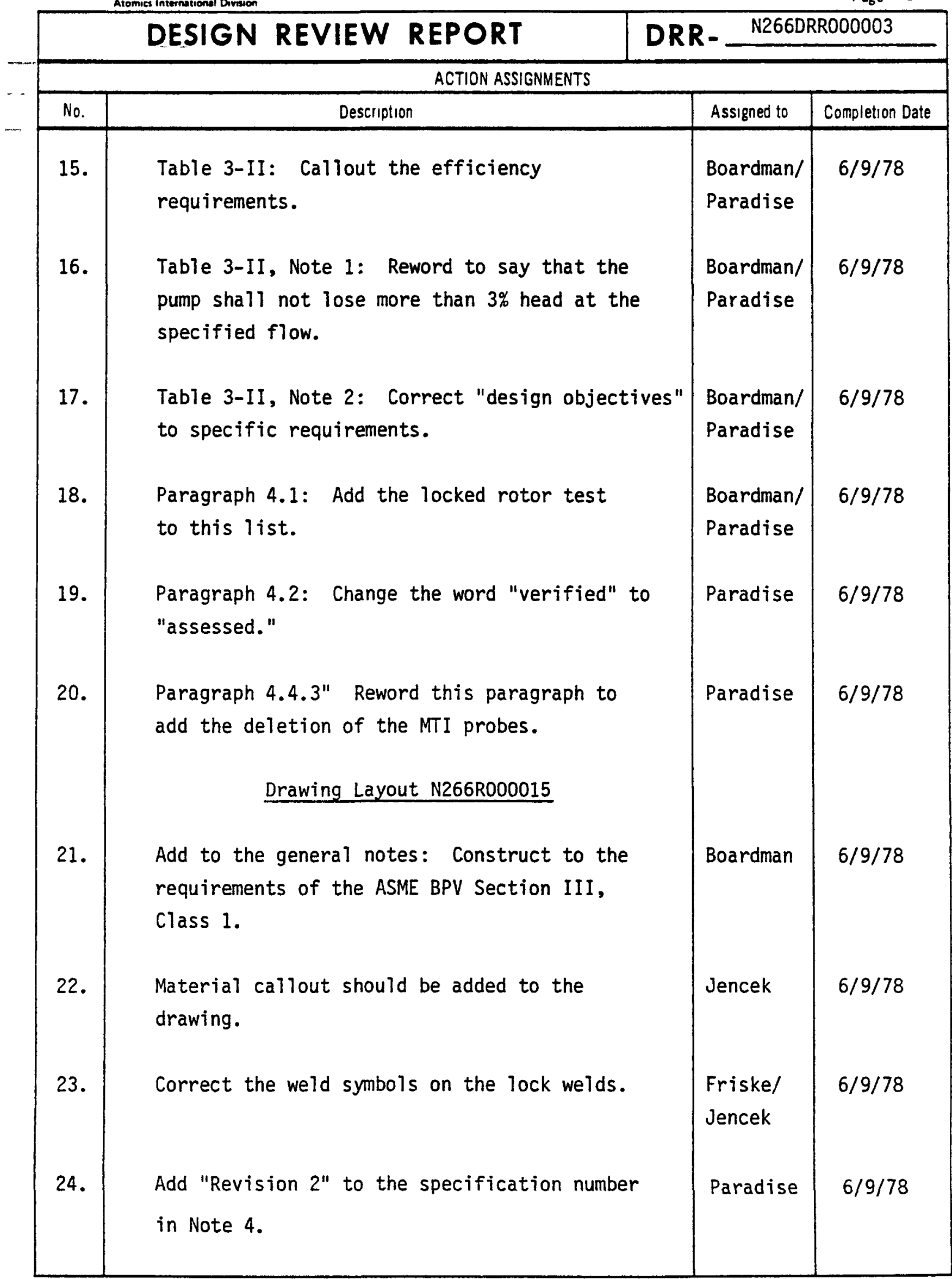


N266ER000-001

Page 158

Rockwell International

Page 9

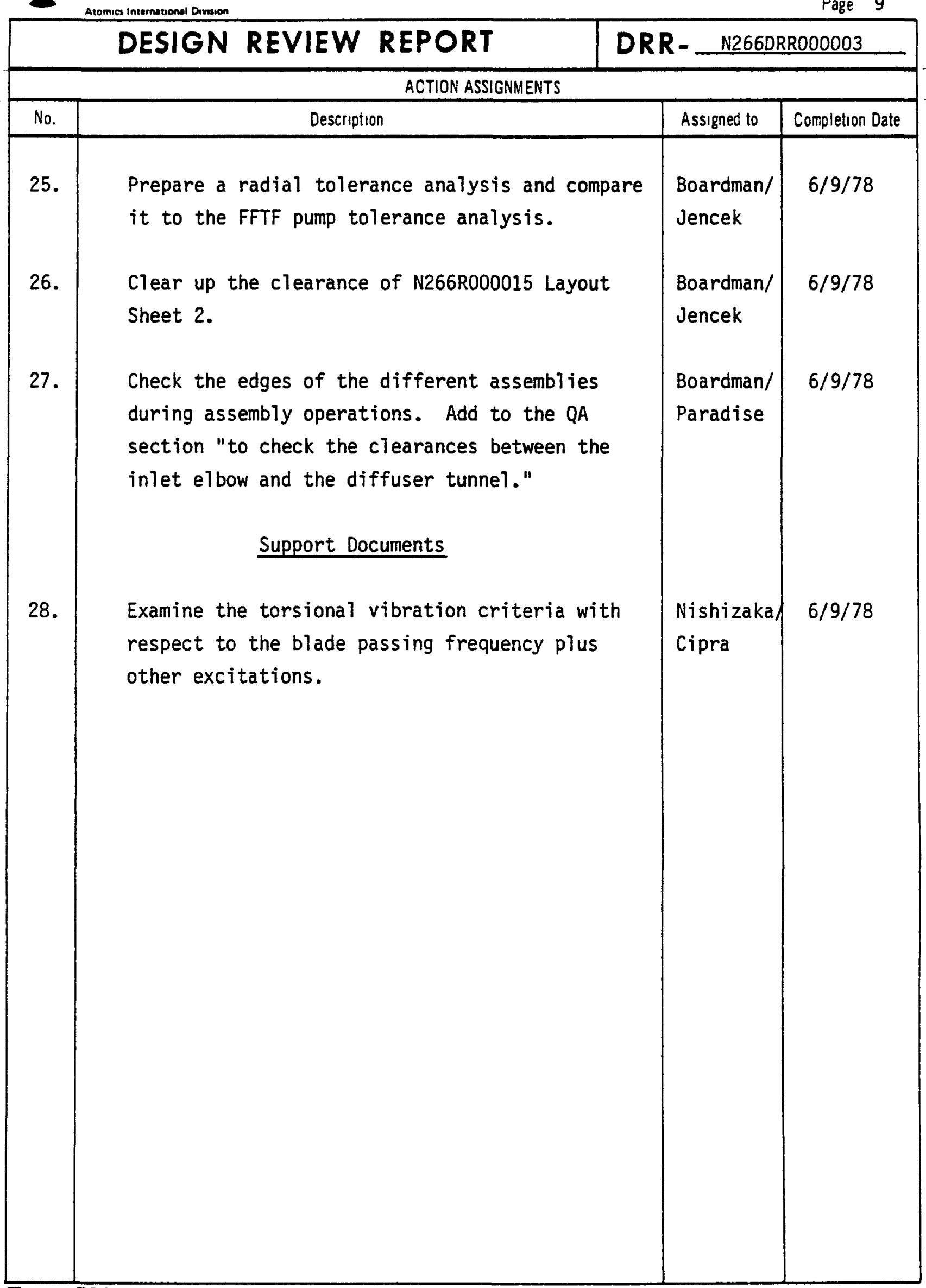

Form 733-X-4 Rev. 7-75 


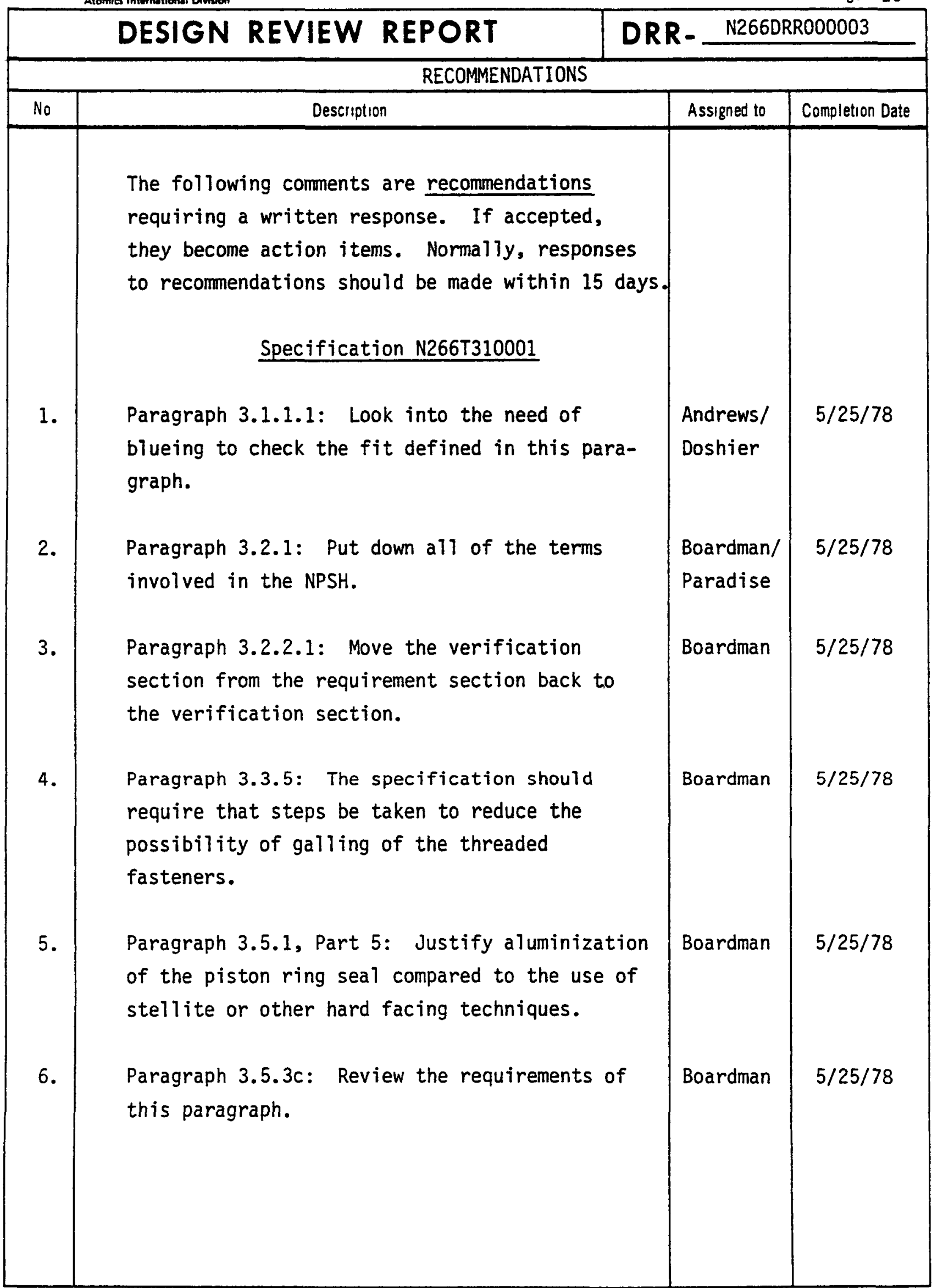


N266ER000-001

Page 160

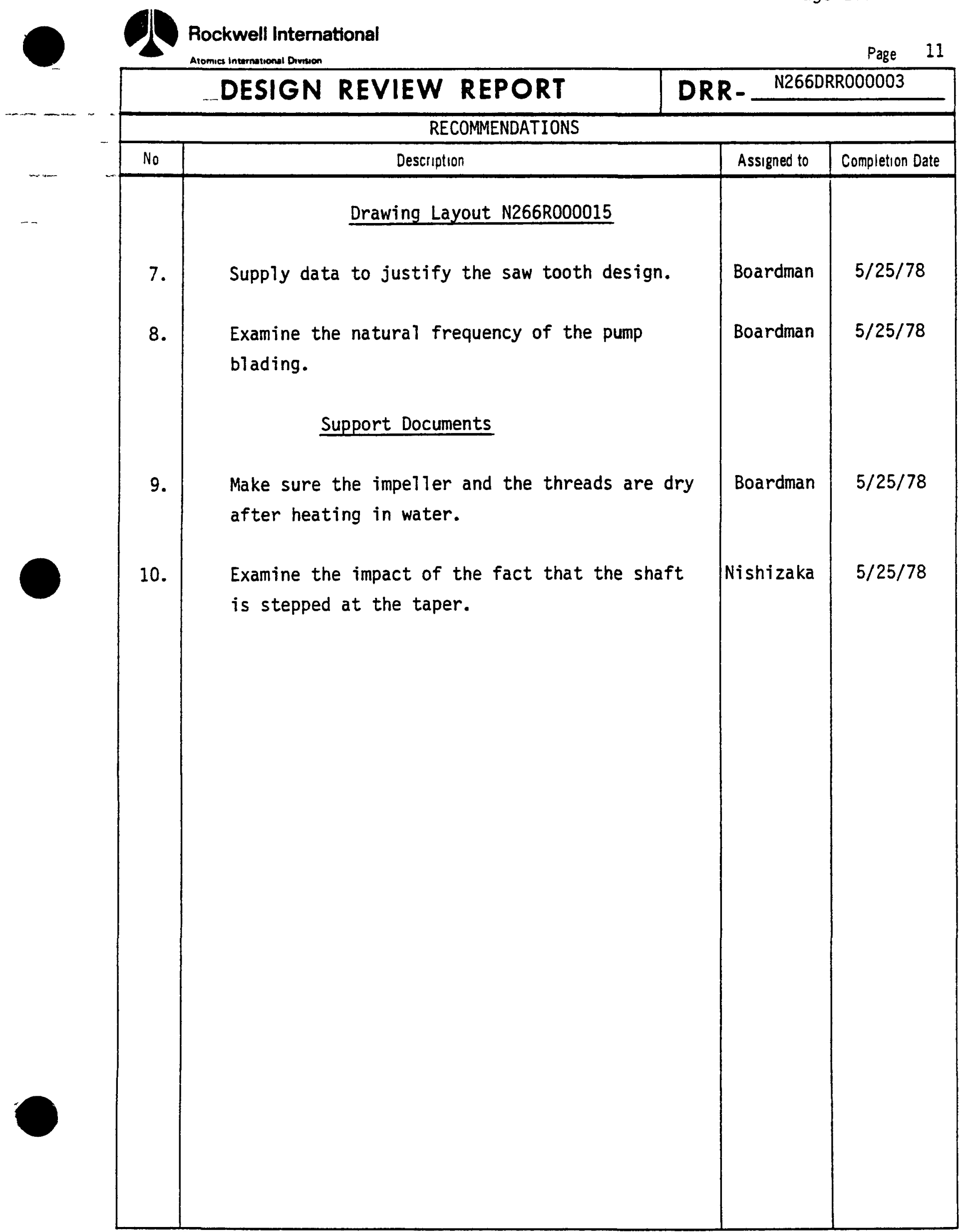




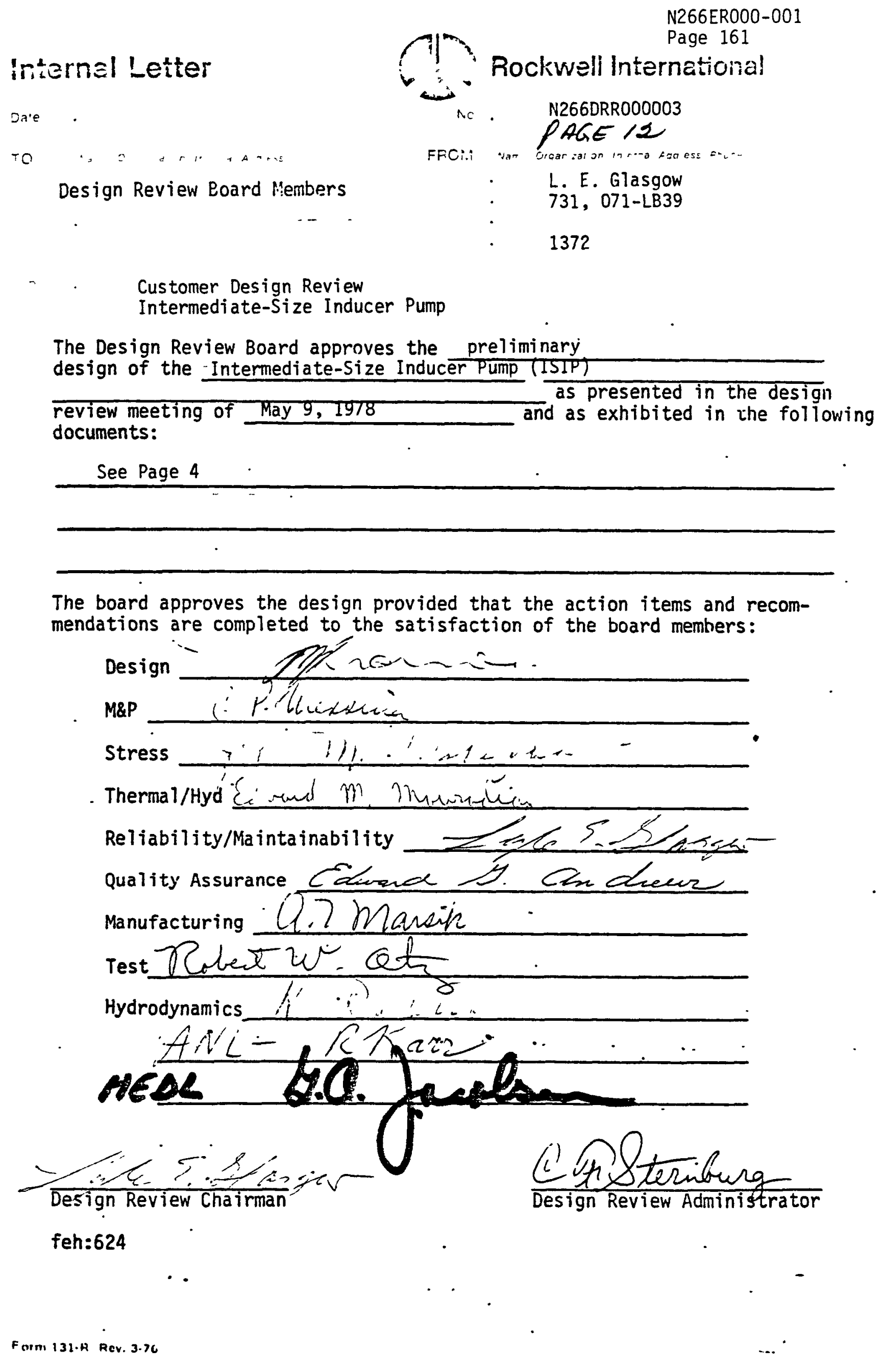


ATTACHMENT I

\author{
. $\because . \cdot$. \\ L. E. Glasoow \\ $731,071-L 8.39$
}

N26GDRRO00003

Page 13

CHANGE 1

T. J. Poardian

$731,071-L 1339$

1759

Intermediate-Size Inducer Pump (ISIP)

Ref: N2660RR000003, Customer liesign Review, Intermediate-Size Inducer Pump

Attached is a list of the steps planned by Project Engineering for resolution of the action items and recommendations listed in the referenced report for the punp layout drawing (N266R000015) and for the supporting documents. Please indicate whether additional effort, other than implementation, is required for resolution.

Response to the action items and recommendations against the specification was transmitted under separate IL.

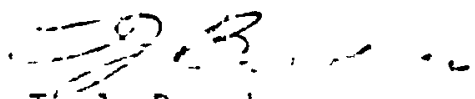

T: J. Boardinan

$j d j: 525$

Attachment

cc: G. Hallinan

$R$. Anderson

C. Dunn

P. Jencek

W. Friske

J. Page

C. Torrijos

R. Schnurstein

J. Wolf (Rocketdyne)

D. Paradise

L. Woehter

C. Sternburg (12) 
21. Comment: Add to the general notes: Construct to the requirements of the A.SME BPV Section III, Class 1.

Response: A note will be added to the drawing covering this requirement.

22. Comment: Material callout should be added to the drawing.

Response: Material callouts for each part will be added to the layout drawing. Basically, the impeller will be CF8; all other points will be 304 forgings excepting the threaded fasteners and the tie bolt which will be A286.

23. Comment: Correct the weld symbols on the lock welds.

Response: The lock weld symbols will be changed to show single $\checkmark$ full penetration joints.

24. Comment: Add "Revision 2" to the specification number in Note 4.

Response: The note will be changed to designate, "OMM-051-00-005, Revision 2, Addendum 1".

25. Comment: Prepare a radial tolerance analysis and compare it to the FFTF pump tolerance analysis.

Response: A comparative radial tolerance analysis will be prepared for the region of concern. That is from the hydrostatic bearing down to the lower end of the rotor assembly.

26. Comment: Clear up the clearance of N266R000015, Layout Sheet 2.

Response: The information shown on Sheet 2 during the design review will be transferred to the original layout (Sheet 1) with all pertinent clearances shown. The layout will then be issued as Revision A.

27. Comment: Check the edges of the different assemblies during assembly operations. Add to the QA section, "to check the clearances between the inlet elbow and the diffuser tunnel".

ResDonse: Checks, measurements, and other assembly monitoring functions will be specified in the OMM Addendum where 
N266ER000-001

Page 164

N26GDRRO00003

Page 15

Change 1

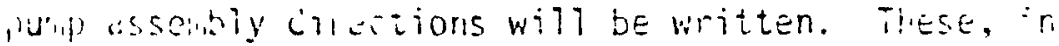
turn, will be described step-by-step in the detall asserbily procedures to be written by ETEC and approved by AI. Assembly procedures include a signoff reauirement for each step and provide forms for recording measurements. Completed assembly procedures become a part of test data.

7. Coment: Supply data to justify the saw tooth design.

Response: This combent resulted from a review meeting discussion concerning the ISIP labyrinth seal tooth spacing and the cavitation potential resulting from using three teeth widely spaced as opposed to closely spaced teeth in the prototype design.

The prototype pump front (lower) labyrinth is a "straight" (not staggered) type having a radial clearance of .100 in. (.050 in. for the back labyrinth) and a tooth spacing of $.125 \mathrm{in}$. The tooth form is tapered (29 deg.) with a zero slant angle and a groove depth of .125 in. (reference WEMD Drawing 160A243). Thus, the tooth spacing, radial clearance, and groove depth (tooth height) were all of the same order of magnitude. The ISIP has a staggered (stepped) labyrinth with a radial clearance of $.050 \mathrm{in}$. and a tooth spacing of approximately $1.0 \mathrm{in}$. The tooth form has a curved back (downstream side), is slanted against the direction of flow, and has a groove depth (tooth height) of $0.5 \mathrm{in.}$ The ratio of radial clearance to tooth spacing is 0.1 as is the ratio of radial clearance to tooth height. The stepped arrangement and the low clearance-to-spacing ratio help minimize the velocity carryover effect, enabling each tooth to act more like an independent restriction with zero approach velocity, thus increasing the friction factor as shown in Figure 4 of Reference 1. (a) The low clearance-to-tooth height ratio permits rapid expansion of the fluid stream after crossing the tooth, encouraging the formation of turbulent eddies (a loss effect).

Figure 7 of Reference $2^{(b)}$ illustrates the increased leakage effect of reducing tooth (blade) spacing for a fixed clearance, despite increasing the number of teeth. Lihile the quantitative data of this reference

(a) Reference 1: W. Zabriskie and B. Sternlicht, "Labyrinth Seal Leakage Analysis," ASiE Paper 58 A-118, Transactions of the ASME, Journal of Basic Engineering (contributed for the Novenber 30-December 5, 1958 , Annual lieeting, New York, New York)

(b) Reference 2: F. E. Heffner, "A General Method for Correlating Labyrinth-Seal Leak-Rate Data" Transactions of the ASME, Journal of Basic Engineering, June 1960 (Pages 265-275) 
N266ER000-001

Page 165

N266DRRO00003

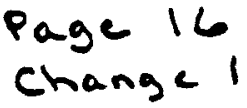

may not be directly applicable due to differences in tooth form and fluid compressibility (the reference was written for compressible flow), the proportional trends are shown to be consistent for low-pressure ratios (which correspond to low-pressure ratio function $\emptyset$ ) where compressibility effects are minor.

The effects of slanting the tooth profile against the direction of flow is also illustrated in Fioure 4 of Reference $1,(a)$ showing that the friction factor for the slanted configuration is higher than for the nonslanted type.

Effects of the rounded back tooth form were presented in the review meeting by $R$. Hoshide. This data, plus additional data developed by General Motors for similar profiles, is being assembled and will be transmitted to the review board. The data shows the increased effectiveness of that Darticular profile.

In order to assess the Dotential for cavitation, the cavitation number will be evaluated at the minimum pressure following the last (third) labyrinth tooth for both the front (lower) and rear (upper) labyrinths. This data will be presented to the review board with the aforementioned profile data.

8. Comment: Examine the natural frequency of the pumo blading.

Response: The natural frequency of the impeller and diffuser blading will be examined and compared to known exciting frequencies. As a sand casting with draft to be added by the foundry, results for the impeller are expected to be qualitative at best. However, since the impeller blades are supported on each side, as were the prototype impeller blades, they are expected to have a fairly high natural frequency which would be difficult to excite.

(a) Reference 1: W. Zabriskie and B. Sternticht, "Labyrinth Seal Leakiage Analysis," ASME Paper 58 A-118, Transactions of the ASME, Journal of Basic Engineering (contributed for the November 30-December 5, 1958, Annual lieeting, New York, New York) 
28. Comnent: Examine the torsional vibration criteria with respect to the blade passing frequency plus other excitations.

Response: The torsional vibration criterion as stated in Paragraph 3.3.2.9 of RDT E 3-2T reads "The first torsional and lateral critical speeds shall not be less than 125\% of the design speed or as specified in the Ordering Data." The HWS 1551 ordering data does not modify this requirement.

For both the prototype pump and the ISIP, the design speed corresponds to a frequency of $18.5 \mathrm{~Hz}$. I'sing the AI model, both pumps have a torsional frequency more than $142 \%$ above the design speed $(26.69 \mathrm{~Hz}$ for ISIP and $26.34 \mathrm{~Hz}$ for the prototype); therefore, the rotating speed will not excite the torsional freauency.

The ISIP has ten impeller discharge vanes and eleven diffuser vanes, potentially generating pulses at $185 \mathrm{~Hz}, 2035 \mathrm{~Hz}$, and $1850 \mathrm{~Hz}$ at design speed. At reduced speeds, these pulses will match the torsional critical frequency at $160 \mathrm{rpm}, 14.5 \mathrm{rpm}$, and $16 \mathrm{rpm}$, none of which are in the steady-state operating range of the pump (94 rpm plus 400 to $1132 \mathrm{rpm}$ ). The $160^{\circ} \mathrm{rpm}$ will occur during the startup transient between pony motor speed $(94 \mathrm{rpm})$ and minimum ma in motor speed $(400 \mathrm{rpm})$ but will be for very short duration due to motor acceleration, and at low energy level due to the low speed. Other torsional excitation due to motor windings and rotor/starter slot combinations in the motor will remain unchanged. Therefore, no torsional vibration problems are predicted.

Similar to the ISIP, the prototype pump blade frequency matched the torsional critical frequency at $263 \mathrm{rpm}$ which also occurred during startup transients. No vibration problems were observed during startups while sodium testing at SPTF. 
N266ER000-001

Page 167

N266DRRO00003

Page 18

Change 1

DFR Fecominendations for Support Nocunierits

9. Comment: Make sure the impeller and the threads are dry after heating in water.

Response: A requirement for drying the threads will be included in the OMM Addendum for assemblino ISIP and in the ETEC assembly procedure, requiring specific signoff by the operator. Based on prototype pumb zssembly experience, the assembly temperature $\left(-180^{\circ} \mathrm{F}\right)$ will greatly enhance drying for exposed tapped holes.

10. Comment: Examine the impact of the fact that the shaft is stepped at the taper.

Response: The impact of the relief in the middle of the shaft taper will be examined by Rocketdyne (Sasaki) as part of the steady-state stress analysis. 


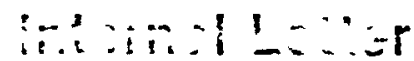

$=1 . \quad$ May 26, 1978

io

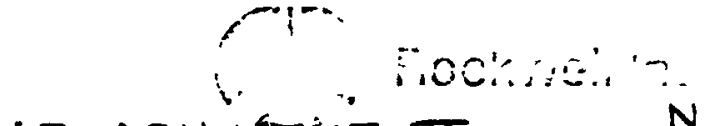

ATTACH MENTT III

N266DRR000003

Page 19

Change 1

ithe

L. E. Glasgow

$731,071-$ LB39

T. J. Boardman

731, 071-LB39

1759

N266ER000-001

Page 168

Intermediate Size Inducer Pump (ISIP)

Ref: N2660RR000003 Customer Design Review Intermediate Size Inducer Pump

Attached is a list of the steps planned by Project Engineering for resolution of the action items and recommendations listed in the referenced report for the pump specification (N266ST310001). Please indicate whether additional effort, other than implementation, are required for resolution.

Response to the action items and recommendations against the layout drawing and supporting documents will be covered under a separate IL.

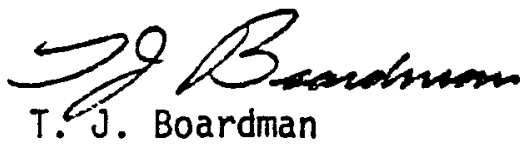

jew: $4 / 1$

Attachments

cc: R. Anderson

C. Dunn

W. Friske

C. Hallinan

R. Hoshide

$P$. Jencek

J. Page

D. Paradise

R. Schnurstein

C. Torrijos

L. Woechler

J. Wolf (Rocketdyne)

C. Sternburg (12) 
Attachment 1

IL to L. E. Glasgow

May 26, 1978

N266 DRRO00003

Page 20

Change 1

I. DRR ACTION ITEMS FOR N266ST3100001

1. Comment - Paragraph 3.1.1: Exhibit evidence that HEDL agrees with the requirements of this paragraph and the meaning of "minimized."

Response - HEDL agreement with the requirements of this paragraph will be evidenced by HEDL approval of AI Drawing N266000017, "Intermediate Size Inducer Pump, Westinghouse Components (Rework)" which shows interface changes to be made on the FFTF pump parts. A statement will be added to 3.1 .1 to the effect that all such changes shall be approved by HEDL prior to implementation.

2. Comment - Paragraph 3.2.2.1: Add an equation as a footnote. Add a paragraph defining NPSH margin to the verification section.

Response - The equation referred to was an equation for NPSH margin.

A period will be put after the second line in the second paragraph then reference to Paragraph 4.4 .5 will be made.

Test requirements and an equation for NPSH margin will be added to Paragraph 4.4.5.

The equation will not be in a footnote since it will be part of a requirement (method of determining margin for this test) not an explanatory note.

3. Comment - Paragraph 3.2: Add the requirement to determine the locked rotor impedance of the pump.

Response - This requirement will be added to the test requirements under Paragraph 6.2 instead of under Performance in 3.2, since there is no specified locked rotor resistance requirement for design or verification.

4. Comment - Paragraph 3.2.2.1: Provide an inspection plan to include visual observation and replicas of the leading and trailing edges of the inducer and impeller. See insert for 3.2.2.1 and 4.3.1.

Response - Requirements for pre- and post-test inspection including measurement, visual observation, and replicas will be included under 4.3.1.

5. Comment - Paragraph 3.2.3.1: Identify the requirement that goes into this paragraph. 
Response - Paragraph 3.2.3.1 and 3.2.3.2 are being rewritten to specify the $12.8 \mathrm{ft}$ NPSH requirement given in the Hydrodynamic Design Report (R/H 8113-3630) distributed as a supporting document for the design review.

6. Comment - Paragraph 3.3.1: Add a parenthetical quantity stating that the stress report shall be signed by the manager of the stress group.

Response - The stress report requires signature by manager of the stress unit and by the project engineer, as indicated in Table 1 on Page 10 of N266RPA000001 for this project.

7. Comment - Paragraph 3.3.2: Add a paragraph to specify the requirements for vibration stiffness of the AI diffuser and inducer tunnel.

Response - A paragraph stating that the pump shall be designed such that no malfunction or damage shall result from vibration will be added, similar to that in Paragraph 3.3.5.4 of Ammendment 2 to RDT E 3-2T.

8. Comment - Compare the structural design requirements of the FFTF pump with those of the ISIP.

Response - Comparison of the structural design requirements has been made. Attachment 2 summarizes the results of this comparison. Generally, with a few additions (such as the vibration requirement), the ISIP requirements are comparable to those for FFTF when the limited life and noncritical function (test as opposed to primary system cooling) are considered.

9. Comment - Paragraph 3.5.1, Part 5: Replace "bellows seal" with "piston ring" which fits into the bellows seal area. Modify the specification to remove "bellows."

Response - These changes will be made to the specification.

10. Comment - Examine the impact of material dilation.

Response - It is presumed that this should be "material densification."

The impact of this phenomenon has been examined and the results of the exaimination are summarized in Attachment 3 . Since information on this subject is severely limited, the results and conclusions represent our best judgement based on available data.

11. Comment - Paragraph 3.5.3b: Remove the word "maximum" from the first sentence.

Response - The word "maximum" will be removed. 
12. Comment - Paragraph 3.5.3b: Separate this paragraph into a heat treatment paragraph and a sensitization protection paragraph.

Response - The two subjects will be separated into two grammatical paragraphs, both under $3.5 .3 \mathrm{~b}$. The requirement is for heat treatment, which will be in the first paragraph. A result will be sensitization, which will be addressed in the second paragraph in terms of handling precautions to be followed. M\&P, with Project Engineering concurrence, does not want these requirements under different paragraph numbers because one is a direct consequence of the other, therefore, the requirements should remain associated.

13. Comment - Paragraph 3.5.3e: Remove the first sentence.

Response - This paragraph will be revised to cover lock welding only and will specify AI requirements equivalent to those specified for lock welds on thi FFTF prototype pump (See W EMD Drawing 114E829). The AI requirements were previousiy approved by HEOL for use in the pump.

The revision will implement removal of the first sentence.

14. Comment - Paragraph 3.5.3e: Lock welding should be to the Code requirements.

Response - See response for Action Item 13. Design of the locking devices will be based on using RDT M 6-2T as a guide.

15. Comment - Table 3-II: Callout the efficiency requirements.

Response - Efficiency requirements will be implied by specifying maximum shaft horsepower (equal to rated motor horsepower.)

16. Comment - Table 3-II, Note 1: Reword to say that the pump shall not lose more than $3 \%$ head at the specified flow.

Response - The note will be reworded as indicated.

17. Comment - Table 3-II, Note 2: Correct "design objectives" to specific requirements.

Response - Note 2 will be revised to require a negative slope between 8,000 and $18,000 \mathrm{gpm}$, corresponding to the estimated performance curve in the Hydrodynamic Design Report. The shutoff head goal will be deleted on the same basis.

These were originally requirements set for the FFTF prototype pump for operation in the FFTF plant. Since the ISIP is essentially a retrofit design to put the inducer and impeller in the same cavity as the prototype pump impeller, the same dimensional design flexibility needed to achieve those requirements is no longer available. Also the primary purpose of ISIP is for suction performance tests, as opposed to plant operation. 
18. Comment - Paragraph 4.1: Add the locked rotor test to this list.

Response - A locked rotor test will be specified under 6.2.2. (see Action Item 7).

19. Comment - Paragraph 4.2: Change the word "verified" to "assessed."

Response - This change will be made to the specification.

20. Comment - Paragraph 4.4.3: Reword this paragraph to add the deletion of the MTI probes.

Response - The MTI probes will be added to those excepted instruments.

II. DRR RECOMMENDATIONS FOR N266ST310001

1. Comment - Paragraph 3.1.1.1: Look into the need of blueing to check the fit defined in this paragraph.

Response - The ISIP impeller bore will be machined to the same dimensions and tolerances as the FFTF impellers, which are interchangeable; therefore, a specification requirement for blueing should not be required in the specification (nor was it required in HWS-1551 or RDT E 3-2T.) However, like W EMD, AI will add this requirement to the assembly procedure as a precaution and final check on the fit.

2. Comment - Paragraph 3.2.1: Put down all of the terms involved in the NPSH.

Response - NPSH may be expressed in terms of a number of different variables, usually depending on those which can be measured. Instead of putting down the "terms," a word description will be provided allowing the use of engineer flexibility to select those measurable variables which can be combined to provide the correct value.

3. Comment - Paragraph 3.2.2.1: Move the verification section from the requirement section back to the verification section.

Response - This will be accomplished as part of the revision under Action Items 2 and 4.

4. Comment - Paragraph 3.3.5: The specification should require that sceps be taken to reduce the possibility of galling of the threaded fasteners.

Response - The specification will include a requirement for mating surfaces of iniernal and external threads to be different materials and for thread lubricants to be used at assembiy.

5. Comment - Paragraph 3.5.1, Part 5: Justify aluminization of the piston ring seal compared to the use of stellite or other hard facing techniques. 
Response - Present plans are to aluminize the bore of the Type 304 steel cylinder. The piston ring will be made of Inco 718. This material combination has been discussed with the AI M\&P Department, LMEC, and HEDL. Inco 718 against an aluminzed surface has been tested in sodium at HEDL and found to have resonable wear resistance. The thickness of the hard surface will be approximately 3-4 mils, of which approximately half will build up on the surface. Based on HEDL information, the expected friction coeffecient is between 0.2 and 0.5 . Stellite was not selected because of its high local heat input and the potential effects of its lower thermal expansion coefficient during thermal transients.

6. Comment - Paragraph 3.5.3c: Review the requirements of this paragraph.

Response - This paragraph will be reviewed carefully and revised as appropriate. From an initial reading, the intent of the paragraph is not clear, despite the fact that the requiremen' is explicit.

jew: $4 / 2-6$ 
N266ER000-001

Page 174
N26GDRROOOOO3

Page 25 Change

Attachment 2

IL to L. E. Glasgow

May 26, 1978

COMPARISON OF STRUCTURAL DESIGN REQUIREMENTS

OF FFTF PUMP WITH THOSE OF ISIP

References: (1) RDT E 3-2T Centrifugal Free-Surface Sodium Pump with Electrical Drive, May 1971; including Amendment 1, February 1972, and Ammendment 2, June 1974.

(2) HWS-1551 LMFBR Low Capacity Prototype Pump--FFTF Primary Pump, Revision 1, January 1974, including Addendum 1P, June 1977.

(3) N266ST310001 Pump, Sodium, Inducer, Intermediate Size (ISIP.)

Structural design requirements for the FFTF pump are to be found under Paragraph 3.3.5, Structural Design, and its subparagraphs in both the RDT standard (Reference 1) and the ordering data (Reference 2.) Structural design requirements for the ISIP may be found under Paragraph 3.3, Design Requirements, in the pump sepcification (Reference 3.)

\section{Allowable Stresses}

a. RDT E 3-2T Ammendment 1, Paragraph 3.3.5.1

Allowable stresses are to be in accordance with the Code, supplemented by Code Case 1331 and RDT F 9-1.

b. N2665T310001, Paragraph 3.3.1 (refers to Table 3-III)

Table 3-III uses allowable stresses extracted from the code and Code Case 1592-10 as guidance for high temperature ( $800^{\circ} \mathrm{F}$ ) application.

Code Case 1592 is an outcome of the initial high-temperature criteria developed on the FFTF program under RDT F 9-1 for application of Code Case 1331.

2. Earthquakes

a. RDT E 3-2T, Paragraphs 3.3.5.2 and 3.4.4

: Requires pump to be designed to seismic criteria specified in ordering data. 
b. HWS-155I, Appendix A

States seismic design loads (JABE-WADCO-02) and performance requirements under various load categories (OBE, DBE, etc.)

c. N266ST310001

Since ISIP has no operational requirements during or after an earthquake, $O B E$ and $D B E$ type requirements are not applicable for the ISIP components. In the event of an earthquake, the pump can be stopped and the-system drained immediately under an emergency operating procedure. The FFTF structure has already been analyzed by Westinghouse. The impeller/inducer assembly mass is of the same order of magnitude, but slightly lighter than the FFTF pump impelier, therefore, no additional loads will be applied to the pump shaft. The diffuser and shroud assembly will be checked against Uniform Building Code (UBC) requirements for this area, under a requirement to be added to the specification.

\section{Vibration}

a. RDT E 3-2T, Paragraph 3.3.5.4

Requires that design avoid damage or malfunction due to internally or externally excited vibration.

b. N266ST310001, Paragraph 3.3 .2

An equivalent requirement is being added under Action Item 7 from the design review.

4. Thermal Stresses and Deflections

a. RDT E 3-2T, Paragraph 3.3.5.5

Requires analysis for transient induced stresses and deflections.

b. N266ST31001

Requires test transient effects to be anaiysed and results evaluated against Code criteria to determine permissable transients. Recirculation (internal) flows and calcualted temperature distributions will be compared to the FFTF pump to determine whether additional deflection analyses are warranted.

\section{Residual Stresses}

a. RDT E 3-2T, Paragraph 3.3.5.6

: Requires design to prevent damage or malfunction due to residual stresses or to utilize stress relief processes to relieve residual stresses. 
b. N266ST310001, Paragraph $3.5 .3(\mathrm{~b})$

Page 27

Change 1

Requires heat treatment to achieve dimensional stability.

6. Creep

a. RDT E 3-2T, Paragraph 3.3.5.7

Requires design to central or limited accumulated creep within limits required for staisfactory operation.

b. N266ST310001, Paragraph 3.3.1 (refers to Table 3-III)

Specifies creep-fatigue and strain accumulation limits.

c. N266ST310001, Paragraph 3.5.3(b)

Requires heat-treatment to achieve dimensional stability. 
N266ER000-001

Page 177

\section{EXAMINATION OF THE IIPACT OF MATERIAL} DENSIFICATION ON ISIP COMPONENTS

The stainless steel internal components of the ISIP will be given a supplemental heat treatment intended to promote dimensional stability during subsequent sodium pump service. This heat treatment is designed to accelerate metallurgical transformations in the microstructure which increases the density and results in dimensional shrinkage of the component. Westinghouse reported that one FFTF sodium pump casting exhibited a density increase of $0.16 \%$ after the stabilizing heat treatment with no change during subsequent heating at $1050^{\circ} \mathrm{F}$ for $1,000 \mathrm{hr}$. HEDL is currently conducting a series of tests on cast CF-8 specimens to further evaluate the effectiveness of the heat treatment. The HEDL tests also indicate an increase in density, up to about $0.15 \%$, following the heat treatment. In subsequent heating at $1050^{\circ} \mathrm{F}$, a small additional increase in density of about $0.02 \%$ was also indicated during the first $500 \mathrm{hr}$, but there were no significant changes during continued exposures. To date, the HEDL specimens have completed more than 4,500-hr exposure time.

The above data indicate that the supplemental heat treatment does promote densification. Since the components will be final machined after the heat treatment, any further increase in density during sodium service should be minimal with no significant dimensional change. 


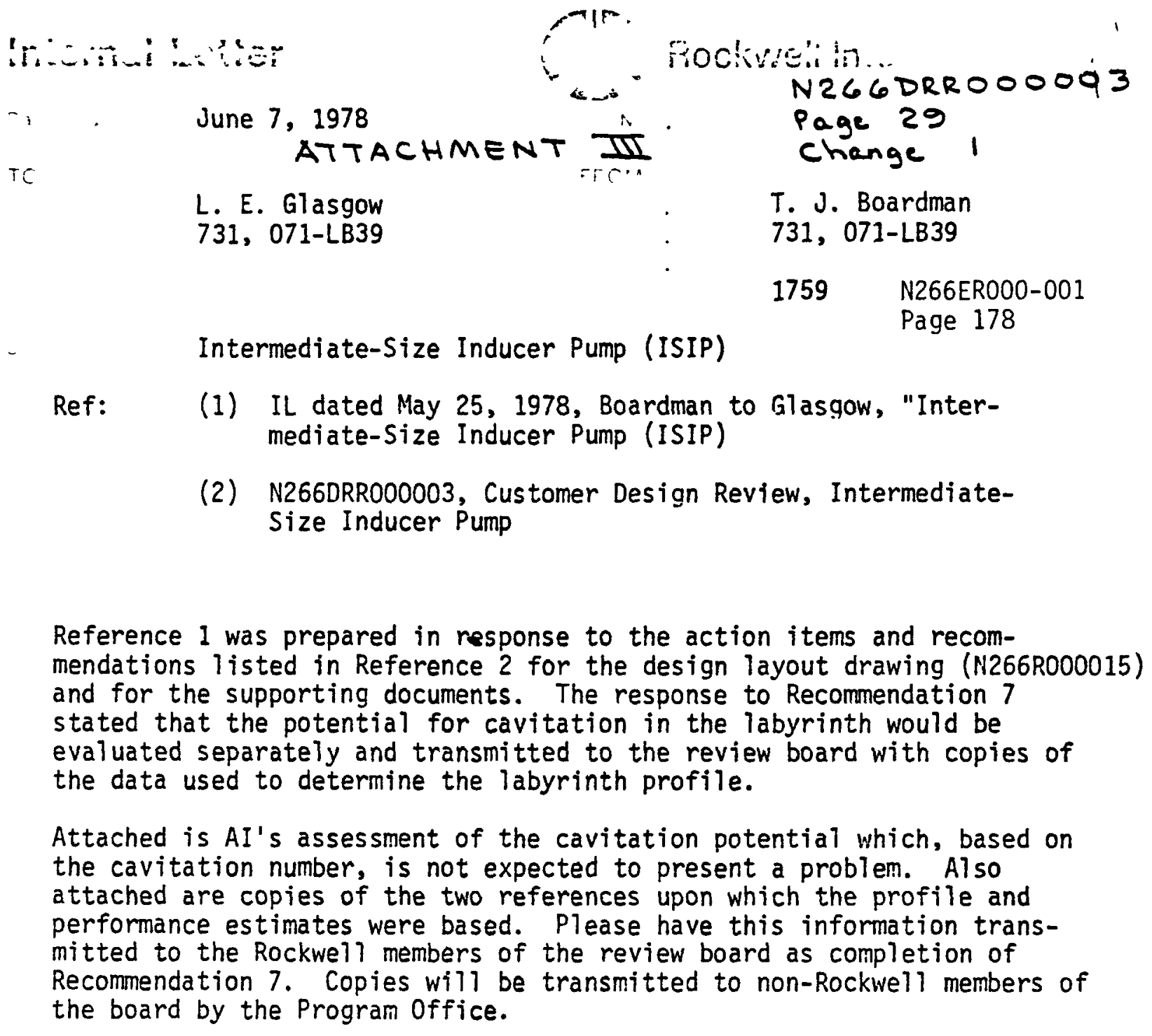

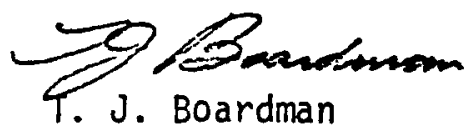

1ad: 67

Attachments

cc w/attachment:

cc w/attachment and references for attachments:
G. Hallinan
R. V. Anderson (7)
C. Dunn
C. Sternburg (10)
P. Jencek
P. Ferry
J. Page
C. Torrijos
R. Schnurstein
J. Wolf
D. Paradise
L. Woehler
R. Hoshide 
Subject: Summary of Intermediate Size Inducer Pump (ISIP) Impeller Labyrinth Seal Design and Evaluation of Cavitation Potential

Ref:

(1) Crewdson, E., "Water-Ring Self-Priming Pumps," Vol. 170, No. 13, Institution of Mechanical Engineers, Westminster, South Wales, 1956

(2) Stocker, H. L., "Advanced Labyrinth Seal Design

Performance for High Pressure Ratio Gas Turbines," ASME Publication 75-WA/GT-22, New York, New York, 1975

\section{INTRODUCTION}

Because the impeller front and rear labyrinth seal configurations were changed from the original Westinghouse design, a briefing on the new seal design was presented at the ISIP Customer Design Revievi held at Atomics International on May 9, 1978. Charts 1 through 4 were presented at the briefing. A summary sheet on the important seal design parameters is also attached along with the two applicable references (References 1 and 2).

\section{SUMMARY}

Test results from $E$. A. Jackson showed that use of slanted round backed teeth gave the highest resistance to flow through the leakage passage. Shutoff pump head was 1-1/2 times higher when compared to the slanted flat topped teeth design. Flow had little tendency to enter the pocket in the flat topped design.

Test results from $H$. L. Stocker showed that increased internal seal cavity turbulence resulted in lower leakage compared to the baseline seal. Leakage rates were reduced from 10 to 29 percent during static tests. Comparable leakage rates from 11 to 25 percent reduction were obtained under rotating conditions. Results of the dynamic tests showed little effect on the leakage rates through the seal.

\section{DISCUSSION}

\section{General}

Impeller labyrinth seal leakages (front and rear) are important in any pump design. Leakage of these seals are recirculated through the impeller and results in efficiency penalties. This leakage can also affect the 
N266ER000-001

Page 180

N26 GDRROOOOOZ
PagE 31

head-flow curve under throttled conditions and especially the shutoff head. Rockwell experience has shown that standard straight circular groove labyrinth seal designs are very poor in reducing leakage of impeller labyrinth seals especially when the clearance sets large. Stepped configurations have shown to be much more effective (about 50\% greater resistance) than the standard straight circular groove design.

Test Results of E. A. Jackson

Charts 1 through 4 were presented at the Customer Design Review and summarize the data obtained by $E$. A. Jackson (Addendum to Reference 1). Three different experimental test programs (stationary model, pump experiments, and large-scale model) were conducted to develop the form of teeth which offered the greatest resistance to water flow through a clearance gap.

Stationary model test results for the slanted flat topped and slanted round backed teeth are shown in Chart 2. Note that the round backed design gave the highest resistance to flow through the passage.

Pump experiments (Chart 3 ) demonstrated that with the slanted round backed design, 1-1/2 times more head was developed at shutoff. The slope of the head-flow curve remained negative and smooth. This characteristic is very desirable for large-scale breeder reactor (LSBR) sodium pumps. Reduction of leakage through the impeller labyrinth seals, especially during throttled conditions, will help maintain the desired negative slope pump characteristic.

Large-scale model tests (Chart 4 ) showed that flow had little tendency to enter the pocket in the flat topped design while flow tended to follow the round backed teeth. The rate of circulation was nearly twice that of the flat topped teeth. Based on previous Rockwell experience and from the results of E. A. Jackson (Reference 1), the ISIP impeller labyrinth seal design was obtained.

Test Results of H. L. Stocker

H. L. Stocker (Reference 2) conducted water tunnel studies, static air rig, and dynamic air rig tests with various labyrinth seal designs. All designs (nine each) were of the stepped configuration and many had slanted round backed teeth.

Water tunnel flow visualization tests were used as a preliminary evaluation of the turbulence generated by the candidate configurations. Results of these tests showed that increased internal seal cavity turbulence resulted in lower leakage compared to the baseline seal.

Static air rig test results demonstrated that leakage over a standard step seal was reduced from 10 to 29 percent with flow going from a Targer diameter to a smaller diameter (as in our desigñ).

Testing under rotating conditions up to $786 \mathrm{ft} / \mathrm{sec}$ resulted in lower leakage compared to the baseline seal from 11 to 25 percent. Results of 
the dynamic tests showed little effect on the flow parameter characteristic of the seals and that the seals tested produced zero to 3.2 percent increase over the static flow parameter. This magnitude of change was within the accuracy of the test data.

\section{ISIP Seal Design}

Impeller labyrinth seal design parameters were obtained from the hydrodynamic analysis and are listed on Chart 5 for both front and rear seals. Note that since the front labyrinth seal leakage discharges between the inducer exit and impeller inlet, the static pressure is $35.8 \mathrm{psia}$. This pressure is high and should prevent cavitation. Also, the maximum fluid velocity through the labyrinth is only $56 \mathrm{ft} / \mathrm{sec}$ (10w). The rear labyrinth seal leakage discharges into a zone where the static pressure is $39.7 \mathrm{rsia}$. Again, this pressure is high and should prevent cavitation. Maximum fluid velocity through the labyrinth is also low at $54 \mathrm{ft} / \mathrm{sec}$. For the front labyrinth, the minimum local cavitation number* across the last labyrinth blade would be 2.2 at $1050 \mathrm{~F}$ if no flow contraction is assumed, as would be expected with the rounded backs. Since the rear labyrinth discharges to a higher pressure, 39.7 psia vs 35.8 psia, the last labyrinth blade would have a higher cavitation number. From this hydrodynamic analysis, cavitation is not anticipated to be a problem at either front or rear impeller labyrinth seal locations or in the zones where the leakage flows are discharged.

$$
K=\frac{P-P_{v}}{1 / 2 P V^{2}}
$$

Where:

$$
\begin{aligned}
& K=\text { cavitation number } \\
& P=\text { static pressure } \\
& P_{V}=\text { vapor pressure } \\
& P=\text { fluid mass density } \\
& V=\text { fluid velocity }
\end{aligned}
$$


CHART 1

JACKSON, E.A., "EXPERIMENTS TO DETERMINE THE BEST SHAPE AND NUIABER OF VANES FOR A GGE PUMP RUNNER," ADDENDUM TO CREWDSON, E., "WATER-RING SELF-PRIMING PUMPS," THE INSTITUTION OF MECHANICAL ENGINEERS, VOL, 170, NO, 13. WESTMINSTER, SOUTH WALES, 1956

- OBJECTIVE - DEVELOP THE FORM OF TEETH WHICH OFFERED THE GREATEST RESISTANCE TO WATER FLOW

- EXPERIMENTAL TESTING

- Stationary hodel

- PUMP EXPERIMENTS

- laRge-SCALE MODEL 


\section{.. TEST SETUP}

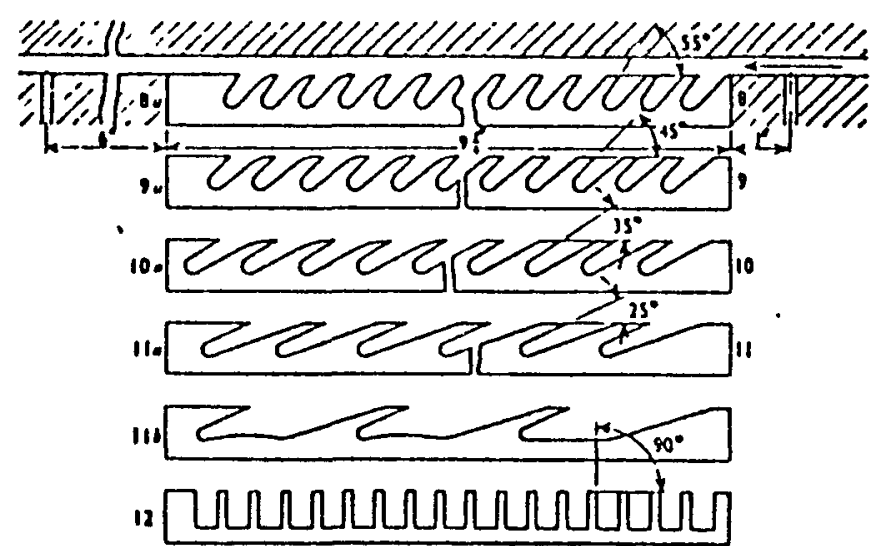

Fig. 13. Experimental Tooth Formas Tested in Stationary Model

$\begin{array}{ll}\text { ROUND } & \text { FLAT } \\ \text { BACKED } & \text { TOPPED } \\ \text { TEETH } & \text { TEETH }\end{array}$

RESULTS

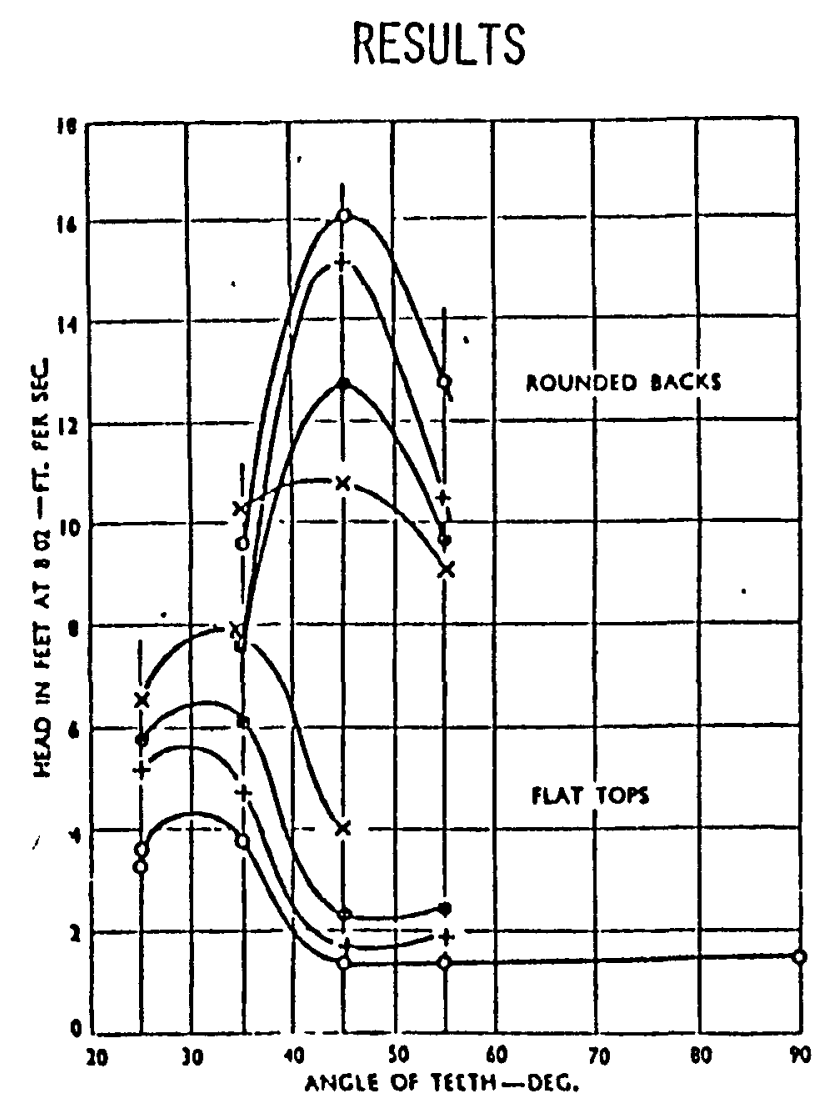

Fig. 14. Curves Shuzving Effect of Tooth Shape on the Flow Resistance

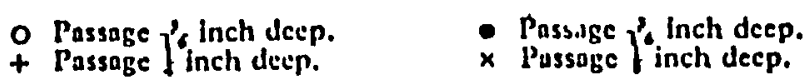

- $\quad$ FLAT TOPPED TEETH - HIGHEST RESISTANCE TO FLOW WITH MINIMUM CLEARANCE

- ROUND BACKED TEETH - HIGHEST RESISTANCE TO FLOW WITH MAXIMUM CLEARANCE 


\section{CHART 3 PUMP EXPERIMENTS}

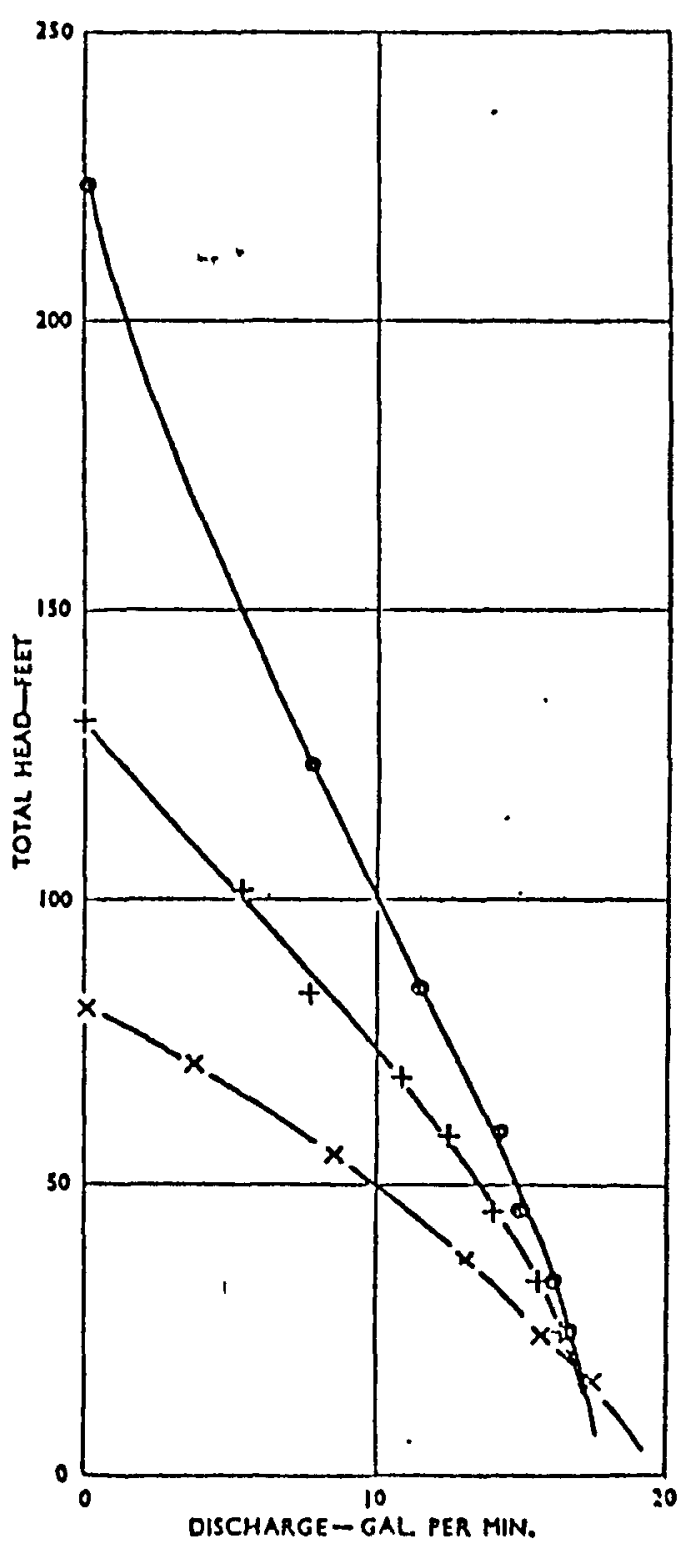

- ROUND BACKED TEETH 1-1/2 TIMES MORE HEAD AT SHUTOFF

- $90^{\circ}$ VANE CONFIGURATION HEAD DEVELOPED WAS CONSIDERABLY LOWER THAN FOR INCLINED VANES

Fig. 15. Performance Curres for Three Types of Pumip Rumner

- Vanes 35 dec., rounded backs.

- Vanes 35 deg., flat tops.

$\times$ Vanes 90 deg., Ilane cops. 
CHART 4 LARGE-SCALE MODEL

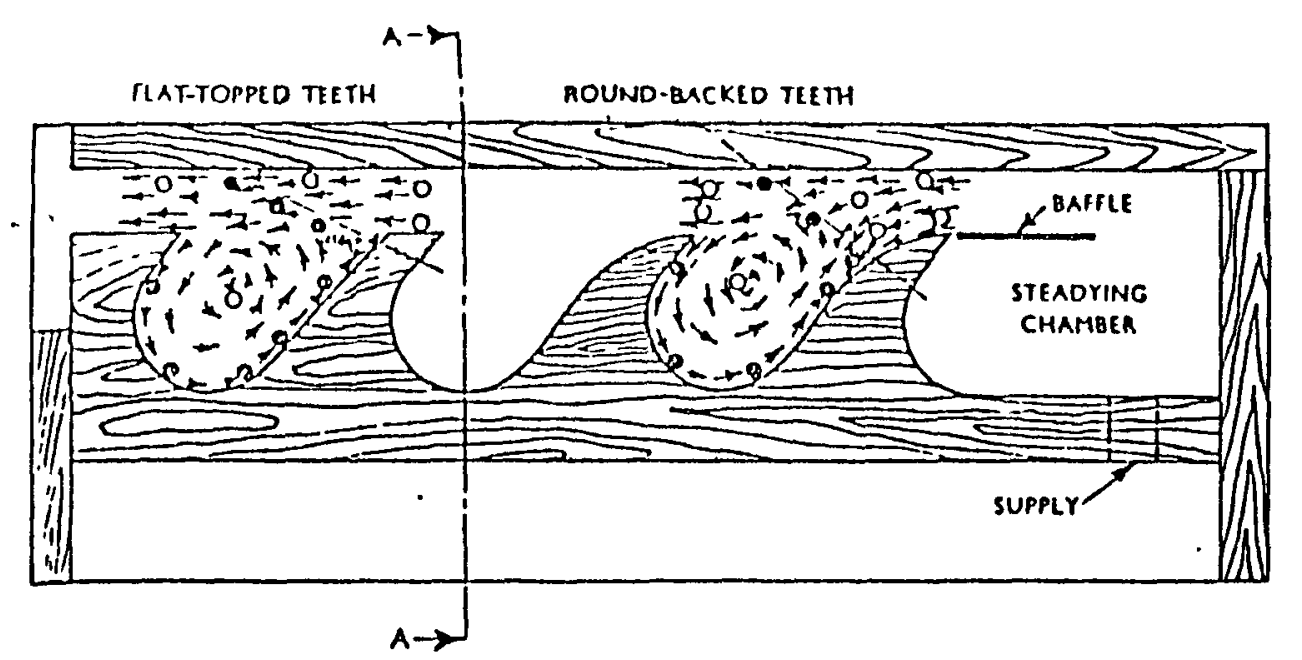

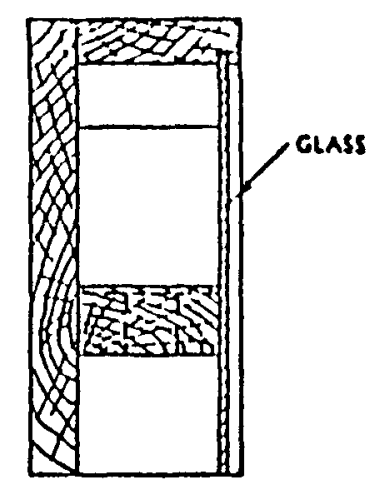

SECTION AA

Fig. 16. Large-scale Madel of Water-ring Self-priming Pump

Regions of high pressure.
$-\quad$ Regions of low pressure.

- - Approximate line of maximum pressure downstream of tooth.

Length and directions of arrows represent approximate velocity and direction of flow.

- $\quad$ FLAT TOPPED TEETH

- FlOẂ had LitTLE TENDENCY TO ENTER POCKET

- ROUND BACKED TEETH

- FLOW TENDED TO FOLLOW ROUND BACKED TEETH

- rate of CiRCULATION NEARLY tWice that OF FLAT topped TEETH 
ISIP IMPELLER LABYRINTH SEAL DESIGN PARAMETERS

DESIGN PARAMETER

LEAKAGE FLOW RATE, GPM

SEAL DELTA PRESSURE, PSID

DISCHARGE STATIC PRESSURE, PSIA

SEAL SPEED, FPS

AVERAGE DIAMETER, IN.

AVERAGE DIAMETRICAL CLEARANCE IN. AVERAGE FLOW THROUGH AREA, IN. ${ }^{2}$

AVERAGE FLUID VELOCITY, FPS
IMPELLER LABYRINTH

\begin{tabular}{lll}
\hline FRONT & & REAR \\
\cline { 1 - 1 } 648 & & 569 \\
93.8 & & 87.2 \\
35.8 & & 39.7 \\
109 & & 99 \\
22.5 & & 20.5 \\
0.105 & & 0.105 \\
3.72 & & 3.38 \\
56 & & 54
\end{tabular}




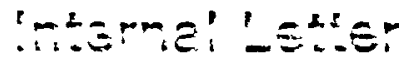

$=-\quad$ June 13,1978

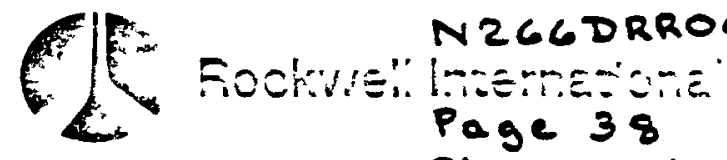
Page 38 ,

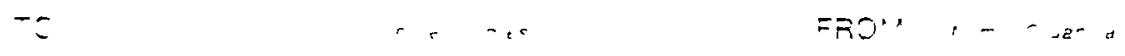

Design Review Board Members

L. E. Glasgow

731, 071-LB39

1754 N266ER000-001

Page 187

Intermediate-Size Inducer Pump Design Review Action Items

Ref: N266DRR000003, Customer Design Review Intermediate-Size

Inducer Pump

The Design Review Board Members have reviewed the action item responses and the updated referenced documents and concur with the implementation of the action items and responses to the recommendations. Approval of this IL by the board members listed below denotes that they concur with the responses to the design review action items.

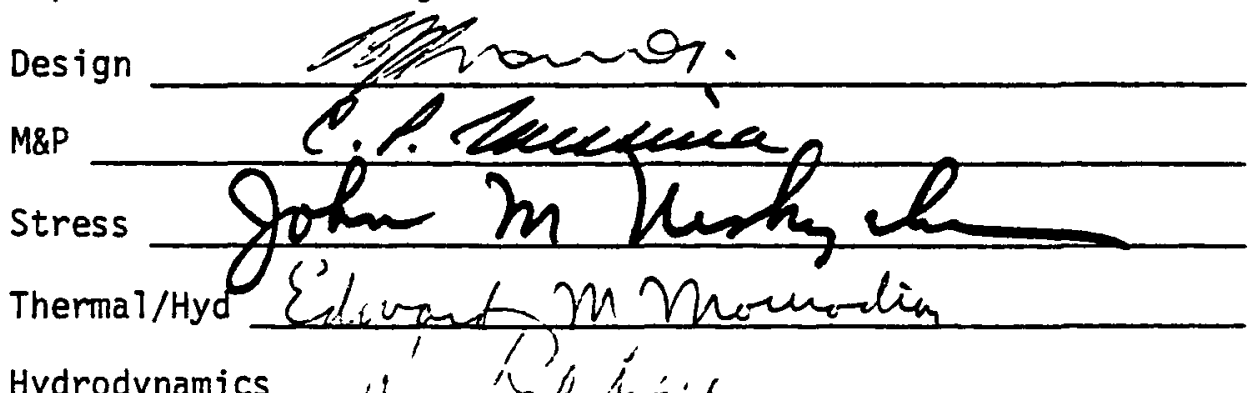

Hydrodynamics il $a \cdot \dot{a}=i c$

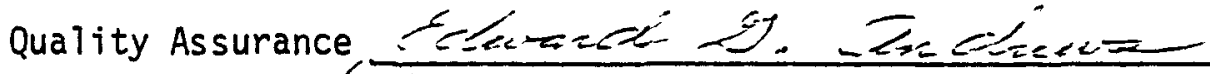

Manufacturing (4.).21 nasik

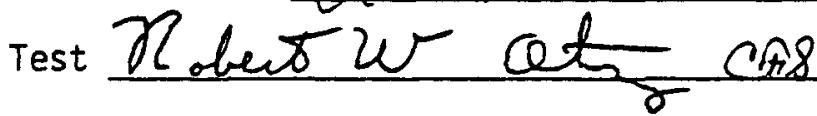
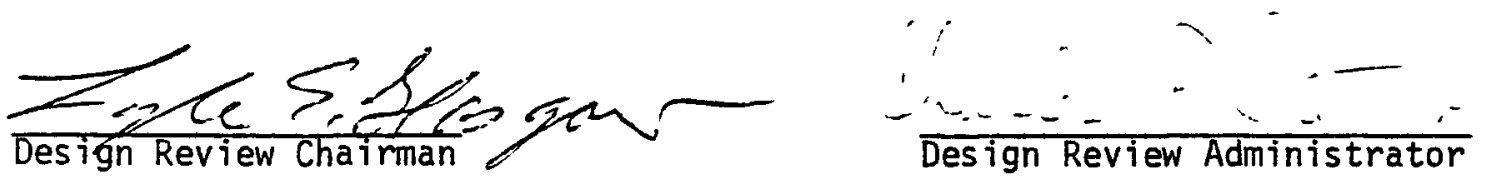

$c p: 2 / 4$

Form 131-R Rev 376 


$$
\begin{aligned}
& \text { June 19, } 1972 \\
& \text { Design Review } \\
& \text { Board Members }
\end{aligned}
$$

N266DRROOO003 Page 39

\section{Change 1}

L. E. Filasgow

731, $071-L B 39$

1754

Intermediate-Size Inducer Pump Design Review Action Items

Ref: N2660RR000003, Customer Design Review Intermediate-Size Inducer Pump

The Design Review Board llembers have reviewed the action item responses and the updated referenced documents and concur with the implementation of the action items and responses to the recommendations for the Equipment Specification (N266ST310001). Approval of this letter by the board members listed below denotes that they concur with the responses to the design review action items for this document. This form is for signature by non-Rockwell board members. A similar Internal Letter form will be signed by Rockwell board members.

Argonne National Laboratory

$$
\text { R. Karr }
$$

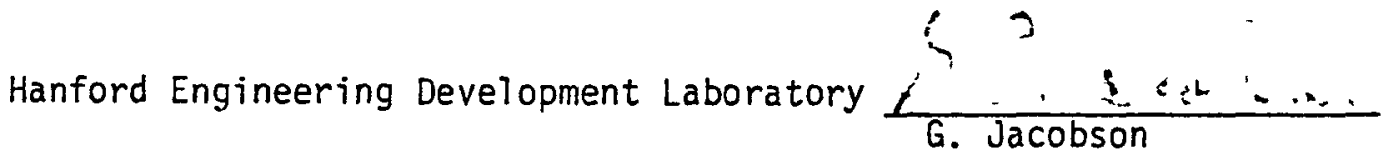

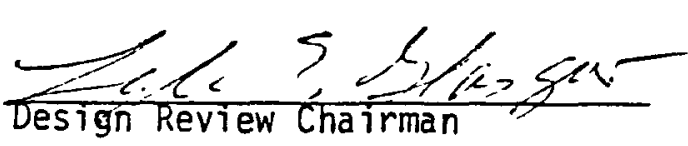

$\frac{\text { OKarles St Sternburg }}{\text { Design Review Administrator }}$ 


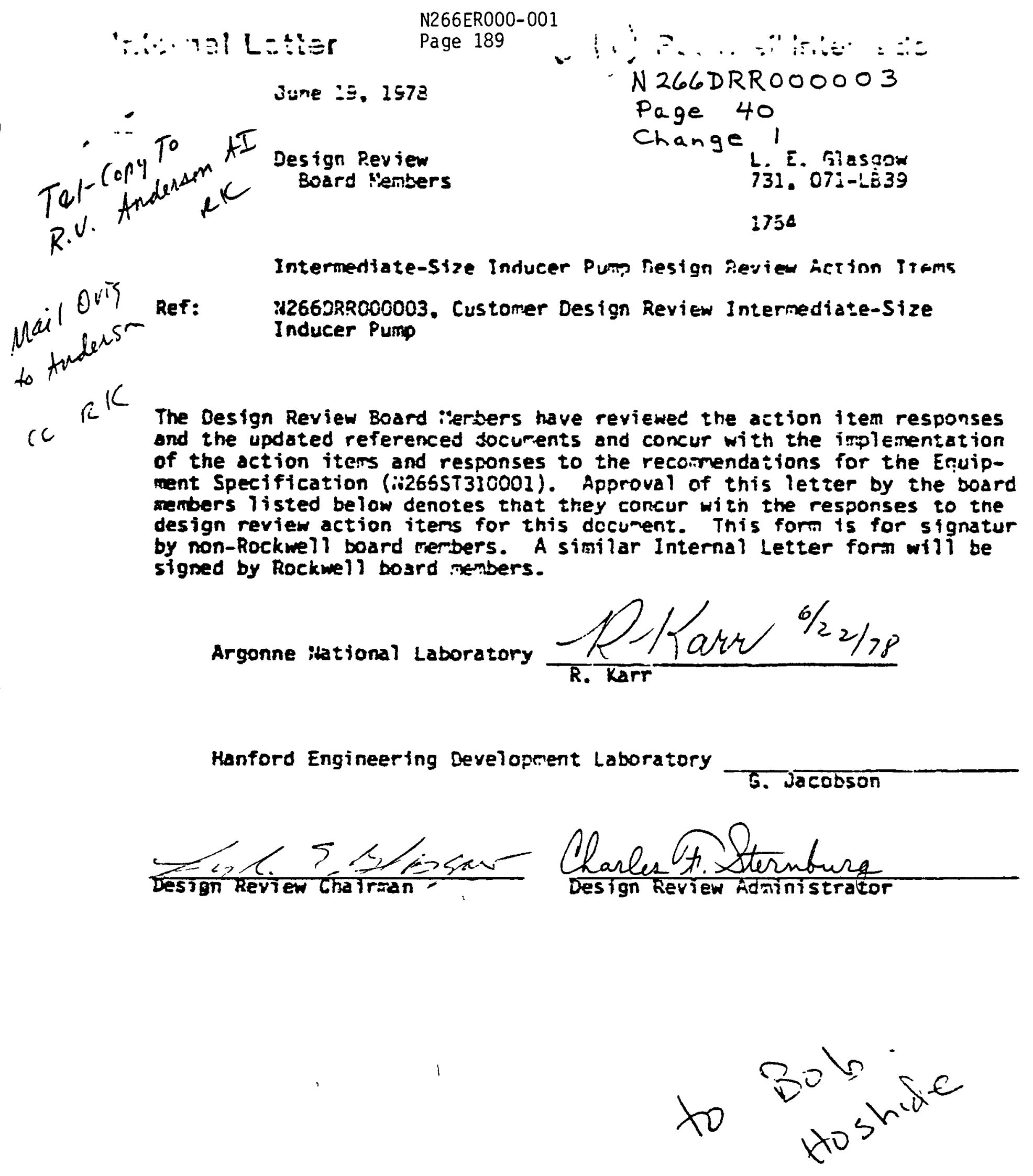

Jbv:1/4 


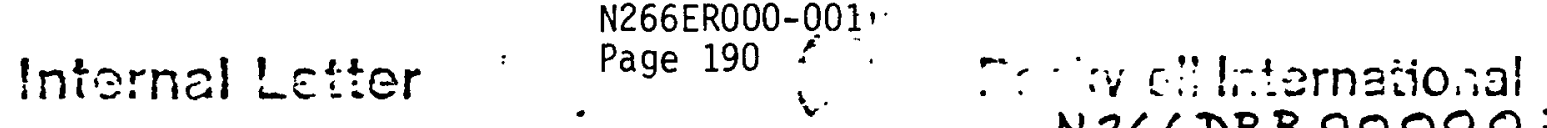

$$
\begin{aligned}
& 2.36 \text { June 30, } 1978 \text { Page } 41
\end{aligned}
$$

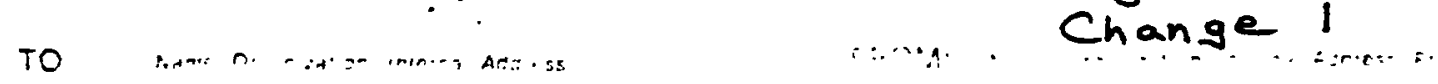

$$
\begin{aligned}
& \text { Design Review . L. E. Glasgow } \\
& \text { Board Members . 731, 071-LB39 } \\
& 1754 \\
& \text { Surf }=\text { Intermediate-Size Inducer Pump Design Review Action Items } \\
& \text { Ref: } \quad \text { N266DRR000003, Customer Design Review Intermediate-Size } \\
& \text { Inducer Pump }
\end{aligned}
$$

The Design Review Board Members have reviewed the action item responses and the updated referenced documents and concur with the implementation of the action items and responses to the recommendations for the ISIP Design Layout, (N266R000015, D2 release). Approval of this letter by the board members listed below denotes that they concur with the responses to the design review action items for this document. This form is for signature by non-Rockwell board members. A similar Internal Letter form will be signed by Rockwell board members.

Argonne National Laboratory

$$
\text { R. Karr }
$$
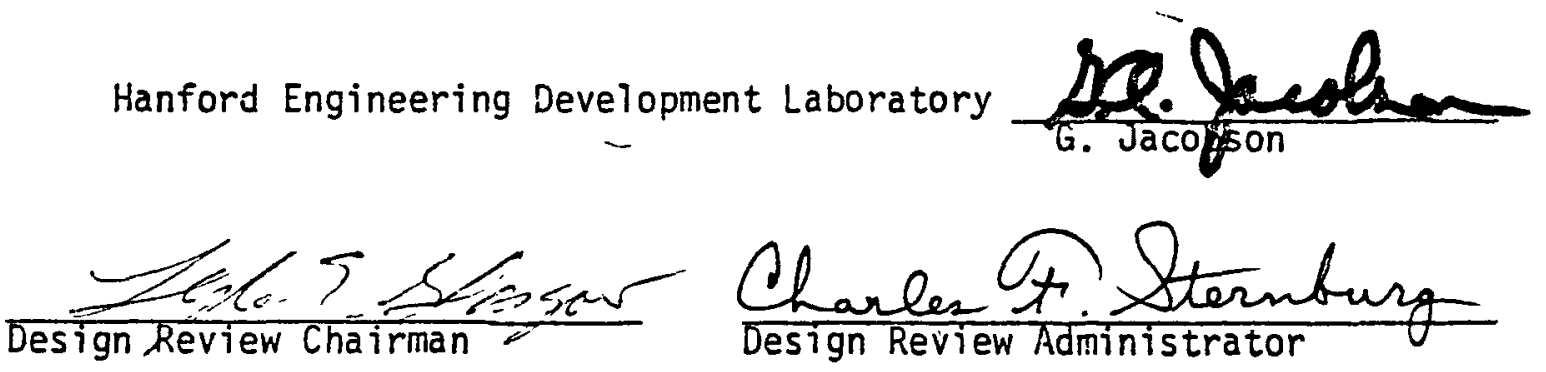


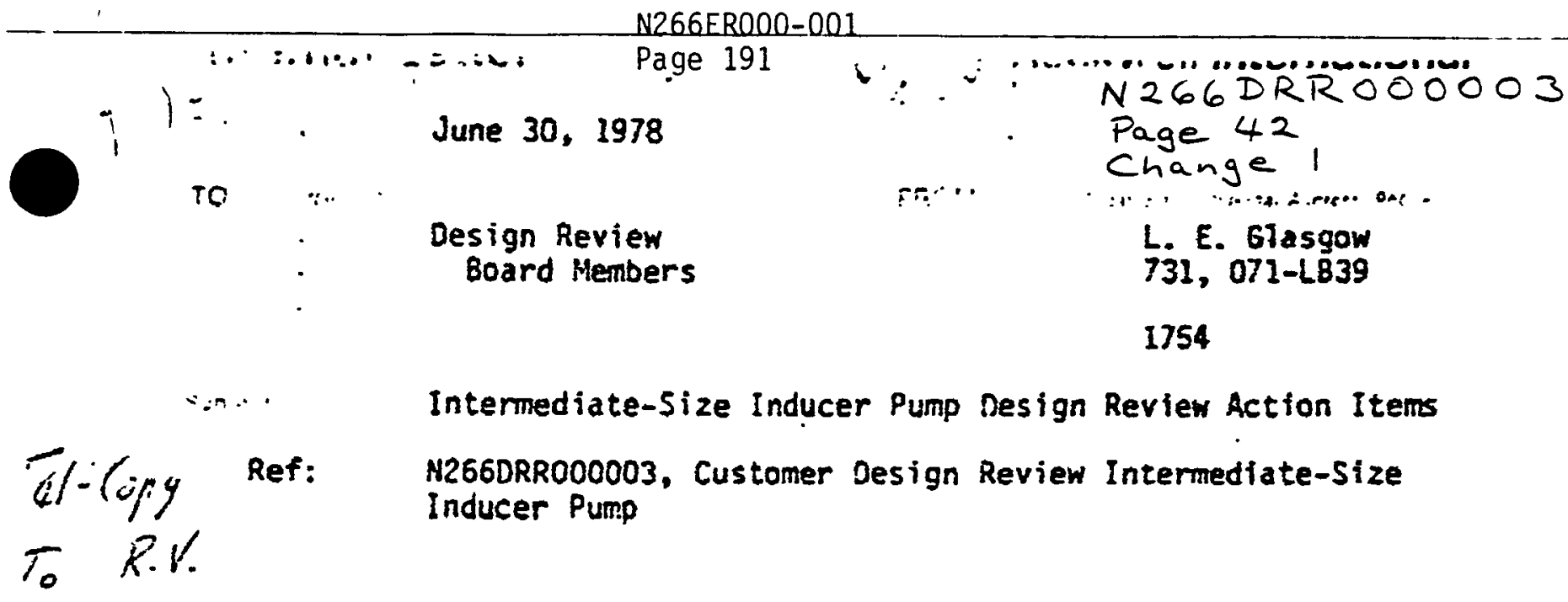

And alison

4.T. The Design Review Board Members have reviewed the action item responses and the updated referenced documents and concur with the implementation of the action items and responses to the recommendations for the ISIP

Mail Orig Design Layout, (II266R000015, 02 release). Approval of this letter by the board members 1 listed below denotes that they concur with the responses to to the design review action items for this document. This form is for

trusion signature by non-Rockwell board members. A similar Internal letter form will be signed by Rockwell board members.

cC RL iN

Argonne National Laboratory

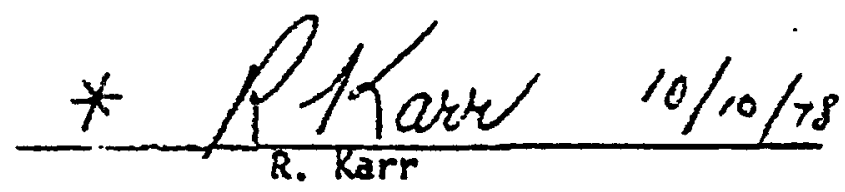

Hanford Engineering Development Laboratory

6. Jacobson

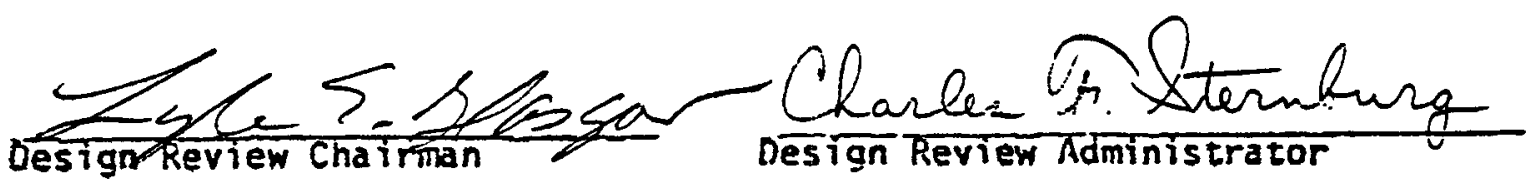

* The draft Test Request N266 RFT c0000' Section 7.6 .1 Inter in Disassembly. Inspection, Data Collection, han a Note that redis, "This date set will inclarle befit inducer messensments to be

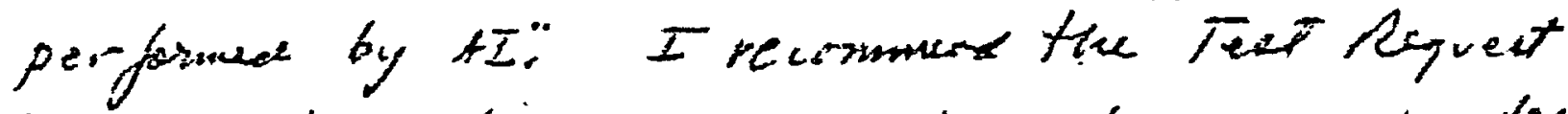
be amplifier to require carbon chrome replicates andre eledtare necrose ope photos be tanner of the replicwien as part of the before, interior

$$
R / C
$$




\section{APPENDIX E \\ ROTORDYNAMICS OF THE INTERMEDIATE \\ SIZE INDUCER PUMP (ISIP)}

ESG Document N266TI000002

Pages A2 thru A23 and B2 thru B93 (computer printout) have been removed from this document for brevity. 


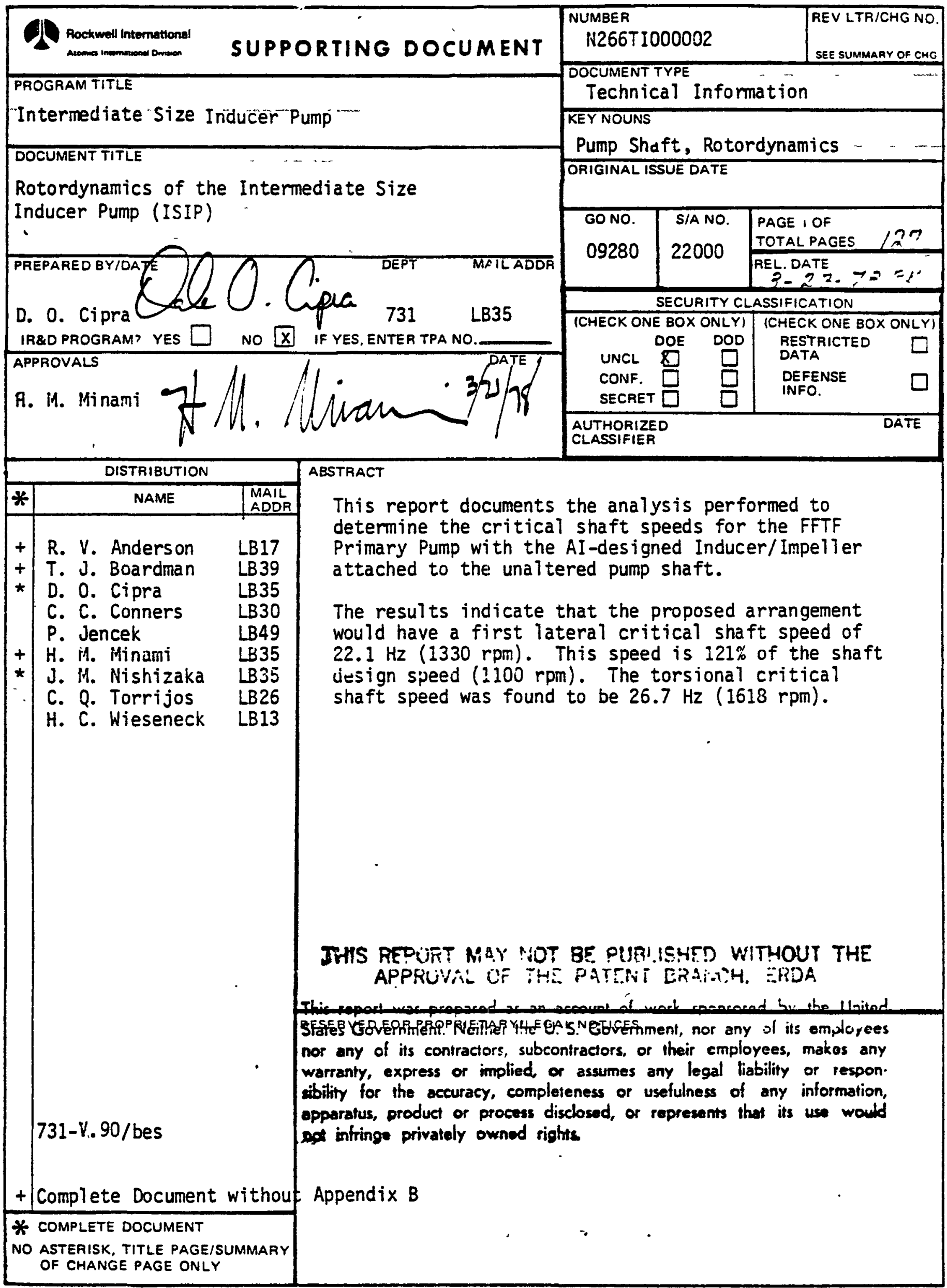


INTRODUCTION...................................... 3

SUMMARY.................................. 4

Discussion.............................. 5

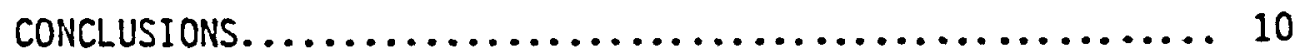

REFERENCES.............................. 11

APPENDIX A $(C R T$ PLOTS $) \ldots \ldots \ldots \ldots \ldots \ldots \ldots \ldots \ldots \ldots \ldots$ Al

APPENDIX B (COMPUTER OUTPUT) .................. BI 
INTRODUCTION

The purpose of this report is to document the rotordynamic analys is of the Intermediate Size Inducer pump (ISIP). This study was performed to determine the rotordynamic effect of installing the AI-designed inducer/impeller subassembly in the existing FFTF primary pump. The pump shaft during this conversion was left unchanged, and, therefore, the dynamic finite element shaft model of the original FFTF pump was remodeled using the proposed inducer/impeller mass and stiffness properties. 
Atomics International

NO N226TI000002

N266ER000-001

Page 196

PAGE . 4

SUMMARY

The rotordynamic analysis performed indicates that the ISIP rotating assembly exhibits little change in frequency when compared to that of the FFTF primary pump. This is because the change of effective mass (both translational and rotational) of the hydraulic assembly is practically negligible compared to the overall mass of the rotating assembiy.

The first lateral critical shaft speed was found to be $22.1 \mathrm{~Hz}$ (121\% of the shaft operating speed), and the critical torsional speed was found to be $26.7 \mathrm{~Hz}$ ( $147 \%$ of the shaft operating speed). 


\section{Atomics International}

NO N266TI000002

PAGE .5

\section{DISCUSSION}

Method of Analysis

The FFTF pump rotor with the inducer/impeller was modeled using the finite element program SAPV (Reference 1). Since the pump shaft is left unchanged, with only the rotating hydraulic assembly being changed, the basic computer rotordynamic model-developed for the FFTF pump (Reference 2) was used. The mass properties of the rotating assembly were calculated based on a preliminary drawing of the inducer/impeller (see Figure 1). The calculated mass properties are presented in Table 1.

TABLE 1. COMPUTED MASS DATA FOR INDUCER/IMPELLER

\begin{tabular}{lccc}
\hline Item & $\begin{array}{c}\text { Weight } \\
(1 \mathrm{~b})\end{array}$ & $\begin{array}{c}\text { Polar Moment } \text { of Inertia } \\
\left(1 \mathrm{~b}-\mathrm{sec}^{2}-\text { in. }^{\prime}\right)\end{array}$ & $\begin{array}{c}\text { Diametrical Moment } \\
\text { of Inestia } \\
\left(1 \mathrm{~b}-\mathrm{sec}^{2}-\text { in. }\right)\end{array}$ \\
\hline $\begin{array}{l}\text { Inducer } \\
\text { Impeller }\end{array}$ & 160. & 26.6 & 18.4 \\
\hline
\end{tabular}

Analytic Model

The SAPV ISIP rotordynamic model is presented in Figure 2. The shaft portion of the model is left unchanged from the Westinghouse FFTF primary pump rotordynamic analysis (Reference 2 ). The computer listing of the Westinghouse model was provided in their report and was used as input data in AI's model. To verify that the model was accurate, the initial FFTF configuration was dynamically analyzed and compared to the FFTF results. The first lateral frequency calculated was $2.5 \%$ lower than the Westinghouse 

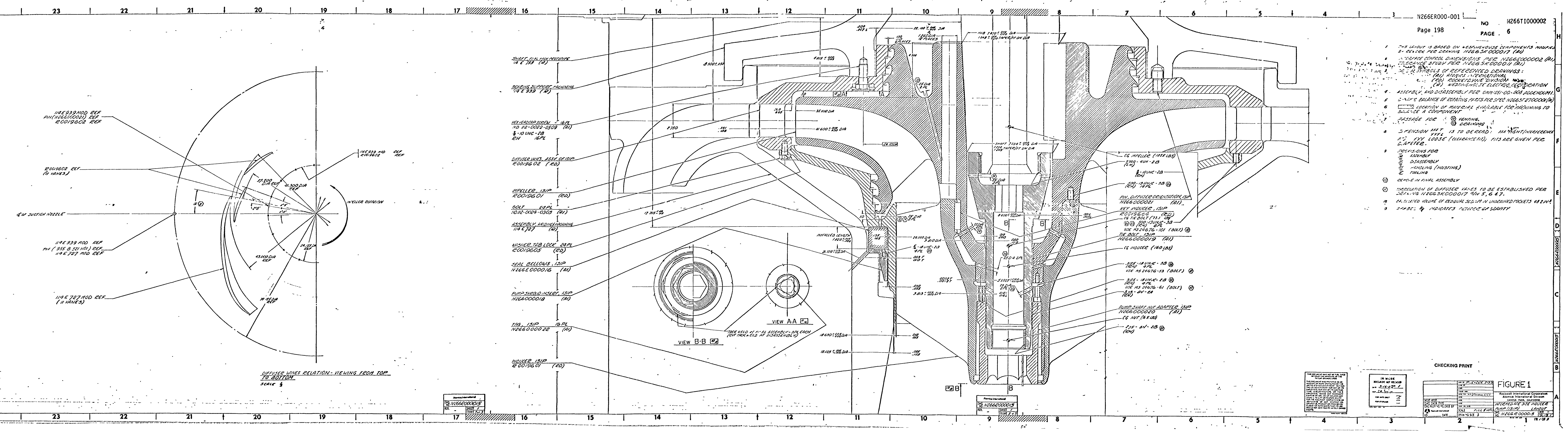


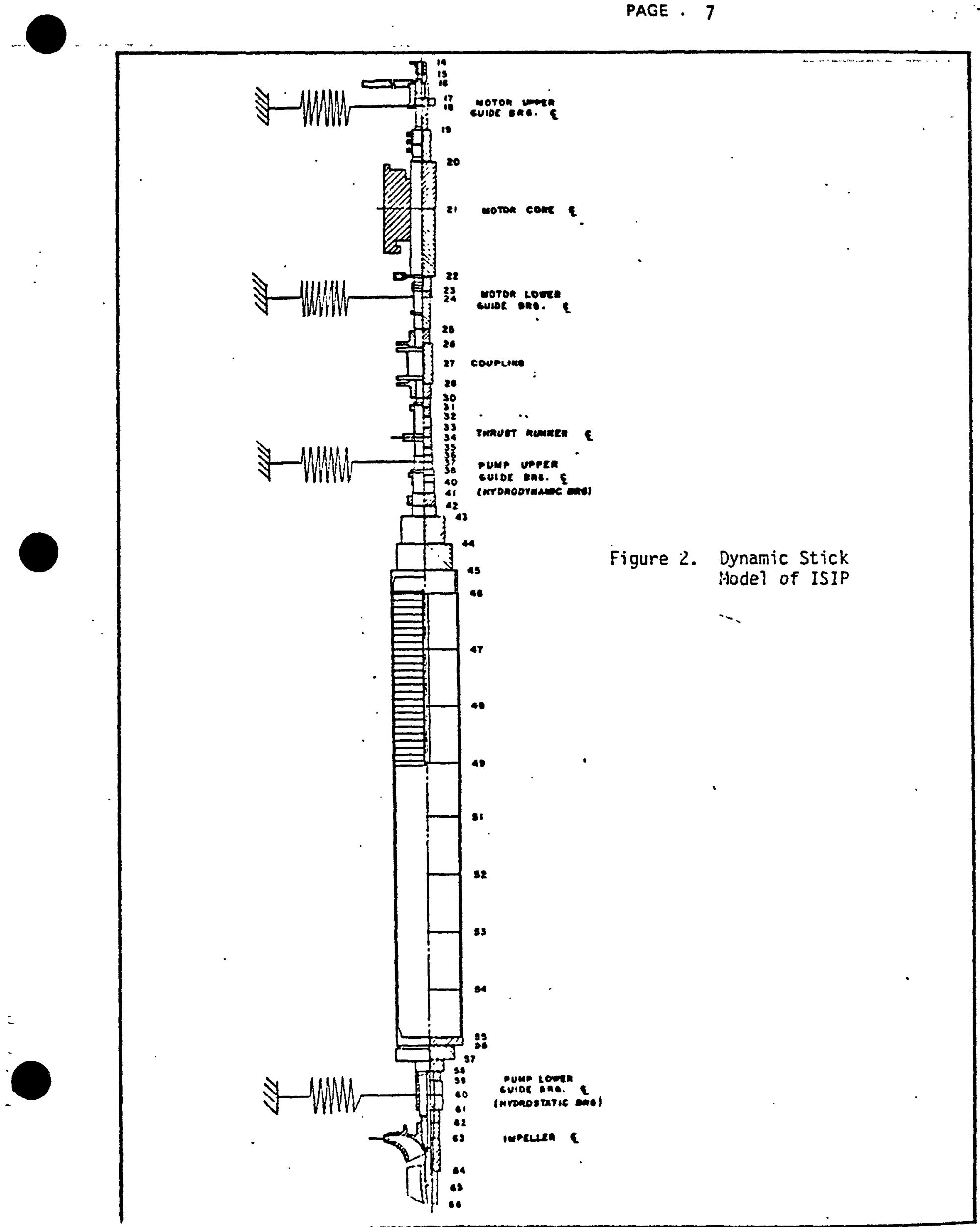


results. The model was also checked for accuracy, and no "bugs" were found to exist. This difference in the two frequencies is considered to be within the allowable tolerance between two different finite element programs. The torsional frequency was found to be high by $9 \%$ when compared to the FFTF results.

In the real sense, the pump shaft is a free-free system in the torsional direction, and SAPV is unable to solve this problem. In order to make the model stable, a relatively soft torsional spring is added to the motor rotor. This first frequency is a fictitious type mode with the shaft acting as a rigid body and does not affect the true shaft torsional frequency. This was verified by lowering the torsion springrate and noting an insignificant change in the true torsional frequency.

\section{Results of Analysis}

The significant natural frequencies and their descriptions are presented in Table 2. The results show the ISIP first critical shaft frequency of $22.13 \mathrm{~Hz}(1,328 \mathrm{rpm})$. The plotted mode shape is presented in Appendix A. This speed is $121 \%$ of the running speed of the pump. Note that there exists some discrepancy between the frequencies obtained from the AI model of the FFTF primary pump and the Westinghouse model. However, the change in frequencies when the inducer/impeller is used is small, suggesting that the installation will have little effect on operating dynamics. The torsional frequency of the ISIP will be higher (as noted in Table 2) because of the lower radius of gyration of the ISIP inducer/impeller. 
TABLE 2. ISIP CRITICAL SHAFT FREQUENCIES

ANO MODE DESCRIPTIONS

\begin{tabular}{|c|c|c|c|c|}
\hline \multirow[t]{2}{*}{ Mode } & \multicolumn{3}{|c|}{ Calculated Natural Frequenctes $(\mathrm{Hz})$} & \multirow[b]{2}{*}{ Mode Description } \\
\hline & ISIP & $\begin{array}{c}\text { FFTF } \\
\text { (AI Model) }\end{array}$ & $\begin{array}{c}\text { FFTF } \\
\text { (Westinghouse llodel) }\end{array}$ & \\
\hline 1 & .28 & .28 & -- & $\begin{array}{l}\text { *Fictitious Rigid } \\
\text { Body Mode }\end{array}$ \\
\hline 2 & 22.14 & 22.14 & 22.87 & $\begin{array}{l}\text { First Pump Shaft } \\
\text { Lateral Frequency } \\
\text { (Critical shaft } \\
\text { speed) }\end{array}$ \\
\hline 3 & 25.08 & 25.08 & 25.36 & $\begin{array}{l}\text { Motor Shaft First } \\
\text { Lateral Frequency }\end{array}$ \\
\hline 4 & 26.69 & 26.34 & 23.95 & $\begin{array}{l}\text { Motor/Pump Shaft } \\
\text { Torsional Frequency }\end{array}$ \\
\hline
\end{tabular}

* Required to make the SAPV model stable in the torsional direction 


\section{CONCLUSIONS}

Based on the observation that little change (less than $2 \%$ ) in frequency is noted with the inducer/impeller hydraulic assembly in place of the existing impeller on the FFTF primary pump, the following conclusion is made: Assuming an inducer/impeller balancing procedure consistent with the procedure used on the original FFTF pump impeller, there will be a minimal effect on the mechanical vibrational response of the ISIP. 


\section{REFERENCES}

1. SAPV, "Structural Analysis Program," E. Wilson, University of California, Berkeley, California, USC Version - 1976

2. "FFTF Primary Pump Rotor Dynamics Analysis," Engineering Memorandum No. 4708, Revision 2, by L. C. McNutt, Westinghouse Electric Corporation, Electro-Mechanical Division, Cheswick, Pennsyivania, February 9, 1977 
Atomics International

No . N266T1000002

PAGE . Al

\section{APPENDIX A}

SAPV CRT PLOTS

(Plots removed for brevity) 
N266ER000-001

Page 205

Atomics International

NO N266T1000002

PAGE . B1

\section{APPENDIX B \\ SAPV COMPUTER OUTPUT}

(Computer printout removed for brevity) 
RADIAL TOLERANCE STACKUP - ISIP

ESG Document N266TI000004 


\begin{tabular}{|c|c|c|c|c|}
\hline & \multicolumn{2}{|c|}{ SUPPORTING DOCUMENT } & $\begin{array}{l}\text { NUMBER } \\
\text { N266TI000004 }\end{array}$ & $\begin{array}{l}\text { REV LTR/CHG NO. } \\
\text { SEE SUMMARY OF CHG }\end{array}$ \\
\hline \multirow{2}{*}{\multicolumn{3}{|c|}{$\begin{array}{l}\text { PROGRAM TITLE } \\
\text { Intermediate-Size Inducer Pump }\end{array}$}} & \\
\hline & & & \multicolumn{2}{|c|}{$\begin{array}{l}\text { Design Verification } \\
\text { KEYNOUNS } \\
\text { Radial Stackup } \\
\end{array}$} \\
\hline \multicolumn{3}{|c|}{$\begin{array}{l}\text { DOCUMENT TITLE } \\
\text { Radial Tolerance Stackup - ISIP }\end{array}$} & \multirow{2}{*}{\begin{tabular}{|c|c|} 
GONO & S/A NO. \\
09280 & 21000 \\
\end{tabular}} & $\begin{array}{l}\text { PAGE } 1 \text { OF } 35 \\
\text { TOTAL PAGES }\end{array}$ \\
\hline \multirow{3}{*}{\multicolumn{3}{|c|}{ 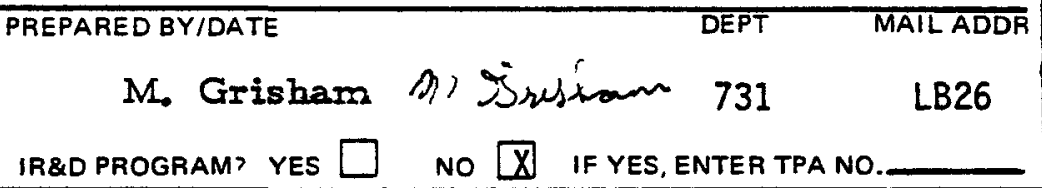 }} & & REL. DATE 79 - $10-$ \\
\hline & & & \multicolumn{2}{|c|}{ SECURITY CLASSIFICATION } \\
\hline & & & \multirow{2}{*}{$\begin{array}{l}\text { (CHECK ONE BOX ONLY) } \\
\text { UNCL } \square \\
\text { CONF } \\
\text { SECRET }\end{array}$} & \multirow{2}{*}{$\begin{array}{l}\text { (CHECK ONE BOX ONLY) } \\
\text { RESTRICTED } \\
\text { DATA } \\
\text { DEFENSE } \\
\text { INFO }\end{array}$} \\
\hline \multirow{2}{*}{\multicolumn{3}{|c|}{ 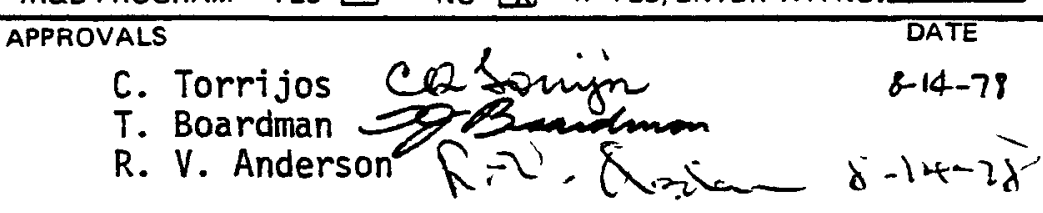 }} & & \\
\hline & & & \multicolumn{2}{|c|}{$\begin{array}{l}\text { AUTHORIZED } \\
\text { CLASSIFIER }\end{array}$} \\
\hline \multicolumn{2}{|r|}{ DISTRIBUTION } & \multicolumn{3}{|l|}{ ABSTRACT } \\
\hline * & $\begin{array}{l}\text { MAIL } \\
\text { ADDR } \\
\end{array}$ & \multirow{2}{*}{\multicolumn{3}{|c|}{$\begin{array}{l}\text { A radial stackup analysis for the Intermediate Sodium } \\
\text { Inducer Pump (ISIP) has been performed to determine } \\
\text { the minimum-maximum clearances between the rotating } \\
\text { and stationary components at room temperature. The } \\
\text { effect of transient temperatures to these clearances } \\
\text { will be determined as a part of the thermal transient } \\
\text { analysis. The calculated radial clearances at the } \\
\text { inducer blade tip for the four conditions examined are: }\end{array}$}} \\
\hline \multirow{6}{*}{\multicolumn{2}{|c|}{$\begin{array}{ll}\text { R. V. Anderson (8) } & \text { LBO7 } \\
\text { H. Minami } & \text { LB30 } \\
\text { E. Andrews } & \text { KB45 } \\
\text { T. Boardman } & \text { LB39 } \\
\text { R. Bremner } & \text { LB49 } \\
\text { N. Doshier } & \text { KB43 } \\
\text { P. Pastor } & \text { KB07 } \\
\text { J. Nishizaka } & \text { LB35 } \\
\text { J. Page } & \text { LBO3 } \\
\text { D. Paradise } & \text { NB14 } \\
\text { C. Dunn } & \text { LB39 } \\
\text { C. Torrijos } & \text { LB26 } \\
\text { P. Jencek } & \text { LB26 }\end{array}$}} & & & \\
\hline & & $\begin{array}{l}\text { 1. being concentric } \\
\text { be }\end{array}$ & $r$ all fits and bea & ring clearance \\
\hline & & $\begin{array}{l}\text { 2. } 069-.036 \text { in. fo } \\
\text { fits and clearan } \\
\text { assembly and imp }\end{array}$ & $\begin{array}{l}\text { maximum parallel } \\
\text { ces of static/hydr } \\
\text { eller assembly }\end{array}$ & $\begin{array}{l}\text { offset of all } \\
\text { aulic diftuser }\end{array}$ \\
\hline & & $\begin{array}{l}\text { 3. } 077-.028 \text { in. fo } \\
\text { fits and clearan } \\
\text { stationary compo }\end{array}$ & $\begin{array}{l}r \text { maximum parallel } \\
\text { ces, and maximum a } \\
\text { nents }\end{array}$ & $\begin{array}{l}\text { offset of all } \\
\text { ngularity of }\end{array}$ \\
\hline & & $\begin{array}{l}\text { 4. } .0930-.0120 \mathrm{in.} \\
\text { offsets and angu }\end{array}$ & $\begin{array}{l}\text { for worst conditio } \\
\text { larity }\end{array}$ & n of parallel \\
\hline & & \multirow{2}{*}{\multicolumn{3}{|c|}{ 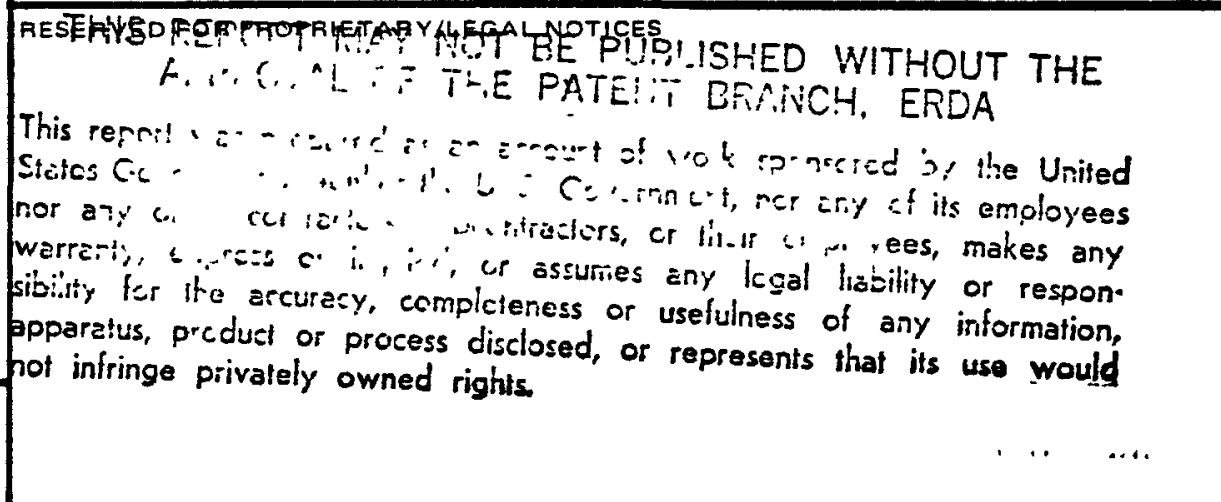 }} \\
\hline \multicolumn{2}{|r|}{$\begin{array}{l}\text { * COMPLETE DOCUMENT } \\
\text { NO ASTERISK, TITLE PAGE/SUMMARY } \\
\text { OF CHANGE PAGE ONLY }\end{array}$} & & & \\
\hline
\end{tabular}


N266ER000-001

Page 208

Energy Systems Group

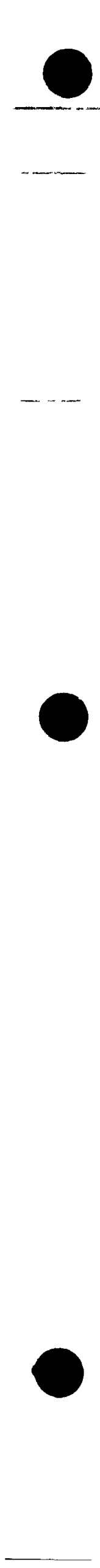

FORM 734-C-1 REV. 6-78
No. N266TI000004

PAGE 1.

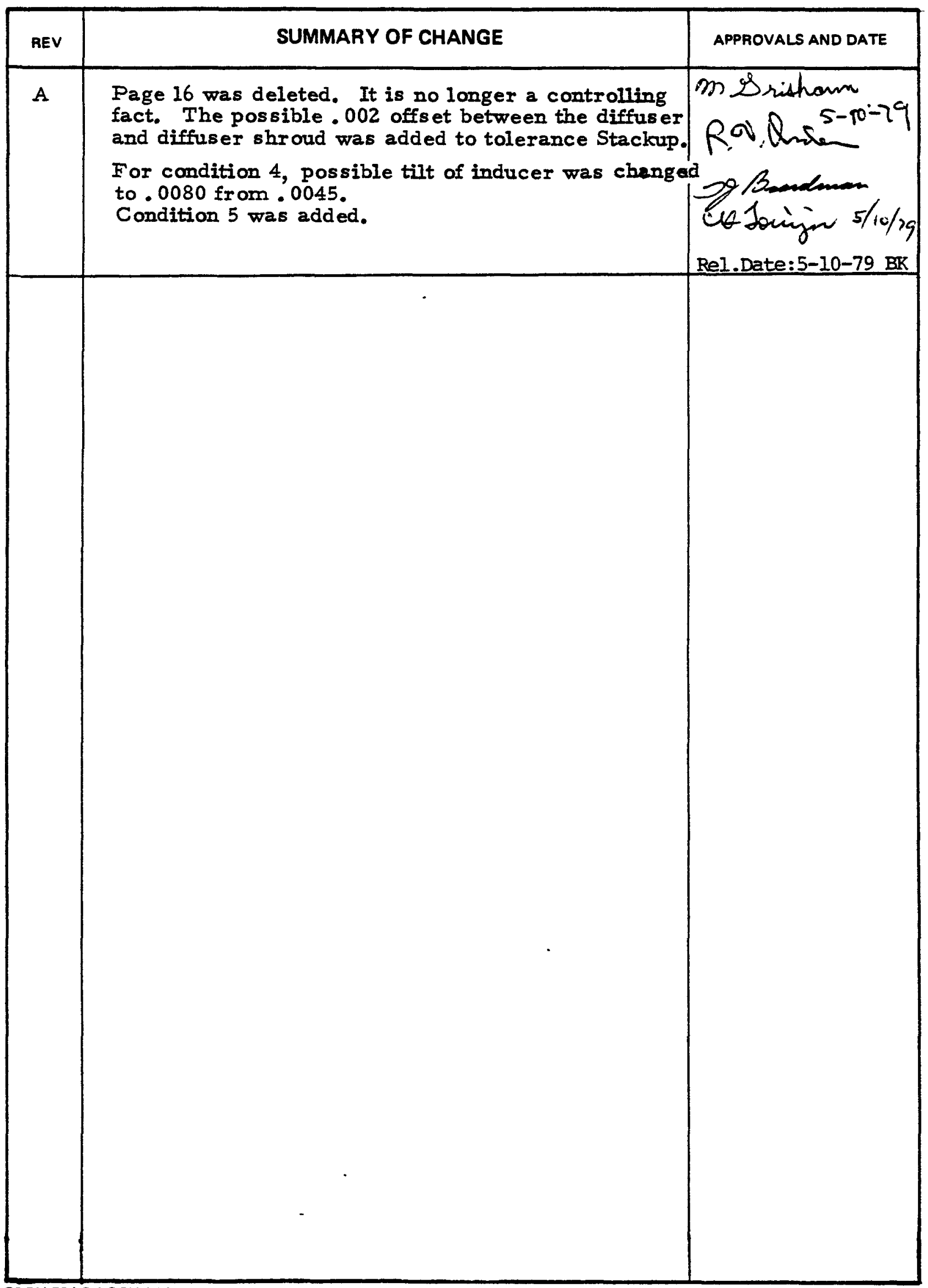




\section{CONTENTS}

\section{Page}

I. INTRODUCTION....................... 3

II. APPLICABLE DRAWINGS.................. 4

III. $\quad$ SUMMARY $\ldots \ldots \ldots \ldots \ldots \ldots \ldots \ldots \ldots \ldots \ldots \ldots \ldots$

IV. $\quad$ COMPUTATION.......................... 7
A. Condition $1 . \ldots \ldots \ldots \ldots \ldots \ldots \ldots \ldots \ldots \ldots$
B. Condition $2 \ldots \ldots \ldots \ldots \ldots \ldots \ldots \ldots \ldots \ldots$
C. Condition $3 . \ldots \ldots \ldots \ldots \ldots \ldots \ldots \ldots \ldots$
D. Condition $4 \ldots \ldots \ldots \ldots \ldots \ldots \ldots \ldots \ldots \ldots \ldots \ldots$
E. Condition $5 . \ldots \ldots \ldots \ldots \ldots \ldots \ldots \ldots \ldots \ldots$ 


\section{INTRODUCTION}

The existing FFTF primary sodium pump is used in the hot leg of the reactor heat transport system. It is designed to pump liquid sodium at $1050^{\circ} \mathrm{F}$. temperature, with the low $350^{\circ} \mathrm{F}$ temperature of transient slugs. The flow rate is $14,500 \mathrm{gpm}$, with total head of $500 \mathrm{ft}$. The FFTF prototype sodium pump was fabricated by Westinghouse (EMD) and initially tested in the sodium test facility (SPTF) in the Energy Technology Engineering Center (ETEC). To build the Intermediate-Size Inducer Pump (ISIP), the prototype sodium pump is to be modified by HEDL to facilitate interchangeable installation of an inducer type pump, engineered and fabricated by Rockwell International. The rework involves modification of the Westinghouse bearing support flange for a closer control of axial dimension and of normality, and of the static hydraulics for a control of axial size and flatness. All rework is to be performed per AI Drawing $\mathrm{N} 266000017$.

This analysis was performed to demonstrate that the radial clearances of assembly will be adequate to prevent rubbing. Evaluation of the results was by magnitude of the calculated minimum clearances and comparison of these values for those in the FFTF Prototype Pump which was tested under similar conditions in SPTF without evidence of rubbing. Completion of this analysis completes the Engineering response for Action Item No. 25 in the ISIP design review report (N22DRR000003).

The computed radial clearances for selected location are performed for four conditions with progressively compounding effects. 
II. APPLICABLE DRAWINGS

\begin{tabular}{|c|c|c|c|}
\hline Item & Drawing Number & Revision & Title \\
\hline 1 & $114 E 799$ & 14 & Shaft, Final Machining Prototype \\
\hline 2 & 114E939 & 8 & $\begin{array}{l}\text { Bearing, Support Machining, Sodium } \\
\text { Pump }\end{array}$ \\
\hline 3 & 114E727 & 14 & $\begin{array}{l}\text { Assembly, Welding and Machining, } \\
\text { Sodium Pump }\end{array}$ \\
\hline 4 & $115 E 116$ & 7 & Bearing Assembly \\
\hline 5 & R0019601 & NC & $\begin{array}{l}\text { Impeller - Intermediate-Size } \\
\text { Inducer Pump (AI Sodium Pump) }\end{array}$ \\
\hline 6 & R0019602 & NC & $\begin{array}{l}\text { Diffuser/Vanes - Assembly of } \\
\text { Intermediate-Size Inducer Pump } \\
\text { (AI Sodium Pump) }\end{array}$ \\
\hline 7 & R0019603 & NC & $\begin{array}{l}\text { Inducer - Intermediate-Size } \\
\text { Inducer Pump (AI Sodium Pump) }\end{array}$ \\
\hline 8 & N266000012 & D1 & Pump Shroud Insert - ISIP \\
\hline 9 & N266000017 & D2 & $\begin{array}{l}\text { Intermediate Size Inducer Pump, } \\
\text { Westinghouse Components Rework } \\
\text { Sketch (ISIP) }\end{array}$ \\
\hline
\end{tabular}


PAGE . 5

\section{SUMMARY}

The computations of radial clearances indicate a minimum gap .012 in. wide between rotating component R0019603 (inducer) and stationary R0019602 (diffuser assembly) in Location "J" of Condition 4, at ambient temperature.

Although mathematically this condition is possible, the stackup of multiple adverse coincidences in maximum values is improbable and represents a hydrostatic bearing failure mode by film depletion expressed in Condition 2. Due to R0019603 rotation, the value " $J$ " in Condition 4 is extreme in one location only, as defined by the plane of maximum tilt of Part R0019602.

All values of radial gaps, in specific locations and under cited conditions, are summarized on Page 6 .

Computation of radial gap values are to be found on Pages 7 through 32. 


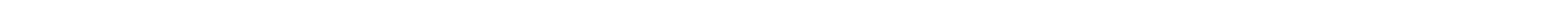




\section{COMPUTATION}

A. CONDITION 1

All parts are concentric, and axes are parallel. This is an ideal condition. Clearance values are nominal. 
N266ER000-001

Page 216

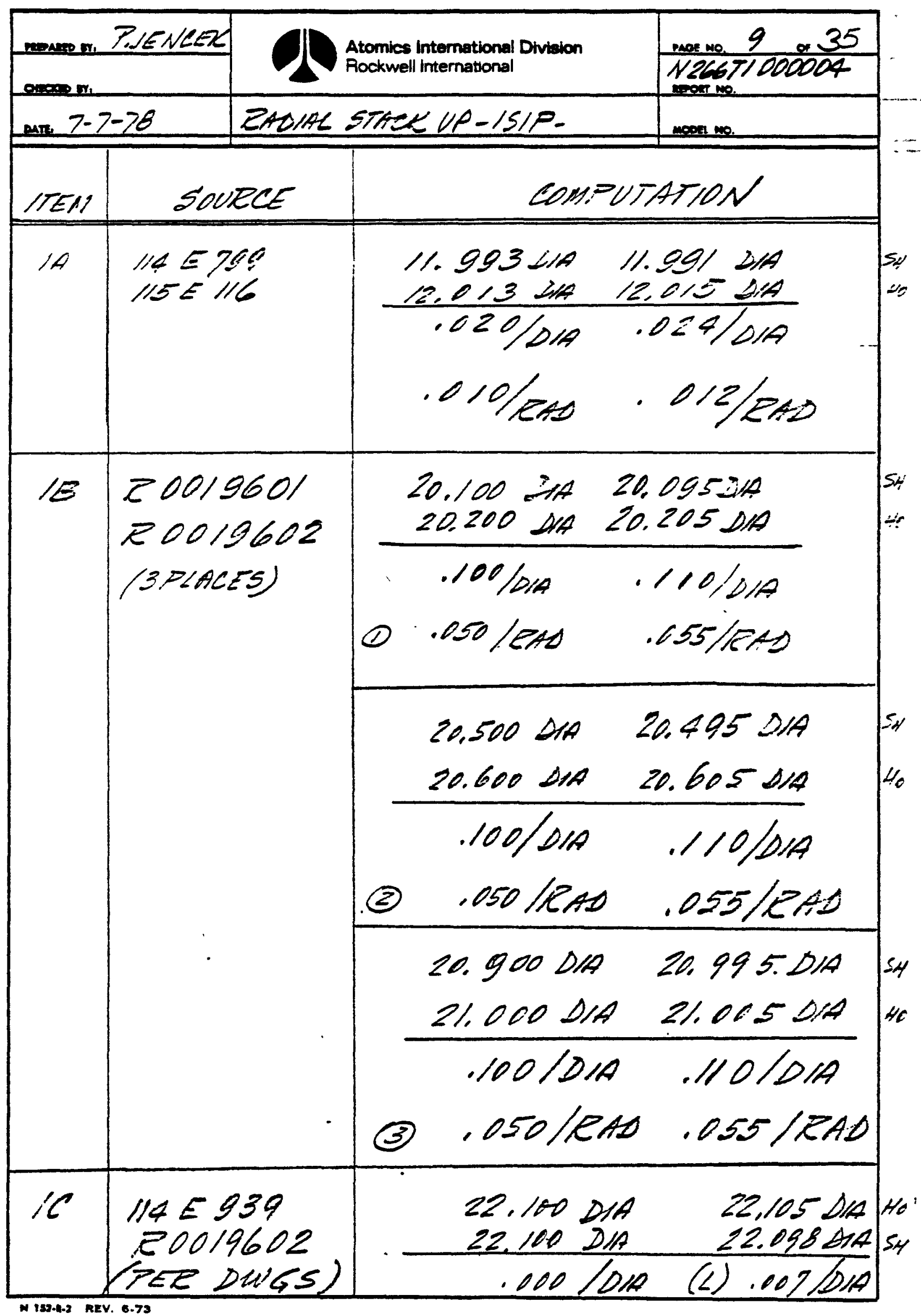


N266ER000-001

Page 217

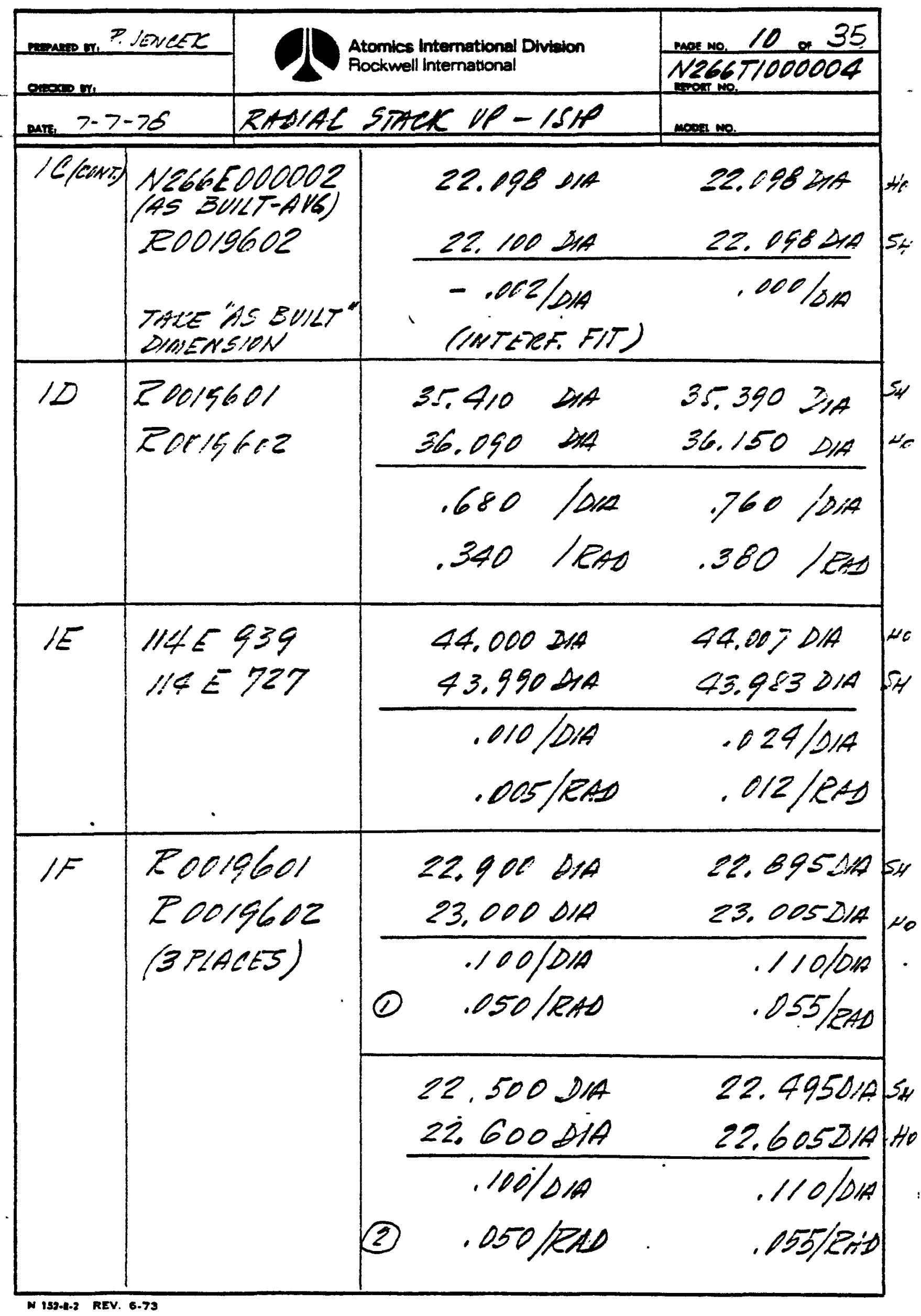


N266ER000-001

Page 218

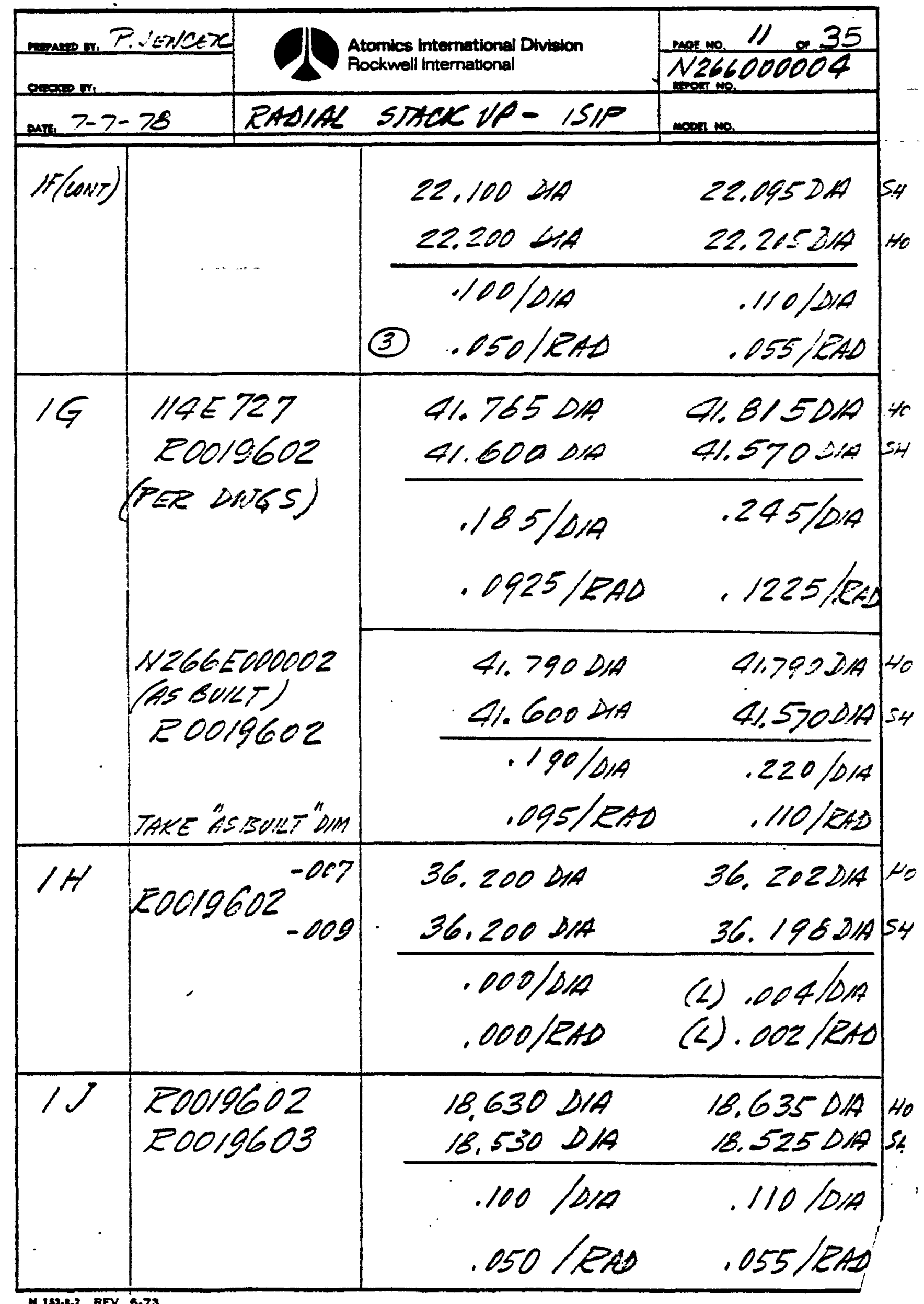




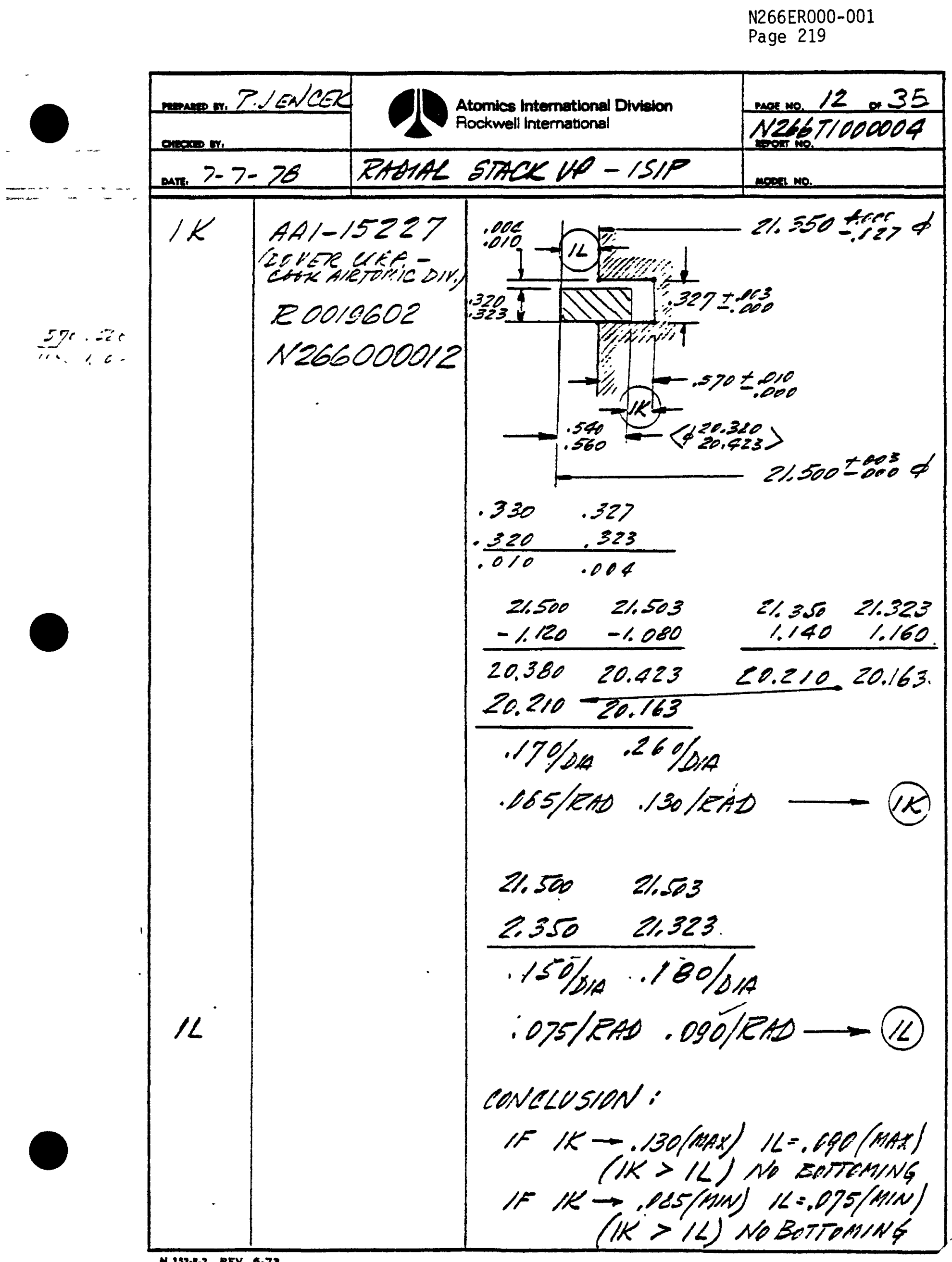


N266ER000-001

Page 220

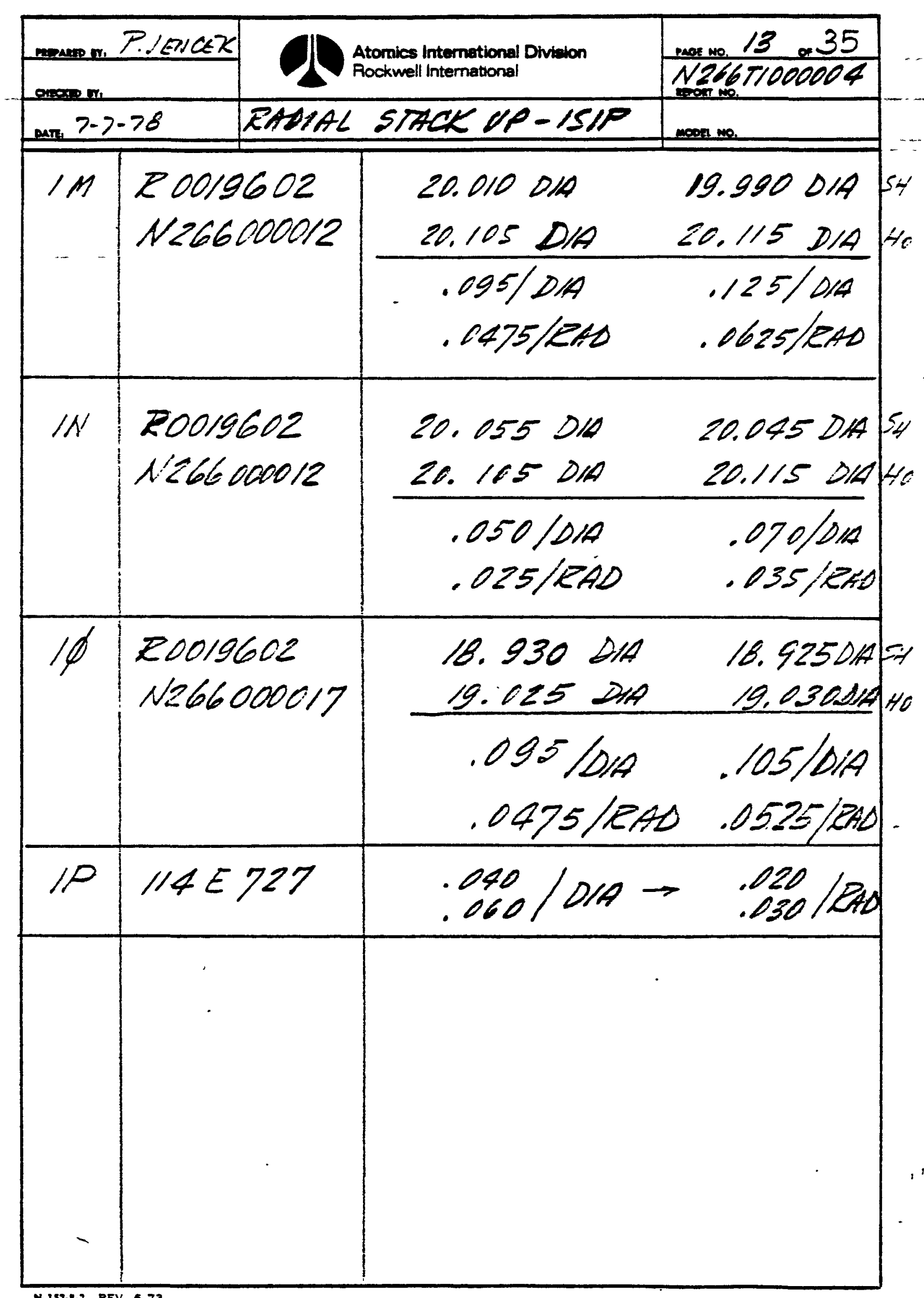


B. CONDITION 2

1) The shaft moves parallel within the bearing by .012 in. for metal - to metal contact. During the pump operation, this repres ents an entry into the failure phase.

2) The static hydraulic moves parallel by . 012 against bearing support in the opposite direction of shaft movement.

3) Parts 114E939, 115E116, and R0019602 are thus approached from both sides to decrease radial clearances for same values as radial clearances increase $180^{\circ}$ apart.

4) The diffuser shroud moves Parallel by .002 relative to the diffus er. 


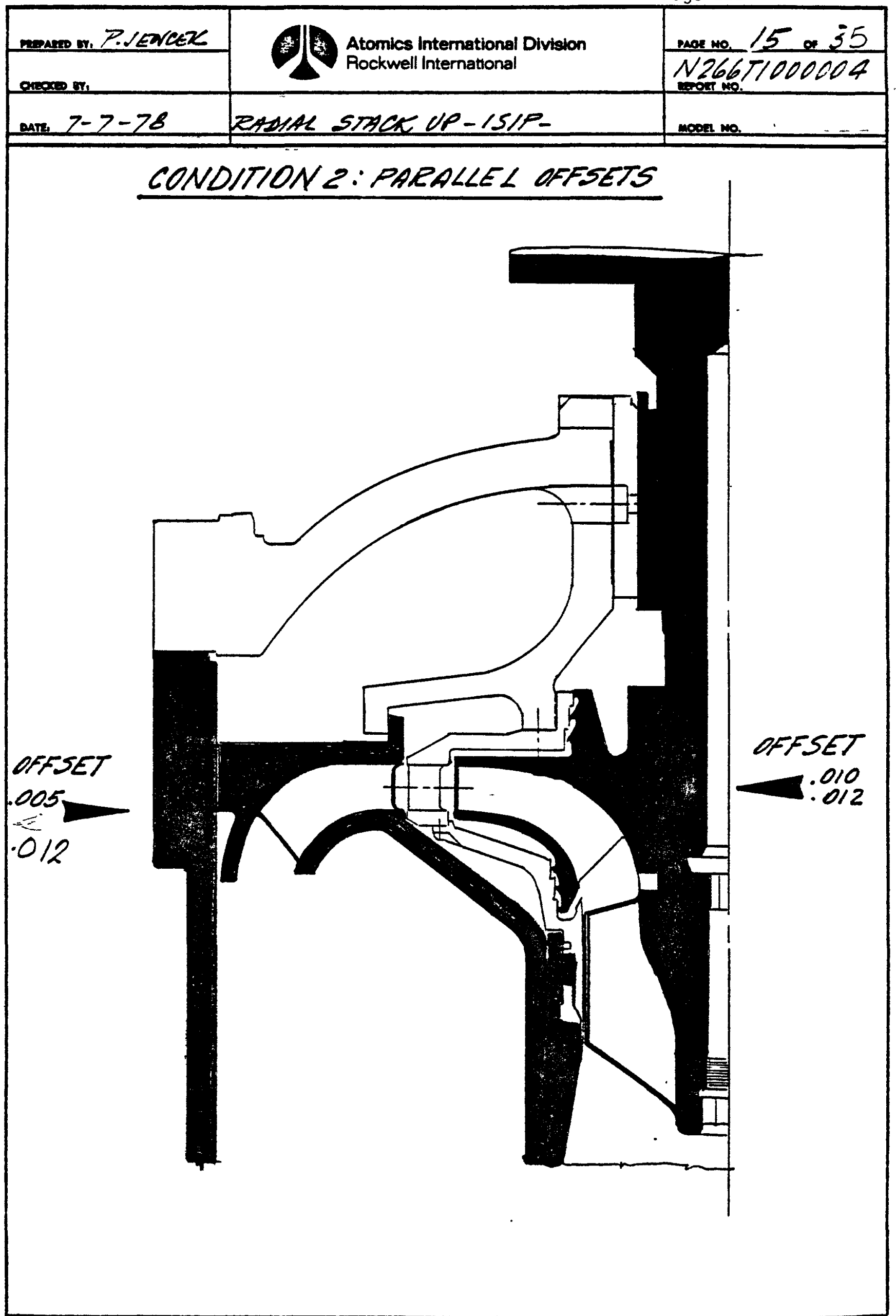


N266ERO00-001

Page 223

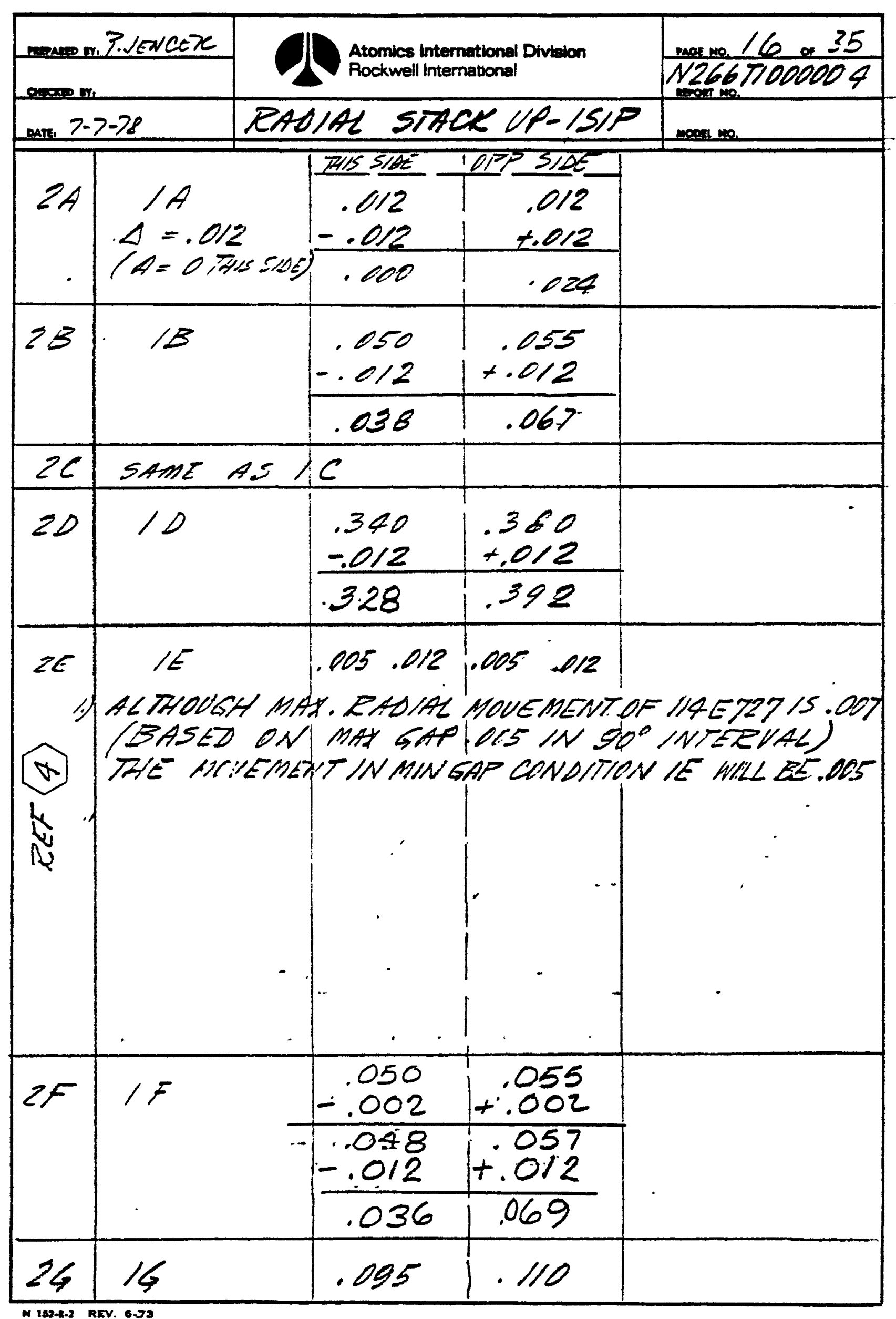


N266ER000-001

Page 224

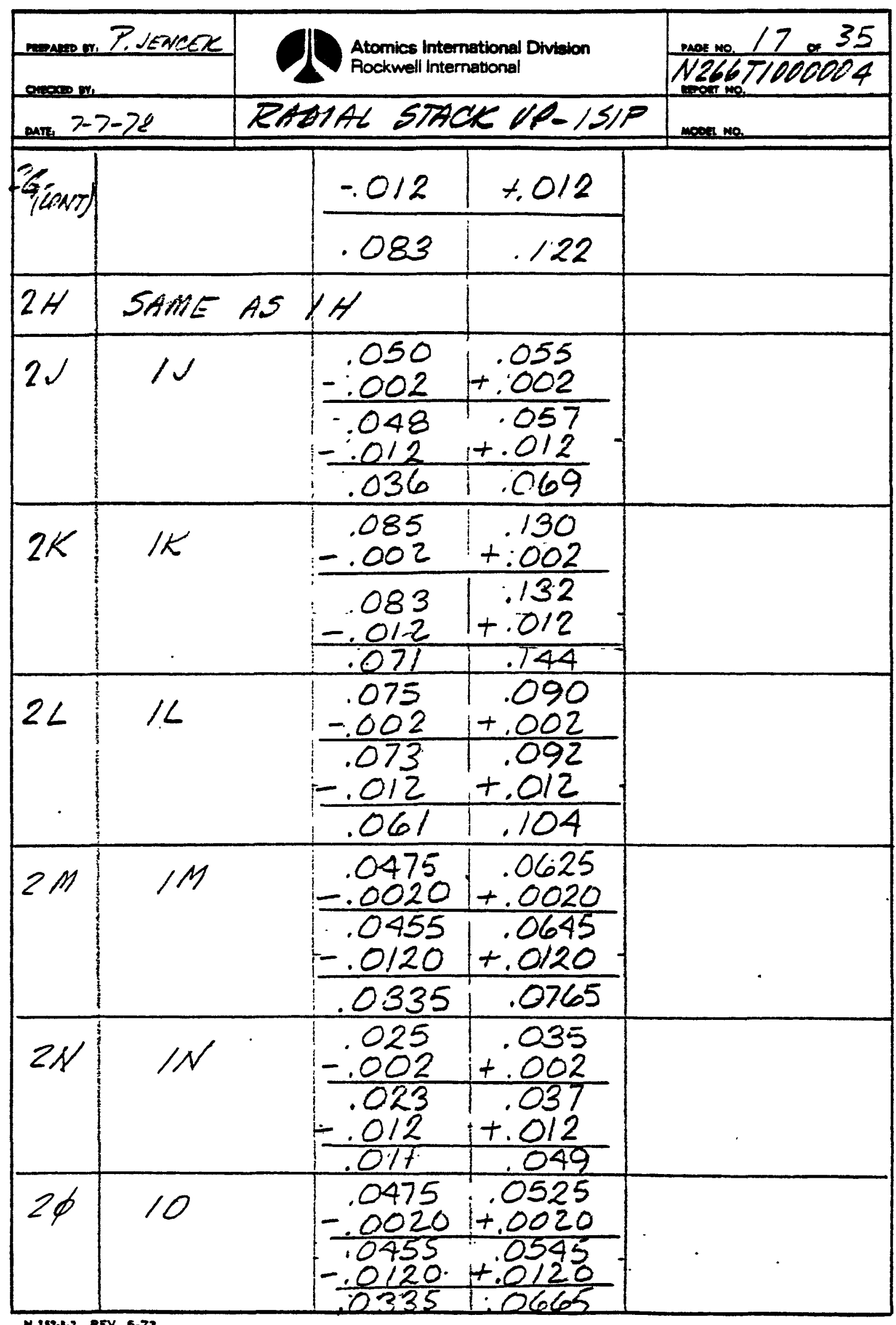




\section{CONDITION 3}

Due to normalcy and parallelism tolerances of Parts 114 E939 and 114E727, Part R0019602 is tilted. The origin of tilt is approximately at elevation of interface between Parts 114 E939 and 114 E727.

Radial clearances are calculated by use of variable correction value as a function of distance from the tilt origin.

The resulting radial clearances of Condition 3 are compounded values including those of Condition 2. 


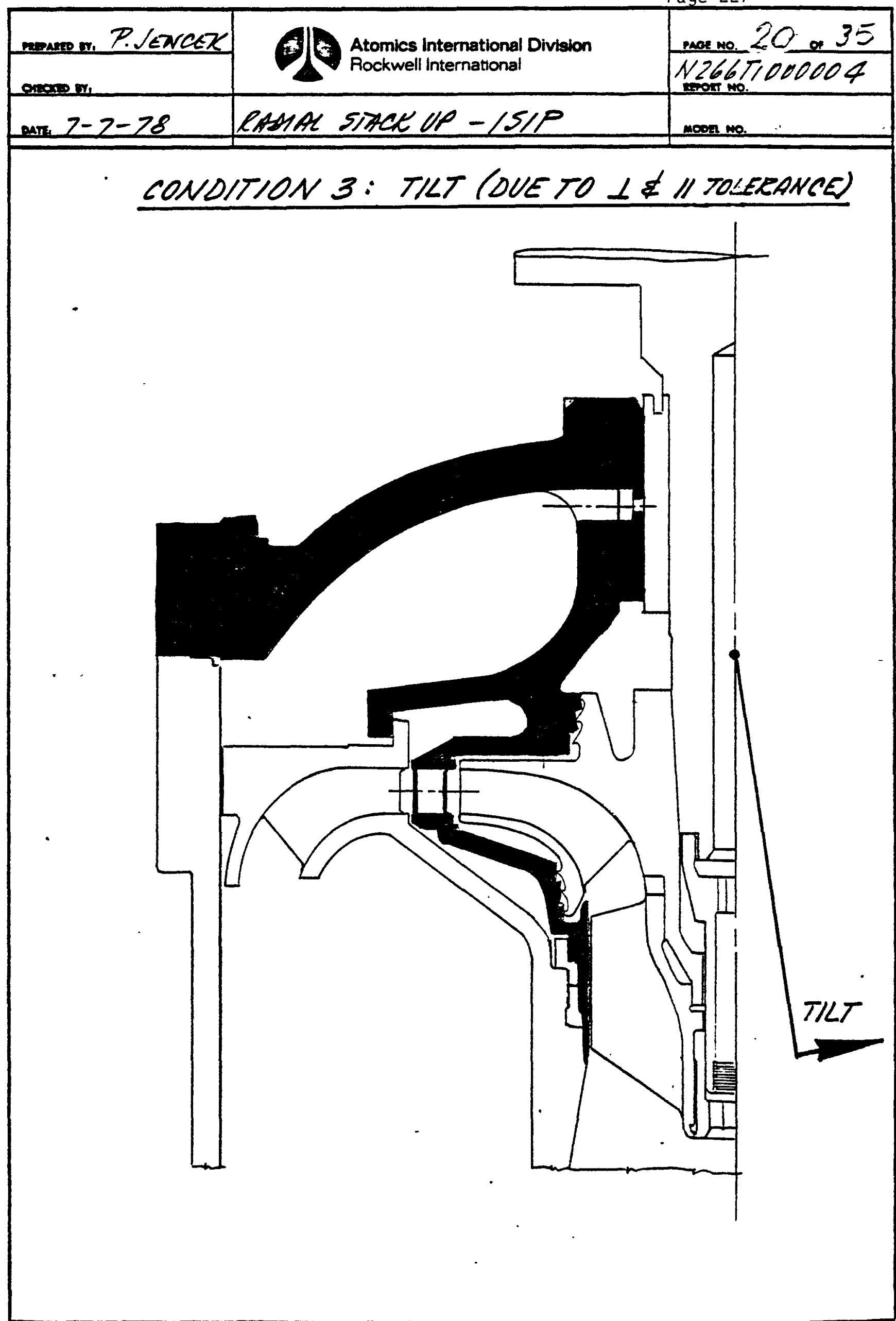




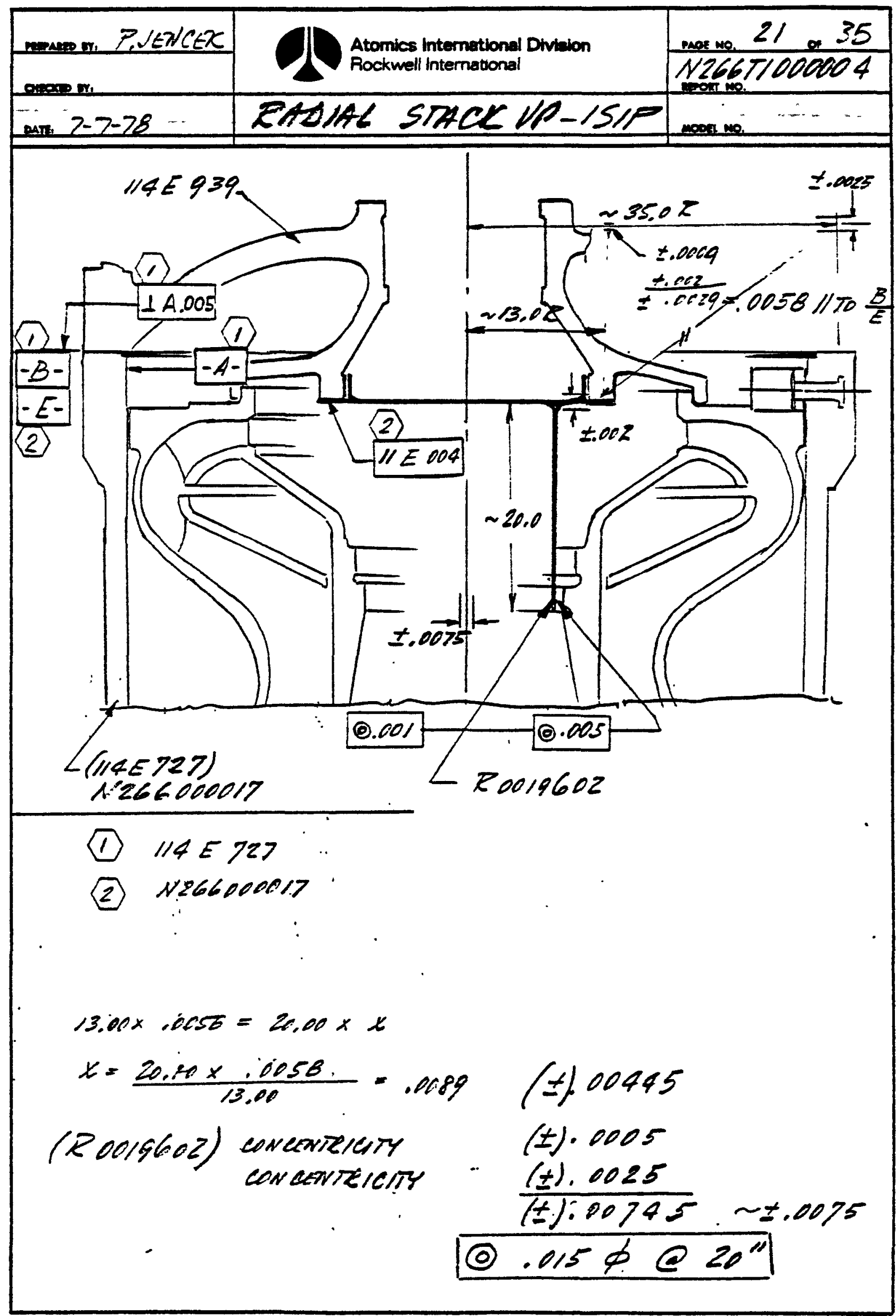


N266ER000-001

Page 229

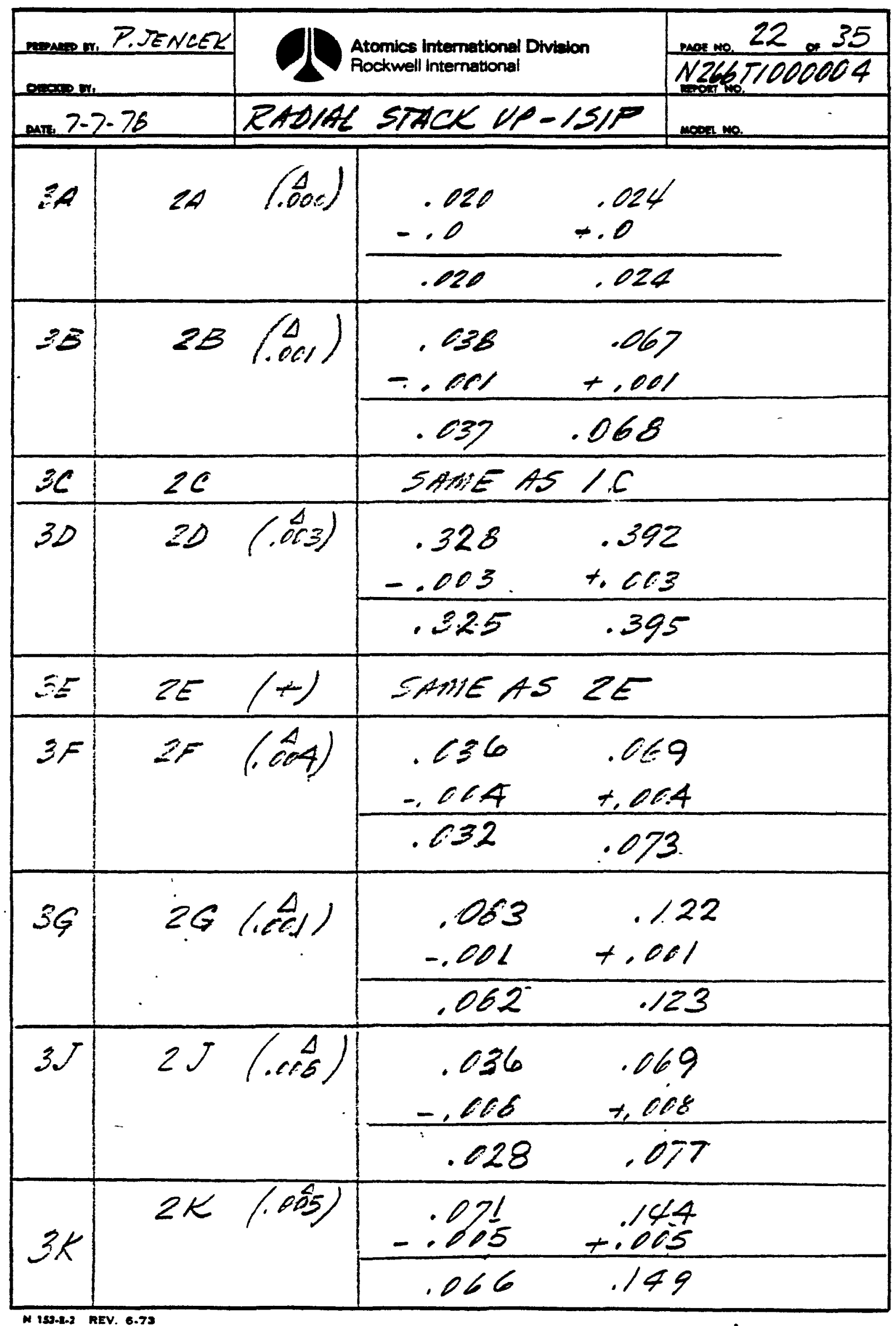


N266ER000-001

Page 230

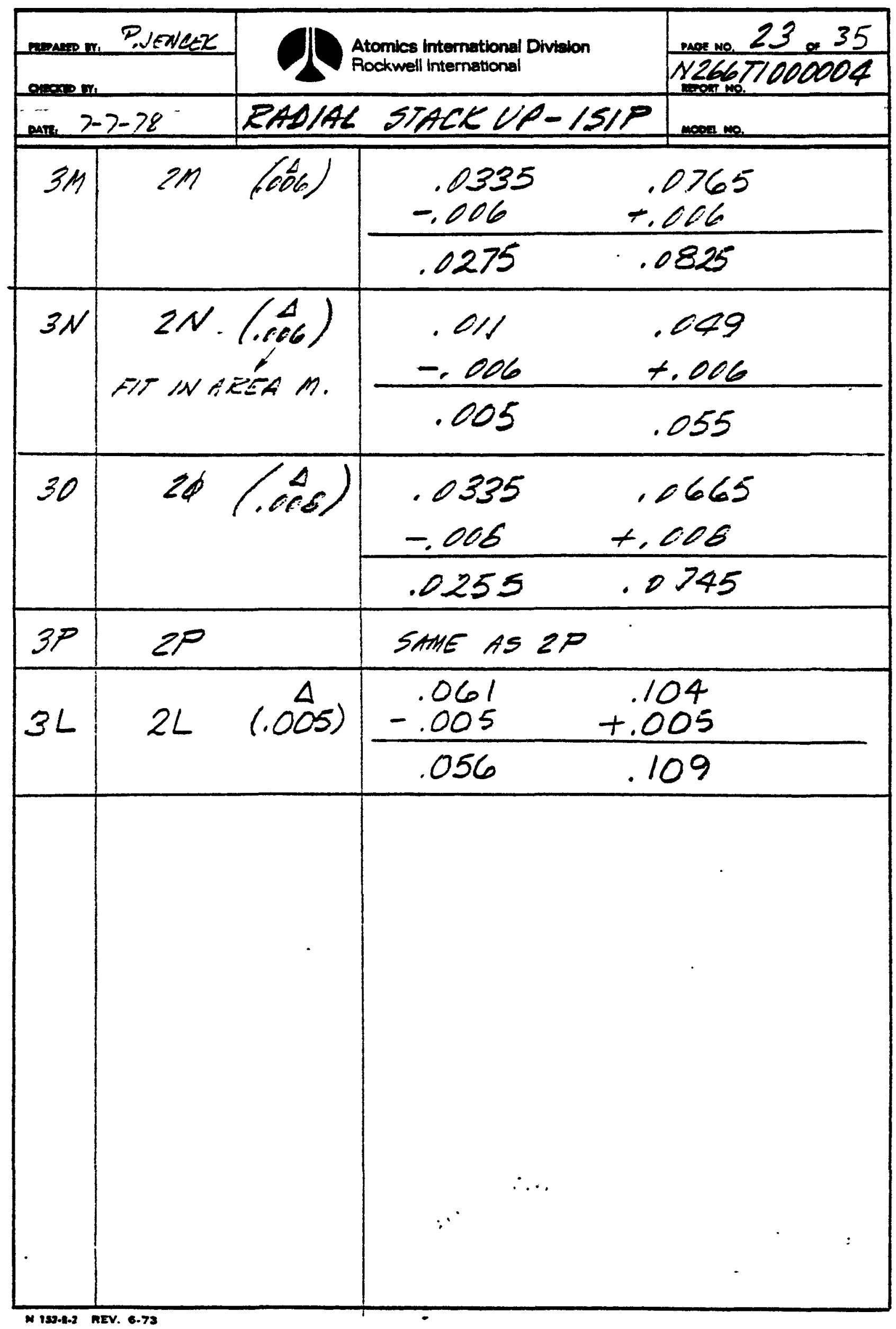


D. CONDITION 4

This condition compounds the effect of tilts, originating in concentricity tolerance callouts of Parts 114E799, R0019602, R0019603 on the radial stackup of values of Condition 3 . Considered are:

1) Concentricities of the shaft taper to the axis of shaft rotation (male taper).

2) Concentricity of the impelier taper ends (female taper).

3) Concentricity and diametrical clearance of two (male) impeller pilots and normalcy of impeller interface plane against the inducer - extrapolated and related to axis of rotation.

4) Concentricity of two (female) pilots and normalcy tolerance of mating plane for the inducer interfacing with the impelier - extrapolated to lower end of the full inducer vane diameter and related to axis of rotation.

5) Item 4 is then related to tilted Part R0019602 from Condition 3. 
N266ER000-001

Page 232

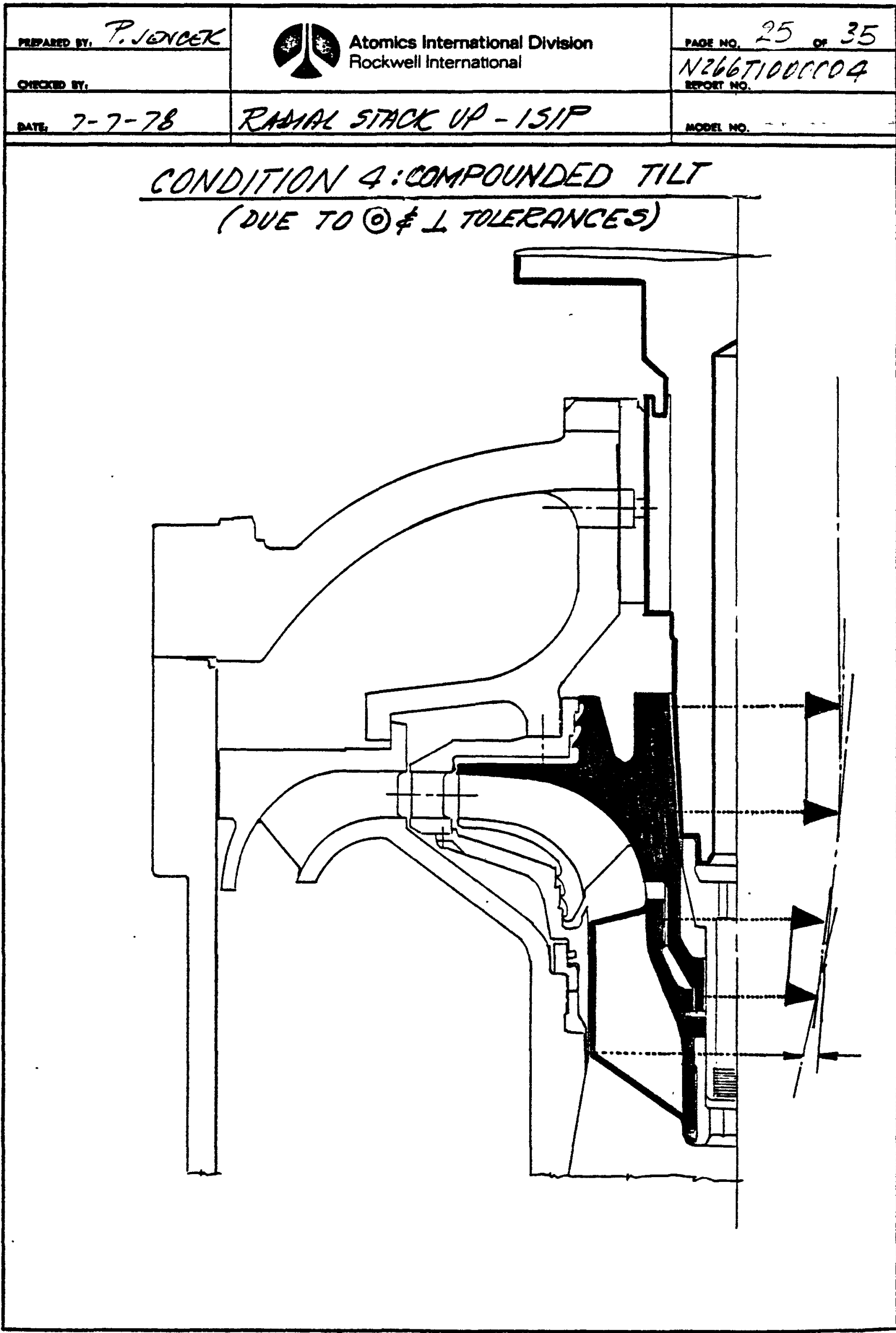


N266ERO00-001

Page 233

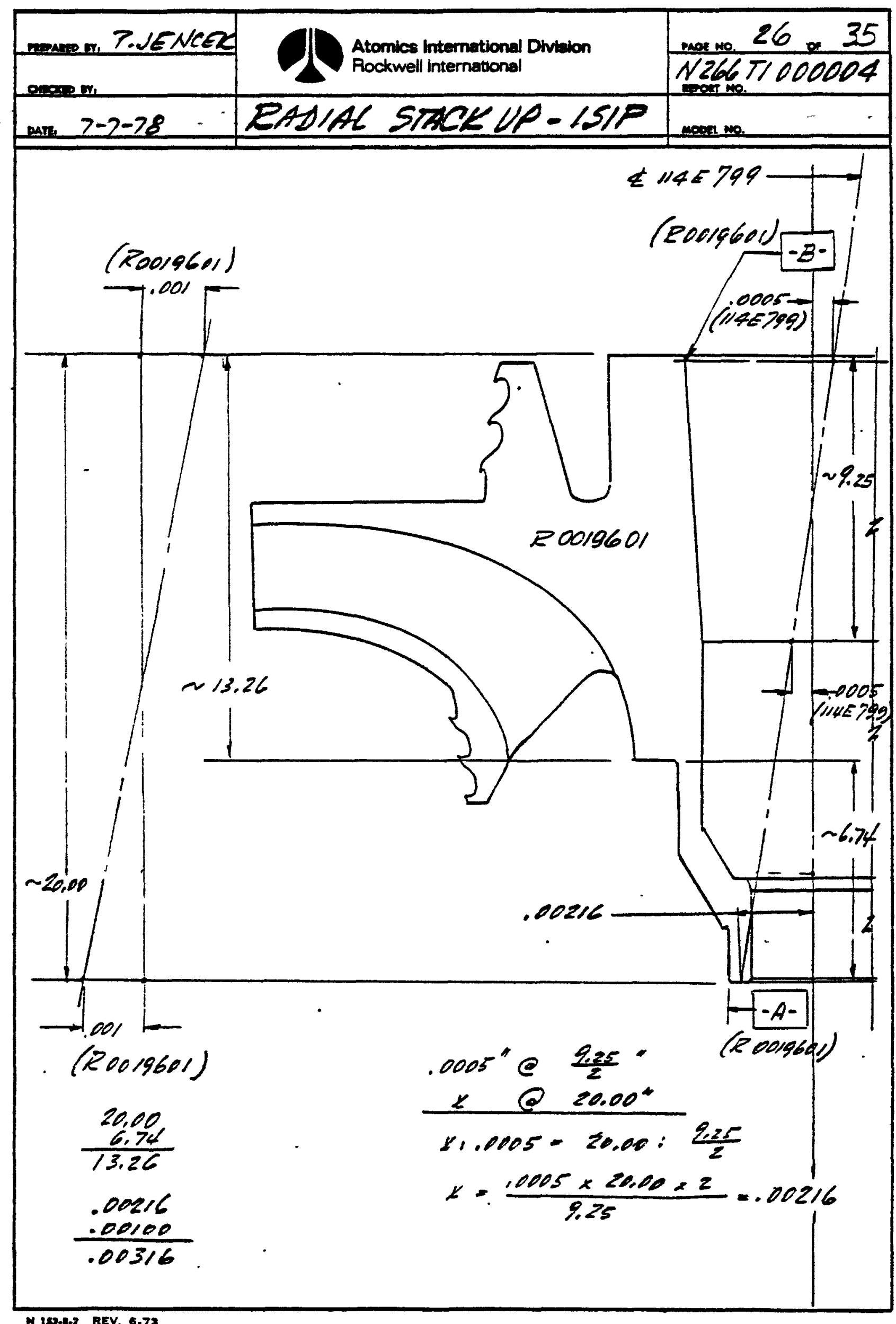


N266ER000-001

Page 234

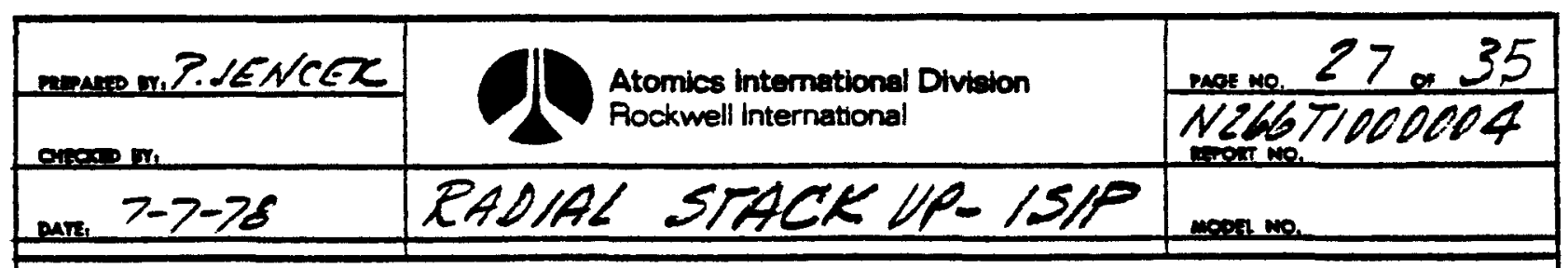

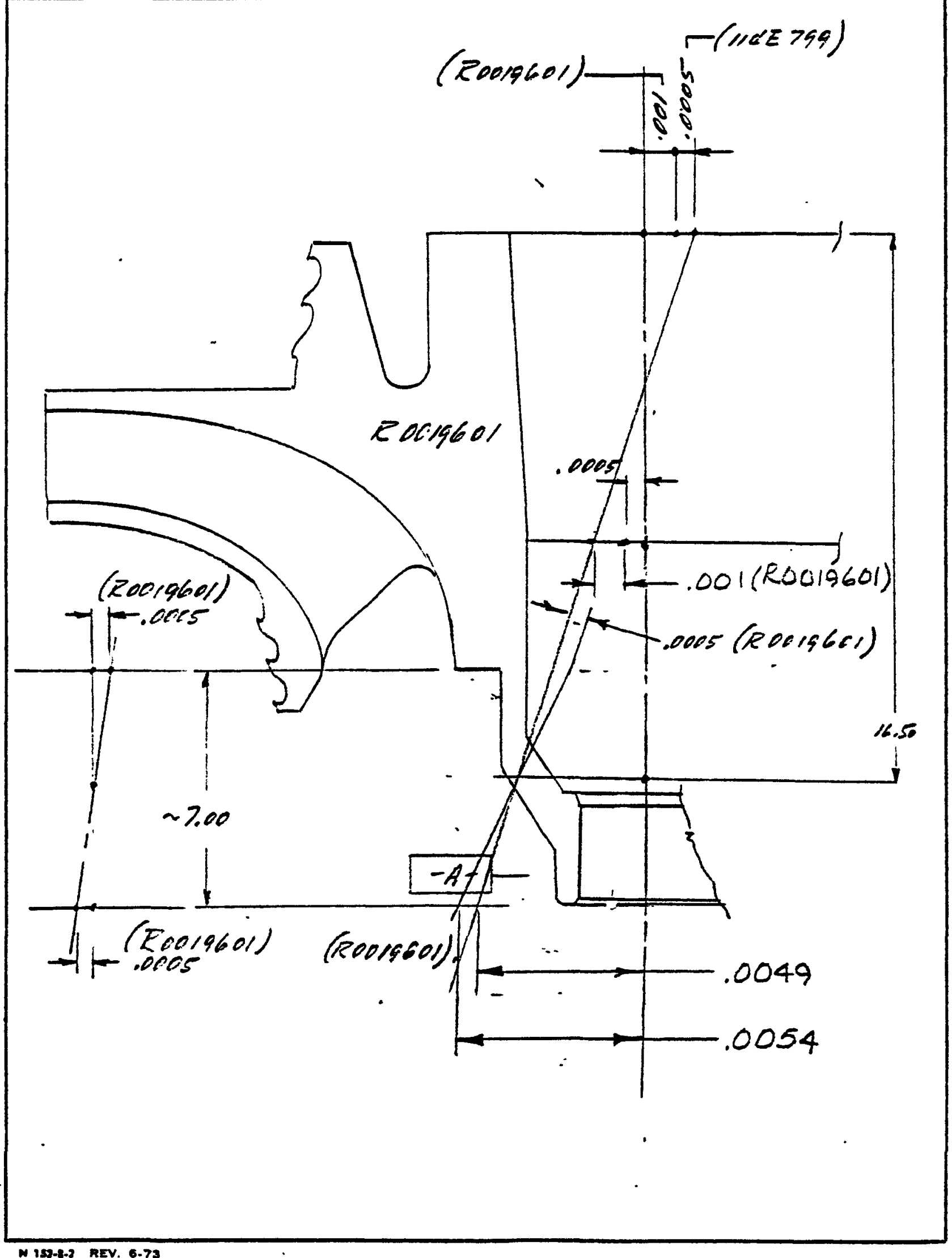




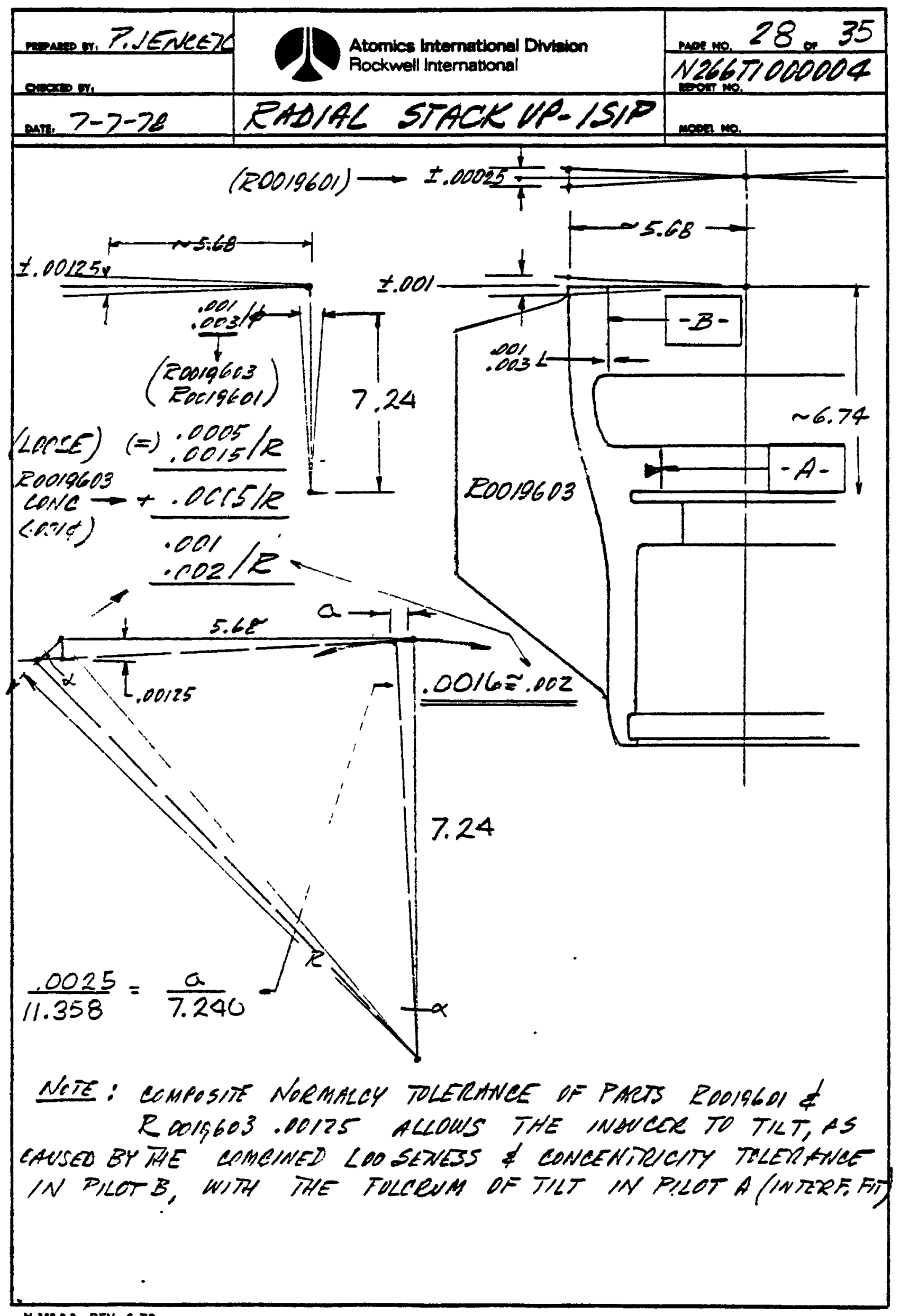


N266ER000-001

Page 237

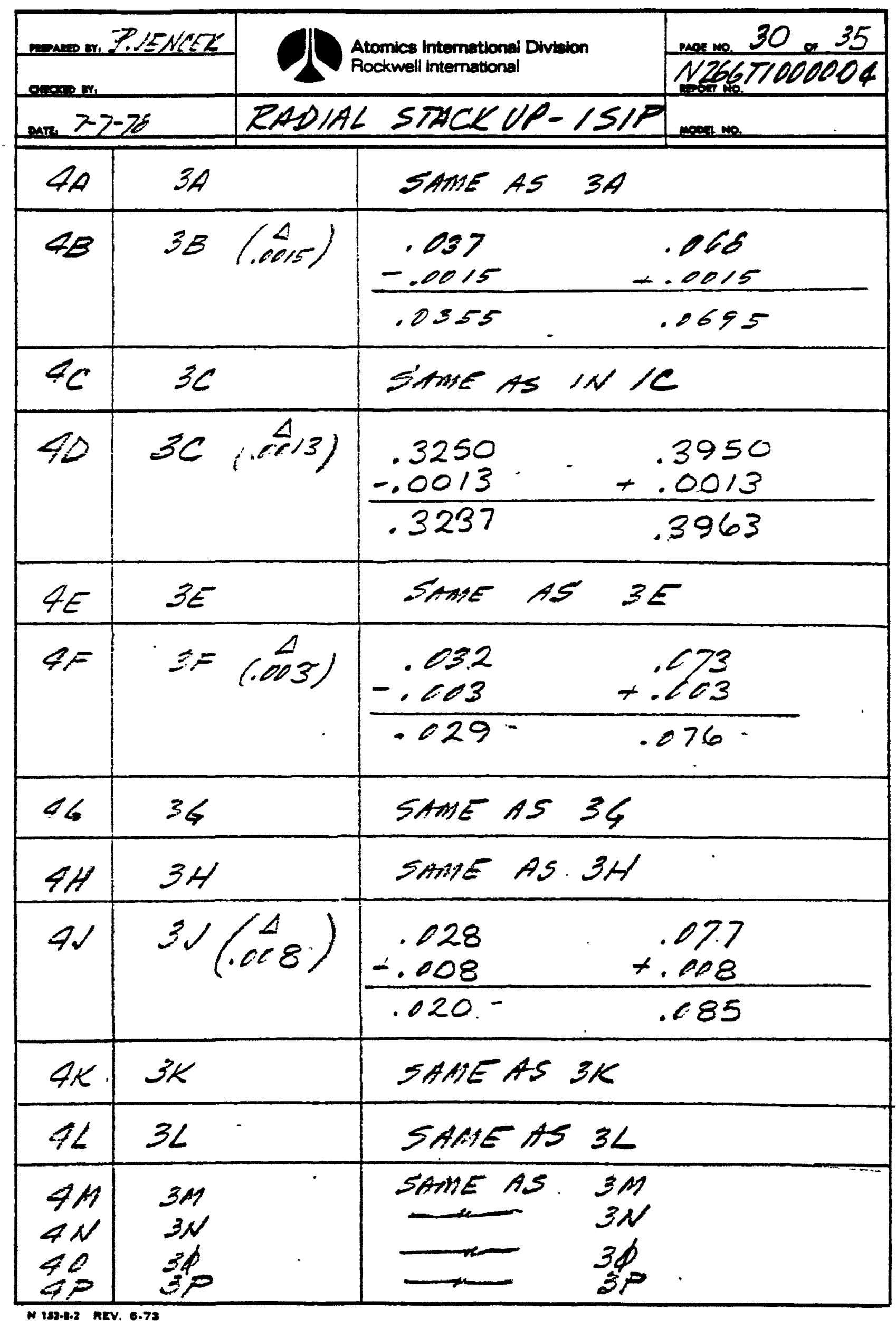


1) There is an .008 addition tolerance due to accumulation of tolerances in those portions of the pump above the bearing which had not been taken into consideration previously. 
Page 239

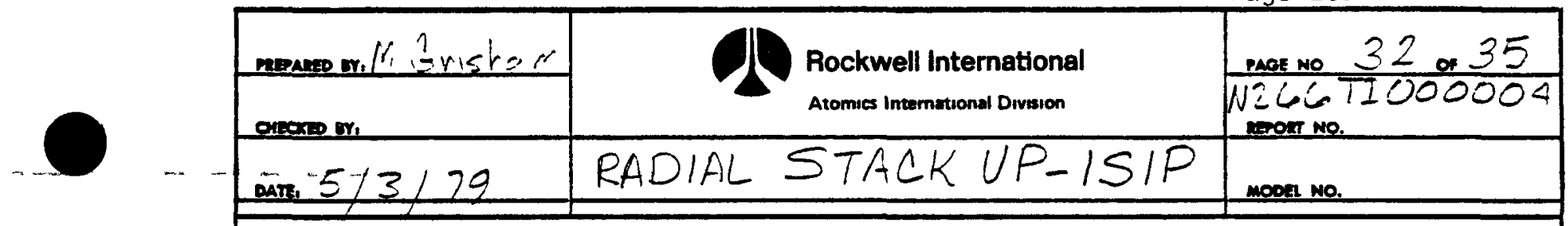

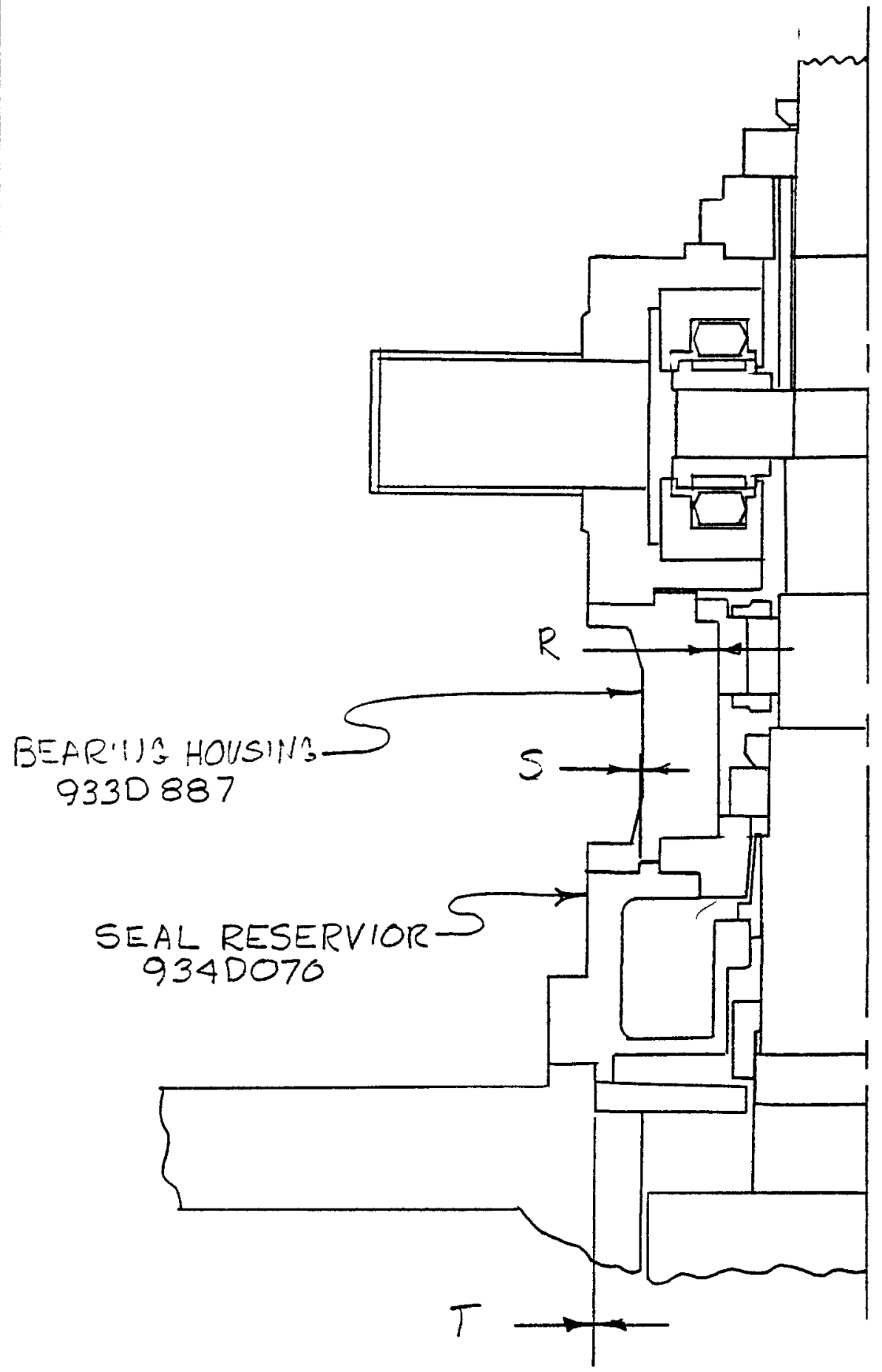




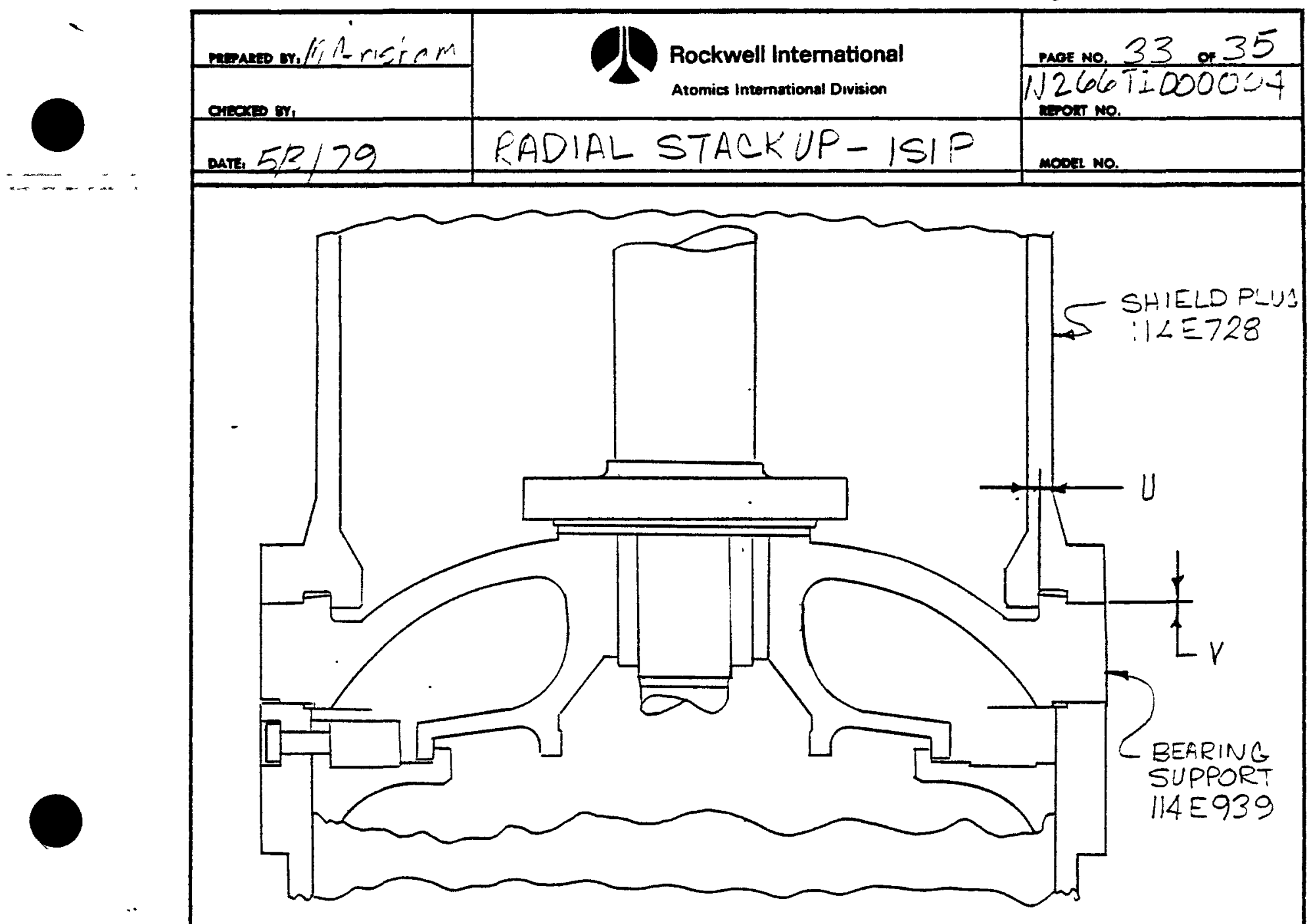


N266ER000-001

Page 242

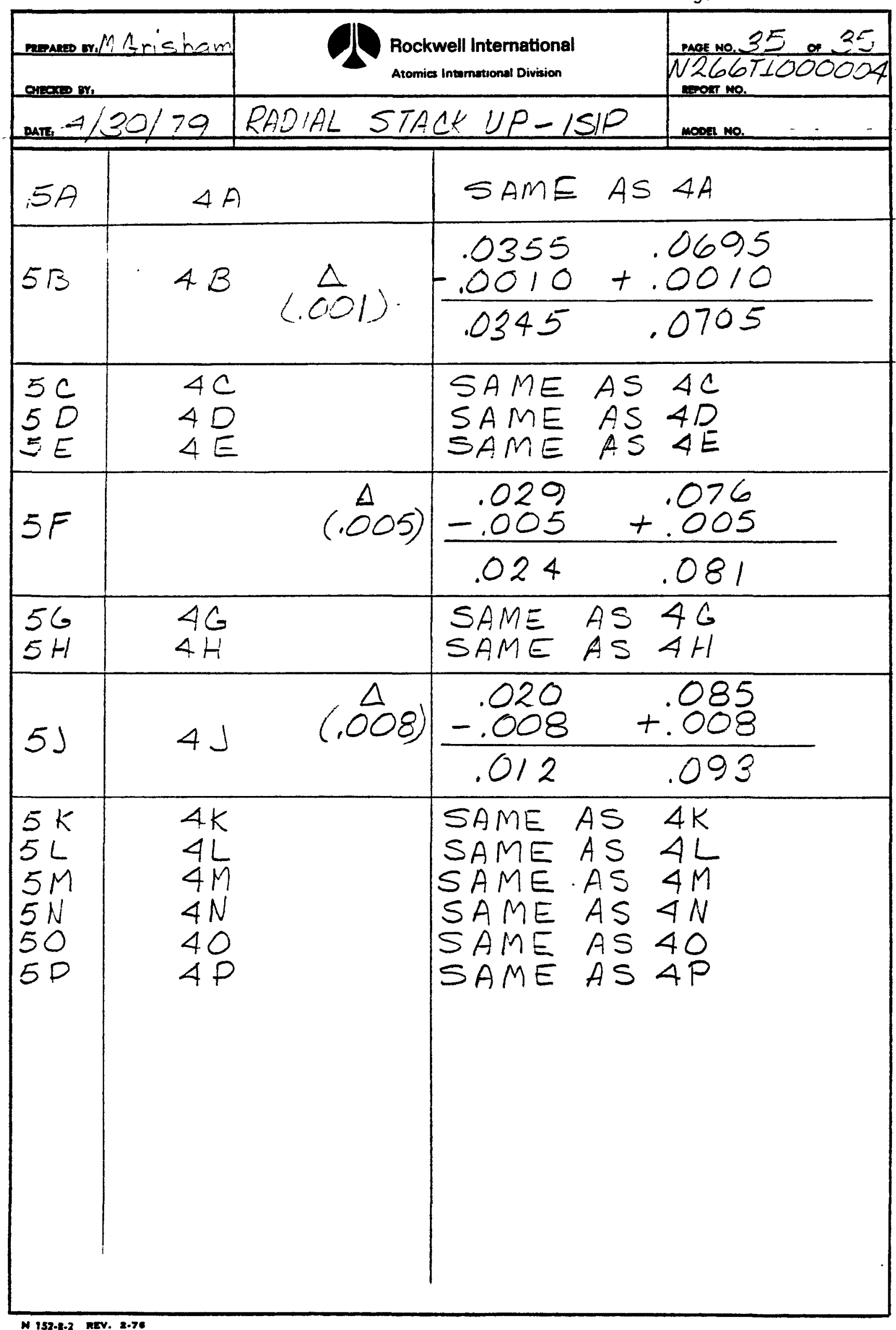




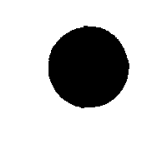

Rocketdyne Document R/H 8113-3630

(Assigned ESG Document number is N266ER000-002) 


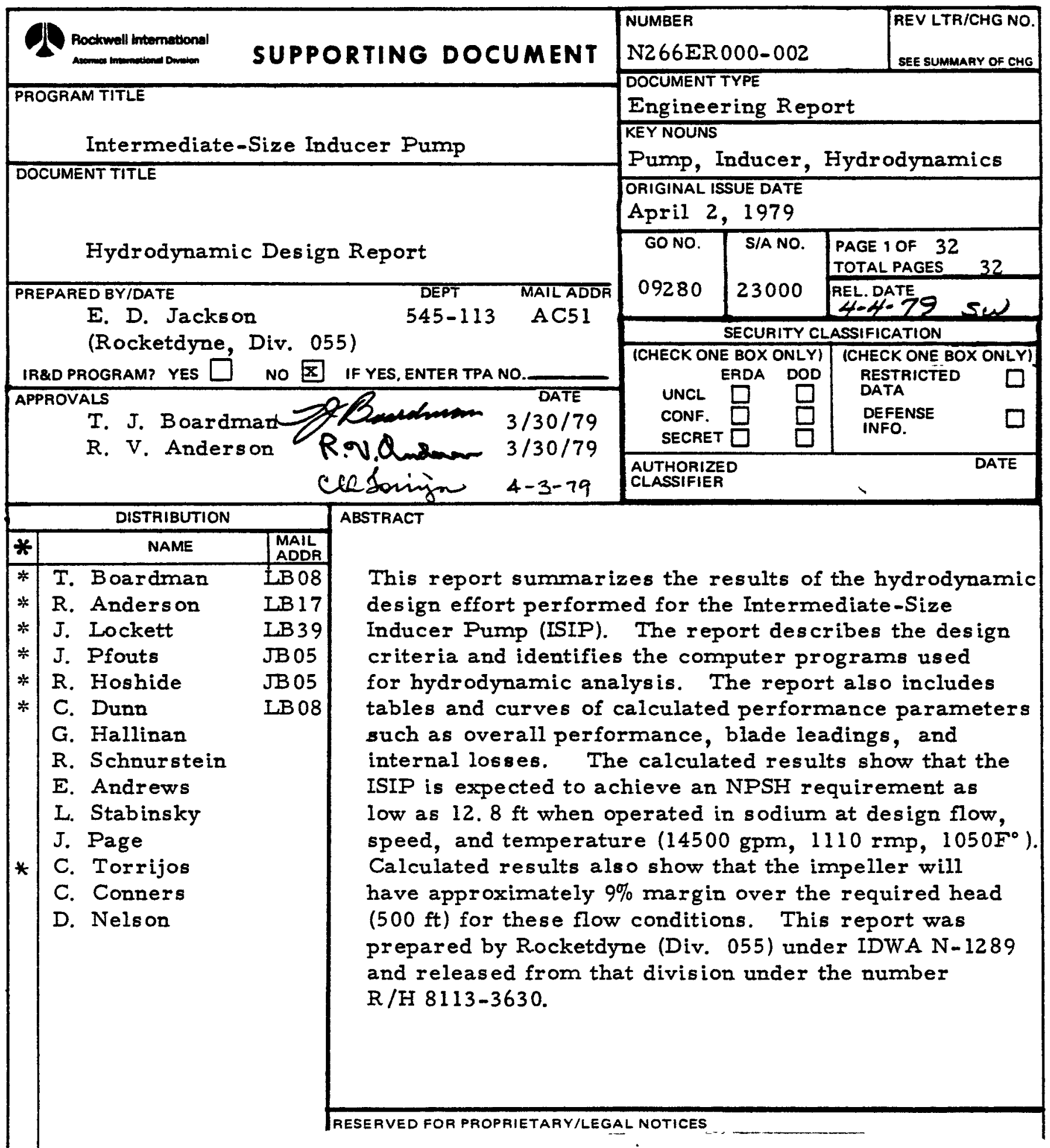

THIS REPOIRT MAY NOT BE PUBLISHED WITHOUT THE APPFIOVAL $F F$ THE PATENT BRANCH, DOE

This report was prepared as an account of work sponsored by the United States Governmi, $t$. Neither the U. \& Covernment, nor any of its employees ror any of its contractors, subcori., ars, or their employees, makes any warranty, express or implied, or a cumes any legal liability or responsibility for the accuracy, completeniss or usefulness of any information, apparatus, product or process disclosed, or represents that its use would not inirnge privately owned rights. 
$\mathrm{R} / \mathrm{H}$ 8113-3630

26 Apri1 1978

HYDRODYNAMIC DESIGN REPORT

INTERMEDIATE SIZE INDUCER PUMP

FOR SODIUM OPERATION

CONTRACT EY-76-C-03-0824

\author{
Prepared for \\ ATOMICS INTERNATIONAL DIVISION \\ ROCKWELL INTERNATIONAL CORPORATION
}

Prepared by:

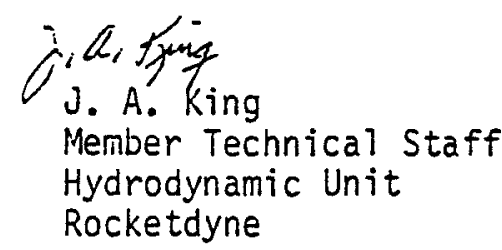

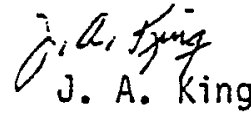

Member Technical

Rocketdyne

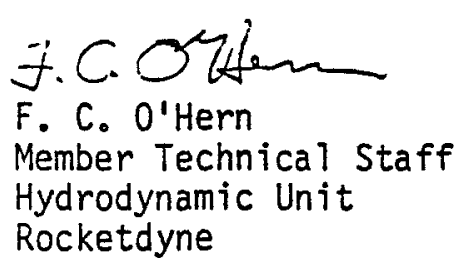

Hydrodynam

Rocketdyne

Approved by:

Rocketdyne

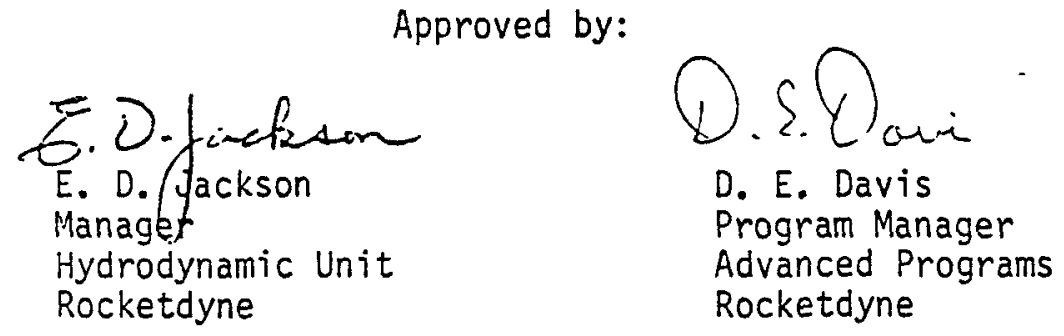

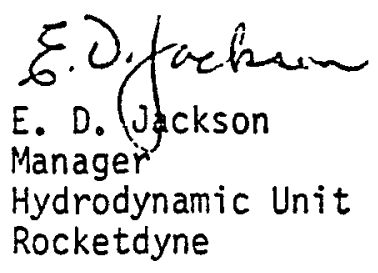


INTRODUCTION

The Intermediate-Size Inducer Pump (I.S.I.P.) was designed to operate in the existing FFTF pump housing and to achieve the required pump head rise at the same speed and flow as the existing pump. The existing pump consists of four basic hydrodynamic elements:

1. Inlet Elbow

2. Centrifugal Impeller

3. Vaned Diffuser

4. Discharge Housing

All of these elements except the centrifugal impeller were to be retained in an unmodified form for the I.S.I.P. design. The centrifugalimpelier was to be replaced with a new design consisting of both an inducer and centrifugal impeller. The objective is to demonstrate the capability of designing an inducer pump for long life in sodium operation so that the advantages of the inducer pump can be realized in future sodium pump applications. These advantages consist primarily in the smaller envelope size and lower weight realized as a result of the better suction performance capability of the inducer. These advantages result in significant cost savings and ease of fabrication and handing for the very large pumps required in many of the reactor coolant loop systems.

The vaned diffuser in the existing design attempts to diffuse the flow while turning it which typically limits the stable range of operation. Tests of the existing pump have demonstrated instability at a flow of approximately seventy percent of the design flow. The I.S.I.P. design must use this same diffuser, therefore to attempt to extend the stable operating range, Rocketdyne has chosen to design the centrifugal impeller to a smaller outer diameter to leave sufficient space to add an intermediate vaned diffuser upstream of the existing diffuser. This new diffuser would be designed to operate over a wider flow range and should provide a wider range of stable operation for the overall pump. 
Thus, the I.S.I.P. design consists of three new hydrodynamic elements:
1. Inducer
2. Centrifugal Impeller
3. Intermediate Vaned Diffuser

This report describes the hydrodynamic design features of each of these. . The report also discusses the design rationale and methods of analysis. Following this, the hydrodynamic performance of the design is presented and compared with the design specification.

The specified sodium characteristics used in the design are:
Fluid Inlet Temperature $=1050^{\circ} \mathrm{F}$
Fluid Specific Weight $=50.97 \mathrm{lb} / \mathrm{ft}^{3}$ 
SUMMARY

An inducer pump has been designed to fit within the existing housing of the FFTF facility. The new design consists of three primary hydrodynamic components: An inducer, centrifugal impeller, and intermediate vaned diffuser. The hydrodynamic design of each component has been based on the design procedures and analytical techniques developed over a twenty-five year period and proven to be accurate by detailed comparison with test data.

The design has been shown to meet the specified requirements in every area where an analytical prediction of the performance can be made. The head-rise and efficiency of the pump have design margins so that the calculated values actually exceed requirements over the full range of operation. The suction performance of the design provides a very large margin at the operating NPSH value which is the major advantage of using the inducer pump. The suction performance margin at off-design is estimated to be adequate for suction performance, but may not be as large as desired for life considerations. Testing of a model inducer is required to verify the suction performance at off-design and to evaluate the life potential. Operation of an impeller pump with similar margins would also require test verification of the life potential.

The design has incorporated features that provide for long life at the design point. These features have been established based on proven performance of commerical waterjet pumps designed by Rocketdyne. Each of the major design parameters contributing to long life fall within the range of previously verified designs except for a somewhat larger tip clearance. Analysis has indicated that the tip clearance is acceptable. 
Inducer

Figure 1 shows a layout of the pump configuration indicating the various hydrodynamic components to be discussed. The inducer design was based on the same design practices established and demonstrated by the successful waterjet inducer designs at Rocketdyne.

The inducer was designed with four blades to minimize the potential of tip vortex collapse on the blade surface and thereby eliminate collapse damage. The four-bladed design also provides minimum potential for radial loads for any NPSH margin provided to the inducer. The envelope of the pump was sufficient to handle the required length of the inducer using only four full blades without any partial blades. Elimination of the partials ', improves confidence in achieving the long life required.

The inducer tip diameter was designed to be 18.53 inches, an unshrouded tip configuration being used to achieve cavitation collapse in the fluid passages and not on the blade material. The tip diameter was dictated by three factors:

1. The existing housing outer diameter.

2. The required operating clearance of $0.050 \mathrm{in}$. radial.

3. The need to provide a smooth wall contour over the inducer tip.

The longer length of the four-bladed inducer requires it to extend beyond the point where the leading edge of the existing impeller was located. As a result, if the existing housing were used without a liner over the tip of the inducer, a circumferential slot would occur over the inducer and could create cavitating vorticees which could-cause hardware damage. Thus, a liner was added to eliminate any slot over the inducer itself. 


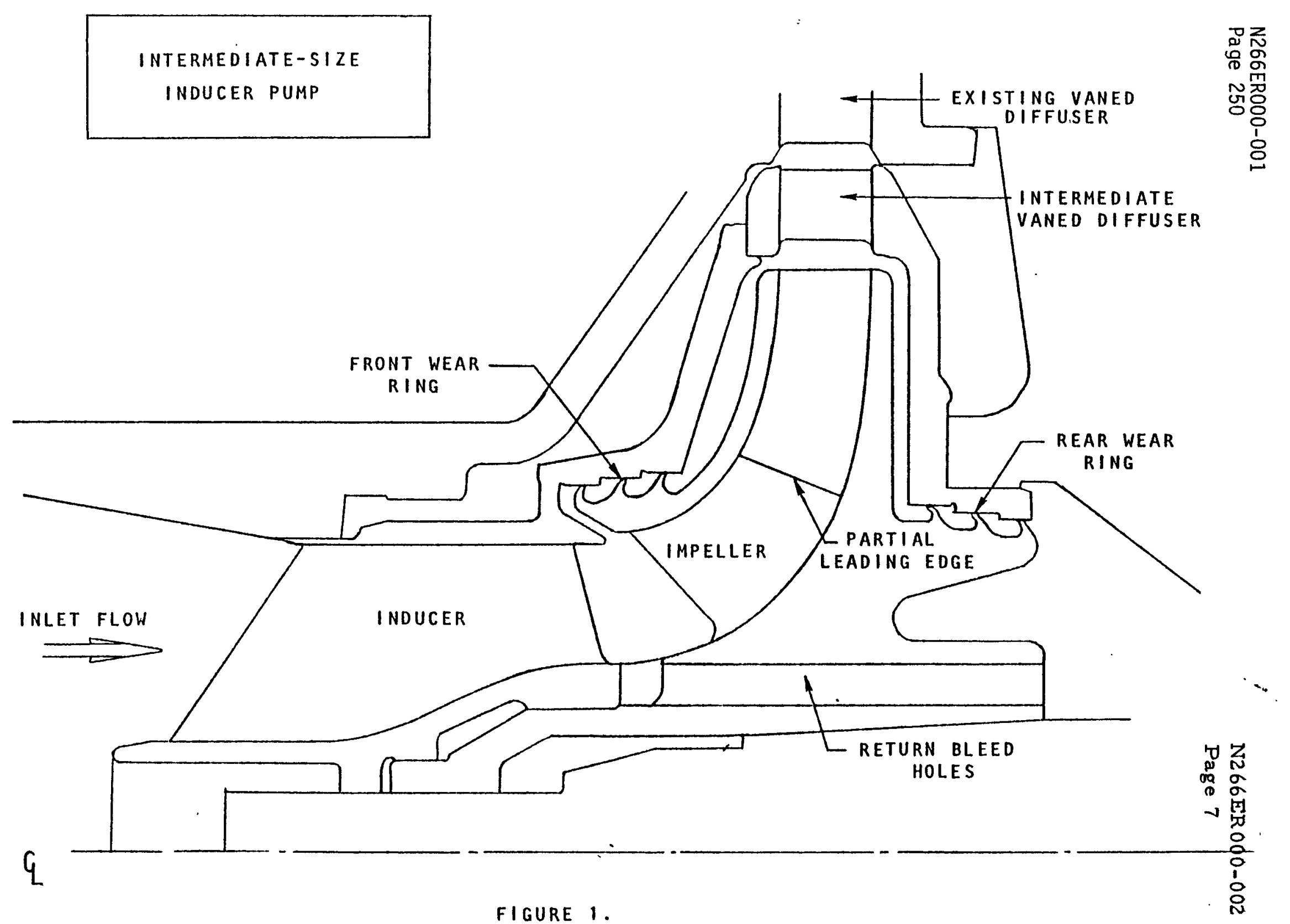


The required tip clearance is set by the rotor dynamics of the pump in the facility. This clearance is somewhat larger than values commonly achievable in waterjet practice. However, the effect of the larger clearance was included in both the performance and life analyses. To further avoid any potential for rubbing at the tip, the blade was designed for zero cant angle so that any blade movement would not decrease the operating clearance.

The hub contour was selected to optimize the performance and match the required impeller inlet design. The hub diameter at the inlet is $6.626 \mathrm{in}$. giving a hub/tip diameter ratio of 0.358 . This inlet diameter is selected to achieve the desired suction performance and to maintain the flow coefficient in the region where confidence in long life is high. The discharge hub diameter is $11.358 \mathrm{in}$. and is selected for optimum efficiency of the inducer-impeller combination. The contour shape of the hub from inlet-to-discharge is based on established procedures optimized for achieving the proper head-rise distribution along the stream surfaces through the inducer.

The blade design includes such factors as leading edge blade angles, blade camber distribution, blade thickness distribution, leading-edge and trailing-edge sweep and blade solidities. These values are selected based on previous commerical experience, and in each case the I.S.I.P. values are consistent with waterjet design experience at Rocketdyne. The blade design is of primary importance in achieving

1. The optimum suction performance capability

2. The long-life with no detrimental blade damage

3. The required head and maximum efficiency

One of the results desired in the design is a head-rise distribution through the inducer that is monotonically increasing at a somewhat uniform rate. Figure 2 shows the result achieved in the I.S.I.P. inducer design 
ISIP INDUCER

PREDICTED HEAD RISE THROUGH INDUCER

(BASED ON R3DP)

$Q=14600$ GPM

$N=1110$ RPM

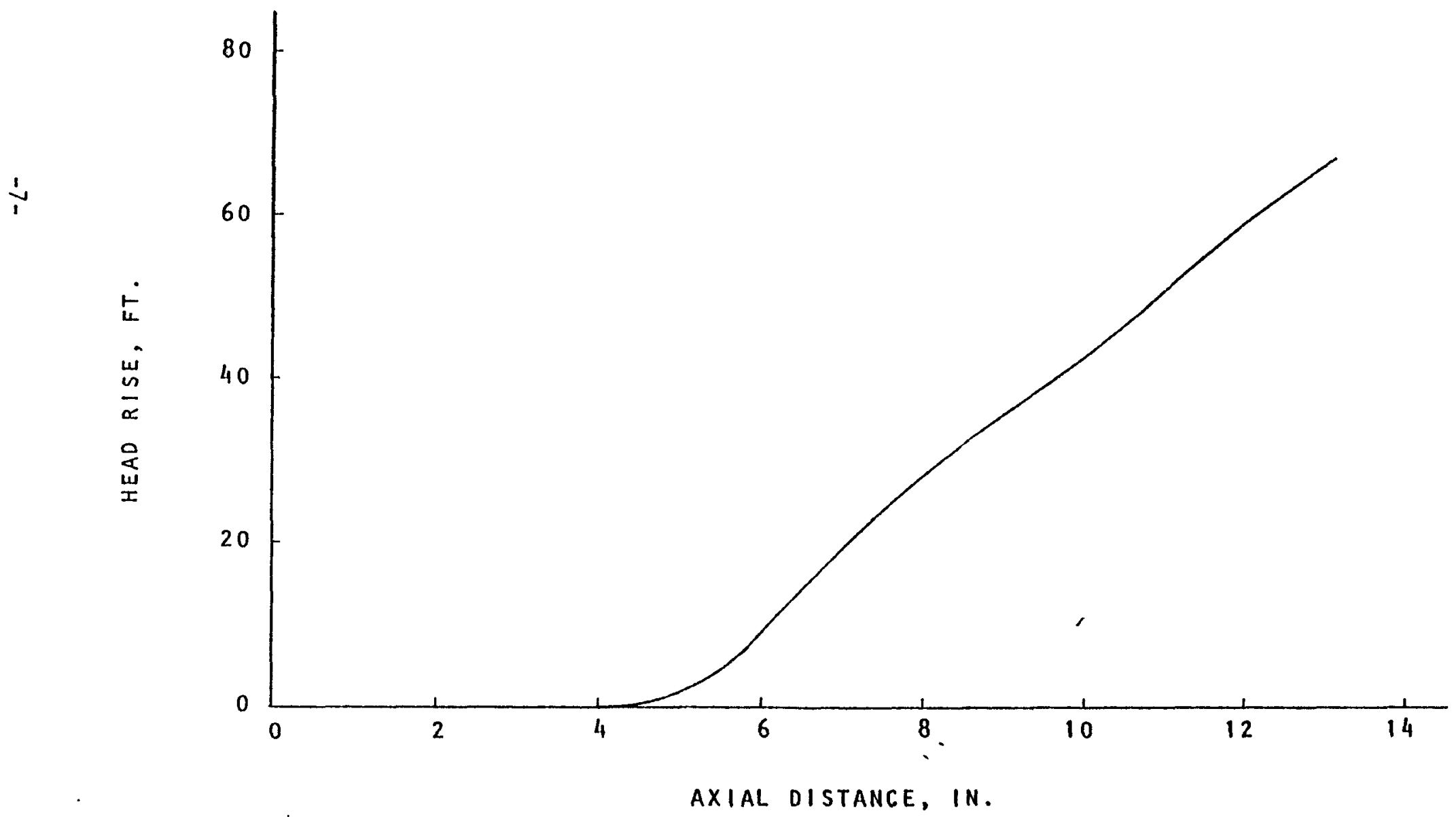

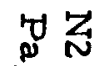

AXIAL DISTANCE, IN. 
indicating its agreement with this design criterion. It is also desirable to achieve a relatively uniform head distribution at the inducer discharge and impeller inlet. Figure 3 indicates that this was accomplished.

Five Rocketdyne computer programs were used in the hydrodynamic design and analysis of the inducer. The first was the nonisentropic radial equilibrium program (NISRE) which calculates the head-rise and meridional velocity leaving the inducer at all radii for a fixed (radial) blade. This was used in the preliminary design portion of the analysis to obtain the desired moderate blade loading.

After the blade meanline was calculated, an initial blade.thickness was assigned on the basis of past experience. The entire inducer geometry was then input into the three-dimensional anaiysis program. This program (unlike the NISRE) takes into account the curvature of the walls before, within, and following the inducer as well as the blade contours. It calculates the local static pressures on the suction and pressure sides of the blades at all stations and at all radij. These pressures are used to determine where the blade will cavitate and where the cavity will collapse. They are also used by Stress to determine the blade loadings from which the final blade thickness is determined. The program also calculates the head-rise at each streamline and the relative velocities entering the centrifugal impeller. These are used to determine the desired blade angles at this station.

The third program used was the blade leading edge loading program which calculates the loading on the leading edge wedge. This loading was combined with that of the three-dimensional analysis program and given to Stress. The combined loads at the design point are shown on Figure 4.

The fourth program predicts the jet stopping distance of a cavity progressing across the passage from the suction side of the blade to the pressure side. If the cavity travels as far as the pressure side of the next blade before collapsing, it might cause damage on that blade. 

N266ER000-001

Page 255
N266ER 000-002

Page 12

\section{ISIP FOUR-BLADED INDUCER \\ BLADE LOADING \\ $Q=14600$ GPM \\ $N=1110 \mathrm{RPM}$}

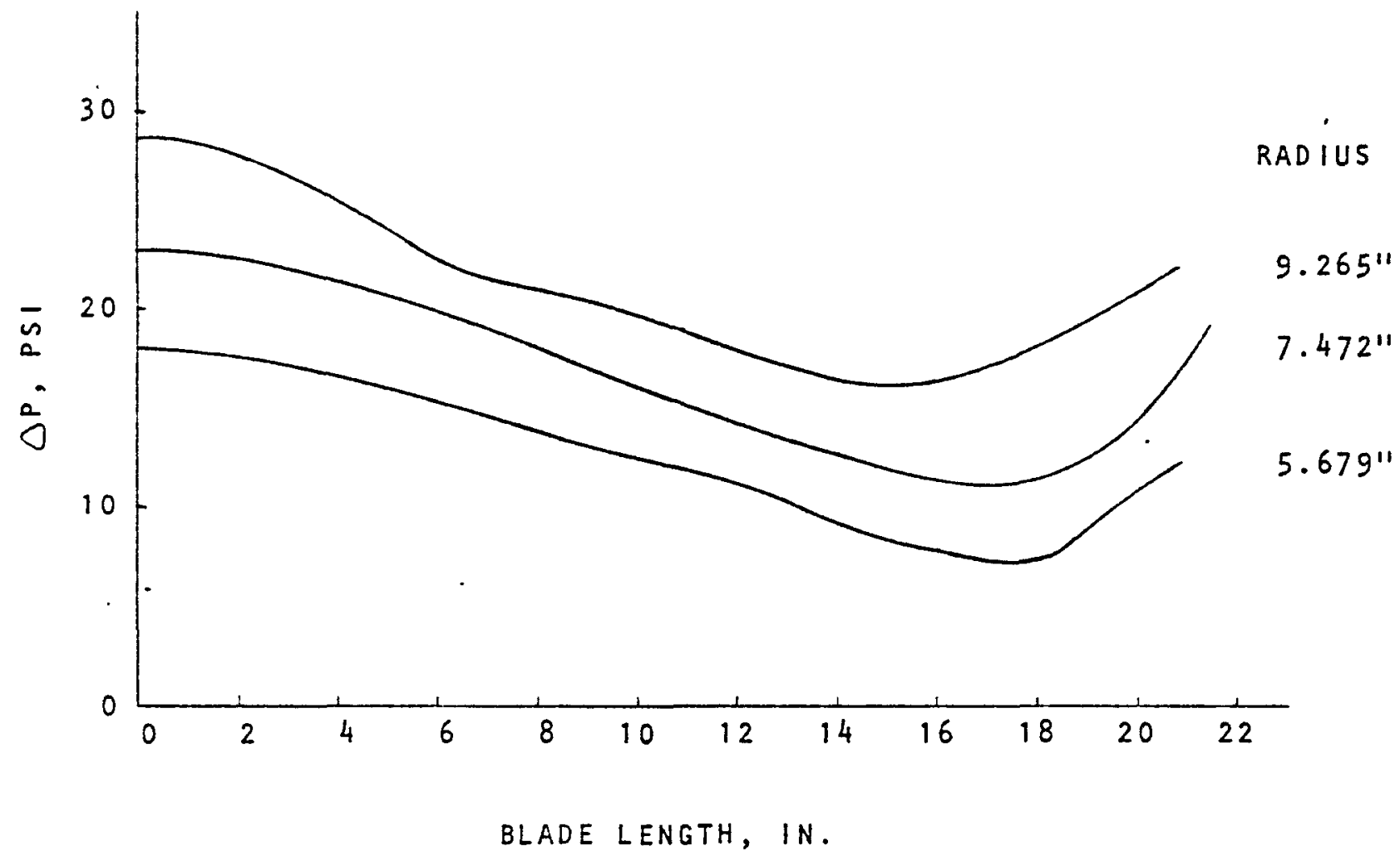

FIGURE 4. 
The fifth program is the "INDANA" program which is used to calculate the inducer head and efficiency over the full operating range. The calculated performance for I.S.I.P. is presented later in the report in the performance section.

\section{Impeller}

The impeller is a shrouded radial-discharge centrifugal-type impeller designed to generate the required head-rise. The impeller has five full blades and five additional partial blades at the discharge. The location of the leading edge of the partials is shown schematically on figure 1. The number of blades is chosen to optimize the efficiency and generate the required head at the design point. The transition from four inducer blades to five inlet impeller blades is not uncommon in optimum design practice and creates no detrimental effects.

The inlet diameters and blade angles were set based on flow conditions at the inducer discharge. " The diameters are essentially a continuation of the inducer discharge diameters. The flow angles at the impeller blade leading edge are a result of an extropolation from the inducer discharge using continuity of flow and constant angular momentum. The eye diameter is 19.0 inches and inlet hub diameter is 11.36 inches. The eye diameter is slightly larger than the inducer diameter to accomodate the additional wear ring leakage flow.

The inlet section of the blades are designed for no cavitation, and therefore no cavitation damage and long life are assured. This is made possible by the inclusion of the upstream inducer which provides sufficient headrise to eliminate impeller cavitation either on the blade or in the vorticees generated in the wear ring return flow.

The discharge width of 2.75 inches was set equal to the first diffuser width which in turn was set equal to that of the existing diffuser. 
This width is wider than required for this operating condition and probably results in a somewhat lower efficiency. However, the I.S.I.P. design must match the existing diffuser in the existing housing, and a mismatch on the width could be a larger efficiency penalty than using the existing width. The discharge diameter of 35.40 inches, number of blades, and blade angle were balanced in such a way to allow room for another diffuser and still generate the required head. This was based on previous Rocketdyne pump experience developed in the design and test of numerous centrifugal impellers used in the turbopumps of the engines for the national space program.

The shroud and hub contour shapes and the blade camber distributions are selected to achieve a uniform loading and head generation distribution. Figure 5 presents the average head-rise at the design point generated through the impeller as a function of meridional length. Similar pressure loading curves at lower flows were generated to assure structural integrity at off design. Figure 6 presents the blade load distribution generated for, the Stress department to determine blade stresses.

Two computer programs are used in the impeller design and analysis effort. The quasi-three-dimensional analysis program "VELDIS" was used to analyze the local velocity and pressure field throughout the impeller bladed section. This program provides the design verification that no detrimental regions of back flow or cavitation are occurring in the impeller. The output from the program also provides the head distribution and blade loads previously presented in Figures 5 and 6 . The second program is an overall pump performance prediction program that performs a detailed calculation of the various losses that can occur in the pumping elements as well as in the diffusers. This program was used to calculate the head and efficiency over the full operating range, and the results are presented in a later section.

\section{Intermediate Vaned Diffuser}

A short, ring diffuser was added between the impeller and the existing 
INTERMEDIATE-SIZE INDUCER PUMP

IMPELLER HEAD RISE ONLY

$$
\begin{aligned}
& Q=15816 \mathrm{GPM} \\
& \mathrm{N}=1110 \mathrm{RPM}
\end{aligned}
$$

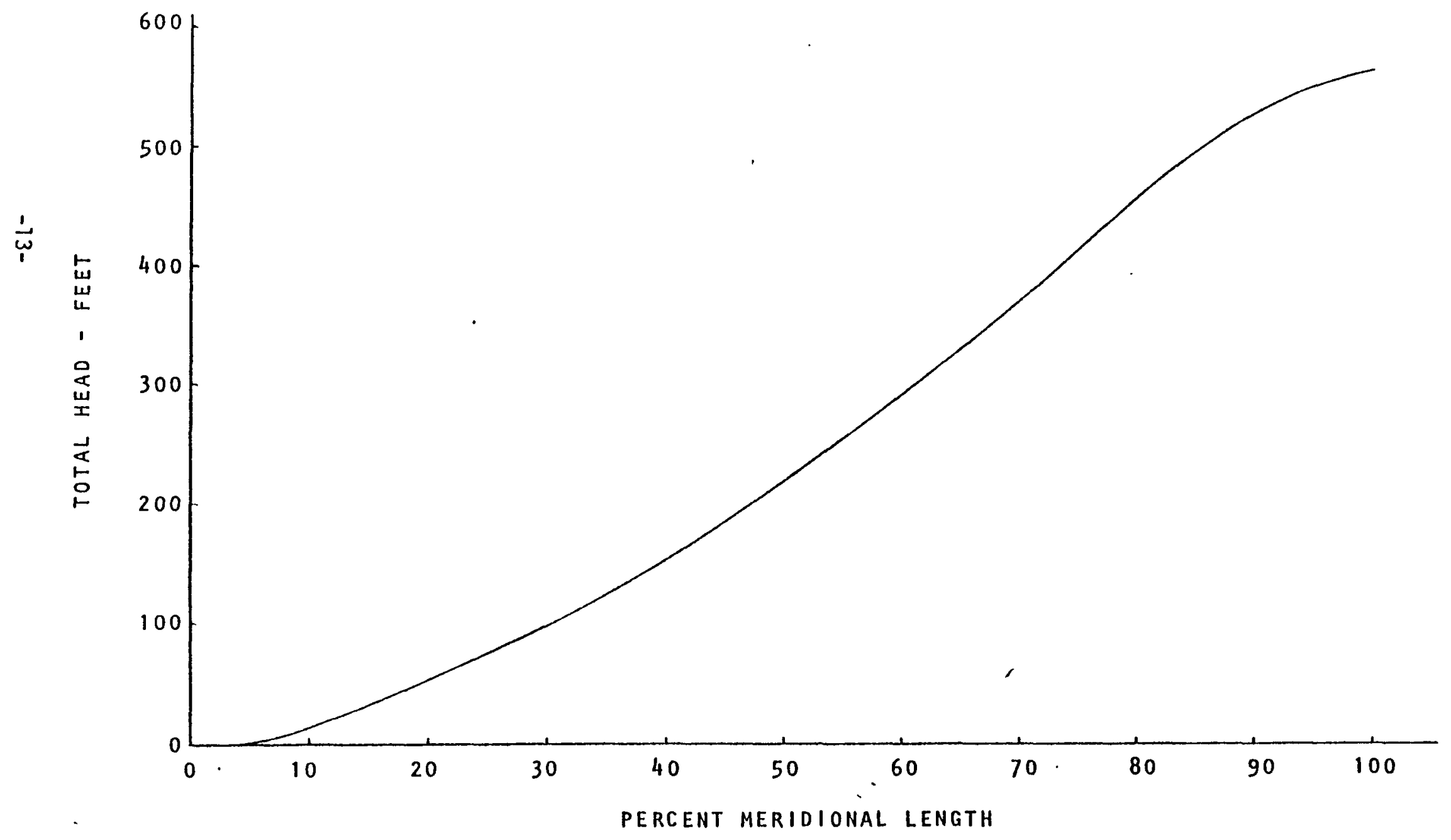

FIGURE 5 . 


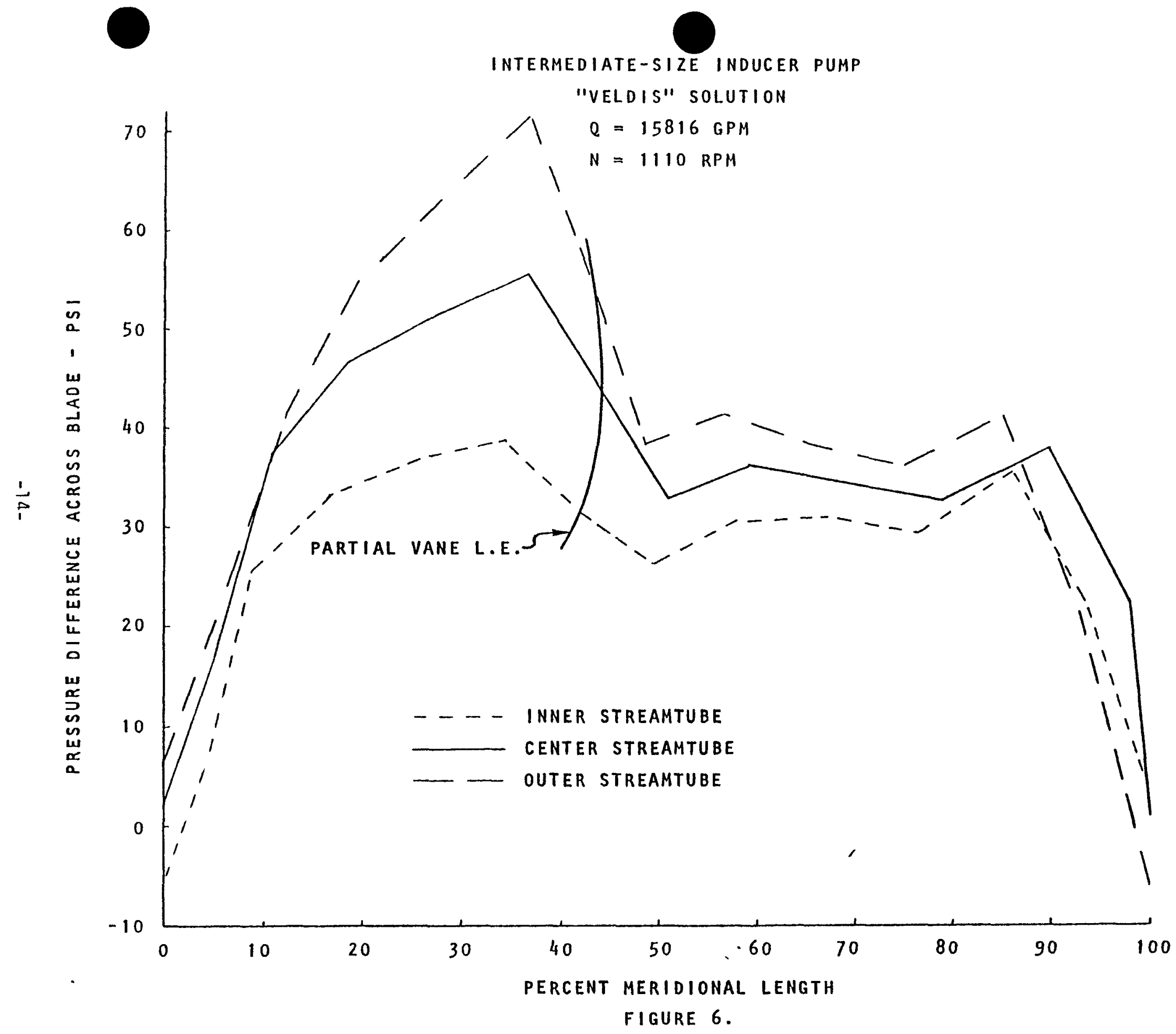

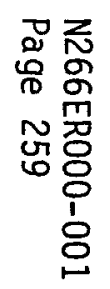


diffuser in an attempt to increase the stable flow range of operation. This diffuser will provide a flow into the Westinghouse diffuser with a smaller angular variation over the flow range than would be available directly from the impeller.

The discharge width and number of vanes were set to provide a match of the inlet flow angles to the vanes of the Westinghouse diffuser. The eleven vanes of the intermediate diffuser are staggered between the eleven vanes of the existing diffuser to minimize boundary layer build up and separation with its attendant loss in efficiency. The diameters of the intermediate diffuser are $37.2 \mathrm{in}$. at the inlet and $42.0 \mathrm{in}$. at the discharge. The discharge diameter was set by the housing geometry and the inlet diameter was set by the impeller diameter, allowing sufficient clearance to avoid cavitation or fatigue damage to the impeller or diffuser.

The vane profile is a double-circular-arc design with a 7.4 percent thickness. The profile and thickness were selected consistent with good hydrodynamic practice and to control the hydrodynamic loading on the vanes to meet the required structural integrity.

The inlet vane angle was set to match the flow from the impeller at the design flow and the discharge angle was set to provide a flow matching the inlet vane angle of the Westinghouse diffuser. The required vane angles and diameters combine to give a solidity that provides the required diffusion.

The diffuser was designed using the same methods developed for the space program centrifugal pump designs. These design techniques have been proven based on tests over an extensive flow range. The losses associated with the flow through the diffuser were calculated using the same centrifugal pump loss program discussed in the impeller section. 


\section{Design Point}

The specification design point required an overall head-rise of 500 feet flange-to-flange while pumping a delivered flow of $14500 \mathrm{gpm}$ of sodium at a rotational speed of $1110 \mathrm{rpm}$. The I.S.I.P. calculated head-rise at these conditions is 546 feet providing a nine percent margin in meeting the required 500 feet. The projected efficiency of the pump at the design point is 74 percent giving a required power of $2037 \mathrm{Hp}$. This quoted efficiency also has a margin, based on calculations, of four percent.

The program used for the analysis has been quite successful in the prediction of performance on other pumps. This program was developed over the past twenty-five years and checked out by consistently comparing predicted results with pump internal data collected in various test facilities. The program calculates the Euler head-rise for each of the rotating elements and the losses that affect both head-rise and power in each of the components. Table 1 presents the respective head and loss values for each of the components at the design point indicating the margin in the design head-rise. The head can easily be reduced to exactly 500 feet, if required, by trimming the impeller. The calculations for the Westinghouse diffuser system were performed with the available information for the design, but they contain a degree of uncertainity due to the lack of more specific design information.

\section{Range of Operation}

The pump is required to operate over a relatively large flow range. The maximum flow at the design speed is $18,000 \mathrm{gpm}$ at which point the head-rise must exceed 375 feet. The minimum flow is not specified, but it was desired to achieve a stable operation for flows lower than that achieved with the Westinghouse design. 
TABLE 1

DESIGN POINT PERFORMANCE CALCULATIONS

$$
\begin{aligned}
& \text { DELIVERED FLOW }=14,500 \mathrm{GPM} \\
& \text { SPEED }=1110 \mathrm{RPM}
\end{aligned}
$$

COMPONENT

INDUCER

IMPELLER

INTERMEDIATE DIFFUSER

WESTINGHOUSE DIFFUSER

DISCHARGE SYSTEM

DESIGN MARGIN $=46 \mathrm{FT} .(9 \%)$
CUMULATIVE

EULER HEAD LOSSES DEVELOPED HEAD

72 FT.

639

622

579

546 FT. 
The predicted overall head and efficiency are shown in Figure 7 assuming that the margin shown by the calculations is not realized in actual operation. The head-rise at the $18,000 \mathrm{gpm}$ flow is projected to be 470 feet well in excess of the 375-foot minimum value. The negative slope of the head-flow curve is predicted to extend down to $8000 \mathrm{gpm}$. The existing pump was reported to have a stability problem between 10,000 and $12,000 \mathrm{gpm}$, and the vaned diffuser is expected to be the primary cause of the instability. The additional diffuser designed by Rocketdyne should help to extend the stable flow range, but the stable range cannot be guaranteed because the same Westinghouse diffuser is being used.

Figure 8 presents the head and efficiency of the inducer portion of the pump. This head must be sufficient to keep the impeller out of the cavitation region which causes head fall-off.

\section{Pony Motor Operation}

The specification required that at the pony motor speed of $94 \mathrm{rpm}$, the head-rise was not to exceed five feet of head. Figure 9 presents the scaled head-rise over the required flow range. The maximum head is four feet which is within the specification requirement.

\section{Life Requirements}

The specification requires a 20 year 1 ife at the design point and a worstcase, off-design life of 250 hours at 18,000 gpm and design speed of $1110 \mathrm{rpm}$. The inducer design incorporates the 1ong-1ife design features established and verified through Rocketdyne's waterjet pump experience. The significant parameters that affect the life of the machine have all been chosen to fall within the range of those parameters actually used in the waterjets. This includes such parameters as the leading edge sweep, flow coefficient, incidence angle, inlet blade angle distribution, cant angle, and tip thickness. The one parameter which was slightly outside 
N266ER000-001

Page 264

N2 66ER 000-002

Page 21

INTERMEDIATE-SIZE INDUCER PUMP

PREDICTED PERFORMANCE

1110 RPM
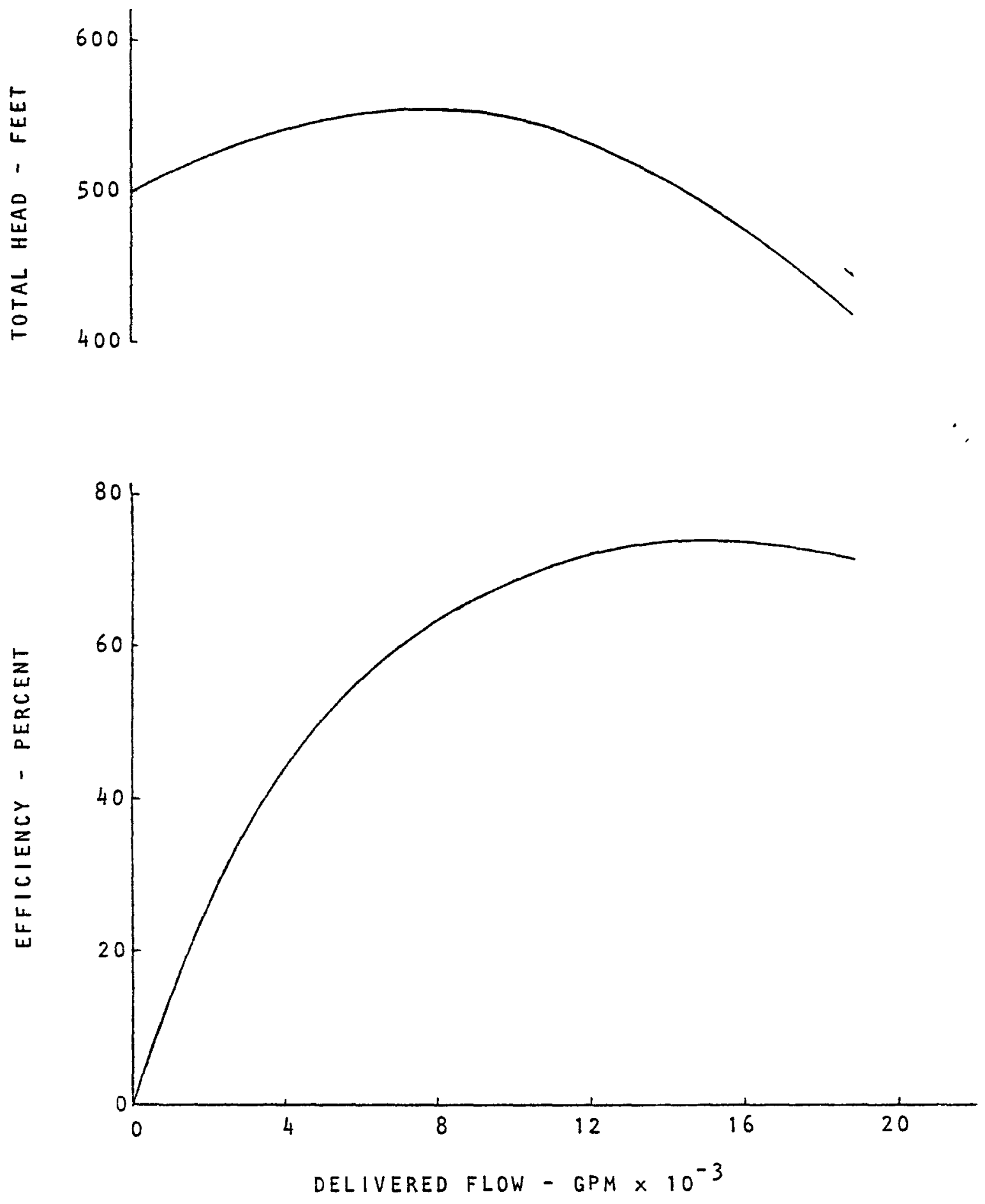

FIGURE 7 . 
N266ER000-001

Page 265
N266ER 000-002

Page 22

INTERMEDIATE - SIZE INDUCER PUMP

PREDICTED PERFORMANCE

INDUCER ONLY

1110 RPM

TIP DIAMETER $=18.53 \mathrm{IN}$.
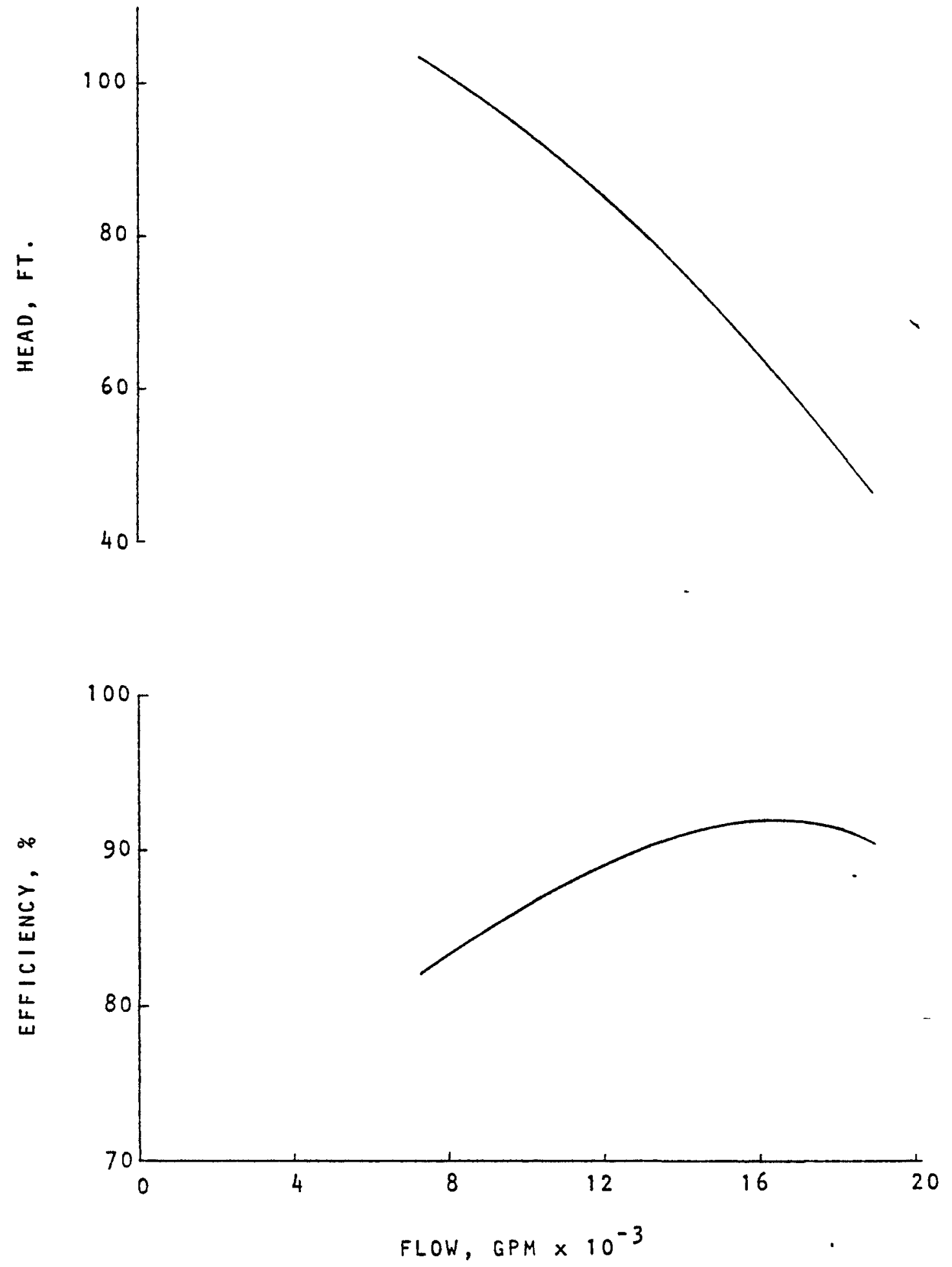

FIGURE 8 . 
INTERMEDIATE-SIZE INOUCER PUMP

PREDICTED PERFORMANCE

PONY MOTOR OPERATION

94 RPM

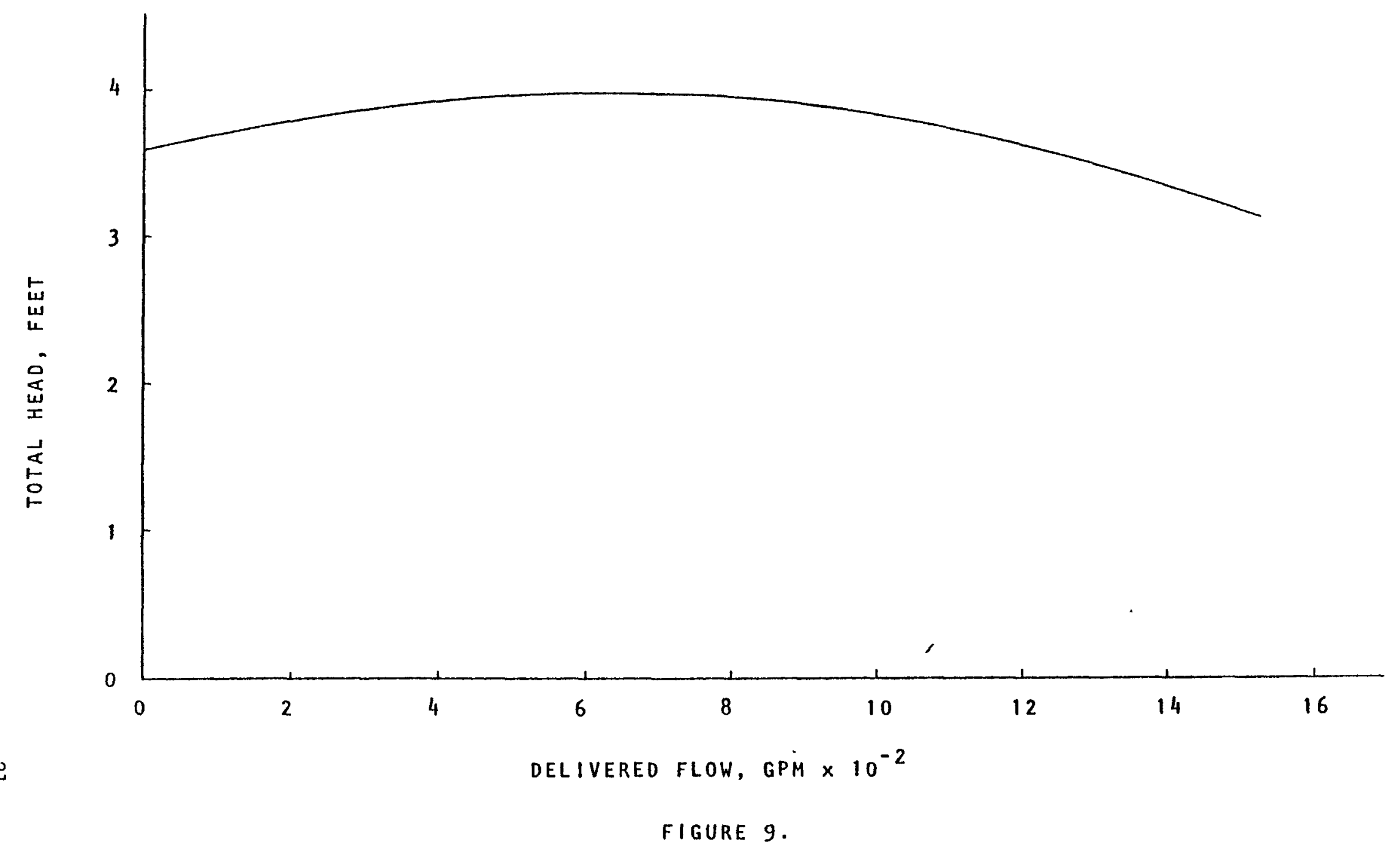


the waterjet experience range was the tip-clearance-to-blade-height ratio. However, Rocketdyne does have an analytical program for predicting the influence of this clearance on the potential damage due to the tip vortex cavity. This analytical program has been correlated with waterjet life test results. The analysis indicates that the selected four-bladed design will be able to operate with long life at the required operating clearance.

Other features incorporated to maximize the life include designing for zero cant angle of the blade to prevent a detrimental minimum tip clearance in case of blade bending, elimination of the slot over the inducer to prevent generation of slot-edge vortex cavitation, and increasing the blade thickness at the tip to the maximum value consistent with good hydrodynamic suction performance. This latter feature was included to provide more structural integrity to the blade to minimize blade movement in the high temperature sodium environment.

The maximum flow of $18,000 \mathrm{gpm}$ represents a 24 percent increase in flow over the design point. At such a large off-design condition any rotating component, inducer or impeller, would experience some cavitation damage if the NPSH margin is low. The NPSH margin required to prevent such damage for the I.S.I.P. design must be determined from water tests of model hardware. Such testing does provide a very economical approach to the problem and yields the required technological data for assessing the design in the very early stages of the overall program. This provides the opportunity for hardware modifications, if necessary, before fabricating any full-size hardware.

\section{Suction Performance}

The available NPSH provided to the inducer at the design flow is 47 feet. At $18,000 \mathrm{gpm}$ this value drops to 40 feet. Rocketdyne's I.S.I.P design is capable of achieving a predicted required NPSH of 12.8 feet at the design flow. This capability is based on the assumption that the required 
suction performance is the same in sodium as in water. Since both fluids have a very low vapor pressure, the thermodynamic suppression head effects should be negligible so that the above assumption is valid.

Rocketdyne's ability to meet this predicted performance is based on an extensive background of designing and testing high suction performance inducers. More recentiy, the capability of the subscale sodium inducer demonstrated the ability to achieve the predicted performance. The design features which are required to achieve these resuits have been designed into the I.S.I.P. consistent with previous Rocketdyne experience. No design compromises were required due to the sodium operation or other pump features with one exception. The outer diameter of the inducer was reduced, raising the required NPSH, to provide a smooth liner over the inducer and eliminate the slot over the inducer present in the existing housing.

The suction performance at off-design conditions is more difficult to predict. Based on the subscale sodium inducer the ratio of breakdown NPSH at 1.24 times design flow $(18,000 \mathrm{gpm})$ compared to that at the design point $(14,500 \mathrm{gpm})$ was 2.26 . Using this ratio, the I.S.I.P. required NPSH at the maximum flow would be 29 feet giving a margin of 38 percent. This is an adequate margin for suction performance but is relatively low for achieving life. An inducer or impeller operating with such small margin at this off-design value would be expected to experience damage, and the life then depends on the damage rate compared to the off-design life requirement. At 250 hours of life over a 20 year period, the inducer could be expected to maintain its performance capability even though some damage occurred.

The presence of the inducer provides sufficient head-rise at the impeller inlet to keep the impeller from experiencing cavitation performance loss. The maximum required suction specific speed of the impeller is only approximately 5200 at the off-design flow of $18,000 \mathrm{gpm}$. At the design flow, it will be significantly less than this. 


\section{Radial Loads}

The specification requires that the design incorporate polar symmetry to minimize radial loads. Such polar symmetry was incorporated in the design. The radial loads are also minimized by the incorporation of a four-bladed inducer, use of a lower impeller diameter than used in the existing pump, use of a more stable vaned diffuser system, and the complete polar symmetry of the existing diffuser discharge. The maximum radial loads to be experienced would occur at the lower flows. The radial loads should be less for the Rocketdyne design than the existing design, but for purposes of analysis a not-to-exceed maximum load was estimated at a low flow of $8000 \mathrm{gpm}$. These not-to-exceed estimates were:

Impeller: 800 pounds

Inducer: $\quad 13,300$ in-16 moment

The impeller load is based on an estimate of six percent of the axial thrust acting as a radial thrust. The inducer moment is based on tests of three-bladed inducers which are more likely to experience radial loads. However, the inducer radial load would not be expected to occur at the NPSH margins expected for the I.S.I.P. design.

\section{Axial Thrust Control}

The specification required that the axial thrust not exceed 70,000 pounds in the upward direction and 40,000 pounds downward. It also required that these thrust values be met with an assumed variation of the impeller discharge static pressure of ten percent from front shroud to rear shroud. The axial thrust control was to be achieved without use of a balance piston.

Figure 10 presents the nominal axial thrust for the I.S.I.P. design. The nominal thrust is less than 13,000 pounds at all operating conditions. 
N266ER000-001

Page 270

\author{
INTERMEDIATE-SIZE INDUCER PUMP \\ $N=1110 \mathrm{RPM}$ \\ INDUCER INLET PRESSURE $=16.64$ PSIA TOTAL \\ 12 BLEED HOLES \\ 1.25 IN. BLEED HOLE DIAMETER
}

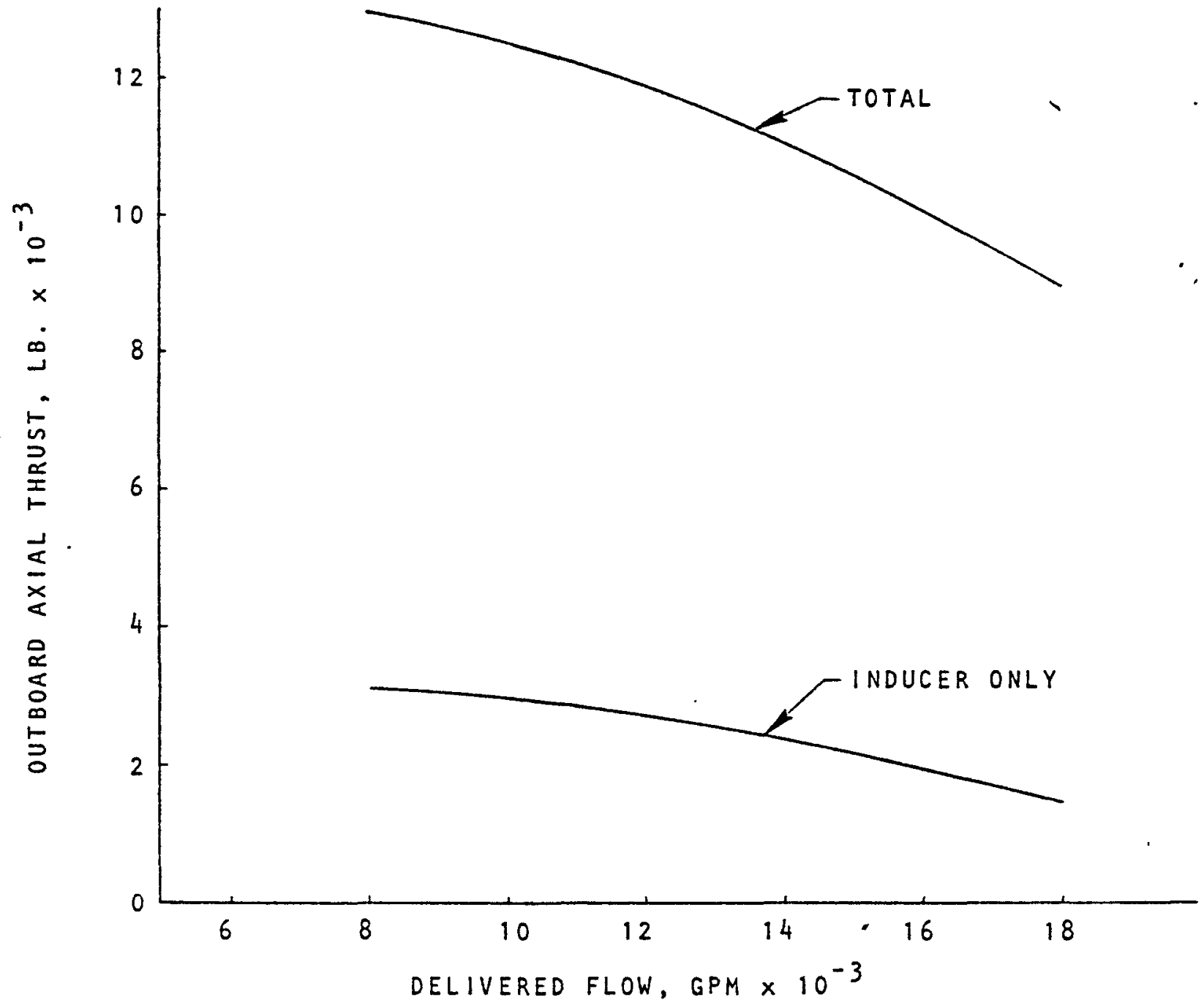

FIGURE 10. 
With the additional assumption of the ten percent variation in static pressure the following maximum conditions were obtained:

1. Maximum thrust equals 24,800 pounds downward at $8000 \mathrm{gpm}$.

2. Maximum thrust equals 7,200 pounds upward at $18000 \mathrm{gpm}$.

Case one assumes the rear shroud pressure is higher by ten percent and case two assumes the front shroud pressure is higher. This ten percent variation in static pressure is believed to be higher than will be experienced in the pump, but the thrust values are all well within the limits specified, and no balance piston system is required.

\section{Recirculating Flows}

The specification originally required that the hydrostatic bearing discharge pressure was not to exceed 10 psi above the inducer inlet pressure at the ', design point. To achieve this goal would require that the bearing discharge flow be ducted back to the inducer inlet. However, because the pump must be fitted into the existing housing, the impeller rear wear ring flow would also have to be dumped into the inducer inlet, or at least a portion of it if another rotating seal were added. Rocketdyne did not like this concept because dumping any significant amount of fluid into the inducer inlet could be detrimental to the suction performance capability. A simpler approach was analyzed and is shown in Figure 11. The bearing discharge flow and rear wear ring flow are collected and dumped into the impeller inlet rather than the inducer inlet. The impeller has the tolerance required to accept the flow without any degradation in overall suction performance. Using this approach gives a bearing discharge pressure that is $13 \mathrm{psi}$ above the inducer inlet pressure rather than the 10 psi originally specified. It was agreed at Atomics International to change the specification to approve the Rocketdyne design. 
RECIRCULATION FLOWS

INTERMEDIATE-SIZE INDUCER PUMP

1110 RPM

DESIGN FLOW

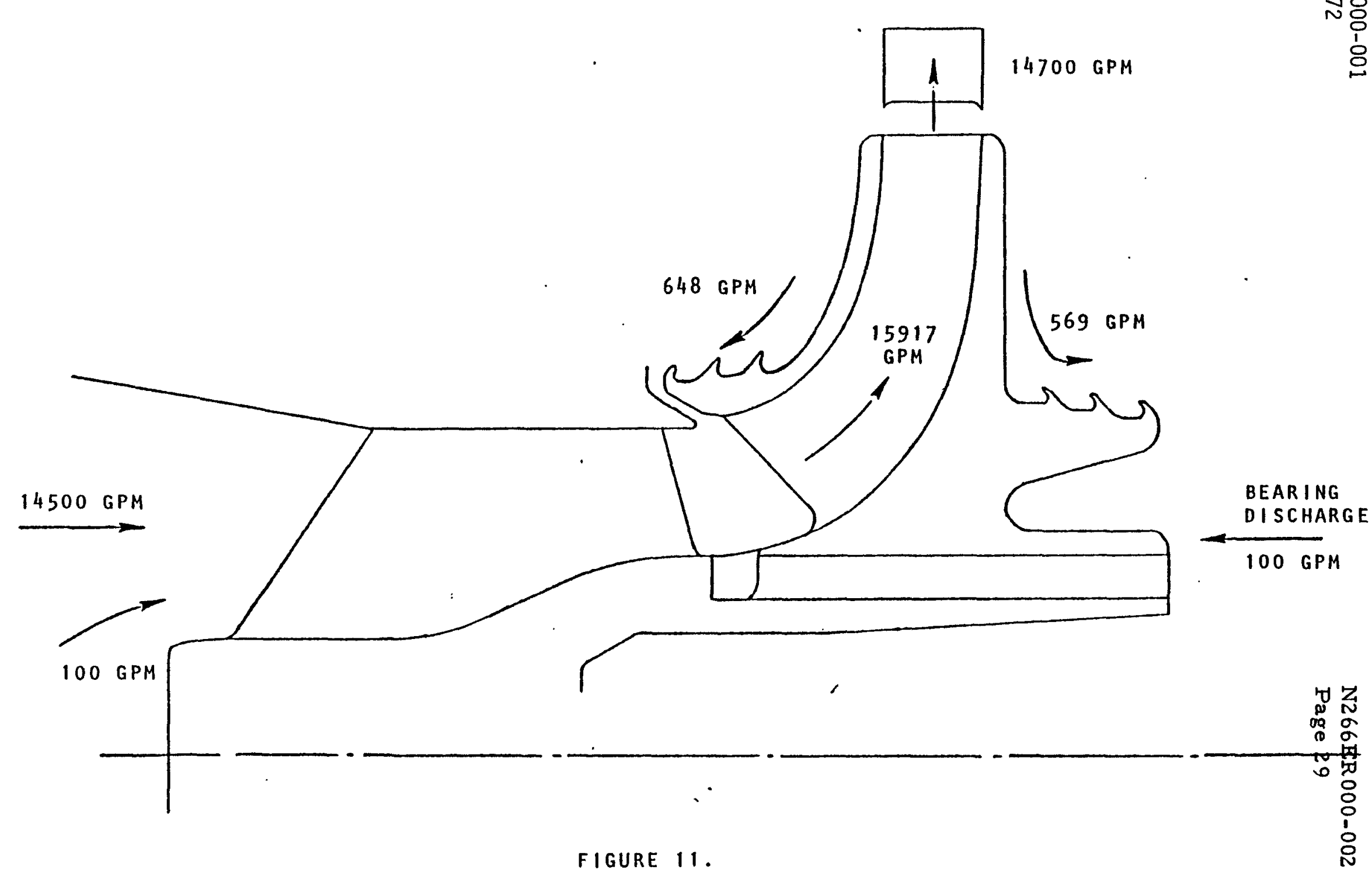


Figure 12 shows the differential pressure of the bearing discharge pressure minus inducer iniet pressure as a function of flowrate. The curve results are based on usage of twelve bleed holes at a diameter of 1.25 inches. The total flowrate through the impeller includes the bearing flow, rear wear ring flow, and front wear ring flow. The wear rings are located to achieve the axial thrust results previously presented. The flow through the wear rings is minimized by using properly designed stepped-labyrinth seals. 


\author{
INTERMEDIATE-SIZE INDUCER PUMP \\ $N=1110$ RPM \\ INDUCER INLET PRESSURE $=16.64$ PSIA TOTAL \\ 12 BLEED HOLES \\ 1.25 IN. BLEED HOLE DIAMETER
}

$\triangle P=B R G$. DISCH. STATIC PRESS. - INDUCER INLET STATIC PR.

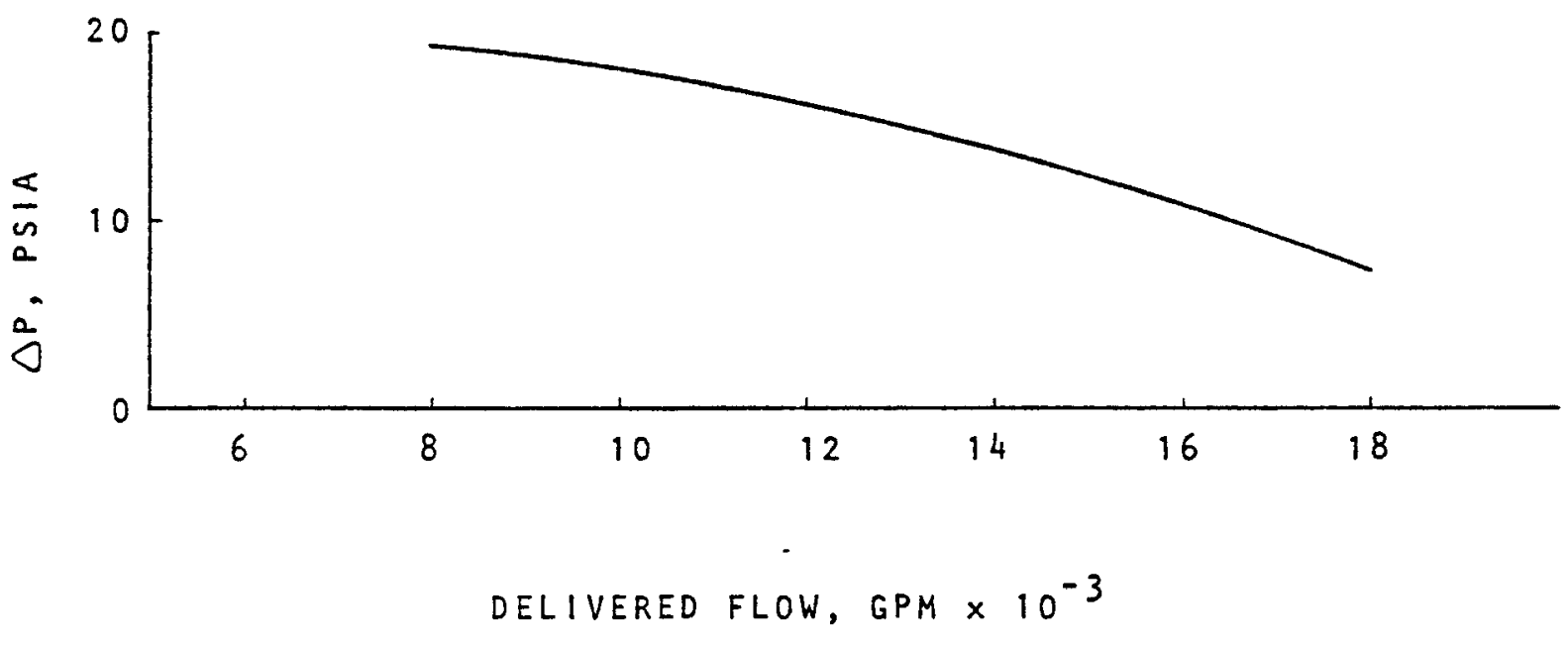

FIGURE 12 . 
The hydrodynamic design has been based on techniques developed and proven over the past twenty-five year period. The analytical tools used are the most advanced available and have been checked out by correlation with available test data. The confidence in achieving the design performance predictions is, therefore, very high.

The design has been shown to meet the specification requirements in all cases where analytical predictions can be made. In fact, design margins have been included in all of these cases to provide additional confidence in meeting the predicted values. Two areas need verification through testing, regardless of whether an inducer pump or an impeller-only design is incorporated. The first is the suction performance margin at the highest flow condition. The quoted margin of 38 percent is expected to be representative but requires test support. The second area is the life characteristics of the design. All of the design features are based on proven designs for long life waterjet pumps at the design point. Life at the off-design flow requires test evaluation. 
PAGE . 276

\author{
APPENDIX $\mathrm{H}$ \\ STEADY-STATE STRUCTURAL ANALYSIS \\ (PUMP INTERNALS)
}

ESG Document N266SR000001

Figures 1 thru 29 (except Figure 9) have been removed from this document because they contain proprietary information, as defined by DOE contract. 


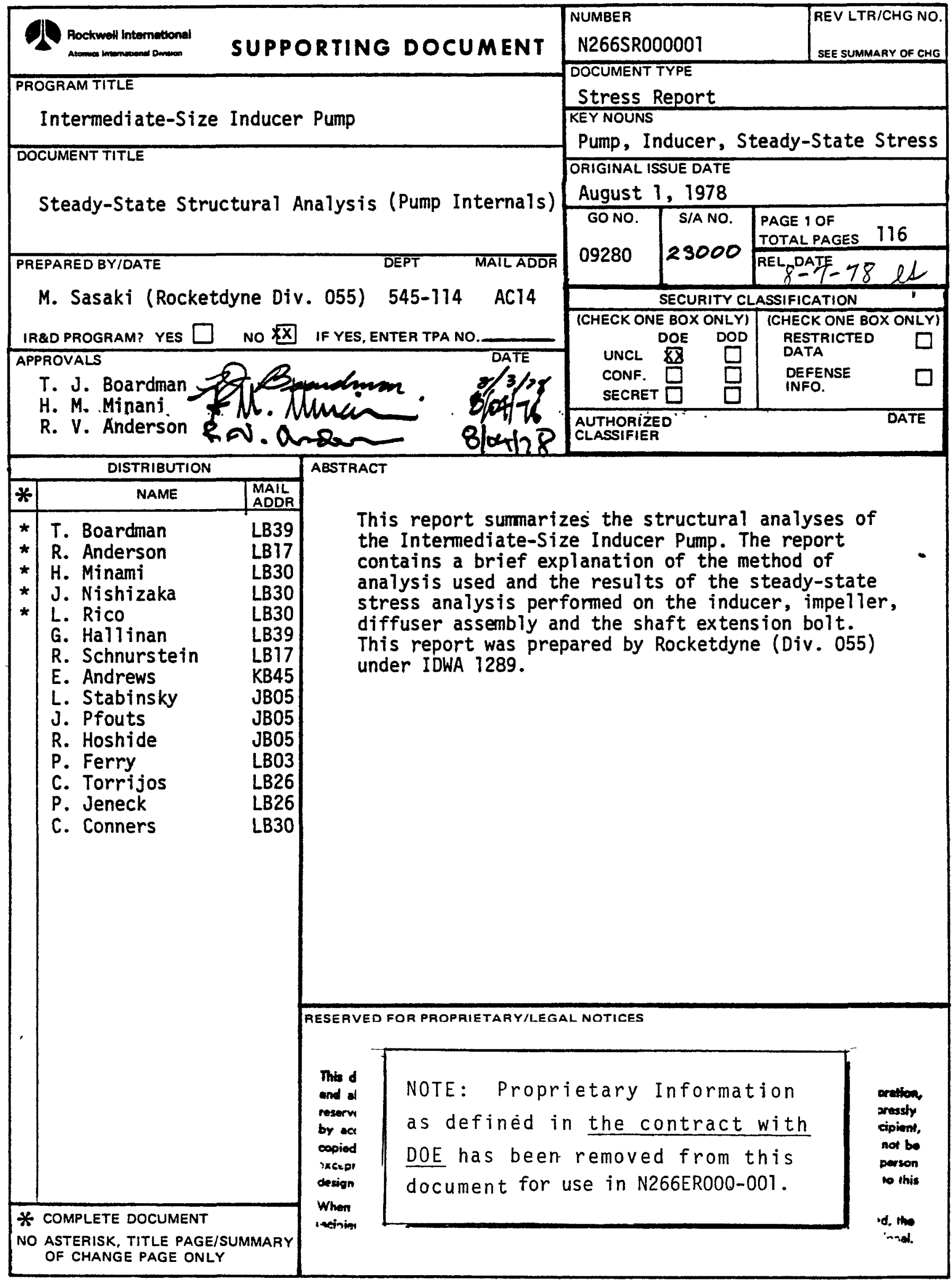


AI INTERMEDIATE-SIZE INDUCER PUMP

STRUCTURAL SUMMARY

\section{Introduction}

In accordance with the Statement of Work per Intermediate-Size Inducer Pump, IDWA N-1289, Ref. 1, a steady-state stress analysis has been performed on the inducer, impeller, diffuser assembly and the shaft extension bolt. The components are structurally adequate for the steady-state operation. The method of analysis and the results are summarized in this summary report.

\section{Design Criteria}

The design criteria used in the analysis was estabilished by Atomics International (AI) and is set forth in Ref. 2. The AI allowable stress 1 imits are lower than those allowed by the ASME Boiler and Pressure Vessel Code to leave margin for thermal transient stresses. The AI allowable stress limits for 304 stainless steel at $1050^{\circ} \mathrm{F}$ are:

1. Primary membrane stress $\left(P_{M}\right)=7450$ psi.

2. Local membrane plus bending $\left(P_{L}+P_{B}\right)=7730$ psi.

However, two specific exceptions were granted by AI to cover the two locations where the $\left(P_{L}+P_{B}\right)$ stresses exceeded the recormended allowables. The two locations are the forward fillet radius in the inside diameter of the inducer hub and the diffuser vane. The calculated inducer fillet stress was 9630 psi. An increase in the allowable stress to 11200 psi was granted for the inducer, Ref. 3. The calculated diffuser vane stress was 8410 psi and the allowable stress was increased to 9000 psi, Ref. 4. 
The design criteria for A286 material used in the shaft extension bolt is set forth in Ref. 4. The recommended allowable stresses at $1050^{\circ} \mathrm{F}$ are 15000 psi for $\left(P_{M}\right)$ and 20000 psi for $\left(P_{L}+P_{B}\right)$.

\section{Operating Conditions}

- The pump components were analyzed for steady-state operation at the following operating points.

1. Steady-state design point.

2. Steady-state maximum pressure condition.

3. Steady-state maximum power condition.

4. Transient maximum operating pressure condition.

Table 1 lists the speed, flowrate and the temperature of the above four operating points.

The pump components were analyzed based on operating points or combination of operating points which produced the maximum load condition. These loads were treated as steady-state loads.

\section{Inducer}

The inducer blade and hub were analyzed under steady-state operating conditions in order to determine their structural adequacy and compliance with the AI steady-state structural criteria (Ref. 1).

Inducer Blade

The inducer blade was analyzed to:

1. Determine stresses at the blade-hub intersection. 
2. Determine stresses throughout the blade.

The analysis of step 1. assumes that the blade acts as a series of wedge-shaped cantilever beams under a combined loading of:
a. Pressure bending moment.
b. Centrifugal radial force.
c. Centrifugal bending moment for canted blades.

Bending and membrane stresses are determined at the root of each wedge-shaped bean and then correction factors are applied in order to account for:
a. the blade twist due to the helix angle;
b. the tangential load carrying capability of the blade (disk effect):
c. the distribution of moment at the hub due to plate behavior of the blade.

Under step 2. a finite element computer program was used to calculate stresses and deflections throughout the blade. The blade was modeled as a grid of elastic, triangular plate elements of linearly varying thickness with $\Delta p$ pressure and centrifugal loads.

The $\Delta p$ pressure load used in the analys is is a composite of the maximum pressure differences for flowrates at a speed of 1710 RPM. Pressures for 8000 GPM control over the first onethird to one-half of the blade length while pressures for 14500 GPM control for the remainder of the blade. The $\Delta p$ pressure distribution contours plots are shown in Figure 1. All centrifugal forces are at 1110 RPM. 
Results of the inducer blade analysis are summarized in Figure 2. The operating conditions corresponding to the most severe blade loading, the resulting stress intensities, stress intensity contour plots, material, allowable $\left(P_{L}+P_{B}\right)$ stress and design margins are shown. The stress intensities shown are located on the blade pressure surface where tension from centrifugal loading and pressure bending combine to produce the most severe stress condition. The maximum stress intensity in the blade is $5.60 \mathrm{KSI}$ and occurs at the blade-hub intersection at a location corresponding to the start of the full blade height. This maximum stress intensity results in a design margin of:

$$
\text { D. M. }=\frac{7.73}{5.60}-1=.38 \text {. }
$$

Figures 3 through 6 are stress contour plots of the radial, tangential, shear in radial and tangential plane and maximum shear on the blade pressure side. Figure 7 is a contour plot of blade deflection in the axtal direction.

Inducer Hub

The inducer hub was analyzed using a finite element computer program for axisymmetric solids. In addition, the hub was analyzed for the non-axisymetric loads. The non-axisymmetric load analysis consisted of hand calculation using the theories of plates and shells. The results from the non-axisymmetric analysis were superimposed on the results from the finite element analysis. 
The inducer hub was evaluated under the following loads:

\section{Axisymmetric loads}

1. Pressure loads on the inner and outer surface.

2. Axial load during operation which includes the effect of initial preload and operating thrust.

3. Centrifugal loading due to rotation of the hub and the brades.

\section{Non-axisymmetric loads}

1. Bending of the hub due to blade bending at the blade-hub $=. .$. intersection.

2. Couple on the hub from the key.

3. Bending of the hub due to a hydrodynamic couple.

The pressure loads are shown in Figure 8. The 695 psia shown in Figure 8 represents axial load in terms of pressure.

The maximum loading condition on the inducer hub results in the stress intensity contours shown in Figure 9. The maximum stress intensity in the hub occurs in the fillet radius joining the hub inlet section and the retaining nut bearing flange. The close spacing of the contours indicates a highly localized stress concentration effect at a gross structural discontinuity. The maximum stress intensity in the hub of 9.63 KSI is due to combined axisymetric and non-axisymmetric loads and results in a design margin of .16. It should be noted that in the inlet region of the inducer hub, provision has been made for the removal of material for balancing purposes. If the maximum material were removed, the maximum stress intensity 
at the balance groove surface will be equal to the maximum allowable stress intensity of $7.73 \mathrm{kSI}$. The Figure 9 also summarizes the operating conditions, material, and design. criteria. Figures 10 through 29 are stress contour plots of the radial, axial, tangential, shear in radial and axial plane, and maximm shear for the axisymetric loads.

Impeller

Compliance of the impeller design with the AI stress criteria was determined through:

1. hand analysis of the impeller full and partial vanes;

2. a two dimensional, axisymetric finite element - analysis of the hub and shroud.

\section{Impeller Vanes}

The impeller vanes were analyzed as fixed-ended beams of constant thickness and unit width connecting the outer shroud to the hub. Loading for each beam was assumed to be:

1. A uniform pressure difference across the vane width.

2. Centrifugal loading due to rotation of the vane.

A typical vane section with the pressure and centrifugal loadings is shown in Figure 30. The pressure distribution imposed on the vanes is shown in Figure 31. The maximum stress intensities as well as the corresponding design margins and wrap angle locations in the full and partial vanes are: 
Ful1 Vanes

Partial Vanes

\begin{tabular}{|c|c|c|}
\hline Wrap Angle & $\begin{array}{l}S_{\text {MAX }} \\
\text { KSI } \\
\end{array}$ & $\underline{D . M}$ \\
\hline $90^{\circ}$ & 2.41 & 2.21 \\
\hline $10^{\circ}$ & 1.08 & 6.16 \\
\hline
\end{tabular}

It should be noted that for the impeller vanes, the wrap angle is measured from the trailing edge which is the reverse of the convention used for the inducer blade.

Impeller Hub and Shroud

The impeller hub and shroud were analyzed for the following loads:

I. Axisymetric loads

1. Fluid pressures.

2. Axial load during operation from the effect of initial preload and operating thrust.

3. Centrifugal loading due to rotation of the hub and shroud as well as the impeller vanes.

4. Shrink fit corresponding to a maximum radial interference of .0013 inches between the impeller hub and pump shaft.

II. Non-axisymmetric loads

1. Couple on the hub from the shear keys.

2. Bearing at the impeller keyway.

For axisymmetric loads, the hub and shroud were analyzed using a finite element computer code for axisymmetric solids. The basic finite element model is modified in the bleed hole and vane regions to account for a reduced tangential (hoop) continuity. 
In the vane region the model is further modified to account for material distribution and vane orientation. Such modifications are made in an attempt to simulate the vane behavior in as much as this behavior affects the stress distribution in the impeller hub and shroud. As a result, stresses in the vane region from the finite elenent model are not true stresses. In order to simulate the impeller-shaft elastic interaction the finite element model also includes a portion of the existing shaft.

Figure 32 shows the impeller profile and the maximum loadings imposed upon fit under steady-state operating conditions. The : resulting stress intensity contours from the finite element model are shown in Figure 33. The maximum stress intensity of $7.48 \mathrm{KSI}$ occurs in the hub at the hub-shaft interface and results in a design margin of .03 .

Figure 34 shows the stress intensity contours on the hub profile resulting from the shrink fit of the impeller onto the stepped, tapered shaft. The shrink fit procedure involves sliding the impeller onto the shaft until contact is made and then removing and heating the impeller. The impeller is then replaced on the shaft to a position .025 inches axially beyond the original contact point and allowed to cool. This results in a maximum radial interference of .0013 inches.

Figures 35 through 59 are stress contour plots in the impeller hub and shroud of the following stresses: radial, axial, tangential, shear in axial and radial plane, and maximum shear for the axisymmetric loads. 


\section{Diffuser Assembly}

The transition diffuser assembly was analyzed using a twodimensional finite element computer program. The loading is primarily a pressure differential across the diffuser thickness and the local effects of the mounting and connecting bolt loads. In the diffuser vane region of the computer model, allowance is made to account for the lack of tangential (hoop) continuity and the actual vane geometry in an attempt to simulate the correct vane behavior. For this reason, stresses in the vane region from the finite element model are used only to determine the membrane loads and bending moments imposed on the vanes. Figure 60 shows the operating conditions corresponding to the maximum diffuser pressure load and the pressure distribution imposed upon the diffuser assembly. Figure 67 summarizes the result of the diffuser assembly analysis. The operating condition, material, allowable stress intensities, stress contour plots and design margin at various locations of the diffuser assembiy are shown. The maximum stress intensity of 8.41 KSI occurs in the diffuser vanes and is shown in Figure 62.

Figures 63 through 102 are stress contour plots of the radial, axial, tangential, shear in radial and axial plane, and maximum shear for the axisymmetric pressure loads.

\section{Shaft Extension}

The shaft extension was examined using appropriate hand analyses based on shell and ring theory. It should be noted that the shaft material is A286 steel while the inducer, impeller, and diffuser materials are all 304 stainless steels. 
The shaft extension maximum load operating conditions as well as the resulting stress intensities and design margins at various locations are listed in Figure 103. The maximum stress intensity of $15.6 \mathrm{kSI}$ with a design margin of .28 occurs at a fillet, (location A), as a result of combined axial membrane tension and bending due to eccentricity of the axial load. 


\section{References}

1. Intermediate-Size Inducer Pump IDWA N-1289.

2. AI Letter 77AT-10423, R. V. Anderson (AI) to R. E. Davis (Rocketdyne), Intermediate-Size Inducer Pump, IDWA N-1289, Revision A, dated November 11, 1977.

3. AI Letter, T. Boardman (AI) to J. Wolf (Rocketdyne), Intermediate-Size Inducer Pump (ISIP) Structural Design Criteria, dated May 17, 1978.

4. AI Letter, T. J. Boardman (AI) to J. E. Wolf (Rocketdyne), Intermediate-Size Inducer Pump (ISIP), IDWA N-1289 Allowable Stress Values, dated April 19, 1978. 
TABLE I

AI INTERMEDIATE SIZE SODIUM PUMP

- OPERATING CONDITIONS:

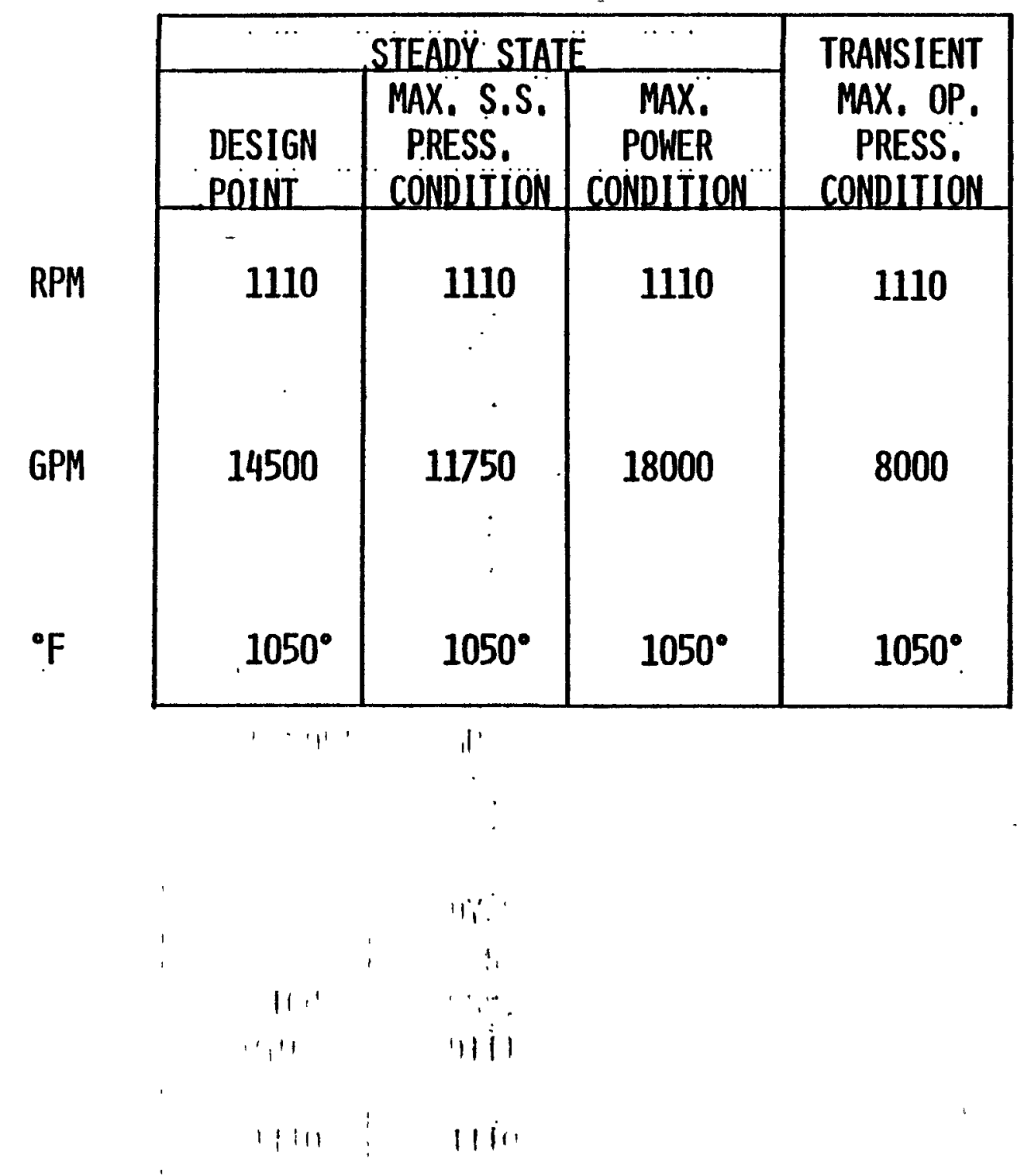

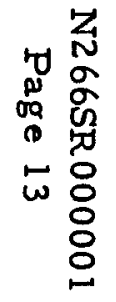

- SPEED

- FLOWRATE

- TEMPERATURE 


\section{FIGURE 9}

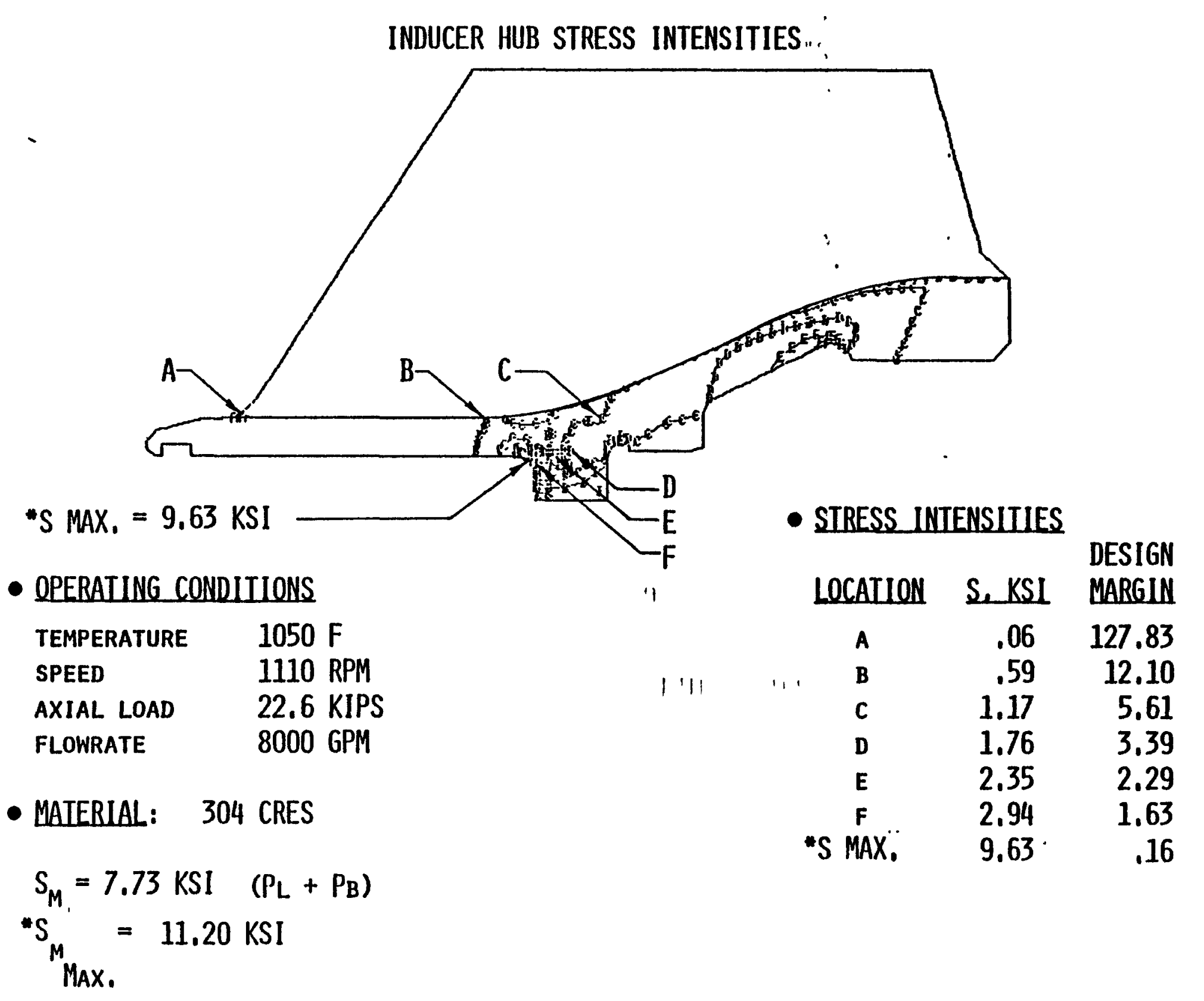




\section{FIGURE 30}

AXIAL VIEW OF IMPELLER FULL VANE LOOKING

\section{FROM IMPELLER INLET TOWARD OUTLET}
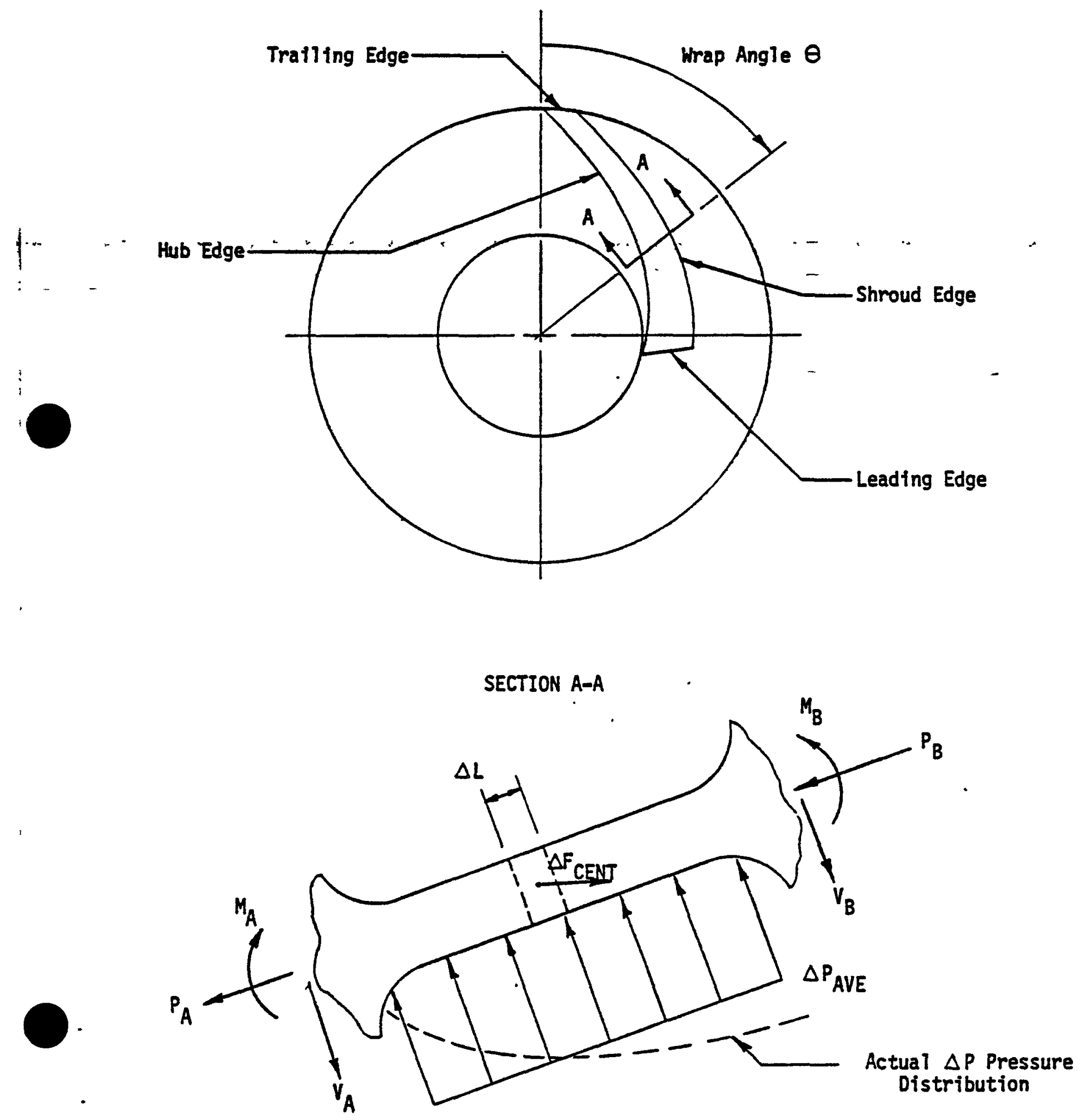


\section{FIGURE 31}

IMPELLER VANE P PRESSURE LOADING

$N=1110$ RPM

$Q=8000$ and $14500 \mathrm{GPM}$

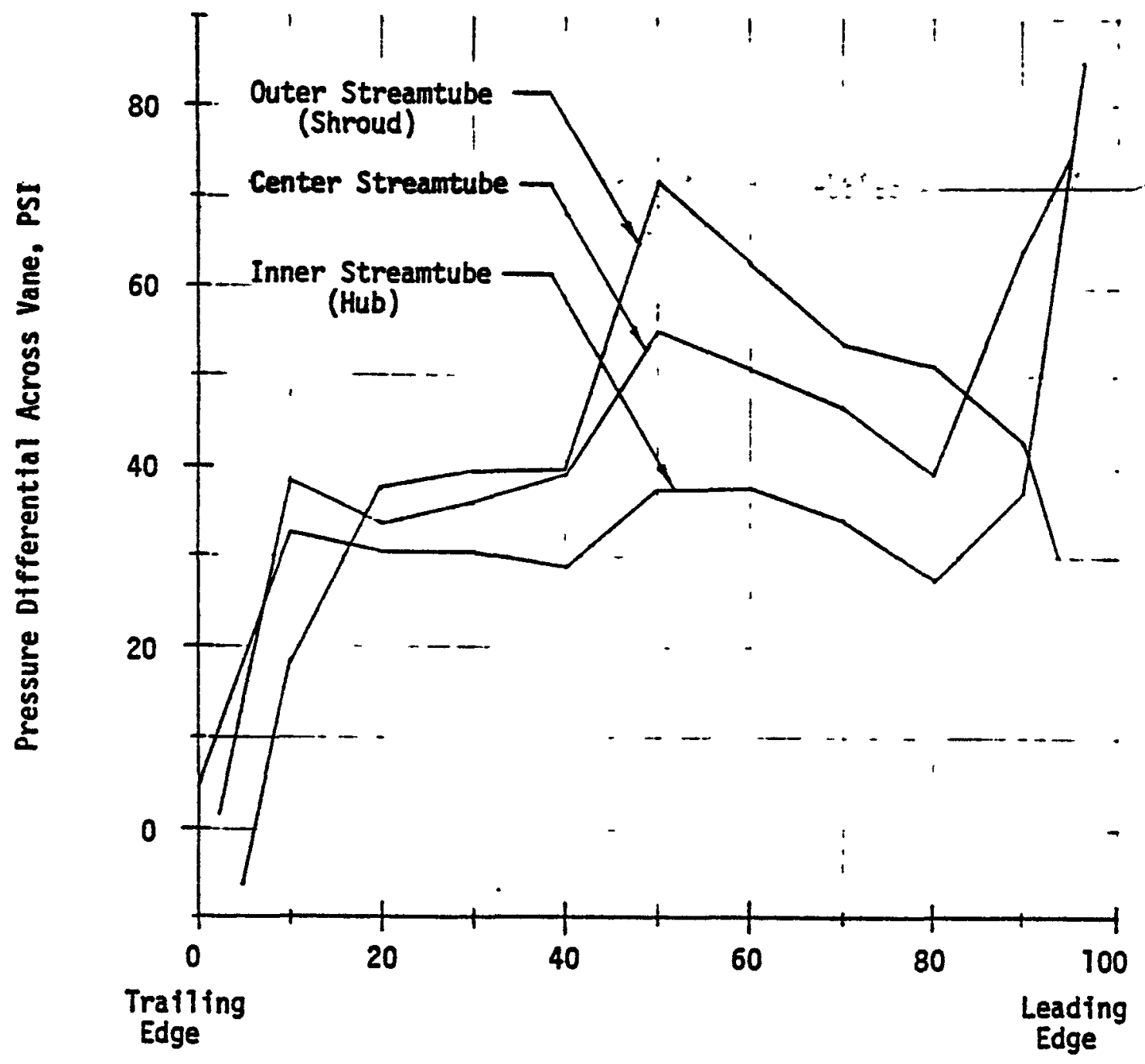

WRAP ANGLE, $\theta$, DEGREES 
FIGURE 32

IMPELLER AND LOADING

Operating Conditions

$\begin{array}{lll} & \text { Temperature } & 1050 \mathrm{~F} \\ & \text { Speed } & 1110 \mathrm{KPM} \\ & \text { Flowrate } & 8000 \mathrm{KPM} \\ & \text { Axial Load } & 21 \mathrm{KIPS} \\ & \text { Shrink FIt } & 0.0013 \mathrm{IN} / \mathrm{RADIAL} \\ & \text { Pressure } & \text { As shown PSIA }\end{array}$
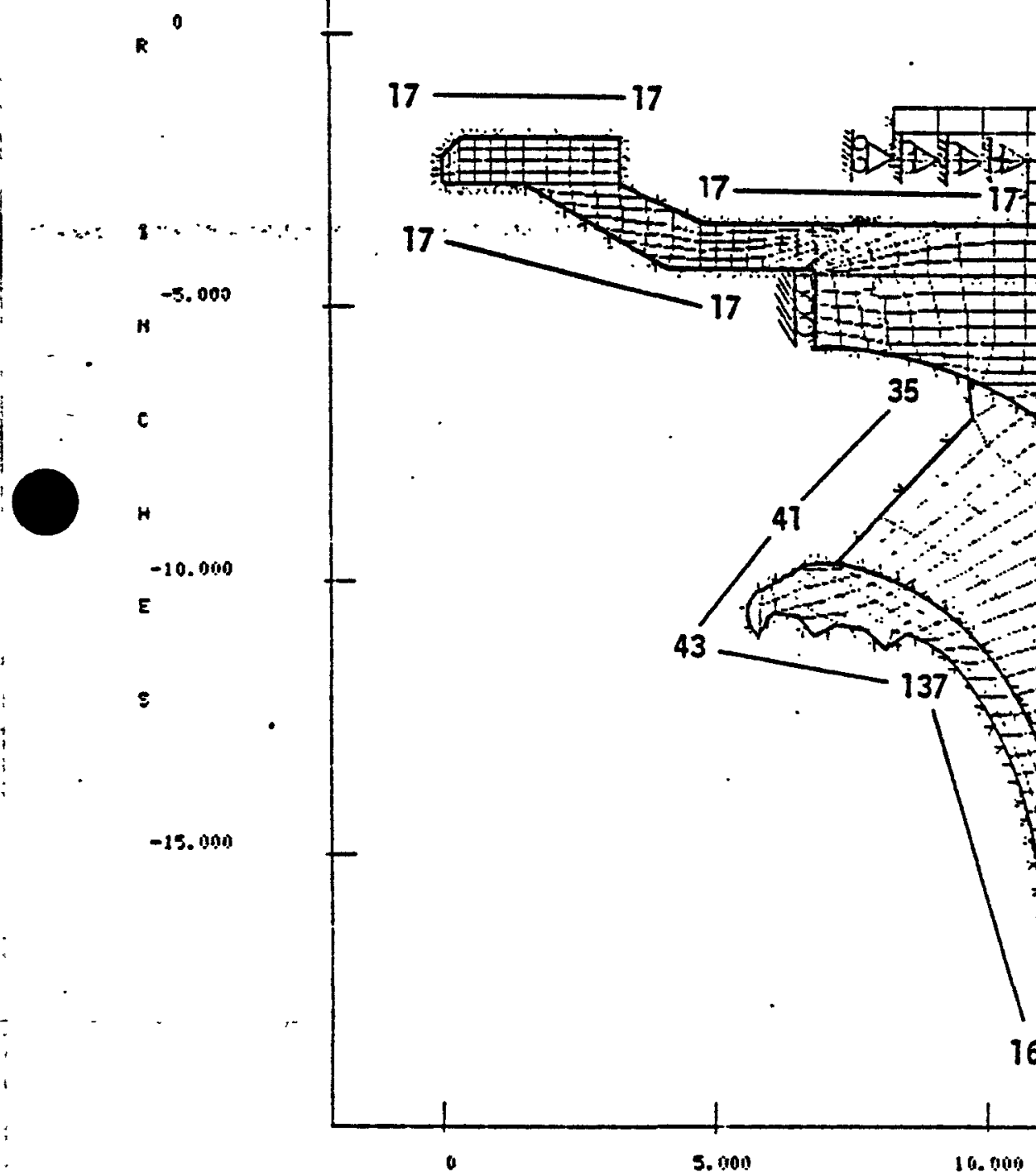

it:
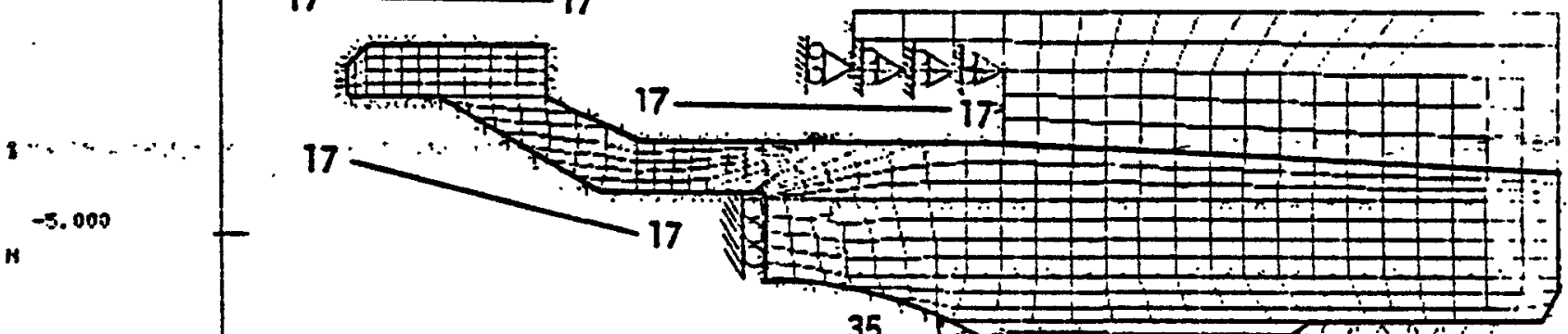

17

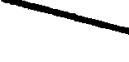

$-17$
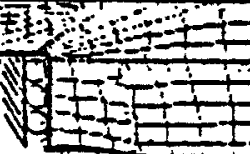

c

H

$-10.000$

E

s
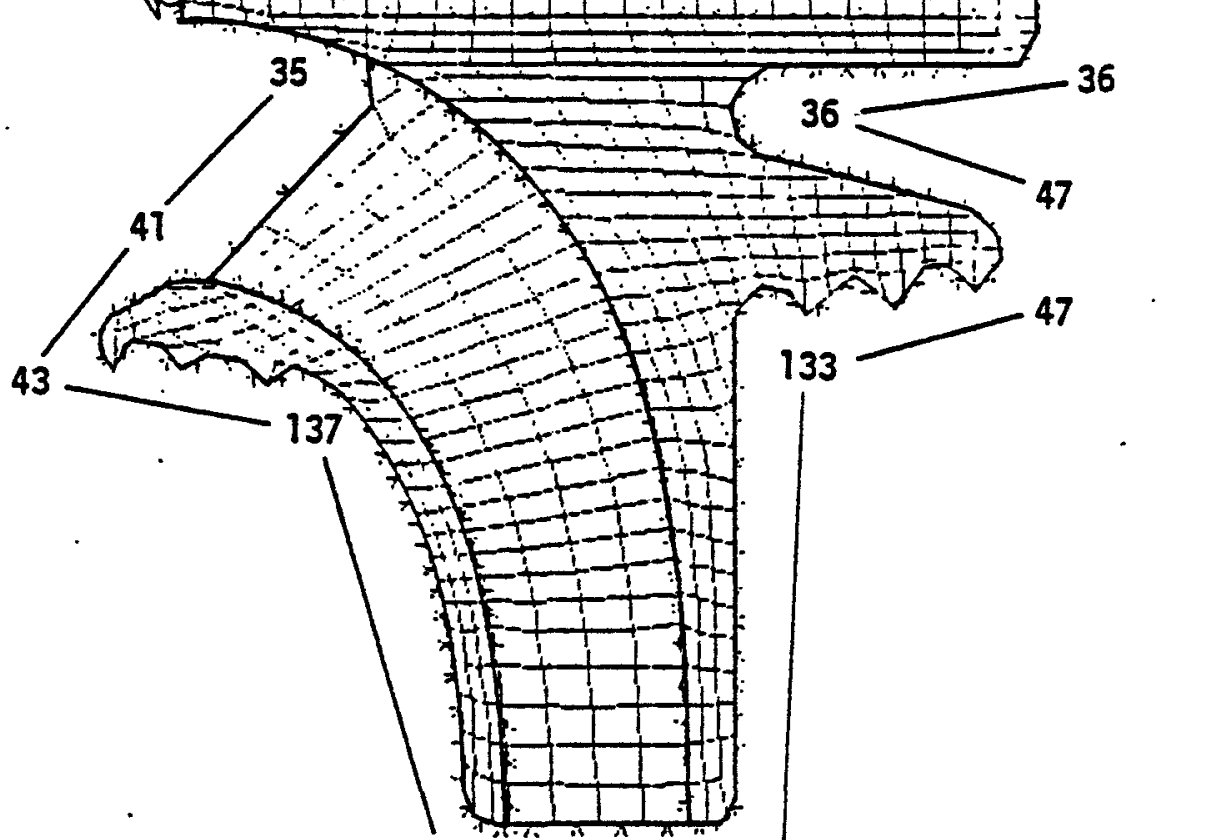

160

160

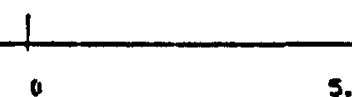

5. 000

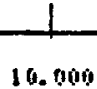

$\frac{1}{1 \text {. } 000 j}$

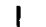

L

DI IE IISI I I

I II C HE: 
- lOADING:

$\begin{array}{ll}\text { SHRINK FIT } & 0,0013 \text { IN, RADIAL } \\ \text { TEMP. } & 1050 F \\ \text { SPEED } & 1110 \mathrm{RPM} \\ \text { FLOWRATE } & 8000 \mathrm{GPM} \\ \text { PRELOAD } & 21 \mathrm{KIPS}\end{array}$

- STRESS INTENSITIES

\begin{tabular}{cccc} 
LOCATION & \multicolumn{1}{c}{ S KSI } & DESIGN MARGIN \\
\cline { 1 - 1 } K & & 7.48 & .03 \\
J & 6.72 & .15 \\
H & 5.88 & .31 \\
G & 5.04 & .53 \\
D & 2.52 & 2.07 \\
B & .84 & 8.20
\end{tabular}

- MATERIAL: 304 CRES

$$
S_{m}=7.73 \text { KSI }\left(P_{1}+P_{b}\right)
$$

FIGURE 33

IMPELLER STRESS INTENSITIES

STEADY STATE CONDITIONS

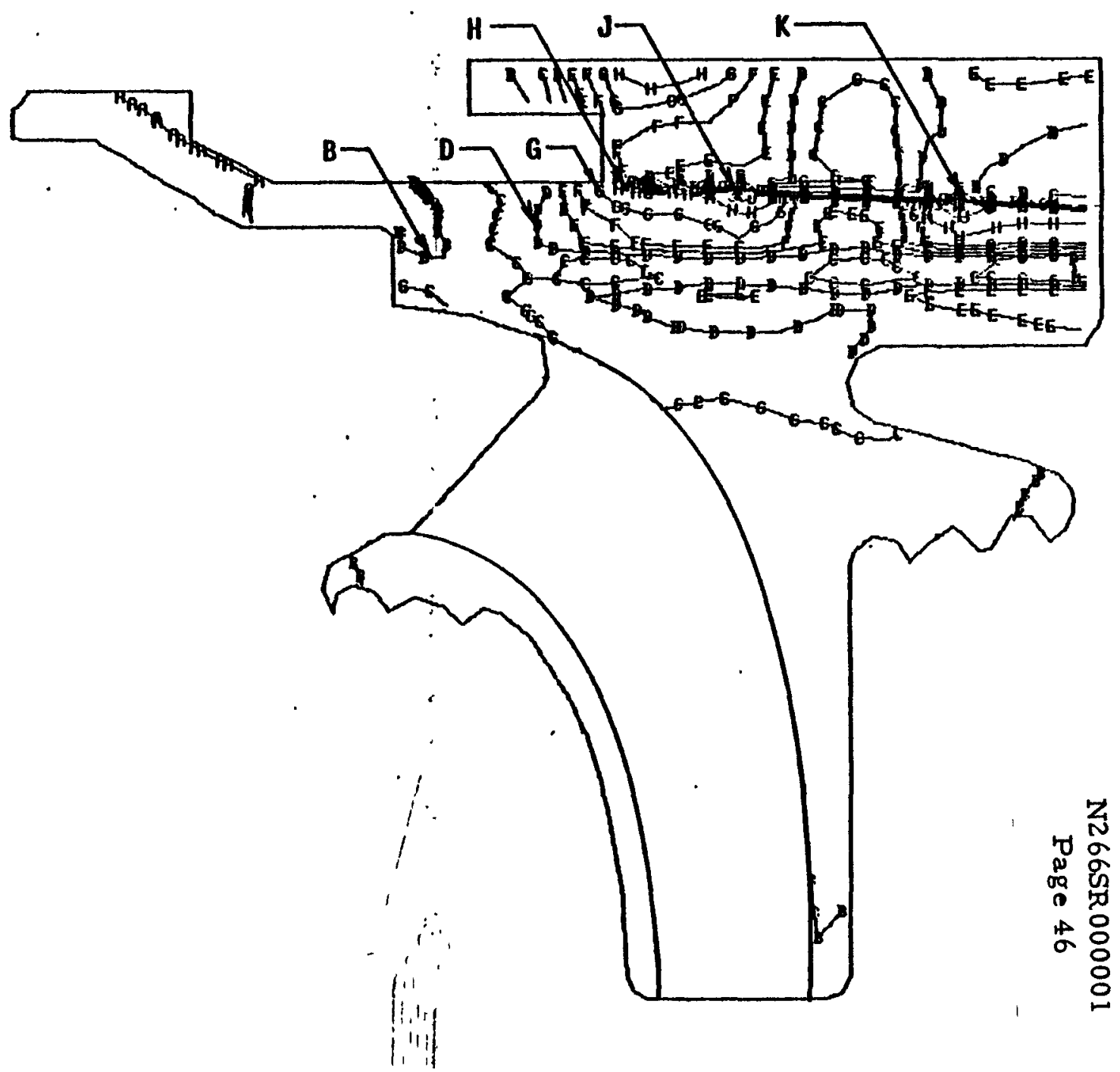


FIGURE 34

\section{IMPELLER STRESS INTENSITIES}

SHRINK FIT

- LOADING:

$\begin{array}{ll}\text { SHRINK FIT } & \text {.0013 IN RADIAL } \\ \text { TEMP. } & 70 F \text { and 1050F } \\ \text { SPEED } & 0 \text { RPM } \\ \text { PRESSURE } & 0 \\ \text { PRELOAD } & 21 \text { KIPS }\end{array}$

- STRESS INTENSITIES

\begin{tabular}{|c|c|c|c|c|}
\hline & \multicolumn{2}{|c|}{ S KSI } & \multicolumn{2}{|c|}{ DESIGN MARGIN } \\
\hline LOCATION & $70 \mathrm{~F}^{-2}$ & 1050F & $70 \mathrm{~F}$ & $1050 \mathrm{~F}$ \\
\hline $\begin{array}{l}\mathbf{K} \\
\mathbf{J} \\
\mathbf{H} \\
\mathbf{G} \\
\mathbf{F}\end{array}$ & $\begin{array}{r}10.50 \\
9.44 \\
8.26 \\
7.08 \\
5.90\end{array}$ & $\begin{array}{l}8.20 \\
7.37 \\
6.45 \\
5.52 \\
4.61\end{array}$ & $\begin{array}{r}.90 \\
1.12 \\
1.42 \\
1.82 \\
2.39\end{array}$ & $\begin{array}{r}-.06 \\
.05 \\
.02 \\
.40 \\
.68\end{array}$ \\
\hline
\end{tabular}

- MATERIAL: - 304 CRES

$\begin{aligned} \text { 70F: } & S_{m}=20.00 \text { KSI }\left(P_{1}+P_{b}\right) \\ \text { 1050F: } & S_{m}=7.73 \text { KSI }\left(P_{1}+P_{b}\right)\end{aligned}$

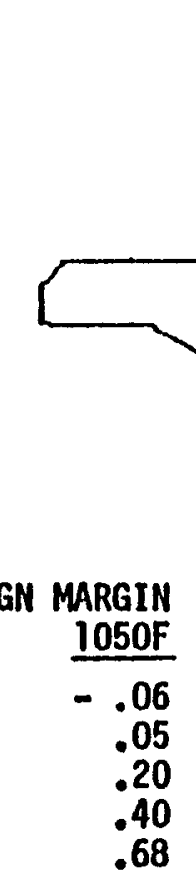




\section{FIGURE 35}

$\Gamma$

AI INTERTEDIATE SODILM PUTP IMPELER

AXISTMRETRIC ANLLISIS SIEMA-P IS PLOTTED

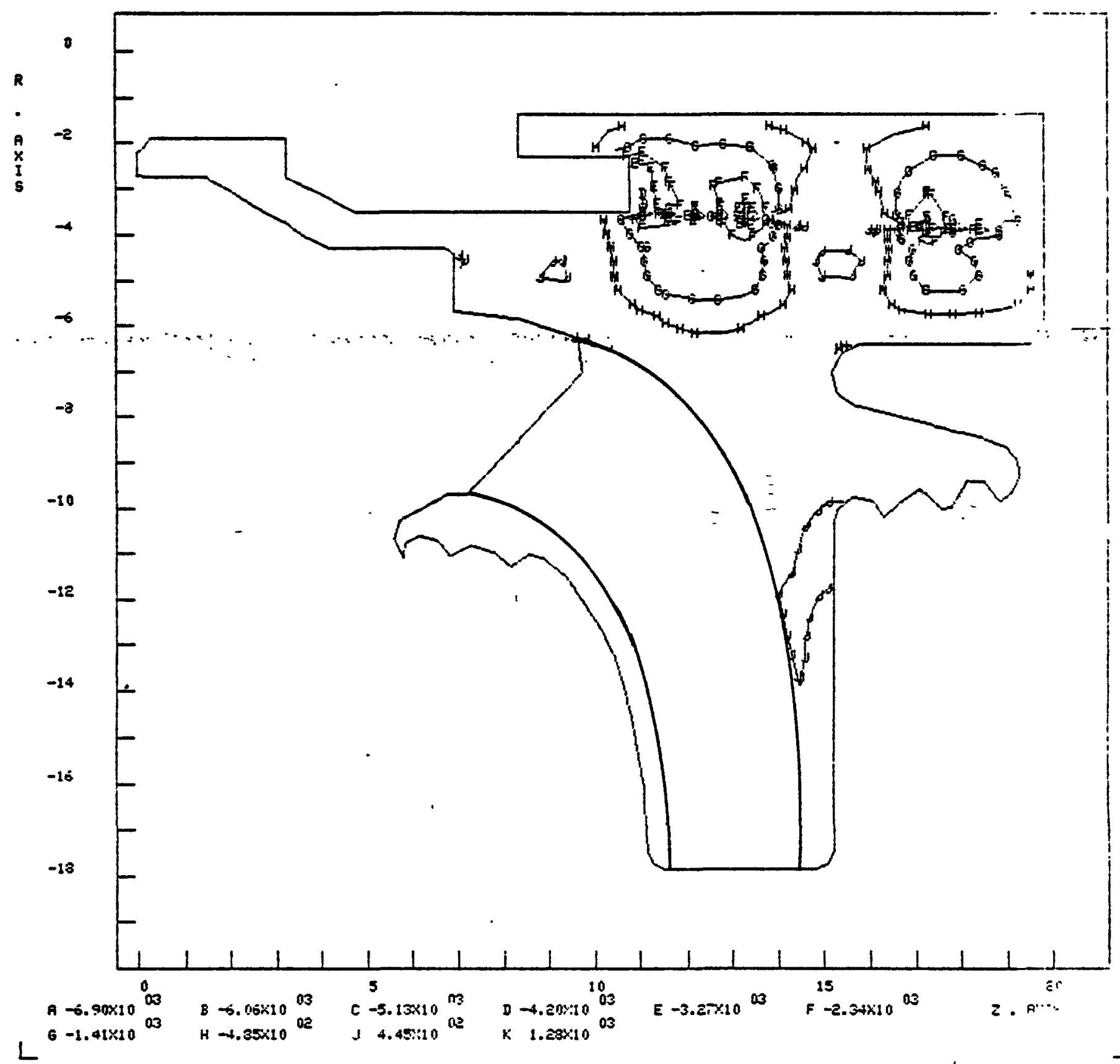




\section{FIGURE 36}

$\Gamma$

AI IITEREDIATE SODIUM PUMP IMPELLER

RXISHMETFIC ANLLISIS SIGMAR IS PLOTTED

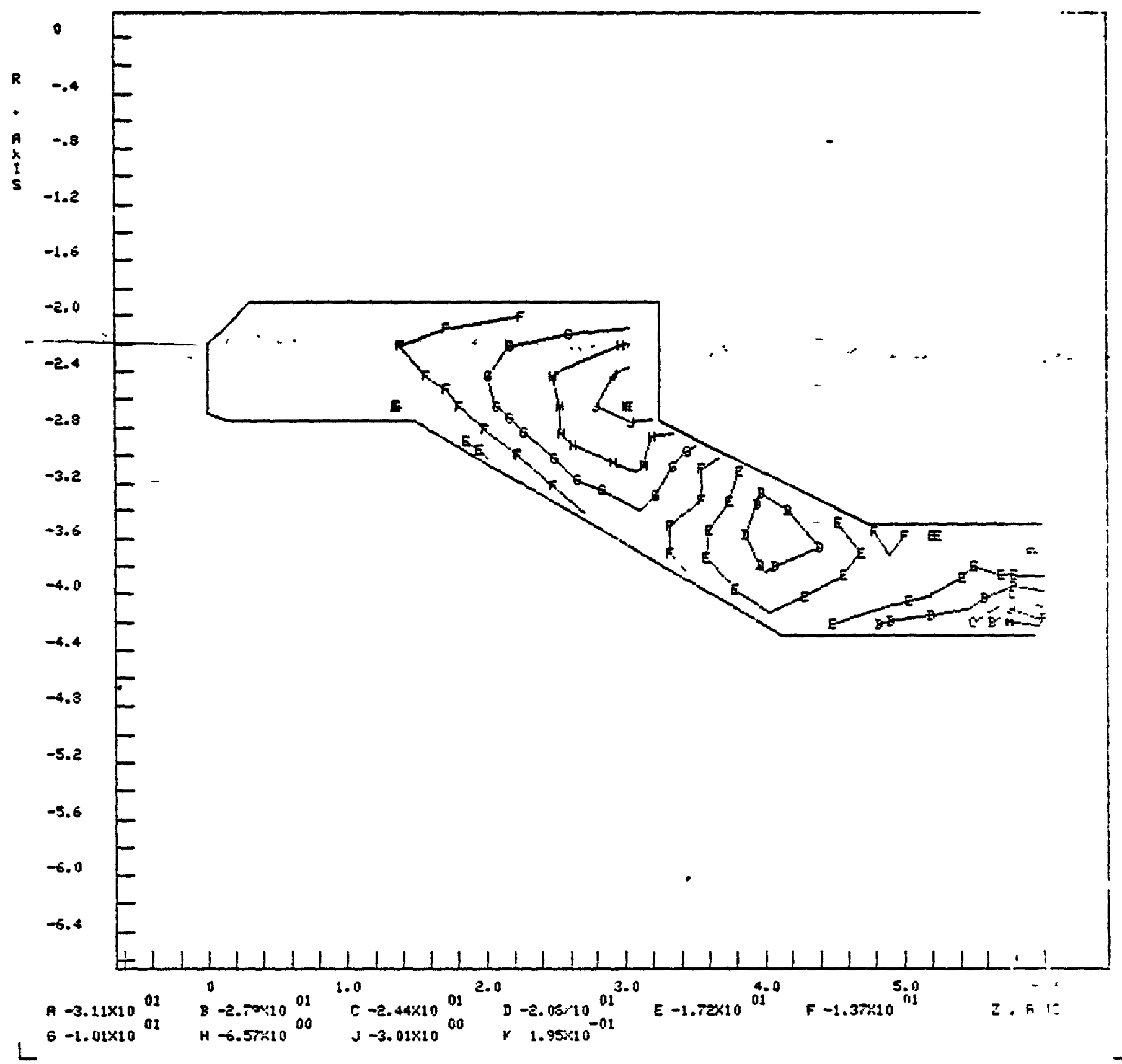




\section{FIGURE 37}

$\Gamma$

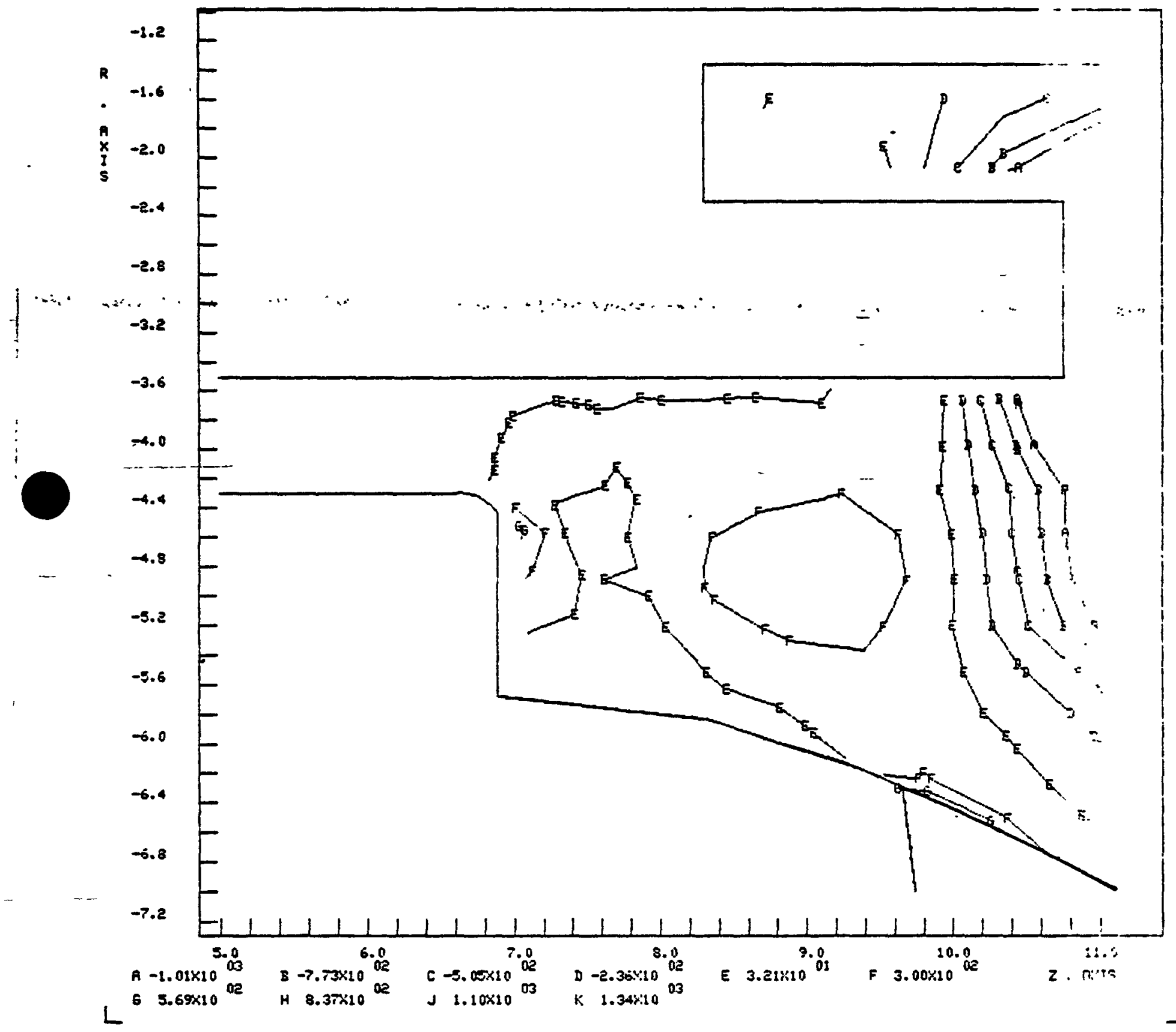




\section{FIGURE 38}

$\Gamma$

AI IMTERTEDIATE SODIUM PUNP IMPELLER

AKISITHETRIC ANRLYSIS SIGMA-R IS PLOTTED

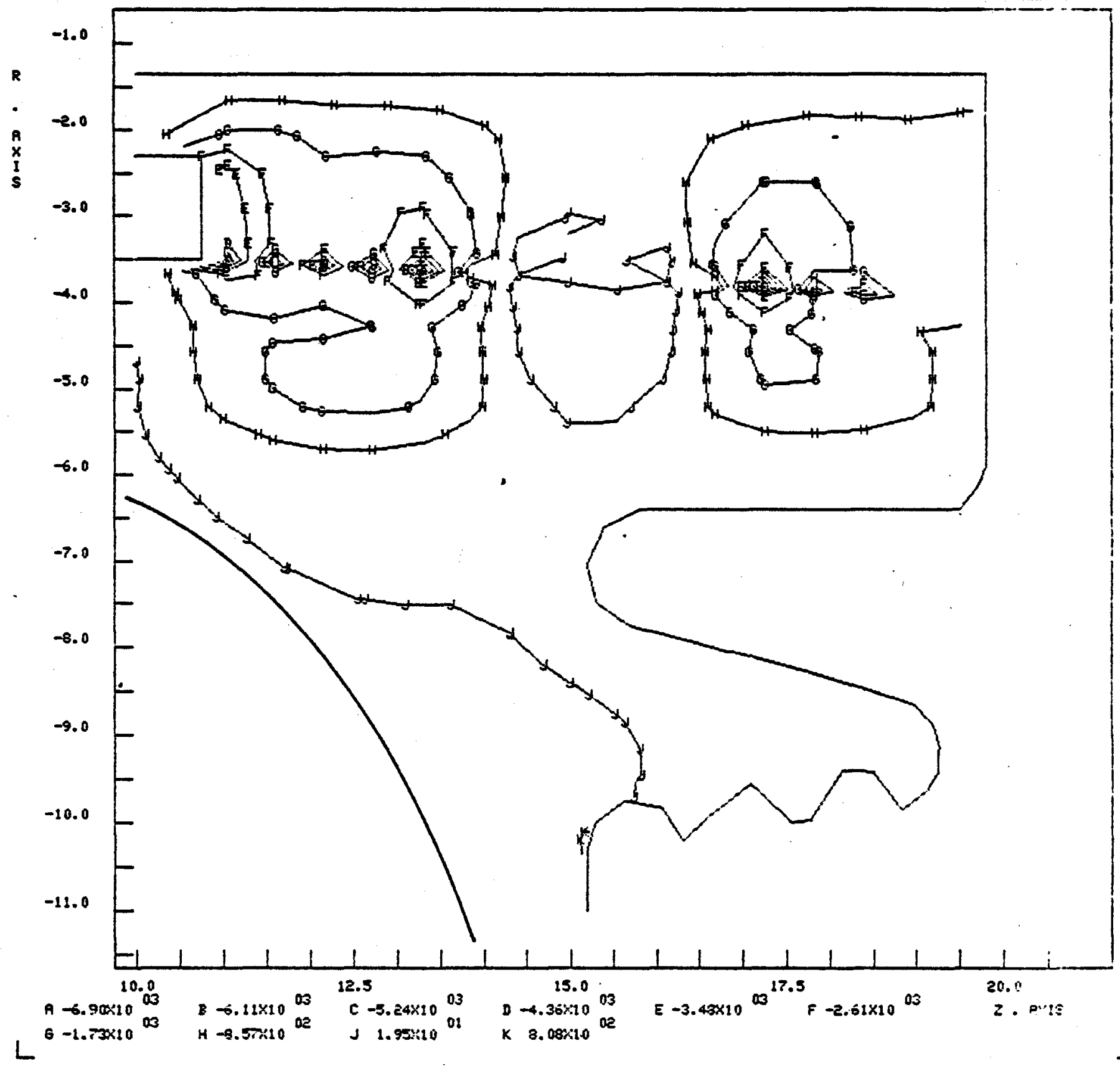




\section{FIGURE 39}

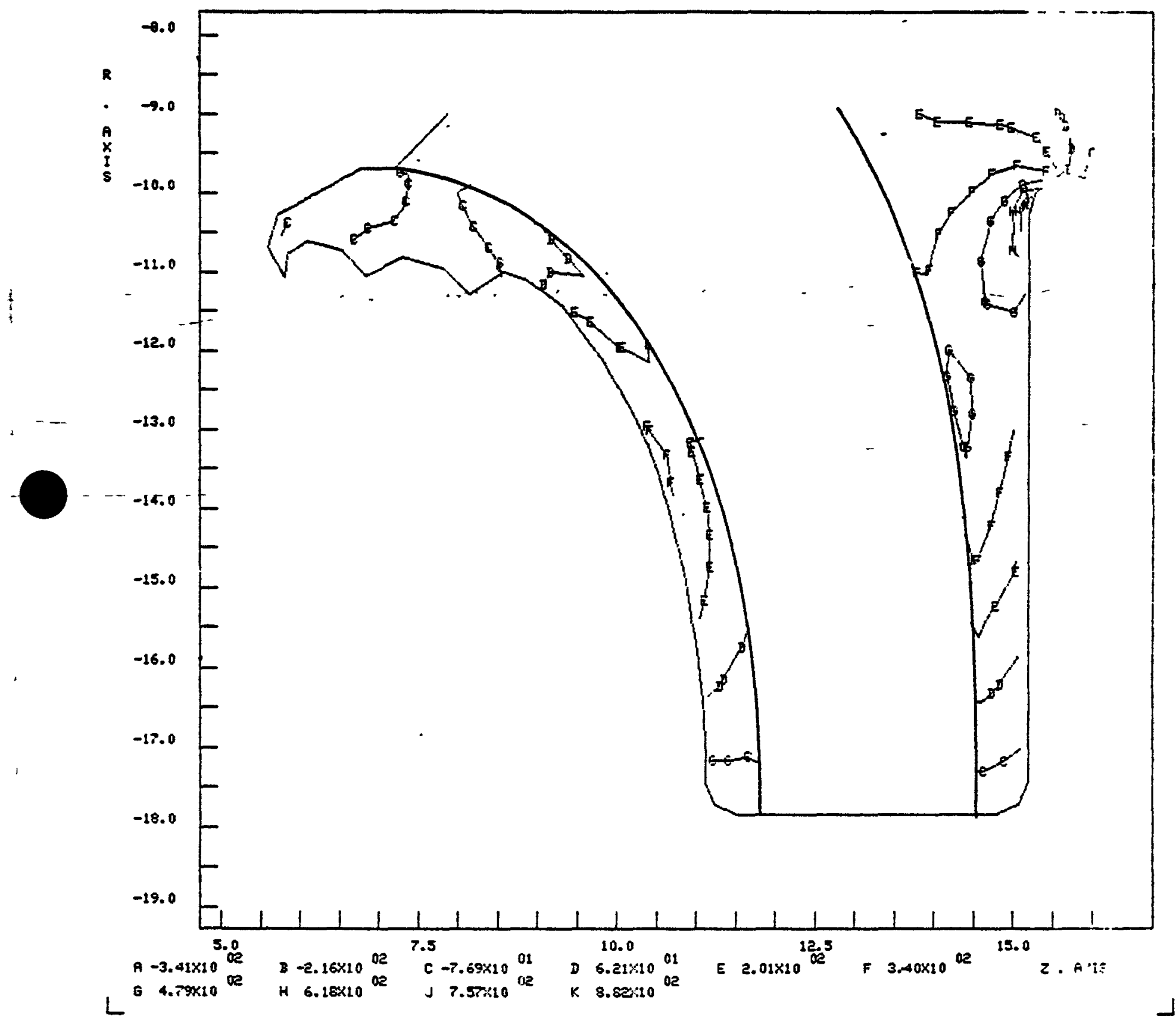




\section{FIGURE 40}

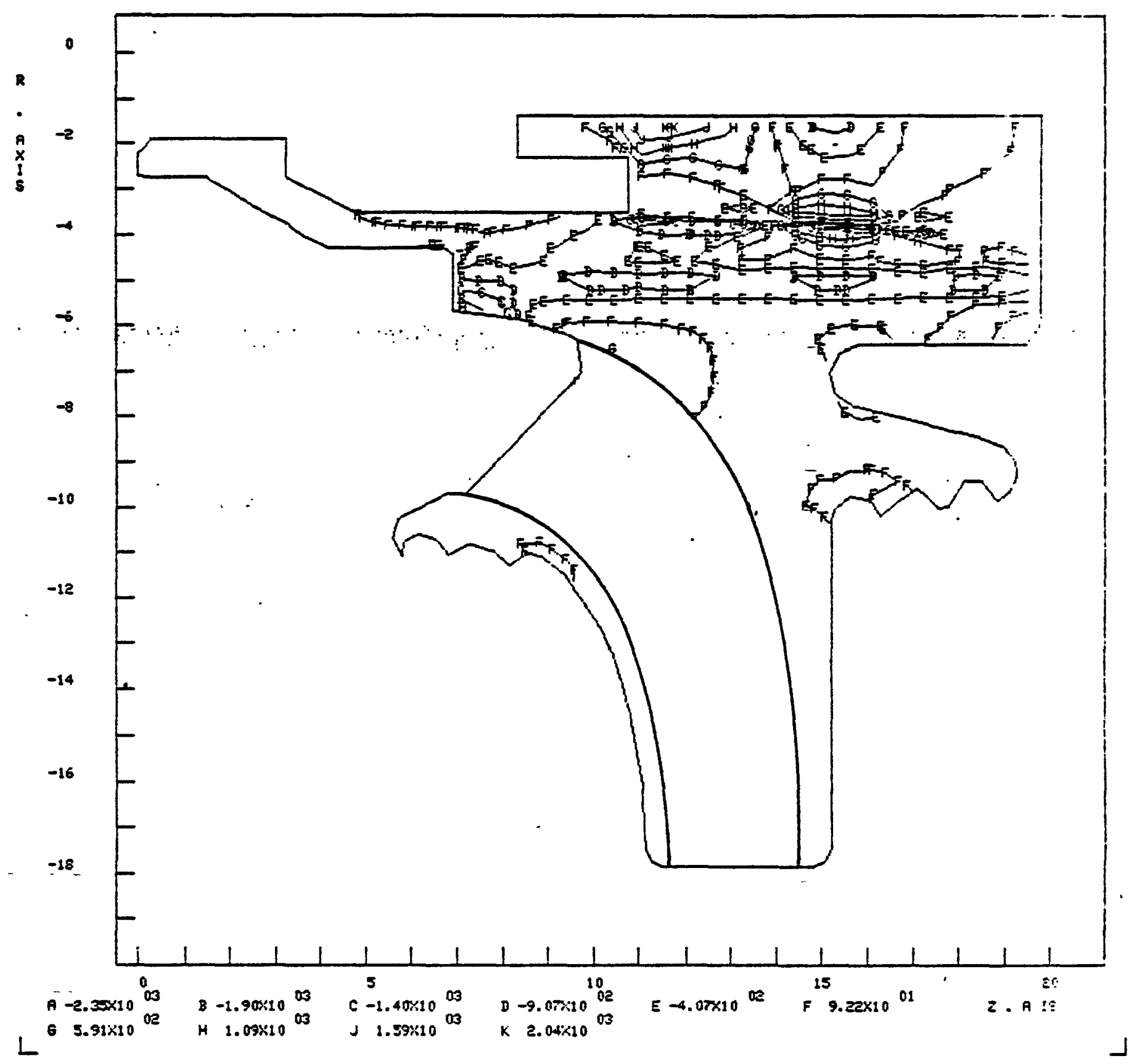


N266ER000-001

Page 302

N266SR000001

Page 54

\section{FIGURE 41}

$\Gamma$

AI IMTERMEDIATE SODIUM PUMP IMPELLER

AXISTMETRIC ATALISIS SIGMA-Z IS PLOTTED

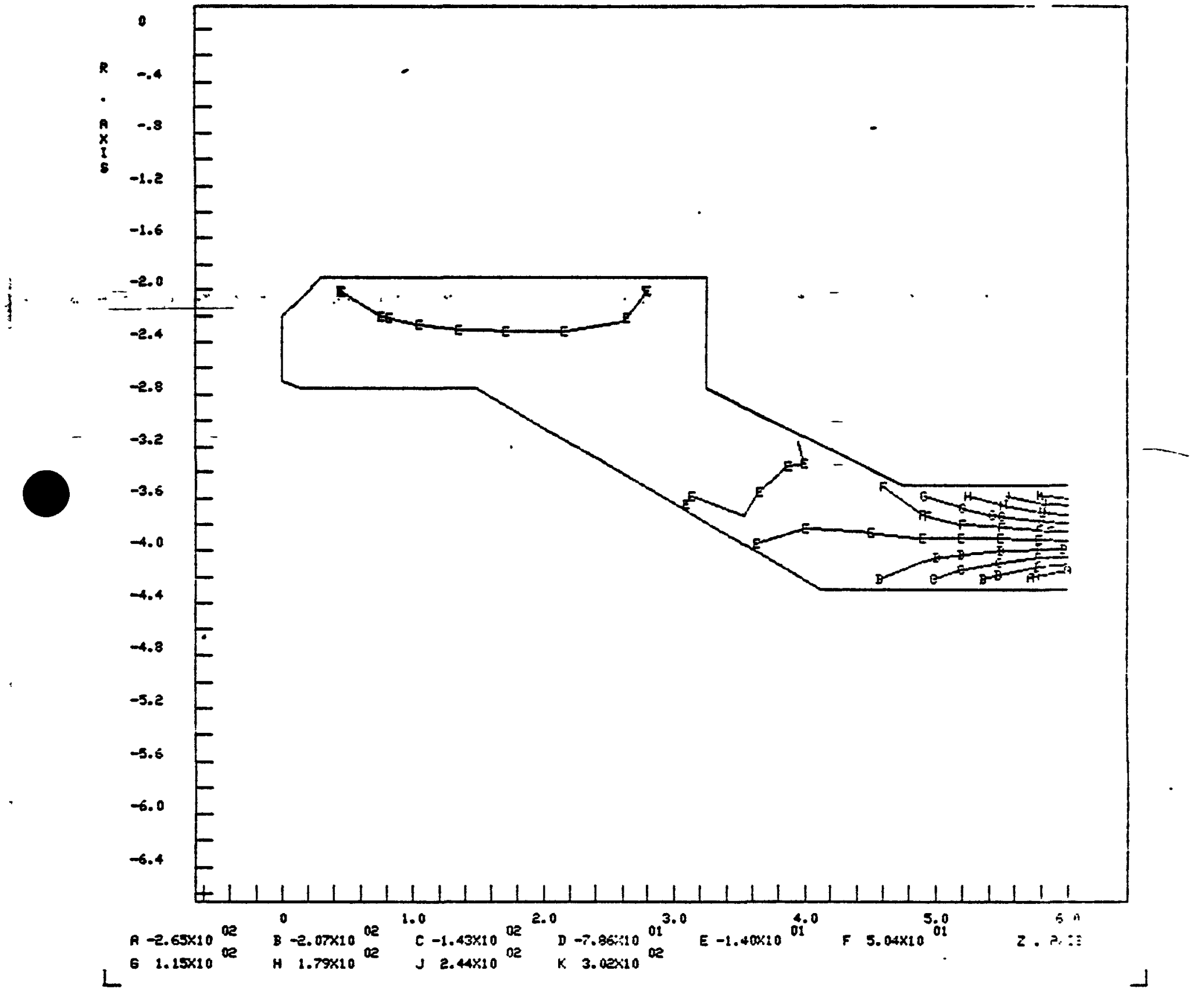




\section{FIGURE 42}

$\Gamma$

AI INTERMEDIATE SODIUM PUMP IMPELLER

AXISTMETRIC ARALYSIS SIEMA-: IS PLOTTED

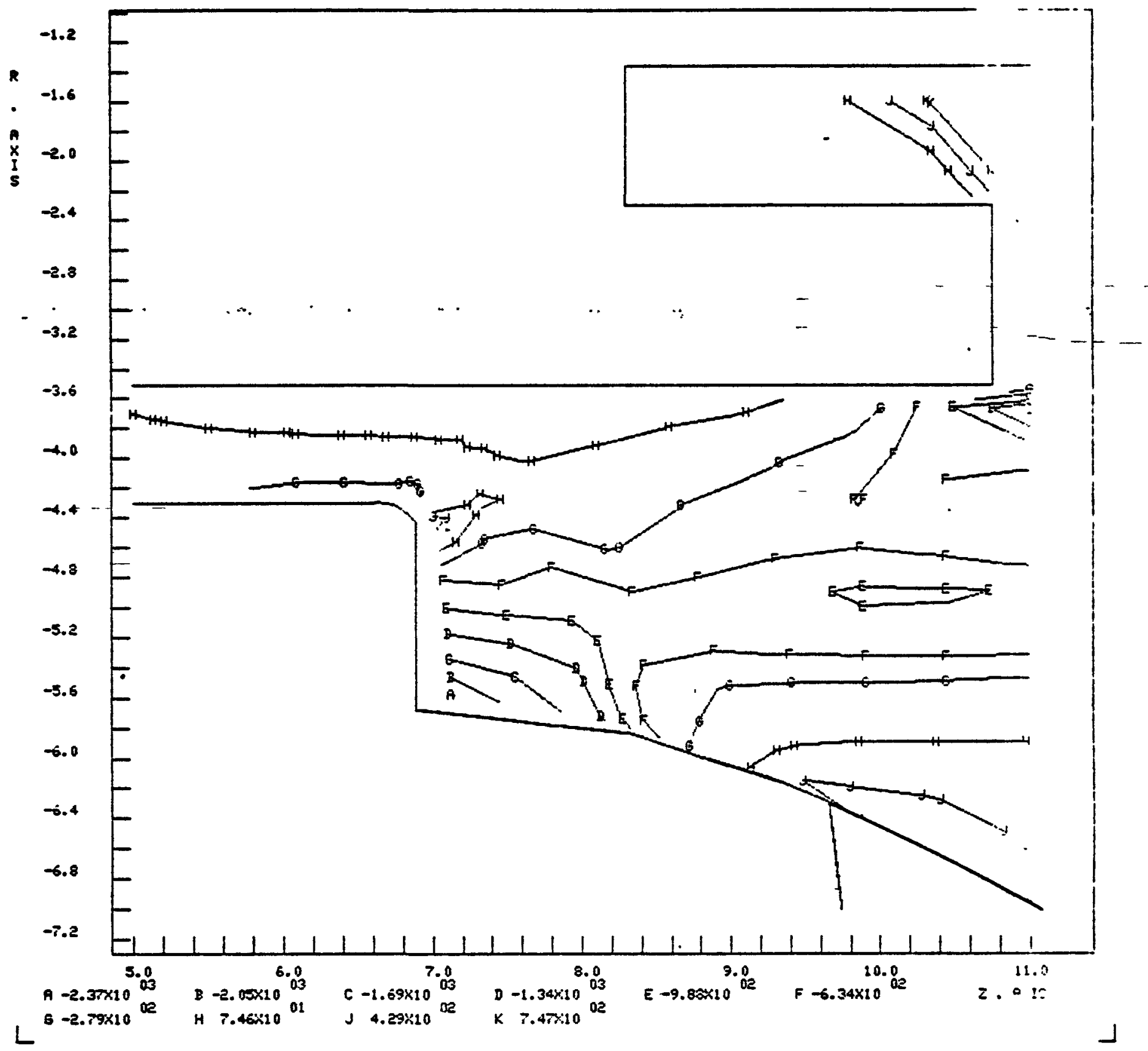




\section{FIGURE 43}

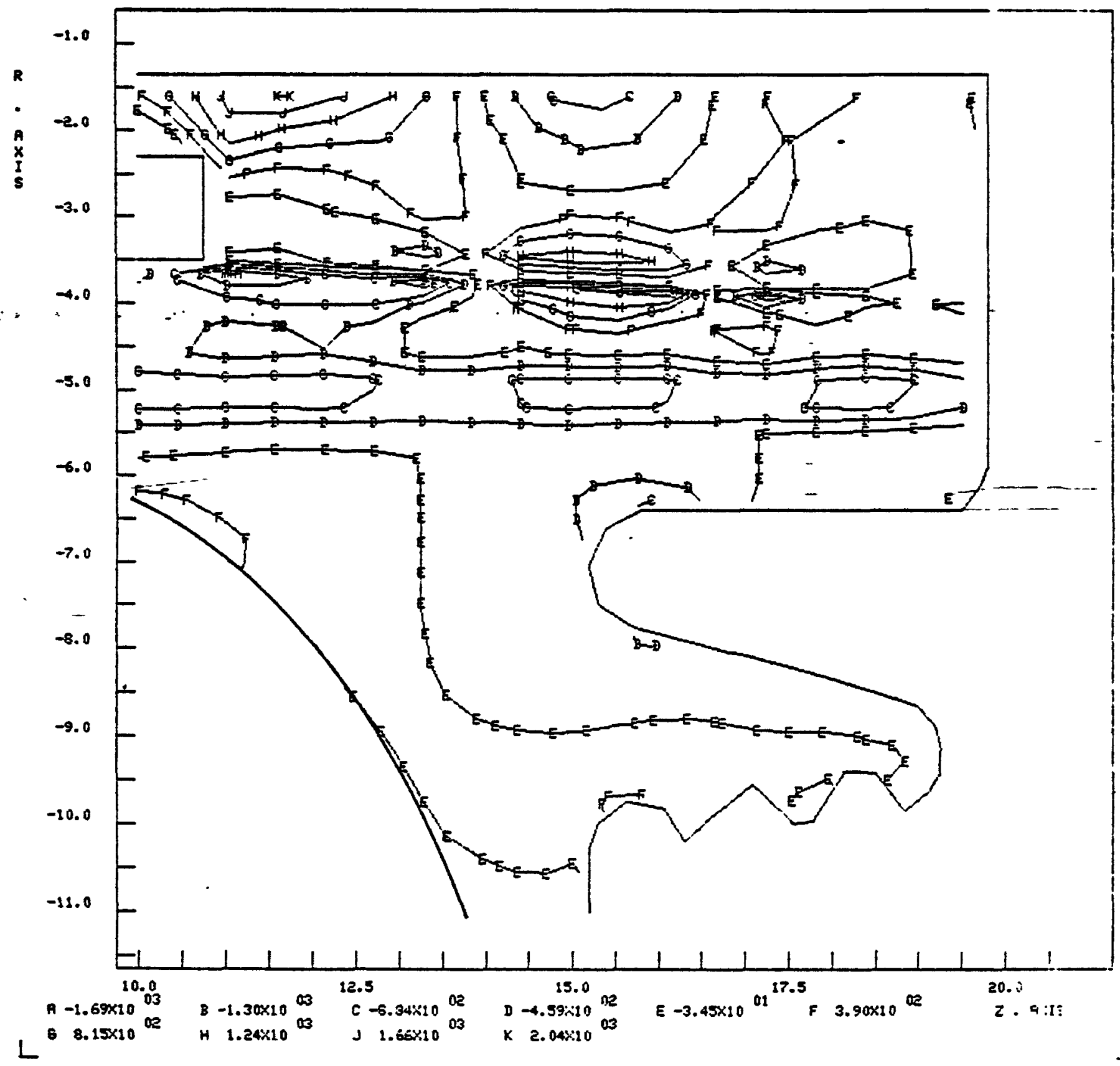




\section{FIGURE 44}

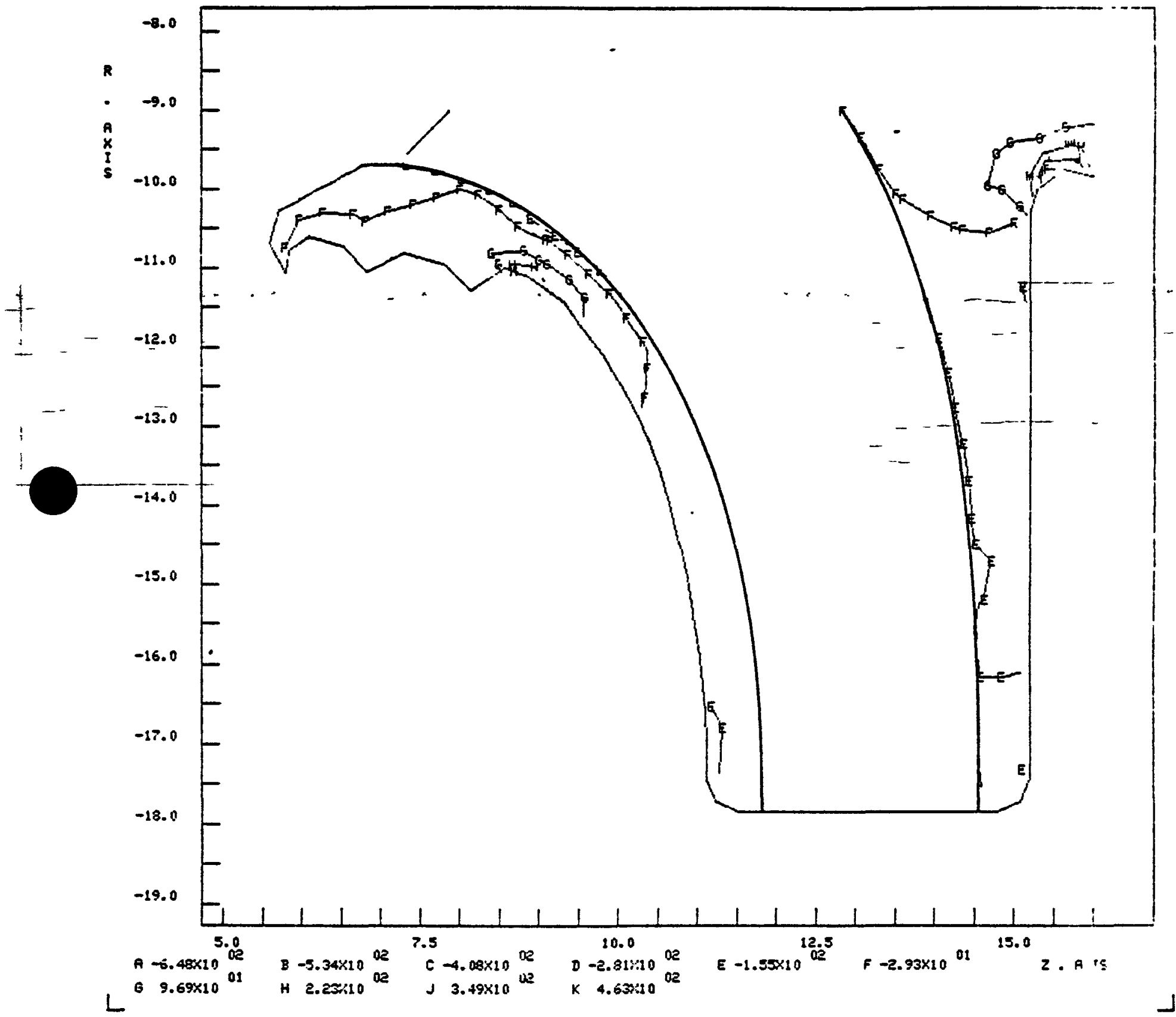




\section{FIGURE 45}

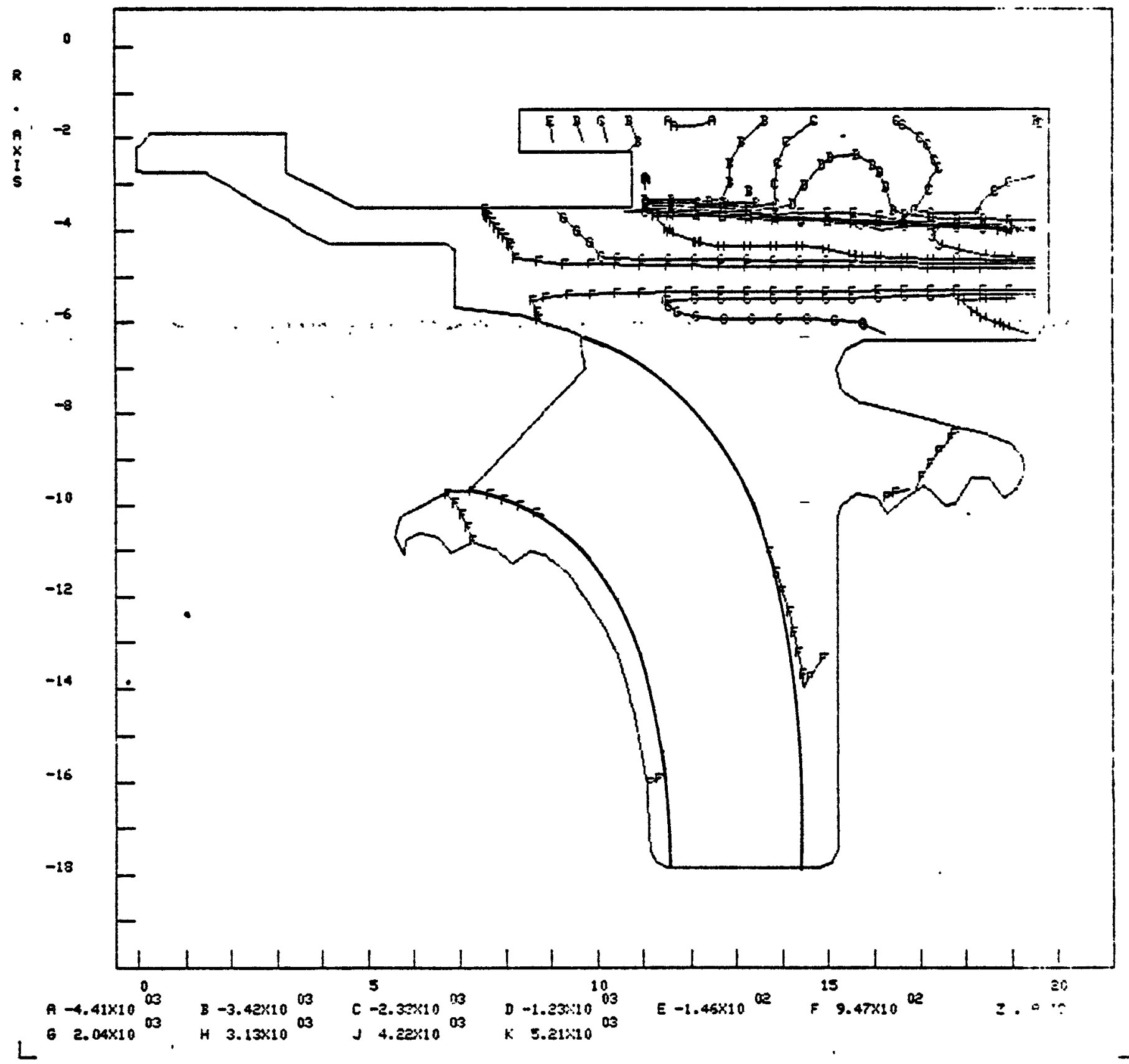




\section{FIGURE 46}

$\Gamma$

AI INTERTEDIATE SODIUM FUMP IMPELLP

ARISIMUETRIC ANFL'RIS SIGHAT IS FLOTTES

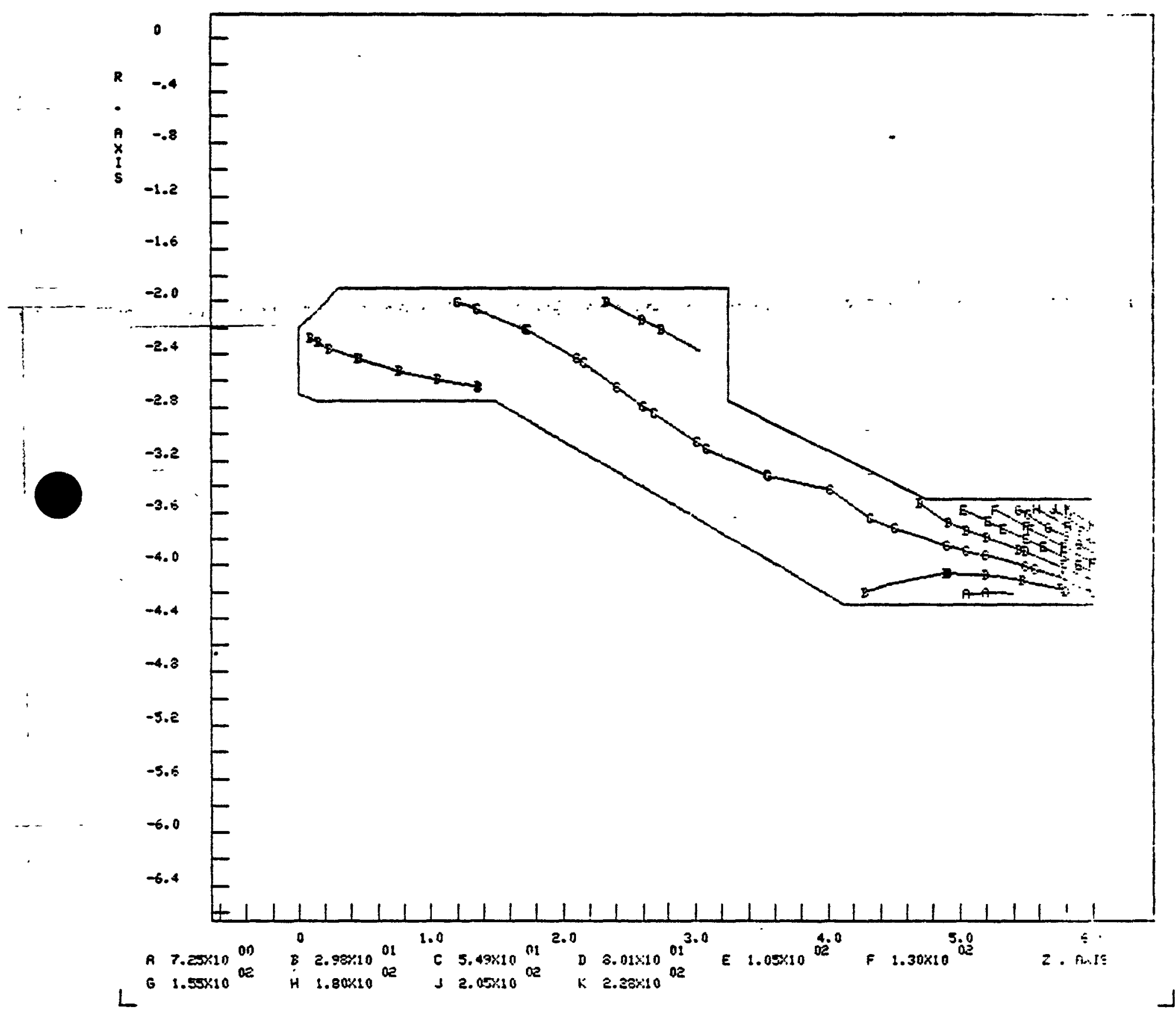




\section{FIGURE 47}

$\Gamma$

'AI IMTERTEDIATE SODIUM PUHP IMPELLER

AXISIMUETRIC ANALIS SIEMTT IS PLOTTEI

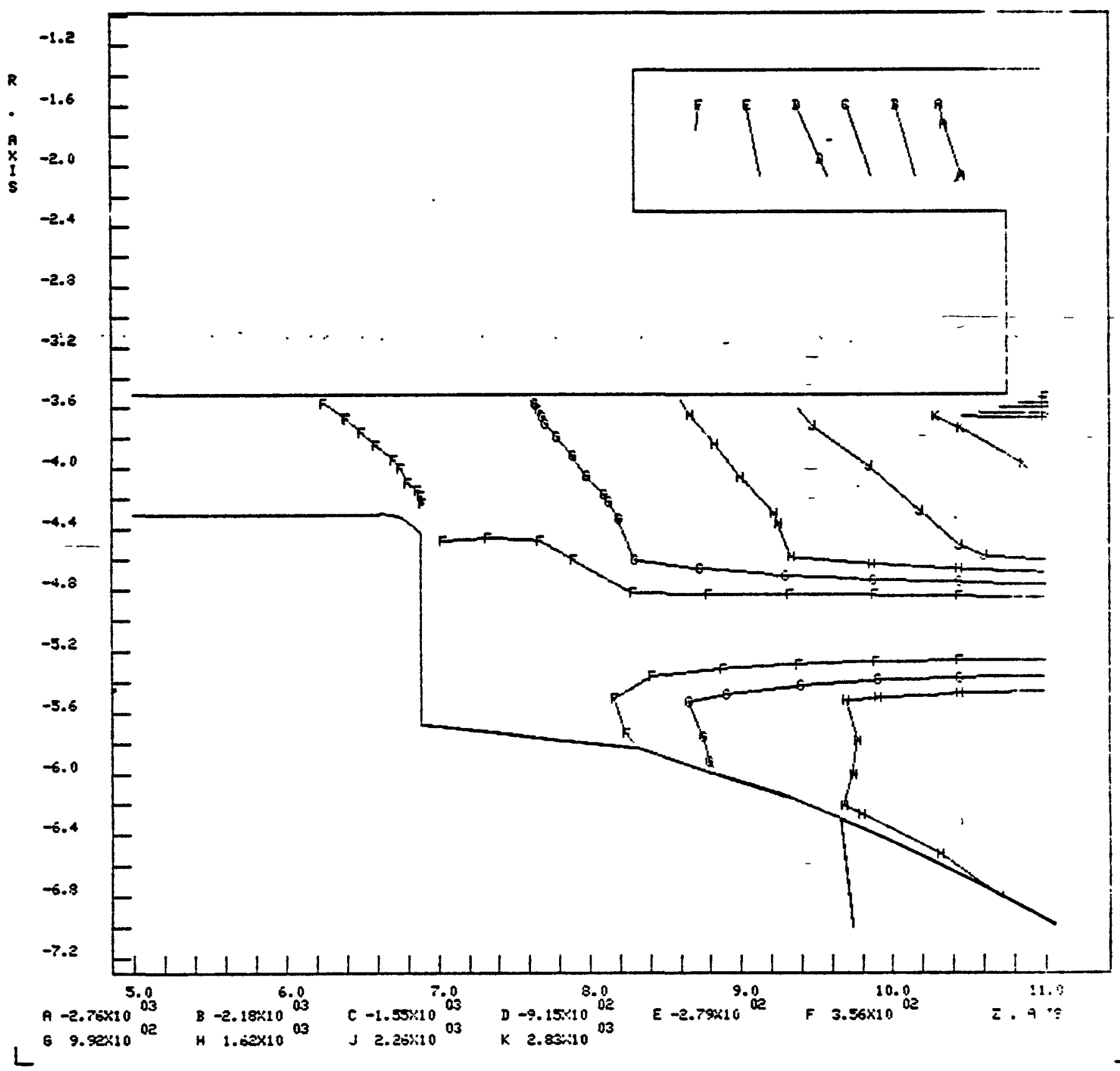


N266ER000-001

Page 309

N266SR000001

Page 61

\section{FIGURE 48}

$\Gamma$

AI INTERTEDIATE SODIUN PUMP IMPELER

RXISYIAETRIC ANALYSIS SIENAT IS PLOTTED

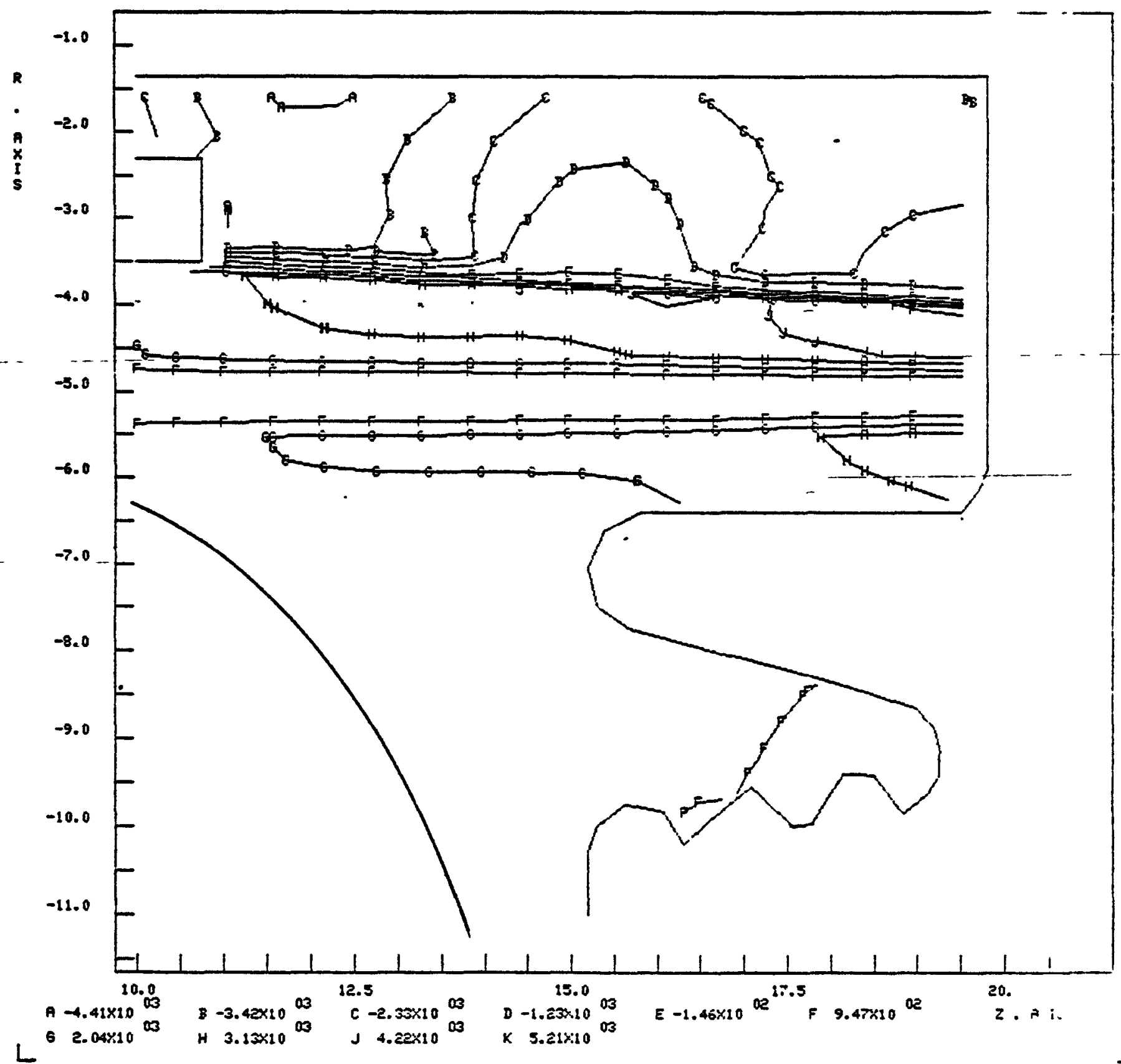




\section{FIGURE 49}

$\Gamma$

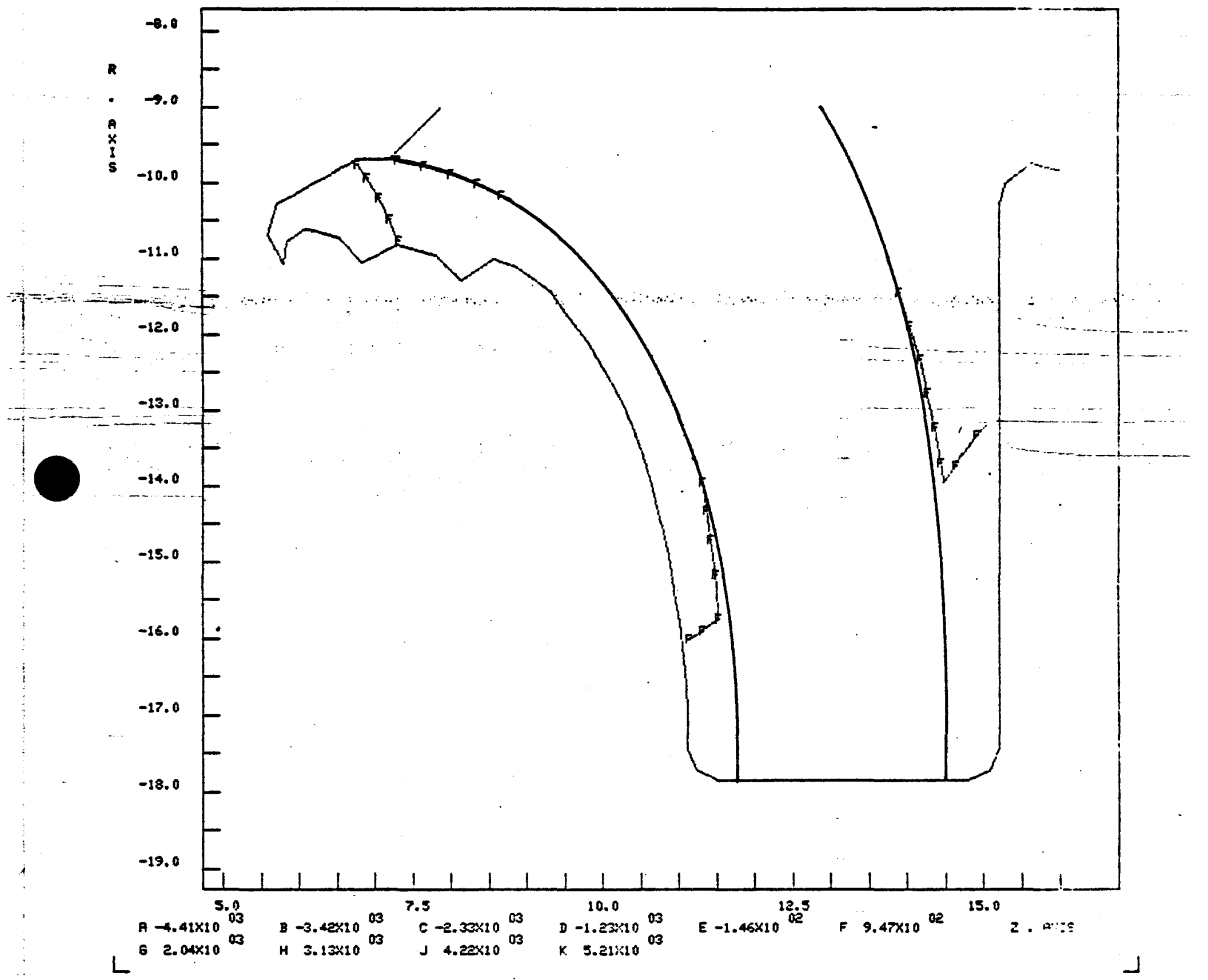




\section{FIGURE 50}

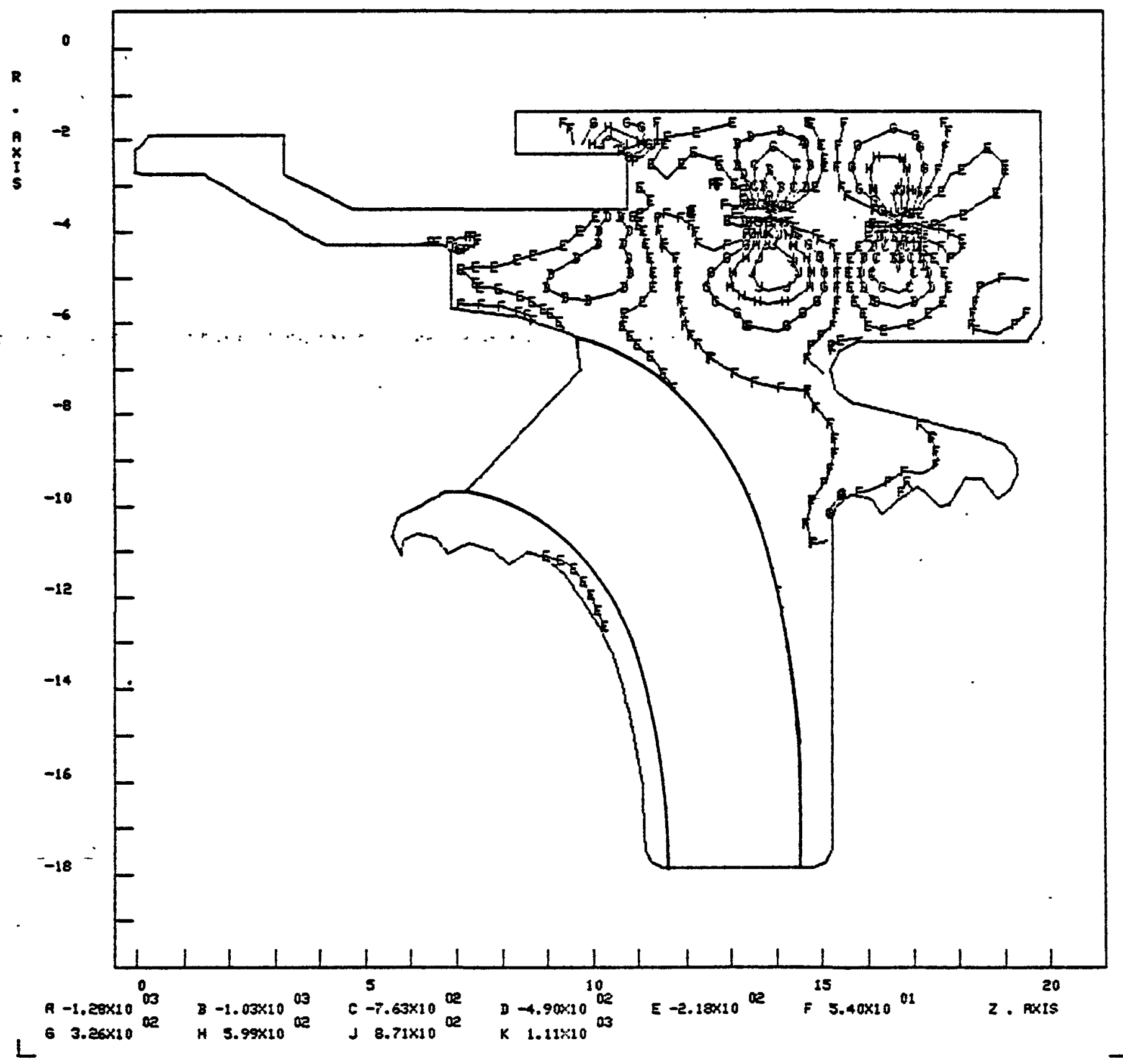




\section{FIGURE 51}

AI IMTERTEIATE SODIUn PUP IMPELLE

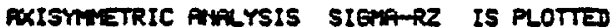

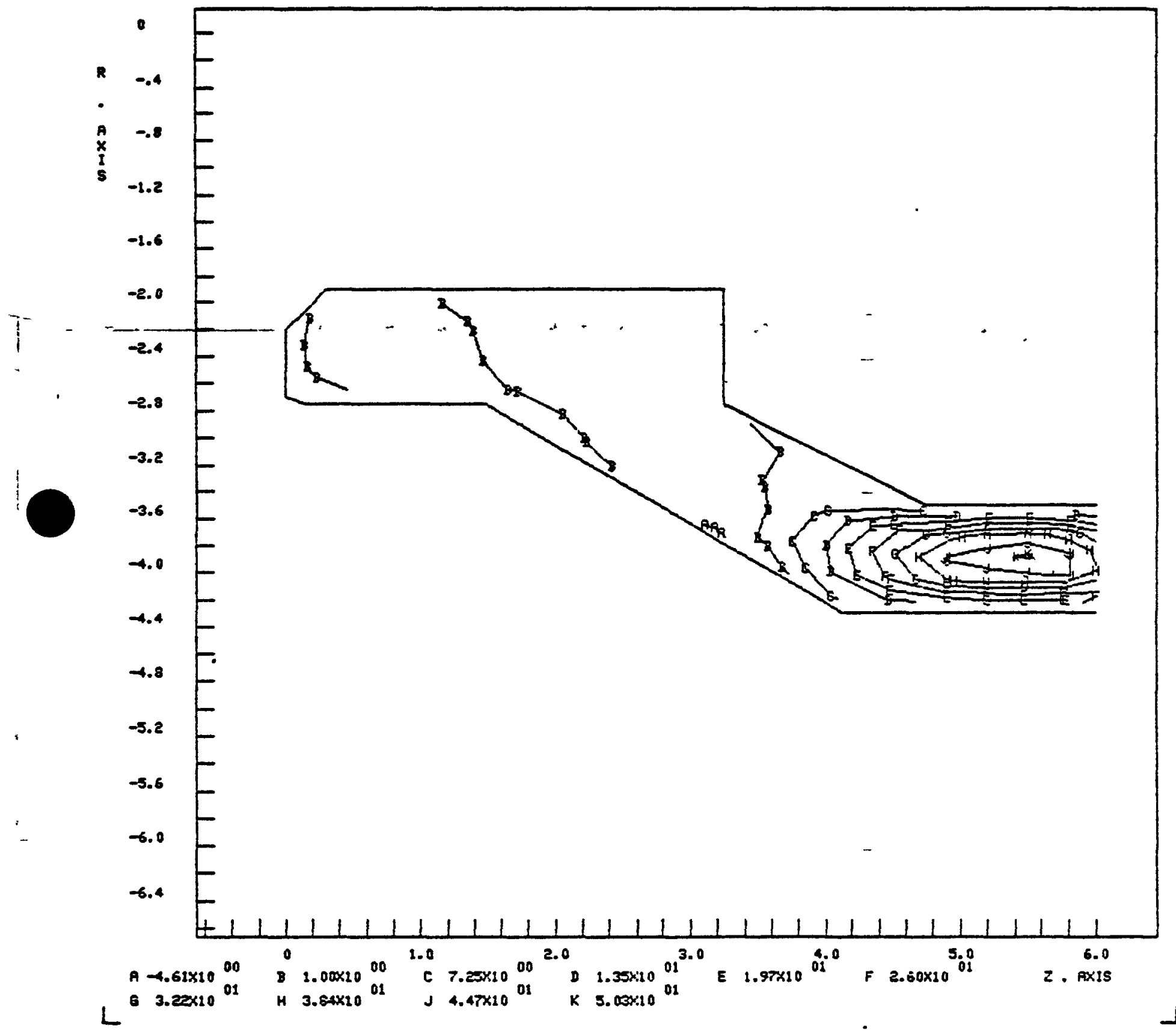




\section{FIGURE 52}

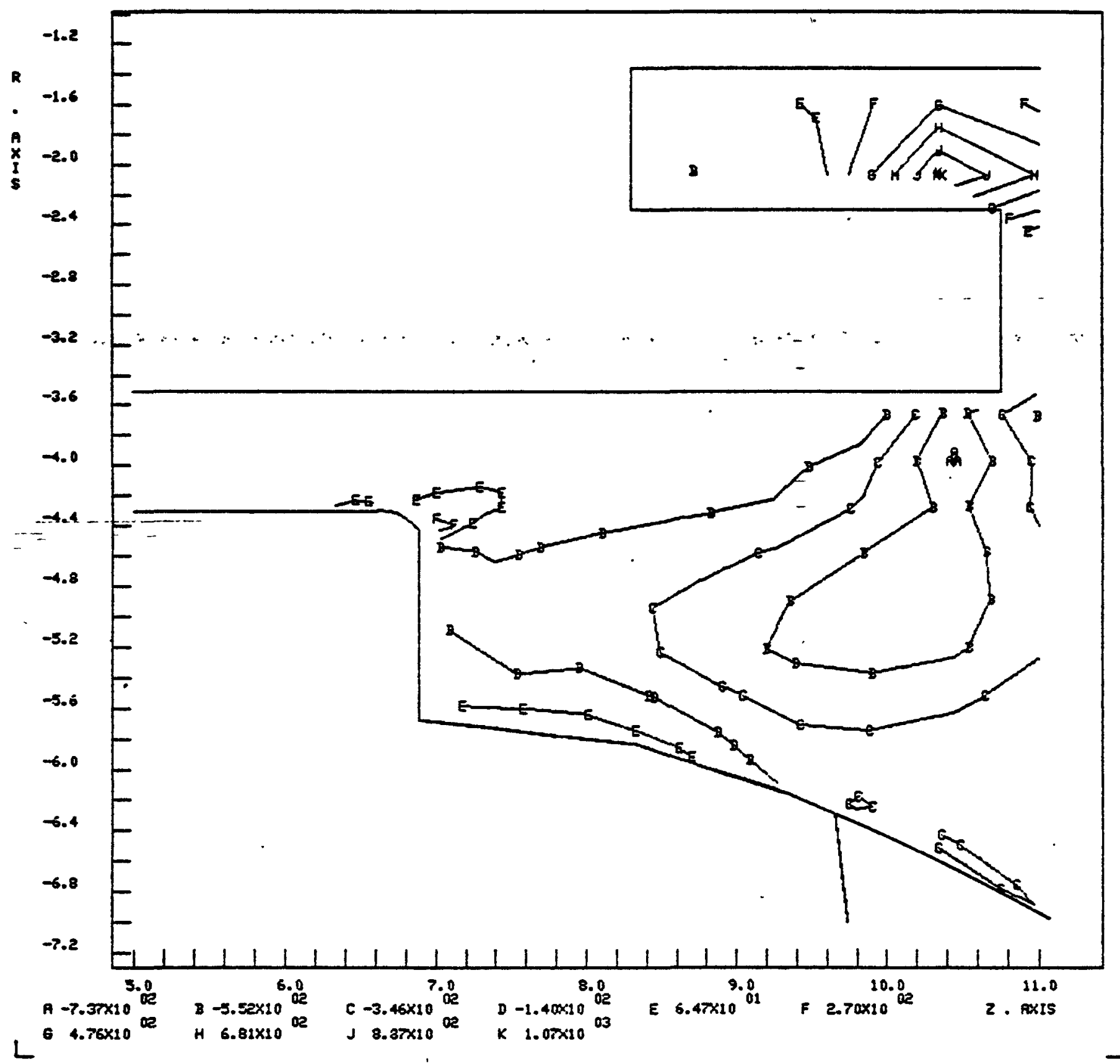


FIGURE 53

AI INTERTEDIATE SODIUN PUMP IMPELER

POXISTMETRIC ANFLYSIS SIGMTRZ is PLOTTED

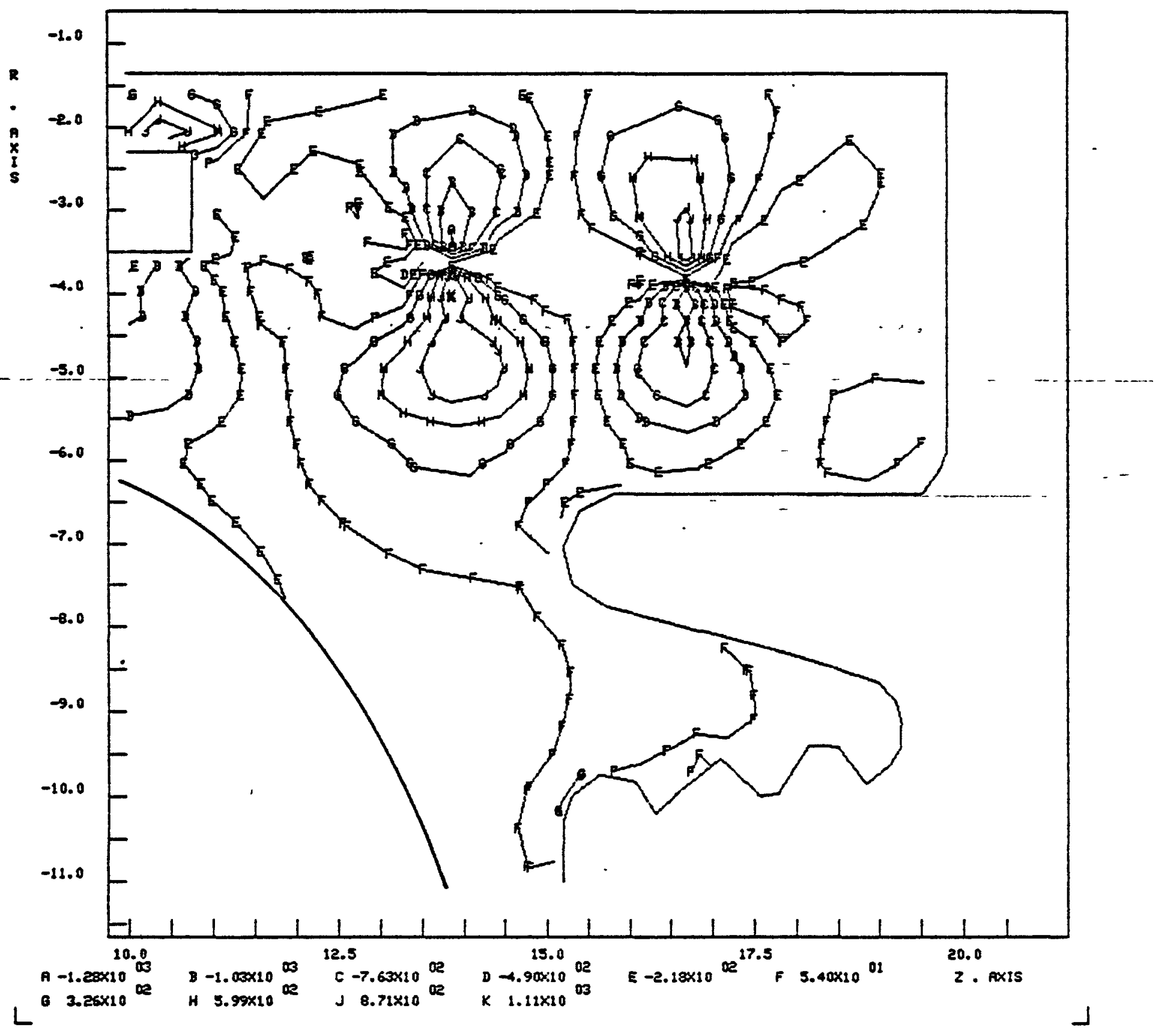




\section{FIGURE 54}

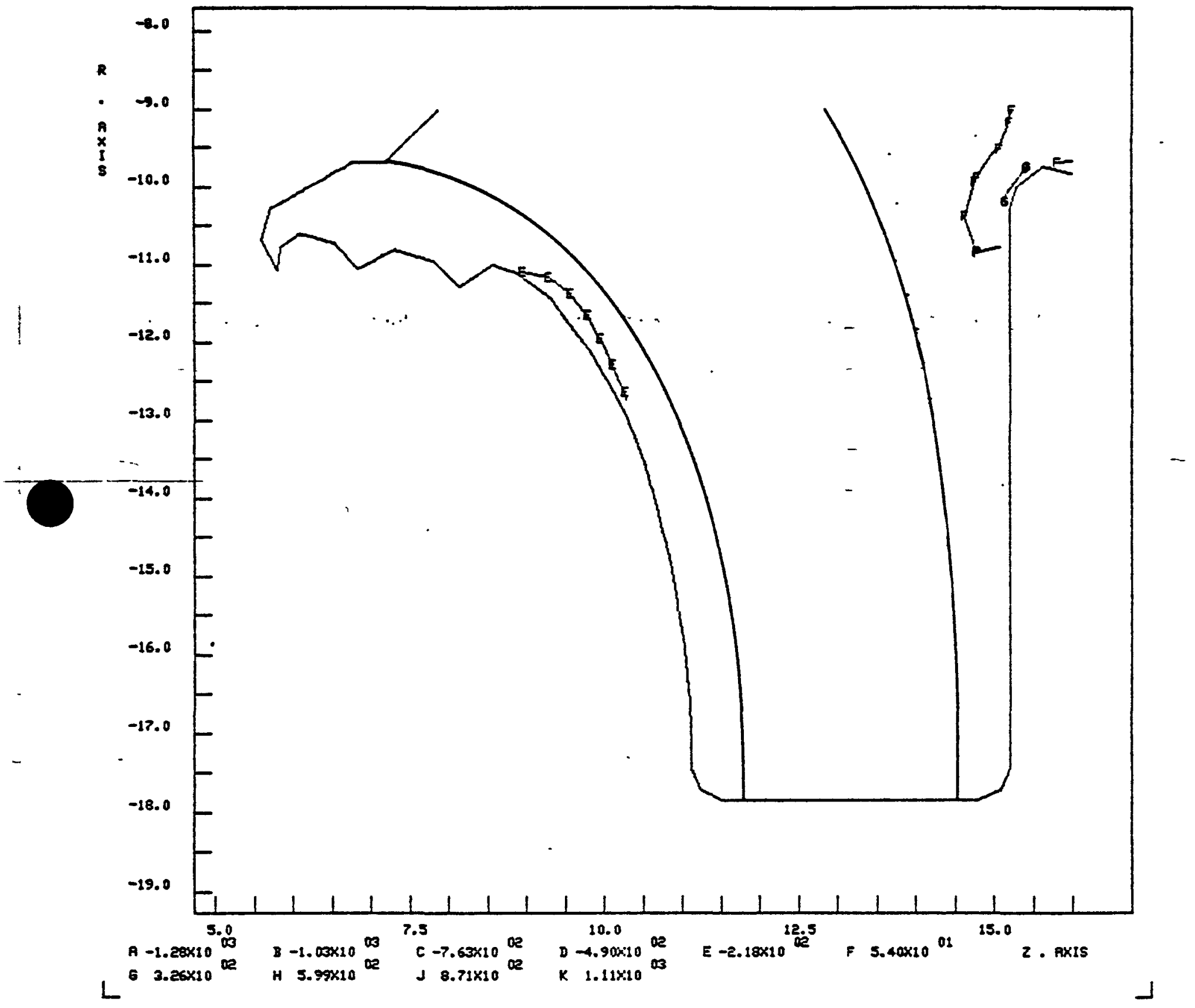




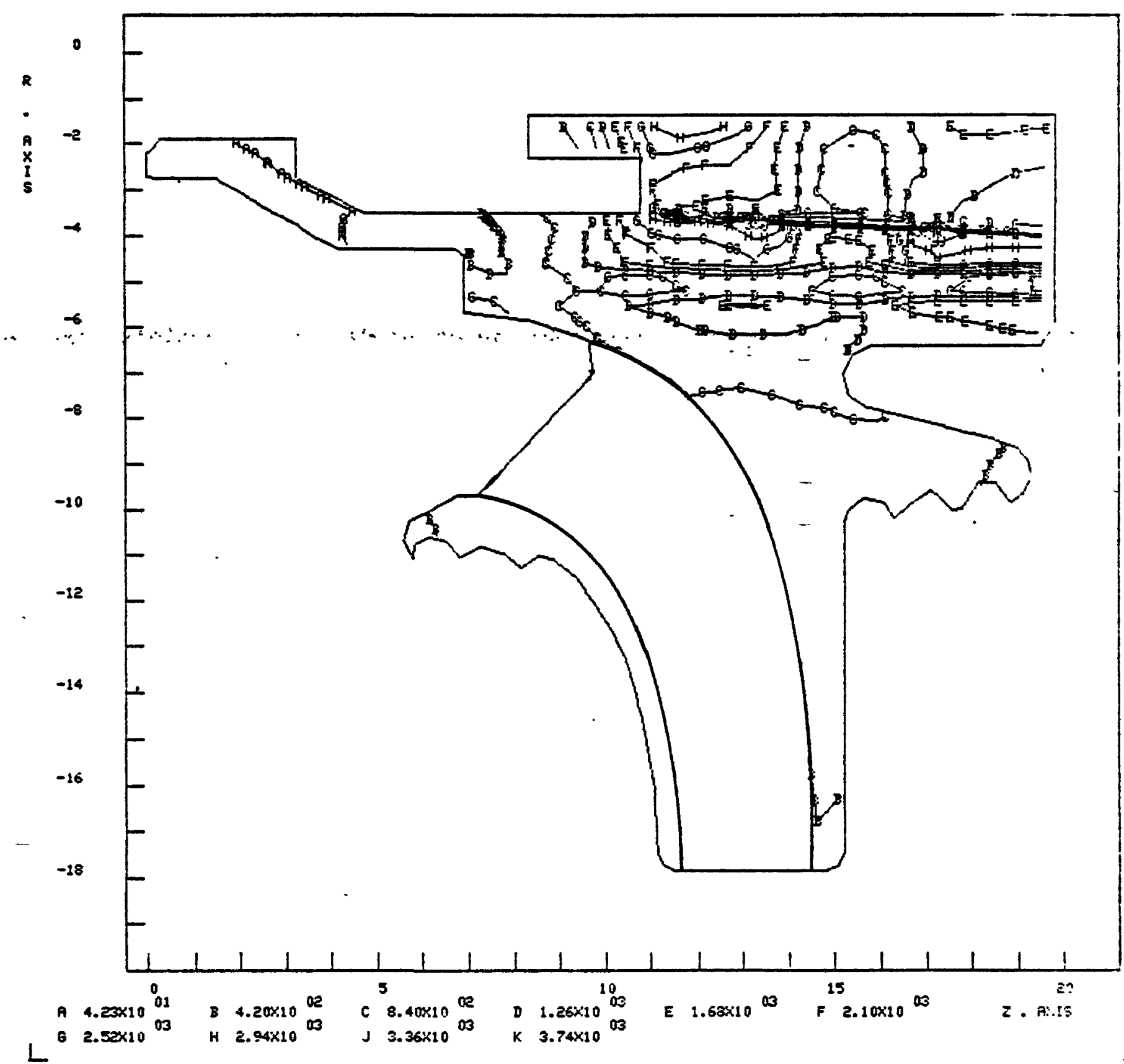




\section{FIGURE 56}

$r$

AI INTEREDIATE SODIUM PUMP IMPELER

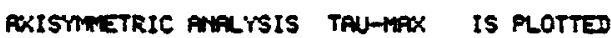

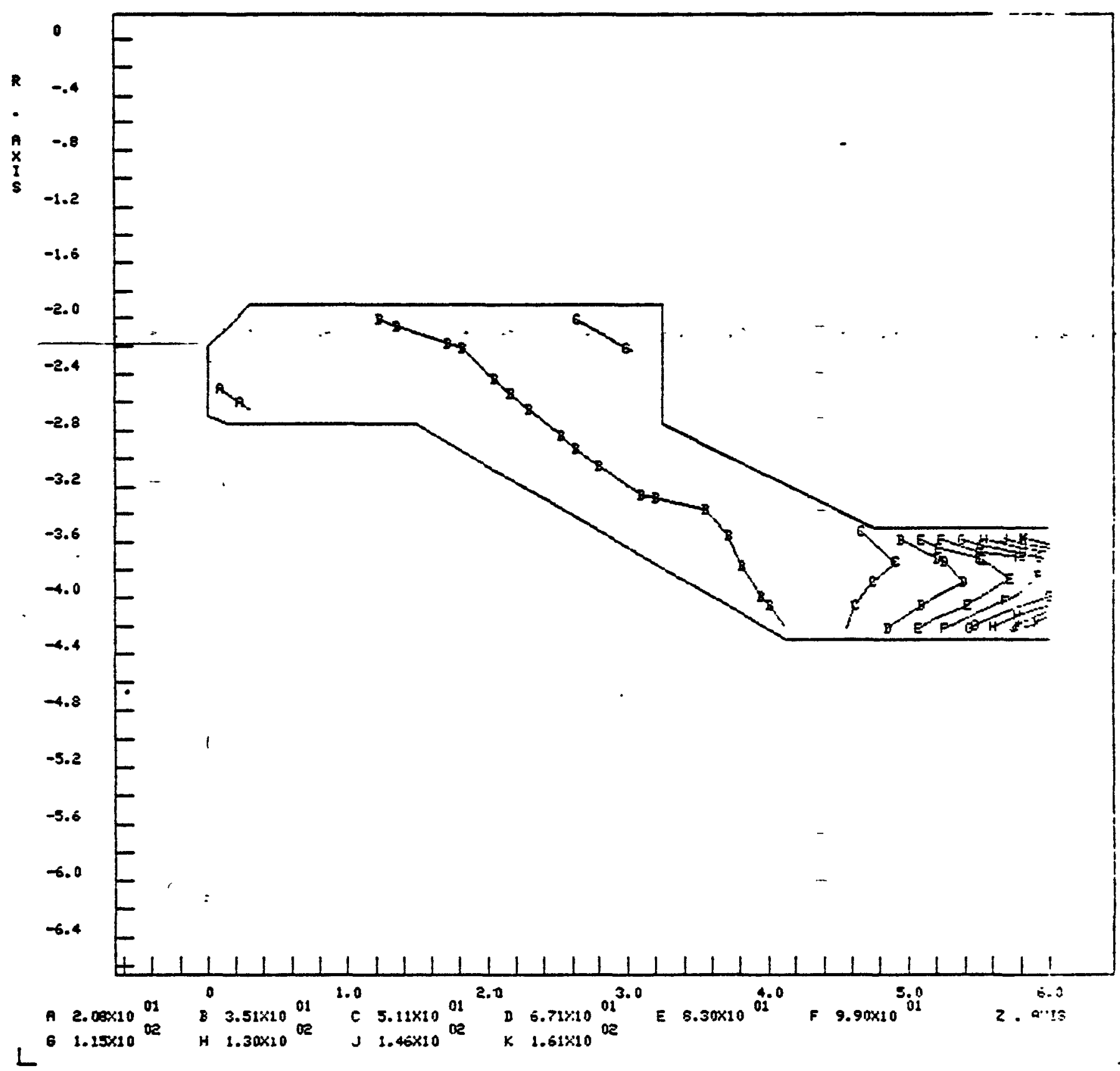




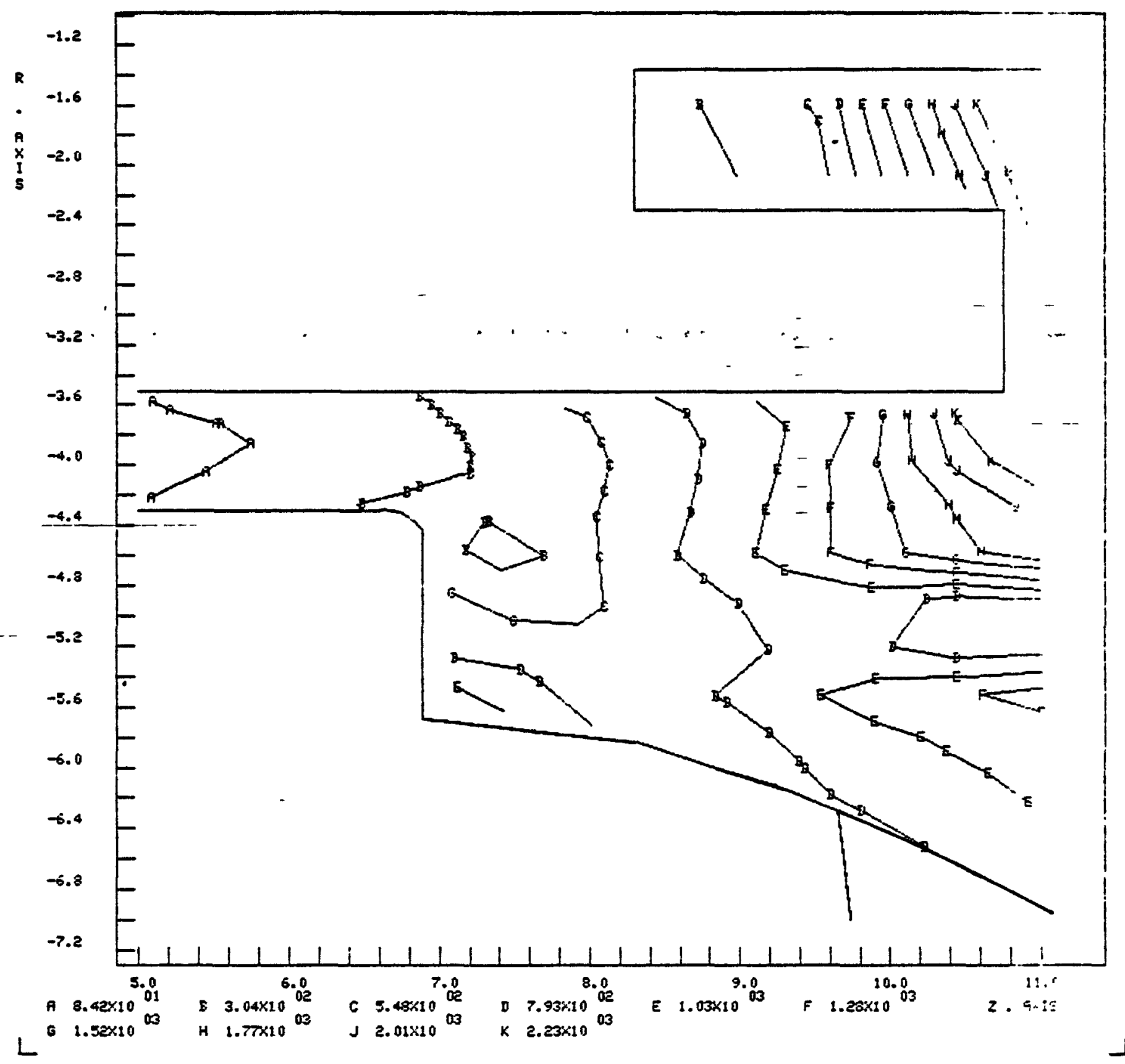


FIGURE 58

$\Gamma$

AI INTERMEDIATE SODIUM PUMP IMPELLEF

AXISTMmETRIC AHALSIS TAUnAR IS PLOTTED

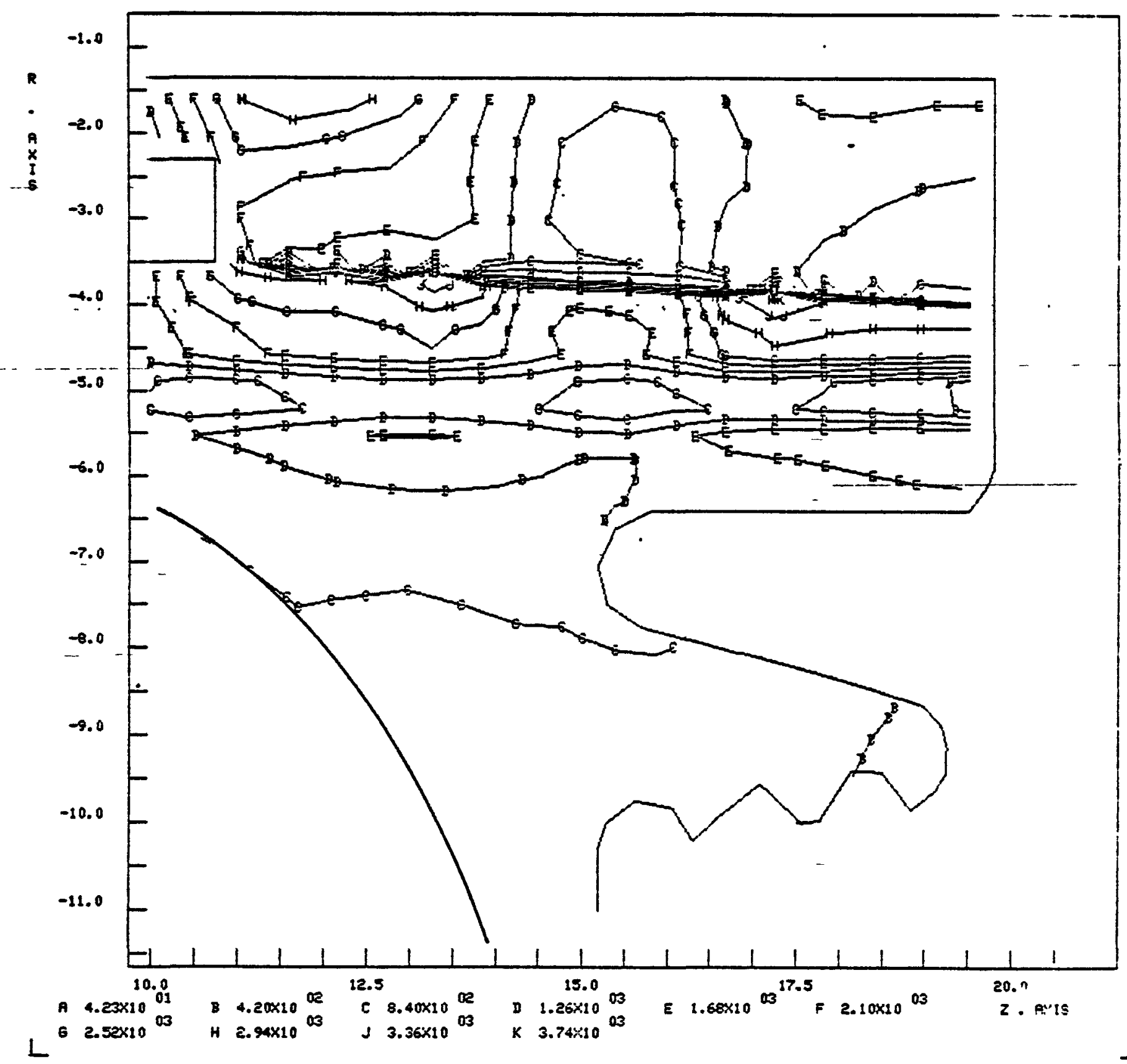


FIGURE 60

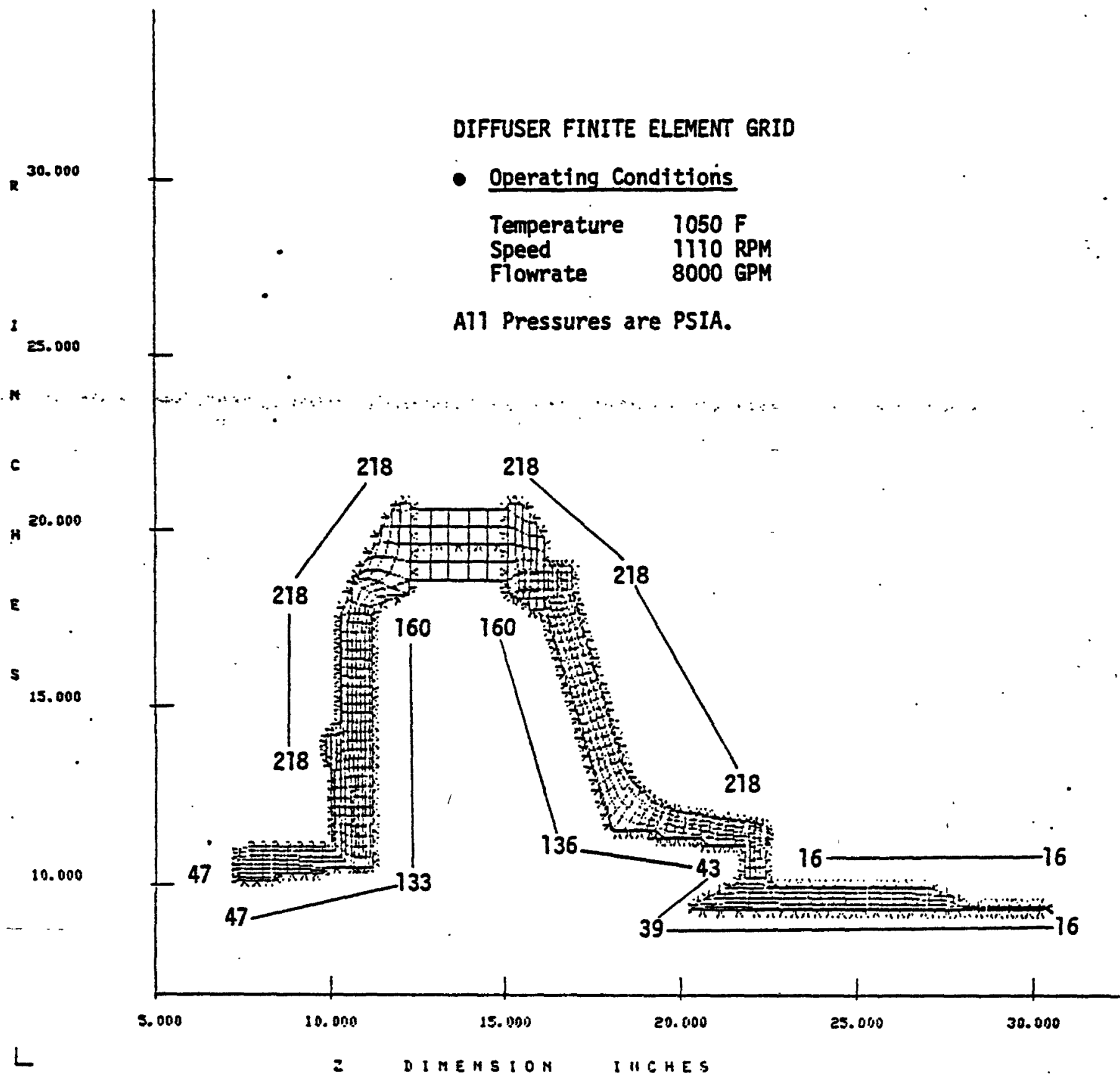


FIGURE 61

DIFFUSER STRESS INTENSITIES

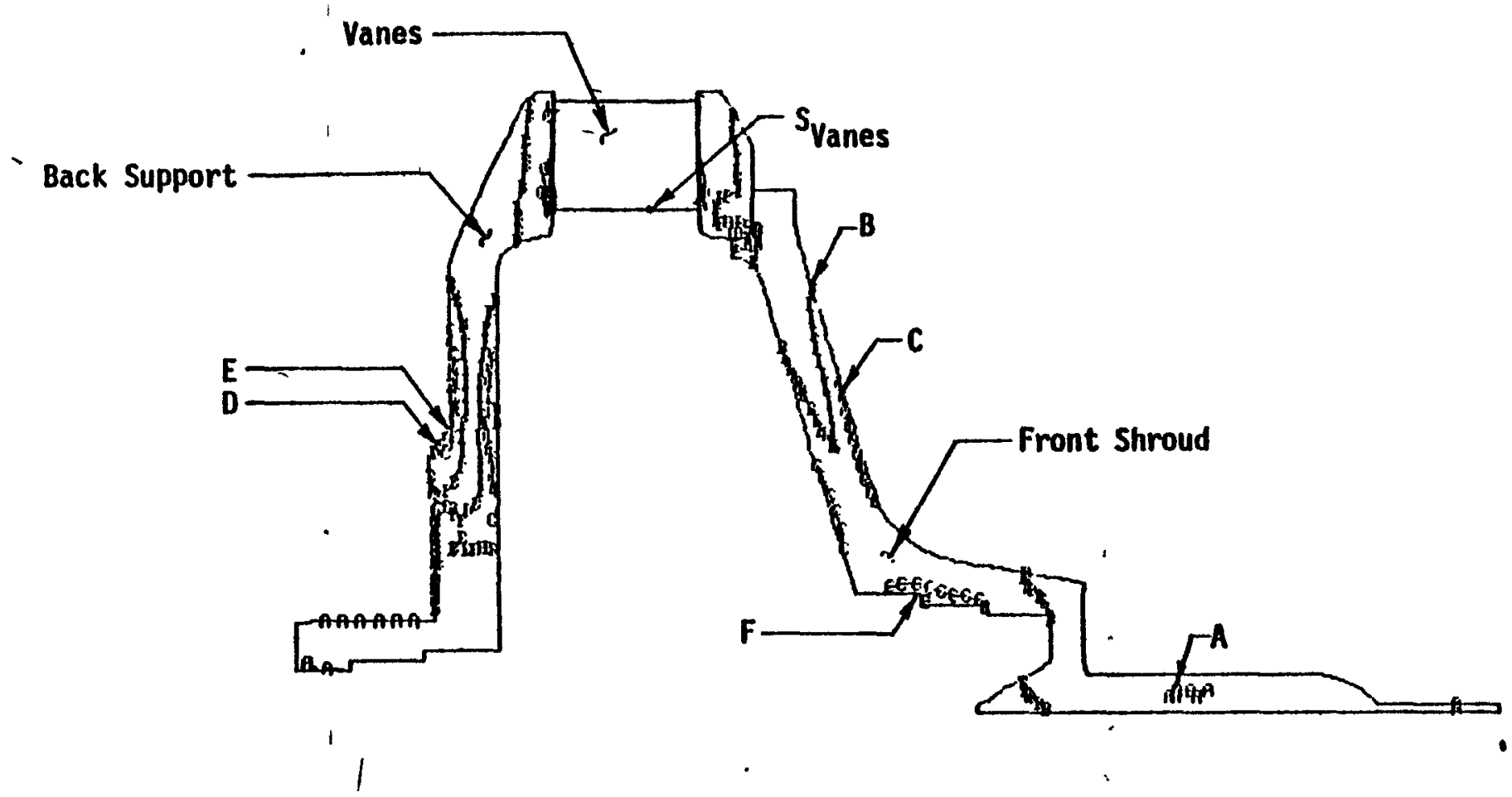

- Operating Conditions

$\begin{array}{ll}\text { Temperature } & 1050 \mathrm{~F} \\ \text { Speed } & 1110 \mathrm{RPM} \\ \text { Flowrate } & 8000 \mathrm{GPM}\end{array}$

- Material: 304 CRES

$S_{M}=7.73 \mathrm{kSI} \quad\left(P_{L}+P_{B}\right)$

${ }^{*} S_{M}=9.00 \mathrm{KSI}$
- Stress Intensities

\begin{tabular}{|c|c|c|}
\hline Location & S, KSI & $\begin{array}{l}\text { Design } \\
\text { Margin }\end{array}$ \\
\hline $\begin{array}{c}A \\
B \\
C \\
D \\
E \\
\star F\end{array}$ & $\begin{array}{r}.14 \\
1.37 \\
2.74 \\
4.11 \\
5.48 \\
7.36 \\
8.41\end{array}$ & $\begin{array}{r}54.21 \\
4.64 \\
1.82 \\
.88 \\
.41 \\
.22 \\
.07\end{array}$ \\
\hline
\end{tabular}


FIGURE 6C

\section{DIFFUSER VANES \\ STRESS INTENSITIES}

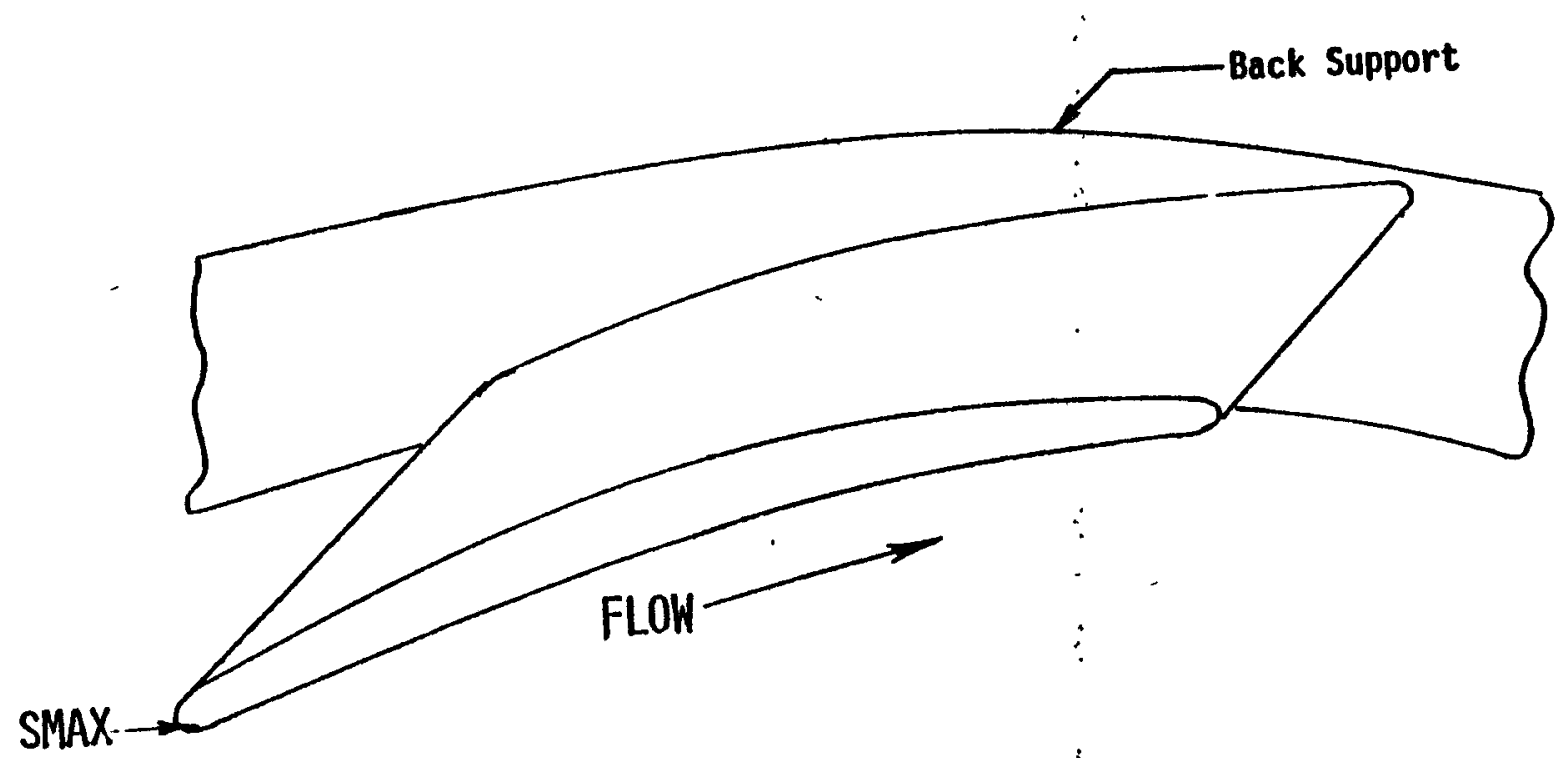

OPËRATING COONDITIOOONS

TEMPERATURE $1050 \mathrm{~F}$

SPEED

FLOWRATE $8000^{*}$ AND $12000 \mathrm{GPM}$
STTRËSS INTTENISIUIES

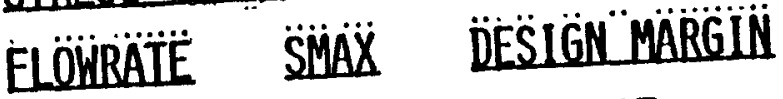

*8000: $\quad * 8.41 \quad \star .07$

$12000 \quad 7.61 \quad .02$

MATERIAL: 304 CRES

$S_{M}=7.73 \mathrm{KSI}\left(P_{L}+P_{B}\right)$

${ }^{*} S M=9.00 \mathrm{KSI}$ 
FIGURE 63

$\sqrt{1} \equiv$

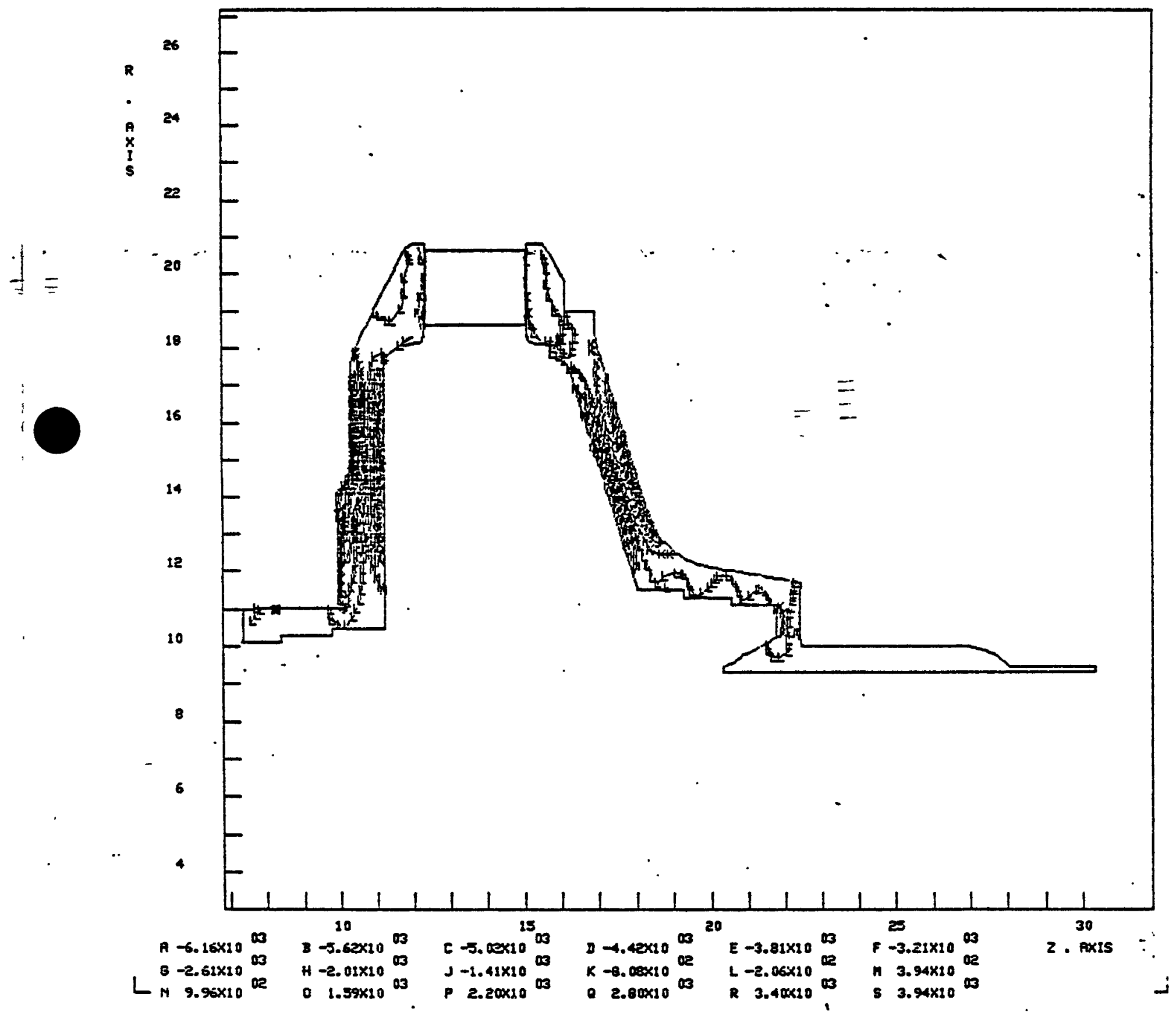


N266ER000-001

Page 325
N266SR 000001

Page 77

FIGURE 64

$\Gamma$

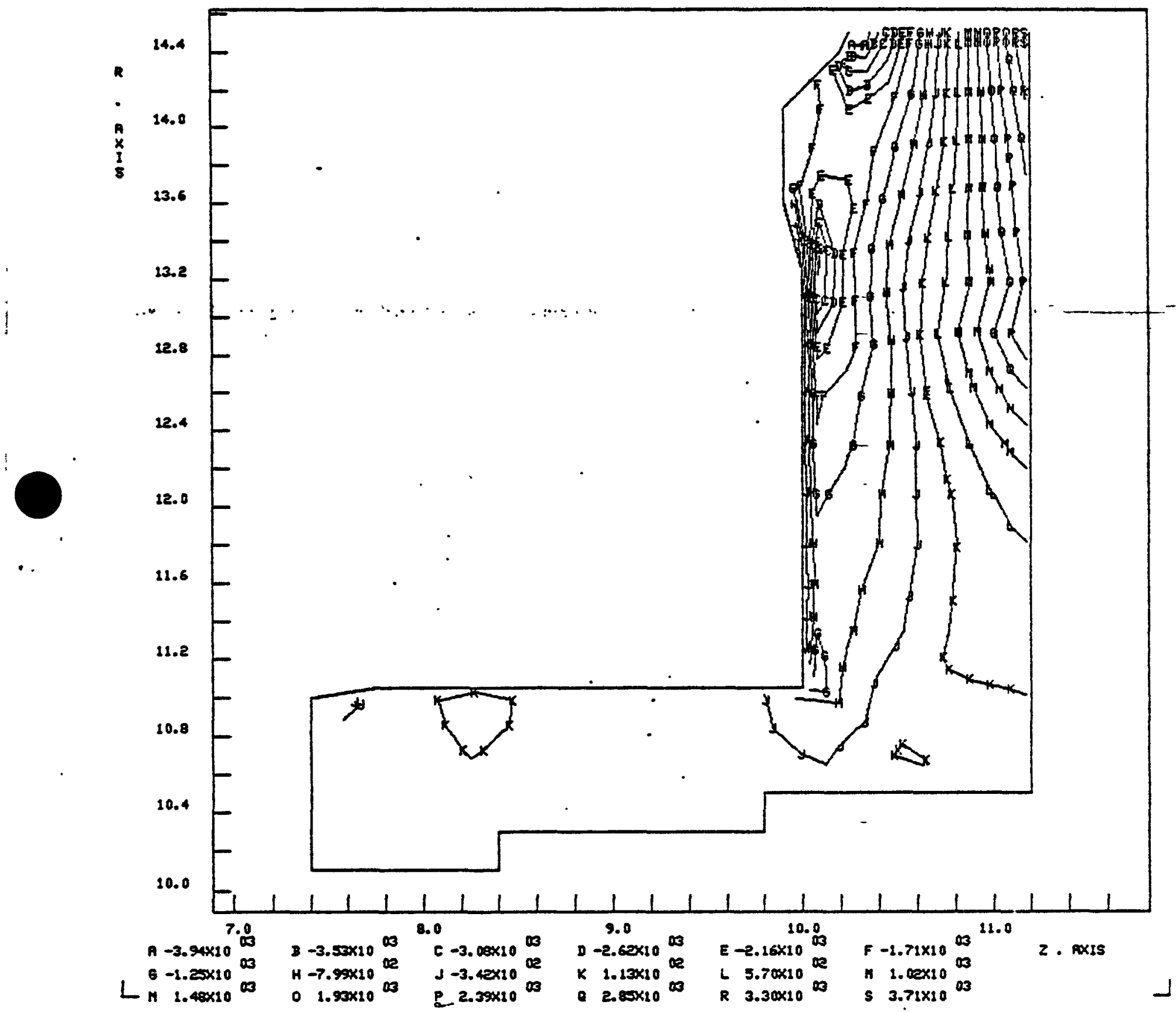

AIISP DIFFUSER - SHOUD T=.9U, SUPPORT T=.90, $8000 \mathrm{EMT}$

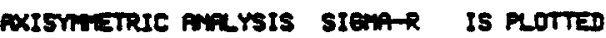


N266ER000-001

Page 326
N266SR000001

Page 78

\section{FIGURE 65}

AIISP DIFFUSER - SHROUD $T=.90$, SUPPORT T=.90, 8000 GPHT

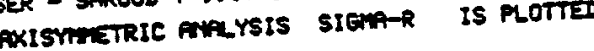

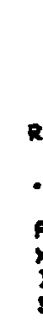

;

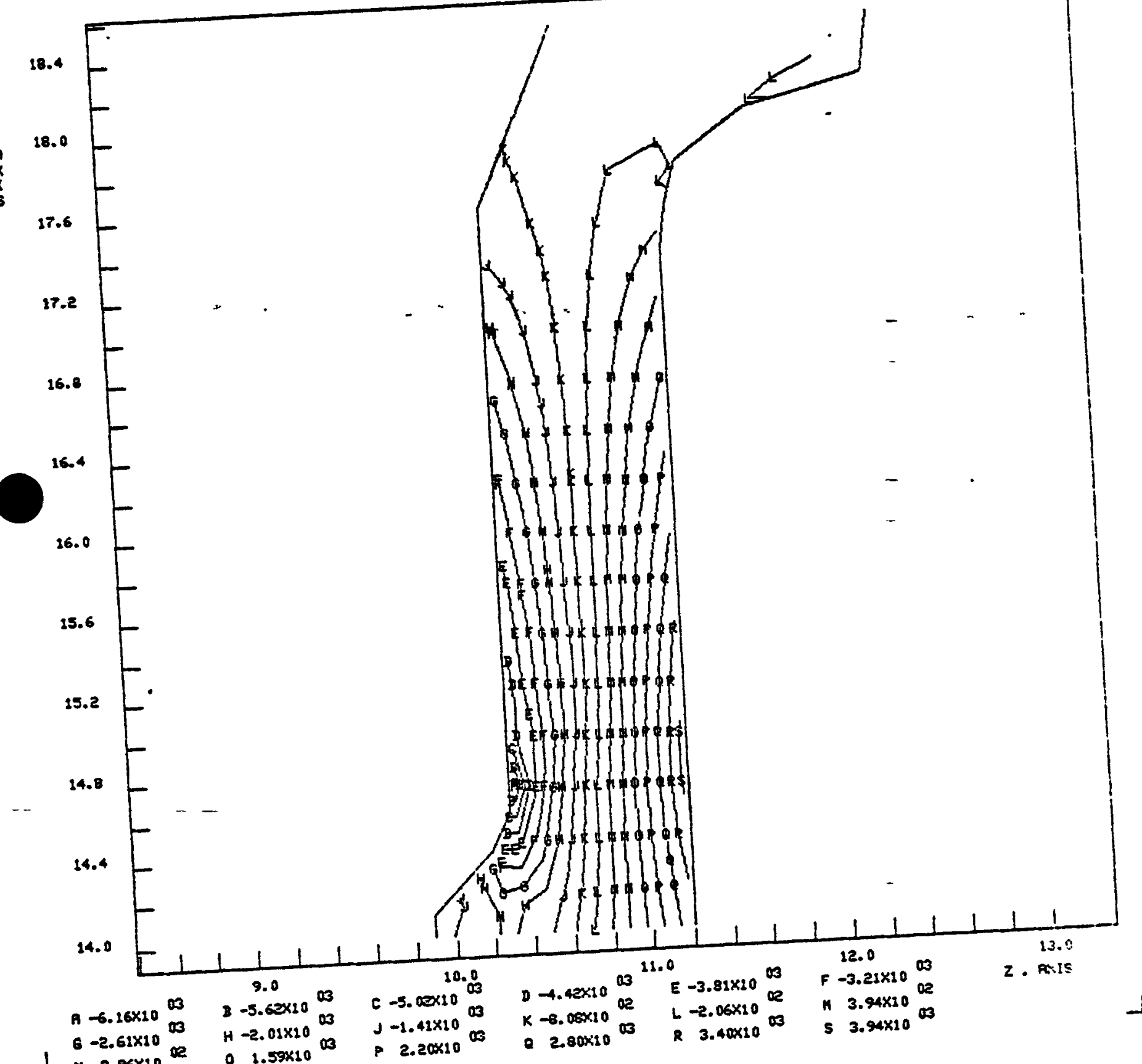




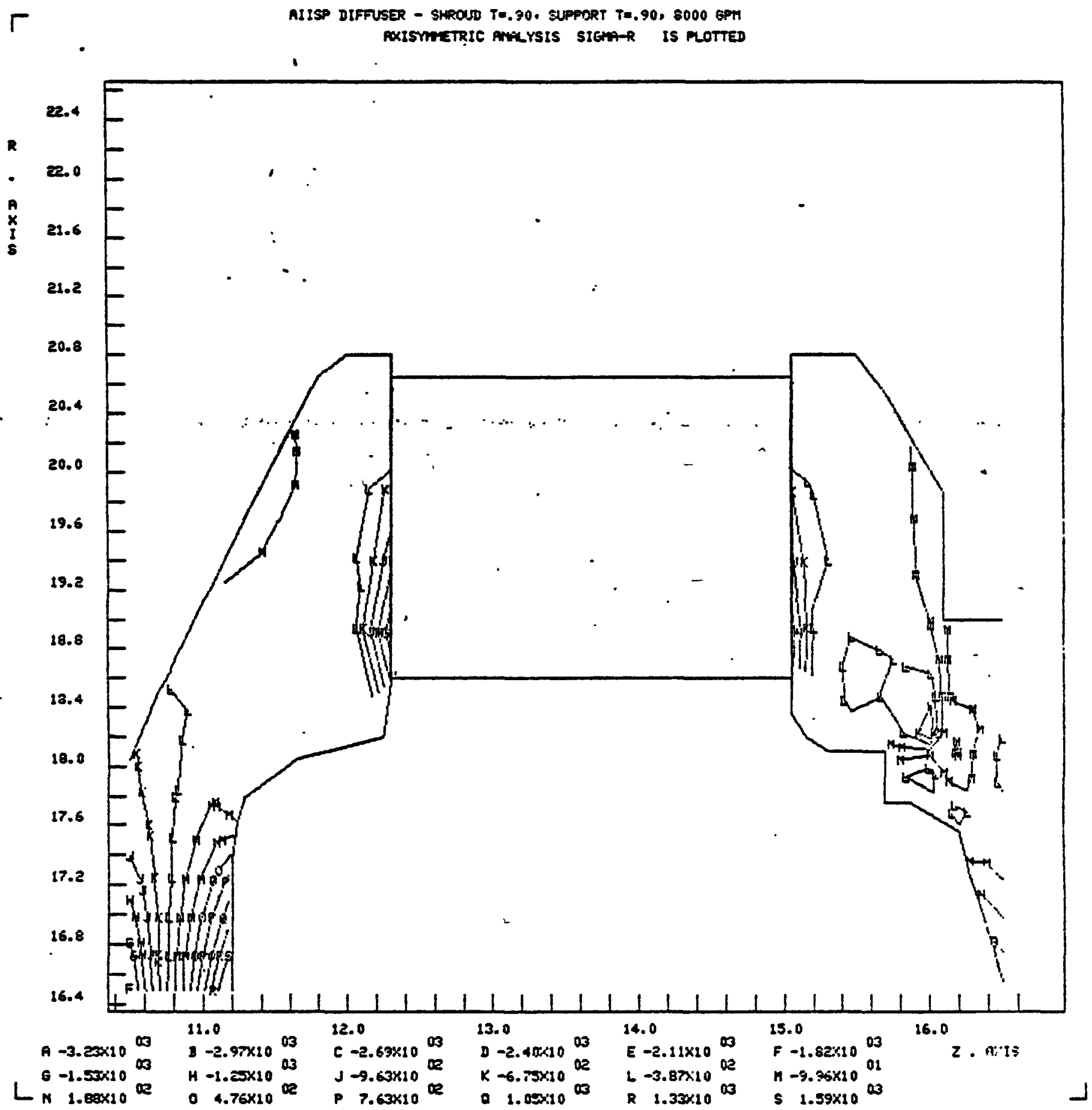




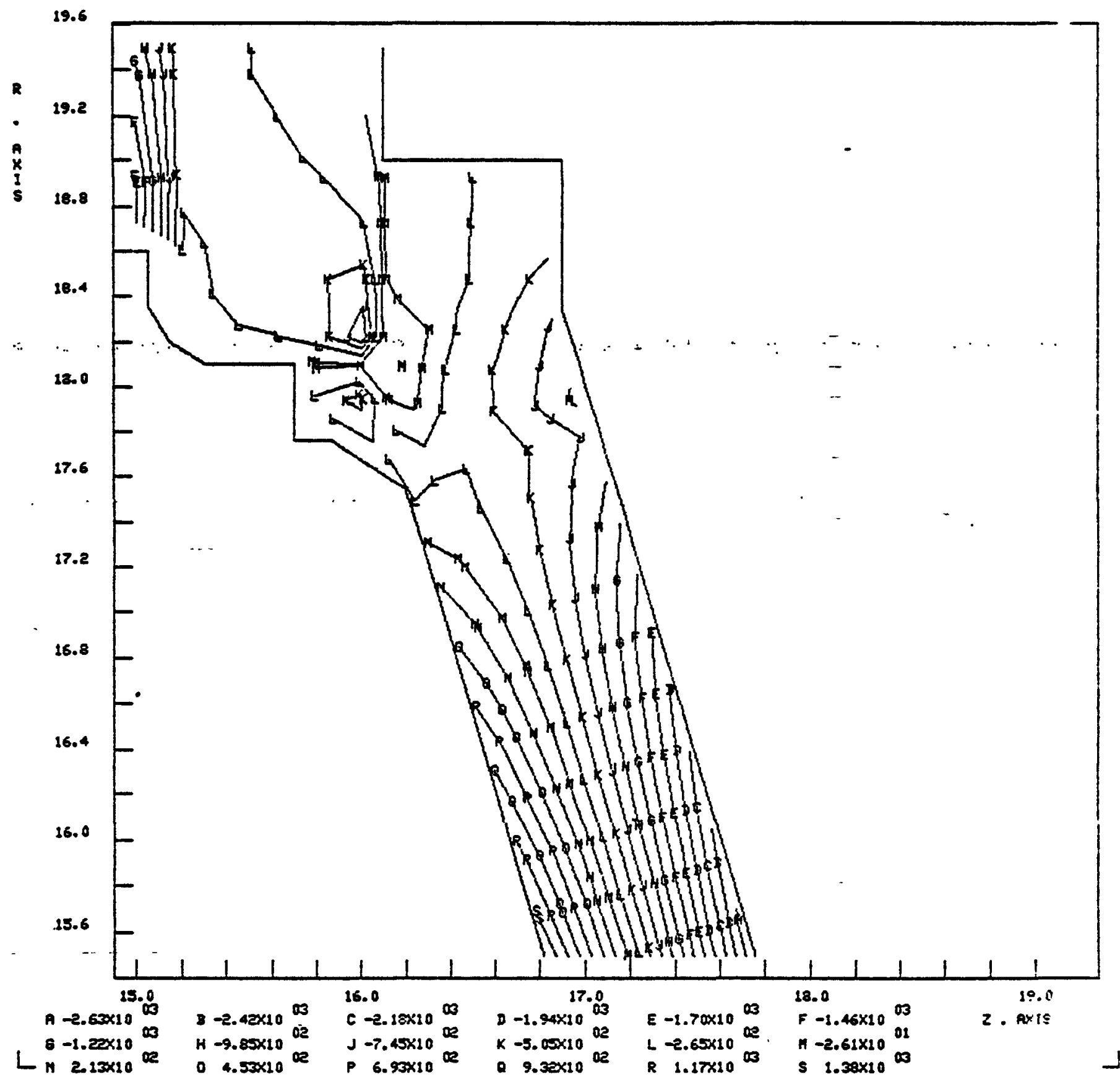




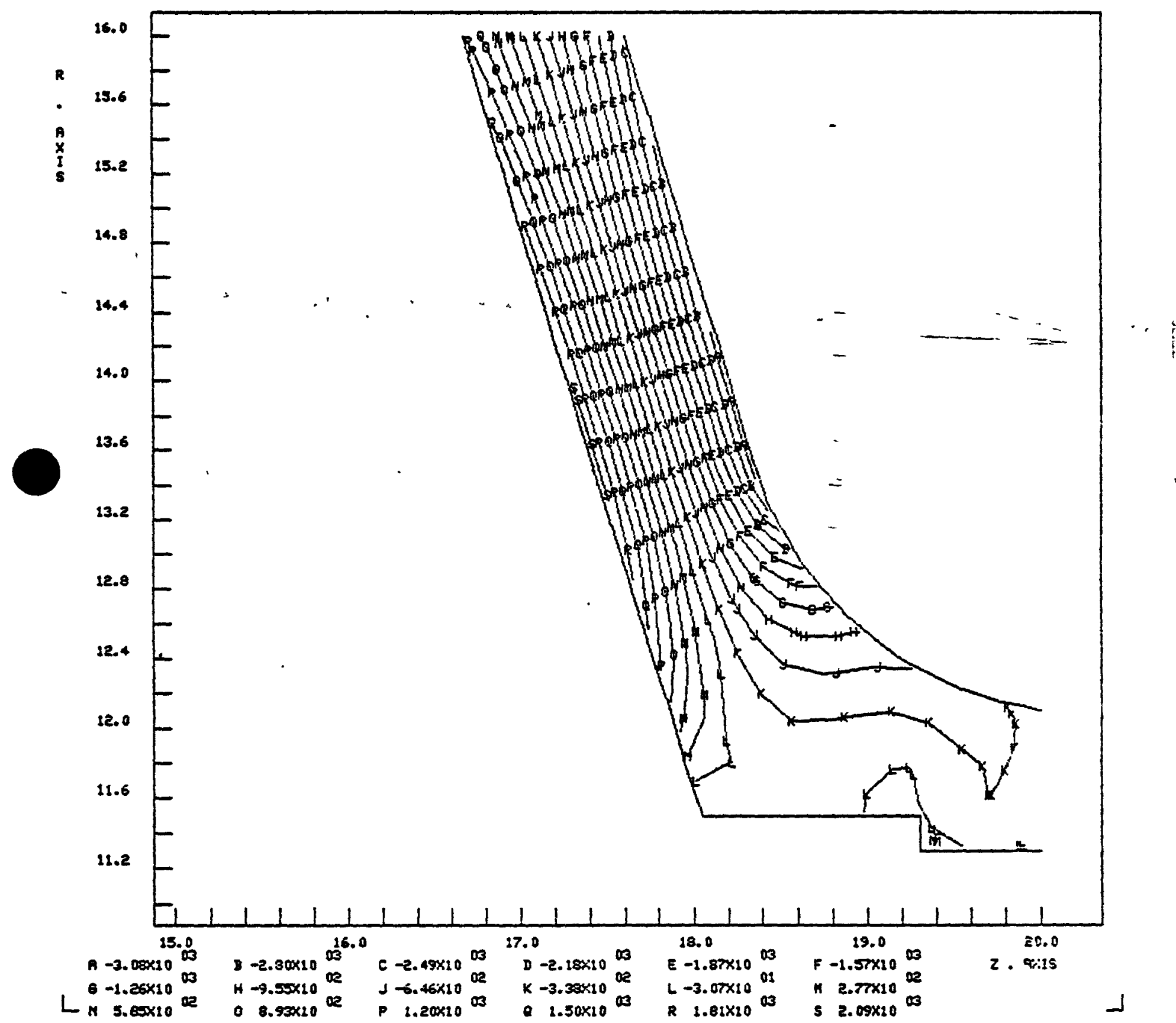


N266ER000-001

Page 330
N266SR000001

Page 82

FIGLRE 69

$\Gamma$

AIISP DIFFUSER - SHROUD T=.90, SUPPORT T=.90, $8000 \mathrm{GPM}$

AXISYMETRIC AWAYSIS SIEMA-R IS PLOTTED
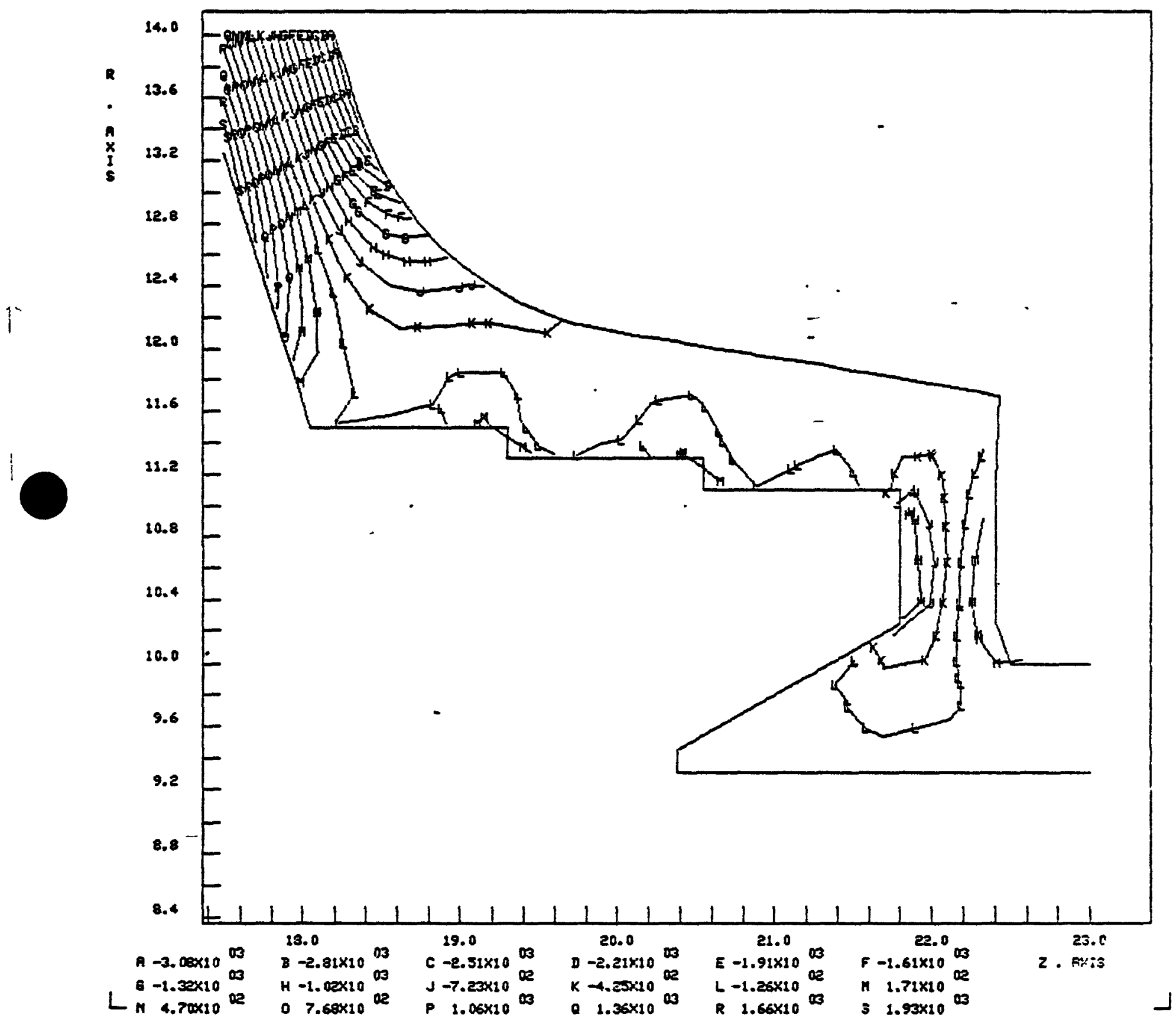
N266ER000-001

Page 331

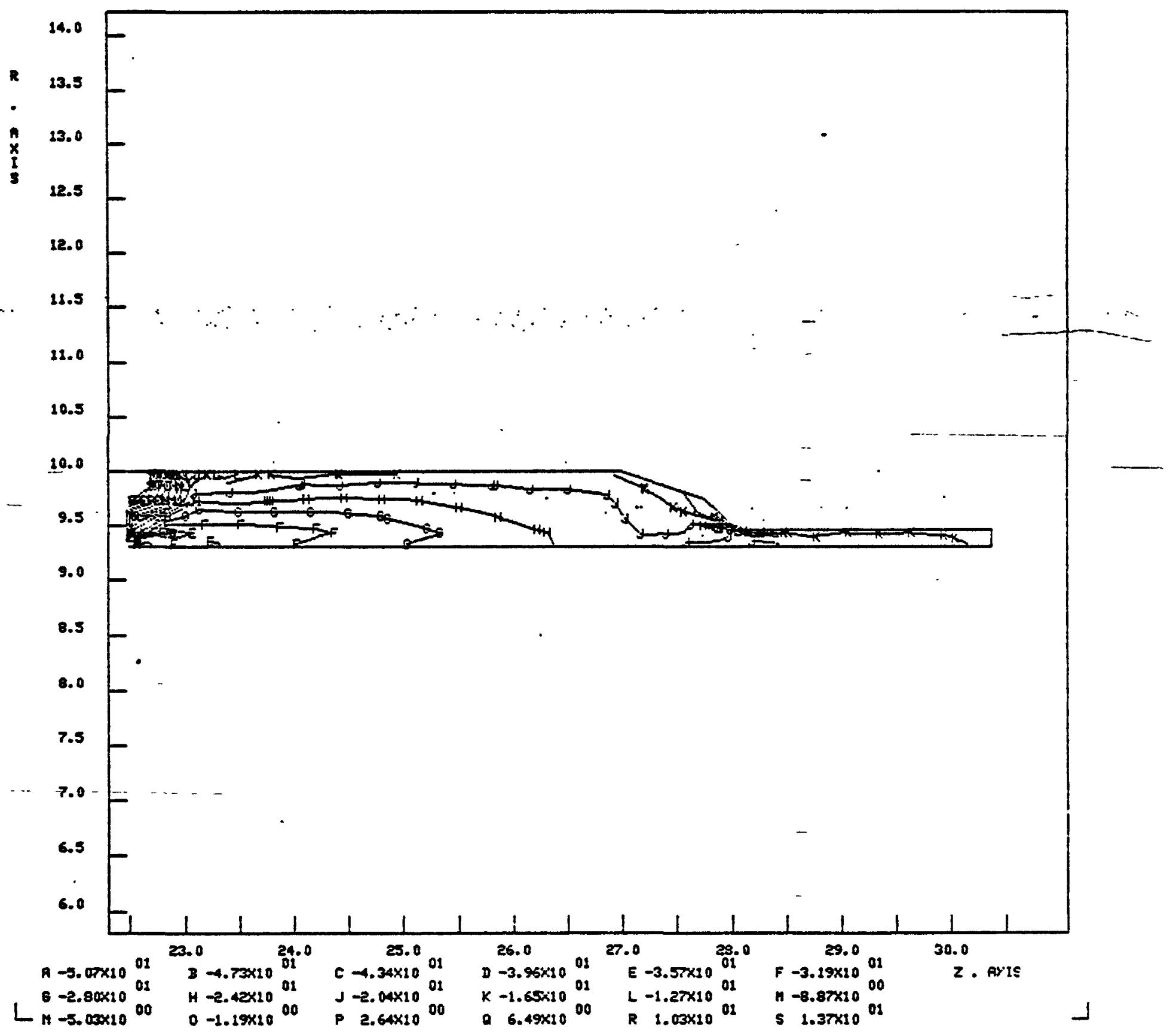




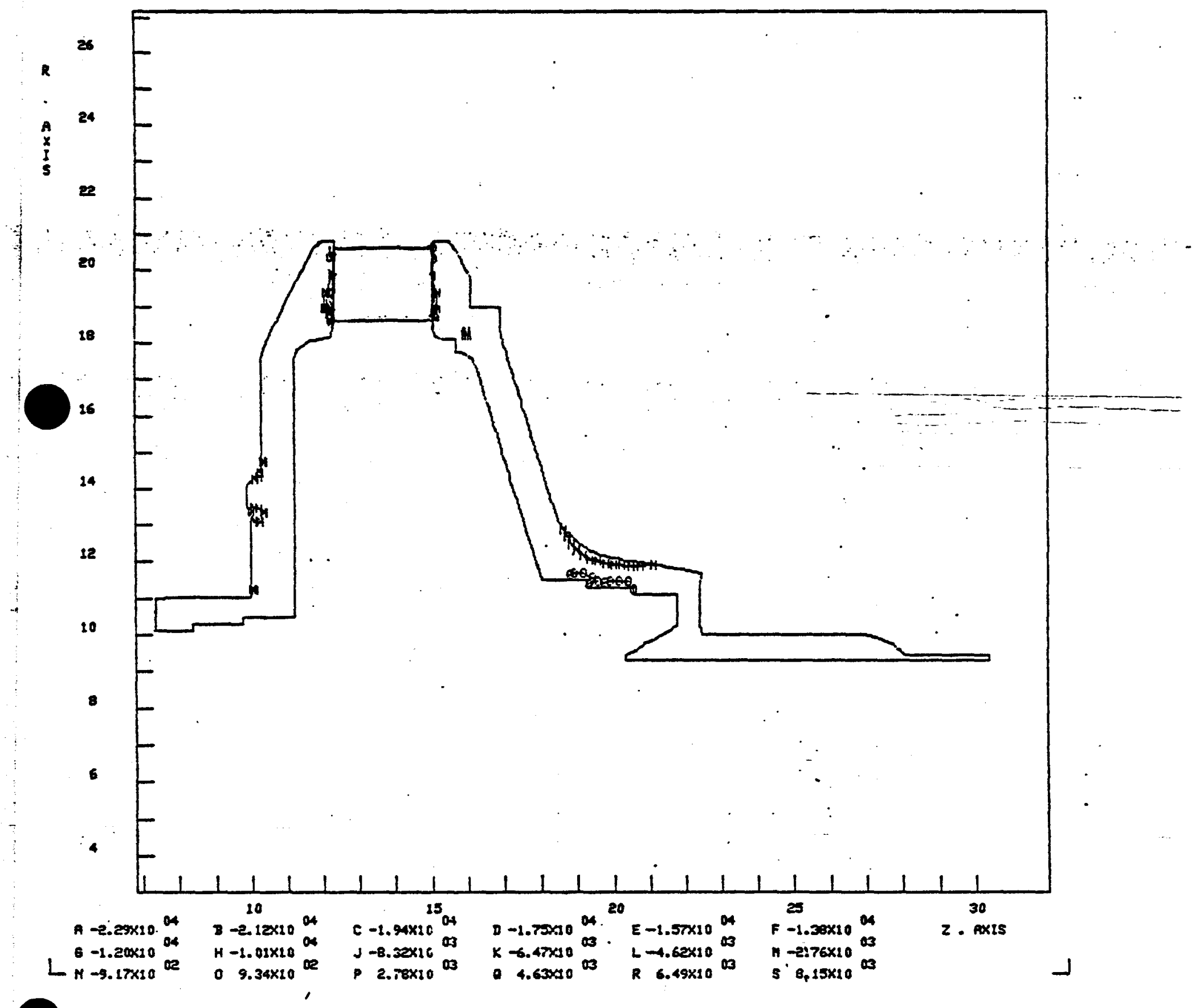


N266ER000-001

Page 333

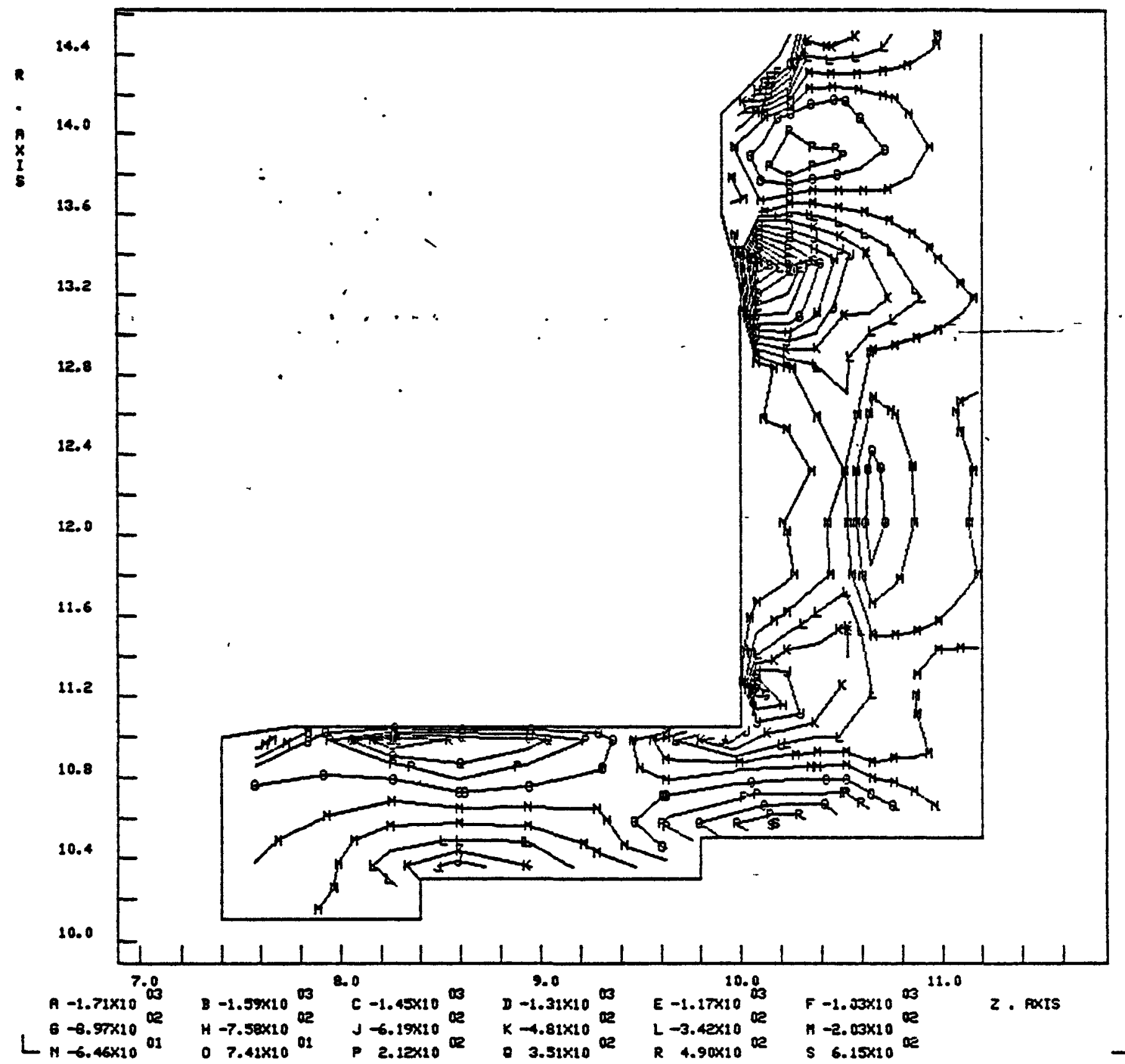


N266ER000-001

Page 334

N266SR000001

Page 86

FIGURE 73

AIISP DIFFUSER - SHAOUD T=.90, SUPPORT T=.90, $8000 \mathrm{EPM}$

AXISTMETRIC RHFLYSIS SIGHAZ IS PLOTIED

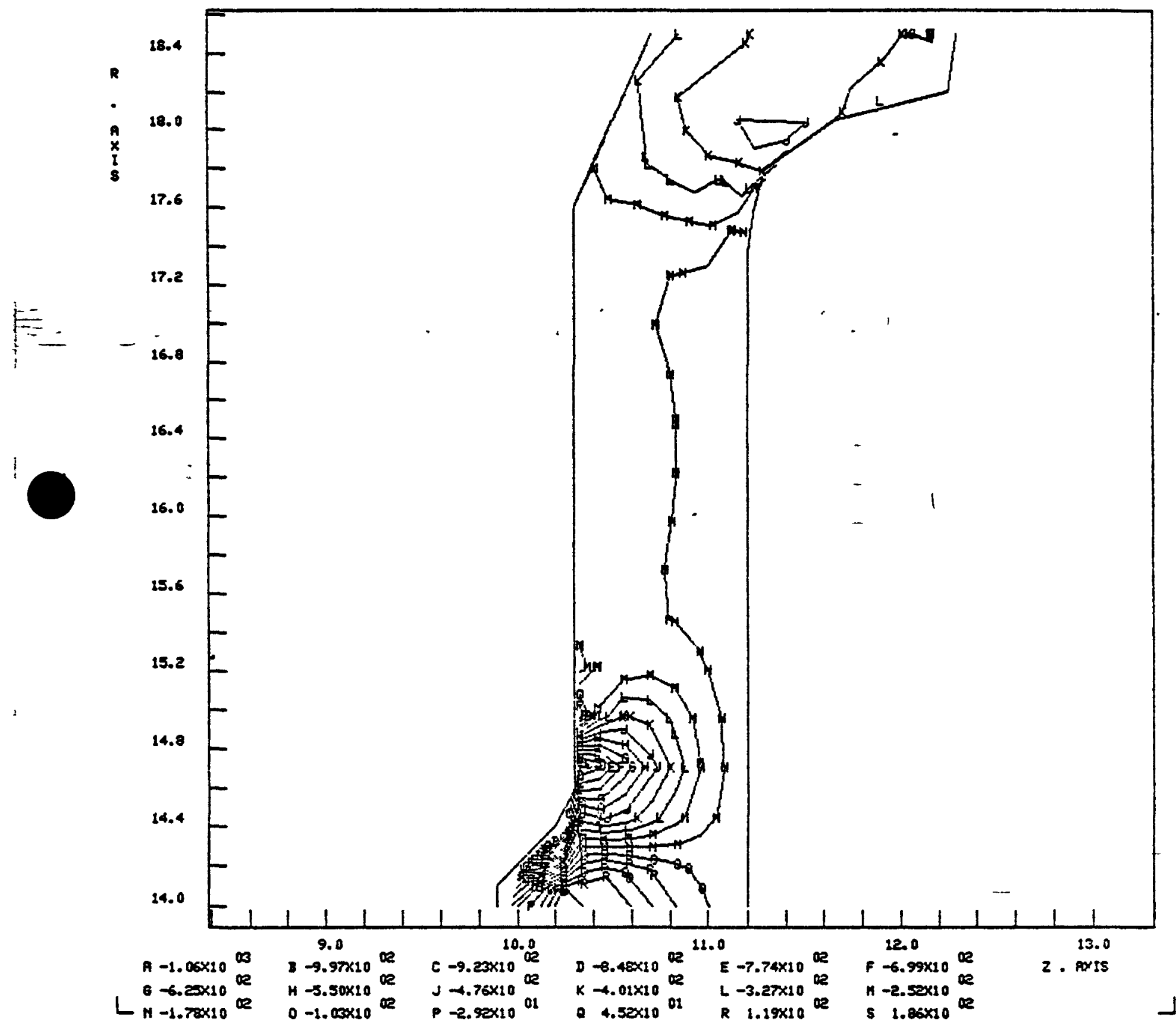




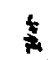

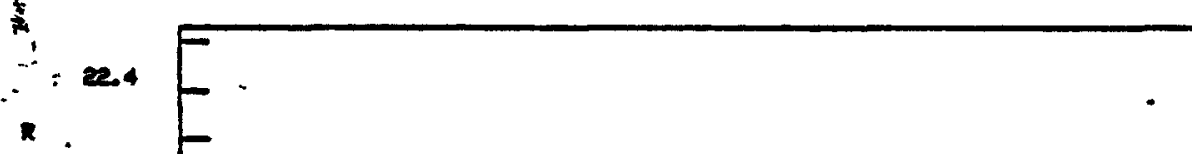

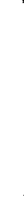

-

$\mathbf{A}$
$\mathbf{x}$
$\mathbf{z}$
$\mathbf{s}$

$\div$

$\div$

e.0.

21.6

21.2

$E$

20.4

$\bullet$

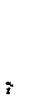

19.2

88.8

18.4

18.0

17.6

: 17
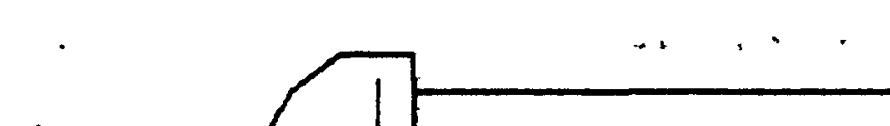

s..

$=16.4$

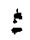

- $1-2.50 \times 10$

$\because \quad 6-9.00 \times 10$

L $-5-3.00 \times 10$

.

$-2.00 \times 200$

H $-8.00 \times 20$

0 - $2.00 \times 20$ ce

c $-1.50 \times 10$

$j-7.00 \times 10$

$J-7.00 \times 20$
$p-1.00020$ 02

23.0
$0-1.00 \times 10$

$k-6.00 \times 10^{-02}$

\section{0}

$E-5.00 \times 20$

L $-5.00 k 10$

R $5.00 \times 1000$

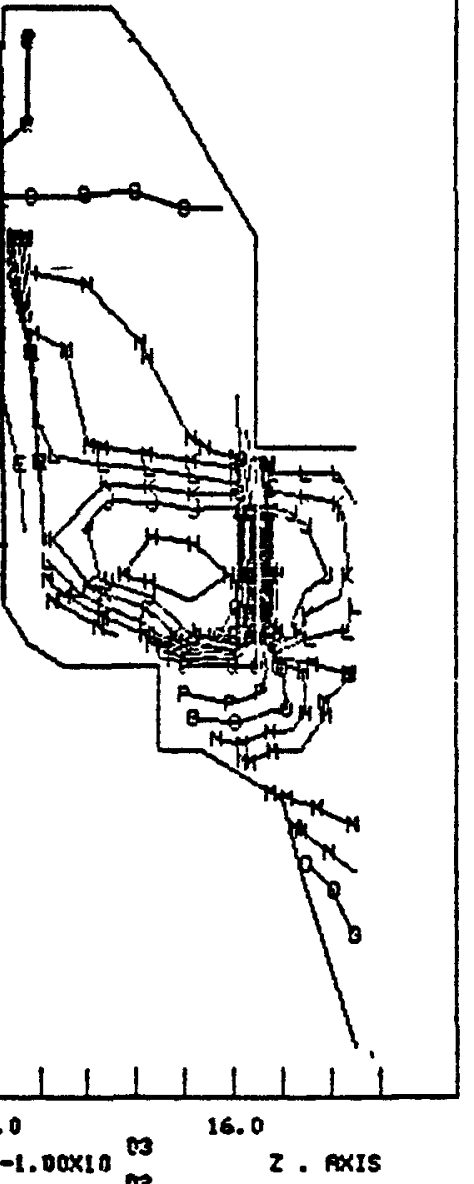

- $4.00 x 10$

s $1.00 \times 10^{\circ}$ 
N266ER000-001

Page 336
FIGURE 75
N266SR000001

Page 88

$\Gamma$

AIISP DIFTUSER - SHROUD T=.90, SUPPORT T=.90, $8000 \mathrm{EPM}$

PXISMTETRIC ANRLISIS SIEM-Z IS PLOTTED

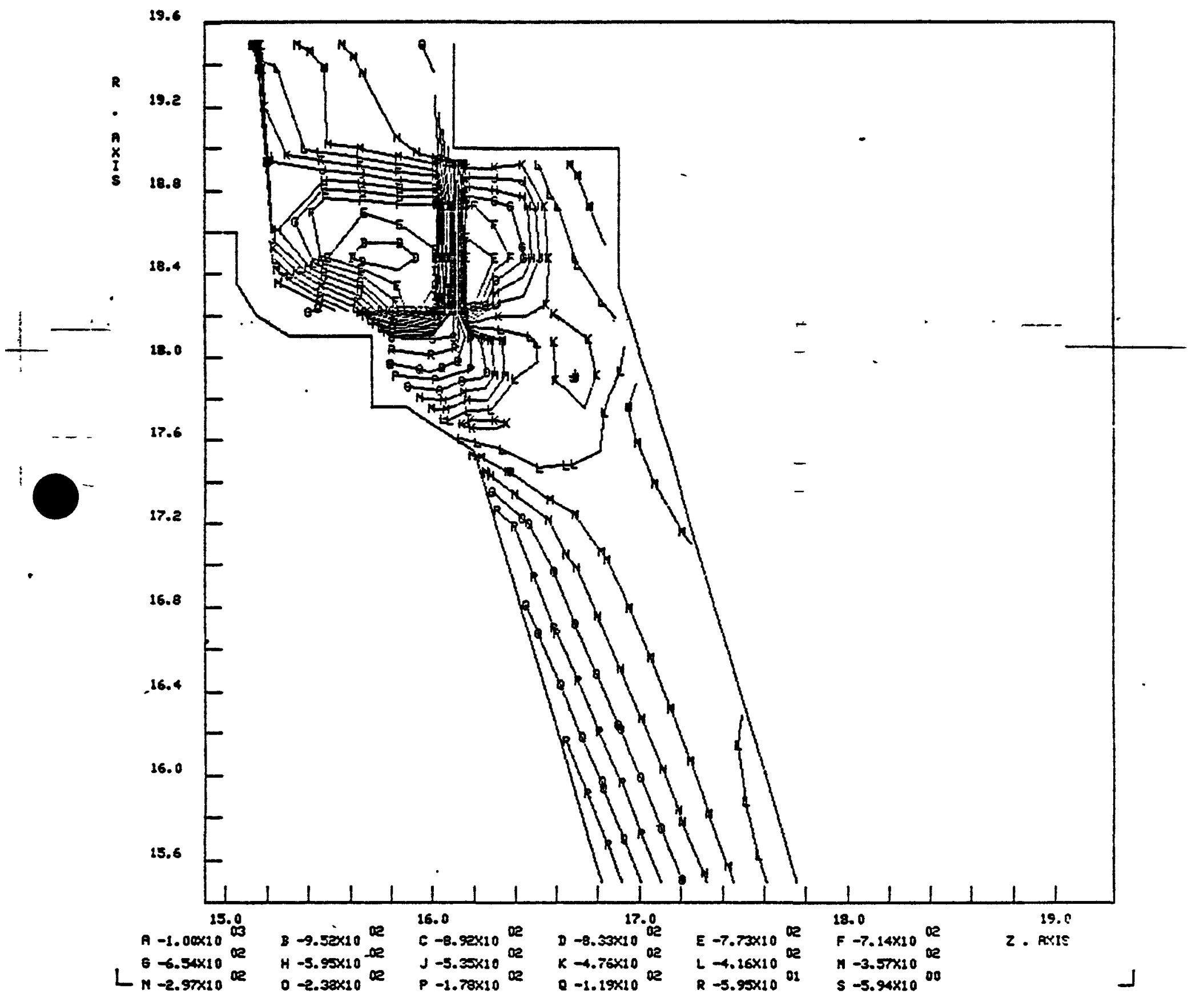


N266ER000-001

N266SR000001

Page 337

FIGURE 76

Page 89

$\Gamma$

AIISP DIFFUSER - SHFOUD T=.90, SUPPLRT T=.90, $8000 \mathrm{EPM}$

PXISYMETRIC AWRYSIS SIEMA-Z IS PLOTTED

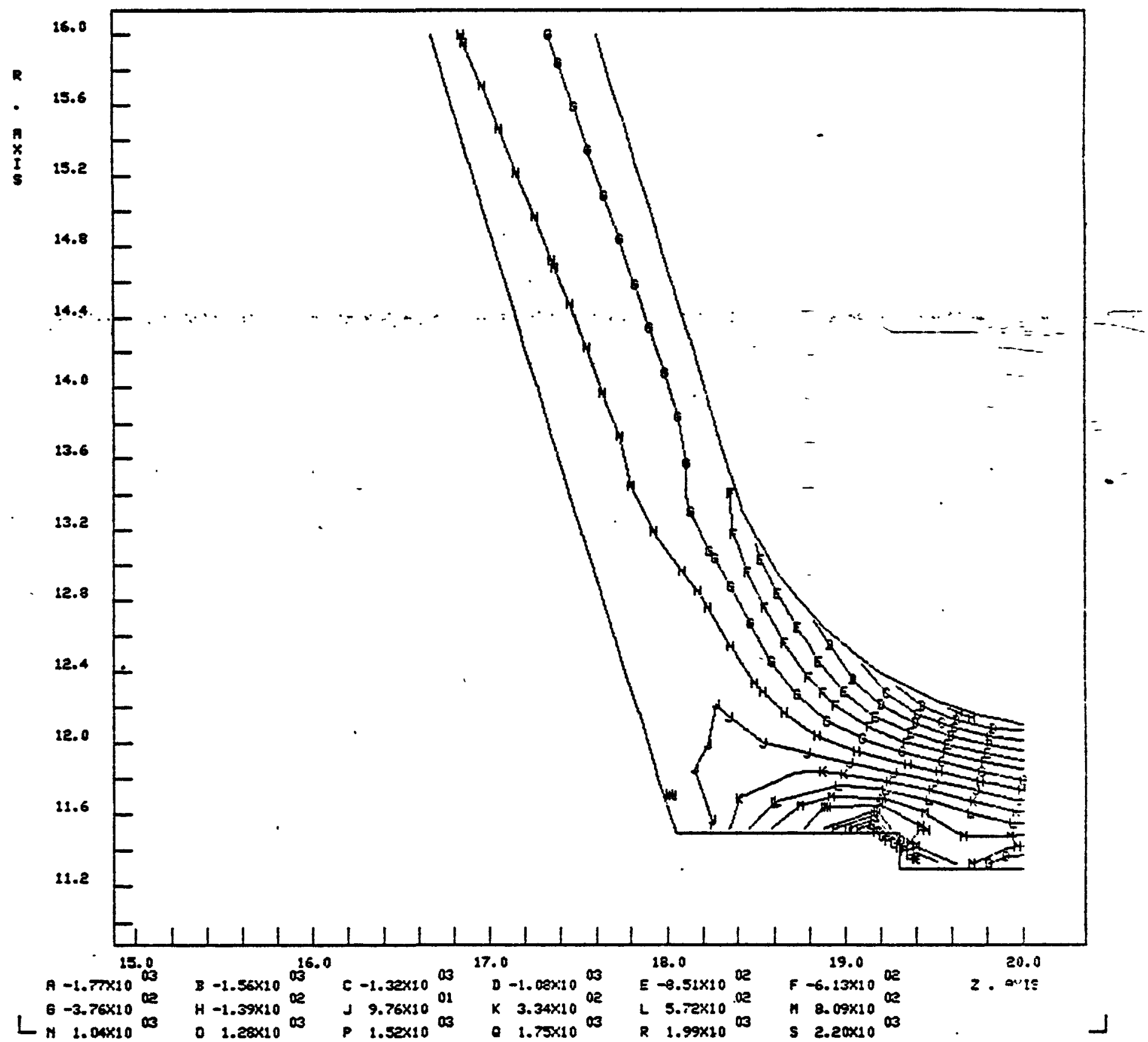


N266ER000-001

Page 338

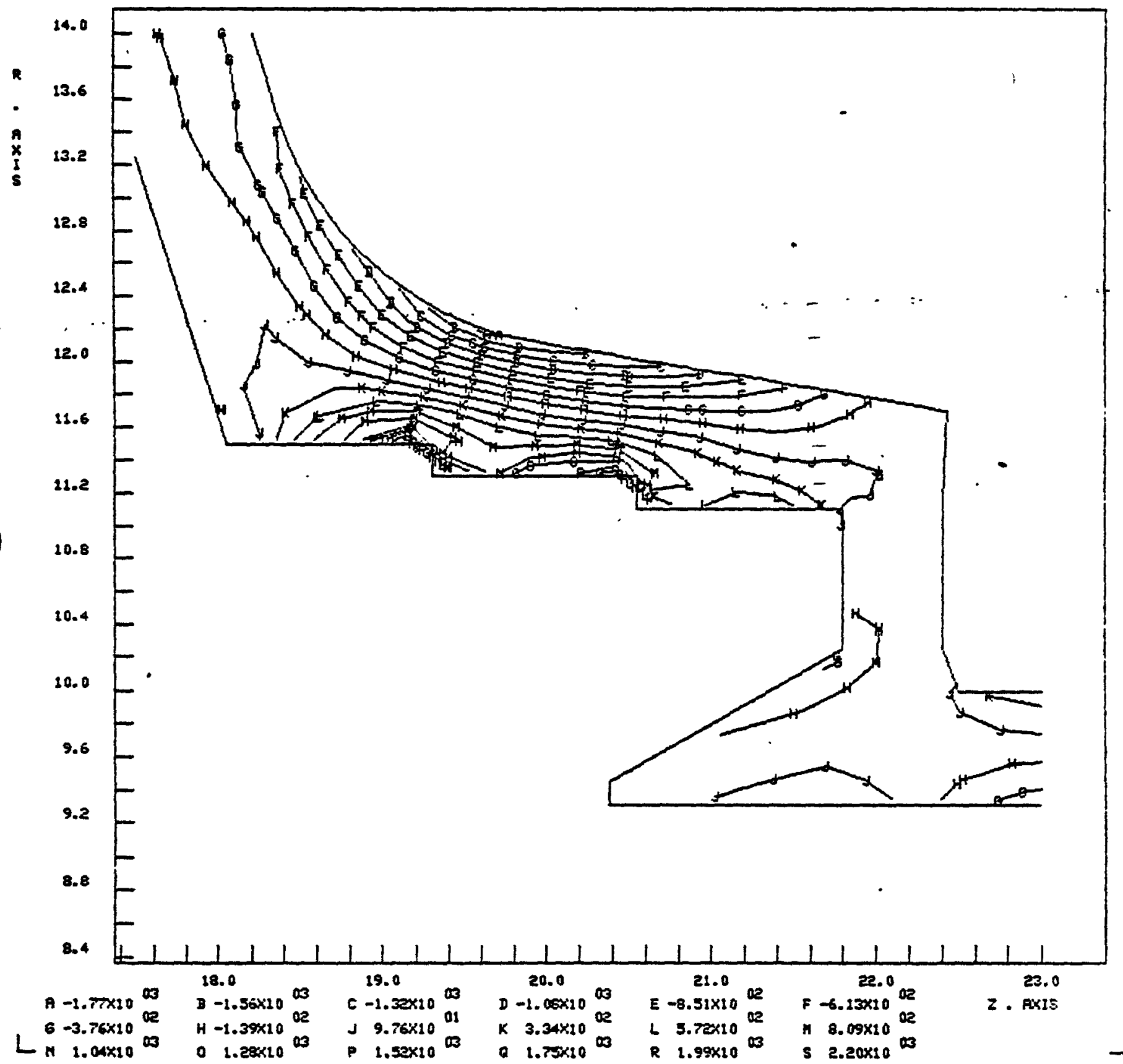


N266ER000-001

Page 339
N266SR000001

Page 91

FIGLRE 78

$\Gamma$

AIISP DIFFUSER - SHROUD T=.90, SAPPORT T=.90, 8000 GPM AXISYMTEIRIC AHEYSIS SIGMA-Z IS PLOTTED

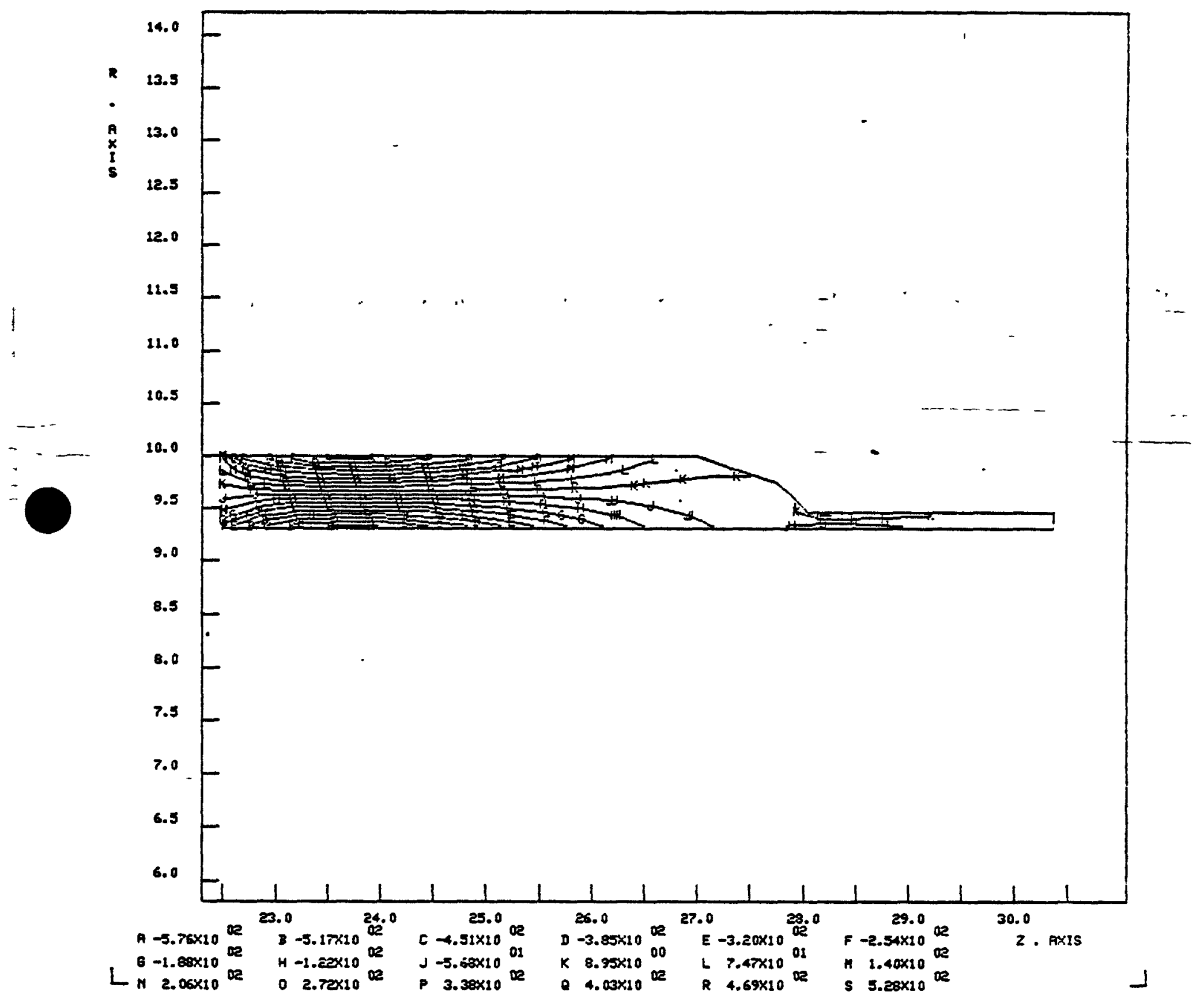


$\Gamma$

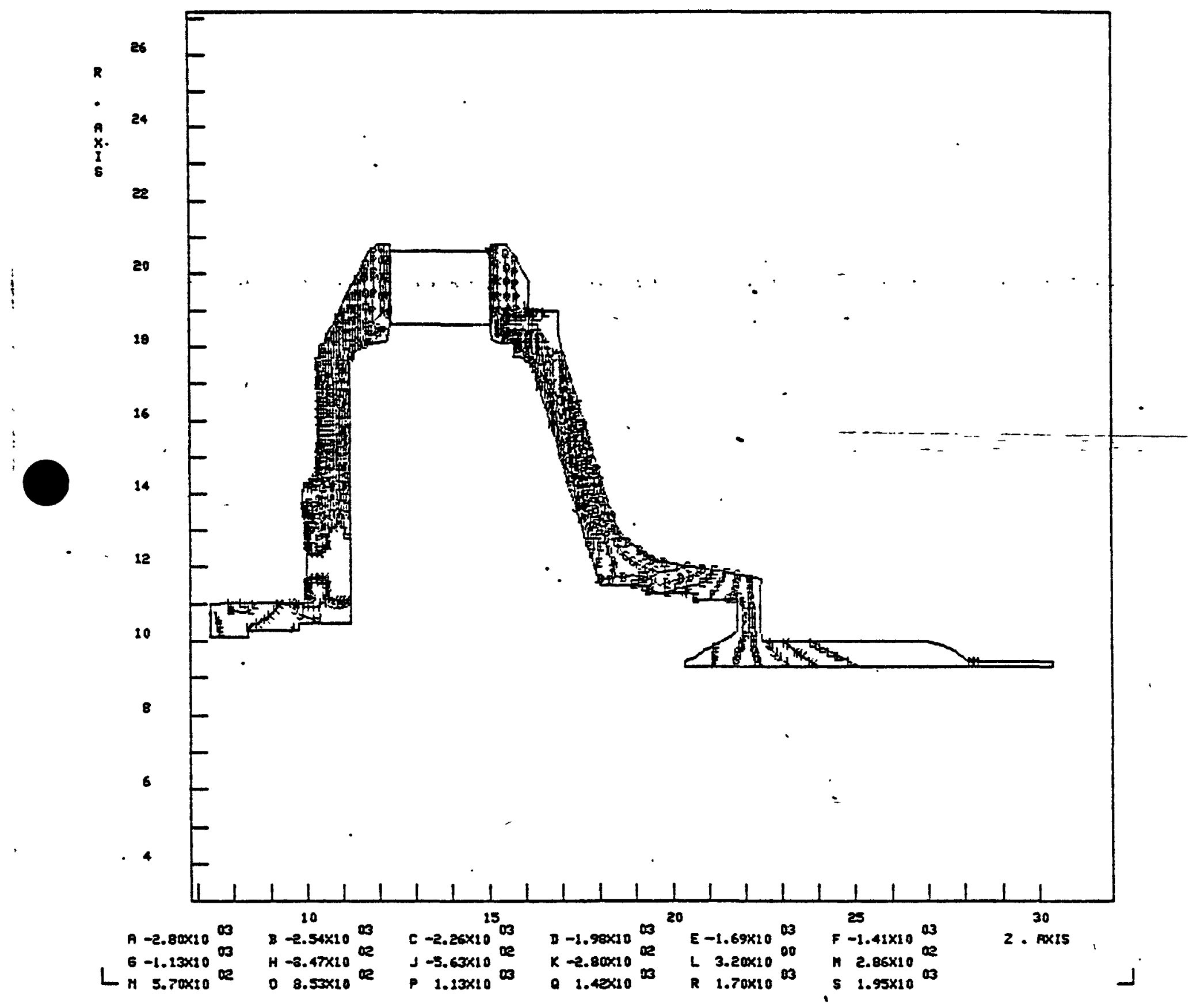




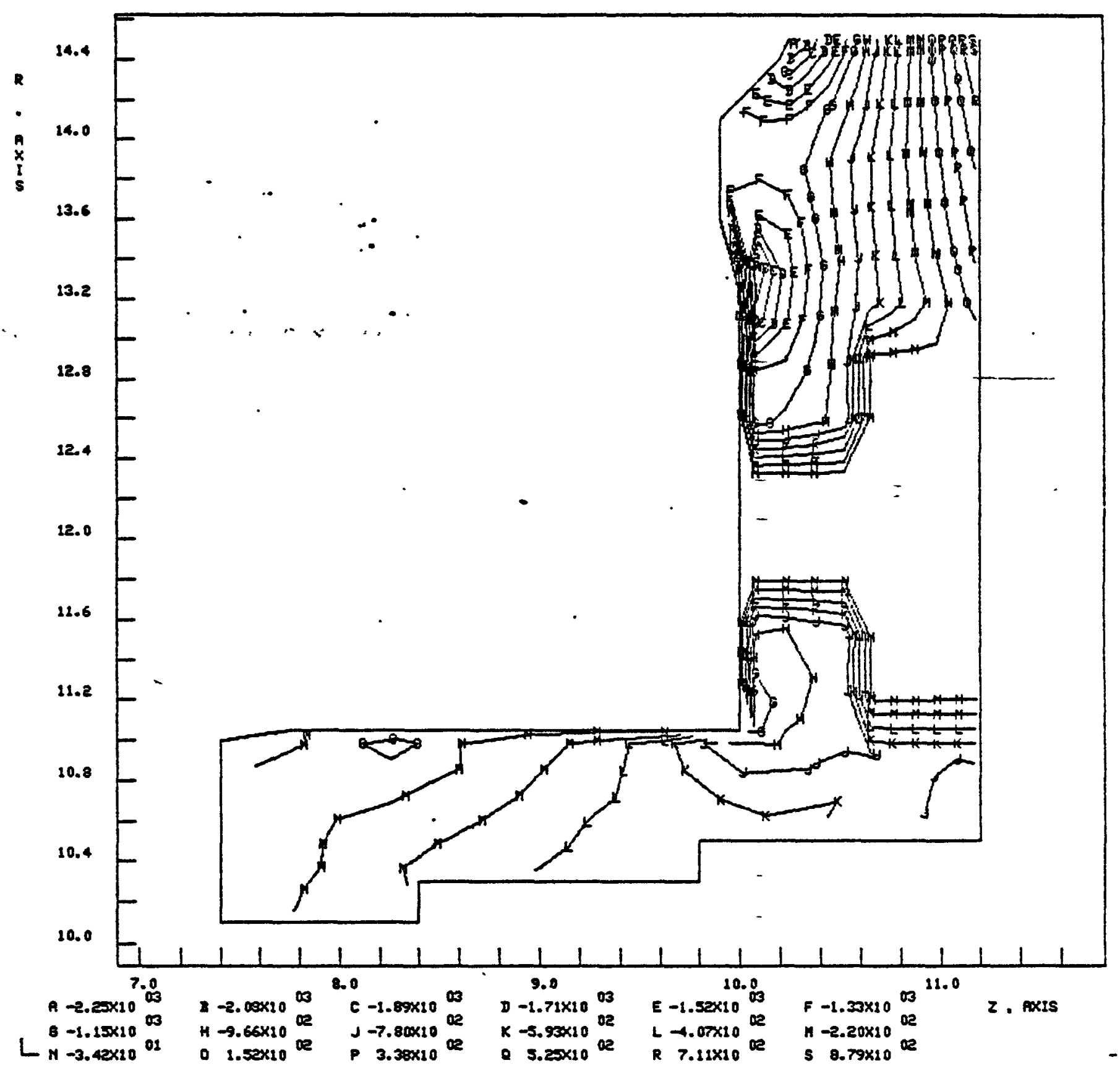




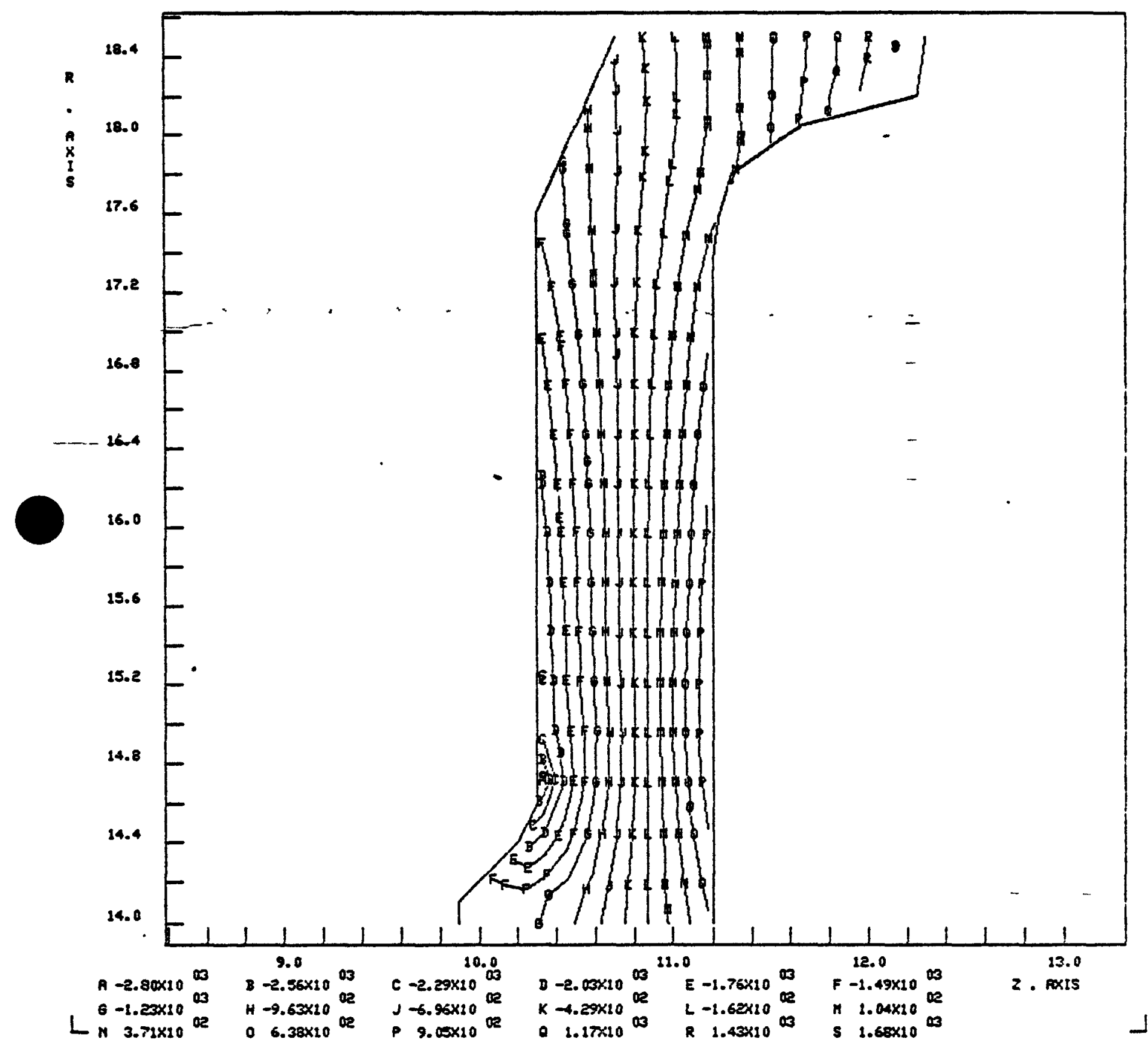




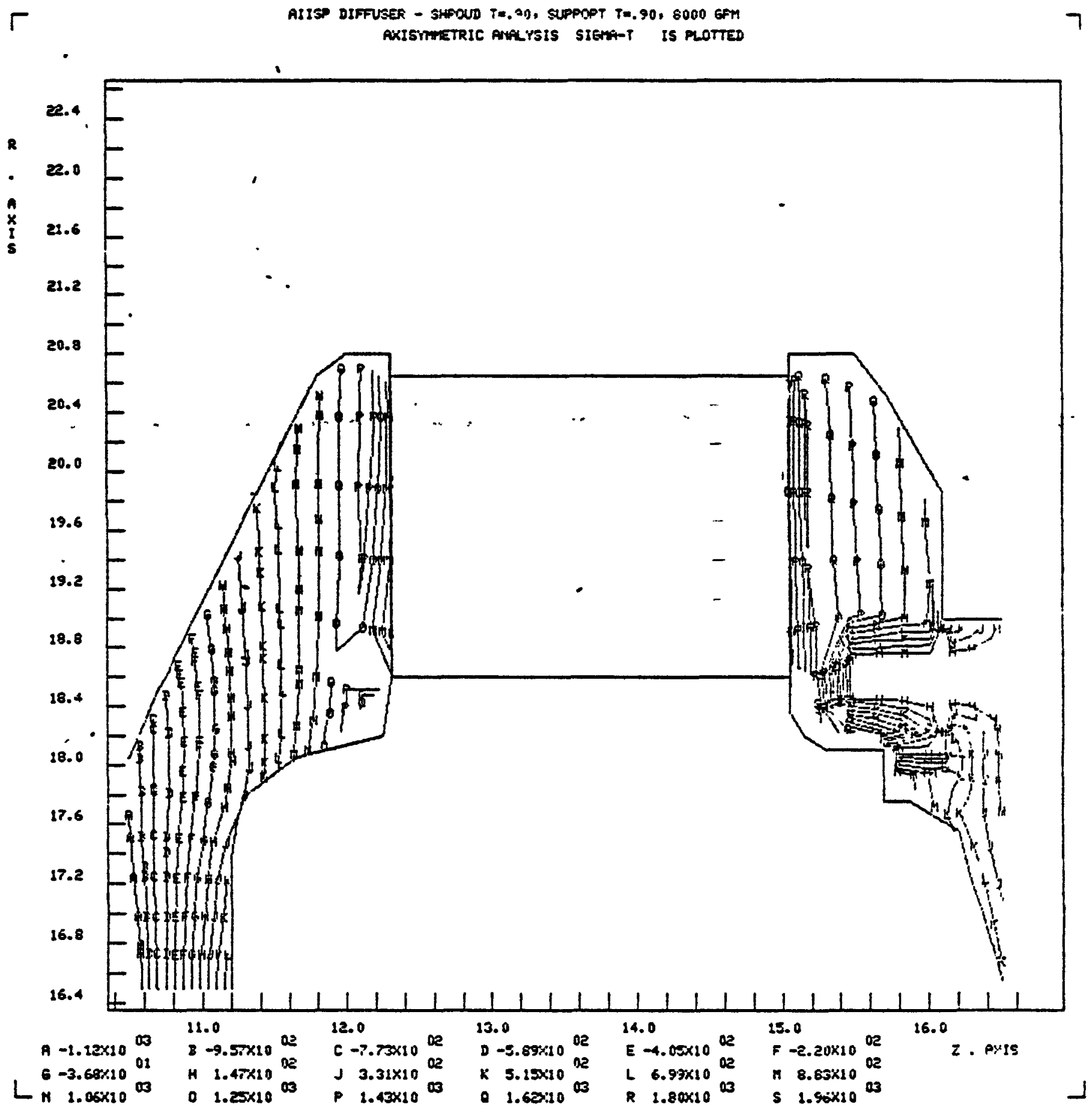




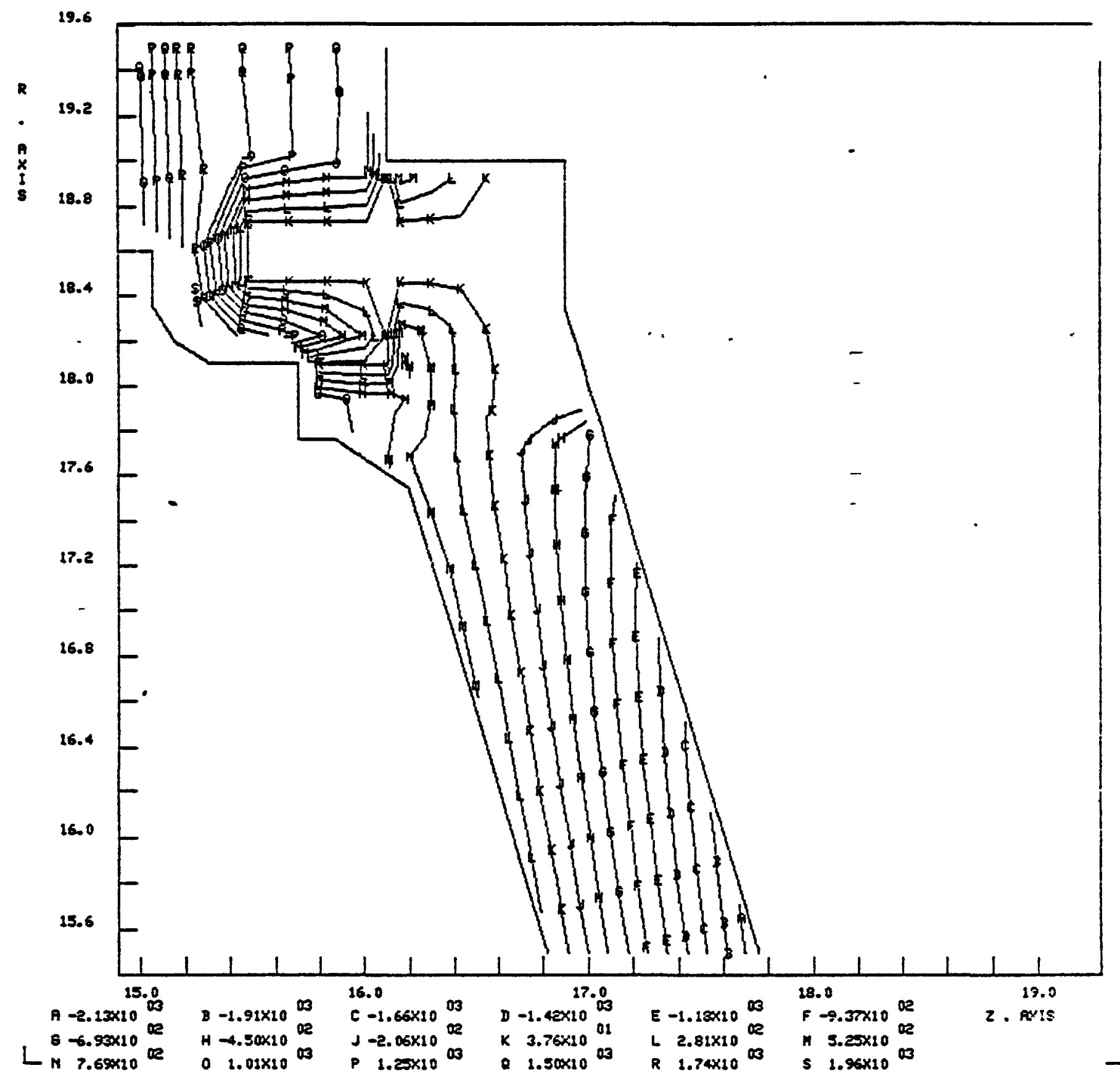




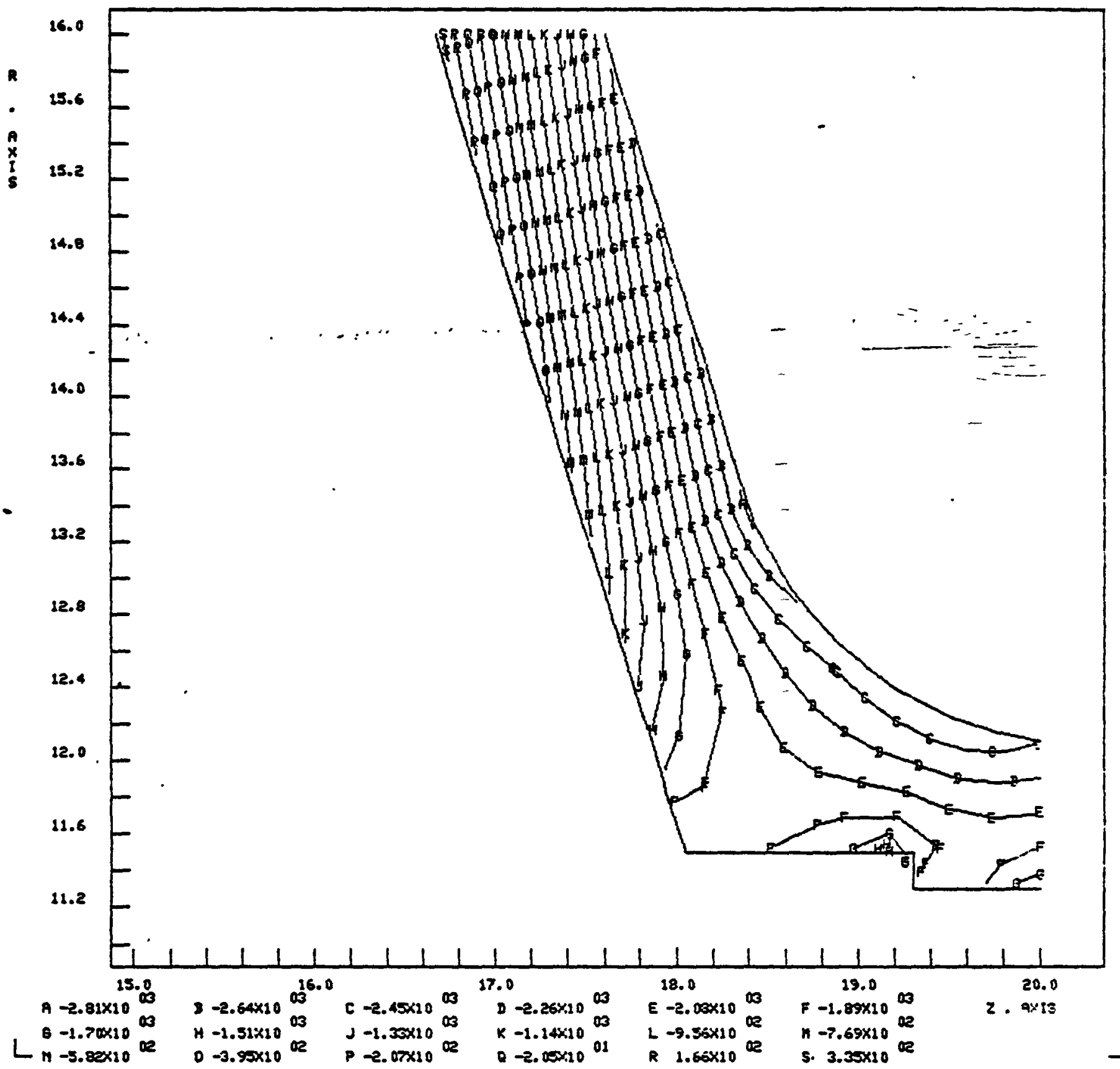




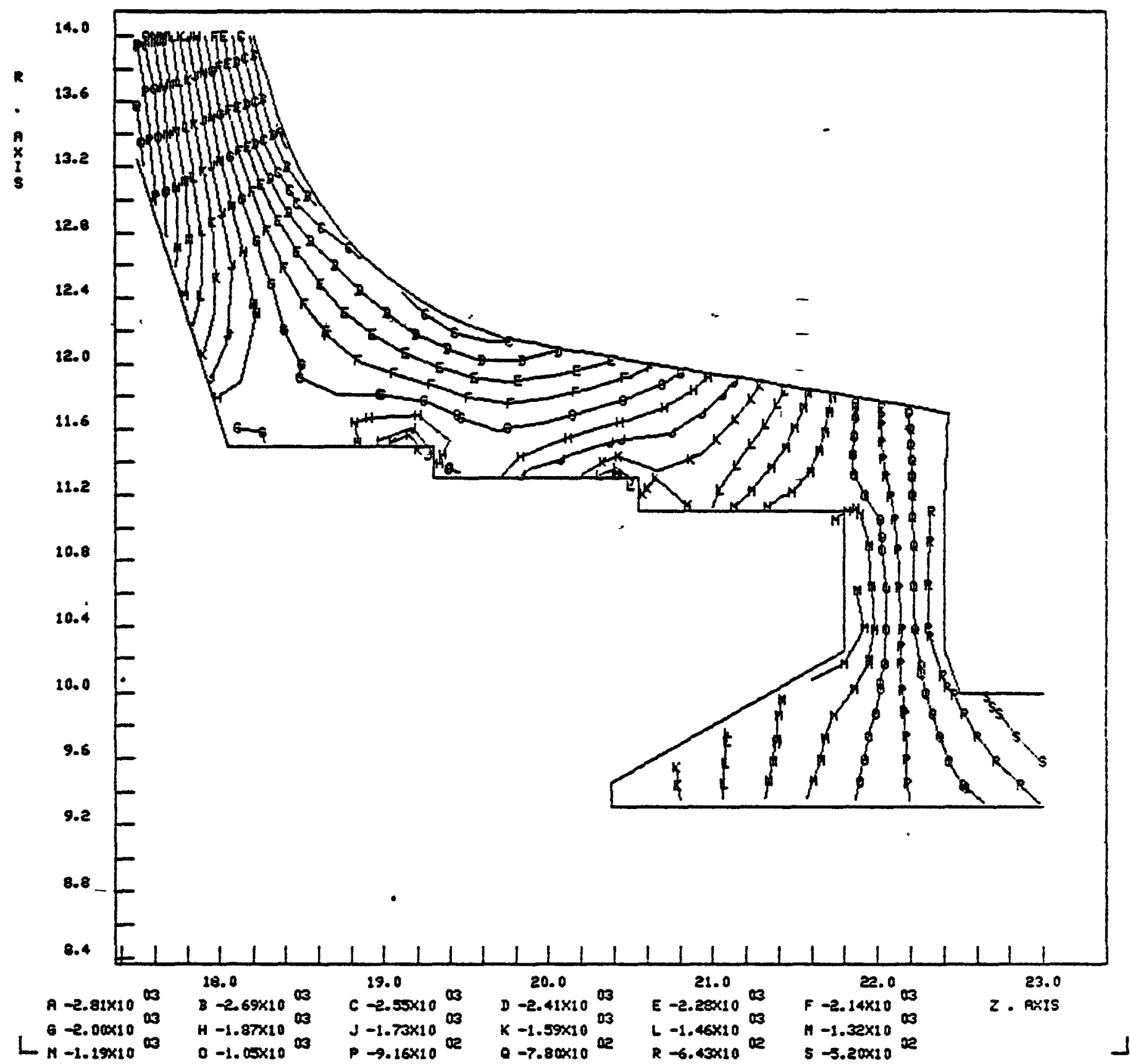




\section{FIGURE 86}

$\Gamma$

AIISP DIFFUSER - SHROUD T=.90, SUPPORT T=.90, $8000 \mathrm{EPM}$ PXISYWETRIC RWLYSIS SIEM-T IS FLOTTED

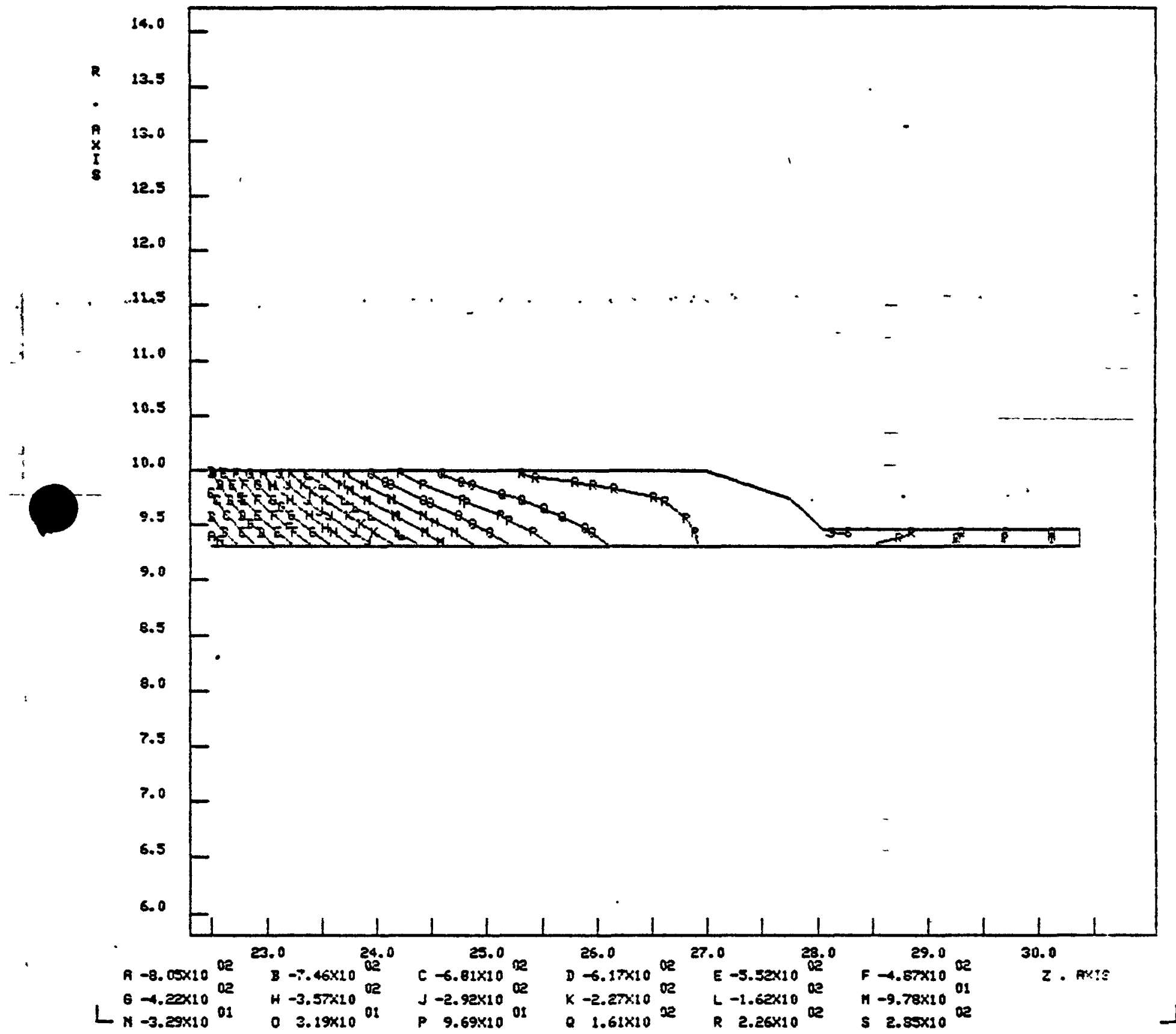




\section{FIGURE 87}

$\Gamma$

AIISP DIFFUSER - SROWD T=.90, SUPPORT T=.90, 8000 6PM AXISTMIETRIC ANALYSIS SIGHA-RZ IS PLOTTED

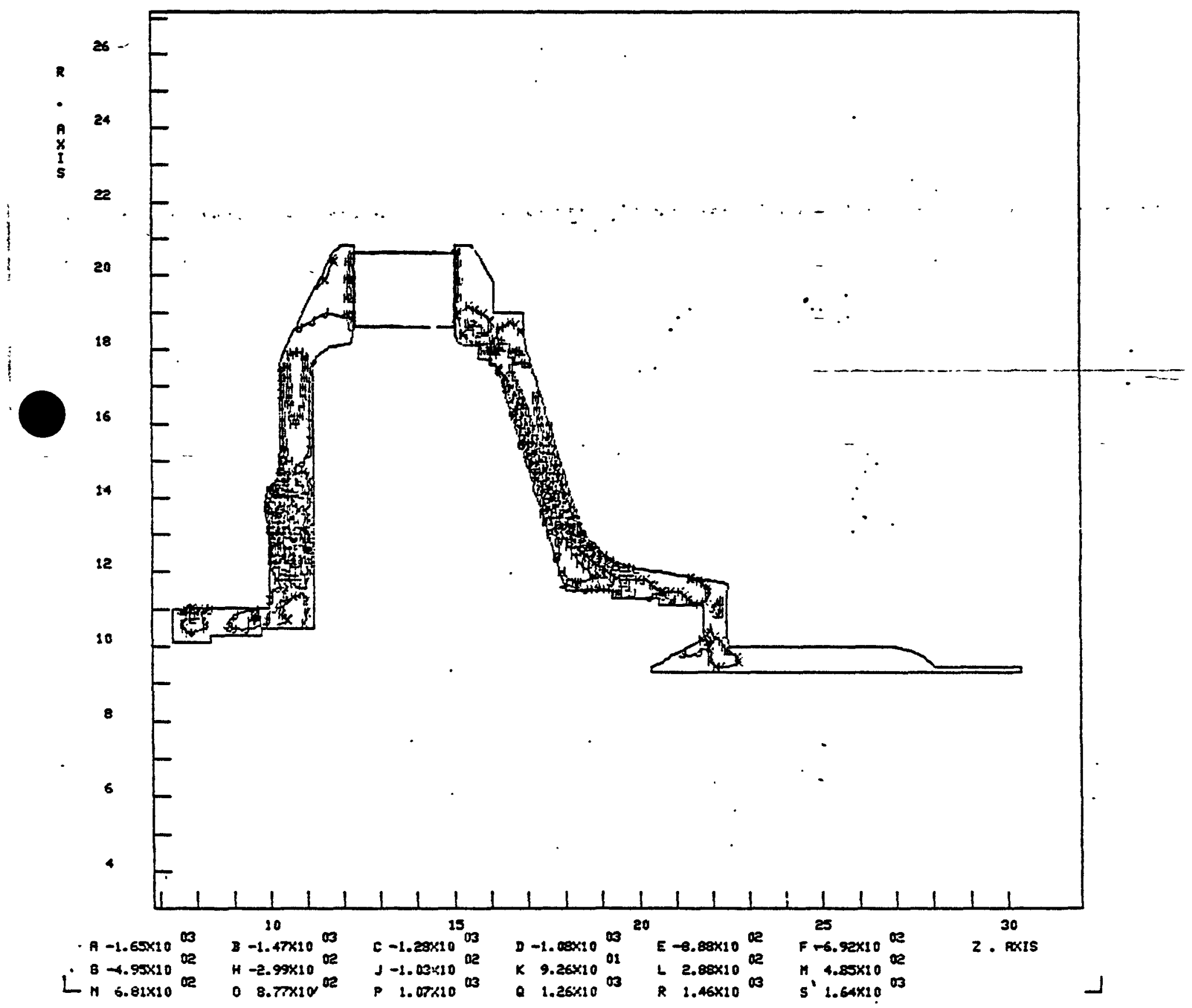




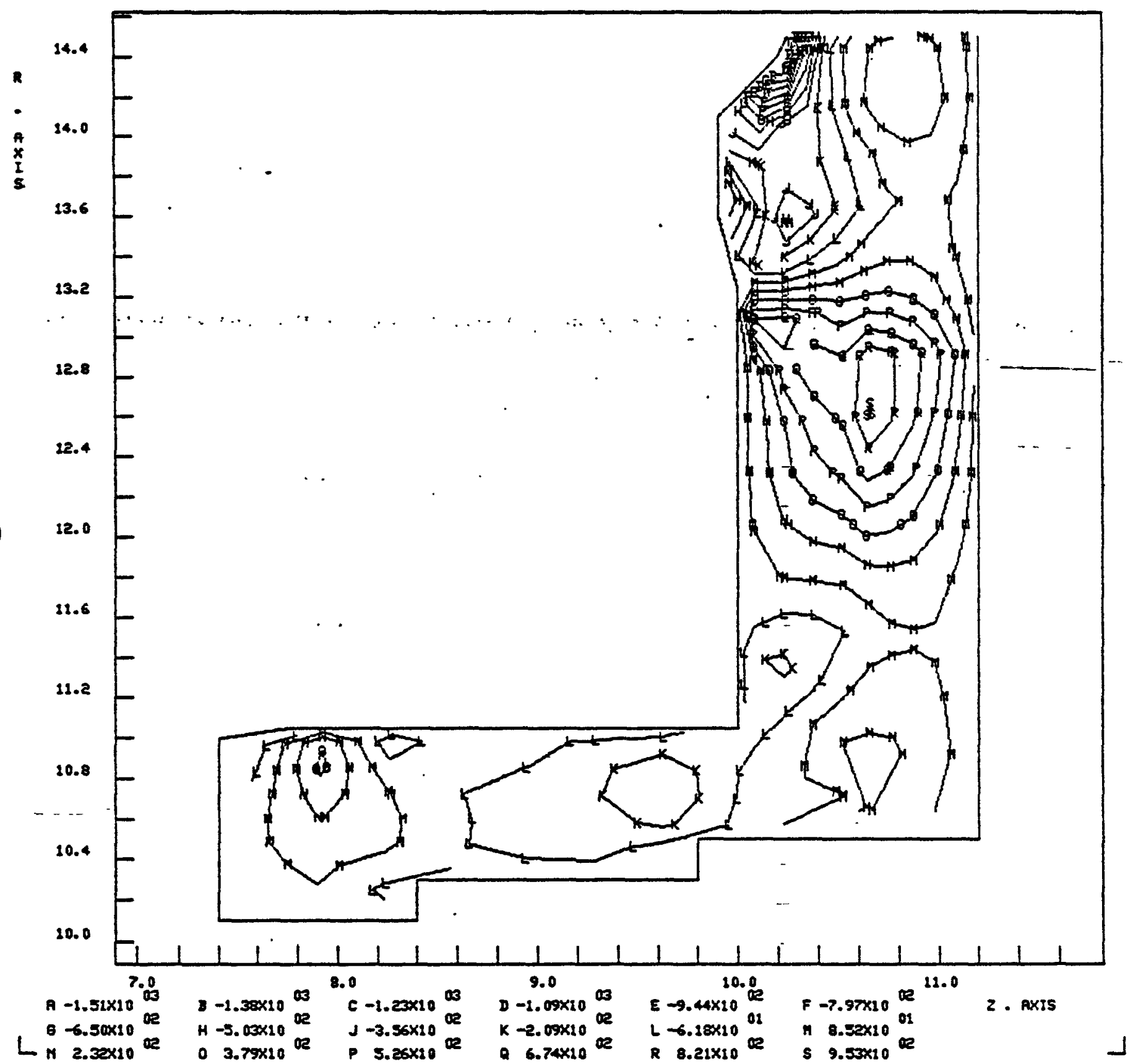




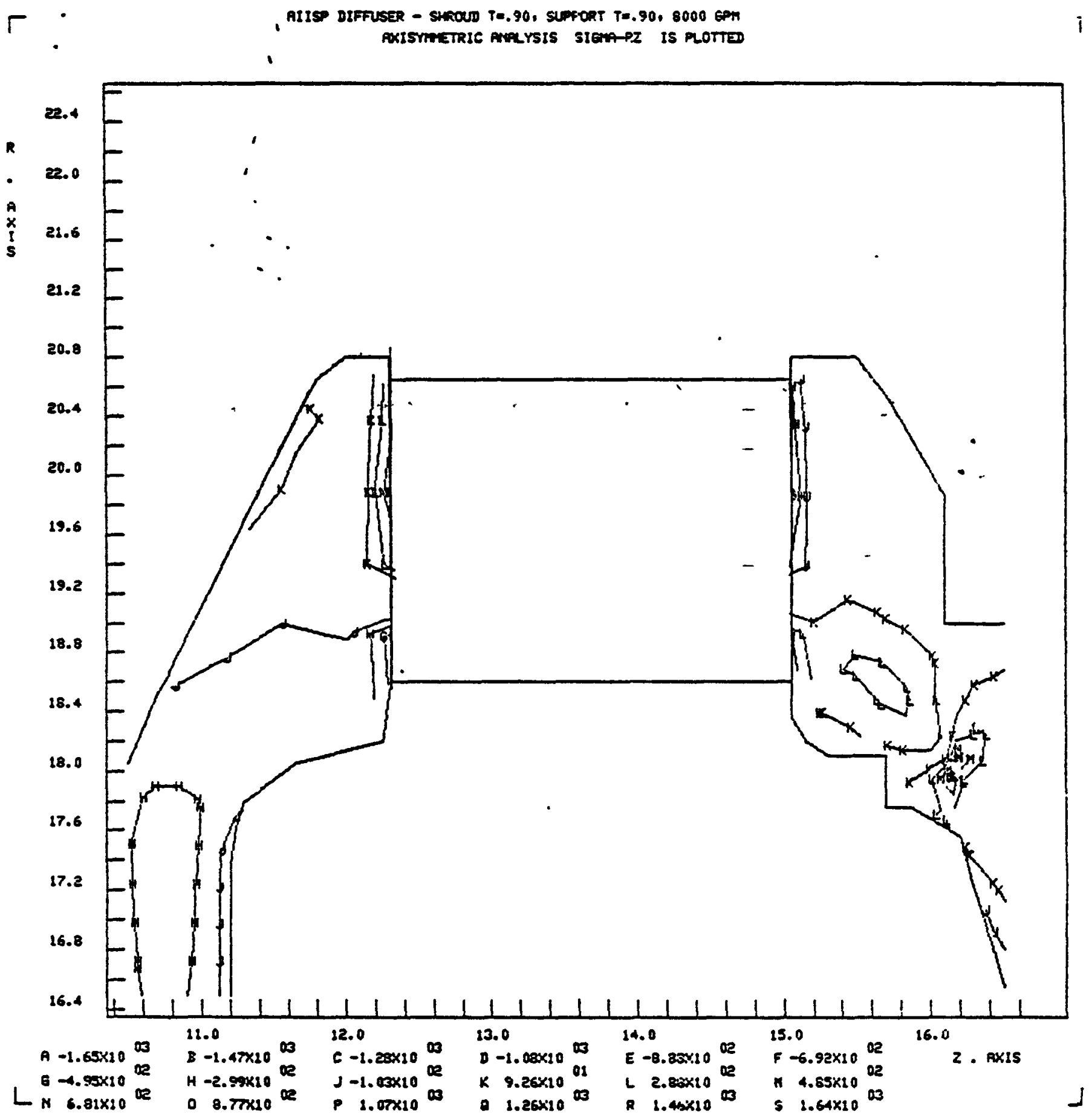




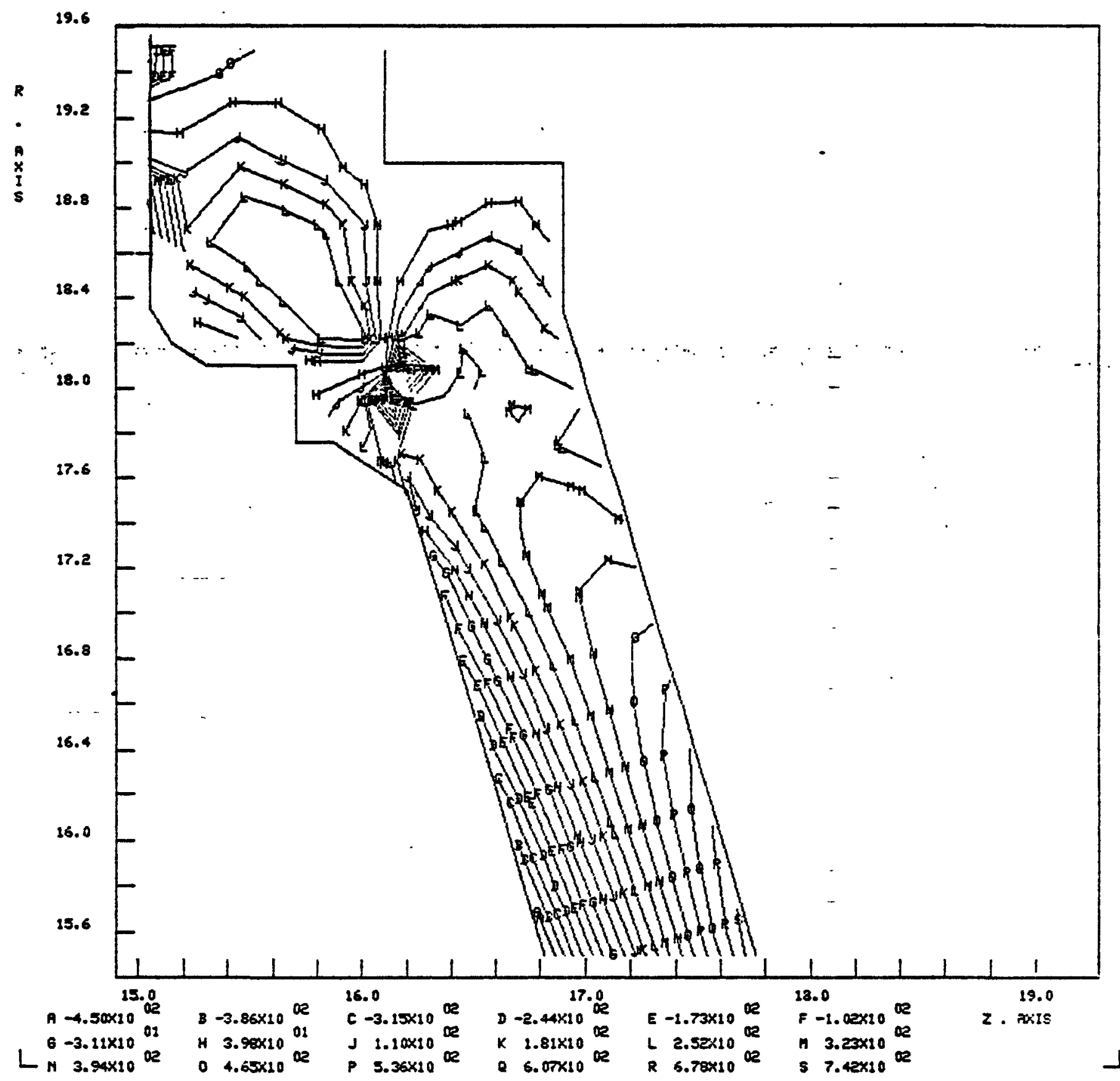




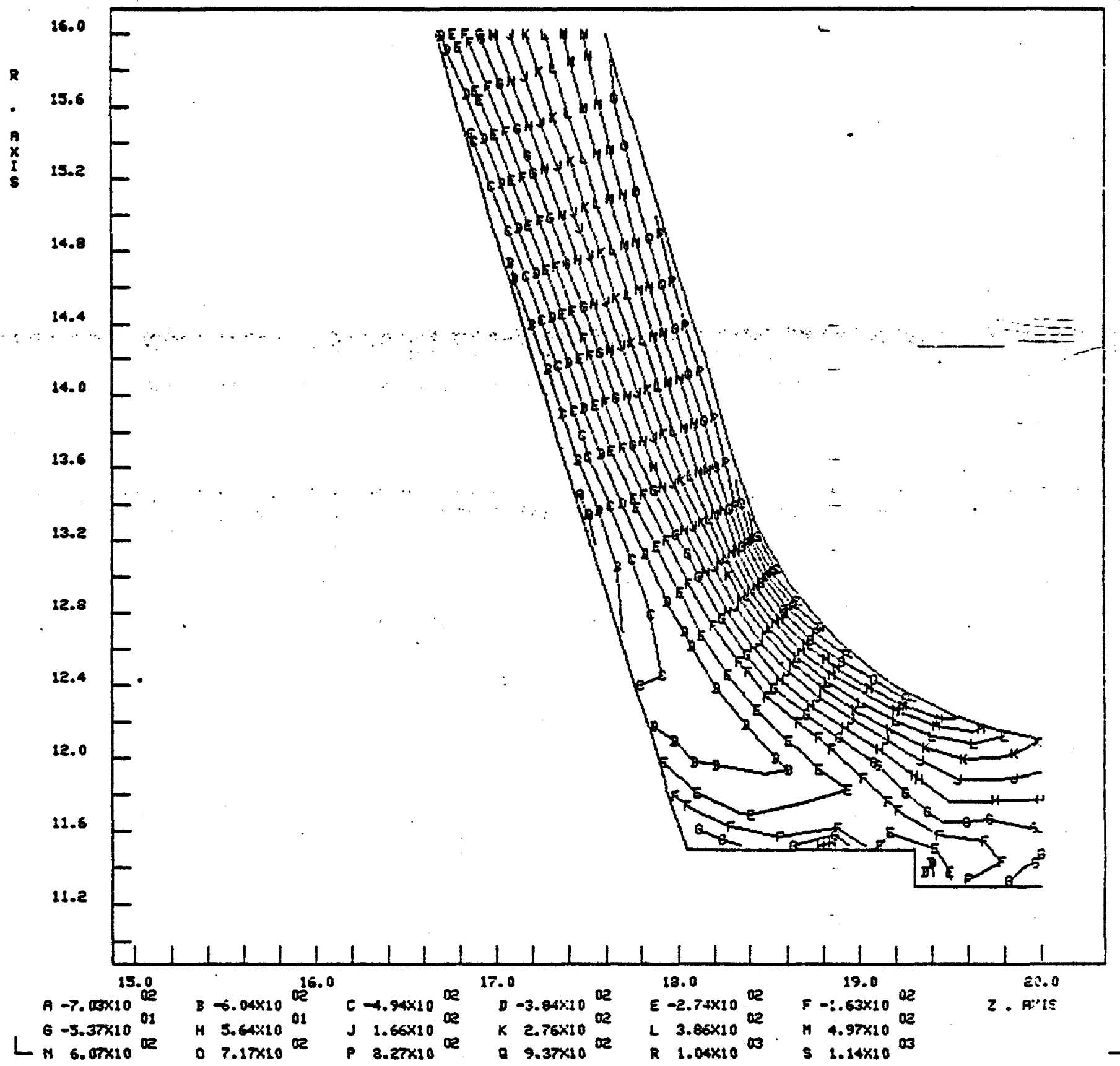




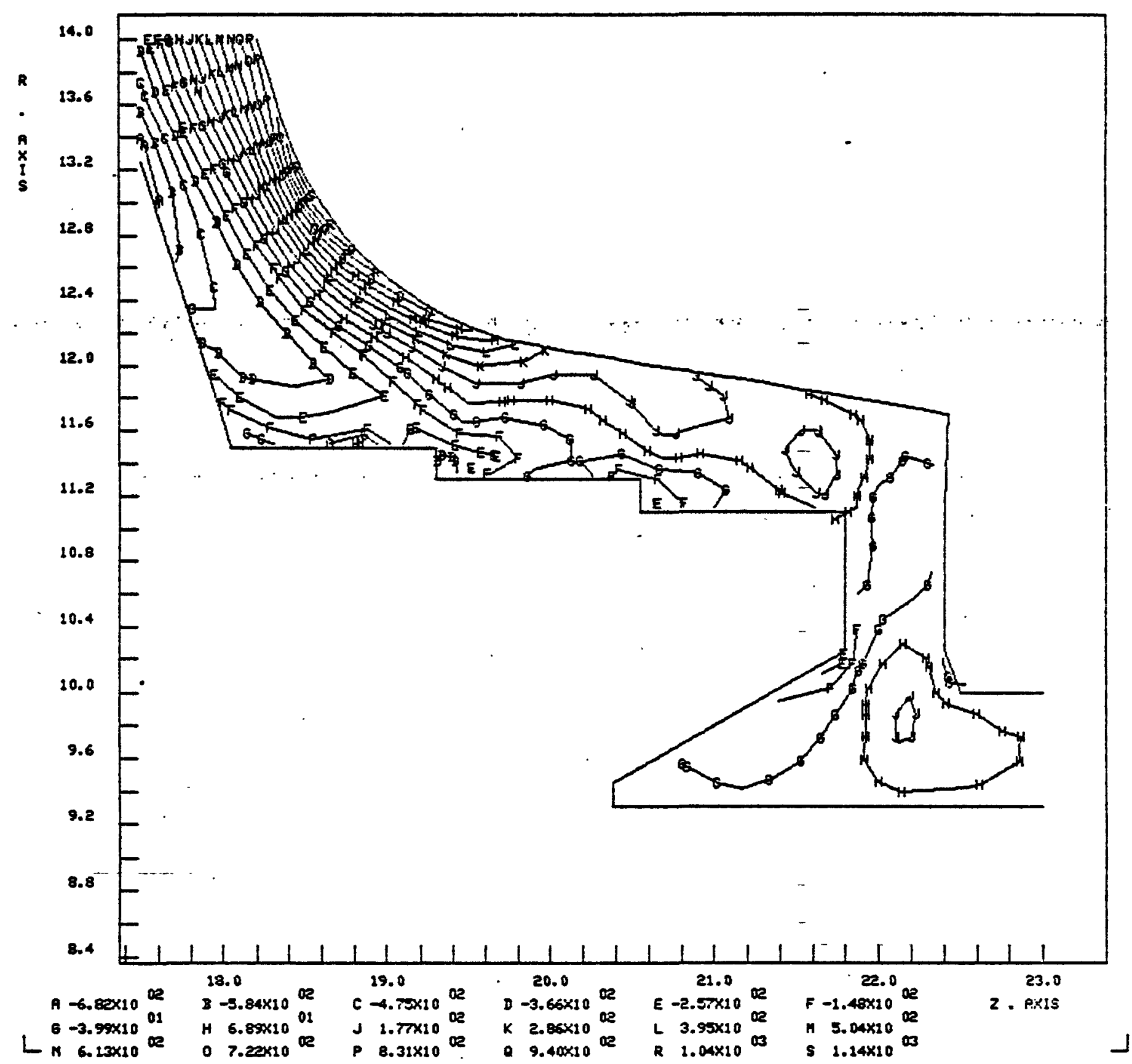


N266ER000-001

N266SR 000001

Page 355

FIGURE 94

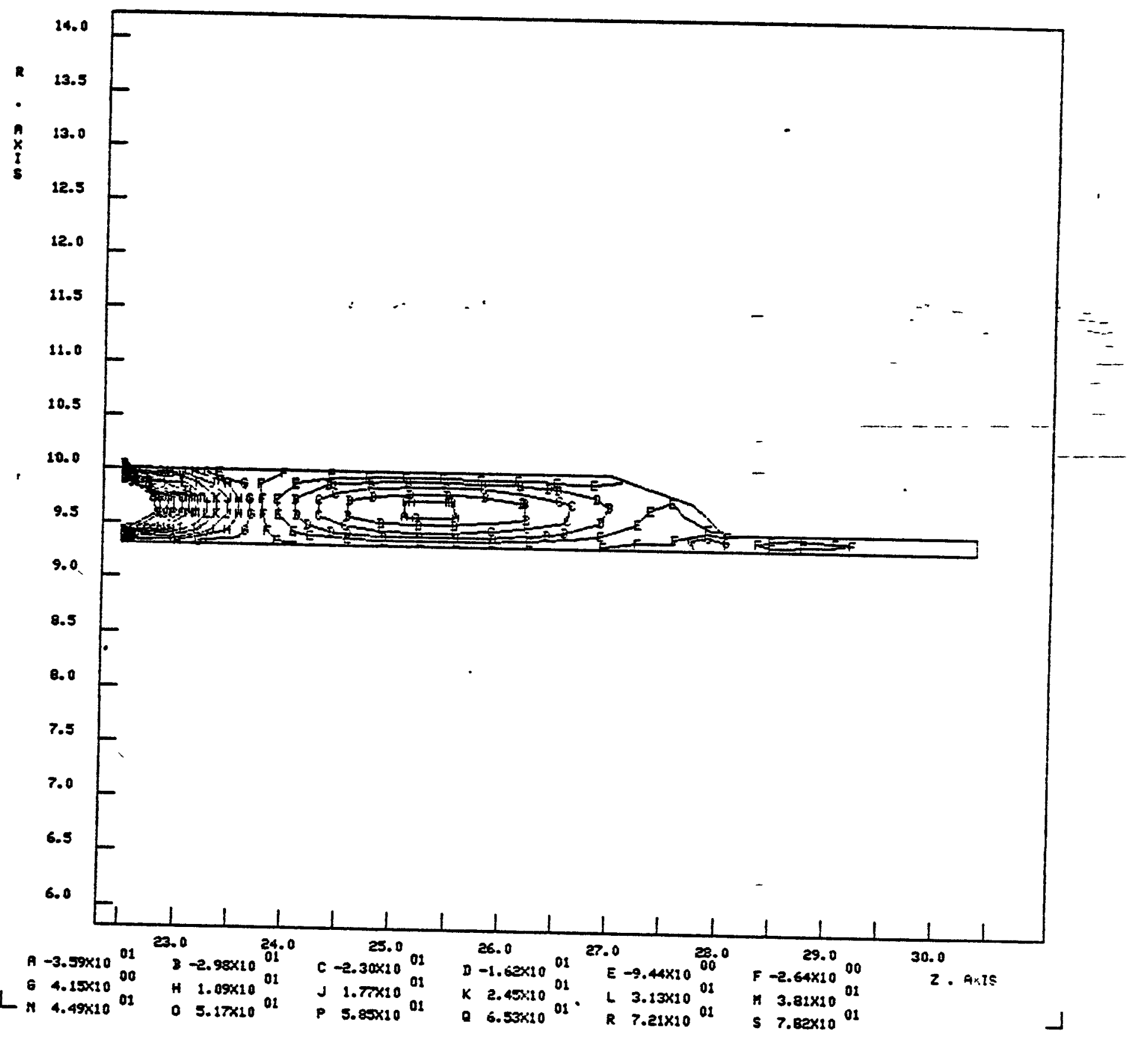




\section{FIGURE 95}

$\Gamma$

AIISP DIFFUSER - SHEOUD T=.90, SUPPORT T=.90, $8000 \mathrm{GPM}$

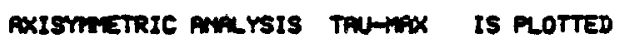

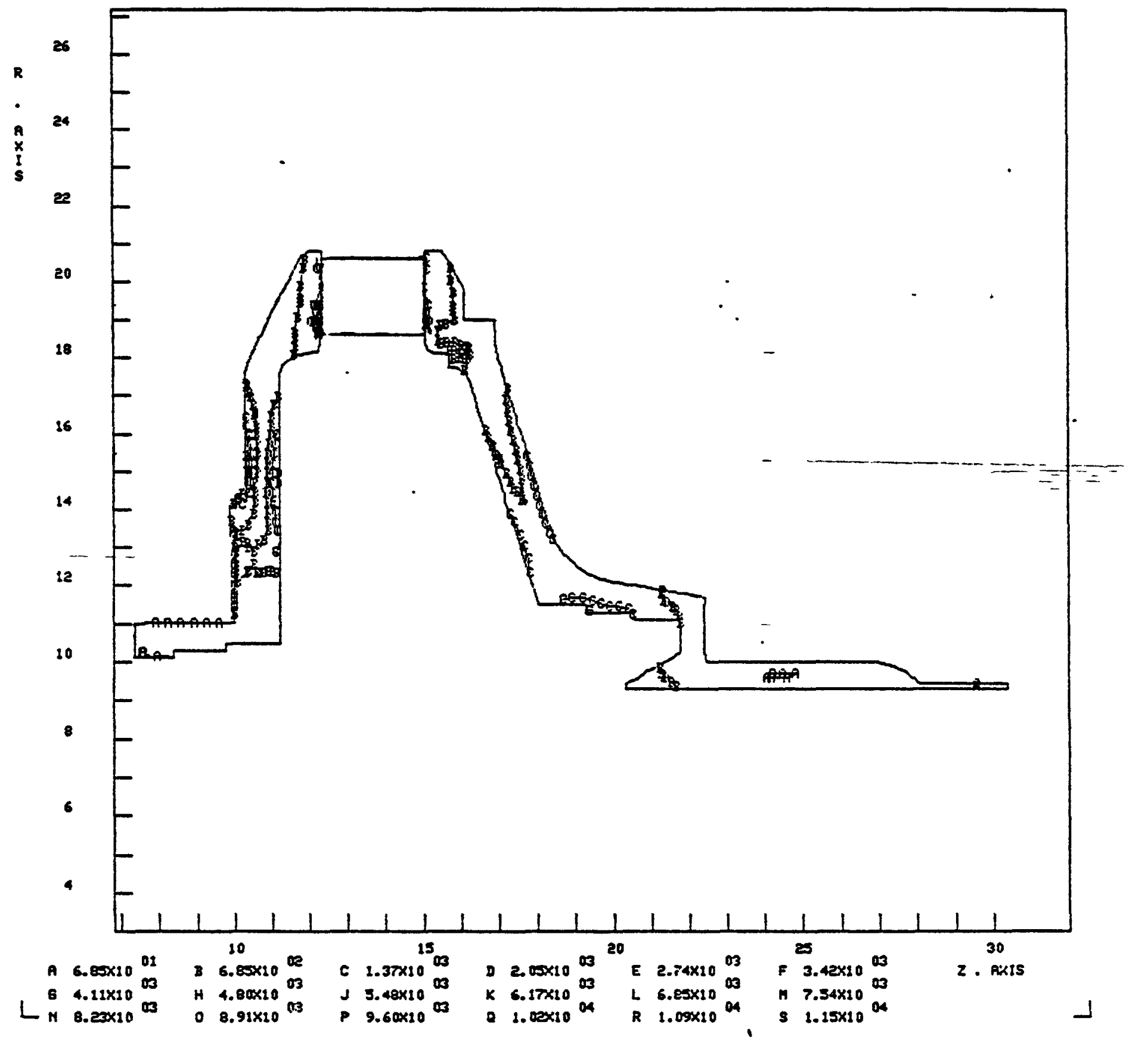




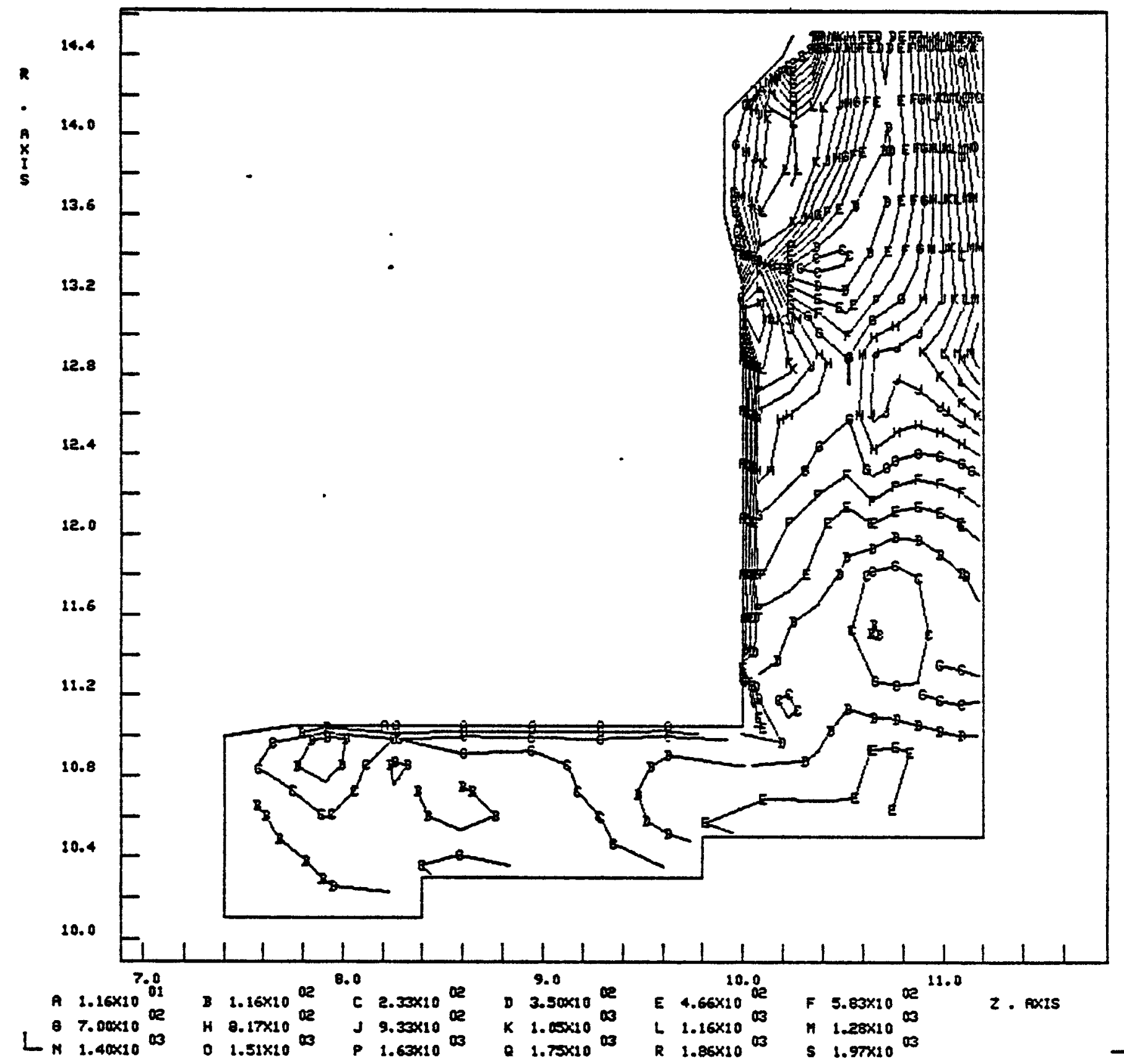




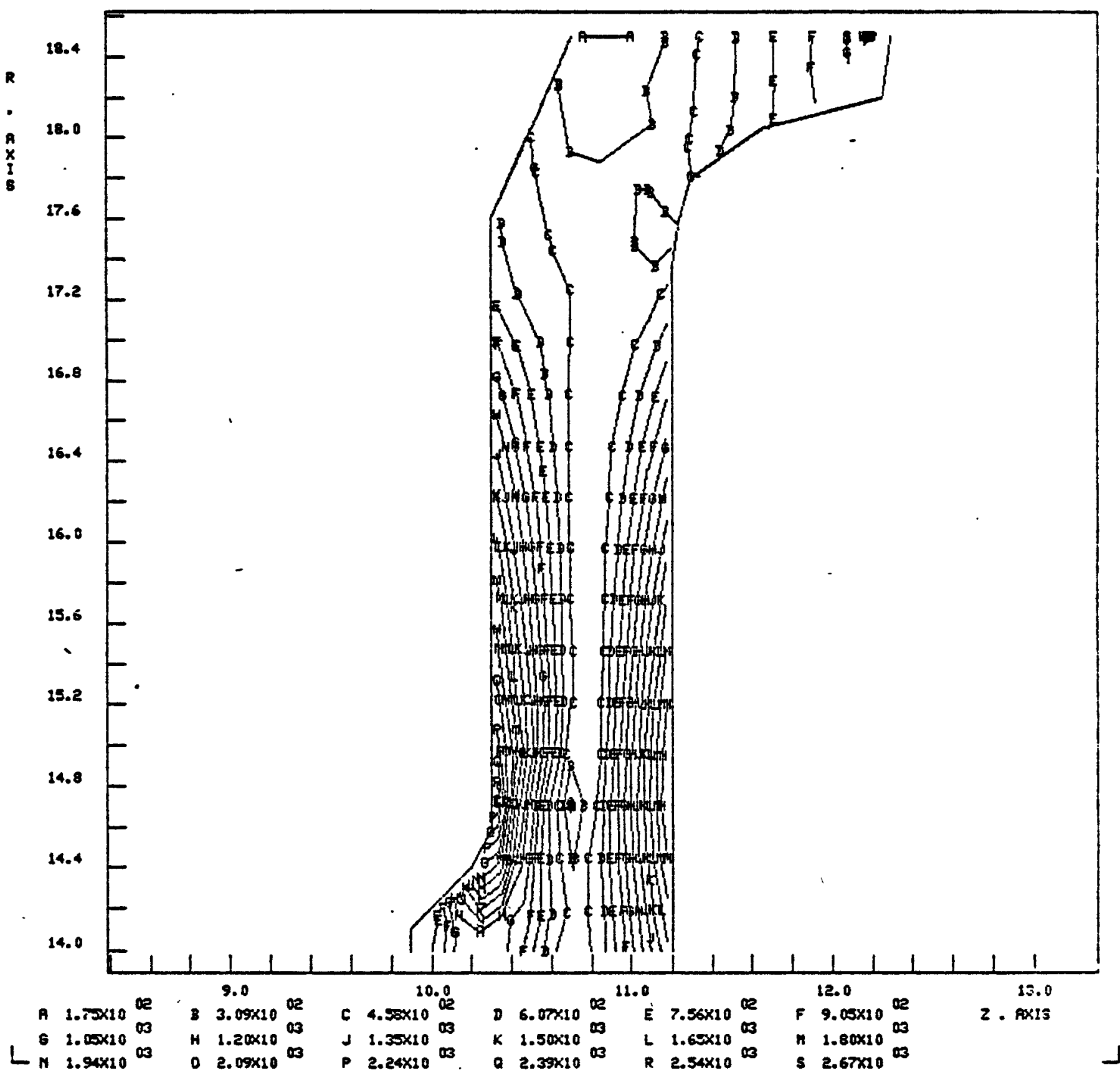




\section{FIGURE 98}

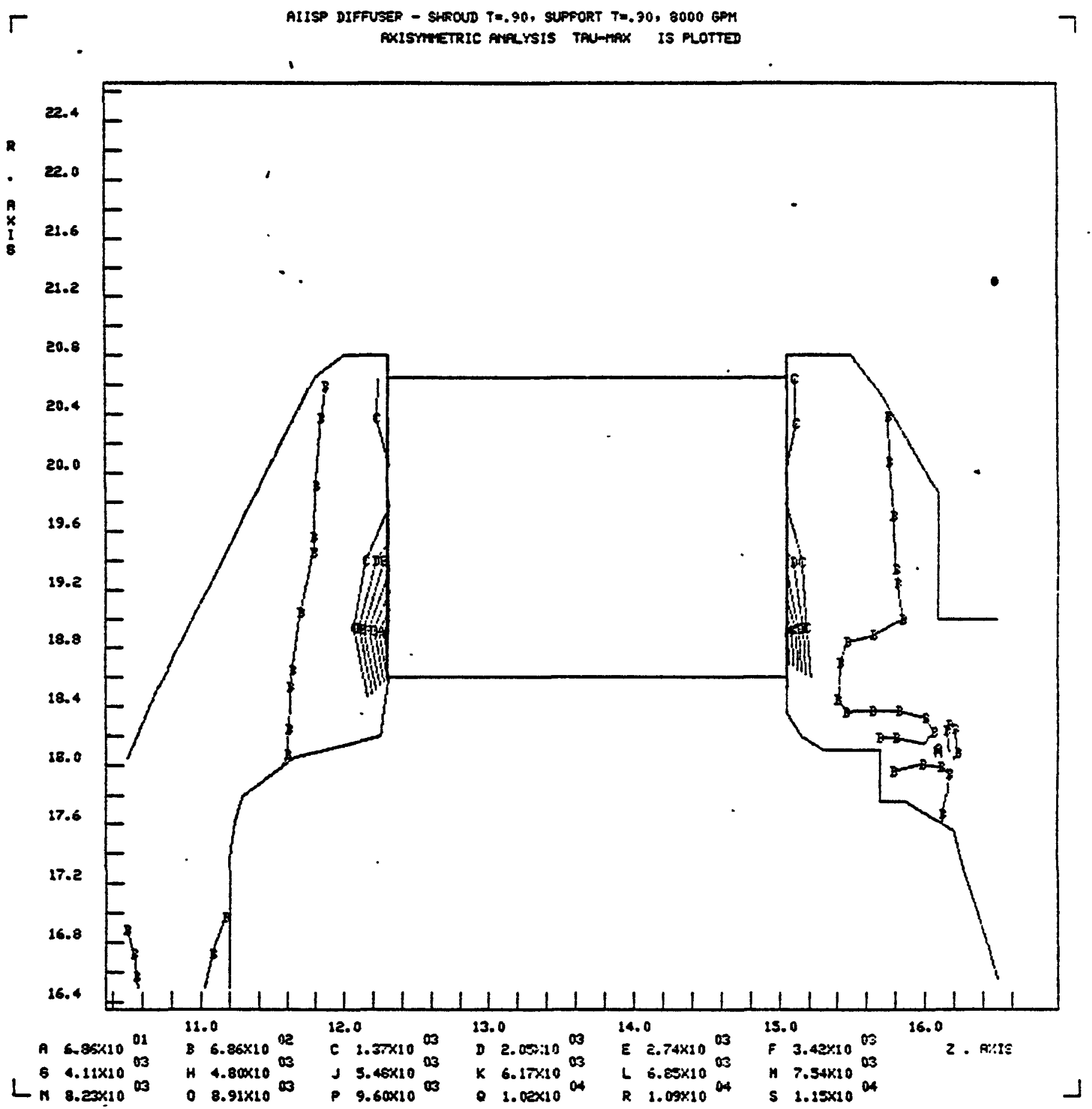




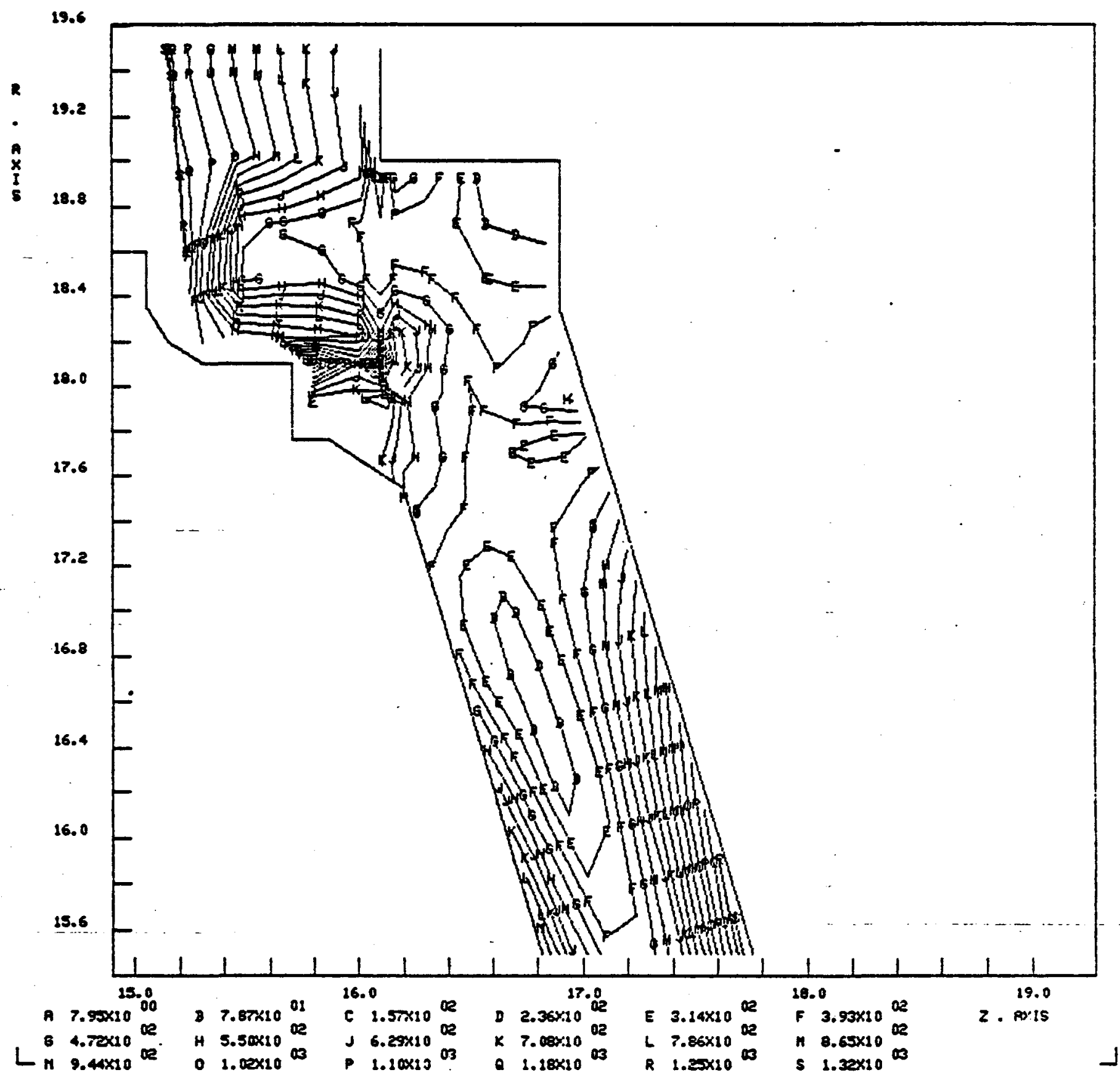




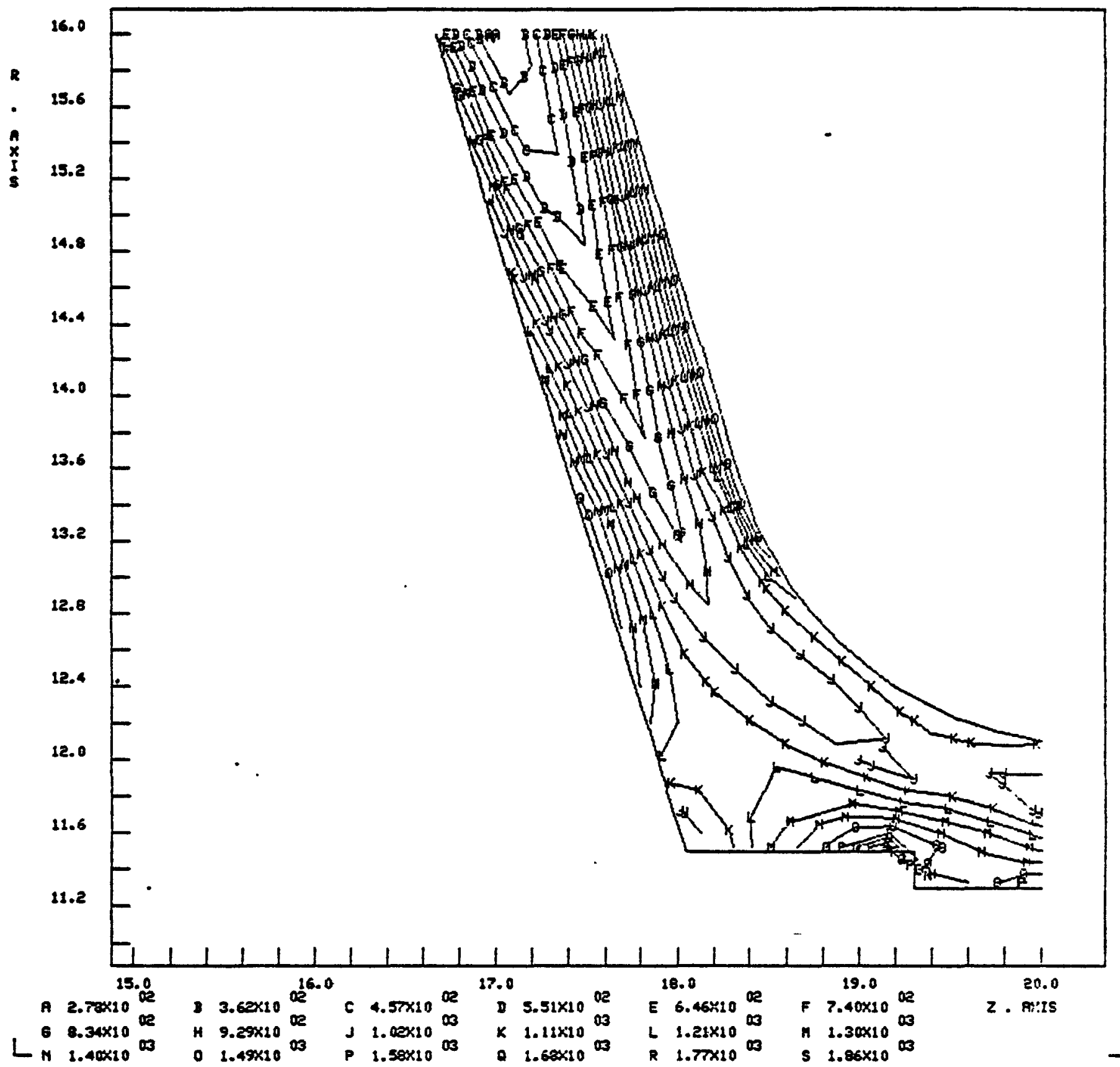

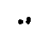




$$
\begin{aligned}
& \text { N266ER000-001 } \\
& \text { Page 362 }
\end{aligned}
$$

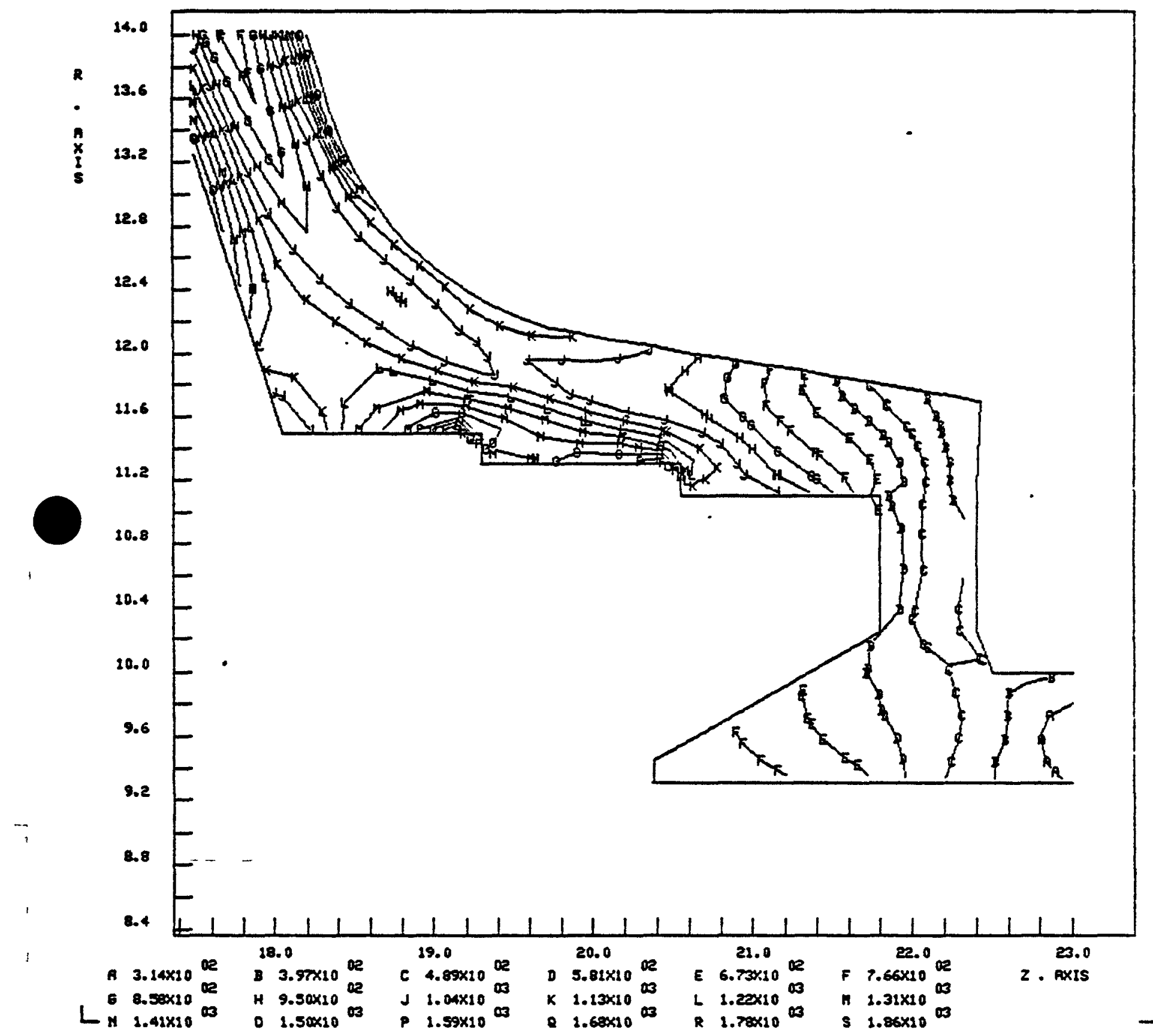




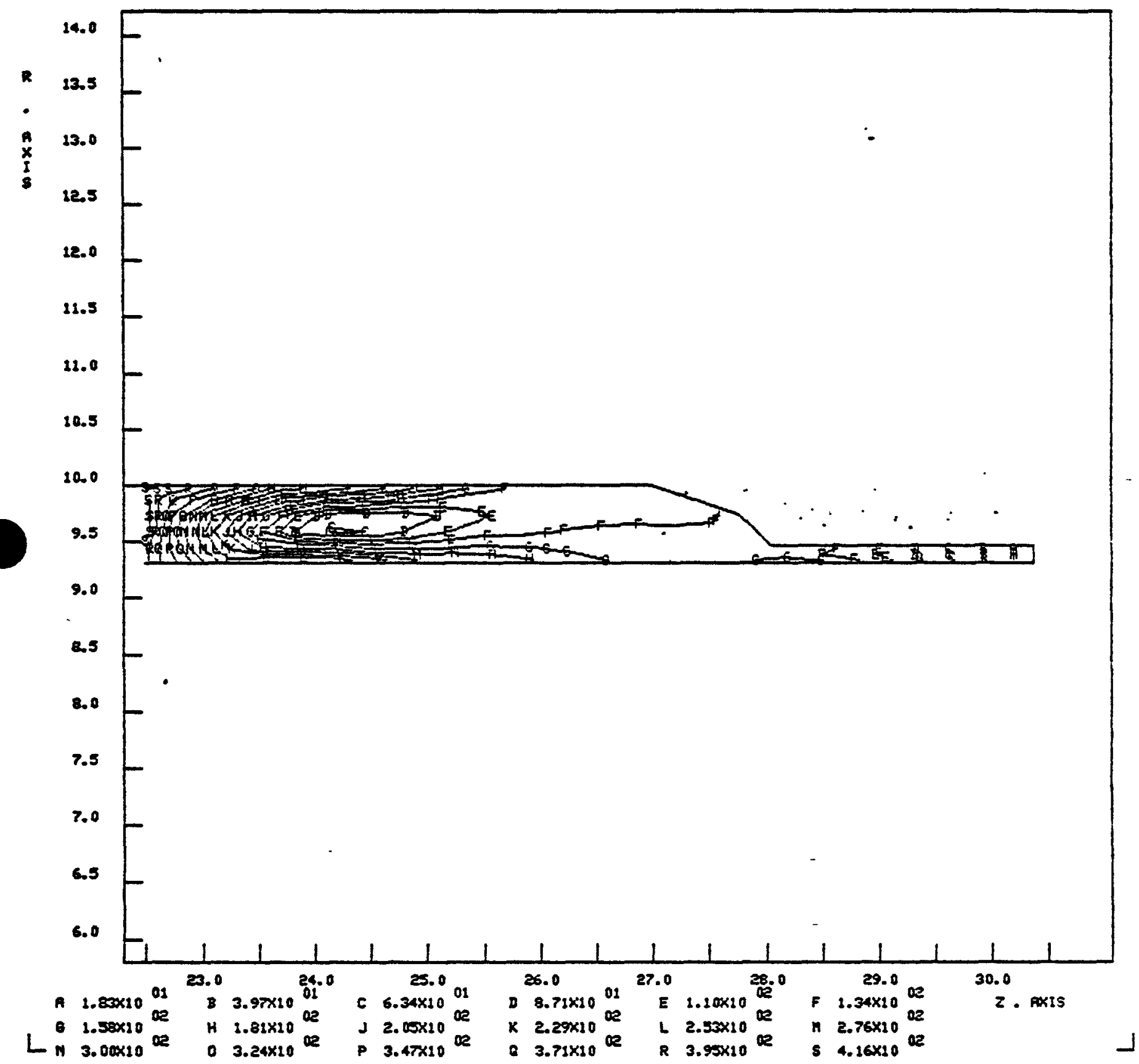


FIGURE 103

SHAFT EXTENSION STRESS INTENSITIES
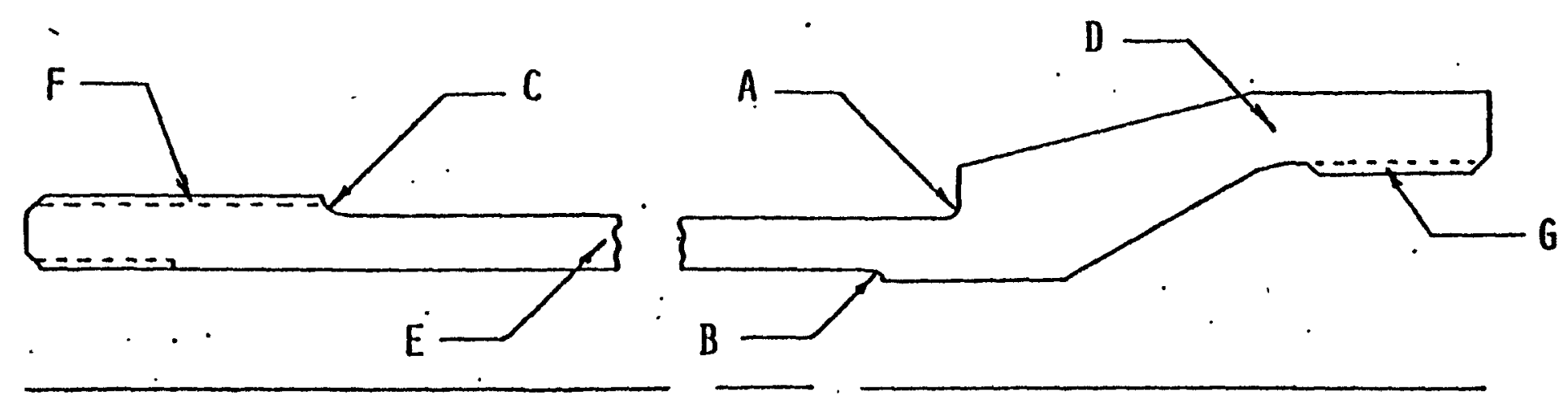

- operating condITIONS

TEMPERATURE $1050^{\circ} \mathrm{F}$

SPEED 1110 RPM

AXIAL LOAD $22.6 \mathrm{KIPS}$

- materlali $\quad$ a286

$1 . S_{M}=15.0 \cdot \mathrm{kSI} \quad\left(P_{M}\right)$

$S_{M}=20.0 \mathrm{KSI} \quad\left(P_{L}+P_{B}\right)$

- STRESS INIEHSIIIES

\begin{tabular}{|c|c|c|}
\hline LOCATION & S KSI & $\begin{array}{l}\text { DESIGN } \\
\text { MARGIN }\end{array}$ \\
\hline$A$ & 15.6 & .28 \\
\hline B & 15,1 & .32 \\
\hline c & 7,9 & 1.53 \\
\hline D & 6.5 & 2.08 \\
\hline $\mathrm{E}^{1}$ & 4.5 & 2.33 \\
\hline$F^{1}$ & 2.7 & 4.56 \\
\hline$G^{1}$ & 4.0 & 2.75 \\
\hline
\end{tabular}


APPENDIX I

INTERMEDIATE SIZE INDUCER PUMP -

STRUCTURAL ANALYSIS AND TRANSIENT

DEFORMATION STUDIES

ESG Document N266SR000-002 


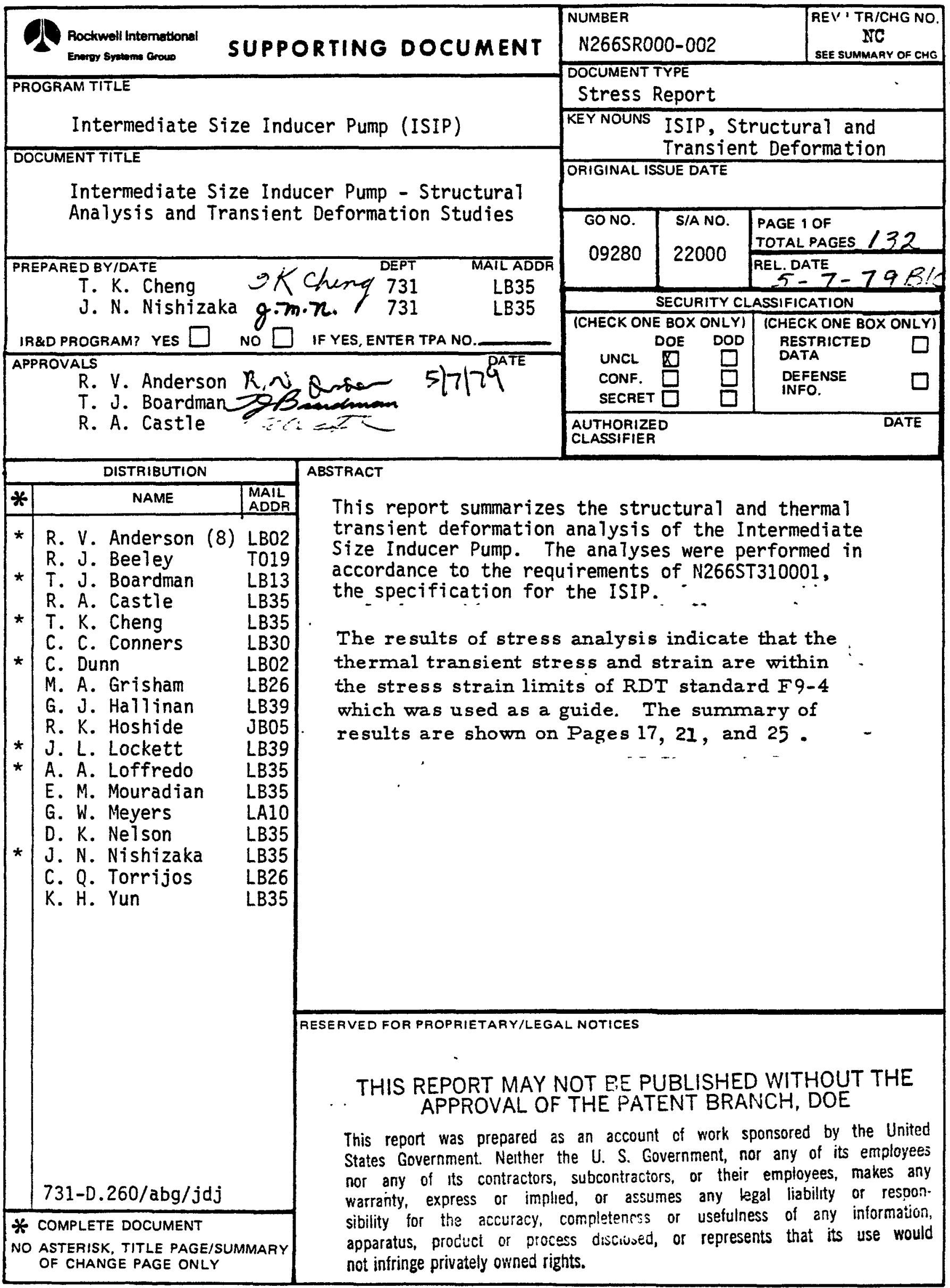




\section{CONTENTS}

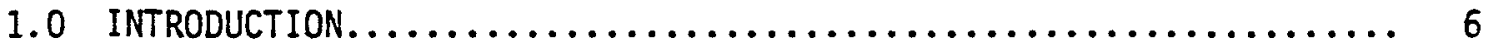

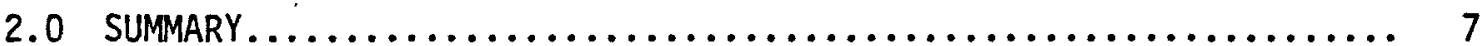

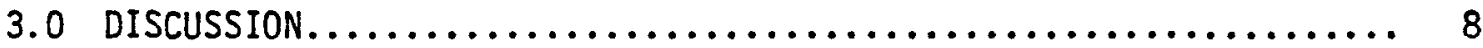

3.1 Test Criteria................................. 9

3.2 Analytical Procedure.......................... 10

3.3 Transient Data............................... 10

3.4 Structurat Criteria.......................... 11

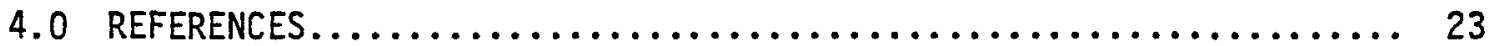

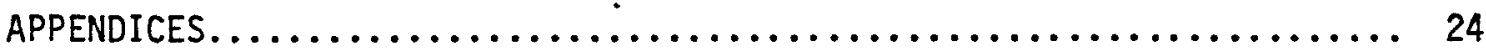

A. Structural Analysis.......................... 24

a. Strain Limit Evaluation..................... 24

b. Creep-Fatigue Damage Evaluation................ 24

B. Thermal Deformation Anatysis...................... 61 


\section{TABLES}

Table

1. Critical Clearance Change........................ 17

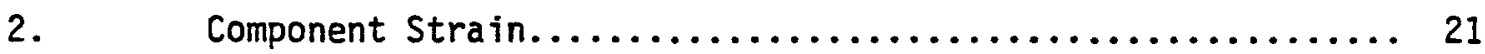

3. Component Thermal Stresses....................... 22

A-1 Component Stresses........................... 27

A-2 Component Strain............................ 28

B-1 Radial Clearance for Test Transient E-202 a Bearing Area.... 74

B-2 Radial Clearance for Test Transient E-203 @ Bearing Area... 75

B-3 Radial Clearance for Test Transient E-204 Bearing Area.... 76

B-4 Radial Clearance for Test Transient E-207 @ Bearing Area... 77

B-5 Radial Clearance for Test Transient E-208 a Bearing Area.... 78

B-6 Radial Clearance for Test Transient E-210 Bearing Area... 79

B-7 Radial Clearance for Test Transient E-202 D Diffuser

Shroud...................................... 80

B-8 Radial Clearance for Test Transient E-203 a Diffuser

Shroud..................................... 81

B-9 Radial Clearance for Test Transient E-204 a Diffuser

Shroud....................................... 82

B-10 Radial Clearance for Test Transient E-207 a Diffuser

Shroud................................... 83

B-11 Radial Clearance for Test Transient E-208 O Diffuser

Shroud........................................ 84

B-12 Radial Clearance for Test Transient E-210 D Diffuser

Shroud..................................... 85

B-13 Radial Clearance Change for Test Transient E-202 0

Front Labyrinth Seal.......................... 86

B-14 Radial Clearance Change for Test Transient E-203 C

Front Labyrinth Sea1............................ 87

B-15 Radial Clearance Change for Test Transient E-204 C

Front Labyrinth Sea $. . \ldots \ldots \ldots \ldots \ldots \ldots \ldots \ldots \ldots \ldots . \ldots 8$

B-16 Radial Clearance Change for Test Transient E-207 0

Front Labyrinth Sea ........................... 89

B-17 Radial Clearance Change for Test Transient E-208 O

Front Labyrinth Sea 1.......................... 90

B-18 Radial Clearance Change for Test Transient E-210 0

Front Labyrinth Sea1.......................... 91 
B-19 Radial Clearance Change for Test Transient E-202

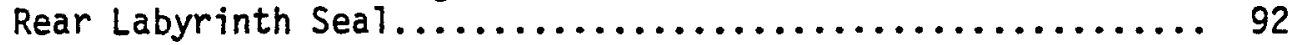

B-20 Radial Clearance Change for Test Transient E-203 O Rear Labyrinth Seal............................ 93

B-21 Radial Clearance Change for Test Transient E-204 0 Rear Labyrinth Seal.............................. 94

B-22 Radial Clearance Change for Test Transient E-207 Rear Labyrinth Seal........................... 95

B-23 Radial Clearance Change for Test Transient E-208 e Rear Labyrinth Seal........................... 96

B-24 Radial Clearance Change for Test Transient E-210 e Rear Labyrinth Seal........................... 97

B-25 Radial Clearance Change for Test Transient E-202 a

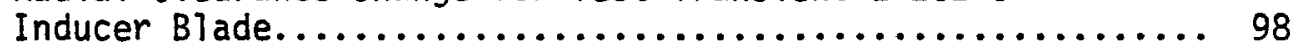

B-26 Radial Clearance Change for Test Transient E-203 0 Inducer Blade.................................. 99

B-27 Radial Clearance Change for Test Transient E-204 C Inducer Blade................................. 100

B-28 Radial Clearance Change for Test Transient E-207 0

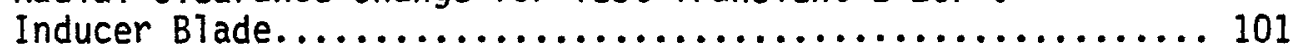

B-29 Radial Clearance Change for Test Transient E-208 0 Inducer Blade............................... 102

B-30 Radial Clearance Change for Test Transient E-210 0 Inducer Blade............................... 103

B-31 Radial Clearance Change for Test Transient E-202 0 Bearing Support.............................. 104

B-32 Radial Clearance Change for Test Transient E-203 O

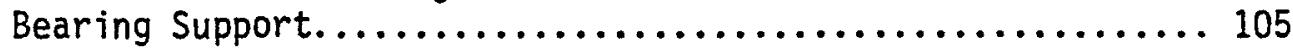

B-33 Radial Clearance Change for Test Transient E-204 0

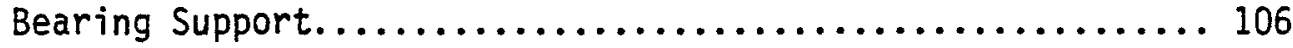

B-34 Radial Clearance Change for Test Transient E-207 Bearing Support.............................. 107

B-35 Radial Clearance Change for Test Transient E-208

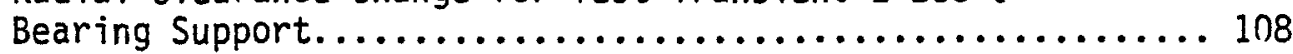

B-36 Radial Clearance Change for Test Transient E-210 @

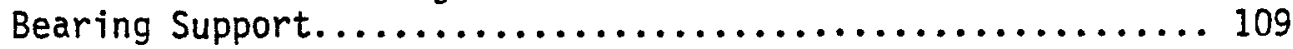

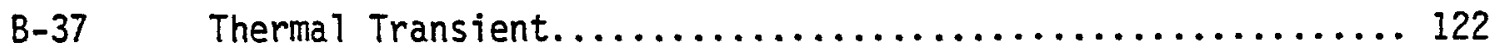




\section{FIGURES}

Figure

Page

1. Schematic of Inducer-Impeller Assembly.............. 16

2. Finite Element Model........................... 18

3. Typical Temperature Field........................ 19

4. Ratchet Limits (Bree Complete Relaxation)................ 20

B-1 APSA Model for Static Assembly.................... 62

B-2 APSA Model for Rotating Assembly................... 63

B-3 Finite Element Model @ Bearing Area - Node Point No........ 64

B-4 Finite Element Model @ Bearing Area - Element No.......... 65

B-5 Finite Element Model O Impeller Shaft - Node Point No...... 66

B-6 Finite Element Model O Impeller Shaft - Element No......... 67

B-7 Finite Element Model a Diffuser - Node Point No.......... 68

B-8 Finite Element Model a Diffuser - Element No............ 69

B-9 Finite Element Model e Inducer Blade - Node Point No....... 70

B-10 Finite Element Model @ Inducer Blade - Element No......... 71

B-11 Finite Element Model \& Diffuser Shroud - Node Point No...... 72

B-12 Finite Element Model a Diffuser Shroud - Element No........ 73

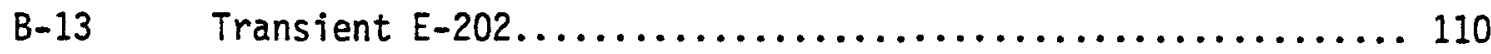

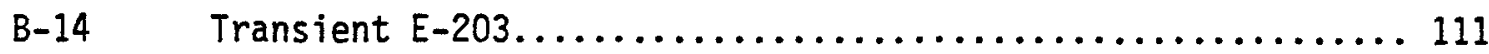

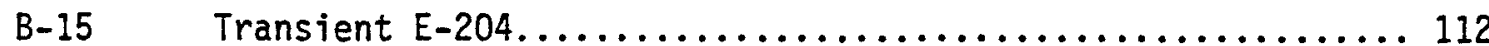

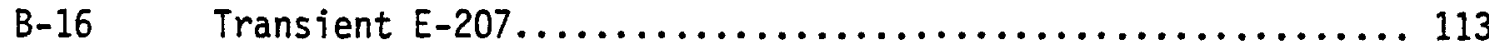

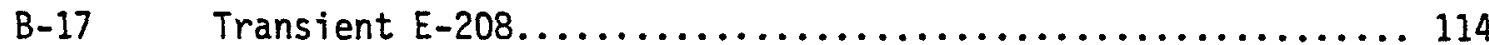

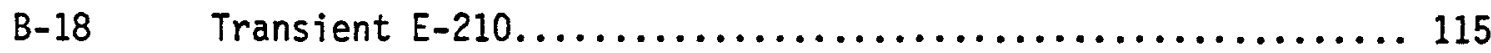

B-19 Stress Intensity C Pump Component for Transient E-207

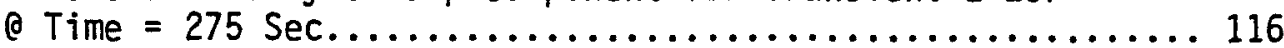

B-20 Stress Intensity a Pump Component for Transient E-207

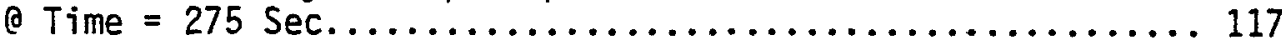

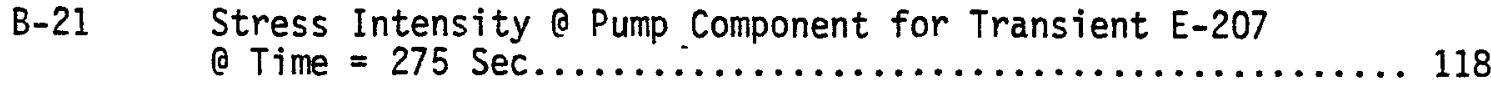

B-22 Stress Intensjty o Pump Component for Transient E-207

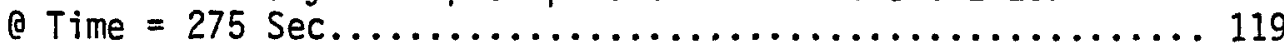

B-23 Stress Intensity e Pump Component for Transient E-207

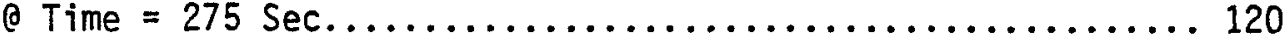

B-24 Stress Intensity de Pump Component for Transient E-207

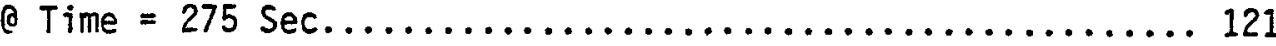




\section{FIGURES \\ (Continued)}

Figure

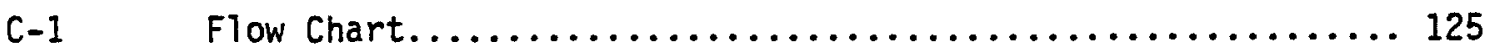

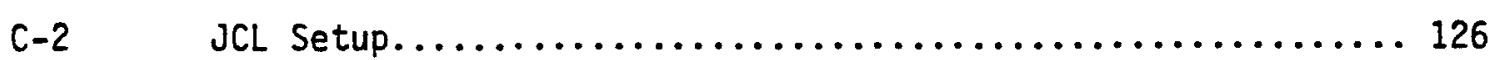

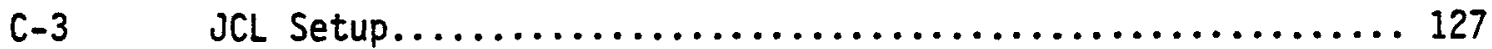

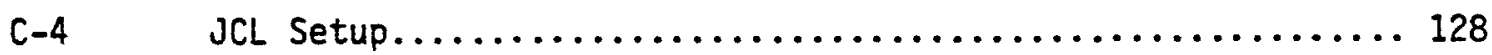




\subsection{INTRODUCTION}

The Intermediate Size Inducer Pump (ISIP) utilizes the pump frame from the FFTF Prototype Pump as a test vehicle for an inducer impeller assembly. Construction requirements for the FFTF prototype pump may be found in Westinghouse Specification EiS-1551, which was written for the complete pump. ESG Specification N266ST310001 covers construction requirements for those parts used in the ISIP design to replace prototype pump parts. A complete description of the prototype pump is given in the Westinghouse Operation and Maintenance Manual, 0MM-051-00-005. The ISIP Operation and Maintenance ManuaT N2660MM000001 (Reference 10) describes those parts of the pump assembly which are different for the ISIP configuration.

Structural analyses of the ISIP components in the region of the inducer/impeller assembly was performed to determine the effects of steady-state operation and of thermal transients which are defined as part of the test requirements in the ISIP specification. Evaluation of the structural integrity of the ISIP parts was based on using analytical methods and acceptance criteria of the Section III ASME Boiler and Pressure Vessel Code and appropriate RDT standards as applied to designs for high-temperature service. Evaluation of the steady-state effects are reported in N266SR000001 (Reference 5). This report covers the effects of operation during thermal transients, superimposed on those steady-state conditions.

In addition to the structural analysis, a thermal deformation analysis was conducted to determine the effects of thermal transients on critical regions such as fits and running clearances to permit evaluation of the functionability of the design and of the restrictions, if any, which should be placed on transient testing. 


\subsection{SUMMARY}

The thermal deformation analysis was performed for the six test transients for which thermal analysis are reported in Reference 7 . The critical clearance changes between rotating and static components are listed in Table 1.

The analysis shows a reduction of $3 \mathrm{mils}$ during thermal transient E-207 at the bearing and journal, and a 7-mil clearance reduction at the rear labyrinth seal during transient E-203.

Table 2 summarizes the results of component strain evaluation. Based on the criteria of RDT Standard F9-4, Section 6, for strain 7imit, the total accumulated strain of $0.23 \%$ is within the $1 \%$, and the total creep-fatigue damage fraction of 0.026 is less than 0.6 as allowed in the specification ( REF. 6) 


\subsection{DISCUSSION}

The functional and structural integrity of the inducer/impeller assembly of the intermediate size inducer pump was evaluated based on Subsection NB, Section III Class 1 and Code Case 1592. In addition to the Code criteria used for evaluation of the final analysis, the following stress limits were used for evaluation of the initial steady-state analysis performed by Rocketdyne (Division 055) under IDWA N-1289 (Reference 5).

Steady-state stress limits for Type 304 SS and CF8 stainless steel parts at $1050^{\circ} \mathrm{F}$ were:

$$
\left.\begin{array}{l}
\text { Primary Membrane Stress }\left(P_{m}\right)=7,450 \text { psi } \\
\text { Local Membrane Plus Bending }\left(P_{L}+P_{b^{-}}\right)=7,730 \text { psi }
\end{array}\right\} \quad \text { Ref. } 8
$$

The design criteria for the A286 material used in the shaft extension tie-bolt at $1050^{\circ} \mathrm{F}$ are:

$$
\left.\begin{array}{l}
P_{m}=15,000 \text { psi } \\
P_{L}+P_{b}=20,000 \text { psi }
\end{array}\right\} \quad \text { Ref. } 8
$$

These steady-state stress limits were selected to have adequate margin below the Code criteria, to provide a high probability of success in meeting the Code criteria during subsequent transient analyses.

Before using the ESG thermal model for analysis of ISIP test transients, an "umbrella" set of transients was selected from those actual transients which had been run during sodium testing of the FFTF prototype pump and analyzed with the ESG thermal model. Reference 4 shows a comparison of the calculated temperatures output from the ESG model 
NO

N266SR000-002

PAGE .

(using actual test input data) to actual temperatures measured during the tests. This data was used to verify the validity of the model. The model was then used with the ISIP test input requirements (which do not differ from previous FFTF pump test requirements) to show that the predicted temperature variations around the critical sodium bearing support structure and other adjacent FFTF parts would not be more severe, or significantly different, than those which had been previously undergone during sodium tests. Structural integrity of the prototype pump parts and functionability of the sodium bearing during ISIP transient tests was based on these results. For the recently designed ISIP parts, results of the thermal analysis were used as input to the ESG stress model for structural evaluation. Calculated stresses for the thermal transient stresses are shown in Table 2.

\subsection{TEST CRITERIA}

The original transient test requirements of the ISIP specification (Reference 6) included nine thermal transients identical to those previously specified for the FFTF prototype pump. Three of the transient tests were subsequentiy deleted, leaving six transient tests to be performed on the ISIP, as presently described in Reference 9 . The three transients which were deleted were judged not to be significant to the ISIP parts and would only retest the overall pump structure. Based on the test request, the total operating time is expected to be approximately 4000 hours. It is estimated that about 3000 hours will be logged as steady-state operation at $950^{\circ} \mathrm{F}$, including a 2000 -hour design point endurance run and a 300-hour off-design endurance run, and the remainder of the time will be at reduced temperatures $\left(400^{\circ} \mathrm{F}\right.$ to $\left.850^{\circ} \mathrm{F}\right)$. The total time during which the pump structure will be responding to thermal transients will be less than 6 hours. 
Table B-37 shows the six thermal transients from the present test request. The original maximum temperature, as listed in the design specification, was $1050^{\circ} \mathrm{F}$. For testing, this temperature was later reduced to $950^{\circ} \mathrm{F}$ as being more representative of the maximum temperature for which present LMFBR's are being designed. $(9)$ The rate and range $(\Delta t)$ of the transients was not changed.

\subsection{ANALYTICAL PROCEDURE}

The analysis of deformation and stress of the inducer/impeller assembly was performed using the APSA (Axisymetrical, Planar Structural Analysis) finite element computer code. Finite element models were developed to structurally represent the area of concern. A separate finite element model consisting of time histories of temperature field for thermal transients was developed. The TAP (Thermal Analys is Program) computer code was used to calculate and provide the temperature field. The worst critical time slice in determining the maximum stress and maximum deformation at various sections of the pump was determined from TAP printout. APSA computer model utilized the TAP temperature field for thermal stress analysis and the deformation analysis.

The steady-state condition (operating condition) which considered the maximum combination of stresses was documented in Reference 5 . The stress intensities of various sections were utilized in the calculation of strain fatigue evaluation.

\subsection{TRANSIENT DATA}

Temperature distributions in the pump inducer/impeller regions were determined as a function of time for the transients. 
Transients, time-history thermal analysis was performed and documented in Reference 7 . The calculated temperature results were stored on tapes that were used as input for the deformation and stress analysis. The points for which temperatures were calculated and stored are exhibited in Figure 3.

The capacitance-weighed average temperature of various locations in the inducer/impeller region were determined as a function of time and transient. The differences between these temperatures were plotted, as exhibited in Appendix B.

The capacitance-weighted average temperature plots were examined to determine the worst time slice for various interfaces. There were six transients considered (Reference 7), and two worst time s7ices for each transient were utilized in determining the deflection and stress. The clearance change at various interfaces utilized the transient time slice and were documented in Appendix B. Table 3 shows the worst stress intensities of the pump element for each transient.

\subsection{STRUCTURAL CRITERIA}

The structural criteria employed in evaluating the pump inducer/ impeller is described below.

Al1 components were evaluated using elastic analysis methods as provided for in the pump specification (Reference 6, Paragraph 3.2.4). The analysis criteria are as presented in the RDT Standard F9-4(RER, I) "Construction of Nuclear System Components at Elevated Temperature."

A summary of the method used in evaluating the strain fatigue limits is outlined below: 


\section{Structural Analysis Method Outline}

\section{Accumulated Strain Analysis (Ref..1)}

: Bree Complete Relaxation Method. Deformation and strain limits for structural integrity are considered to have been satisfied and a detailed inelast1c ratcheting analysis need not be performed if the following four conditions are satisfied:

1. The approximate inelastic strain averaged through the thickness,

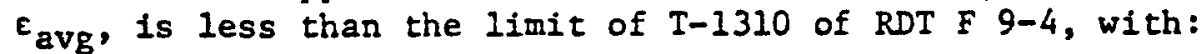

$$
\varepsilon_{\text {avg }}=\varepsilon_{c}+\varepsilon_{T} \text {, }
$$

where: $\varepsilon_{c}=$ cumulative creep strain based on the primary stress $\left(\mathrm{P}_{\mathrm{I}}+\mathrm{P}_{\mathrm{b}} / \mathrm{K}_{\mathrm{t}}\right)^{\circ}$ and the appropriate isochronous stressstrain curves,

$$
E_{I}=\begin{aligned}
& \text { cumulative ratchet strain based on Bree's complete } \\
& \text { relaxation analysis. }
\end{aligned}
$$

The values of $\varepsilon_{r}$ are given by:

$$
\varepsilon_{r}=\sum_{i} N_{i}\left(\Delta \varepsilon_{r}\right)_{1}
$$

where: $\quad N_{1}=$ number of type 1 cycles,

$$
\begin{aligned}
\left(\Delta \varepsilon_{I}\right)_{1}= & \text { ratchet strain per cycle for type } 1 \text { cycles } \\
& \text { from Bree's complete relaxation equations. }
\end{aligned}
$$




$$
\left(\Delta \varepsilon_{\tau_{1}}\right)_{1}=\frac{S_{m}}{E}\left\{1-x^{\prime \prime}+y^{\prime \prime}\left[1-2\left(\frac{1-x^{\prime \prime}}{y^{\prime \prime}}\right)^{1 / 2}\right]\right\},
$$

in region $s_{1}$ of Fig. 4

$$
\left(\Delta \varepsilon_{I}\right)_{i}=\frac{S_{m}}{E}\left\{1-x^{\prime \prime}+2 y^{\prime \prime}\left[1-2\left(\frac{1-x^{\prime \prime}}{y^{\prime \prime}}\right)^{1 / 2}\right]\right\},
$$

in region $R_{1}$ of Fig. 4

$$
\left(\Delta \varepsilon_{T}\right)_{1}=-\frac{S_{m}}{E}\left[x^{\prime \prime}\left(y^{\prime \prime}-1\right)\right],
$$

in regions $\mathrm{S}_{2}$ and $\mathrm{P}$ of Fig. 4 and:

$$
\left(\Delta \varepsilon_{x^{\prime}}\right)_{1}=\frac{S_{m}}{E}\left[x^{\prime \prime}\left(2 y^{\prime \prime}-1\right)-1\right],
$$

in region $R_{2}$ of Fig. 4 In the above:

$$
x^{\prime \prime}=\left(P_{I}+\frac{P_{b}}{K_{t}}\right)_{\max } / S_{m}
$$

and:

$$
y^{\prime \prime}=\left(Q_{R}\right)_{\max } / S_{m},
$$




\section{Creep-Fatique Damage Analysis ( SIFIPLIFIED IETHOD )}

Assume $\epsilon_{\text {eff }}=\epsilon_{\text {eff range }}=\epsilon_{t}$

Assume $\epsilon_{\text {eff }}=\frac{\sigma_{\text {eff }}}{E}$

1) Pick $\sigma_{\text {eff }}$ and $E$ for the relevant element in the APSA printout (namely, the element at the critical surface of the selected section), for every transient.

2) Using the "Design $\epsilon_{t}$ vs No. of Allowable Cycles" plot, Figure TI430 (CODE CASE 1592) , find $N_{d}$ for every transient.

3) Determine the number of occurrences for each transient

4) Total fatigue damage fraction $=\sum \frac{n}{N_{d}}$.

5) Creep Damage Analysis: Creep Damage Fraction - Simplified Analysis Method for the. Cycle Selection 
N266ER000-001

Page 381

Rockwell International

Energy Systems Group $\begin{array}{ll}\text { NO } & \text { N266SR000002 } \\ & 15\end{array}$

Determine $\left[\left(P_{L}+P_{B}+Q_{\max }\right]\right.$

If $S_{y} \geq\left[P_{L}+P_{B}+Q_{\max }\right]$ then $S_{K}=\left[P_{L}+P_{B}+Q_{\max }\right]$

If $S_{y} \leq\left[P_{L}+P_{B}+Q_{\max }\right]$ then

$S_{K}=$ lesser of $1.25 \times S_{y}$

In stress rupture curve, find $T_{d}$ using $\frac{S_{k}}{0.9}$.

6) $\sum \frac{n}{N_{d}}+\sum \frac{t}{T_{d}} \leq 0.6$

FORM 719.P REV. 7.78 


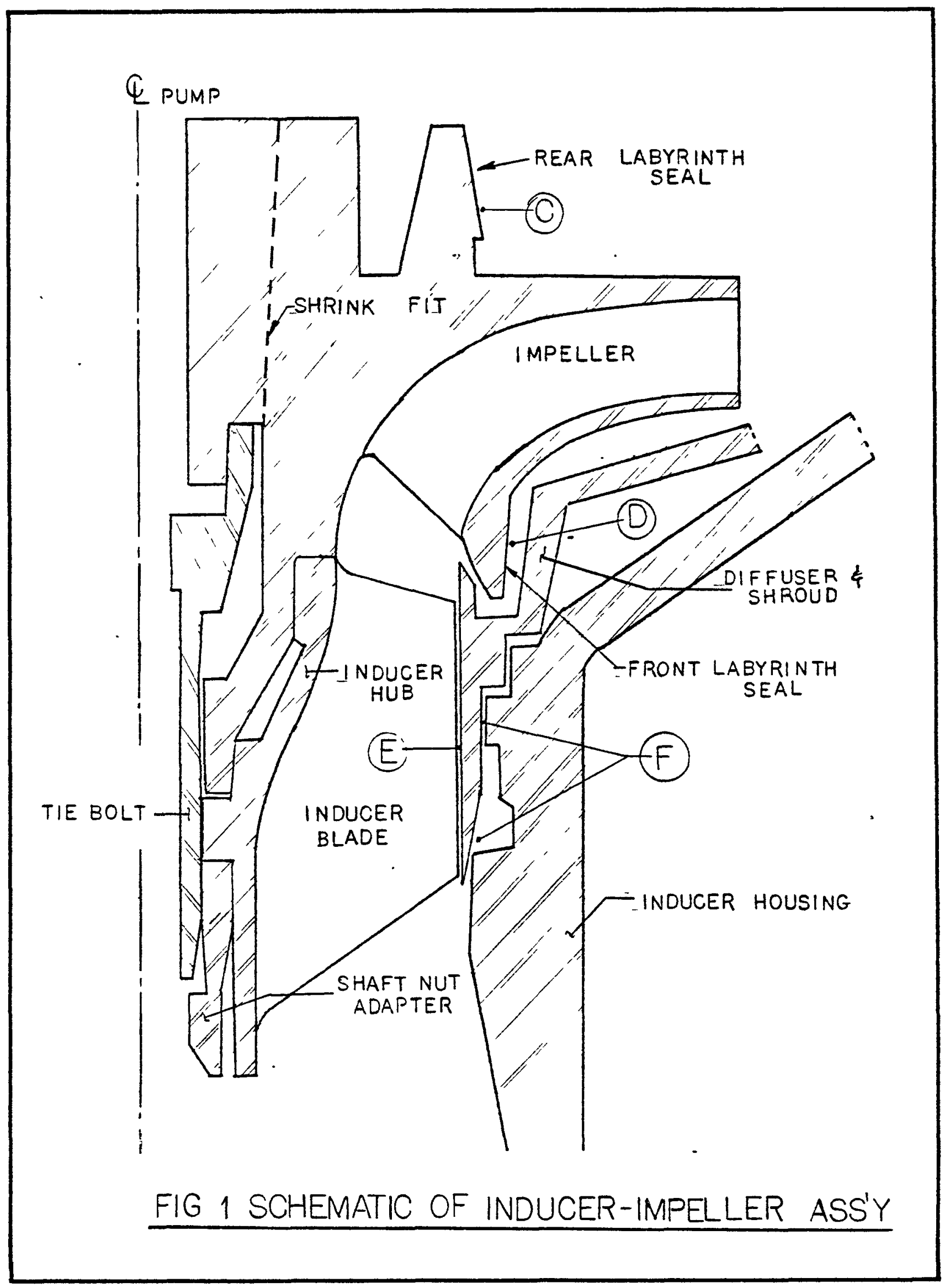


TABLE 1

CRITICAL CLEARANCE CHANGES

(miTs)

\begin{tabular}{cccccccc}
\hline & \multirow{7}{c}{ Transient } \\
\cline { 3 - 7 } Location* & $\begin{array}{c}\text { Design } \\
\text { Clearance }\end{array}$ & $\begin{array}{c}E-202 \\
100 \mathrm{sec}\end{array}$ & $\begin{array}{c}E-203 \\
100 \mathrm{sec}\end{array}$ & $\begin{array}{c}E-204 \\
100 \mathrm{sec}\end{array}$ & $\begin{array}{c}E-207 \\
275 \mathrm{sec}\end{array}$ & $\begin{array}{c}E-208 \\
115 \mathrm{sec}\end{array}$ & $\begin{array}{l}E-210 \\
50 \mathrm{sec}\end{array}$ \\
\hline $\mathrm{A}$ & 13 & +2.4 & -1.7 & +3.1 & +4.6 & +3.7 & +2.2 \\
$B$ & 13 & +1.9 & -1.3 & +2.6 & +3.5 & +2.8 & +2.4 \\
$C$ & 50 & +6.7 & -7.2 & +9.2 & +11.8 & +10.6 & +6.6 \\
$D$ & 50 & +0.9 & +5.2 & -0.7 & -1.5 & -0.9 & +2.6 \\
$E$ & 50 & +2.0 & +2.9 & -3.3 & -2.9 & -3.7 & -3.0 \\
$F$ & 50 & +8.7 & -6.1 & +11.6 & +13.0 & +13.1 & +10.5 \\
\hline
\end{tabular}

Note: The values 1 isted under the transient column are changes in the original clearance at isothermal temperature conditions.

For example, at Location $A$, the original clearance (13 mils) is increased by 0.0024 in. during Event E-202 and decreased by 0.0017 in. during E-203.

*See Figures 1 and 2. 
N266ER000-001

Page 384

Rockwell International

NO N266SR000002

PAGE 18

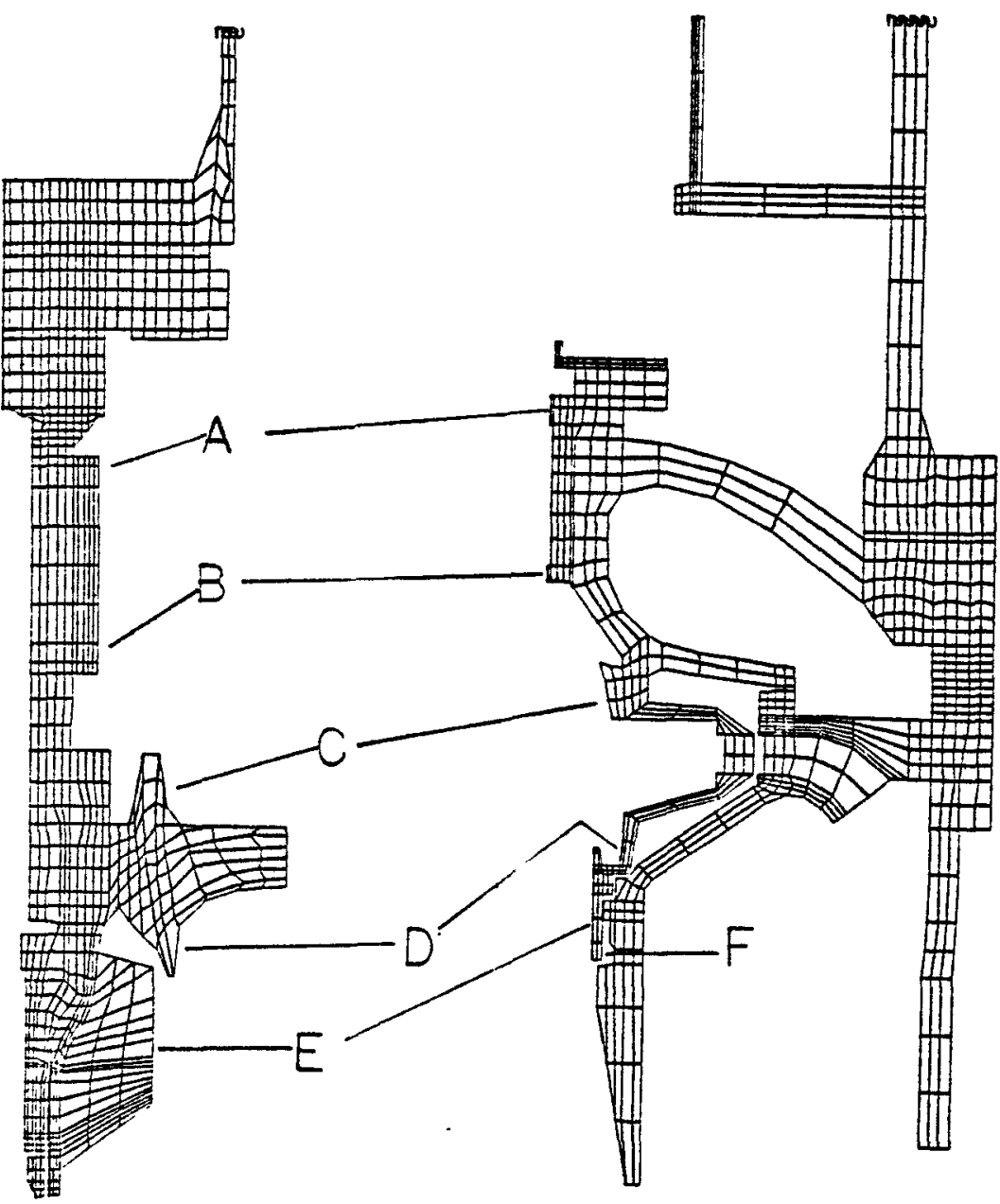

- ROTATING ASSEMBLY STATIC ASSEMBLY

FIG. 2 FINITE ELEMENT MODEL 


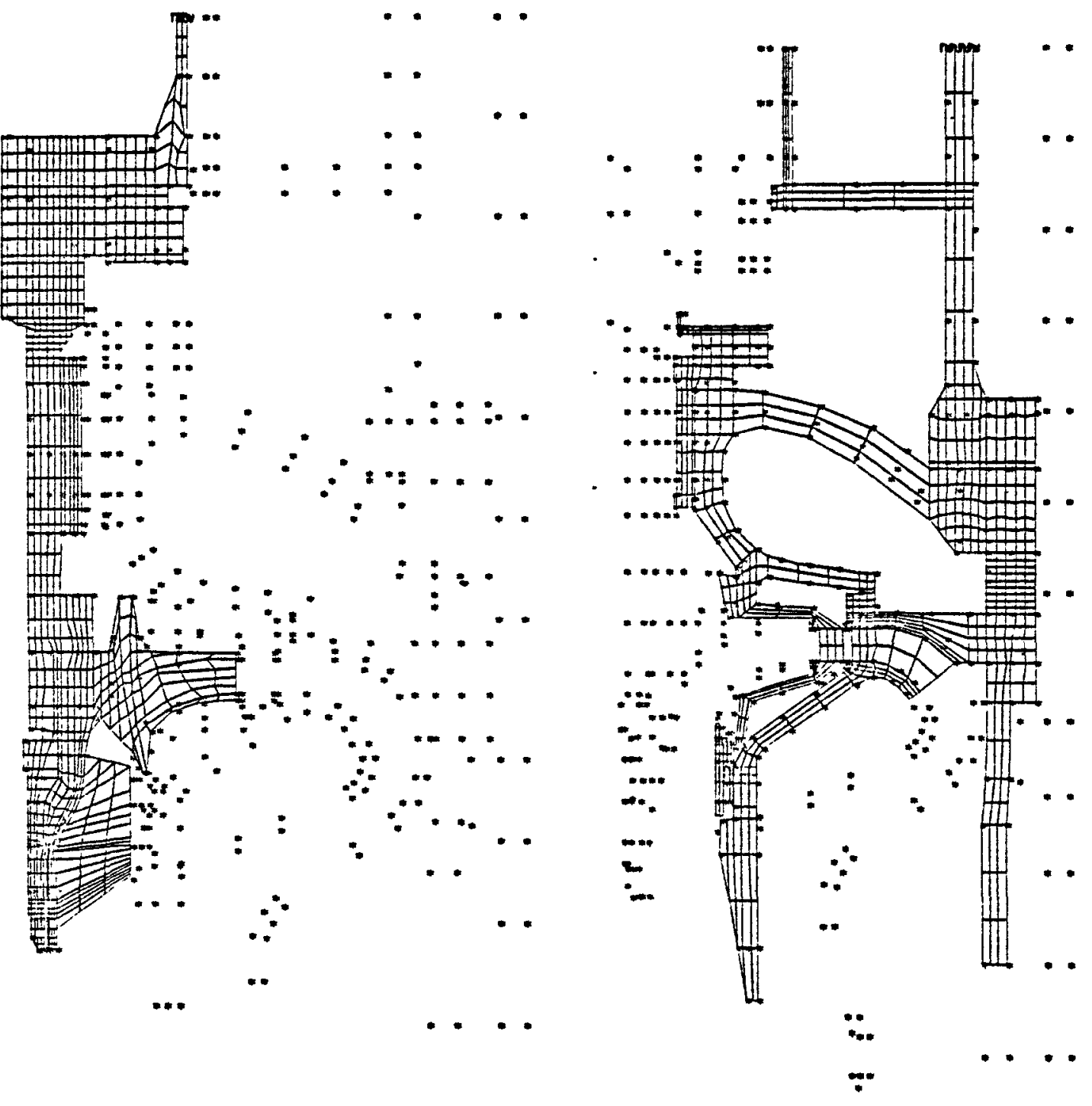

FIG. 3 TYPICAL TEMPERATURE FIELD 


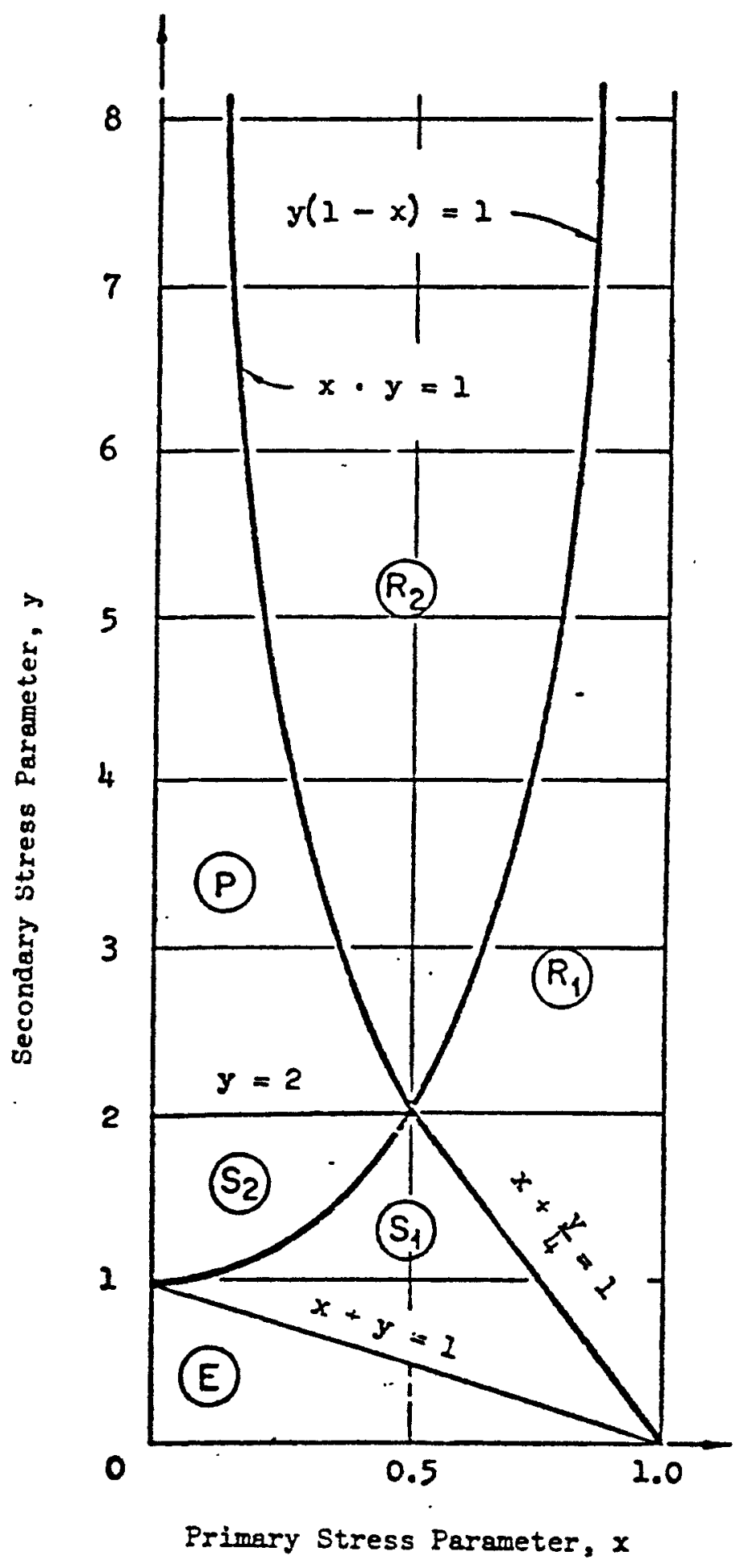

Fig. $4^{-}$Ratchet IImits 


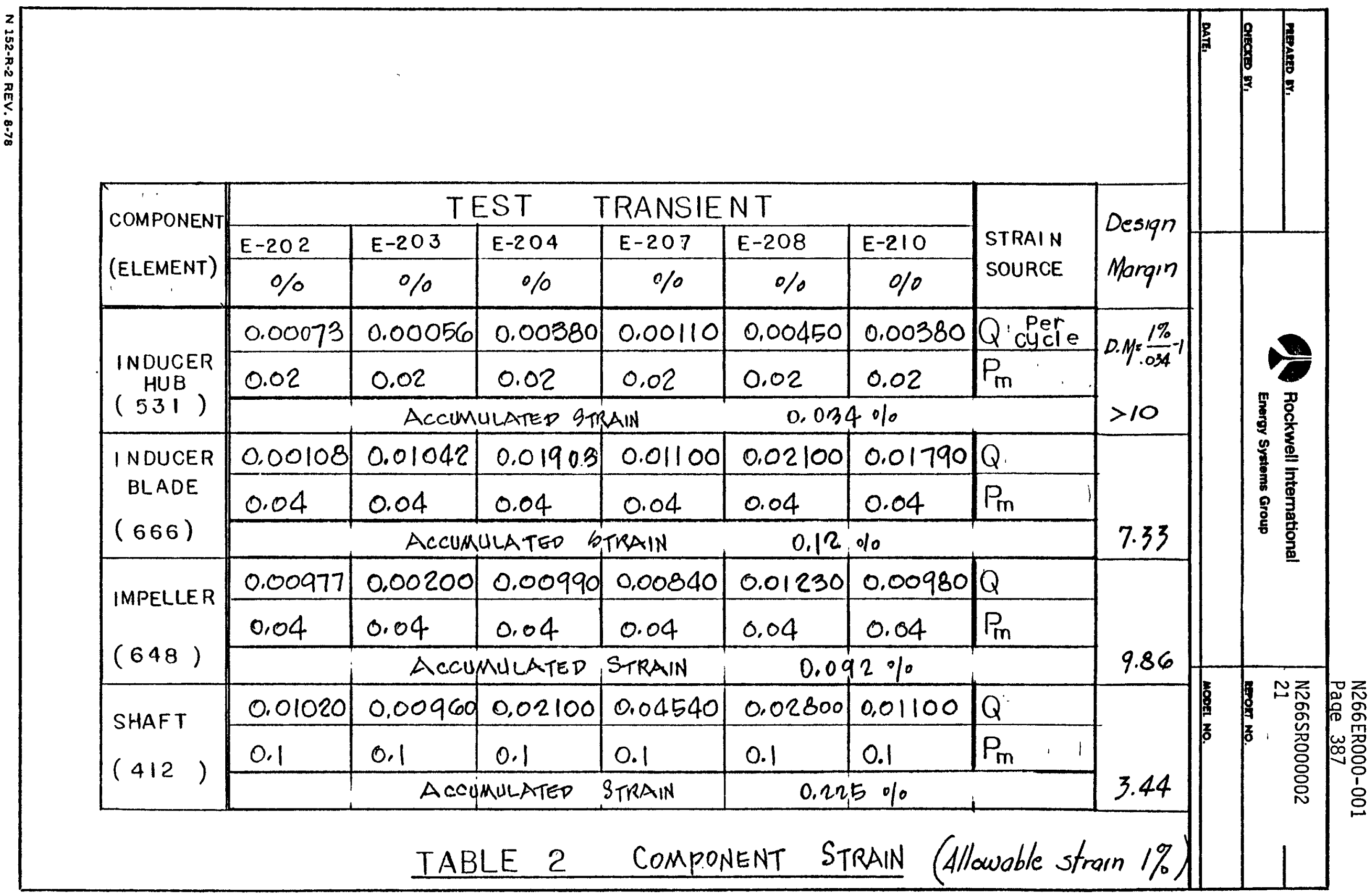




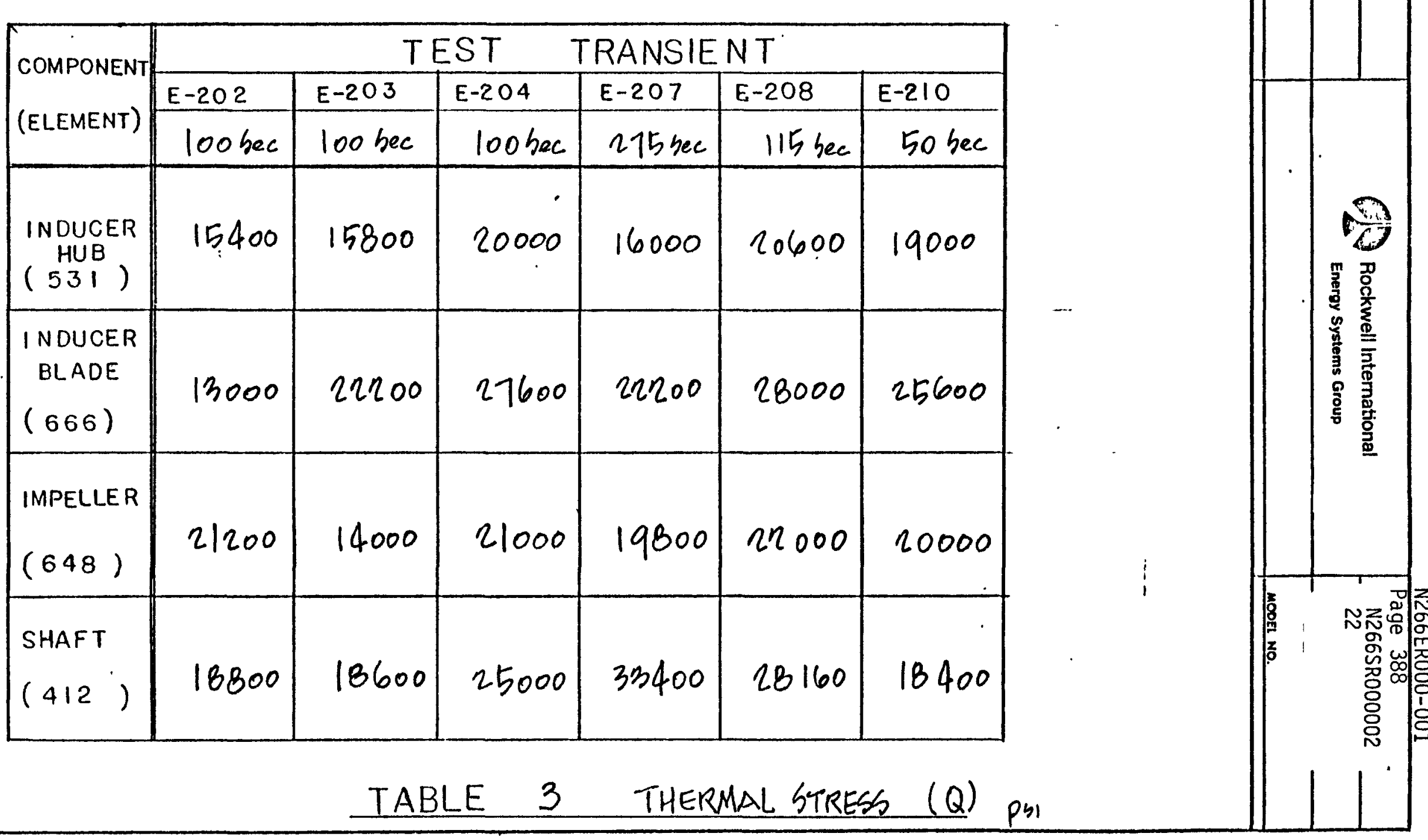


NO

PAGE
N266SR000-002

23

\subsection{REFERENCES}

1. Guidelines and Procedures for Design of Nuclear System Components at Elevated Temperature, RDT F 9- 4

2. Rules for Class 1 Components in Elevated Temperature Service, ASME Boiler and Pressure Vessel Code, Code Case N-47-12 (1592)

3. Intermediate Size Inducer Pump (ISIP) Design Layout Drawing N266R000015, Atomics International, Rockwell International

4. E. M. Mouradian, A. A. Loffredo, and K. H. Yun, "Verification of Thermal Model for ISIP (Intermediate-Size Inducer Pump)," N266TI000-007, Atomics International, Rockwell International (March 7, 1979)

5. M. Sasaki, "Steady-State Structural Analysis (Pump Internal)," N266SR00001, Rocketdyne Division, Rockwell International (August 7, 1978)

6. Design Specification, "Pump Sodium, Inducer Intermediate (ISIP) (Impeller/Inducer/Diffuser Retrofit)," N266ST310001

7. E. M. Mouradian, A. A. Loffredo, and K. H. Yun, "Transient Thermal Analysis of ISIP (Intermediate-Size Inducer Pump)," N266TI000-008, Atomics International, Rockwell International (April 30, 1979)

8. T. J. Boardman, "Intermediate-Size Inducer Pump Technical Requirements," N266T1000001, Atomics International, Rockwell International (January 20, 1978)

9. J. 0. Pfouts, "Sodium Testing of Intermediate-Size Inducer Pump in SPTF at ETEC," N266RFT000001, Atomics Internationa1, Rockwell International (April 24, 1979, Revision C) 
NO N266SR000-002

PAGE . $\quad 2 \overrightarrow{3.1}$

10. Operating and Maintenance Manual Addendum to Westinghouse 0MM-051-00-005 for Intermediate-Size Inducer Pump, Model 266, N2660MM000001, Atomics International, Rockwell International (November 20, 1978) 


\section{APPENDIX A}

STRUCTURAL ANAYSIS
a. Strain Limit Evaluation
b. Creep-Fatigue Damage Evaluation 


\section{STRUCTURAL ANALYSIS}

The Bree Complete Relaxation Method of RDT Standard (Reference 1 ) was used to determine the creep strain limit for pump components. The primary stress $\left(\mathrm{Pb}+\mathrm{P}_{\mathrm{I}}\right)$ has utilized the stress intensity value from the stress report by Rocketdyne on the steady-state stress analysis (N266SR000001, Reference 5). The thermal transients stress (Q) were obtained from the time-history iteration of transients. Two worsttime slices were selected for each transient. The procedure was described in Section 3 of this report.

Table $\underline{A-1}$ and Table $A-2$ summarized the stresses and strains, respectively, for different parts of inducer-impeller assembly for each transient.

The total creep-fatigue damage fraction was analyzed based on the method described in Section 3 of this report. The calculation showed that the creep-fatigue darage fraction of 0.026 which was smaller than 0.6 . 
N266ER000-001

Page 393

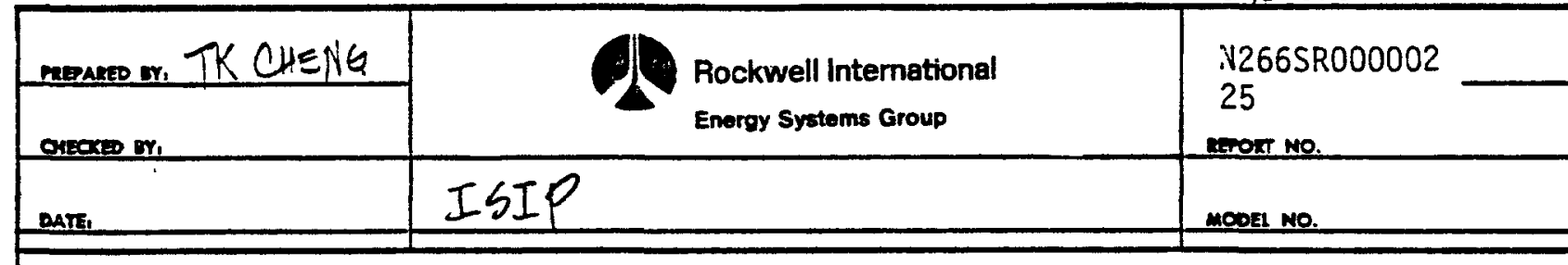

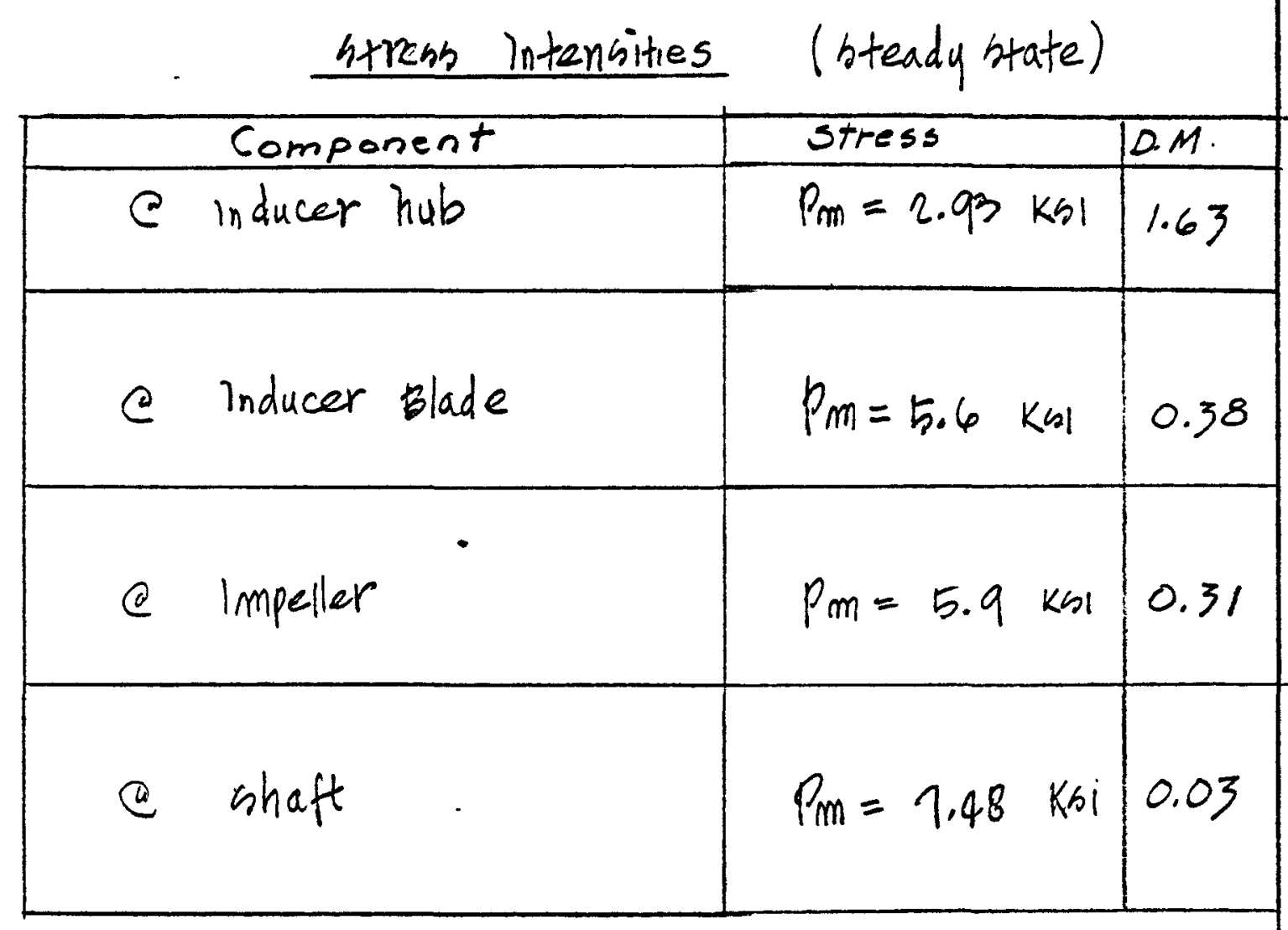

* sirens intensity are from N266 hRoooool (ref. 5)

1) See page 8

2) Stress intensities base on $1050^{\circ} \mathrm{F}$

3.) Actual $T=950^{\circ} \mathrm{F}$

4) $S_{0}=14,300$ psi (used 7,730 psi in this Analysis)

N 152-R-2 REV. 8-78 
N266ER000-001

Page 394

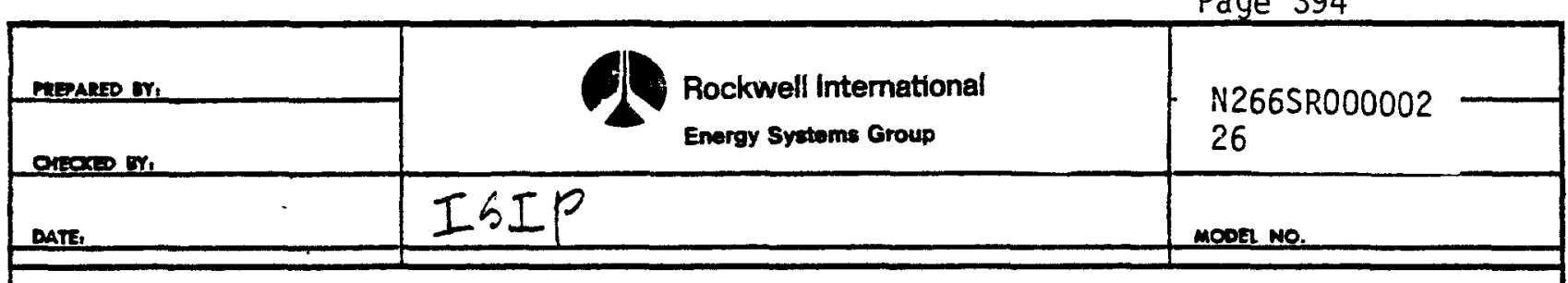

Strain Limits Evaluation

a Inducer Hub

$$
\begin{aligned}
& P_{b}+P_{L} / 0.9=2.9 \mathrm{kml} \\
& \epsilon_{c}=0.02 \%
\end{aligned}
$$

(FF G.T.1800-A.4

code cure 1592)

(2) Inducer Blade

$$
\begin{aligned}
& p_{b}+p_{L} / 0.9=5.6 \mathrm{~K} b 1 \\
& \epsilon_{c}=0.04 \%
\end{aligned}
$$

Q Impeller

$$
\begin{aligned}
& P_{b}+P_{L} 10.9=5.9 \mathrm{~kb} \\
& \epsilon_{C}=0.04 \%
\end{aligned}
$$

(a) shaft

$$
\begin{aligned}
& P_{b}+P_{b} / 0.9=7.5 \mathrm{~km} 1 \\
& \epsilon_{c}=0.1 \%
\end{aligned}
$$

N 152-R-2 REV, 8.78 


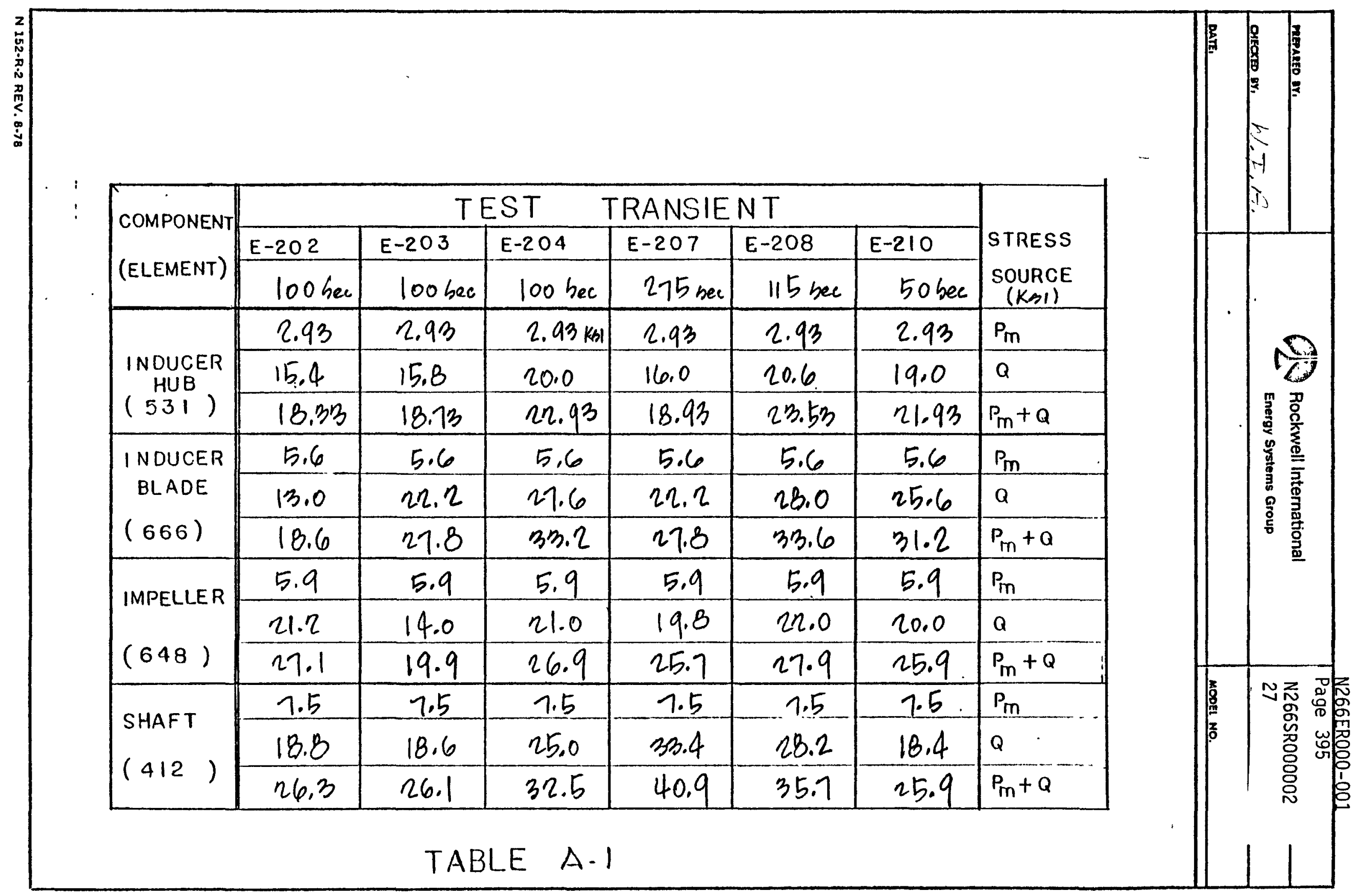




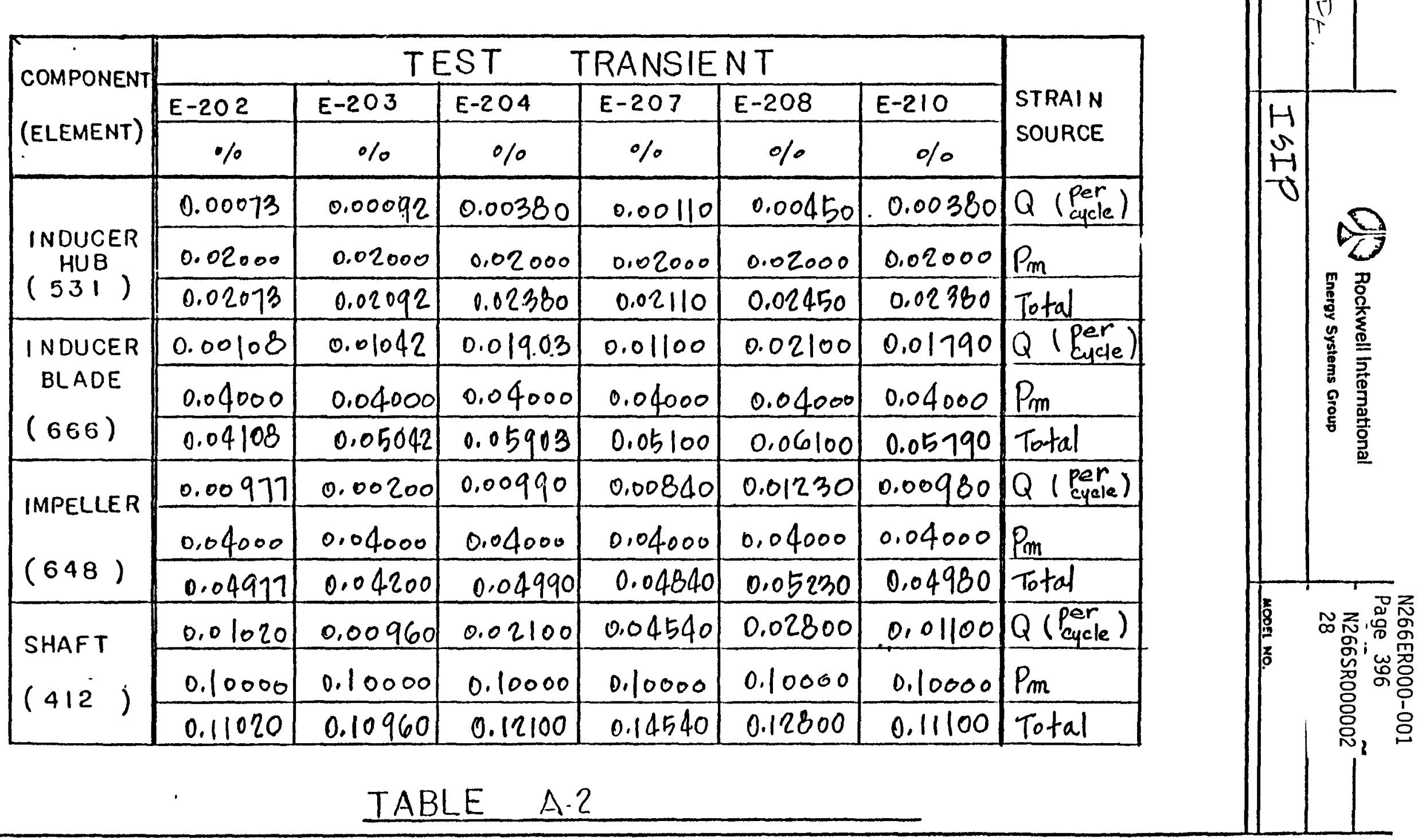




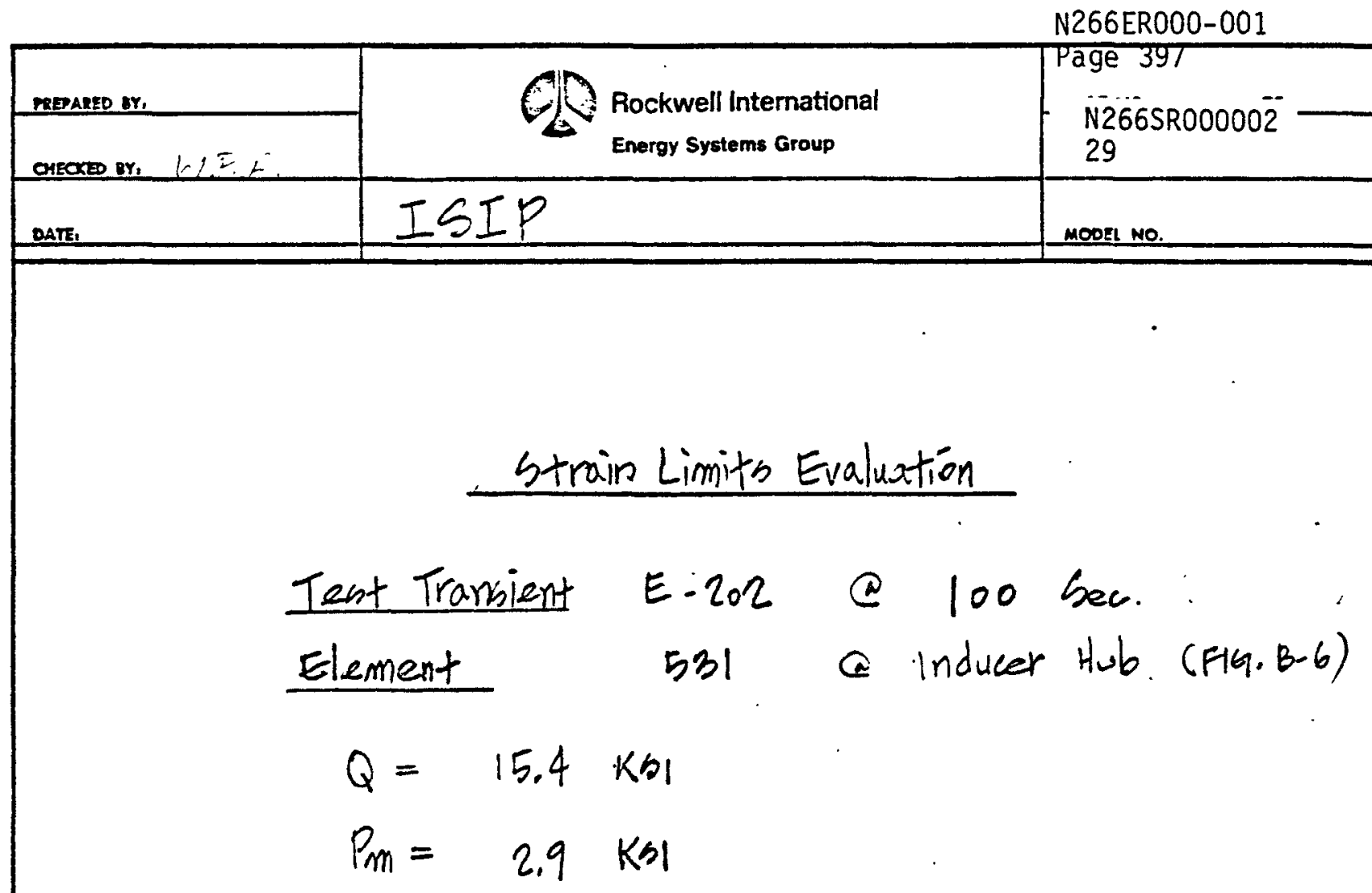

Temperature for $E-202 \quad 750^{\circ} \mathrm{F} \rightarrow 600^{\circ} \mathrm{F}$

$$
\begin{aligned}
& \left.S_{y}=17.3 \mathrm{ksi} @ 750^{\circ} \mathrm{F}\right]-b_{Y_{\text {mean }}}=17.8 \mathrm{kri} \\
& S_{y}=18.2 \mathrm{ksi} @ 600^{\circ} \mathrm{F} \\
& S_{m}=15.1 \mathrm{ksi} @ 675^{\circ} \mathrm{F}(\text { mean temp. })
\end{aligned}
$$

(Table I-14.3A code cane 1592)

$$
E=25.0 \times 10^{6} \mathrm{psi}
$$

1. Bree Relaxation Method

$$
\begin{aligned}
& \left.\begin{array}{l}
x^{\prime \prime}=2.9 / 15.1=0.19 \\
Y^{\prime \prime}=15.4 / 15.1=1.02
\end{array}\right\} \text { Region } \zeta_{1} \\
& \Delta \epsilon_{r}=\frac{S_{m}}{E}\left\{1-x^{\prime \prime}+y^{\prime \prime}\left[1-2\left(\frac{1-x^{\prime \prime}}{y^{\prime \prime}}\right)^{1 / 2}\right]\right\} \\
& =\frac{15100}{25 \times 10^{6}}\left\{1-0.19+1.02\left[1-2\left(\frac{1-0.19}{1.02}\right)^{1 / 2}\right]\right\} \\
& =0.00073 \% \text { per cycle }
\end{aligned}
$$

N 152-A-2 REV. 8-78 


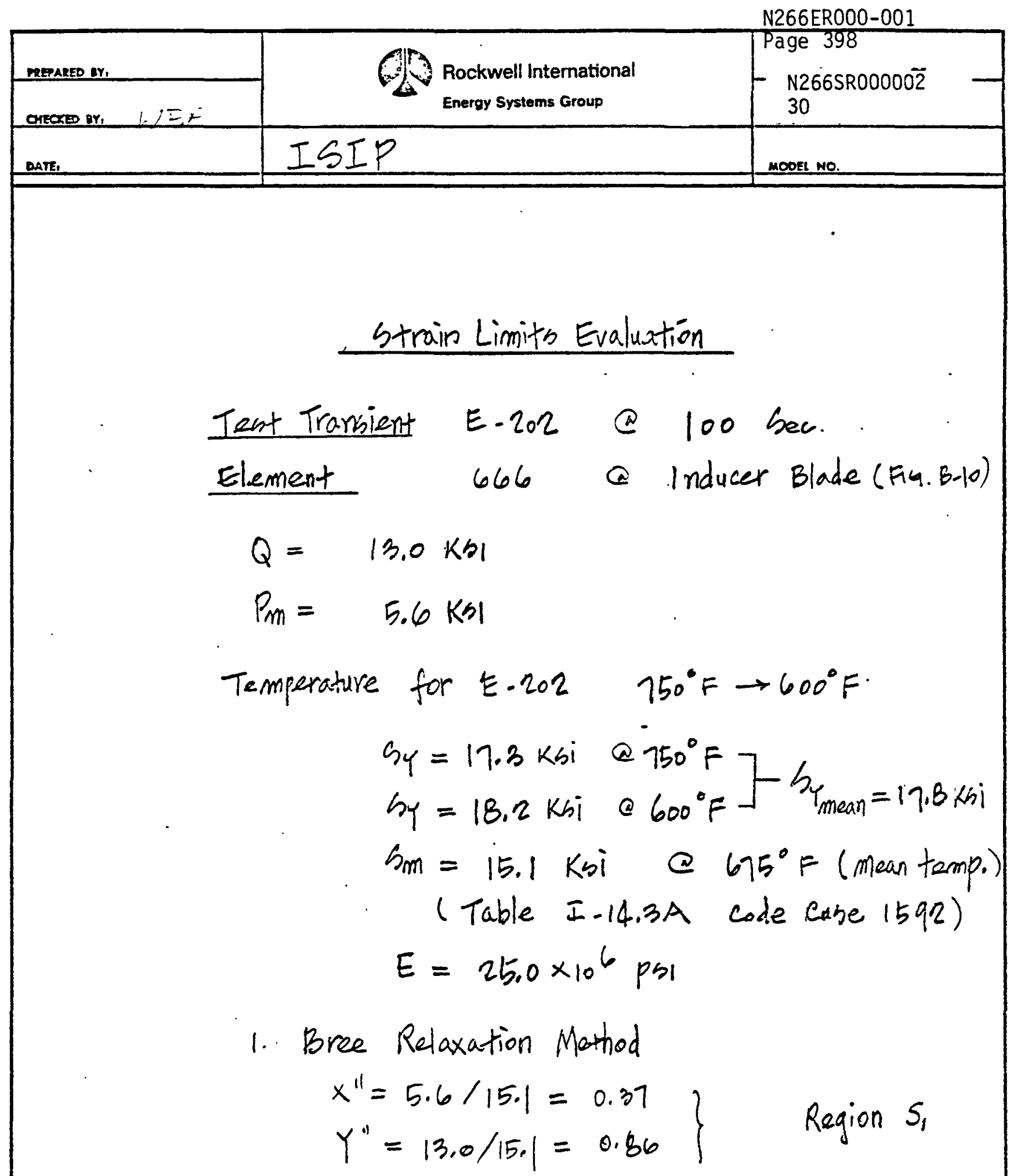

ratchet strain per cycle $\left(\Delta \epsilon_{r}\right)$

$$
\begin{aligned}
\left(\Delta \epsilon_{r}\right) & =\frac{S_{m}}{E}\left\{1-x^{\prime \prime}+y^{\prime \prime}\left[1-2\left(\frac{1-x^{\prime \prime}}{y^{\prime \prime}}\right)^{1 / 2}\right]\right\} \\
& =\frac{15100}{25 \times 10^{6}}\left\{1-0.37+0.86\left[1-2\left(\frac{7-0.37}{0.86}\right)^{1 / 2}\right]\right\} \\
& =0.00108 \%
\end{aligned}
$$

N 152-R-2 REV. B-78 


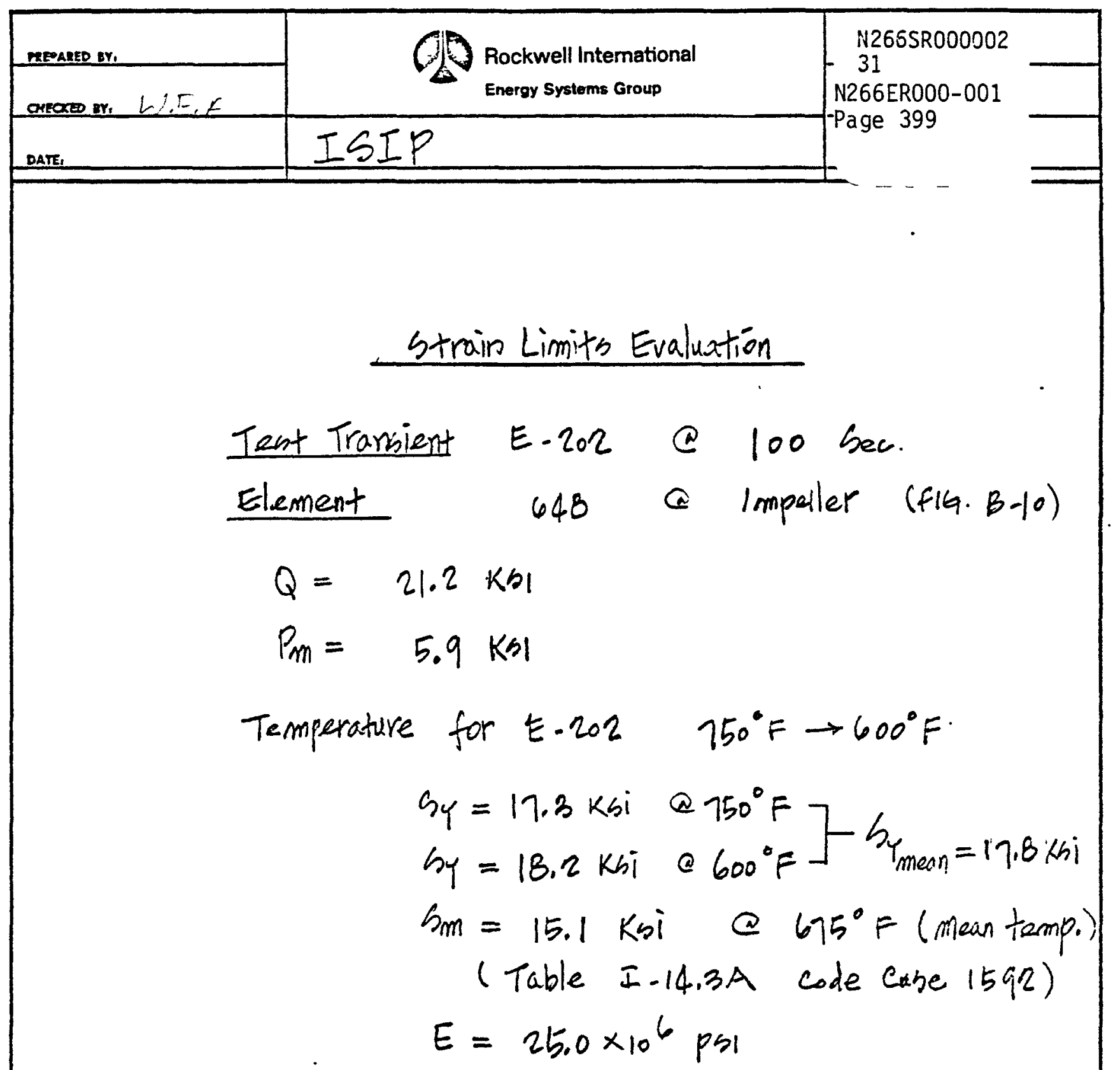

1. Bree Relaxation Method (RDT F 9-5T)

$$
\left.\begin{array}{l}
x^{\prime \prime}=5.9 / 15.1=0.39 \\
Y^{\prime \prime}=21.2 / 15.1=1.4
\end{array}\right\} \quad \text { Region } s_{1}
$$

ratchet strain per cycle $\left(\Delta \epsilon_{r}\right)$

$$
\begin{aligned}
\left(\Delta G_{r}\right) & =\frac{\operatorname{Sm}}{E}\left\{1-x^{\prime \prime}+y^{\prime \prime}\left[1-2\left(\frac{1-x^{\prime \prime}}{y^{\prime \prime}}\right)^{1 / 2}\right]\right\} \\
& =\frac{15100}{25 \times 10^{6}}\left\{1-0.39+1.4\left[1-2\left(\frac{1-0.39}{1.4}\right)^{1 / 2}\right]\right\} \\
& =0.00977 \%
\end{aligned}
$$

N 152-R.2 REV. 8.78 


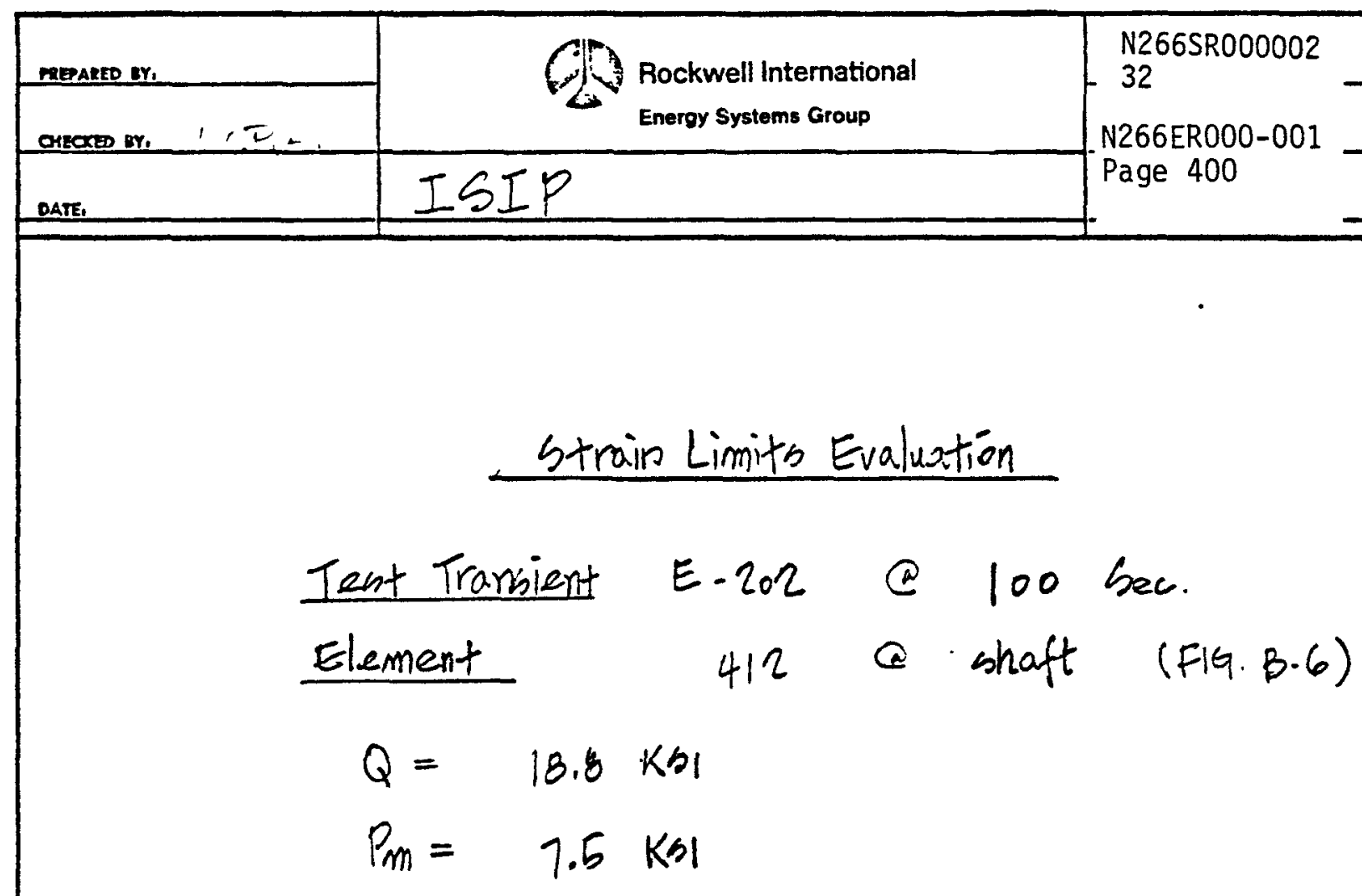

Temperature for $E .202 \quad 750^{\circ} \mathrm{F} \rightarrow 600^{\circ} \mathrm{F}$.

$$
\begin{aligned}
& \left.S_{Y}=17.3 \mathrm{ksi} @ 750^{\circ} \mathrm{F}\right]-h_{Y_{\text {mean }}}=17.8 \mathrm{ksi} \\
& S_{Y}=18.2 \mathrm{ksi} @ 600^{\circ} \mathrm{F} \\
& S_{m}=15.1 \mathrm{ksi} @ 675^{\circ} \mathrm{F}(\text { mean temp. })
\end{aligned}
$$

(Table I-14.3A code cane 1592)

$$
E=25.0 \times 10^{6} \mathrm{psi}
$$

1. Bree Relaxation Method

$$
\left.\begin{array}{l}
x^{\prime \prime}=7.5 / 15.1=0.5 \\
Y^{\prime \prime}=18.8 / 15.1=1.25
\end{array}\right\} \quad \text { Region } S_{1}
$$

ratchet strain per cycle $\left(\Delta \epsilon_{r}\right)$

$$
\begin{aligned}
\left(\Delta G_{r}\right) & =\frac{\text { bm }}{E}\left\{1-x^{\prime \prime}+y^{\prime \prime}\left[1-2\left(\frac{1-x^{\prime \prime}}{Y^{\prime \prime}}\right)^{1 / 2}\right]\right\} \\
& =\frac{15100}{25 \times 10^{6}}\left\{1-0.5+1.25\left[1-2\left(\frac{1-0.5}{1.25}\right)^{1 / 2}\right]\right\} \\
& =0.0102 \%
\end{aligned}
$$

N 152-R-2 REV. 8-78 


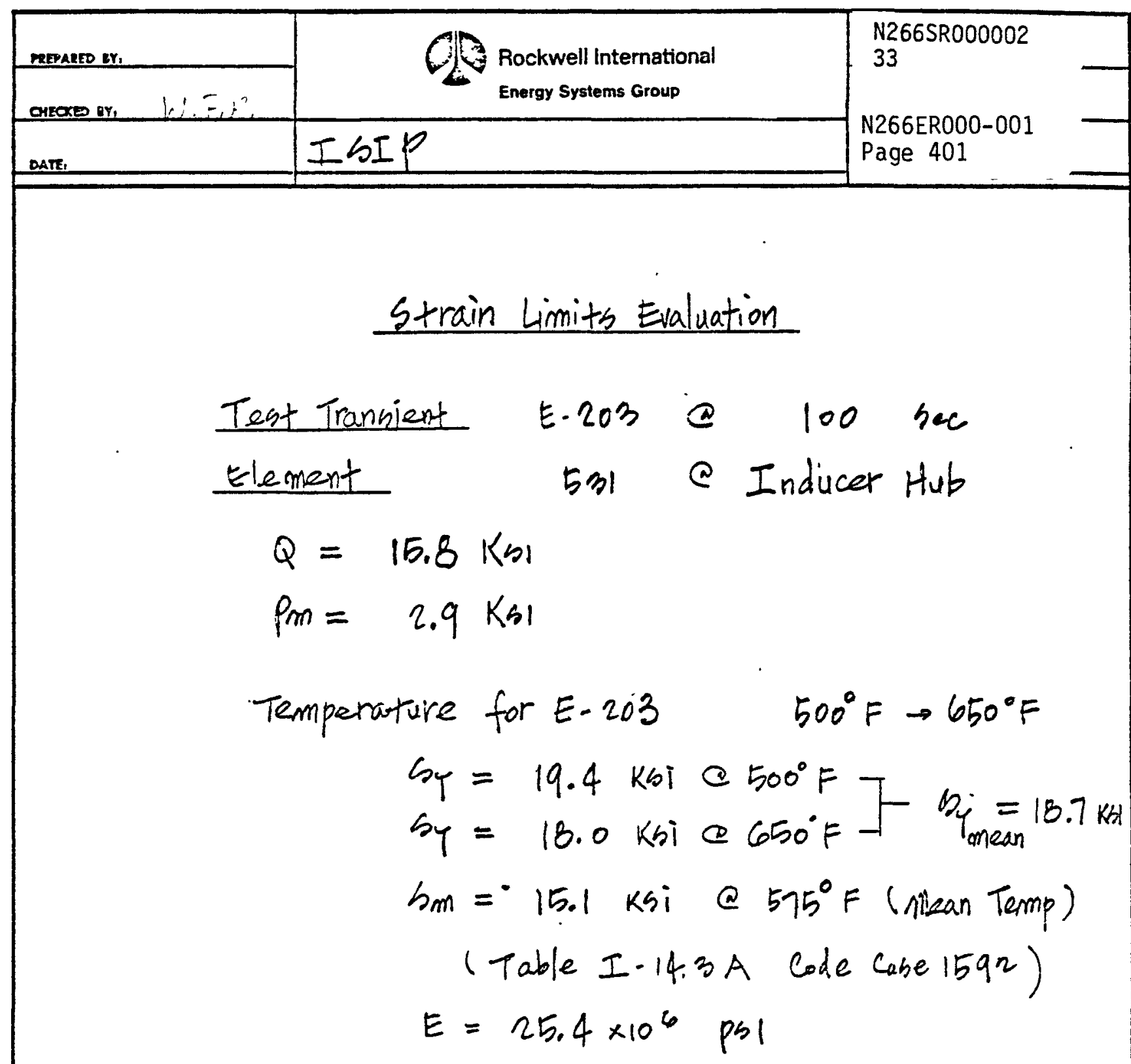

1. Bree Relaxation Method

$$
\left.\begin{array}{l}
x^{\prime \prime}=2.9 / 15.1=0.19 \\
y^{\prime \prime}=15.8 / 15.1=1.05
\end{array}\right\} \quad \text { Region } b_{1}
$$

ratchet b̈train per cycle $\left(\Delta \epsilon_{r}\right)$

$$
\begin{aligned}
\left(\Delta E_{r}\right) & =\frac{S_{m}}{E}\left\{1-x^{\prime \prime}+y^{\prime \prime}\left[1-2\left(\frac{1-x^{\prime \prime}}{Y^{\prime \prime}}\right)^{1 / 2}\right]\right\} \\
& =\frac{15100}{25.4 \times 10^{6}}\left\{1-0.19+1.05\left[1-2\left(\frac{1-0.19}{1.05}\right)^{1 / 2}\right]\right\} \\
& =0.00092 \%
\end{aligned}
$$

N 152-R.2 REV. 8.78 


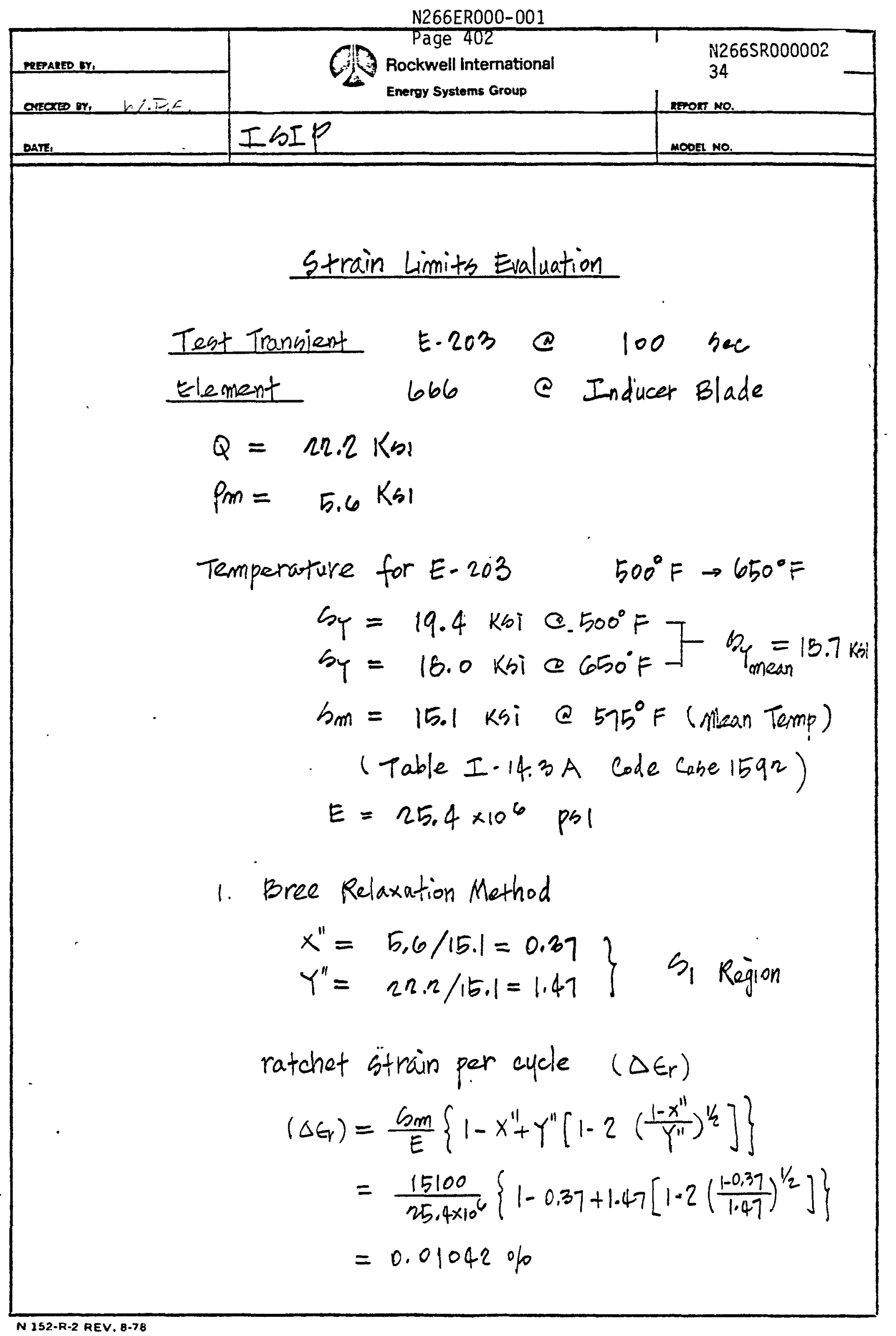




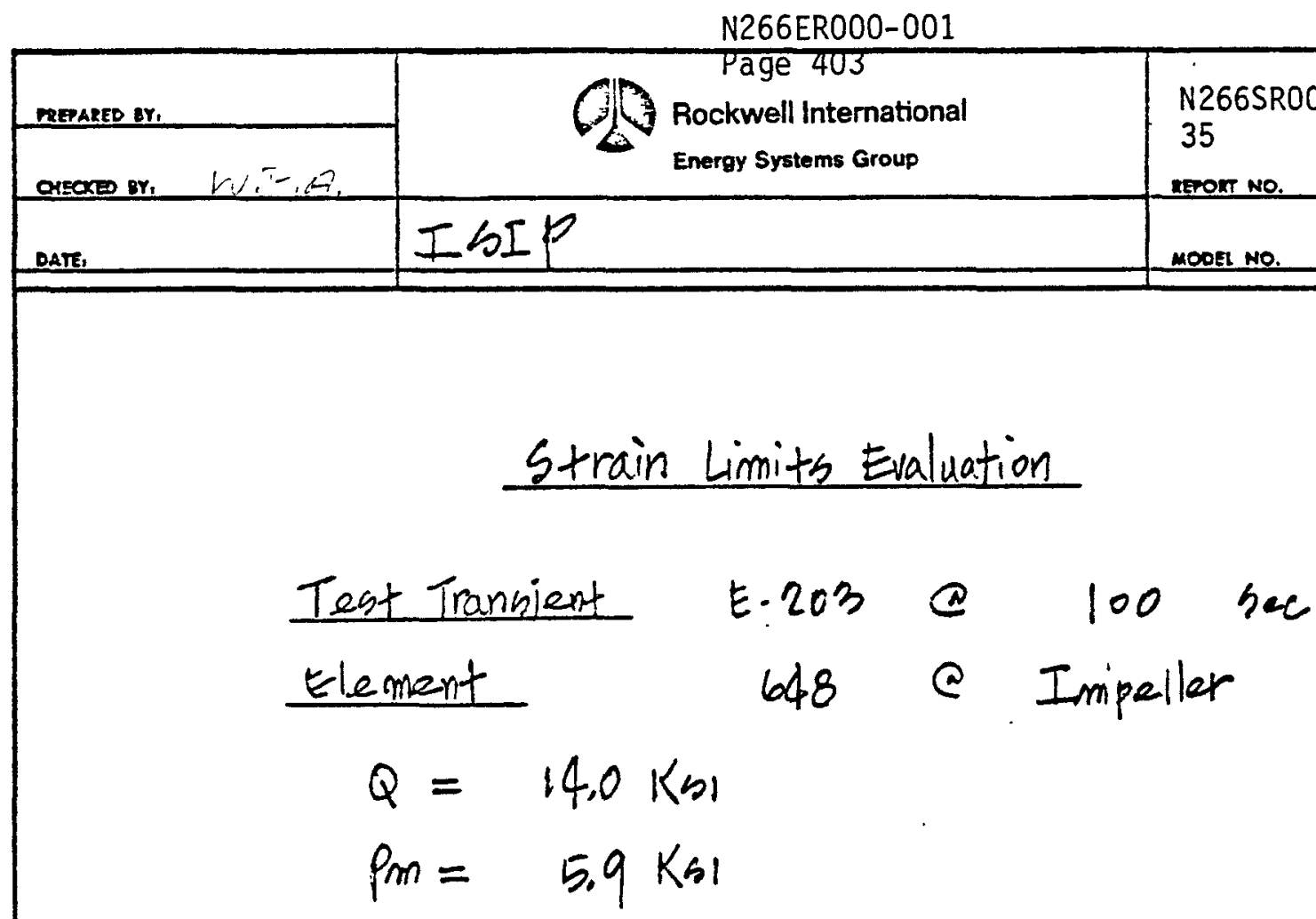

Temperature for E-203 $500^{\circ} \mathrm{F} \rightarrow 650^{\circ} \mathrm{F}$

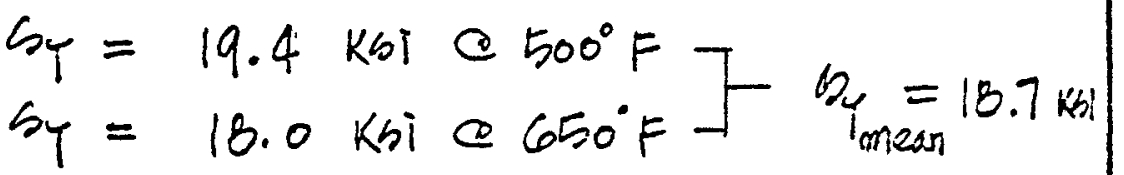

$$
\begin{aligned}
& h_{m}=15.1 \mathrm{ksi} @ 575^{\circ} \mathrm{F} \text { (Mlean Temp) } \\
& \text { (Table I.14.3 A Code cabe 1592) } \\
& E=25.4 \times 10^{6} \mathrm{psi}
\end{aligned}
$$

1. Bree Relaxation Merthod

$$
\left.\begin{array}{l}
X^{\prime \prime}=5.9 / 15.1=0.39 \\
Y^{\prime \prime}=14.0 / 15.1=0.93
\end{array}\right\} \quad g_{1} \text { Region }
$$

ratchat stroin per cycle $\left(\Delta \epsilon_{r}\right)$

$$
\begin{aligned}
\left(\Delta \epsilon_{r}\right) & =\frac{\sin }{E}\left\{1-x^{\prime \prime}+y^{\prime \prime}\left[1-2\left(\frac{1-x^{\prime \prime}}{Y^{\prime \prime}}\right)^{1 / 2}\right]\right\} \\
& =\frac{15100}{25,4 \times 10^{6}}\left\{1-0.39+0.93\left[1-2\left(\frac{1-0.39}{0.93}\right)^{1 / 2}\right]\right\} \\
& =0.002 \%
\end{aligned}
$$

N 152-R-2 REV. B-78 


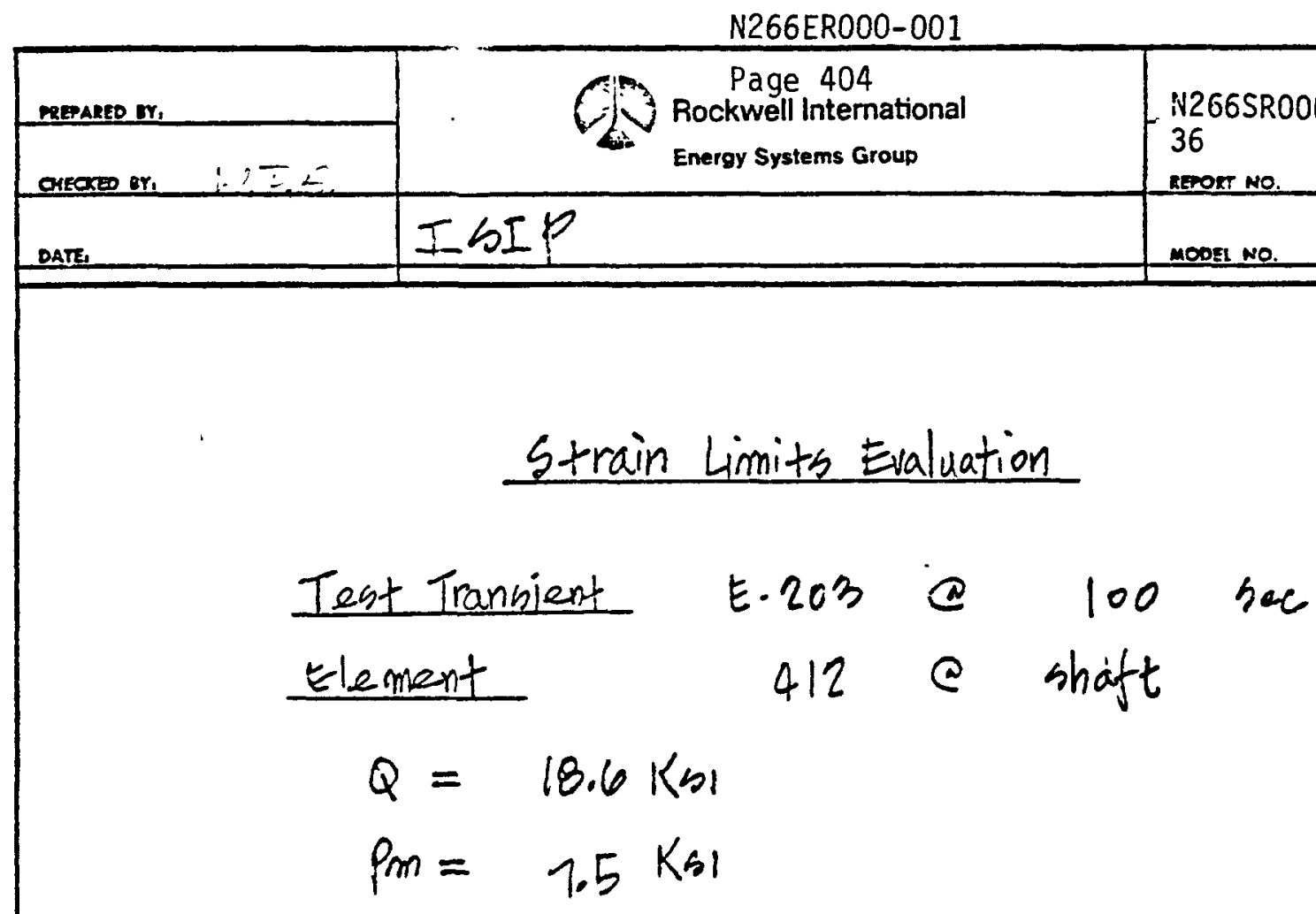

Temperature for $E-203 \quad 500^{\circ} \mathrm{F} \rightarrow 650^{\circ} \mathrm{F}$

$$
\begin{aligned}
& \begin{array}{l}
S_{Y}=19.4 \mathrm{ksi} \odot 500^{\circ} \mathrm{F} \text { - } \Delta_{Y_{\text {mean }}}=18.7 \mathrm{kal} \\
S_{Y}=18.0 \mathrm{ksi} \odot 650^{\circ} \mathrm{F}
\end{array} \\
& h_{m}=15.1 \mathrm{ksi} \& 575^{\circ} \mathrm{F} \text { (Nisan Temp) } \\
& E=25.4 \times 10^{6} \mathrm{ps} 1
\end{aligned}
$$

1. Bree Relaxation Method

$$
\left.\begin{array}{l}
x^{\prime \prime}=1.5 / 15.1=0.5 \\
Y^{\prime \prime}=18.6 / 15.1=1.23
\end{array}\right\} \text { S Region }
$$

ratchet retrain per cycle ( $\Delta \epsilon_{r}$ )

$$
\begin{aligned}
\left(\Delta t_{r}\right) & =\frac{\operatorname{bm}}{E}\left\{1-x^{\prime \prime}+y^{\prime \prime}\left[1-2\left(\frac{1-x^{\prime \prime}}{Y^{\prime \prime}}\right)^{1 / 2}\right]\right\} . \\
& =\frac{15100}{25.4 \times 10^{6}}\left\{1-0.5+1.23\left[1-2\left(\frac{1-0.5}{1.23}\right)^{1 / 2}\right]\right\} \\
& =0.009690
\end{aligned}
$$

N 152-R.2 REV. B.78 
N266ER000-001

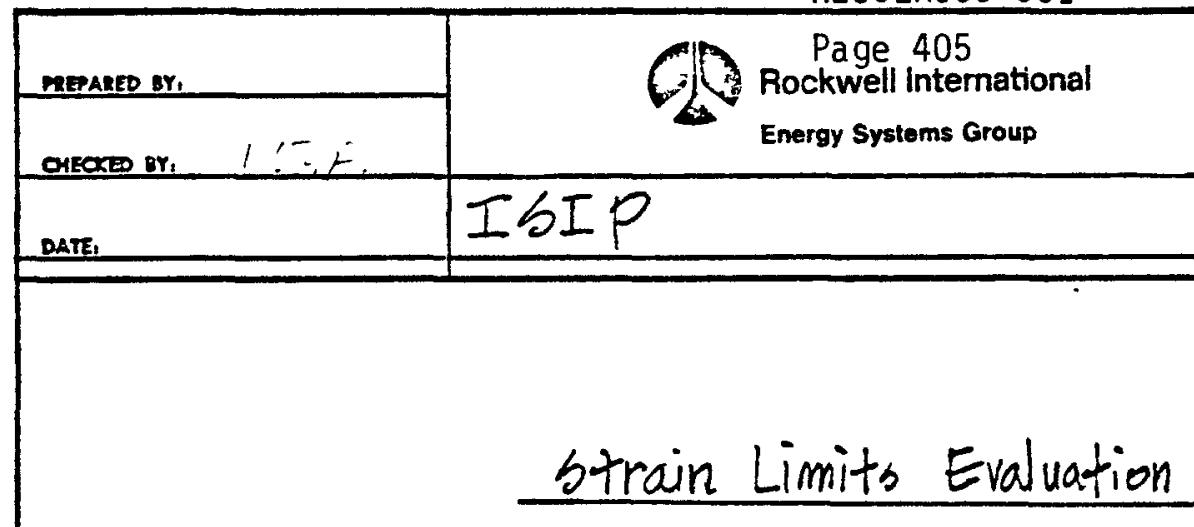

Teat Transient E.204@ 100 sec.

Element

531

(a) Inducer Hub

$$
\begin{aligned}
& Q=20.0 \mathrm{knl} \\
& P_{m}=2.9 \mathrm{ks}
\end{aligned}
$$

Temperature for E. 204

$$
\begin{aligned}
& 850^{\circ} \mathrm{F} \rightarrow 650^{\circ} \mathrm{F} \\
& \begin{array}{l}
s_{y}=16.5 \mathrm{ksi} \& 850^{\circ} \mathrm{F} \\
s_{y}=17.9 \mathrm{kbl} @ 650^{\circ} \mathrm{F}-S_{y}=17.2 \mathrm{ks}
\end{array}
\end{aligned}
$$$$
S_{m}=15.0 \mathrm{ksl} \quad \text { en 50 } \mathrm{F} \text { (mean temp.) }
$$

(Table I-14.3A code cane 1592)

$$
E=24.5 \times 10^{6} \mathrm{psi}
$$

1. Bree Relaxation Method

$$
\left.\begin{array}{l}
X^{\prime \prime}=2.9 / 15.0=0.19 \\
Y^{\prime \prime}=20.0 / 15.0=1.33
\end{array}\right\} \quad S_{2} \text { Region }
$$

ratchet strain par cycle $\left(\Delta \epsilon_{r}\right)$

$$
\begin{aligned}
\left(\Delta \epsilon_{r}\right) & =\frac{S_{m}}{E}\left[x^{\prime \prime}\left(Y^{\prime \prime}-1\right)\right] \\
& =\frac{15000}{24.5 \times 10^{6}}[0.19(1.33-1)] \\
& =0.0038 \%
\end{aligned}
$$

N 152-R-2 REV. B-78 


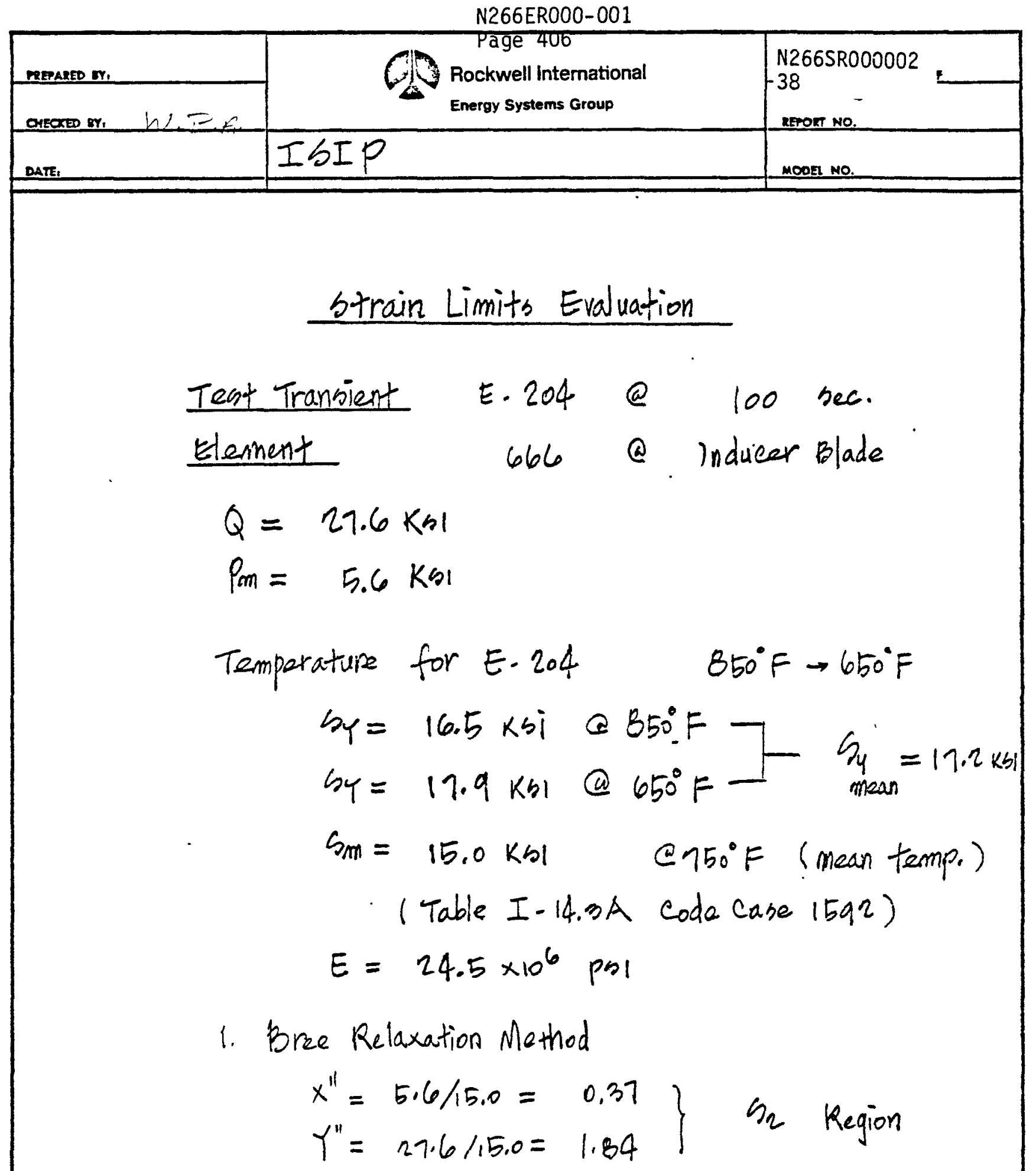

ratchet by ain per cycle

$$
\begin{aligned}
\left(\Delta \epsilon_{r}\right) & =\frac{S_{m}}{E}\left[x^{\prime \prime}\left(Y^{\prime \prime}-1\right)\right] \\
& =\frac{15000}{24.5 \times 10^{6}}[0.37(1.84-1)] . \\
& =0.01903 \%
\end{aligned}
$$

N 152-R-2 REV. 8-78 


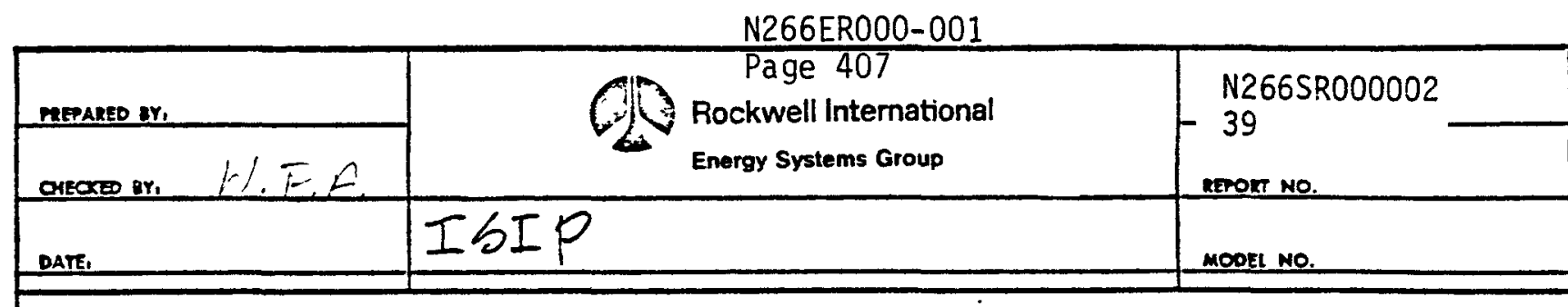

strain Limits Evaluation

Teat Transient E.204@ 100 nee.

Element 648 @ Impeller

$$
\begin{aligned}
& Q=21.0 \mathrm{Kml} \\
& P_{m}=5.9 \mathrm{Kal}
\end{aligned}
$$

Temperature for E. 204

$$
850^{\circ} \mathrm{F} \rightarrow 650^{\circ} \mathrm{F}
$$

$$
\begin{aligned}
& \begin{array}{l}
s_{y}=16.5 \mathrm{ksi} \text { \& } 850^{\circ} \mathrm{F} Z-s_{y}=17.2 \mathrm{ks} \\
s_{y}=17.9 \mathrm{kb1} @ 650^{\circ} \mathrm{F}-{ }_{\text {mean }}
\end{array} \\
& S_{m}=15.0 \mathrm{kbl} \quad\left[750^{\circ} \mathrm{F}\right. \text { (mean temp.) } \\
& E=24.5 \times 10^{6} \mathrm{pos}
\end{aligned}
$$

1. Bree Relaxation Method

$$
\left.\begin{array}{l}
X^{\prime \prime}=5.9 / 15.0=0.39 \\
Y^{\prime \prime}=21.0 / 15.0=1.40
\end{array}\right\} \quad n_{1} \text { Region }
$$

ratchet strain per cycle $(\Delta \in r)$

$$
\begin{aligned}
\left(\Delta \epsilon_{r}\right) & =\frac{\operatorname{sm}_{m}}{E}\left\{1-x^{n}+y^{\prime \prime}\left[1-2\left(\frac{1-x^{\prime \prime}}{y^{\prime \prime}}\right)^{1 / 2}\right]\right\} \\
& =\frac{15000}{24.5 \times 10^{6}}\left\{1-0.39+1.4\left[1-2\left(\frac{1-0.39}{1.40}\right)^{1 / 2}\right]\right\} \\
& =0.0099 \%
\end{aligned}
$$

N 352.R.2 REV. B-78 


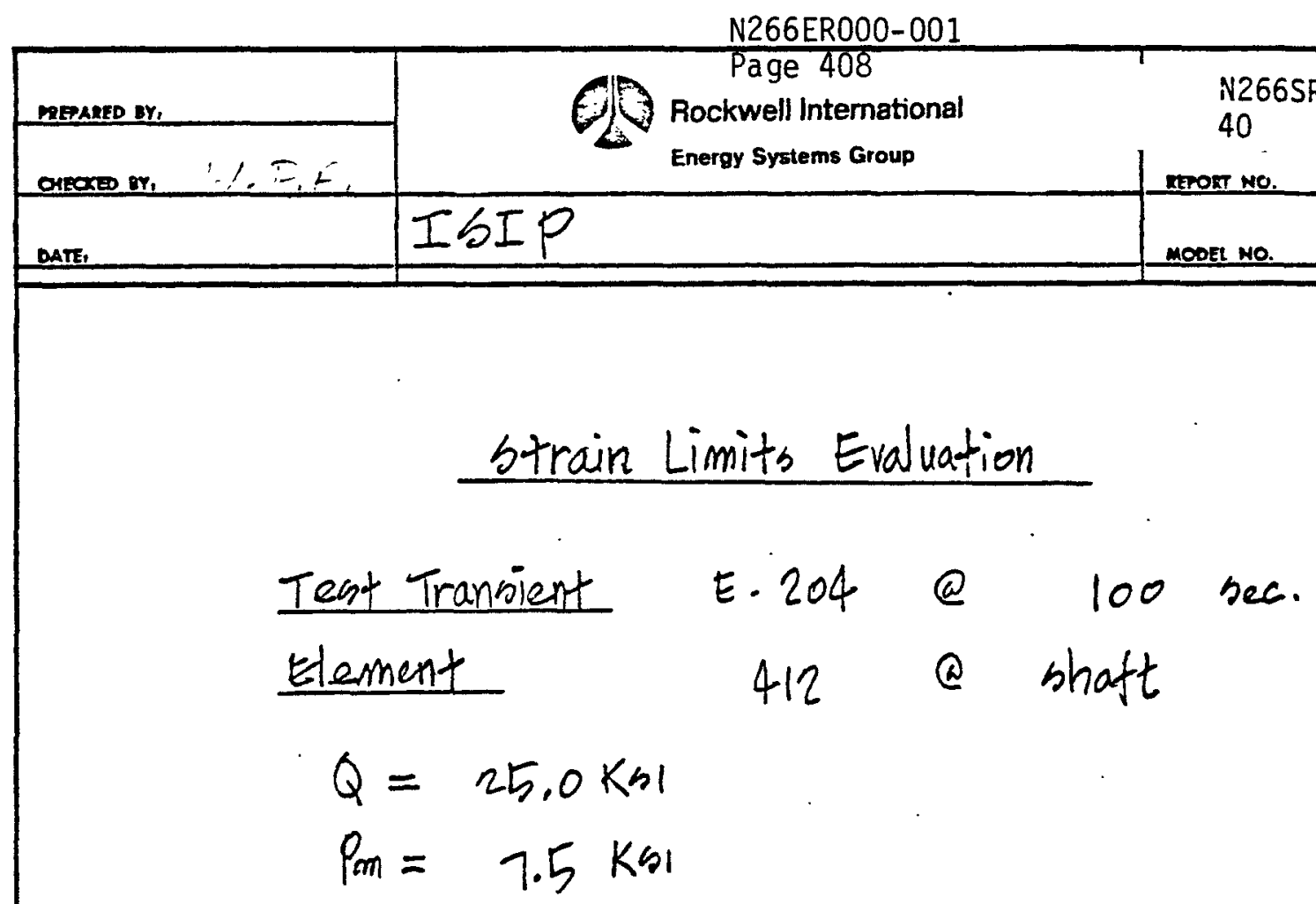

Temperature for E. 204

$$
\begin{aligned}
& 850^{\circ} \mathrm{F} \rightarrow 650^{\circ} \mathrm{F} \\
& \begin{array}{l}
s_{y}=16.5 \mathrm{kbi} \text { \& } 850^{\circ} \mathrm{F}-s_{y}=17.2 \mathrm{kbi} \\
s_{y}=17.9 \mathrm{kb1} \text { @ } 650^{\circ} \mathrm{F} \text { mean }
\end{array}
\end{aligned}
$$$$
S_{m 1}=15.0 \mathrm{kbl} \quad \text { CN50 } \mathrm{F} \text { (mean tempo) }
$$

(Table I-14.3A code care 159r)

$$
E=24.5 \times 10^{6} \mathrm{pos}
$$

1. Bree Relaxation Method

$$
\left.\begin{array}{l}
X^{\prime \prime}=1.5 / 15.0=0.5 \\
Y^{\prime \prime}=25.0 / 15.0=1.67
\end{array}\right\} \quad S_{1} \text { Region }
$$

ratchet strain per cycle $\left(\Delta \epsilon_{r}\right)$

$$
\begin{aligned}
\left(\Delta t_{r}\right) & =\frac{\operatorname{sim}}{E}\left\{1-x^{\prime \prime}+y^{\prime \prime}\left[1-2\left(\frac{1-x^{\prime \prime}}{Y^{\prime \prime}}\right)^{1 / 2}\right]\right\} \\
& =\frac{15000}{24.5 \times 10^{6}}\left\{1-0.5+1.67\left[1-2\left(\frac{1-0.5}{1.67}\right)^{i / 2}\right]\right\} \\
& =0.0210 \%
\end{aligned}
$$

N 152-R-2 REV. 8-78 


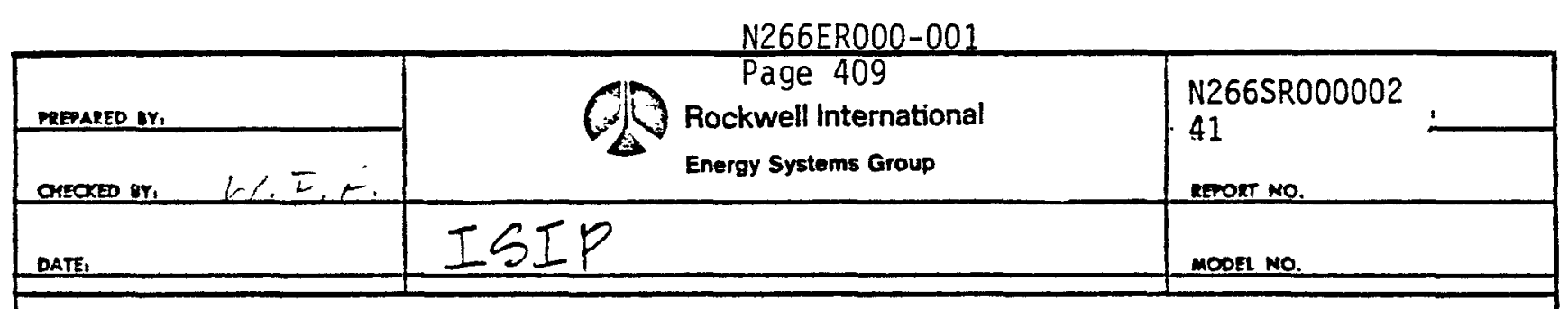

Strain Limits Evaluation

Tent Transient E.207 \& $275 \mathrm{bec}$.

Element 531 a Inducer Hub

$$
\begin{aligned}
& Q=16.0 \mathrm{~km} \\
& P_{m}=2.9 \mathrm{kgl}
\end{aligned}
$$

Temperature for $E-207 \quad 950^{\circ} \mathrm{F} \rightarrow 620^{\circ} \mathrm{F}$.

$$
\begin{aligned}
s_{y}= & 15.9 \mathrm{ksi} \otimes 950^{\circ} \mathrm{F} \\
s_{y}= & =18.0 \mathrm{ksi} @ 620^{\circ} \mathrm{F}-b_{Y_{\text {mean }}}=11.0 \mathrm{ksi} \\
s_{m}= & 15.0 \mathrm{ksi} @ 755^{\circ} \mathrm{F} \text { (mean temp.) } \\
& (\text { Table I-14.3A code Case } 1592) \\
E= & 24.1 \times 10^{6} \mathrm{psi}
\end{aligned}
$$

1. Bree Relaxation Method

$$
\left.\begin{array}{l}
X^{\prime \prime}=2.9 / 15.0=0.19 \\
Y^{\prime \prime}=16.0 / 15.0=1.07
\end{array}\right\} \quad \text { S. Region }
$$

ratchet "strain per egcle $\left(\Delta \epsilon_{r}\right)$

$$
\begin{aligned}
\left(\Delta E_{r}\right) & =\frac{\zeta_{m}}{E}\left\{1-x^{\prime \prime}+Y^{\prime \prime}\left[1-2\left(\frac{1-x^{\prime \prime}}{Y^{\prime \prime}}\right)^{1 / 2}\right]\right\} \\
& =\frac{15000}{24.1 \times 10^{6}}\left\{1-0.19+1.07\left[1-2\left(\frac{1-0.19}{1.07}\right)^{1 / 2}\right]\right\} \\
& =0.0011 \%
\end{aligned}
$$

N 252-R.2 REV. B-78 


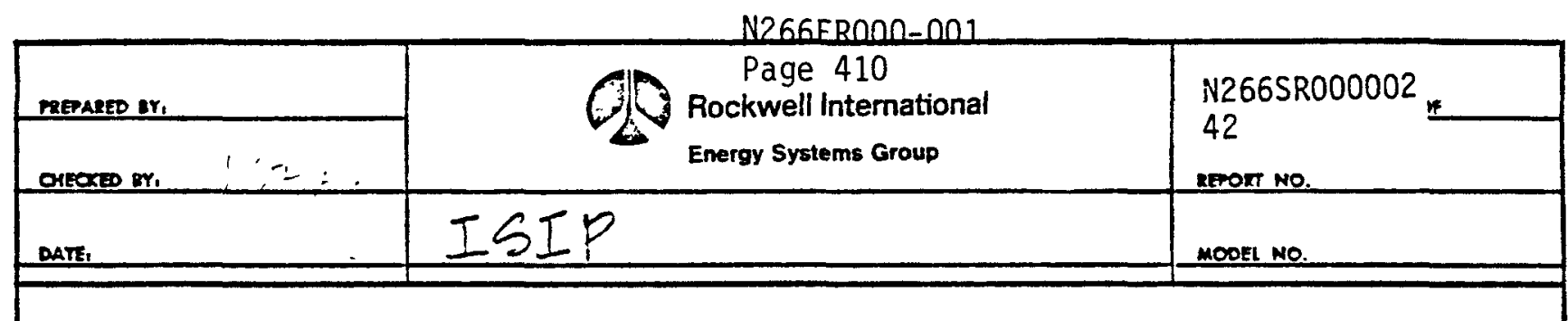

Strain Limits Evaluation

Tent Transient E-207 \& 275 Sec.

Element 666 \& Inducer Blade

$$
\begin{aligned}
& Q=2 n .2 \mathrm{~km} 1 \\
& P_{m}=\quad 5.6 \mathrm{kbl}
\end{aligned}
$$

Temperature for $E-207950^{\circ} \mathrm{F} \rightarrow 620^{\circ} \mathrm{F}$.

$$
\begin{aligned}
& \begin{array}{l}
S_{Y}=15.9 \mathrm{ksi} \otimes 950^{\circ} \mathrm{F} \\
S_{y}=18.0 \mathrm{ksi} \otimes 620^{\circ} \mathrm{F}-b_{Y_{\text {mean }}}=17.0 \mathrm{ksi}
\end{array} \\
& S_{m}=15.0 \mathrm{Ksi} @ 795^{\circ} \mathrm{F} \text { (mean temp.) } \\
& \text { (Table I-14.3A code cane 1592) } \\
& E=24.1 \times 10^{6} \mathrm{ps}
\end{aligned}
$$

1.. Brae Relaxation Method

$$
\left.\begin{array}{l}
X^{\prime \prime}=5.6 / 15.0=0.37 \\
Y^{\prime \prime}=27.2 / 15.0=1.48
\end{array}\right\} S_{1} \text { Region }
$$

ratchet strain per cycle $\left(\Delta \epsilon_{r}\right)$

$$
\begin{aligned}
\left(\Delta E_{r}\right) & =\frac{s_{m}}{E}\left\{1-x^{\prime \prime}+y^{\prime \prime}\left[1-2\left(\frac{1-x^{\prime \prime}}{Y^{\prime \prime}}\right)^{\frac{1}{2}}\right]\right\} \\
& =\frac{15000}{24.1 \times 10^{6}}\left\{1-0.37+1.43\left[i-2\left(\frac{1-0.37}{1.48}\right)^{\frac{1}{2}}\right]\right\} \\
& =0.011 \%
\end{aligned}
$$

N 152-R-2 REV. 8-78 


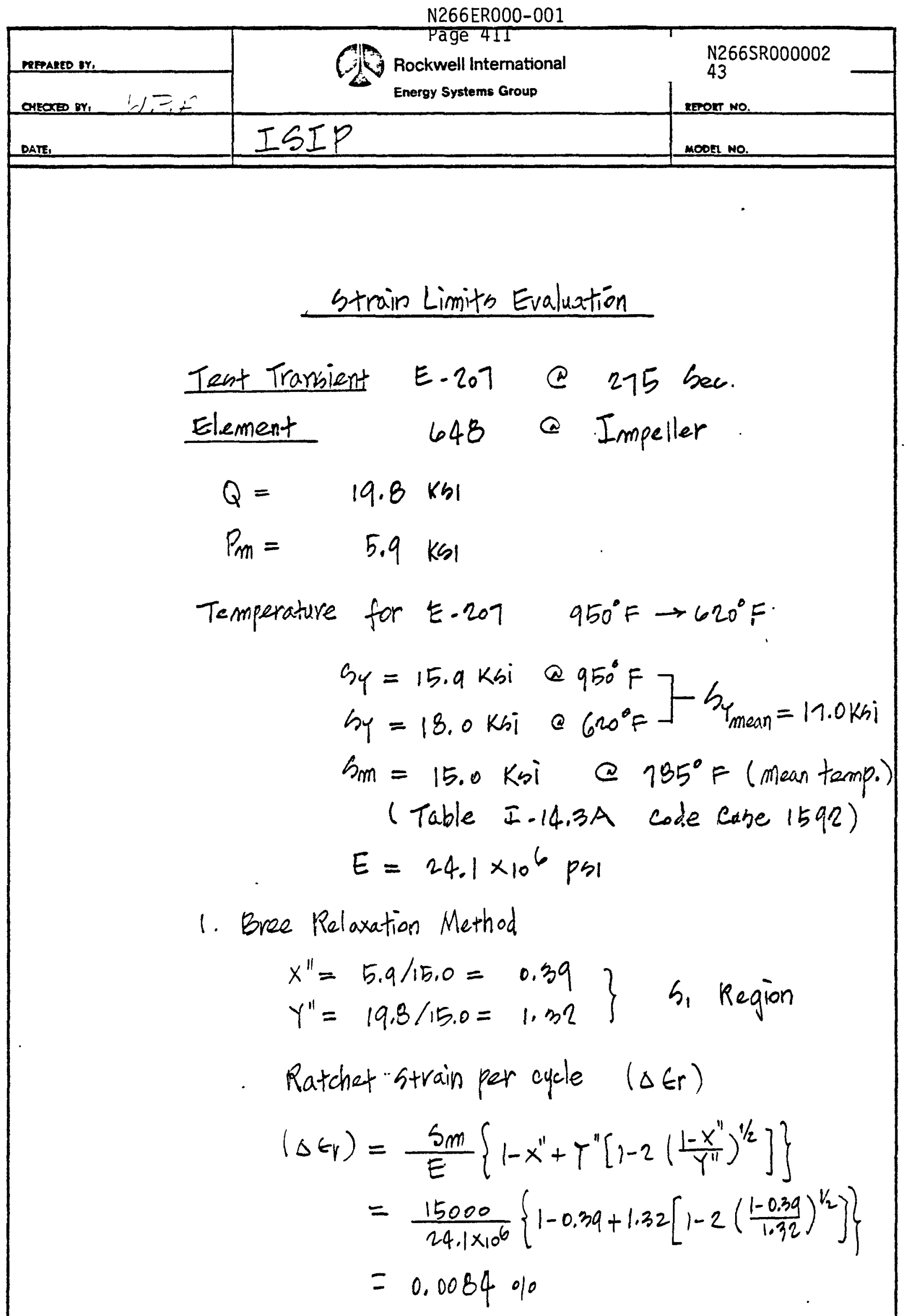




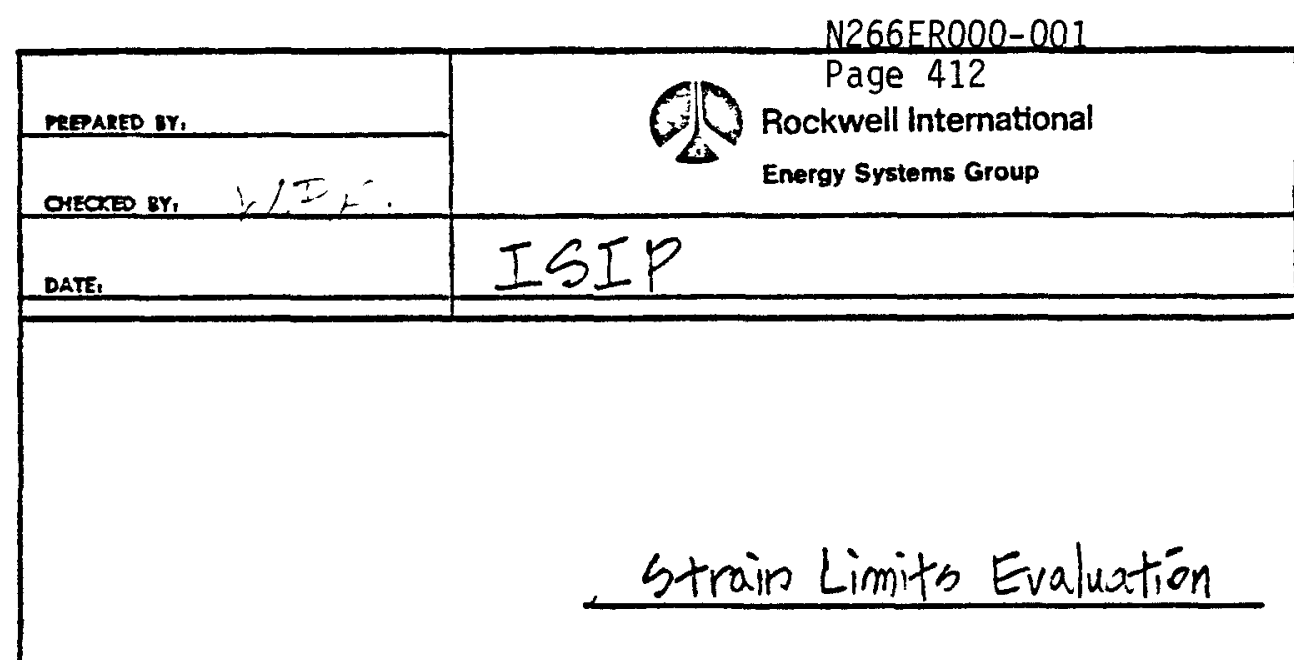

Tent Transient E-207@ 275 Sec.

Element 412 Q shaft

$$
\begin{aligned}
& Q=33.4 . \mathrm{km} \\
& P_{m}=7.5 \mathrm{~km}
\end{aligned}
$$

Temperature for $E-207 \quad 950^{\circ} \mathrm{F} \rightarrow 620^{\circ} \mathrm{F}$.

$$
\begin{aligned}
& \left.s_{y}=15.9 \mathrm{ksi} @ 950^{\circ} \mathrm{F}\right]-h_{Y_{\text {mean }}}=11.0 \mathrm{ksi} \\
& s_{y}=18.0 \mathrm{ksi} @ 620^{\circ} \mathrm{F} \\
& s_{m}=15.0 \mathrm{ksi} @ 735^{\circ} \mathrm{F}(\text { mean tempo })
\end{aligned}
$$

(Table I-14.3A code labe 1592)

$$
E=24.1 \times 10^{6} \mathrm{psi}
$$

1. Bree Relaxation Method

$$
\left.\begin{array}{l}
x^{\prime \prime}=1.5 / 15.0=0.5 \\
Y^{\prime \prime}=33.4 / 15.0=2.23
\end{array}\right\} R_{2} \text { Region }
$$

ratchet strain per cycle $\left(\Delta \epsilon_{r}\right)$

$$
\begin{aligned}
\left(\Delta t_{r}\right) & =\frac{s_{m}}{E}\left[x^{\prime \prime}\left(2 Y^{\prime \prime}-1\right)-1\right] \\
& =\frac{15000}{24.1 \times 10^{6}}[0.5(2 \times 2.23-1)-1] \\
& =0.0454 \%
\end{aligned}
$$

N 152-R.2 REV. 8.78 


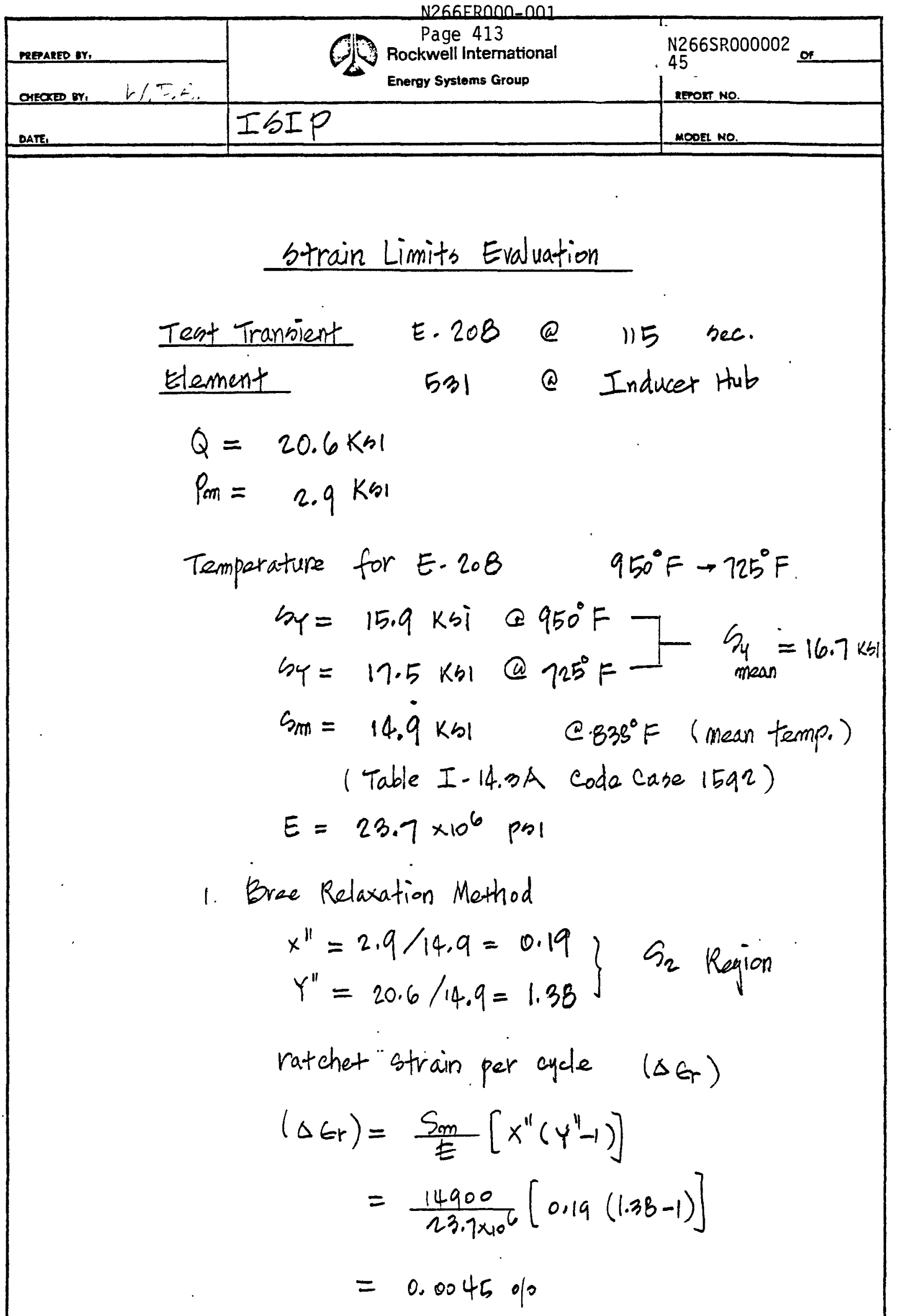

N 152-R-2 REV. 8-78 


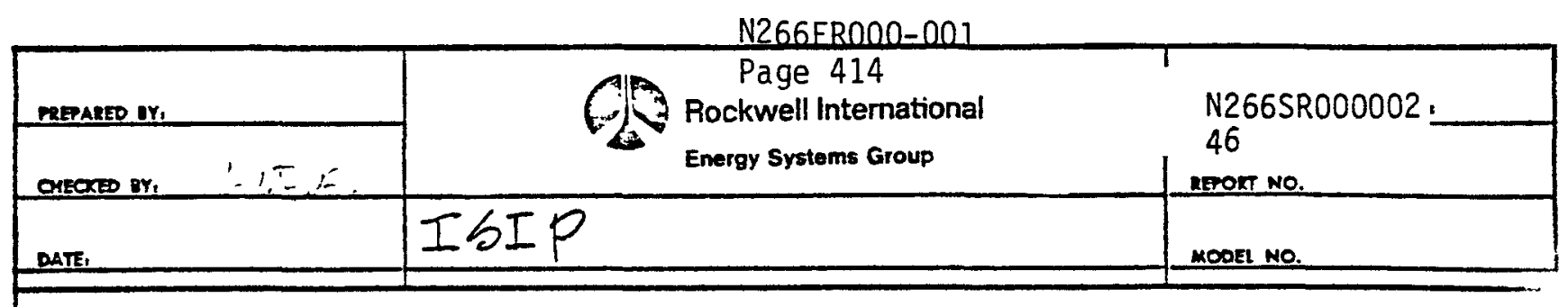

strain Limits Evaluation

Teat Transient E.20B @ 115 sec.

Element $666 @$ Inducer Blade

$$
\begin{aligned}
& Q=28.0 \mathrm{Km} \\
& P_{m}=5.6 \mathrm{~km}
\end{aligned}
$$

Temperature for $E-208 \quad 950^{\circ} \mathrm{F} \rightarrow 725^{\circ} \mathrm{F}$

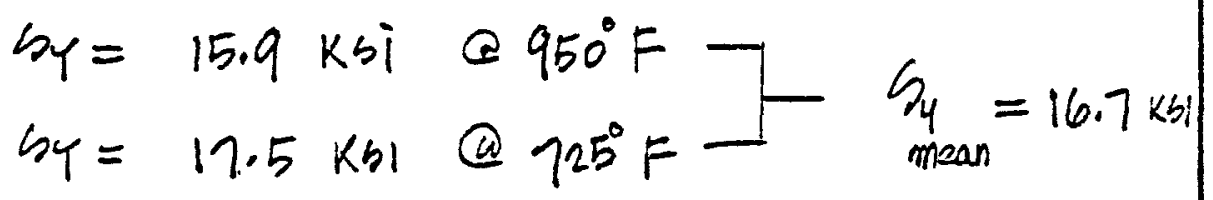

$$
\begin{aligned}
& S_{m}=14.9 \mathrm{~km} \quad C .833^{\circ} \mathrm{F} \text { (mean tempo) } \\
& E=23.7 \times 10^{6} \mathrm{pm}
\end{aligned}
$$

1. Bree Relaxation Method

$$
\left.\begin{array}{l}
x^{\prime \prime}=5.6 / 14.9=0.38 \\
Y^{\prime \prime}=28.0 / 14.9=1.88
\end{array}\right\} \quad h_{2} \text { Region }
$$

ratchet Strain per cycle $\left(\Delta \epsilon_{r}\right)$

$$
\begin{aligned}
\left(\Delta \epsilon_{r}\right) & =\frac{s_{m}}{E}\left[x^{\prime \prime}\left(y^{\prime \prime}-1\right)\right] \\
& =\frac{14900}{23.7 \times 10^{6}}[0.38(1.83-1)] \\
& =0.021 \%
\end{aligned}
$$

N 152-R-2 REV. 8-78 


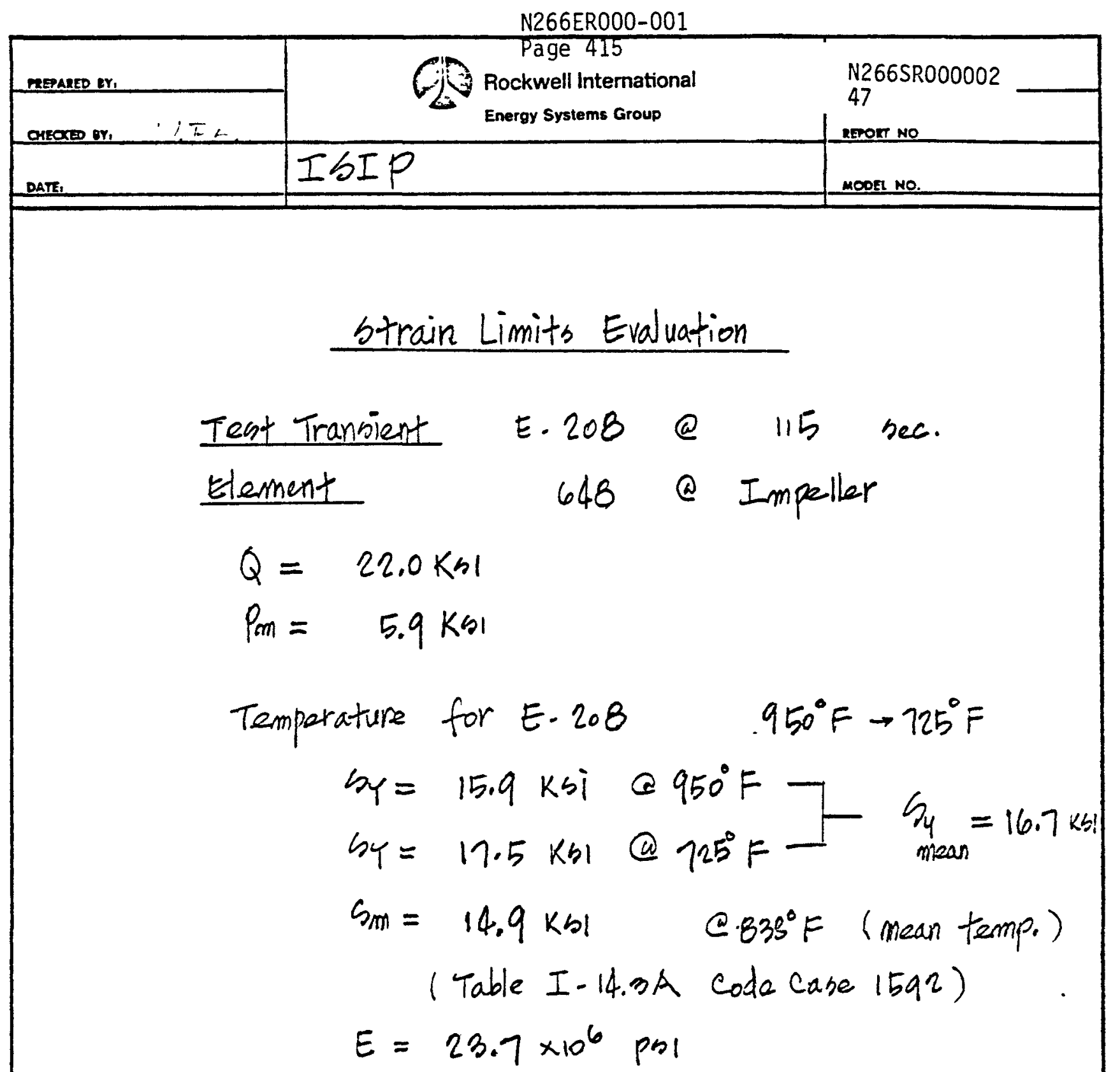

1 Bree Relaxation Method

$$
\left.\begin{array}{l}
x^{\prime \prime}=5.9 / 14.9=0.4 \\
Y^{\prime \prime}=22.0 / 14.9=1.48
\end{array}\right\} \text { Region } S_{1}
$$

ratchet strain per cycle $\left(\Delta \epsilon_{r}\right)$

$$
\begin{aligned}
\left(\Delta \epsilon_{r}\right) & =\frac{S_{m}}{E}\left\{1-x^{\prime \prime}+y^{\prime \prime}\left[1-2\left(\frac{1-x^{\prime \prime}}{Y^{\prime \prime}}\right)^{1 / 2}\right]\right\} \\
& =\frac{14900}{23.7 \times 10^{6}}\left\{1-0.4+1.4 B\left[1-2\left(\frac{1-0.4}{1.48}\right)^{1 / 2}\right]\right\} \\
& =0.0123 \%
\end{aligned}
$$

N 152-R+2 REV. B-78 


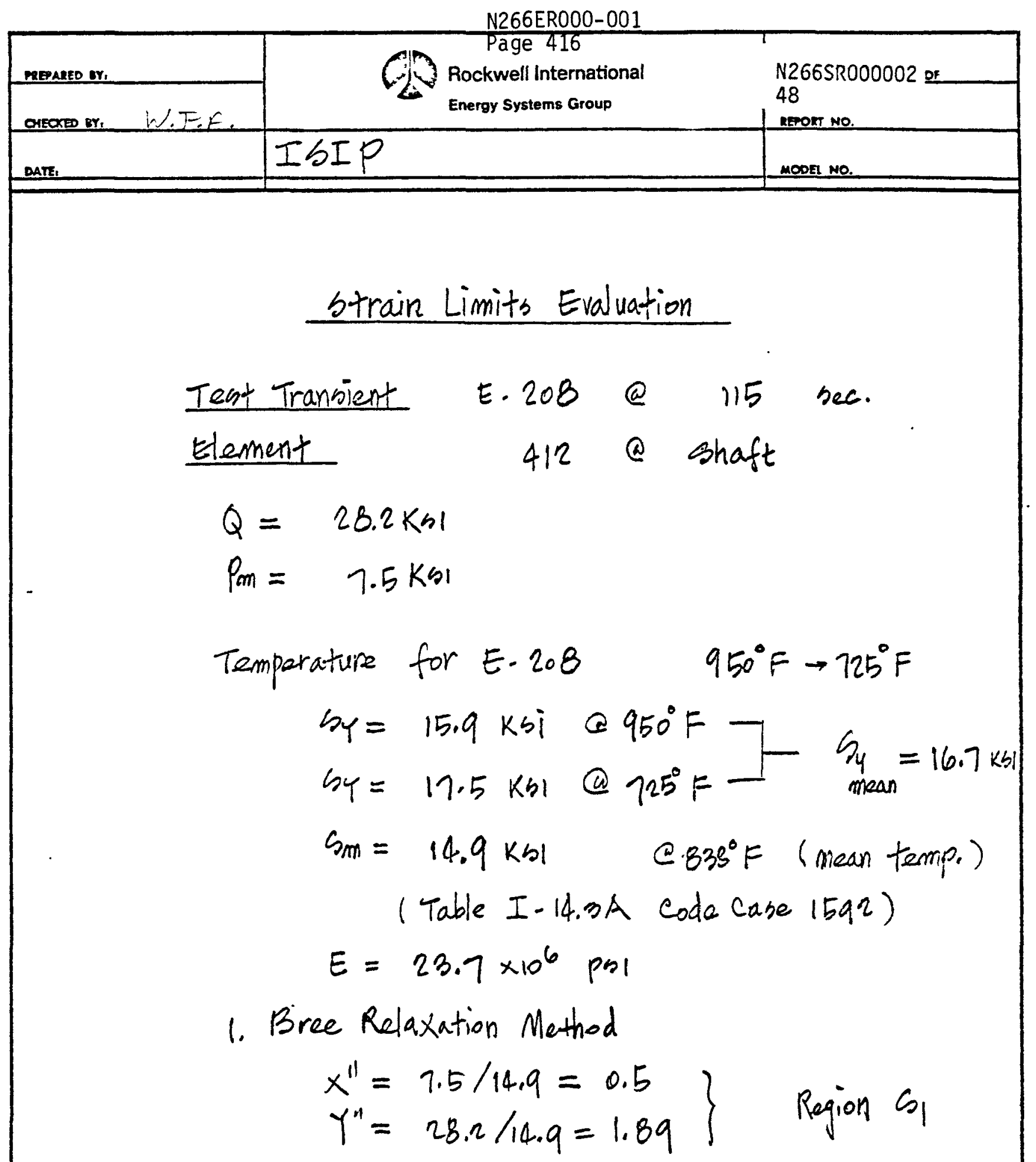

ratchat"strain por cycle $\left(\Delta \epsilon_{r}\right)$

$$
\begin{aligned}
\left(\Delta \epsilon_{r}\right) & =\frac{s_{m}}{E}\left\{1-x^{\prime \prime}+Y^{\prime \prime}\left[1-2\left(\frac{1-x^{\prime \prime}}{Y^{\prime \prime}}\right)^{1 / 2}\right]\right\} \\
& =\frac{14900}{23.7 \times 10^{6}}\left\{1-0.5+1.89\left[1-2\left(\frac{1-0.5}{1.89}\right)^{1 / 2}\right]\right\} \\
& =0.028 \%
\end{aligned}
$$

N 152-R.2 REV. 8-78 


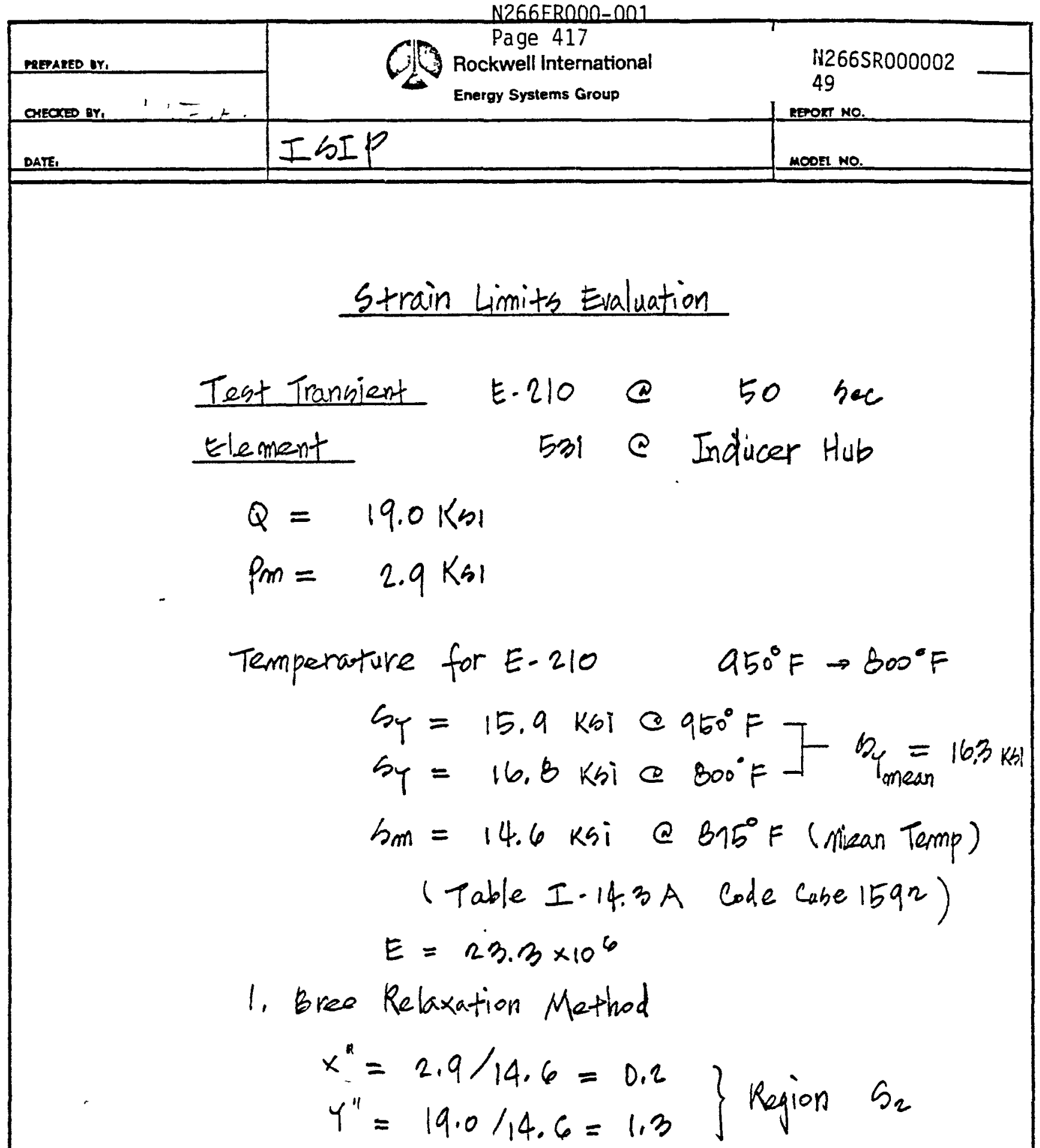

ratchet strain per cycle $\left(\Delta t_{r}\right)$

$$
\begin{aligned}
\left(\Delta G_{r}\right) & =\frac{S_{m}}{E}\left[X^{\prime \prime} \cdot\left(Y^{\prime \prime}-1\right)\right] \\
& =\frac{14600}{23.3 \times 10^{60}}[0.2(1.3-1)] \\
& =0.0036 \%
\end{aligned}
$$

N 152-R-2 REV. 8.78 


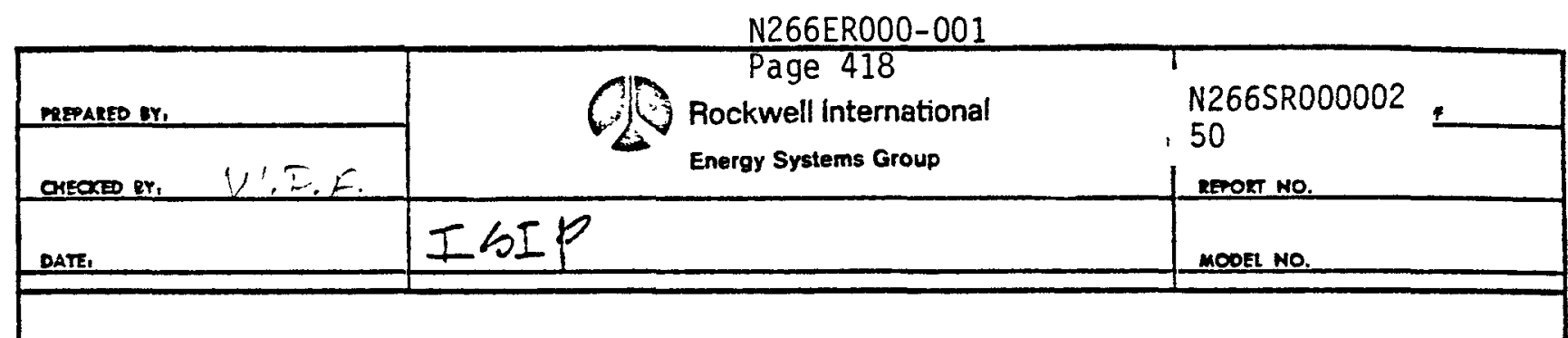

Strain Limits Evaluation

Teat Transient E.210 @ $50 \mathrm{hec}$ Element 666 \& Inducer Blade

$$
\begin{aligned}
& Q=25.6 \mathrm{Km} \\
& P_{m}=5.6 \mathrm{Kml}
\end{aligned}
$$

Temperature for E-210 $950^{\circ} \mathrm{F} \rightarrow 800^{\circ} \mathrm{F}$

$$
\begin{aligned}
& \begin{array}{l}
s_{Y}=15.9 \mathrm{ksi} @ 950^{\circ} \mathrm{F} \text { F } s_{y_{\text {mean }}}=16.3 \mathrm{kH} \\
s_{Y}=16.8 \mathrm{ksi} \text { \& } 800^{\circ} \mathrm{F}
\end{array} \\
& h_{m}=14.6 \mathrm{ksi} @ B 15^{\circ} \mathrm{F} \text { (Nan Temp) } \\
& \text { (Table I. 14.3 A code abe 159n) } \\
& E=23.3 \times 10^{6}
\end{aligned}
$$

1. Bree Relaxation Method

$$
\left.\begin{array}{l}
x^{\prime \prime}=5.6 / 14.6=0.38 \\
Y^{\prime \prime}=25.6 / 14.6=1.75
\end{array}\right\} \text { Region } S_{2}
$$

ratchet. strain per cycle $\left(\Delta \epsilon_{r}\right)$

$$
\begin{aligned}
\left(\Delta G_{r}\right) & =\frac{S_{m}}{E}\left[x^{\prime \prime}\left(Y^{\prime \prime}-1\right)\right] \\
& =\frac{14600}{v_{33.3 \times 10^{6}}}[0.36(1.75-1)] \\
& =0.0179 \%
\end{aligned}
$$

N 152-R-2 REV. 8-78 


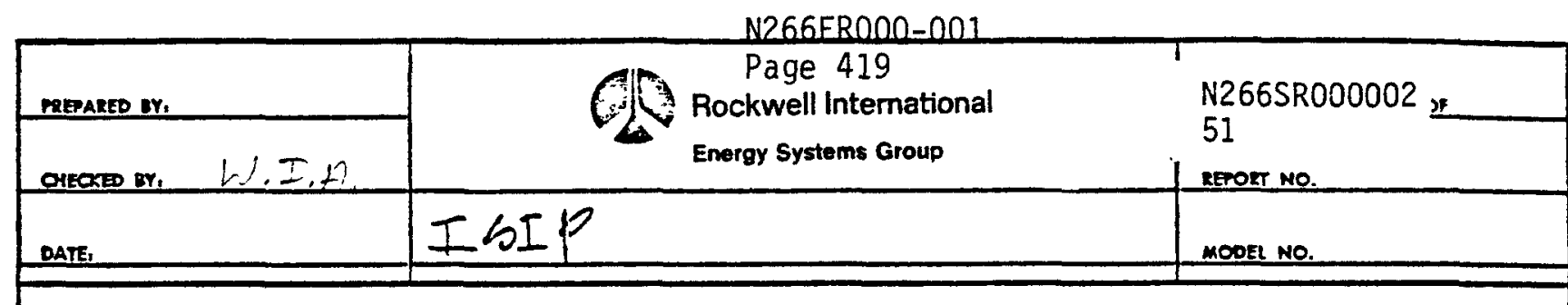

Strain Limits Evaluation

Test Transient E.210 \& $50 \mathrm{hec}$ Element 648 \& Impeller

$$
\begin{aligned}
& Q=20.0 \mathrm{~K} s 1 \\
& P_{m}=5.9 \mathrm{~K} s 1
\end{aligned}
$$

Temperature for E-210 $\quad 950^{\circ} \mathrm{F} \rightarrow 800^{\circ} \mathrm{F}$

$$
\begin{aligned}
& s_{Y}=15.9 \mathrm{ksi} \propto 950^{\circ} \mathrm{F}
\end{aligned}
$$

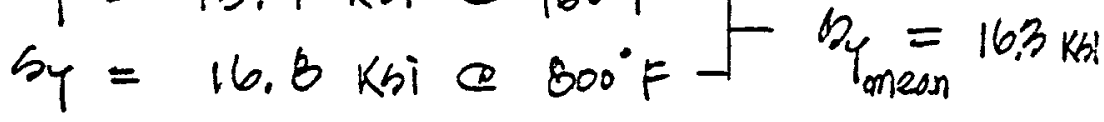

$$
\begin{aligned}
& h_{m}=14.6 \mathrm{ksi} \& B 15^{\circ} \mathrm{F} \text { (Nikon Temp) } \\
& \text { (Table I-14.3 A code case 159n). } \\
& E=23.3 \times 10^{6}
\end{aligned}
$$

1. Bree Relaxation Method

$$
\left.\begin{array}{l}
x^{\prime \prime}=5.9 / 14.6=0.4 \\
y^{\prime \prime}=20.0 / 14.6=1.31
\end{array}\right\} \text { Region } s_{1}
$$

ratchet strain per cycle ( $\left.\Delta \epsilon_{r}\right)$

$$
\begin{aligned}
\left(\Delta \epsilon_{r}\right) & =\frac{\operatorname{Sin}}{E}\left\{1-x^{\prime \prime}+y^{\prime \prime}\left[1-2\left(\frac{1-x^{\prime \prime}}{y^{\prime \prime}}\right)^{1 / 2}\right]\right\} \\
& =\frac{14600}{23.3 \times 10^{-6}}\left\{1-0.4+1.37\left[1-2\left(\frac{1-0.4}{1.31}\right)^{1 / 2}\right]\right\} \\
& =0.0098 \%
\end{aligned}
$$

N 252-R.2 REV. 8-78 


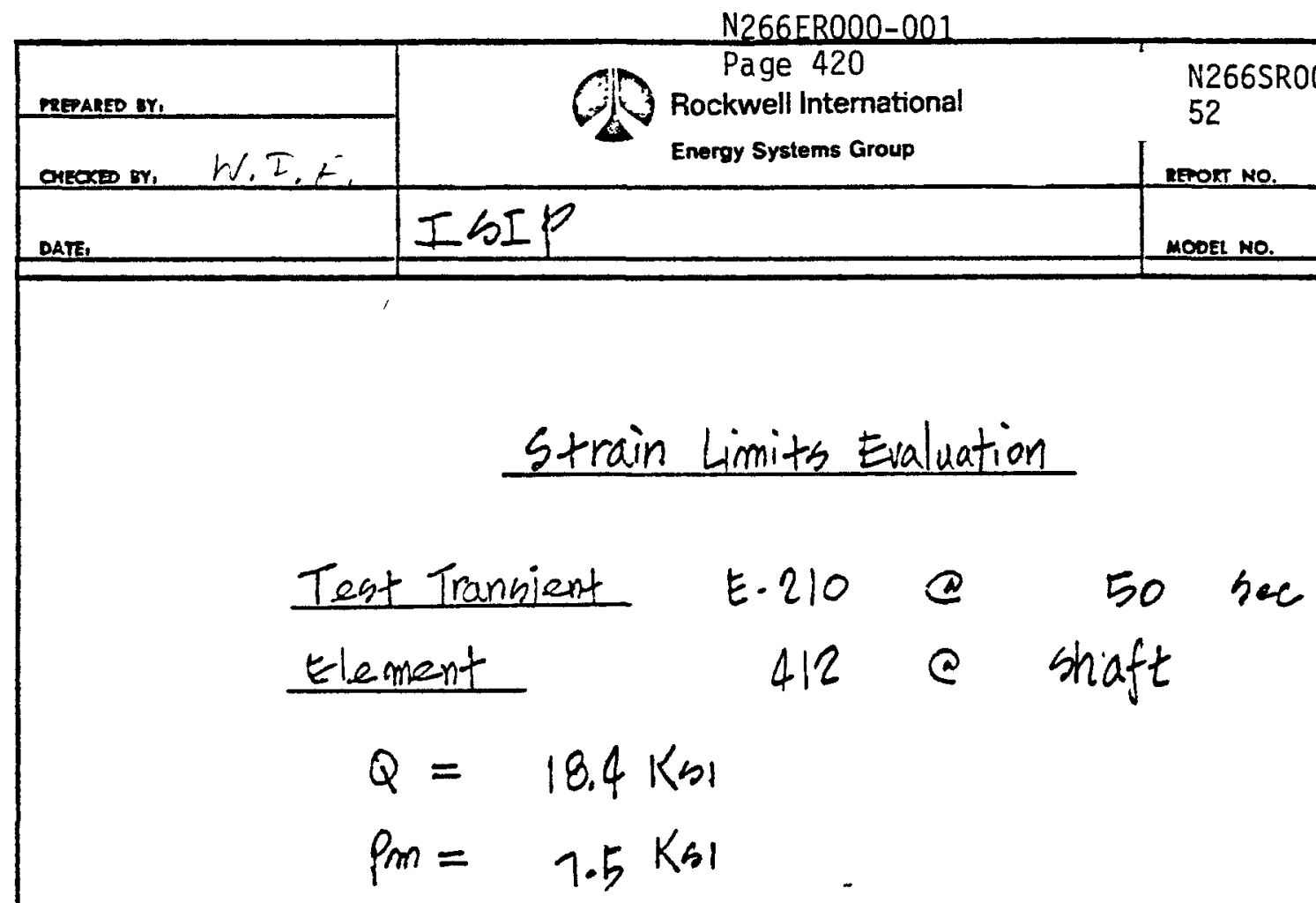

Temperature for E-210 $950^{\circ} \mathrm{F} \rightarrow 300^{\circ} \mathrm{F}$

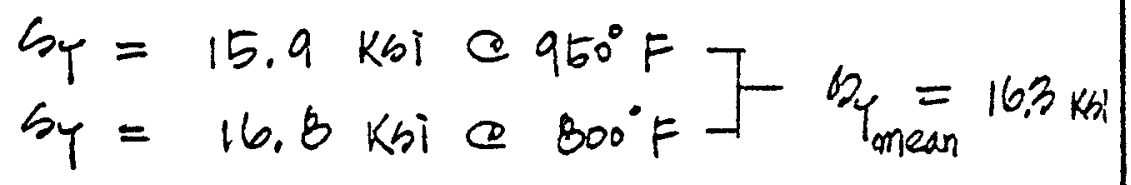

$$
\begin{aligned}
& h_{m}=14.6 \mathrm{ksi} @ B 15^{\circ} \mathrm{F} \text { (Nan Temp) } \\
& \text { (Table I. 14.3 A code abe 159n) } \\
& E=23.3 \times 10^{6}
\end{aligned}
$$

1. Bree Relaxation Method

$$
\left.\begin{array}{l}
x^{\prime \prime}=1.5 / 14.6=0.51 \\
y^{\prime \prime}=18.4 / 14.6=1.26
\end{array}\right\} \text { Region } s_{1}
$$

Ratchet Strain per cycle $\left(\Delta \epsilon_{r}\right)$

$$
\begin{aligned}
\left(\Delta G_{r}\right) & =\frac{S_{m}}{E}\left\{1-X^{\prime \prime}+Y^{\prime \prime}\left[1-2\left(\frac{1-X^{\prime \prime}}{Y^{\prime \prime}}\right)^{1 / 2}\right]\right\} \\
& =\frac{14600}{23.3 \times 10^{6}}\left\{1-0.51+1.26\left[1-2\left(\frac{1-0.51}{1.26}\right)^{1 / 2}\right]\right\} \\
& =0.011 \%
\end{aligned}
$$

N 252-R-2 REV. 8-78 


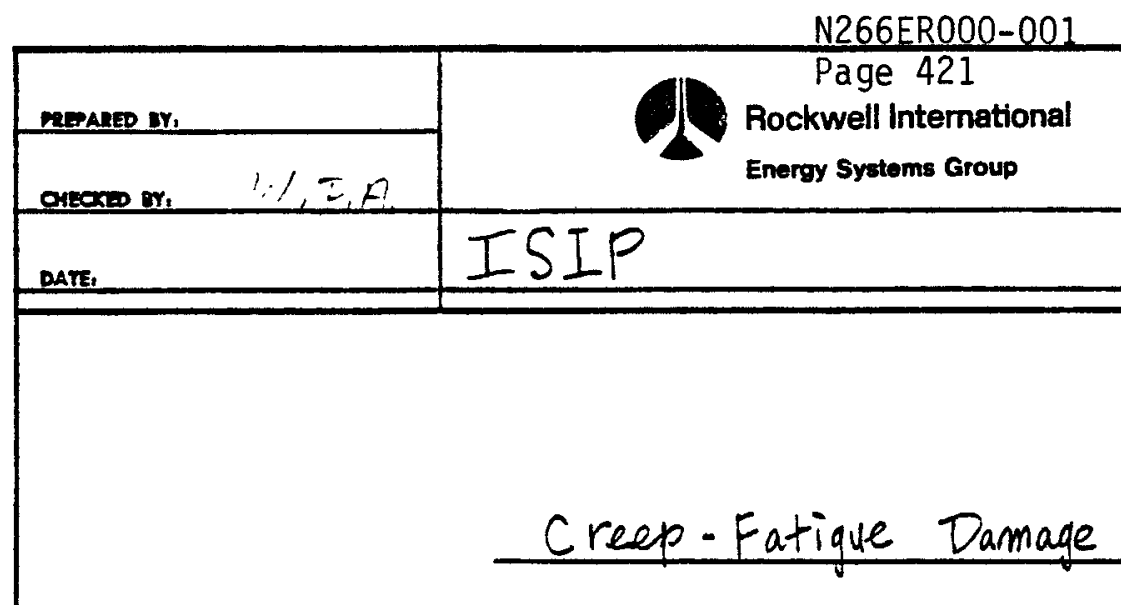

Test Transient

E. 207

Element

$$
\begin{aligned}
& P_{m}+Q=40.9 \mathrm{kni}>S_{y}=15.9 \mathrm{kbl} \\
& 1.25 S_{Y} / 0.9=22.08 \mathrm{k}(\mathrm{si}
\end{aligned}
$$

1. Creep Damage

The allowable duration Td, from Fig. I.14.6 A Code cane 1592

$$
T d=6 \times 10^{4} \text { Hrs. }
$$

the cycle duration of transient looters. (Assumed) the creep damage per cycle

$$
\frac{t}{T d}=\frac{100}{6 \times 10^{4}}=0.0017
$$

N 152-R-2 REV. B-78 


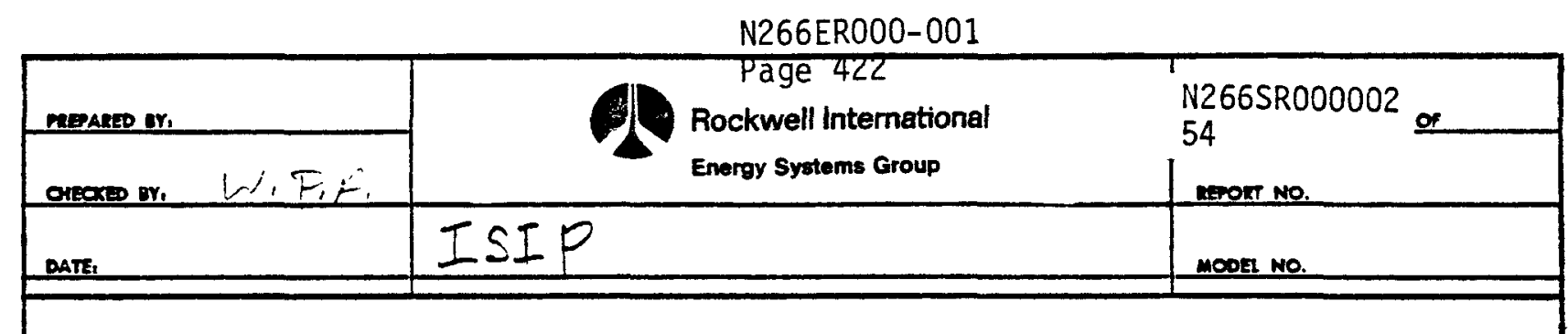

Creep. Fatigue Damage

2. Fatigue, Damage

Element .412@ shaft Q transient E.207

$$
\begin{aligned}
& E_{t^{\prime}}=40.9 \times 10^{3} / 22.9 \times 10^{6}=0.001786 \\
& N_{d}=2 \times 10^{3} \text { cycles (Fig. T-1420.1A } \\
& \text { code cube } 1592)
\end{aligned}
$$

The fatigue damage fraction per cue will be

$$
\frac{n}{N d}=\frac{1}{2 \times 10^{3}}
$$

3. The total ereep-Fatigue Damage

$$
\begin{aligned}
\sum \frac{t}{T d}+\sum \frac{n}{N_{d}} \leqq 1 & \\
\sum \frac{t}{T d}+\sum \frac{n}{N_{d}} & =(6 \times 2) \frac{100}{6 \times 10^{4}}+(6 \times 2) \frac{1}{2 \times 10^{3}} \\
& =0.02+0.006 \\
& =0.026<1
\end{aligned}
$$

N 152-R-2 REV. 8.78 
Table 1-14.3A

$S_{m t}$ - Allowablo Stress Intensity Values, 1000 pet

Type 304 SS - 30.YS, 76-UTS (30-YS, 70-UTS)

\begin{tabular}{|c|c|c|c|c|c|c|c|c|c|c|c|}
\hline Tomp. $F$ & I hr & $10 \mathrm{hr}$ & $30 \mathrm{hr}$ & $10^{2} \mathrm{hr}$ & $3 \times 10^{\prime} \mathrm{hr}$ & $10^{3} \mathrm{hr}$ & $3 \times 10^{\circ} \mathrm{mr}$ & $10^{\circ} \mathrm{hr}$ & $3 \times 10^{4} \mathrm{hr}$ & $10^{\circ} \mathrm{hr}$ & $3 \times 10^{\circ} \mathrm{hr}$ \\
\hline $\begin{array}{l}800 \\
850 \\
900\end{array}$ & $\begin{array}{l}15.1 \\
14.8 \\
14.6\end{array}$ & $\begin{array}{l}15.1 \\
14.8 \\
14.6\end{array}$ & $\begin{array}{l}15.1 \\
14.8 \\
14.6\end{array}$ & $\begin{array}{l}15.1 \\
14.8 \\
14.6\end{array}$ & $\begin{array}{l}15.1 \\
14.8 \\
14.6\end{array}$ & $\begin{array}{l}15.1 \\
14.0 \\
11.0\end{array}$ & $\begin{array}{l}15.1 \\
14.0 \\
11.0\end{array}$ & $\begin{array}{l}15.1 \\
14.8 \\
14.6\end{array}$ & $\begin{array}{l}15.1 \\
14.8 \\
14.6\end{array}$ & $\begin{array}{l}15.1 \\
14.0 \\
14.0\end{array}$ & $\begin{array}{l}15.1 \\
11.8 \\
11.6\end{array}$ \\
\hline $\begin{array}{r}950 \\
1000 \\
1050\end{array}$ & $\begin{array}{l}14.3 \\
14.0 \\
13.6\end{array}$ & $\begin{array}{l}14.3 \\
14.0 \\
13.6\end{array}$ & $\begin{array}{l}11.3 \\
14.0 \\
13.6\end{array}$ & $\begin{array}{l}14.3 \\
11.0 \\
13.6\end{array}$ & $\begin{array}{l}14.3 \\
14.0 \\
13.6 \\
\end{array}$ & $\begin{array}{l}14.3 \\
14.0 \\
13.6\end{array}$ & $\begin{array}{l}14.3 \\
11.0 \\
13.6\end{array}$ & $\begin{array}{l}11.3 \\
11.0 \\
12.2 \\
\end{array}$ & $\begin{array}{l}14.3 \\
13.1 \\
10.3 \\
\end{array}$ & $\begin{array}{r}14.2 \\
11.1 \\
8.7 \\
\end{array}$ & $\begin{array}{r}12.2 \\
9.3 \\
7.3 \\
\end{array}$ \\
\hline $\begin{array}{l}1100 \\
1150 \\
1200\end{array}$ & $\begin{array}{l}13.2 \\
12.9 \\
12.7 \\
\end{array}$ & $\begin{array}{l}13.2 \\
12.9 \\
12.7\end{array}$ & $\begin{array}{l}13.2 \\
12.9 \\
12.7 \\
\end{array}$ & $\begin{array}{l}13.2 \\
12.9 \\
12.2 \\
\end{array}$ & $\begin{array}{l}13.2 \\
12.9 \\
10.6 \\
\end{array}$ & $\begin{array}{r}13.2 \\
11.0 \\
8.9\end{array}$ & $\begin{array}{r}11.5 \\
9.3 \\
7.4 \\
\end{array}$ & $\begin{array}{l}9.7 \\
7.7 \\
6.1 \\
\end{array}$ & $\begin{array}{l}8.2 \\
6.4 \\
5.1 \\
\end{array}$ & $\begin{array}{l}6.0 \\
5.3 \\
4.1 \\
\end{array}$ & $\begin{array}{r}5.7 \\
+\quad 1.4 \\
3.4 \\
\end{array}$ \\
\hline $\begin{array}{l}1250 \\
1300 \\
1350\end{array}$ & $\begin{array}{c}12.3 \\
11.9(11.8) \\
10.9(10.5)\end{array}$ & $\begin{array}{r}12.3 \\
11.4 \\
9.7\end{array}$ & $\begin{array}{r}11.9 \\
10.0 \\
8.4\end{array}$ & $\begin{array}{r}10.3 \\
8.5 \\
7.1\end{array}$ & $\begin{array}{l}0.7 \\
7.0 \\
5.9\end{array}$ & $\begin{array}{l}7.2 \\
5.9 \\
4.8\end{array}$ & $\begin{array}{l}5.9 \\
4.8 \\
3.9\end{array}$ & $\begin{array}{l}4.9 \\
3.9 \\
3.1\end{array}$ & $\begin{array}{l}4.0 \\
3.2 \\
2.5\end{array}$ & $\begin{array}{l}3.2 \\
2.5 \\
2.0\end{array}$ & $\begin{array}{l}2.7 \\
2.1 \\
1.6\end{array}$ \\
\hline $\begin{array}{l}1400 \\
1450 \\
1500\end{array}$ & $\begin{array}{l}9.5(9.0) \\
8.2(7.5) \\
7.0(6.1)\end{array}$ & $\begin{array}{l}6.1 \\
6.8 \\
5.3\end{array}$ & $\begin{array}{l}6.9 \\
5.0 \\
4.4\end{array}$ & $\begin{array}{l}5.9 \\
4.6 \\
3.5\end{array}$ & $\begin{array}{l}4.8 \\
3.0 \\
2.8\end{array}$ & $\begin{array}{l}3.9 \\
3.0 \\
2.2\end{array}$ & $\begin{array}{l}3.1 \\
2.4 \\
1.7\end{array}$ & $\begin{array}{l}2.5 \\
1.9 \\
1.3\end{array}$ & $\begin{array}{l}2.0 \\
1.5 \\
1.0\end{array}$ & $\begin{array}{l}1.6 \\
1.2 \\
0.0\end{array}$ & $\begin{array}{l}1.2 \\
0.9 \\
0.6\end{array}$ \\
\hline
\end{tabular}

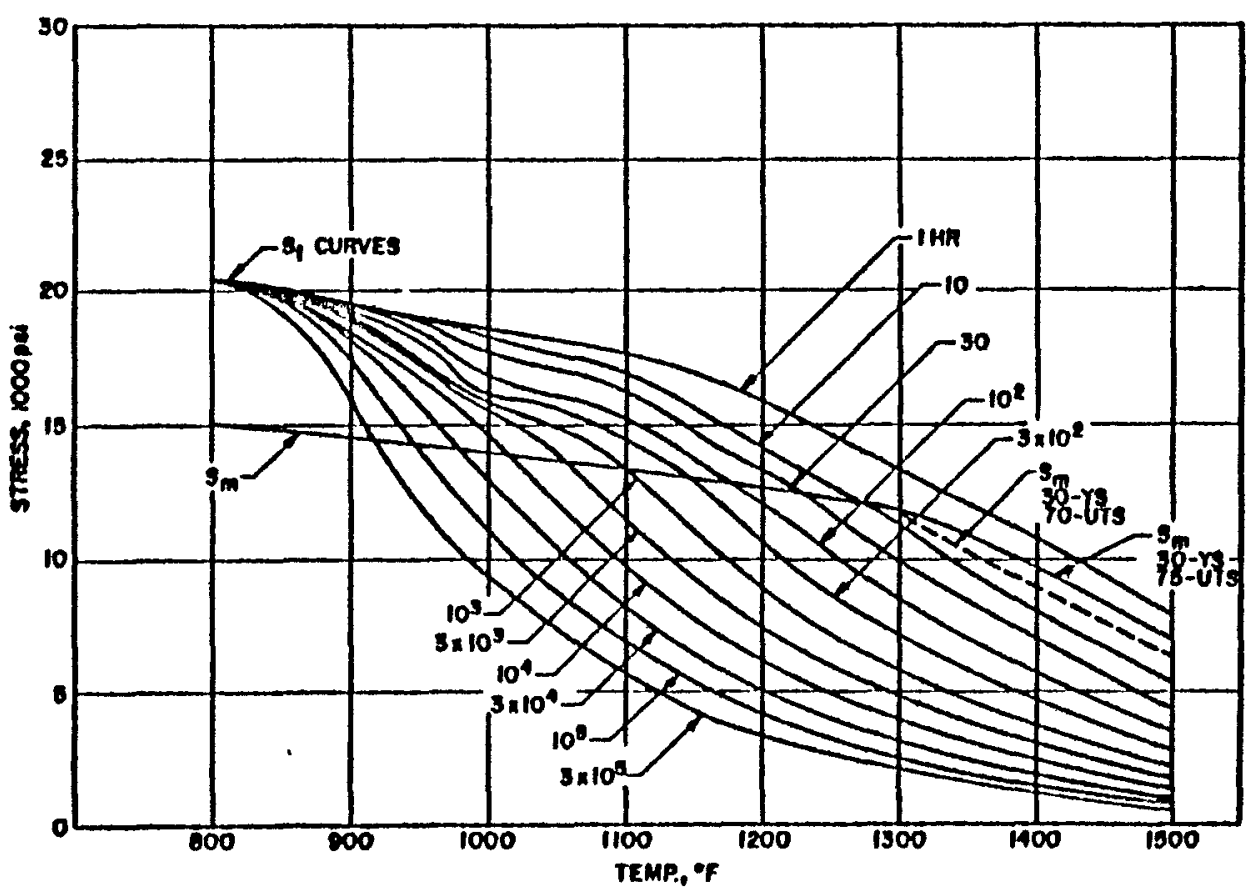

Fig. 1.14.3A $S_{m f}-$ Trpo 304 sS 
Table 1.14 .5

Yield Strength Values, 'Sy, re. Tomperature

\begin{tabular}{|c|c|c|c|c|c|}
\hline \multirow{2}{*}{ Tomp., F } & \multirow[t]{2}{*}{304 SS } & \multirow{2}{*}{\multicolumn{2}{|c|}{$\begin{array}{cc} & \text { Ni-Fo-Cr } \\
316 \text { sS } & \text { Altoy } 800 H \\
\text { (Stroses in lesi Units) }\end{array}$}} & \multirow[t]{2}{*}{$2 \% \mathrm{Cr}-1 \mathrm{Mo}$} & \multirow[t]{2}{*}{$\begin{array}{c}\text { Ni-Cr-Facb } \\
\text { Alloy } 718\end{array}$} \\
\hline & & & & & \\
\hline $\begin{array}{l}\mathrm{RT} \\
100 \\
200 \\
300 \\
400 \\
500 \\
600 \\
\end{array}$ & $\begin{array}{l}30.0 \\
28.8 \\
25.0 \\
22.5 \\
20.7 \\
19.4 \\
18.2\end{array}$ & $\begin{array}{l}30.0 \\
29.2 \\
25.8 \\
23.3 \\
21.4 \\
19.9 \\
18.8\end{array}$ & $\begin{array}{l}25.0 \\
24.3 \\
22.5 \\
21.1 \\
20.0 \\
19.0 \\
19.3 \\
\end{array}$ & $\begin{array}{l}30.0 \\
29.4 \\
27.8 \\
26.8 \\
26.6 \\
26.5 \\
26.5 \\
\end{array}$ & $\begin{array}{l}150.0 \\
148.4 \\
143.9 \\
140.7 \\
138.3 \\
136.7 \\
135.4 \\
\end{array}$ \\
\hline $\begin{array}{r}700 \\
750 \\
800 \\
850 \\
900 \\
950 \\
1000 \\
\end{array}$ & $\begin{array}{l}17.7 \\
17.3 \\
16.8 \\
16.5 \\
16.2 \\
15.9^{\circ} \\
15.6\end{array}$ & $\begin{array}{l}18.1 \\
17.8 \\
17.6 \\
17.4 \\
17.3 \\
17.1 \\
17.0 \\
\end{array}$ & $\begin{array}{l}17.5 \\
17.2 \\
16.8 \\
16.5 \\
16.3 \\
16.1 \\
15.8 \\
\end{array}$ & $\begin{array}{l}26.5 \\
26.5 \\
26.5 \\
26.3 \\
25.6 \\
24.7 \\
23.6 \\
\end{array}$ & $\begin{array}{l}134.3 \\
133.7 \\
133.1 \\
132.4 \\
131.5 \\
130.5 \\
129.4 \\
\end{array}$ \\
\hline $\begin{array}{l}1050 \\
1100 \\
1150 \\
1200 \\
1250 \\
1300 \\
1350 \\
1400 \\
\end{array}$ & $\begin{array}{l}15.2 \\
14.7 \\
14.4 \\
14.1 \\
13.7 \\
13.2 \\
12.5 \\
11.6 \\
\end{array}$ & $\begin{array}{l}16.7 \\
16.5 \\
16.4 \\
16.2 \\
15.8 \\
15.3 \\
14.9 \\
14.4 \\
\end{array}$ & $\begin{array}{l}15.6 \\
15.3 \\
15.0 \\
14.8 \\
14.5 \\
14.3 \\
14.0 \\
13.7 \\
\end{array}$ & $\begin{array}{l}22.1 \\
20.4 \\
28.4 \\
16.1\end{array}$ & 128.0 \\
\hline $\begin{array}{l}1450 \\
1500 \\
1550 \\
1600 \\
\end{array}$ & $\begin{array}{r}10.6 \\
9.5\end{array}$ & $\begin{array}{l}13.8 \\
13.1\end{array}$ & $\begin{array}{l}13.4 \\
13.0 \\
12.3 \\
11.0\end{array}$ & & \\
\hline
\end{tabular}

The tabulated values of yield strength are those which the Committee believes are suitable for use in design calculations required by this Case. At temperatures above room temperature the yield strength values correspond to the yield strength trend curve adjusted to the minimum specified room temperature yield strength. The yield strength values do not correspond exactly to either "average" or "minimum" as these terms are applied to a statistical treatment of a homogeneous set of data.

Neither the ASME Materials Specifications nor the rules of this Case require elevated temperature testing for yield strengths of production material for use in Code components. It is not intended that results of such tests, if performed, be compared with these tabulated yield strength values for AS.ME Code acceptance/ rejection purposes for materials. If some elevated temperature test results on production material appear lower than the tabulated values by a large amount (more than the typical variability of material and suggesting the possibility of some error) further investigation by retests or other means should be considered. 
Table 1-14.6A

Expected Minimum Stress-to-Aupture Values, $1000 \mathrm{pst}$ Type 304 SS

\begin{tabular}{|c|c|c|c|c|c|c|c|c|c|c|c|}
\hline Tomp., $F$ & $1 \mathrm{hr}$ & $10 \mathrm{hr}$ & $30 \mathrm{hr}$ & $10^{2} \mathrm{hr}$ & $3 \times 10^{2} \mathrm{hr}$ & $10^{3} \mathrm{hr}$ & $3 \times 10^{3} \mathrm{hr}$ & $10^{\circ} \mathrm{hr}$ & $3 \times 10^{\circ} \mathrm{hr}$ & $10^{5} \mathrm{hr}$ & $3 \times 10^{\circ} \mathrm{hr}$ \\
\hline $\begin{array}{l}800 . \\
850 \\
900\end{array}$ & $\begin{array}{l}57 \\
56.5 \\
55.5\end{array}$ & $\begin{array}{l}57 \\
50.5 \\
55.5\end{array}$ & $\begin{array}{l}57 \\
56.5 \\
55.5\end{array}$ & $\begin{array}{l}57 \\
56.5 \\
55.5\end{array}$ & $\begin{array}{l}57 \\
56.5 \\
51.5\end{array}$ & $\begin{array}{l}57 \\
56.5 \\
46.9\end{array}$ & $\begin{array}{l}57 \\
50.2 \\
41.2\end{array}$ & $\begin{array}{l}57 \\
45.4 \\
36.1\end{array}$ & $\begin{array}{l}31 \\
40 \\
31.5\end{array}$ & $\begin{array}{l}11.3 \\
31.7 \\
27.2\end{array}$ & $\begin{array}{l}39 \\
30.5 \\
24\end{array}$ \\
\hline $\begin{array}{r}950 \\
1000 \\
1050\end{array}$ & $\begin{array}{l}54.2 \\
52.5 \\
50\end{array}$ & $\begin{array}{l}54.2 \\
50 \\
11.9\end{array}$ & $\begin{array}{l}51 \\
41.5 \\
37\end{array}$ & $\begin{array}{l}48.1 \\
39.8 \\
32.9\end{array}$ & $\begin{array}{l}13 \\
35 \\
28.9\end{array}$ & $\begin{array}{l}30.0 \\
30.9 \\
25.0\end{array}$ & $\begin{array}{l}33.5 \\
26.5 \\
21.6\end{array}$ & $\begin{array}{l}20.8 . \\
22.9 \\
10.2\end{array}$ & $\begin{array}{l}24.9 \\
19.7 \\
15.5\end{array}$ & $\begin{array}{l}21.2 \\
16.6 \\
13.0\end{array}$ & $\begin{array}{l}18.3 \\
11.0 \\
11.0\end{array}$ \\
\hline $\begin{array}{l}1100 \\
1150 \\
1200\end{array}$ & $\begin{array}{l}45 \\
38 \\
32\end{array}$ & $\begin{array}{l}35.2 \\
29.5 \\
24.7\end{array}$ & $\begin{array}{l}31 \\
26 \\
21.5\end{array}$ & $\begin{array}{l}27.2 \\
22.5 \\
18.6\end{array}$ & $\begin{array}{l}23.9 \\
19.3 \\
15.9\end{array}$ & $\begin{array}{l}20.3 \\
16.5 \\
13.4\end{array}$ & $\begin{array}{l}17.3 \\
13.9 \\
11.1\end{array}$ & $\begin{array}{r}11.5 \\
11.6 \\
9.2\end{array}$ & $\begin{array}{r}12.3 \\
9.6 \\
7.6\end{array}$ & $\begin{array}{r}11.2 \\
8.0 \\
6.2\end{array}$ & $\begin{array}{l}11.6 \\
6.6 \\
5.0\end{array}$ \\
\hline $\begin{array}{l}1250 \\
1300 \\
1350\end{array}$ & $\begin{array}{l}27 \\
23 \\
19.5\end{array}$ & $\begin{array}{l}20.7 \\
17.4 \\
14.6\end{array}$ & $\begin{array}{l}17.9 \\
15 \\
12.6\end{array}$ & $\begin{array}{l}15.4 \\
12.7 \\
10.6\end{array}$ & $\begin{array}{l}13 \\
10.5 \\
B .8\end{array}$ & $\begin{array}{r}10.8 \\
8.8 \\
7.2\end{array}$ & $\begin{array}{l}0.9 \\
7.2 \\
5.8\end{array}$ & $\begin{array}{l}7.3 \\
5.1 \\
4.6\end{array}$ & $\begin{array}{l}6.0 \\
1.0 \\
3.8\end{array}$ & $\begin{array}{l}1.9 \\
3.0 \\
3.0\end{array}$ & $\begin{array}{l}4.0 \\
3.1 \\
2.4\end{array}$ \\
\hline $\begin{array}{l}1100 \\
1150 \\
1500\end{array}$ & $\begin{array}{l}16.5 \\
14.0 \\
12.0\end{array}$ & $\begin{array}{r}12.1 \\
10.2 \\
8.6\end{array}$ & $\begin{array}{r}10.3 \\
8.0 \\
7.2\end{array}$ & $\begin{array}{l}7.8 \\
7.3 \\
6.0\end{array}$ & $\begin{array}{l}7.2 \\
5.0 \\
4.9\end{array}$ & $\begin{array}{l}5.0 \\
4.6 \\
3.6\end{array}$ & $\begin{array}{l}4.7 \\
3.6 \\
3.0\end{array}$ & $\begin{array}{l}3.7 \\
2.9 \\
2.4\end{array}$ & $\begin{array}{l}3.0 \\
2.3 \\
1.0\end{array}$ & $\begin{array}{l}2.3 \\
1.0 \\
1.4\end{array}$ & $\begin{array}{l}1.9 \\
1.4 \\
1.1\end{array}$ \\
\hline
\end{tabular}

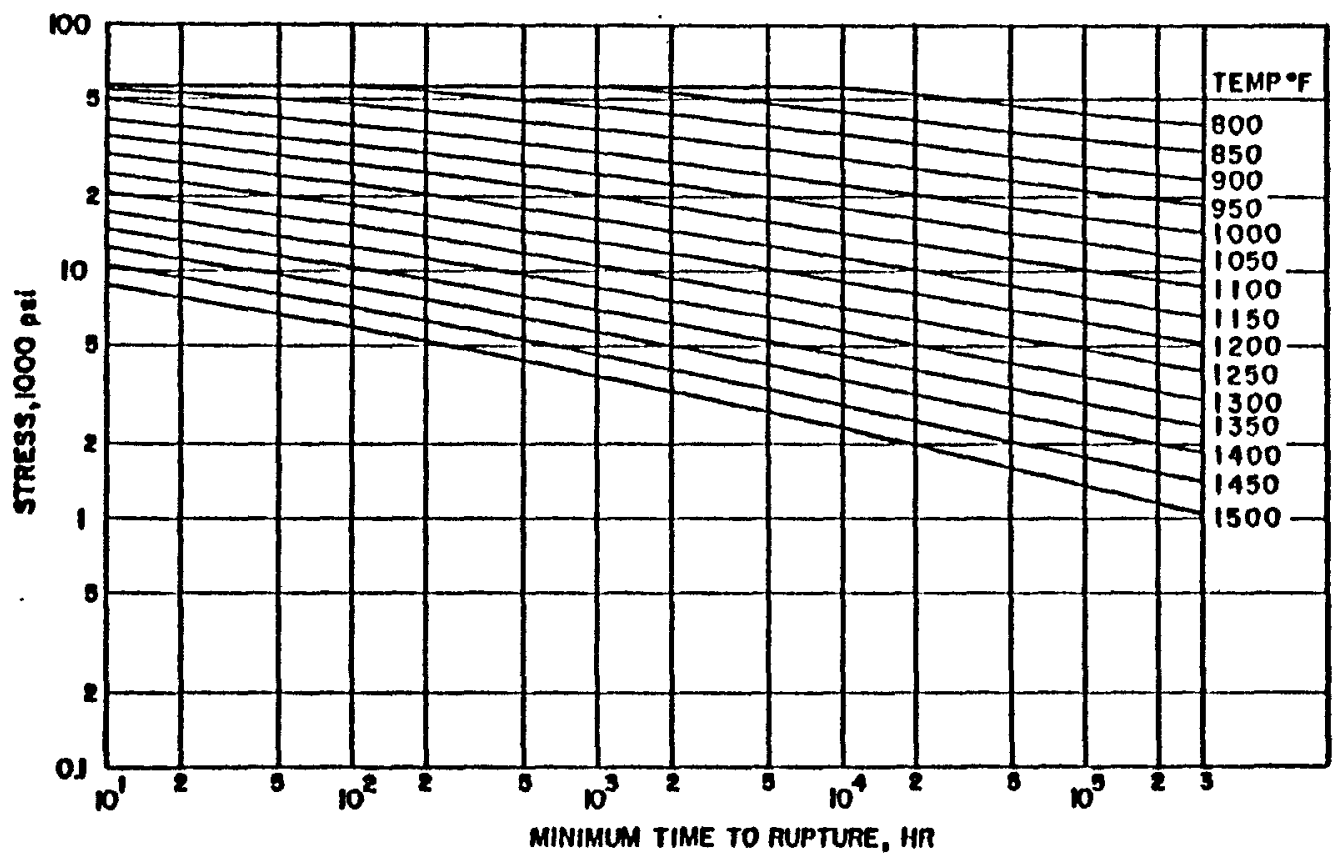

Fig. I-14.6A Stress-to-suplure (minimum) 
Table 1-14.7.

Modulus of Elastieity ve. Temperature

\begin{tabular}{|c|c|c|c|c|}
\hline \multirow[t]{2}{*}{ Tamp., ${ }^{\circ} \mathrm{F}$} & \multicolumn{4}{|c|}{ (Statie) Modulus of Elasticity, pri $\times 10^{-4}$} \\
\hline & 304 SS and 316 SS & $\begin{array}{l}\text { Ni-Fe-Cr } \\
\text { Alloy } 800 \mathrm{H}\end{array}$ & $2 \% \mathrm{Cr}-9 \mathrm{Mo}$ & $\begin{array}{l}\text { Ni-Cr-Fo-Cb } \\
\text { Alloy } 718\end{array}$ \\
\hline $\begin{array}{r}70 \\
100 \\
200 \\
300 \\
400 \\
500 \\
600\end{array}$ & $\begin{array}{c}28.3 \\
- \\
27.7 \\
27.1 \\
26.6 \\
26.1 \\
25.4\end{array}$ & $\begin{array}{c}28.5 \\
- \\
27.8 \\
27.3 \\
20.8 \\
26.3 \\
25.7\end{array}$ & $\begin{array}{c}29.9 \\
- \\
29.5 \\
29.0 \\
28.6 \\
28.0 \\
27.4\end{array}$ & $\begin{array}{l}-\overline{29.0} \\
28.38 \\
27.93 \\
27.51 \\
27.10 \\
26.69\end{array}$ \\
\hline $\begin{array}{r}700 \\
750 \\
800 \\
850 \\
900 \\
950 \\
1000\end{array}$ & $\begin{array}{l}24.8 \\
-\overline{-1} \\
24.1 \\
23.7 \\
23.3- \\
22.9 \\
22.5\end{array}$ & $\begin{array}{l}25.2 \\
24.6 \\
24.4 \\
24.1 \\
23.8 \\
23.5\end{array}$ & $\begin{array}{c}26.6 \\
\overline{25.7} \\
\overline{24.5} \\
\overline{23.0}\end{array}$ & $\begin{array}{c}26.26 \\
- \\
25.82 \\
- \\
25.35 \\
\overline{24.84}\end{array}$ \\
\hline $\begin{array}{l}1050 \\
1100 \\
1150 \\
1200 \\
1250 \\
1300 \\
1350 \\
1400\end{array}$ & $\begin{array}{l}22.1 \\
21.7 \\
21.3 \\
20.9 \\
20.5 \\
20.1 \\
19.7 \\
19.2 \\
\end{array}$ & $\begin{array}{l}23.3 \\
22.9 \\
22.7 \\
22.4 \\
22.1 \\
21.7 \\
21.4 \\
21.1 .\end{array}$ & $\begin{array}{c}\overline{20.4} \\
\overline{15.6}\end{array}$ & 24.56 \\
\hline $\begin{array}{l}1450 \\
1500 \\
1550 \\
1600\end{array}$ & $\begin{array}{l}18.7 \\
18.3\end{array}$ & $\begin{array}{l}20.7 \\
20.3 \\
19.8 \\
19.2\end{array}$ & & \\
\hline
\end{tabular}


CASE

$\mathrm{N}-47$

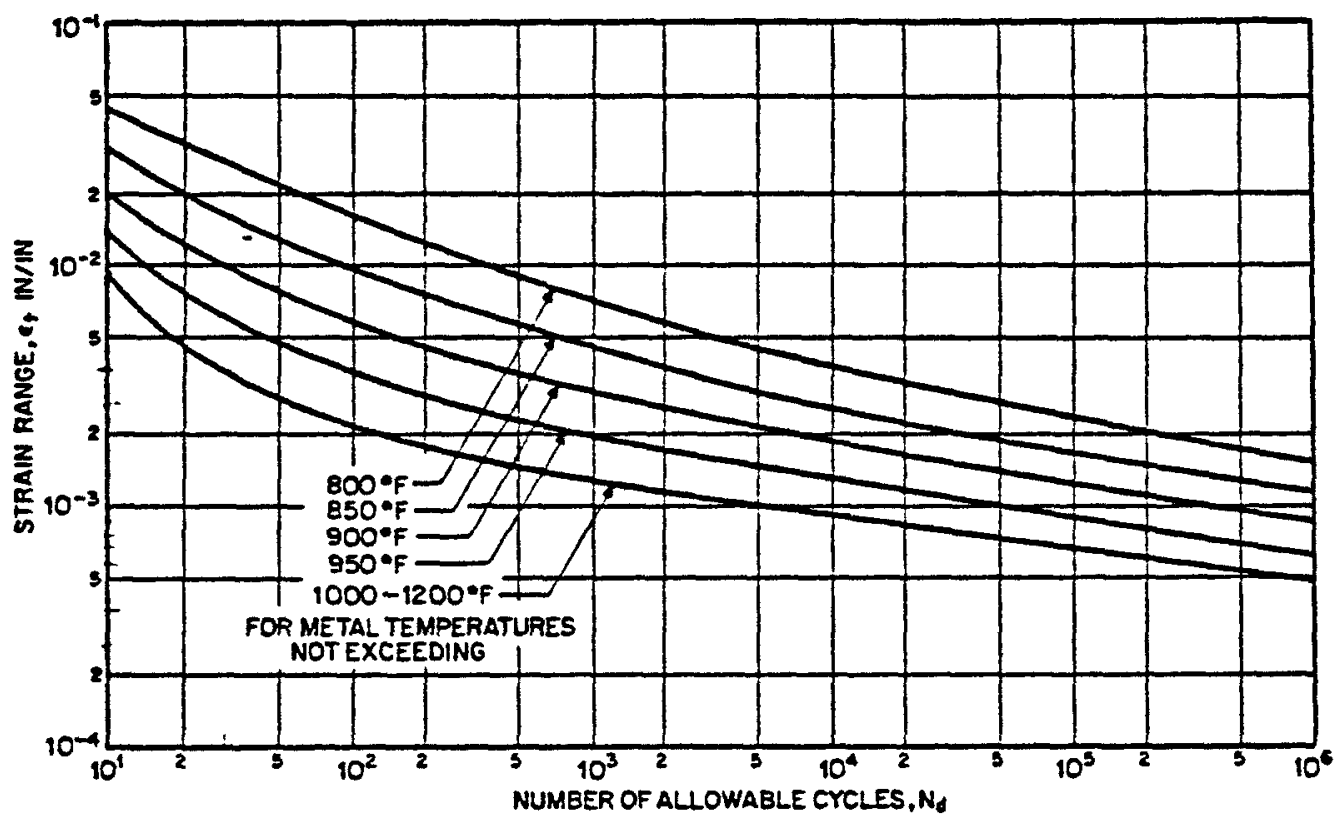

N266SR000002 59

Fig. T-1430-1A,1B Design tatigue strain range, $C_{7}, 304$ SS and 316 SS -lastic analysis

Table T-1430-1A, 1B

Design Fatigue Strain Range, $\epsilon_{t}$, for 304 SS and 316 SS

(Elastic Analysis)

\begin{tabular}{|c|c|c|c|c|c|}
\hline \multirow{2}{*}{$\begin{array}{c}\text { No } \\
\text { Number } \\
\text { of } \\
\text { Cyeles }\end{array}$} & \multicolumn{5}{|c|}{$e_{t}$, Strain Range (in./in.) at Temperature } \\
\hline & $800 \mathrm{~F}$ & $850 \mathrm{~F}$ & $900 \mathrm{~F}$ & $950 \mathrm{~F}$ & $1000-1200 \mathrm{~F}$ \\
\hline $\begin{array}{r}10^{1} \\
2 \times 10^{2} \\
4 \times 10^{2}\end{array}$ & $\begin{array}{l}.0448 \\
.0318 \\
.0231\end{array}$ & $\begin{array}{l}.0303 \\
.020 \\
.0145\end{array}$ & $\begin{array}{l}.0201 \\
.0124 \\
.00867\end{array}$ & $\begin{array}{l}.0137 \\
.0078 \\
.0051\end{array}$ & $\begin{array}{l}.00915 \\
.00472 \\
.00322\end{array}$ \\
\hline $\begin{array}{r}10^{2} \\
2 \times 10^{2} \\
4 \times 10^{2}\end{array}$ & $\begin{array}{l}.0168 \\
.0125 \\
.00956\end{array}$ & $\begin{array}{l}.00982 \\
.00772 \\
.00612\end{array}$ & $\begin{array}{l}.00587 \\
.00469 \\
.00387\end{array}$ & $\begin{array}{l}.00355 \\
.0028 \\
.0024\end{array}$ & $\begin{array}{l}.00212 \\
.00174 \\
.00152\end{array}$ \\
\hline $\begin{array}{r}10^{3} \\
2 \times 10^{3} \\
4 \times 10^{3}\end{array}$ & $\begin{array}{l}.00711 \\
.00576 \\
.00476\end{array}$ & $\begin{array}{l}.00462 \\
.00382 \\
.00322\end{array}$ & $\begin{array}{l}.00304 \\
.00257 \\
.00222\end{array}$ & $\begin{array}{l}.00198 \\
.00173 \\
.00153\end{array}$ & $\begin{array}{l}.00129 \\
.00114 \\
.00104\end{array}$ \\
\hline $\begin{array}{r}10^{4} \\
2 \times 10^{4} \\
4 \times 10^{4}\end{array}$ & $\begin{array}{l}.00376 \\
.00316 \\
.00269\end{array}$ & $\begin{array}{l}.00261 \\
.00222 \\
.00202\end{array}$ & $\begin{array}{l}.00186 \\
.00164 \\
.00144\end{array}$ & $\begin{array}{l}.0013 \\
.00116 \\
.00106\end{array}$ & $\begin{array}{l}.000922 \\
.000842 \\
.000762\end{array}$ \\
\hline $\begin{array}{r}10^{3} \\
2 \times 10^{8} \\
4 \times 10^{4}\end{array}$ & $\begin{array}{l}.00224 \\
.00196 \\
.00176\end{array}$ & $\begin{array}{l}.00162 \\
.00147 \\
.00131\end{array}$ & $\begin{array}{l}.00122 \\
.00108 \\
.000966\end{array}$ & $\begin{array}{l}.000899 \\
.000799 \\
.000719\end{array}$ & $\begin{array}{l}.000662 \\
.000602 \\
.000544\end{array}$ \\
\hline $10^{6}$ & .00151 & .00112 & .000826 & .000619 & .000482 \\
\hline
\end{tabular}


CASE (continued) $N-47$

$(1592-10)$
N266SR000002

60

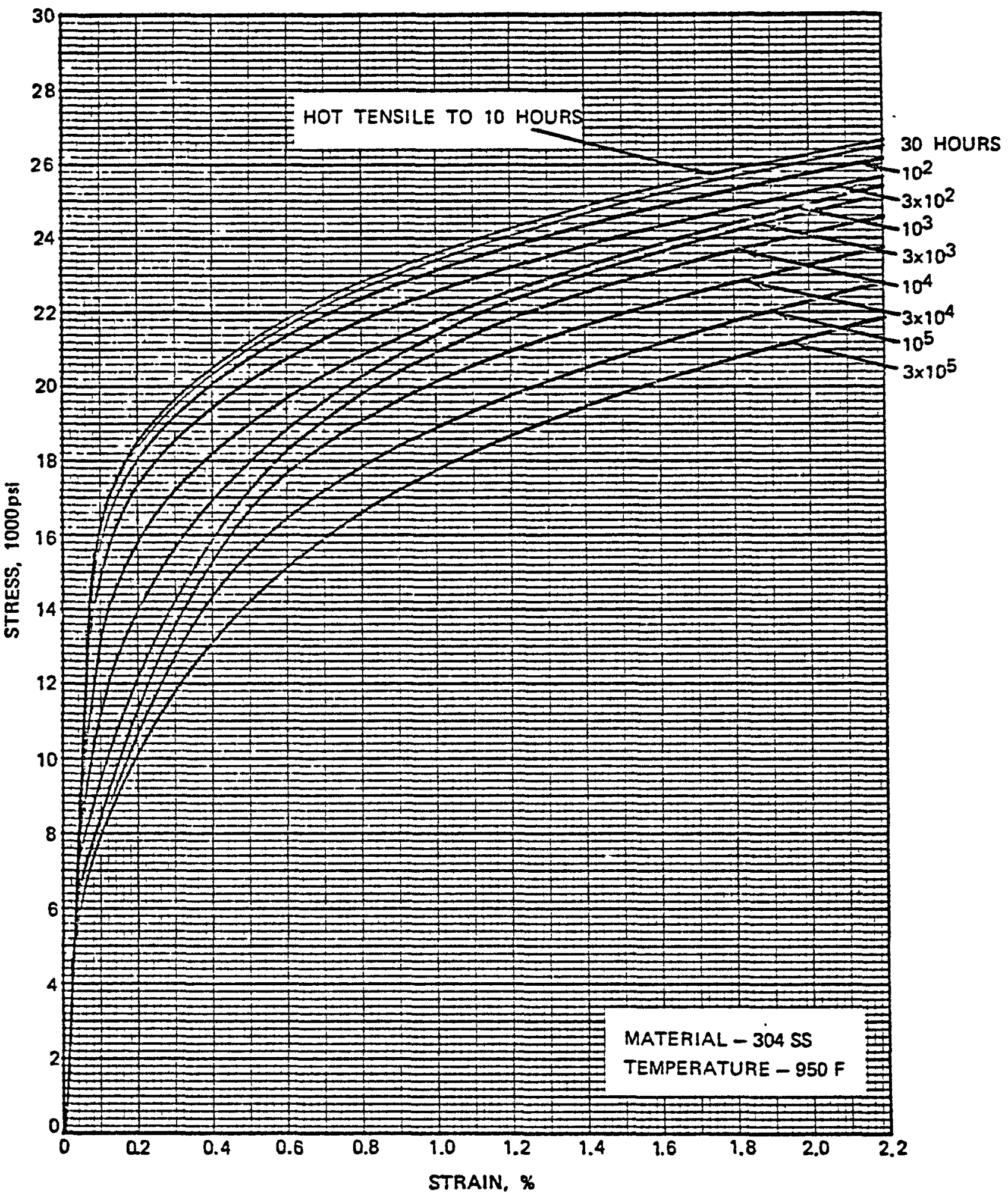

Fig. T-1800-A-4 Averege isochronous strestrain curwe 


\section{APPENDIX B}

THERMAL DEFORMATION ANALYSIS

\section{Figure}

B-1 APSA Model for Static Assembly

B-2 APSA Model for Rotating Assembly

B-3 Finite Element Model B Bearing Area - Node No.

B-4 Finite Element Model o Bearing Area - Element No.

B-5 Finite Element Model o Bearing Area - Node No.

B-6 Finite Element Model o Bearing Area - Element No. 
The finite element computer program (APSA) has been used to determine the deflection of pump component during thermal transient events. As descrilued in Section 3 of this report, the worst-time slices with maximum temperature difference $(\Delta T)$ were obtained through the iteration of the temperature time-history process. The worst-time slices for each transient were used in the stress-deformation model to determine the clearance change between all critical components. Figure B-1 through Figure B-12 showed the APSA stress model of nodes and element for various parts of the inducer-impeller assembly. Table B-I through Table B-36 indicated the calculation of clearance from computer output for pump elements. 
N266ER000-001

Page 431

N266SR000002

62

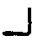

INTEPEEDIA SOOIUM INOUCER PUPP - BOLL (APSA MOOEL)

-0719083 L

UNDEF ORMED STRUCTURE

AXISTMETRIC ANALYSIS

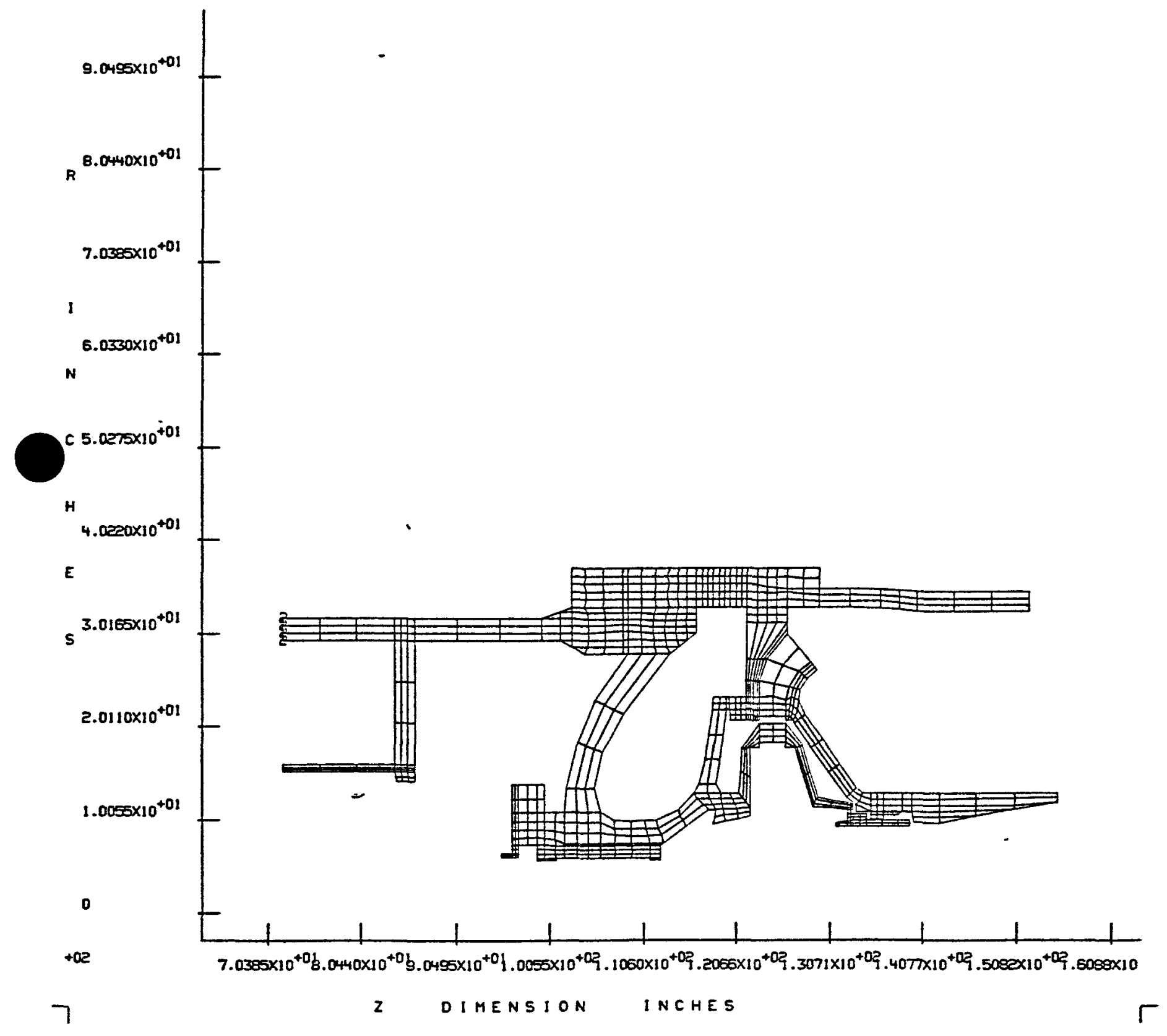

FIG B-I APSA MODEL

STATIC ASSEMBLY 
$-1,11$,

$\bullet$

$\downarrow$

INTEREOIATE SOOIUM INOUCER PUP T PUP SHAT REGION

UNDEFORMED STRUCTURE
N266ER000-001.

Page 432

N266SR000002 63

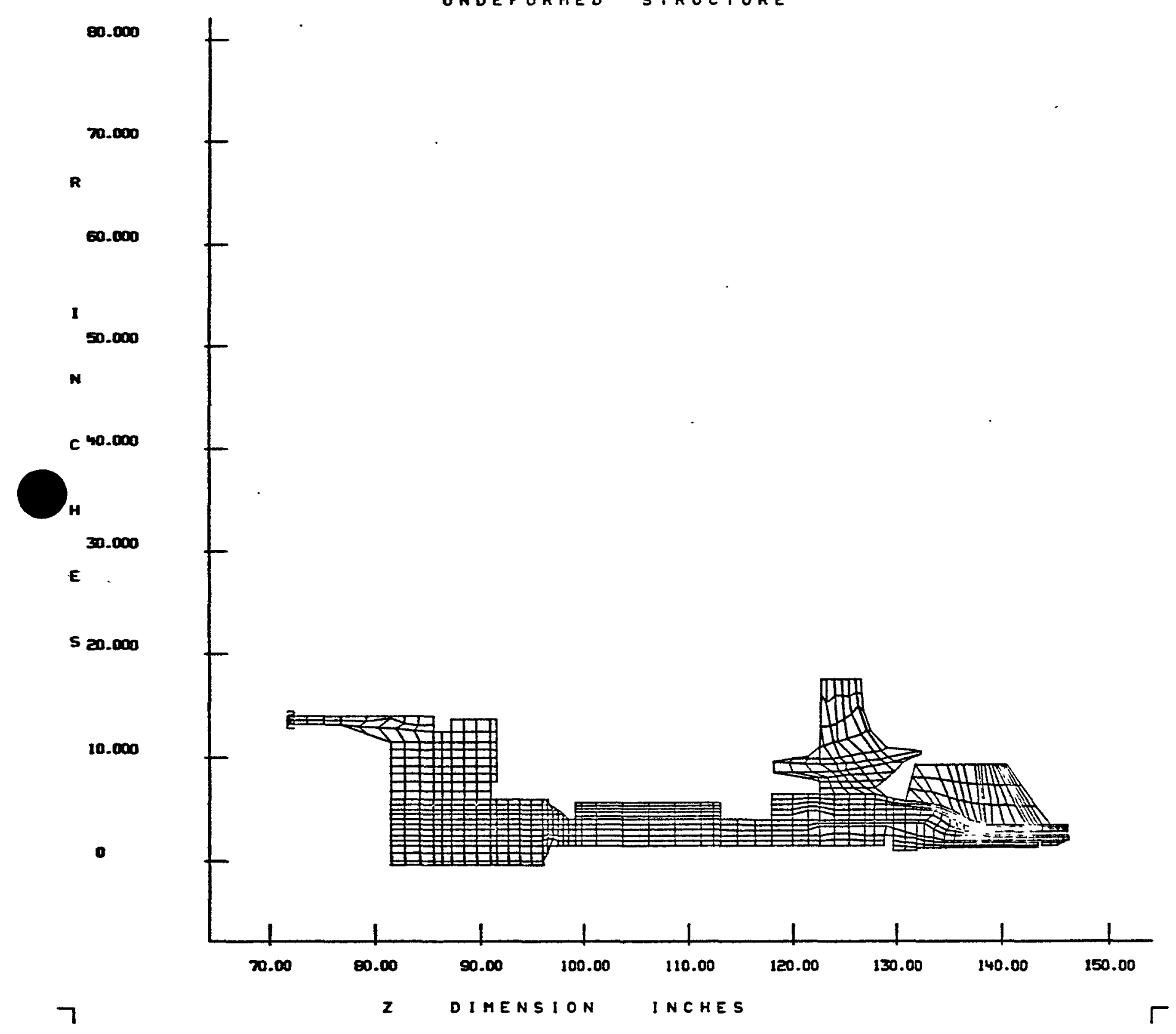

FIG. B-2 APSA MODEL 
PAGE

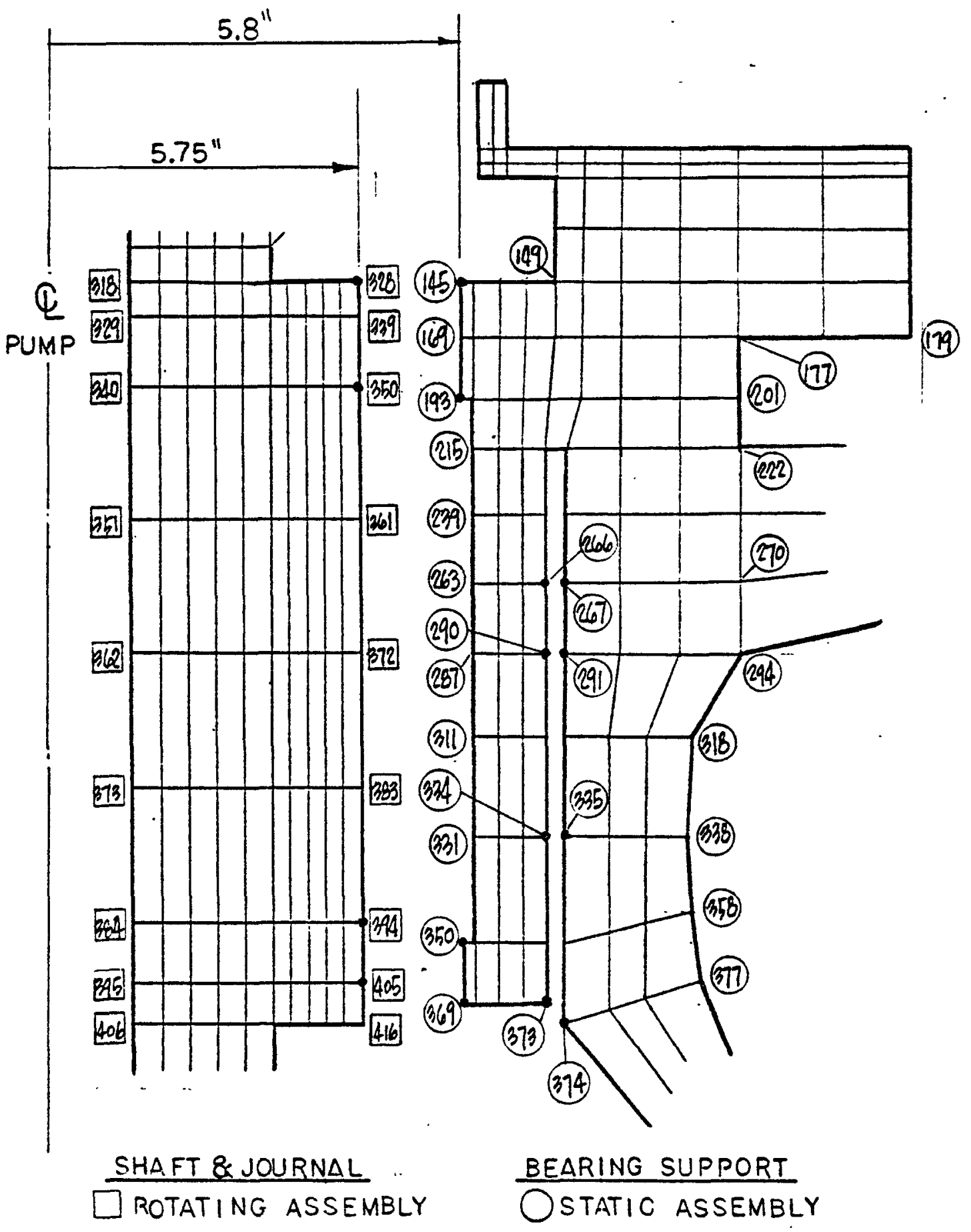

\section{FIG.B3 FINITE ELEMENT. MODEL NODE POINT NUMBER}




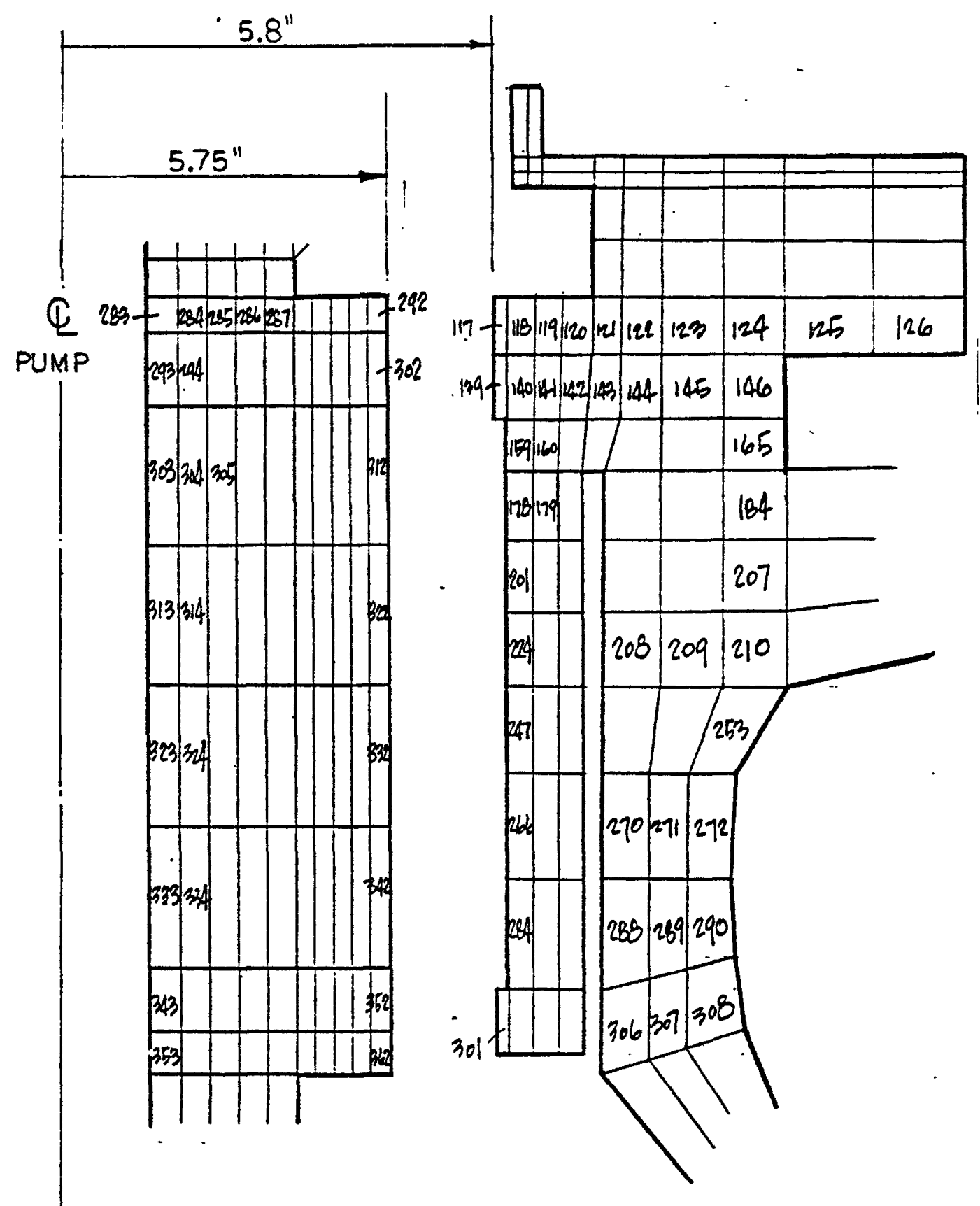

SHAFT \& JOURNAL ROTATING ASSEMBLY
BEARING SUPPORT

STATIC ASSEMBLY

FIG.B.4 FINITE ELEMENT MODEL 

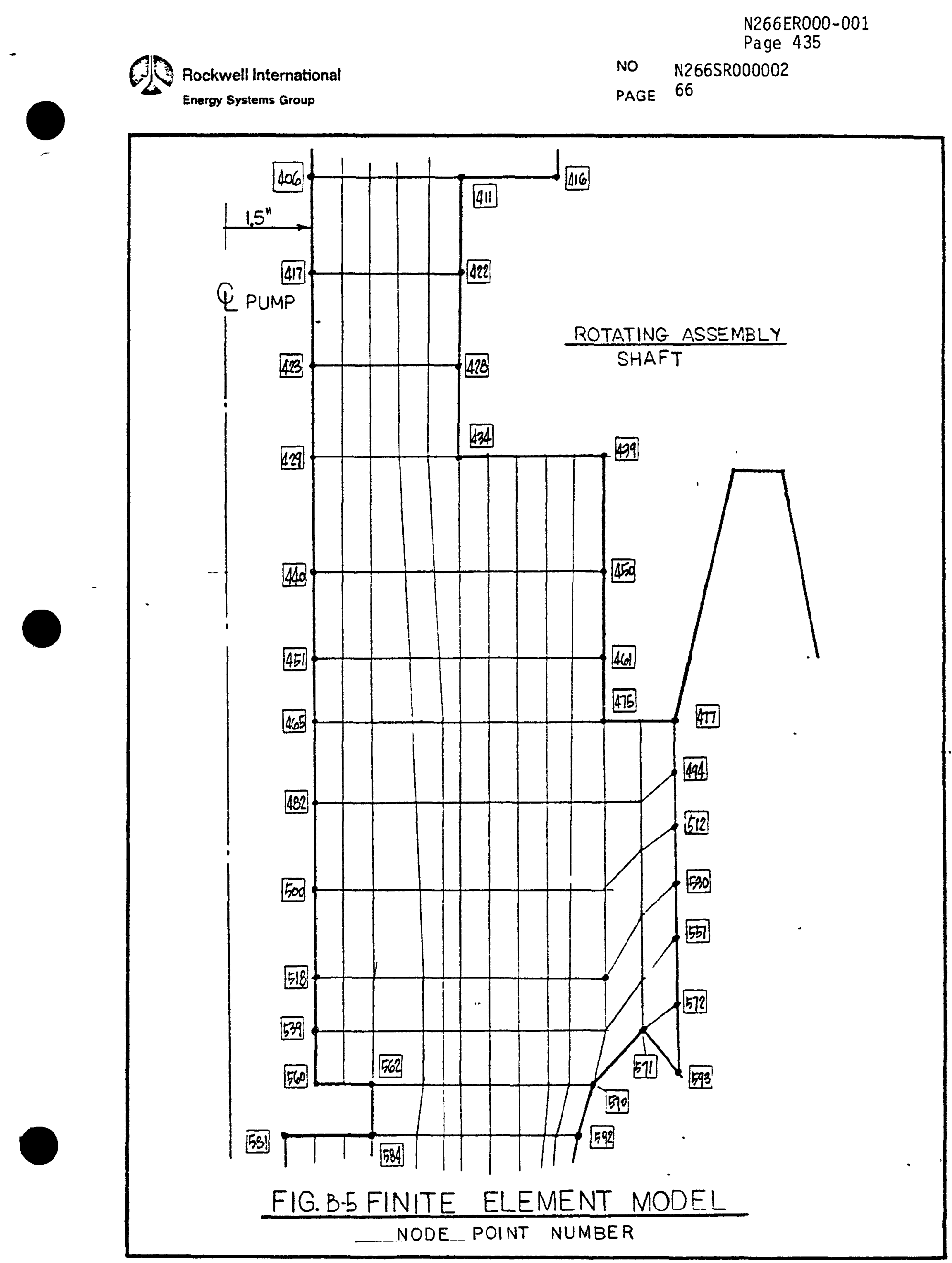


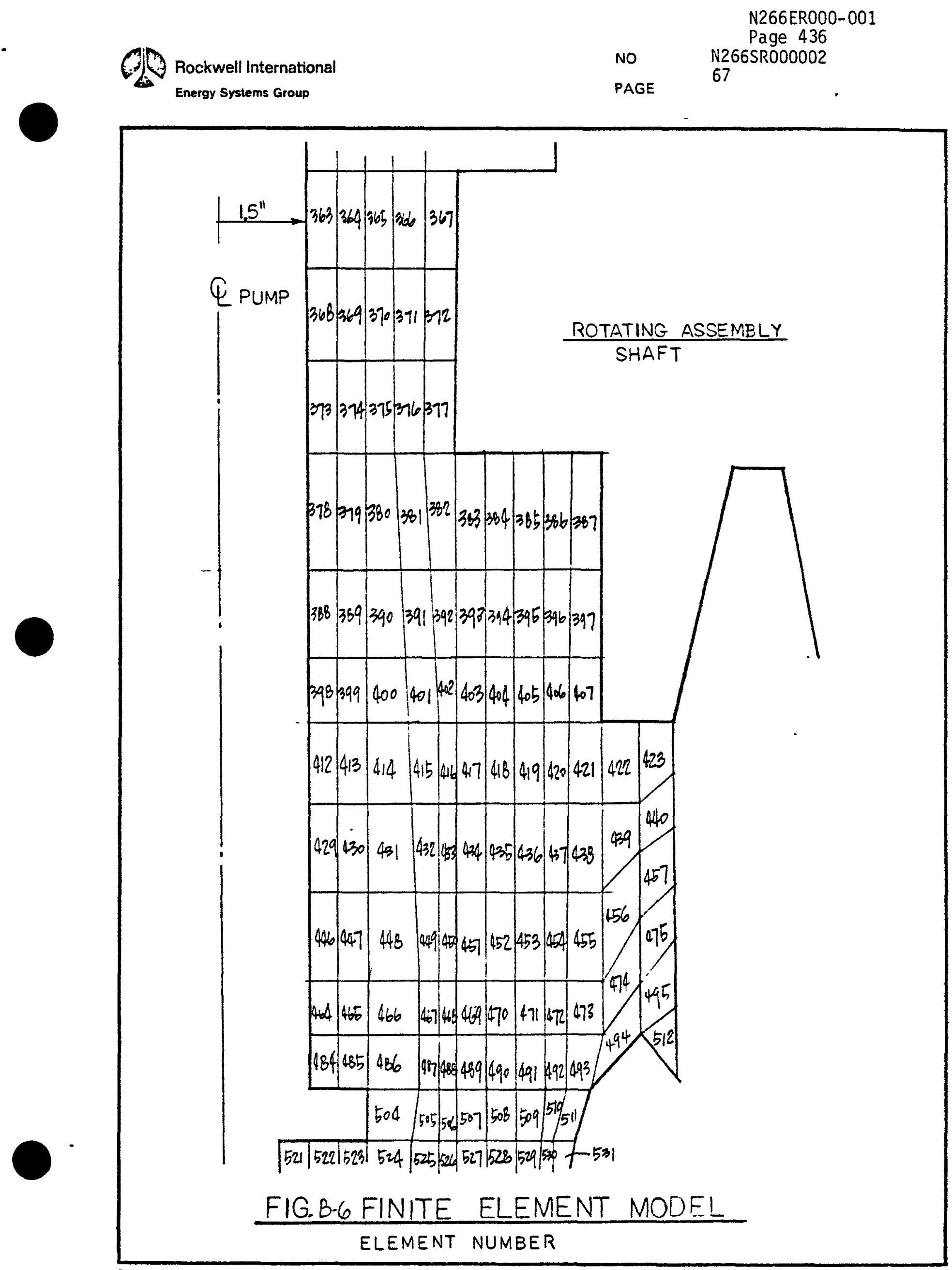



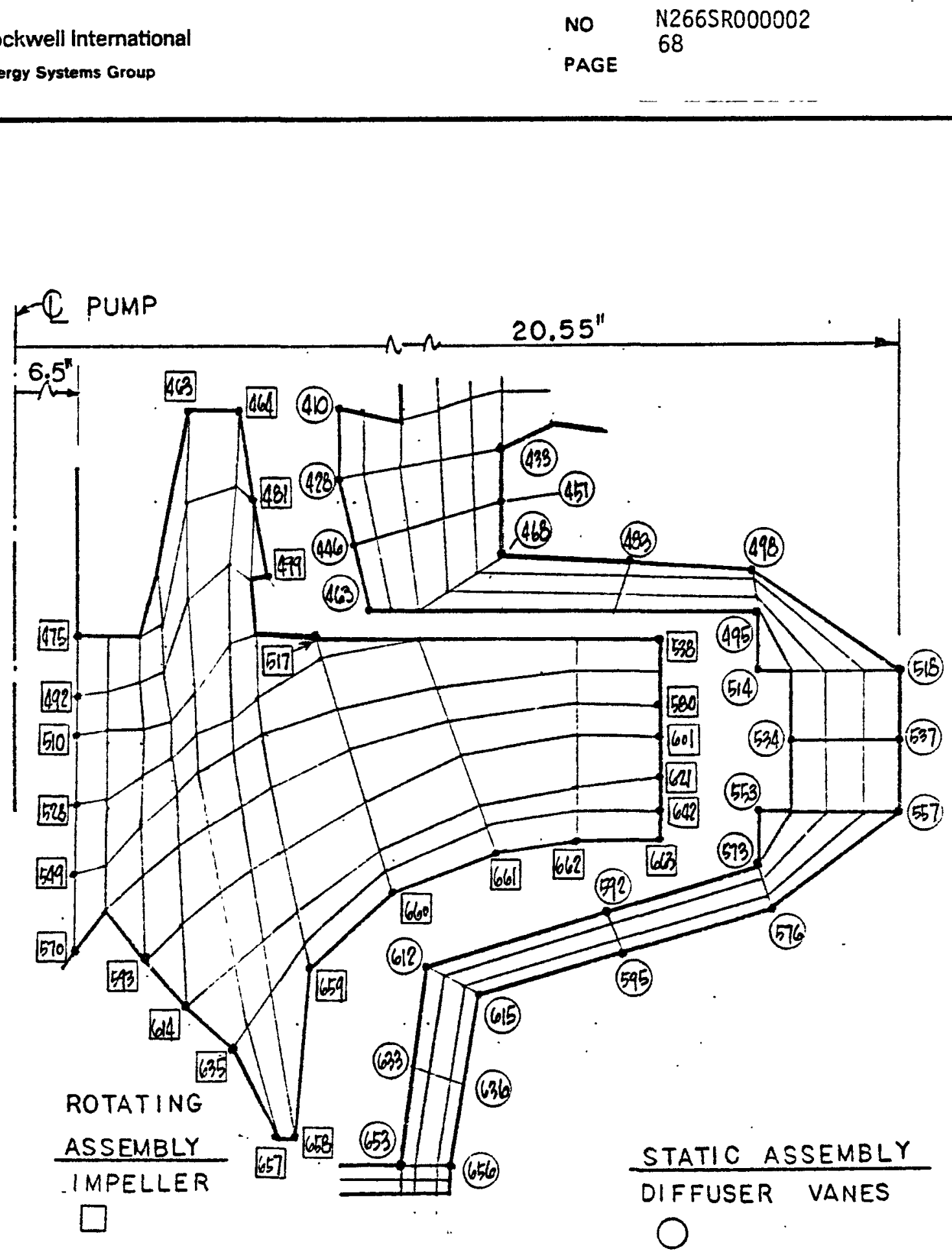

FIG. B-7 FINITE ELEMENT MODEL NODE POINT NUMBER 


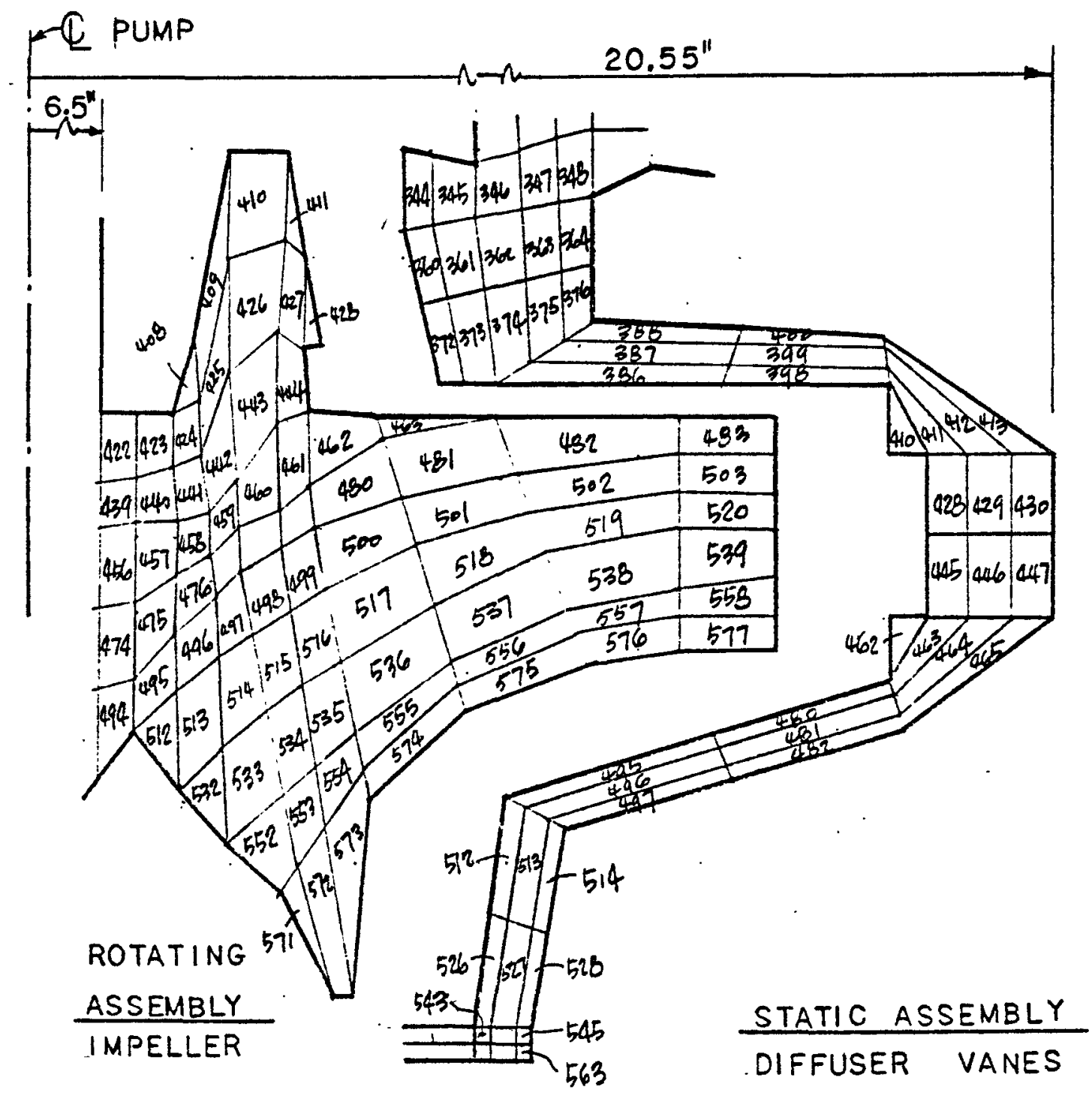

FIG.B.8 FINITE ELEMENT MODEL ELEMENT NUMBER 


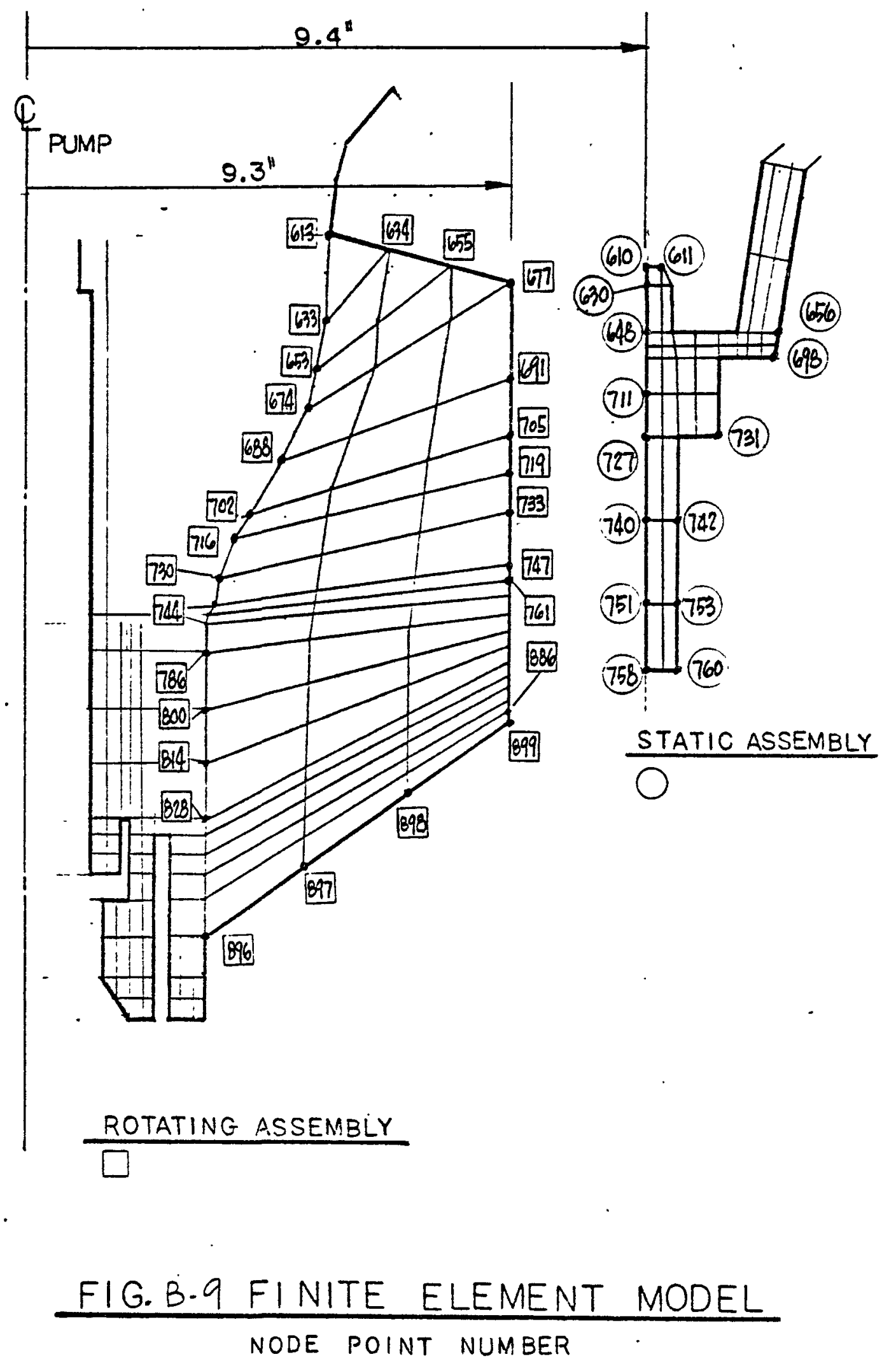




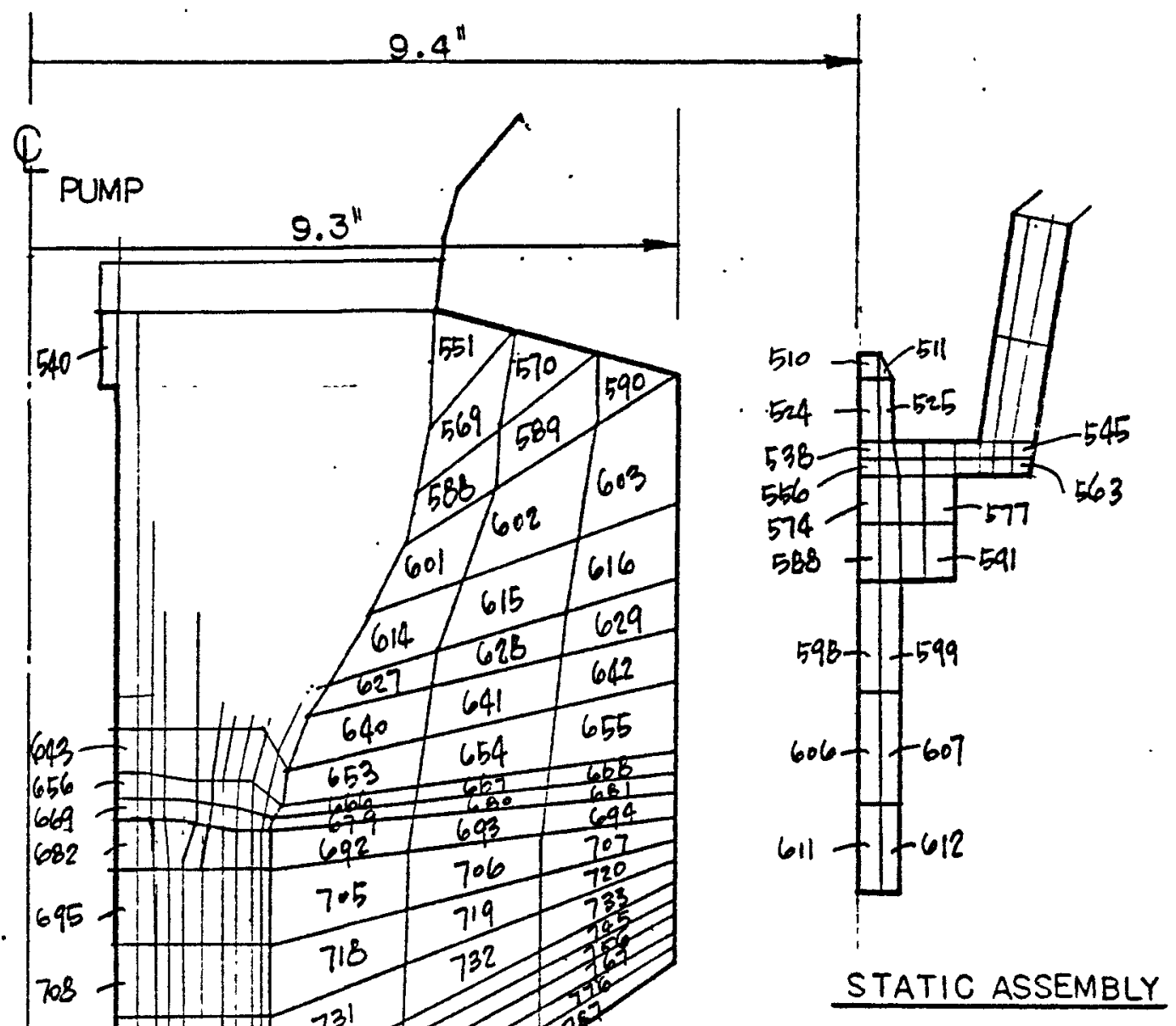

ROTATING ASSEMBL̈Y

FIG.B.10 FINITE ELEMENT MODEL

ELEMENT NUMBER 


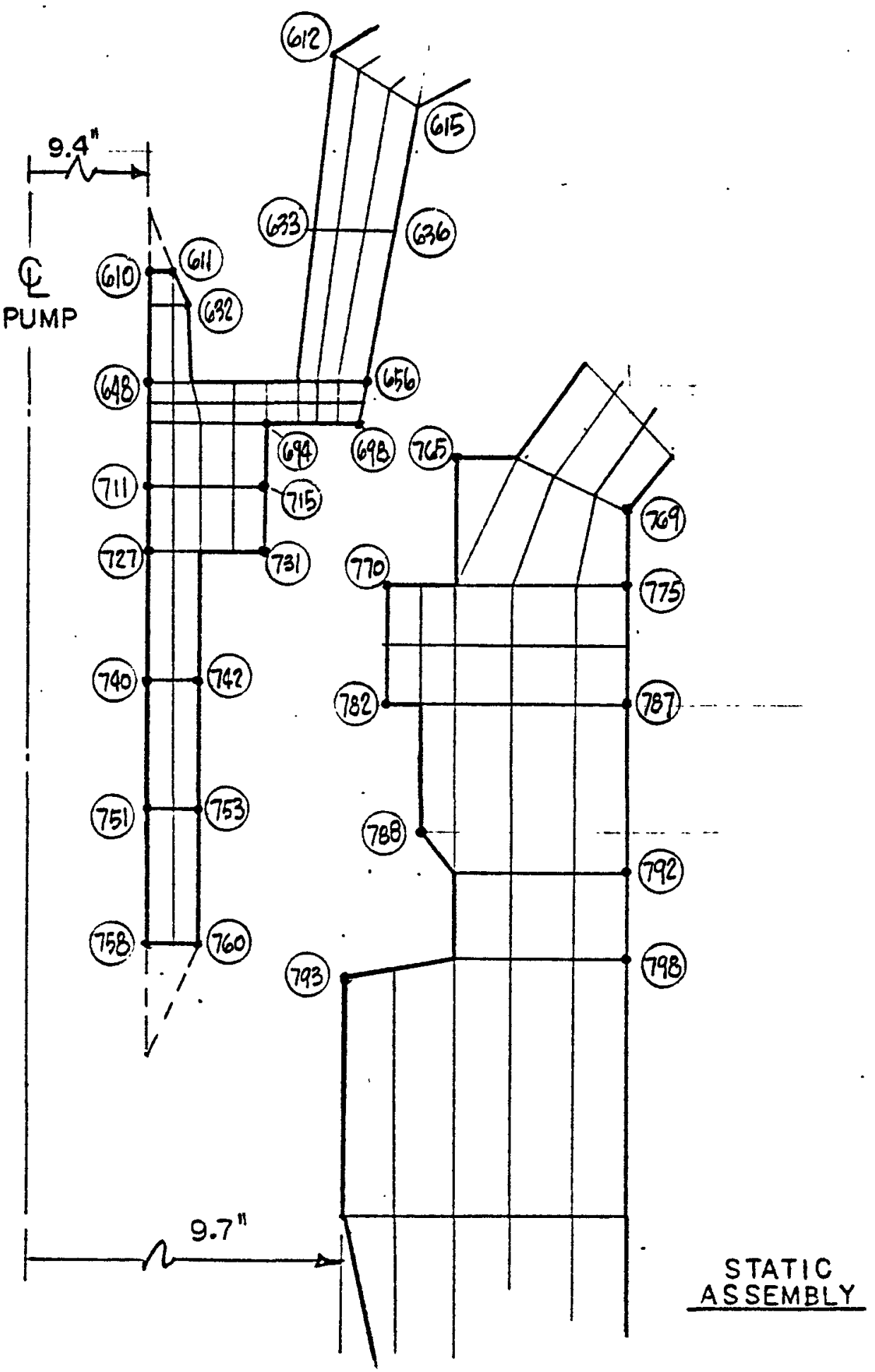

FIG.B-II FINITE ELEMENT MODEL NODE POINT NUMBER 


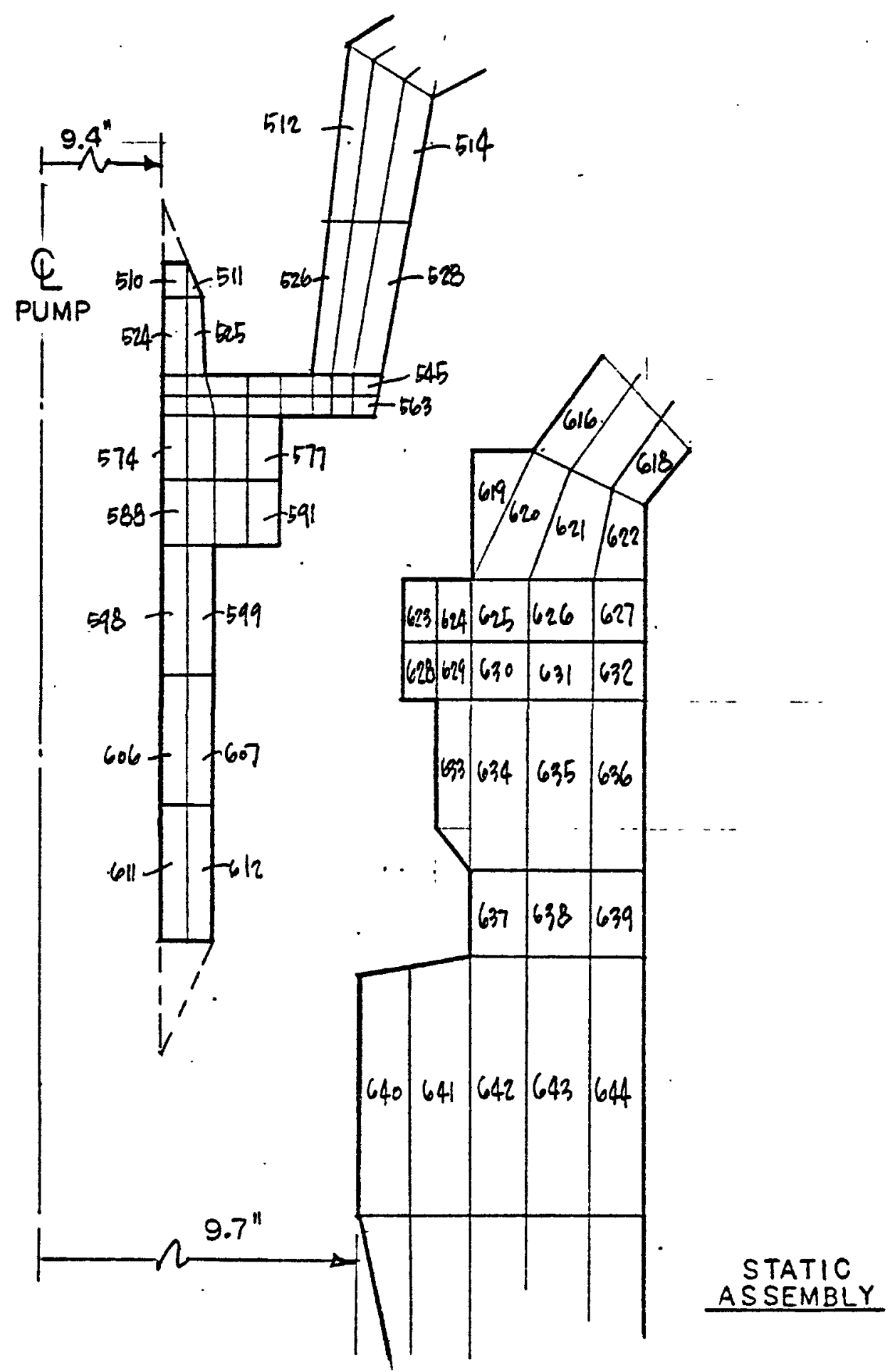

FIG.B-12 FINITE ELEMENT MODEL ELEMENT NUMBER 


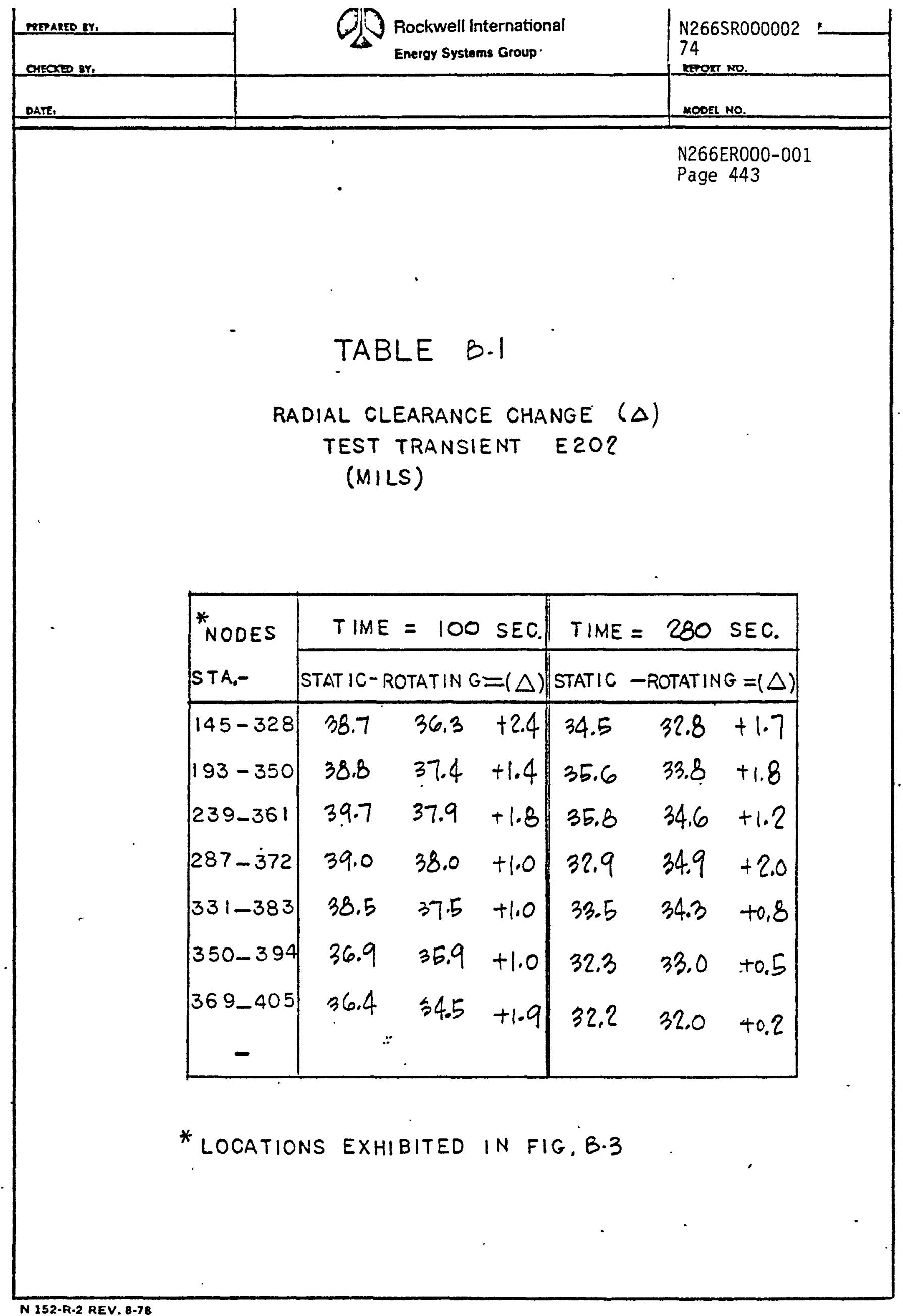




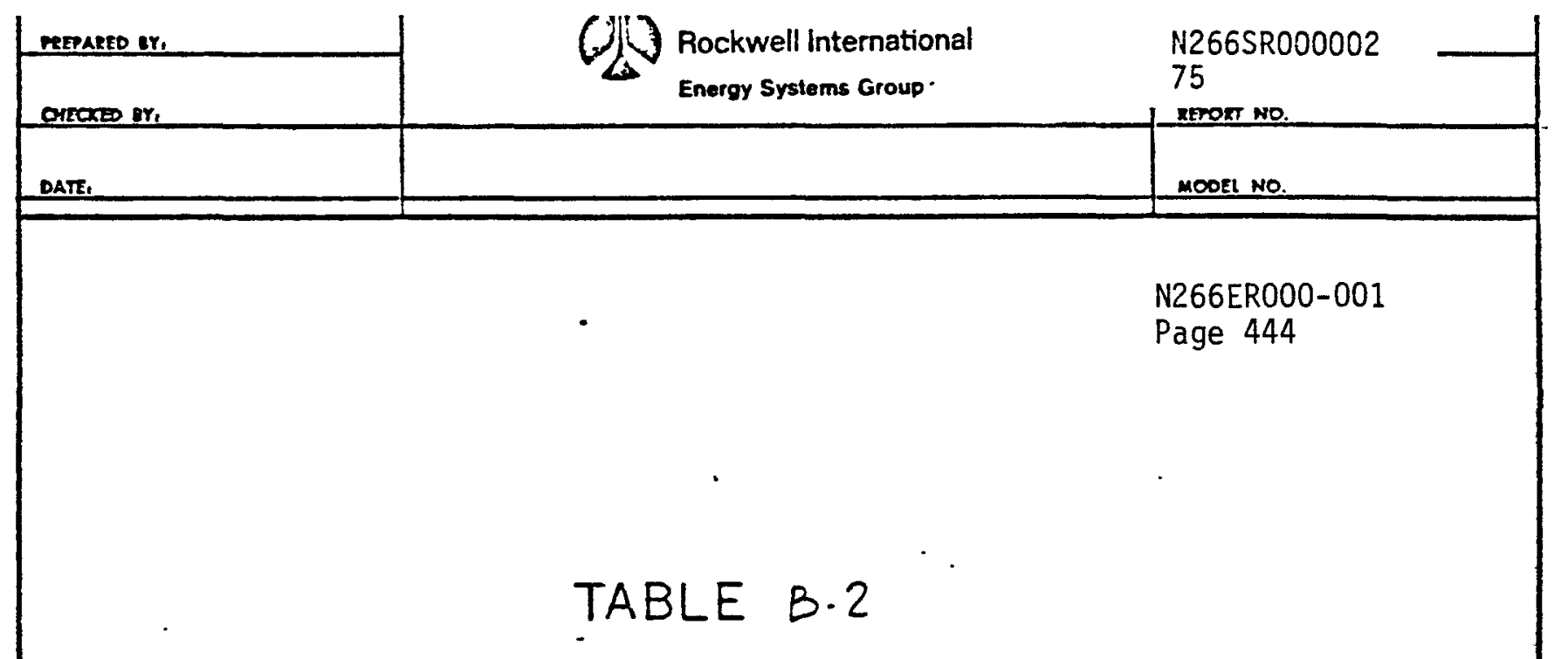

RADIAL CLEARANCE CHANGE $(\Delta)$

TEST TRANSIENT EZO3

(MILS)

\begin{tabular}{|c|c|c|c|c|c|c|}
\hline \multirow{2}{*}{$\begin{array}{l}\text { *NODES } \\
\text { STA.- }\end{array}$} & \multicolumn{3}{|c|}{$T I M E=100$} & \multicolumn{2}{|c|}{ TIME $=280$} & SEC. \\
\hline & \multicolumn{3}{|c|}{ STATIC-ROTATIN G $=(\triangle)$} & \multicolumn{3}{|c|}{ STATIC - ROTATING $=(\triangle)$} \\
\hline $145-328$ & 24.9 & 26.6 & -1.7 & 29.0 & 30.1 & -1.1 \\
\hline $193-350$ & 24.8 & 25.5 & -0.7 & 27.9 & 29.0 & -1.1 \\
\hline $239-361$ & 26.0 & 25.1 & $+0,9$ & 29.8 & 28.3 & -1.5 \\
\hline $287-\dot{3} 72$ & 26.7 & 25.0 & +1.7 & 31.6 & 28.0 & +3.6 \\
\hline $331-383$ & 27.2 & 25.4 & +1.8 & 32.2 & 28.5 & +3.7 \\
\hline $350-394$ & 26.6 & 27.0 & $-0,4$ & 31.1 & 29.9 & +1.2 \\
\hline $369-405$ & 27.1 & $2 B .4$ & -1.3 & 31.2 & 30.9 & +0.3 \\
\hline
\end{tabular}

* locations exhibited in fig. B.3 


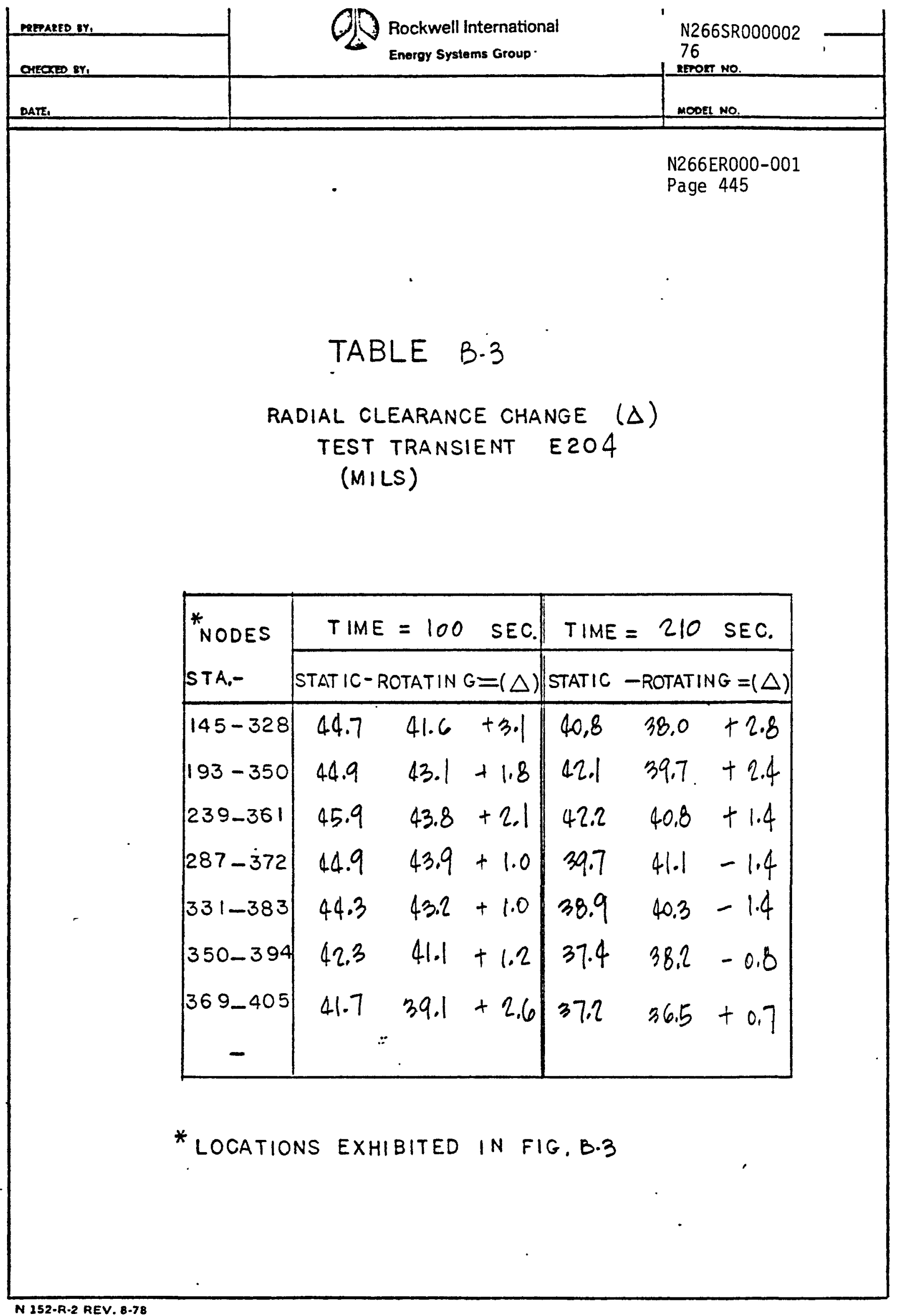




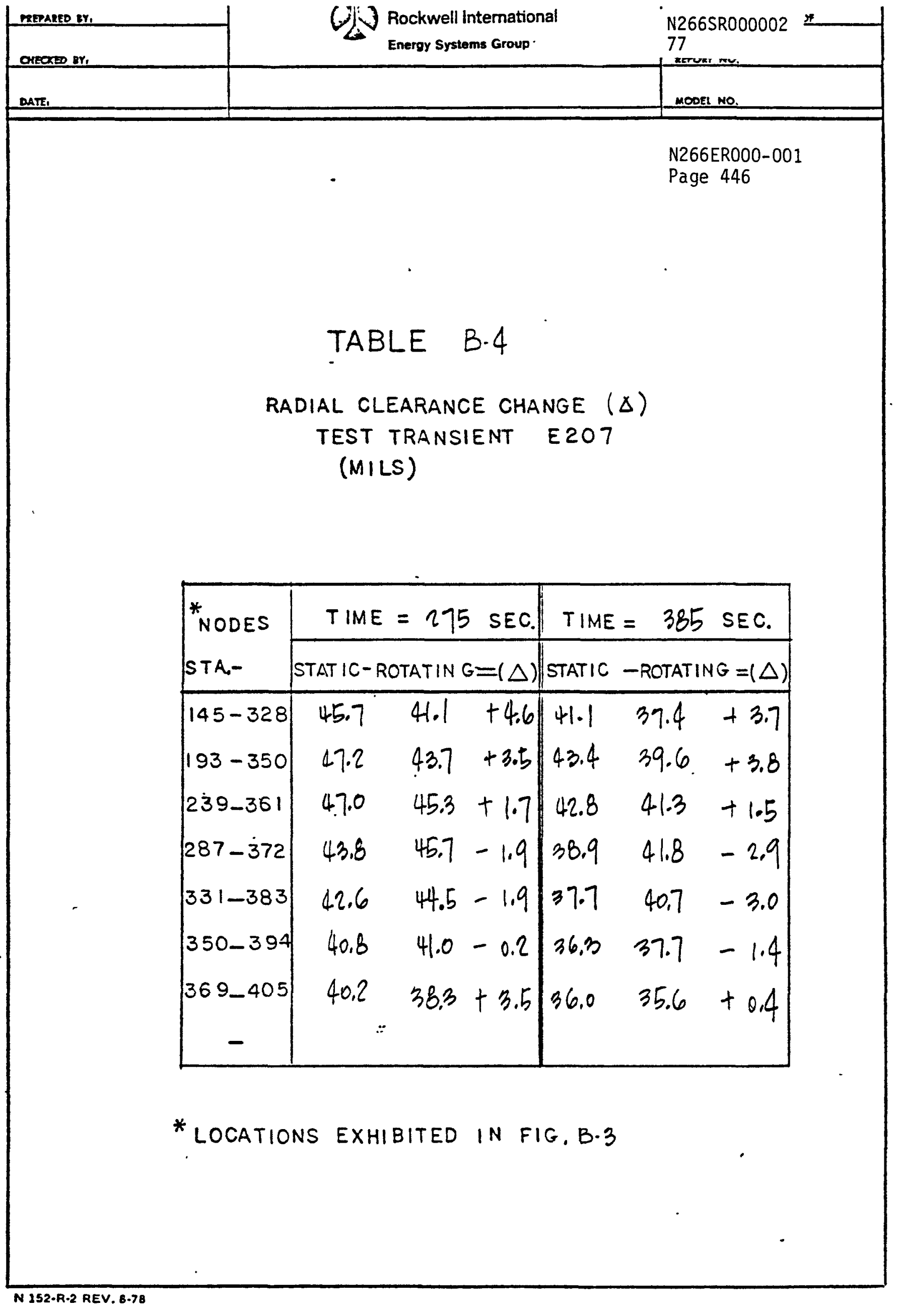




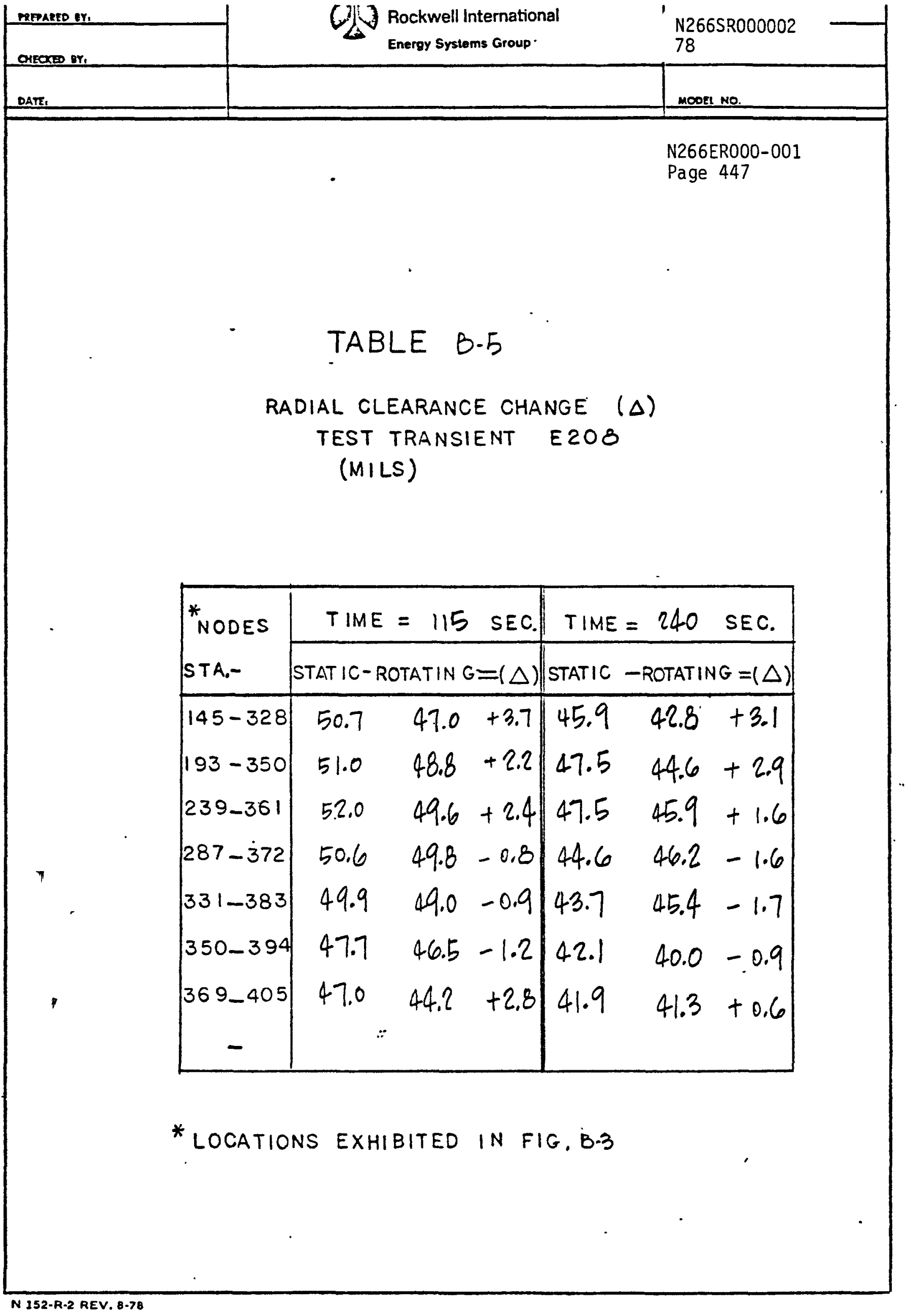




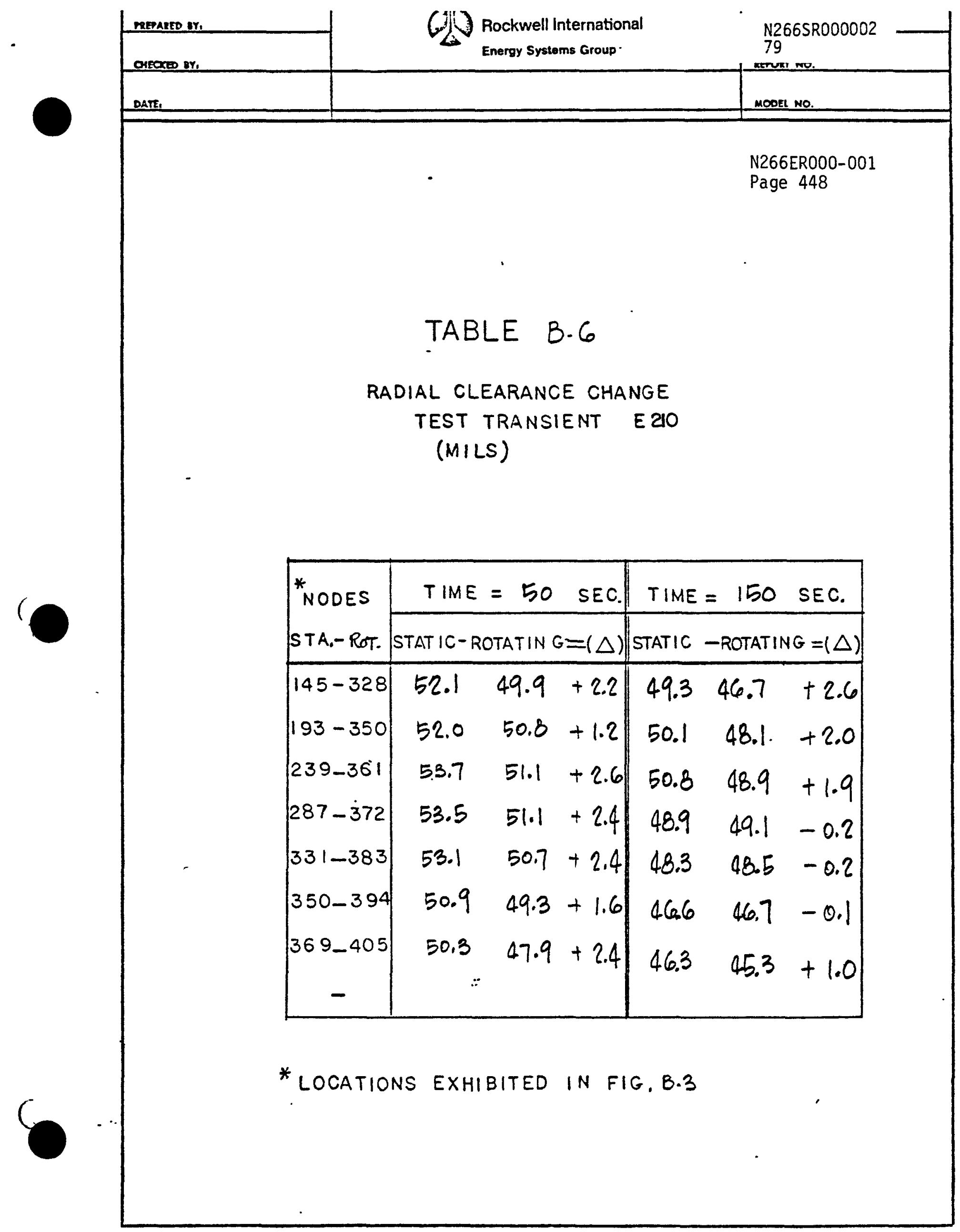




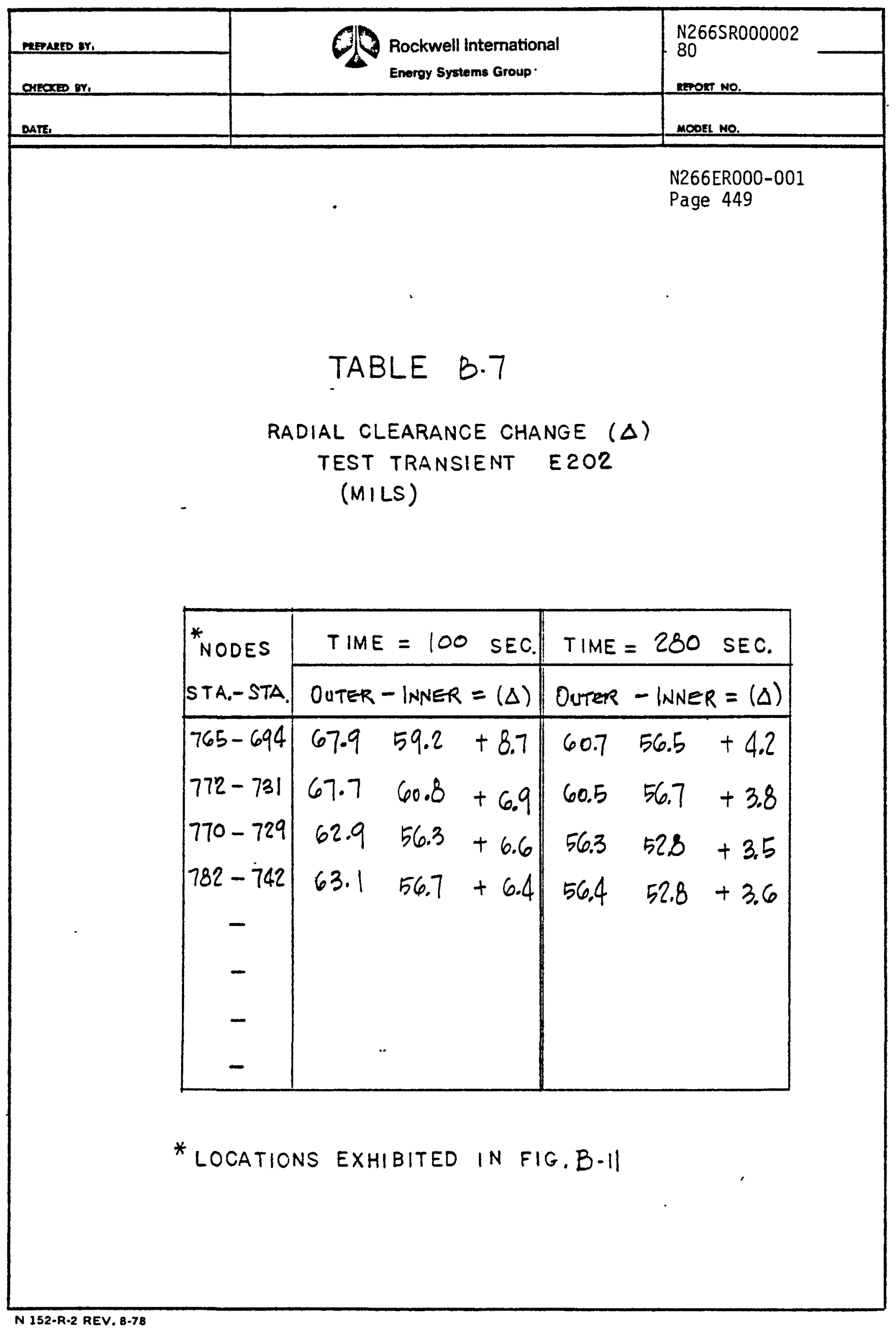




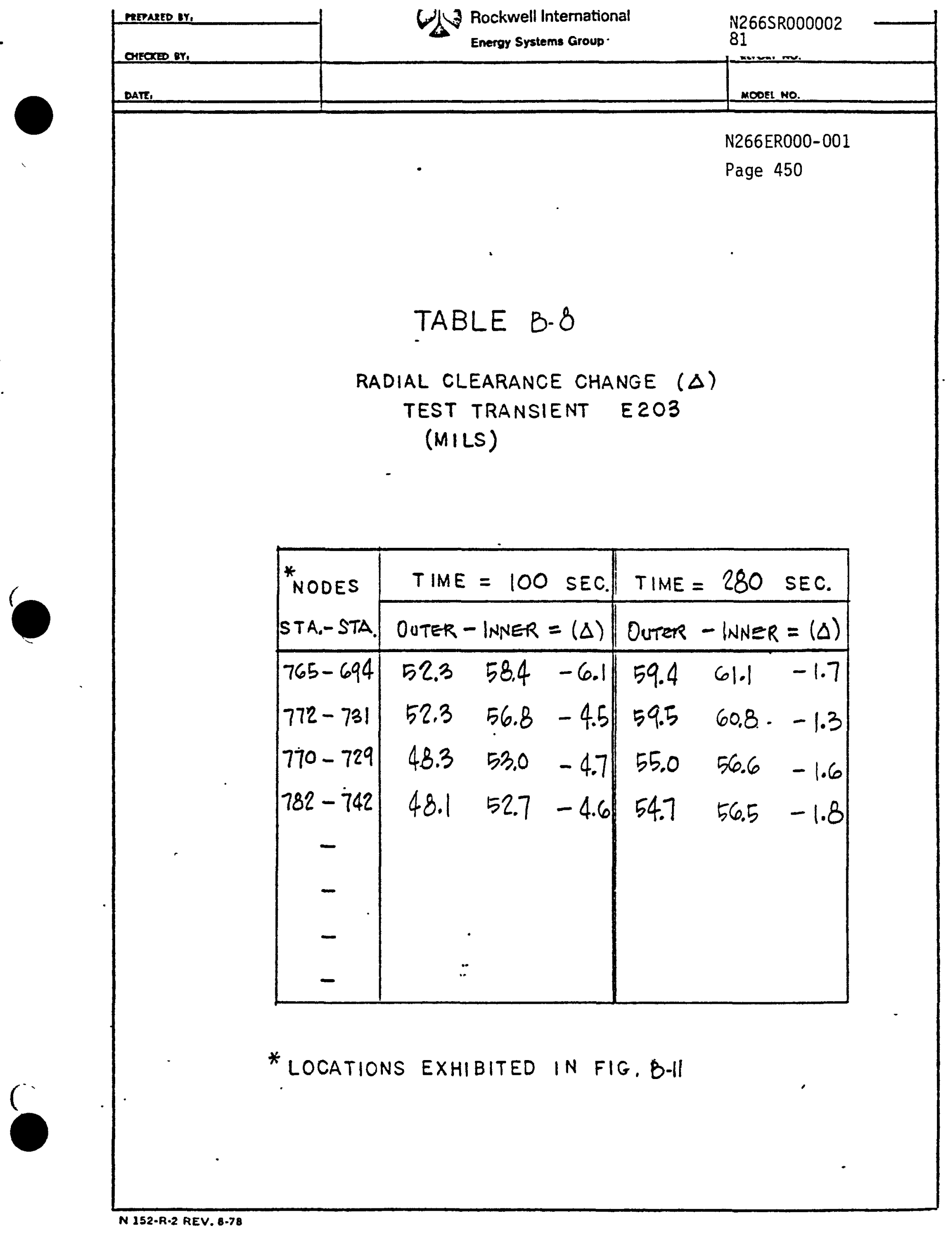




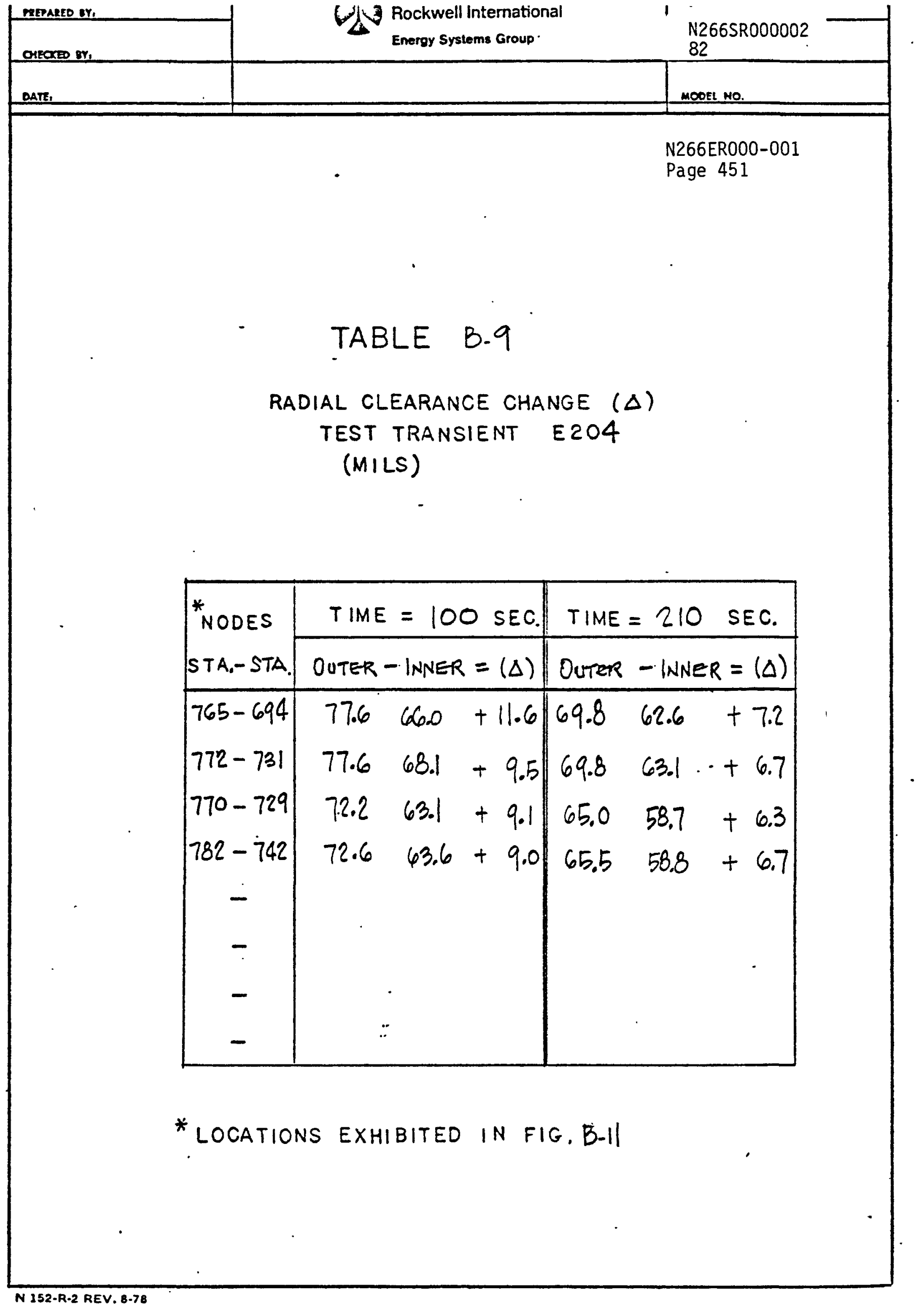




\begin{tabular}{|c|c|c|}
\hline MeFAREO BY. & $W_{\text {Energy Systems Group }}$ & $\begin{array}{l}\text { N266SR000002 } \\
83\end{array}$ \\
\hline DATE. & & MODEL NO \\
\hline
\end{tabular}

TABLE B.10

RADIAL CLEARANCE CHANGE $(\Delta)$ TEST TRANSIENT EZOT (MILS)

N266ER000-001

Page 452

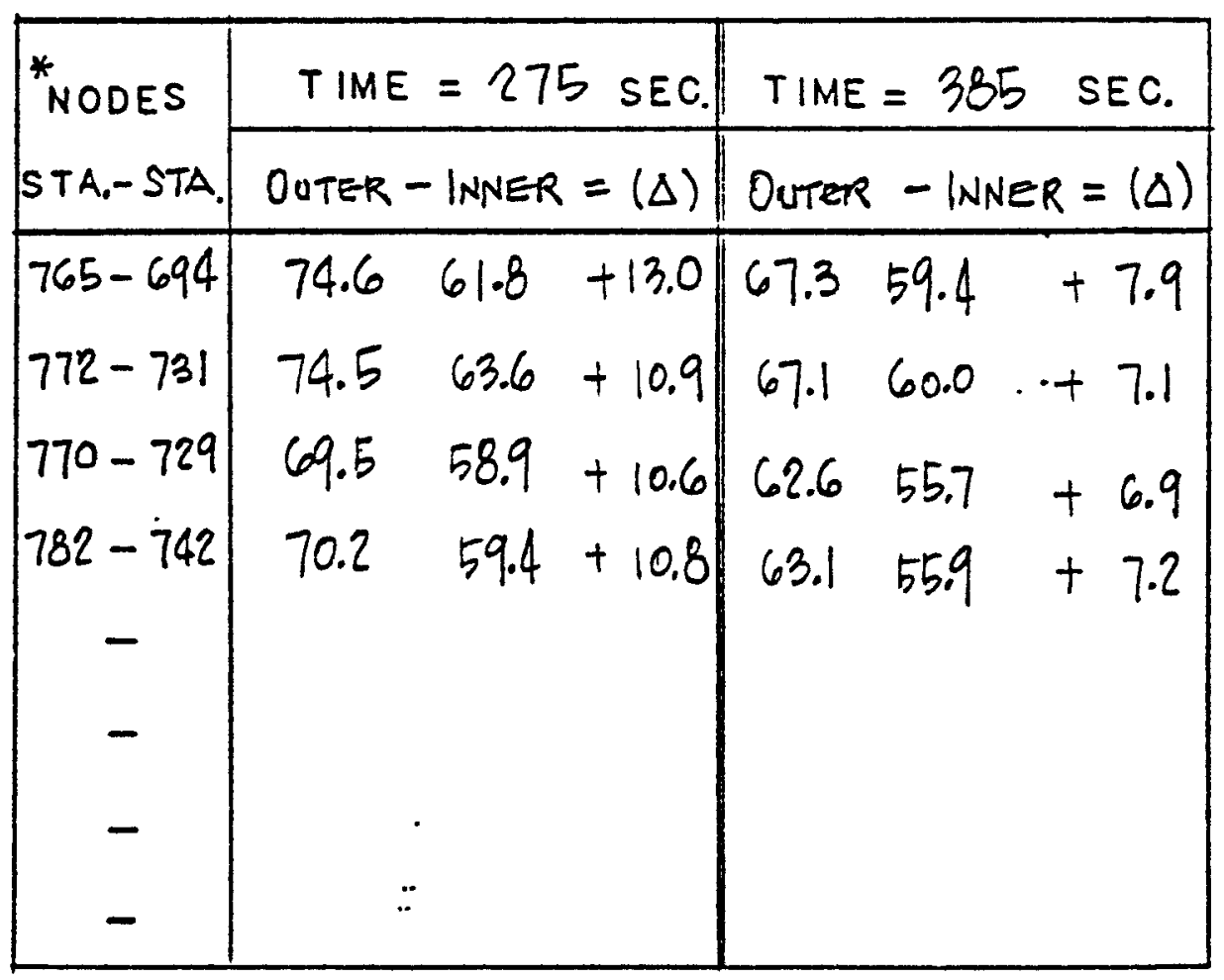

* locations exhibited in fig.B. 


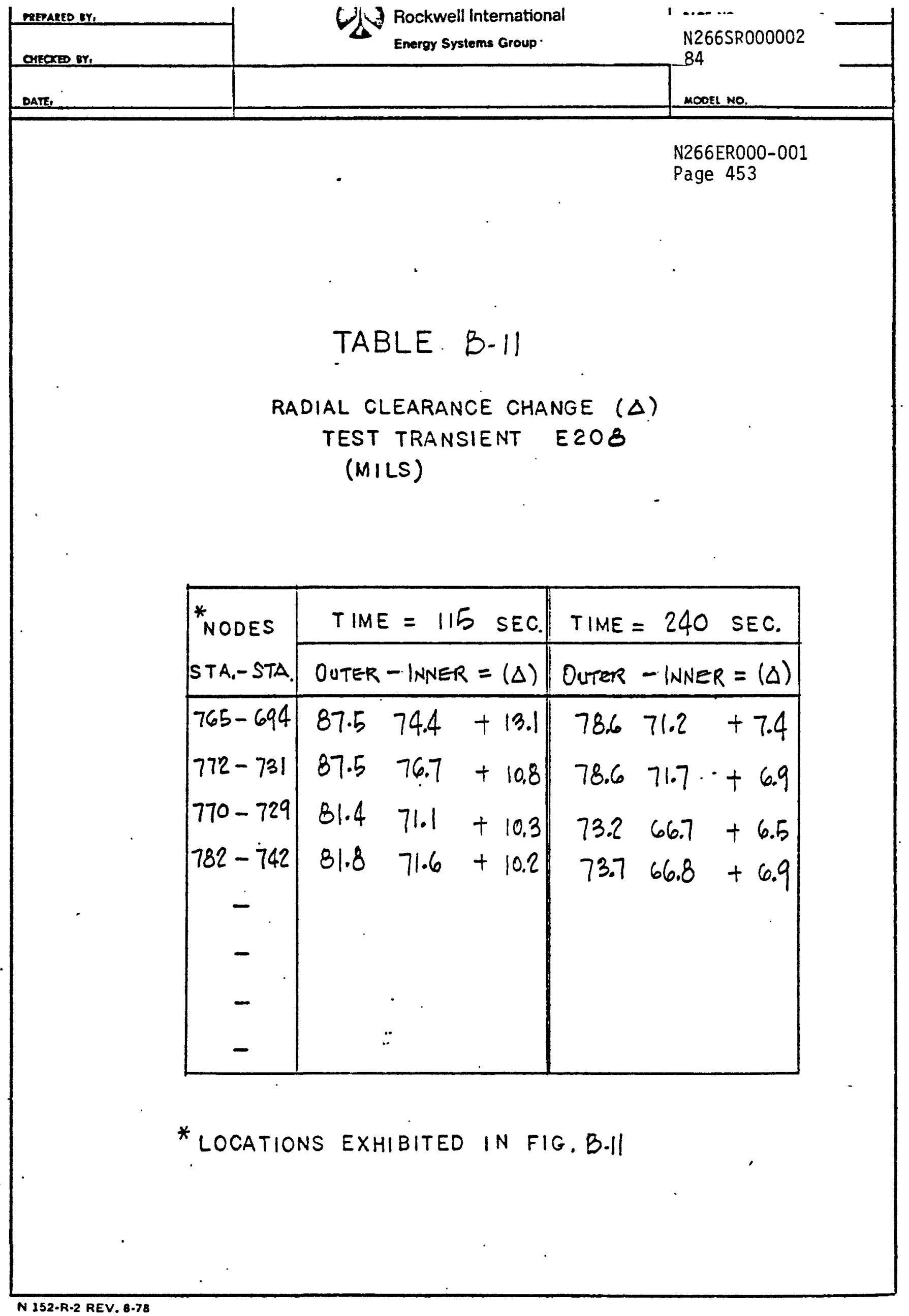

N 152-R-2 REV. 8-78 


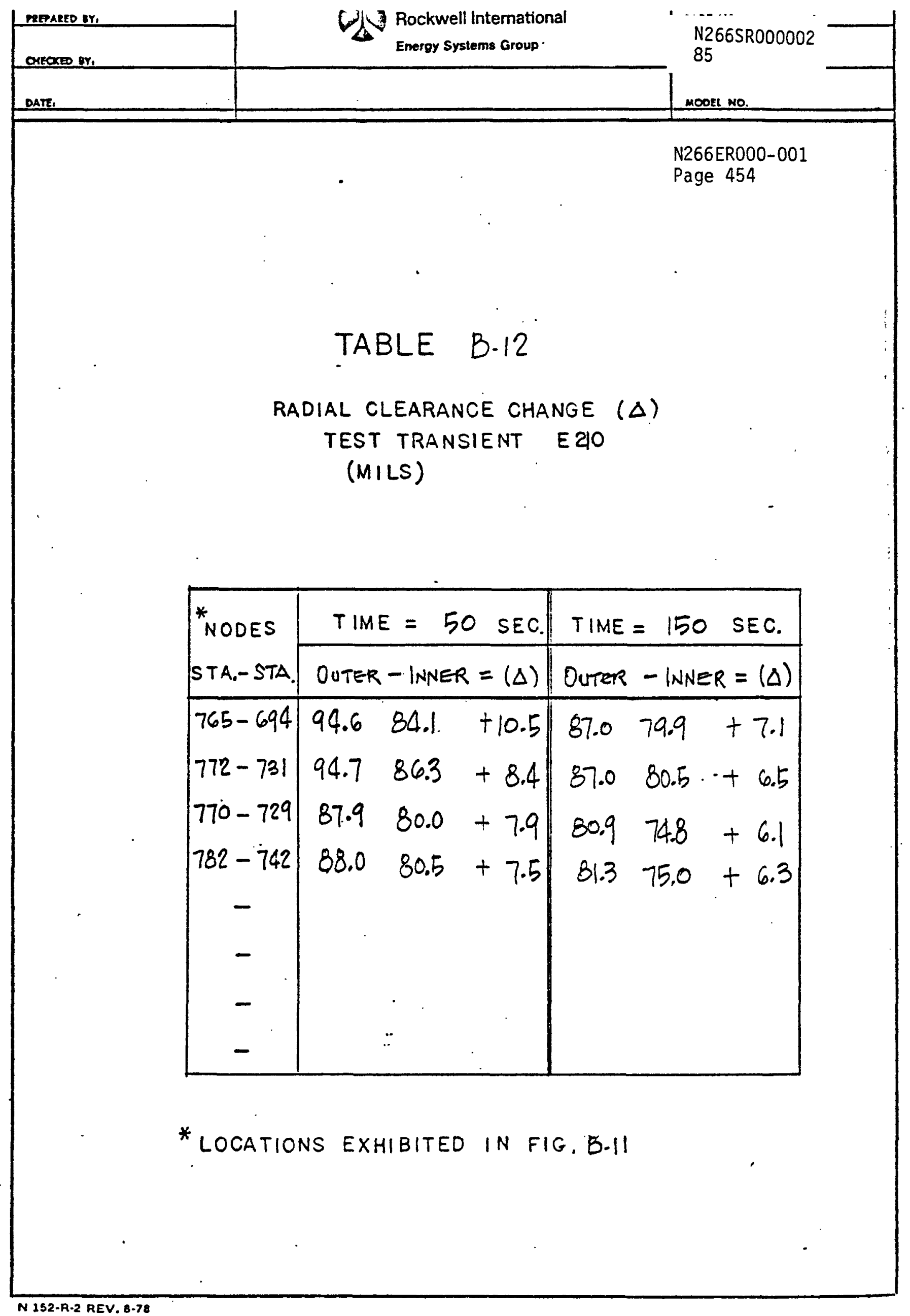




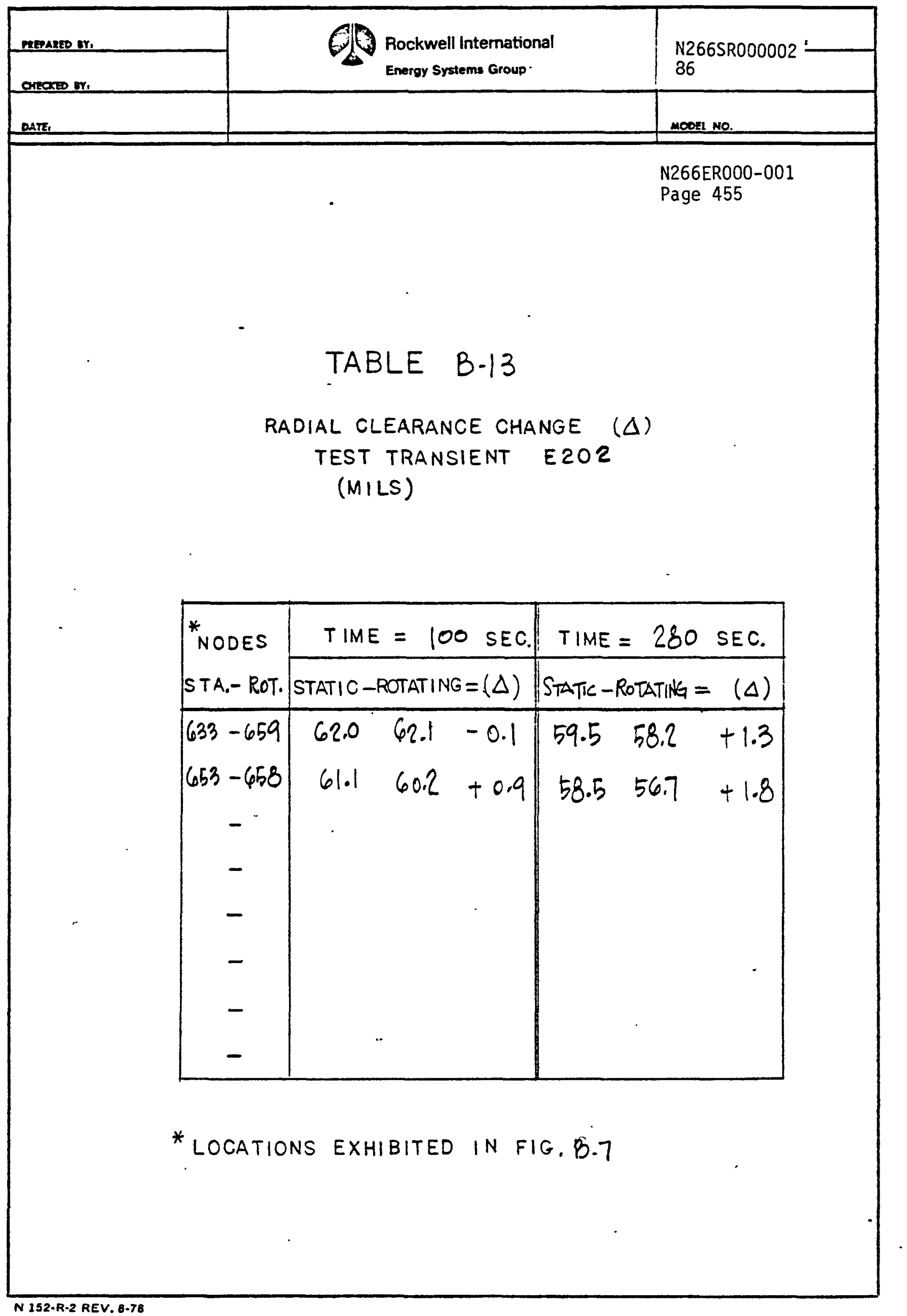




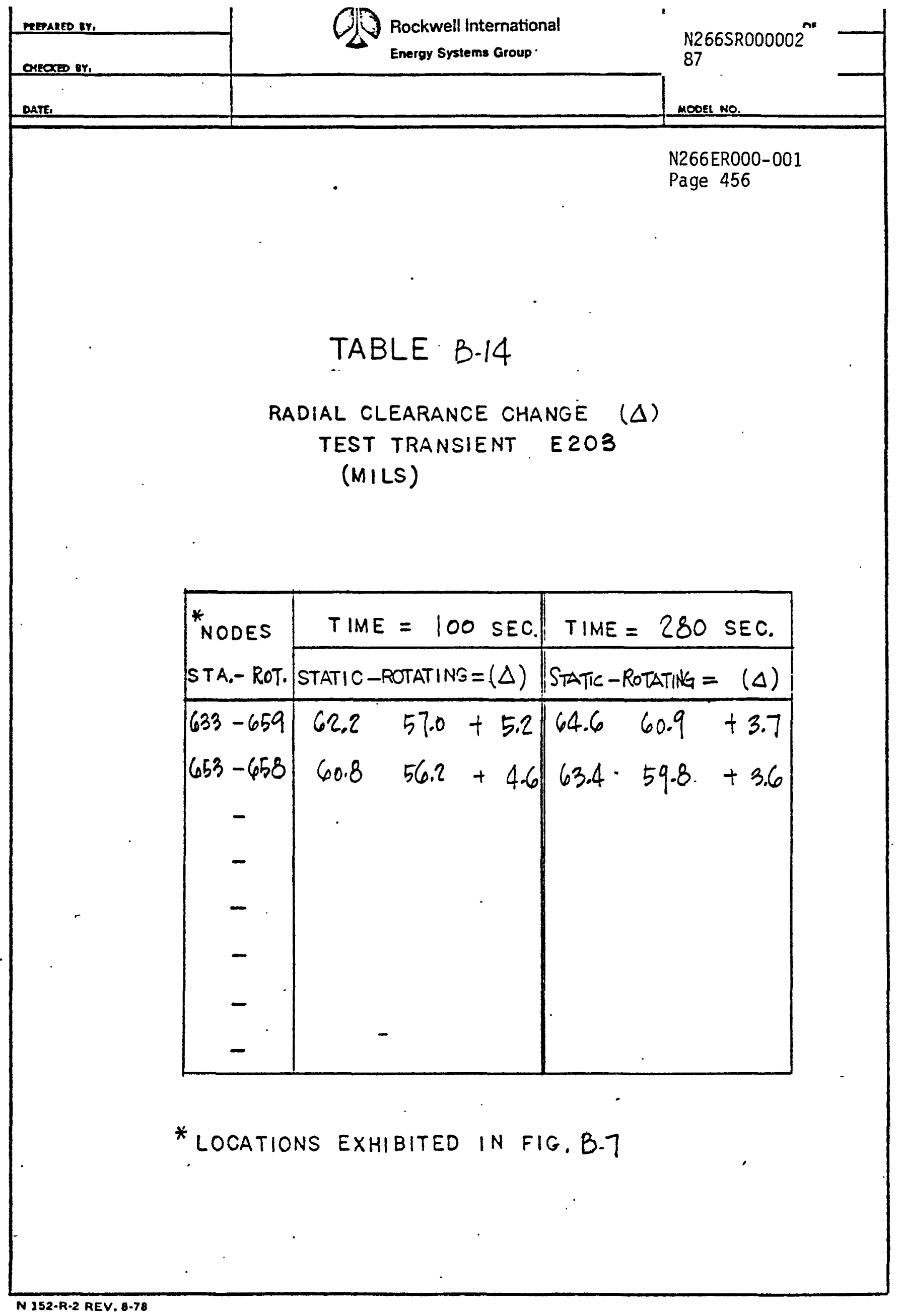




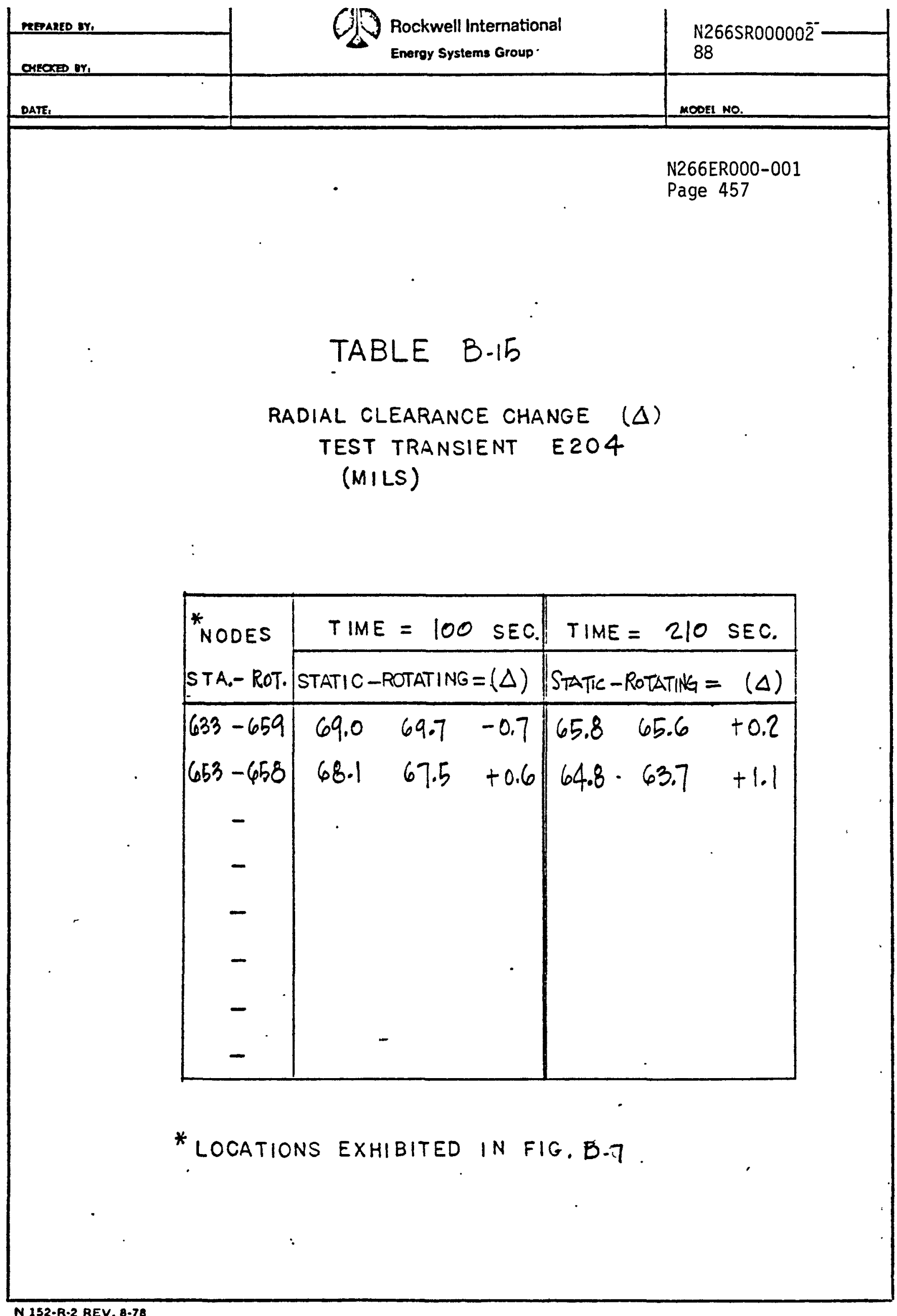

N 152-R.2 REV. 8.78 


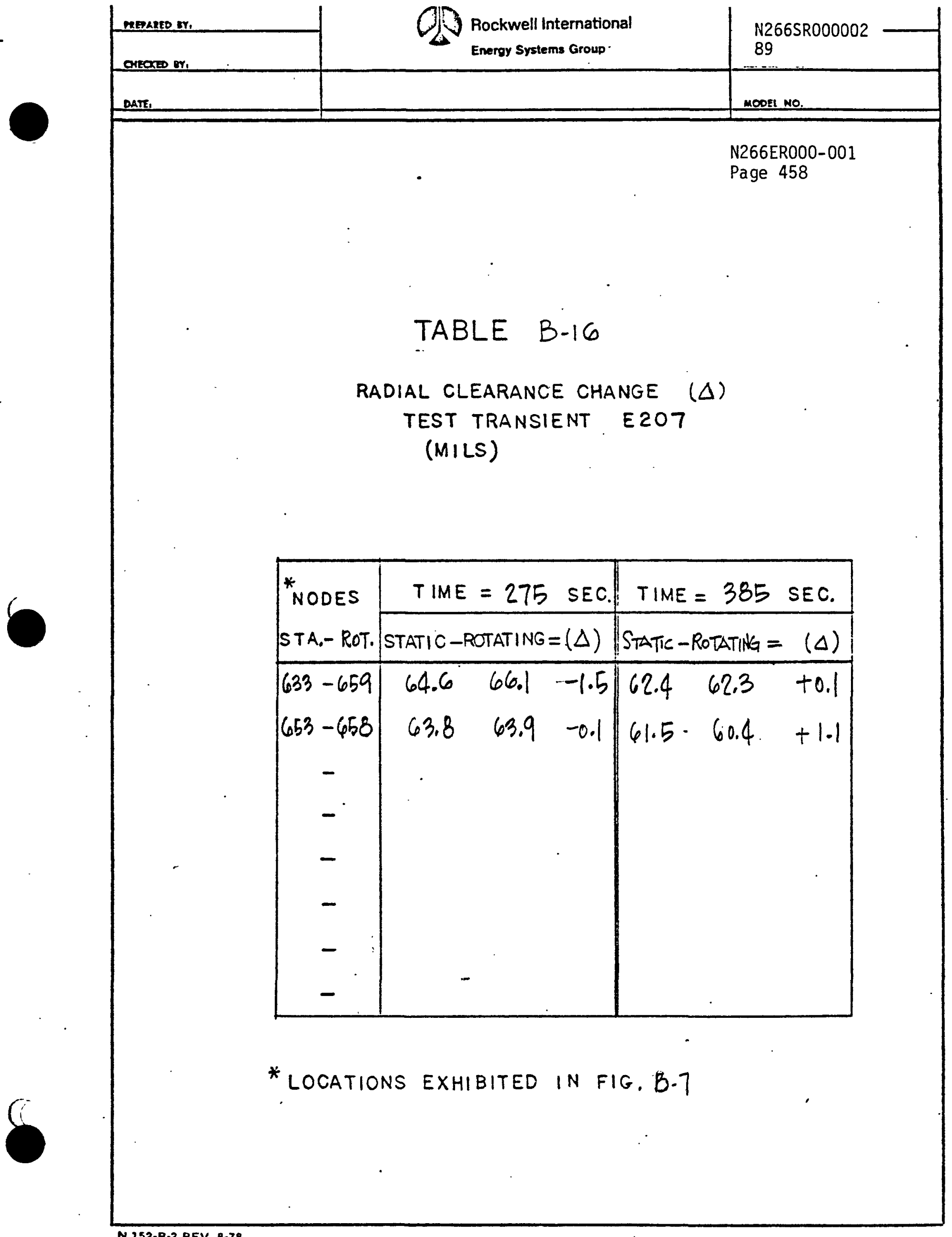

N 352-R-2 REV. 8.78 


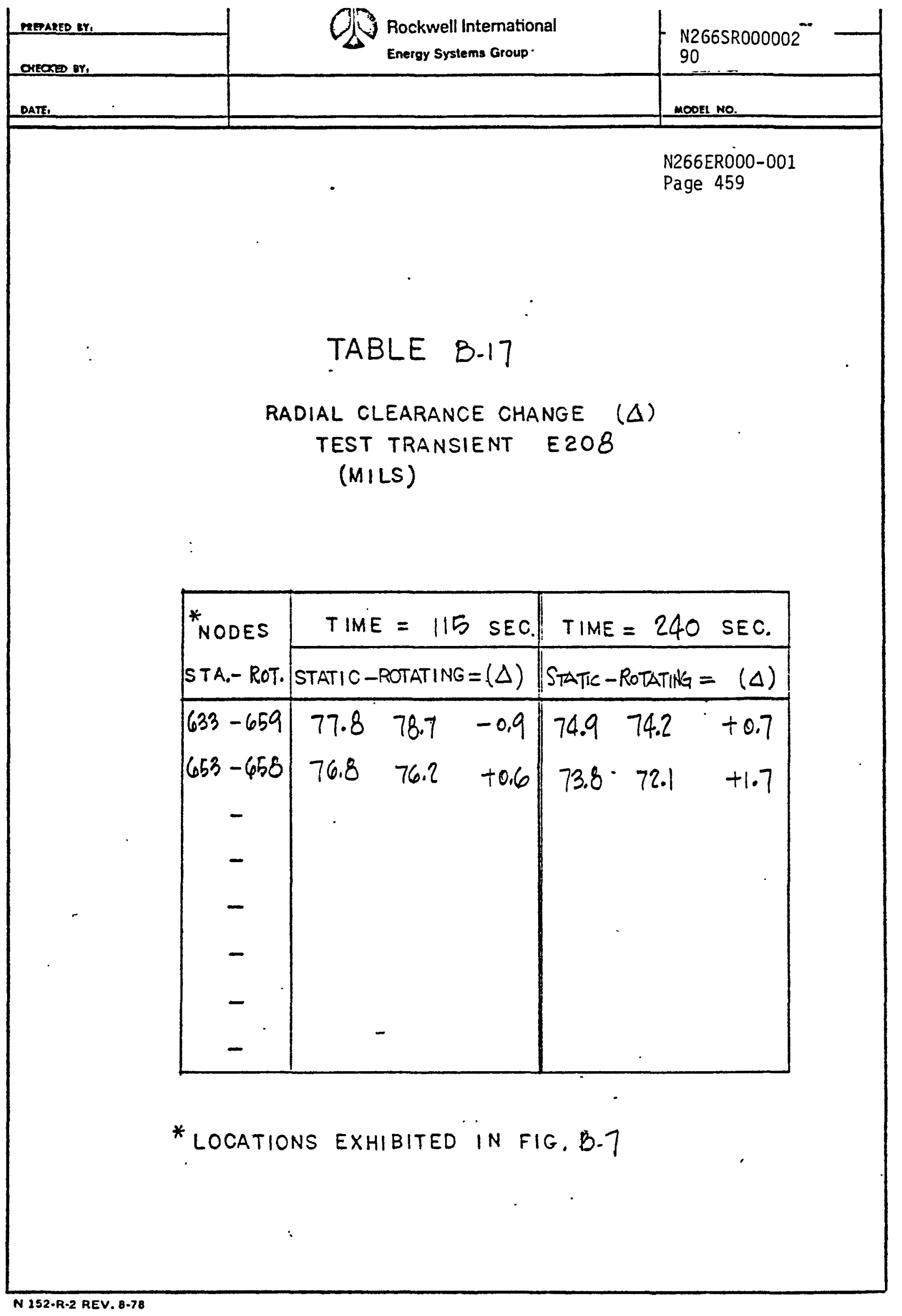




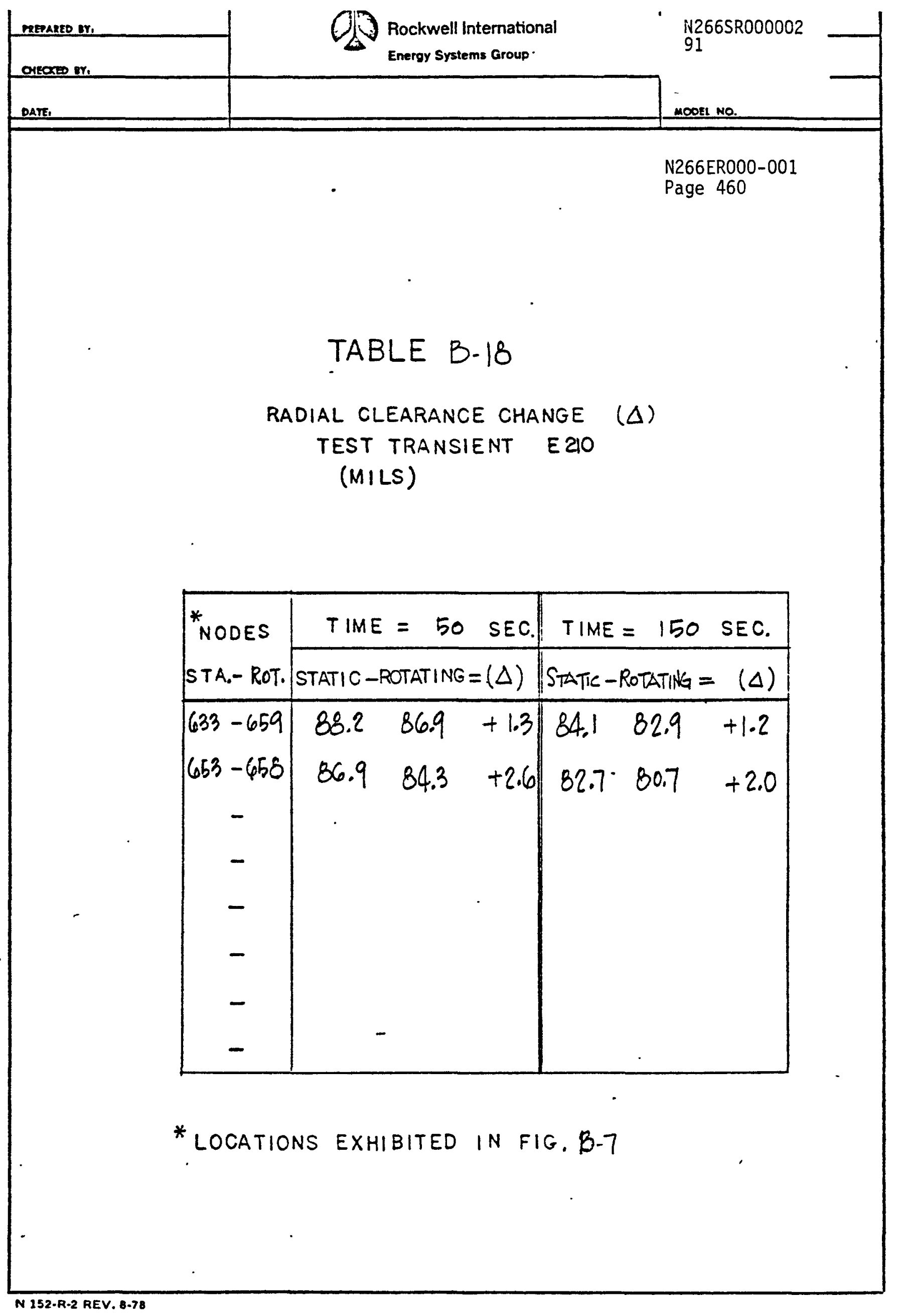




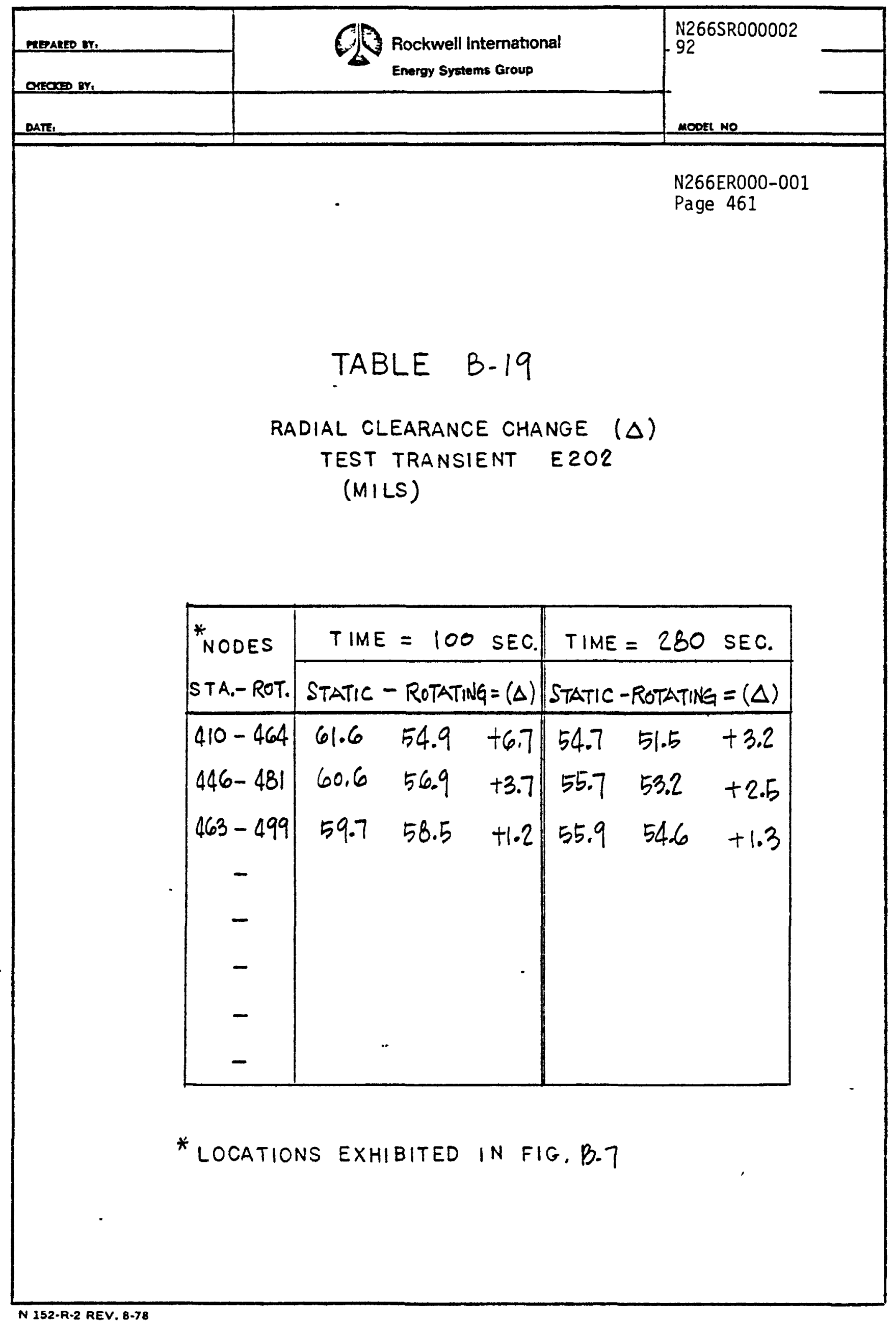




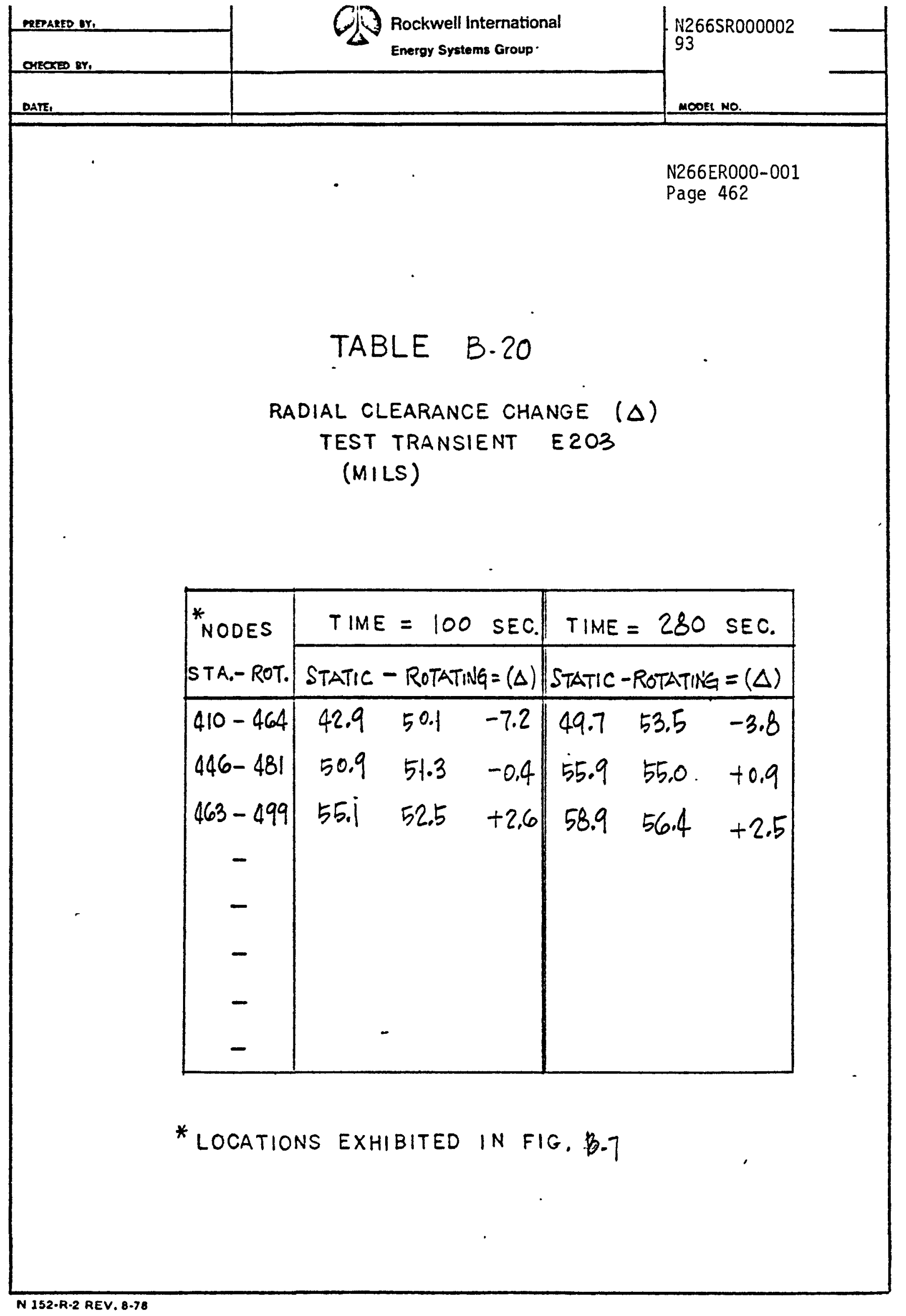




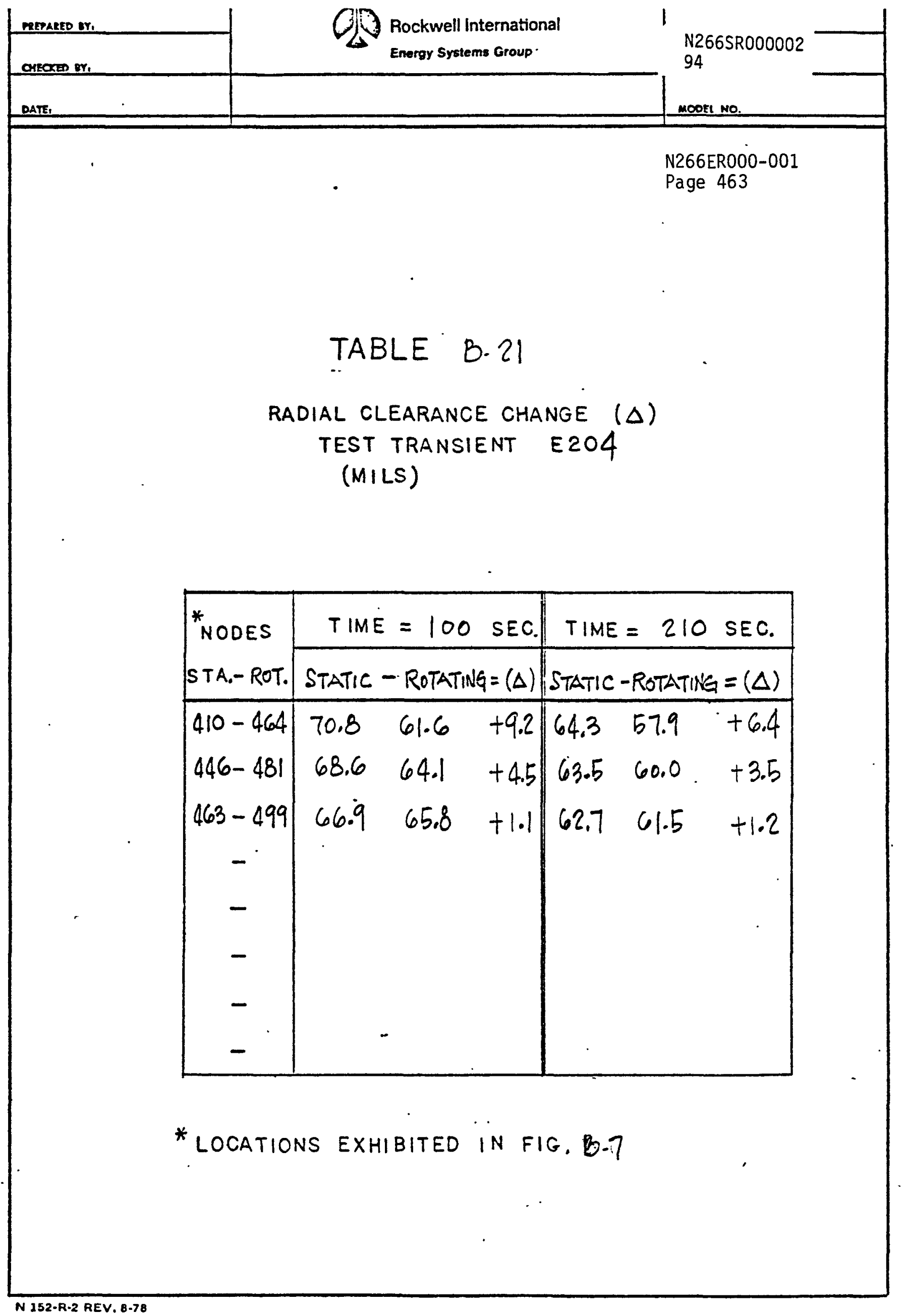




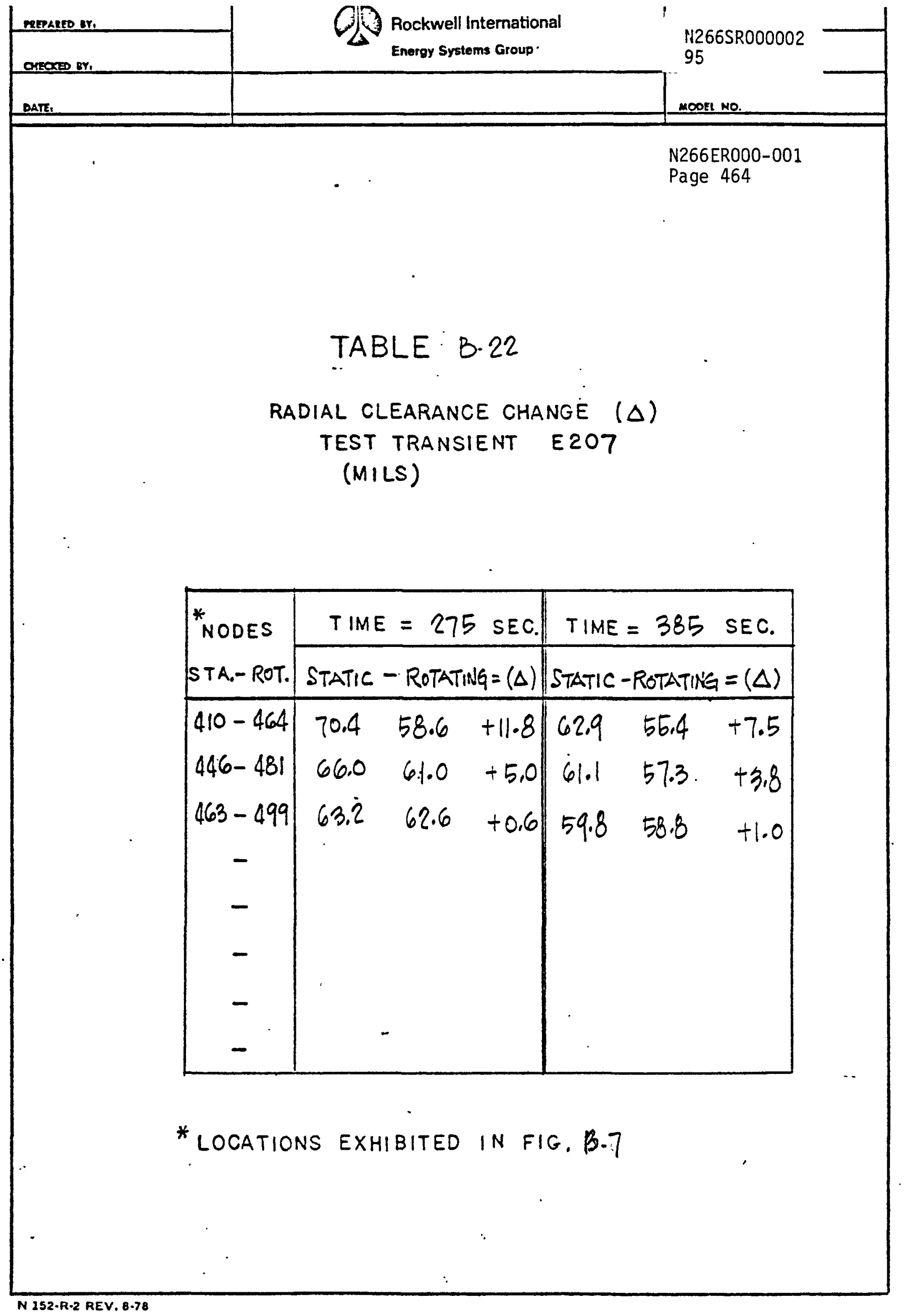




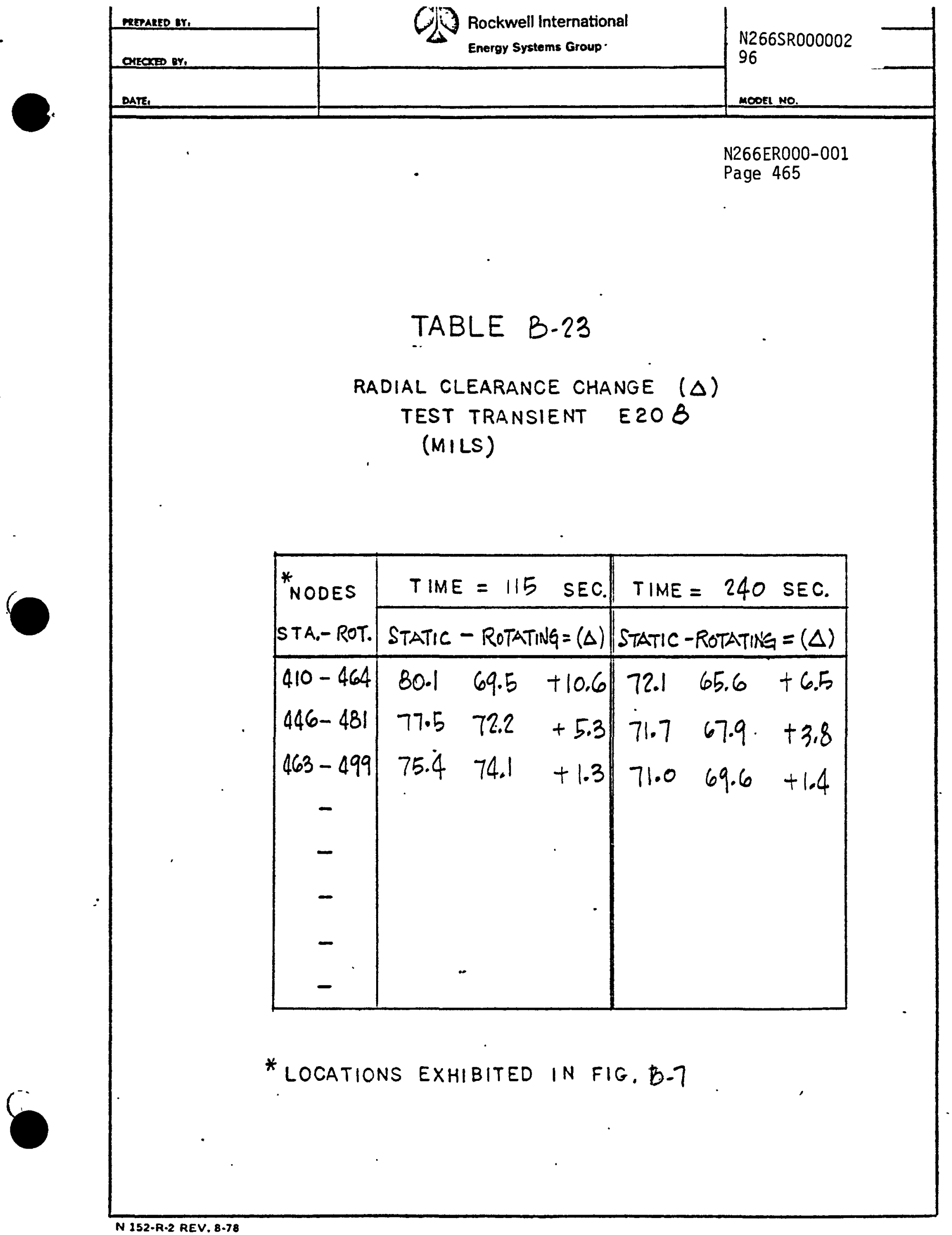




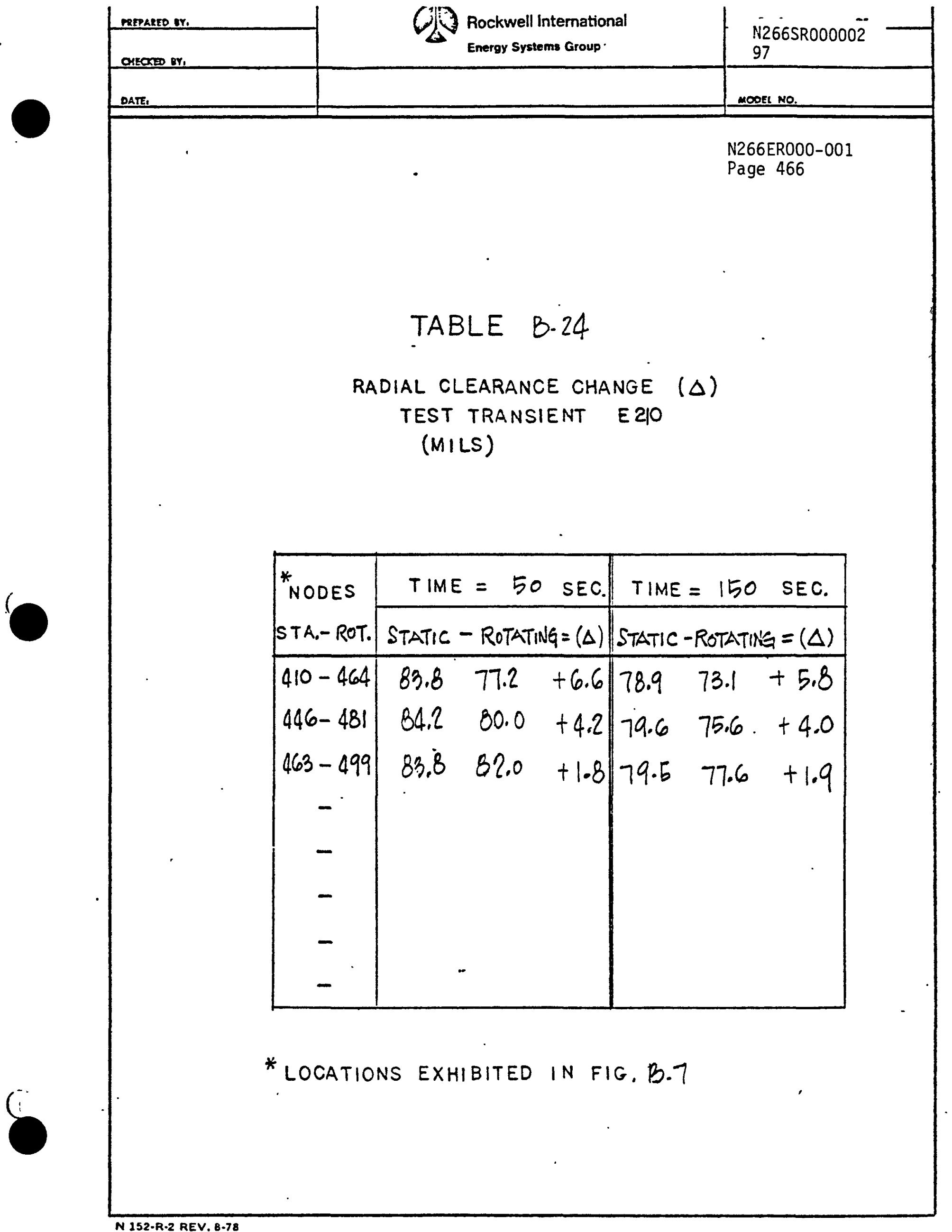




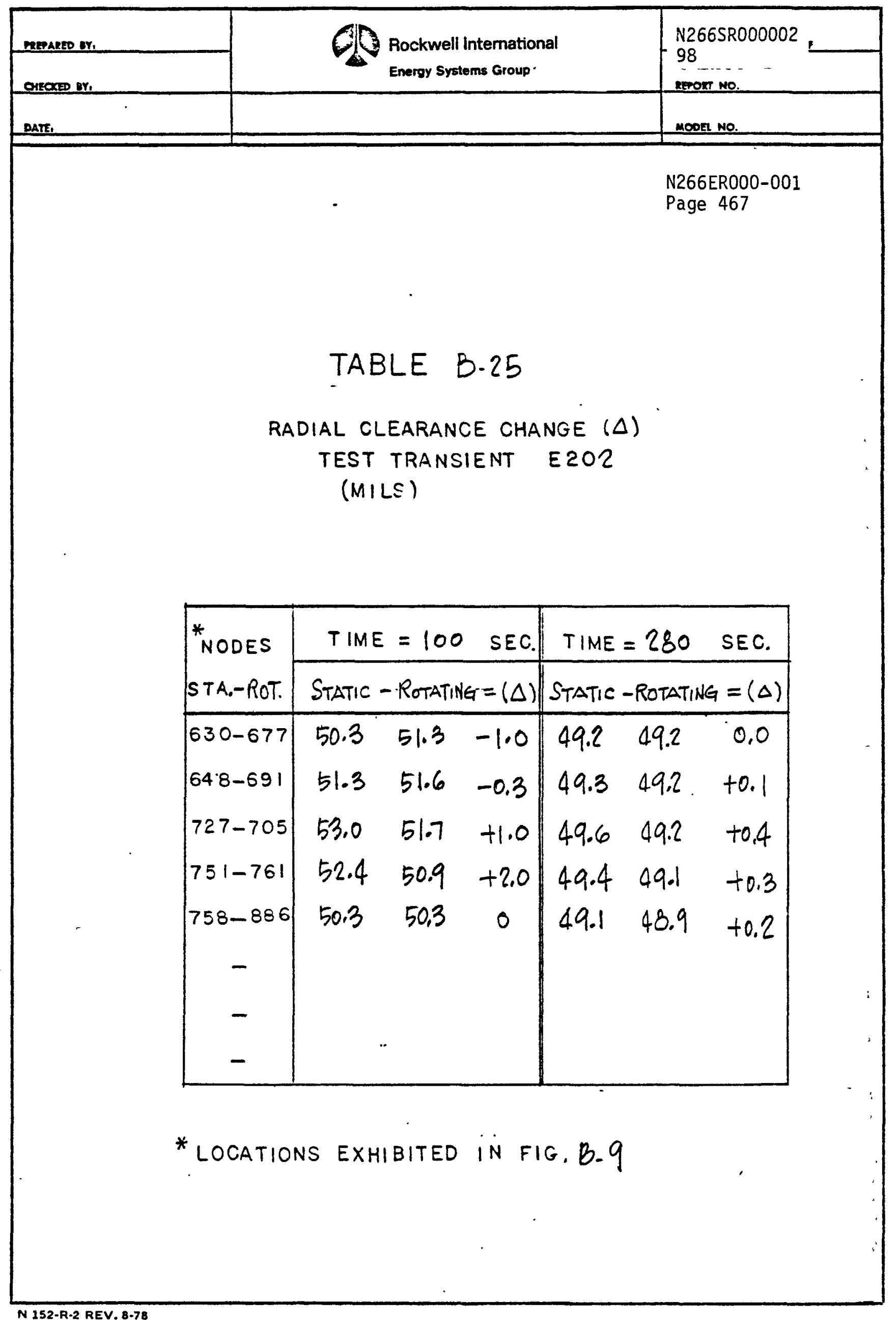




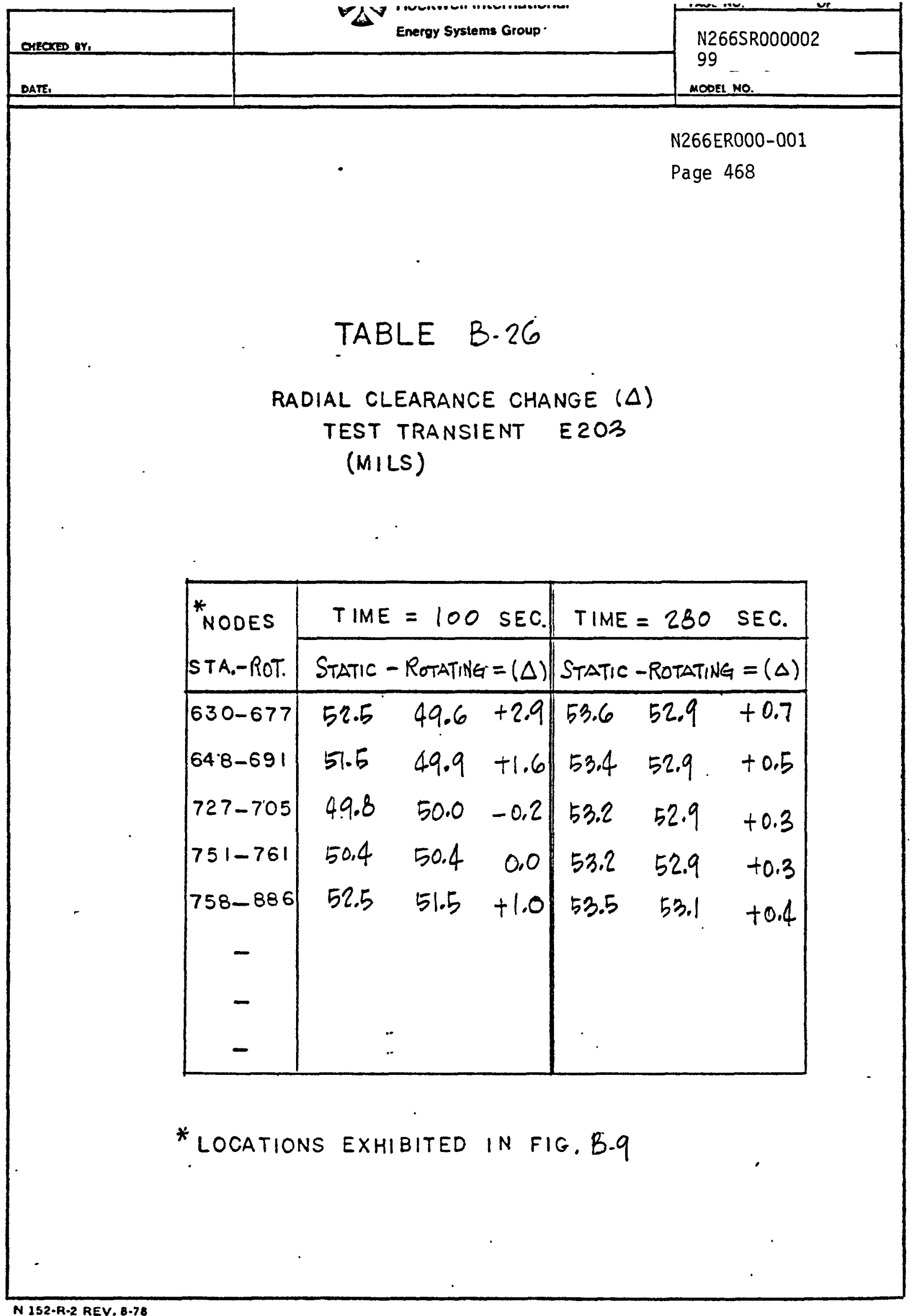

N 152-R-2 REV. 8.78 


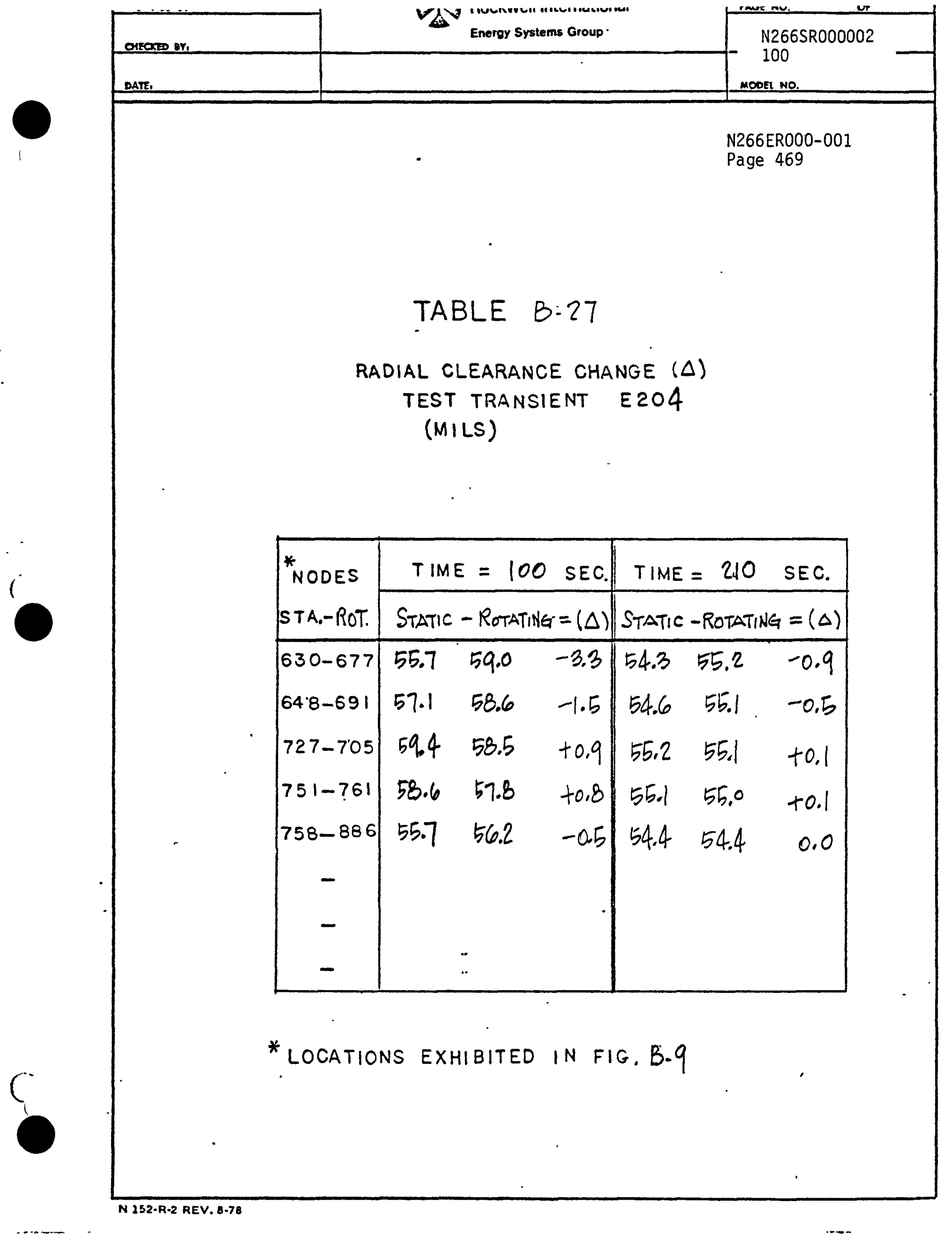




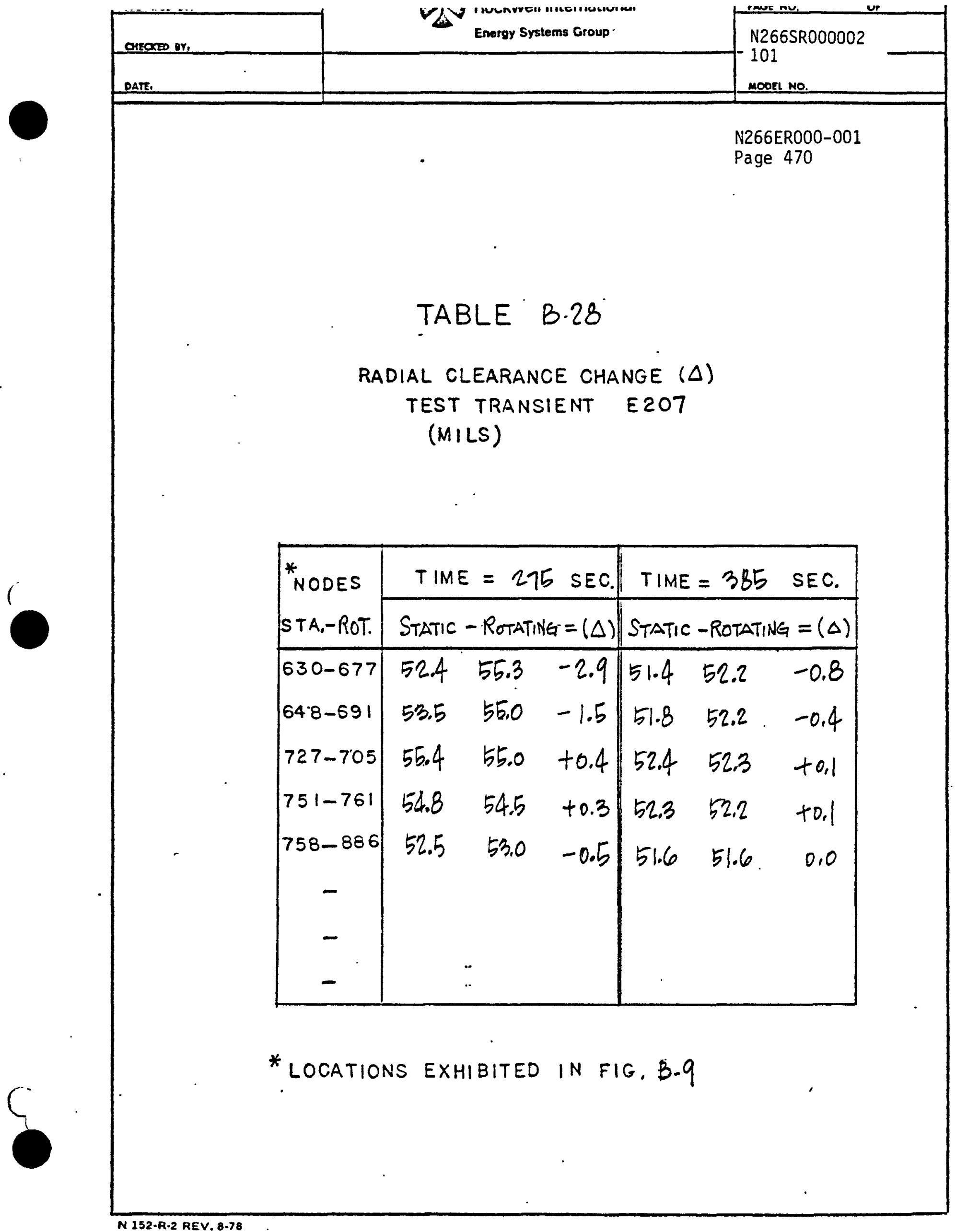

N 152-R.2 REV. 8.78 


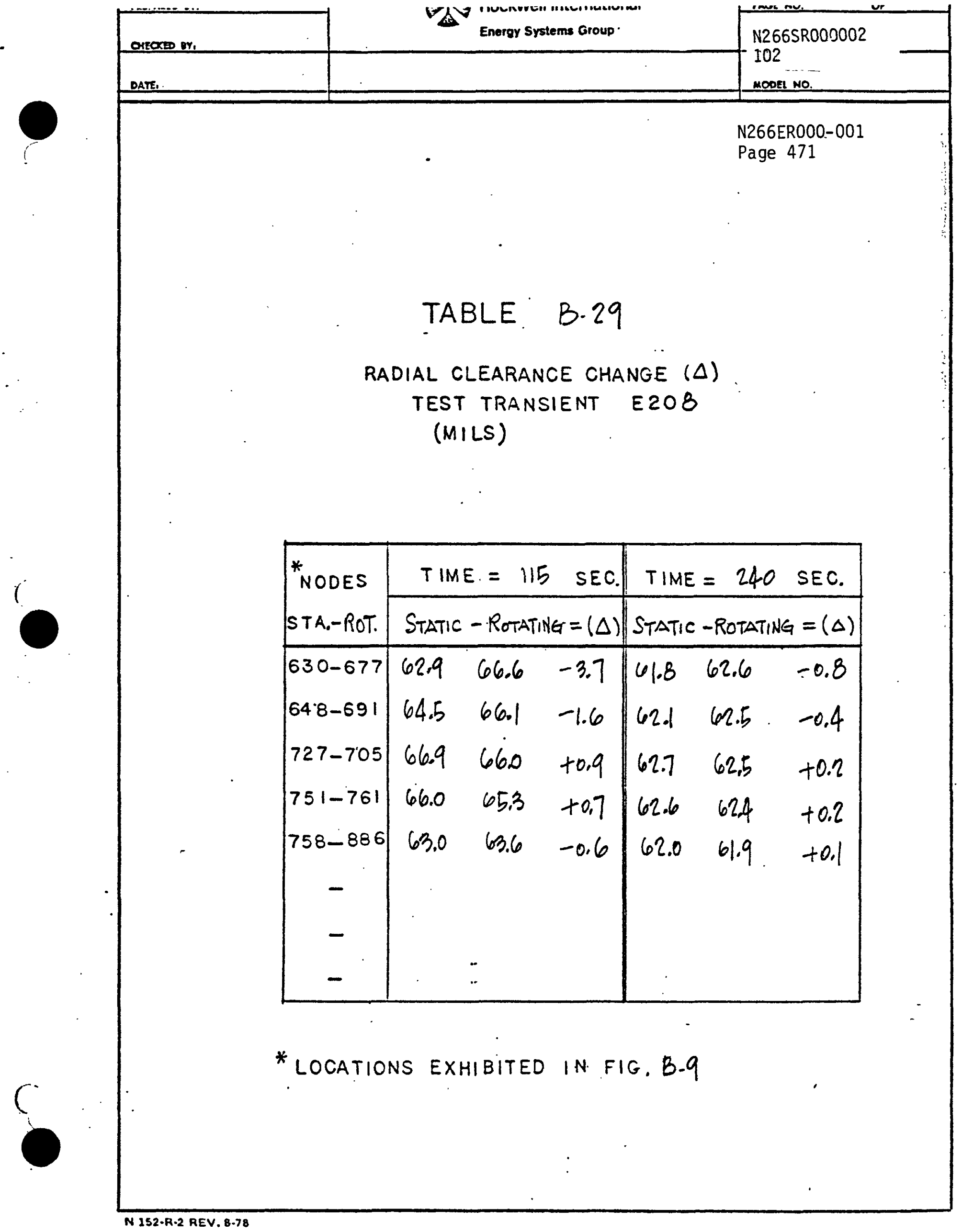




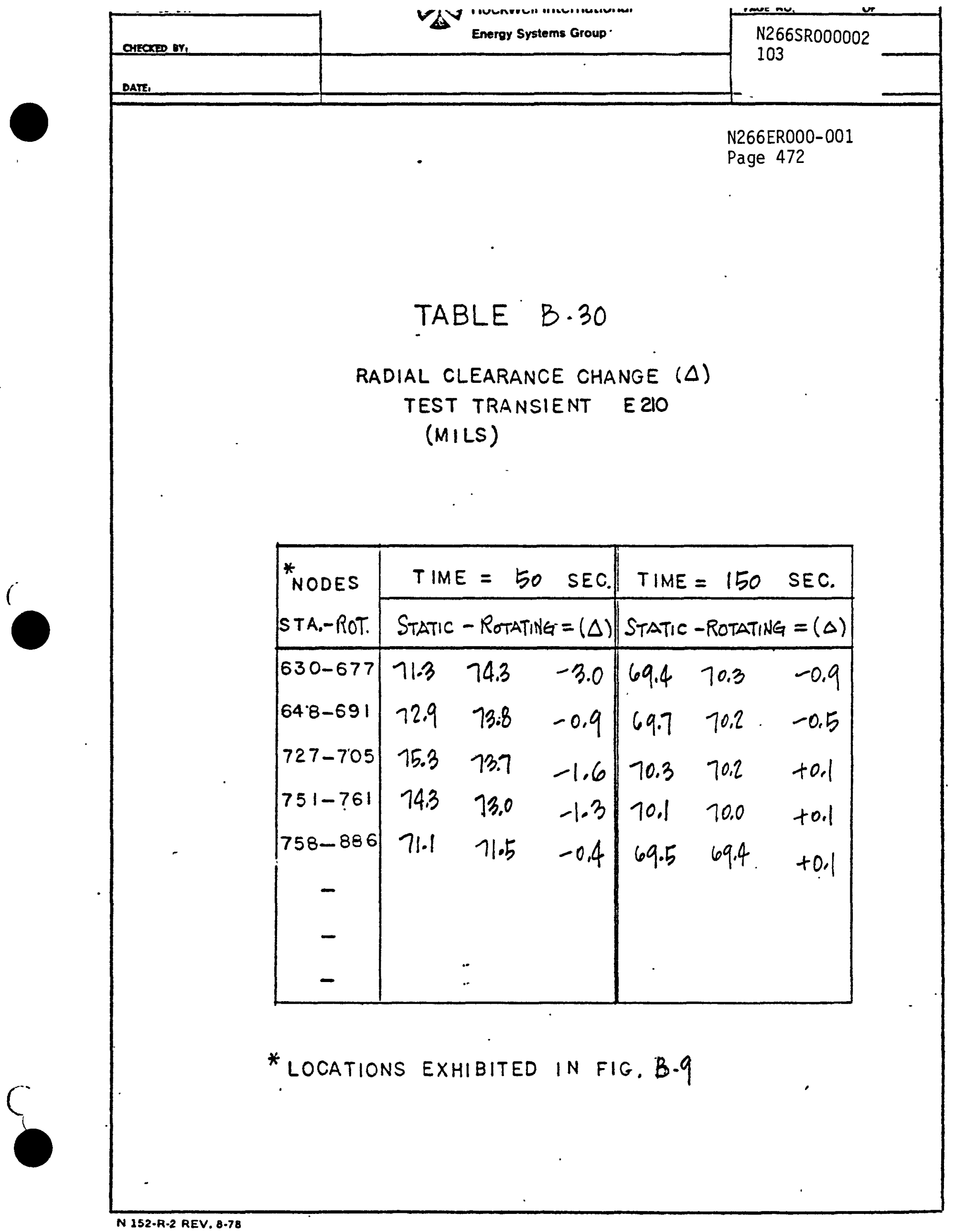

N 152-R-2 REV. 8.78 


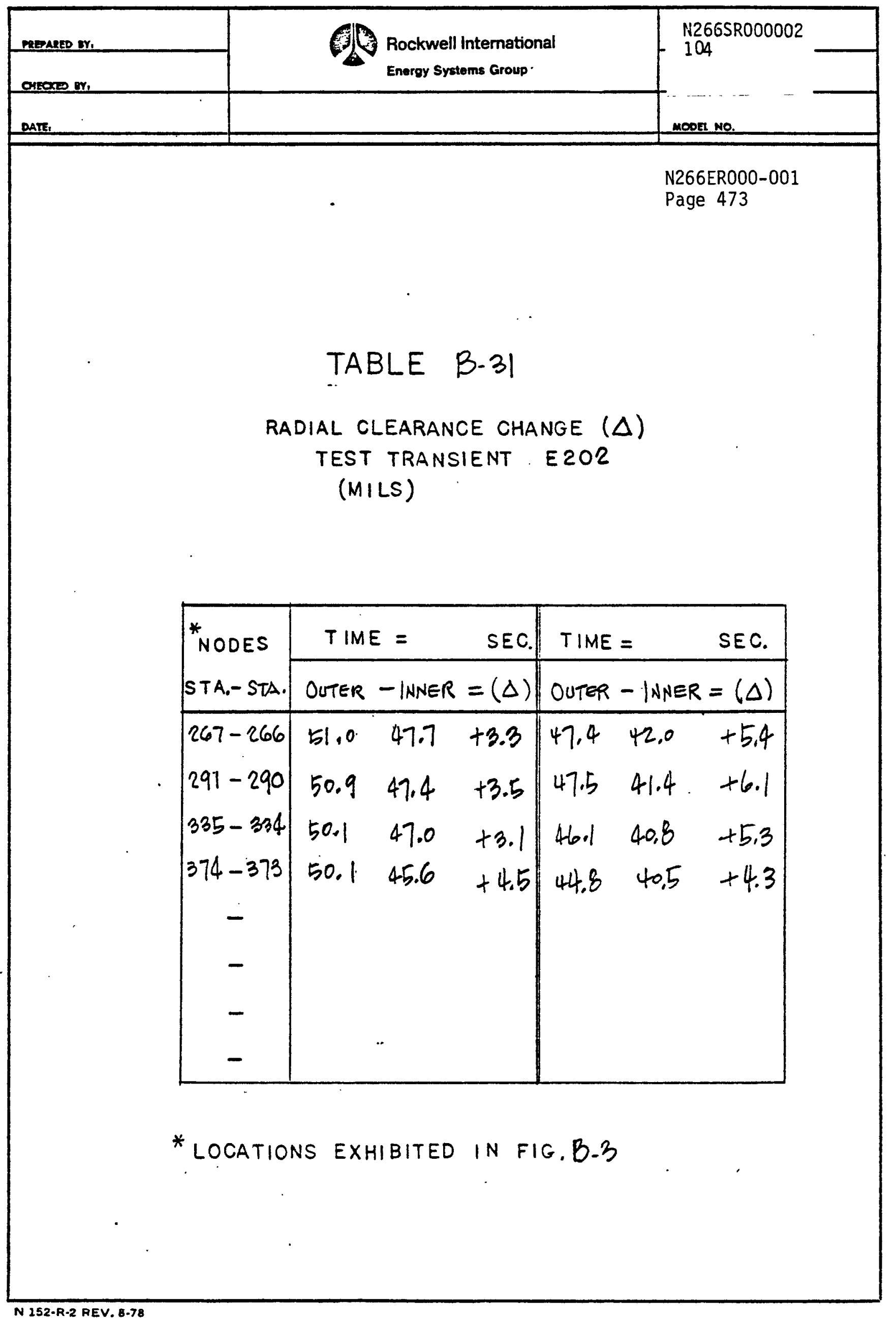




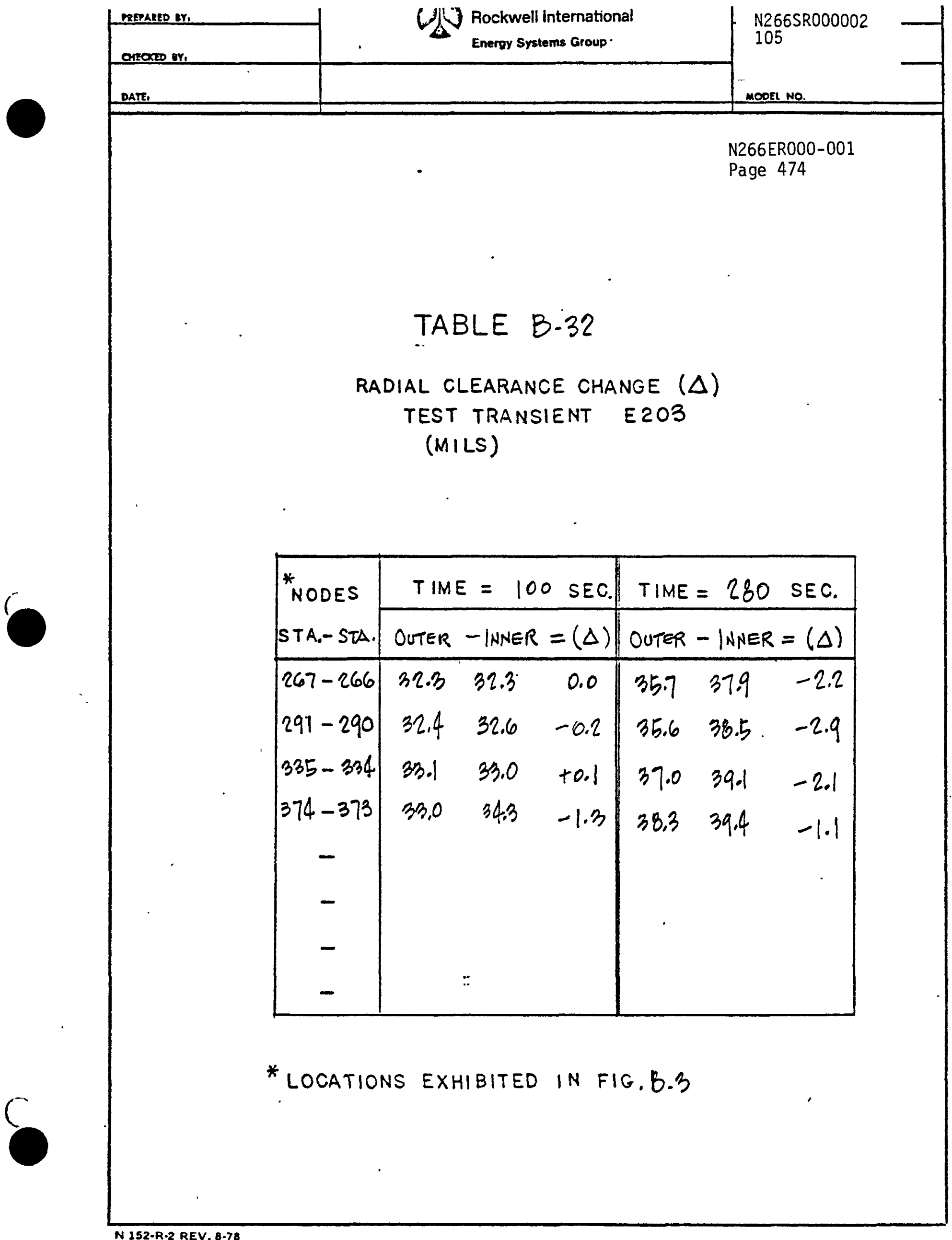




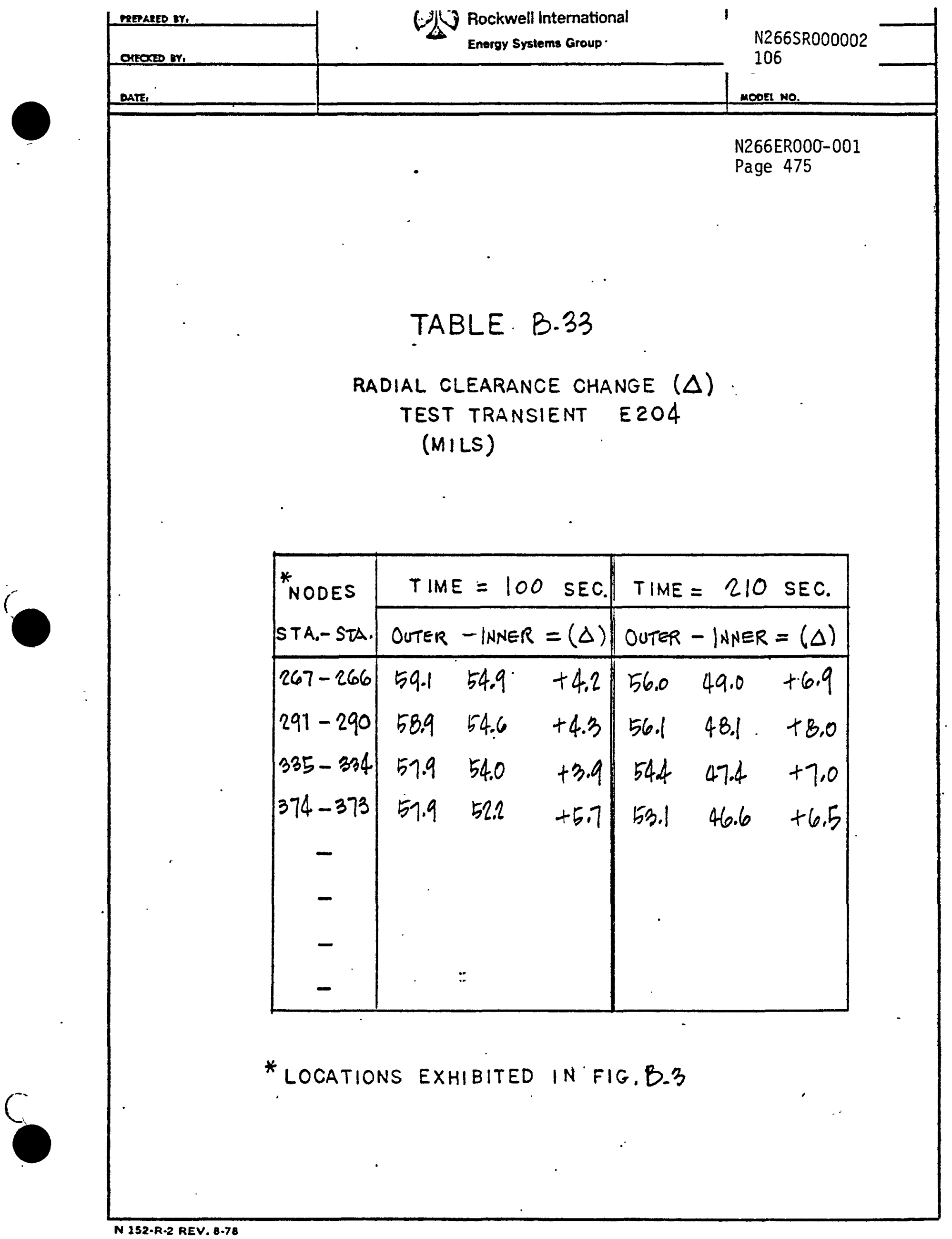




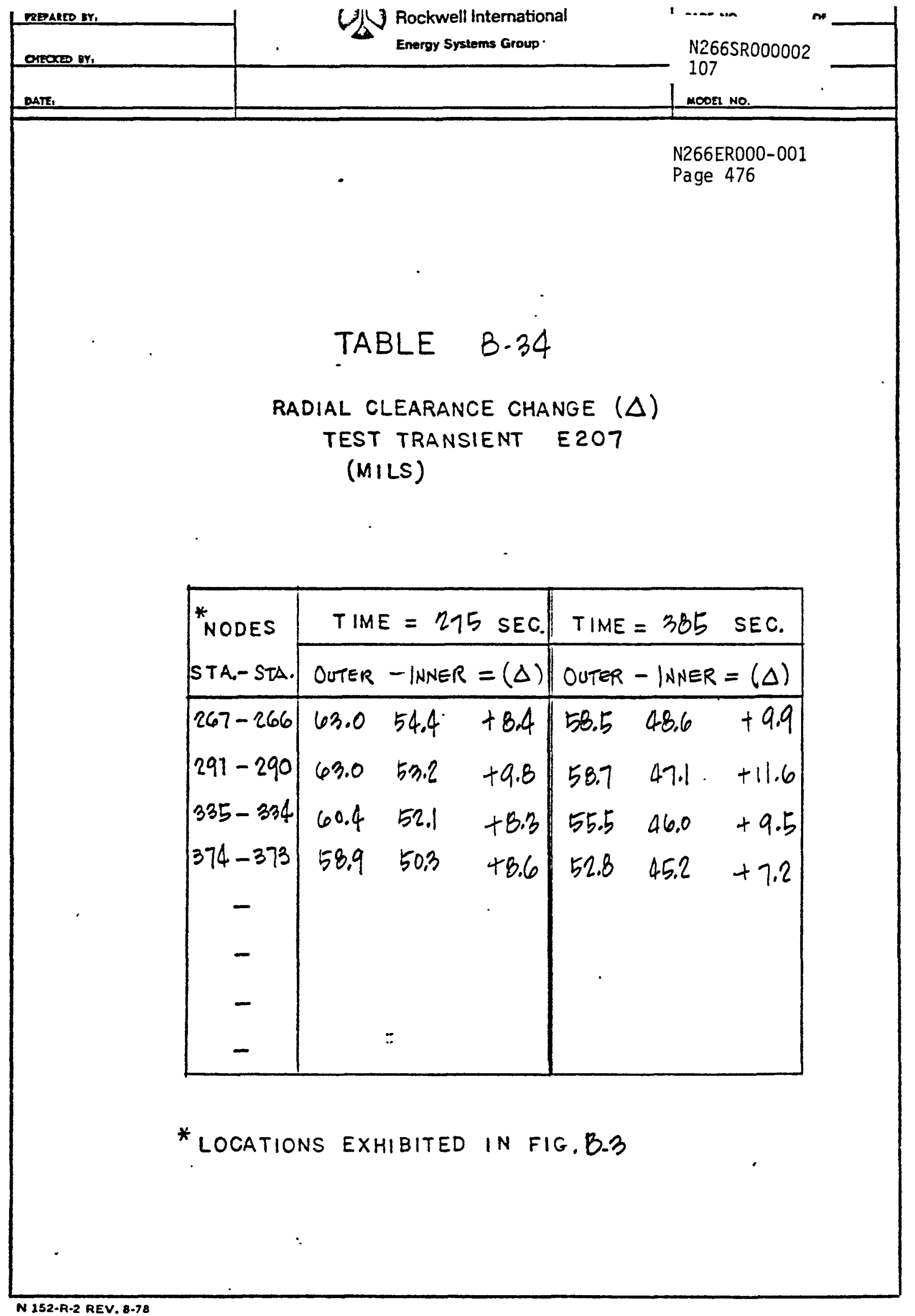




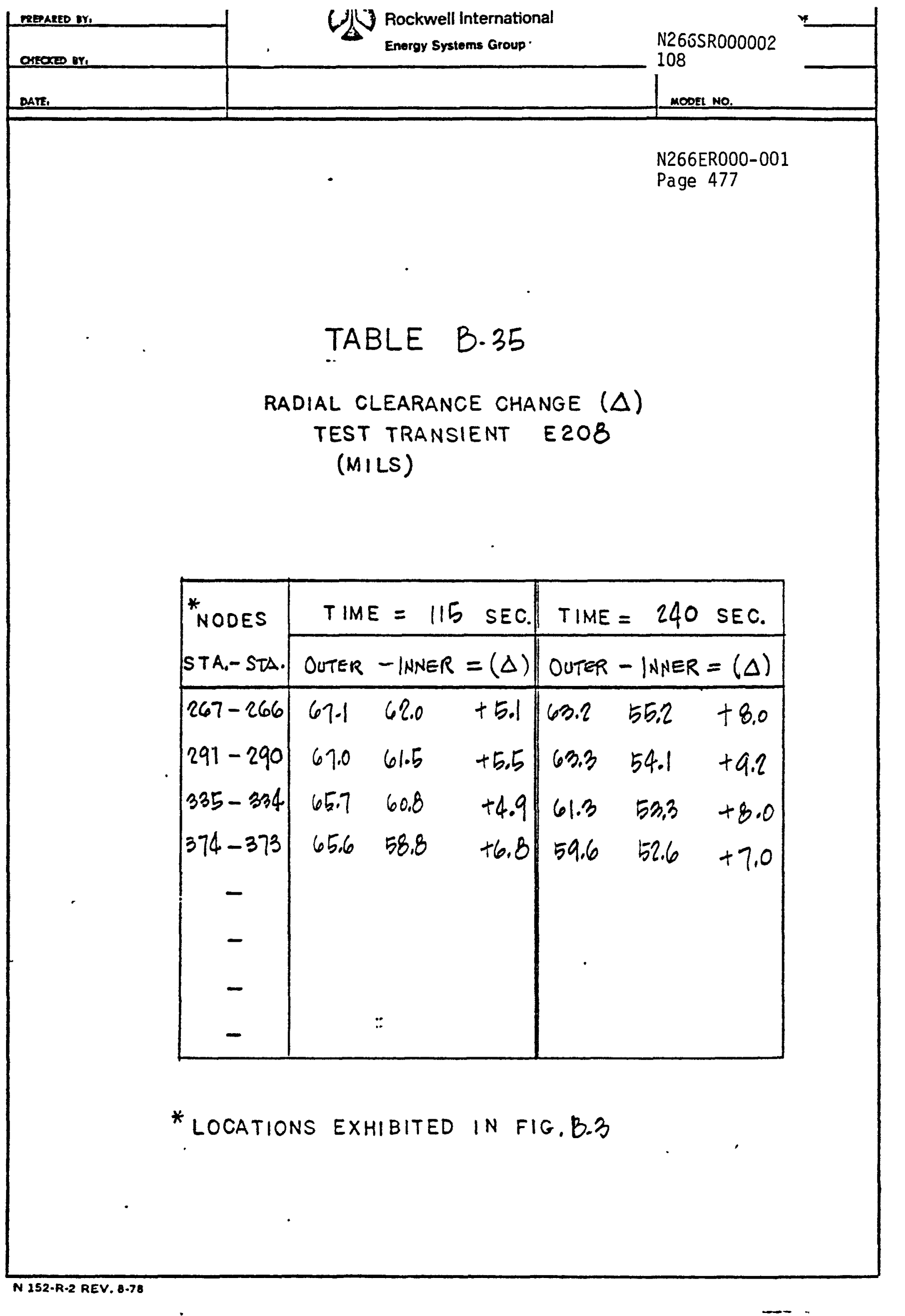


N266ER000-001

Page 479

-TRANSIENT 202 BEARTUGREION $C-A D D A$

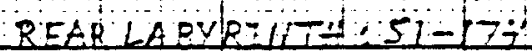
$R A S I A Q C=$ WUICE $\beta-\alpha, Y-\beta, \varepsilon-\Delta$

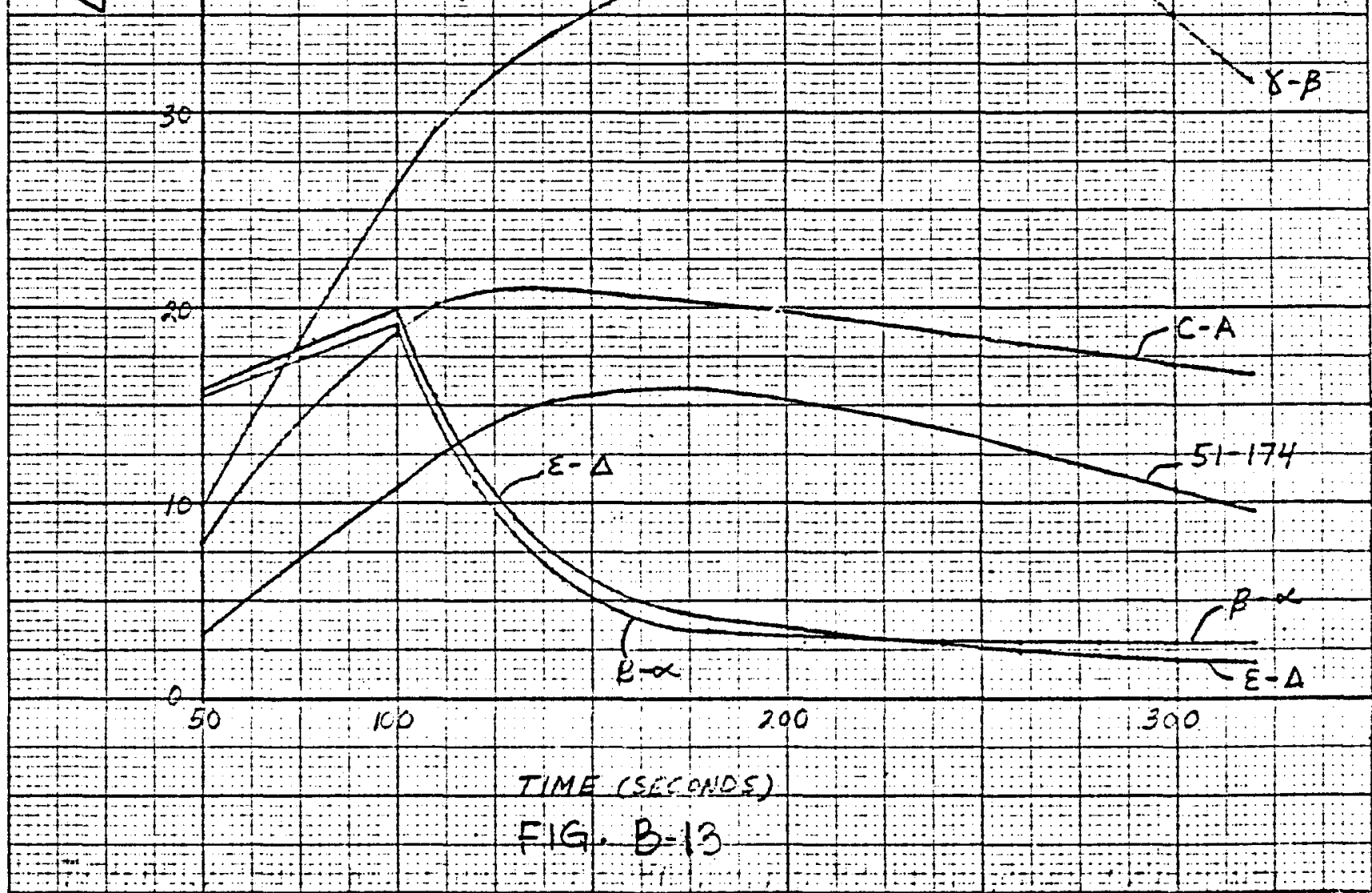




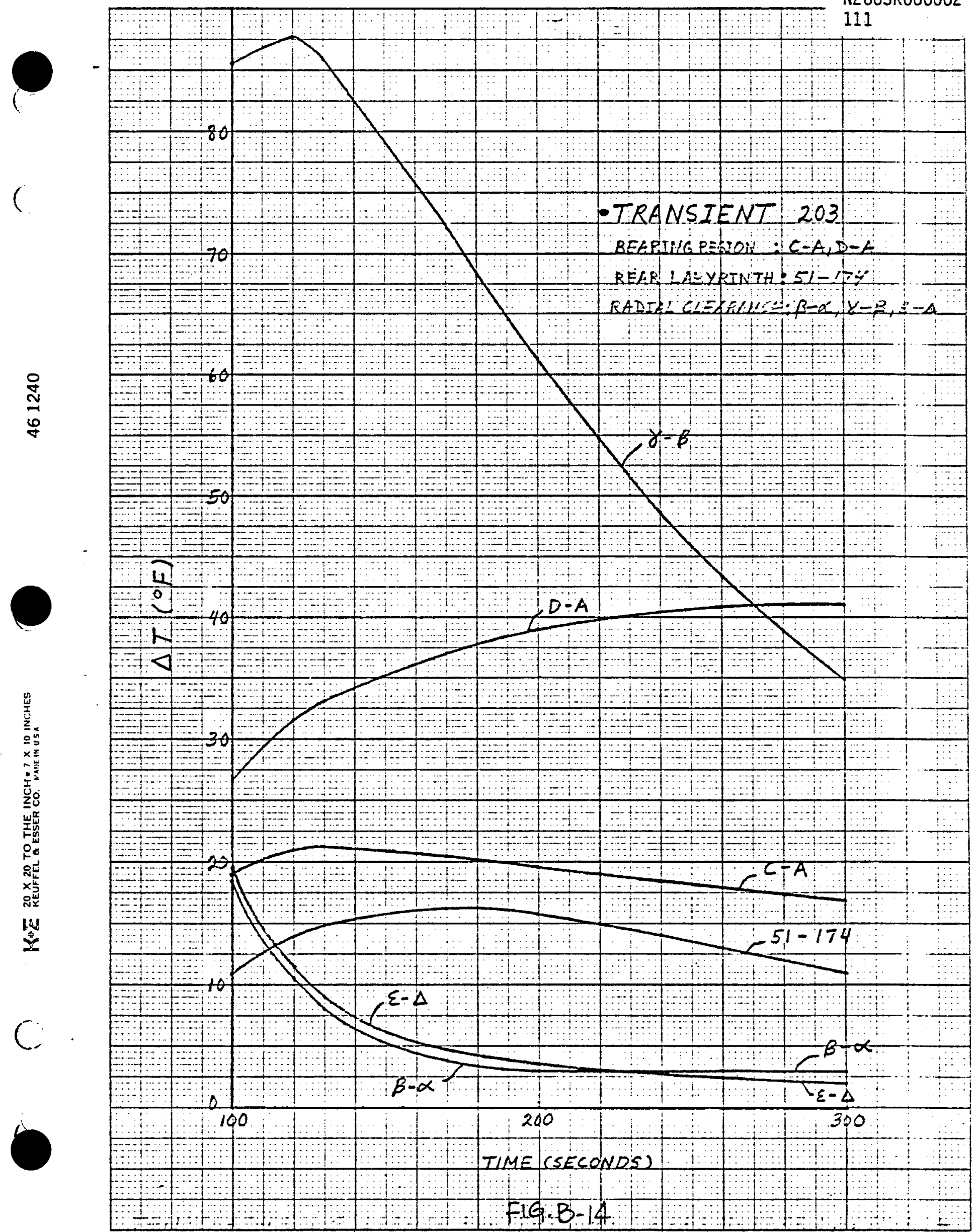


N266ER000-001

Page 481

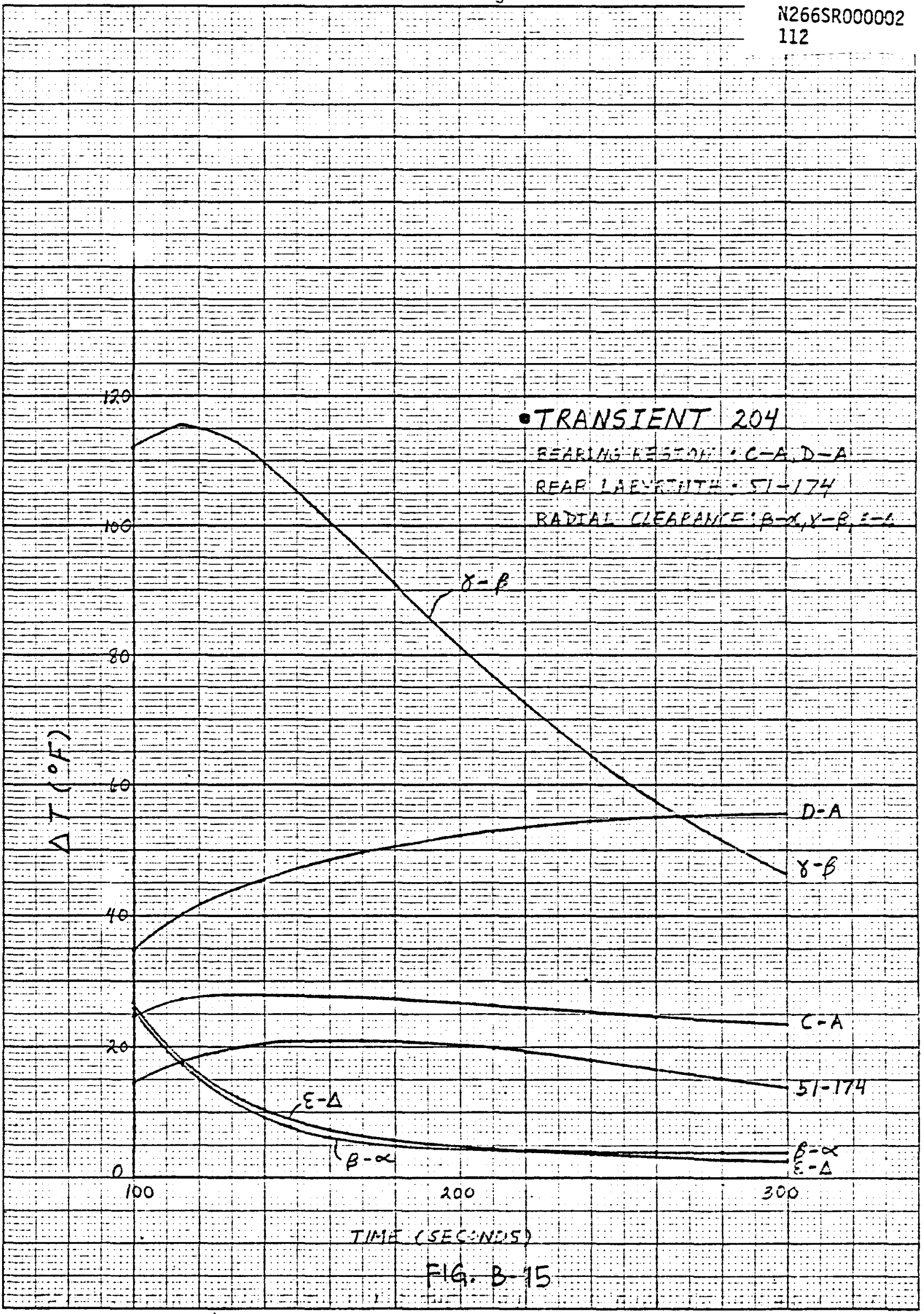




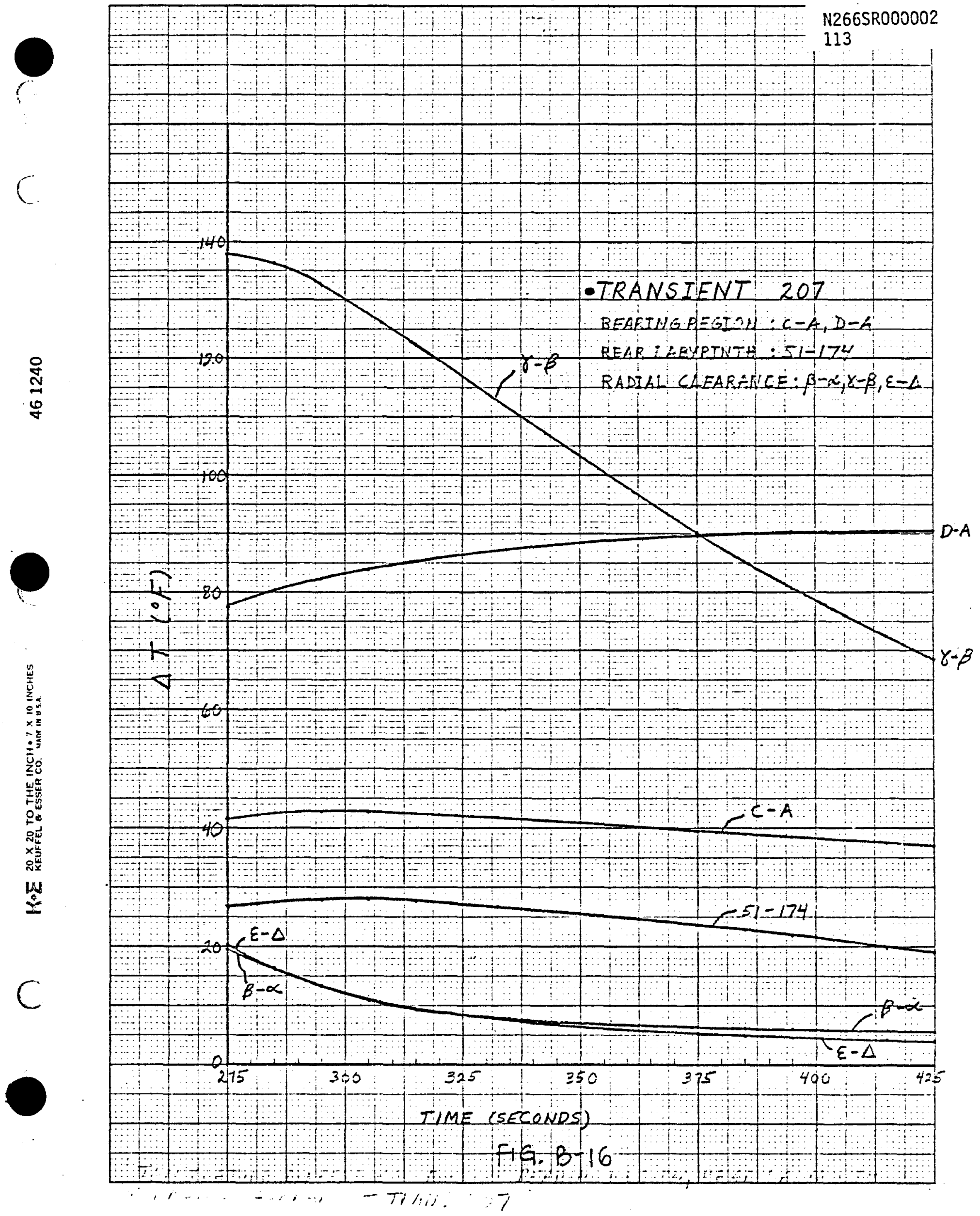


N266ER000-001

Page 483

N266SR000002

114

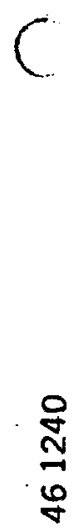

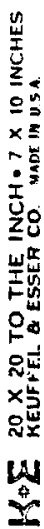

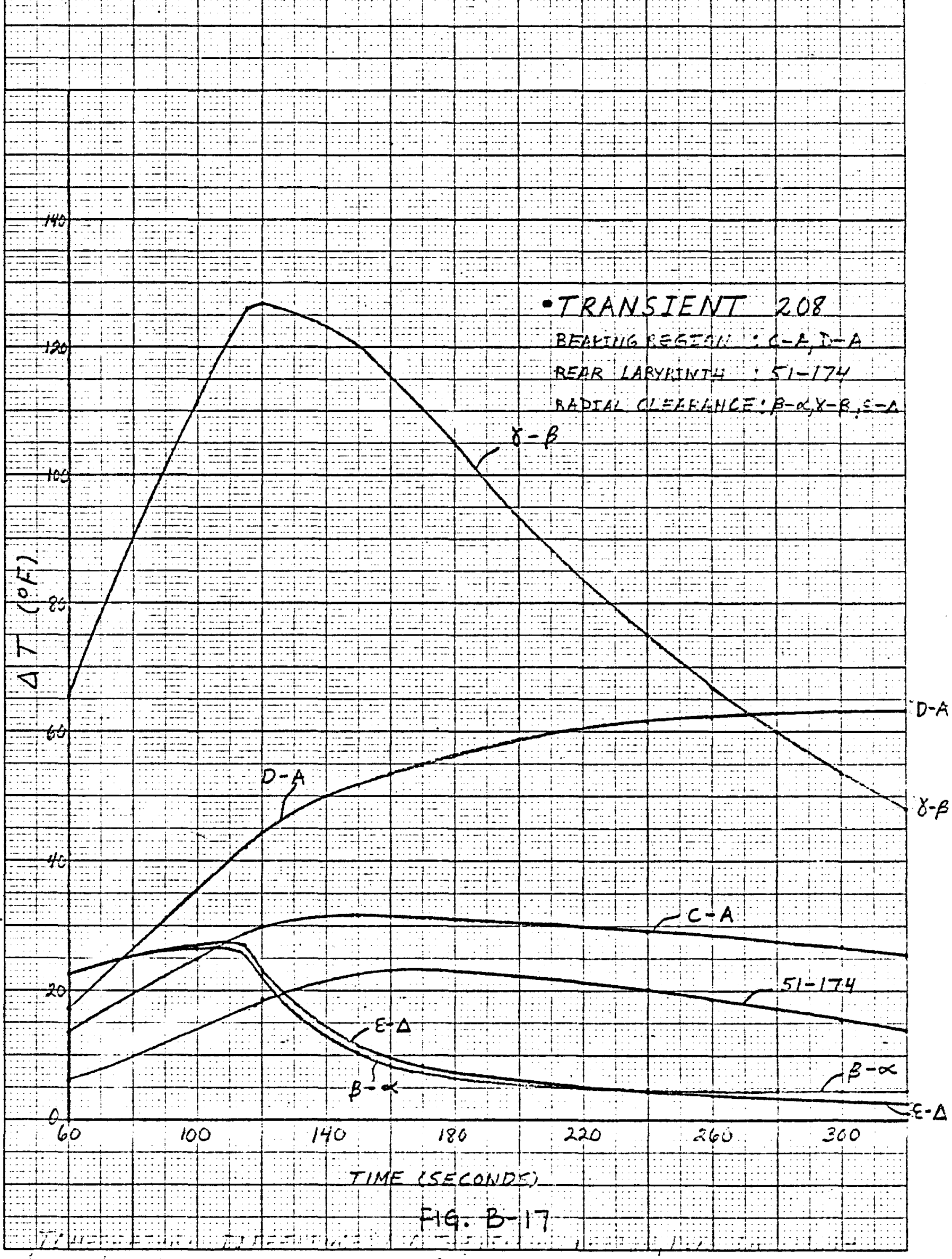




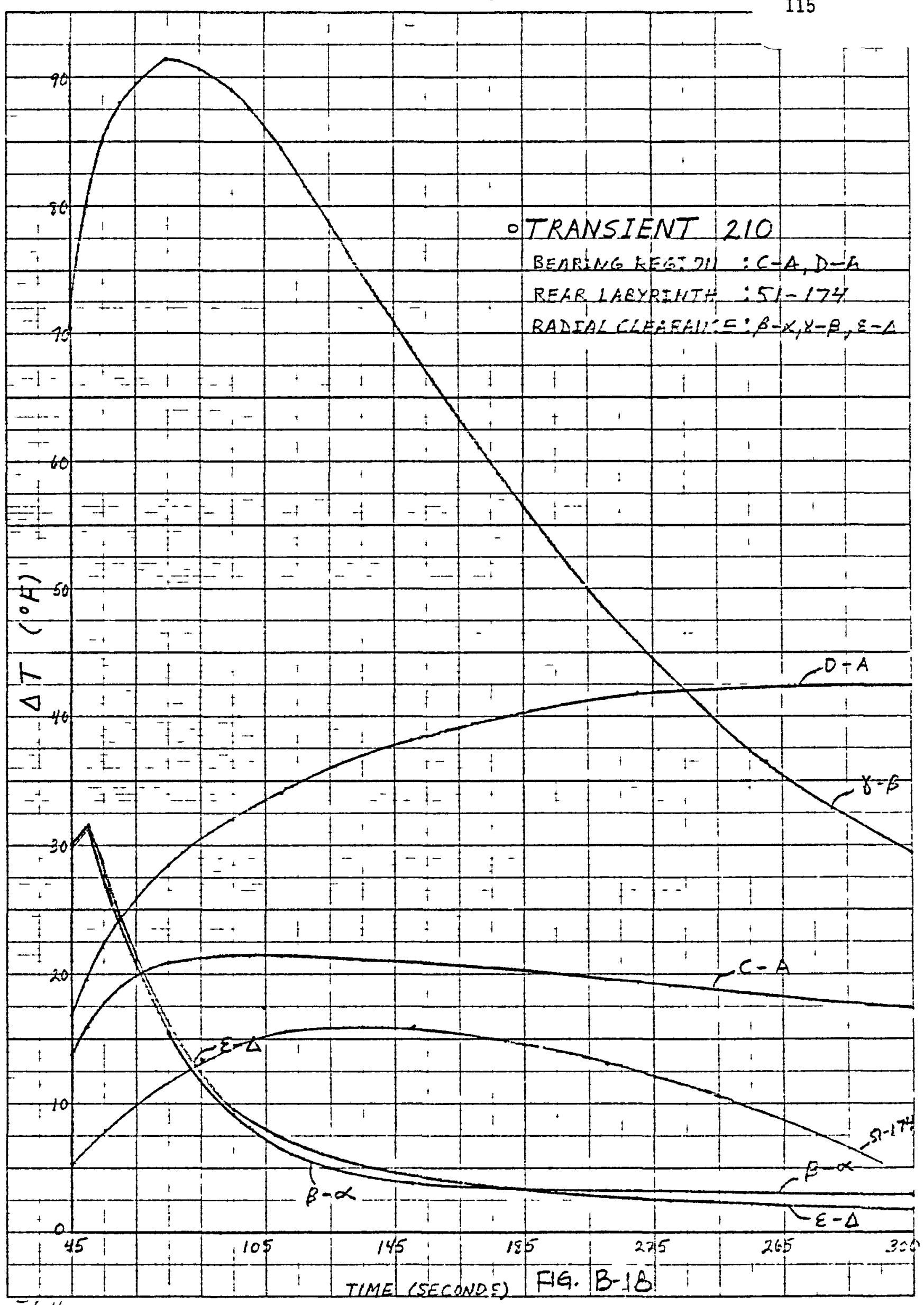


N266ER000-001

Page 485

N266SR000002

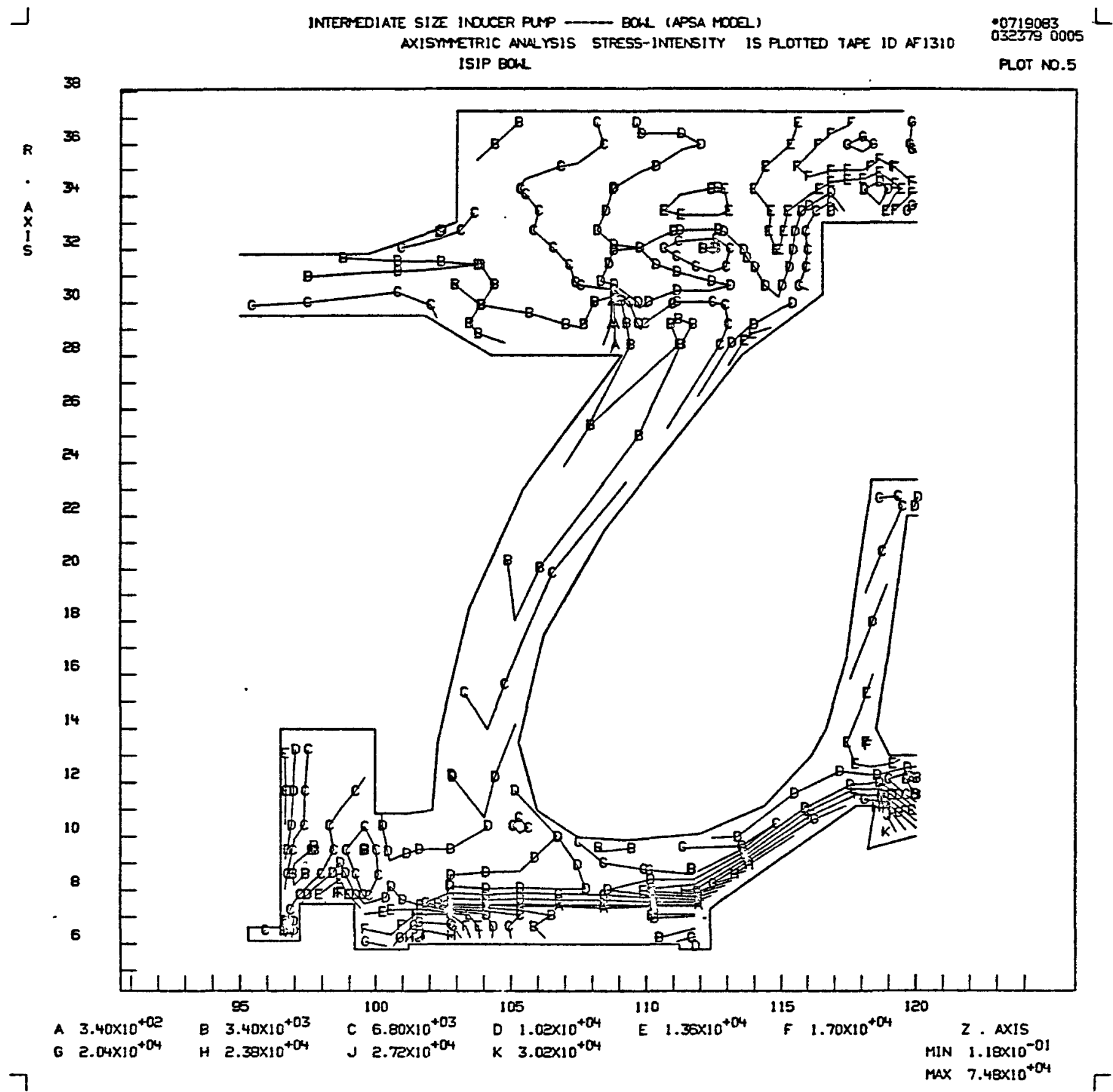

FIG.B-19 STRESS INTENSITY

(TEST TRANSIENT E-207 at 275 seconds) 
N266ER000-001

Page 486

1 N266SR000002 117

INTEFEDIATE SIEE INDUCER PUP --... BOW (APSA MDOEL) AXISTMETRIC ANLYSIS STRESS-INTENGITY IS PLOTTEO TAPE IO AF1310

.0719083 0323790010 ISIP BOAL

PLOT No.10

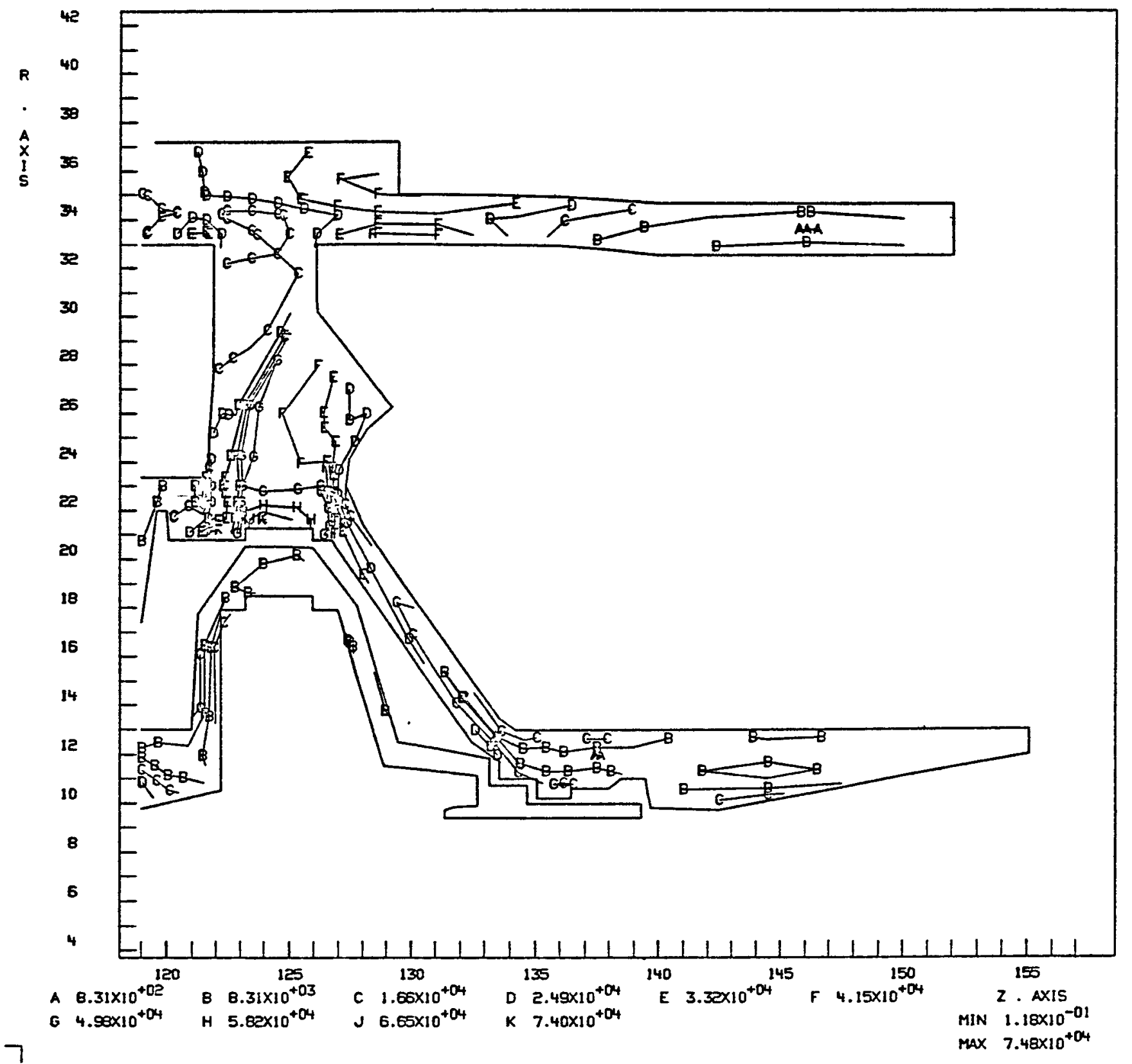

FIG. B-20 STRESS INTENSITY

(TEST TRANSIENT E-207 at 275 Seconds) 
INTERTEDIATE SIII INOUCER PUP _- BOL (APSA MOOEL)

AXISUTETRIC ANALYSIS STPESS-INTENSITY IS PLOTTED TAPE ID AF 1310 ISIP EOL

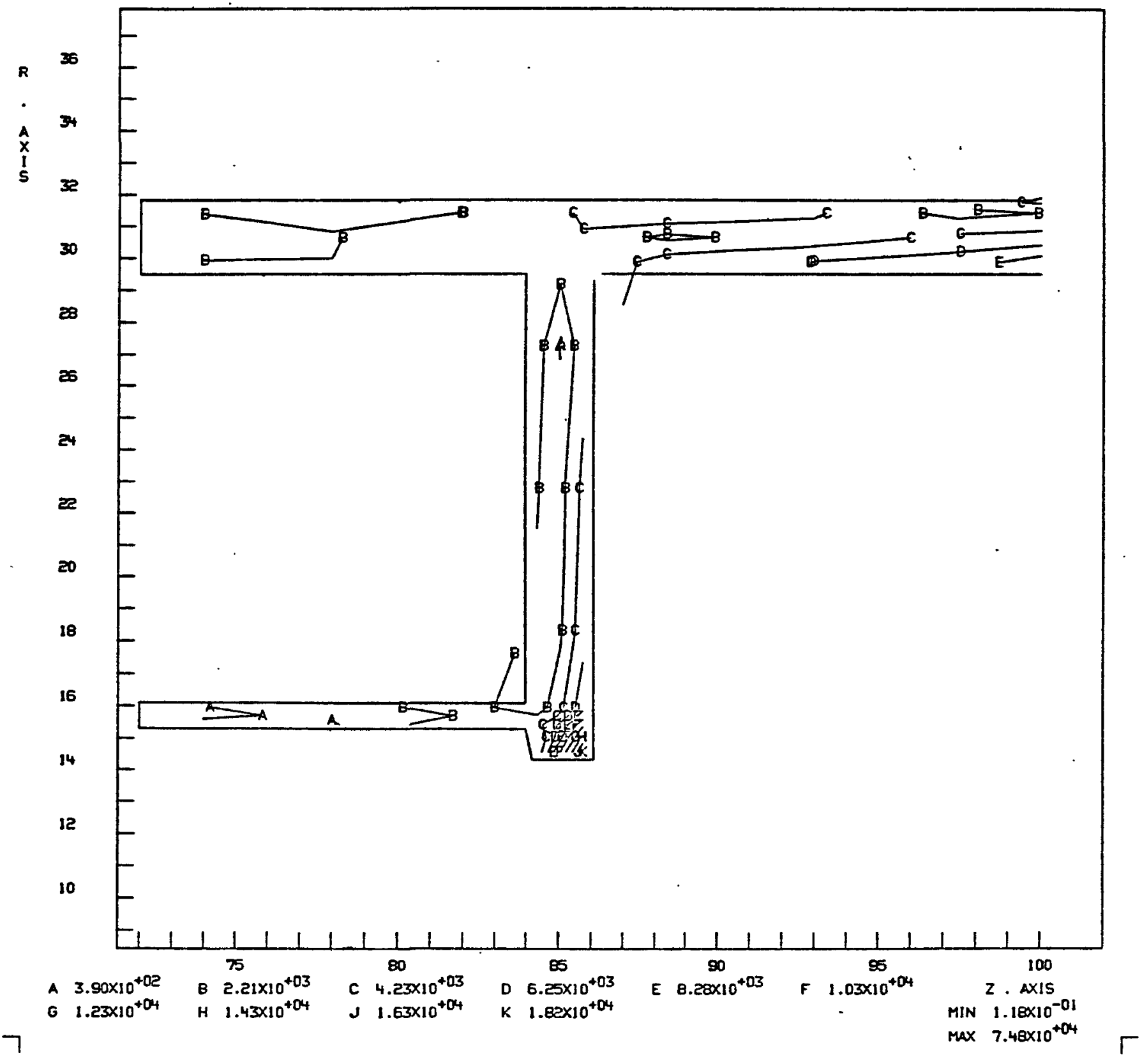

FIG. B-21 STRESS INTENSITY

(TEST TRANSIENT E-207 at 275 seconds) 


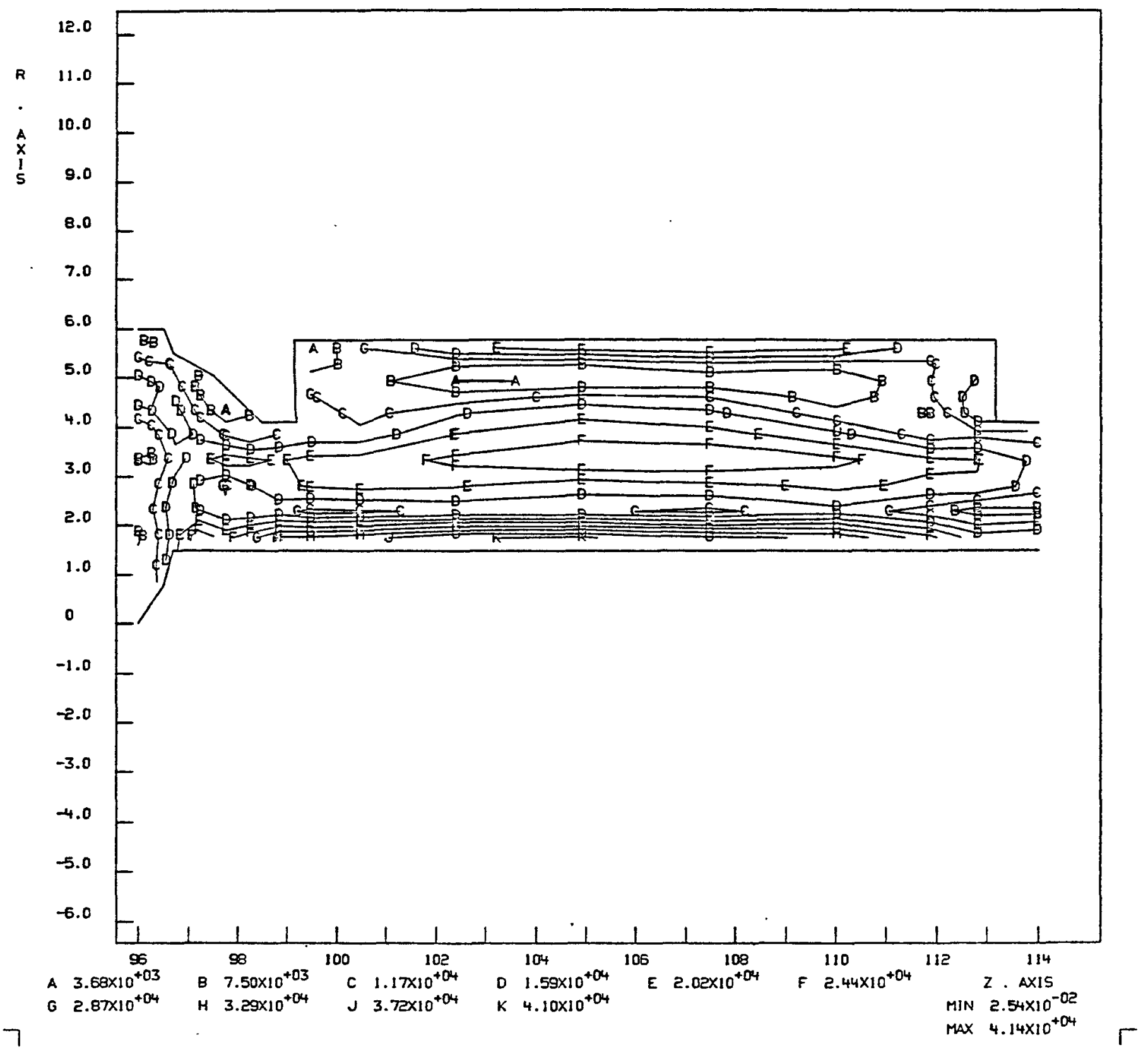

FIG. B-22 STRESS INTENSITY

(TEST TRANSIENT E-207 at 275 seconds) 
INTEREDIATE SOOIUM PUP----SHATT (APSA PLOT) AXISMTETRIC ANALYSIS STPESS-INTENSITY IS RLOTTEO TAPE ID UNOIBE

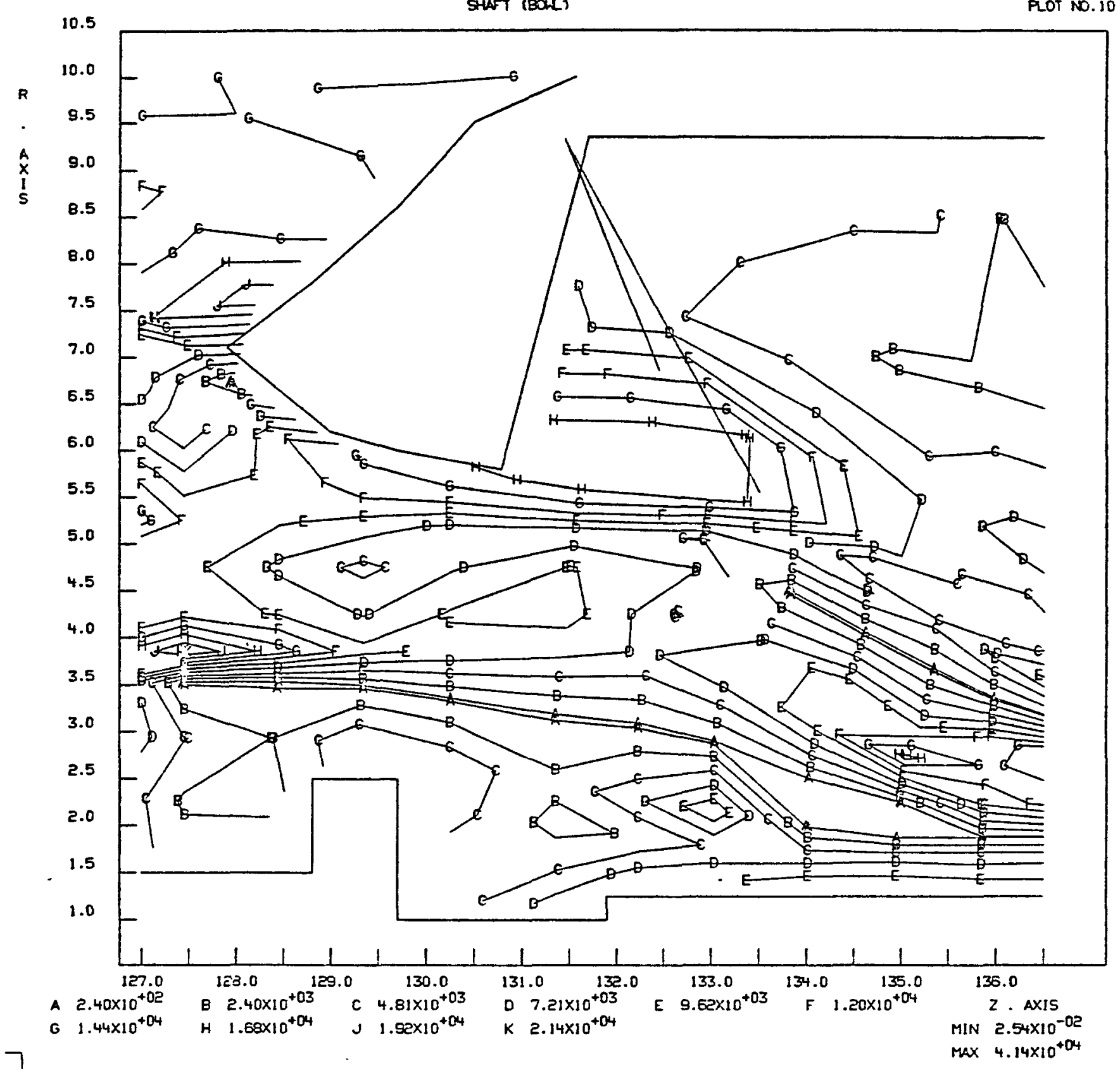

\section{FIG. B- 23 STRESS INTENSITY}



SHAFT (BON)

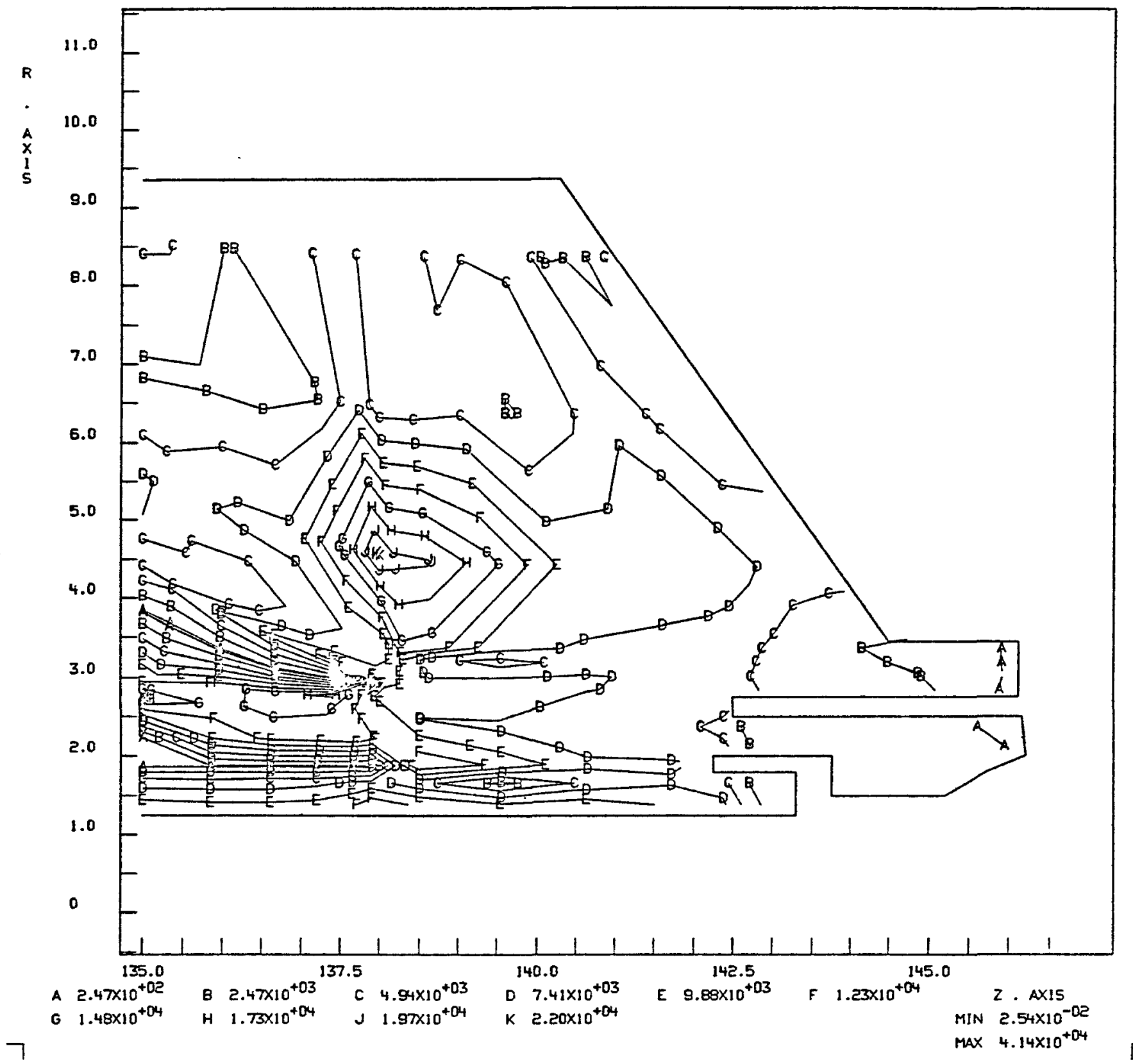

FIG. B-24 STRESS INTENSITY

(TEST TRANSIENT E-207 at 275 seconds) 


\section{TABIE B-37}

THERHAL TRANSIENTS

\begin{tabular}{|c|c|c|c|c|c|}
\hline $\begin{array}{c}\text { Transient } \\
\text { Number* }\end{array}$ & $\begin{array}{c}\text { Sodium } \\
\text { Flow } \\
\text { Rate } \\
\text { (gpm) }\end{array}$ & $\begin{array}{c}\text { Initial } \\
\text { Temp. } \\
{ }_{F}\end{array}$ & $\begin{array}{l}\text { Final } \\
\text { Temp. } \\
\delta_{F}\end{array}$ & $\sum \Delta{ }_{F} T$ & ${ }^{0} \mathrm{dT} / \mathrm{dt} / \mathrm{sec}$ \\
\hline 201 & & & & & . \\
\hline - 202 & 14500 & 750 & 600 & -150 & -1.5 \\
\hline 203 & 14500 & 500 & 650 & +150 & +1.5 \\
\hline 204 & 14500 & 850 & 650 & -200 & -2.0 \\
\hline 205 & & & & & \\
\hline 206 & & & & & \\
\hline 207 & 14500 & $950 \star \star$ & $620 \star \star$ & -330 & -1.2 \\
\hline 208 & 14500 & $950 * \star$ & $725 * \star$ & -225 & -2.0 \\
\hline 210 & 14500 & $950 * \star$ & $800 * \star$ & -150 & -3.0 \\
\hline
\end{tabular}

*From Specification N266ST310001, Table 4-II (Re?.6)

* Hote see Roference 9 


\section{APPENDIX C \\ COMPUTER PROCEDURES FOR STRUCTURAL AND \\ THERMAL DEFORMATION ANALYSIS}

\section{References}

1. J. F. Newell and S. F. Persselin, "Finite Element Axisymetric and Planar Structural Analysis," SSME 74-1282, Rocketdyne Division, Rockwell International, Canoga Park, California 91304, April 18, 1974

2. H. C. Hsiung, "Computer Procedures to Make Thermal Stress Runs Using the APSA Computer Code," IL 600-77-216, Atomics International Division, Rockwell International, Canoga Park, California 91306, June 13, 1977 
In the evaluation of structural and thermal deformation analyses for ISIP, APSA-Mark Interface Computer Code has been utilized to input thermal transient data into APSA finite element program. TAP (Thermal Analysis Program) was used to determine critical temperature difference $(\Delta T)$ through the time-history iteration of each transient for various cross section of pump components. The critical temperature field and time slices of each transient were then used as input for calculating thermal stress and deflection in APSA program. Figure C1 shows the flow chart of computer procedure used. The basic purpose using APSA-Mark Interface Computer Code was that the two programs have different purposes of usage. The computer input cards setup is shown in Figures $\mathrm{C}_{2}$, C3, and C4. Figure C2 shows the coordinates input of temperature field nodes from TAP tape into APSA tape File 1 . Figure $C 3$ is the setup for storing TAP temperature field and time slices in APSA tape File 2. APSA finite element model uses the temperature time slice from File 2 for determining the stress and deflection as shown in Figure C4. 


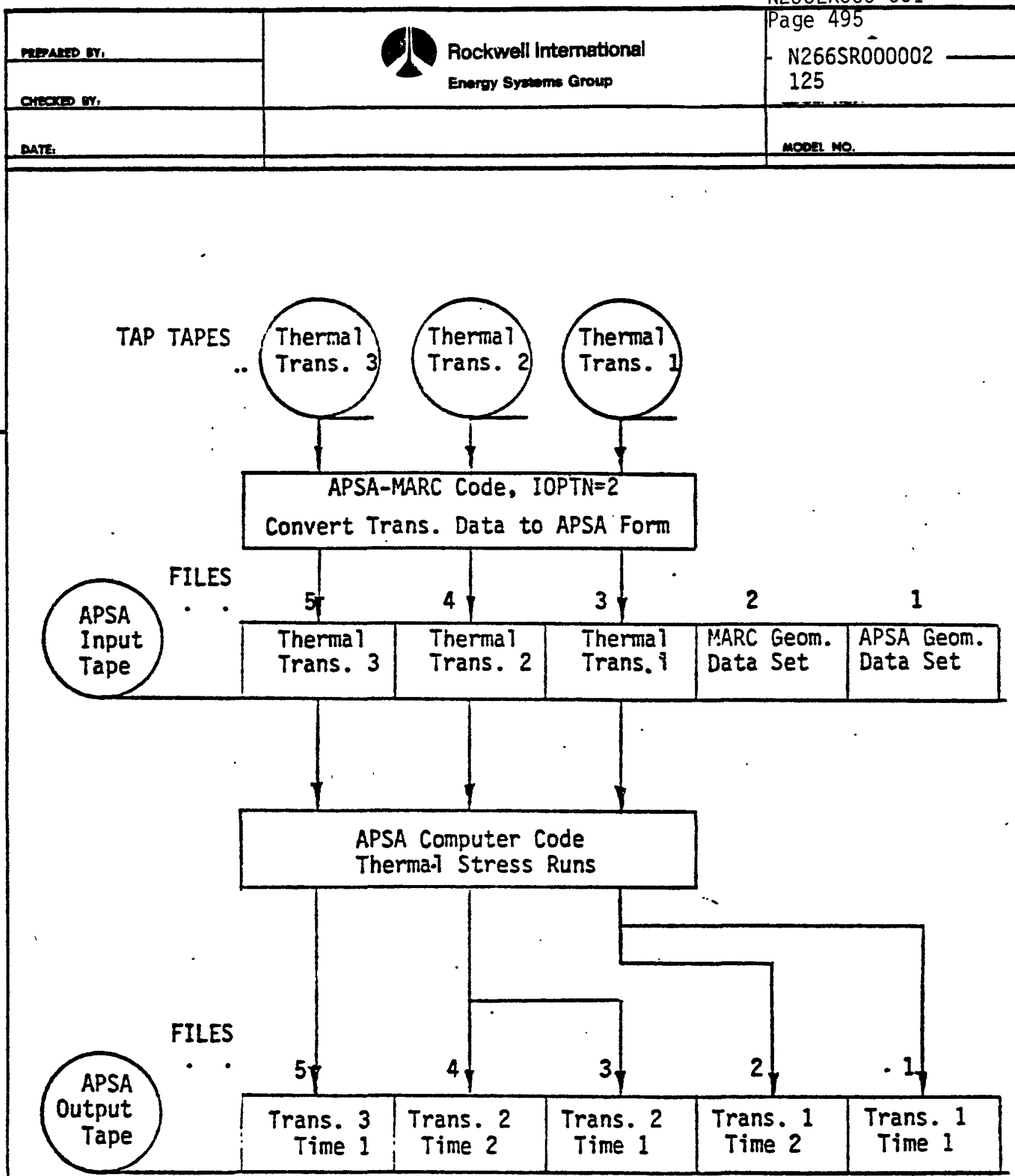

Note:

The APSA input tape contains the temperature field history data of the selected transients, while the output tape contains the thermal stress analysis results.

FIGURE C1 - Flow Chart of Computer Procedures to Use the APSA Code for Thermal Stress Analysis 


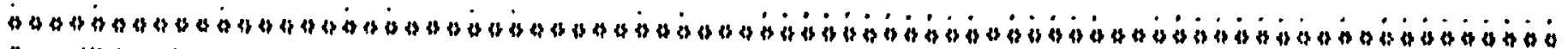

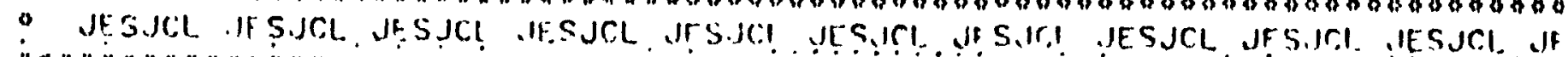

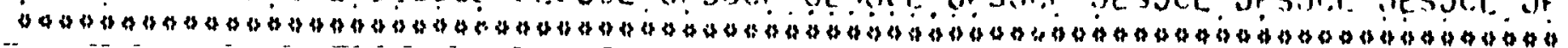

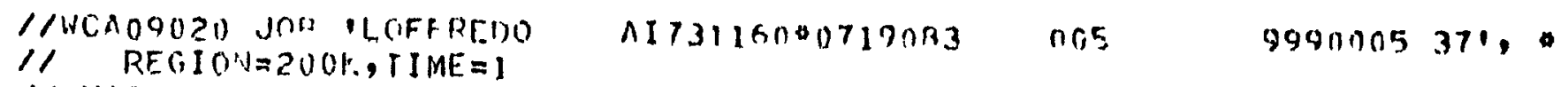

/ OMAIN TAPEAIITHEWOY

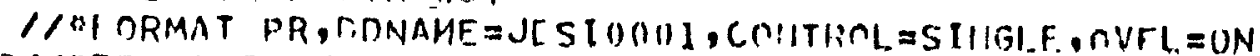

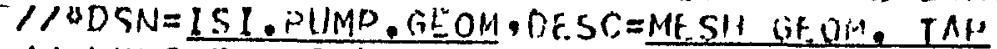

$1 /$ LXIC "IS $1=$ IEBGFNER

//SYSIN DU DUMMY

I/SYSHAINT CO SYSOUTEA

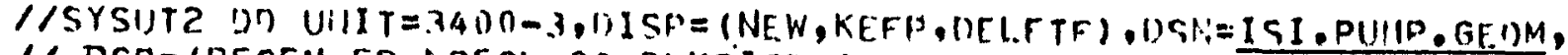

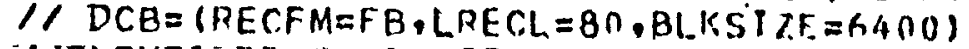

I/SYSUTI DD

BLANK CARD

( TEMPERATURE NODES CORDINATE CARDS FOLlOW THE BLANK CARD)

NOTE: THE UNDERLINED PORTION OF THE JCL.

HAS TO BE MODIFIED FOR EACH CASE

FIG C-2 JCL SETUP

(TAP CORDINATES STORE IN APSA TAPE FILE 1)

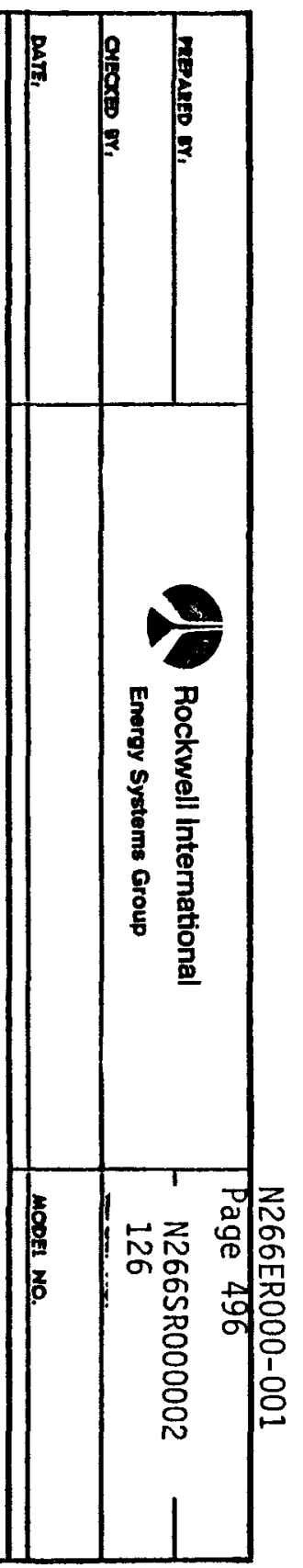




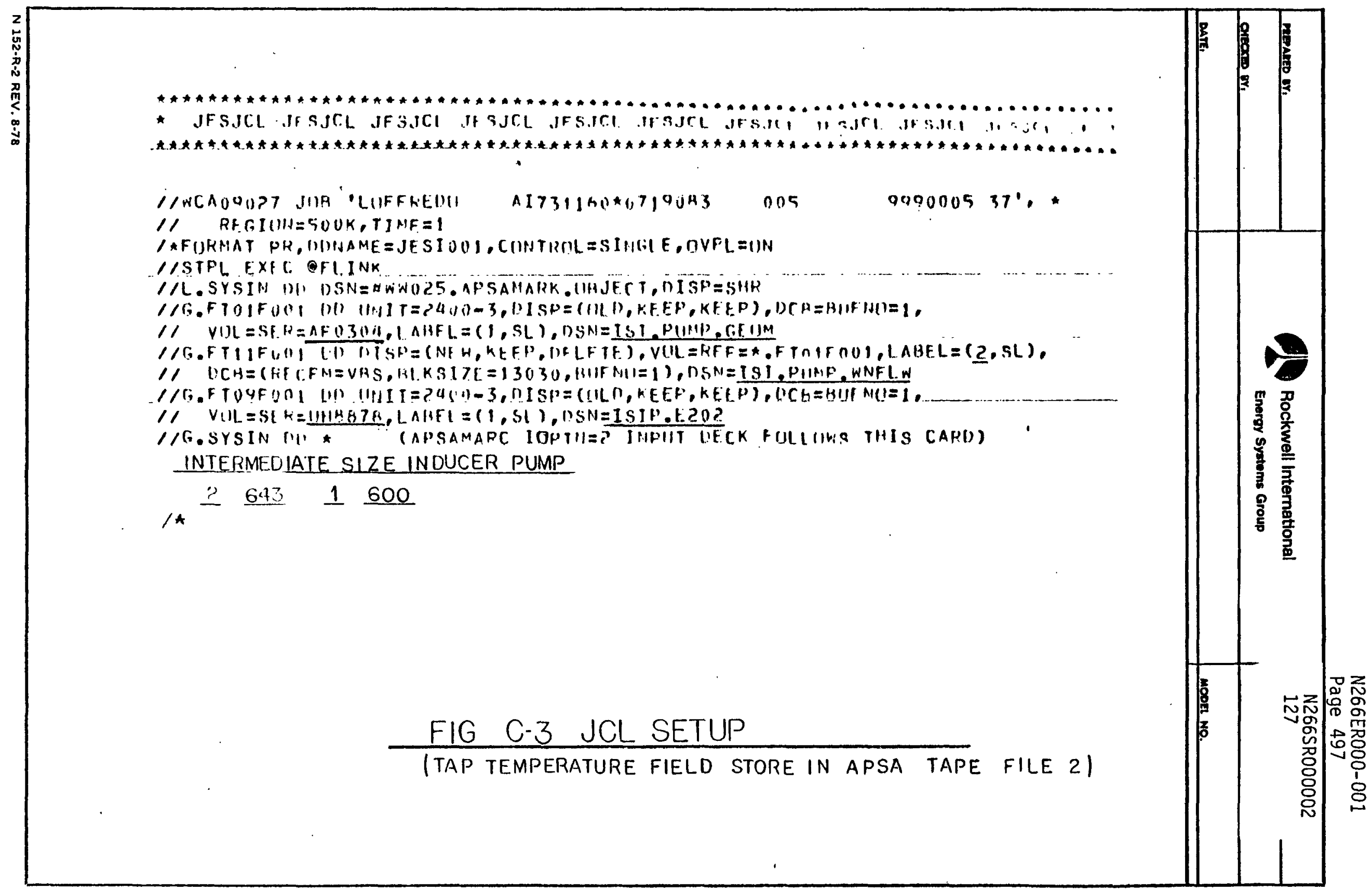




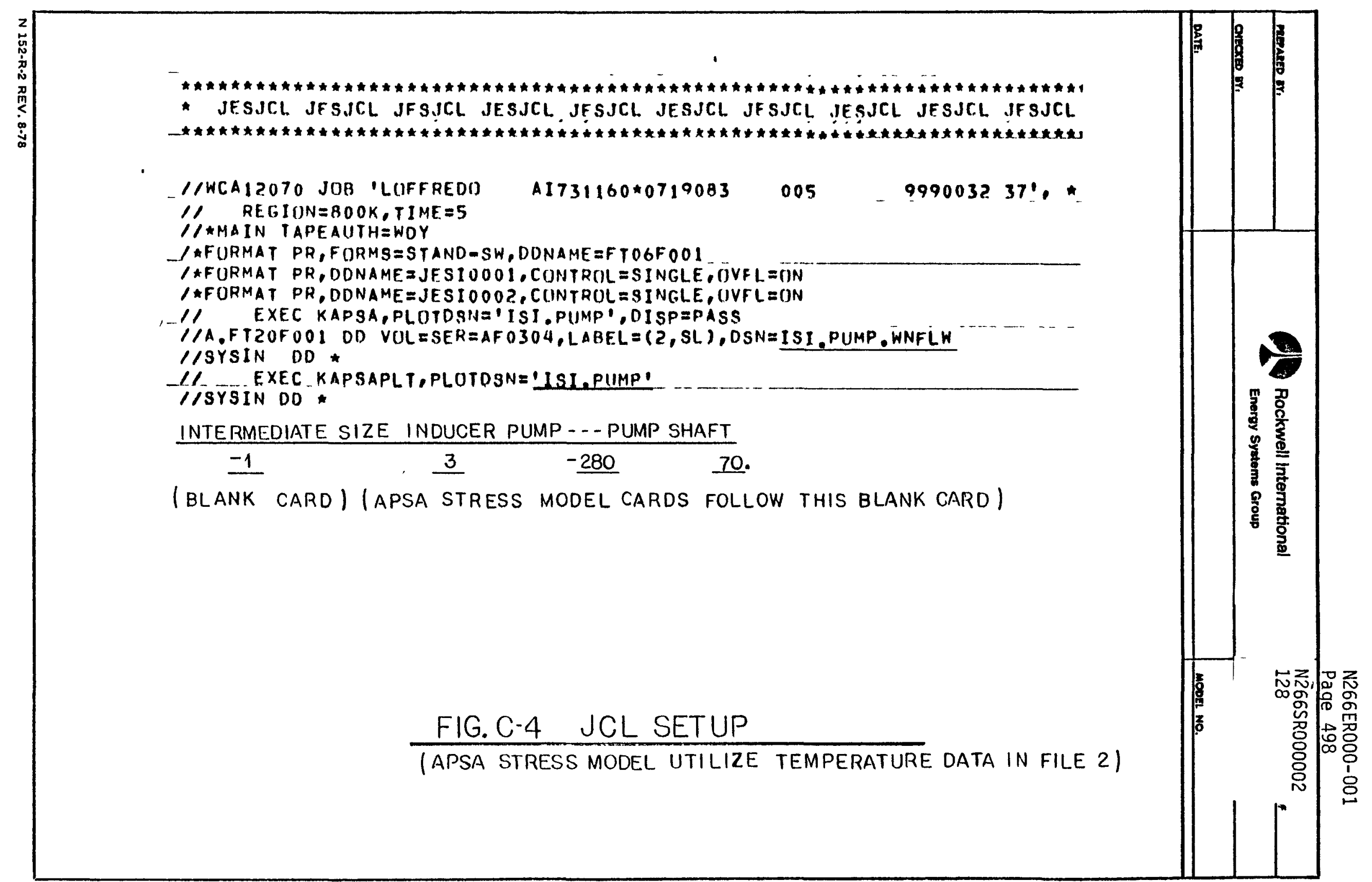


APPENDIX J

TRANSIENT THERMAL ANALYSIS OF ISIP

ESG Document N266TI000-008

Pages 108 thru 281 (computer printout) have been removed from this document for brevity. 
620-79-065

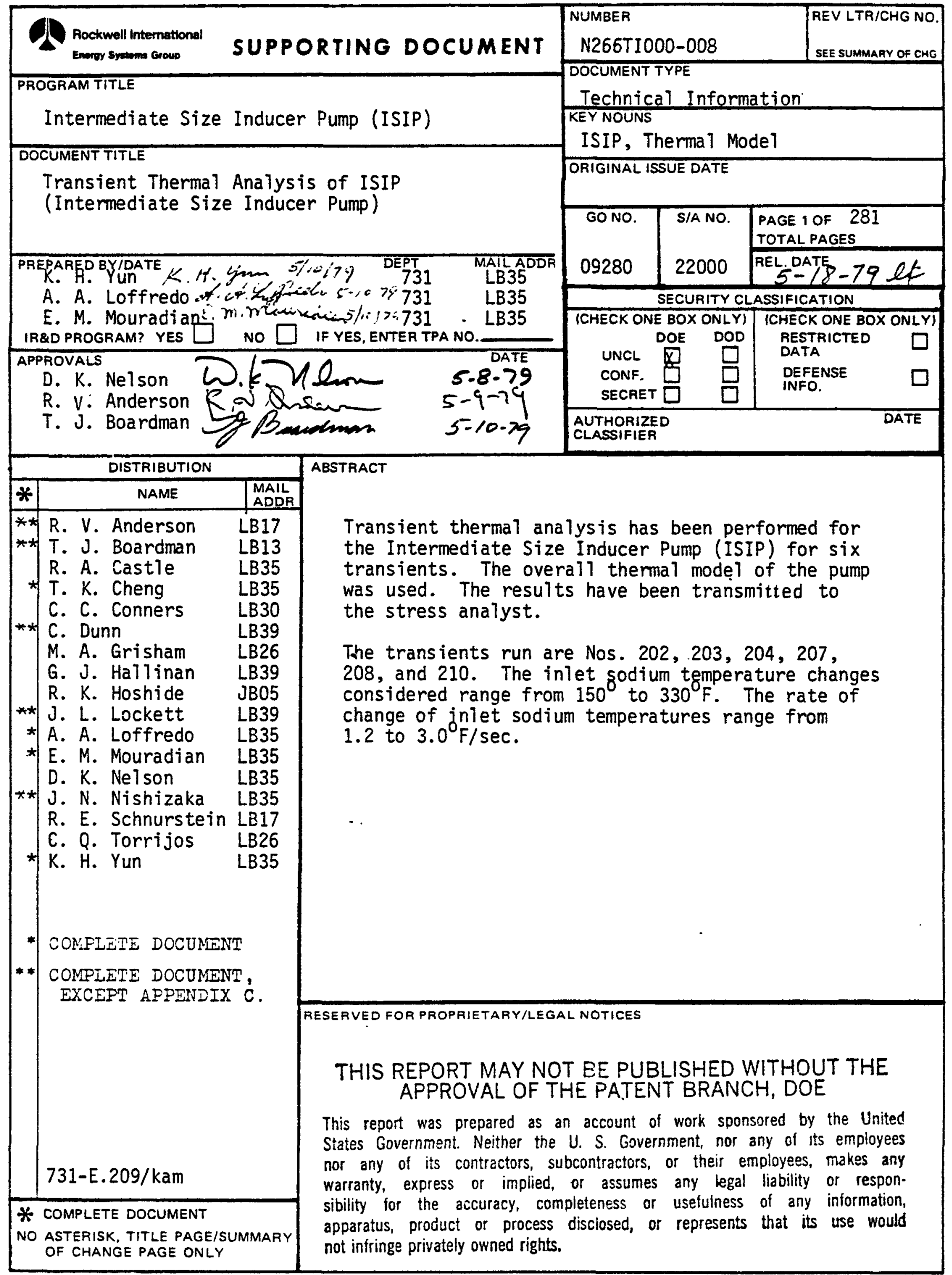




\section{CONTENTS}

\section{Page}

I. INTRODUCTION AND SUMMARY..................... 5

II. ANALYSIS $\ldots \ldots \ldots \ldots \ldots \ldots \ldots \ldots \ldots \ldots \ldots \ldots \ldots \ldots \ldots \ldots \ldots$

III. DISCUSSION OF RESULTS ....................... 10

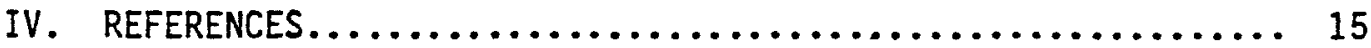

APPENDICES $\ldots \ldots \ldots \ldots \ldots \ldots \ldots \ldots \ldots \ldots \ldots \ldots \ldots \ldots \ldots \ldots \ldots \ldots \ldots \ldots$

A. Supporting Calculations.................... 40

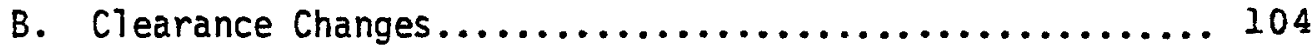

C. Transient Analysis \& Computer Listing.............. 107 
FIGURES

Figure

Page

1. Layout: Intermediate Sodium Inducer Pump.............. 16

2. ISIP: Overal1 Thermal Model...................... 17

3. Flow Pattern for Sodium Nodes....................... 18

4. Stamp Output CRT.............................. 19

5. ISIP New Hardware............................ 20

6. Weighted Average Temperature - TRANS 202.............. 21

7. Weighted Average Temperature - TRANS 203.............. 22

8. Weighted Average Temperature - TRANS 204.............. 23

9. Weighted Average Temperature - TRANS $207 \ldots \ldots \ldots \ldots \ldots \ldots . . \ldots 24$

10. Weighted Average Temperature - TRANS 208.............. 25

11. Weighted Average Temperature - TRANS $210 \ldots \ldots \ldots \ldots \ldots \ldots \ldots . . \ldots 26$

12. Node Number Across Inducer, Tie Bolt \& Inducer Tunne1...... 27

13. Temperature Differences Across the Inducer, Tie Bolt \& Inducer Tunnel - TRANS 2020203.................... 28

14. Temperature Differences Across the Inducer, Tie Bolt \& Inducer Tunnel - TRANS 204D207........................ 29

15. Temperature Differences Across the Inducer, Tie Bolt \& Inducer Tunnel - TRANS 208D210................... 30

16. ISIP - Thermal Effect on Radial Clearance.............. 31

17. Rear Labyrinth............................. 32

18. Rearing Region............................. 33

19. Temperature Difference for the Bearing Region, Rear Labyrinth \&-Radial Clearance - TRANS 202............... 34-

20. Temperature Difference for the Bearing Region, Rear Labyrinth \& Radial Clearance - TRANS 203............... 35

21. Temperature Difference for the Bearing Region, Rear Labyrinth \& Radial Clearance - TRANS 204................ 36

22. Temperature Difference for the Baring Region, Rear Labyrinth \& Radial Clearance - TRANS 207.............. 37

23. Temperature Difference for the Bearing Region, Rear Labyrinsth \& Radial Clearance - TRANS 208.............. 38

24. Temperature Difference for the Bearing Region, Rear Labyrinth \& Radial Clearance - TRANS $210 \ldots . \ldots \ldots . . \ldots . . . .39$ 


\section{TABLES}

Table

1. Hydrodynamic Design Report........................ 6

2. Test Thermal Transients........................ 7

3. Transient Temperature Data......................... 11 


\section{INTRODUCTION AND SUMMARY}

The purpose of this study is to evaluate the transient thermal behavior of the intermediate size inducer pump (ISIP) during the six thermal transients.

An overall thermal model (Figure 2) has been set up for the pump based on the drawing of Figure 1 (Reference 1 ).

Approximately 10 thermal transients are indicated in the specification (Reference 2). Of these, six were analyzed, some with minor temperature modification, as discussed in Reference 3. Table I shows the updated pump design point, and Table II shows the list of six transients that were analyzed.

The basic pump frame for the ISIP is from the FFTF prototype pump. Some of the pump internals have been changed according to the Rockwell International design. The changes included new inducer, impeller, diffuser, and other necessary adapter hardware. The original impeller has been replaced.

The results of the thermal analysis are stored on magnetic computer tape (corresponding to the nodal model of Figure 2). Some of the results are summarized in the figures of this report.

The purpose of the analytical effort (both thermal and structural) is to establish the pump's capability to withstand thermal transients without damage or alternatively, to indicate that particular transients must not be run in the test program. 
PAGE . 6

Flow Rate

Total Head Across Pump

Shaft Speed

Type of Fluid

Maximum Inlet Transient Temperature

Minimum Inlet Transient Temperature
$14,500 \mathrm{gpm}$

$500 \mathrm{ft}$

$1,100 \mathrm{rpm}$

Sodium

$950^{\circ} \mathrm{F}$

$600^{\circ} \mathrm{F}$

\section{TABLE I}

HYDRODYNAMIC DESIGN POINT

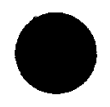


TABLE II

TEST THERMAL TRANSIENTS

\begin{tabular}{|c|c|c|c|c|c|c|}
\hline $\begin{array}{l}\text { TRANSIEN? } \\
\text { NUII IEER }\end{array}$ & $\begin{array}{l}\text { SODIUN } \\
\text { FLOW } \\
\text { RATE } \\
\text { (GPAI) }\end{array}$ & $\begin{array}{l}\text { INITIAL } \\
\text { TENIP. } \\
{ }^{\circ} \mathrm{F}\end{array}$ & $\begin{array}{l}\text { FINAL } \\
\text { TEMP. } \\
{ }^{\circ} F\end{array}$ & $\begin{array}{l}{ }_{i} \Delta T \\
{ }^{\circ} \mathrm{F}\end{array}$ & $\begin{array}{l}d T / d t \\
{ }^{\circ} \mathrm{F} / \mathrm{SEC}\end{array}$ & $\begin{array}{l}\text { CRITICAL } \\
\text { TIMES } \\
(S E C)\end{array}$ \\
\hline 202 & 14500 & 750 & 600 & -150 & -1.5 & $\begin{array}{l}100 \\
280\end{array}$ \\
\hline 203 & 14500 & 500 & 650 & +150 & +1.5 & $\begin{array}{l}100 \\
280\end{array}$ \\
\hline 204 & .14500 & 850 & 650 & -200 & -2.0 & $\begin{array}{l}100 \\
210\end{array}$ \\
\hline 207 & 14500 & 950 & 620 & -330 & -1.2 & $\begin{array}{l}275 \\
385\end{array}$ \\
\hline 208 & 14500 & 950 & 725 & -225 & -2.0 & $\begin{array}{l}115 \\
240\end{array}$ \\
\hline 210 & 14500 & 950 & 800 & -150 & -3.0 & $\begin{array}{l}50 \\
150\end{array}$ \\
\hline
\end{tabular}




\section{ANALYSIS}

Thermal analysis was conducted using the TAP computer program package. A conservative two-dimensional model (Figures 2 and 3) was constructed to simulate the geometry of the ISIP. Symmetry was assumed in setting up the model. In Reference 9, calculations were made with this model and the results compared with FFTF tests. These results verified the validity of this model.

The design specification for the thermal model required the ISIP to withstand the specified thermal transients. The effects of thermaliy induced stresses and deflections must be evaluated.

Figure 3 shows the nodal network and flow pattern for the sodium nodes. Flow paths were obtained from Reference 4. Flow conditions are discussed in Appendix A. The sodium flow pattern is built into the model.

The overall thermal model of the ISIP was set up based on Figure 1. The thermal model in Figure 4 was processed using the STAMP program (Reference 5) generating the nodal network with the areas, form factors, and nodal volumes for use in the TAP program (References 6 and 7). Additional supporting calculations are shown in Appendix $A$. These inciude form factor calculations for the inducer, impeller, diffuser, sodium flow node volumes, and heat transfer coefficients.

The thermal properties of sodium were taken as constant as shown in Appendix A. The properties of the stainless steel and sodium were taken from Reference 8 . The thermal conductivity and therma 1 capacity for the stainless steel were input into the TAP program as functions of temperature. 
N266ER000-001

Page 508

Rockwell International

NO $\quad$ N266TI000-008

Energy Systems Group

PAGE.

9

Heat transferred by mass transport between volumes was accounted for by fluid channel elements. For these, specific mass flow rate and direction were specified by Reference 4. Pump bowl and pump casing wall outer surfaces were assumed adiabatic. The inlet nozzle was added to the network generated by hand as shown in Figure 2.

FORM 719.P REV. 7.78 


\section{DISCUSSION OF RESULTS}

The results of the transients computer runs are stored on magnetic tapes, as indicated in Table III. The data now shown on the computer output sheets or CRT's can be retrieved a a later time. Also, the data can be called from the tapes for use with the APSA program for stress and deflection analysis.

The critical times for thermal deflection (i.e., when the deflection is a maximum) during transients has been determined. This determination has been made for three different locations: (1) AI modification, (2) rear labyrinth, and (3) bearing region.

\section{A. AI MODIFICATIONS}

Figure 5 shows the relative position of the ISIP new hardware. This includes the impeller, inducer, shaft nut, and tie bolt. The weighted temperature for each of the four components were plotted versus time. It can be seen that for each of the six transients in Figure 6 through Figure 11, the greatest temperature difference occurs between the impeller and the shaft nut. Thus, the critical time is taken to be when the greatest temperature difference occurs. Figure 12 shows some thermal nodes at particular places, tie bolt, inducer, and inducer tunnel. The temperature differences across the tie bolt, inducer, and inducer tunnel can be seen on Figures 13 through 15. Figure 16 shows subdivisions of the ISIP for the rotating and nonrotating parts with their nominal radial clearances. 
TABLE III

TRANSIENT TEMPERATURE DATA

\begin{tabular}{ccc}
\hline Transient Number & Tape Name & Tape VoTume Serial Number \\
\hline 202 & ISIP.E202 & UH 8878 \\
203 & ISIP.E203 & UG 5728 \\
204 & ISIP.E204 & UP 8892 \\
$2 \uparrow 7$ & ISIP.E207 & AE 9996 \\
208 & ISIP.E208 & UP 7819 \\
210 & ISIP.E210 & UL 1717 \\
\hline
\end{tabular}


PAGE . 12

\section{B. REAR LABYRINTH}

Figure 17 shows the position of the rear labyrinth with its respective radial clearance. For temperative deflections, Nodes 174 and 51 were chosen for the nonrotating part and rotating part, respectively.

C. BEARING REGION

For radial thermal deflection, Figure 18 shows the subdivisions of the bearing region. Temperature differences between the shaft and the bearing, shaft and the bearing support and bearing were plotted as functions of time.

The results of the thermal analysis were made available to the stress unit. On the basis of temperature differences for the three regions discussed above, the critical times for thermal deflections were determined. The temperature distributions for these time slices are employed by the stress analyst to determine stress distributions and gap defelctions. Two critical times were determined for each of the six transients. Appendix $B$ shows the thermal deflections for each of the six transients (Reference 10).

The individual transients are discussed below.

\section{Transient 202}

It is a down transient. The first cirtical time, $100 \mathrm{sec}$ after the start of the transient, was selected for the region of the inducer and impelier (Figures 6 and 13) and for the radial clearance of the blade and the static assembly (Figure 19). The second critical time (280 sec) 
was determined for the bearing region. For the rear labyrinth region, the time was determined to be $180 \mathrm{sec}$. However, the highest temperature difference at this particular time is only $16^{\circ} \mathrm{F}$, and the gap has a radial clearance of $50 \mathrm{mils}$.

\section{Transient 203}

This is the only up transient. The slope of the transient $\left(1.5^{\circ} \mathrm{F} / \mathrm{sec}\right)$ is the same value as in Transient 202. Due to the same identical conditions (but different startup temperatures), the critical times were found to be the same as in Transient 202, that is at 100 and $280 \mathrm{sec}$. It can be seen from Figures 7, 13, and 20, that the temperature differences for the three separate regions are essentailly the same as Transient 202 except for a change in sign.

\section{Transient 204}

It is a down transient. The first critical time (100 sec) was selected for the inducer and impeller (Figures 8 and 14) and for the radial clearance of the blade and the nonrotating part of the ISIP (Figure 21). The second critical time was dtermined to be $210 \mathrm{sec}$. At this time, the bearing region and rear labyrinth portion have temperature differentials of $94 \%$ and $95 \%$, respectively, of their peak values.

\section{Transient 207}

This is a down transient with the greatest overall temperature change (nominally $330^{\circ} \mathrm{F}$ ). According to Figures 9, 14, and 22, the first critical time was determined to be $275 \mathrm{sec}$ for the new hardware of the ISIP. At this time, the rear labyrinth region at $96 \%$ of its peak value (Figure 22). For the bearing area, the time chosen was $385 \mathrm{sec}$. Both temperature differentials are over $95 \%$ of their peak values at $t=335 \mathrm{sec}$. 


\section{Transient 208}

The weighted temperature and temperature differences for the down Transient 208 can be seen in Figures 10, 15, and 23. The first critical time was determined to be $115 \mathrm{sec}$ for the inducer and the impeller region. The second critical time was determined to be $240 \mathrm{sec}$ for the bearing portion and the rear labyrinth area (Figure 23).

\section{Transient 210}

This is the down transient with the steepest slope, dT/dt (nominally $-3.0^{\circ} \mathrm{F} / \mathrm{sec}$ ). Figures 11,15 , and 24 show the first ciritcal time to be $50 \mathrm{sec}$ for the new hardware area. The second critical time was determined to be $150 \mathrm{sec}$ for the rear labyrinth portion and the bearing region. 


\section{REFERENCES}

1. Westinghouse Electric Corporation, Drawing No. 689J080, "General Layout FFTF Prototype Pump"

2. D. R. Paradise, "Design Specification: Pump, Sodium, Inducer, Intermediate Size," N266ST310001, June 10, 1978, Atomics International Division

3. J. M. Nishizaka/E. M. Mouradian, "Estimate for Completion of ISIP Program Thermal/Stress Analys is," IL 620-79-043, March 12, 1979, Atomics International Division

4. R. K. Hashide, "Recirculation Flow Analyses of Intermediate Size Inducer Pump (ISIP)," TI N266TI000003, April 20, 1978, Atomics International Division

5. R. E. Craig, "Stress to Thermal Adaptation Model Program (STAMP) Description and User's Manua1," TI 036-610-007, Ju7y 29, 1974, Atomics International Division

6. E. Moody, "Thermal Analyses Program Revision (TAP-4F)," TI 099-411-015, August 1974, Atomics International Division

7. A. V. VonArx, "Thermal Analysis Program (TAP) Description and User's Manua 1," N036CPM620006, January 1979, Atomics International Division

8. Hanford Engineering Development Laboratory, "Nuclear System Materials Handbook," Volume 1, Book 1 (Steel), and Book 3 (Sodium), TID-26666

9. K. H. Yun/A. A. Loffredo/E. M. Mouradian, "Verification of Thermal Model for ISIP.," N266TI000-007, March 9, 1979, Atomics International Division

10. T. K. Cheng/J. N. Nishizaka, "ISIP-Structural and Transient Deformation Analysis," N266SR000-002, May 5, 1979, Atomics International Division 


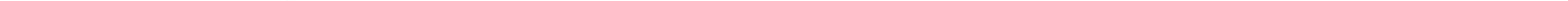




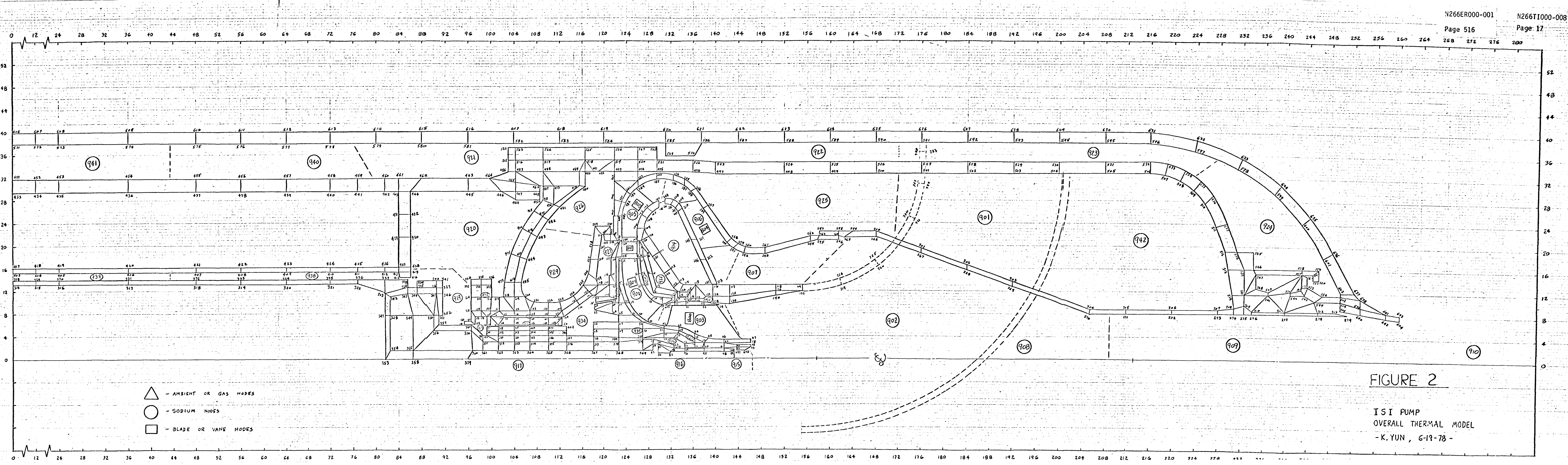




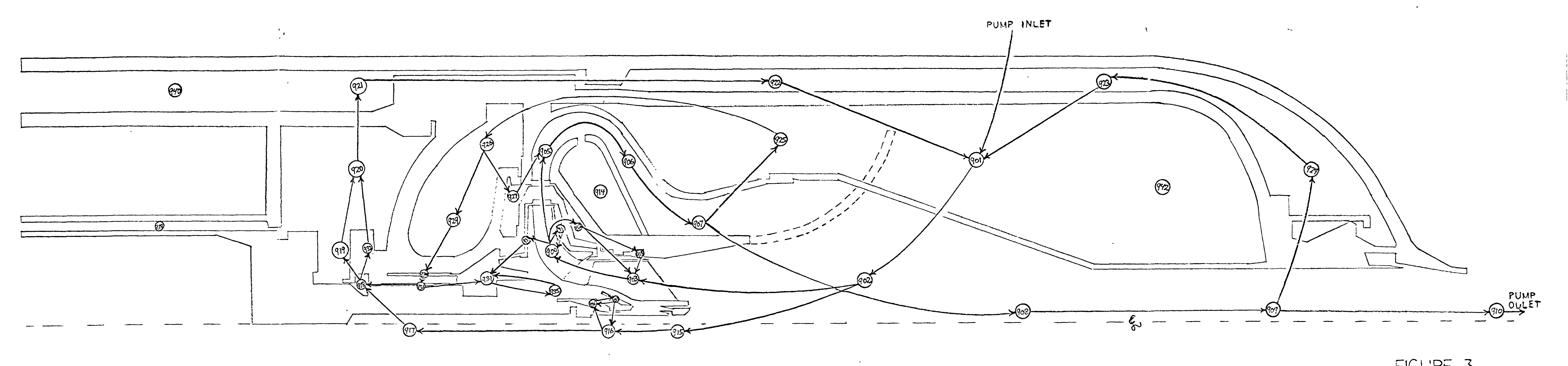




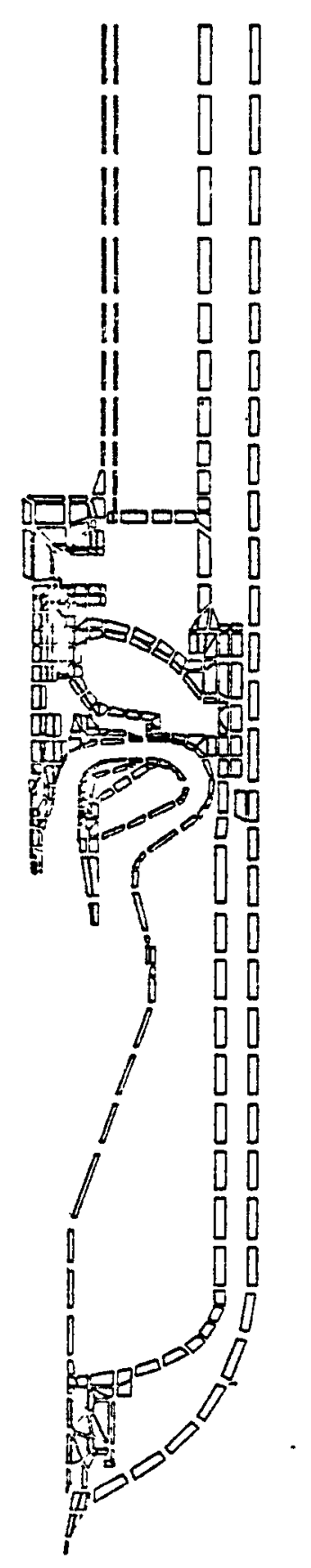



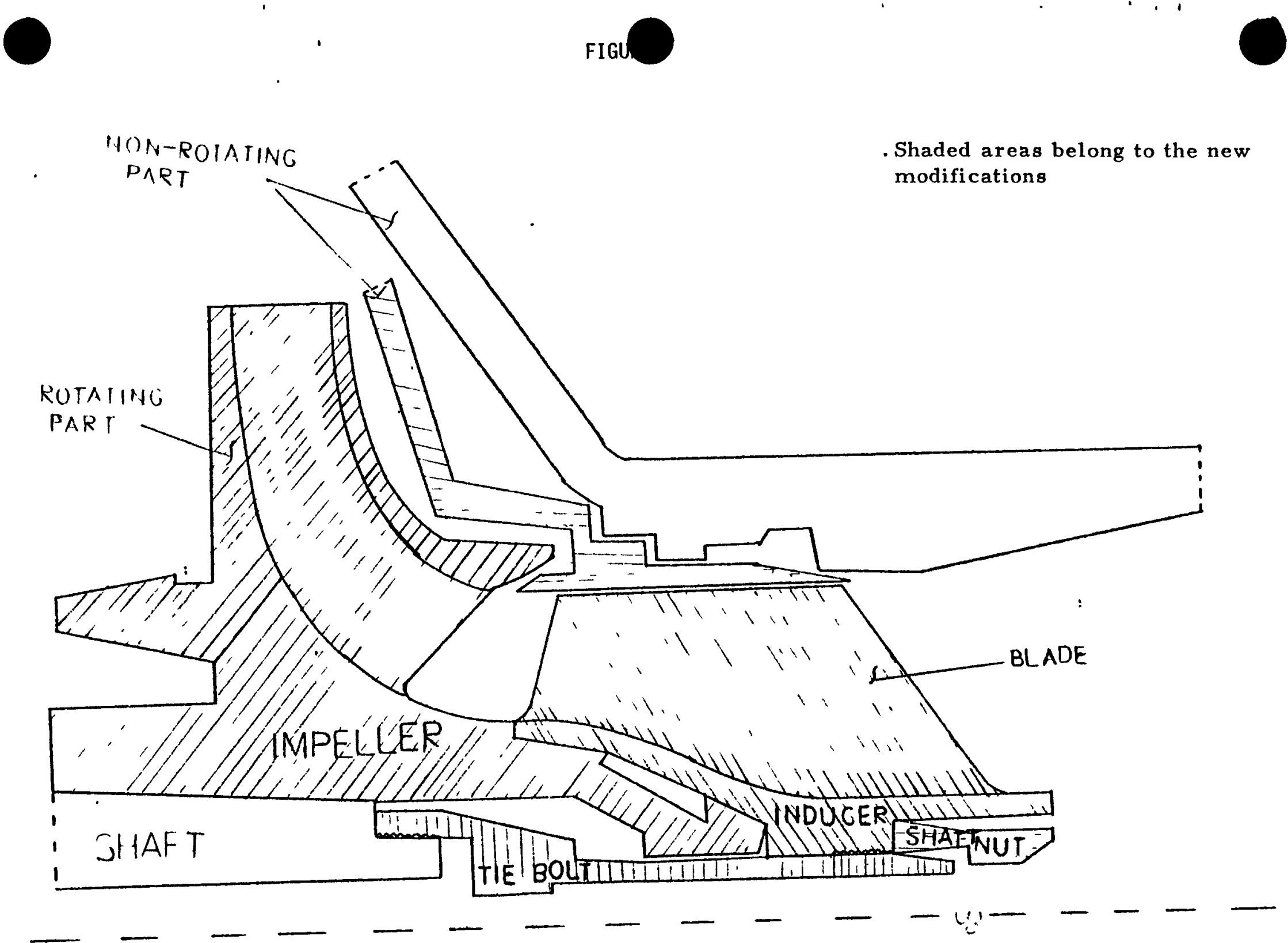

ISIP NEW HARDWARE 


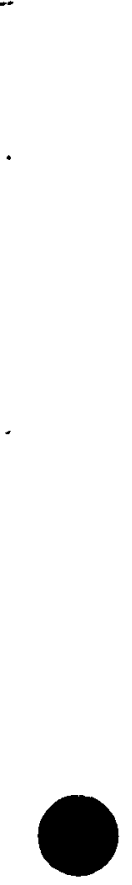

$$
\text { , }
$$

CASE ND. 1
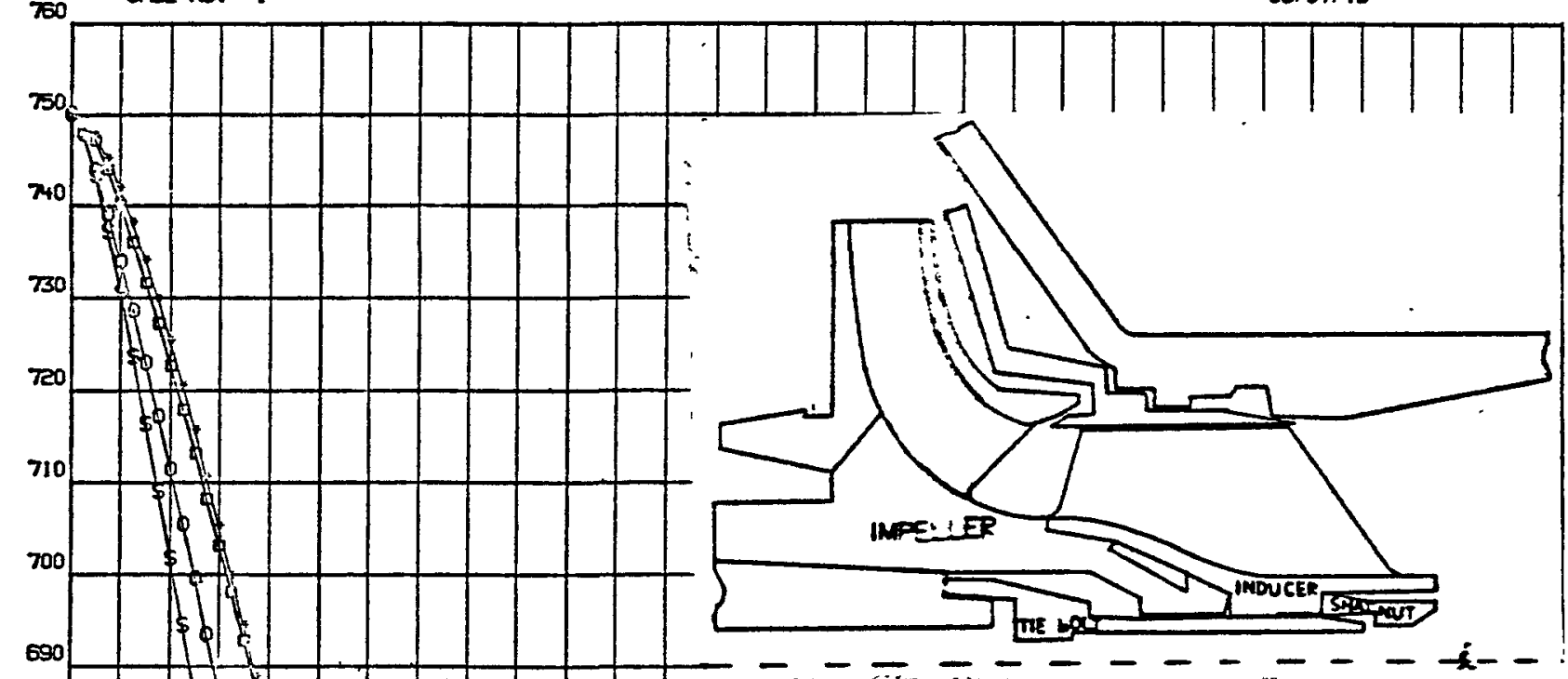

$600+2$
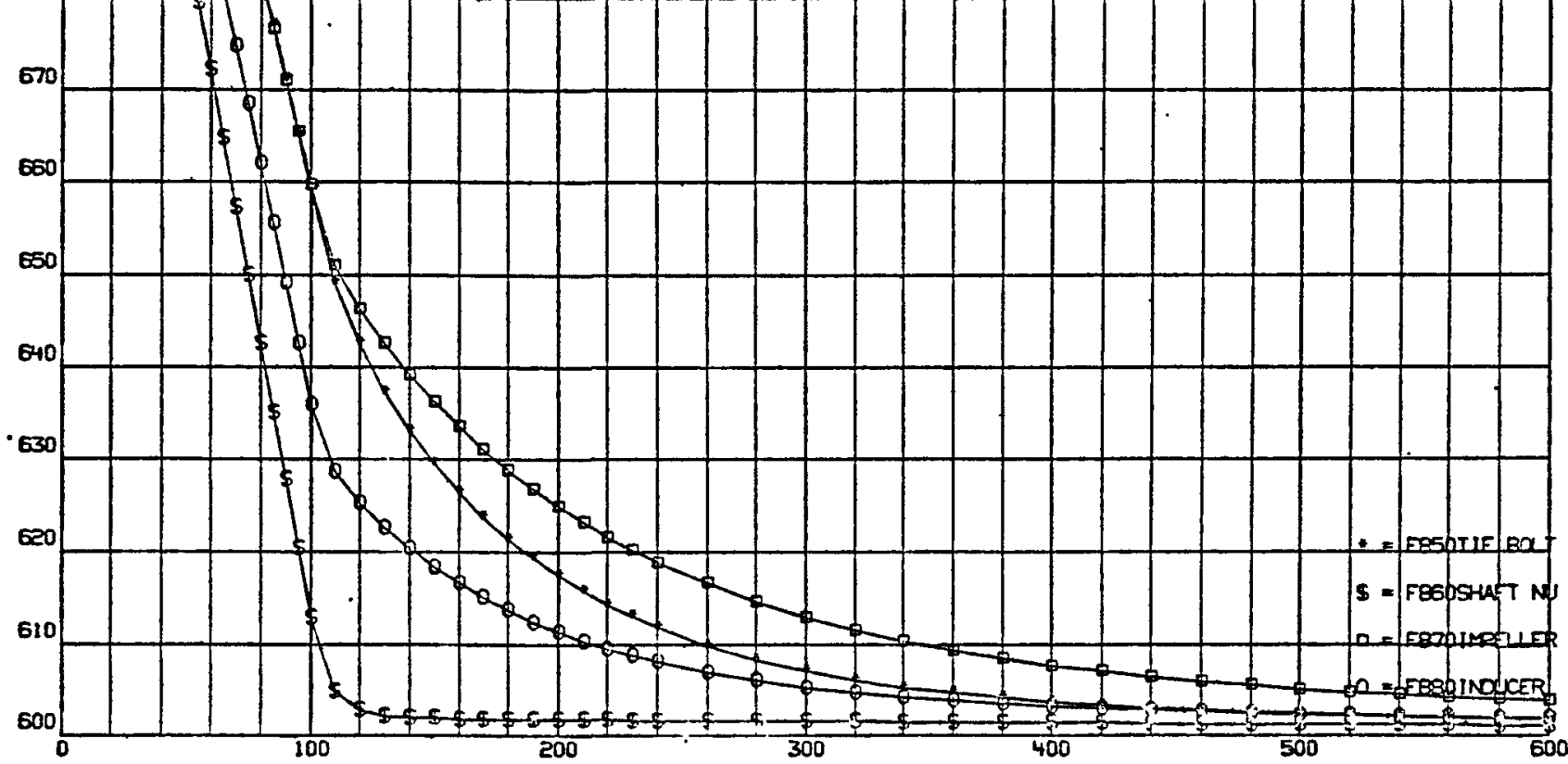

IEIGHTED AVERAGE TEMPERATURE - TRANS $20_{\mathrm{C}}^{\circ}$ 
N266ER000-001

Page 521

N266TI000-008

Page 22

FIGURE 7

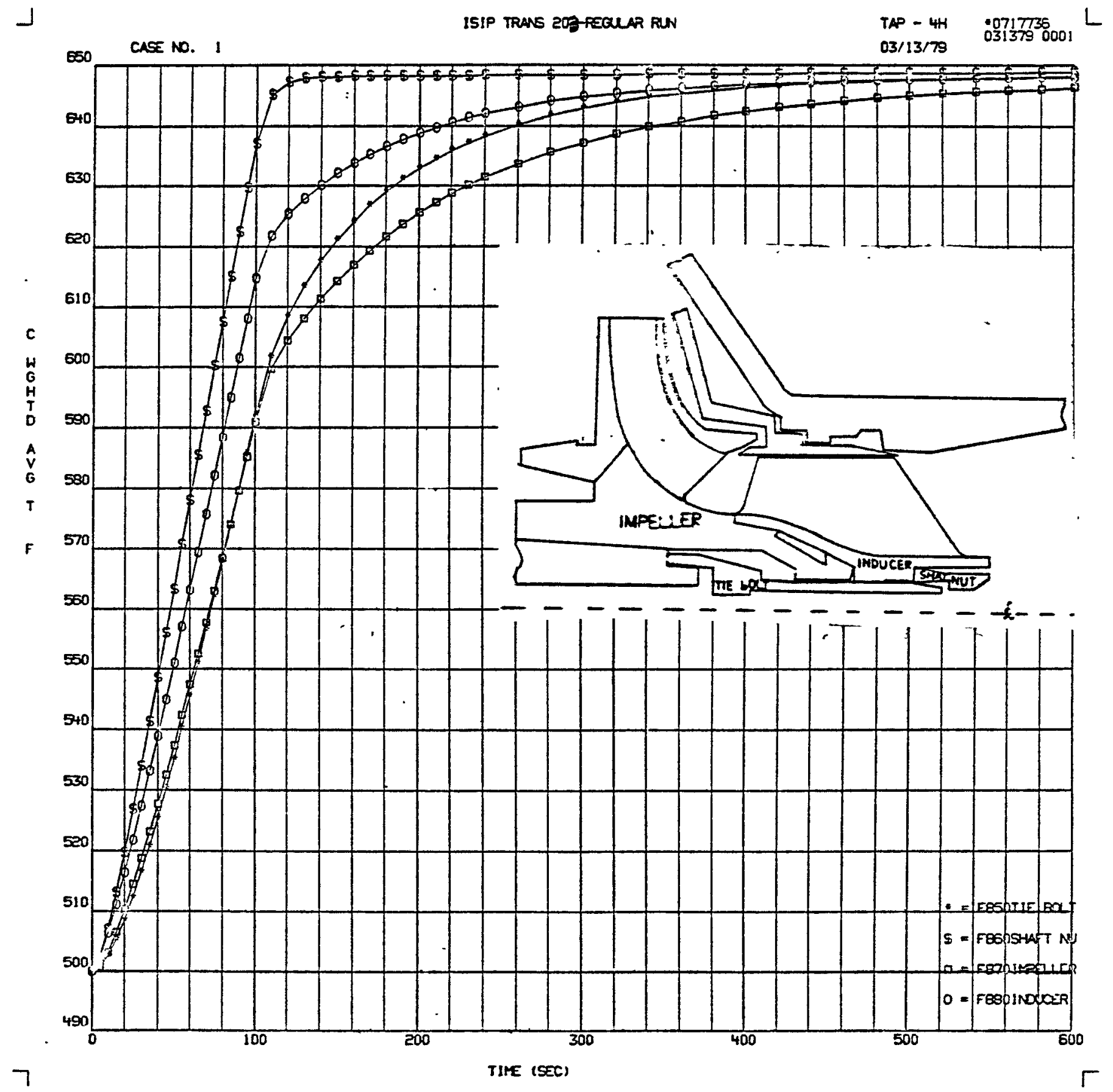

WEIGHTED AVERAGE TEMPERATURE -. TRANS 203 
FIGURE 8

\lrcorner

ISIP TRANS 204-FEQUAR FUN

TAP - $4 H$

0717736 L

03/23/79 0323790001

860 CASE No. 1
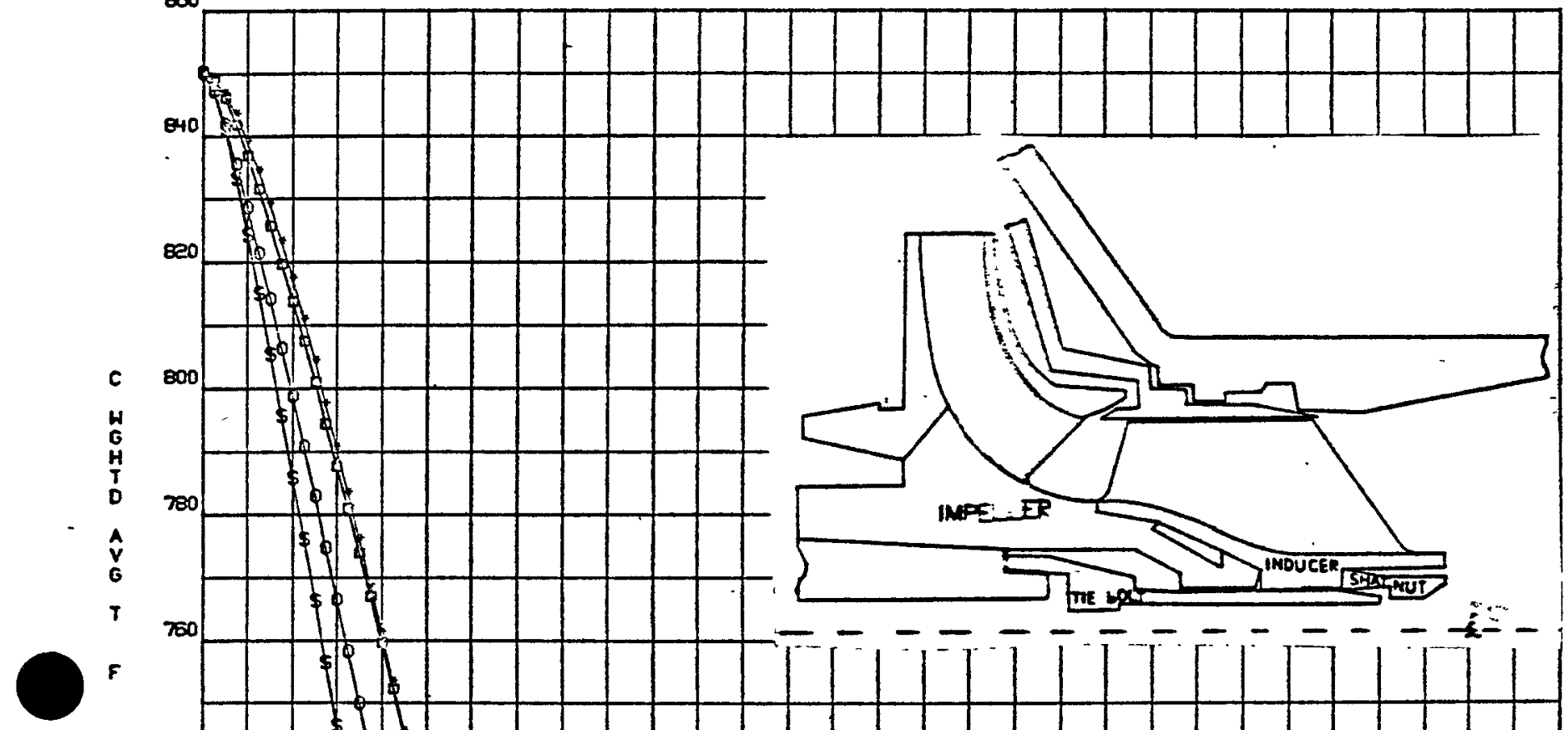

\begin{tabular}{|l|l|l|l|l|l|l|l|l|l|l|l|l|l|l|l|l|l|}
\hline & & & & & & & & & & & & & & & & & \\
\hline
\end{tabular}

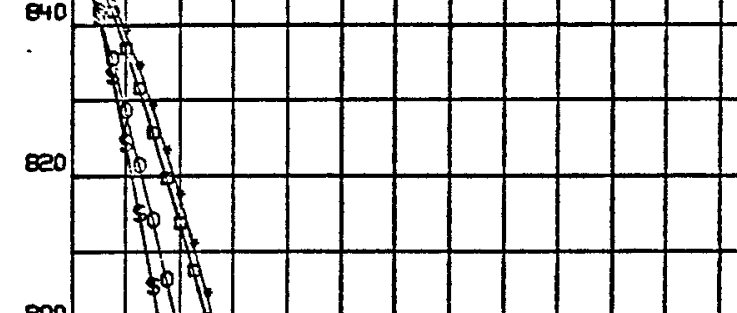

\begin{tabular}{l}
$\mathbf{C}$ \\
$\mathbf{H}$ \\
$\mathbf{G}$ \\
$\mathbf{H}$ \\
$\mathbf{T}$ \\
$\mathbf{D}$ \\
$\mathbf{A}$ \\
$\mathbf{V}$ \\
$\mathbf{G}$ \\
$\boldsymbol{T}$ \\
\hline $\boldsymbol{F}$
\end{tabular}
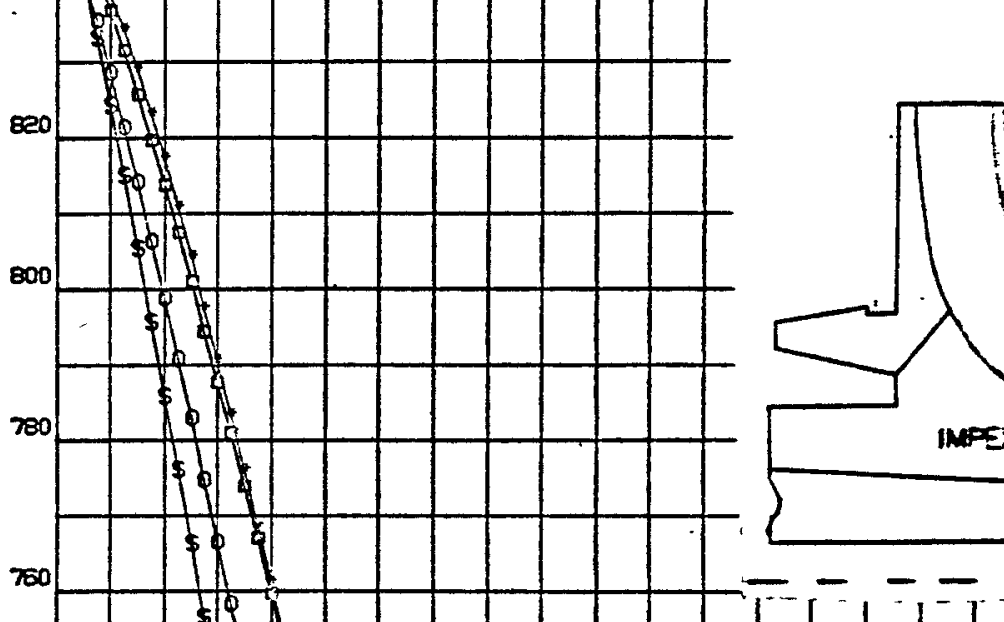

2
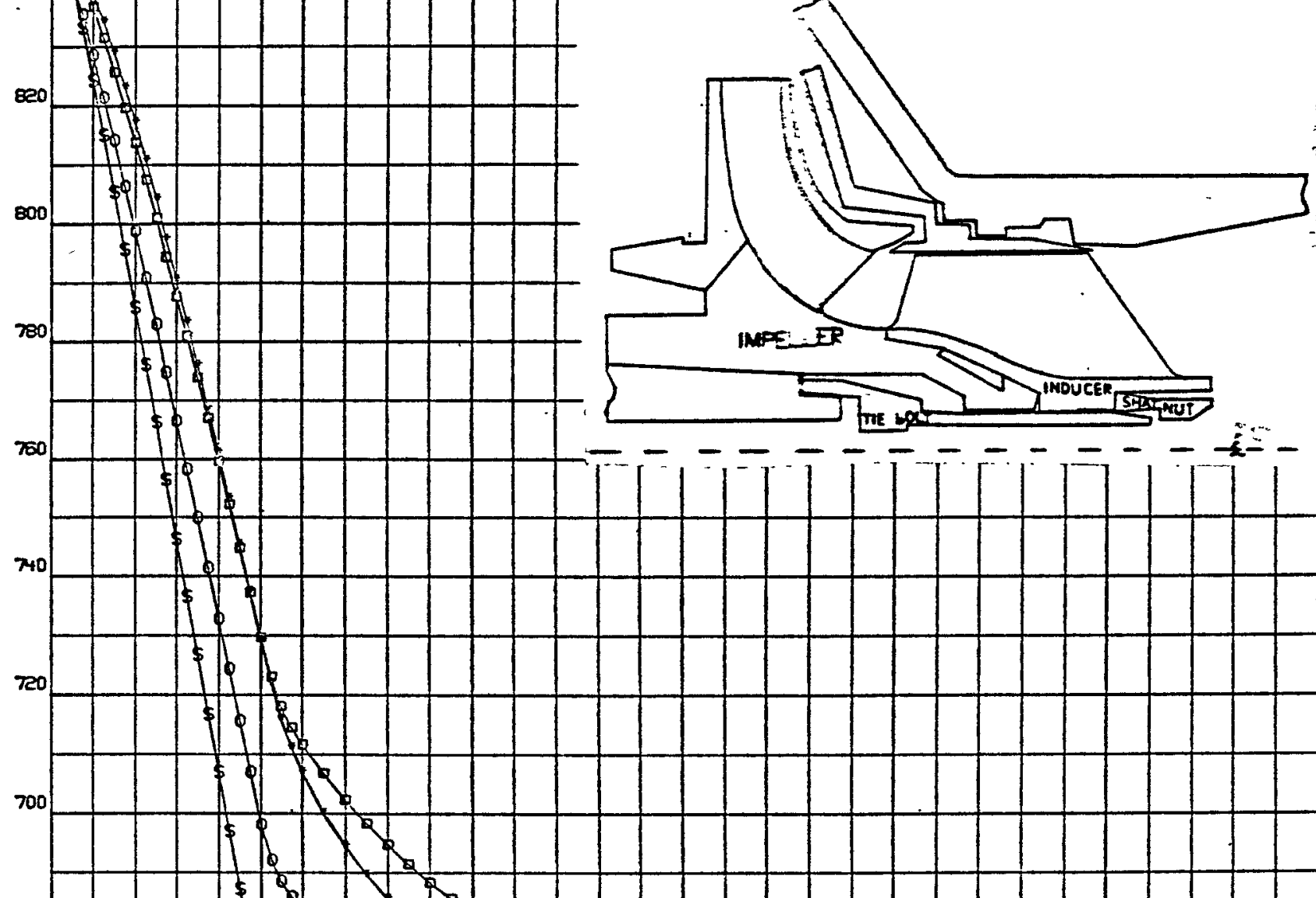

630
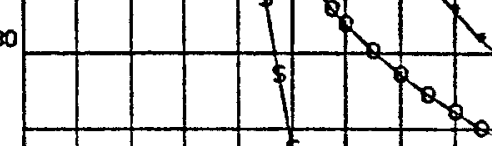

$+$
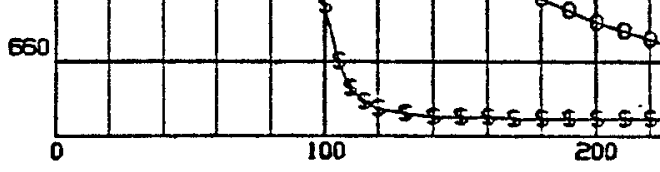

TIRE (SEC)

WEIGHTED AVERAGE TEMPERATURE - TRAi:s cir 
FIGURE 9

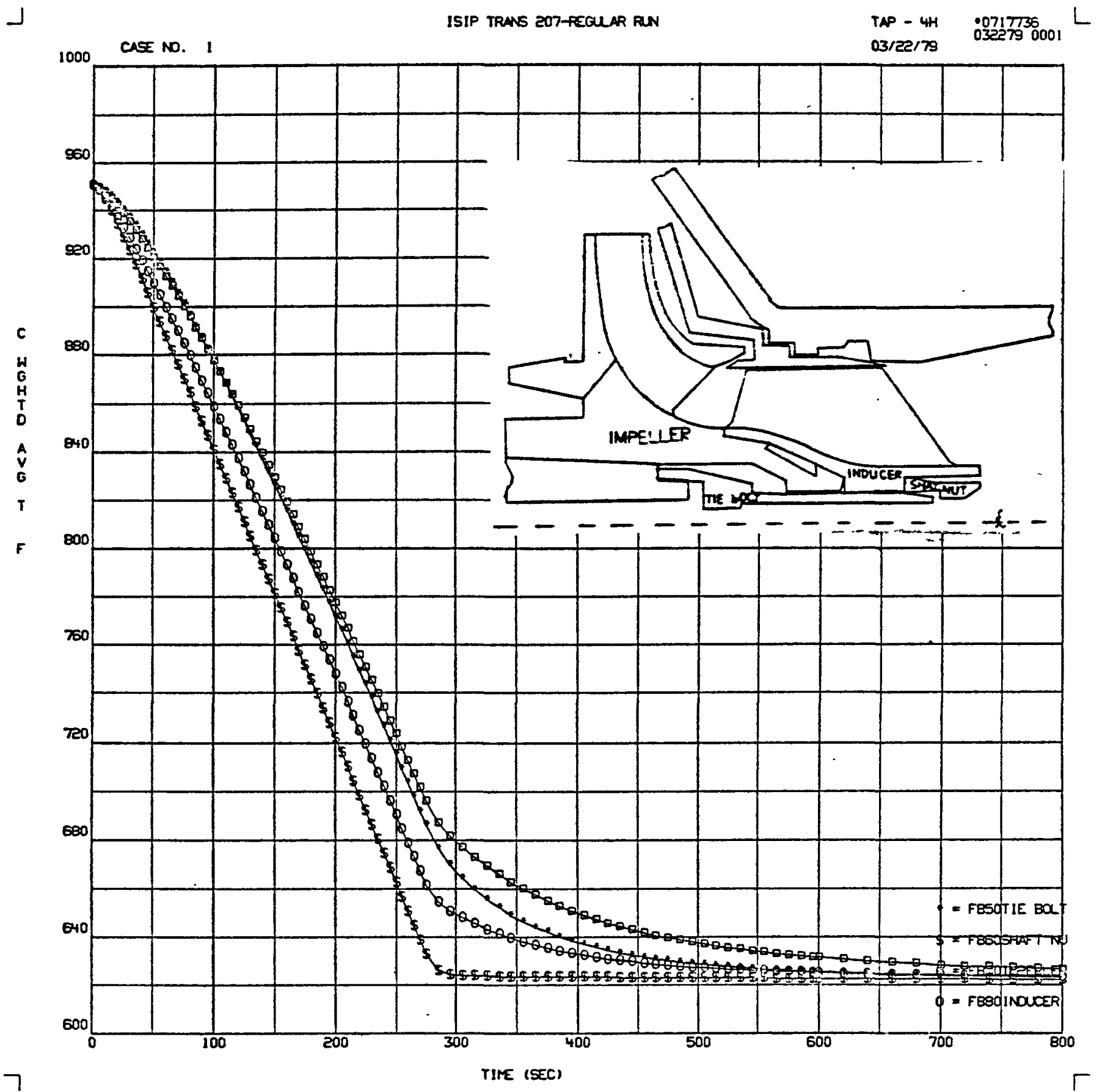




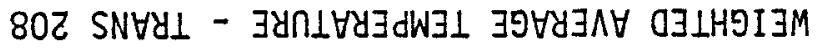

$\downarrow$

(J3) 3N11

009

oon DOE $\quad 002$

10

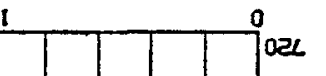

Fin

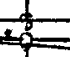

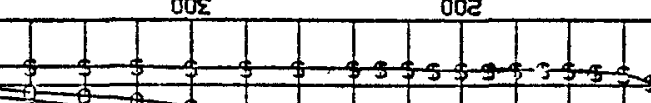

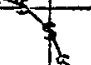

ov LFSOS98 $=\$$

$\rightarrow 0$
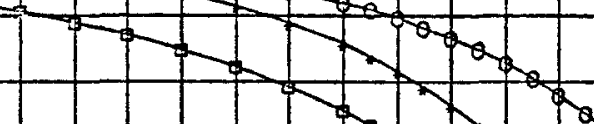

2

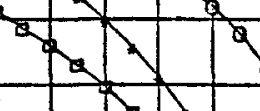

(n)
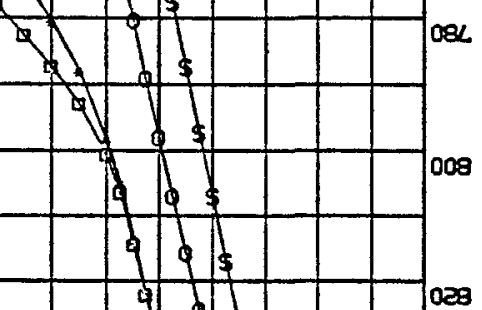

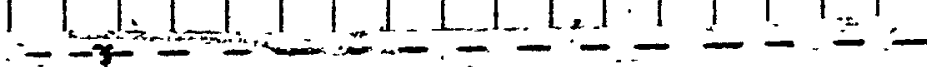

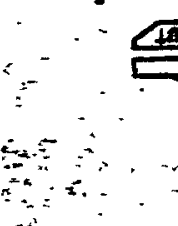

and

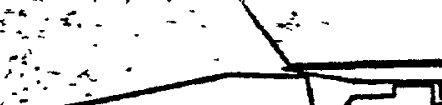

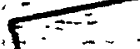

$\because$

,

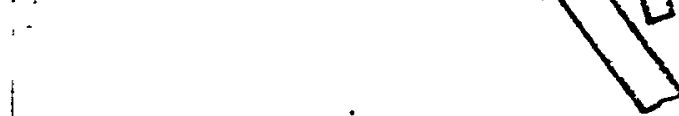

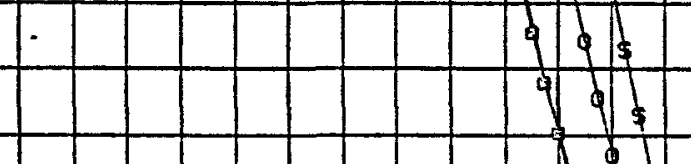
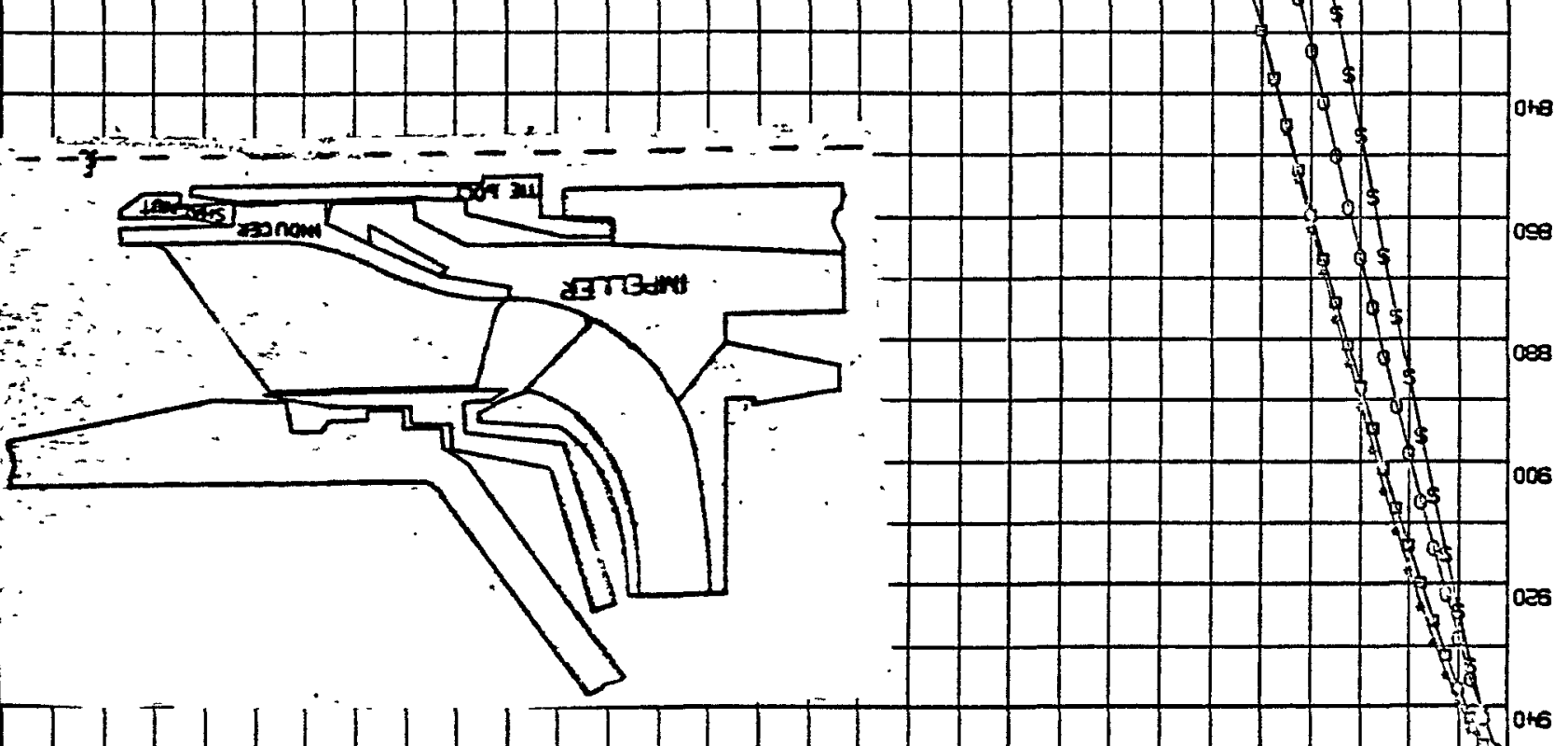
FIGURE :!

\lrcorner

ISIP TRANS 210-FEOLAR RIN

$\begin{array}{ll}\text { TAP }-4 H & 0717736{ }^{\circ} L \\ 03116 / 79 & 031679001\end{array}$

so CASE No.
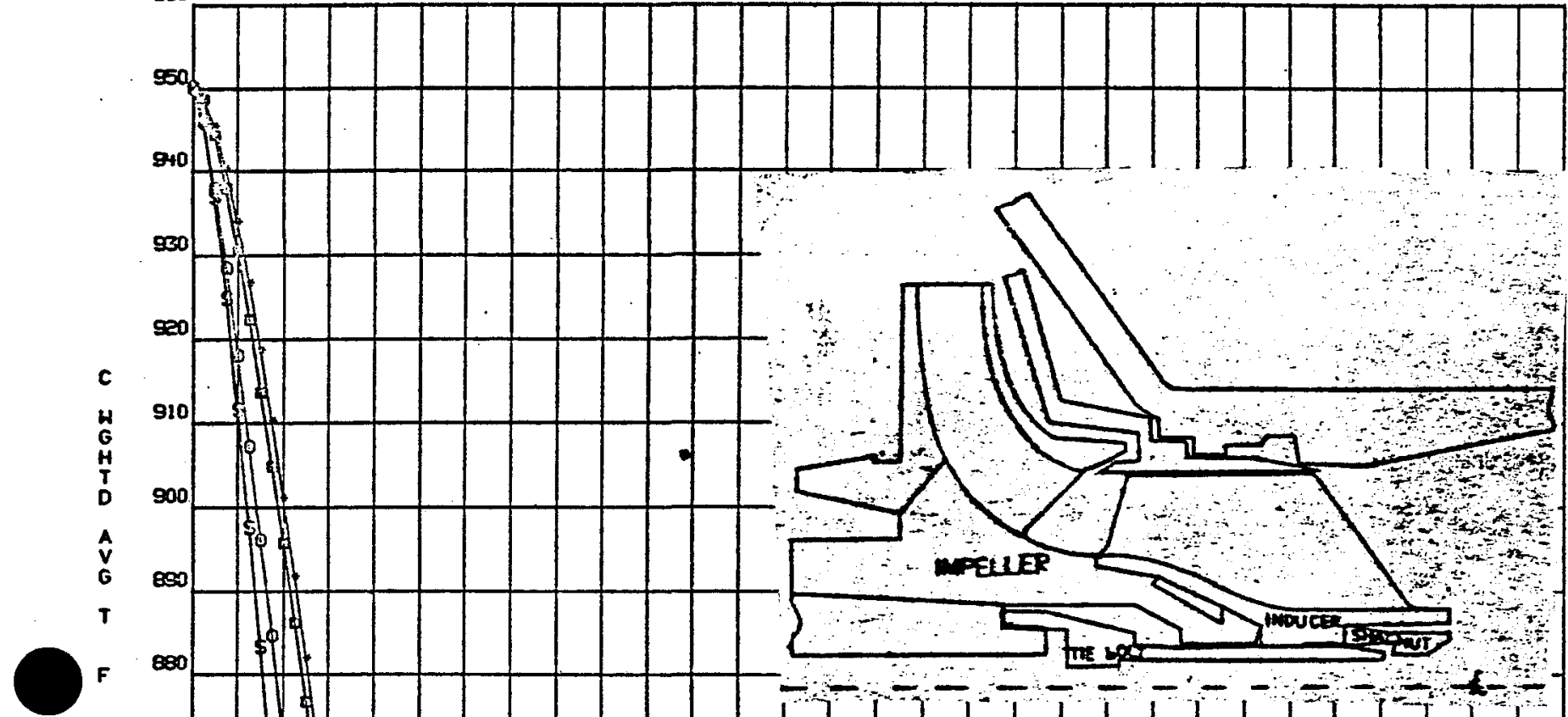

9.

$9 1 0 \longdiv { 5 1 }$

90011
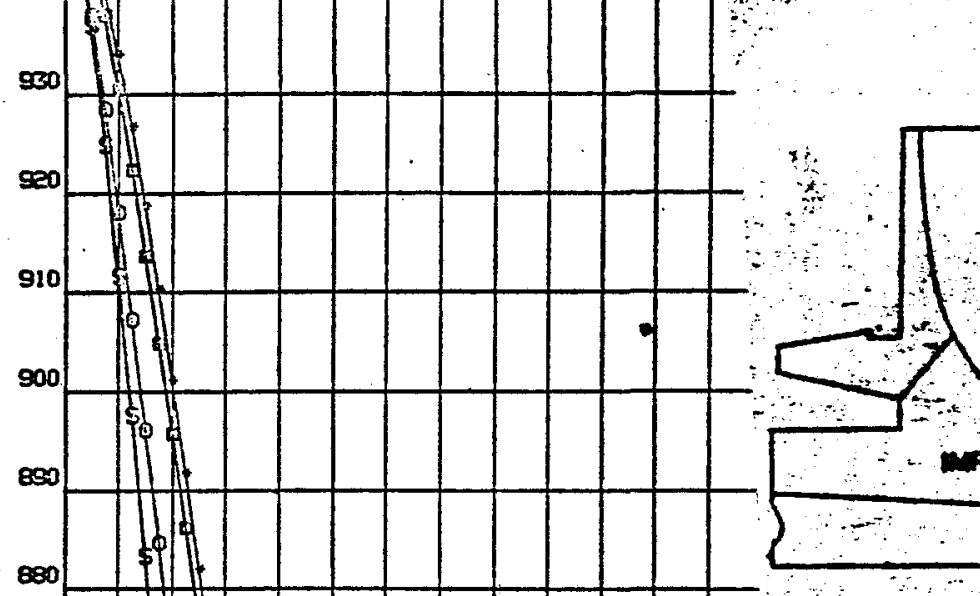

F
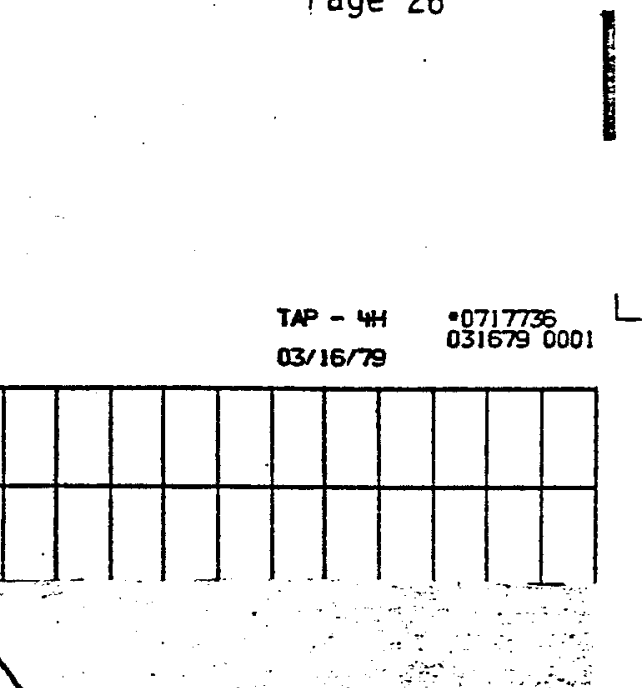

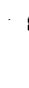

870

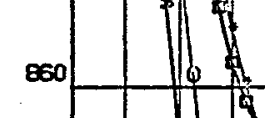

$600 \$$
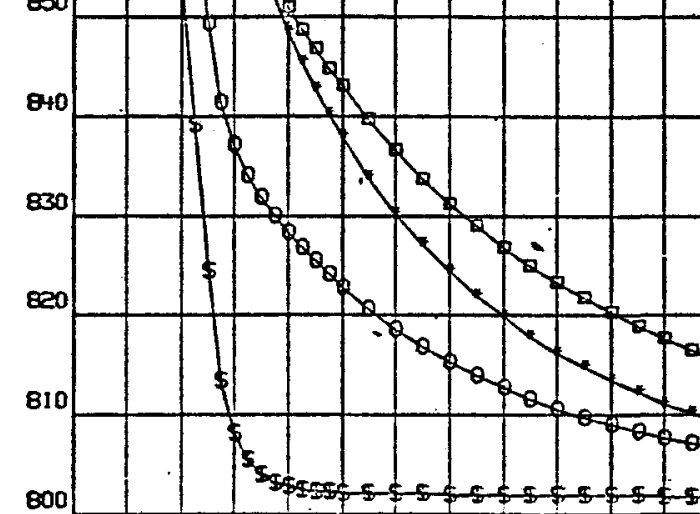

600

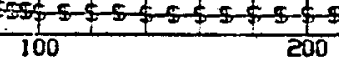

TIHE (SEC) 


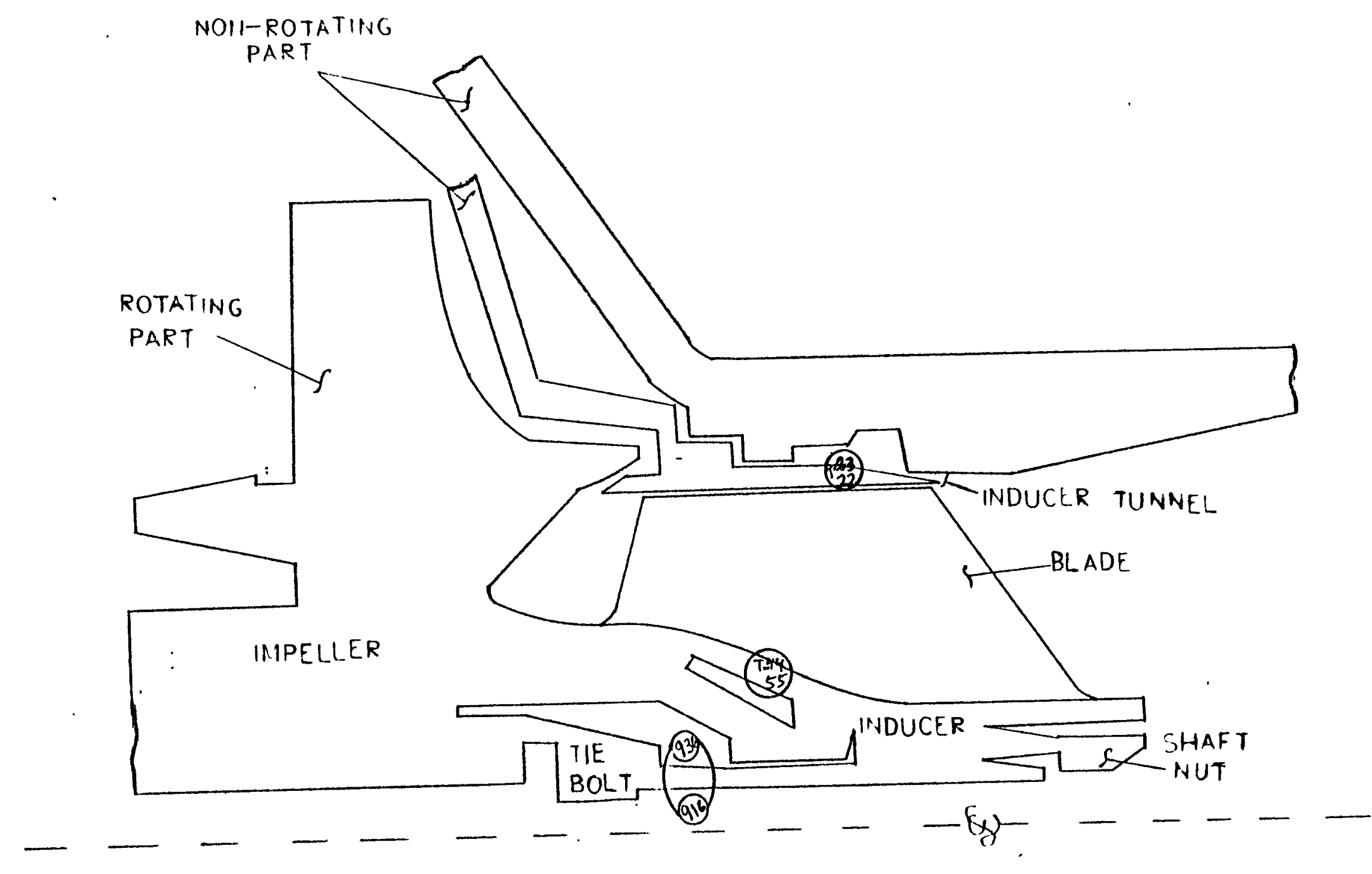

NODE NUMBER ACROSS INDUCER, TIE BOLT, AND INDUCER TUNNEL 


\section{N266ER000-001 \\ FIGURE 13 Page 527

ISIP TFUS ER-RETLAR RUN

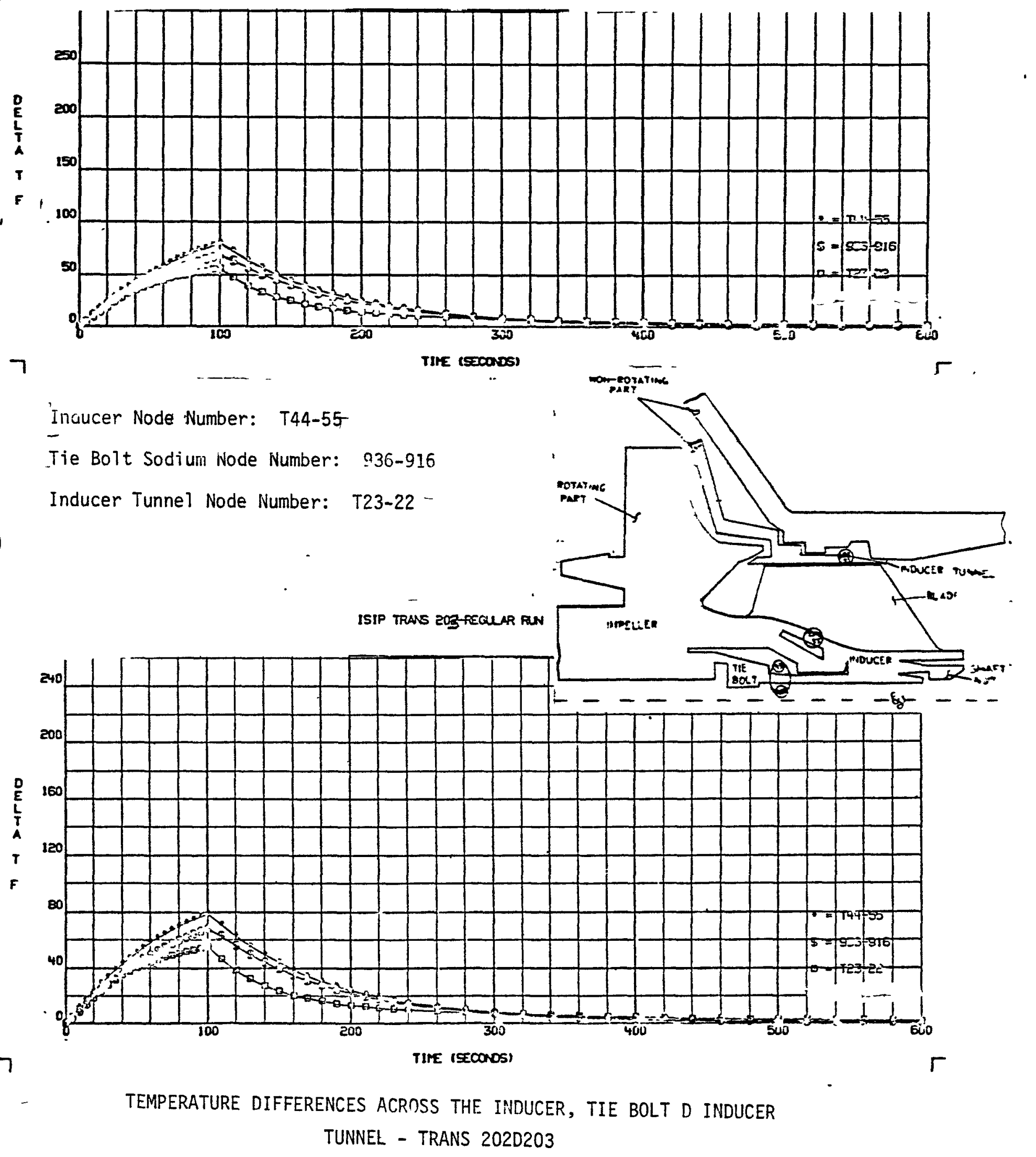


ISIP TRANS EOH FECULAR RAN

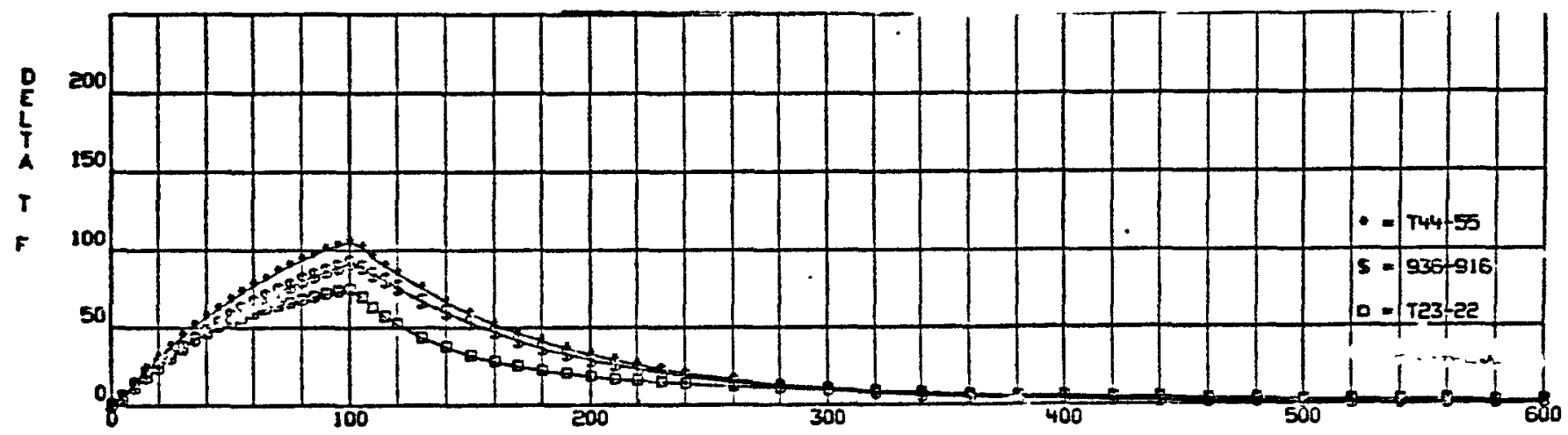

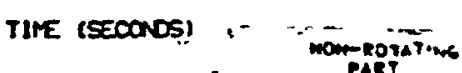

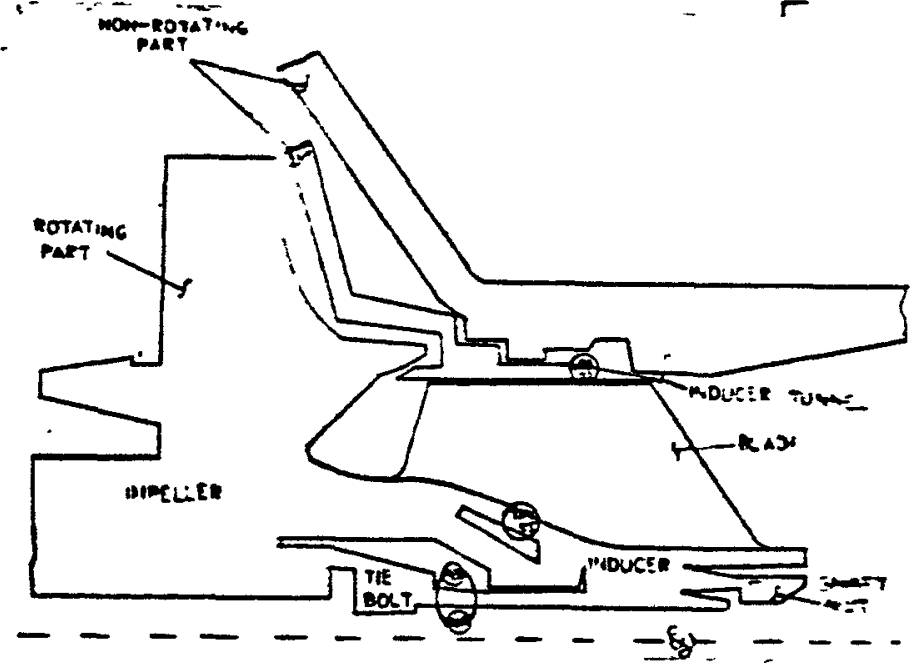

ISIP TRAN 207-PEQULAR RUN

Inducer Node Number: T44-55

Tie Bolt Sodium Node Number: $936-916$

Inducer Tunne] Node Number: T23-22

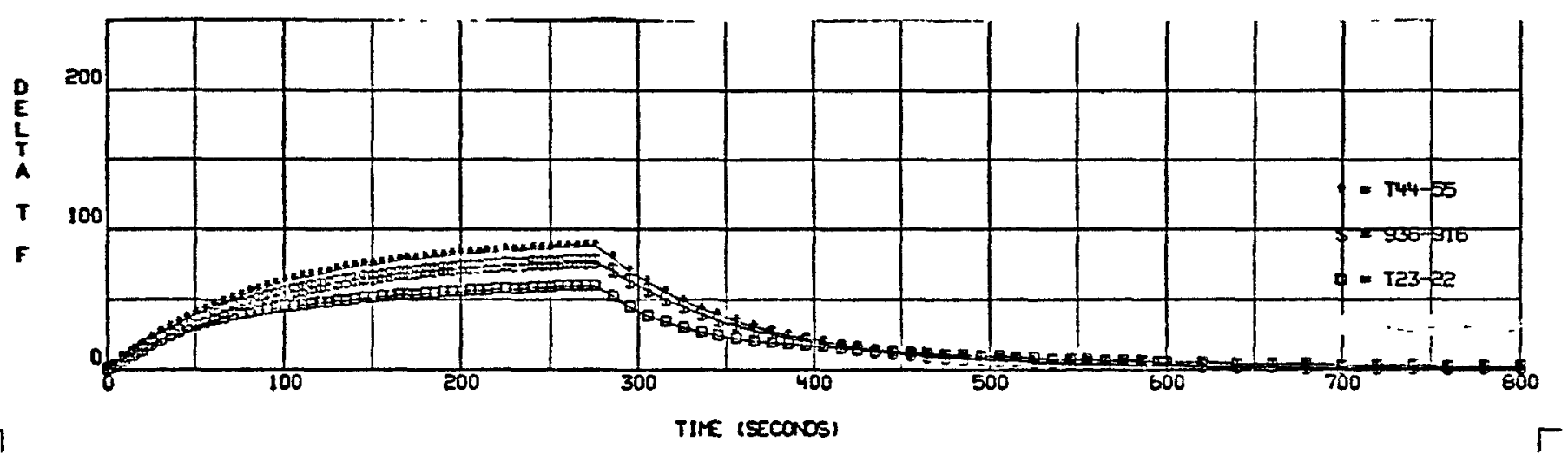

TEMPERATURE DIFFERENCES ACROSS THE INDUCER, TIE BOLT D INDUCER

TUINIEL - TRANS 20AD207 
ISIP TRANS ZOOTECULAR RIN

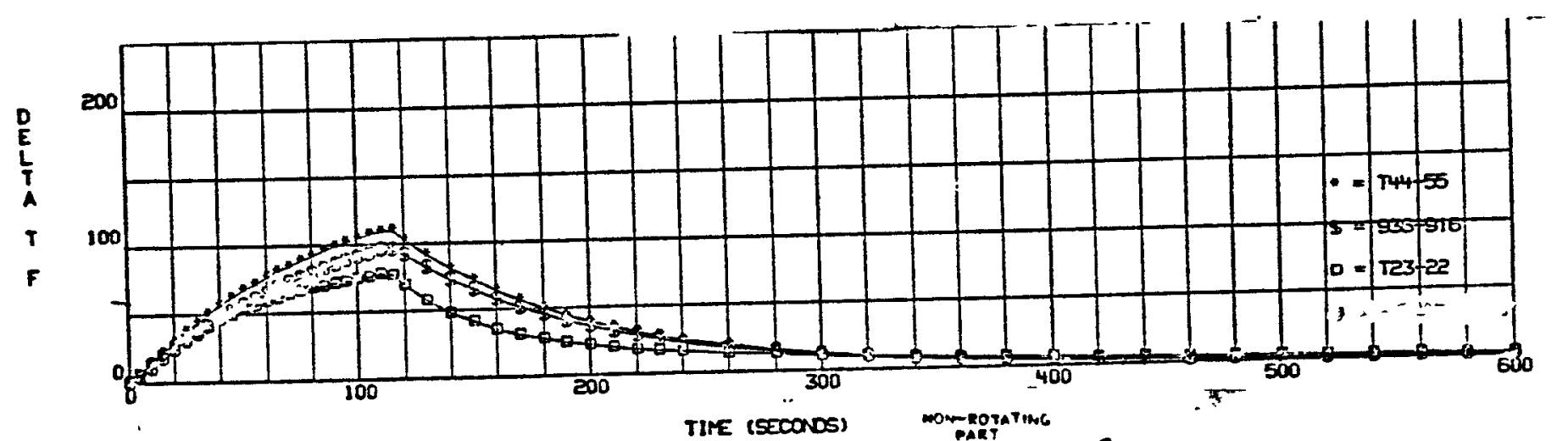

TIRE (SECONDS)
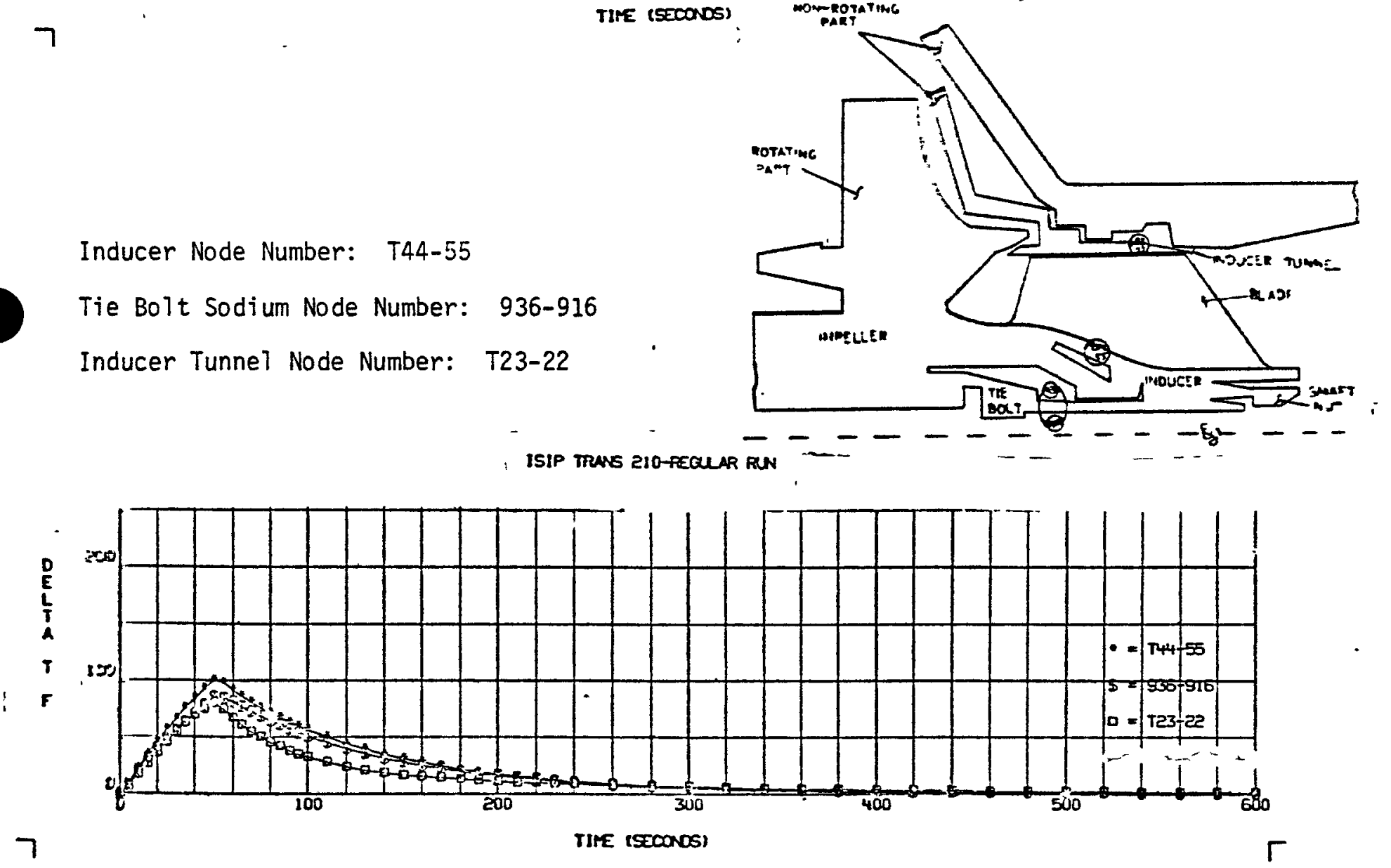

TEMPERATURE DIFFERENCES ACROSS THE INDUCER, TIE BOLT D INDÜCER

TUNNEL - TRANS 208D210 
FIGURE 16

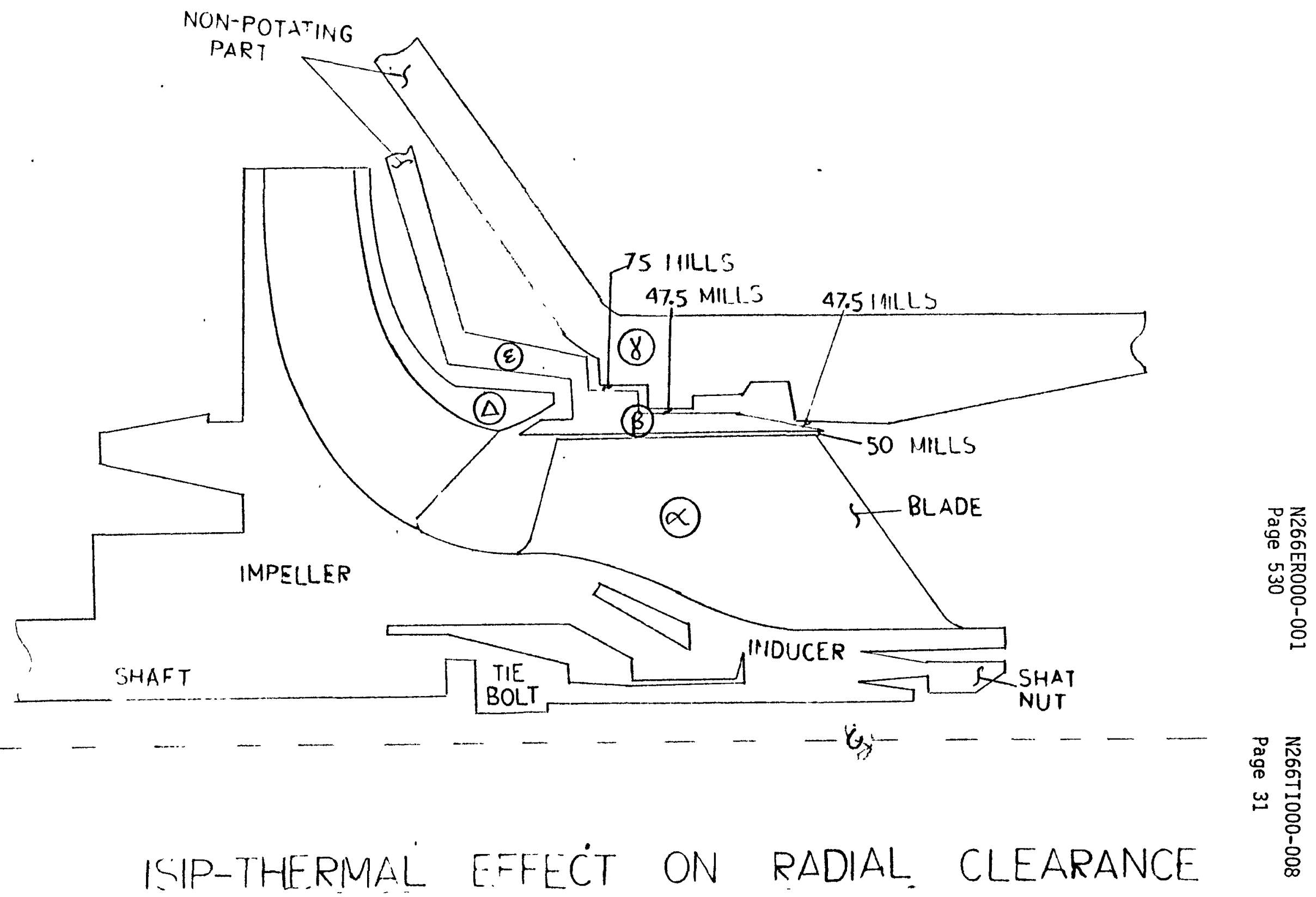


N266ER000-001

Page 531

FIGURE 17

N266TI000-008

Page 32

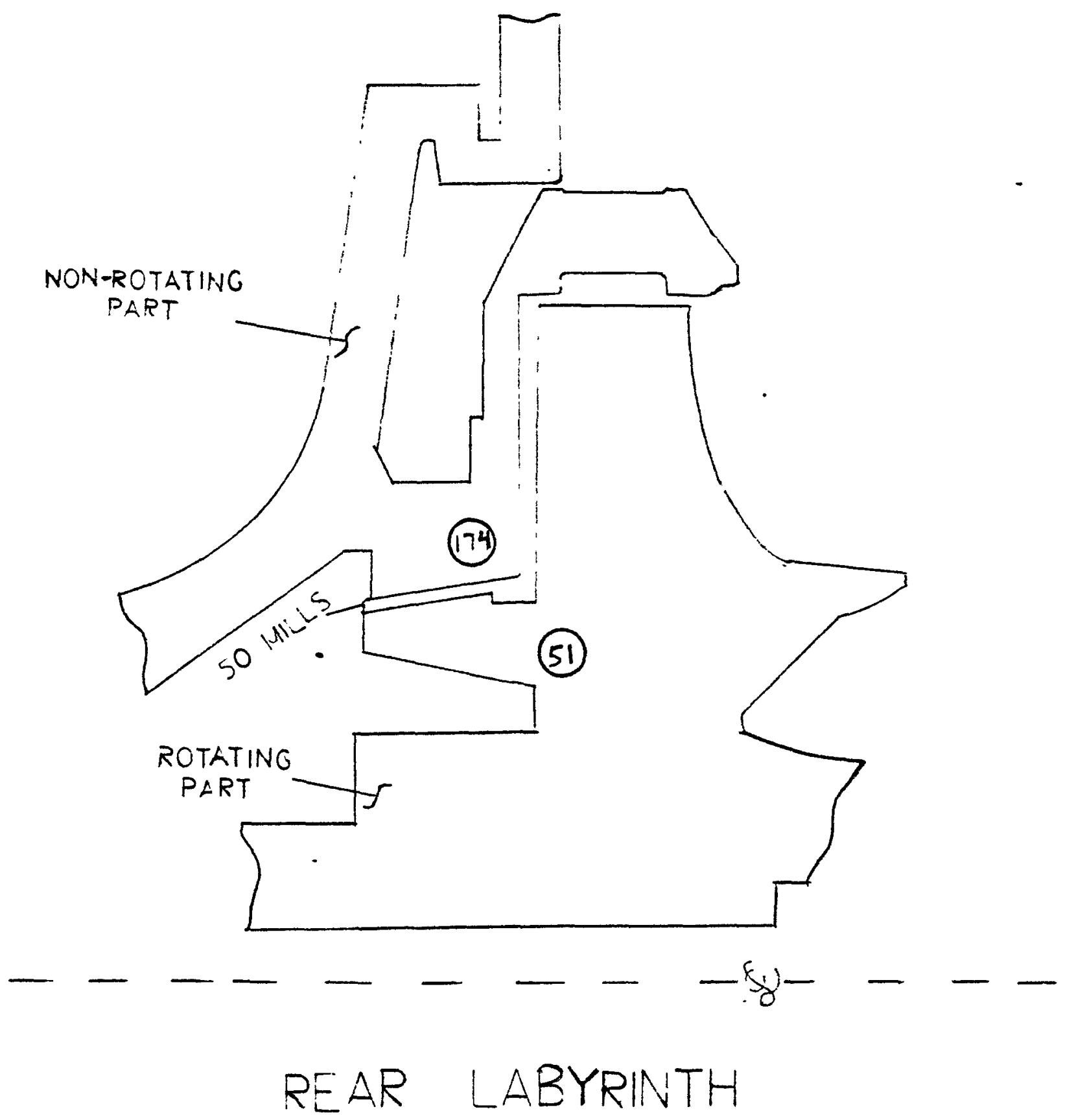


N266ERO00-001

FIGURE 18

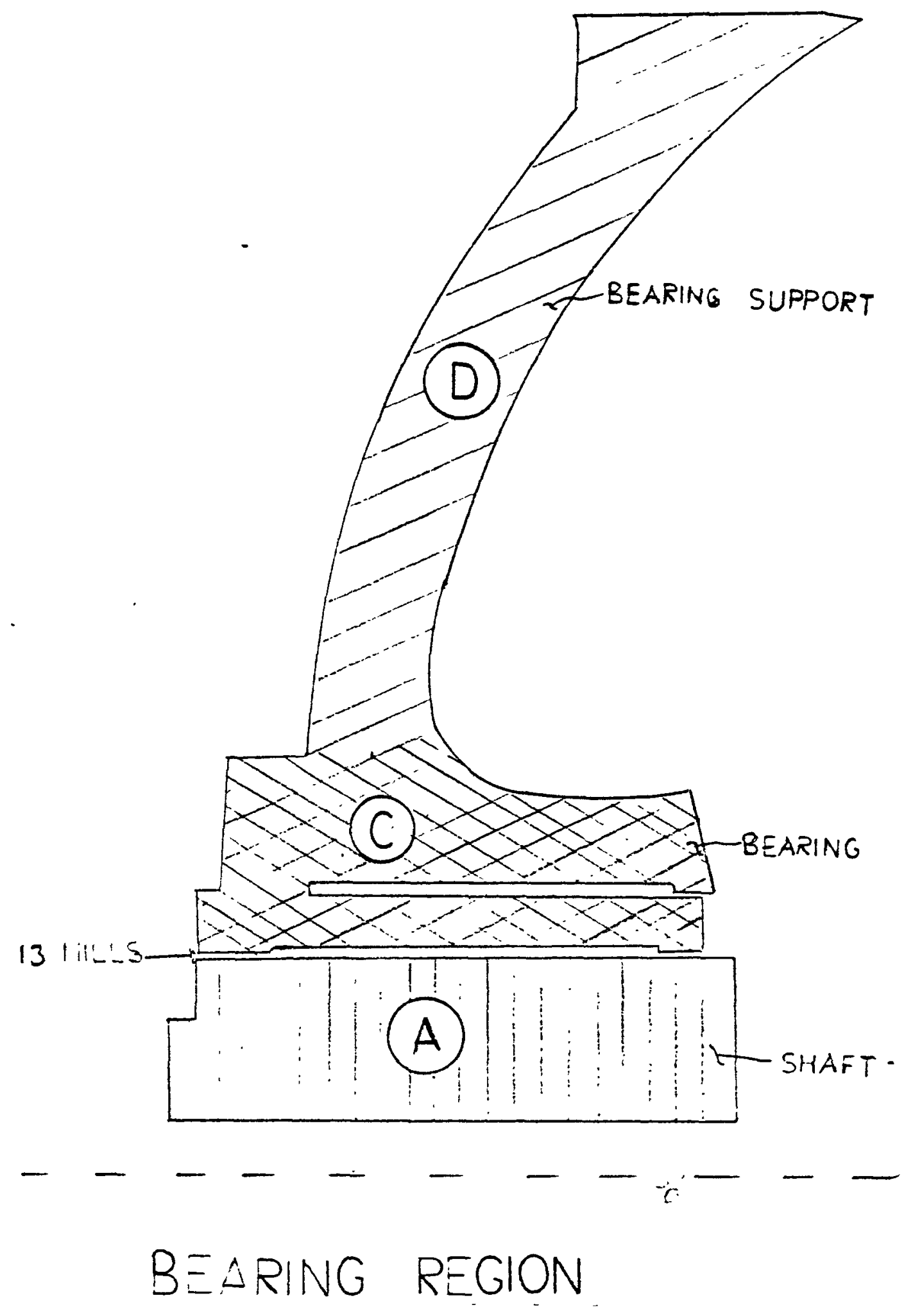




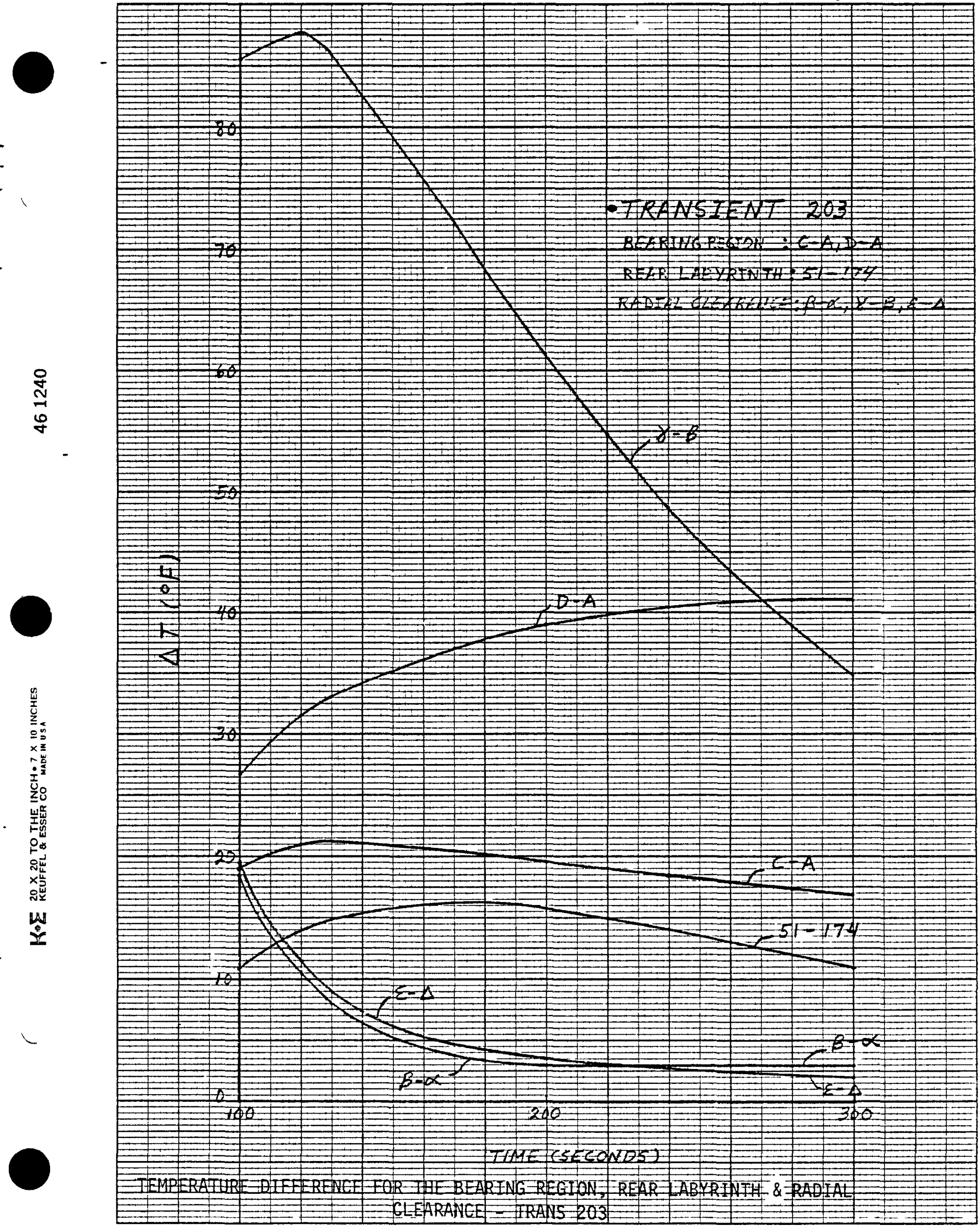




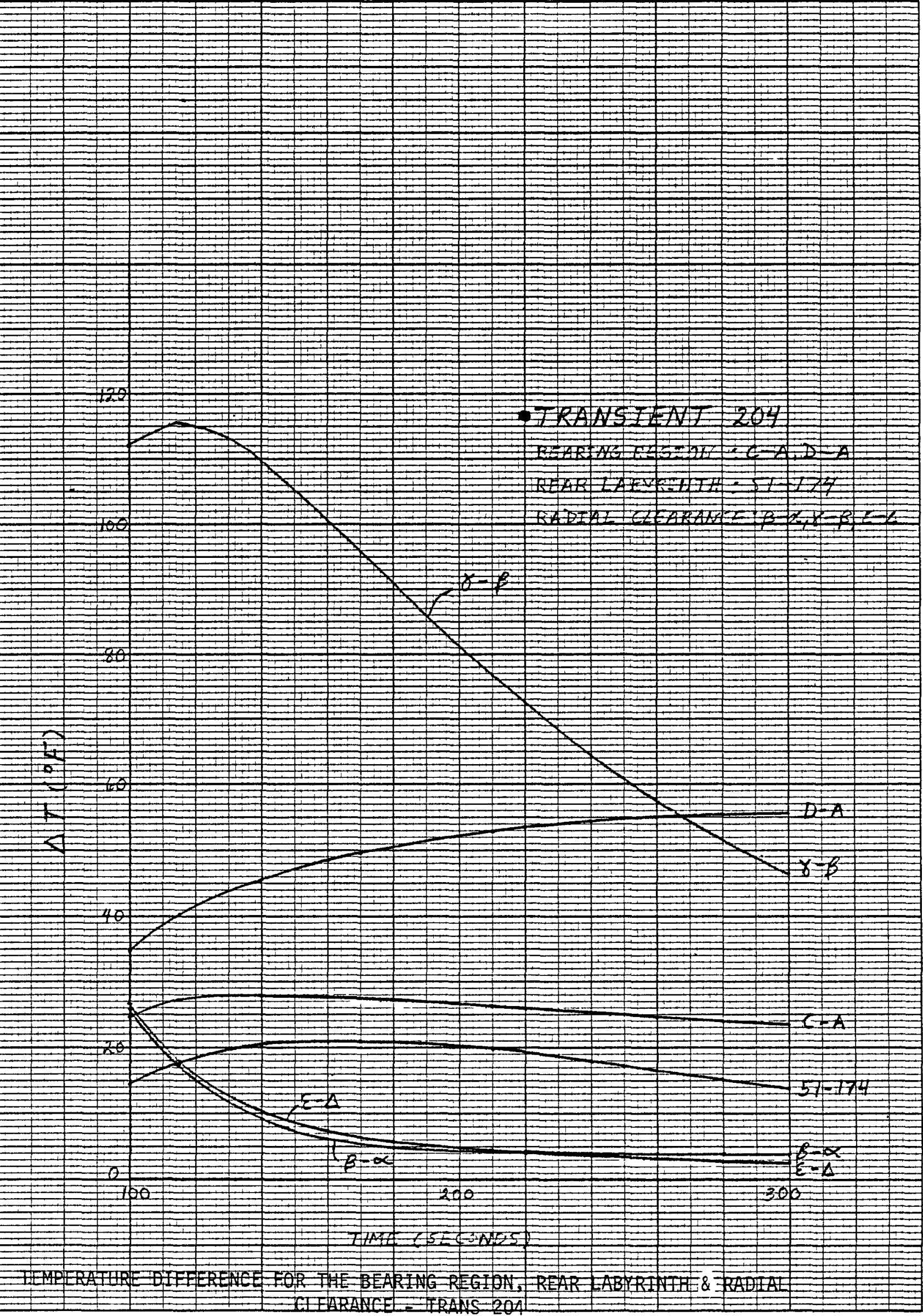




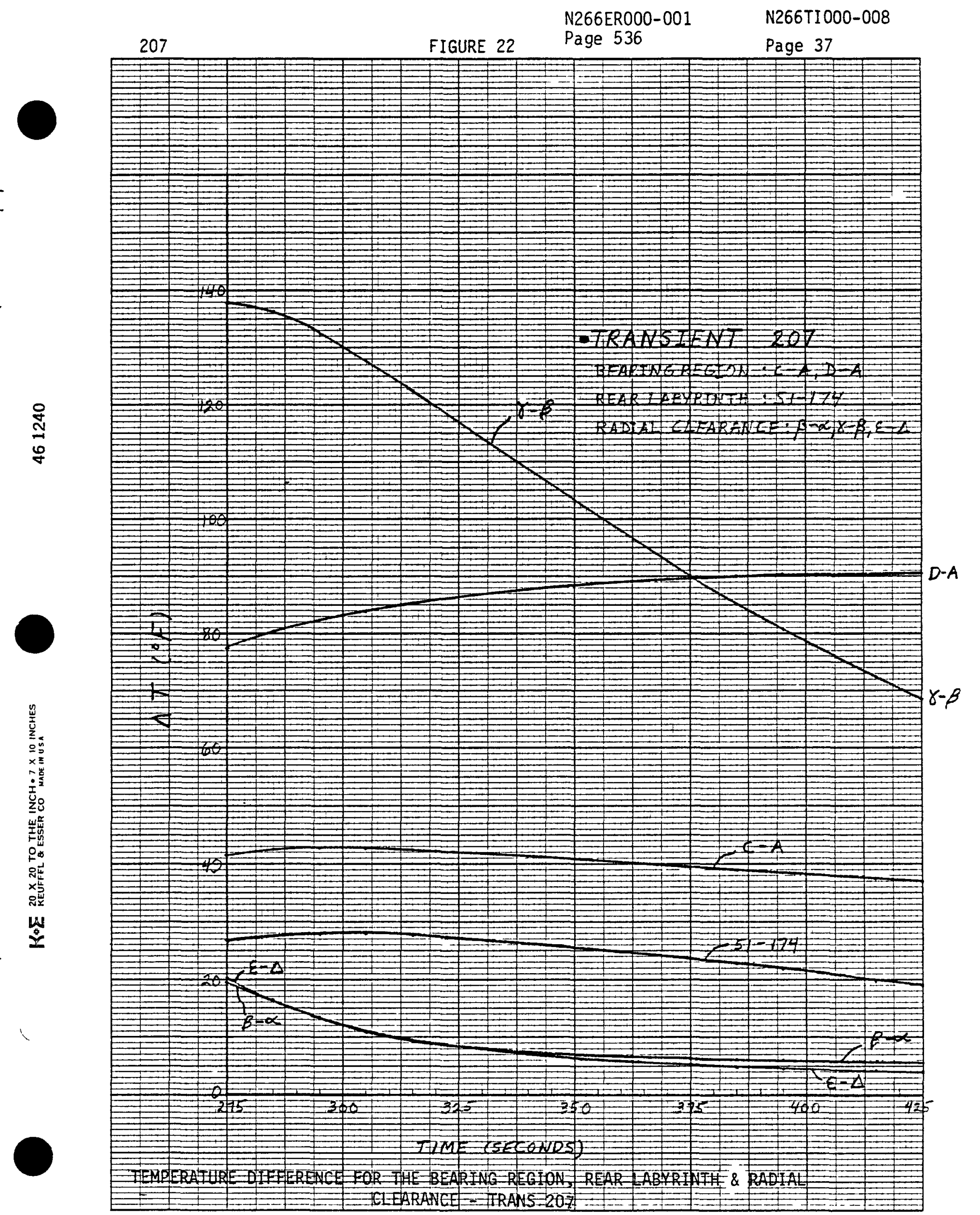




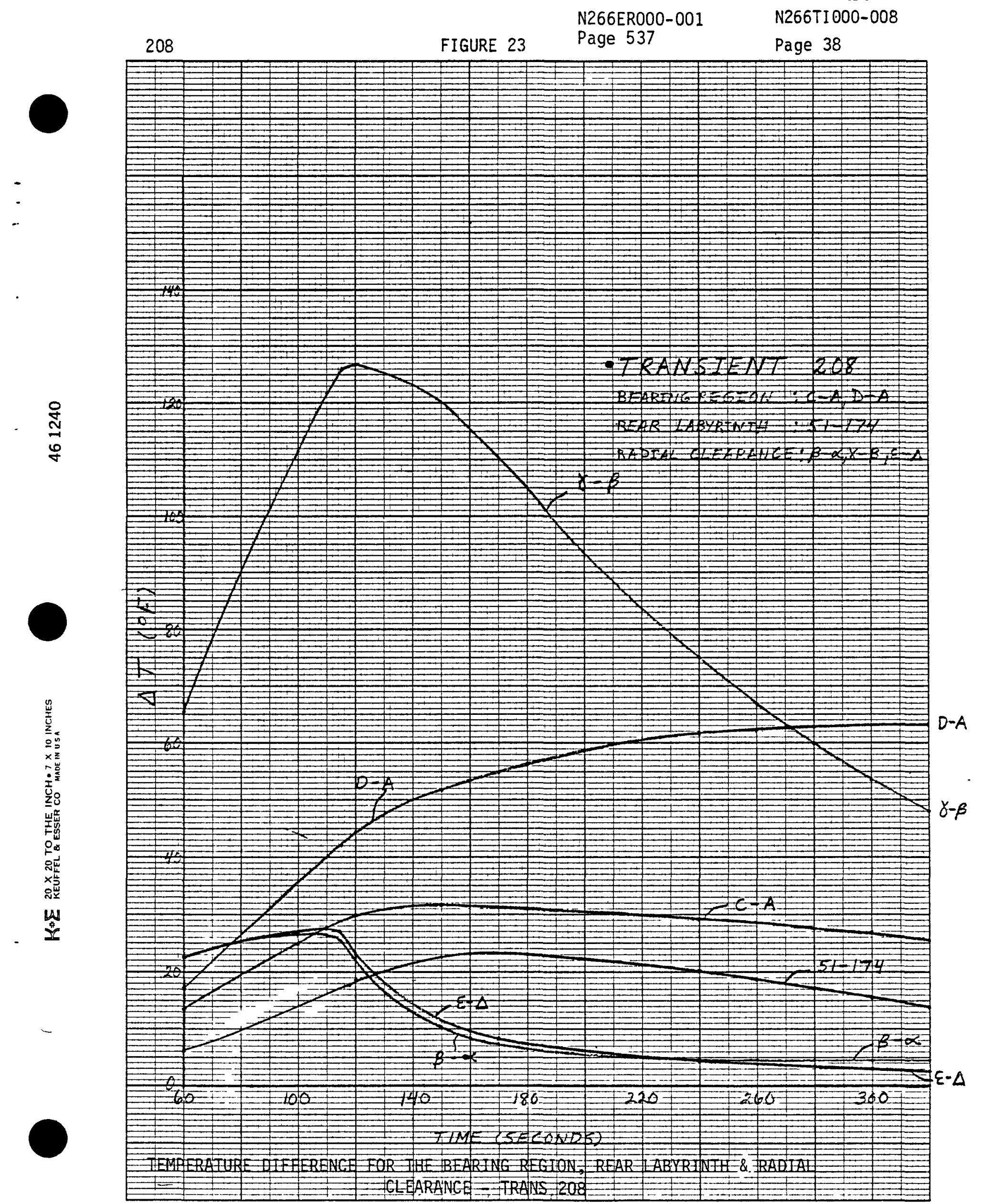




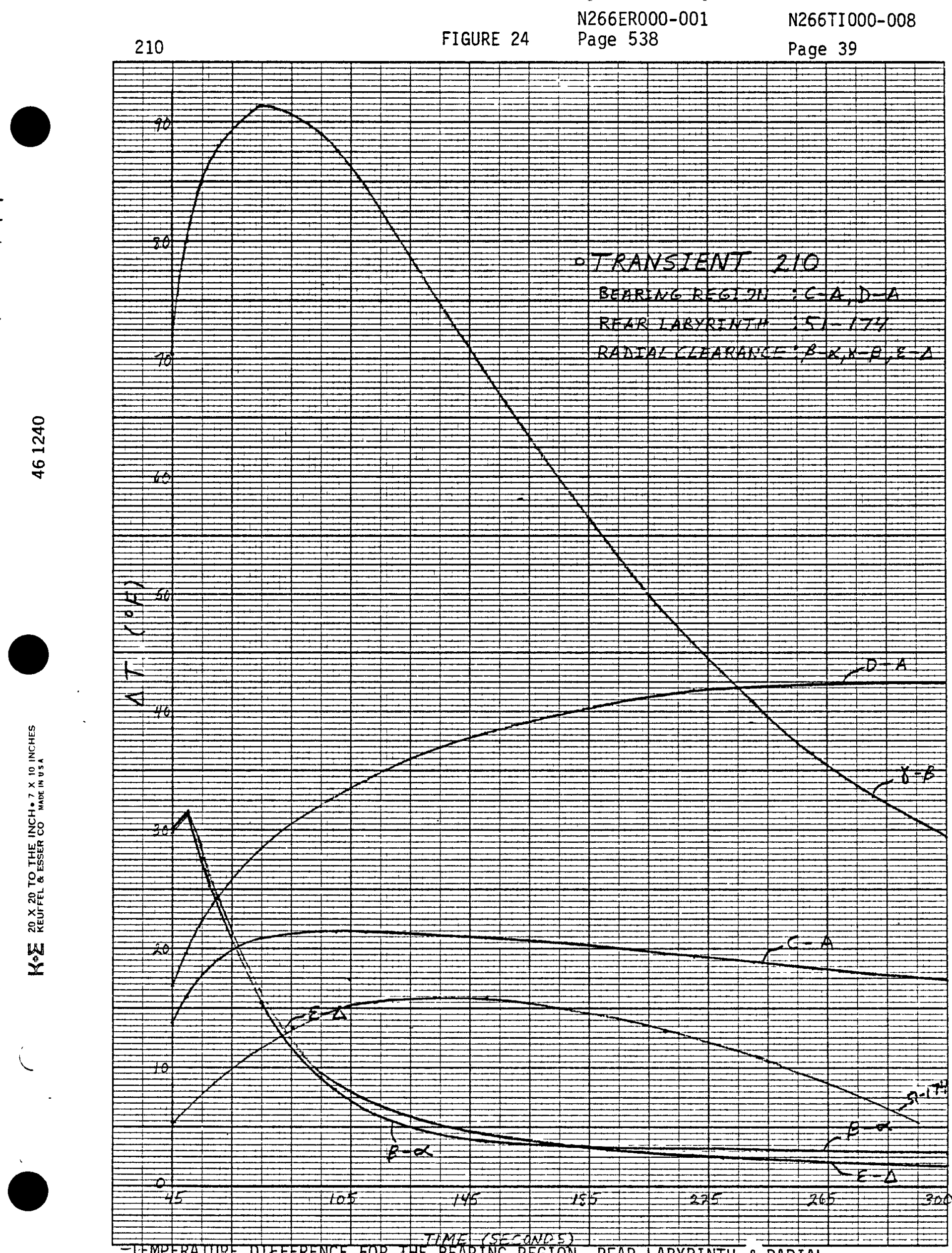

TEMPERATURE DIPFERENCE FOR THE BEARING REGION, REAR LABYRINTH \& RADIAL CLEARANCE - TRANS 210 


\section{APPENDIX A \\ SUPPORTING CALCULATIONS}

This appendix contains hand calculations made in support of setting up the TAP computer model of the ISIP. Included are calculations on conductances and capacintances of the blade and diffuser regions, sodium node volumes and capacitances, sodium zone flow areas, and hydraulic diameters, and sodium side heat transfer coefficients. 


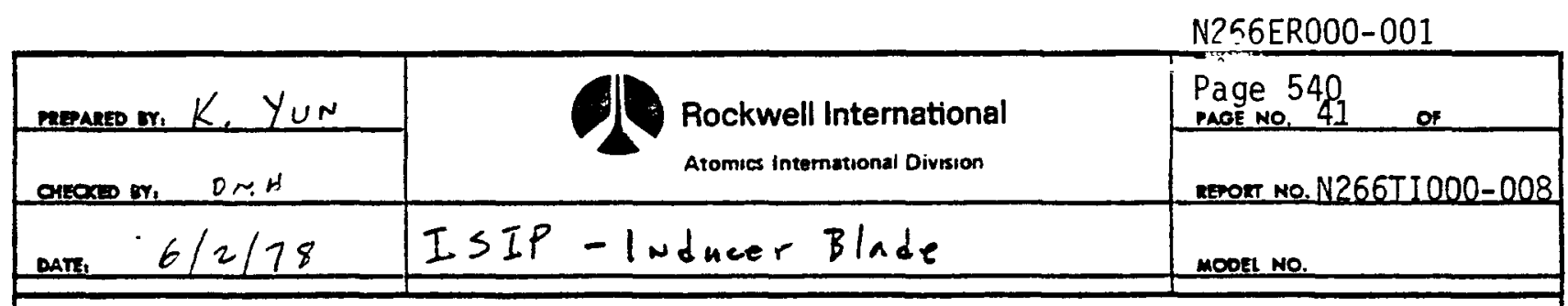

INDUCER BLADE - FORM FACTOR CALCULATIONS

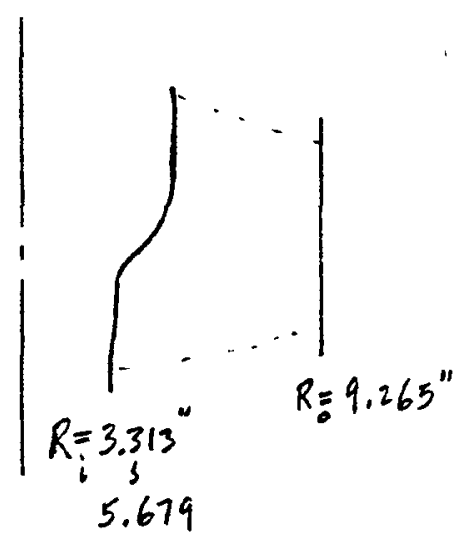

From AI Drawing No. R0019603 - Section A-A:

Average Radius $(\bar{R})$ of Inducer Base :

$$
\bar{R}=\frac{1}{2}(3.313+5.679)=4.5^{\prime \prime}
$$

- From Drawing No.Rool9603 Section B-B:

$$
\frac{\text { Blade length }}{\text { Circus terence }}=\frac{15.5+6.7}{14.55}=1.526
$$

- Total Effective Blade Cireneterence $=1.526 \times$ Inducer Circumferouge

- Projected Surface Area of 1 tull

Circumference of Blades (one tau only)

$$
=\pi\left(R_{0}^{2}-\bar{R}^{2}\right)=\pi\left(9.265^{2}-4.5^{2}\right)=206.06 \mathrm{in}^{2}
$$

- However, we have 1.526 Blades, 2 faces per blade

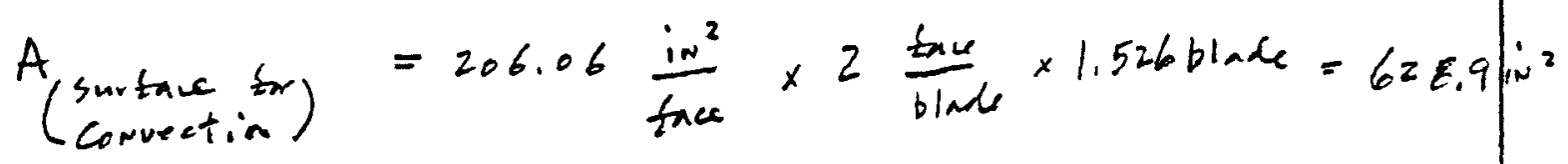

- Blade Cross section

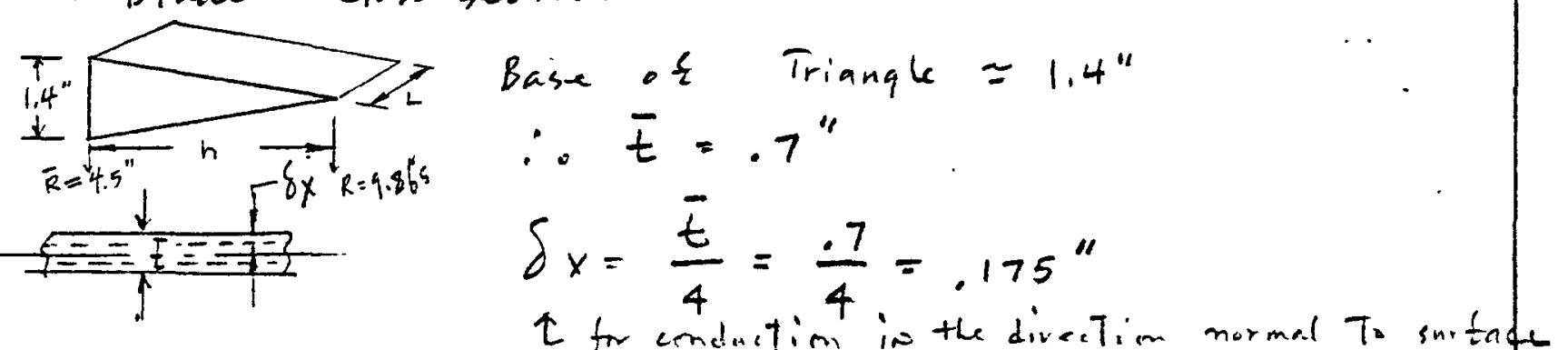

N 132-1.2 nEv. 2.76 


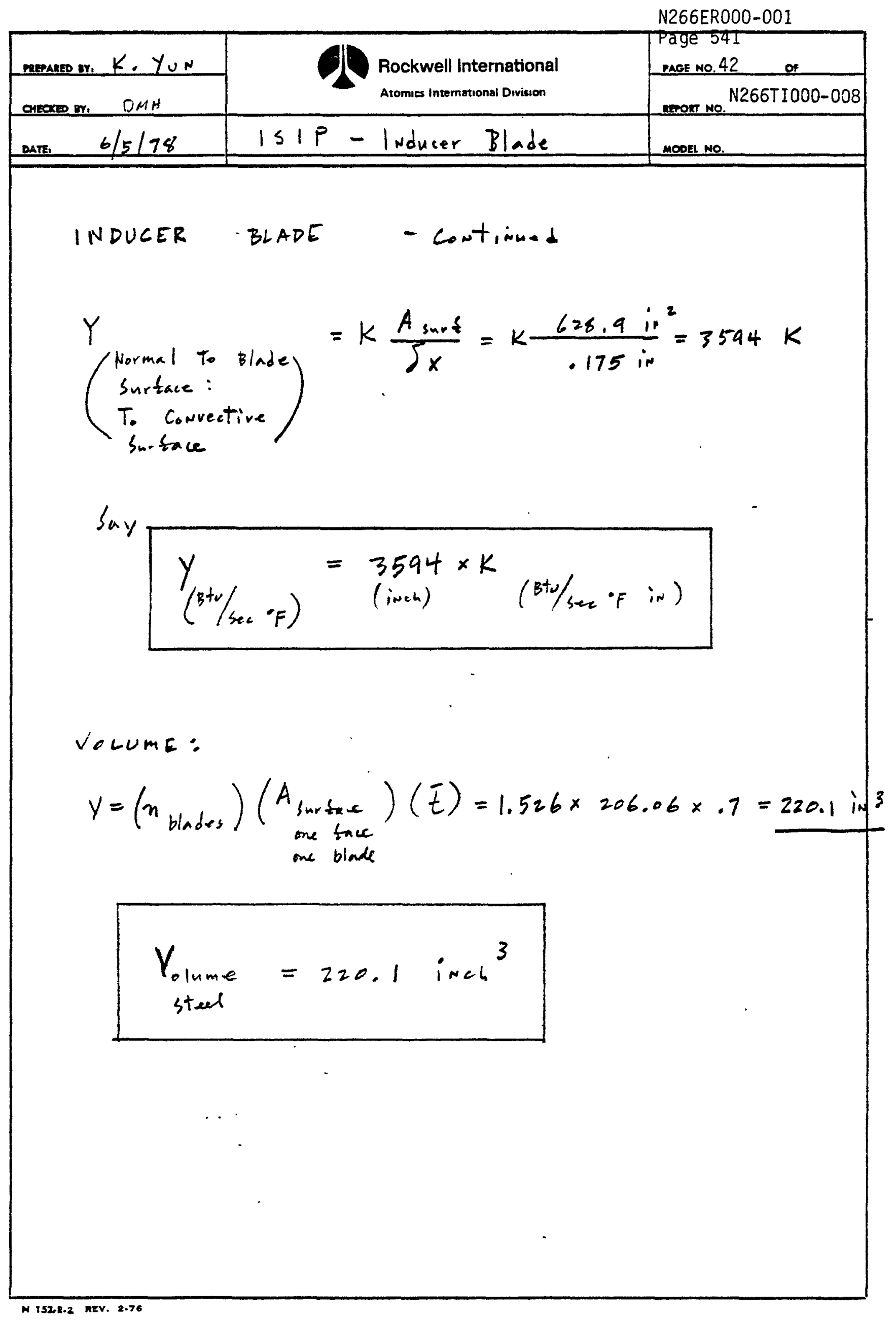




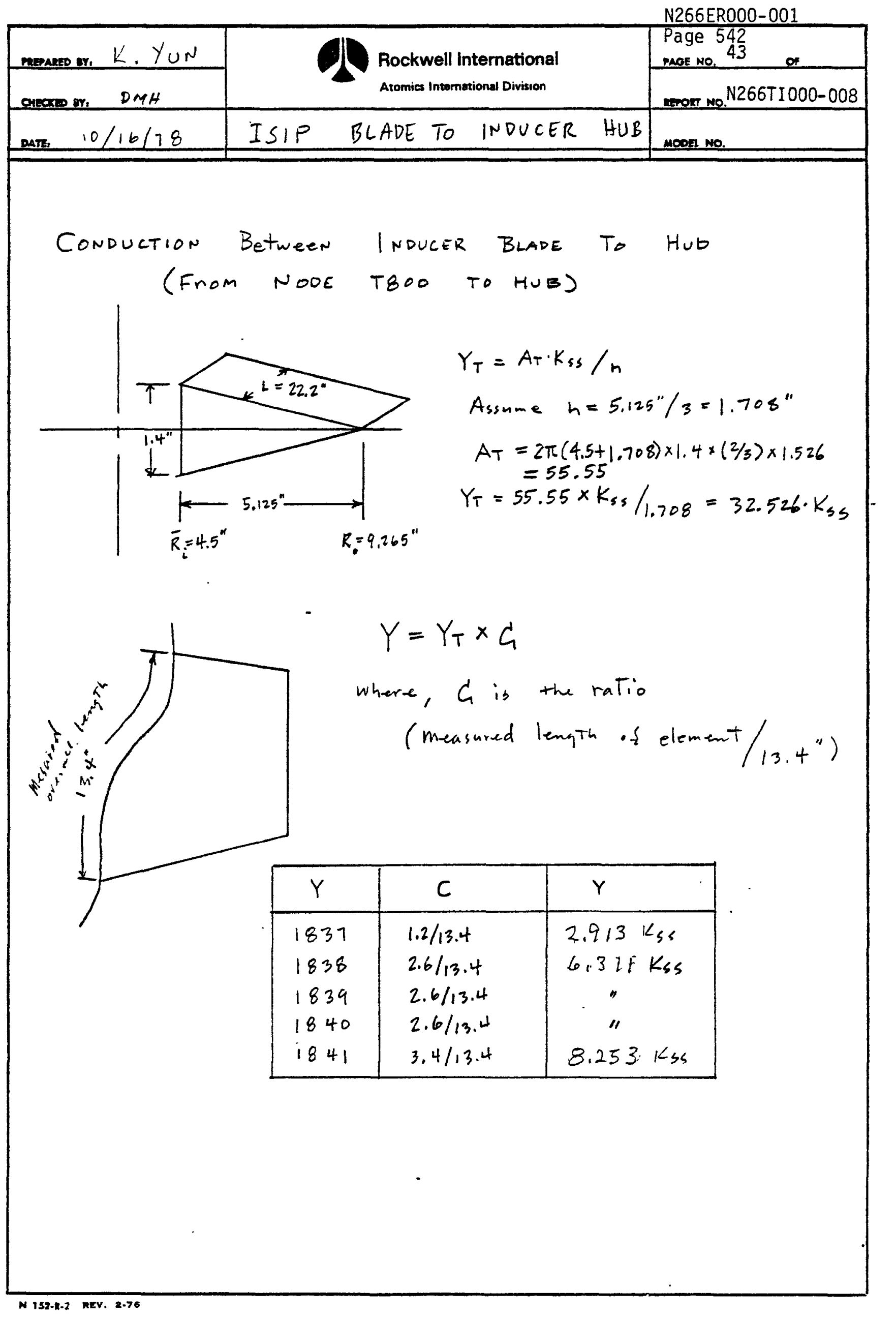




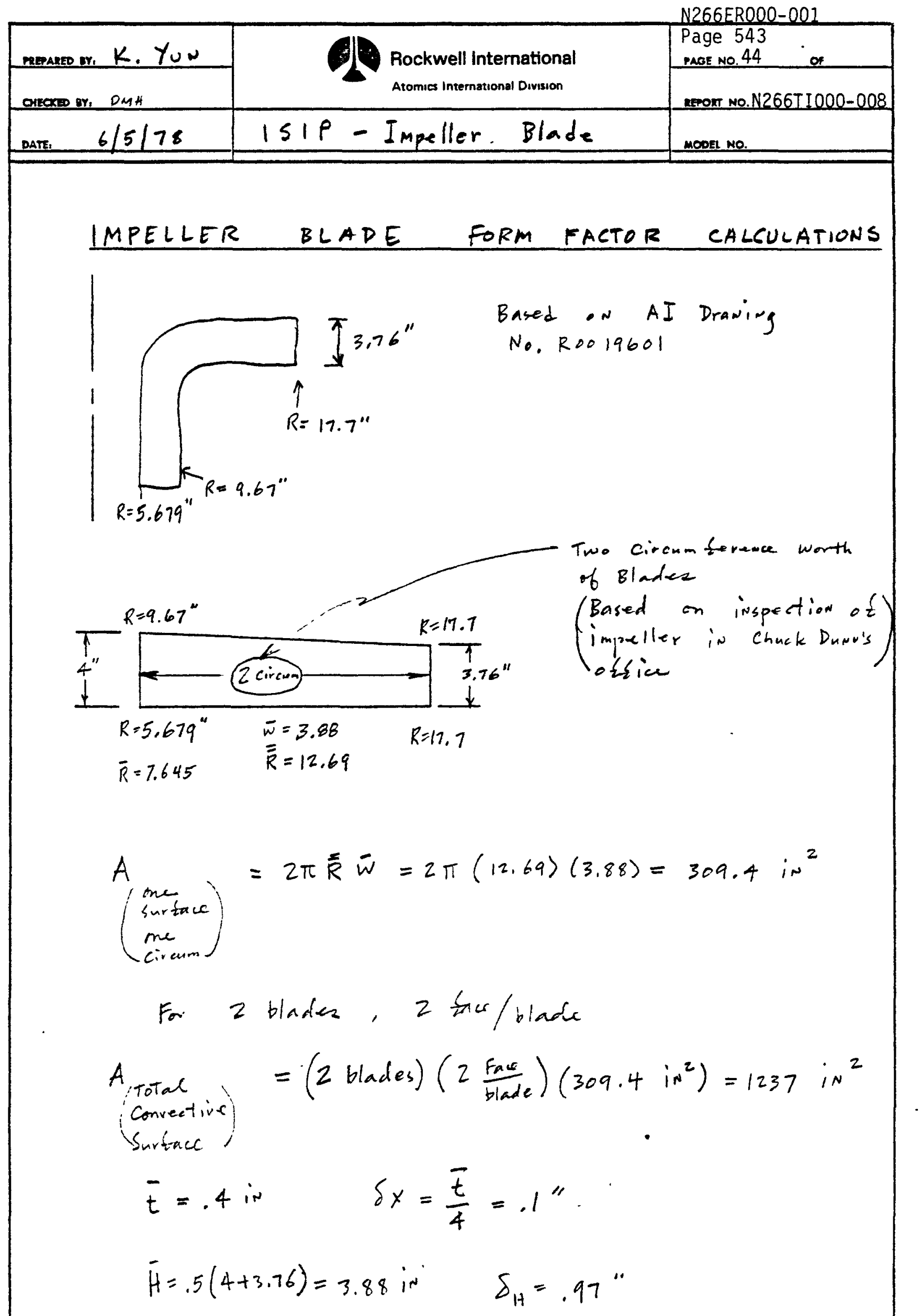

N 152-R-2 REV. 2.76 


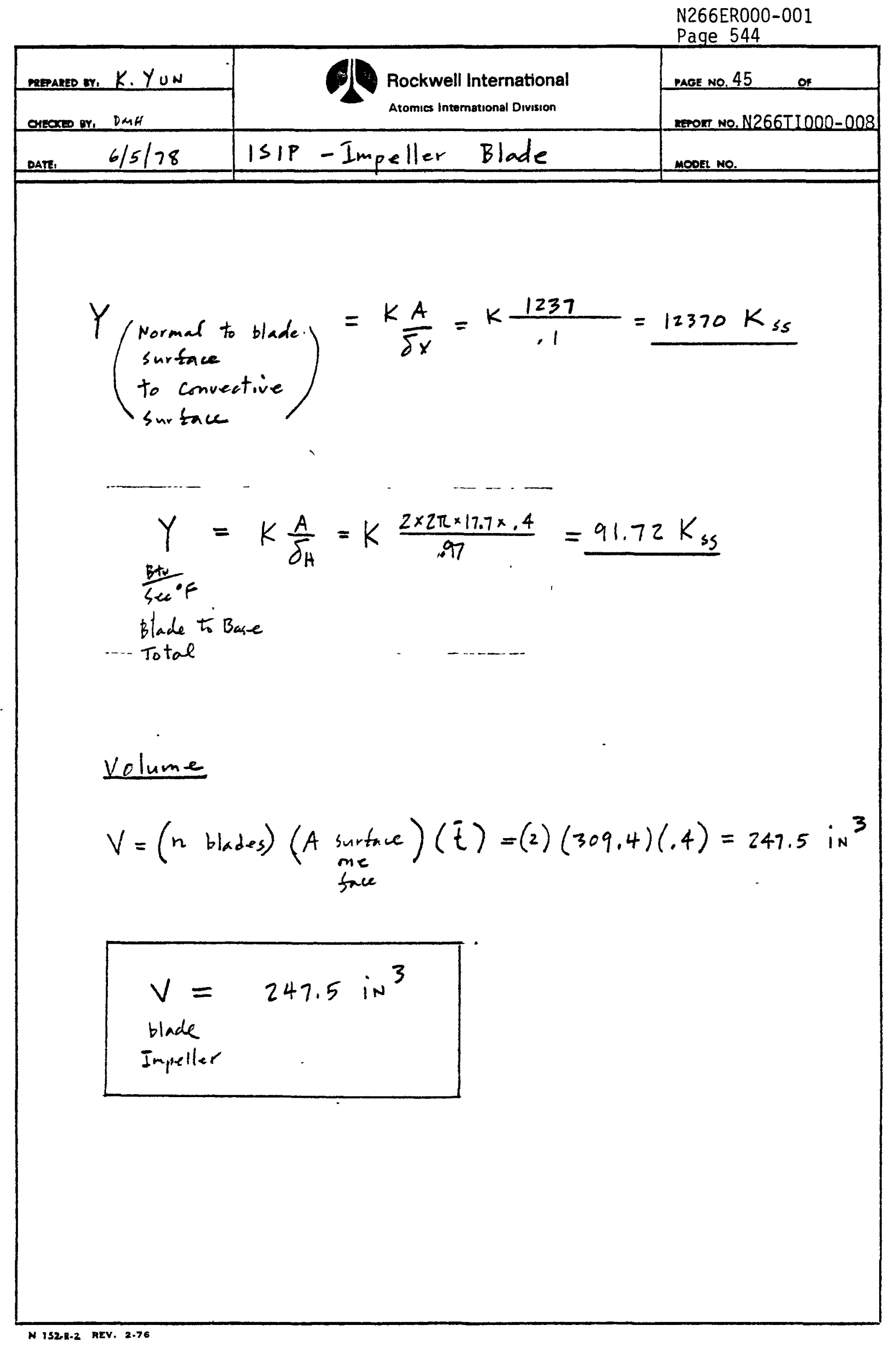




\begin{tabular}{|c|c|c|}
\hline mepales or, K. $K \cup \mathrm{N}$ & Rockwell International & $\begin{array}{l}\text { Page } 545 \\
\text { PAaE No. } 46 \\
\end{array}$ \\
\hline OHeCXs DY, DMH & Atomies Intermational Division & Neron wo. N266TIO000-008 \\
\hline Dare: $10 / 17 / 78$ & Isip - Impeller Blade & MOOKL NO. \\
\hline
\end{tabular}

Conouction From Impeller Blade To Hub

$Y_{T}=91.72 K_{S S}$

For $Y 1842 \sim Y_{1846}, Y=C_{1} \times Y_{T}$

For $Y 1847 \sim Y 1851, Y=C_{2} \times Y_{T}$

\begin{tabular}{|c|c|c|}
\hline$Y$ & $C_{1}$ or $C_{2}$ & $Y$ \\
\hline 1842 & $2.4 / 12.5$ & $17.61 \mathrm{Kss}_{s}$ \\
1843 & $4.1 / 12.5$ & $30.08 \mathrm{Kss}$ \\
1844 & $3.1 / 12.5$ & $22.75 \mathrm{Kss}^{\prime}$ \\
1845 & $2.3 / 12.5$ & $16.88 \mathrm{Kss}$ \\
1846 & $1.6 / 12.5$ & $11.74 \mathrm{Kss}$ \\
1847 & $1.35 / 10$. & $12.38 \mathrm{Kss}$ \\
1848 & $2.45 / 10$. & $22.47 \mathrm{Kss}$ \\
1849 & $2.6 / 10$. & $23.85 \mathrm{Kss}_{s}$ \\
1850 & $2.6 / 10$. & $23.85 \mathrm{Kss}$ \\
1851 & $1.0 / 10$. & $9.172 \mathrm{Kss}$ \\
\hline
\end{tabular}




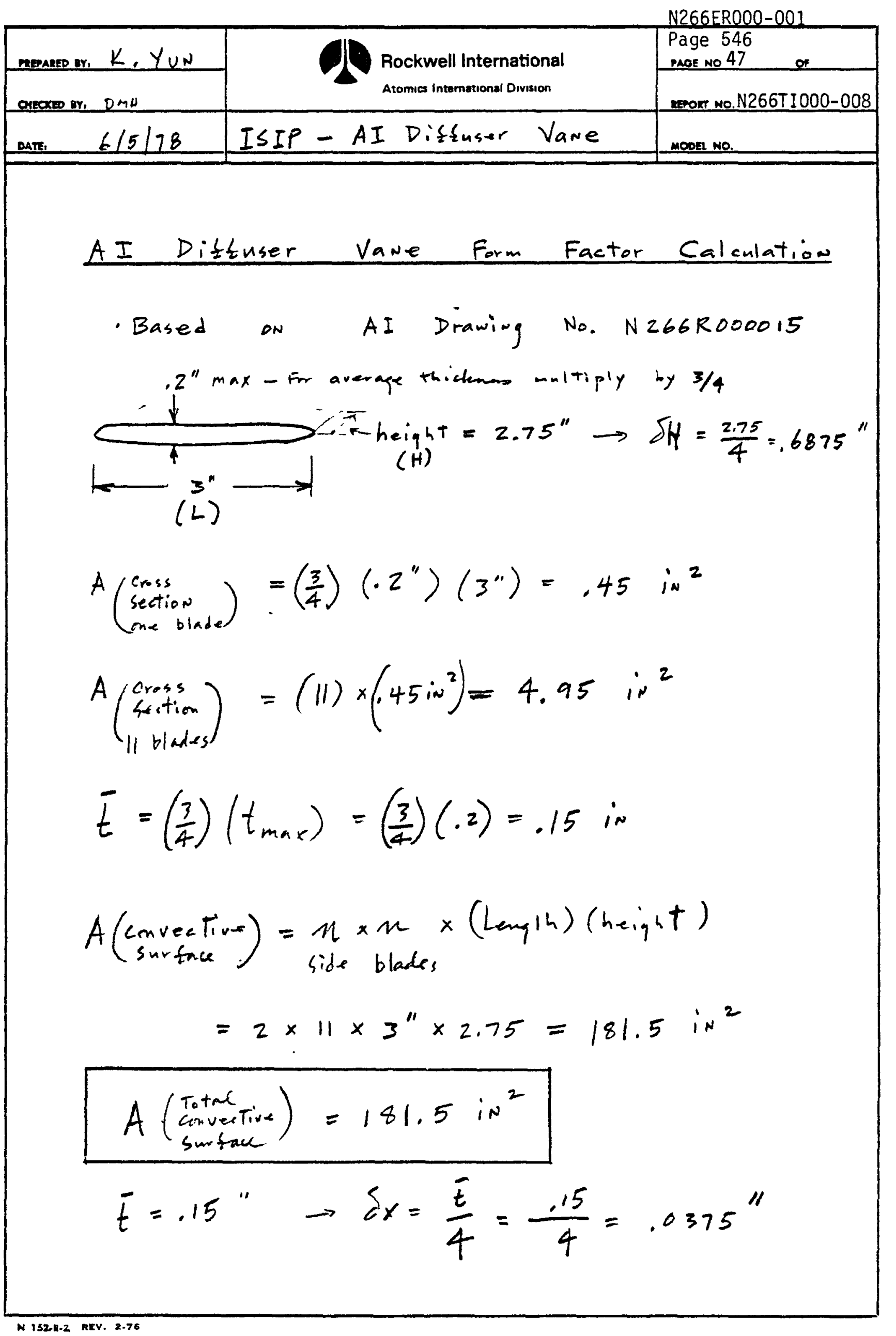




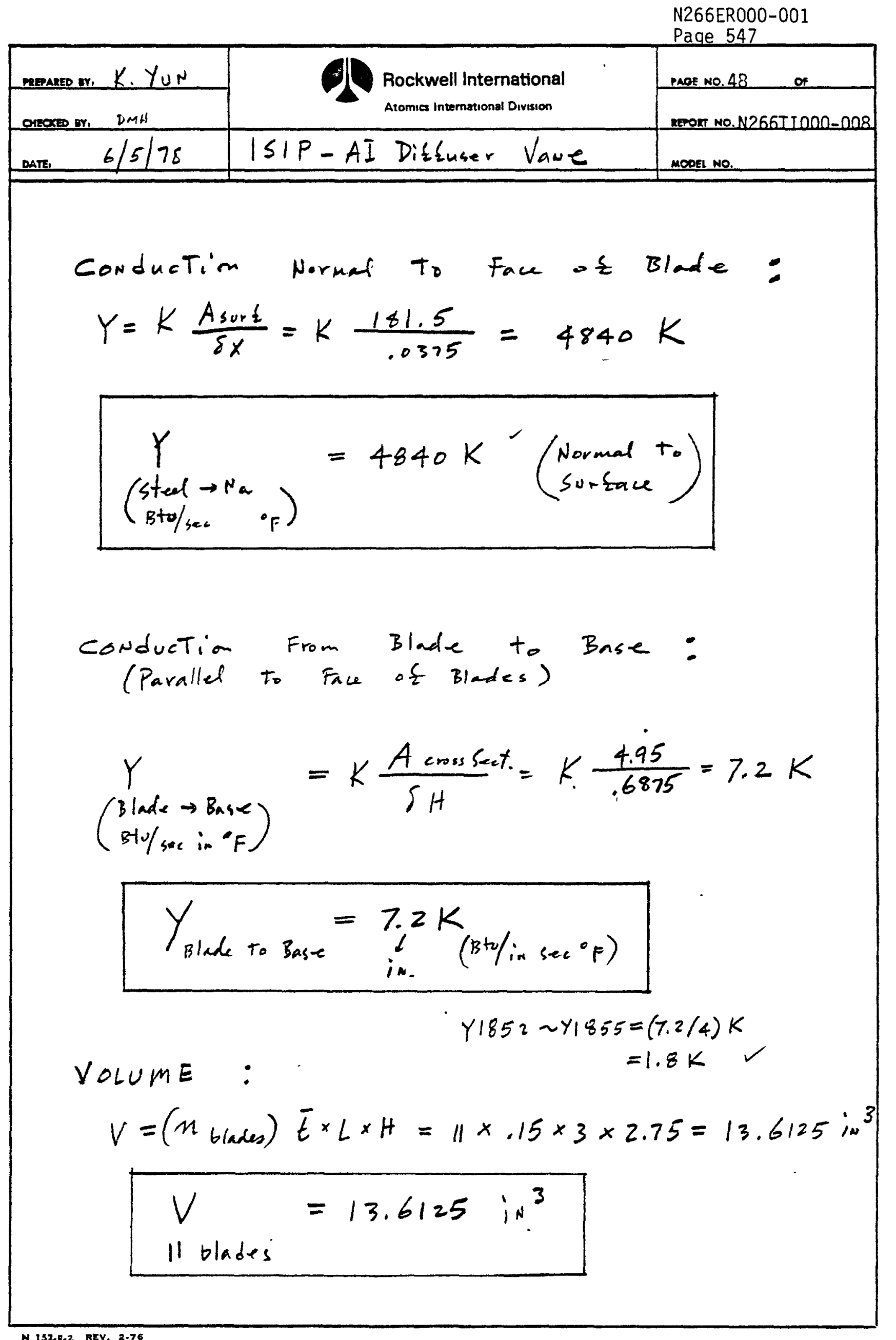




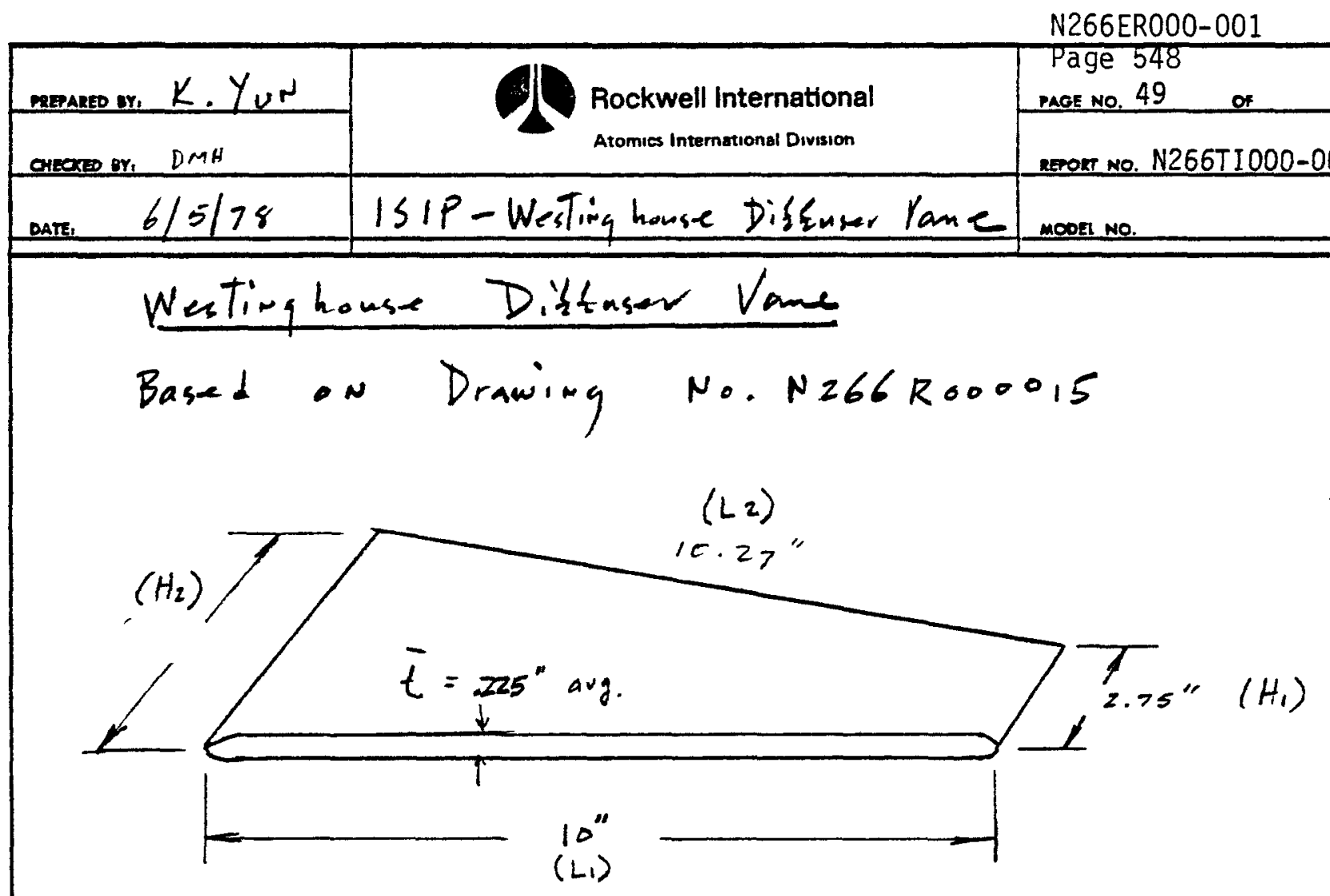

' $\mathrm{H}_{2}$ : From Westieghouse Drw. 9330757

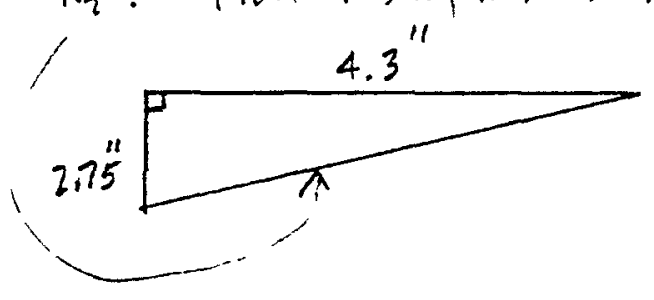

$$
\begin{aligned}
& H_{2}=\left(4.3^{2}+2.75^{2}\right)^{1 / 2}=5.104^{\prime \prime} \\
& L_{2}=\left[\left(H_{2}-H_{1}\right)^{2}+L_{1}{ }^{2}\right]^{1 / 2}=10.27^{\prime \prime}
\end{aligned}
$$

$$
\begin{aligned}
& A\left(\begin{array}{l}
\text { Cross } \\
\text { Section } \\
\text { il blade }
\end{array}\right)=(11)\left[\left(10^{\prime \prime}+10.27^{\prime \prime}\right) / 2\right]\left(.225^{\prime \prime}\right)=25.08 \mathrm{in}^{2} \\
& \text { For Conductiony }
\end{aligned}
$$

$$
\begin{aligned}
& A\left(\begin{array}{l}
\text { Convectives } \\
\text { sursace }
\end{array}\right)=(11)\left(2 \frac{\text { sides }}{\text { blated }}\right)[(2.75+5.106) / 2] \times\left(10^{\prime \prime}\right) \\
& \text { Bothside }=863.9 \text { in }^{2} \\
& \bar{t}=.225^{\prime \prime} \rightarrow S_{t}=\frac{\bar{t}}{4}=\frac{.225}{4}=.05625^{\prime \prime} \\
& \bar{H}=(2.75+5.104) / 2=3.927 \rightarrow \delta_{H}=\frac{\bar{H}}{4}=.98175 \\
& I=(10+10.27) / 2=10.135^{11}
\end{aligned}
$$

N 152-R.2 REV 2.76 


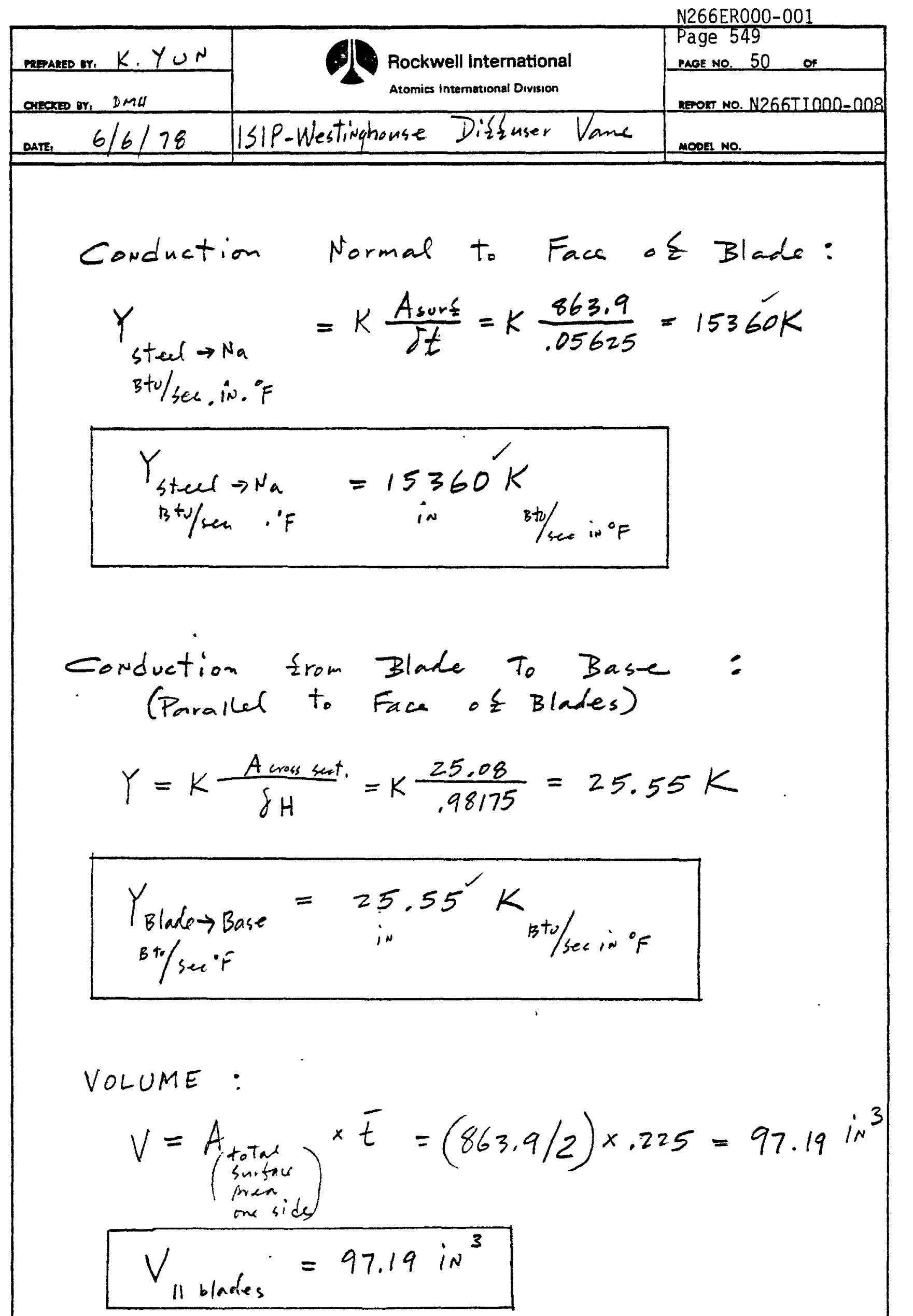




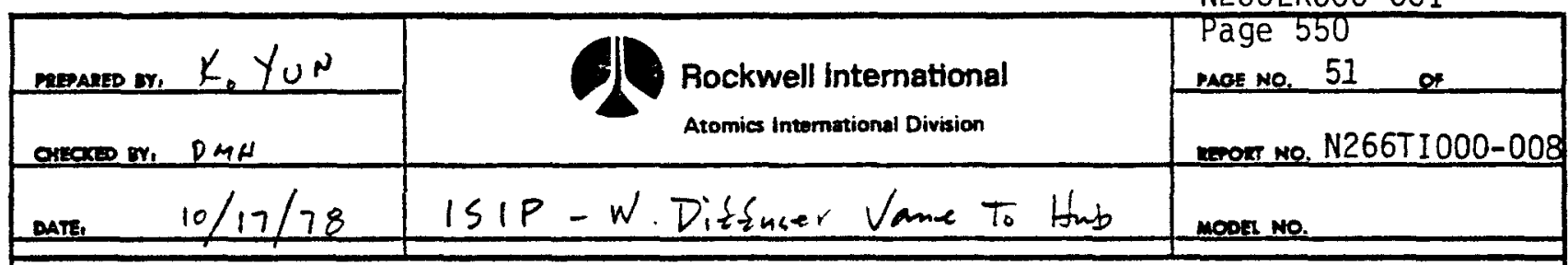

Conduction From Westinghouse Diffuser Vane To HUB.

$$
\begin{gathered}
Y_{T}=2.5 .55 \mathrm{~K} \text { ss (Bto/sec of ) } \\
Y=C \times Y_{T}
\end{gathered}
$$

\begin{tabular}{|c|c|c|}
\hline$Y$ & $C_{1}$ or $C_{2}$ & $Y$ \\
\hline 1856 & $.6 / 10$ & $1.533 \mathrm{~K}_{4 s}$ \\
1857 & $1.8 / 10$ & $4.599 \mathrm{~K}_{4 s}$ \\
1858 & $2.2 / 10$ & $5.621 \mathrm{~K}_{4 s}$ \\
1859 & $3.2 / 10$ & $8.176 \mathrm{~K}_{4 s}$ \\
1860 & $2.2 / 10$ & $5.621 \mathrm{~K}_{4 s}$ \\
1861 & $2.1 / 7.2$ & $7.452 \mathrm{Kss}$ \\
1862 & $2.1 / 7.2$ & $7.452 \mathrm{Kss}$ \\
1863 & $2.2 / 7.2$ & $7.807 \mathrm{Kss}$ \\
1864 & $.8 / 7.2$ & $2.839 \mathrm{Kss}$ \\
\hline
\end{tabular}




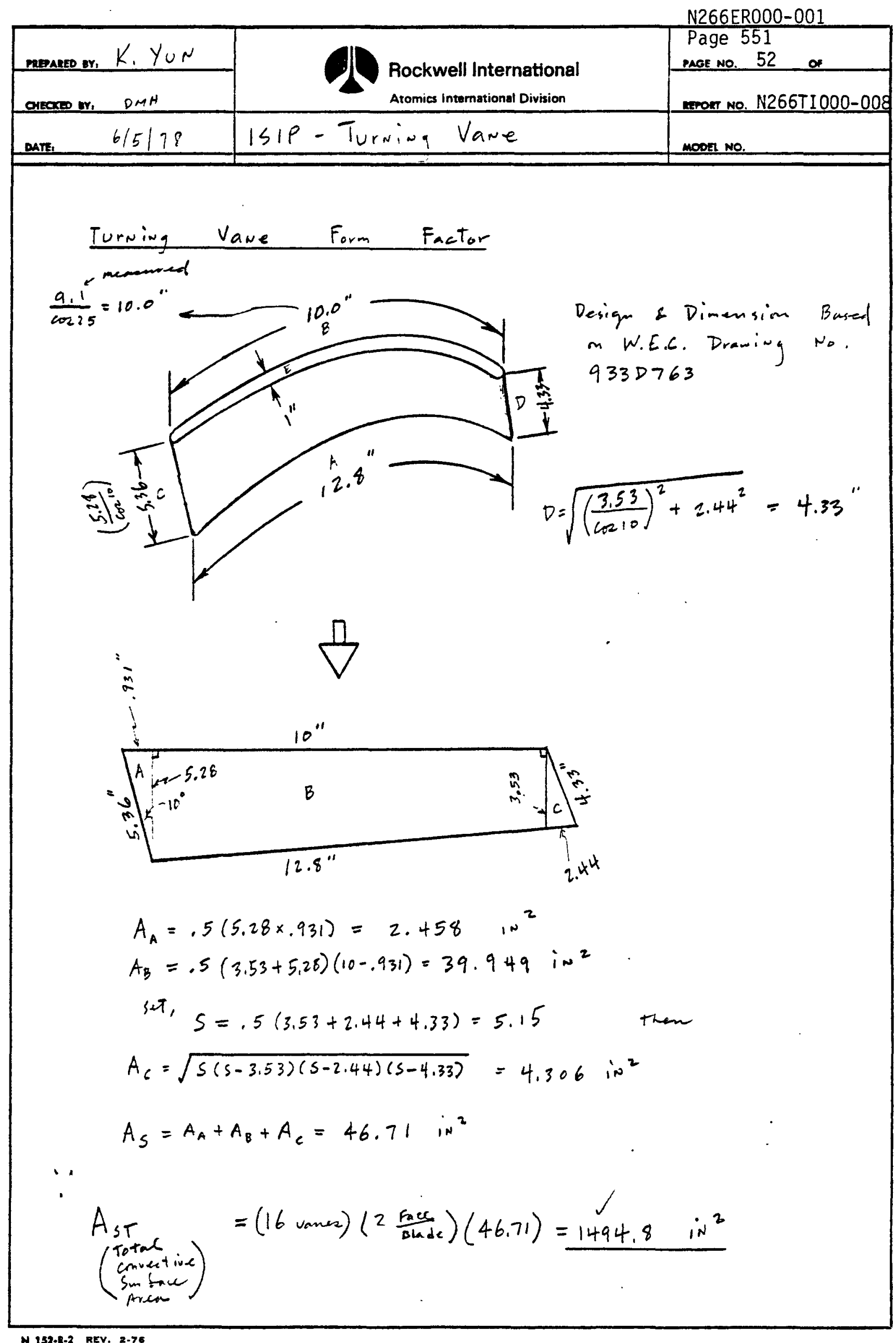




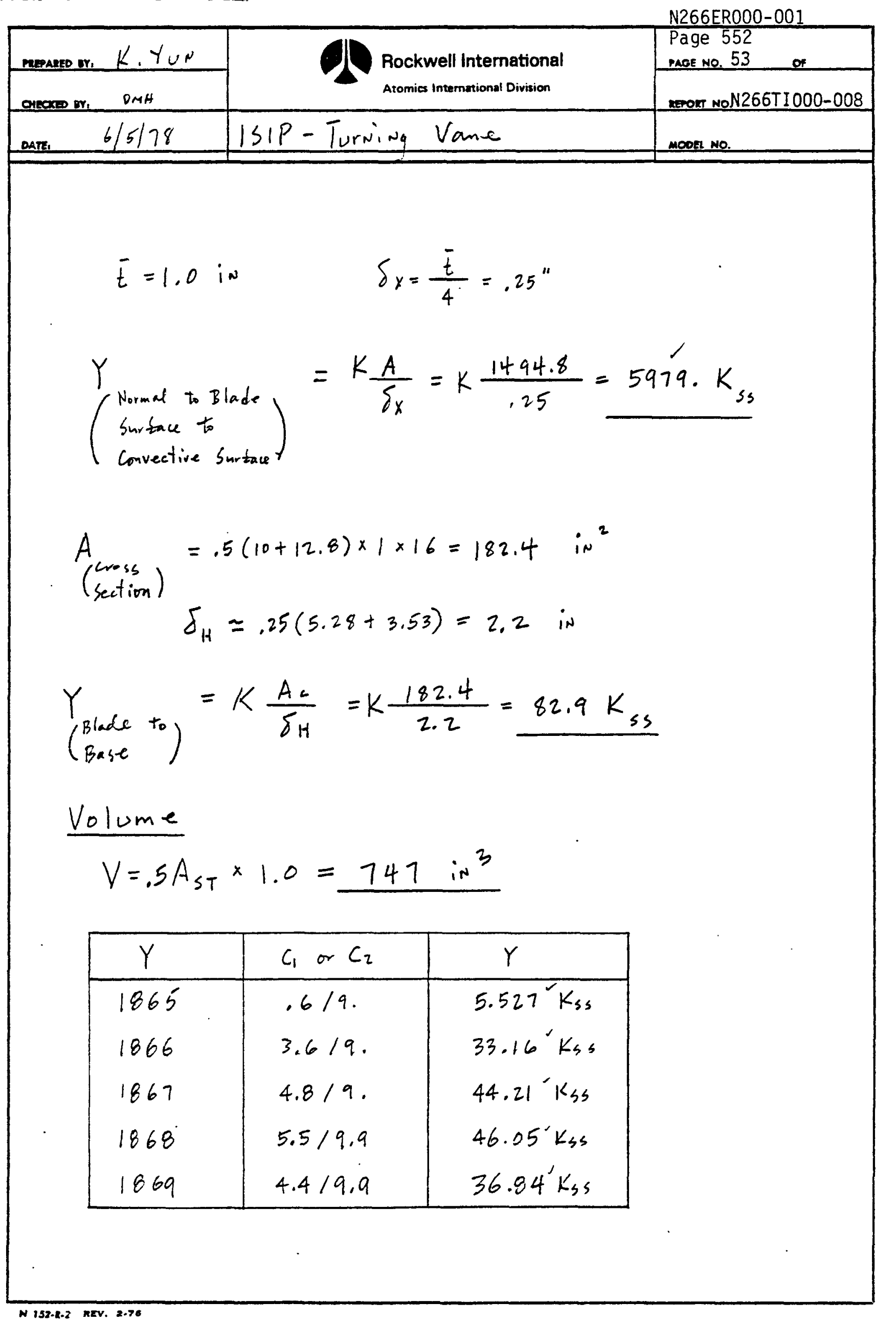




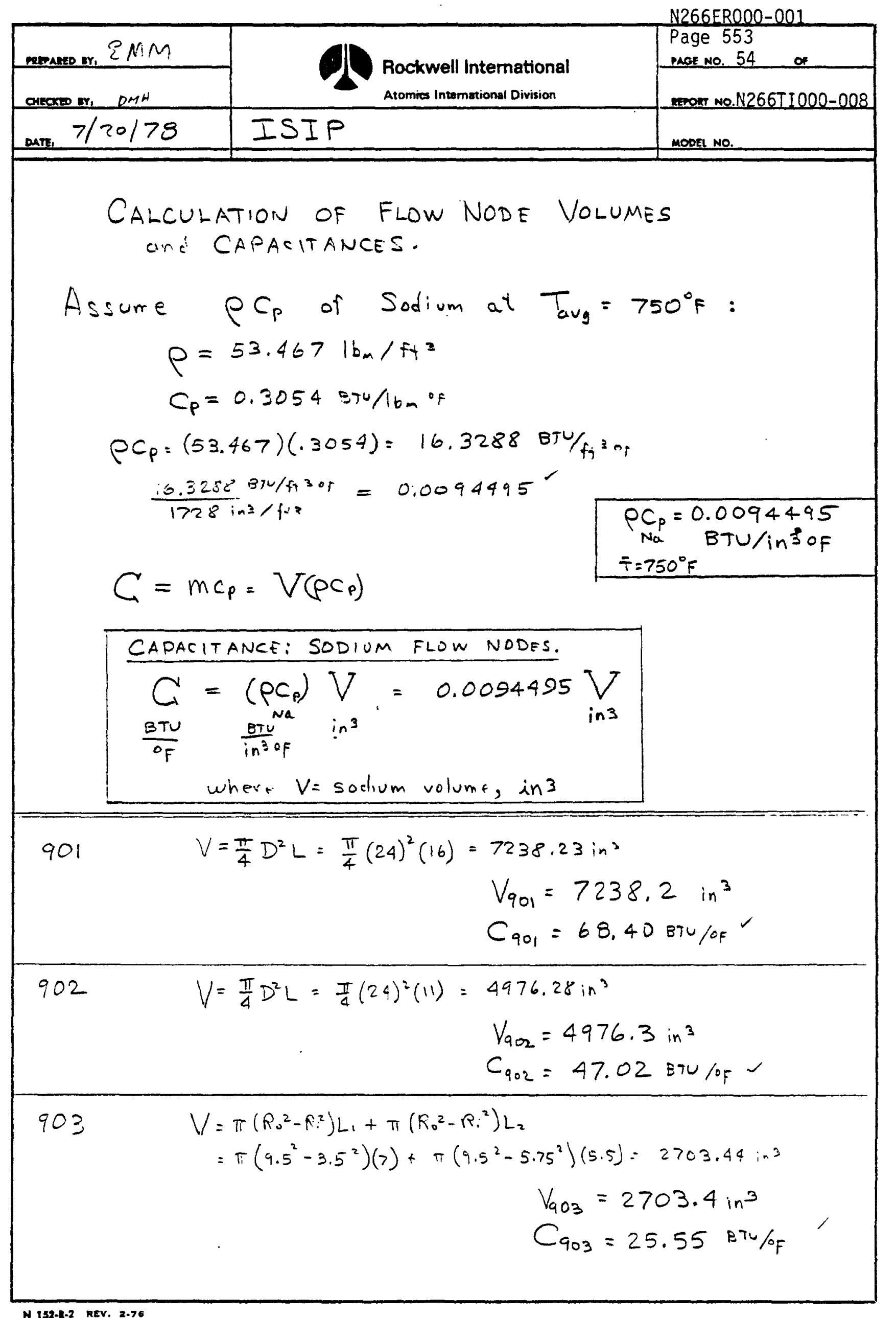




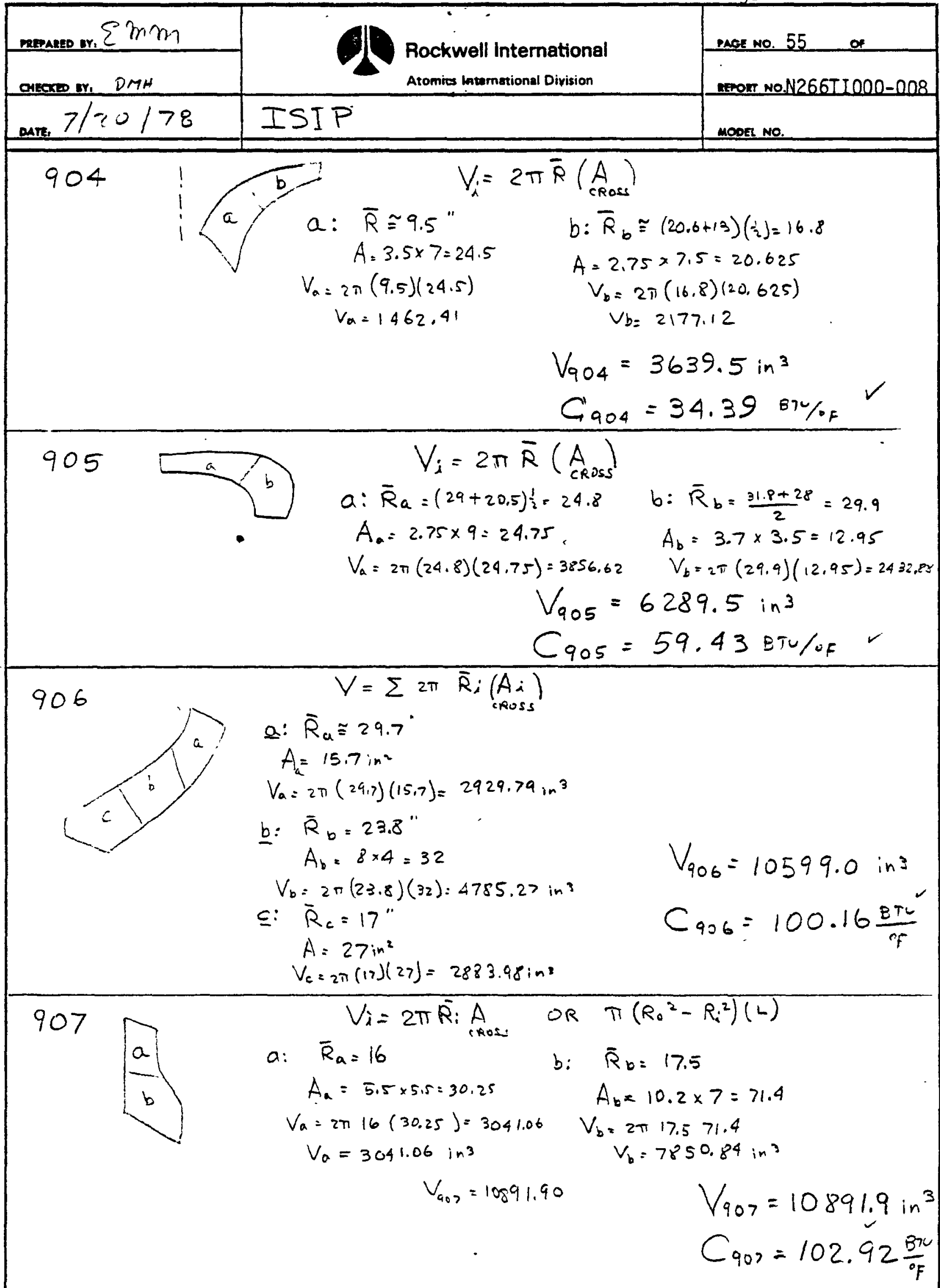


3

N266ER000-001

Page 555

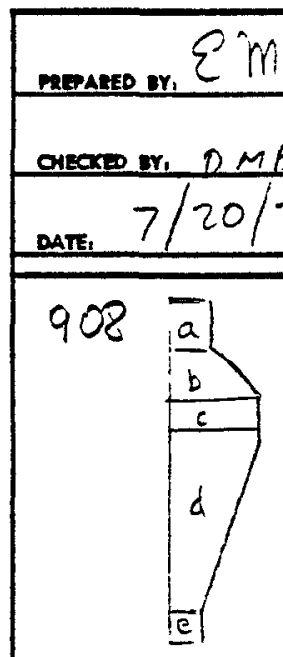

$$
\begin{aligned}
& V_{a}= \pi R^{2} \Delta L=\pi\left(11^{2}\right)(11.5)=4371.53 \\
& V_{b}= \pi\left(R_{u}^{2}+R_{L}^{2}+R_{u} R_{L}\right)(\Delta L)\left(\frac{1}{3}\right)=\pi\left(13^{2}+21.5^{2}+13 \times 21.5\right)\left(\frac{1}{3}\right)(9)=8583.62 \\
& V_{c}=\pi R^{2} \Delta L=\pi(21.5) L^{2}(4)=5808.80 \\
& V_{d}=\pi\left(R_{u}^{2}+R_{L}^{2}+R_{u} R_{L}\right)(\Delta L)\left(\frac{1}{3}\right)=\pi\left(21.5^{2}+8^{2}+8 \times 21.5\right)(37.5)\left(\frac{1}{3}\right)=27420.21 \\
& V_{e}=\pi R^{2} \Delta L=\pi(8)^{2}(3.5)=703.72 \\
& V_{908}^{\prime}=46.887 .89
\end{aligned}
$$

Subtract Volume of Node 902 :

$$
\begin{aligned}
V_{908}=V_{908}^{\prime}-V_{902}=46,887.9-4976.3 & =41911.6 \mathrm{in}^{3} \\
V_{908} & =41,911.6 \mathrm{in}^{3} \\
C_{908}^{\prime} & =396.05 \frac{\mathrm{BTU}}{0 \mathrm{~F}}
\end{aligned}
$$

$$
\begin{aligned}
& 909 \quad V=\pi R^{2} \Delta L=\pi(8)^{2}(51)=10,254.16 \\
& V_{909}=10,254.2 \mathrm{in}^{3} \\
& C_{909}=96.90 \mathrm{PT} \%
\end{aligned}
$$$$
910
$$

Discharge node

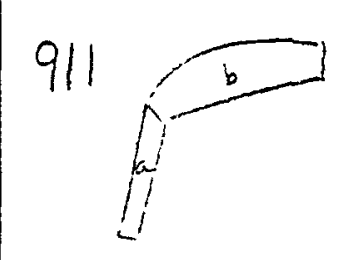

$$
V_{i}=2 \pi \bar{R} \underset{\text { cross }}{A}
$$

$a:$

$$
\begin{aligned}
a: \bar{R}_{a} & =11.5 \\
A_{a} & =(4)(.6)=2.4 \\
V_{a}=2 \pi & (11.5)(2.4) \\
V_{a} & =173.42 \mathrm{in}^{3}
\end{aligned}
$$$$
\text { b: } \bar{R}_{b}=14.5^{\prime \prime}
$$$$
A_{b}=(6.5)(.55)=5.525
$$$$
V_{b}=2 \pi(14.5)(5.525)
$$$$
V_{b}=503,36
$$

$$
\begin{aligned}
V_{911}=676.78 \quad V_{911} & =676.8 \mathrm{im} \\
C_{911} & =6.40 \frac{\mathrm{BT}}{\mathrm{OF}_{\mathrm{F}}}
\end{aligned}
$$

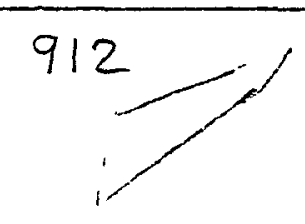

$$
\begin{aligned}
& V=2 \pi \bar{R}_{\text {Cross }} . \\
& \bar{R}=14.5 \text { inch } \\
& \text { Across }=\bar{i}(s)(2.5)=10 \\
& V=2 \pi \bar{R} A=2 \pi(14.5)(10)=911.06
\end{aligned}
$$

$$
\begin{aligned}
& V_{912}=9 ! 1.1 \mathrm{in}^{3} \\
& C_{912}=8.61 \frac{B^{3}}{C_{F}}
\end{aligned}
$$

N 152-R-2 REV. 2.76 


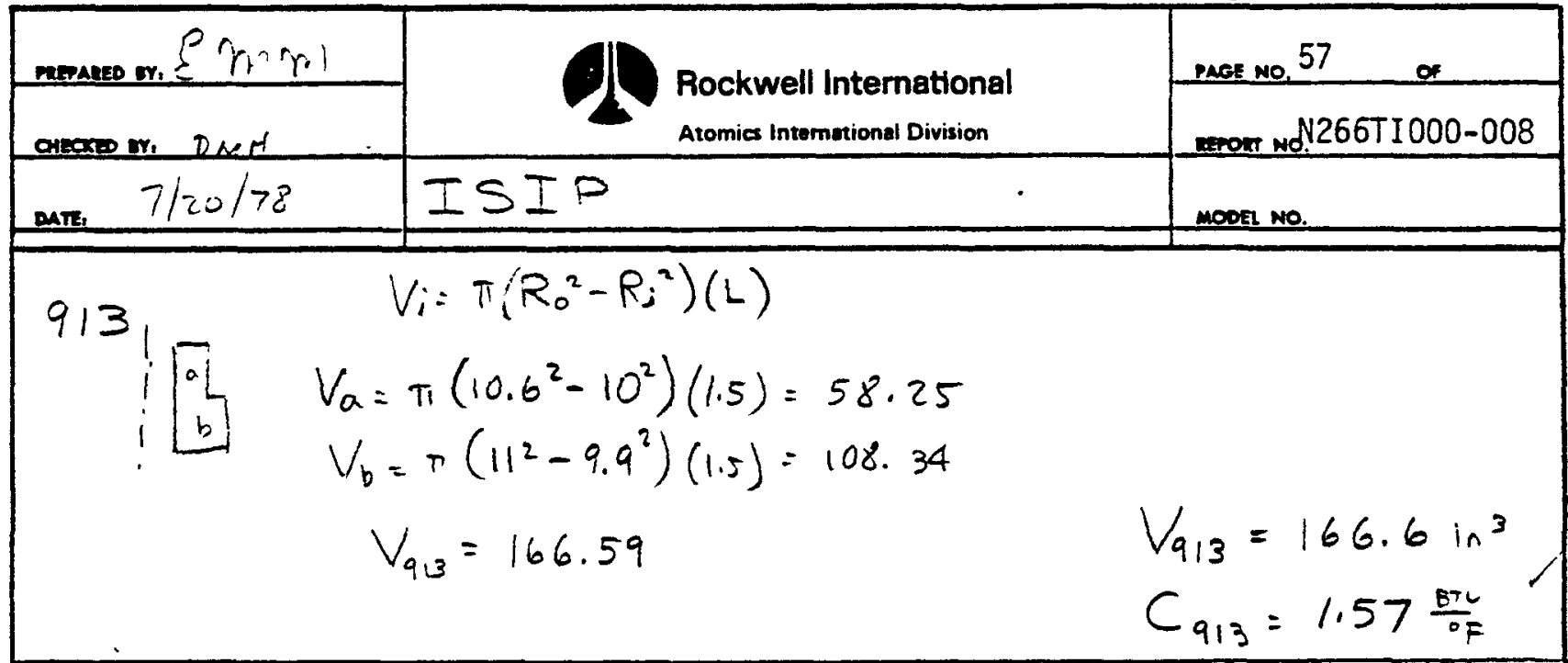

914

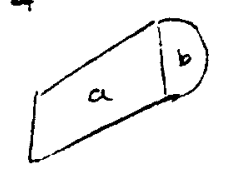

$$
V_{a}=2 \pi \bar{R} A
$$

$\bar{R}=\frac{1}{2}(24+13)=18.5$

$A=13 \times 5.6=72.8$

$V_{a}=2 \pi(18.5)(72.8)$

$V_{a}=8462.19$

$$
\begin{aligned}
& V_{914}=9176.12 \\
& 915 \quad V=\pi R^{2} L=\pi(1.25)^{2}(6.5) \\
& 915 \quad V=\pi R^{2} L=\pi(1.25)^{2}(6.5) \\
& V_{915}=31.91 \mathrm{in}^{3} \\
& V_{914}=9176.1 \mathrm{in} \\
& C_{914}=86.71 \frac{\text { e.t. }}{\text { if }} \\
& V_{915}=31.9 \mathrm{in}^{3} \\
& C_{915}=0.30 \quad \frac{\mathrm{eT}^{2}}{\mathrm{~F}^{2}} \\
& 916 \quad V=\pi R^{2} L=\pi(1.25)^{2}(12) \\
& V_{916}=58.90 \mathrm{in}^{3} \\
& V_{916}=58.9 \mathrm{in}^{3} \\
& C_{910}=0.56 \frac{\text { Exv }}{. F} \\
& 917 \quad V=\pi R^{2} L=\pi(1.25)^{2}(31.6) \\
& V=155.12 \mathrm{in}^{3} \\
& V_{917}=155.1 \text { in }^{3} \\
& C_{917}=1.47 \frac{B T V}{{ }^{\circ} \mathrm{F}} \\
& \Delta_{\text {eross }}=(3.5)(2)-\frac{1}{2}(1.5)(1.5)=5.875 \\
& V=2 \pi(6)(5.875)=221.48 \mathrm{im} \text {. } \\
& V_{918}=221.5 \mathrm{in}^{3} \\
& C_{918}=2.09 \frac{\mathrm{BT}}{\mathrm{F}_{\mathrm{F}}}
\end{aligned}
$$

$V_{b}=2 \pi \bar{R} A$

$\bar{R}=25.25$

$A=\frac{1}{2}\left(3^{2}\right)=4.5$

$V=2 \pi(25.25)(4.5)=$

$V_{b}=713.93$ 


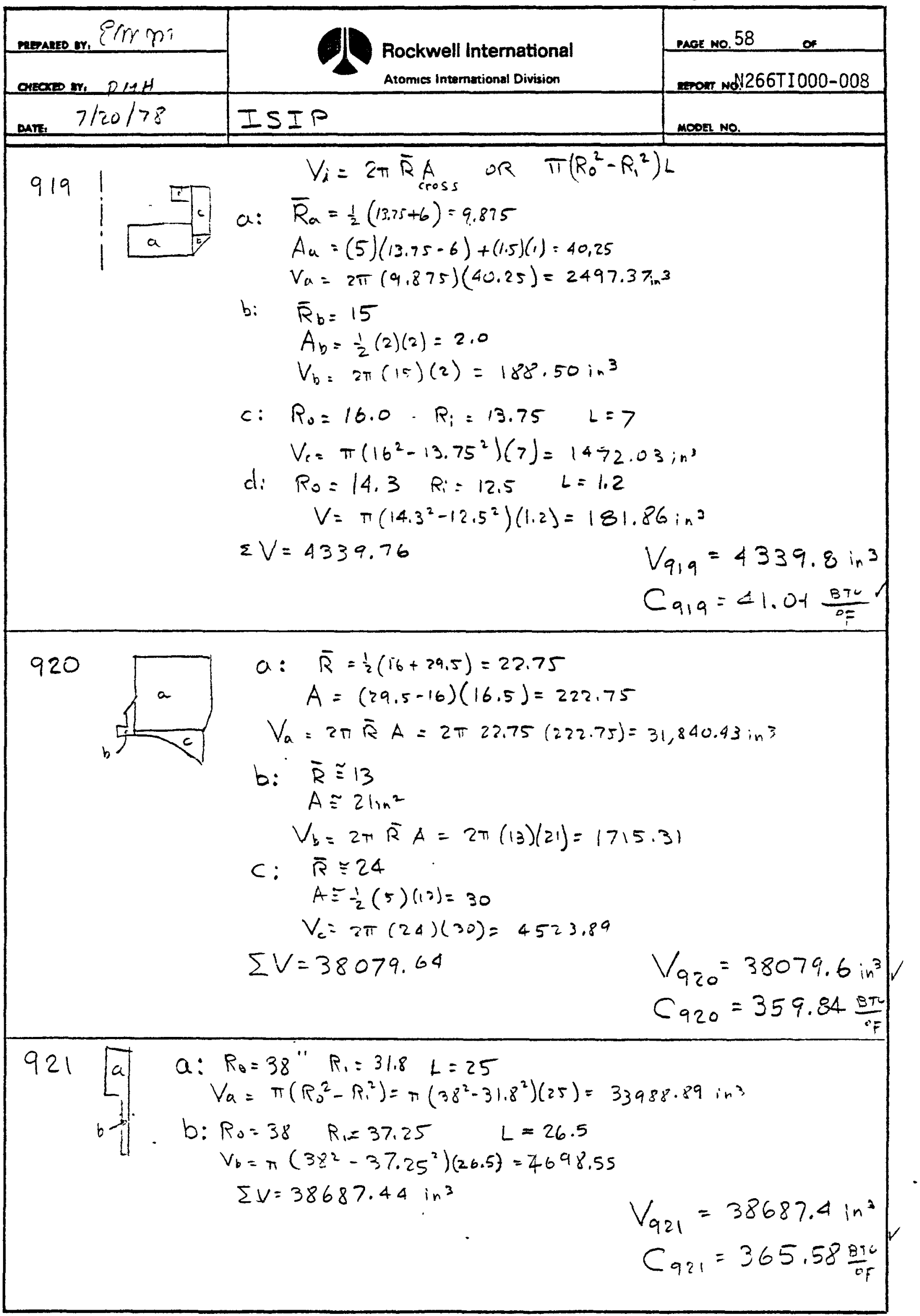




\begin{tabular}{|c|c|c|}
\hline 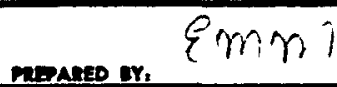 & & PAEE NO 59 \\
\hline oneckes or. DMH & Atomies Intemartional Division & N N266TI 1000-008 \\
\hline $7 / 20 / 78$ & ISIP & \\
\hline
\end{tabular}

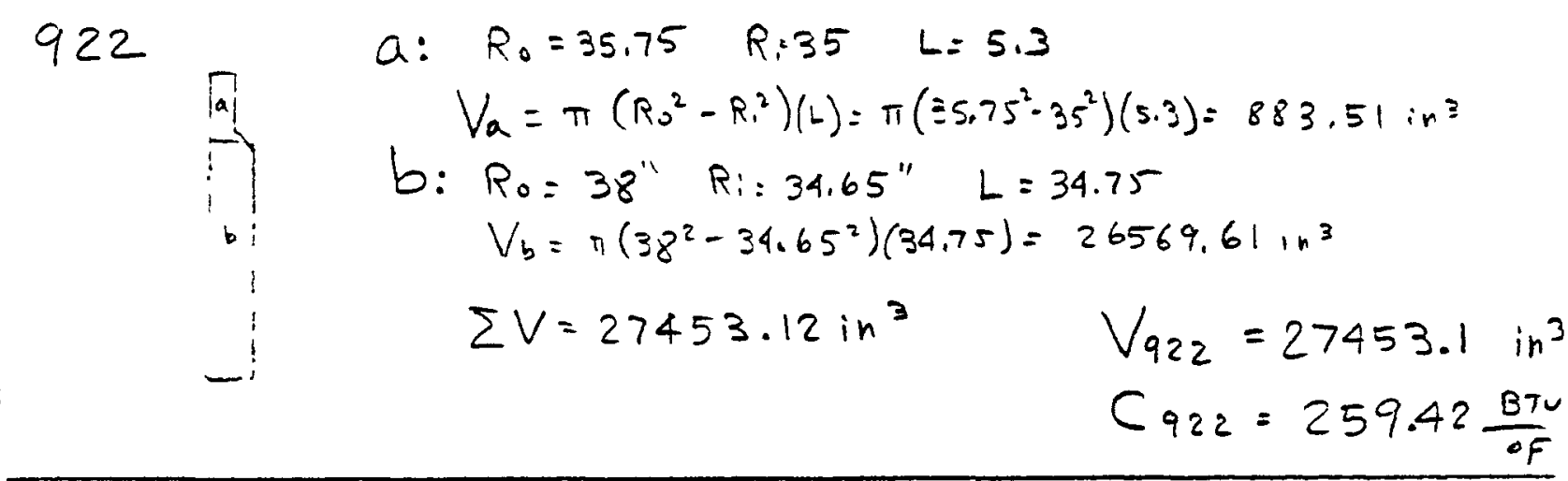

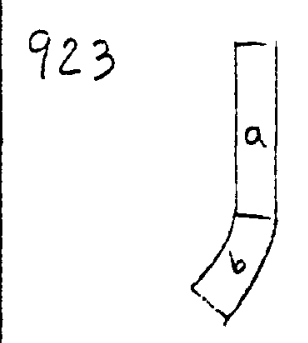

$$
\begin{aligned}
& a: R_{0}=38 \quad R_{i}=34.65 \quad L=44 \\
& V_{a}=\pi\left(38^{2}-34.65^{2}\right)(44)=33642.09 \mathrm{in}^{3} \\
& b: \quad \bar{R}_{b} \cong 35.5 \\
& A \cong 10 \times 3.5=35 \\
& V_{b}=2 \pi \bar{R} A=2 \pi(35.5)(35)=7806.86 \mathrm{in}^{3} \\
& \Sigma V=41.448 .95 \mathrm{in}^{3} \quad V_{923}=41,448.9 \mathrm{in}^{3} \\
& C_{923}=391.67 \frac{8 \mathrm{TV}}{{ }^{\circ} \mathrm{F}}
\end{aligned}
$$

924

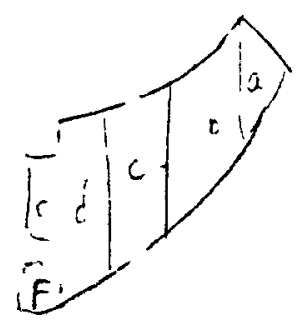

a: $\bar{R}_{a}=33^{\prime \prime}$

$$
A=\frac{1}{2}(10)(3.2)=16
$$$$
V_{a}=2 \pi \bar{R} A=2 \pi(33)(16)=3317.52 \mathrm{in}^{3}
$$

$b: R_{0}=32 \quad R_{1}=28 \quad L=10.8$

$V_{b}=n\left(32^{2}-28^{2}\right)(10.8)=8143.01 \mathrm{in}^{3}$

c: $R_{0}=28 \quad R_{1}=24 \quad L=12.5$

$V_{c}=\pi\left(28^{2}-24^{2}\right)(12.5)=8168.14 \mathrm{in}^{3}$

$d: R_{0}=24 \quad R_{i}=19 \quad L=14,3$

$V_{d}=\pi\left(24^{2}-19^{2}\right)(14.3)=9658.83$

$i \cdot$

$e:$

$R_{1}=16 \quad L=12.7$

$V_{e}=\pi\left(19^{2}-16^{2}\right)(12.7)=4189.31$

$f_{i} \quad \bar{R}_{F}=13.5$

$A=(4)(3)=12$

$V_{f}=2 \pi \bar{R} A=2 \pi(13.5)(12)=1017.88$

$\Sigma V=34,494.69$ 
7

N266ER000-001

Page 559

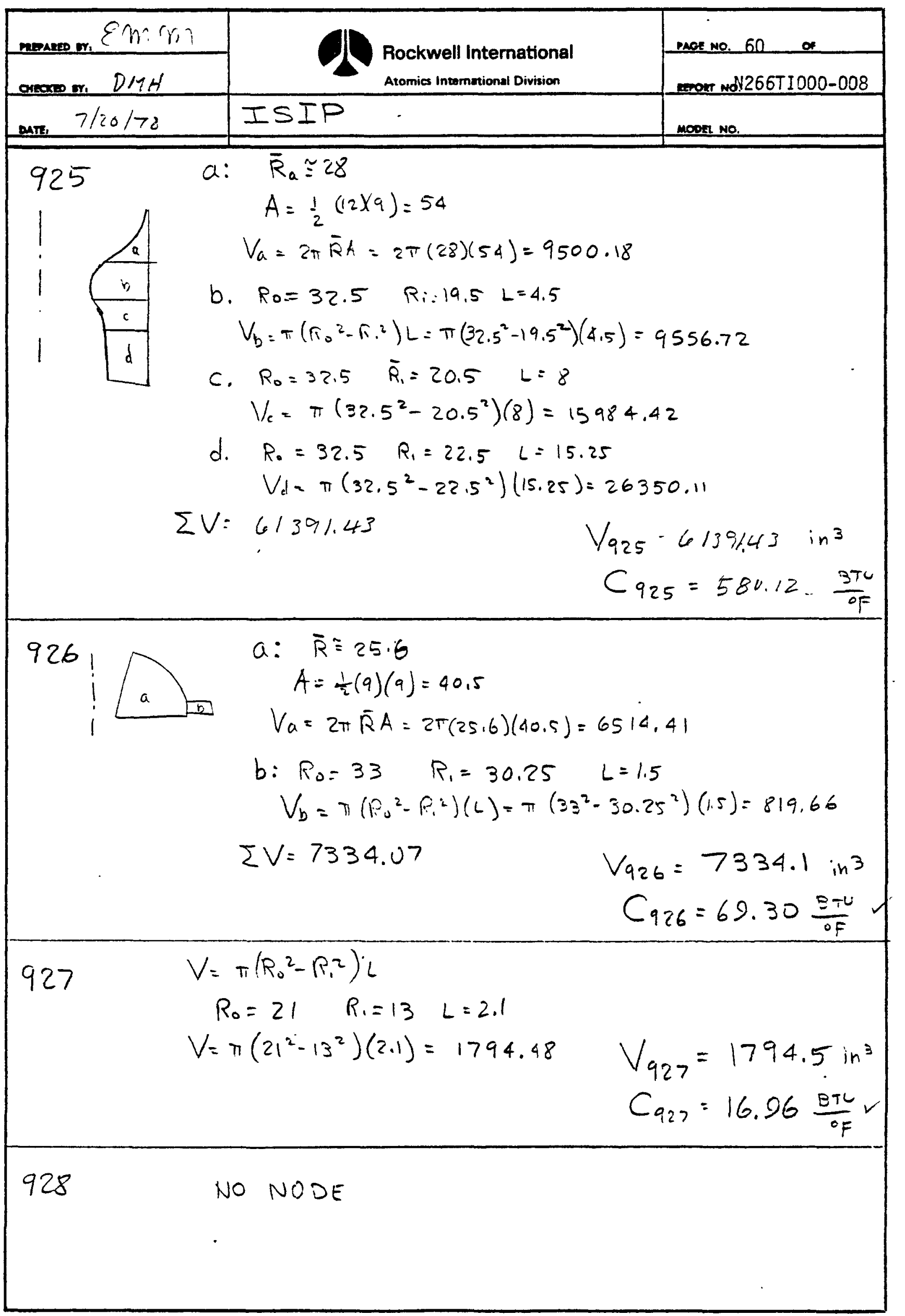

N 132-2-2 nEY. 2.76 
N266ERO00-001

8

Page 560

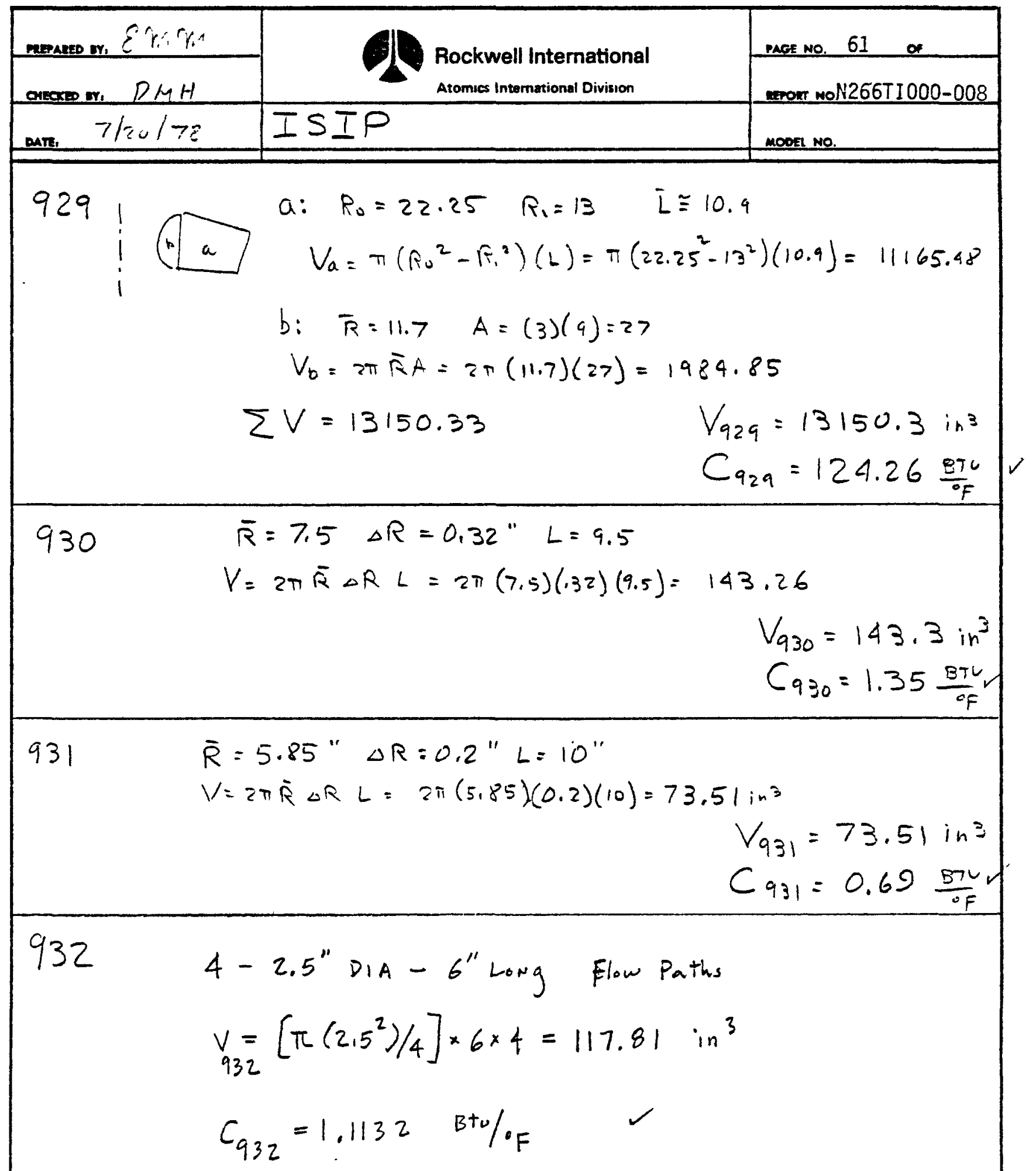


9

$\begin{array}{ll}\text { N266ER000-001 } & \text { Page 561 } \\ & \end{array}$

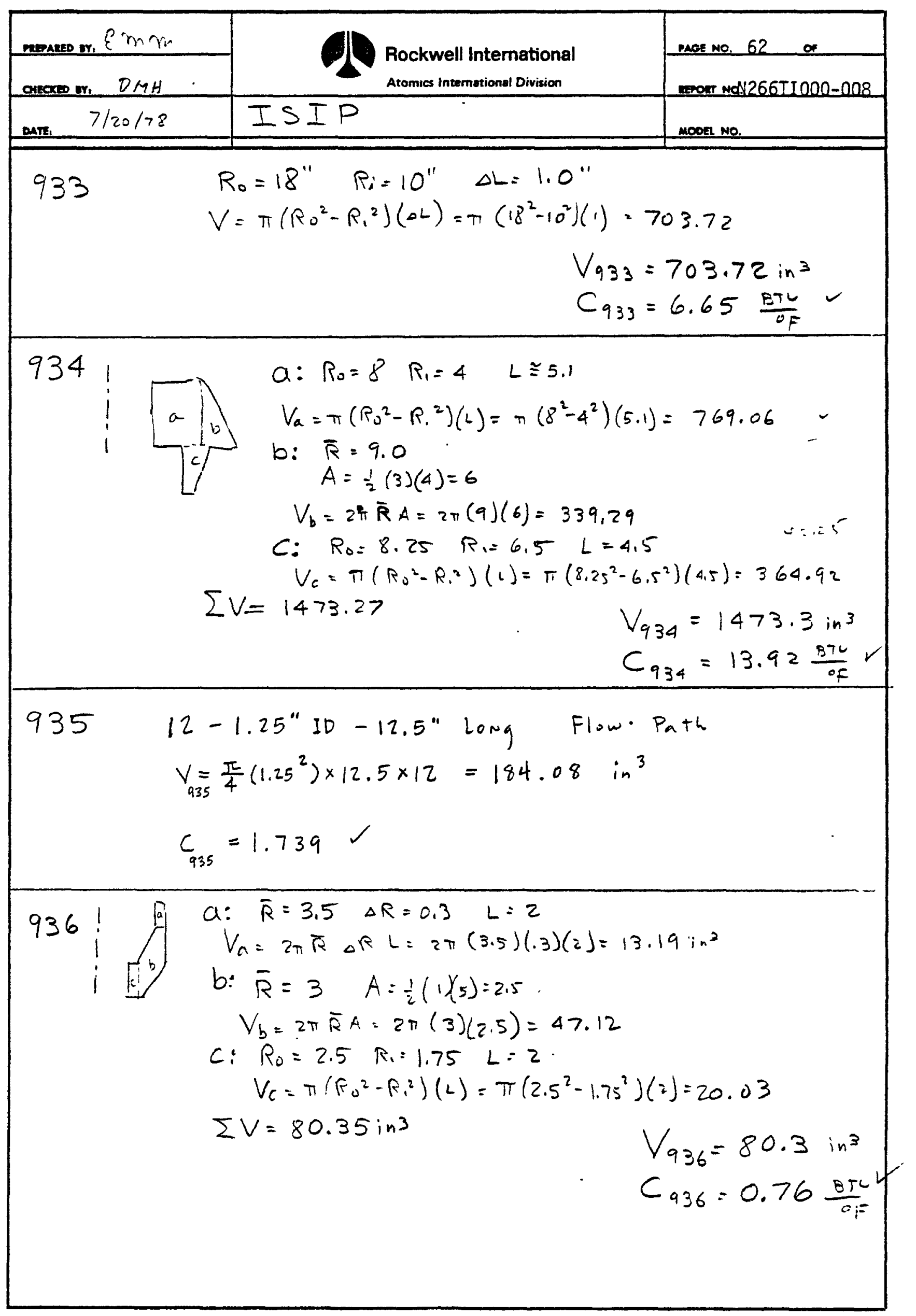

4 139.8-2 REV. 2-76 
N266ER000-001

10

Page 562

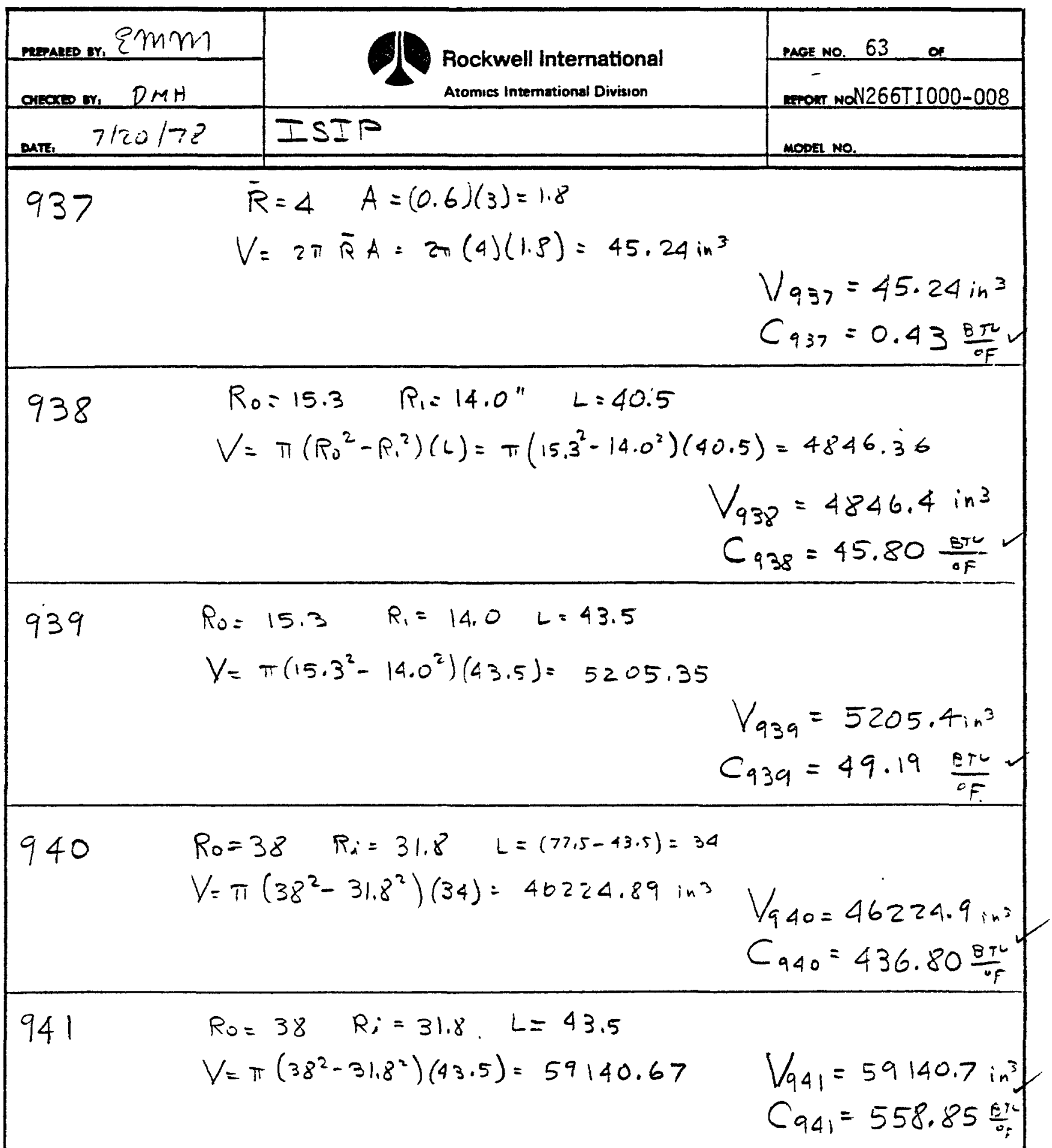

N 159-14-2 REY. 2-76 
N266ER000-001

Page 563

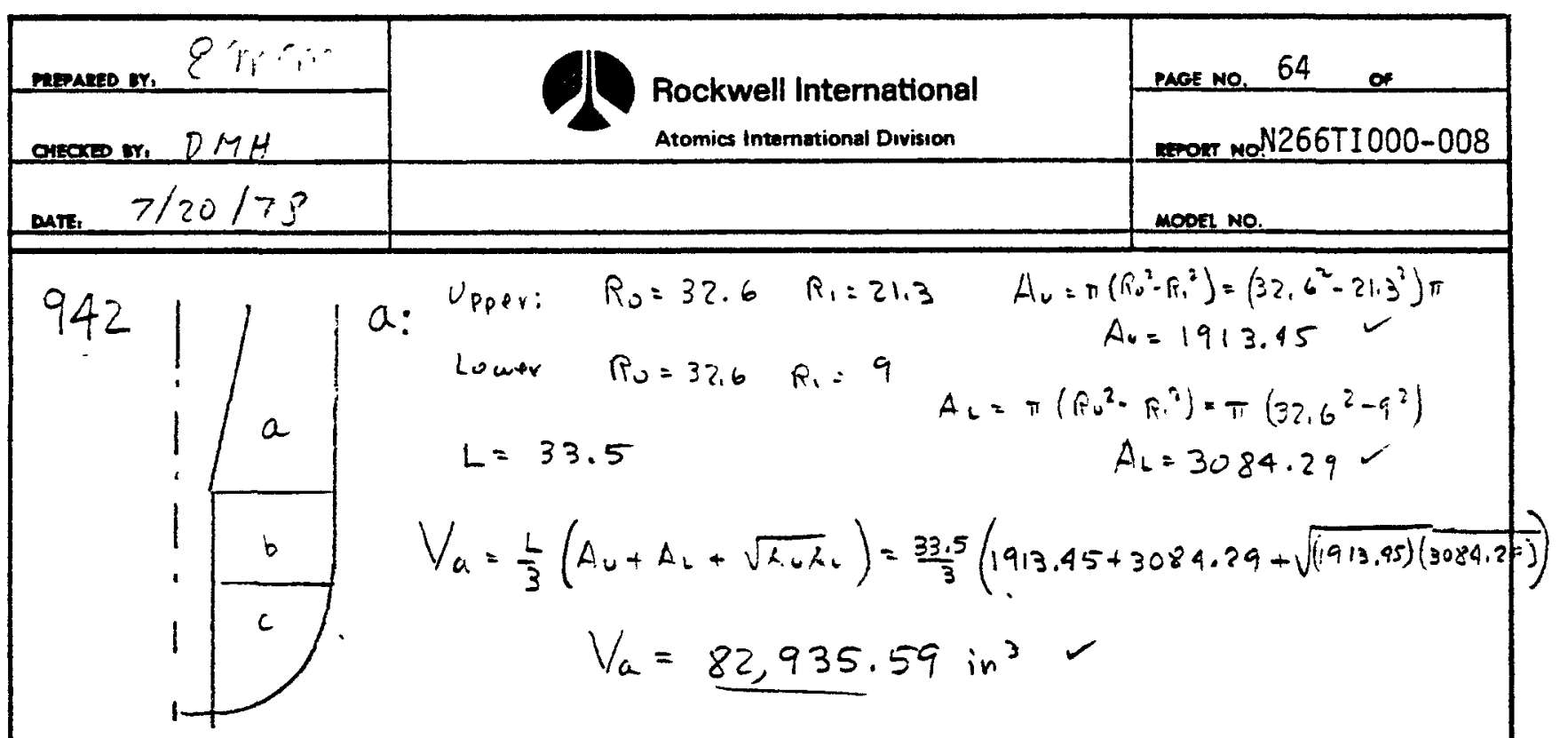

$$
\begin{gathered}
\text { b: } R_{0}=32.6 \quad R_{1}=9 \quad L=10.5 \\
V_{b}=\pi\left(R_{0}{ }^{2}-R_{1}{ }^{2}\right)(L)=\pi\left(32.6^{2}-9^{2}\right)(10.5)=32385.05 \mathrm{in}^{3} \\
c: \quad E l l i p s 0 . d \cdot(h a l f) \\
V=\frac{1}{2}=\frac{\pi}{3} a b c=\frac{4 \pi}{2 \times 3}(32.6)(32.6)(15)=33,387.59- \\
\Sigma V^{\prime}=82935.59+32,385.05+33387.59=148708.8 \mathrm{in}^{3}
\end{gathered}
$$

Subtrot volume $901 \quad V_{901}=7238.2$

$$
\begin{aligned}
V_{942}=148,708.23-7238.2=141470.0 \\
V_{942}=141,470.0 \mathrm{in}^{3} \\
C_{942}=1336.83 \frac{3 \pi}{4}
\end{aligned}
$$

N 159-11-2 nEV. 2-70 
N266ER000-001

Page 564

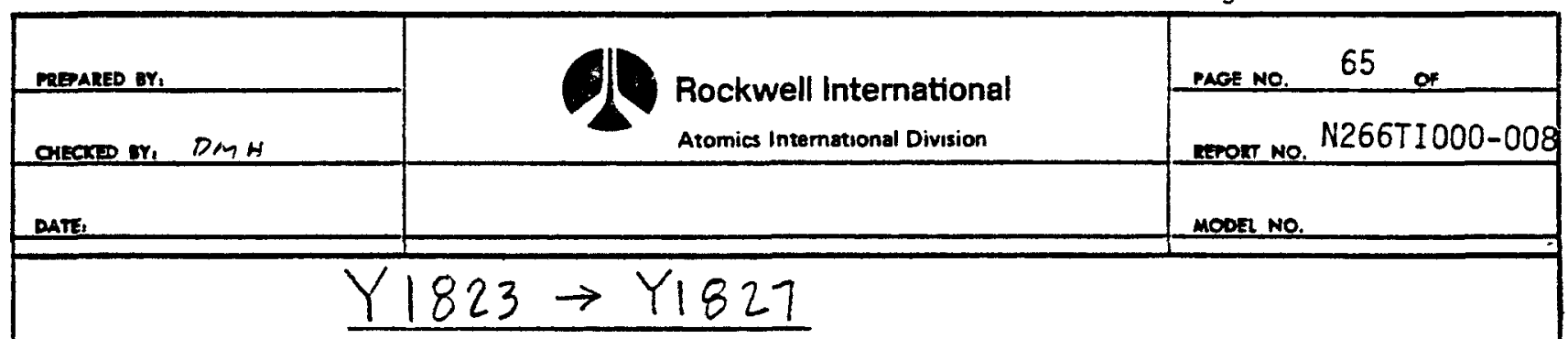

$$
\begin{aligned}
& A_{\substack{\text { sutalate } \\
\text { sutal }}}=\pi \bar{D}_{\text {Pipt }}\left(\frac{\pi}{2}_{90^{\circ} \mathrm{APR}}^{\bar{R}_{\text {ARC }}}\right)=\pi(25 \mathrm{in})\left(\frac{\pi}{2} 35\right)=4318 \mathrm{in}^{2} \\
& \Delta x \text { (Thicteness) }=1.0 \text { inch }
\end{aligned}
$$

$$
\begin{aligned}
& Y 1823 \quad(T 719 \rightarrow T 724) \\
& \phi \text { (central angle) }=27^{\circ} \\
& A=\frac{27}{90}(4318)=1295 \mathrm{in}^{2} \quad\left(\frac{A}{\Delta x}\right)=\frac{1295}{1}=1295 \mathrm{in}
\end{aligned}
$$

$$
\begin{aligned}
& \text { Y1824 (T720 } \rightarrow \text { T725) } \\
& \phi(\text { rentual Angle })=21^{\circ} \\
& A_{\text {surf }}=\frac{21}{90}(4318)=1008 \text { in }^{2} \quad\left(\frac{A}{\Delta x}\right)_{1740}=1008 \mathrm{in}, \\
& \text { Y1825 (T721 } \rightarrow \text { T726) } \\
& \phi(\text { central Angle })=21^{\circ} \\
& A_{\text {surt }}=\frac{21}{40}(4318)=1008 \mathrm{in}^{2} \quad\left(\frac{A}{\Delta x}\right)_{1741}=1008 \mathrm{in} . \\
& \text { Y } 1826 \quad(T 722 \rightarrow T 727) \\
& \Phi(\text { centual Angle })=16^{\circ} \\
& A_{\text {surf }}=\frac{16}{90}(4318)=768 \mathrm{in}^{2} \quad\left(\frac{A}{\Delta x}\right)_{1742}=768 \mathrm{in} \\
& \text { Y } 1827 \quad\left(T 723 \rightarrow T_{722}\right) \\
& \phi=8^{\circ} \\
& \text { Asu.f }=\frac{8}{40}(4318)=384 \mathrm{in}^{2} \quad\left(\frac{A}{\Delta x}\right)_{1743}=384 \mathrm{in},
\end{aligned}
$$

N 152-R-2 REY, 2.76 


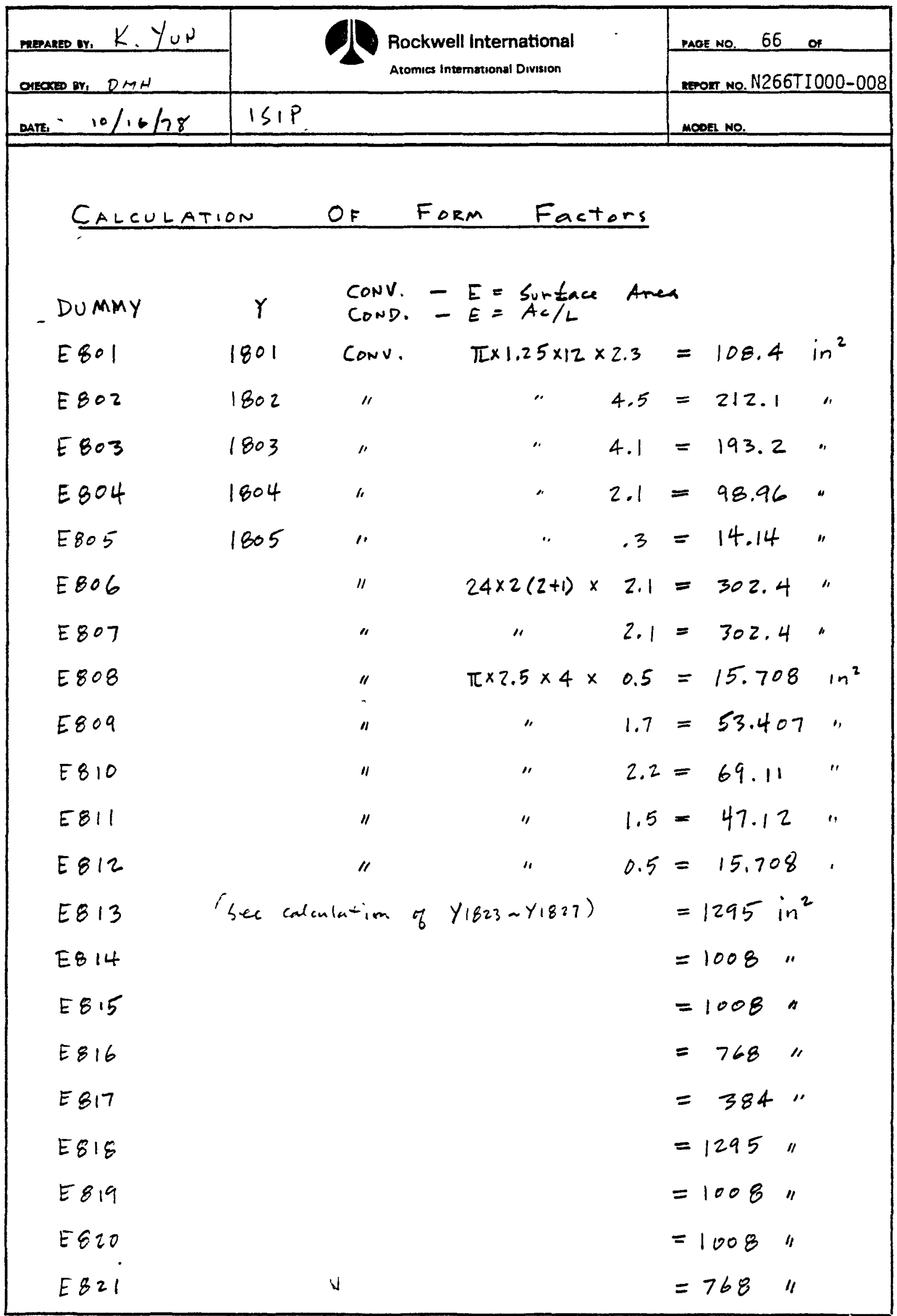




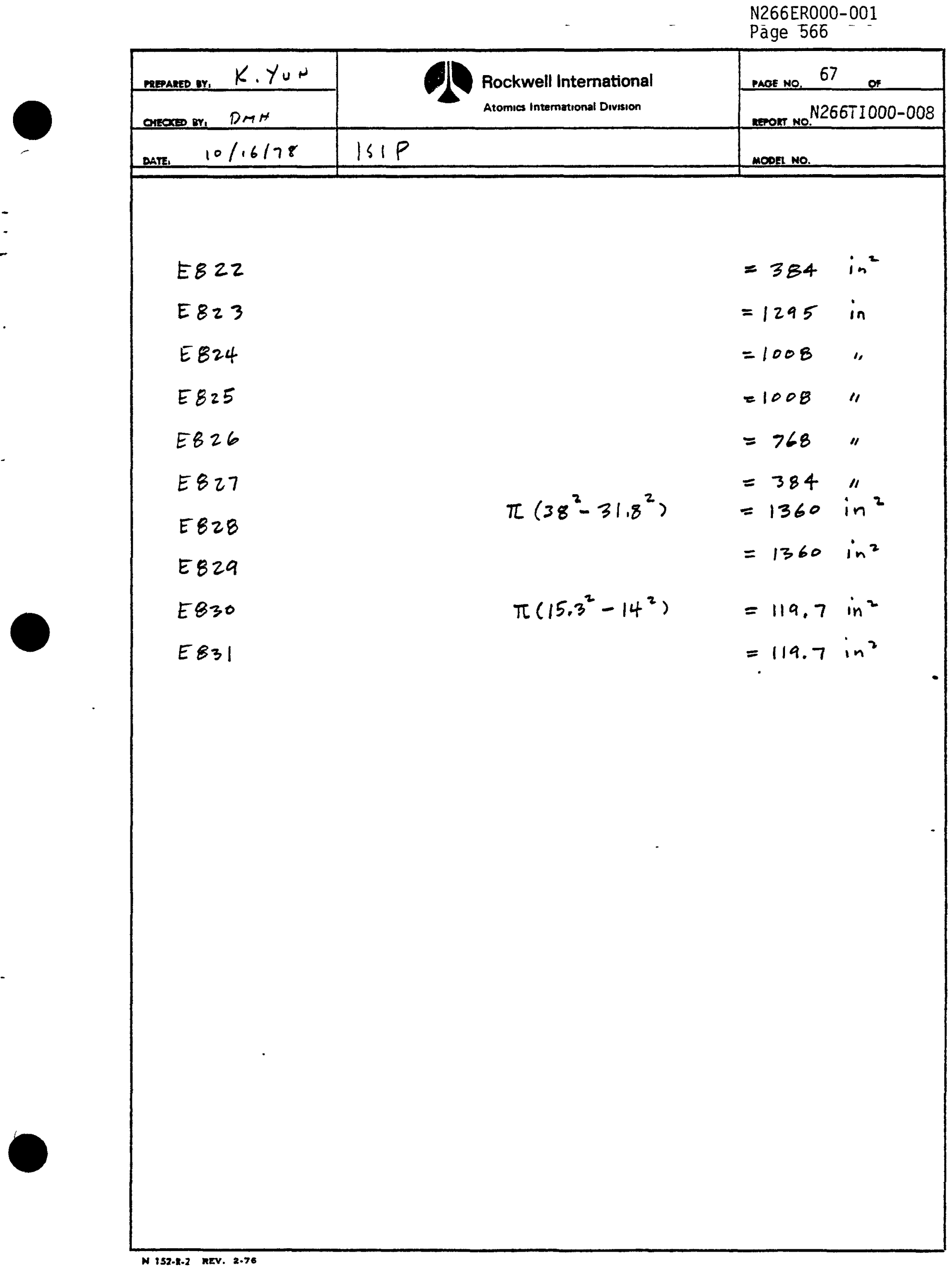


N266ER000-001

Page 567

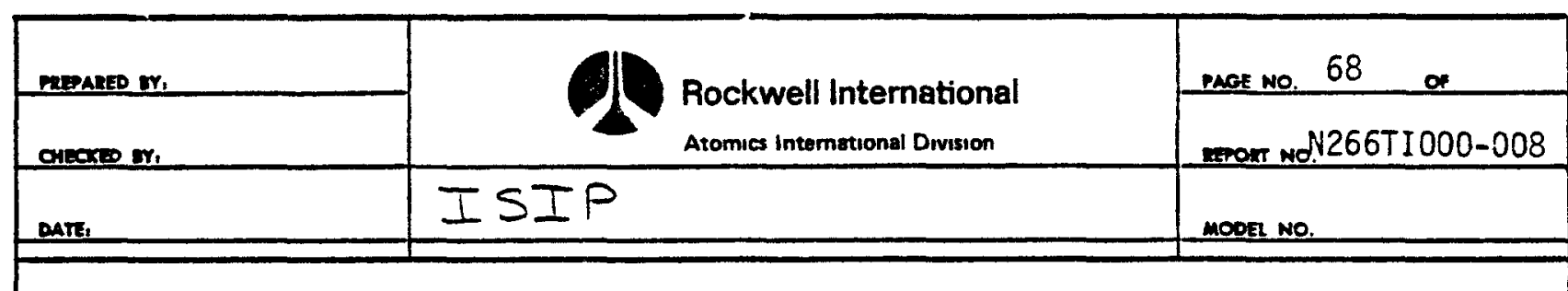

Transients:

$$
\begin{aligned}
& \text { \# T P } \quad \bar{T} \\
& \begin{array}{lll}
201 & 750 \rightarrow 600 & 675 \\
202 & 750 \rightarrow 600 & 675
\end{array} \quad \text { of deketed by T, T.B.-3-5-79 } \\
& 203 \quad 500 \rightarrow 650 \quad 575 \\
& 204850 \rightarrow 650 \\
& 750 \quad \overline{2} \cong 793 \\
& 205 \quad 700 \rightarrow 850 \\
& 875 \text { \}teleted by } 7,1,3,-3-5-79 \\
& 206 \quad 1050 \rightarrow 720 \\
& 207 \quad 1050 \rightarrow 720 \\
& 208 \quad 1050 \rightarrow 825 \\
& 855 \\
& 938 \\
& 210 \quad 1050 \rightarrow 900 \\
& 975 \\
& \text { Assume } \\
& T_{\mathrm{Na}} \cong 800^{\circ} \mathrm{F} \\
& \text { SODIUM Properties (c) } 800^{\circ} \mathrm{F} \text { (Golden \&. Tokar) } \\
& K=40.62 \mathrm{BTU} / \mathrm{hr} \text { ft }{ }^{\circ} \mathrm{F} \\
& \mu=0.6437 \mathrm{lbm} / \mathrm{hr} f+ \\
& e=53.053 \cdot 16 \mathrm{~m} / \mathrm{ft}^{3} \\
& z=\frac{\nu}{e}=\frac{.6437}{53.053}=0.01213 \frac{\mathrm{ft2}}{\mathrm{hr}} \\
& v=\frac{.6437}{53.053} \times \frac{1}{3600}=3.37032 \times 10^{-6} \frac{\mathrm{ft}^{2}}{\mathrm{sec}}
\end{aligned}
$$

N 138-2-2 REV. 2.76 
N266ER000-001

Page 568

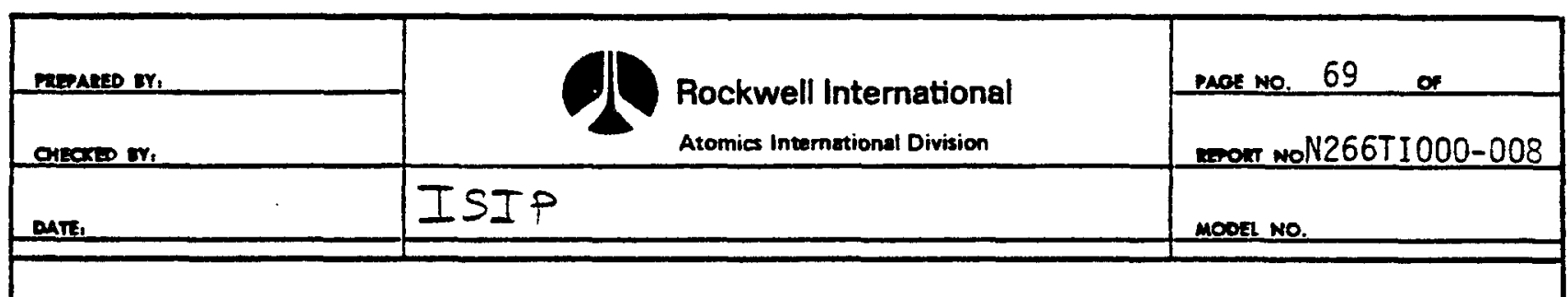

$$
\begin{gathered}
Q \frac{f+3}{\mathrm{sec}}=G P M \frac{\mathrm{gal}}{\mathrm{min}} \times \frac{\mathrm{min}}{60 \mathrm{sec}} \times \frac{231}{1728} \frac{\mathrm{ft}+3}{\mathrm{gal}}=.002228 \\
Q \frac{\mathrm{ft}^{3}}{\mathrm{sec}}=0.002228 \times G P M=\frac{6 P M}{448.83} \\
V \frac{\mathrm{ft}}{\mathrm{sec}}=\frac{Q \mathrm{Pt}^{3} / \mathrm{sec}}{A \mathrm{ft}^{2}}=\frac{Q \mathrm{FPS}}{A \mathrm{ft}^{2}}
\end{gathered}
$$

$$
\begin{aligned}
& R_{e}=\frac{V D_{H}}{2}=\frac{V_{\text {FPs }} D_{H F r}}{3.37 \times 10^{-6}}=2.9671 \times 10^{5} \mathrm{VD} \\
& \begin{array}{r}
R e \cong 3.0 \times 10^{5} \bigvee_{F P S} D_{F t} \\
N u=7.0+\frac{1}{40}(\underbrace{\operatorname{Re} P_{r}}_{P_{t} P_{r}})^{0.80482}
\end{array}
\end{aligned}
$$

$$
h=N_{U} \frac{k}{D_{H}}
$$

N 15-10 REV \pm-76 


\begin{tabular}{|c|c|}
\hline $\begin{array}{l}F 10 \mathrm{~V} \\
100 \mathrm{DE}\end{array}$ & $\begin{array}{l}\text { FULL (100D) } \\
\text { FLOW RATE } \\
\text { (GPM) }\end{array}$ \\
\hline 900 & 14,500 \\
\hline 901 & 14,660 \\
\hline 902 & 4000 \\
\hline 903 & $176 \div 4$ \\
\hline 904 & 16,001 \\
\hline 905 & 14,841 \\
\hline 500 & 14,841 \\
\hline$\because 97$ & $14,8 \div 1$ \\
\hline$\theta=\overline{0}$ & 14,510 \\
\hline$\therefore=$ & 14,510 \\
\hline$\because 0$ & 14,500 \\
\hline 911 & 648 \\
\hline $9 / 2$ & 74 \\
\hline 9.3 & 34 \\
\hline $9 / 4$ & - \\
\hline 4,5 & 50 \\
\hline $9 / 6$ & 54 \\
\hline$\because 7$ & 50 \\
\hline$\therefore 5$ & 158 \\
\hline$=19$ & 60 \\
\hline 920 & 150 \\
\hline 921 & $=0$ \\
\hline 922 & 150 \\
\hline 223 & 10 \\
\hline$\therefore 4$ & $\therefore 0$ \\
\hline 925 & 331 \\
\hline 26 & 331 \\
\hline 227 & 136 \\
\hline 928 & - \\
\hline 529 & 200 \\
\hline 130 & 200 \\
\hline 031 & 100 \\
\hline $5: 2$ & $\div 2$ \\
\hline 53 & - \\
\hline$\because \because$ & 678 \\
\hline 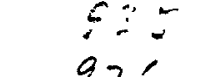 & $\begin{array}{l}678 \\
6\end{array}$ \\
\hline $\begin{array}{r}736 \\
77 \\
\end{array}$ & $\dot{-}$ \\
\hline
\end{tabular}

\begin{tabular}{|c|c|}
\hline FLOW & FULL (OOOO) \\
FOLE & $\begin{array}{c}\text { FLOW RATE } \\
\text { (GPM) }\end{array}$ \\
\hline 938 & 0 \\
939 & 0 \\
040 & 0 \\
94 & 0 \\
\hline
\end{tabular}




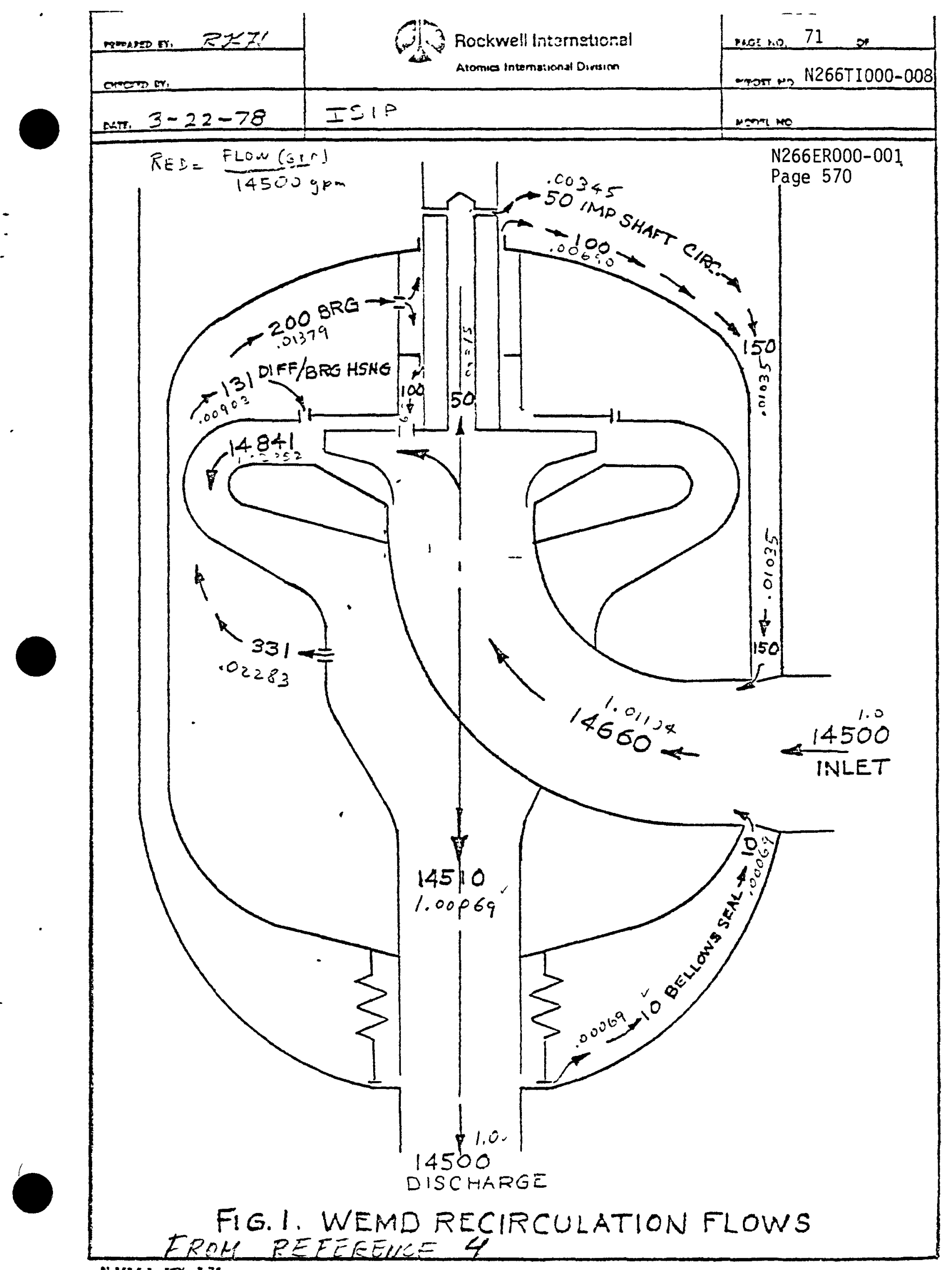


N266ER000-001

Page 571

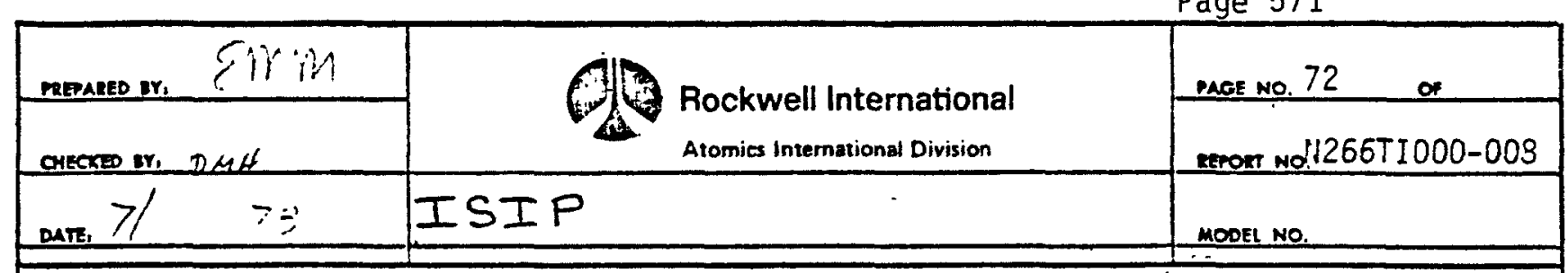

NODE 901,902 TH $24 \quad$ FULL FLOW $=14,660 \mathrm{gpm}$

FLOW CONDIT!OI:

PIDE FLOW.

(6) $A=\frac{\pi}{4} D^{2}=\frac{\pi}{4}(24)^{2}\left(\frac{1}{144}\right)=3.1416 f+2$

(5) $\quad D_{H}=2 \times(R)=2.0 \mathrm{ft}$

$\frac{=31}{7.860}$

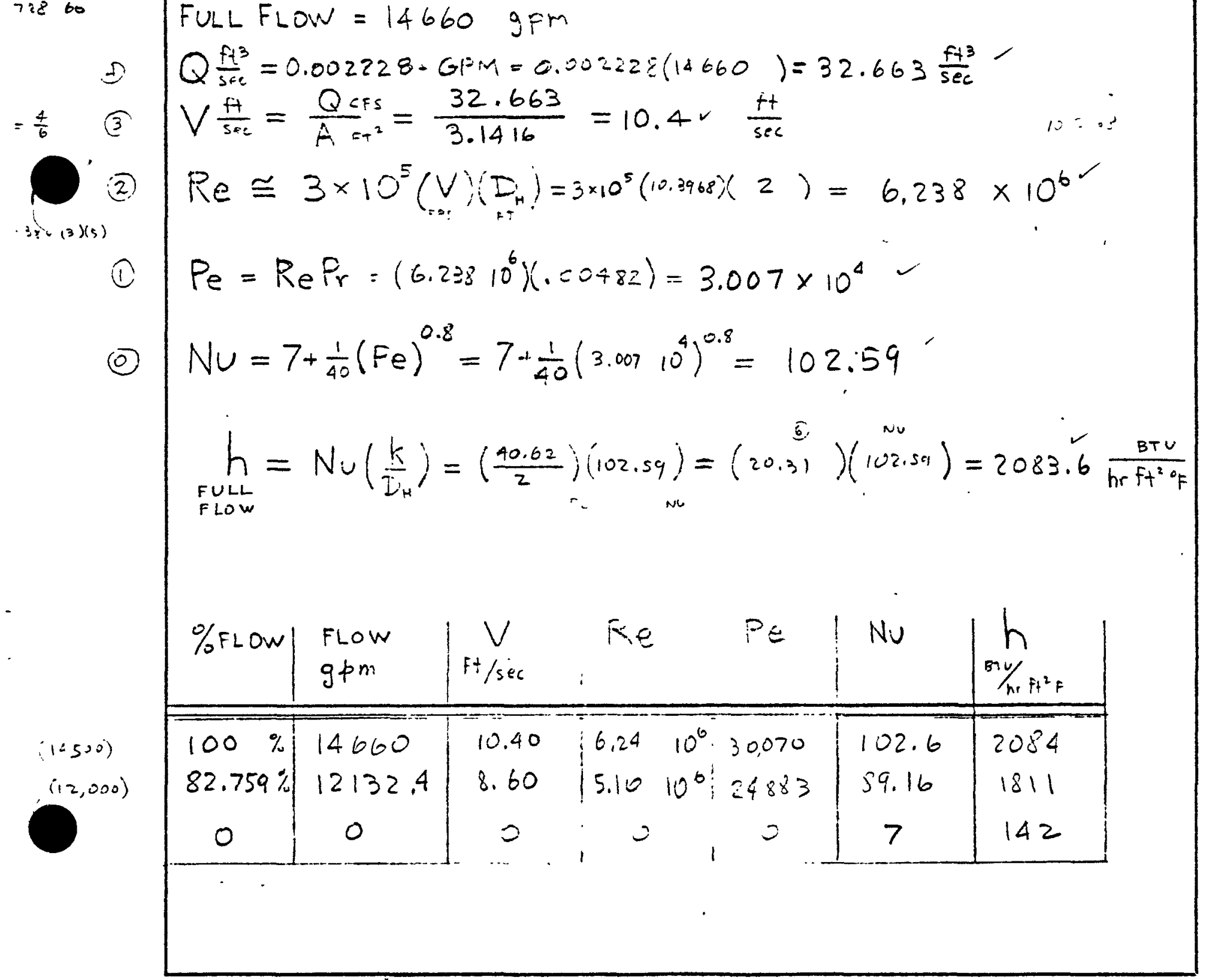

N 152-1n-2 REV. 2.76 


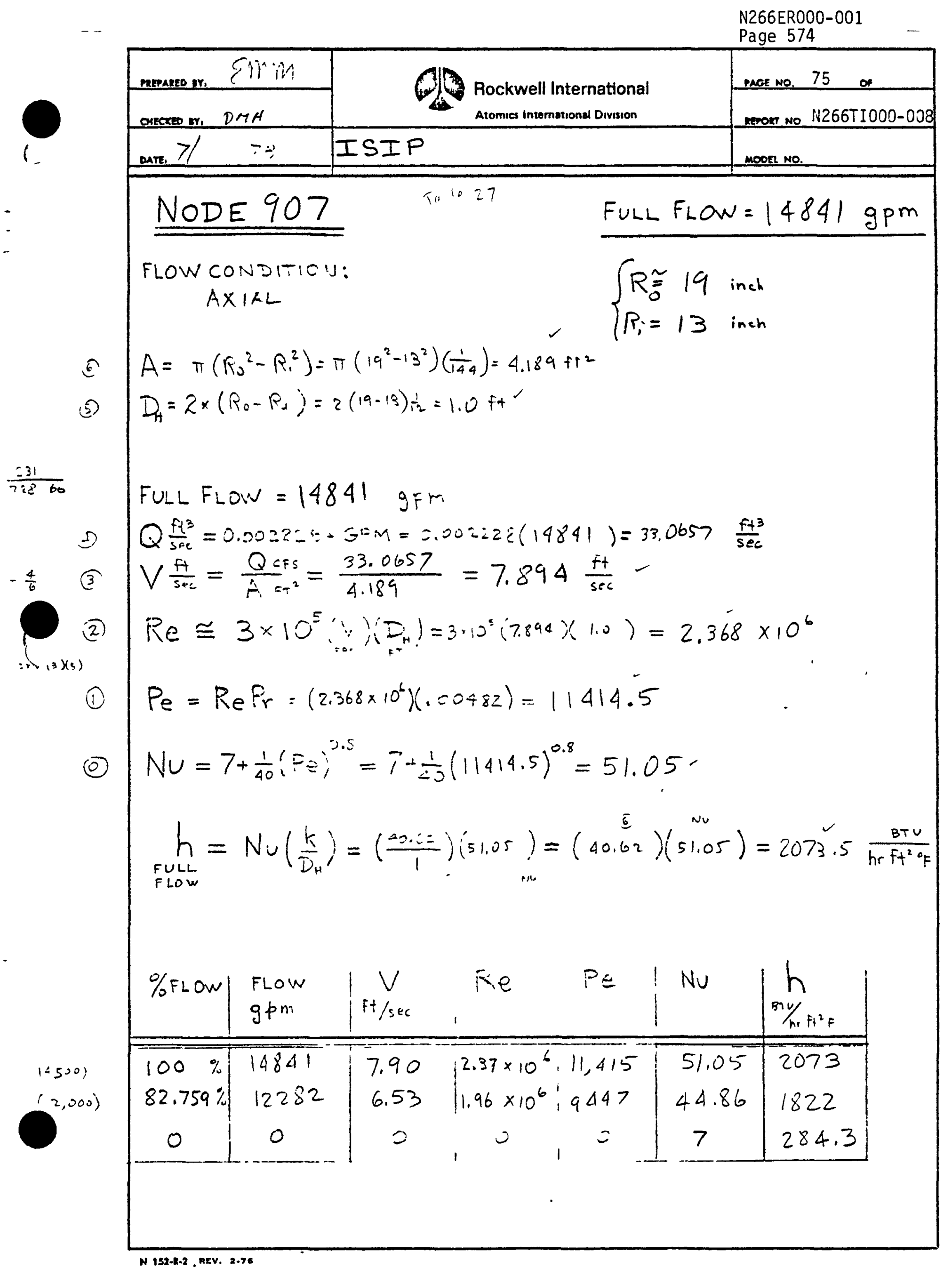




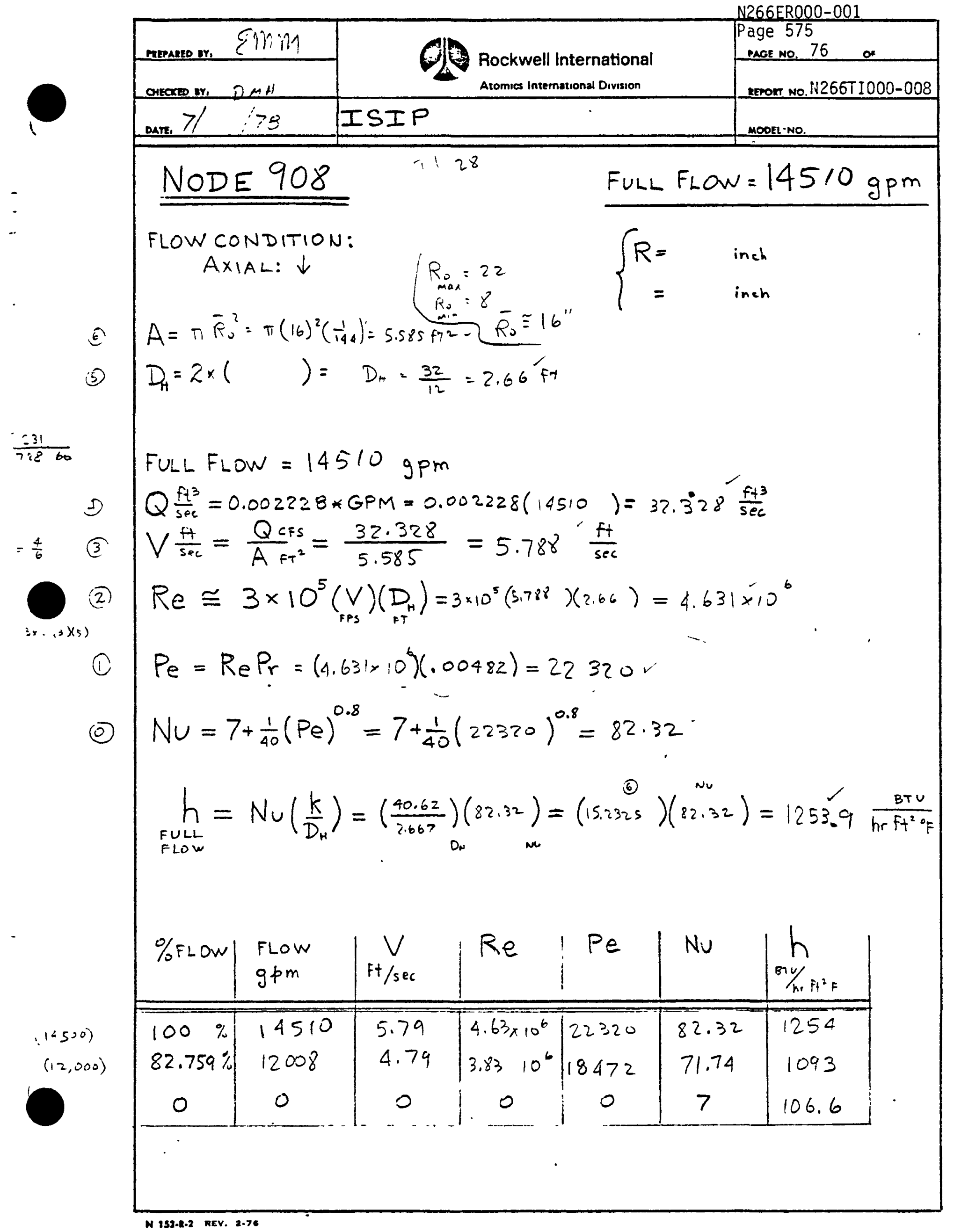




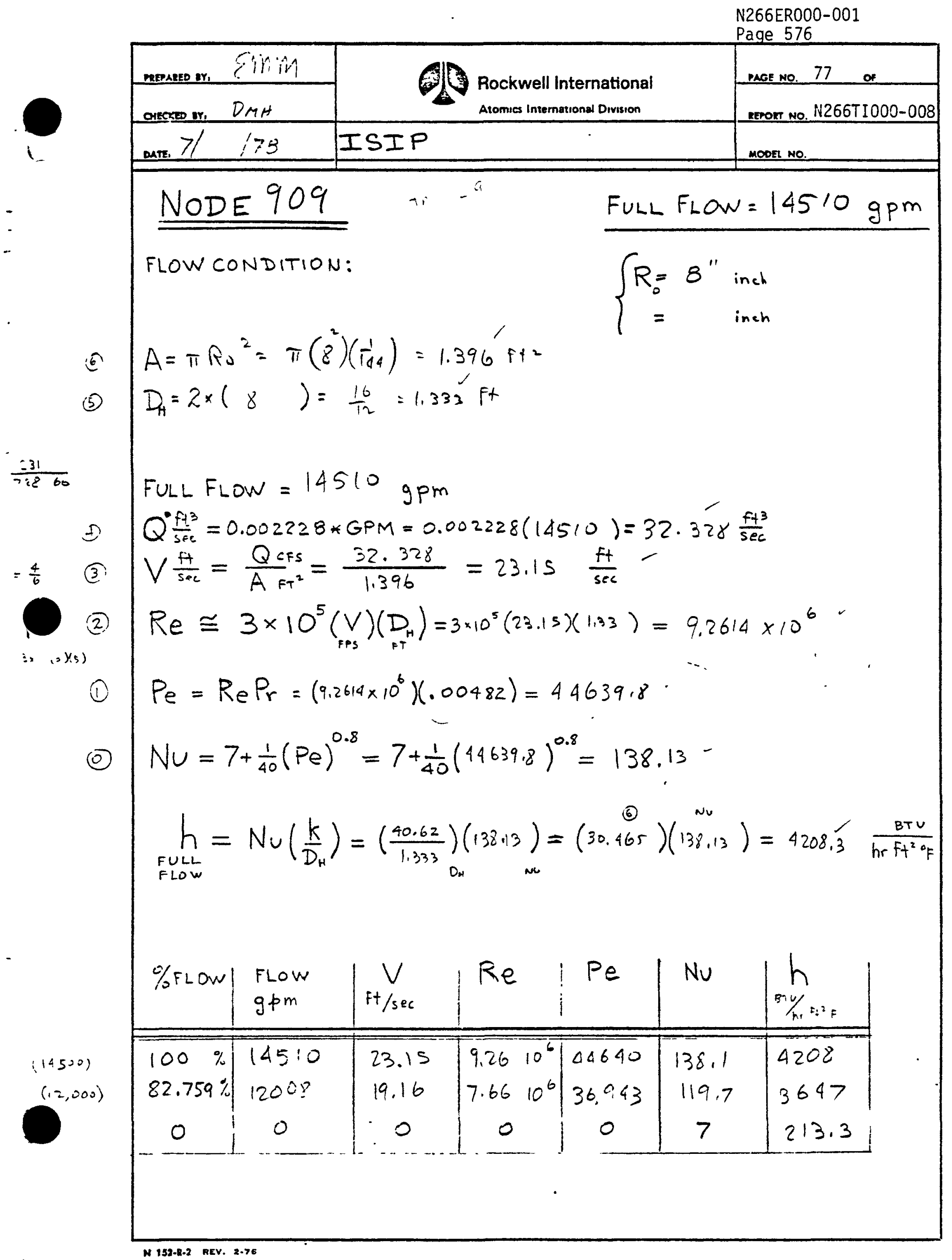




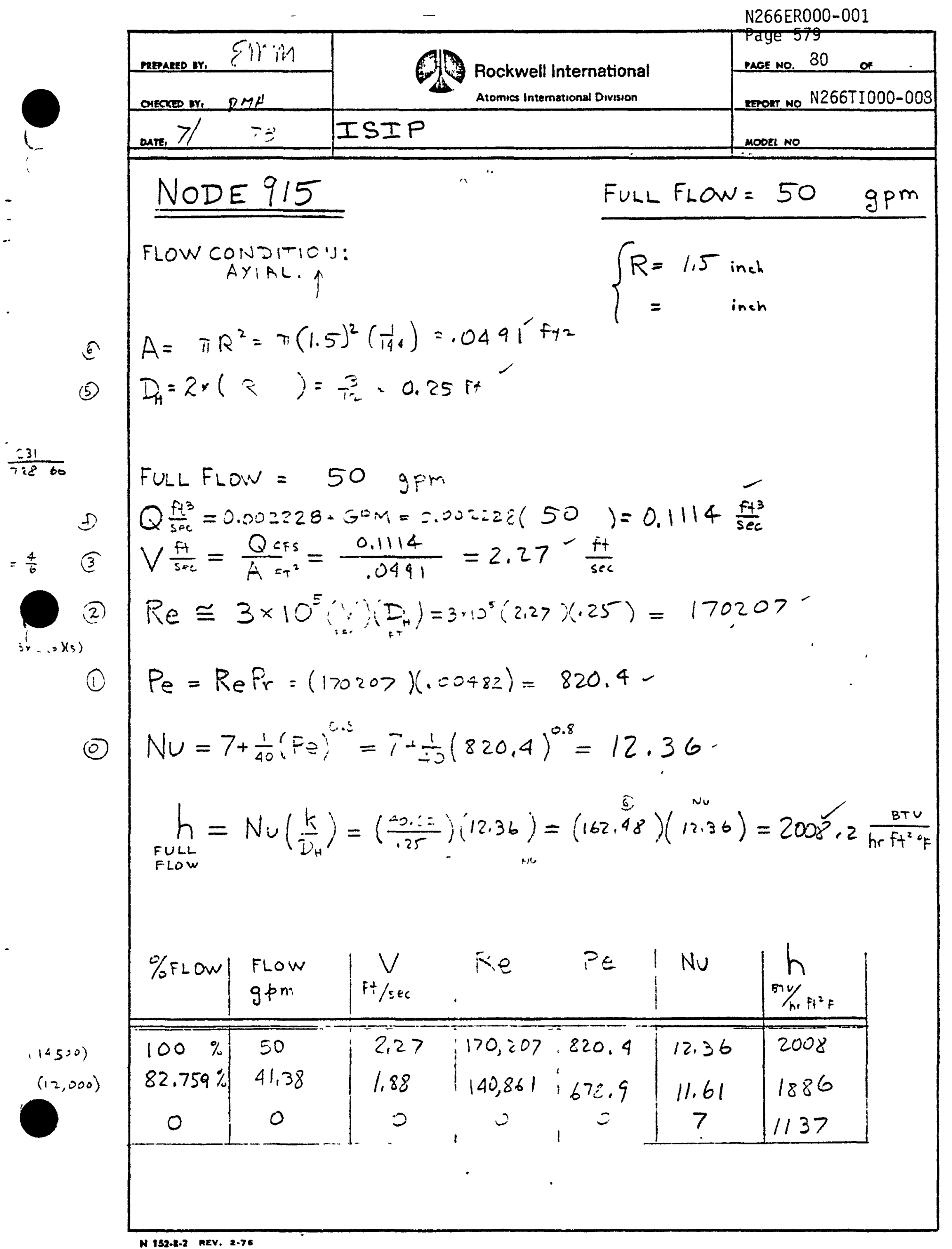




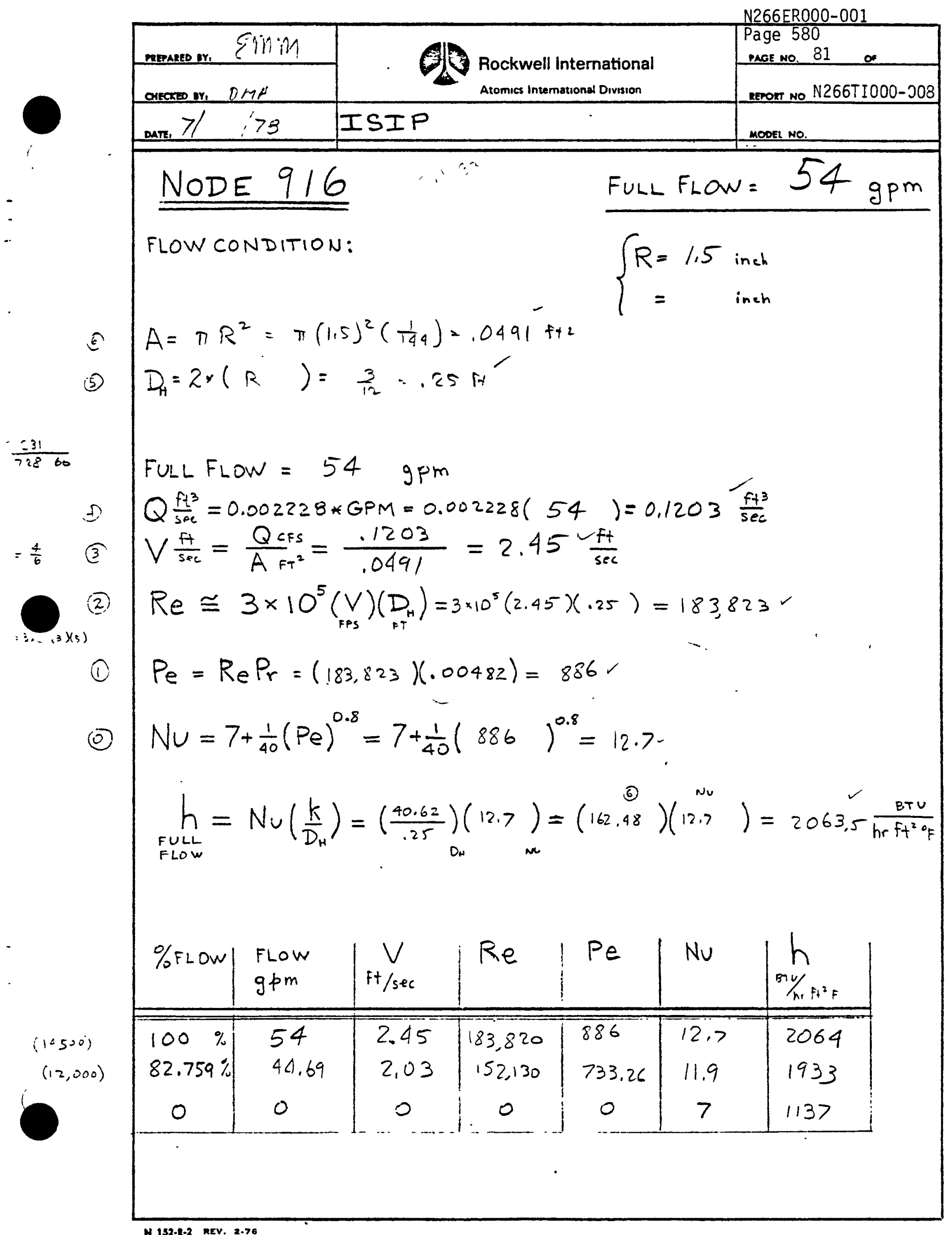




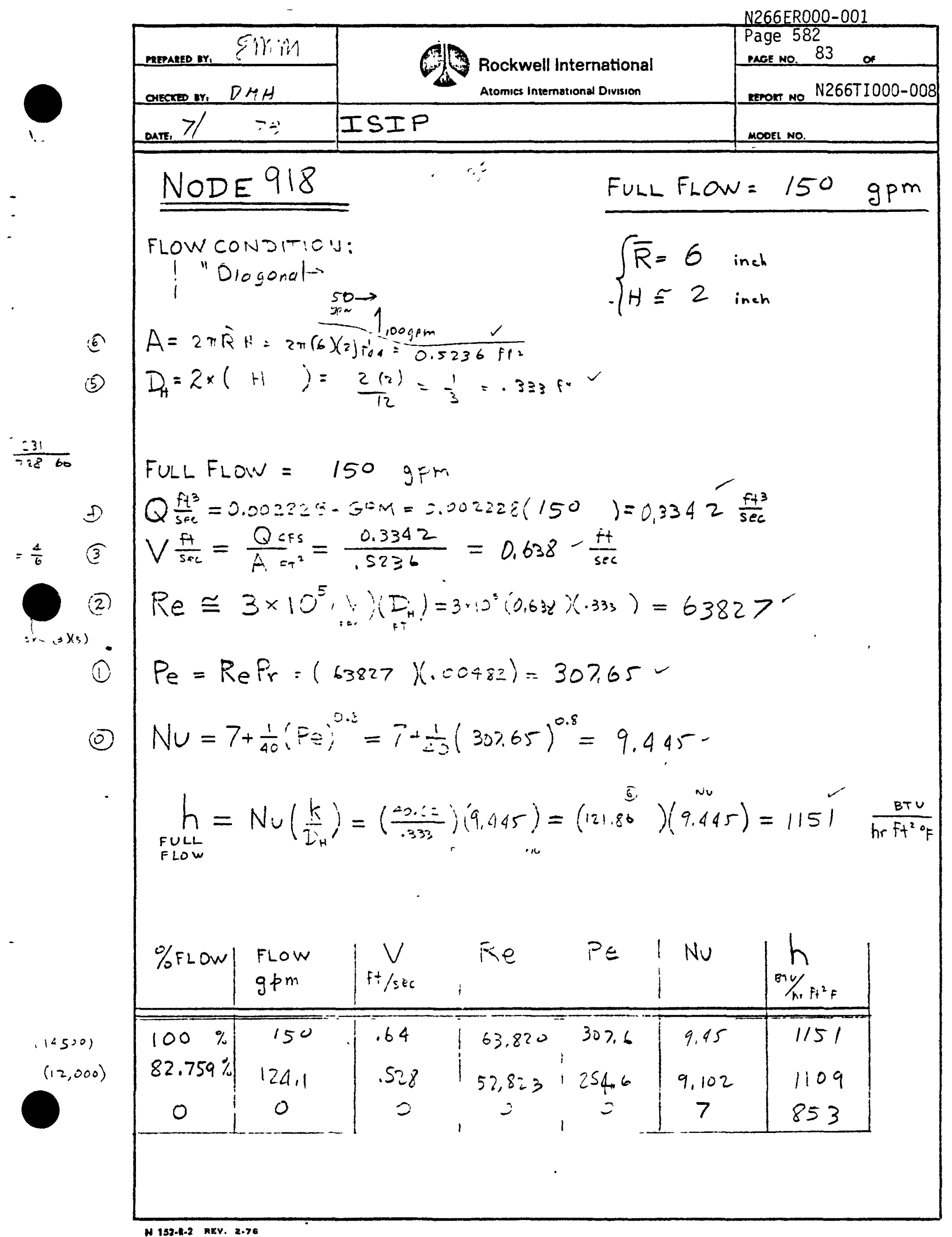




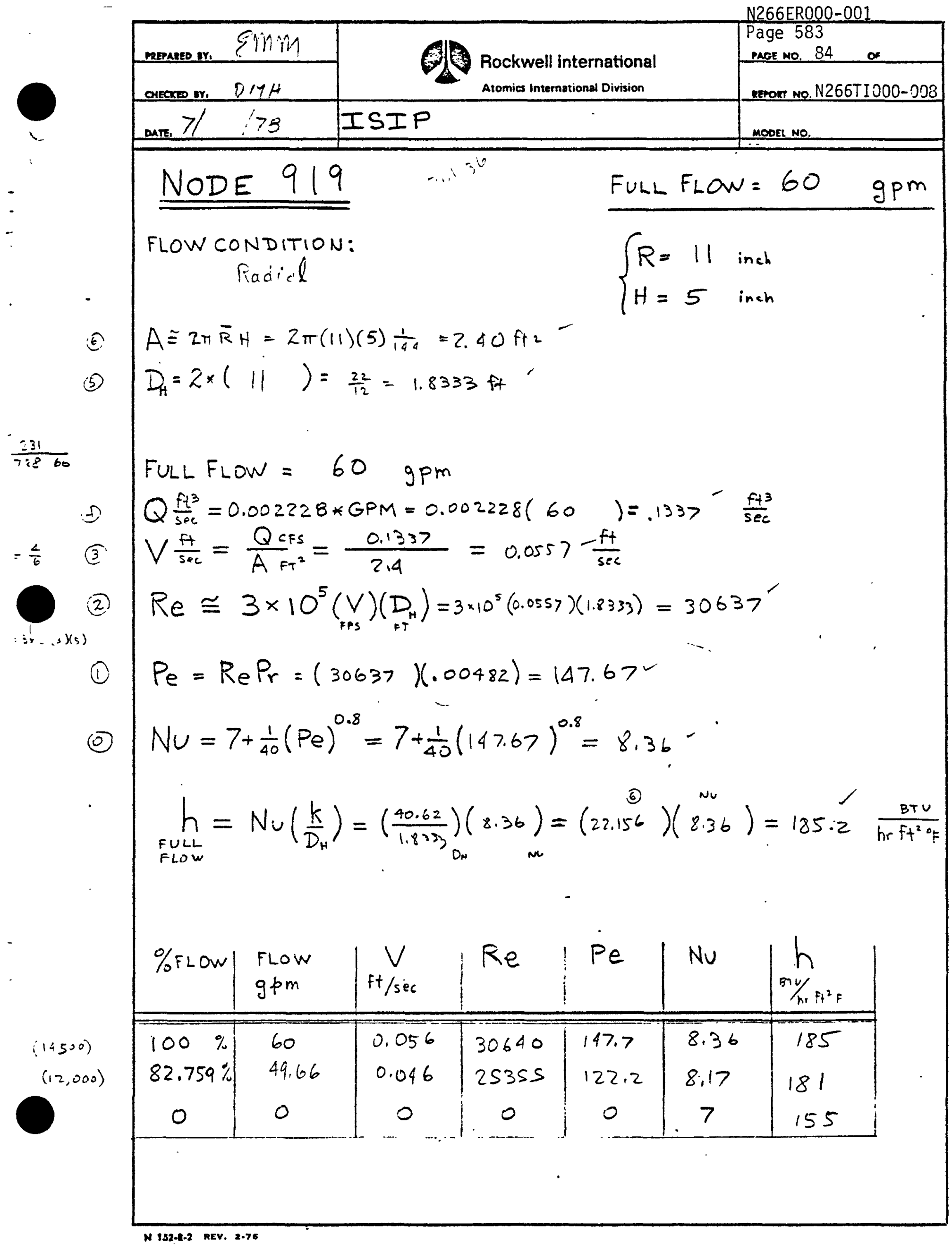




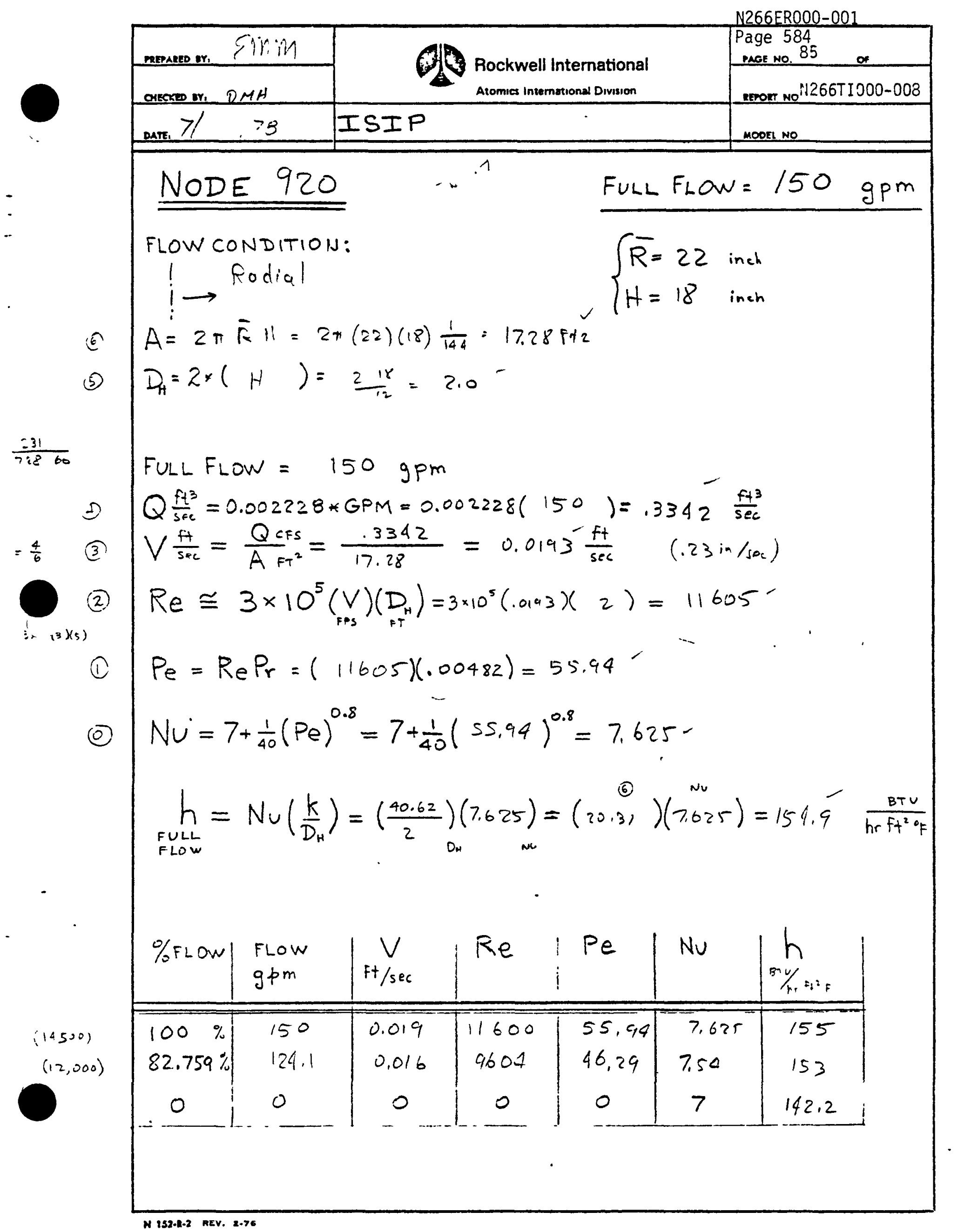




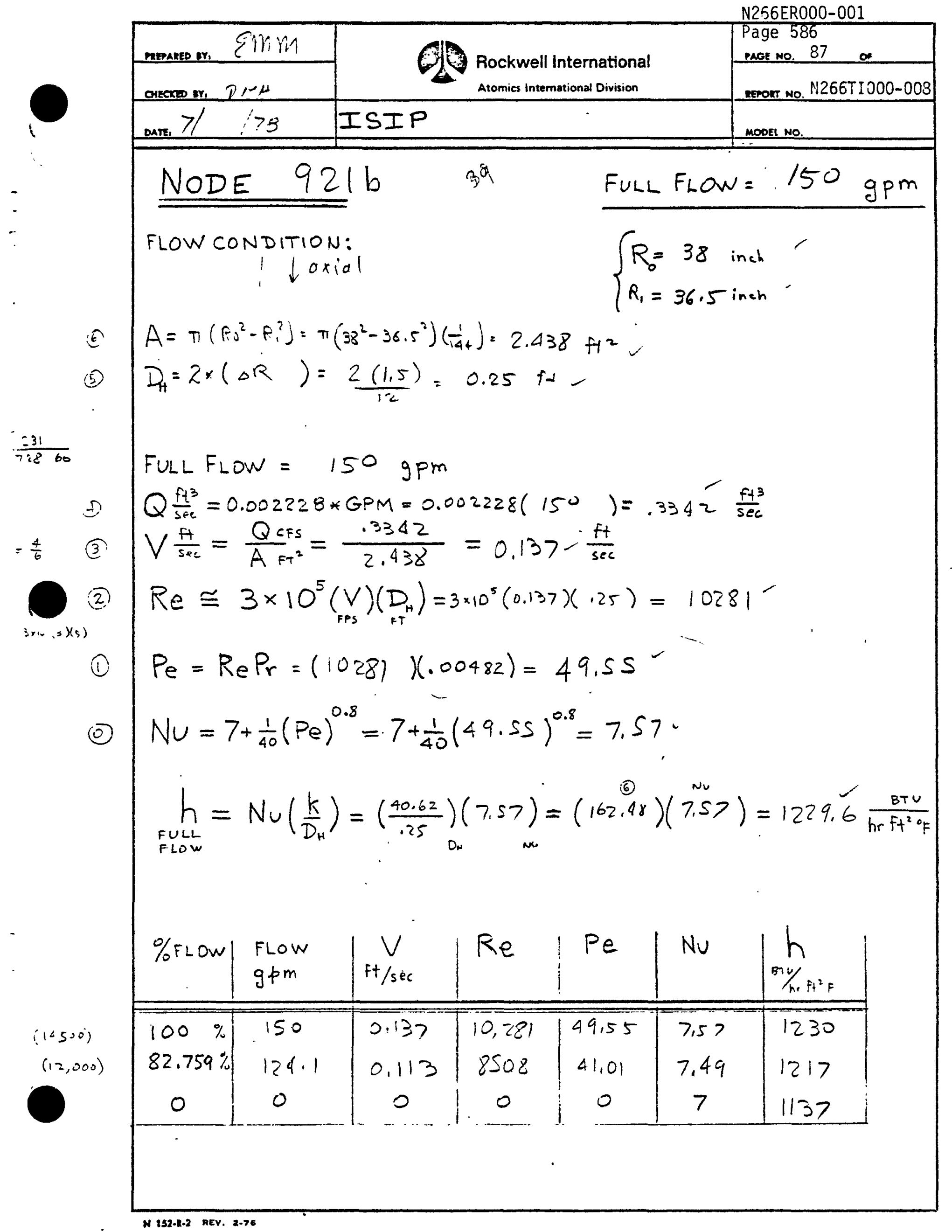




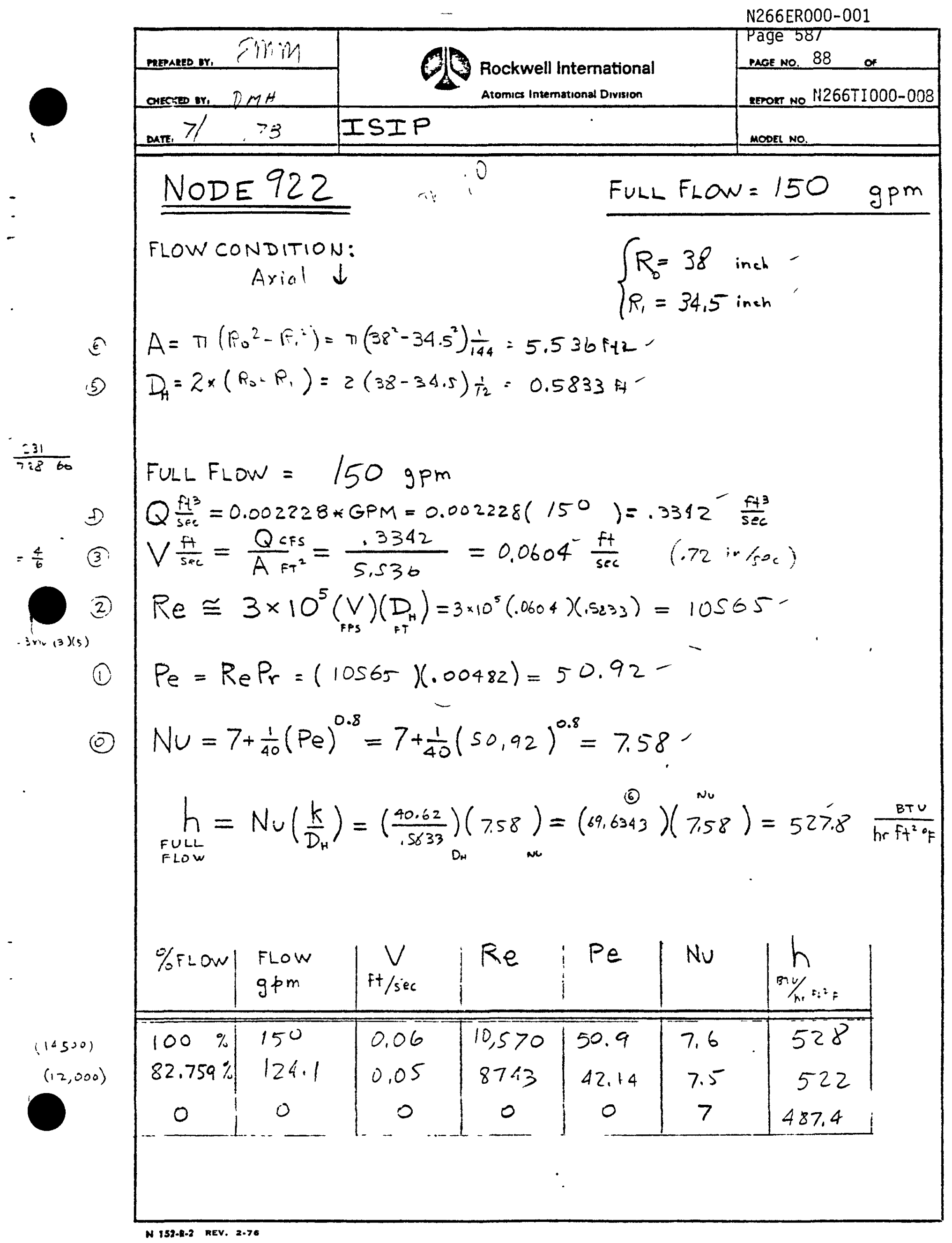




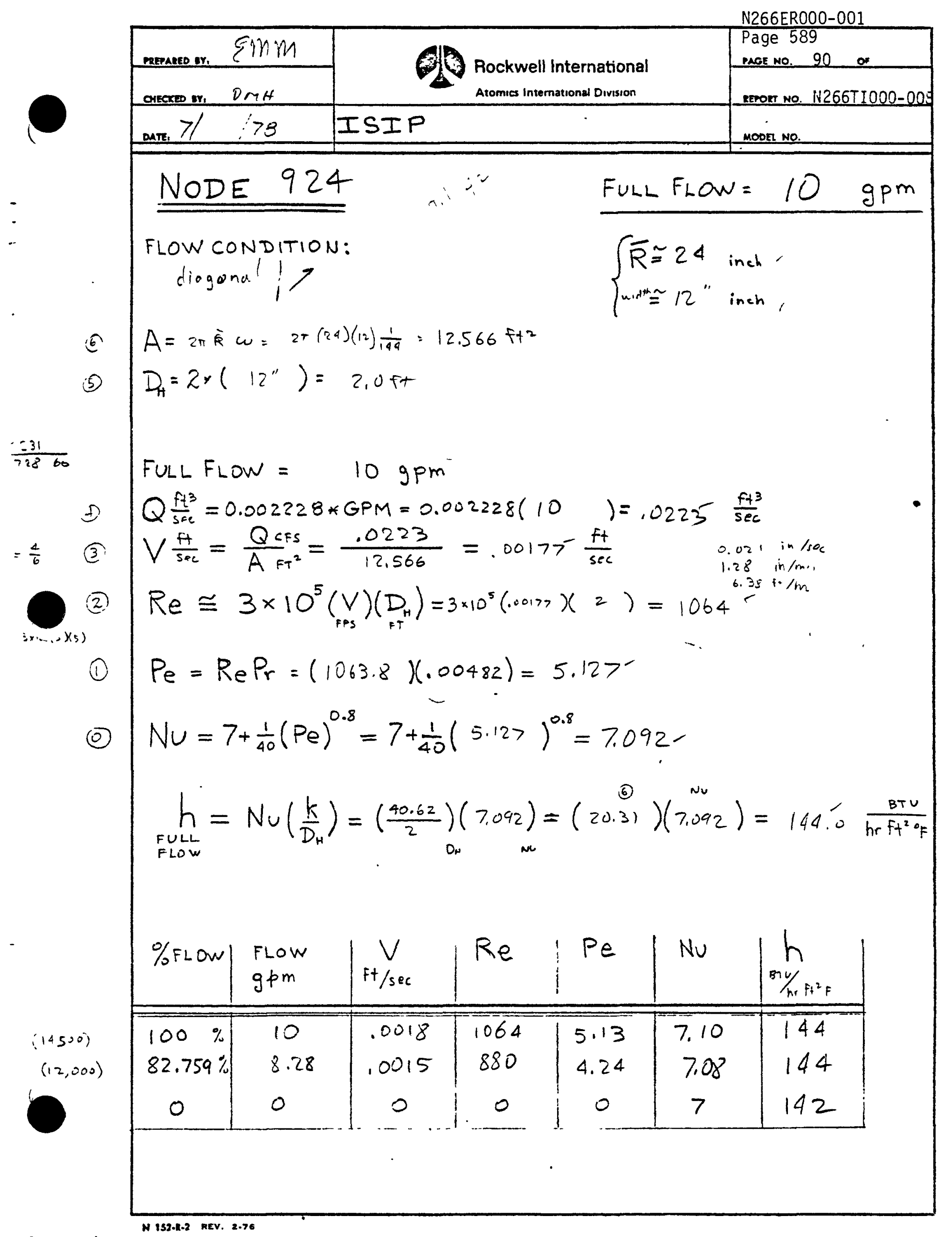




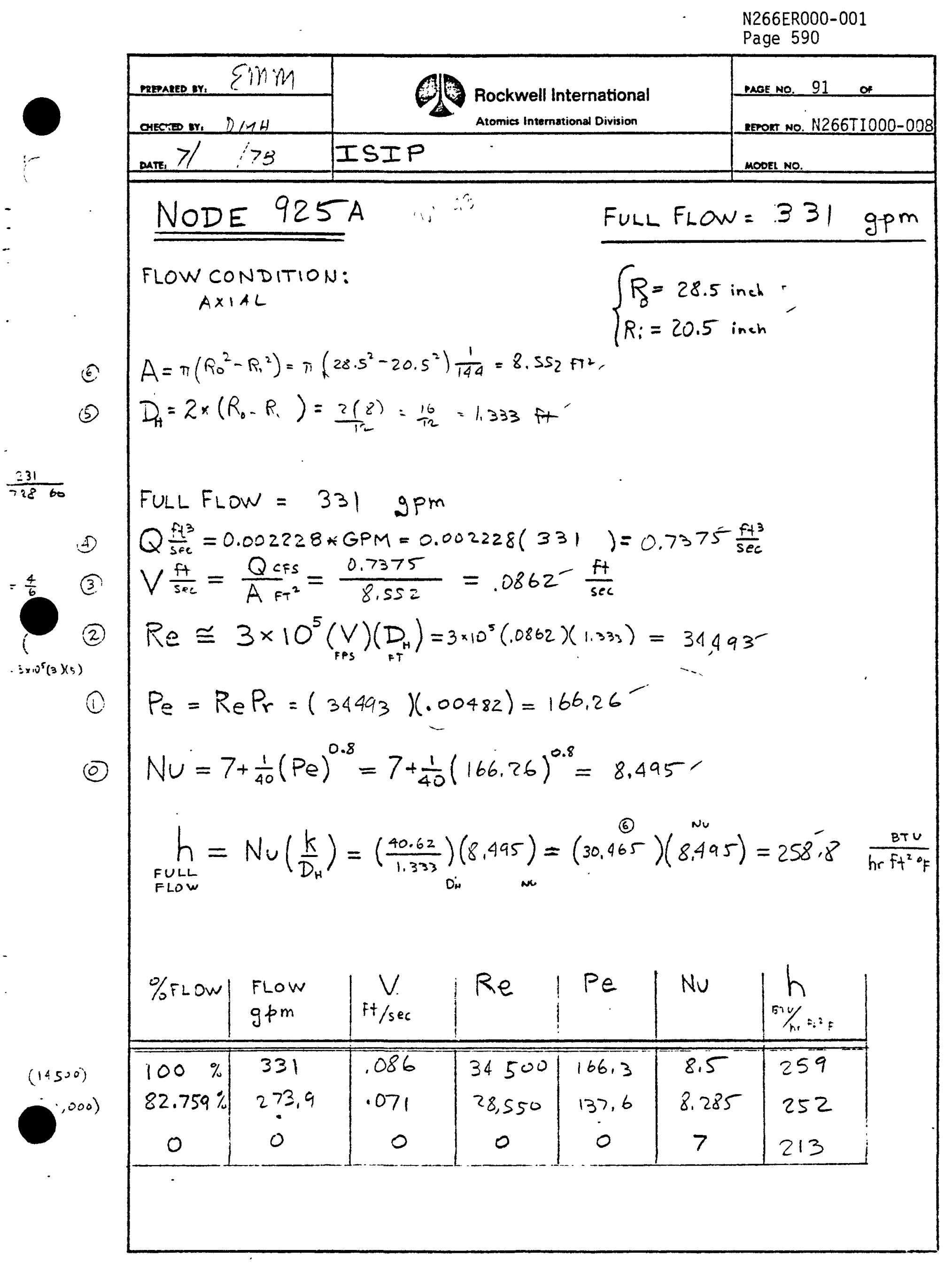


N266ER000-001

Page 591

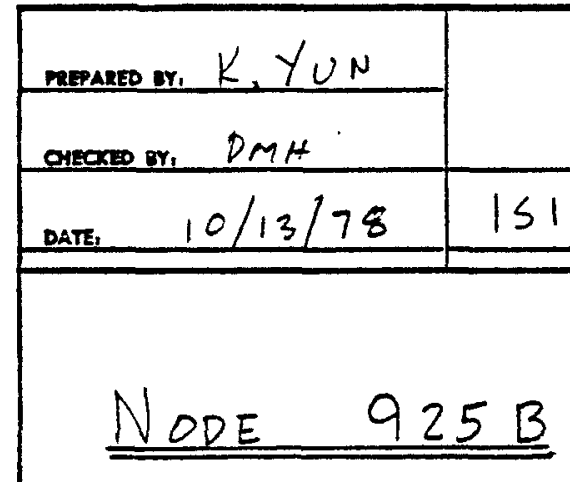

FLOW CONDITION:

$$
\text { AXIAL }
$$

$$
\begin{aligned}
& A=24 \times 2 \times 1=48 \mathrm{in}^{2}=.333 \mathrm{Ft}^{2} \\
& D_{H}=4 \times A_{C} / P=4 \times 2 \times 1 / 2 \times(2+1)=1.333^{\prime \prime}=.111^{\prime \prime}
\end{aligned}
$$$$
Q=0.002228 \times G P M=0.002228 \times 331=0.7375 \mathrm{st} / \mathrm{sec}
$$$$
V=Q_{C F S} / A_{F T^{2}}=0.7375 / .333=2.212 \mathrm{Ft} / \mathrm{sec}
$$$$
R_{e}=3 \times 10^{5}(V)\left(D_{H}\right)=3 \times 10^{5}(2.212)(.111)=7.3674 \times 10^{4^{\prime}}
$$$$
P_{e}=\operatorname{Re} P_{r}=(73674)(0.00482)=355.1-
$$$$
\begin{aligned}
& N_{u}=7+\frac{1}{40}\left(P_{e}\right)^{0.8}=7+\frac{1}{40}(355.1)^{0.8}=9.743- \\
& h_{\text {full flow }}=N_{u}\left(\frac{K}{D_{H}}\right)=9.743 \frac{40.62}{.111}=3562 . \mathrm{Btu} / \mathrm{hr} \mathrm{st}^{2}{ }^{\circ} \mathrm{F}
\end{aligned}
$$

$\%$ Flow

$100 \%$

82.759

0.0 h $B t u / h r t t^{2} \circ \mathrm{F}$ 3562 .

3421 .

2559 .

N 152-2.2 nEV. 2.76 


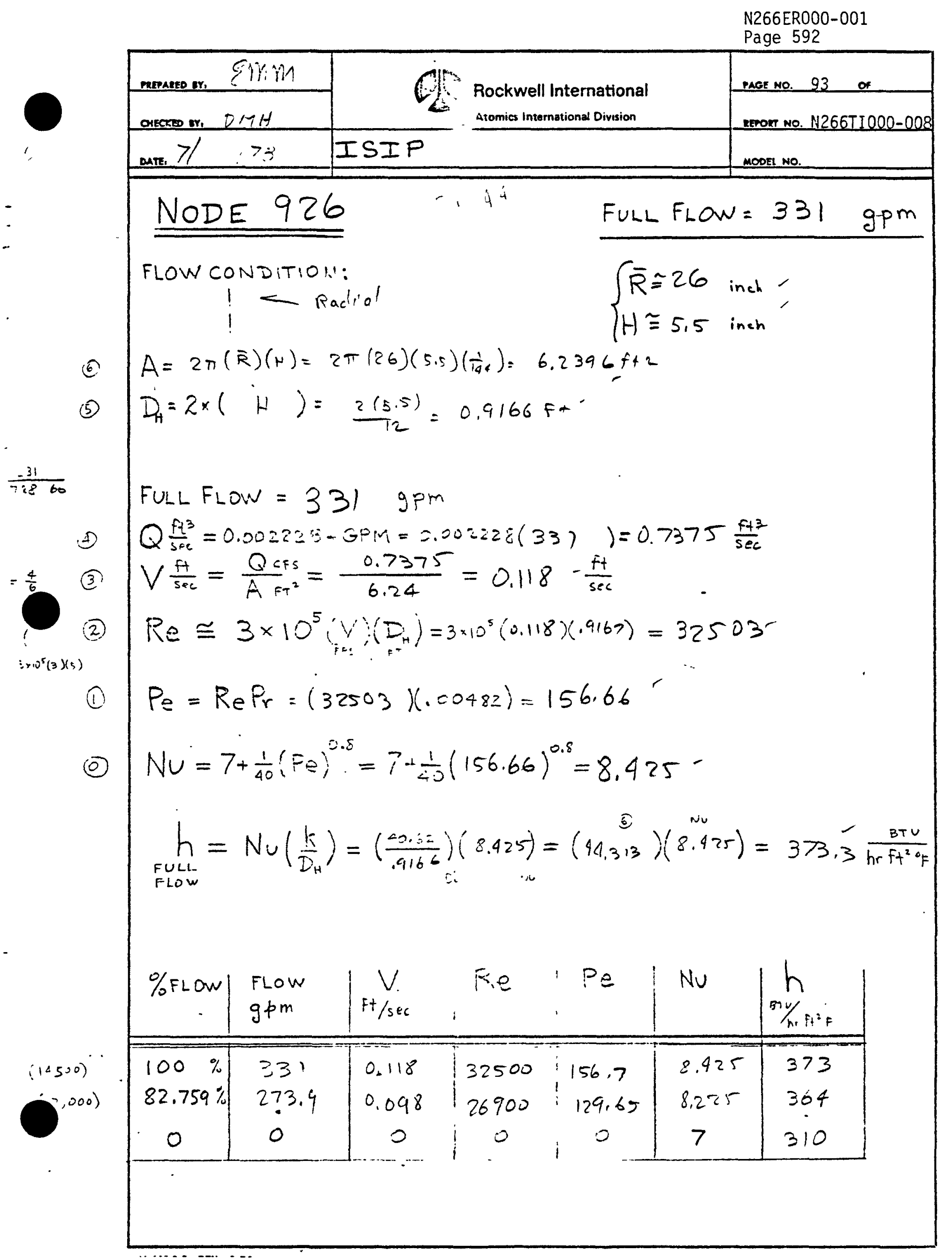




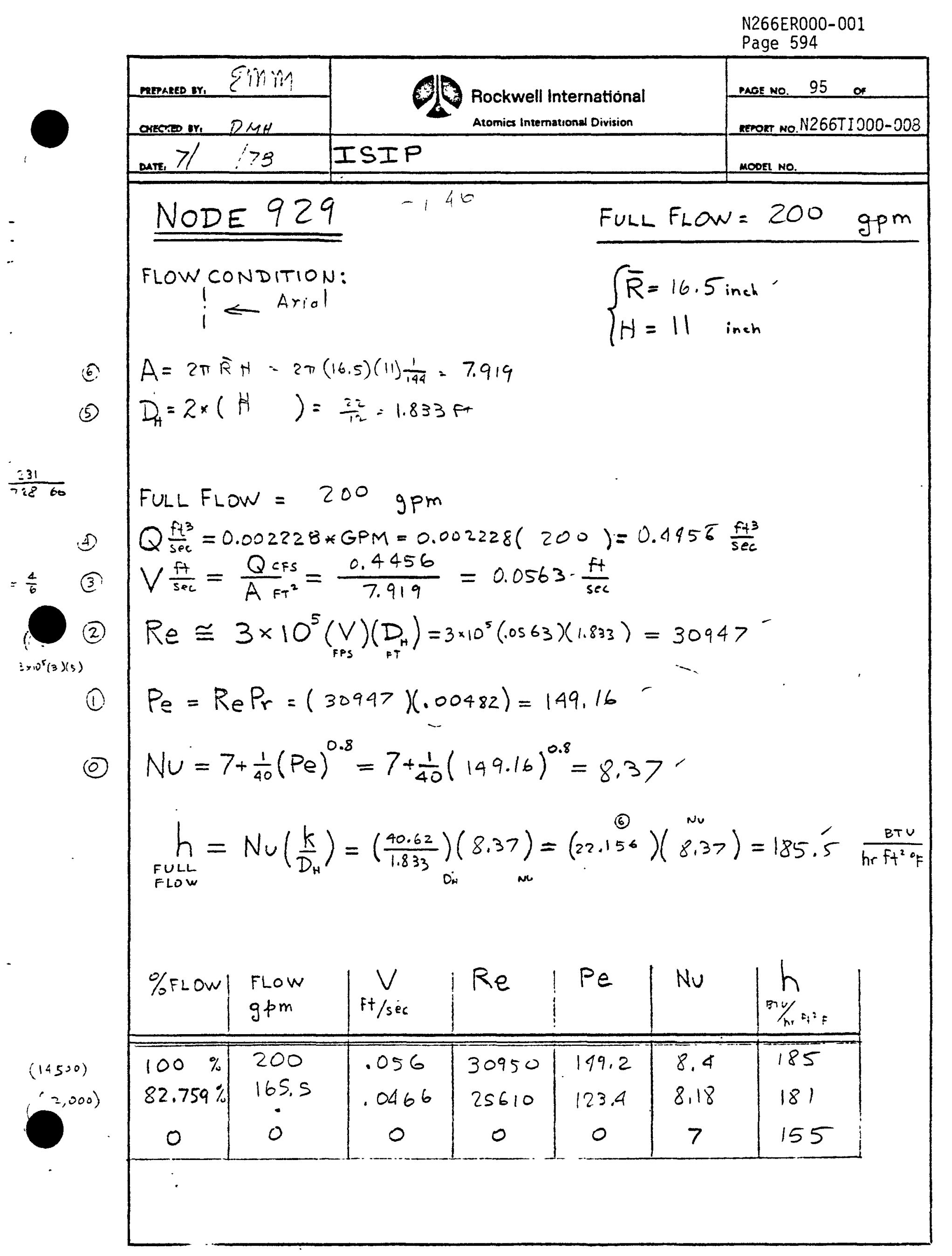




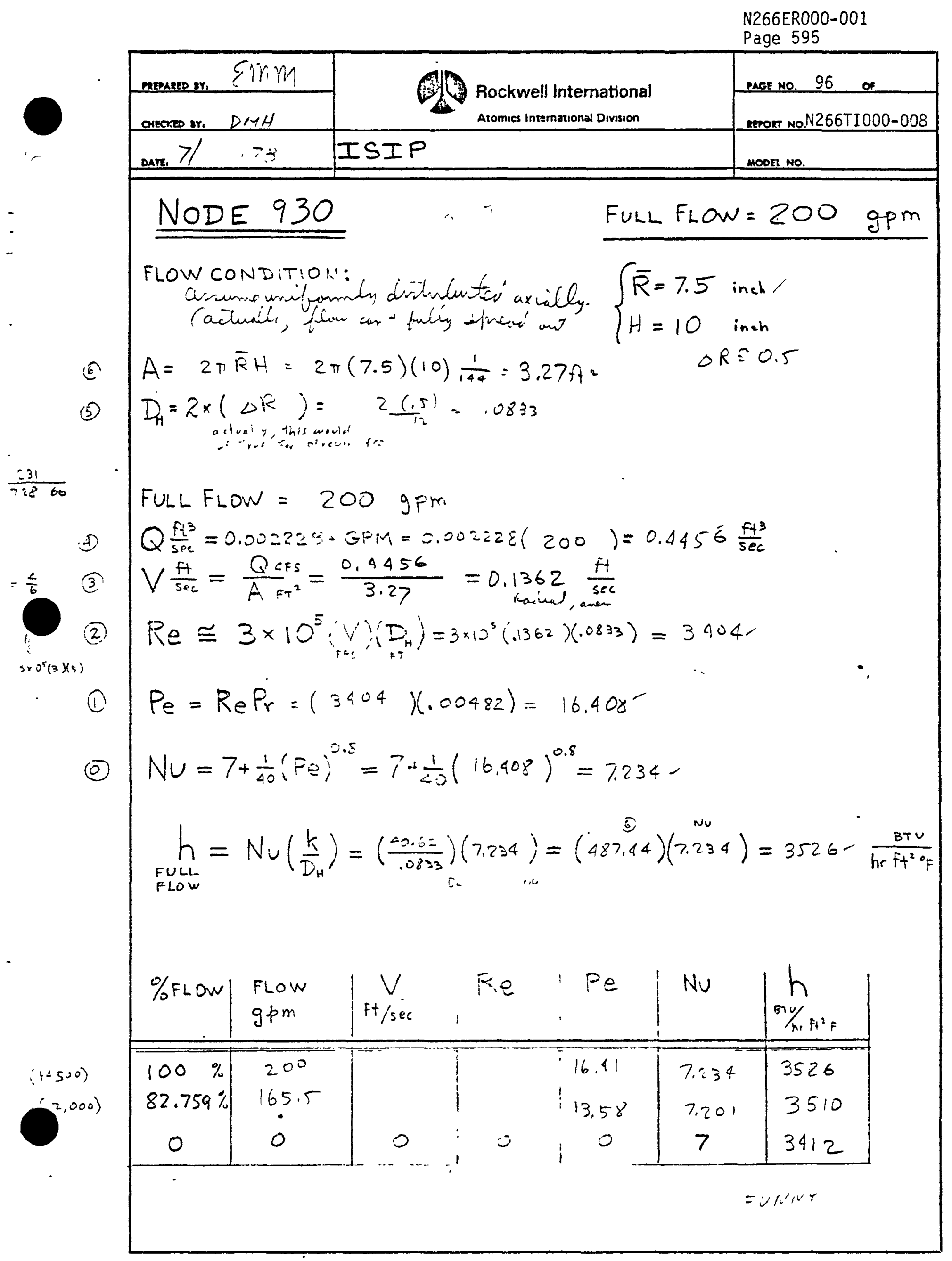


N266ER000-001
Page 596

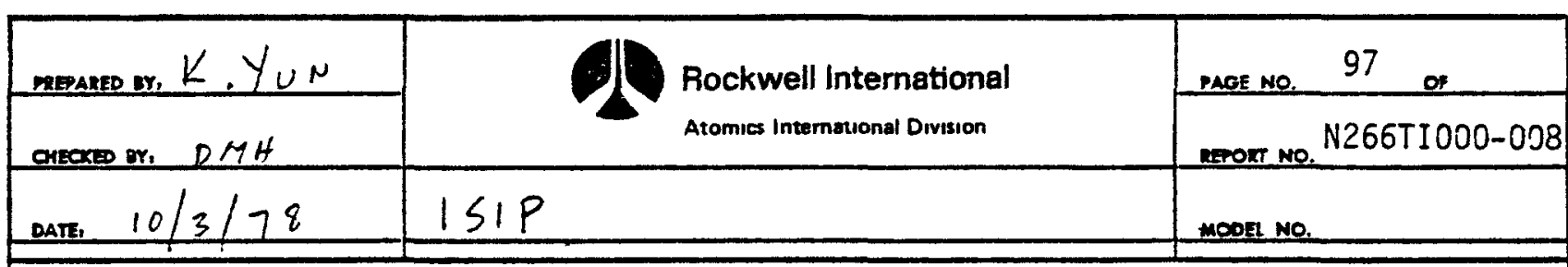

NODE 932

Flow Condition: Radial slow through 4-2.5"Dia6" Long flow path.

$$
\begin{aligned}
& A=\left[\pi\left(2.5^{2}\right) / 4\right] \times 4=19.635 \mathrm{in}^{2}=.13635 \mathrm{st}^{2} \\
& D_{H}=D=2.5^{\prime \prime}=.2083 \mathrm{ft} \\
& \text { Full Flow }=\text { Assume } 2 / 3 \text { of }(100+50) \mathrm{GPm}=100 \mathrm{GPm} \\
& Q^{\left\{t^{3}\right.} / \mathrm{sec}=0.002228(100)=0.2228 \mathrm{st} / \mathrm{sec} \\
& V_{s t} t / \mathrm{sec}=Q_{c t s} / A_{t t^{2}}=0.2228 / .13635=1.634 \mathrm{t} t / \mathrm{sec} \\
& R_{e} \simeq 3 \times 10^{5}(V)\left(D_{H}\right)=3 \times 10^{5}(1.634)(.2083)=1.021 \times 10^{5} \\
& P_{e}=R_{e} \cdot P_{r}=\left(1.021 \times 10^{5}\right)(.00482)=492.17- \\
& N_{u}=7+\frac{1}{40}\left(P_{e}^{.8}\right)=10.561 \text {. } \\
& h_{t_{u l l}}=N_{u}\left(\frac{K}{D_{H}}\right)=(10.561)\left(\frac{40.62}{.2083}\right)=2060^{-} \mathrm{Btu} / \mathrm{hr}_{\mathrm{t}} \mathrm{ft}^{2}-{ }^{\circ} \mathrm{F} \\
& \text { slow }
\end{aligned}
$$

\begin{tabular}{l|c} 
& $h$ \\
\hline $100 \%$ & 2060 \\
\hline $82.759 \%$ & 1962 \\
\hline 0 & 1365 \\
\hline
\end{tabular}

N 152.16-2 REV. 2.76 
N266ER000-001

Page 597

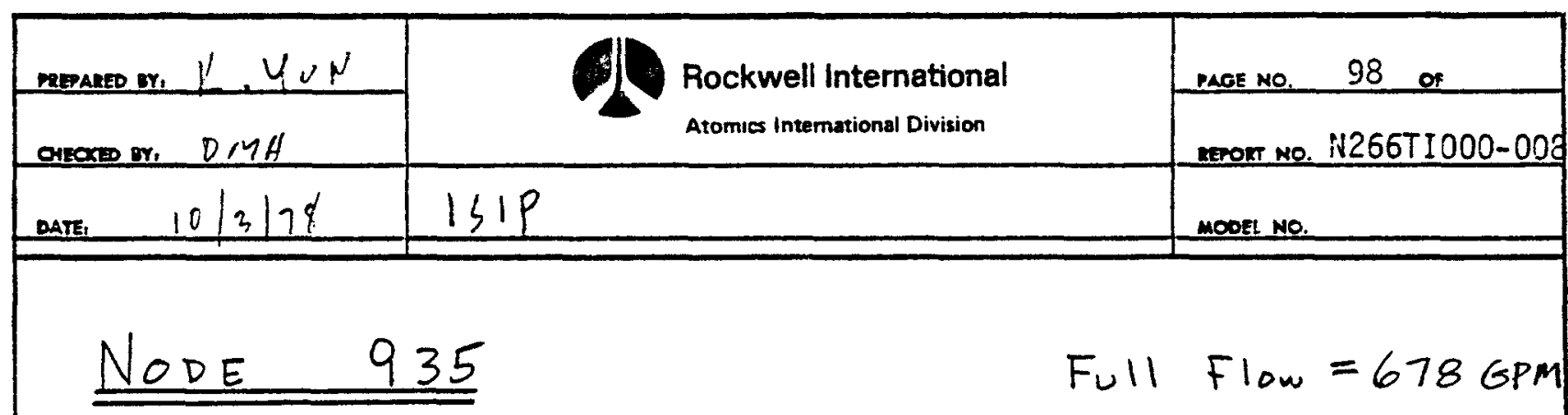

Flow Condition:

Axial flow through $12-1.25$ "DIA-12.5" LONG flow paths.

$$
\begin{aligned}
& A=\left[\pi\left(1.25^{2}\right) / 4\right] \times 12=14.726 \mathrm{in}^{2}=0.10226 \mathrm{st}^{2} \\
& D_{H}=D=1.25^{\prime \prime}=0.10417 \mathrm{zt} \\
& \text { Full Flow }=678 \mathrm{GPM} \\
& Q \frac{\mathrm{ft}^{3}}{\mathrm{sec}}=0.002228(678)=1.5106 \mathrm{ft} \mathrm{ft}^{3} / \mathrm{sec} \\
& V \frac{s t}{\mathrm{sec}}=\frac{Q_{C F S}}{A t t^{2}}=\frac{1.5106}{0.10226}=14.772 \mathrm{ft} / \mathrm{sec} \\
& R_{e} \cong 3 \times 10^{5}(V)\left(D_{H}\right)=3 \times 10^{5}(14.772)(0.10417)=4.616 \times 10^{5} \\
& P_{e}=R_{e} \cdot P_{r}=\left(4.616 \times 10^{5}\right)(.00482)=2225 . \\
& N_{n}=7+\frac{1}{40}\left(P_{e}\right)^{.8}=18.907- \\
& h_{\substack{\text { tull } \\
\text { tow }}}=N_{u}\left(\frac{K}{D_{H}}\right)=(18.907)\left(\frac{40.62}{.10417}\right)=7373 .-\frac{B+v}{\mathrm{hr} \mathrm{tt}^{2}{ }^{\circ} \mathrm{F}}
\end{aligned}
$$

\begin{tabular}{l|c} 
& $h$ \\
\hline $100 \%$ & 7373 \\
\hline $82.759 \%$ & 6720. \\
\hline 0 & 2730. \\
\hline
\end{tabular}

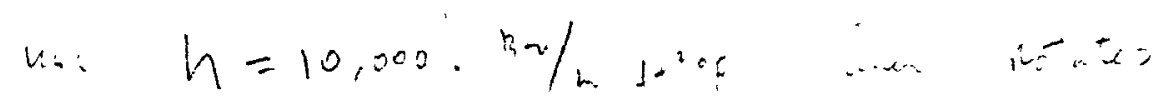

N 152-14-2 REV. 2.76 
N266ER000-001

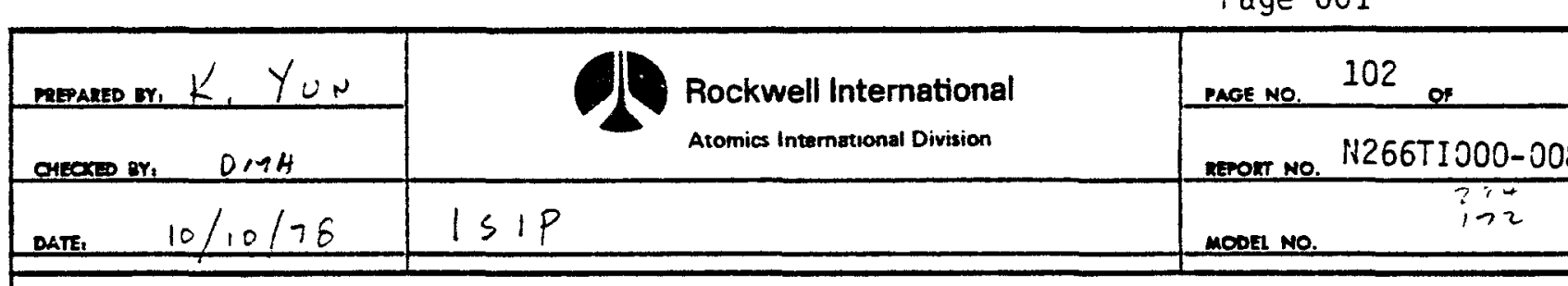

NODE 942

Flow Condition: Stagnant

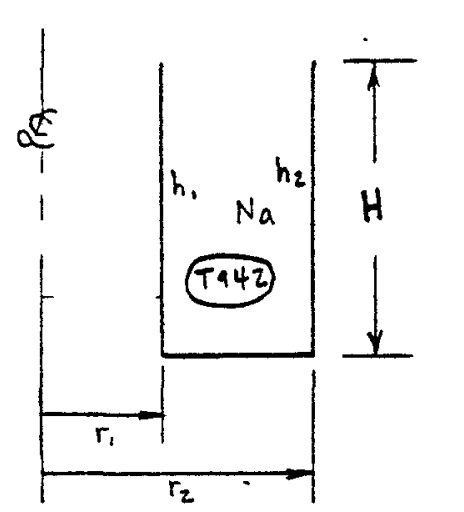

Operating Temp. Range: $600^{\circ} \mathrm{F} \sim 1050^{\circ} \mathrm{F}$

Use,

$$
\begin{aligned}
& r_{1}=9 \text { in }=.75 \mathrm{ft} \\
& r_{2}=33 \text { in }=2.75 \mathrm{ft} \\
& H=52 \text { in }=4.33 \mathrm{ft}
\end{aligned}
$$

$$
R_{a_{H}}=G_{r_{H}} \cdot P_{r}=A \cdot H^{3} \cdot \Delta T \cdot P_{r}
$$

where $A=\rho^{2} g \beta / \mu^{2}$

$$
1.35 \times 10^{8} \times \Delta T<R_{Q_{H}}=G_{r_{H}} \cdot \operatorname{Pr}<2.25 \times 10^{8} \times \Delta T
$$

$\because$ For $|\Delta T|$ (wall- Na) between $37^{\circ} \mathrm{F} \sim 89^{\circ} \mathrm{F}$,

$$
5 \times 10^{7} \leqslant R a_{H} \leqslant 2 \times 10^{10}
$$

Therefore, Eq. 5.107 of O.E. Dryer can be applied.

$$
\begin{aligned}
\bar{N}_{u_{H}}=\frac{\bar{h} \cdot H}{h} & =0.16\left[\left(R_{a_{H}}\right)(r / H)\right]^{0.3} \\
& =0.16\left[\left(A \cdot P_{r} \cdot H^{3} \cdot \Delta T\right)(r / H)\right]^{0.3} \\
& =0.16\left[A \cdot P_{r} \cdot \Delta T \cdot H^{2} \cdot r\right]^{0.3}
\end{aligned}
$$

At a given surface $(H, r) \quad \bar{h}$ becomes

$$
\begin{aligned}
& \bar{h}=.16 \frac{k}{H}\left(A \cdot P_{r} \cdot H^{2} \cdot r\right)^{0.3}(\Delta T)^{0.3} \\
& =C(\Delta T)^{0.3}
\end{aligned}
$$

N 152.1.2 REV. 2.76 
N266ER000-001

Page 602

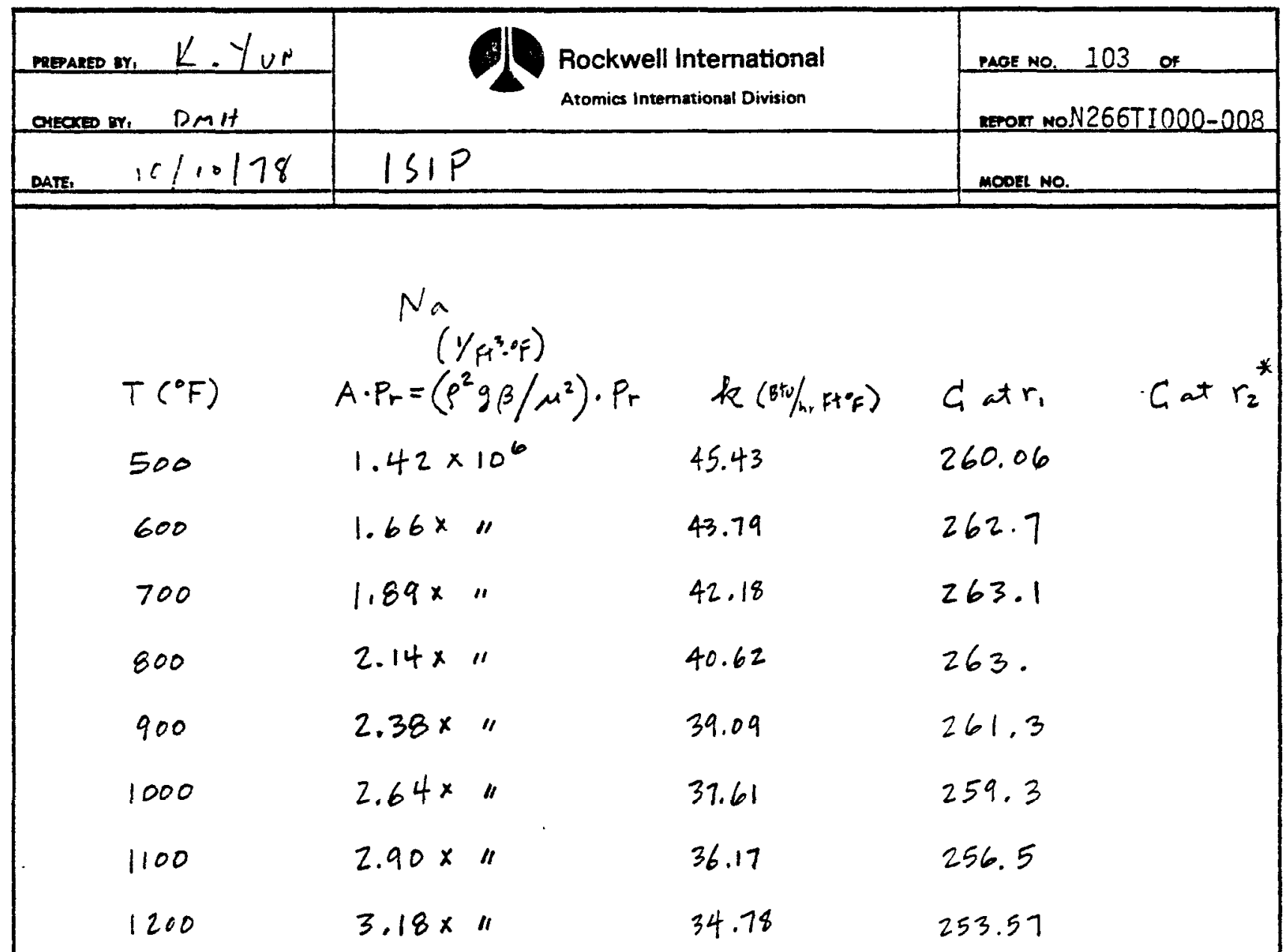

Data from Golden \& Tolar

$C$ at $r_{2}$ is 1.477 times greater than $G$ at $r_{1}$

$G$ at $r_{1}$ can be averaged an 260. at all operating temperature range

$$
\begin{aligned}
& \because{ }^{\text {dst }} C \text { at } r_{1}=260 \text {. } \\
& c \text { at } r_{2}=384 \text {. }
\end{aligned}
$$

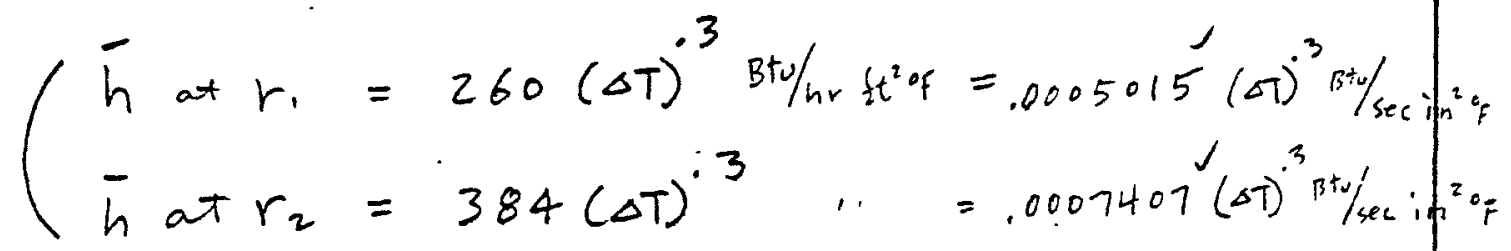

N 152.R.2 REV. 2.76 


\section{APPENDIX B}

\section{CLEARANCE CHANGES}

This appendix contains the results of the thermal radial clearance effect using the APSA program given in Reference 10. 
N266ER000-001

Page 604

N266TI000-003

Page 105

CRITICAL CLEAKANCE cHANGES (MUS)

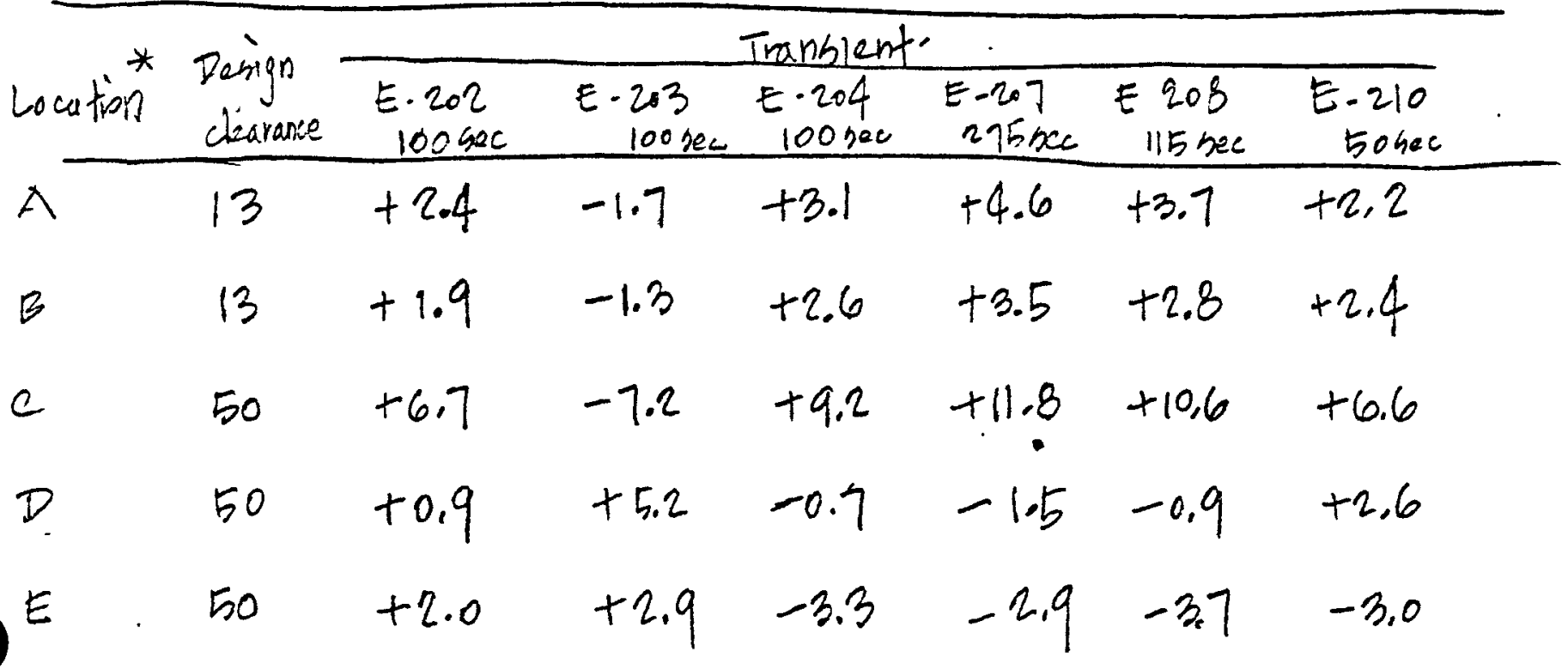

Note:

1. The value listed under the transient column are changes in the original clearance at isothermal temperature conditions.

For example, at location $A$, the origins clearance ( 13 mils) is increased by 0.0024 inch during Event E202 and decreased by 0.0017 inch during $E 203$.

* bee Figures 2 


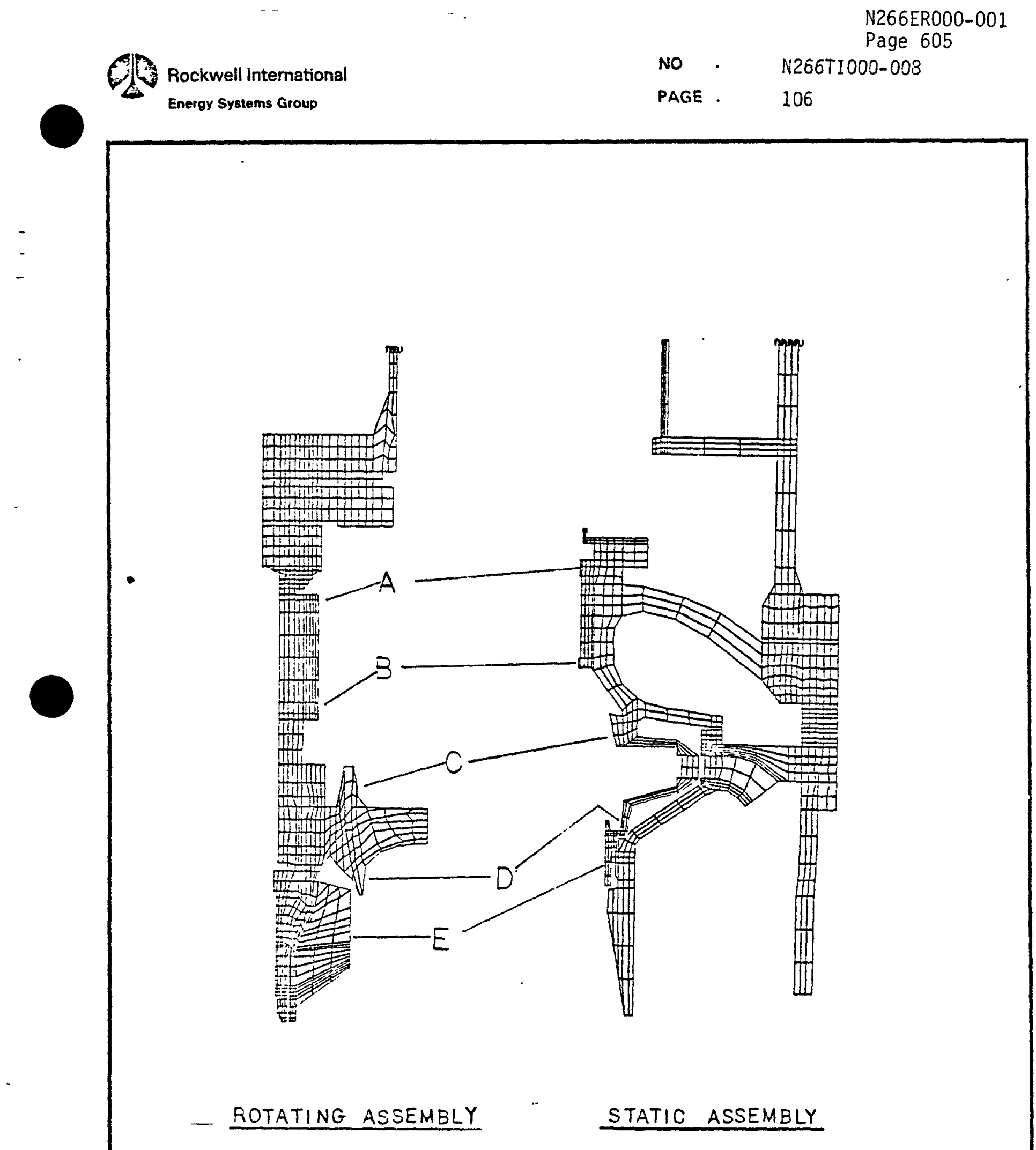


PAGE . 107

\section{APPENDIX C}

TRANSIENT ANALYSIS - COMPUTER LISTING

(TAP PROGRAM)

(Computer printout removed for brevity.) 


\section{APPENDIX K}

VERIFICATION OF THERMAL MODEL FOR ISIP

(INTERMEDIATE-SIZE INDUCER PUMP)

ESG Document N266TI000-0007 
$620-78-35$

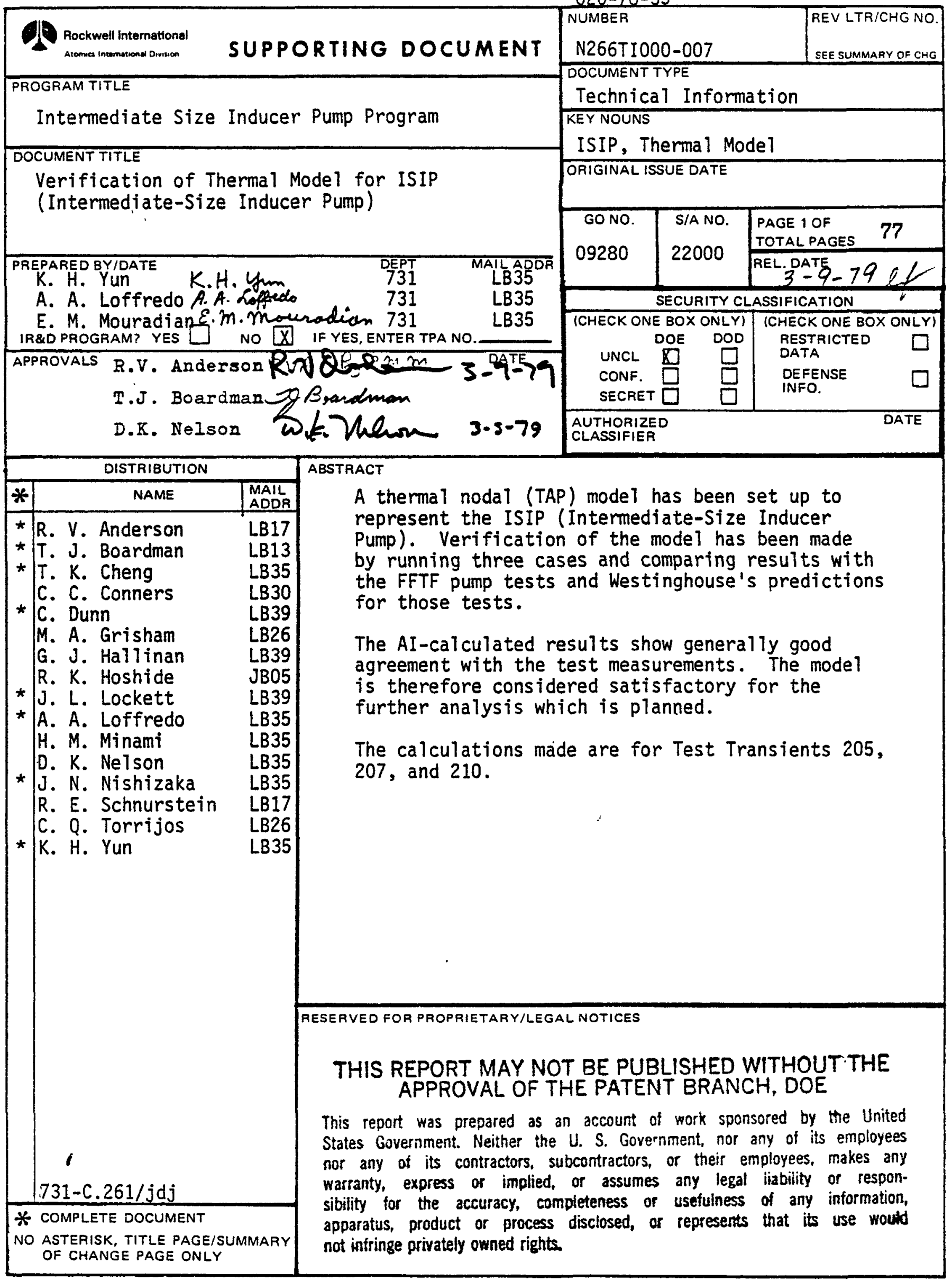




\section{CONTENTS}

\section{Page}

I. INTRODUCTION.......................... 5

II. PURPOSE. $\quad \ldots \ldots \ldots \ldots \ldots \ldots \ldots \ldots \ldots \ldots \ldots \ldots \ldots \ldots \ldots \ldots$

III. $\quad$ DISCUSSION............................ 7

IV. $\quad$ CONCLUSION................................ 10

V. REFERENCES $\ldots \ldots \ldots \ldots \ldots \ldots \ldots \ldots \ldots \ldots \ldots \ldots \ldots$

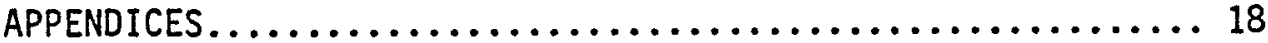

A. COMPARISON OF AI CALCULATIONS WITH FFTF TEST MEASUREMENTS AND WESTINGHOUSE PREDICTIONS.... 18

A-1. TRANSIENT 205-TEST................ 20

A-2. TRANSIENT 207-TEST.............. 35

A-3. TRANSIENT $210-$ TEST.............. 50

B. TRANSIENT TEMPERATURE DIFFERENTIALS (LOCATION PAIRS $4-8,4-9,4-10$, AND 4-11)..........6 65

B-1. TEMPERATURE DIFFERENTIAL PLOTS........66 66

B-2. TEMPERATURE DIFFERENTIAL TABLES.......69 


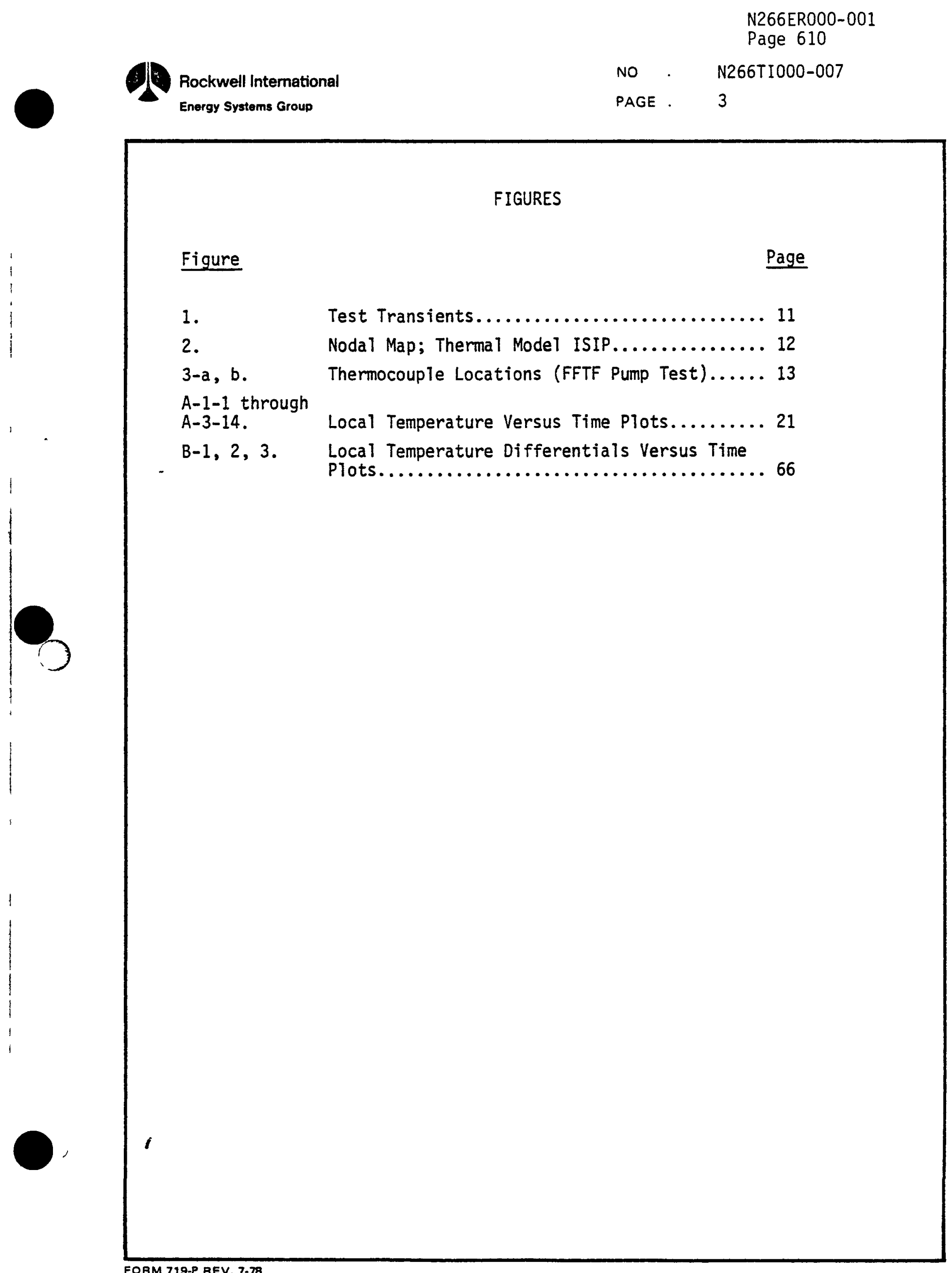

FORM 719-P REV. 7.78 


\section{TABLES}

Table

\section{Page}

I. Specification Transients............... 15

II. Test Transients $(205,207,210) \ldots \ldots \ldots \ldots 16$

A. Temperature Measurement Locations......... 19

$B-1 a, b, c . \quad L$ Local $\Delta T$ Versus Time.................. 69

$\mathrm{B}-2 \mathrm{a}, \mathrm{b}, \mathrm{c} . \quad$ Local $\Delta \mathrm{T}$ Versus Time................. 72

$\mathrm{B}-3 \mathrm{a}, \mathrm{b}, \mathrm{c} . \quad$ Local $\Delta \mathrm{T}$ Versus Time................ 75 


\section{INTRODUCTION}

The ISIP (Intermediate-Size Inducer Pump) is to be installed within the FFTF pump casing. A thermal model has been set up by AI to represent the ISIP, using techniques of the STAMP and TAP computer programs. The purpose of this thermal model is for use in calculating the thermal behavior of the ISIP during transients. The results are to be employed in stress and deflection analysis. 
The purpose of this report is to show the results of checkout runs with the computer thermal model of the ISIP (Intermediate-Size Inducer Pump). The calculated results are compared to the experimental measurements taken during the thermal testing of the FFTF pump. The agreement between the experimental and computer temperature values is reasonably good, such that the thermal model of the ISIP can be considered to be an adequate thermal representation of the pump. 


\section{DISCUSSION}

The FFTF pump underwent extensive thermal transient testing, as reported in Reference 1 (Westinghouse Report 5080). A series of nine transients were planned to be run. Herein,. these are referred to as "SPECIFICATION TRANSIENTS," and are shown in Table I (also see Reference 2 ). The sodium flow rate and pump inlet sodium temperature versus time is indicated.

The manipulation of the experimental facility does not allow exact duplication of the transient that is planned (due to imperfect control on flow rates, temperatures, etc.). Thus, the transients to which the FFTF pump was actually subjected were somewhat different, and are herein referred to as "test transients." These are shown in Figure 1 and Table II, as taken from Reference 1.

The casing of the FFTF pump has been modified somewhat for the installation of different components, such as to form the ISIP (ISI pump). Much of the overall structure remains unchanged. A thermal model has been set up to represent the ISIP using the STAMP and TAP computer programs (References 3 and 4 ). As a checkout of this model, three test transients were run: 205-TEST, 207-TEST, and 210-TEST (see Figure 1). These three were chosen because:

1) Transient 205 is one of only two "up" transients (the other being almost identical in nature)

2) Transient 207 is the "down" transient with the greatest overall temperature drop (nominally $330^{\circ} \mathrm{F}$ )

3) Transient 210 is the "down" transient with the steepest slope, $\mathrm{dT} / \mathrm{dt}$ (nomina $71 \mathrm{y} 3.0^{\circ} \mathrm{F} / \mathrm{sec}$ ). 
In Reference 1, temperature versus time plots are shown for 14 different locations (where thermocouples were installed) for both test measurements and Westinghouse's prediction of temperature response. Plots of AI's calculational results for those some 14 locations have been superimposed on the measured and Westinghouse prediction curves taken from Reference 1. These are shown in Appendix $A$.

The AI data is the calculated response of the nodal points in the AI TAP thermal computer model lying closest to the thermocouple locations. The nodal map for the AI thermal model is shown. in Figure 2.

The thermocouple locations are shown in Figures $3 \mathrm{a}$ and $3 \mathrm{~b}$. A7so indicated are the location designations ( 1 through 14) used in the plots of Appendix $A$ and the AI thermal model node numbers. Reasonabiy good agreement was obtained between AI's calculations and the measured data, as can be seen by inspection of the figures of Appendix $A$.

For Location 1, quite good agreement was obtained between AI calculations and measured data.

For Location 2, there was no measured data for 205, with a wide discrepancy between AI and Westinghouse predictions. For 207, there is good agreement with measured data. For 210 , there is moderately good agreement, although AI is showing somewhat faster response. The zone of Location 2 is a large sodium cavity in which the mode of mixing is quite uncertain. However, it is a region that does not affect bearing behavior.

For Location 3, Transient 205, agreement between measurements and AI data is not very close, although AI's preduction is closer than the Westinghouse values. For 207 and 210, AI's data shows more sluggish 
PAGE . 9

response than the measured data. Location 3 is a large sodium zone wherein mixing mode is uncertain. Also, it is a zone that does not influence the bearing region. It would appear that the natural convection parameters in the Westinghouse made gives good response for down transients, but does not for up transients. AI's results are intermediate.

For Locations $4,5,6,7$, and 8 , agreement is generaliy quite good, although occasionally there appears to be a stray measurement curve (which does not agree with its fellow TC data).

For Location 9, AI's data shows considerably slower response than both the measurements and the Westinghouse prediction. This is because in this region the ISIP's design is different. The zone represented by Location 9 has an extra steel barrier between itself and the flow sodium, so as to delay the transient being felt there.

For Locations $10,11,12,13$, and 14 , agreement between $A I$ values and the measured data is quite good.

When inspecting the temperature versus time curves of Appendix $A$, it should be borne in mind that there is some displacement of the measured temperature, due to an offset in the reading of the thermocouples. This is sometimes as much as $20^{\circ} \mathrm{F}$. Mental adjustment for this displacement should be made when comparing the curves of measured and calculated data.

In addition to the temperature versus time plots shown in Appendix $A$, several sets of temperature differentials versus time are shown in Appendix B. Temperature differentials between Location Pairs 4-8, 4-9, 4-10, and 4-11 are given. A11 are expected to show agreement, except Location Pair 4-9. Because of the design change and the resultant more sluggish response at Location 9, the temperature differential, $\Delta T=T 4-T 9$, should be considerably less than in the FFTF test. The figure of Appendix $B$ shows that that is the case. 


\section{CONCLUSION}

The purpose of this set of three transient calculations was to check out the thermal computer model set up for the Intermediate-size Inducer Pump (ISIP). Comparison of the test with the FFTF pump indicates that the model is satisfactory. On this basis, it is judged that the model can be used for further calculations involved in the thermal analysis of the ISIP. 
FIGURE i

"TEST-TRANSIENTS" FOr FFTF Testing

Taken from $\mathrm{Pg} \cdot 34$, Figure 9 of

Westinghouse E.M. $\# 5080$,

Reference 1 .

See: 205-TEST

207-TEST

210-TEST

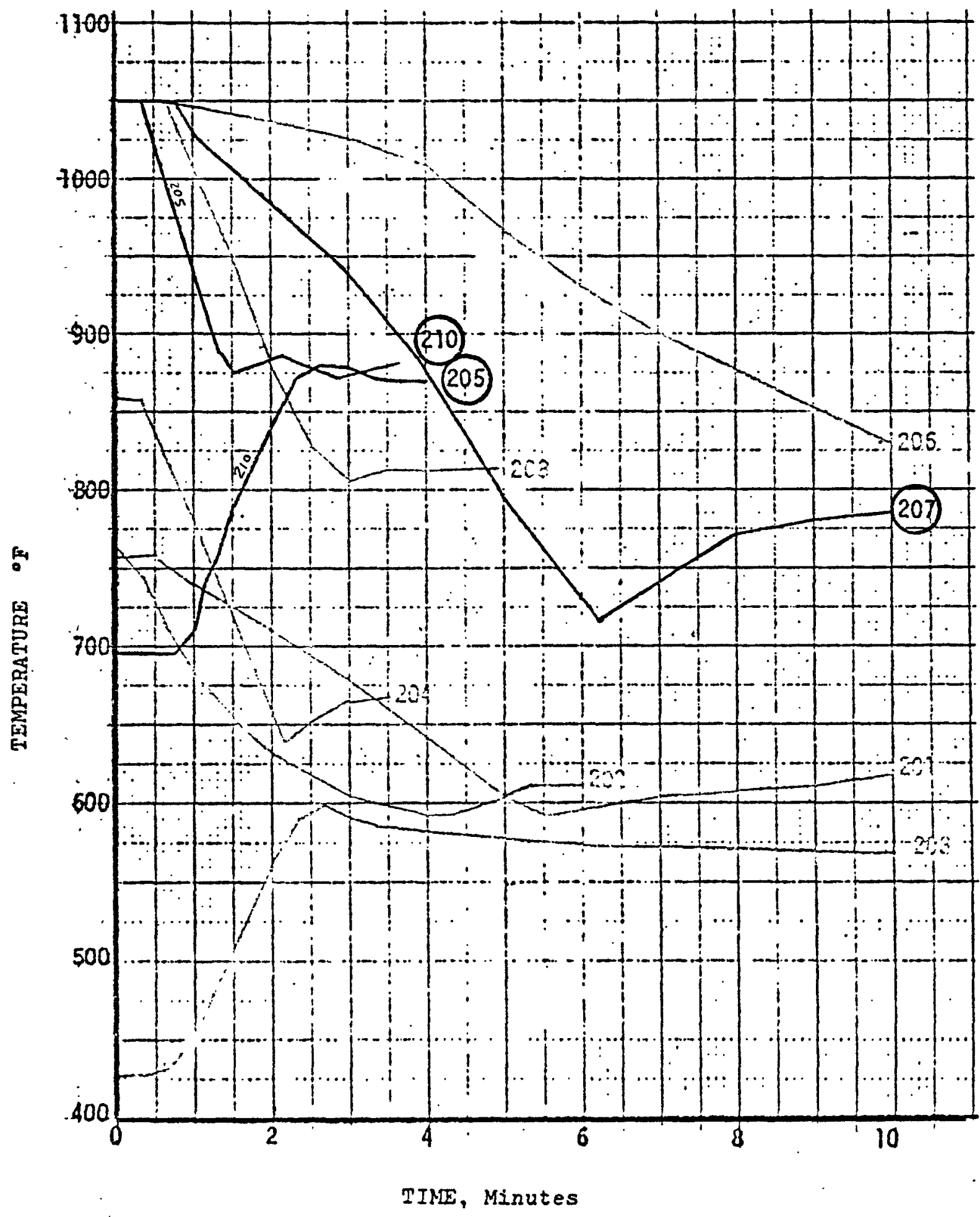


N266ER000-001

Page 620

N266TI000-007

FIGURE 3-a

Page 13

FFTF TEST THERMOCOUSIE LOCATICNS

Taken from $\mathrm{PE} .30$, Figure 5 of

Westinghouse E.M. \#5080,

Reference 1 .

(1) Circled locations correspond to Aprendix A locations.

(14) MIO TANK NA

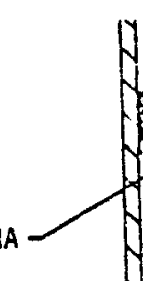

(10)

BRG TOP OUT

(12) BRG RETURN TEMP UP
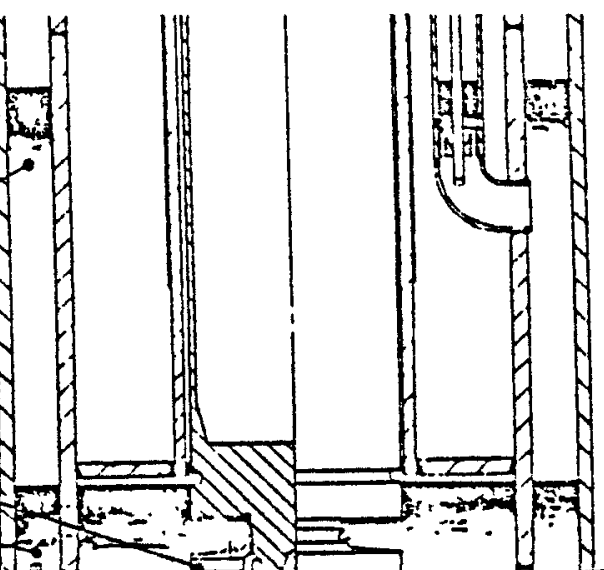

(11) VORTEX CHAMB

(4) BRG FEED

(5) BRG FEED OUT

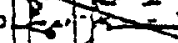

通的
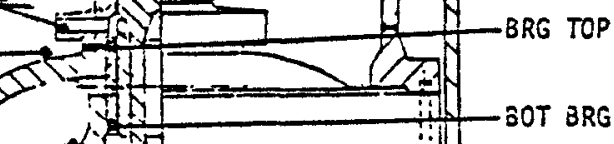

(6)

(13)

(3) BRG RETURN -

(1) BRG FEED UP
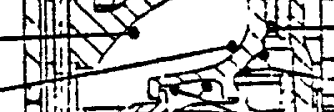

(7)

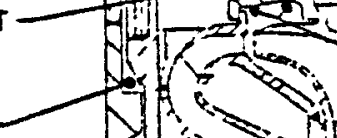

BRG BOT OUT

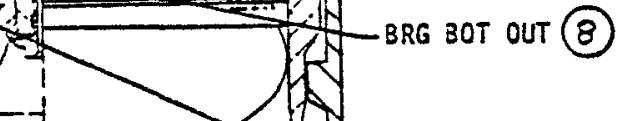

UP IMPL LEAK(9)

(3) GRG FEED BOT

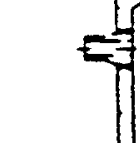

7
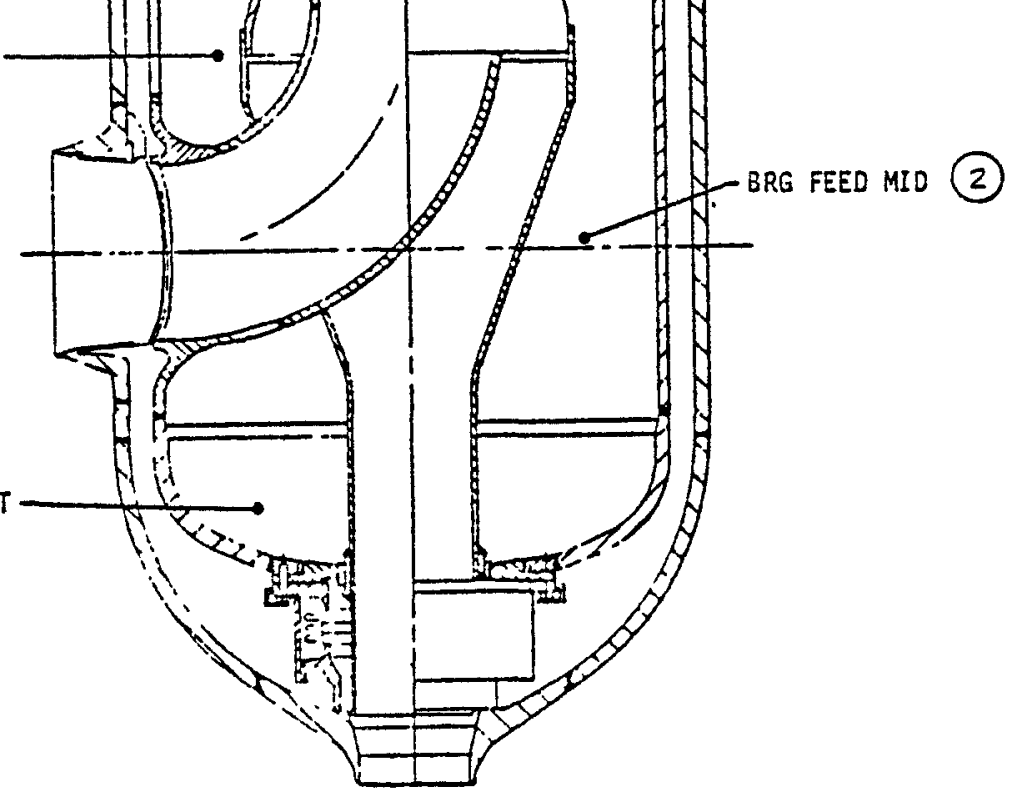

SPTF THERMOCOUPLE LOCATIONS 
N266ER000-001

Page 621

N266TI000-007

Page 14

FIGURE 3-b

FFTE TEST THERMOCOUPLE LOCATIONS

(Bearing Area)

Taken from $\mathrm{Pg} .29$, Figure 4 of Wiestinghouse E.M. \#5080, Reference 1 .

(2) Circled locations correspond to Appendix A locations.

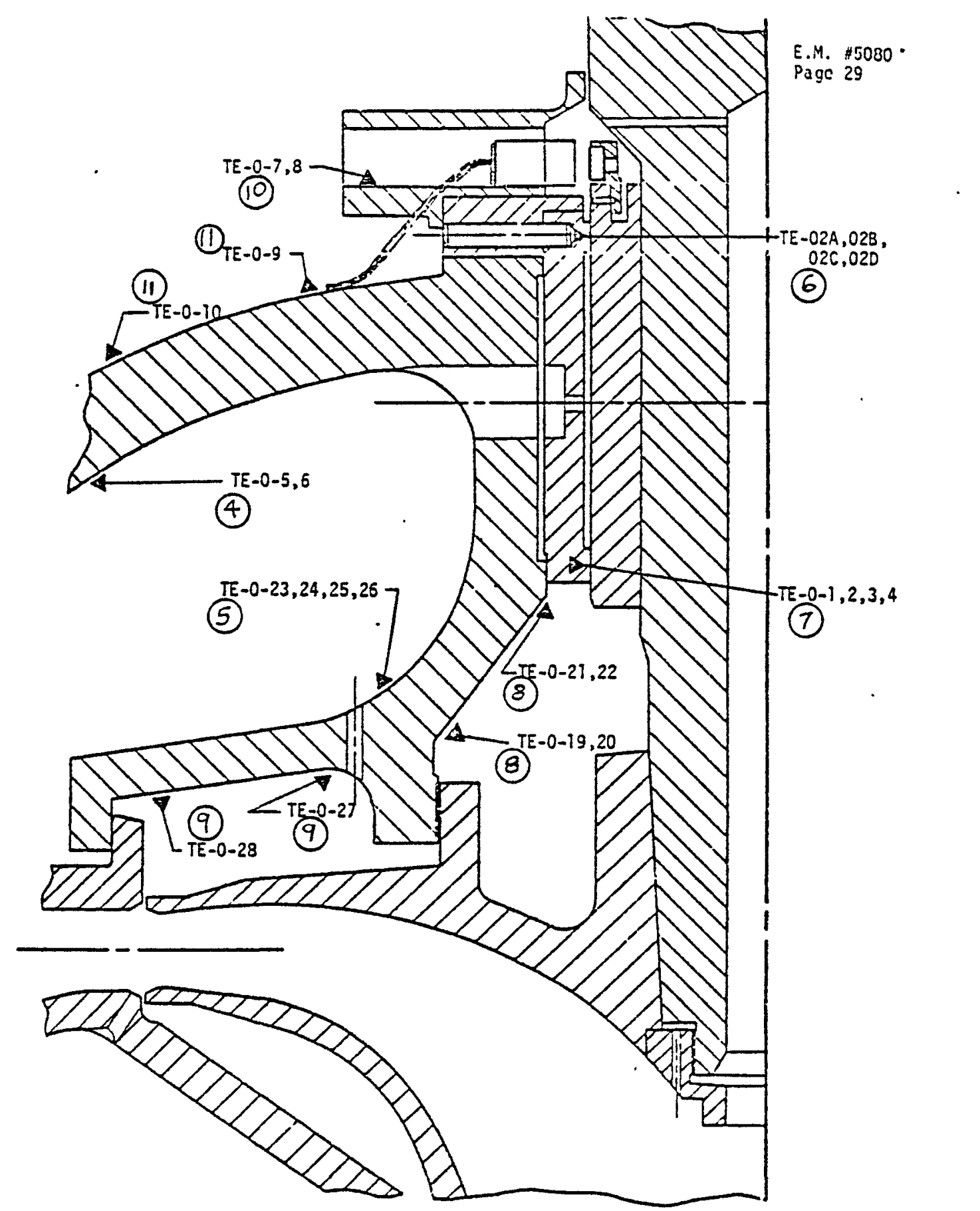

FFTF PROTOTYPE PUMP BE.ARING AREA THERMOCOUPLES 
TABLE I

SPECIFICATION TRANSIENTS

(Taken from Table 4-II, Reference 2)

\begin{tabular}{cccccc}
\hline $\begin{array}{c}\text { Transient } \\
\text { Number }\end{array}$ & $\begin{array}{c}\text { Flow } \\
(\mathrm{gpm})\end{array}$ & $\begin{array}{c}\text { Initial } \\
\text { Temp. } \\
(\mathrm{F})\end{array}$ & $\begin{array}{c}\text { Final } \\
\text { Temp. } \\
(\mathrm{F})\end{array}$ & $\begin{array}{c}\text { Temp. } \\
\text { Change } \\
(\mathrm{F})\end{array}$ & $\begin{array}{c}\text { Trans } \\
\text { Rate } \\
(\mathrm{F} / \mathrm{sec})\end{array}$ \\
\hline 201 & 14,500 & 750 & 600 & -150 & -0.4 \\
202 & 14,500 & 750 & 600 & -150 & -1.5 \\
203 & 14,500 & 500 & 650 & +150 & +1.5 \\
204 & 14,500 & 850 & 650 & -200 & -2.0 \\
205 & 14,500 & 700 & 850 & +150 & +1.5 \\
206 & 12,000 & 1050 & 720 & -330 & -0.4 \\
207 & 14,500 & 1050 & 720 & -330 & -1.2 \\
208 & 14,500 & 1050 & 825 & -225 & -2.0 \\
210 & 14,500 & 1050 & 900 & -150 & -3.0 \\
\hline
\end{tabular}


-

\begin{tabular}{|c|c|c|c|c|c|}
\hline \multicolumn{2}{|c|}{ TRANSIENT \#205 - } & & & & \\
\hline \multicolumn{6}{|c|}{$\begin{array}{l}\text { From E.M. } \\
(\text { Ren } 1)\end{array}$} \\
\hline \multirow{2}{*}{ 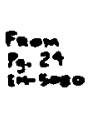 } & $\begin{array}{l}\text { TEST } \\
\text { OEDETTNE }\end{array}$ & $700 / 850$ & +150 & 100 & +1.5 \\
\hline & $\begin{array}{c}\text { TEST } \\
\text { Summaky }\end{array}$ & $695 / 880$ & +185 & 72.5 & +2.0 \\
\hline
\end{tabular}

Sooium Flow: $=14,500 \mathrm{gpon}=100 \%$

Em-5080, P..34, Fig. 9 :

\begin{tabular}{|c|c|c|c|c|c|}
\hline$t$ & $t_{\text {sec }}^{t}$ & $T_{\text {No-Imet }}$ & $d T / d t$ & $\delta T$ & $\int_{\text {sit }}$ \\
\hline 0 & 0 & 695 & & a & \\
\hline 0.75 & 45 & 695 & 0 & , & 45 \\
\hline 1 & 60 & 710 & +1.0 & $1+15$ & 15 \\
\hline $1 \frac{1}{2}$ & 70 & 742 & +3.2 & +32 & 10 \\
\hline 1.5 & 90 & 787 & +2.25 & +45 & 20 \\
\hline 2.3 & 138 & 871 & +1.75 & +84 & 48 \\
\hline $2 \frac{2}{3}$ & 160 & 880 & +0.41 & +9 & 22 \\
\hline 3 & 180 & $\frac{800}{879}$ & -0.05 & -1 & 20 \\
\hline $3 \frac{1}{6}$ & 190 & $\frac{877}{873}$ & -0.60 & -6 & 10 \\
\hline $3 \frac{1}{2}$ & 200 & $\frac{812}{871}$ & -0.20 & -2 & 10 \\
\hline 4 & 240 & 870 & -0.025 & -1 & 40 \\
\hline$\infty$ & $\alpha$ & 870 & 0 & 0 & $=$ \\
\hline
\end{tabular}

TRANSIENT "210 -

FROM E.M."

(Re. I)

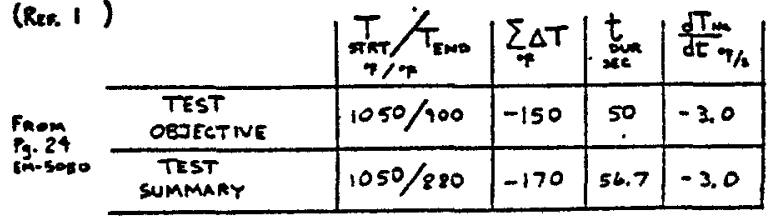

Sopum FLOW: $=14,500 \mathrm{gpm}=100 \%$

Em-5080, Py.34, Fig. 9 :

\begin{tabular}{|c|c|c|c|c|c|}
\hline$t$ & $\sec _{\text {sec }}^{t}$ & $T_{\text {Ne. Imat }}$ & $\begin{array}{l}d T / d t \\
T / z e t\end{array}$ & $\delta T$ & St \\
\hline 0 & 0 & 1050 & & & \\
\hline 0.4 & 24 & 1050 & 0 & 0 & 24 \\
\hline 1.3 & 78 & 890 & $1-2.96$ & -160 & 54 \\
\hline 1.5 & 90 & 875 & -1.25 & -15 & 12 \\
\hline $2 \frac{1}{6}$ & 130 & 885 & +0.25 & +10 & 40 \\
\hline $2 \frac{5}{6}$ & 170 & 871 & -0.35 & -14 & 40 \\
\hline 3.6 & 216 & 883 & +0.26 & +12 & 46 \\
\hline$\infty$ & $\infty . . .$. & 883 & 0 & 0 & $\infty$ \\
\hline
\end{tabular}

\section{TABLE II}

"TEST TRANSIENTS"

\# 205, $207 \& 210$

Taken from Westinghouse EM \#5080 Figure 9, Page 34 (Reference I).

See Figure 1

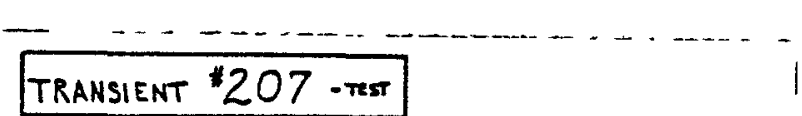

FROM E.M" 5080

(Re. I)

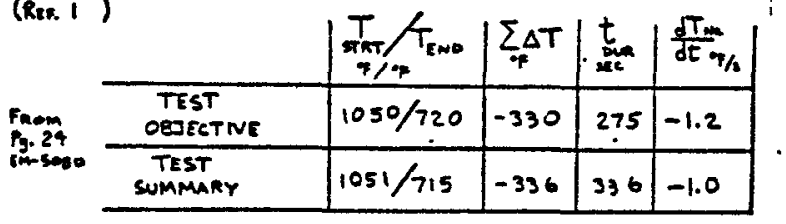

Sodium FLOW: $=14.500_{\text {gpm }}=100 \%$

EM-5080, P. 34, Pig. 2:

\begin{tabular}{|c|c|c|c|c|c|}
\hline$t$ & $\sec _{\text {sec }}^{t}$ & $T_{\text {M. Imet }}$ & $d T / d t$ & $\delta T$ & $\delta t$ \\
\hline 0 & 0 & 1050 & & & \\
\hline 0.8 & 48 & 1050 & 0 & 0 & 48 \\
\hline 1 & 60 & 1028 & -1.83 & -22 & 12 \\
\hline 2 & 120 & 985 & -0.72 & -43 & 60 \\
\hline 3 & 180 & 939 & -0.77 & -46 & 60 \\
\hline 4 & 240 & 875 & -1.07 & -64 & 60 \\
\hline 5 & 300 & 795 & -1.33 & -80 & $\infty$ \\
\hline 6.2 & 372 & 720 & -1.04 & -75 & 72 \\
\hline 8 & 480 & 770 & +0.46 & +50 & 108 \\
\hline 10 & 600 & 784 & +0.12 & +14 & 120 \\
\hline$\infty$ & $\infty$ & 724 & 0 & 0 & $\infty$ \\
\hline
\end{tabular}




\section{REFERENCES}

1. A. E. Reed, "SPTF Thermal Transient Testing: A Comparison of Analys is and Test Results," Engineering Memorandum E.M. 5080, August 1977, Westinghouse Electric Corp., Electro-Mechanical Division, Cheswick, Pennsylvania

2. D. R. Paradise, "Specification: Pump, Sodium, Inducer, Intermediate-Size (ISIP," N266ST310001, April 1978, and Rev. A, June 1978, Atomics International

3. R. E. Craig, "Stress to Thermal Adaptation Model Program (STAMP) Description and User's Manual," TI-036-610-007, July 1974, Atomics International.

4. E. Moody, "Thermal Analyzer Program Revision (TAP-4SG)," TJ-099-411-015, August 1974, Atomics International 
APPENDIX A

COMPARISON OF AI CALCULATIONS WITH FFTF TEST

MEASUREMENTS AND WESTINGHOUSE PREDICTIONS

Reference 1 (Westinghouse E.M. 5080) shows plots of temperature versus time for 14 locations within the FFTF pump. These are results of test measurements and Westinghouse prediction calculations. The plots for Test Transients 205-TEST, 207-TEST, and 210-TEST are shown in this appendix. The results of AI calculations for the same transients and the same locations have been superimposed upon these curves for comparison. The AI curves are the heavy-dashed lines.

Appendices A-1, A-2, and A-3 are for Test Transients 205, 207, and 210, respectively. The 14 locations are as shown in Figure 3 and in Table A. The location is also shown on each individual plot. 
TABLE A

TEMPERATURE MEASUREMENT LOCATIONS

(See Figure 3)

\begin{tabular}{clll}
\hline $\begin{array}{c}\text { Figure and } \\
\text { Location } \\
\text { Number }\end{array}$ & \multicolumn{1}{c}{$\begin{array}{c}\text { Location } \\
\text { Description }\end{array}$} & $\begin{array}{c}\text { AI Thermal } \\
\text { Model } \\
\text { Node Number }\end{array}$ & TE Numbers \\
\hline 1 & Brg. Feed Up & 925 & 33,34 \\
2 & Brg. Feed Mid & 925 & 35 \\
3 & Brg. Feed Bot & 942 & 36 \\
4 & Brg. Feed & 929 & 5,6 \\
5 & Brg. Feed Out & 929 & $23,24,25,26$ \\
6 & Brg. Top & 144 & $2 A, 2 B, 2 C, 20$ \\
7 & Brg. Bot & 168 & $1,2,3,4$ \\
8 & Brg. Bot, Out & 934 & $19,20,21,22$ \\
9 & Up Impl. Leak & 927 & 27,28 \\
10 & Brg. Out Top & 932 & 7,8 \\
11 & Vortex Chamber & 920 & 9,10 \\
12 & Brg. Return Temp Up & 921 & $11,12,13,14$ \\
13 & Brg. Return & 922 & $29,30,31,32$ \\
14 & Mid Tank Na & 940 & $15,16,17,18$
\end{tabular}




$$
\text { APPENDIX A-1 }
$$

TRANSIENT 205-TEST 


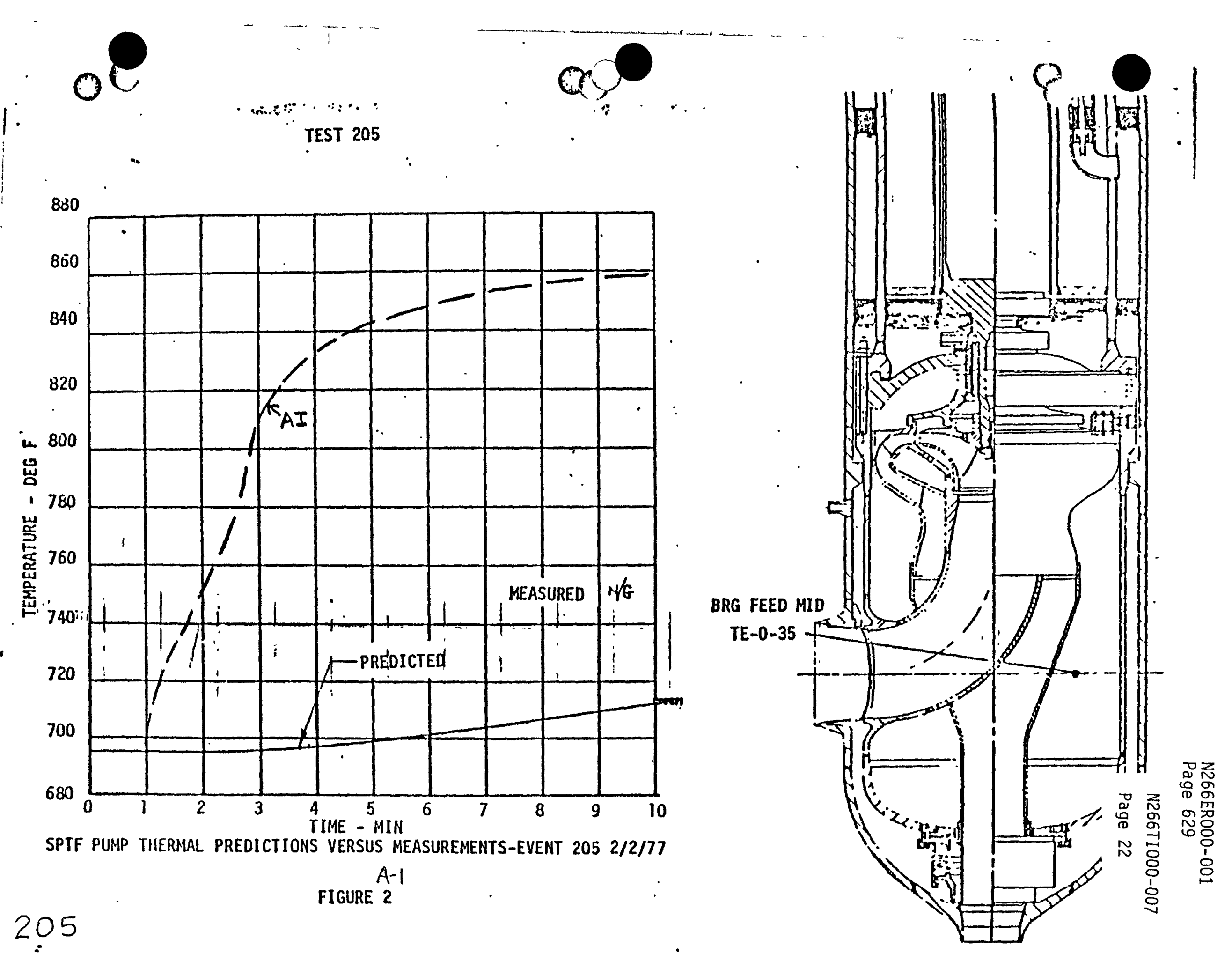


o

1!:

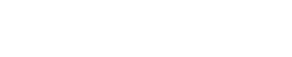

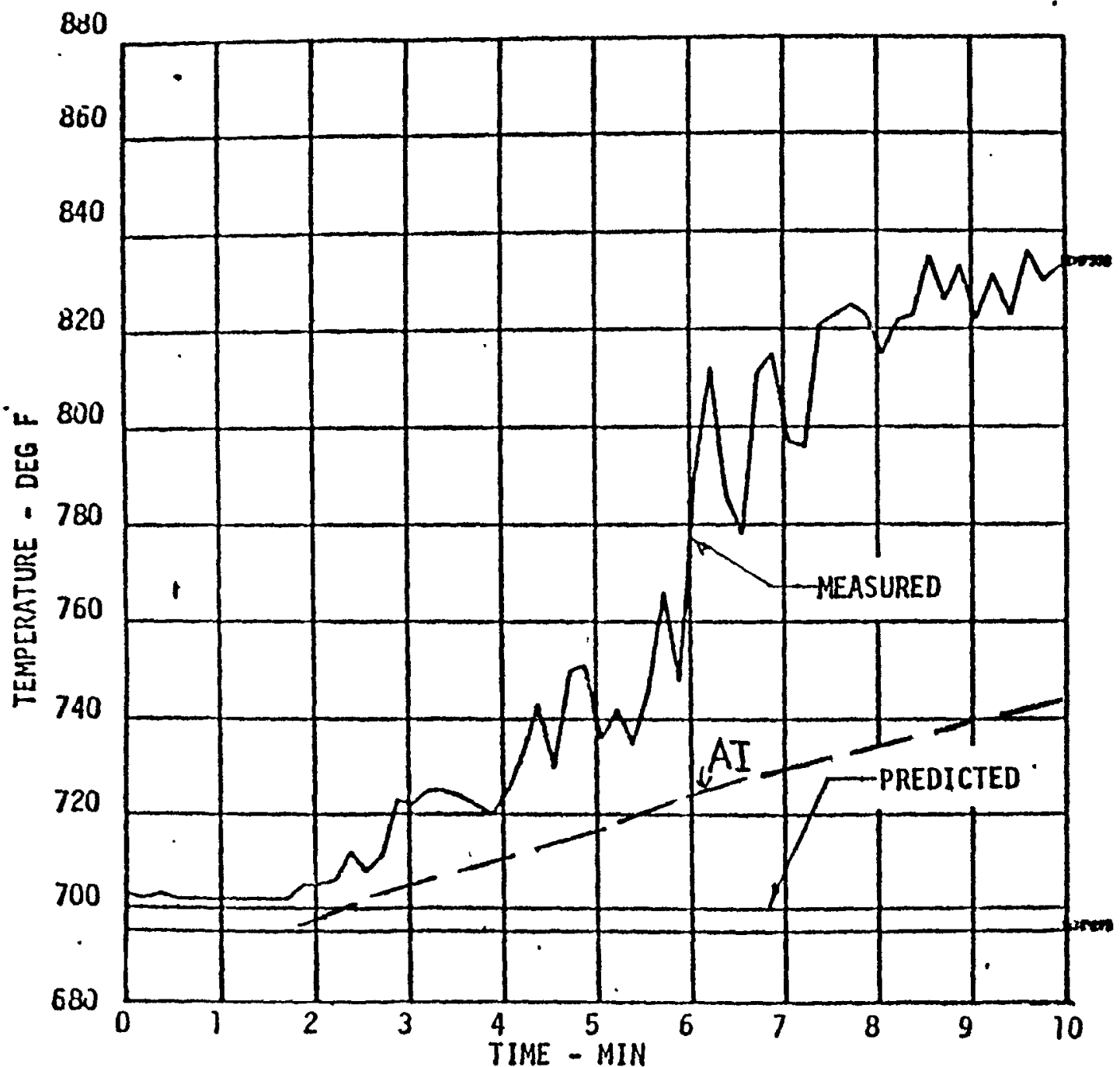

SPTF PUMP THERHAL PREOICTIONS VERSUS MEASUREMENTS-EVENT 205 2/2/77 $A-1$ FIGURE 3

205

TEST 205 . 
ol

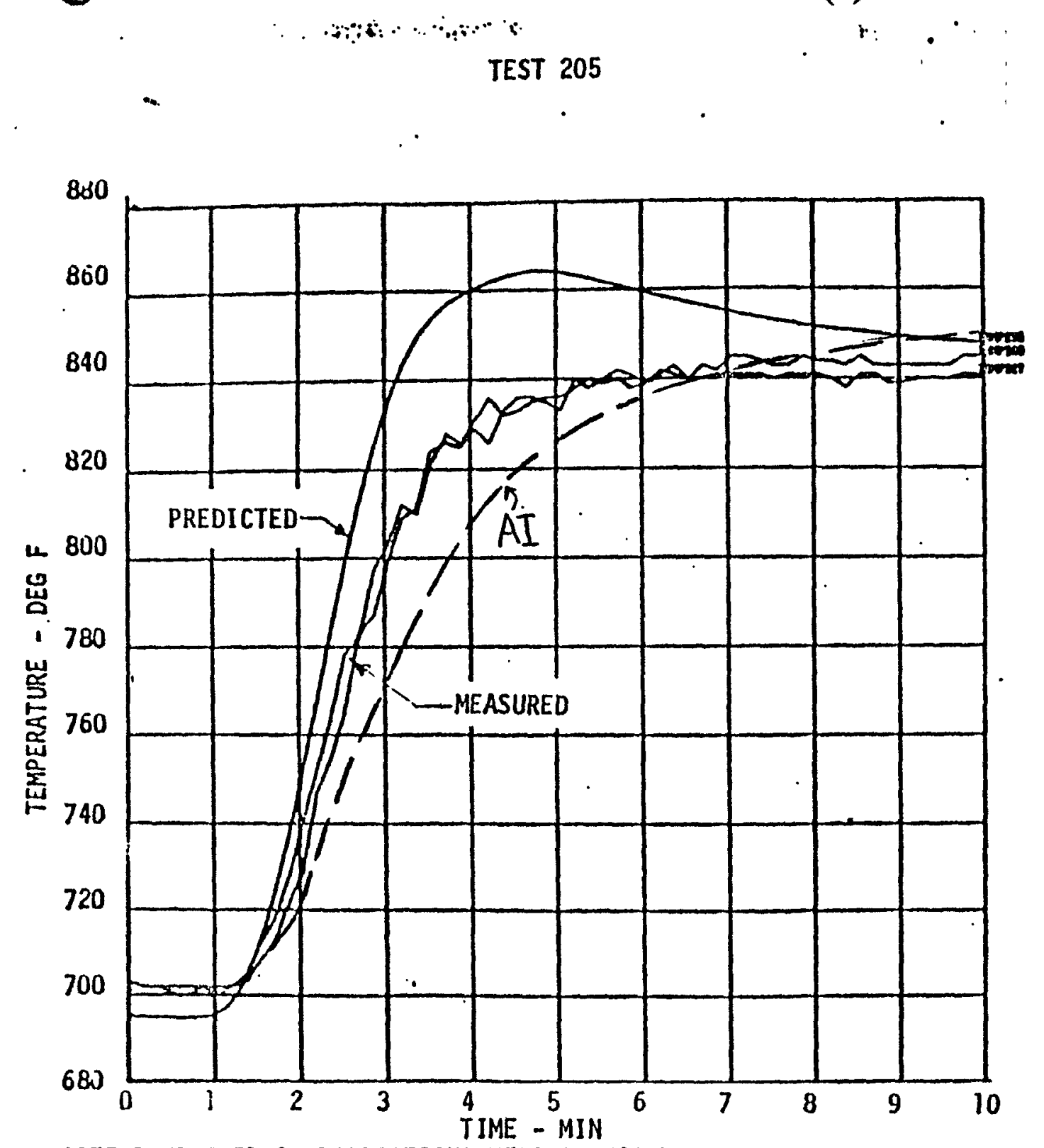

SPTF PUMP THERMAL PREDICTIONS VERSUS MEASUREMENTS-EVENT 205 2/2/77 FIGURE 4

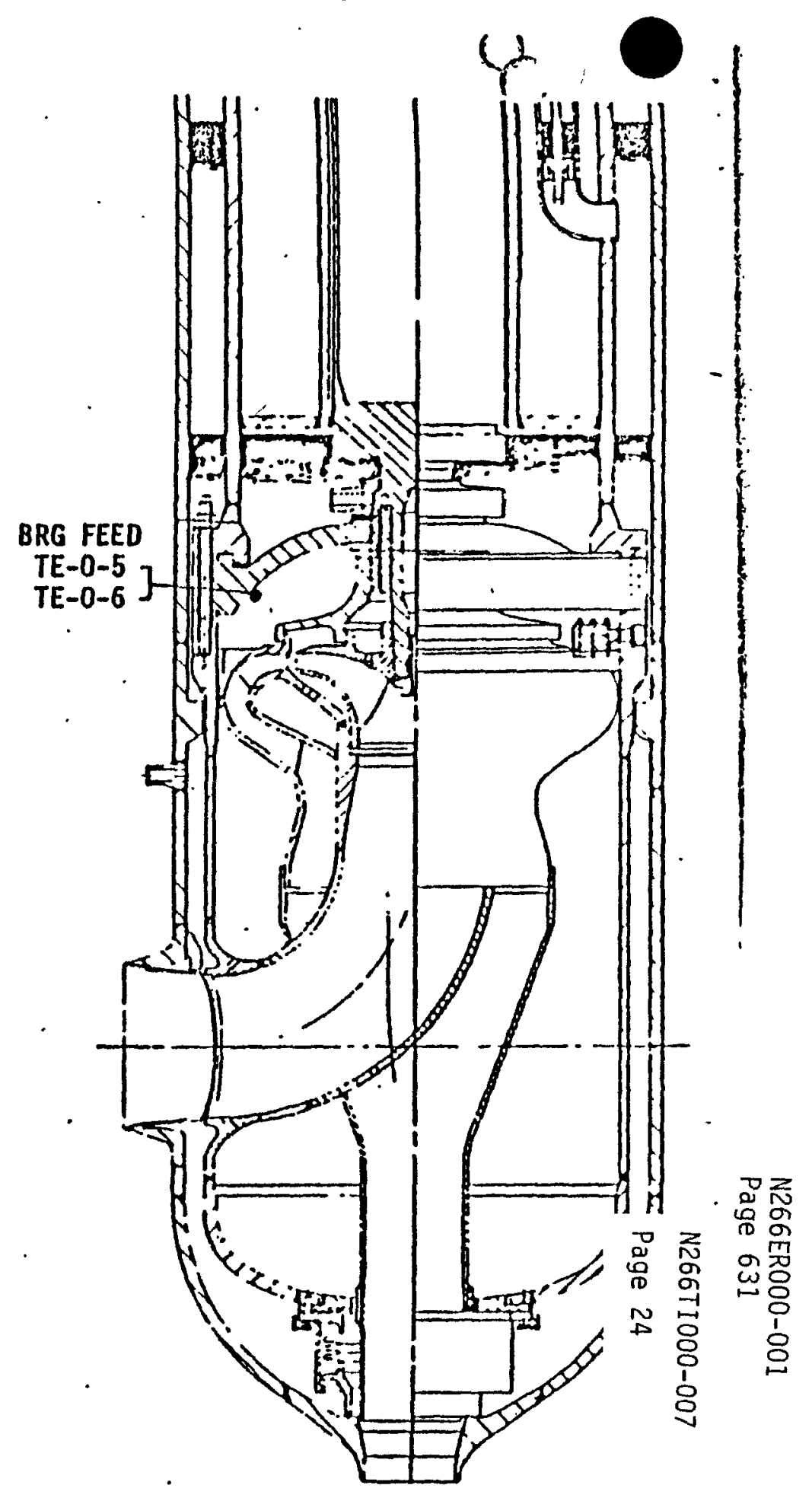

205 


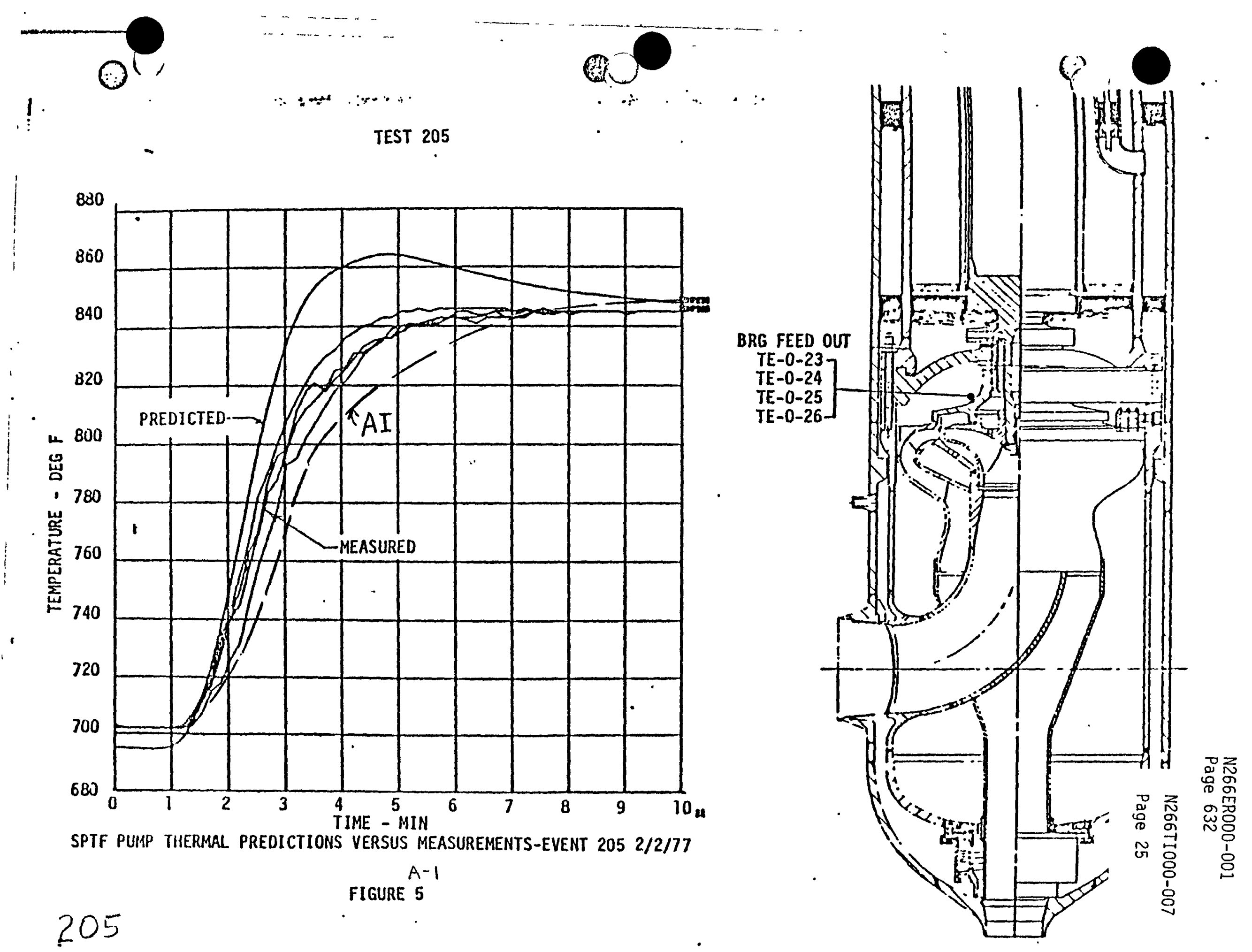



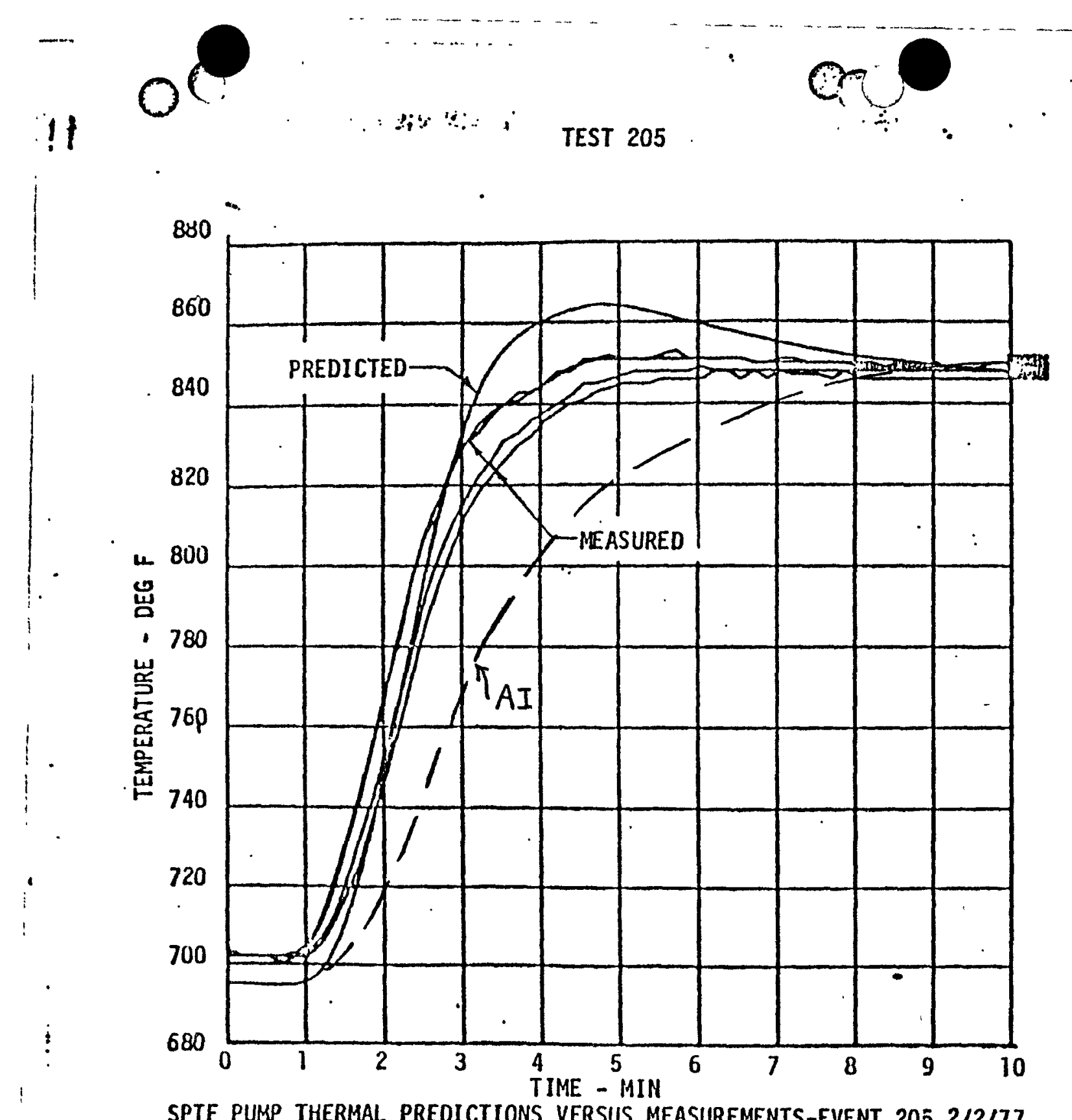

SPTF PUMP THERMAL PREDICTIONS VERSUS MEASUREMENTS-EVENT 205 2/2/77

FIGURE 7

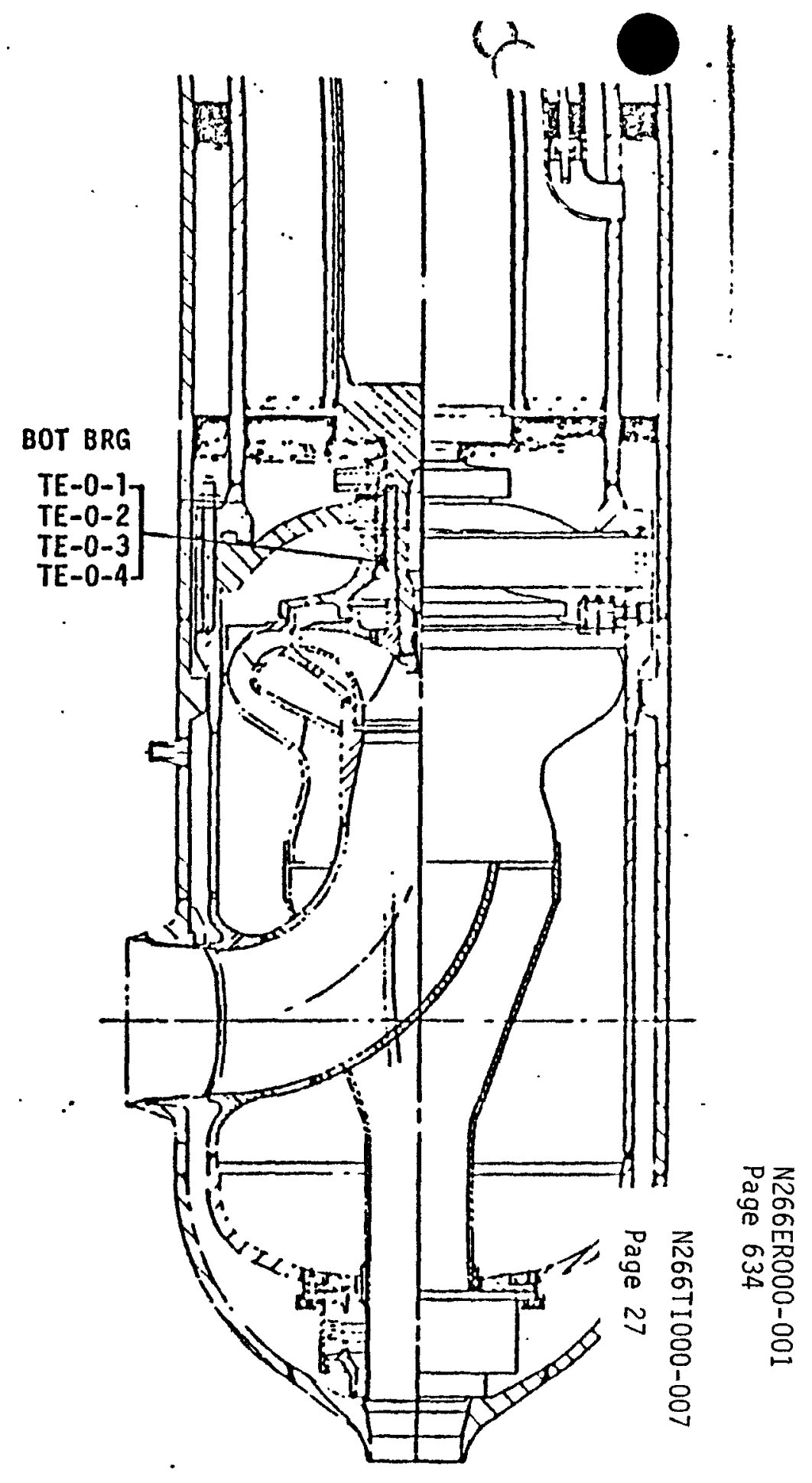


o

TEST 205

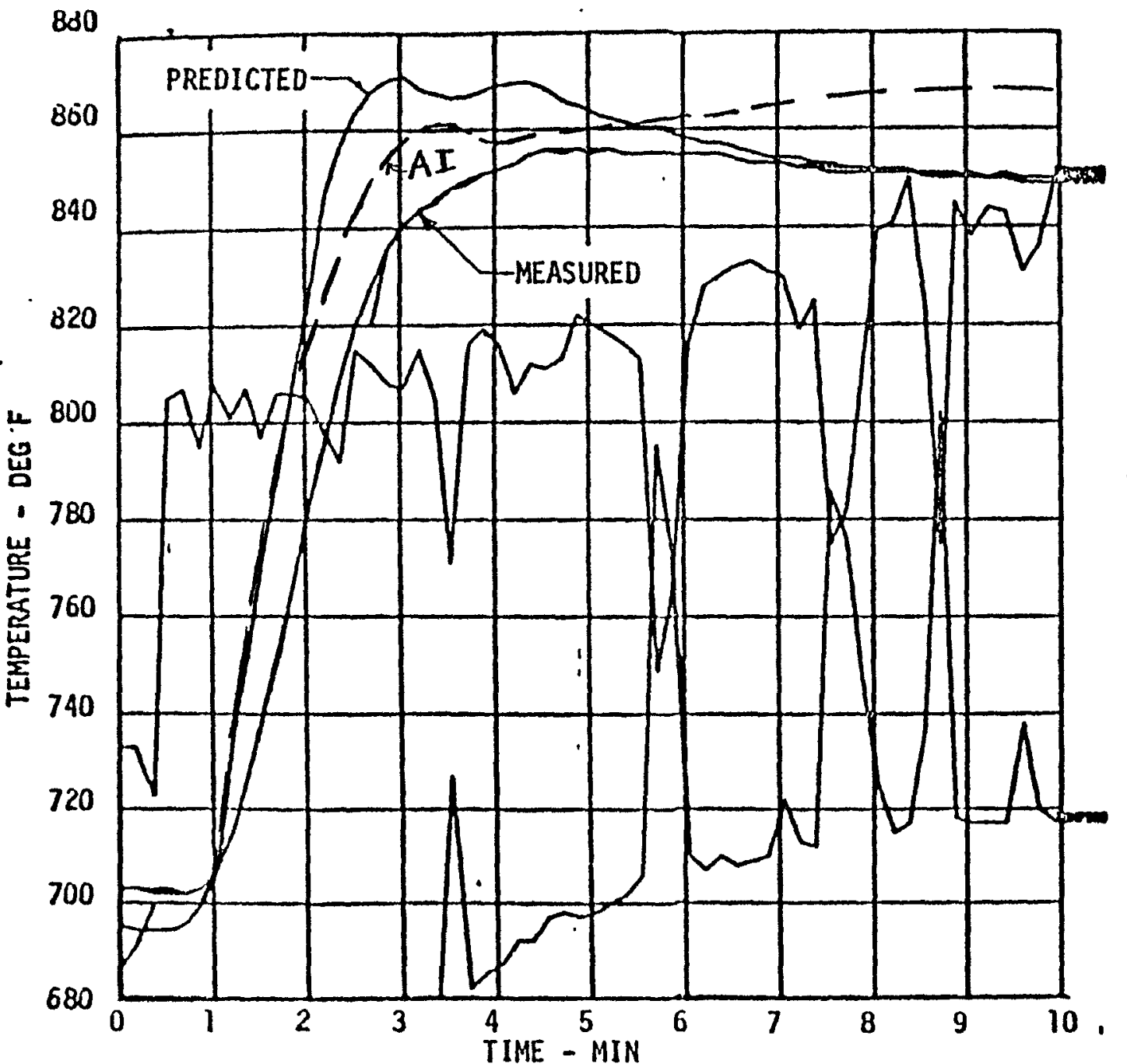

BRG BOT OUT

TE-0-19 J.

TE- $0-21$

TE-0-22

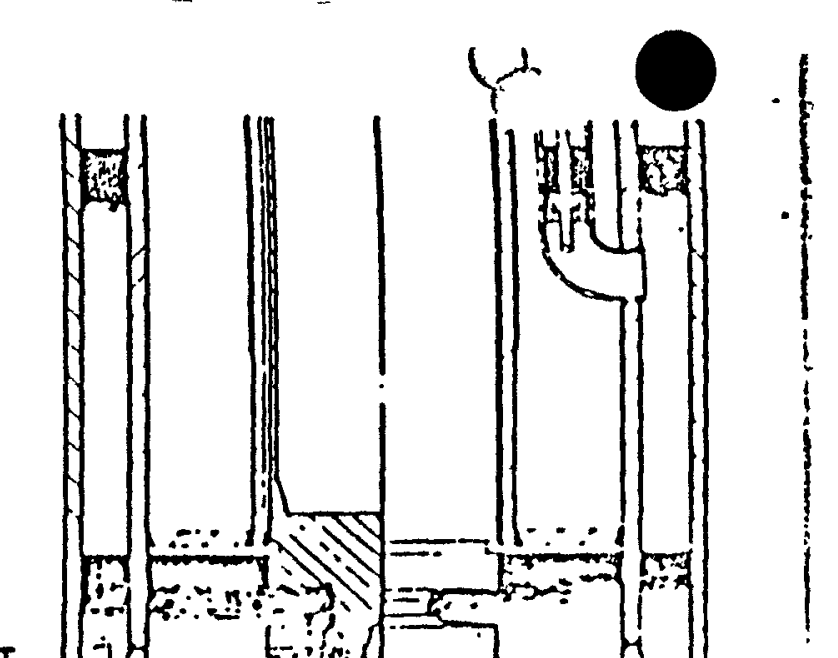

SPTF PUMP THERMAL PREDICTIONS VERSUS MEASUREMENTS-EVENT 205 2/2/77 FIGURE ${ }^{A-1}$

205

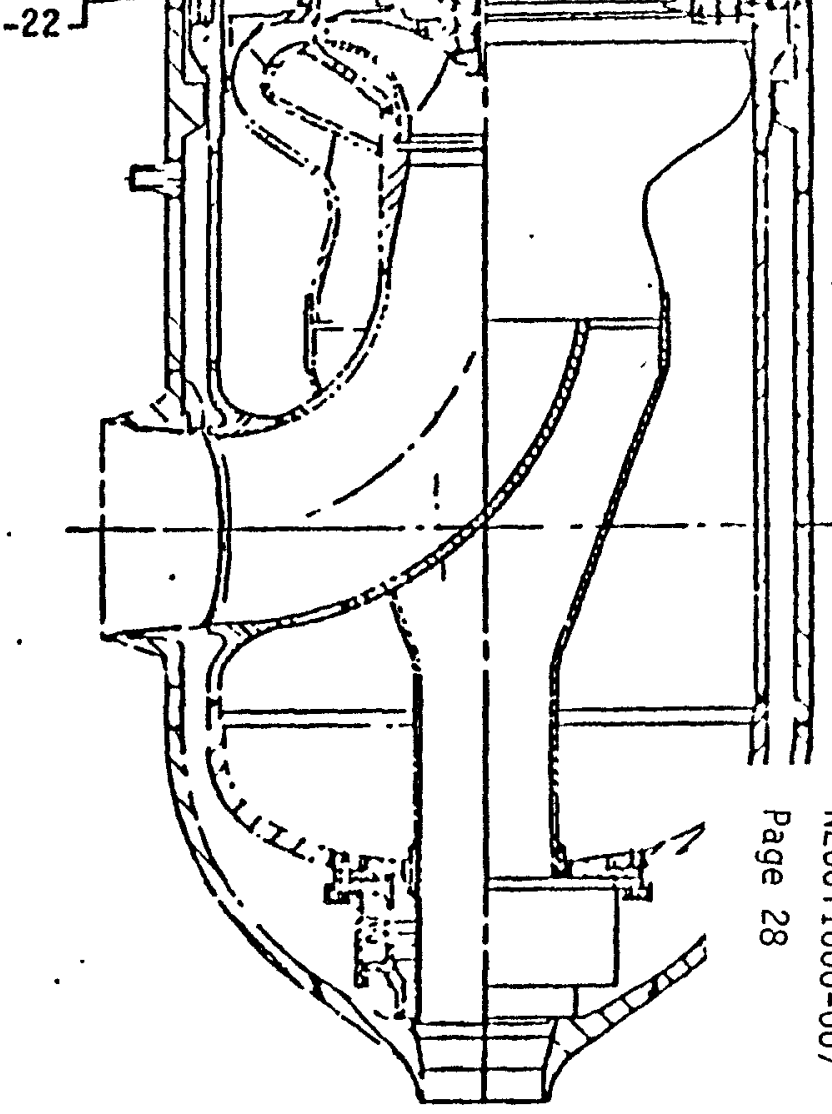

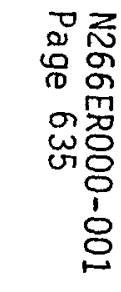
要 
$O^{\prime}$

880
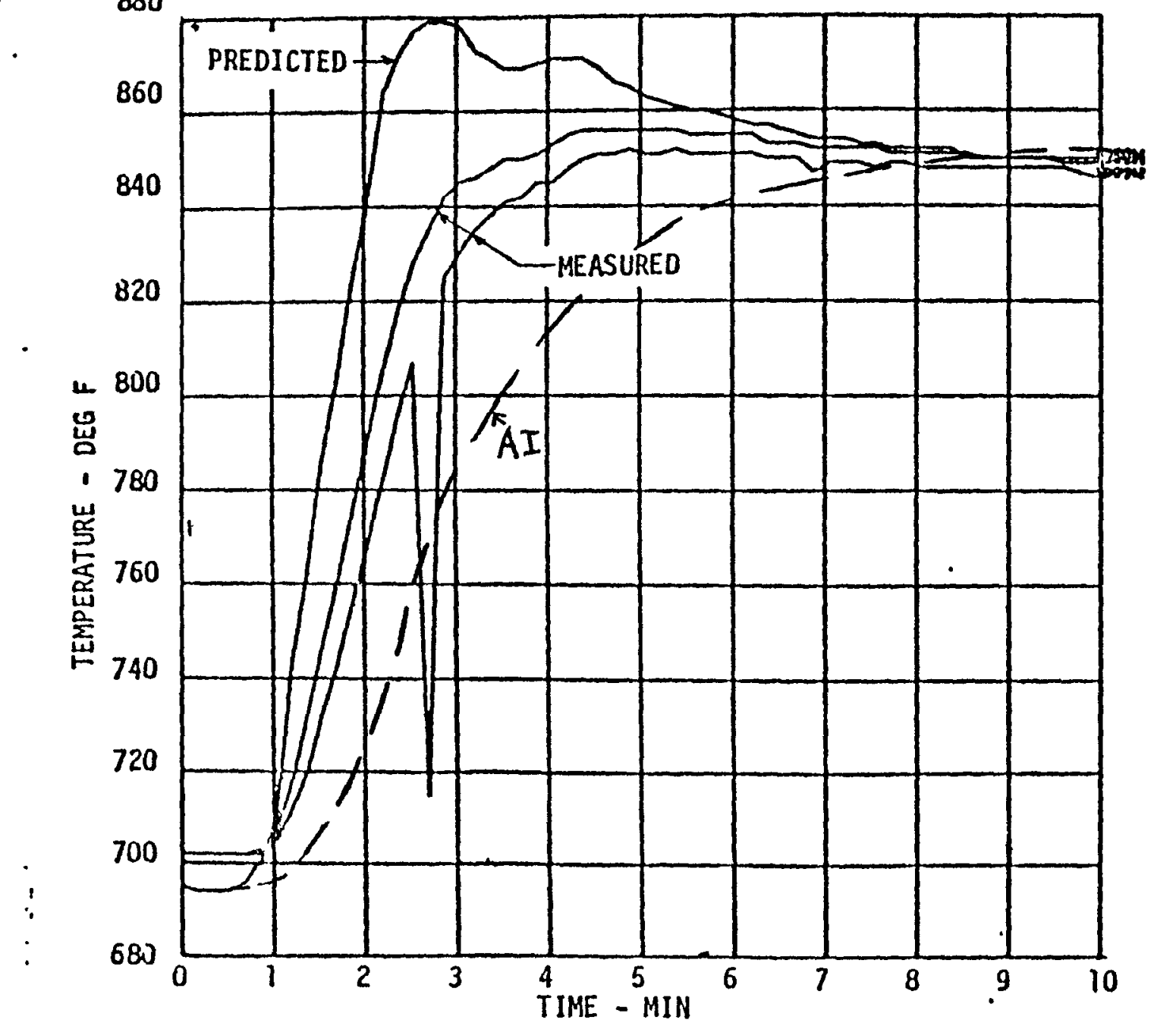

SPIF PUMP THERMAL PREDICTIONS VERSUS MEASUREMENTS-EVENT 205 2/2/77 205

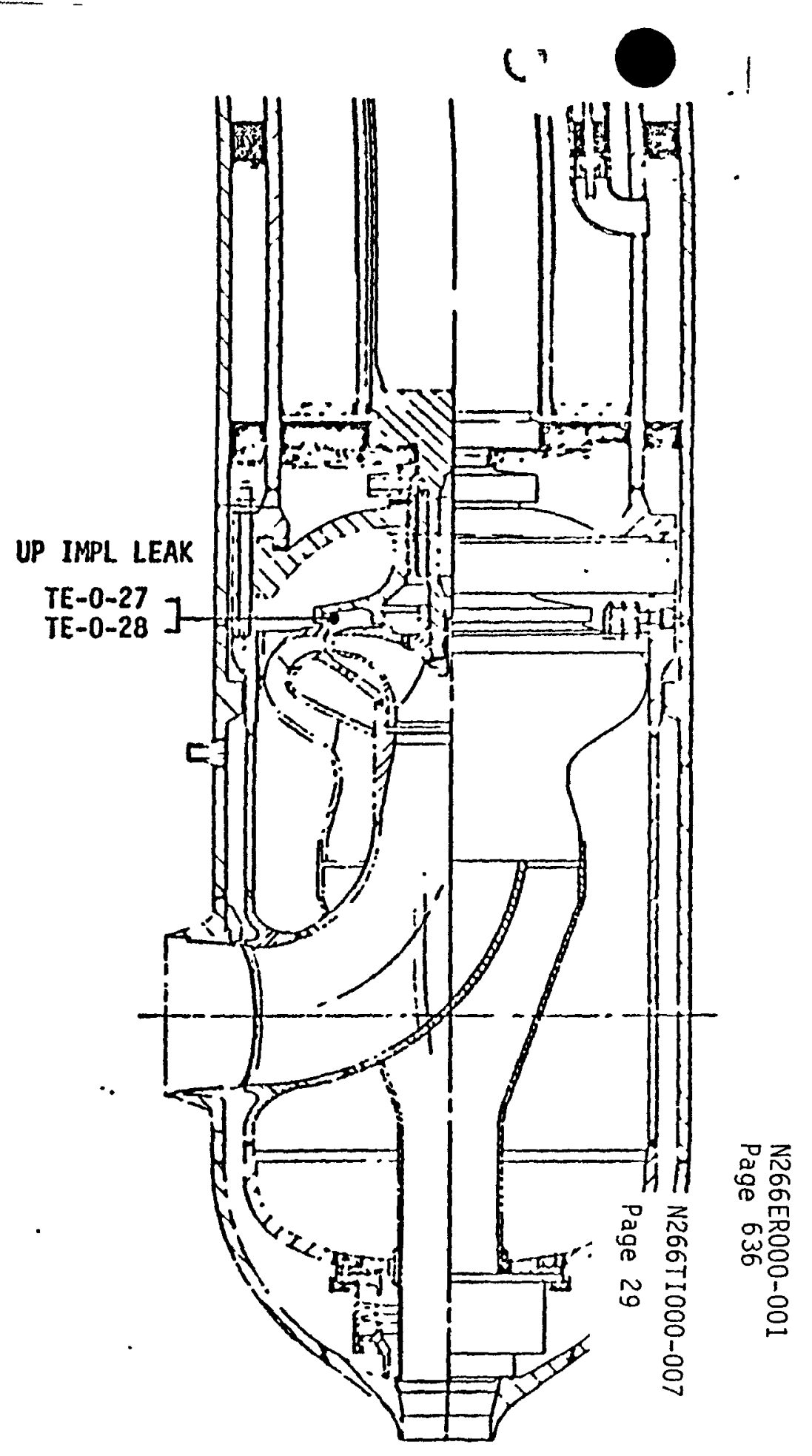


o

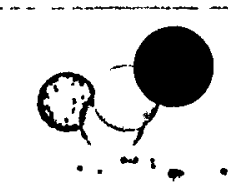

TEST 205

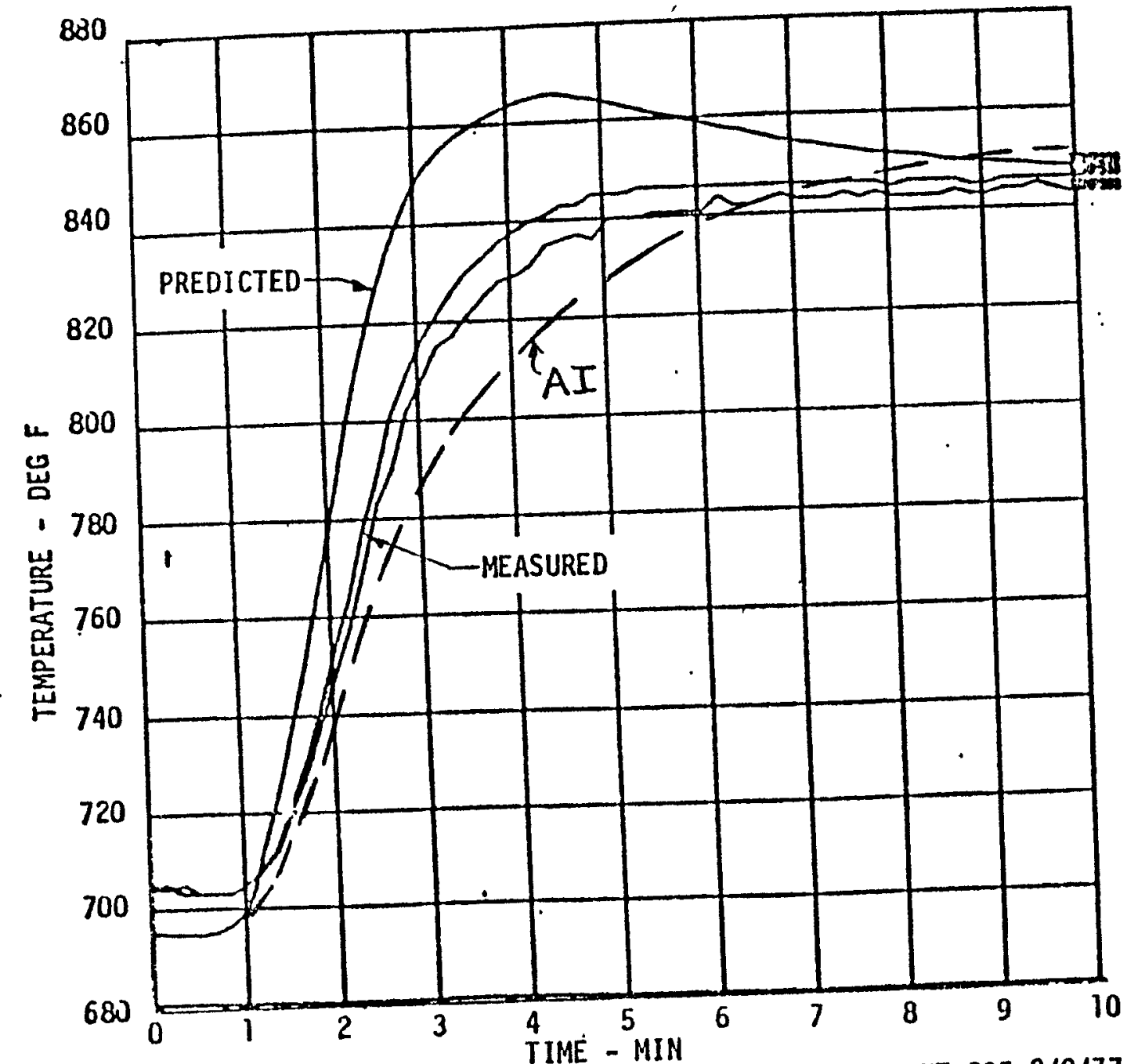

BRG OUT TOP

Hit $\left.\begin{array}{l}\text { TE-0-7 } \\ \text { TE-0-8 }\end{array}\right]$

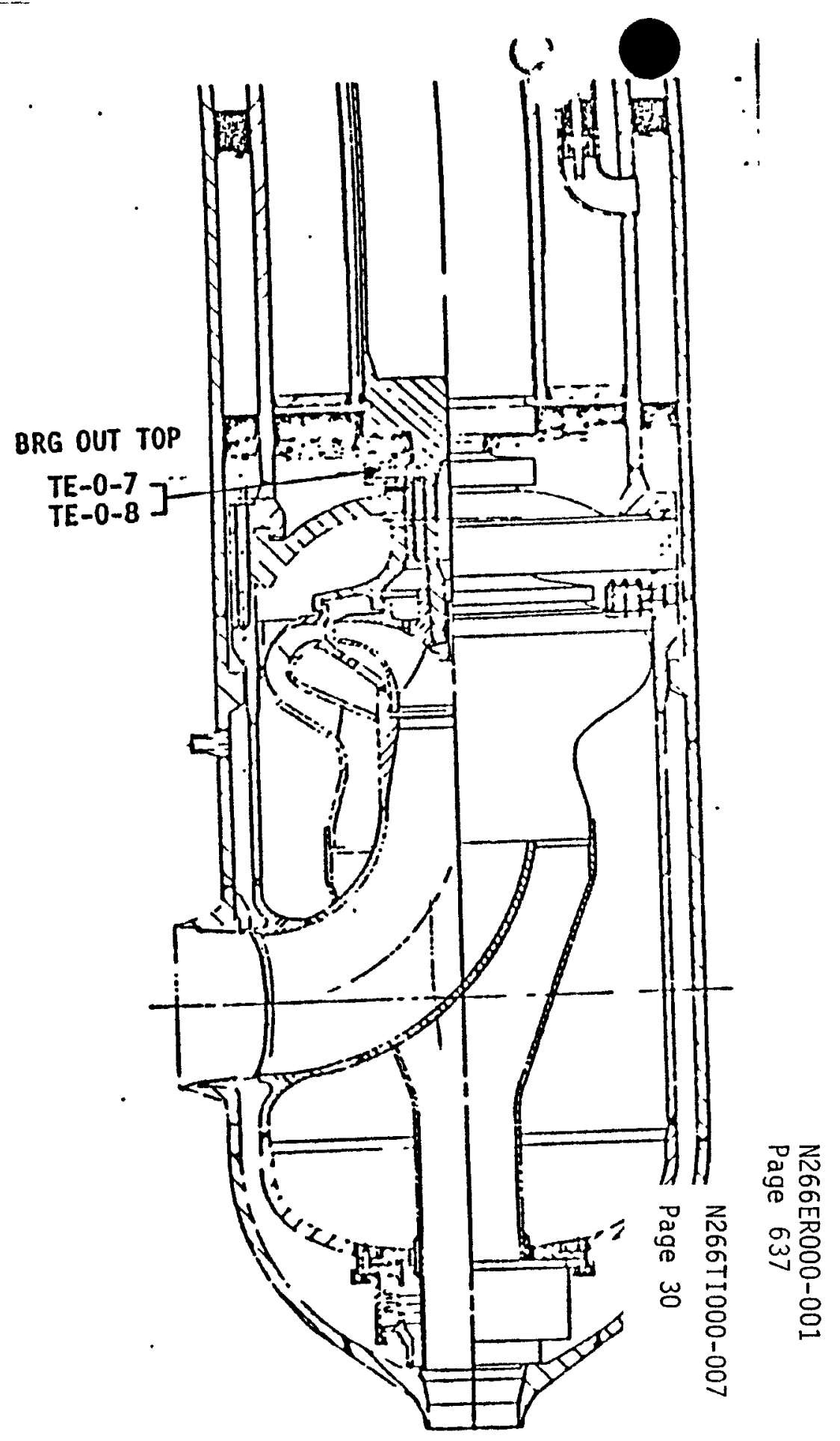
SPTF PUMP TIERMAL PREDICTIONS VERSUS MEASUREMENTS-EVENT 205 2/2/77 $A-1$ FIGURE 10 205 


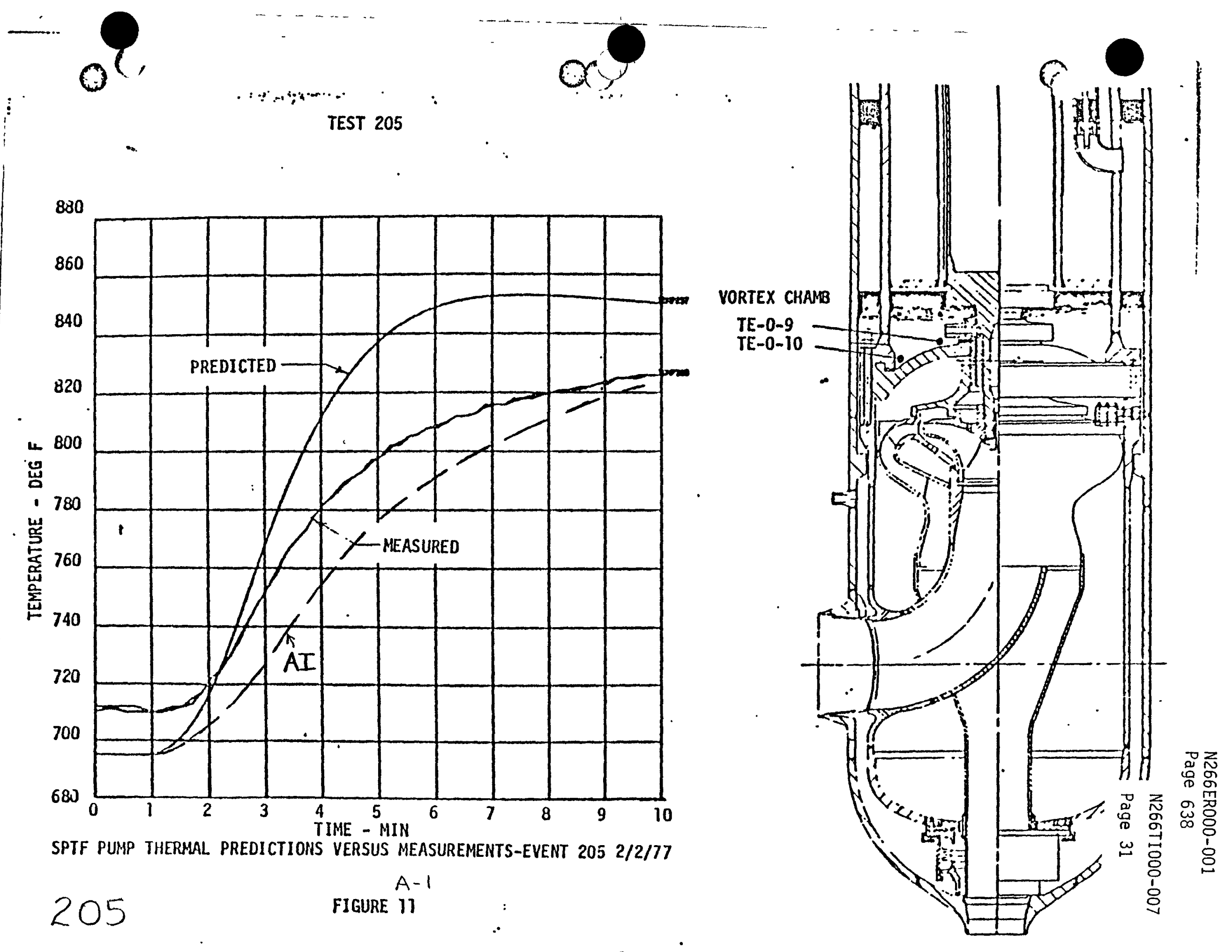




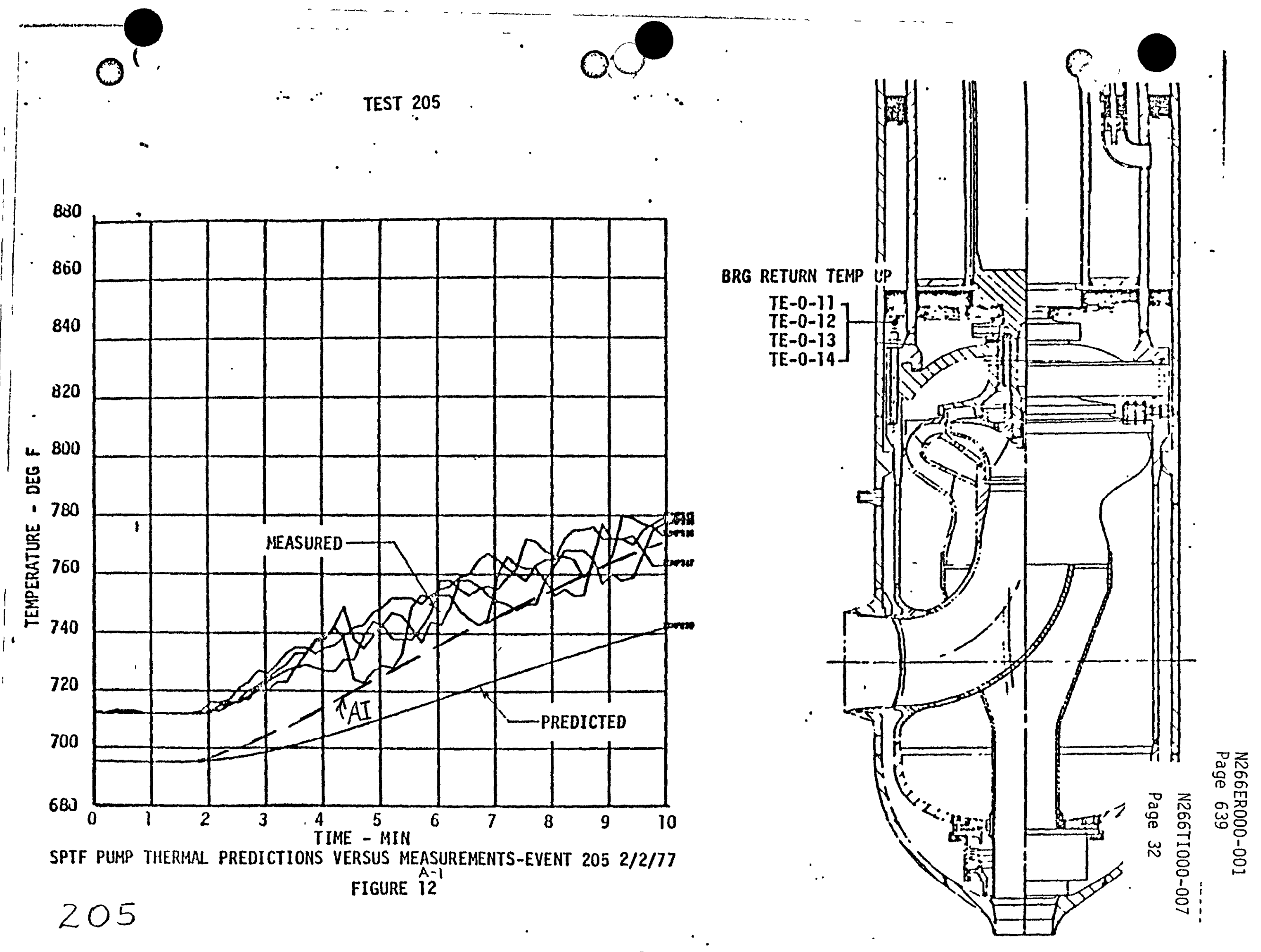




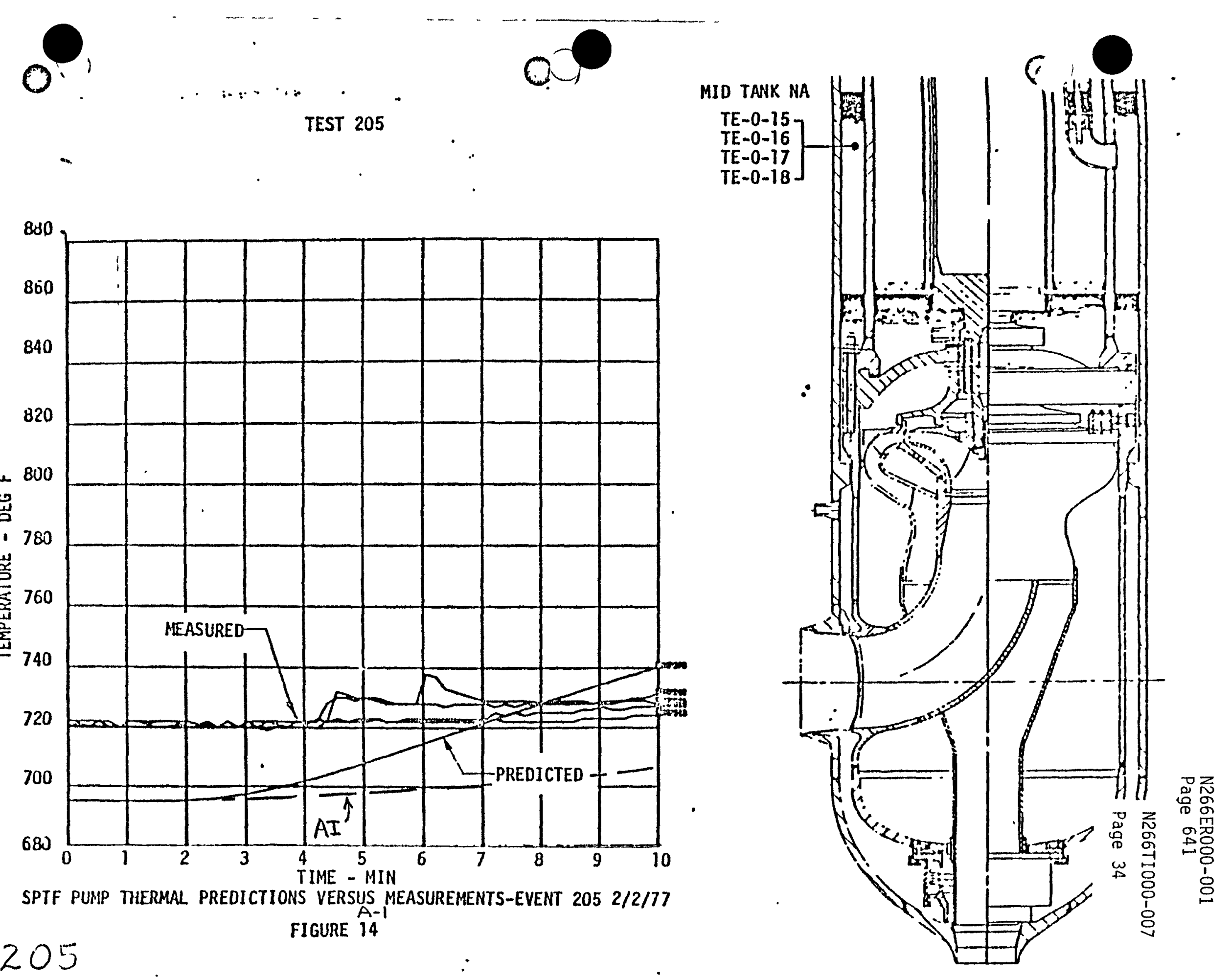

\section{5}




\section{APPENDIX A-2}

TRANSIENT 207-TEST 

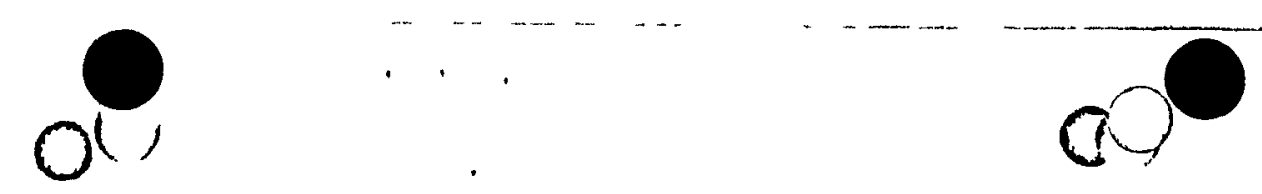

TEST 207

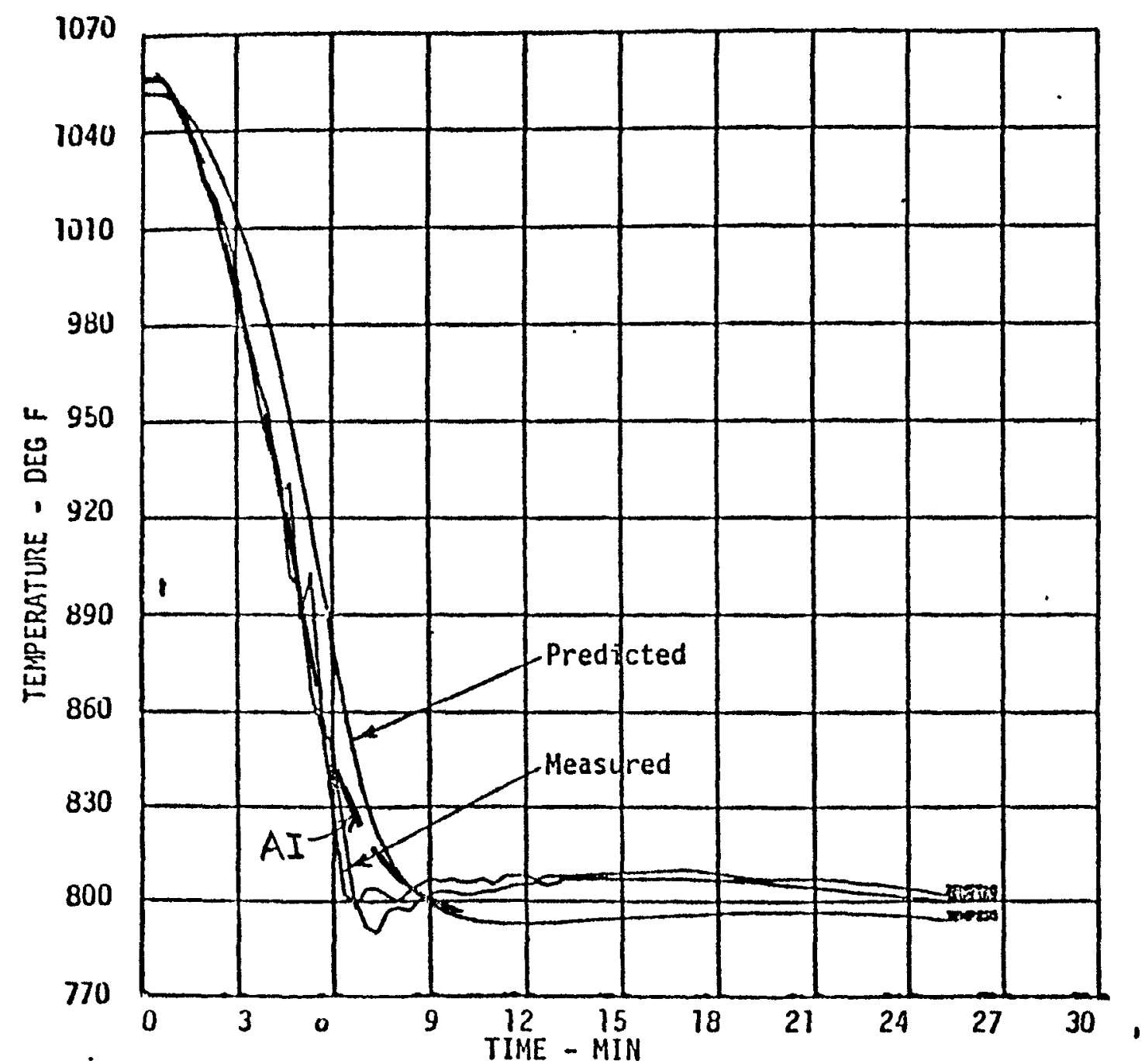

SPTF PUMP THERMAL PREDICTIONS VERSUS MEASUREMENTS-EVENT 207 2/24/77 $A-2$ FIGLRE I

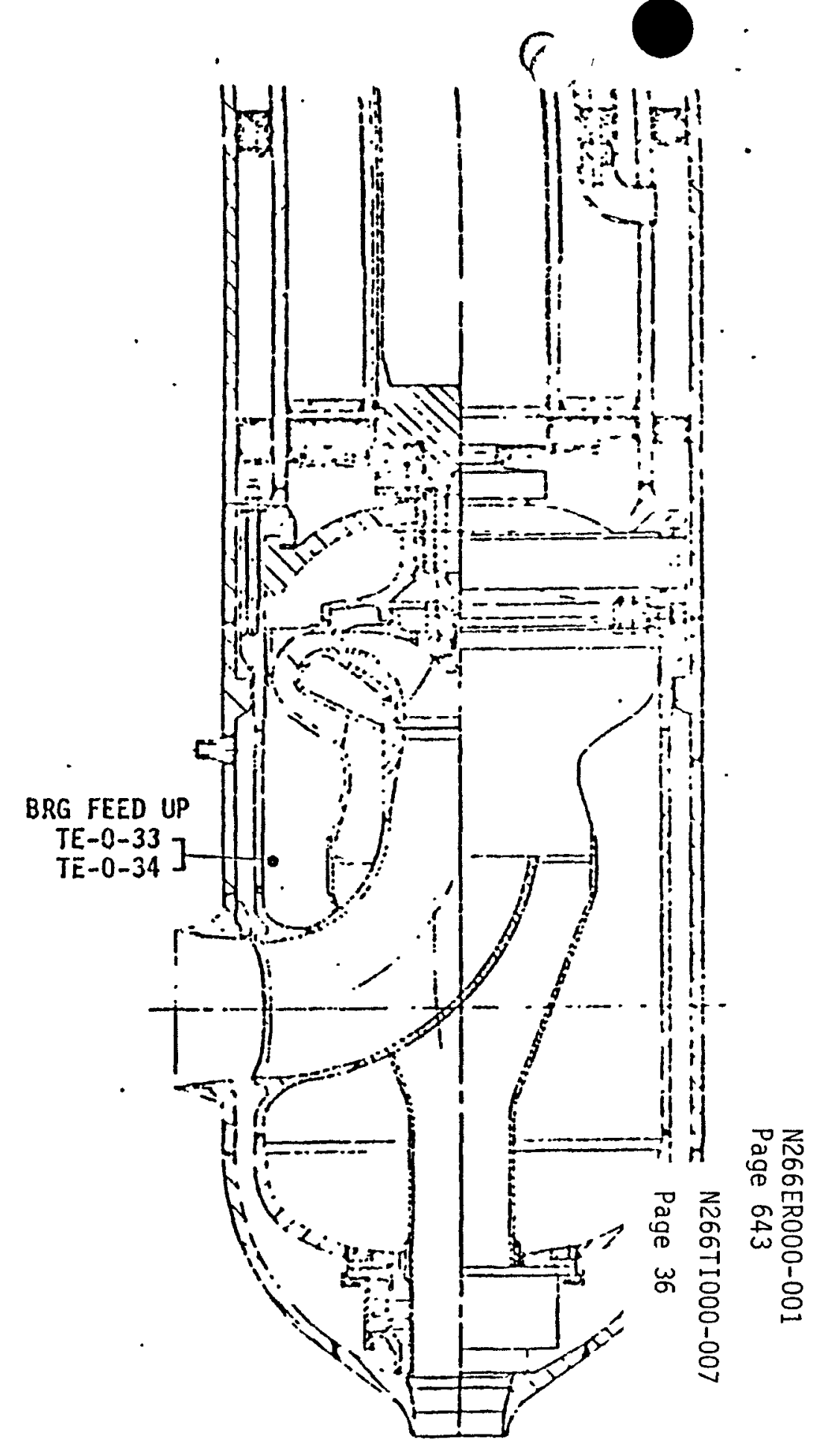

\section{7}




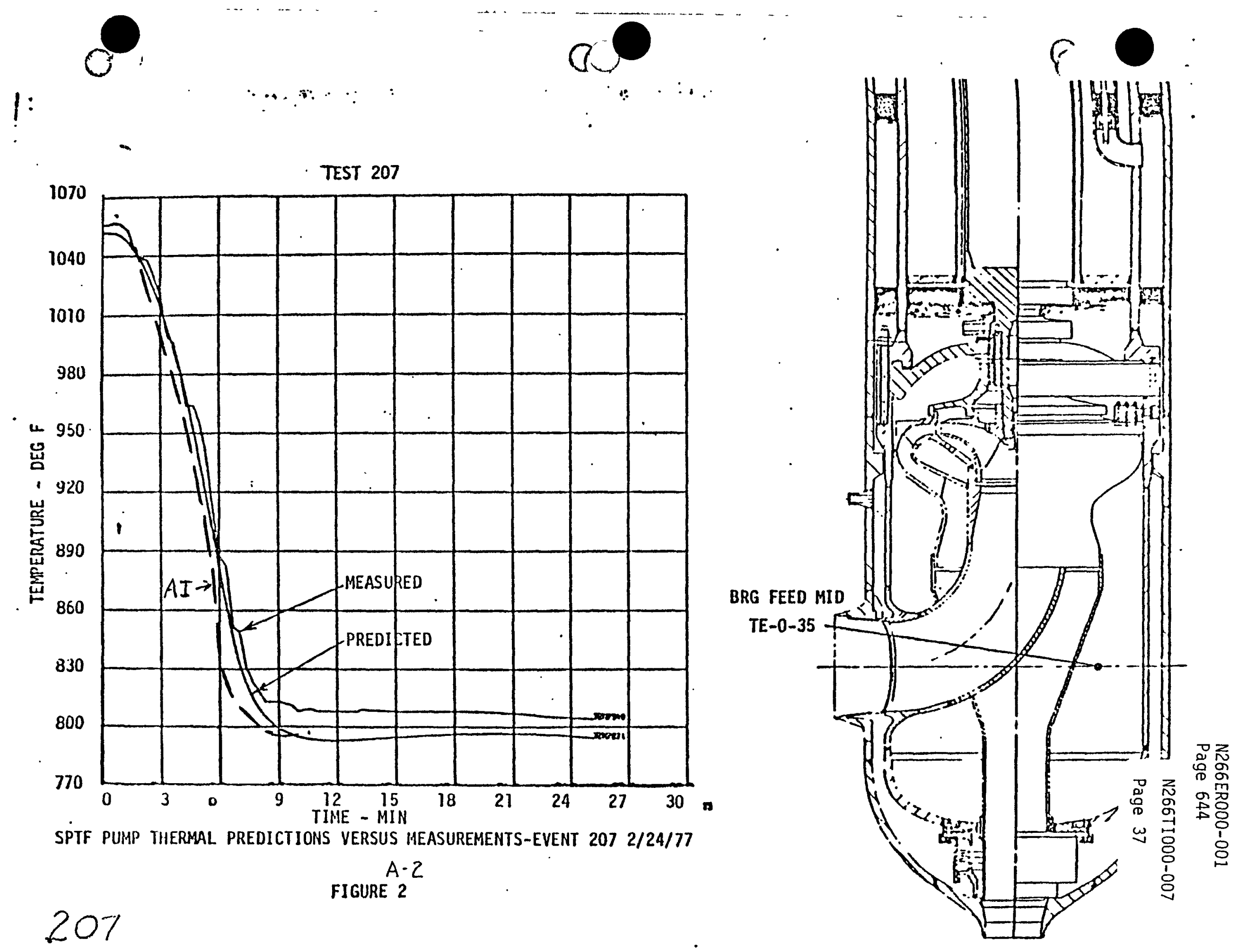


TEST 207

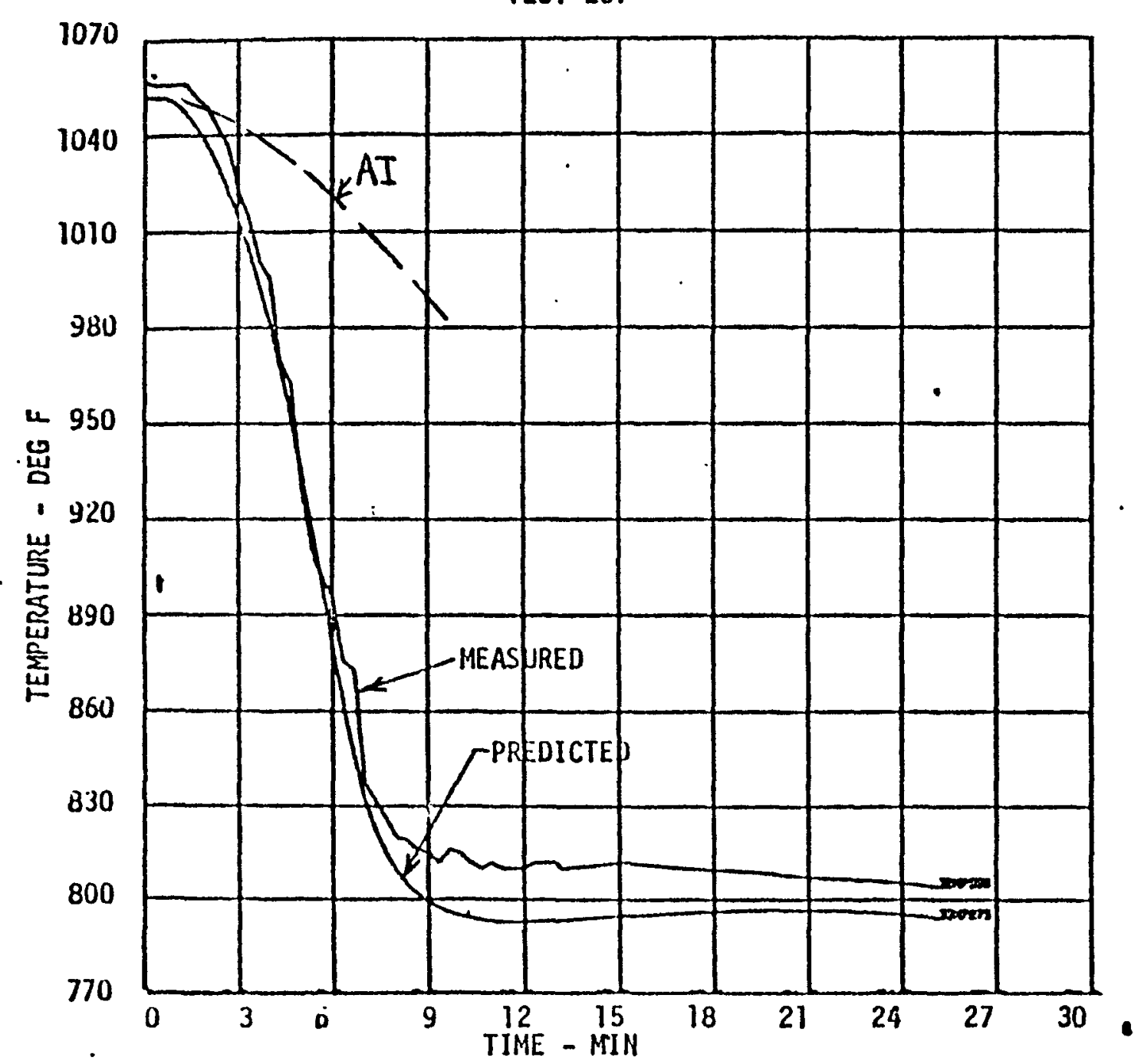

SPTF PUMP THERMAL PREDICTIONS VERSUS MEASUREMENTS-EVENT. 207 2/24/77 FIGURE 3

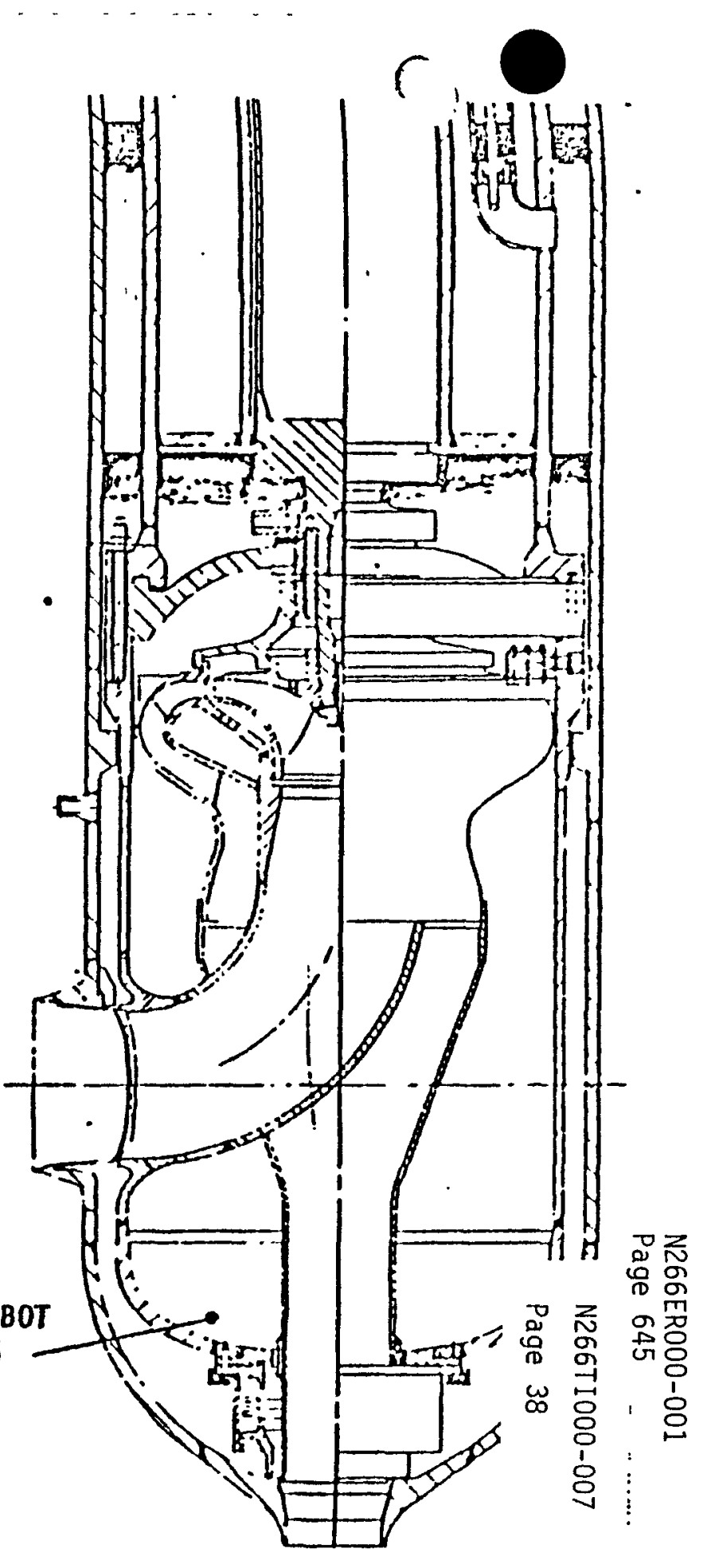

BRG FEED BOT 
$0^{\circ}$

!

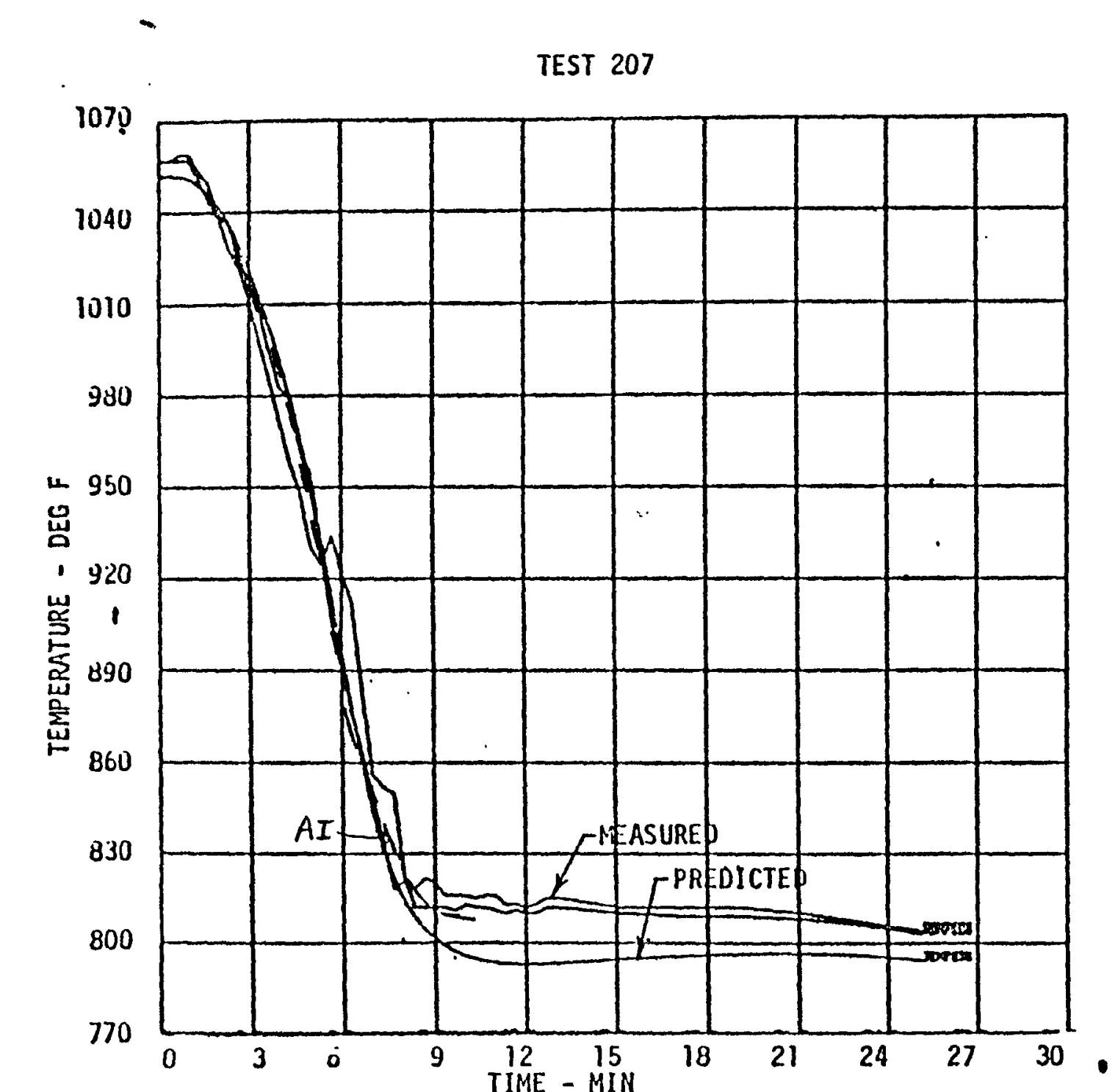

SPIF PUAP THERMAL PREOICTIONS VERSUS MEASUREMENTS-EVENT 207 2/24/77

FIGURE 4 $a$
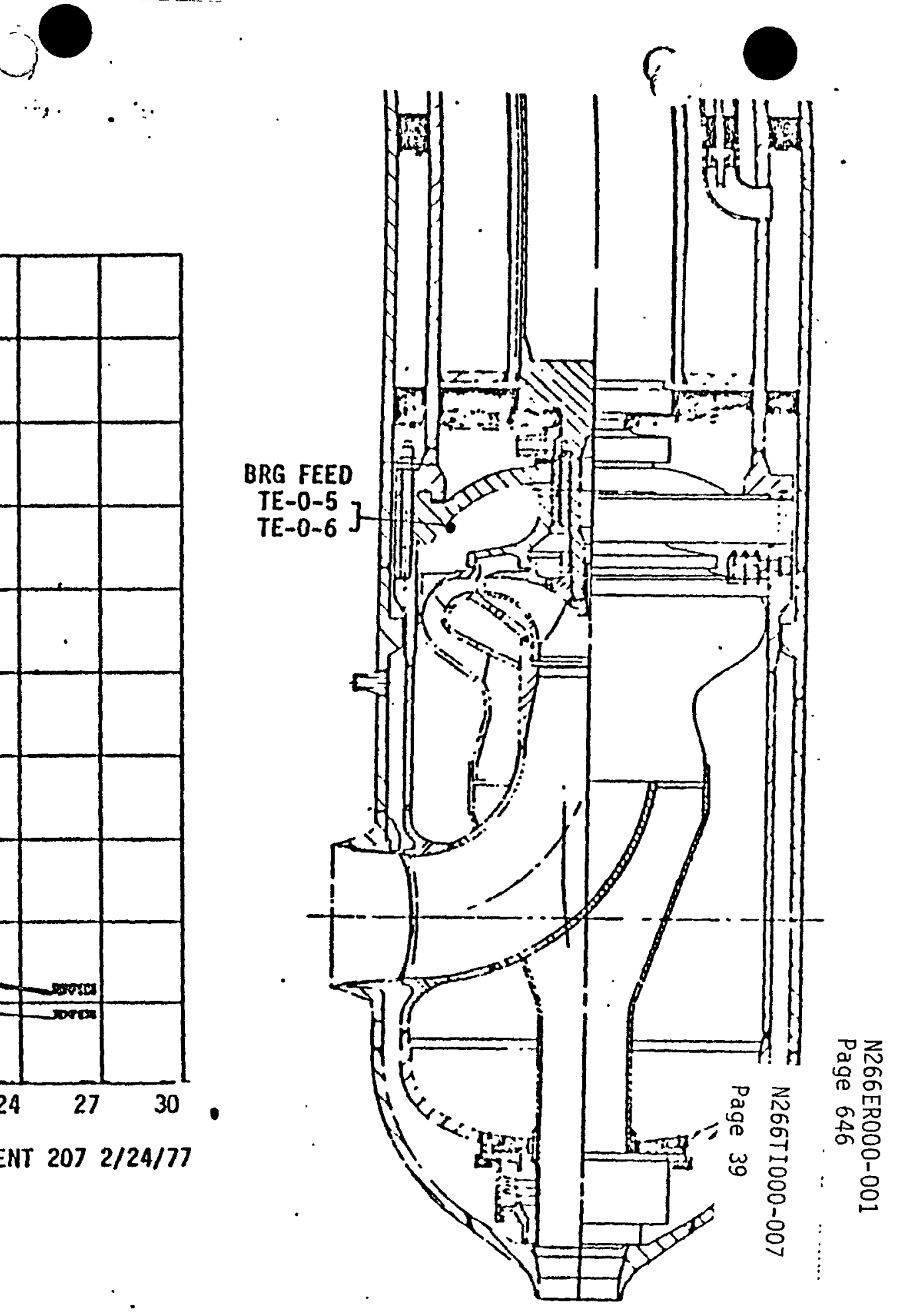
de

1.

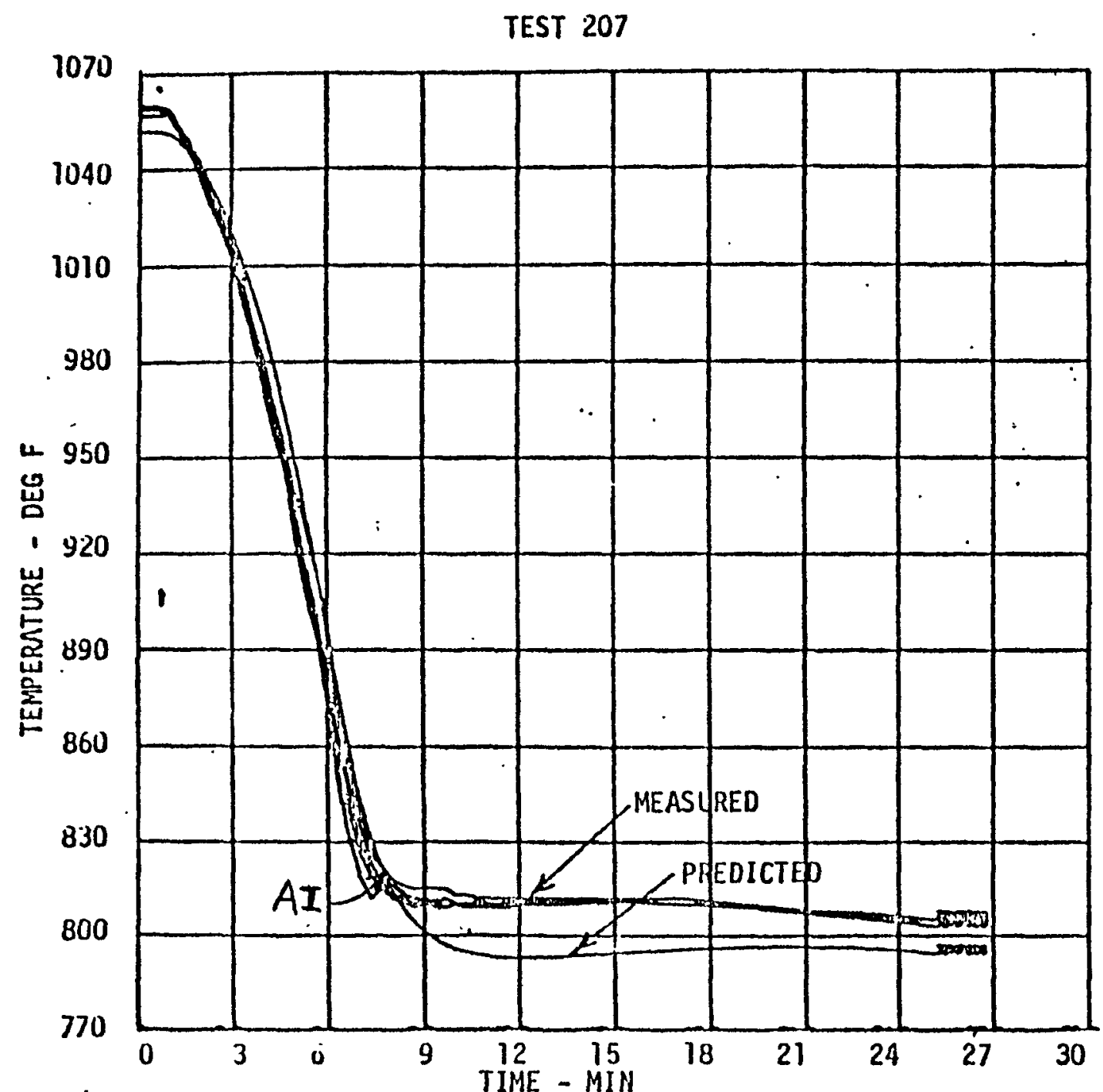

SPTF PUMP THERMAL PREDICTIONS VERSUS MEASUREMENTS-EVENT 207 2/24/77 FIGURE ${ }^{A-2}$

- 207
BRG FEED OUT

TE-0-23 TE-0-24

TE-0-25

$T E-0-26]$

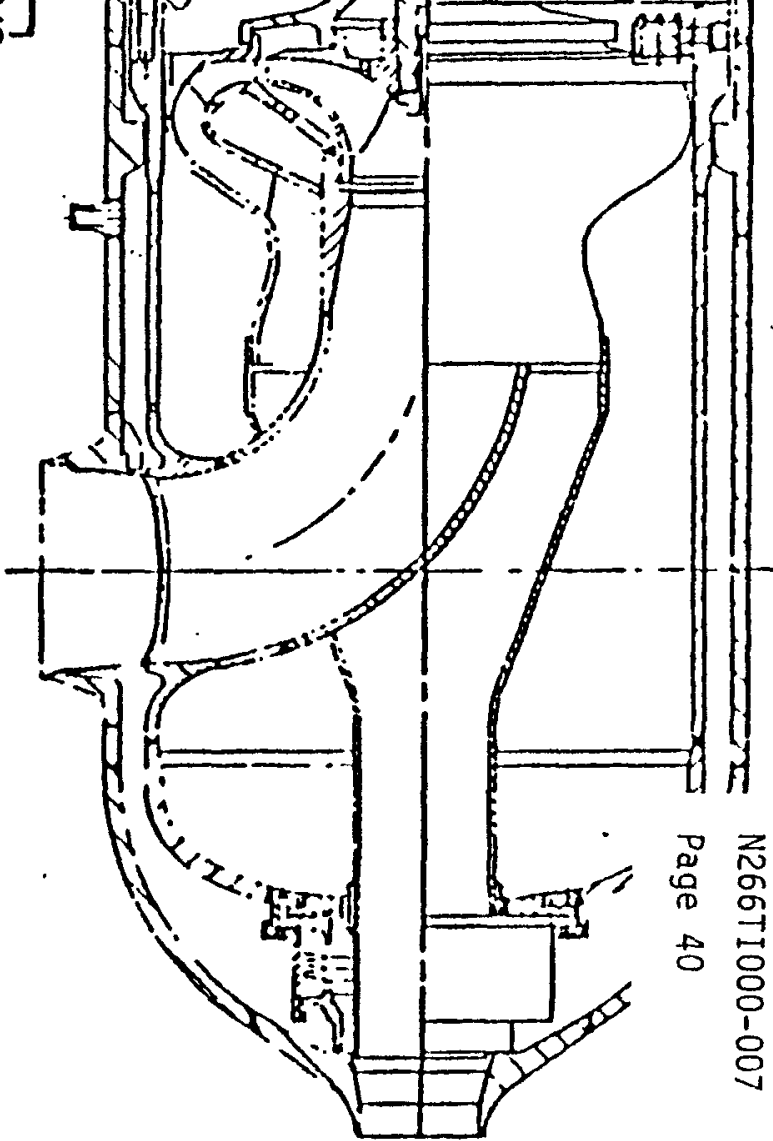

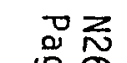

家

잃

웅 


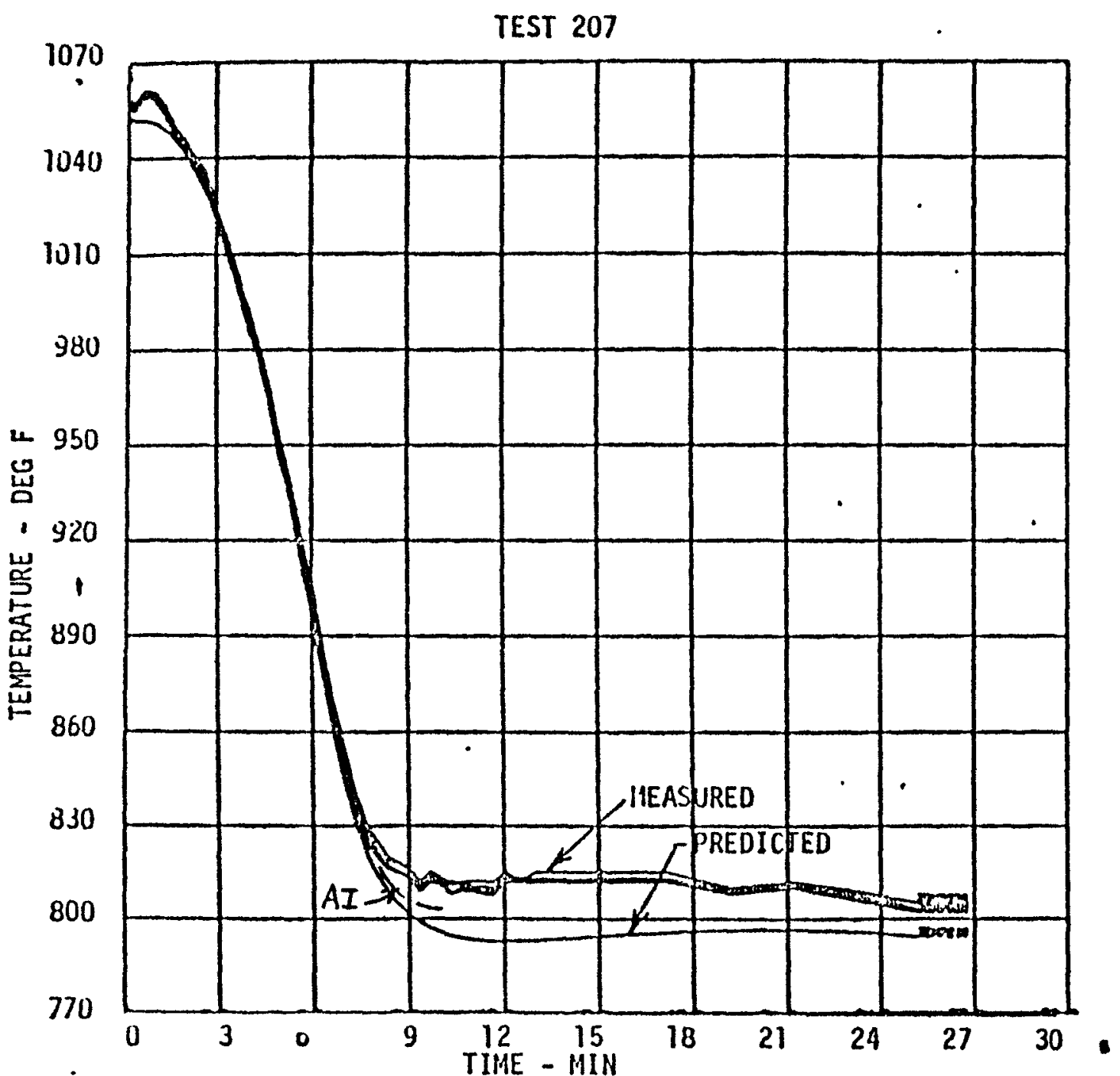

SPTF PUMP THERMAL PREDICTIONS VERSUS MEASUREMENTS-EVENT 207 2/24/77

$$
A-2
$$

FIGURE 6

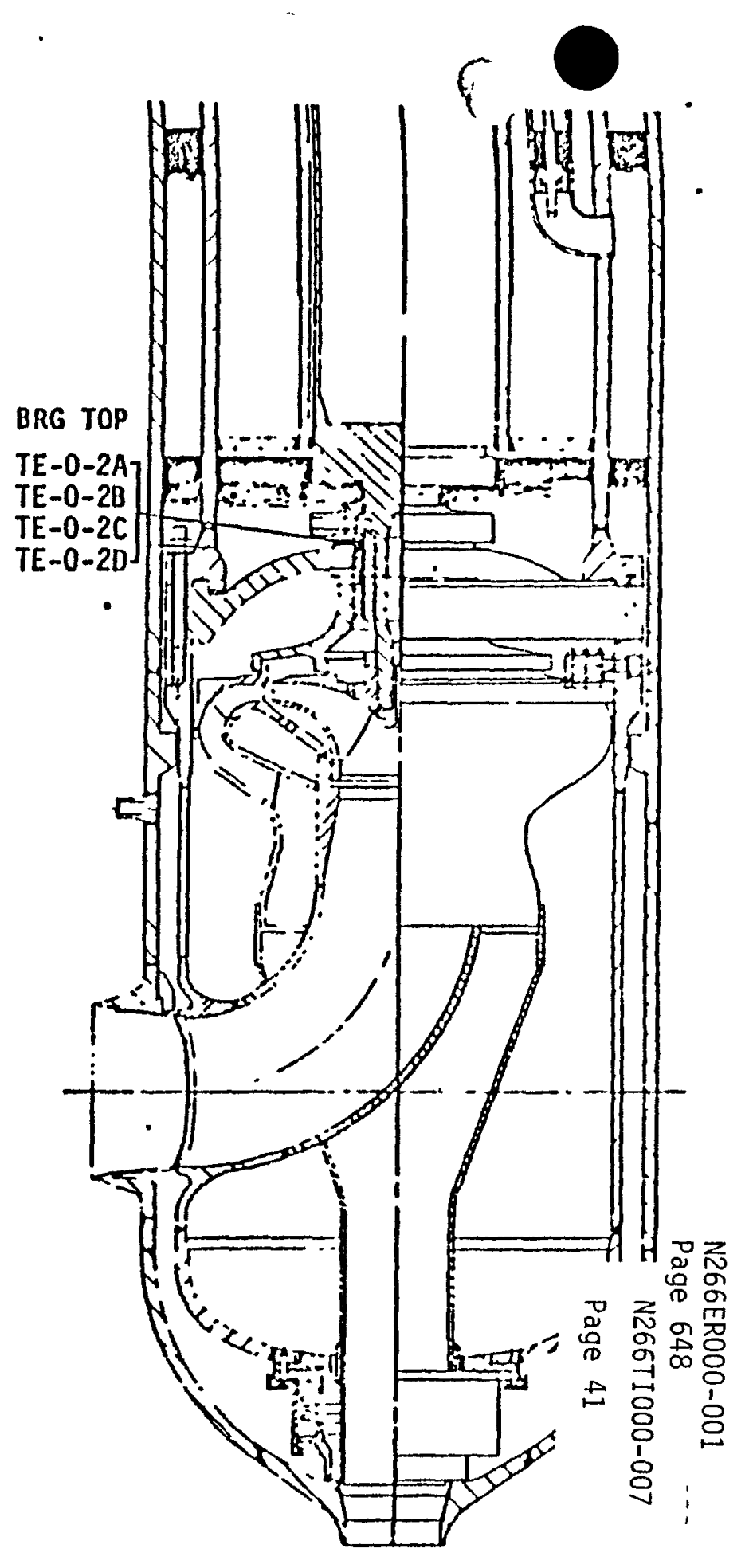



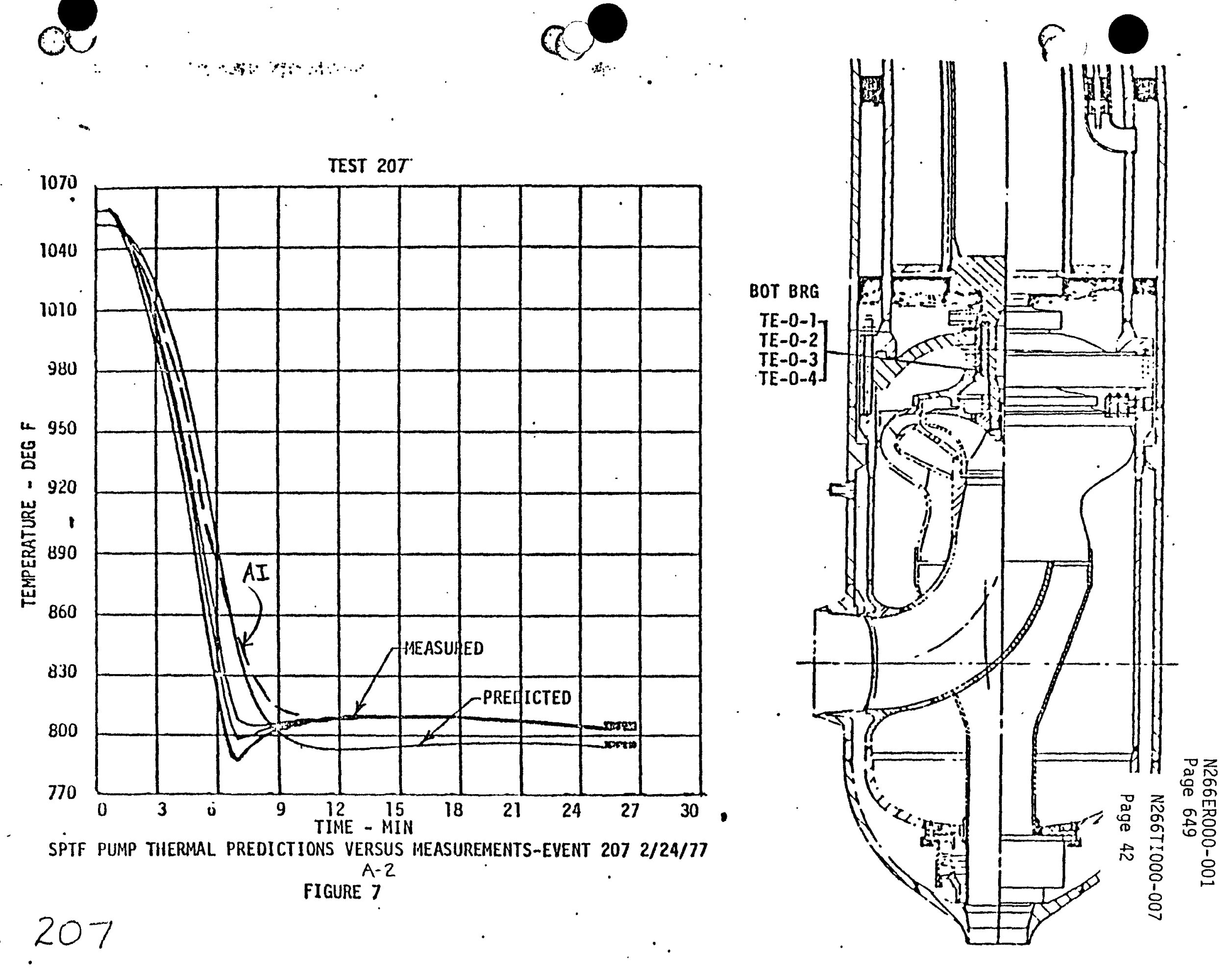

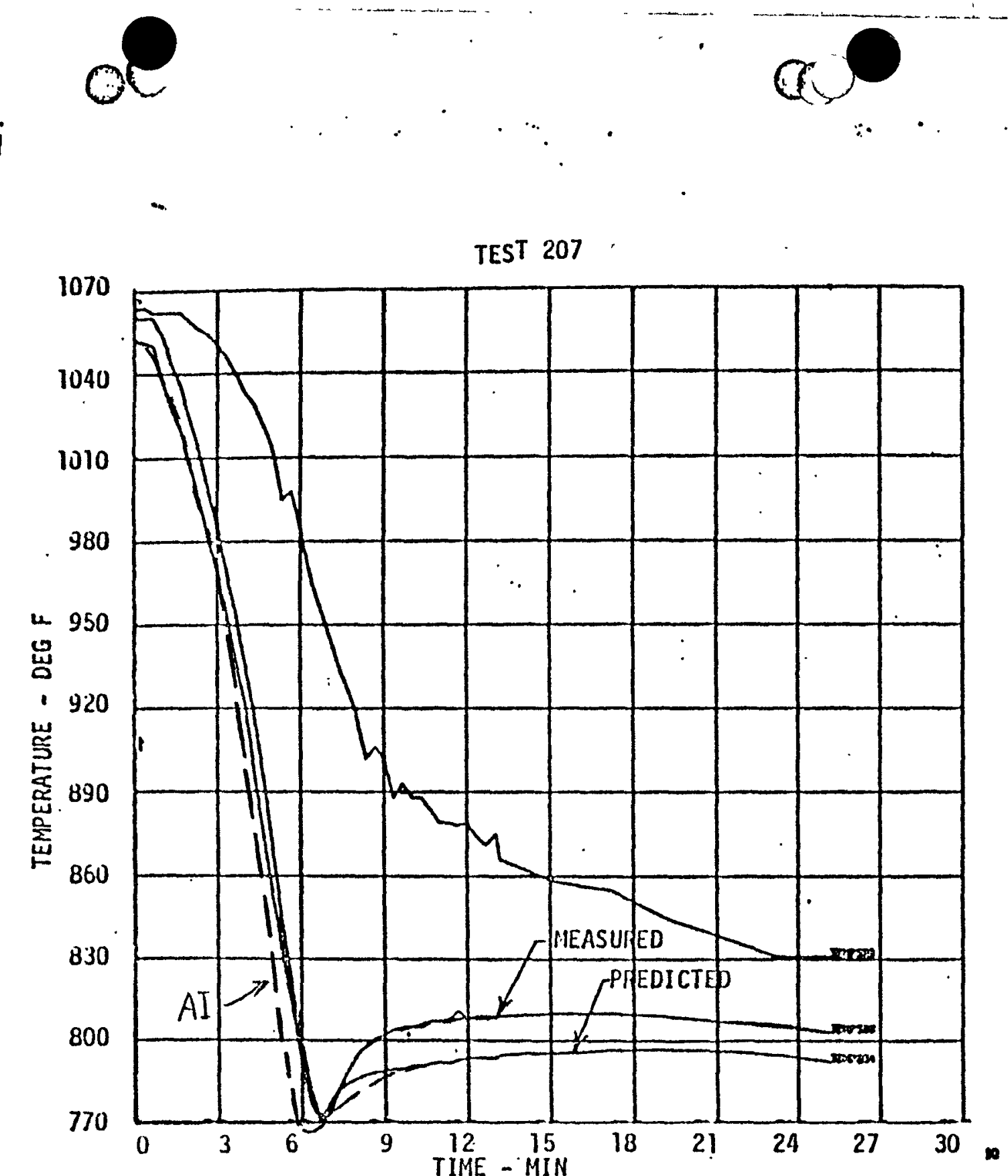

SPTF PUMP THERMAL PREDICTIONS VERSUS MEASUREMENTS-EVENT 207 2/24/77 FIGURE 8

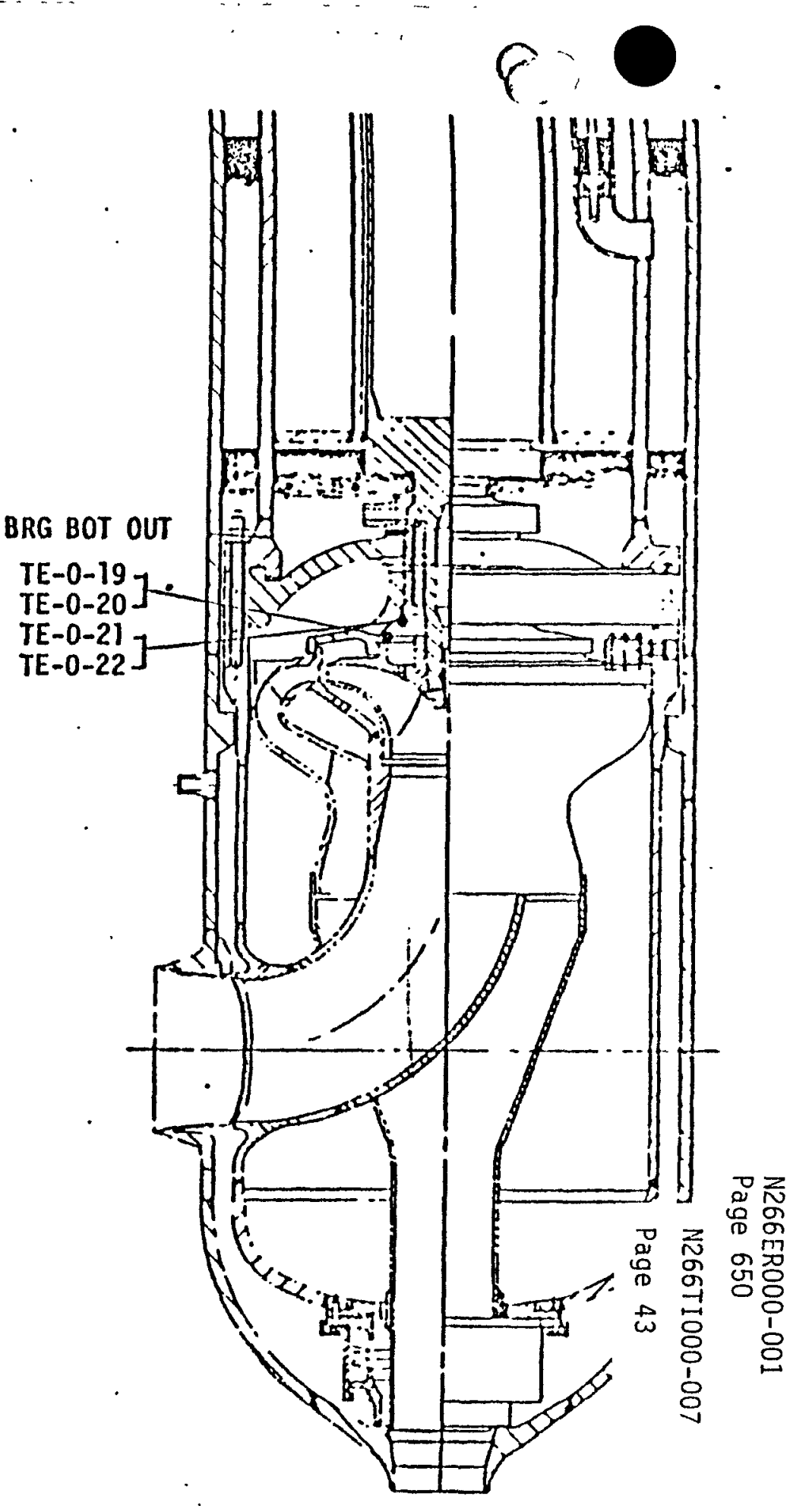




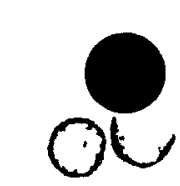

$a$
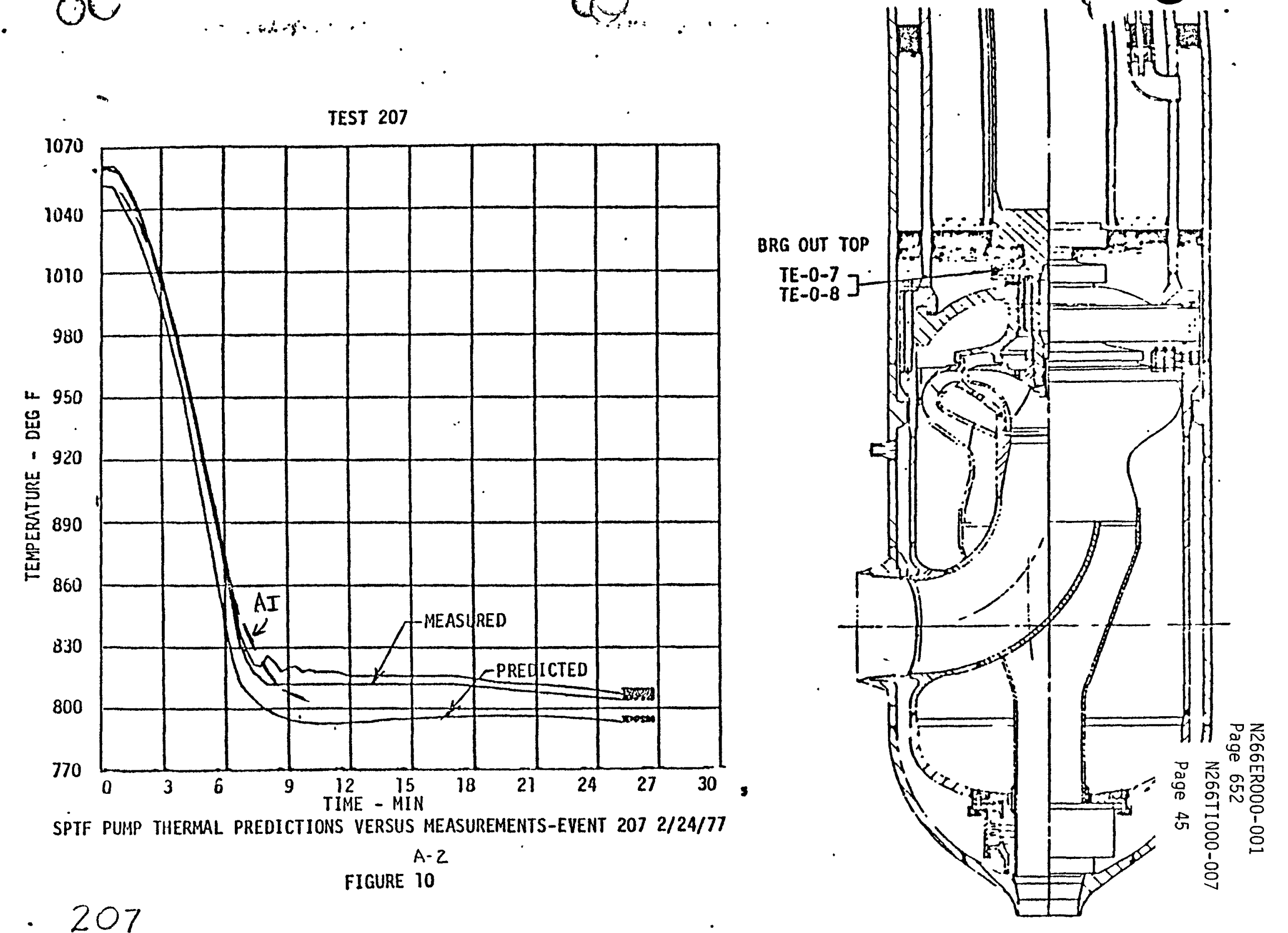


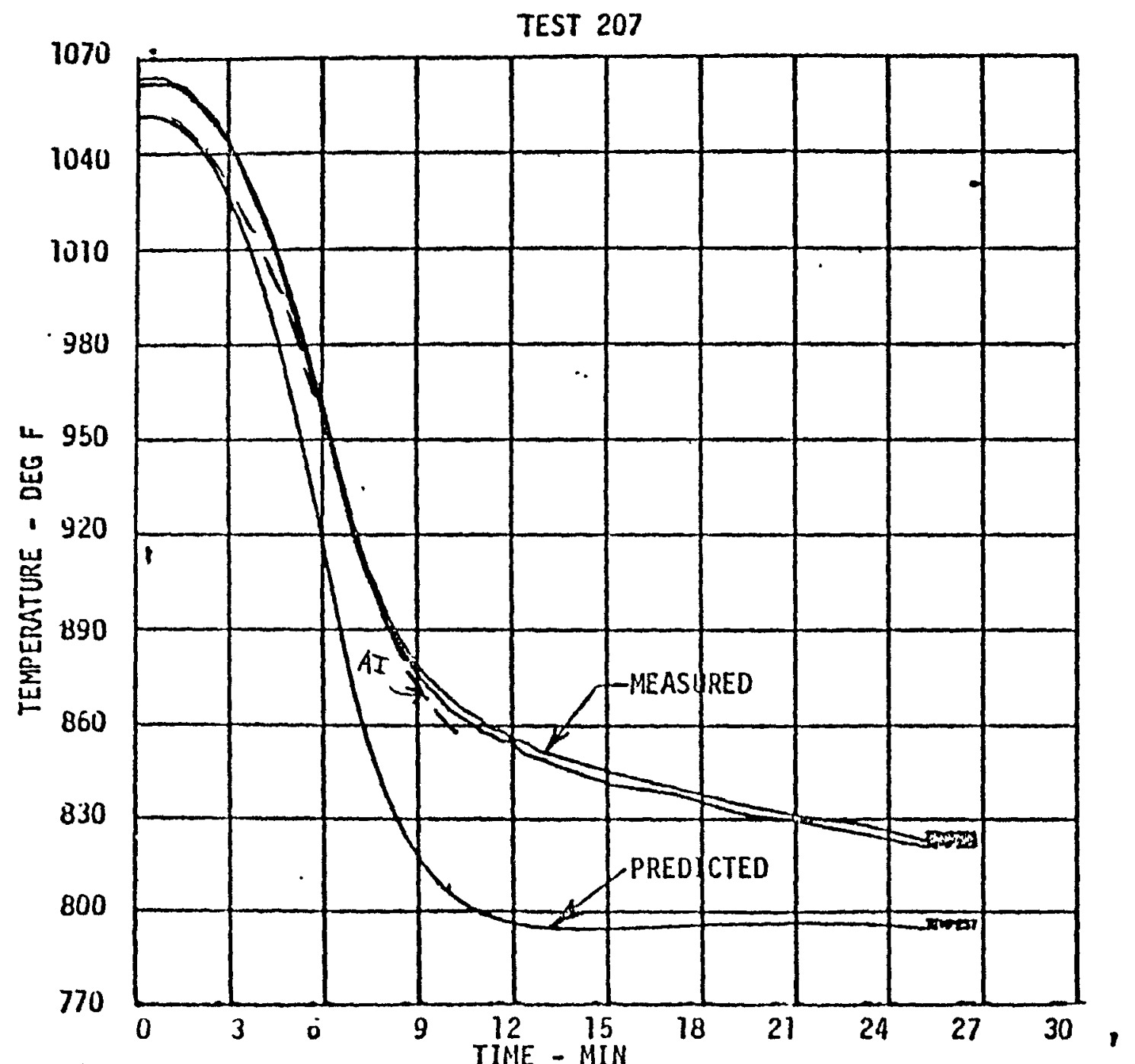

SPTF PUMP THERMAL PREDICTIONS VERSUS MEASUREMENTS-EVENT 207 2/24/77

FIGURE $\|^{A-2}$

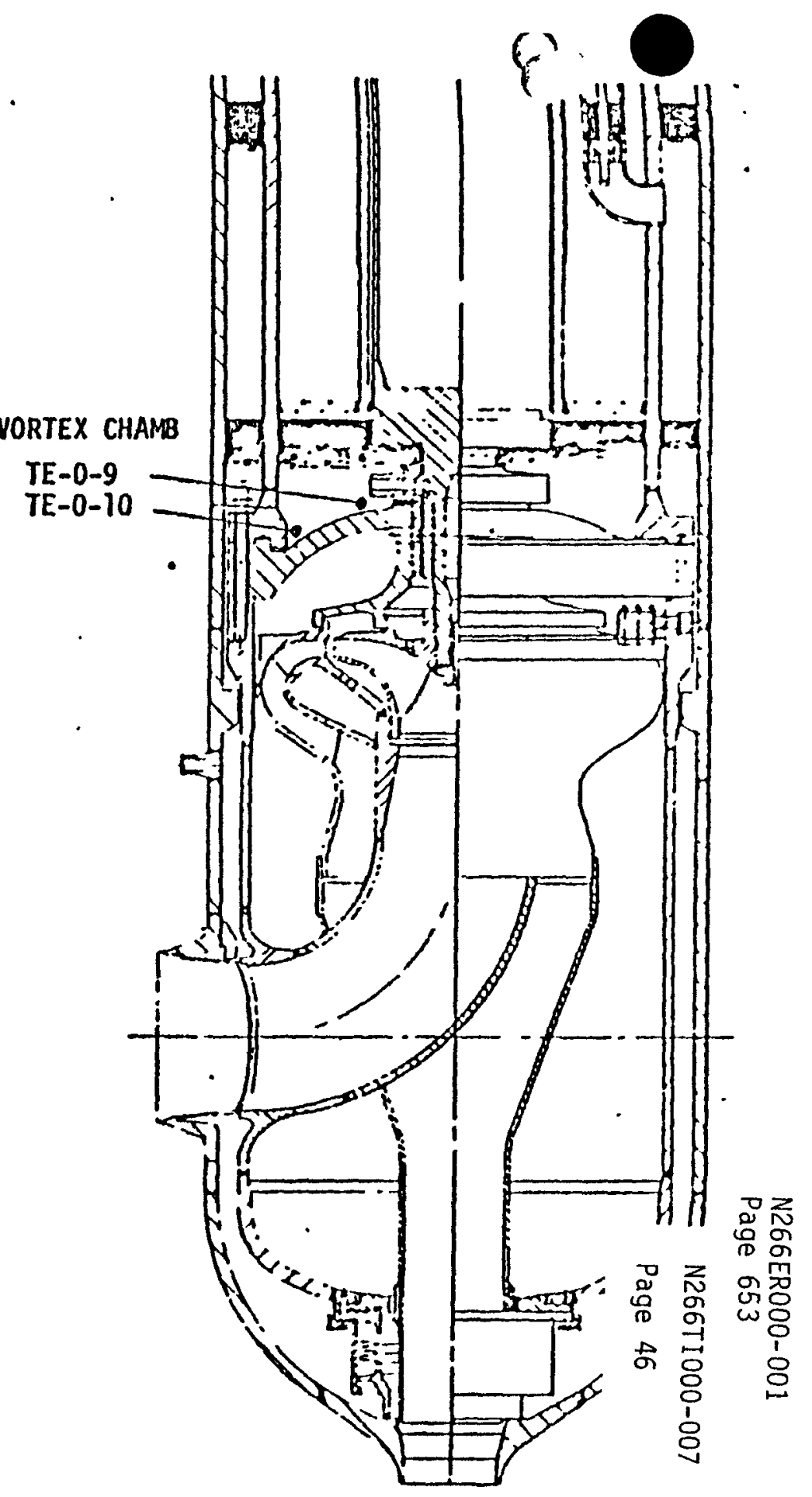




\section{2}
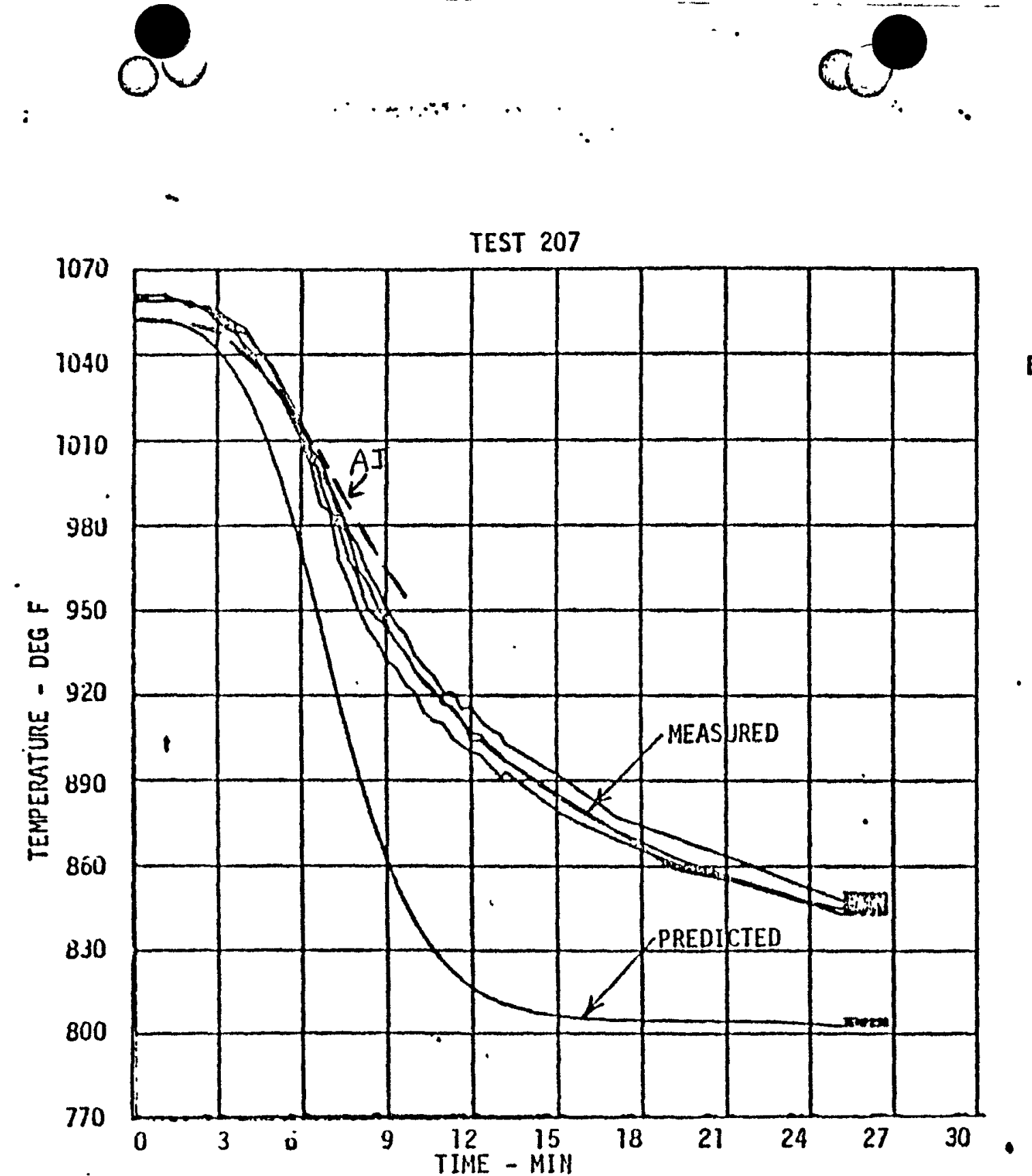

SPTF PUMP TIIERMAL PREDICTIONS VERSUS MEASUREMENTS-EVENT 207 2/24/77 A- 2

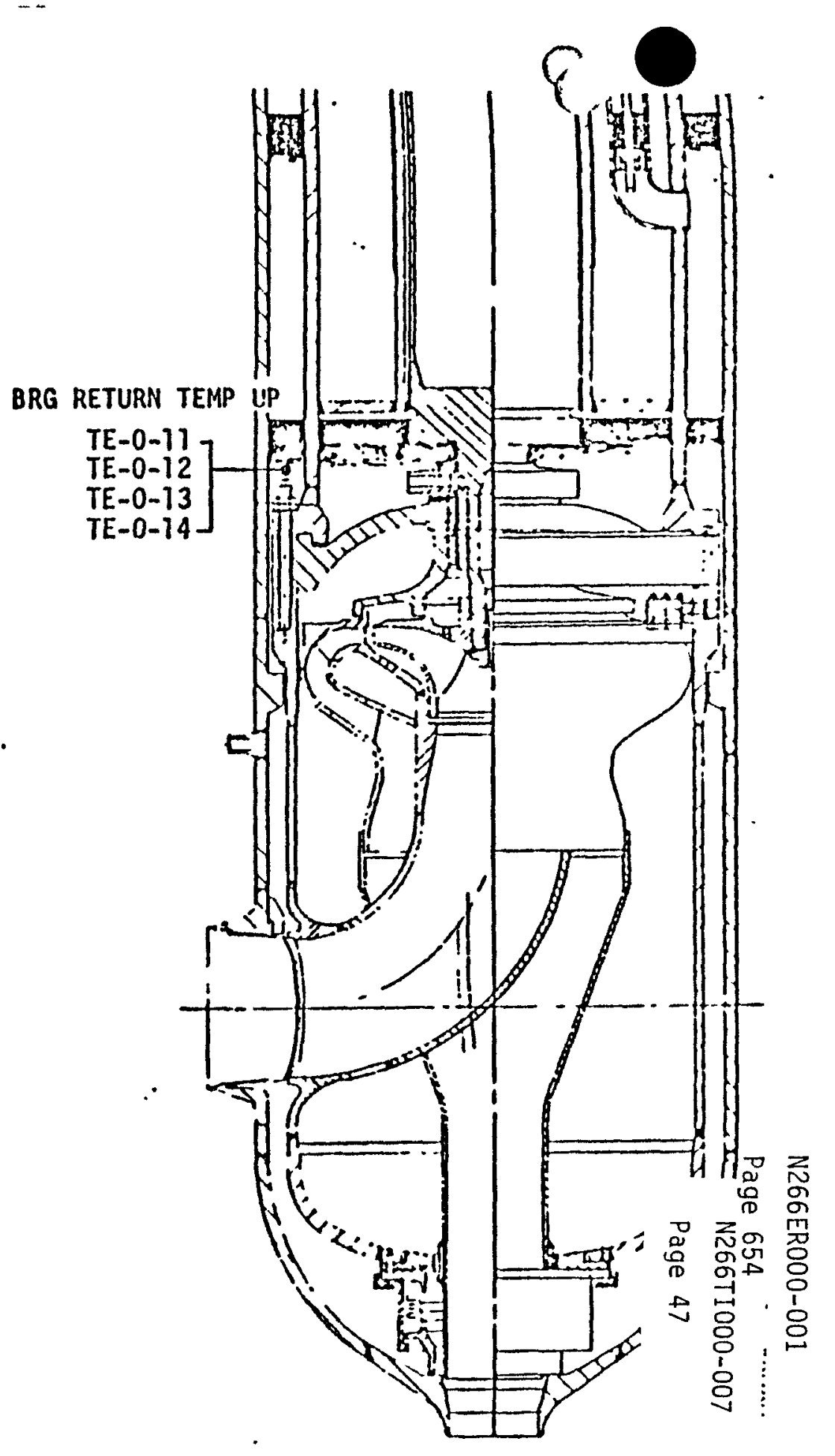


$O$

:

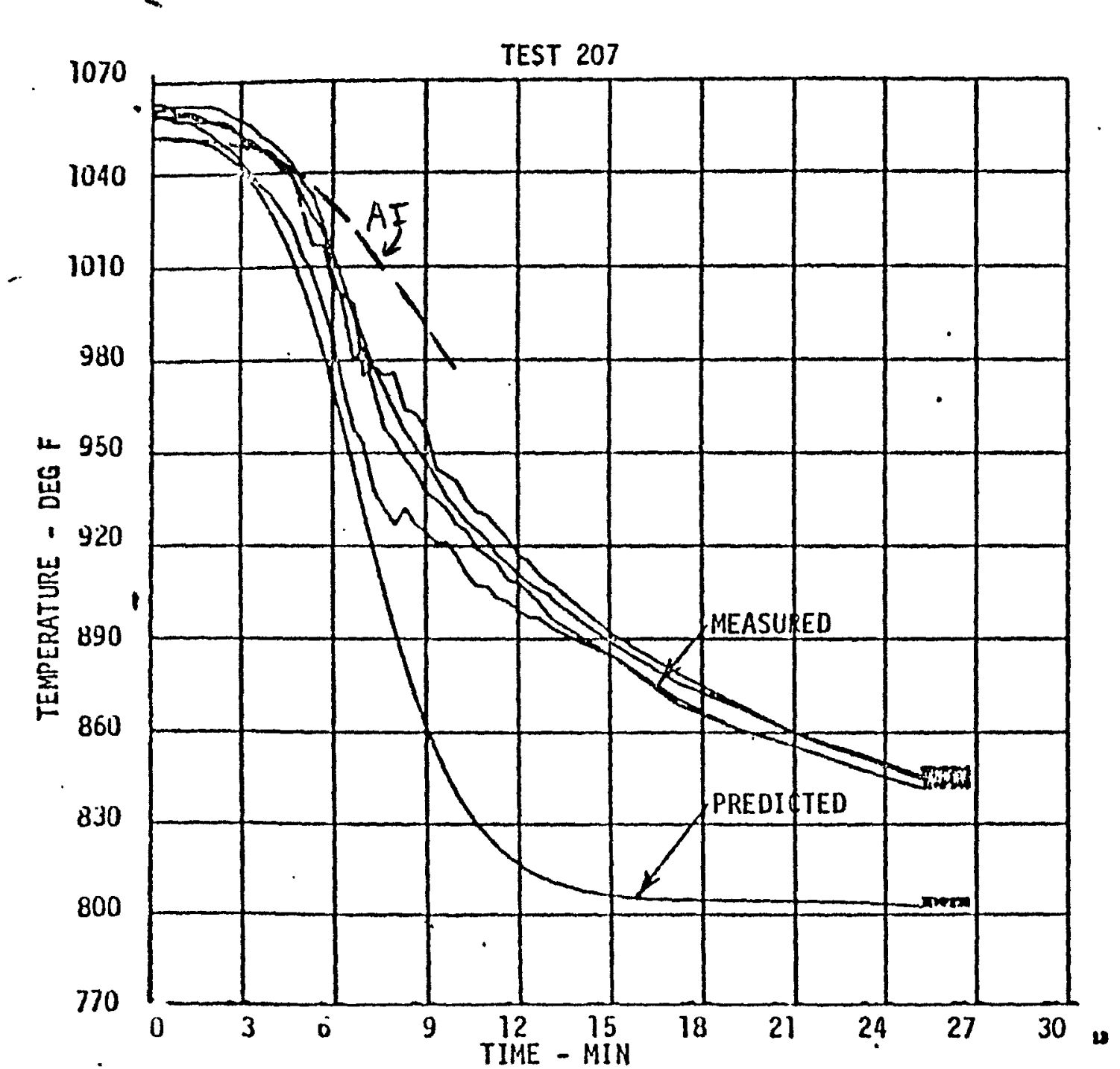

SPTF PUMP THERMAL PREDICTIONS VERSUS MEASUREMENTS-EVENT 207 2/24/77

$$
\text { A- } 2
$$

FIGURE 13

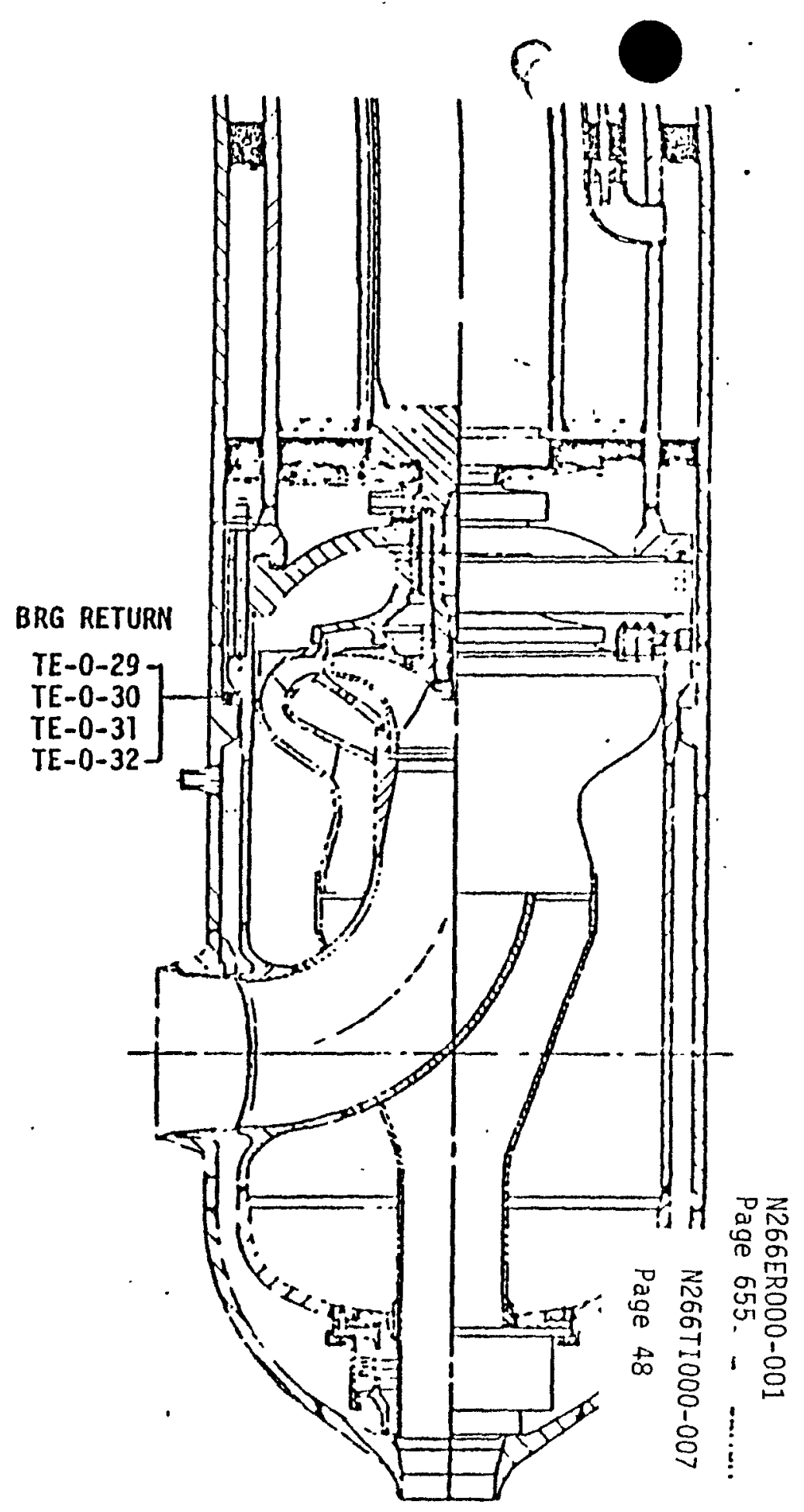



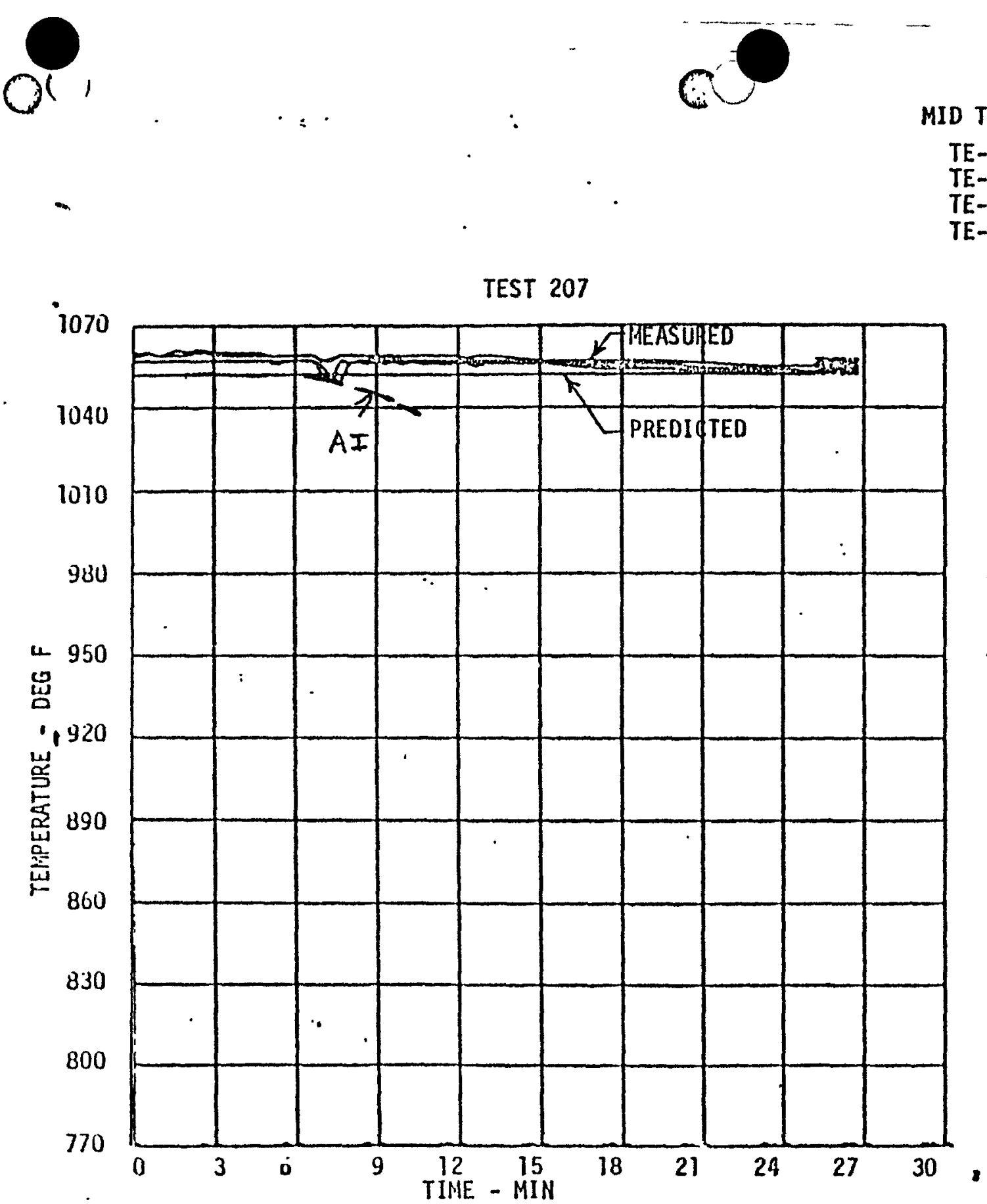

SPIF PUMP THERMAL PREDICTIONS YERSUS MEASUREMENTS-EVENT 207 2/24/77 207
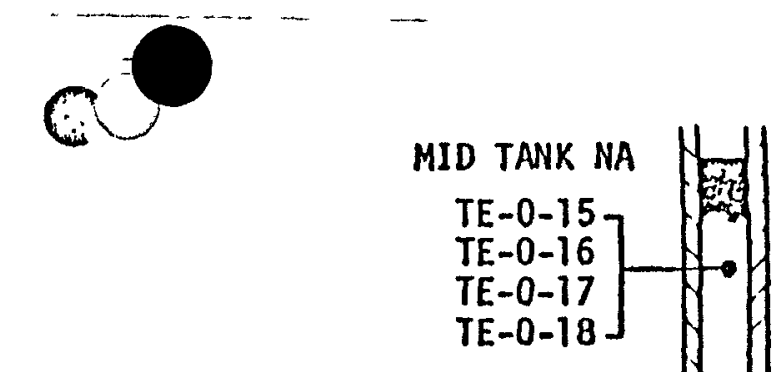

$\left.\begin{array}{c}\text { MID TANK NA } \\ \text { TE-0-15 } \\ \text { TE- }-16 \\ \text { TE-0-17 } \\ \text { TE-0-18 }\end{array}\right]$

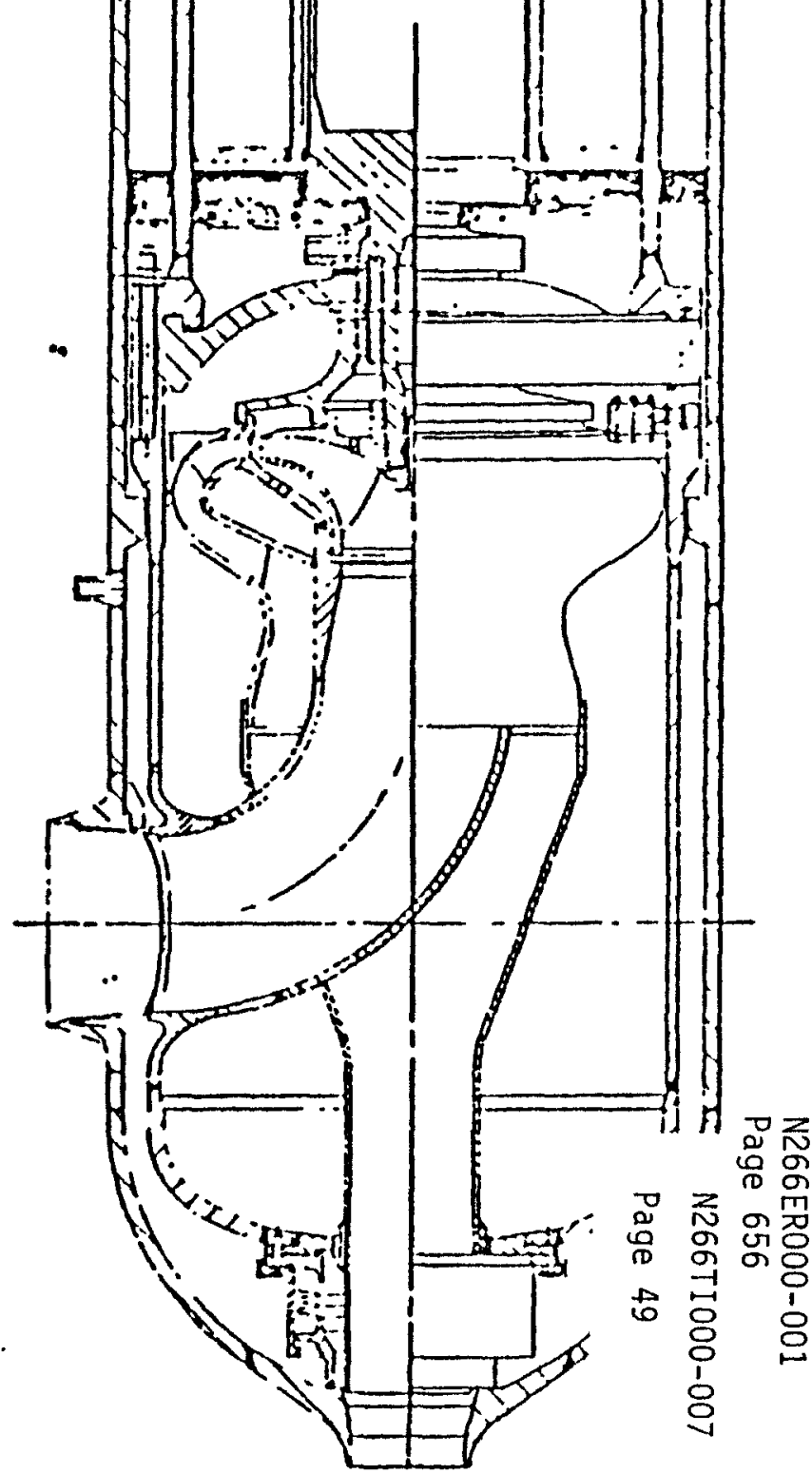


PAGE . 50

\section{APPENDIX A-3}

TRANSIENT 210-TEST 

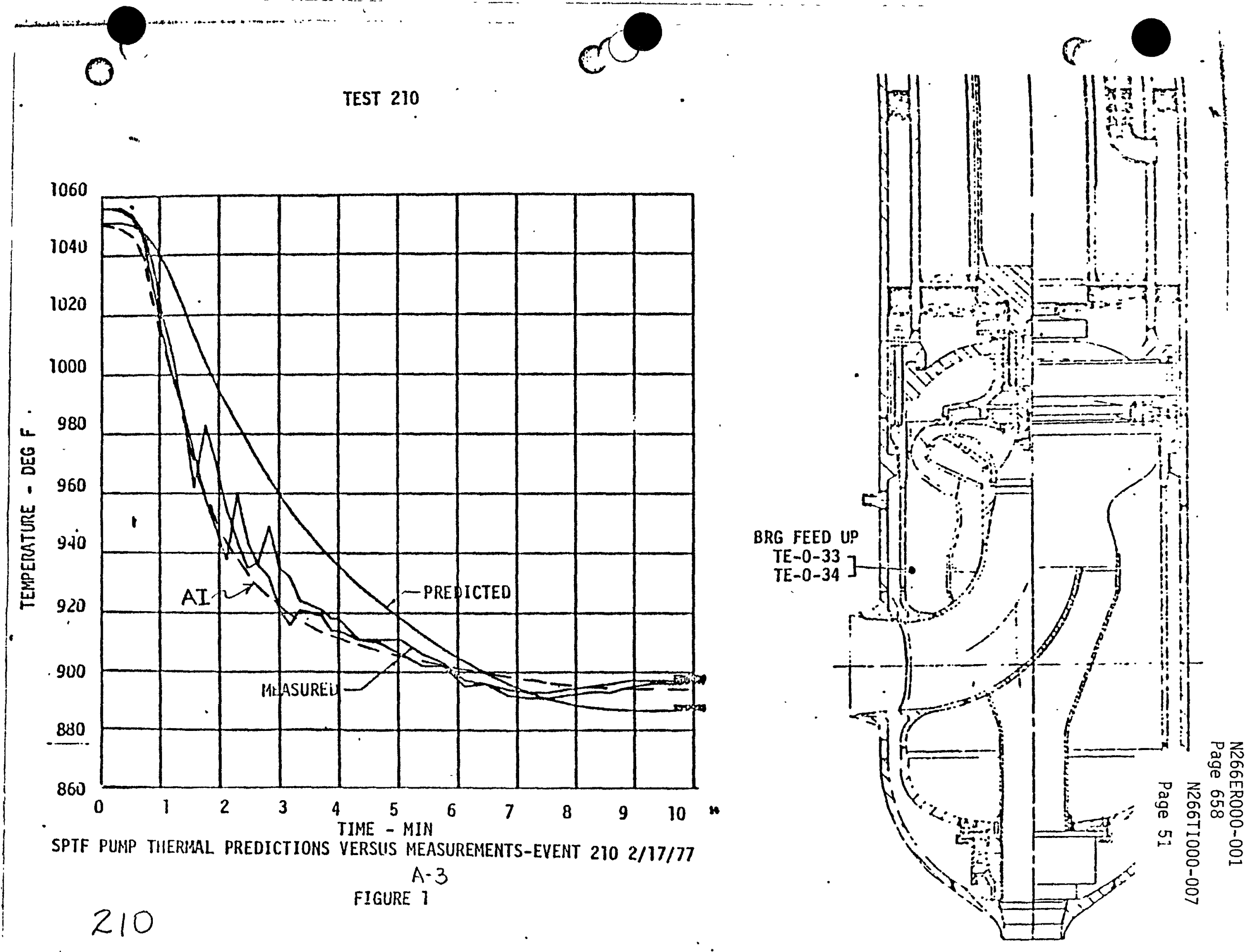


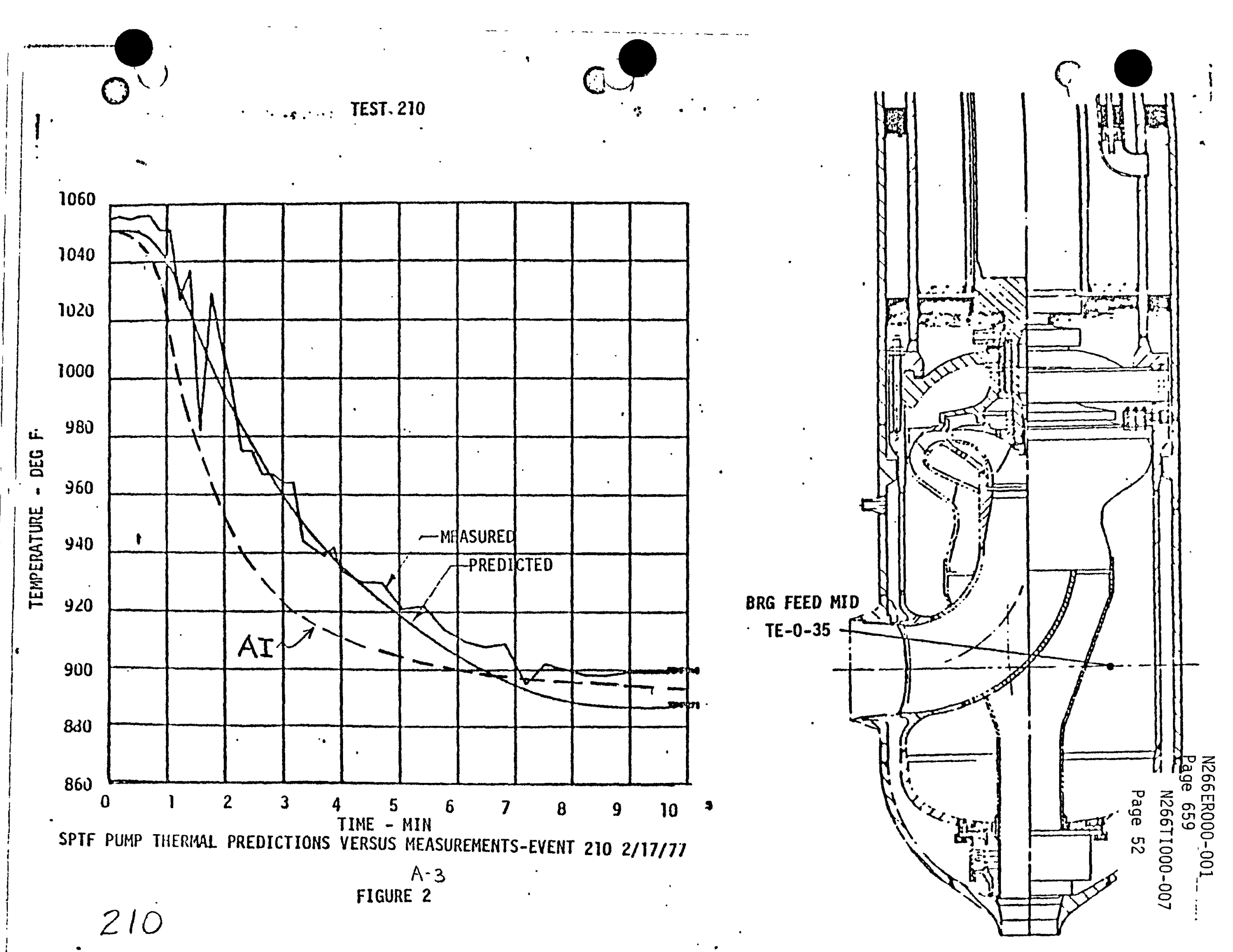




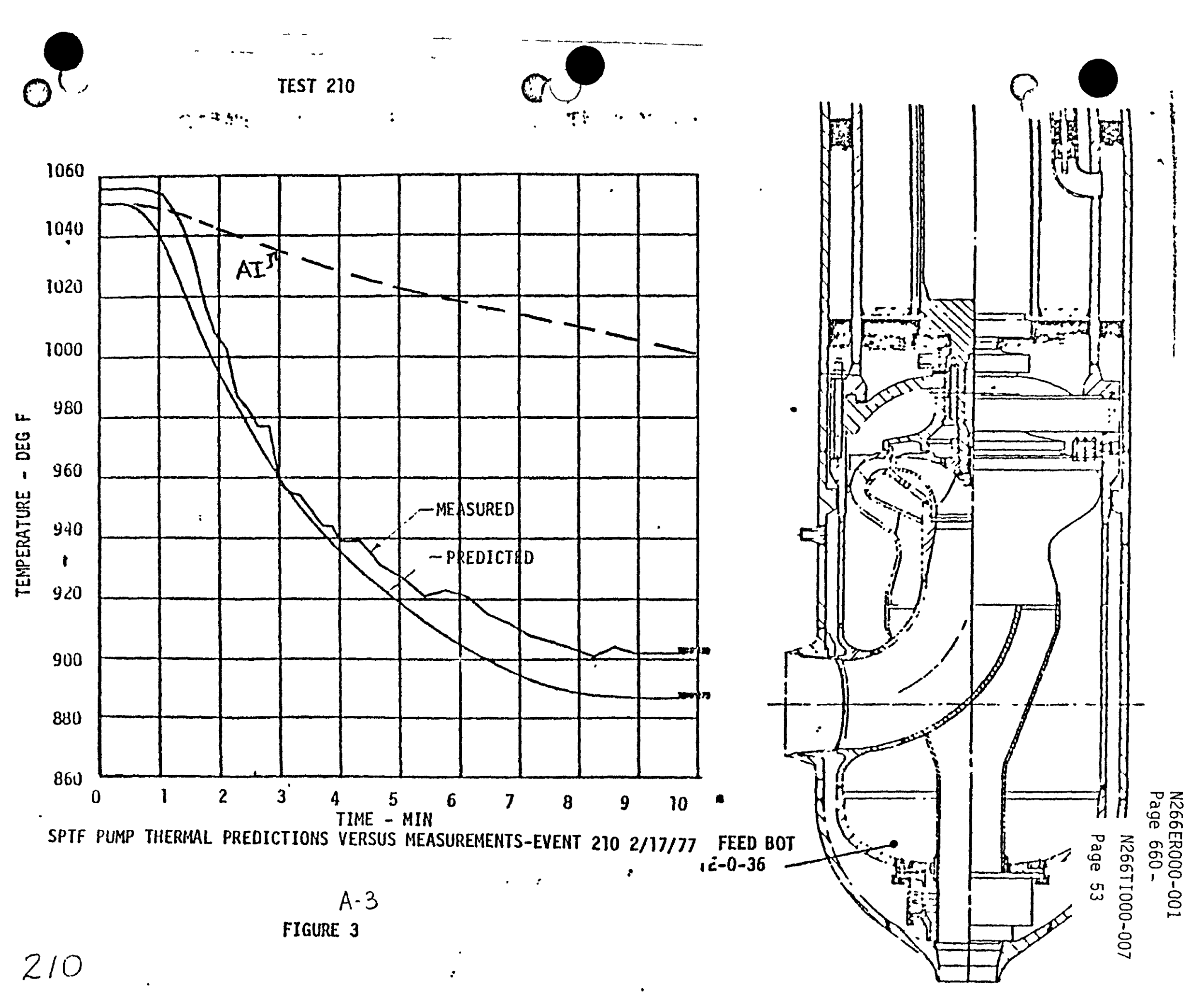


O

$a$

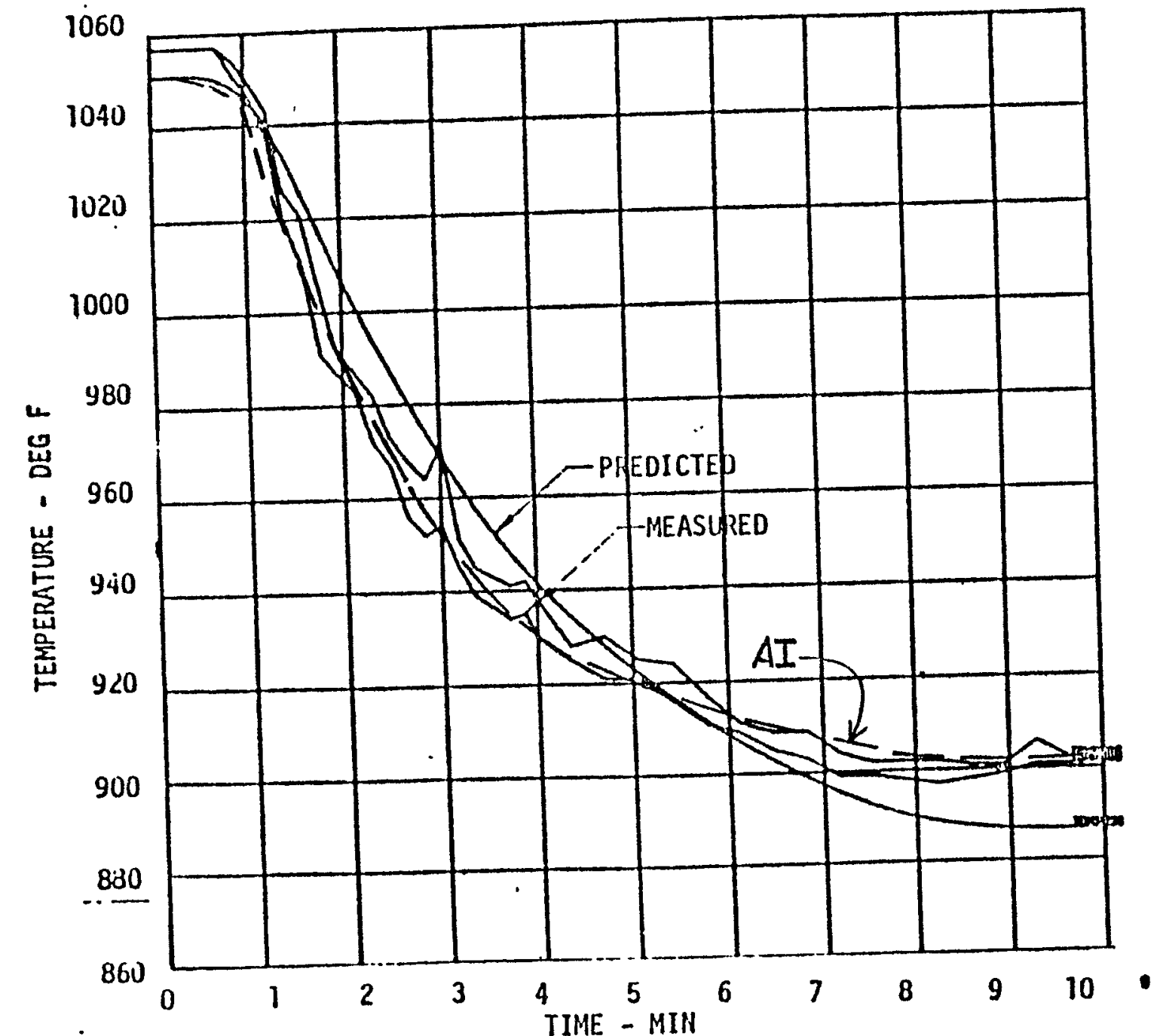

SPTF PUMP THERMAL PREDICTIONS VERSUS MEASUREMENTS-EVENT $210 \quad 2 / 17 / 77$

FIGURE 4

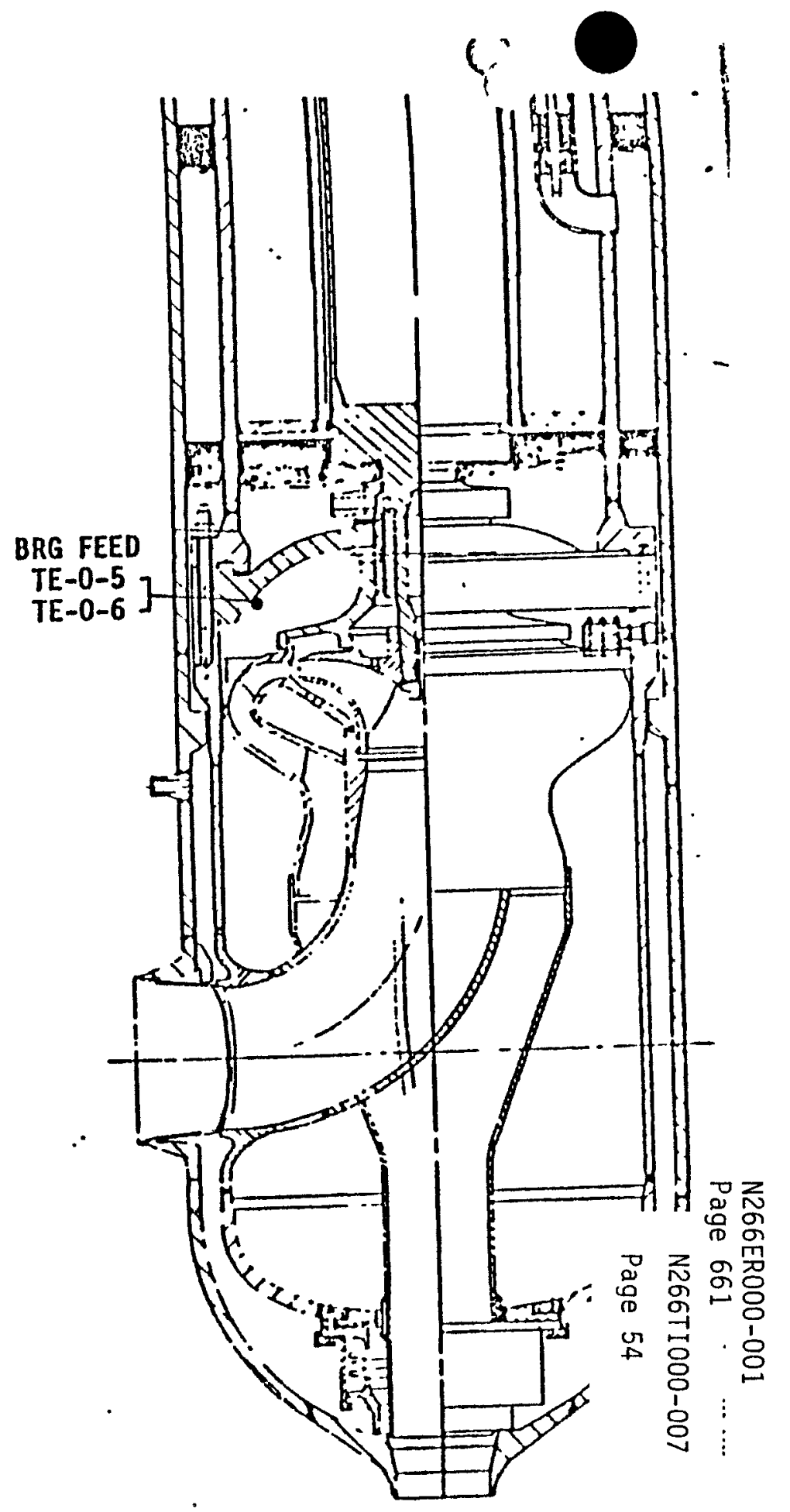




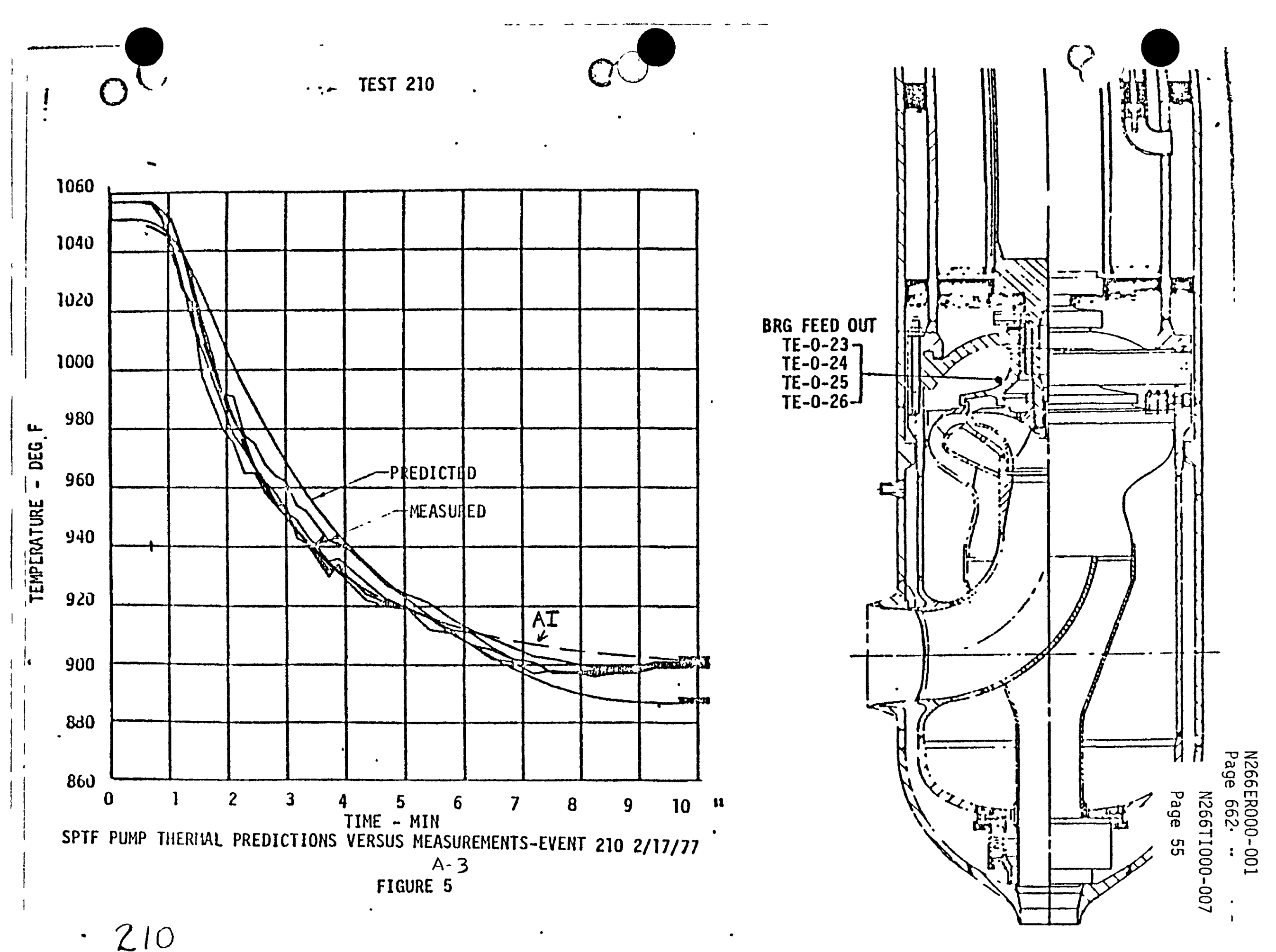

\section{0}



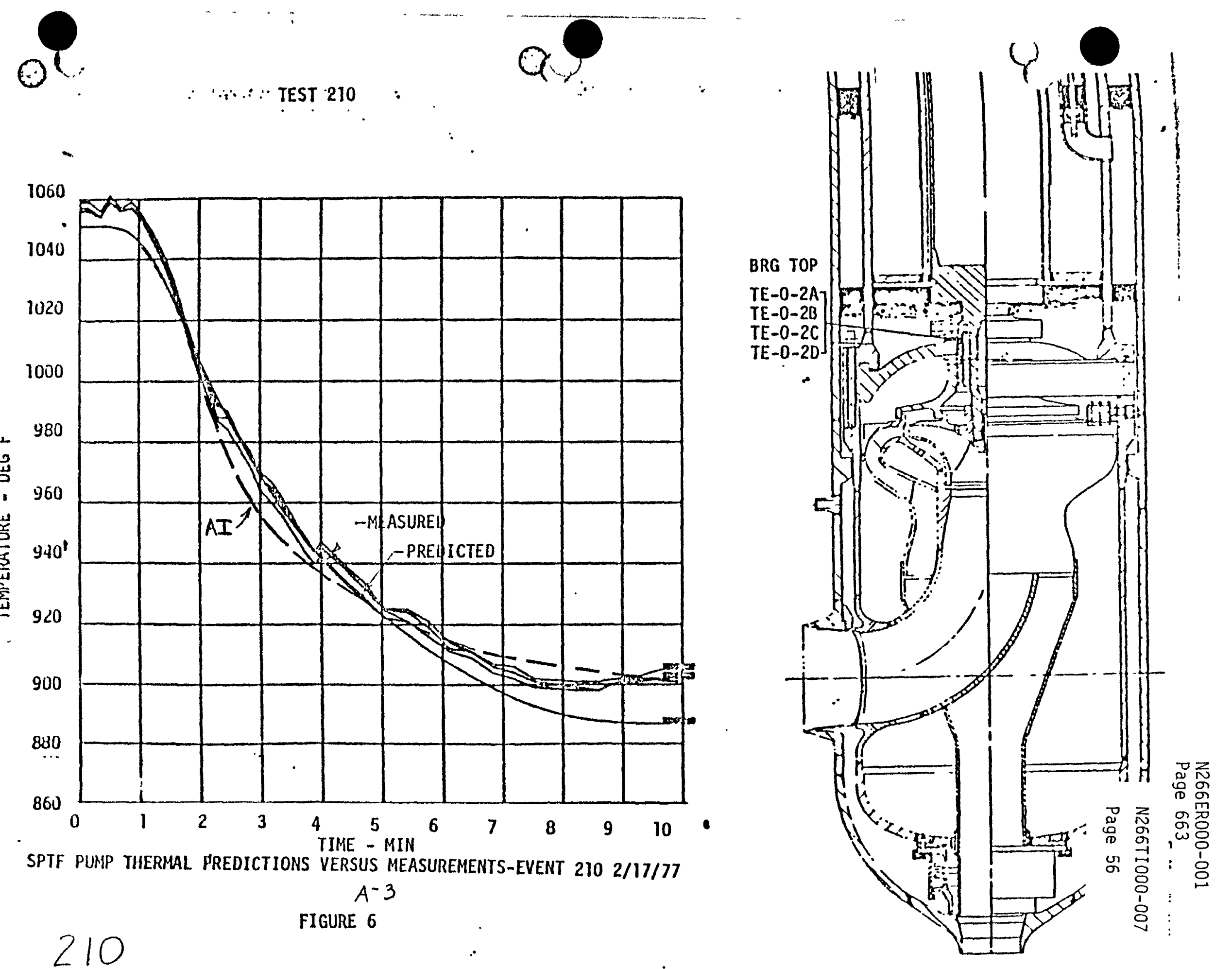

FIGURE 6 


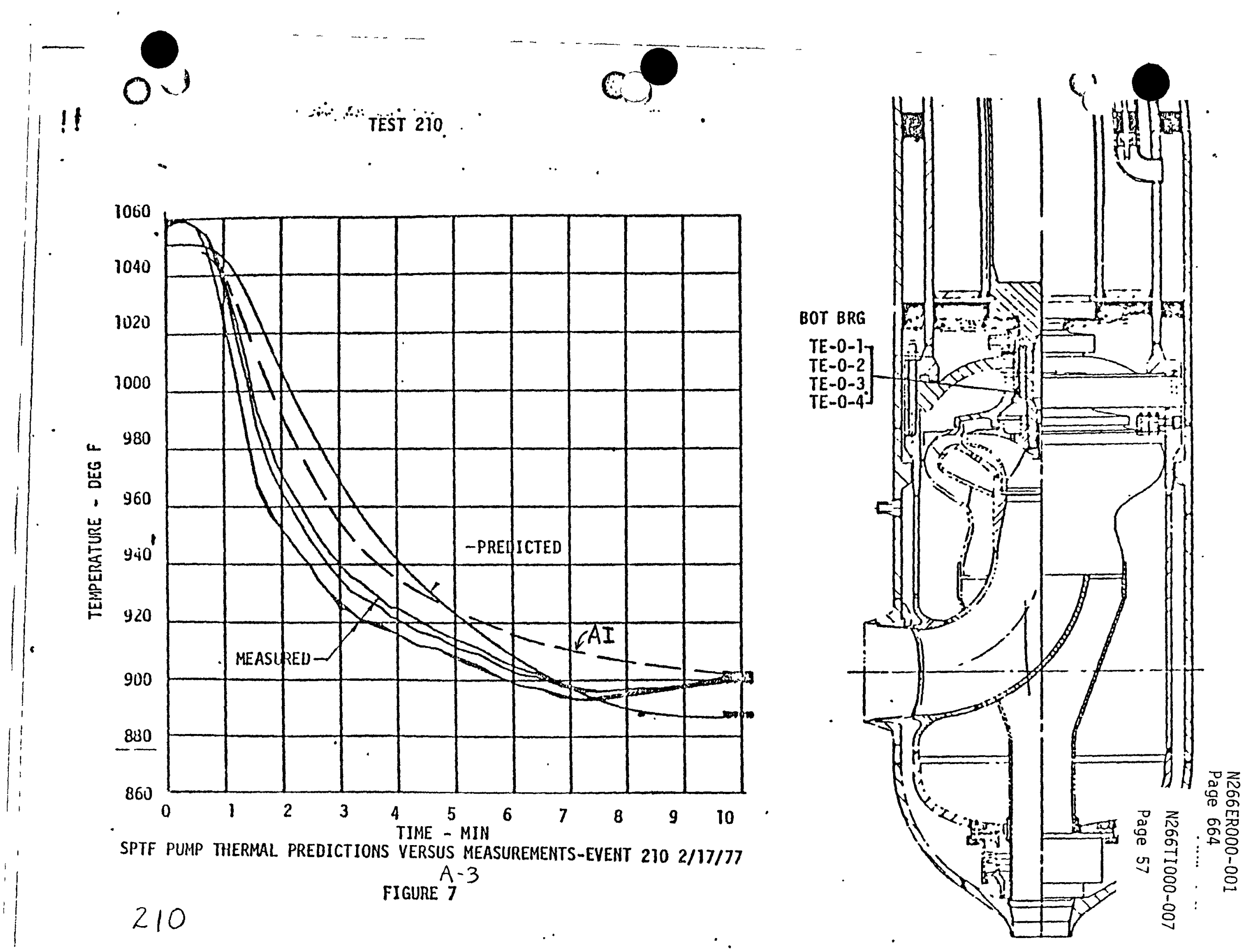


Q

TEST 210

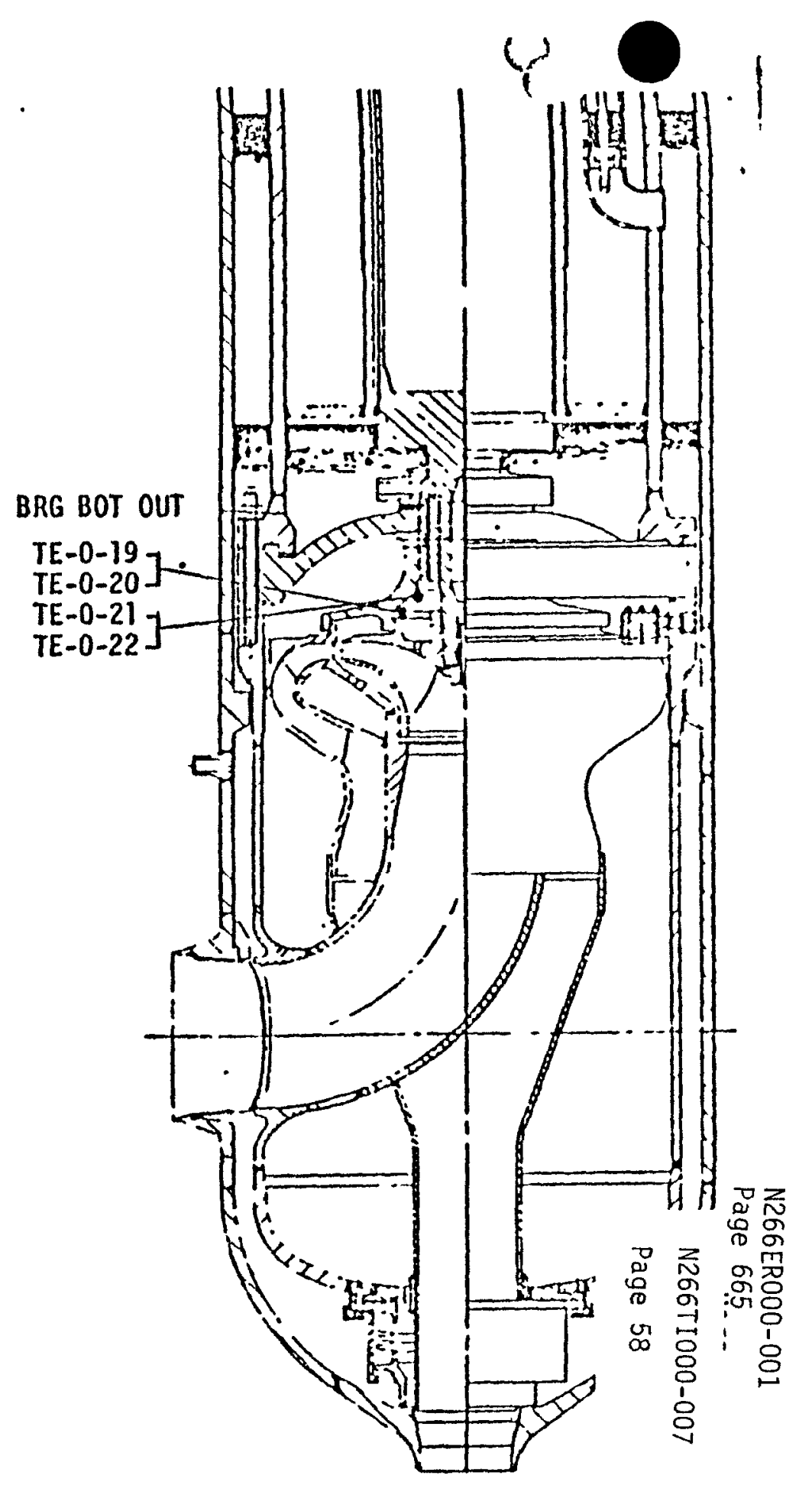




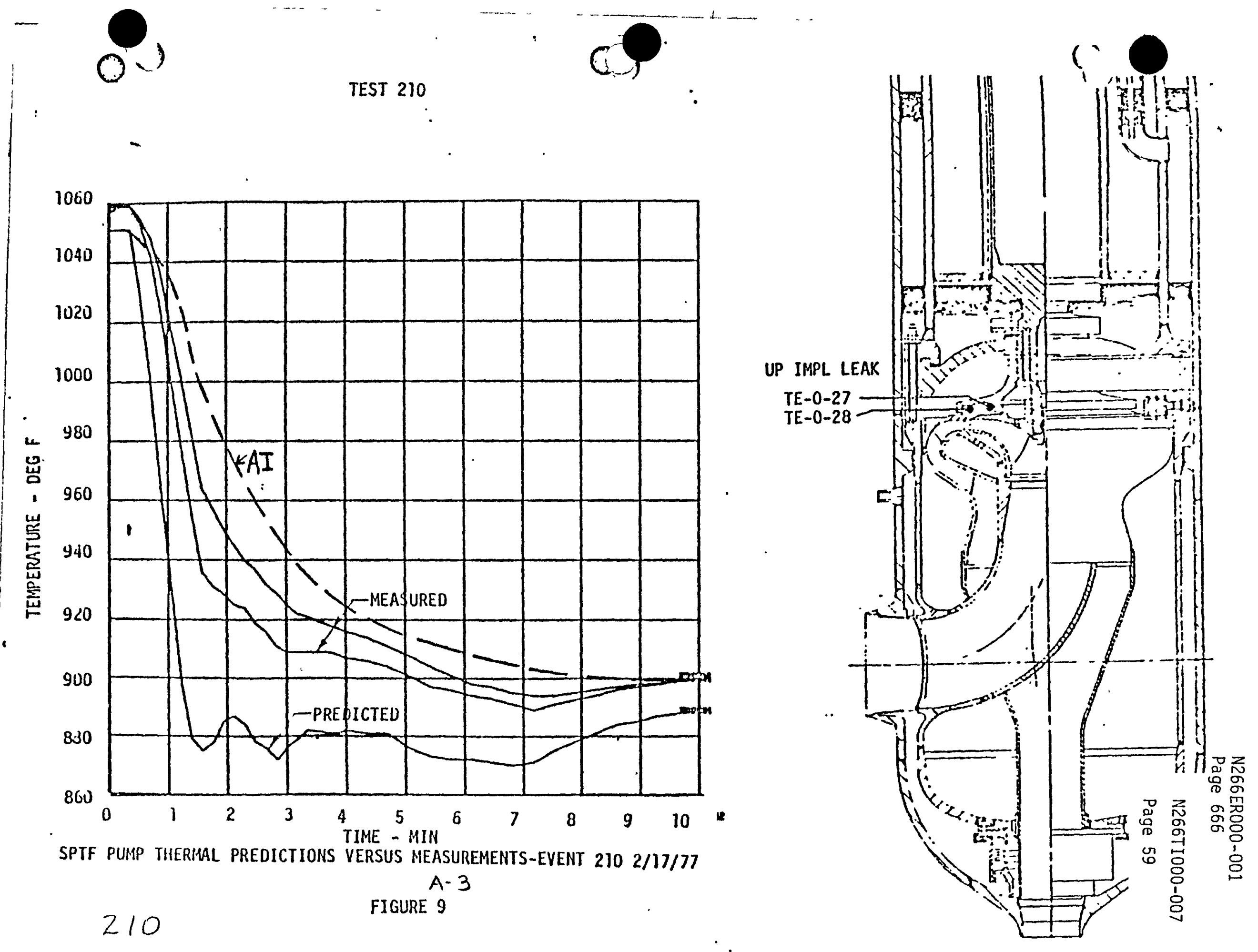




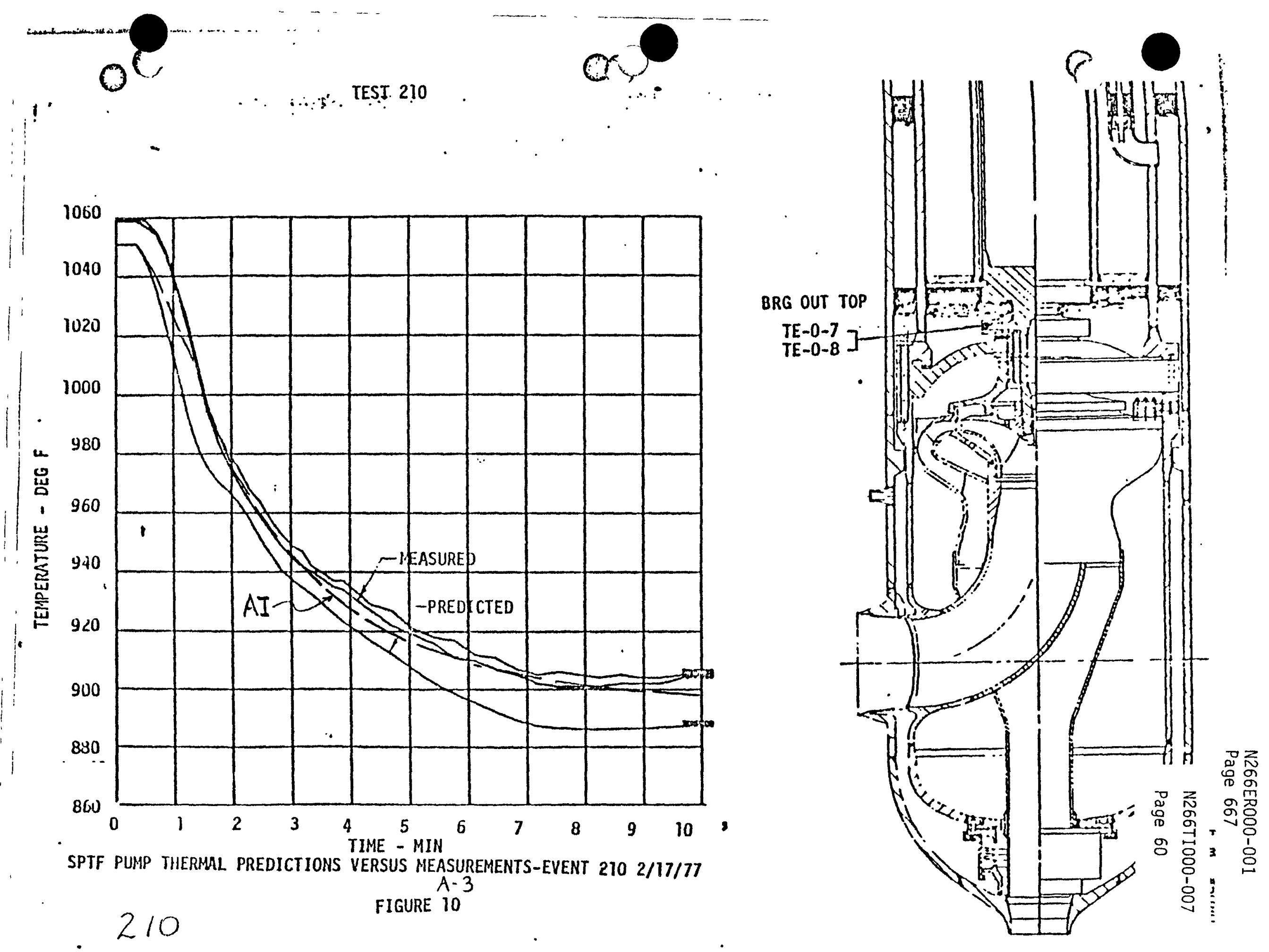




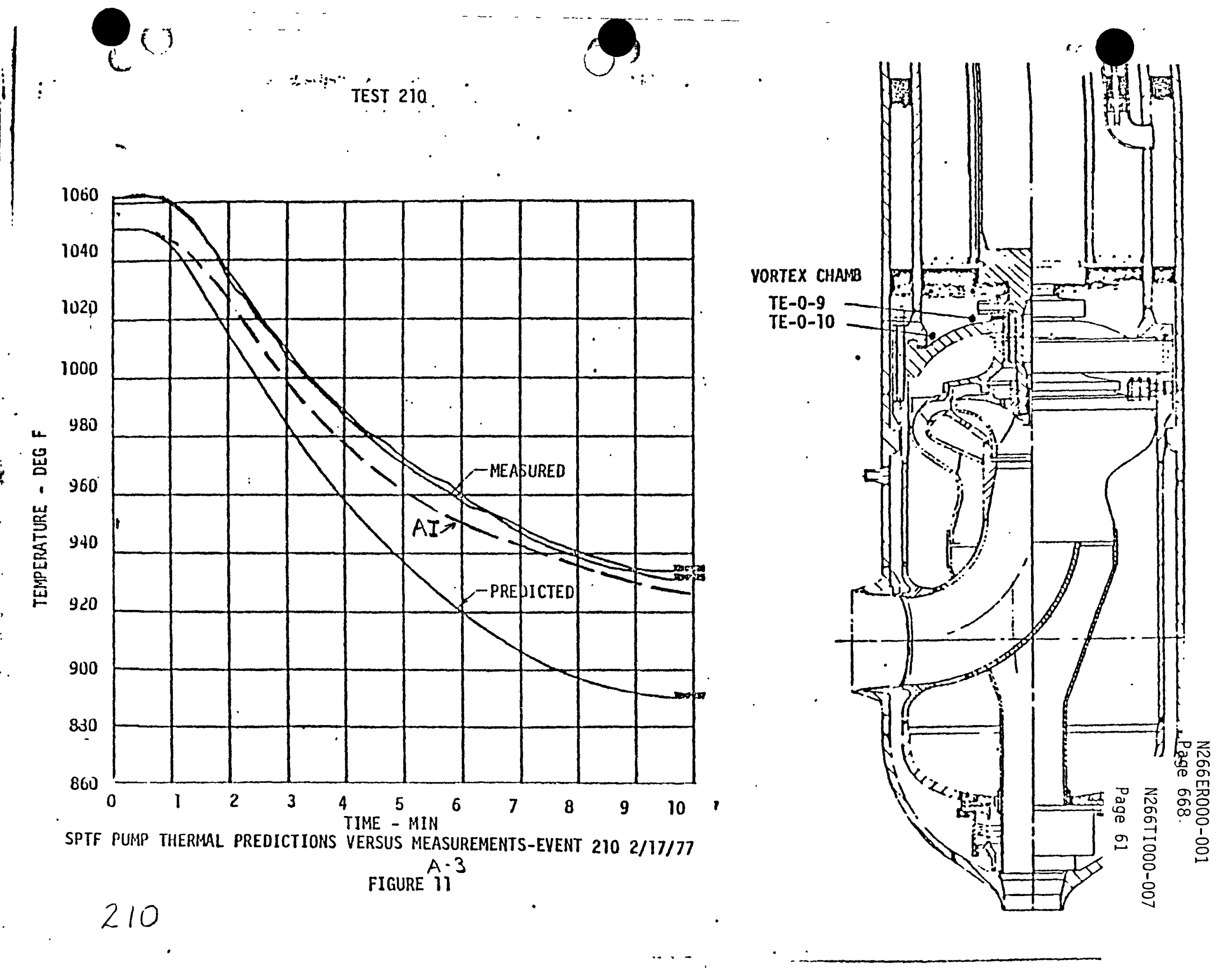




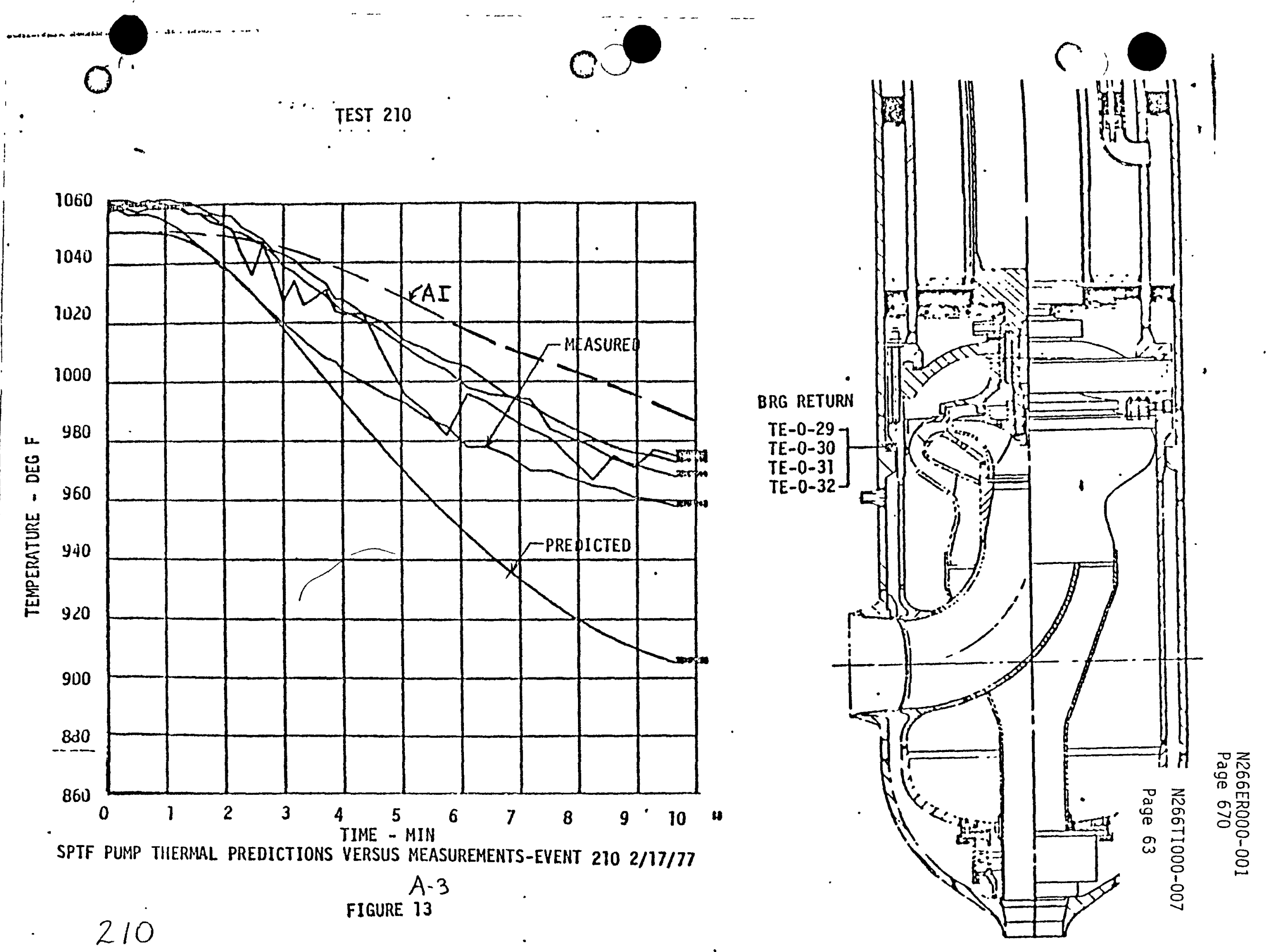




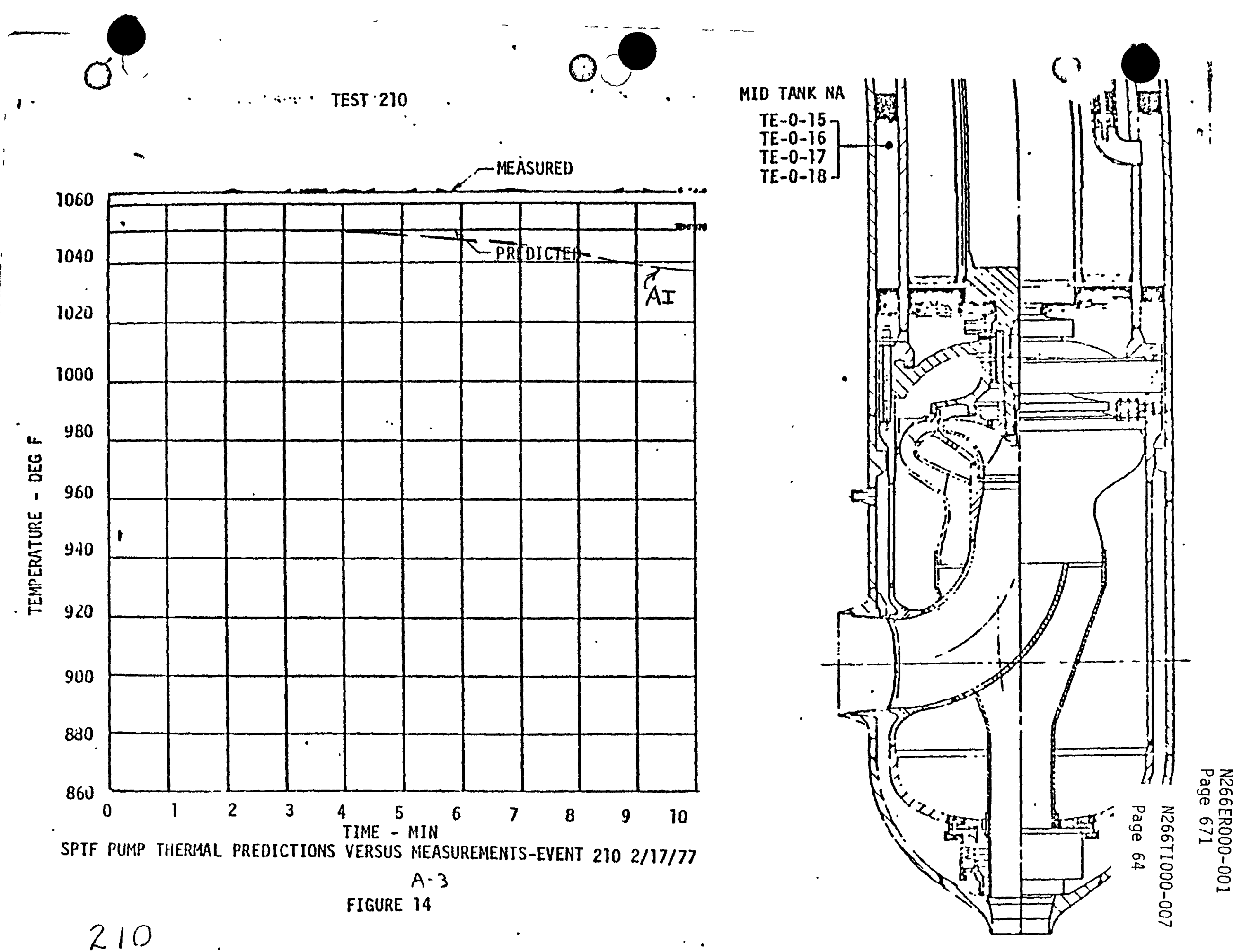

210 
APPENDIX B

TRANSIENT TEMPERATURE DIFFERENTIALS

(Location Pairs: 4-8, 4-9, 4-10, 4-11)

In Appendix $A$, temperature versus time plots are shown for the 14 thermocouple locations. Based on this information, temperature differentials between four pairs of locations were determined and plotted. These plots are shown in Figures $B-1, B-2$, and $B-3$ for Test Transients 205, 207, and 210, respectively. The data is shown: measured, solid line; AI results, dashed line; and Westinghouse prediction, dotted line.

The results show generally good agreement. An important exception is the $\Delta T$ data for the Location Pair 4-9. In the ISIP, there are design changes in the vicinity of Location 9 which cause that region to respond more slowly to the transient. Thus, $\Delta T$ (4-9) is expected to be less than for the FFTF test, and this indeed is the case.

Locations for Points 4,8,9,10, and 11 are shown in Figure 3 (a)so see Table A of Appendix A).

Tables B-1-a through B-3-C are the local temperatures and temperature differentials versus time for the locations indicated. The data for the T.C. measurements and Westinghouse data are taken from the plots of Reference 1, which are also shown in Appendix $A$. The AI data has been taken from the computer run output. 
EIGURE B-I

TRANSIENT \#205.TEST

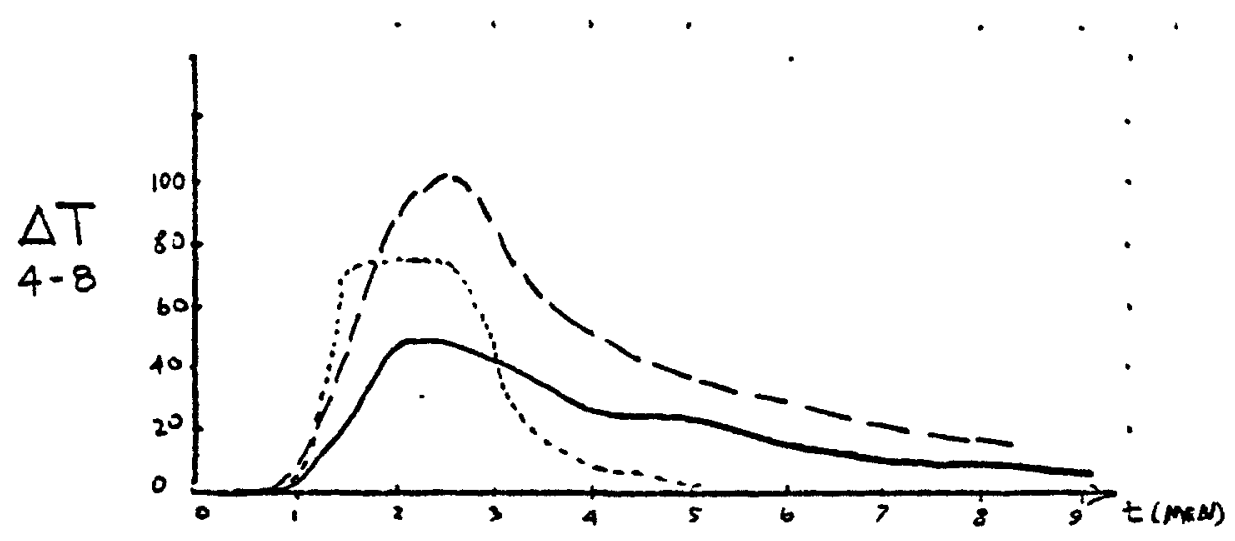

N266TI000-007

Page 66 .

Measured

1
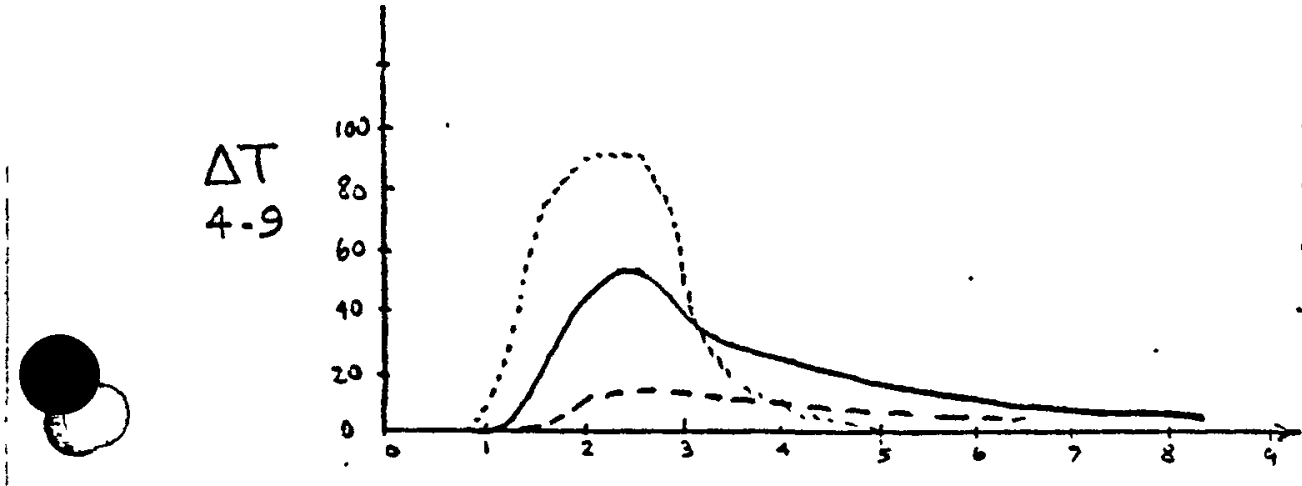

\section{$A I$}

A.I Calculation should be considerably lower due to change in design in - vicinity of location 9 ,
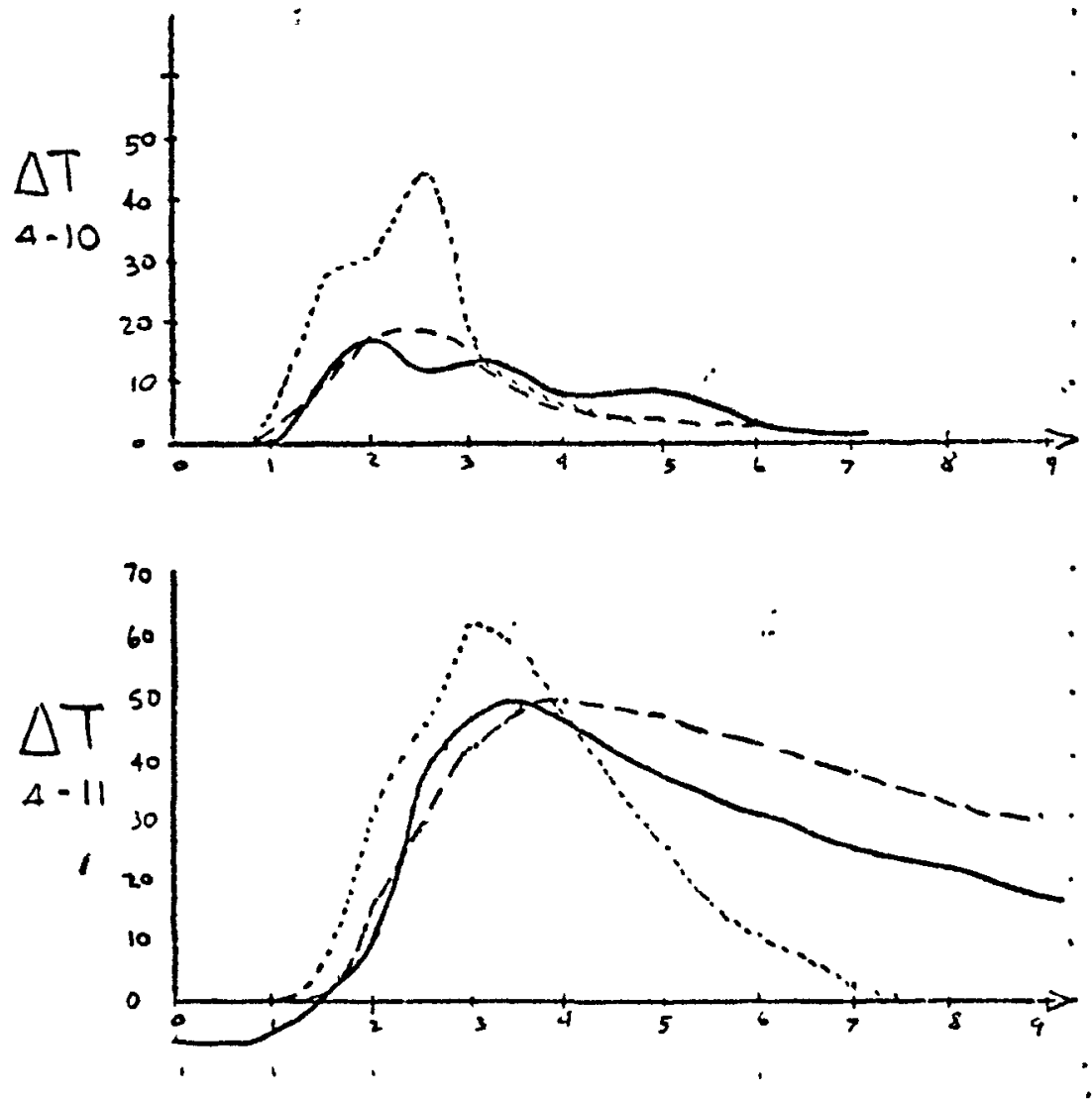
FIGURE B-2

\section{TRANSIENT $\# 207 . T E S T$}

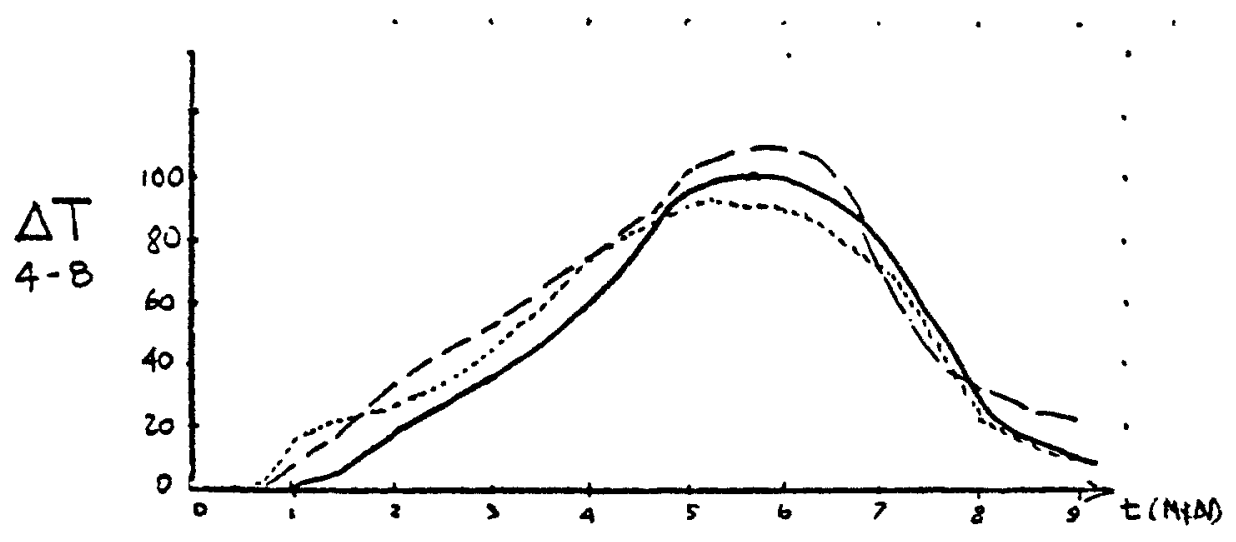

Measured
N266r I000-C07

Page 67.

C

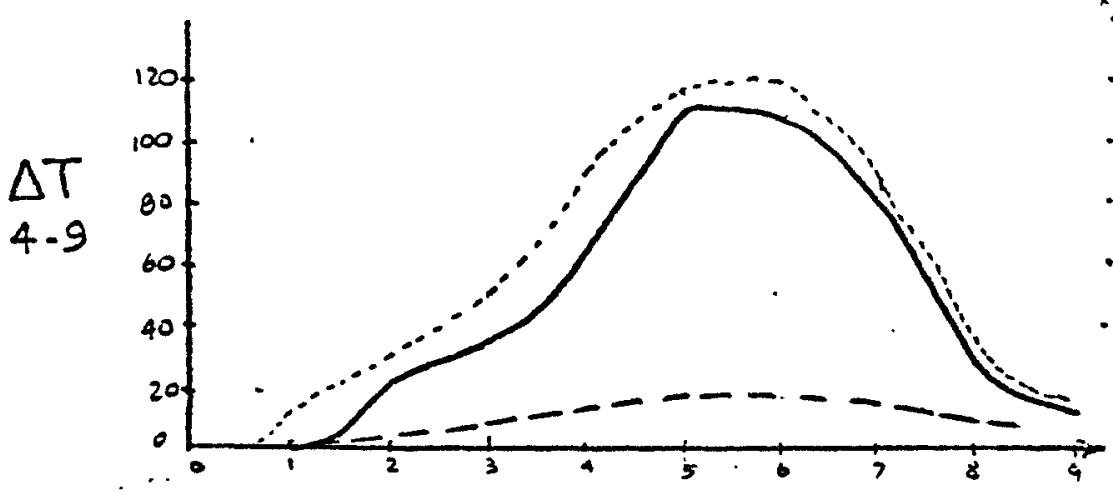

CAI Calculation should be considerably lower due to change in design in vicinity of location 9 . and it is.
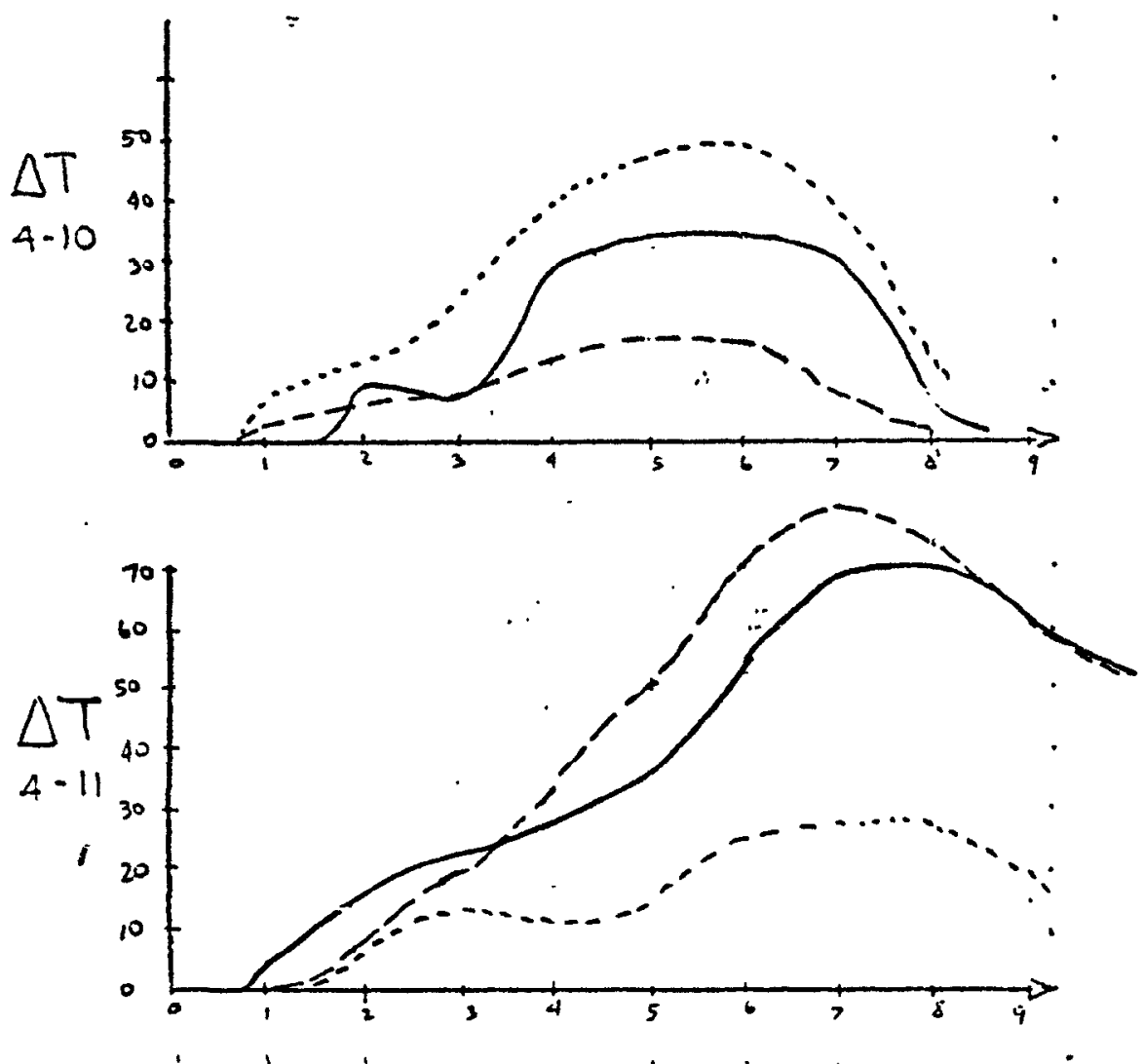

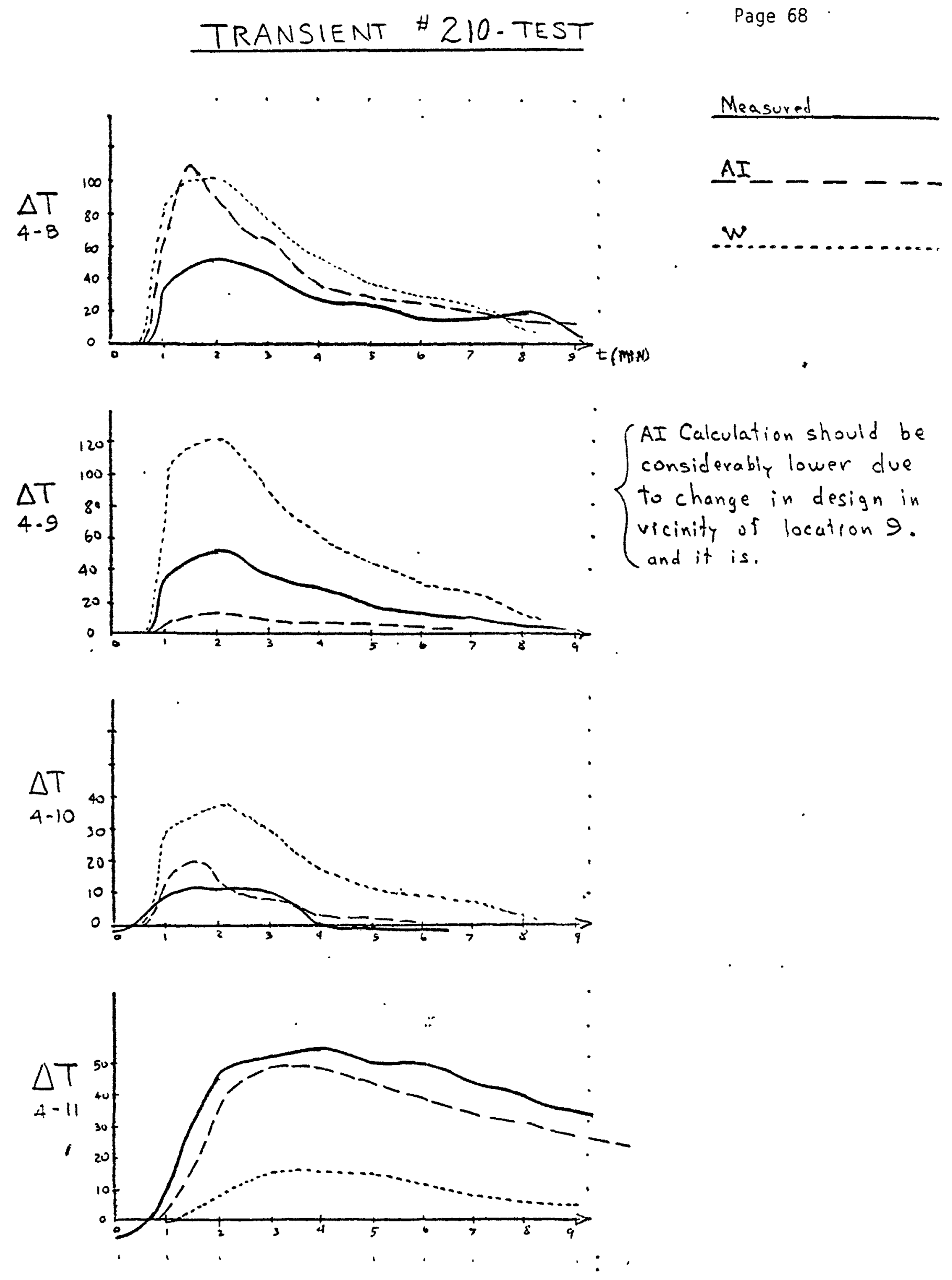
TABLE B-1-a

TRANSIENT ${ }^{*} 205$-TEST

FROM T.C. MEASUREMENTS

\begin{tabular}{|c|c|c|c|c|c|c|c|c|c|c|}
\hline $\begin{array}{l}\text { TIME } \\
\text { SEC. }\end{array}$ & $E$ & $\begin{array}{c}4 . \\
T 229 . .33) \\
T E 5,6\end{array}$ & $\begin{array}{l}\text { (8) } \\
T 934 \\
T E 19, \\
20,21,22\end{array}$ & $\begin{array}{l}9 \\
T 927 \\
T=27,28\end{array}$ & $\begin{array}{r}10 \\
T 932 \\
T E 7.8\end{array}$ & $\begin{array}{l}\text { (11) } \\
T 920 \\
T E 9.10\end{array}$ & $\begin{array}{c}\Delta T \\
(4-8)\end{array}$ & $\begin{array}{c}\Delta T \\
(4-9)\end{array}$ & $\begin{array}{c}\Delta T \\
(4-10)\end{array}$ & $\begin{array}{c}\Delta T \\
(4-11)\end{array}$ \\
\hline & & & & & & & & & & \\
\hline 0 & 0 & 703 & 703 & 703 & 704 & 710 & 0 & 0 & -1 & -7 \\
\hline & & & & & & & & & & \\
\hline 60 & $T$ & 703 & 705 & 705 & 704 & 710 & -2 & -2 & -1 & -7 \\
\hline & & 713 & 740 & 739 & 720 & 712 & -27 & -26 & -7 & +1 \\
\hline 120 & 2 & 732 & 780 & 776 & 748 & 721 & $(-48)$ & -44 & $(-16)$ & +11 \\
\hline & & 774 & 820 & 826 & 785 & 735 & -46 & $(-52)$ & -11 & +39 \\
\hline 180 & 3 & 799 & 840 & 836 & 811 & 752 & -41 & -37 & -12 & +47 \\
\hline & & 819 & & & & 769 & & & & 750 \\
\hline 240 & 4 & 828 & 851 & 850 & .835 & 781 & -23 & -22 & -7 & 47 \\
\hline & & & & & & & & & & \\
\hline 300 & 5 & 834 & 856 & 852 & 842 & 798 & -22 & -18 & -8 & 36 \\
\hline 360 & 6 & 840 & 855 & 852 & 843 & 809 & -15 & -12 & -3 & 31 \\
\hline 420 & 7 & 842 & 853 & 850 & 844 & 816 & -11 & -8 & -2 & 26 \\
\hline & & & & & & & & & & \\
\hline 480 & 8 & 842 & 851 & 849 & 844 & 820 & -9 & -7 & -2 & 22 \\
\hline & & & & & & & & & & \\
\hline 540 & 9 & 842 & 850 & 848 & 844 & 824 & -8 & -6 & -2 & 18 \\
\hline & & & & & & & & & &. \\
\hline 600 & 10 & 842 & 850 & 847 & 844 & 826 & -8 & -5 & -2 & 16 \\
\hline & & & & & & & & & & \\
\hline & & & & & & & & & & \\
\hline
\end{tabular}


TAble $B-1-b$

TRANSIENT ${ }^{*} 205$-TEST

AI CALCULATION. 1/10/79

\begin{tabular}{|c|c|c|c|c|c|c|c|c|c|c|}
\hline $\begin{array}{l}\text { TIM } \\
\text { SEC. }\end{array}$ & $\min$ & 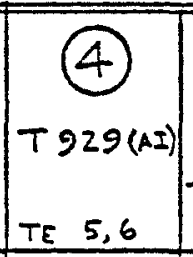 & $\begin{array}{r}\text { (8) } \\
T 934 \\
T E 19, \\
20,21,22 \\
\end{array}$ & $\begin{array}{r}9 \\
T 927 \\
T E 27.28 \\
\end{array}$ & $\begin{array}{r}10 \\
T 932 \\
T E 7.9 \\
\end{array}$ & $\begin{array}{l}\text { (11) } \\
T 920 \\
T E \quad 9,10 \\
\end{array}$ & $\begin{array}{c}\Delta T \\
(4-8)\end{array}$ & $\begin{array}{c}\Delta T \\
(4-9)\end{array}$ & $\begin{array}{c}\Delta T \\
(4-10)\end{array}$ & $\begin{array}{c}\Delta T \\
(4-11)\end{array}$ \\
\hline & & & & & & & & & & \\
\hline 0 & 0 & 695 & 695 & 695 & 695 & 695 & 0 & 0 & 0 & 0 \\
\hline & & & & & & & & & & \\
\hline 60 & 1 & 695 & 703 & 695 & 697 & 695 & -8 & 0 & 2 & 0 \\
\hline 110 & $1.5 / 6$ & 712 & & 721 & 728 & 702 & -80 & -9 & -16 & 10 \\
\hline 120 & 2 & 720 & 808 & 729 & 736 & 704 & -88 & -9 & -16 & 16 \\
\hline $\begin{array}{l}180 \\
150 \\
150\end{array}$ & & 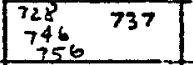 & {$\left[\begin{array}{l}823 \\
847893\end{array}\right.$} & 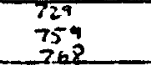 & $\begin{array}{l}7964 \\
764\end{array}$ & 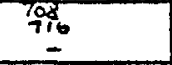 & 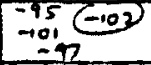 & 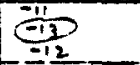 & 需 & 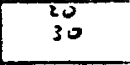 \\
\hline 180 & 3 & 773 & 857 & 785 & 787 & 731 & -84 & -12 & -14 & 42 \\
\hline 210 & & 794 & 855 & 803 & 802 & 745 & -61 & -9 & -8 & 49 \\
\hline 240 & 4 & 807 & 857 & 816 & 813 & 757 & -50 & -9 & -6 & 50 \\
\hline $\begin{array}{l}260 \\
280\end{array}$ & $\begin{array}{l}4 \cdot 1 / 3 \\
4 \cdot-2 / 3\end{array}$ & $\begin{array}{l}814 \\
820\end{array}$ & $\begin{array}{l}858 \\
859\end{array}$ & $\begin{array}{l}8222 \\
827\end{array}$ & 819 & $\begin{array}{l}764 \\
771\end{array}$ & $\begin{array}{l}-44 \\
-39\end{array}$ & $\begin{array}{l}-8 \\
-7\end{array}$ & $\begin{array}{l}-5 \\
-4 \\
-4\end{array}$ & $\begin{array}{l}50 \\
49\end{array}$ \\
\hline 300 & 5 & 824 & 860 & 831 & 828 & 777 & -36 & -7 & -4 & 47 \\
\hline 360 & 6 & 834 & 867 & 810 & 837 & 791 & -28 & 76 & -3 & 43 \\
\hline & & & & 040 & 031 & 11 & & & & \\
\hline 420 & 7 & 841 & 863 & 846 & 843 & 802 & -22 & -5 & -2 & 39 \\
\hline & & & & & & & & & & \\
\hline 480 & 8 & 845 & 864 & 849 & 848 & 811 & -19 & -4 & -3 & 34 \\
\hline & & & 0 & & & & & & & \\
\hline 540 & 9 & 848 & 865 & 852 & 851 & 817 & -17 & -4 & -3 & 31 \\
\hline 600 & 10 & 851 & 865 & 851 & 052 & 873 & -14 & -3 & -2 & 78 \\
\hline 1 & 10 & & 865 & 854 & 853 & $8<3$ & & 3 & 2 & 20 \\
\hline & & & & & & & & & & \\
\hline
\end{tabular}


Table B-1-C

$\frac{\text { TRANSIENT }{ }^{*} 205-\text { TEST }}{W \text { PREDICTION }}$

\begin{tabular}{|c|c|c|c|c|c|c|c|c|c|c|}
\hline $\begin{array}{l}\text { TIM } \\
\text { SEC. }\end{array}$ & MIN & $\begin{array}{c}\text { (4) } \\
T 929(\mathrm{Az}) \\
T E 5,6\end{array}$ & $\begin{array}{c}\text { (8) } \\
T S 34 \\
T E 19, \\
20,21,22\end{array}$ & $\begin{array}{l}(9) \\
T 927 \\
T E 27.28\end{array}$ & $\begin{array}{r}10 \\
T 932 \\
T E 7.8\end{array}$ & $\begin{array}{c}\text { (11) } \\
T 920 \\
T E 9,10\end{array}$ & $\begin{array}{c}\Delta T \\
(4 \cdot 8)\end{array}$ & $\begin{array}{c}\Delta T \\
(4-9)\end{array}$ & $\begin{array}{c}\Delta T \\
(4-10)\end{array}$ & $\begin{array}{r}\Delta T \\
(4-11)\end{array}$ \\
\hline & & & & & & & & & & \\
\hline \multirow[t]{2}{*}{0} & 0 & 695 & 695 & 695 & 695 & 695 & 0 & 0 & 0 & 0 \\
\hline & & 695 & 695 & 695 & .695 & 695 & 0 & 0 & $\circ$ & $\circ$ \\
\hline \multirow[t]{2}{*}{60} & 1 & 696 & 702 & 707 & 700 & 695 & -6 & -11 & -4 & 0 \\
\hline & & 708 & 778 & $780^{\circ}$ & 735 & 703 & -70 & -72 & -27 & 5 \\
\hline \multirow[t]{2}{*}{120} & 2 & 748 & 820 & 839 & 778 & 717 & -72 & $(-91)$ & -30 & 31 \\
\hline & & 788 & 861 & 876 & 822 & 742 & -73 & -88 & $(-44)$ & 46 \\
\hline \multirow[t]{2}{*}{180} & 3 & 832 & 870 & 878 & 848 & 768 & -38 & -46 & -16 & (64) \\
\hline & & 851 & 867 & 868 & 858 & 792 & -16 & -17 & -7 & 59 \\
\hline \multirow[t]{2}{*}{240} & 4 & 860 & 868 & 870 & 864 & 812 & -8 & -10 & -4 & 48 \\
\hline & & 863 & 868 & 869 & 865 & 826 & -5 & -6 & -2 & 37 \\
\hline \multirow[t]{2}{*}{300} & 5 & 864 & 864 & 864 & 864 & 837 & 0 & 0 & 0 & 27 \\
\hline & & 862 & 861 & 860 & 862 & 844 & +1 & +2 & 0 & 18 \\
\hline \multirow[t]{2}{*}{360} & 6 & 860 & 858 & 858 & 859 & 848 & +2 & +2 & +1 & 12 \\
\hline & & 857 & & & & 851 & & & & 6 \\
\hline 420 & 7 & 855 & 855 & 854 & 855 & 852 & 0 & +1 & 0 & 3 \\
\hline \multirow{2}{*}{480} & 8 & 851 & 852 & 853 & 852 & 857 & -1 & -2 & -1 & -1 \\
\hline & & & & & & 806 & & & -1 & -1 \\
\hline \multirow[t]{2}{*}{540} & 9 & 849 & 851 & 852 & 849 & 851 & -2 & -3 & 0 & -2 \\
\hline & & & & & & & & & & \\
\hline \multirow[t]{3}{*}{ p०o } & 10 & 848 & 850 & 851 & 848 & 851 & -2 & -3 & 0 & -4 \\
\hline & & & & & & & & & & \\
\hline & & & & & & & & & & \\
\hline
\end{tabular}


table $B-2-a$

TRANSIENT \#207-TEST

FROM T.C. MEASUREMENTS

\begin{tabular}{|c|c|c|c|c|c|c|c|c|c|c|}
\hline $\begin{array}{l}\text { TIM } \\
\text { SEC. }\end{array}$ & $\varepsilon$ & $\begin{array}{c}4 \\
T 929(A \mathrm{~A}) \\
\operatorname{TE} 5,6 \\
\end{array}$ & $\begin{array}{l}8 \\
T 934 \\
T=19, \\
20,21,22\end{array}$ & $\begin{array}{r}9 \\
T 927 \\
T=27.28\end{array}$ & $\begin{array}{r}10 \\
T 932 \\
T E 7.9 \\
\end{array}$ & $\begin{array}{l}\text { (11) } \\
T 920 \\
T E 9,10\end{array}$ & $\begin{array}{c}\Delta T \\
(4.8)\end{array}$ & $\begin{array}{c}\Delta T \\
(4-9)\end{array}$ & $\begin{array}{c}\Delta T \\
(4-10)\end{array}$ & $\begin{array}{c}\Delta T \\
(4-11)\end{array}$ \\
\hline & & & & & & & & & & \\
\hline \multirow[t]{2}{*}{0} & 0 & 1058 & 1063 & 1060 & 1060 & 1060 & -5 & -2 & -2 & 0 \\
\hline & & & & & $\therefore$ & & & & & \\
\hline \multirow[t]{2}{*}{60} & 1 & 1056 & 1054 & 1055 & 1058 & 1060 & 2 & 1 & -2 & -4 \\
\hline & & & & & & & & & & \\
\hline \multirow[t]{2}{*}{120} & 2 & 1040 & 1020 & 1020 & 1030 & 1055 & 20 & 20 & 10 & -15 \\
\hline & & & & & & & & & & \\
\hline \multirow[t]{2}{*}{180} & 3 & 1016 & 981 & 982 & 1008 & 1042 & 35 & 34 & 8 & -26 \\
\hline & & & & & &. & & & & \\
\hline \multirow[t]{2}{*}{240} & 4 & 1005 & 944 & 935 & 975 & 1022 & 61 & 61 & 30 & -17 \\
\hline & & & & - & & & & & & \\
\hline 300 & 5 & 955 & 855 & 845 & 920 & 992 & 100 & 110 & 35 & -37 \\
\hline \multirow[t]{2}{*}{360} & 6 & 905 & 800 & 797 & 870 & 958 & 105 & 108 & 35 & -53 \\
\hline & & & & & & & & & & \\
\hline \multirow[t]{2}{*}{420} & 7 & 855 & 772 & 774 & 825 & 925 & 83 & 81 & 30 & -70 \\
\hline & & & & & & & & & & \\
\hline \multirow{2}{*}{480} & 8 & 821 & 792 & 794 & 816 & 893 & 29 & 27 & 5 & -72 \\
\hline & & & & & & & & & & \\
\hline 540 & 9 & 815 & 803 & 803 & 815 & 877 & 12 & 12 & 0 & -62 \\
\hline \multirow[t]{3}{*}{600} & 10 & 815 & 805 & 805 & 815 & 868 & 10 & 10 & 0 & -53 \\
\hline & & & & & & & & & & \\
\hline & & & & & & & & & & \\
\hline
\end{tabular}


Table $B-2-b$

$\frac{\text { TRANSIENT }}{\text { \#207-TEST }}$

\begin{tabular}{|c|c|c|c|c|c|c|c|c|c|c|}
\hline $\begin{array}{l}\text { TIME } \\
\text { SEC. }\end{array}$ & $E$ & $\begin{array}{c}\text { (4) } \\
T 929(A) \\
T E 5,6\end{array}$ & $\begin{array}{r}\text { (8) } \\
T 934 \\
T \varepsilon 19, \\
20,21,2= \\
\end{array}$ & $\begin{array}{r}9 \\
T 927 \\
T E \quad 27,28 \\
\end{array}$ & $\begin{array}{r}10 \\
T 932 \\
T E 7.8\end{array}$ & $\begin{array}{l}\text { (11) } \\
T 920 \\
T \in 9,10\end{array}$ & $\begin{array}{c}\Delta T \\
(4-8)\end{array}$ & $\begin{array}{c}\Delta T \\
(4-9)\end{array}$ & $\begin{array}{c}\Delta T \\
(4-10)\end{array}$ & $\begin{array}{c}\Delta T \\
(4-11)\end{array}$ \\
\hline & & & & & & & & & & \\
\hline 0 & 0 & 1050 & 1050 & 1050 & 1050 & 1050 & 0 & 0 & 0 & 0 \\
\hline & & & & & & & & & & \\
\hline 60 & 1 & 1050 & 1040 & 1050 & 1048 & 1050 & 10 & 0 & 2 & 0 \\
\hline & & & & & & $\cdot$ & & & & \\
\hline 120 & 2 & 1037 & 999 & 10.33 & 1030 & 1045 & 38 & 4 & 7 & -8 \\
\hline & & & & & & & & & & \\
\hline 180 & 3 & 1012 & 958 & 1006 & 1003 & 1033 & 54 & 6 & 9 & -21 \\
\hline & & & & & & $\cdot$ & & & & \\
\hline 240 & 4 & 979 & 901 & 969 & 966 & 1014 & 78 & 10 & 13 & -35 \\
\hline 280 & $4^{2 / 3}$ & $95^{\circ}$ & 854 & 938 & 935 & 996 & $9 b$ & 12 & 15 & -46 \\
\hline 300 & 5 & 934 & 830 & 920 & 917 & 986 & 104 & 14 & (17) & -52 \\
\hline $\begin{array}{l}320 \\
340 \\
340\end{array}$ & $\begin{array}{l}51 / 3 \\
52 / 3 \\
\end{array}$ & $\begin{array}{l}916 \\
898 \\
\end{array}$ & $\begin{array}{l}809 \\
788\end{array}$ & $\begin{array}{l}902 \\
883 \\
\end{array}$ & $\begin{array}{l}900 \\
882\end{array}$ & $\begin{array}{r}975 \\
964 \\
\end{array}$ & 107 & $\begin{array}{l}18 \\
15 \\
15\end{array}$ & 16 & $\begin{array}{l}-59 \\
-66 \\
\end{array}$ \\
\hline 360 & 6 & 880 & 768 & 865 & 864 & 952 & 112 & 15 & 16 & -72 \\
\hline $\begin{array}{l}380 \\
400 \\
\end{array}$ & $\begin{array}{l}61 / 3 \\
62 / 3 \\
\end{array}$ & $\begin{array}{l}862 \\
846\end{array}$ & $\begin{array}{l}752 \\
755 \\
\end{array}$ & $\begin{array}{l}846 \\
831\end{array}$ & $\begin{array}{l}846 \\
834\end{array}$ & $\begin{array}{l}939 \\
927\end{array}$ & $\begin{array}{l}110 \\
91\end{array}$ & $\begin{array}{c}168 \\
-15 \\
\end{array}$ & $\begin{array}{l}76 \\
12 \\
\end{array}$ & $\begin{array}{r}-77 \\
-81 \\
-81\end{array}$ \\
\hline 420 & 7 & 833 & 760 & 820 & 824 & 915 & 73 & 13 & 9 & $=82$ \\
\hline 440 & $7^{7 / 3}$ & 824 & 766 & 812 & 818 & 905 & 58 & $\frac{12}{12}$ & 6 & \\
\hline 480 & 8 & 814 & 779 & 806 & 812 & 888 & 35 & 8 & 2 & -74 \\
\hline & & & & & & & & & & \\
\hline 540 & 9 & 811 & 785 & 804 & 808 & 872 & 26 & 7 & 3 & -61 \\
\hline & & & & & & & & & & \\
\hline 800 & 10 & 810 & 790 & 805 & 808 & 862 & 20 & 5 & 2 & -52 \\
\hline & & & & & & & & & & \\
\hline & & & & & & & & & & \\
\hline
\end{tabular}


TABLE B-2-C

TRANSIENT ${ }^{*}$ 207-TEST

$W$ PREDICTION

\begin{tabular}{|c|c|c|c|c|c|c|c|c|c|c|}
\hline $\begin{array}{l}\text { TIME } \\
\text { SEC. }\end{array}$ & $\begin{array}{l}E \\
I_{\text {Min }}\end{array}$ & $\begin{array}{c}\text { (4) } \\
T 929(\mathrm{AI}) \\
T E \quad 5,6\end{array}$ & $\begin{array}{l}\text { (8) } \\
T 934 \\
T E 19, \\
20,21,22\end{array}$ & $\begin{array}{l}9 \\
T 927 \\
T E 27.28 \\
\end{array}$ & $\begin{array}{r}10 \\
T 932 \\
T E 7.9 \\
\end{array}$ & $\begin{array}{l}\text { (11) } \\
T 920 \\
T E \quad 9,10 \\
\end{array}$ & $\begin{array}{c}\Delta T \\
(4 \cdot 8)\end{array}$ & $\begin{array}{c}\Delta T \\
(4-9)\end{array}$ & $\begin{array}{c}\Delta T \\
(4-10)\end{array}$ & $\begin{array}{r}\Delta T \\
(4-11)\end{array}$ \\
\hline & & & & & & & & & & \\
\hline \multirow[t]{2}{*}{0} & 0 & 1050 & 1050 & 1050 & 1050 & 1050 & 0 & 0 & 0 & 0 \\
\hline & & & & & & & & & & \\
\hline \multirow[t]{2}{*}{60} & 1 & 1049 & 1034 & 1037 & 1041 & 1049 & 15 & 12 & 8 & 0 \\
\hline & & & & & & & & & & \\
\hline \multirow[t]{2}{*}{120} & 2 & 1034 & 1010 & 1004 & 1020 & 1041 & 24 & 30 & 14 & -7 \\
\hline & & & & & & & & & & \\
\hline 180 & 3 & 1010 & 966 & 960 & 994 & 1025 & 44 & 50 & 16 & -15 \\
\hline \multirow{2}{*}{240} & 4 & 997 & 920 & 906 & 950 & 1007 & & 91 & 45 & -5 \\
\hline & & & & & & & 11 & 71 & & \\
\hline \multirow[t]{2}{*}{300} & 5 & 950 & 857 & 831 & 920 & 961 & 93 & 119 & 30 & -11 \\
\hline & & & & & & & & & & \\
\hline \multirow[t]{2}{*}{360} & 6 & 890 & 798 & 770 & 839 & 920 & 92 & (120) & (51) & -30 \\
\hline & & & & & & & & & & \\
\hline \multirow[t]{2}{*}{420} & 7 & 847 & 774 & 766 & 809 & 868 & 73 & 81 & 38 & -21 \\
\hline & 0 & 010 & 701 & 770 & 797 & 820 & 75 & 7 & 3 & \\
\hline 480 & 0 & 810 & 185 & 179 & $(4)$ & 838 & 62 & 31 & 13 & -28 \\
\hline \multirow[t]{2}{*}{540} & 9 & 802 & 789 & 785 & 795 & 817 & 13 & .17 & 7 & -15 \\
\hline & & & & & & & & & & \\
\hline \multirow[t]{3}{*}{600} & 10 & 795 & 791 & 785 & 794 & 808 & 4 & 8 & 1 & -13 \\
\hline & & & & & & & & & & \\
\hline & & & & & & & & & & \\
\hline
\end{tabular}


Table B-3-a

TRANSIENT ${ }^{*} 210$ - TEST

FROM T.C. MEASUREMENTS

\begin{tabular}{|c|c|c|c|c|c|c|c|c|c|c|}
\hline $\begin{array}{l}\text { TIME } \\
\text { SEC. }\end{array}$ & $E$ & $\begin{array}{c}4 \\
T g 29(A) \\
T E \quad 5,6 \\
\end{array}$ & $\begin{array}{c}8 \\
T S 34 \\
T E 19 \\
20,21,22 \\
\end{array}$ & $\begin{array}{c}9 \\
T 927 \\
T E \quad 27,28 \\
\end{array}$ & $\begin{array}{r}10 \\
T 932 \\
T E 7.8\end{array}$ & $\begin{array}{l}\text { (11) } \\
T 920 \\
T E 9.10\end{array}$ & $\begin{array}{c}\Delta T \\
(4.8)\end{array}$ & $\begin{array}{c}\Delta T \\
(4-9)\end{array}$ & $\begin{array}{c}\Delta T \\
(4-10)\end{array}$ & $\begin{array}{c}\Delta T \\
(4-11)\end{array}$ \\
\hline & & & & & & & & & & \\
\hline 0 & 0 & 1057 & 1058 & 1059 & 1059 & 1062 & -1 & -2 & -2 & -5 \\
\hline & & & & & & & & & & \\
\hline 60 & $T$ & 1050 & 1012 & 1015 & 1040 & 1060 & 38 & 35 & 10 & -10 \\
\hline & & & & & & & & & & \\
\hline 120 & 2 & 988 & 936 & 938 & 977 & 1035 & (52) & 50 & (11) & -47 \\
\hline & & & & & & & & & & \\
\hline 180 & 3 & 956 & 915 & 918 & 946 & 1008 & 41 & $\overline{38}$ & 10 & -52 \\
\hline & & & & & & - & & & & \\
\hline 240 & 4 & 934 & 909 & 910 & 934 & 988 & 25 & 24 & 0 & -54 \\
\hline & & & & & & & & & & \\
\hline 300 & 5 & 922 & 902 & 905 & 920 & 972 & 20 & 17 & 2 & -50 \\
\hline 360 & 6 & 910 & 895 & 896 & 912 & 960 & 15 & 14 & -2 & -50 \\
\hline & & & & & & & & & & \\
\hline 420 & 7 & 904 & 890 & 894 & 906 & 948 & 14 & 10 & -2 & -44 \\
\hline & & & & & & & & & & \\
\hline 480 & 8 & 900 & 882 & 895 & 903 & 940 & 18 & 5 & -3 & -40 \\
\hline & & & & & & & & & & \\
\hline 540 & 9 & 900 & 895 & 897 & 903 & 935 & 5 & 3 & -3 & -35 \\
\hline & & & & & & & & & & \\
\hline 600 & 10 & 902 & 900 & 900 & 904 & 935 & 2 & 2 & -2 & -33 \\
\hline & & & & & & & & & & \\
\hline & & & & & & & & & & \\
\hline
\end{tabular}


Table $B-3-b$

TRANSIENT ${ }^{*} 210-$ TEST

AI CALCULATION 12/13/78

\begin{tabular}{|c|c|c|c|c|c|c|c|c|c|c|}
\hline $\begin{array}{l}\text { TIME } \\
\text { SEC. }\end{array}$ & $E$ & $\begin{array}{c}4 \\
T 929(\mathrm{Ax}) \\
T E 5,6 \\
\end{array}$ & $\begin{array}{l}8 \\
\text { (8) } \\
T=194 \\
20,21,22\end{array}$ & $\begin{array}{l}9 \\
T 927 \\
T E 27,28 \\
\end{array}$ & $\begin{array}{r}10 \\
T 932 \\
T E 7.8 \\
\end{array}$ & $\begin{array}{l}\text { (11) } \\
T 920 \\
T E 9.10 \\
\end{array}$ & $\begin{array}{c}\Delta T \\
(4-8)\end{array}$ & $\begin{array}{c}\Delta T \\
(4-9)\end{array}$ & $\begin{array}{c}\Delta T \\
(4-10)\end{array}$ & $\begin{array}{c}\Delta T \\
(4-11)\end{array}$ \\
\hline & & & & & & & & & & \\
\hline 0 & 0 & 1050 & 1050 & 1050 & 1050 & 1050 & 0 & 0 & 0 & 0 \\
\hline & & & & & & & & & & \\
\hline 60 & 1 & 1044 & 977 & 1039 & 1031 & 1048 & 67 & 5 & 13 & -4 \\
\hline 90 & $1 \frac{1}{2}$ & 1021 & 911 & 1009 & 1001 & 1039 & 110 & (12) & 20 & -18 \\
\hline 120 & 2 & 991 & 904 & 979 & 977 & 1026 & 87 & 12 & 14 & -35 \\
\hline 150. & $2 \frac{1}{2}$ & 969 & 899 & 959 & 959 & 1012 & 70 & 10 & 10 & -43 \\
\hline 180 & 3 & 952 & 889 & 943 & 944 & 1000 & 63 & 9 & 8 & -48 \\
\hline 210 & $3 \frac{1}{2}$ & 939 & 893 & 931 & 934 & .988 & 46 & 8 & 5 & -49 \\
\hline 240 & 4 & 930 & 894 & 924 & 927 & 978 & 36 & 6 & 3 & -48 \\
\hline & & & & & & & & & & \\
\hline 300 & 5 & 920 & 891 & .914 & 917 & 963 & 29 & 6 & 3 & -43 \\
\hline 360 & 6 & 913 & 890 & 908 & 911 & 952 & 23 & 5 & 2 & -39 \\
\hline 420 & 7 & 909 & 889 & 904 & 906 & 943 & 20 & 5 & 3 & -34 \\
\hline 480 & 8 & 905 & 888 & 902 & 903 & 936 & 17 & 3 & 2 & -31 \\
\hline 540 & 9 & 903 & 888 & 900 & 900 & 921 & 15 & 2 & 3 & -25 \\
\hline & & 10 & 002 & 100 & 100 & 731 & 13 & 3 & 2 & 20 \\
\hline 600 & 10 & 901 & 887 & 898 & 898 & 926 & 14 & 3 & 3 & -25 \\
\hline & & & & & & & & & & \\
\hline & & & & & & & & & & \\
\hline
\end{tabular}


table B-3-C

TRANSIENT ${ }^{*} 210$-TEST

$W$ PREDICTION

\begin{tabular}{|c|c|c|c|c|c|c|c|c|c|c|}
\hline $\begin{array}{l}\text { TIME } \\
\text { SEC. }\end{array}$ & $E$ & $\begin{array}{c}4 \\
T 229(\mathrm{AI}) \\
T E 5,6 \\
\end{array}$ & $\begin{array}{l}\text { (8) } \\
T 934 \\
T=19, \\
20,21,2=\end{array}$ & $\begin{array}{c}9 \\
T 927 \\
T E 27,28 \\
\end{array}$ & $\begin{array}{r}10 \\
T 932 \\
T E 7.9\end{array}$ & $\begin{array}{l}\text { (11) } \\
T 920 \\
T E 9.10 \\
\end{array}$ & $\begin{array}{c}\Delta T \\
(4.8)\end{array}$ & $\begin{array}{c}\Delta T \\
(4-9)\end{array}$ & $\begin{array}{c}\Delta T \\
(4-10)\end{array}$ & $\begin{array}{c}\Delta T \\
(4-11)\end{array}$ \\
\hline & & & & & & & & & & \\
\hline 0 & 0 & 1050 & 1050 & 1050 & 1050 & 1050 & 0 & 0 & 0 & 0 \\
\hline & & & & & & & & & & \\
\hline 60 & 1 & 1046 & 962 & 940 & 1015 & 1045 & 84 & 106 & 31 & 1 \\
\hline & & & & & & & & & & \\
\hline 120 & 2 & 1006 & 904 & 885 & 966 & 1015 & 102 & (121) & 40 & -9 \\
\hline & & & & & & & & & & \\
\hline 180 & 3 & 969 & 890 & 875 & 938 & 984 & 79 & 94 & 31 & -15 \\
\hline & & & & & &. & & & & \\
\hline 240 & 4 & 942 & 890 & 881 & 922 & 958 & 52 & 61 & 20 & -16 \\
\hline & & & & & & & & & & \\
\hline 300 & 5 & 922 & 884 & 878 & 908 & 937 & 38 & 44 & 14 & -15 \\
\hline 360 & 6 & 908 & 878 & 871 & 896 & 920 & 30 & 37 & 12 & -12 \\
\hline & & & & & & & & & & \\
\hline 420 & 7 & 898 & 875 & 870 & 888 & 907 & 23 & 28 & 10 & -9 \\
\hline & & & & & & & & & & \\
\hline 480 & 8 & 889 & 881 & 879 & 885 & 896 & 8 & 10 & 4 & -7 \\
\hline & & & & & & & & & & \\
\hline 540 & 9 & 886 & 885 & 884 & 885 & 892 & 1 & 2 & 1 & -6 \\
\hline & & & & & & & & & & \\
\hline 600 & 10 & 886 & 887 & 888 & 887 & 891 & -1 & -2 & -1 & -5 \\
\hline & & & & & & & & & & \\
\hline & & & & & & & & & & \\
\hline
\end{tabular}


APPENDIX L

MODEL INDUCER WATER TUNNEL

TEST REPORT

Rocketdyne Document R/H 9113-3741

(Assigned ESG Document number is N266TR000-002)

Figures 12 thru 26 have been removed from this document because they contain proprietary information, as defined by DOE contract. 
N266ER000-001

Page 686

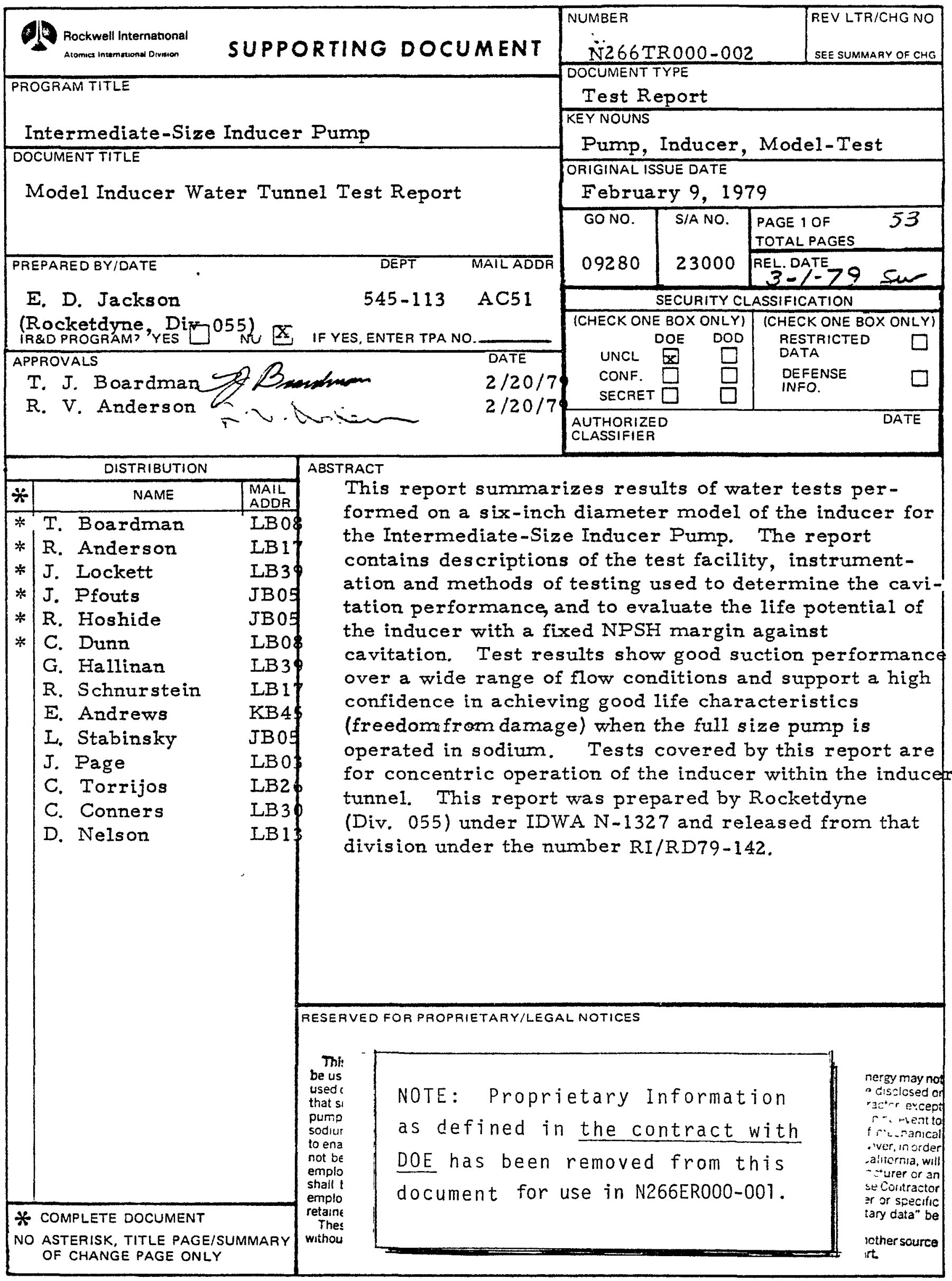


Rocketdyne Divialon

6633 Canoga Avenue

Canoga Park, California 91304

\section{RI/RD79-142}

INTERMEDIATE SODIUM INDUCER PUMP

MODEL INDUCER WATER TUNNEL TEST REPORT

$\mathrm{R} / \mathrm{H}$ 9113-3741

9 FEBRUARY 1979

\section{PREPARED BY}

Rockwell International Corporation Rocketdyne Division 6633 Canoga Avenue Canoga Park, California 91304

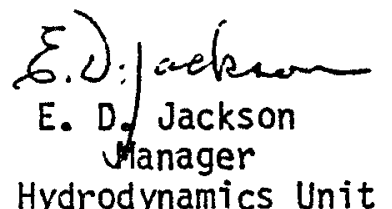

Hydrodynamics Unit

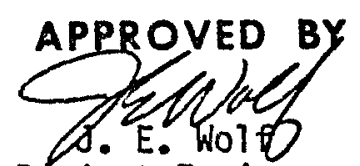

Project Engineer Sodium Pump Program

PREPARED FOR

Energy Systems Group

Atomics International Division

Under IDWA No. N-1327

Authorized Under ESG Prime Contract EY-76-C-03-0824
Q. S. Q a

D. E. Davis

Program Manager

Dynamic Power Programs 
TABLE OF CONTENTS

$\begin{array}{lr}\text { INTRODUCTION } & 1 \\ \text { TEST ARTICLE } & 4 \\ \text { TEST FACILITY } & 6 \\ \text { TEST INSTRUMENTATION } & 11 \\ \text { TEST PROGRAM } & 14 \\ \text { TEST RESULTS } & 17 \\ \text { CONCLUSIONS } & 49 \\ \text { REFERENCES } & 50\end{array}$

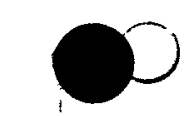




\section{INTRODUCTION}

The Intermediate-Size Inducer Pump (I.S.I.P.) was designed to operate in the existing FFTP pump housing and to achieve the required pump head rise at the same speed and flow as the existing pump. The existing pump consists of four basic hydrodynamic elements:

1. Inlet Elbow

2. Centrifugal Impeller

3. Vaned Diffuser

4. Discharge Housing

All of these elements except the centrifugal impeller were to be retained in an unmodified form for the I.S.I.P. design. The centrifugal impeller was to be replaced with a new design consisting of both an inducer and centrifugal impeller. The objective is to demonstrate the capability of designing an inducer pump for long life in sodium operation so that the advantages of the inducer pump can be realized in future sodium pump applications. These advantages consist primarily in the smaller envelope size and lower weight realized as a result of the better suction performance capability of the inducer. These advantages result in significant cost savings and ease of fabrication and handling for the very large pumps required in many of the reactor coolant loop systems.

Figure 1 shows a cross-section of the primary pump comoonents. The most significant hydrodynamic challenge in the design is to achieve the long 

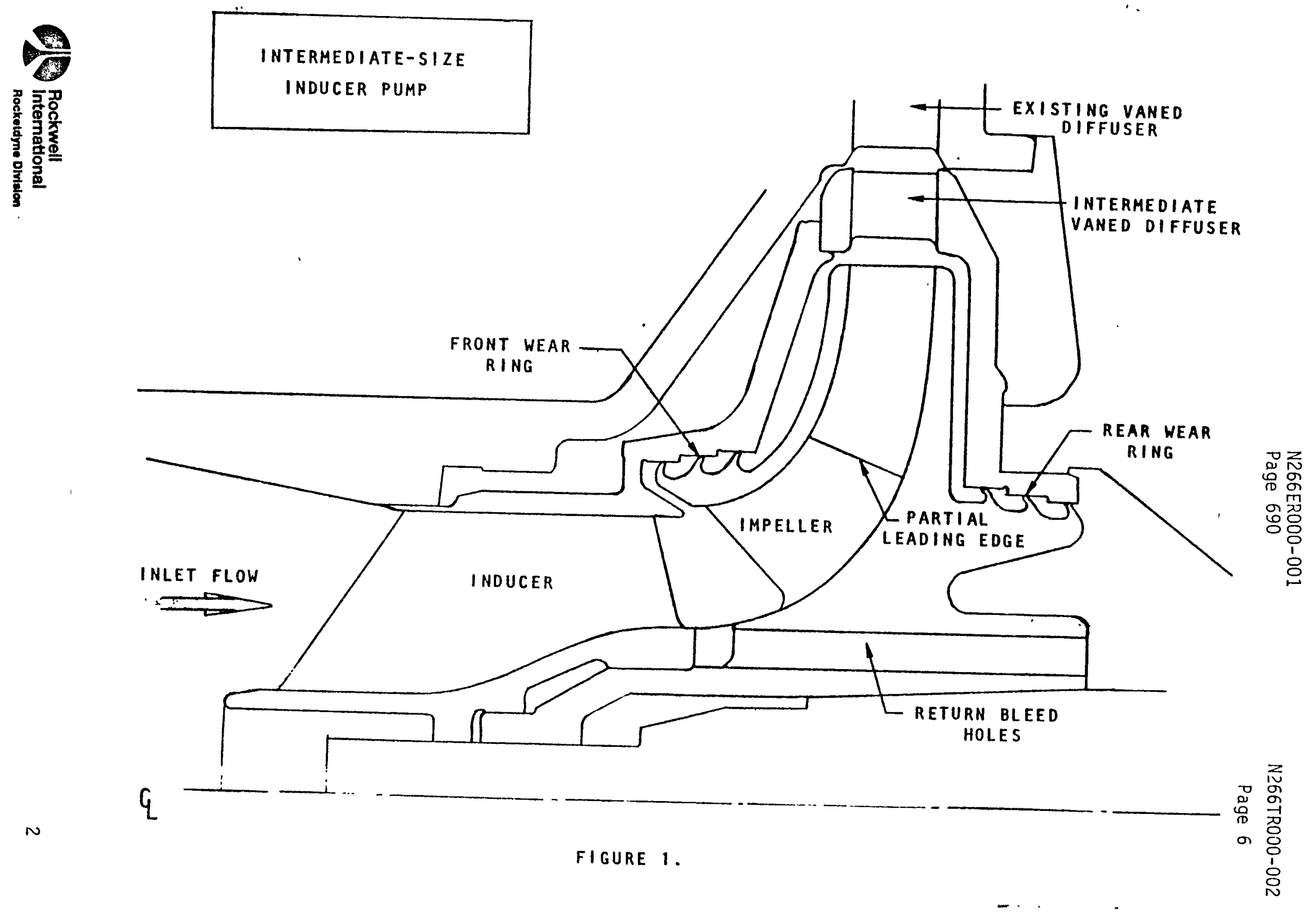
life in the inducer. To provide early confidence in the design before finalizing the fabrication and initiating testing of the full-size pump in sodium, a model of the inducer was fabricated for testing in the Rocketdyne water tunnel. The testing included both life and performance tests using a one-third scale model. The testing was successful and demonstrated both excellent performance and life characteristics for the Rocketdyne design. This report describes both the test program and test results. 


\section{TÉST ARTICLE}

The inducer was designed based on the same design practices established and demonstrated by the successful waterjet inducer designs by Rocketdyne. The primary dimensions of both the full-size and water model of the inducer are given in Table 1. As can be seen, the model is almost exactly a onethird scale version of the full-size. The model inducer is defined by drawing number EWR 344240.

This test article was installed in the test adapter as shown in drawing number EWR 344200. The test adapter consisted of an inducer shaft supported on the test rolling element bearings and splined to an impeller assembly. The impeller assembly, which was driven by the facility gearbox, provided the head requirements to circulate the fluid through the system. 
TABLE 1. I.S.T.P. INDUCER FEATURES

\section{PARAMETER}

No. of Blades

Tip Diameter, In.

Inlet Hub Diameter, In.

Disch Hub Diameter, In.

Tip Radial Clearance, In.

Speed, RPM

Tip Speed, FPS

Design Flow, GPM

Inlet Flow Coefficient

Disch Flow Coefficient \begin{tabular}{l} 
FULL-SIZE WATER-MODEL \\
HARDWARE \\
\hline
\end{tabular}

4

4

18.53

5.986

6.626

2.140

11.358

3.669

0.050

0.016

1110

6322

89.7

165.1

14,600

2803

0.222

0.222

0.310

0.310 
The testing was conducted at Rocketdyne's Pump Calibration Facility in Dept. 592. The pump was driven by a 1200 RPM, reversible, synchronous electric motor, which is rated at 4000 horsepower. The motor drives through a 4000 horsepower gearbox, which has two output shafts. One shaft is capable of producing speeds of 6322 and 8013 RPM. The other shaft is capable of producing speeds of 6322 and 10,029 RPM. The pump was run on the North powerhead (pump position No. 1) at 6322 RPM for this inducer test.

Figure 2 shows a schematic of the drive system and flow 10op. An 8000 gallon water tank supplies water for the flow loop. This tank is rated at 150 psi with a vacuum capability of 28.5 inches of vacuum. The flow is measured by a turbine flow meter in the inlet line and regulated by a motor-operated throttle value in the discharge line, whereas, the inlet pressure is regulated by controlling the tank pressure.

The inlet ducting consists of 8 -inch schedule 40 steel piping, and the discharge loop is 4 -inch diameter steel piping. All metallic coupling joints were heavily greased to assure an air tight system. An orifice was installed in the inlet line to keep the tank pressure up during cavitation tests to further avoid air leaks. 


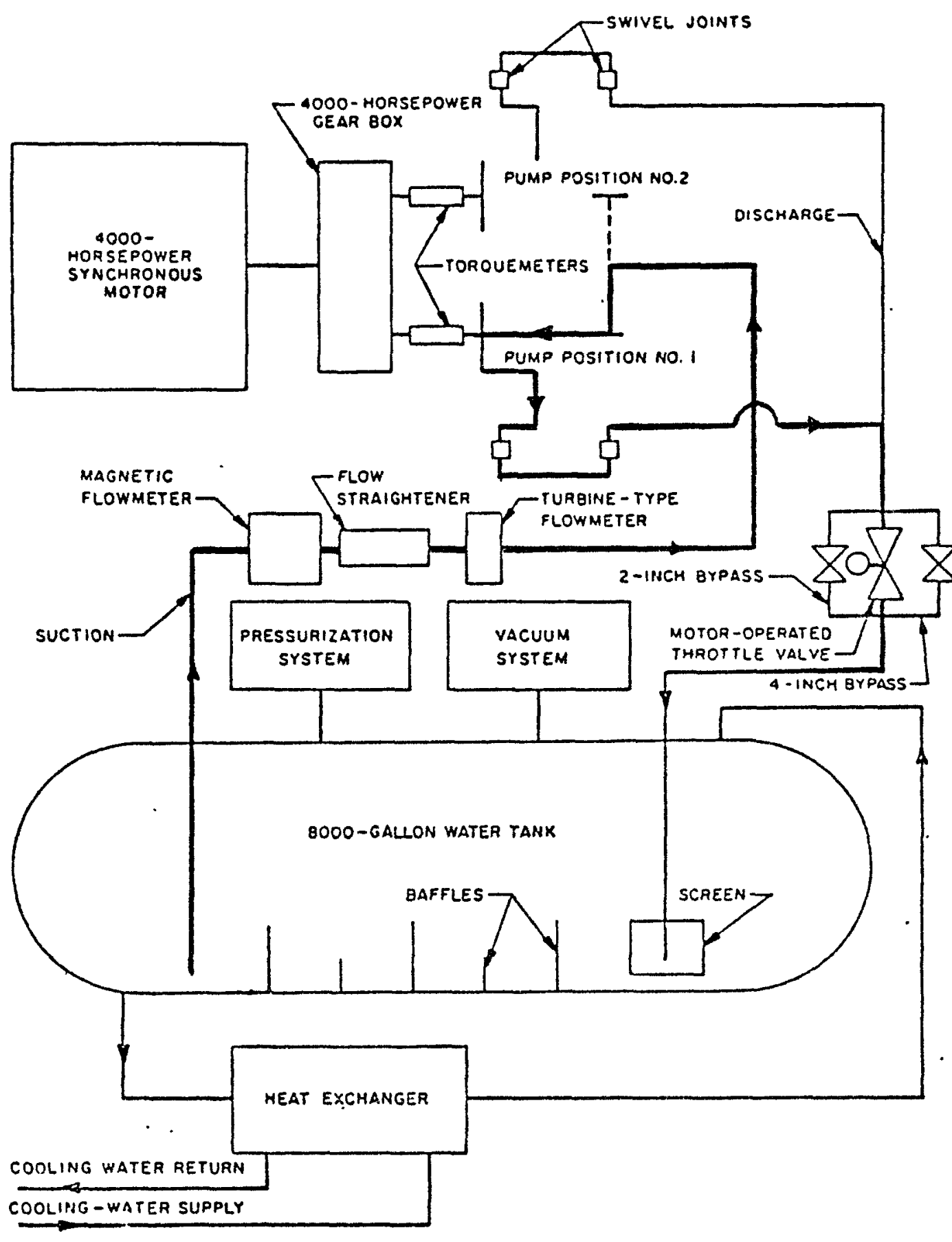

FIG. 2 Drive System and Flow Loop Schematic 
The inducer is mounted on its shaft which is supported by its own bearing system as shown in drawing number EWR 344200. The inducer shaft is connected to an impeller shaft by a quill shaft. The impeller is an 11-inch tip diameter centrifugal impeller previously designed and fabricated at Rocketdyne and used in the current program as a slave impeller to generate the required head to provide the design flow of the inducer. The impeller is far enough downstream of the inducer to permit instrumentation to be inserted between the two for measuring inducer performance without impeller interference. The test arrangement is designed to establish the inducer performance characteristics as an independent component. The only drawback of this facility arrangement is that the only facility torquemeter available is located between the impeller and the drive gearbox. Thus, there is no way to separate the drive torque of the inducer from the slave. impeller, hence no way to determine the efficiency of the inducer. This is not a significant problem because the overall sodium pump efficiency is determined during sodium pump tests and is primarily driven by the centrifugal impeller and discharge system rather than the inducer.

The impeller housing and shaft system was mounted rigidly to a steel frame to assure perfect alignment with the driving motor and, thus, avoid possible oscillation of the system. Testing verified that both the alignment and quill shaft arrangement were satisfactory to prevent any significant rotor dynamic vibrations in either the inducer or impeller.

The inducer was enclosed in a plastic viewing tunnel, which allowed both 
photographic and visual observation of the cavitation characteristics of the flow through the inducer. The test setup is shown in Fig. 3 . The inducer-to-tunnel clearance was measured to be $0.016 \pm 0.001$ inch radially for the initial test series representing a concentric build. Later testing was done with an eccentric tunnel and a reduced clearance concentric tunnel, but only the results of the initial testing are reported here. 


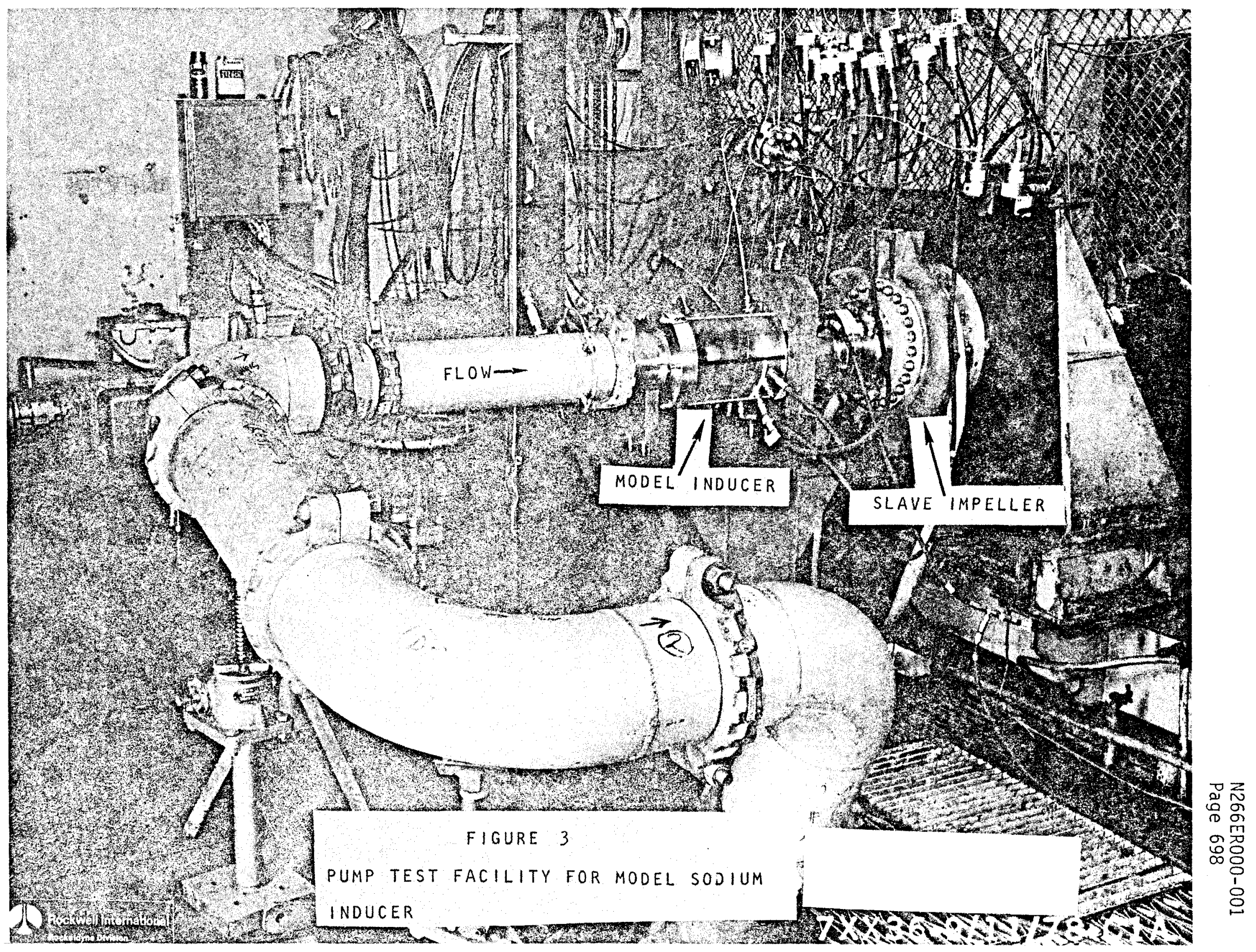




\section{TEST INSTRUMENTATION}

Table 2 presents a list of the instrumentation used during the testing. The inlet pressure consisted of a 4-hole piezometer ring located sufficiently upstream of the inducer to avoid interference effects due to the inducer tip backflow. Downstream of the inducer, two total pressure (Kiel) probes were used to measure the discharge pressure at the mid-blade height position. These probes are subject to clogging due to solid material in the water, and the use of two probes provides more assurance of getting good data during the tests. Yaw probe surveys were planned to provide head distribution as a function of radius but were not carried out due to scheduling conflicts in the facility. There were also numerous static pressures recorded along the tip over the inducer and at the inducer discharge. These were all single point static pressures and provide an indication of the head distribution through the inducer. Drawing number EWR 344205 shows the location of these taps with the same identification keys as used in Table 2.

Other instrumentation included the turbine flowmeter, speed, and torquemeter. These are all standard facility instruments. The speed is fixed during these tests by the electric motor and is recorded only for measuring transients if desired. As previously discussed, the torquemeter measures the input torque to both the inducer and slave impeller so it cannot be used to determine inducer efficiency. Water temperature is measured in the inlet line to permit calculation of the water density and vapor pressure. The other measured pressures are used 
TABLE 2. INSTRUMENTATION

RANGE

Inlet Static Pressure, Piezometer, PSIA

Discharge Total Pressure, \#1 Tunnel (A) PSIG

Flowrate, GPM

Speed, RPM

Torquemeter, IN LB

Water Temperature, ${ }^{\circ} \mathrm{F}$

Discharge Total Pressure $\# 2$ Tunnel (A) PSIG

Pump Discharge Static Pressure, Pipe, PSIG

Pump Delta Pressure, PSI

Static Pressure, Tunnel (A), PSIG

Static Pressure, Tunnel

(C) PSIG

Static Pressure, Tunnel

(D) PSIG

Static Pressure, Tunnel

(E) PSIG

Static Pressure, Tunnel

(F) PSIG

Static Pressure, Tunnel

(G) PSIG

Static Pressure, Tunne1 (1) PSIG

Static Pressure, Tunnel

(3) PSIG
$0 \div 100$

$0 \div 500$

$0 \div 4000$

6322

$0 \div 10,000$

$40 \div 140$

$0 \div 500$

$0 \div 500$

$0 \div 500$

$0 \div 100$

$0 \div 200$

$0 \div 200$

$0 \div 200$

$0 \div 200$

$0 \div 200$

$0 \div 200$

$0 \div 200$

+ Circled letters refer to section locations on Drawing No. EWR 344205 
for facility diagnostics and conducting of the tests.

All of the data are recorded by a digital acquisition system (Autodata 9 by Accurex) on a "floppy disk" which is transmitted post-test to a digital computer. The data are reduced to provide all pertinent data and calculated parameters by a data reduction program written specifically for the Pump Test Facility. The data are then printed in tabular form, and if desired, selected CRT (cathode ray tube) printouts are obtained.

In addition to the recorded data, photographic techniques were used with strobe-light stop-action cameras to record the cavitation patterns during certain tests. These photographic records were then spliced together to form an annotated presentation of the results. Still photographs were also used post-test to record the dye patterns after running life tests (to be described). 


\title{
TEST PROGRAM
}

\begin{abstract}
The purpose of the test program was to conduct head-flow tests, cavitation tests, and dye tests for demonstrating the long life potential of the inducer by the absence of cavitation damage.
\end{abstract}

\section{Head-Flow Test}

Head-flow tests were conducted using an inducer shaft speed of 6322 RPM, and an inlet pressure of 65.0 psia, well above the region of cavitation. Flowrates from 1950 to 3650 GPM were achieved in the test representing a variation of -30 to +30 percent about design flow. Data were sampled recorded on the Autodata 9 system at each specific flow after the flow had been stabilized. The basic purpose of the test was to define the head-flow characteristic of the inducer.

\section{Cavitation Test}

An inducer shaft speed of 6322 RPM was used for the cavitation tests. Inlet pressure was set initially at approximately 50 psia and was allowed to continuousiy decay until the pump head fell off. This test sequence was performed at flowrates from 2100 to $3650 \mathrm{gpm}$, representing a flow variation of -25 to +30 percent about desian flow. Data were continuously recorded on the AD9 system during the pressure decay. The purpose of the tests was to establish the suction performance characteristics of the inducer. 
With the head generated by the inducer, the sodjum impeller operates at a low enough suction specific speed that it does not experience any head fall-off due to cavitation until the inducer head falls off significantly (approximately 15 percent inducer head fall-off generally results in approximately 2-3 percent overall pump head fall-off). Thus, the suction performance established for the inducer from these tests also establishes the overall pump. suction performance.

Design Point Life Tests

After coating the inducer blades with an insoluble dye, a twenty minute test was performed at 200 percent NPSH margin at the design flow of 2803 GPM. The inducer shaft speed was 6322 RPM and the inlet pressure determined based on the suction performance results of preceding tests. Five samples of data were recorded every five minutes on the Autodata 9. The dye used in the tests was the brand name "Magic Marker" marking ink applied to the blade pressure and suction surfaces by cotton swabs. This particular dye has been used extensively by Rocketdyne in developing other long-life inducer designs. The dye has been shown to be an effective indication of cavitation damage potential in that the dye is clearly removed during the 20 minute test if there is cavitation collapse on the blade, but no dye is removed if the cavitation collapse occurs in the fluid stream. Rocketdyne has tested parts in the field to demonstrate long life without cavitation damage after verifying the long-life design by the same type of dye tests described here. Rocketdyne has also tested models of inducers experiencing damage in the field and duplicated the 
damage potential by the dye removal in the model facility. Thus, it is believed such tests are an excellent screening test for providing confidence in the design at an early state in the design process with minimal costs. The use of the "Magic Marker" dye has a degree of correlation with field results and is easily and quickly applied. Thus, Rocketdyne believes that it is a valuable test procedure.

\section{Off-Design Life Test}

These tests were conducted in the same manner as the Design Point Life Tests described above. Several flows were used in the test including 130 percent of design flow. The flow and NPSH margin were varied to establish 7 ife characteristics over a range of operating conditions to establish the best operating point and provide more confidence in the design. The NPSH margin at each flow was compared to the value resulting from operation at the proper speed and flow for the sodium in its facility. Five samples of data were recorded every five minutes on the Autodata 9 system. 


\section{TEST RESULTS}

\section{Inducer Head-Flow Performance}

Figure 4 shows the head rise for the model inducer. Two computer programs were used to predict the head rise trend, and both showed excellent agreement, both with each other and with the test data. The analytical programs correctly predicted both the design point head and the slope of the headflow curve (the off-design performance) over a large flow range.

Figure 5 presents the head-flow curve for the full-sized inducer. The slope of the head-flow curve is sufficiently flat to enable the inducer to continue to produce significant head rise at flows over 130 percent of the design flow. This head is sufficient to keep the impeller blades from experiencing cavitation in the sodium operation eliminating cavitation damage to the impeller. This is one of the advantages of the inducer pump over those without an inducer. Conventional centrifugal impellers cannot operate over a large flow range without significant cavitation unless the NPSH supplied is very large.

The slope of the inducer head-flow curve is negative down to at least 70 percent of design flow. This covers the expected range of steady-state operation of the sodium pumps at all but the lowest speed points. The pump would be expected to maintain a negative slope over an even larger 
ISIP MODEL INDUCER

TIP DIAMETER $=5.986 \mathrm{IN}$.

$N=6322 \mathrm{RPM}$

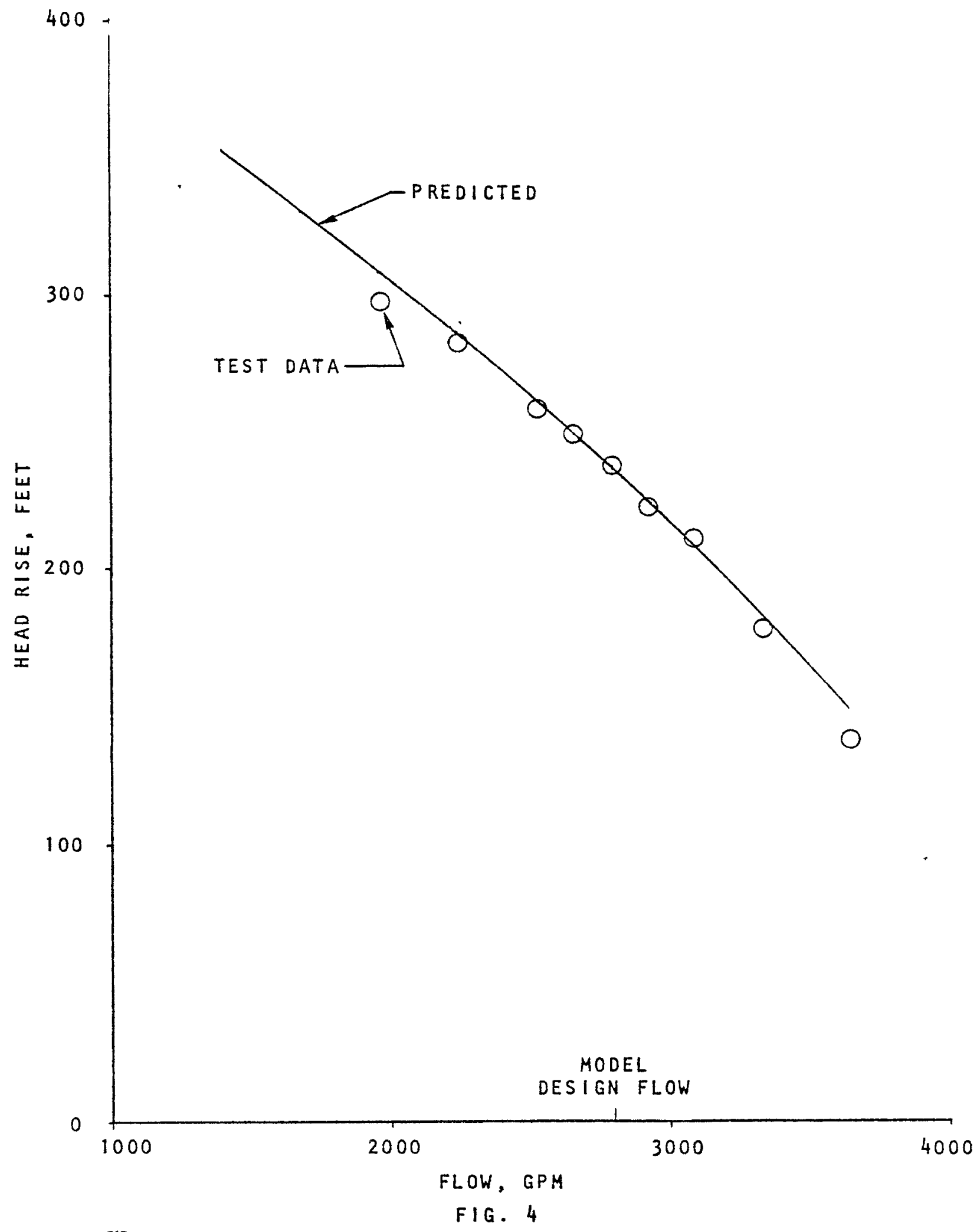


ISIP FULL SIZE INDUCER

TIP DIAMETER $=18.53 \mathrm{IN}$.

$N=1110$ RPM

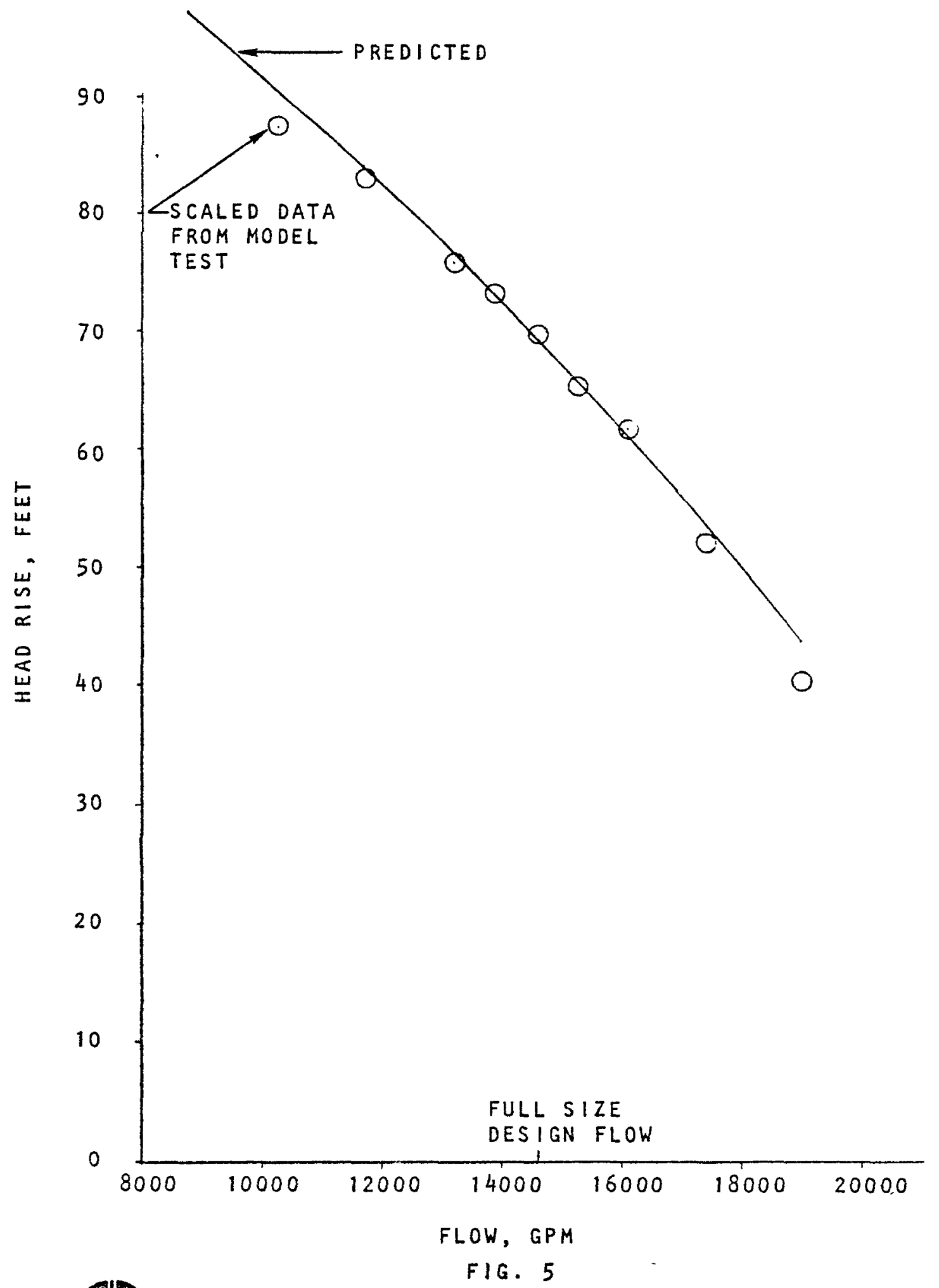


flow range because the centrifugal impeller following the inducer has sufficient NPSH from the inducer to keep it out of cavitation at these low flows, and it would continue to develop more head after the inducer head began to decrease.

The data from the wall static pressures along the tip of the inducer give an indication of the head rise distribution through the inducer. Figure 6 presents the static pressure rise above inlet static pressure for various flow ratios. The figure also presents a sketch of the inducer with the indicated locations of the pressure taps. The data show an excellent trend of increasing pressure through the inducer. The agreement with theory is also seen to be very good. The data actually are higher than the prediction which probably indicates that there is less blockage through the blade rows than assumed in the quasi-three-dimensional flow analysis model. These results are sufficiently close to the desired distribution to give confidence in the design and its long-life potential.

\section{Inducer Suction Performance}

The suction performance tests are run in the test facility with the throttle valve adjusted to maintain constant flow while dropping inlet pressure. The inlet pressure is decreased until a significant loss in head across the inducer is achieved. The data are reduced using computer generated CRT plots as shown in Fig. 7 and 8 , the former showing the 
ISIP MODEL INDUCER

PRESSURE TAP LOCATIONS

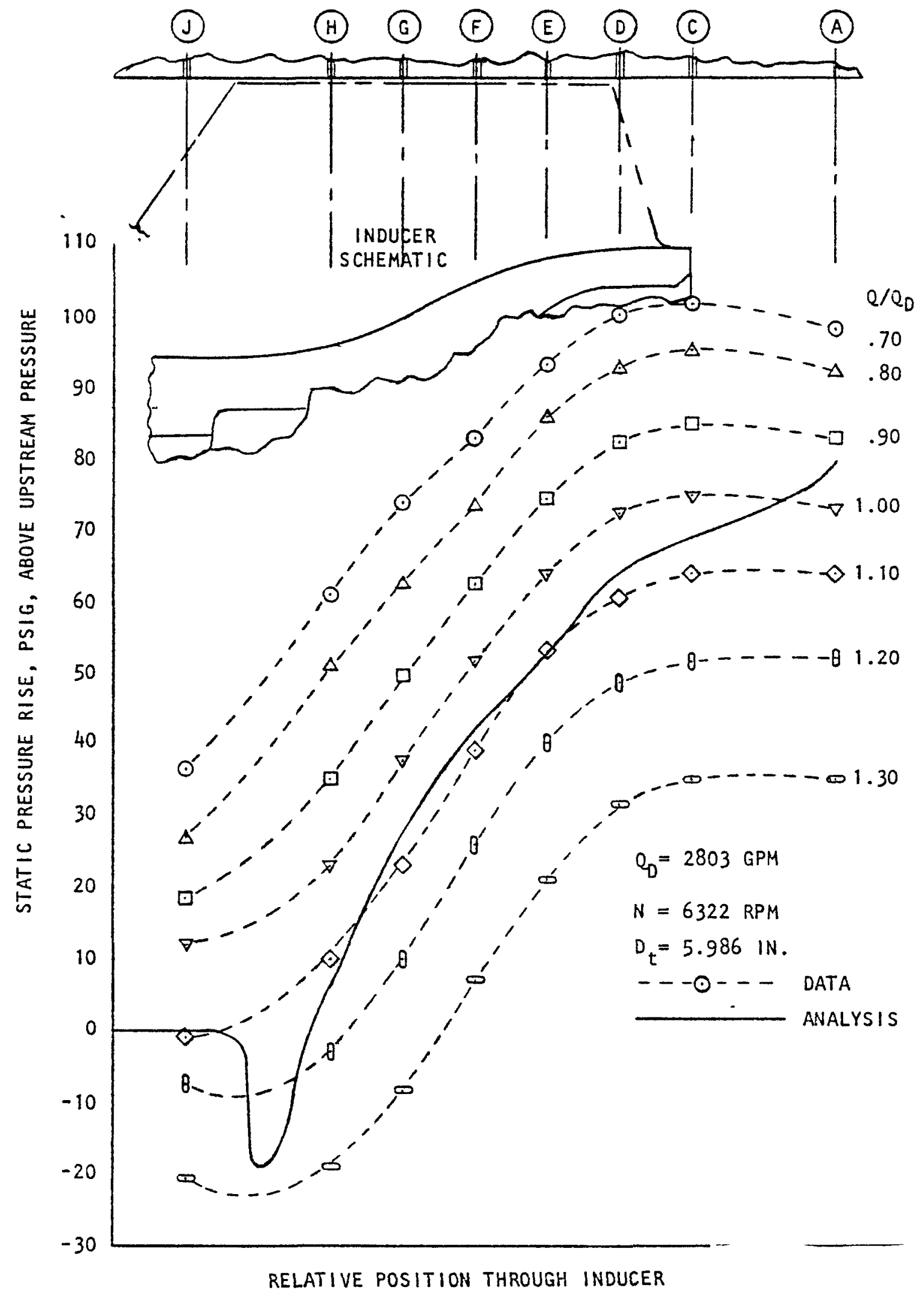

RELATIVE POSITION THROUGH INDUCER 
1 ( 12 -24 IND HERD RISE QI (FT)

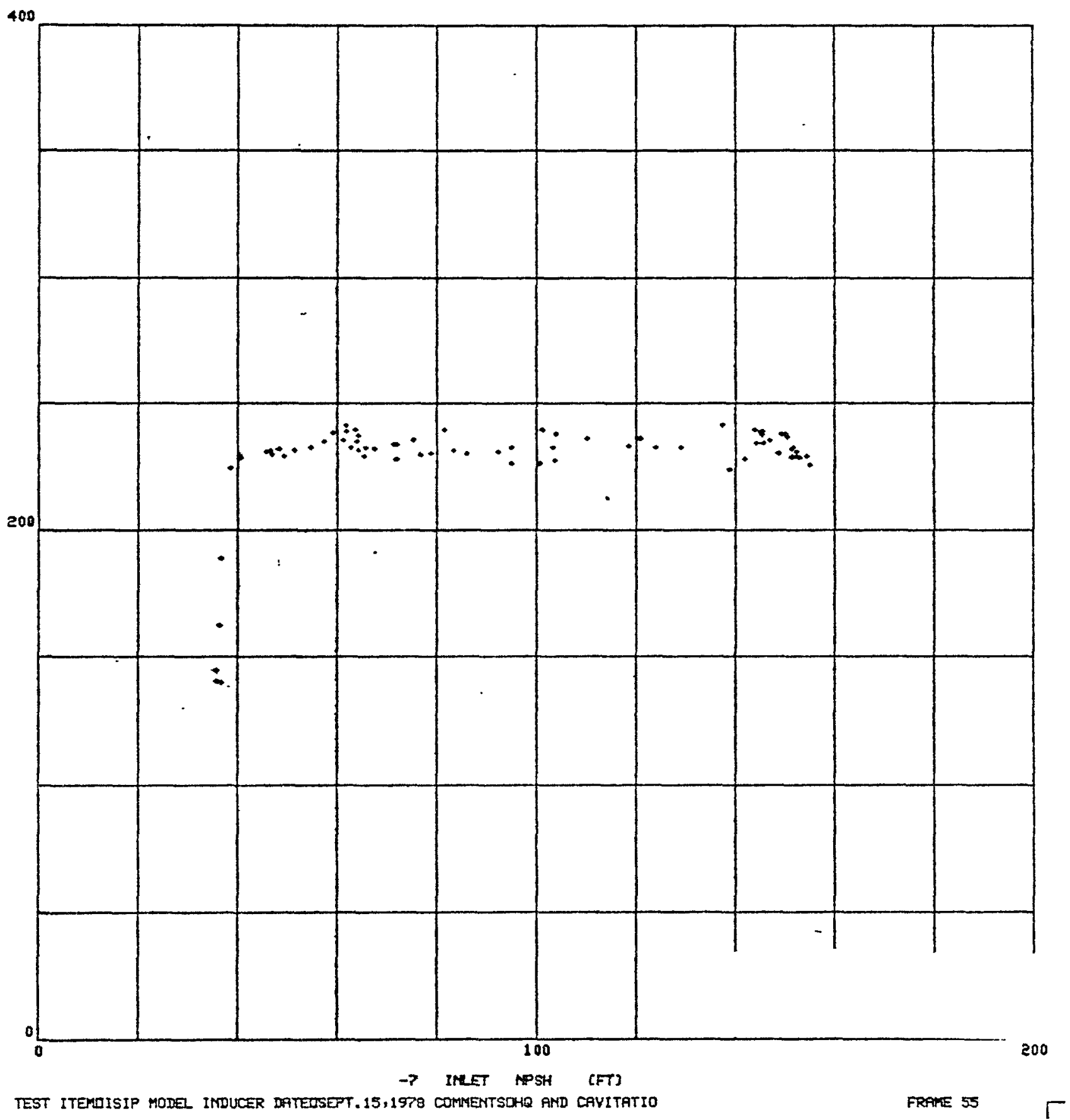

FIG. 7. CRT OF INDUCER HEAD RISE VS NPSH 
J $\quad$ C+3 T4 IND HERD RISE QI (FT)

400

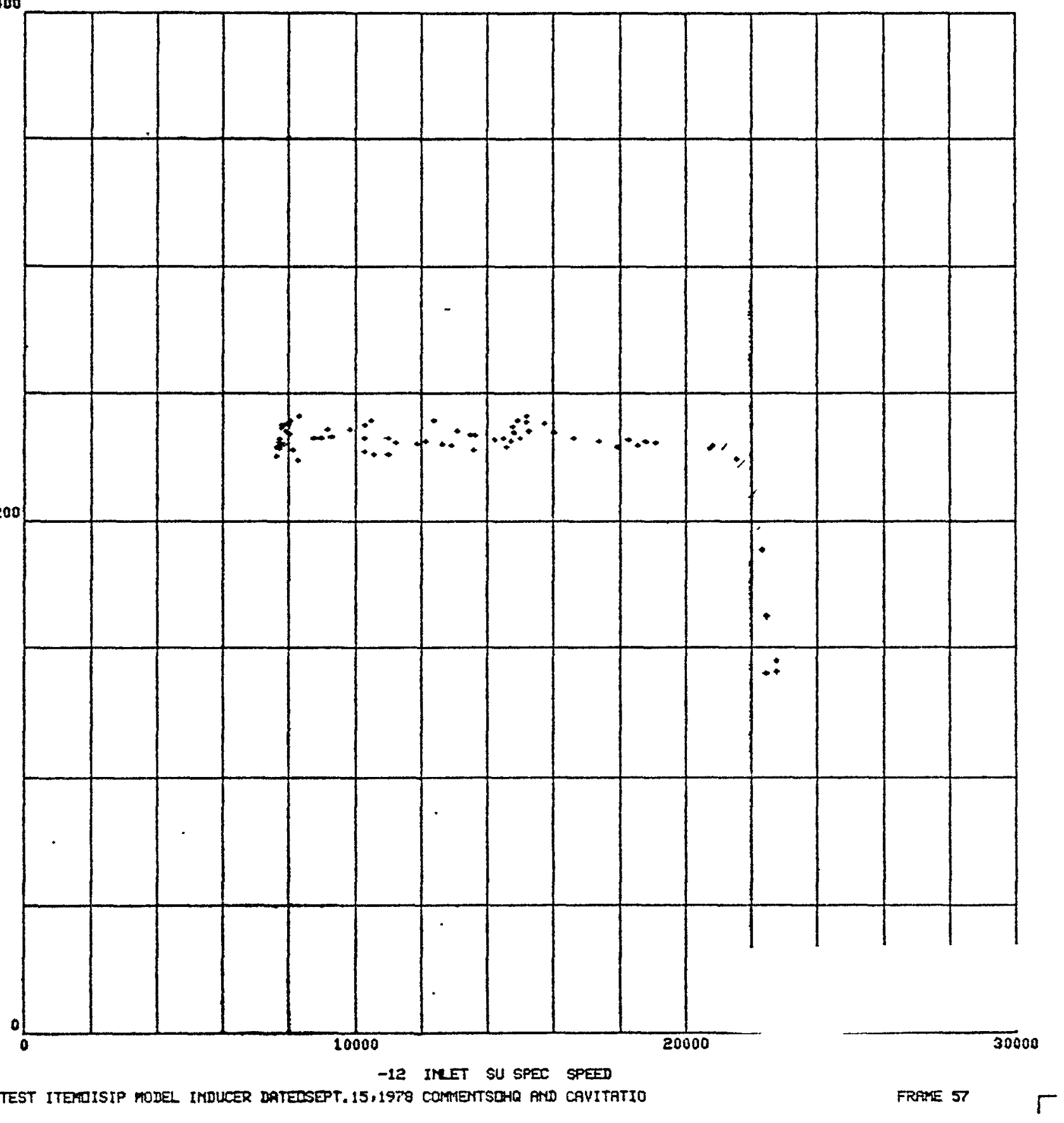

FIG 8. CRT OF INDUCER HEAD RISE VS SUCTION SPECIFIC SPEED 
inducer head rise as a function of inlet NPSH and the latter showing the same inducer head rise but as a function of suction specific speed. From these data, the NPSH and/or the suction specific speed can be determined for various percent fall-off of inducer head from its non-cavitating value. Generally, it is more accurate to work with the suction specific speed curve to get better resolution of the data.

A pump typical of the I.S.I.P. sodium pump will generate most of its head in the impeller. The inducer will only generate from 10 to 20 percent of the total head rise, and this inducer falls in the middle of this range. Thus, if the inducer head drops off by a certain percent, the total pump head will drop by a much smaller percent (from one-tenth to one-fifth as much) as long as the inducer is still generating sufficient head to keep the impeller out of cavitation head fall-off. This effect is even further accentuated by the fact that the impeller will actually make up for some of the loss experienced in the inducer because of the effect of the relative fluid angles. Thus, typically for this type of inducer-impeller combination, the critical NPSH quoted for the inducer based on tests without the impeller is defined as occurring at 15 to 20 percent inducer head fall-off. For the I.S.I.P. sodium inducer, the critical NPSH and suction specific speed were conservatively assumed to be at the 15 percent fall-off point. Thus, the total pump head should degrade by less than three percent for the quoted suction specific speeds.

The suction specific speed of the model inducer based on this criterion is shown in Fig. 9. The figure also shows the suction specific speed 


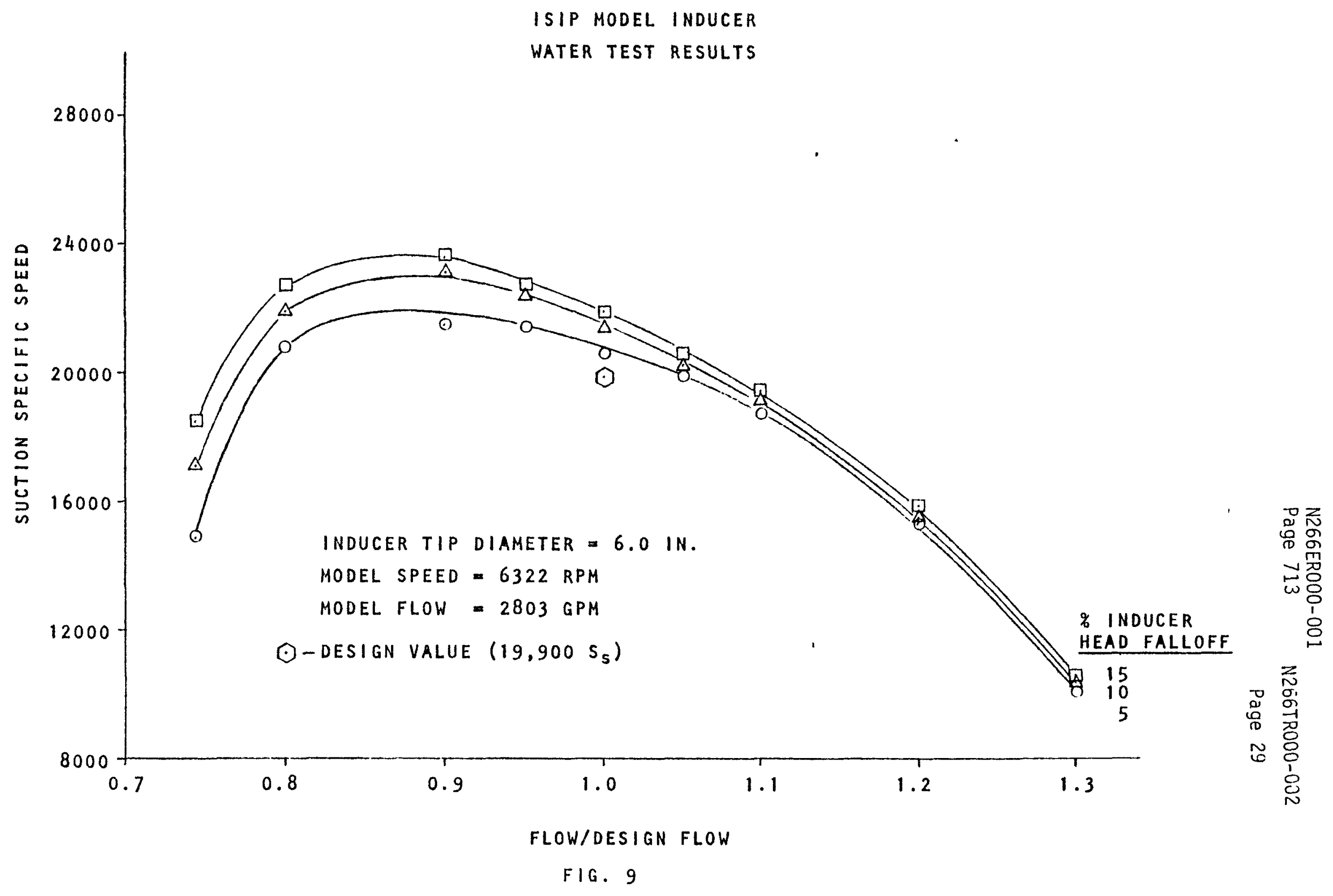


based on 5 and 10 percent of inducer head fall-off. All three curves are seen to be above the predicted value at the design flow. They also show good suction performance over a very large flow range. This will provide a much better NPSH margin to the impeller at the off-design points.

It should, be understood that the data presented in Fig. 9 are direct resuits from water tests with no sodium-to-water correction factor. Rocketdyne's experience in testing cryogenic fluids has led to approaches to correct for the transition from water to cryogenic based on the difference in vapor pressure between the two fluids. This approach has also been used by other industrial and academic communities and is analytically sound. The vapor pressures in water and sodium are both so low that no correction factor should be needed. Such correction factors have been reported in some instances but are probably a result of the test facility rather than fluid thermodynamic behavior.

Using the suction specific speed data of Fig. 9, the required NPSH can be calculated for either the full-size or model pump. The calculation is based on the familiar equation

$$
N P S H=\left[N \sqrt{Q} / N_{S S}\right]^{4 / 3}
$$

where NPSH is in feet, speed $(N)$ is in rpm, flow $(R)$ is in gpm, and $N_{S S}$ 
is the suction specific speed. This calcuiation was made using the flow and speed of the full-size pump to achieve the results shown in Fig. 10 . It should be noted that the required NPSH shown in this figure is for a constant speed of $1110 \mathrm{rpm}$. If speed is varied, the required NPSH would vary directly with speed squared. At the design flow, the required NPSH is slightly over 11 feet. The required NPSH at the lower flows remains low as is typical of a good inducer design. At the higher flows, the required NPSH does increase with flow, but the increase is gradual enough that pump operation will be achieved over the full expected region of operation of flow.

During the cavitation testing, photographic movies were taken to permit observation of the development of the cavities as inlet pressure was dropped. A pressure gage was mounted adjacent to the plastic view tunnel to provide a direct correlation of inlet pressure and cavity development. Selected still photographs were made from the movies to illustrate the cavity patterns in the tip vortex. Figure 11 presents the ratio of the head divided by non-cavitating head as a function of inlet pressure and NPSH with flags to indicate where the still photographs were taken. The photographs included here are all at the design flow and represent NPSH margins from 243 percent down to zero percent.

The photographs are presented in Fig. 12 through 15, beginning at high INPS and decreasing with successive figures. The inducer is to the left of the pressure gage. Flow direction is from the bottom of the figure up. 

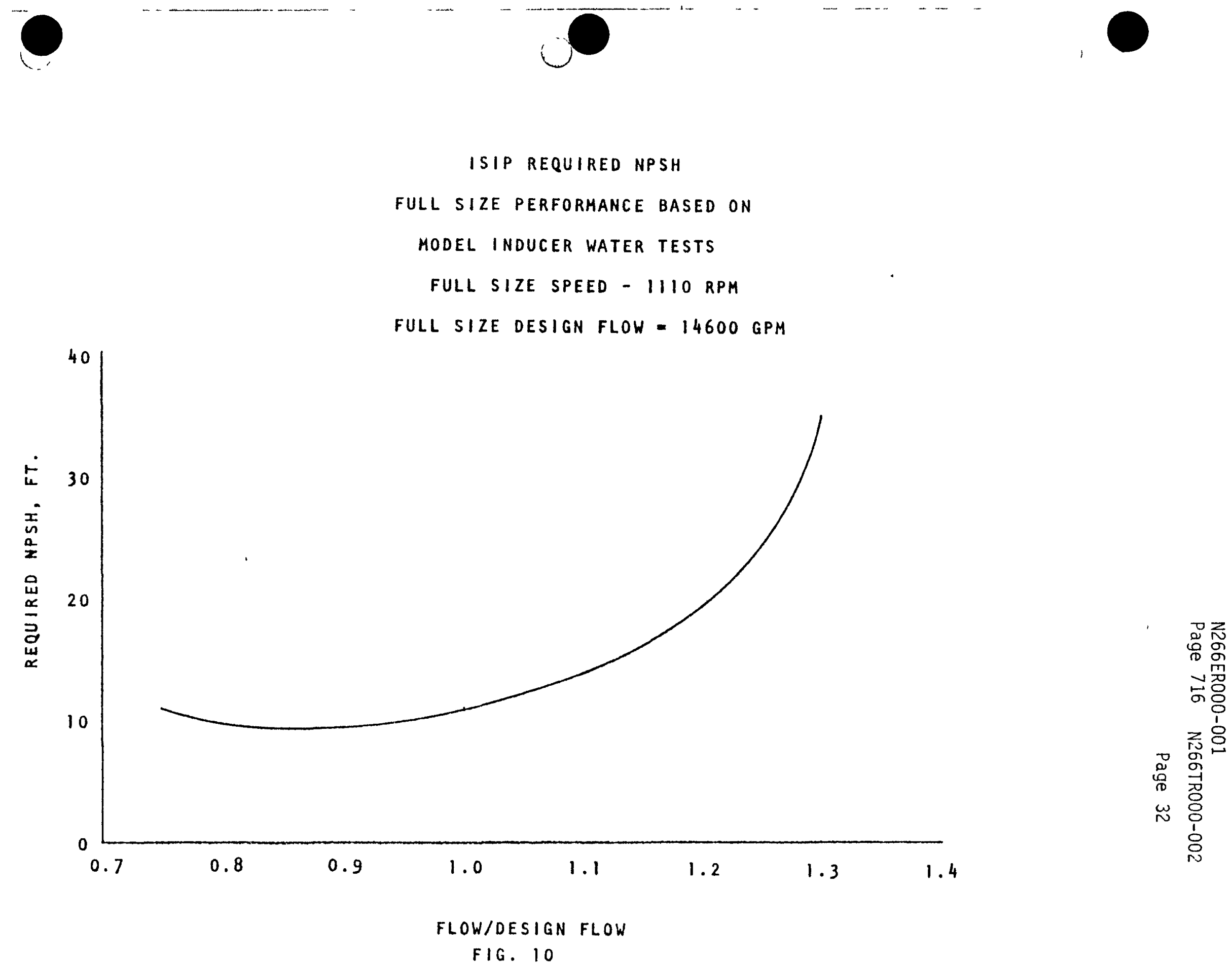

$\infty$

$$
\text { FIG. } 10
$$



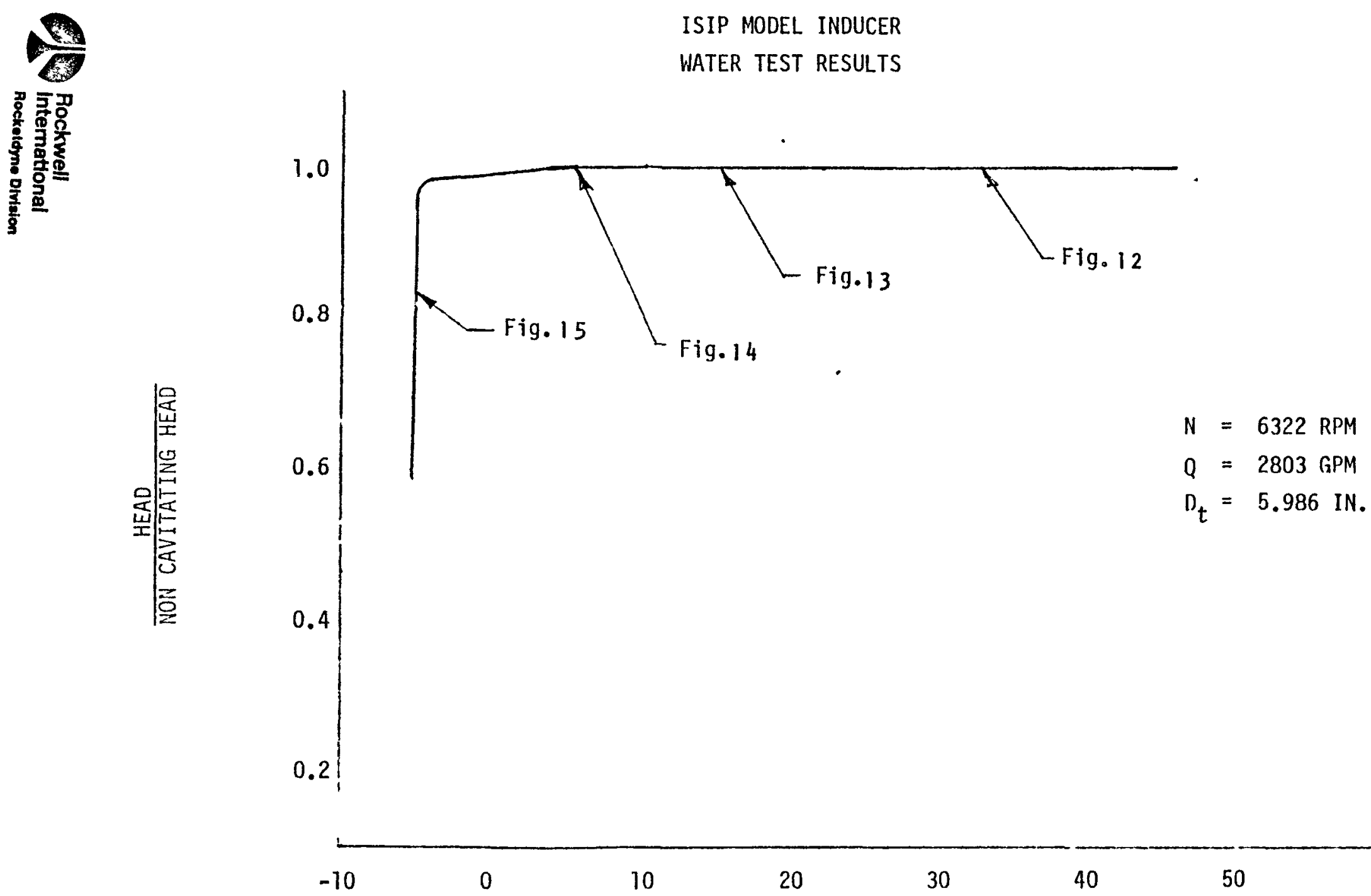

20

INLET STATIC PRESSURE, PSIG

$\begin{array}{llllll}40 & 60 & 80 & 100 & 120 & 140\end{array}$


The inducer is rotating from left to right. The blades can be seen in part, and the tip vortex cavitation is fairly clear. In Fig. 12, this cavity is very small, and the collapse of the vortex can be seen between adjacent blades. In Fig. 13, the cavity has grown but still clearly collapses between blades. In Fig. 14, the cavity can be seen on two adjacent blades, but is still very well contained in the fluid passage and does not extend into the region of the channel flow of the inducer. The last figure (Fig. 15) shows the cavity extended over the full length of the blade, but note that the NPSH margin is down to zero. These photographs indicate in general that the cavity is collapsing in the flow system rather than on the blade, but the dye tests (to be discussed) provide a more positive confirmation of this feature.

\section{$\underline{\text { Life Test Results }}$}

Testing for life in water is not as stringent as testing in sodium for Jaboratory tests have shown that if cavitation is collapsing in an area to cause damage, the damage rate in sodium is higher than it is in water. The magnitude of the variation has been quoted at different levels ranging from two orders of magnitude (Ref. 1) to a factor of approximately 3.0 (Ref. 2). Part of this difference was compensated for in the water tests of the model by testing at a higher inducer tip speed. Laboratory measurements of the effect of tip speed have not been totally consistent, but the majority of the data appear to support the dependency of damage 
on the sixth power of the velocity. The model inducer was tested with a tip speed of 165.1 feet per second (fps) compared to 89.7 fps for the fullsize pump in sodium. Using the sixth-power relationship, this is equivalent to a damage rate 39 times faster due to the higher tip speed of the model.

However, the advantage of performing life tests with dye coatings is that the test is not attempting to identify and/or match damage rates. No attempt is made to measure the extent of damage and scale the rate to predict rate of failure of the full-size hardware. The dye test is designed to identify any potential region of cavitation damage regardless of rate. It takes very little time for a cavity bubble collapsing on the blade to remove the dye. Therefore, for a long-life design, no dye removal would be expected, and the dye test would have to verify that condition. Rocketdyne's design approach is to design to eliminate any cavitation collapse near the inducer blades. Thus, no dye removal during dye testing would be the expected result.

Table 3 presents the various operating conditions tested with dye, indicating both the target and actual test conditions. The flow was varied from approximately 95 to 130 percent of design flow, and the NPSH margin was varied for some of the flows. There was no removal of dye for any of the tests performed substantiating the long-life design features of this inducer. In fact, the I.S.I.P. model inducer showed a greater flow 
TABLE 3. MODEL I.S.I.P. SODIUM INDUCER DYE TESTS IN WATER

\begin{tabular}{|c|c|c|c|c|c|c|c|c|}
\hline & \multicolumn{4}{|c|}{ TARGET VALUES } & \multicolumn{4}{|c|}{ TEST RESULT VALUES } \\
\hline BUILD & $\begin{array}{l}\text { FLOW } \\
\text { (GPM) }\end{array}$ & $Q / Q_{\text {DESIGN }}$ & $\begin{array}{c}\text { INLET } \\
\text { PRESSURE } \\
\text { (PSIA) }\end{array}$ & $\begin{array}{l}\text { NPSH } \\
\text { MARGIN }\end{array}$ & $\begin{array}{l}\text { FLOW } \\
\text { (GPM) }\end{array}$ & $Q / Q_{\text {DESIGN }}$ & $\begin{array}{c}\text { INLET } \\
\text { PRESSURE } \\
\text { (PSIA) }\end{array}$ & $\begin{array}{c}\text { NPSH } \\
\text { MARGIN }\end{array}$ \\
\hline \multirow[t]{11}{*}{ CONCENTRIC } & 2663 & 0.95 & 50.4 & 270 & 2662 & 0.95 & 48.5 & 258 \\
\hline & 2803 & 1.00 & 50.4 & 240 & 2804 & 1.00 & 48.6 & 230 \\
\hline & & & 43.3 & 200 & 2811 & 1.00 & 43.0 & 197 \\
\hline & & & 31.7 & 130 & 2812 & 1.00 & 29.6 & 115 \\
\hline & & & 27.0 & 100 & 2806 & 1.00 & 26.0 & 97 \\
\hline & 2943 & 1.05 & 50.4 & 210 & 2943 & 1.05 & 48.4 & 197 \\
\hline & 3083 & 1.10 & 54.5 & 200 & 3087 & 1.10 & 54.4 & 199 \\
\hline & & & 34.0 & 100 & 3086 & 1.10 & 33.8 & 98 \\
\hline & 3364 & 1.20 & 48.7 & 100 & 3372 & 1.20 & 48.2 & 99 \\
\hline & 3476 & 1.24 & 49.4 & 70 & 3473 & 1.24 & 49.4 & 68 \\
\hline & 3644 & 1.30 & 67.0 & 50 & 3657 & 1.30 & 66.1 & 47 \\
\hline
\end{tabular}


range for no dye removal due to cavitation than any previous inducer tested to date. The dye tests would indicate that long life could be expected in the sodium testing for flows varying from 95 to 130 percent of design flow and over a significant NPSH range. This provides the very highest confidence in the sodium testing, particularly considering the large difference in tip speeds between model and full-size.

The only way to document the results of the dye tests is through photographs of the blades post-test. Such photographs were made of each inducer blade for each test of Table 3. The photographs are not ideal in that light reflections and dye streaking that occurred when the blade was originally coated can appear as dye removal when no such removal was experienced. Nevertheless, it is instructive to include representative photographs to verify the results. Photographs were taken of each of the four blades of the inducer after each of the tests of Table 3 . Reproductions of all of the photographs would be an unnecessary expense, but a representative photograph from each test is shown in Figs. 16 through 26. A mirror was used behind the inducer to show the backside of the blades.

The effects of lighting and dye streaking on the photographic coverage are evident on some of the photographs. Figure 16 shows some evidence of streaking. Several photographs indicate streaking near the trailing edge of the blade, but this is due to the light reflection. The light reflection also presents a light spot near the junction of the blade and the hub at the blade leading edge. The tips of the blades were not coated to prevent smearing any dye on the plastic tunnel. 


\section{CONCLUSIONS}

The testing of the model I.S.I.P. inducer with a concentric scaled tip clearance has been completed with the highest degree of success. The inducer met its design head and exceeded its design suction performance. The slope of the head-flow curve was consistent and negative over the full test range of \pm 30 percent about design flow. The excellent suction performance was maintained over a wide flow range providing good NPSH margin to the impeller over this range. The life tests demonstrated the long-life characteristics of the design, indicating no evidence of dye removal due to cavitation from 95 to 130 percent of design flow and over a significant NPSH range. There was no dye removal under any of the test conditions tested on this inducer. Thus, the full-size pump can be tested in sodium with the highest confidence in its life characteristics.

Further testing of the model inducer with both an eccentric tunnel and with a reduced clearance concentric tunnel have been initiated but will be reported in a separate report. 


\section{APPENDIX M}

MODEL INDUCER WATER TUNNEL

\section{TEST REPORT - ECCENTRIC OPERATION}

Rocketdyne Document $\mathrm{R} / \mathrm{H}$ 9113-3756

(Assigned ESG Document number is N266TR000-004)

Figures 13 thru 36 have been removed from this document because they contain proprietary information, as defined by DOE contract. 


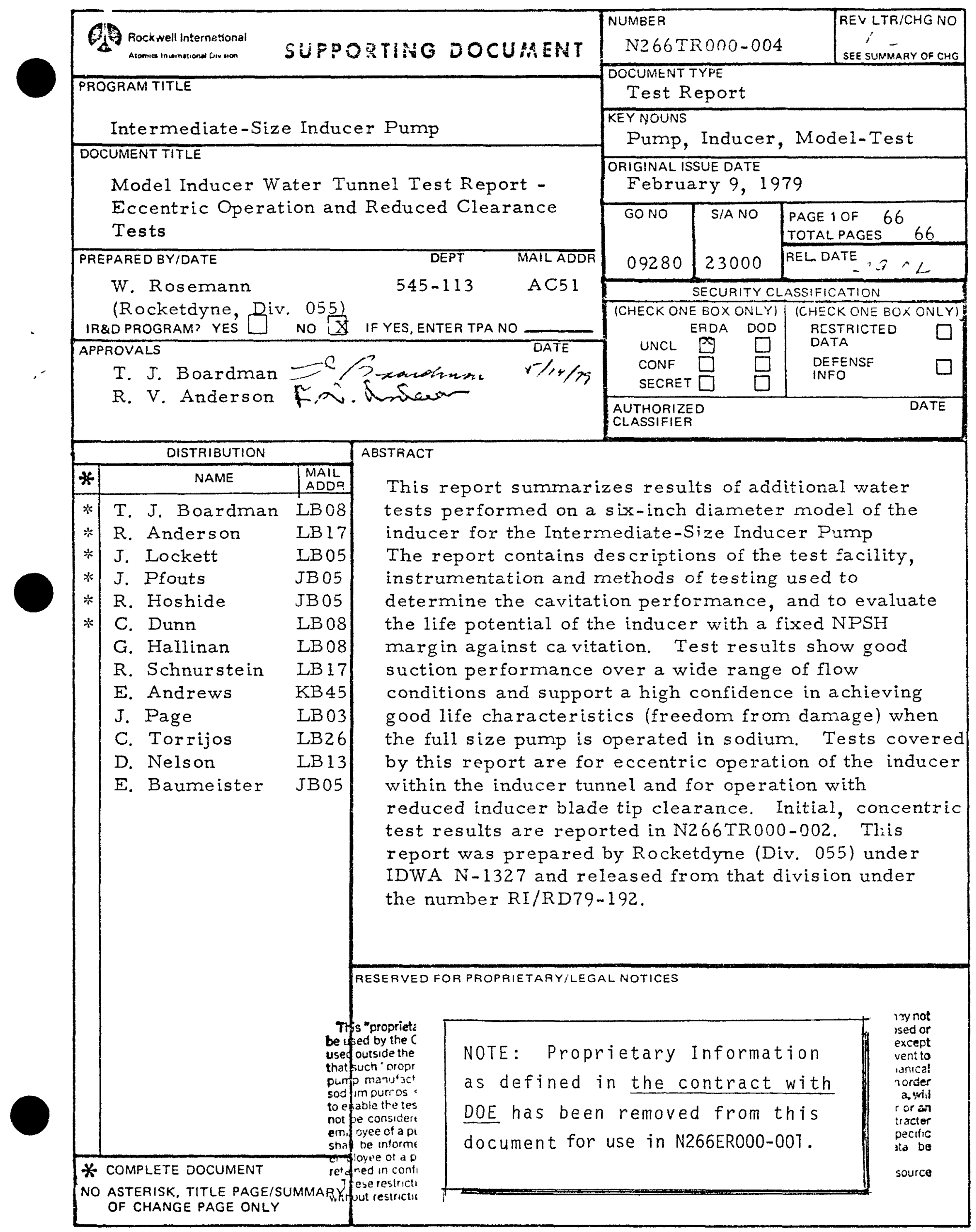




\section{RI/RD 79-192}

\section{Rockwell International}

Rocketdyne Division

6633 Canoga Avenue

Canoga Park, Californa 91304

INTERMEDIATE SODIUM INDUCER PUMP

MODEL INDUCER WATER TUNNEL TEST REPORT

INFLUENCE OF ECCENTRIC AND REDUCED

TIP CLEARANCE UPON PERFORMANCE

$R / H \quad 9113-3756$

28 March 1979

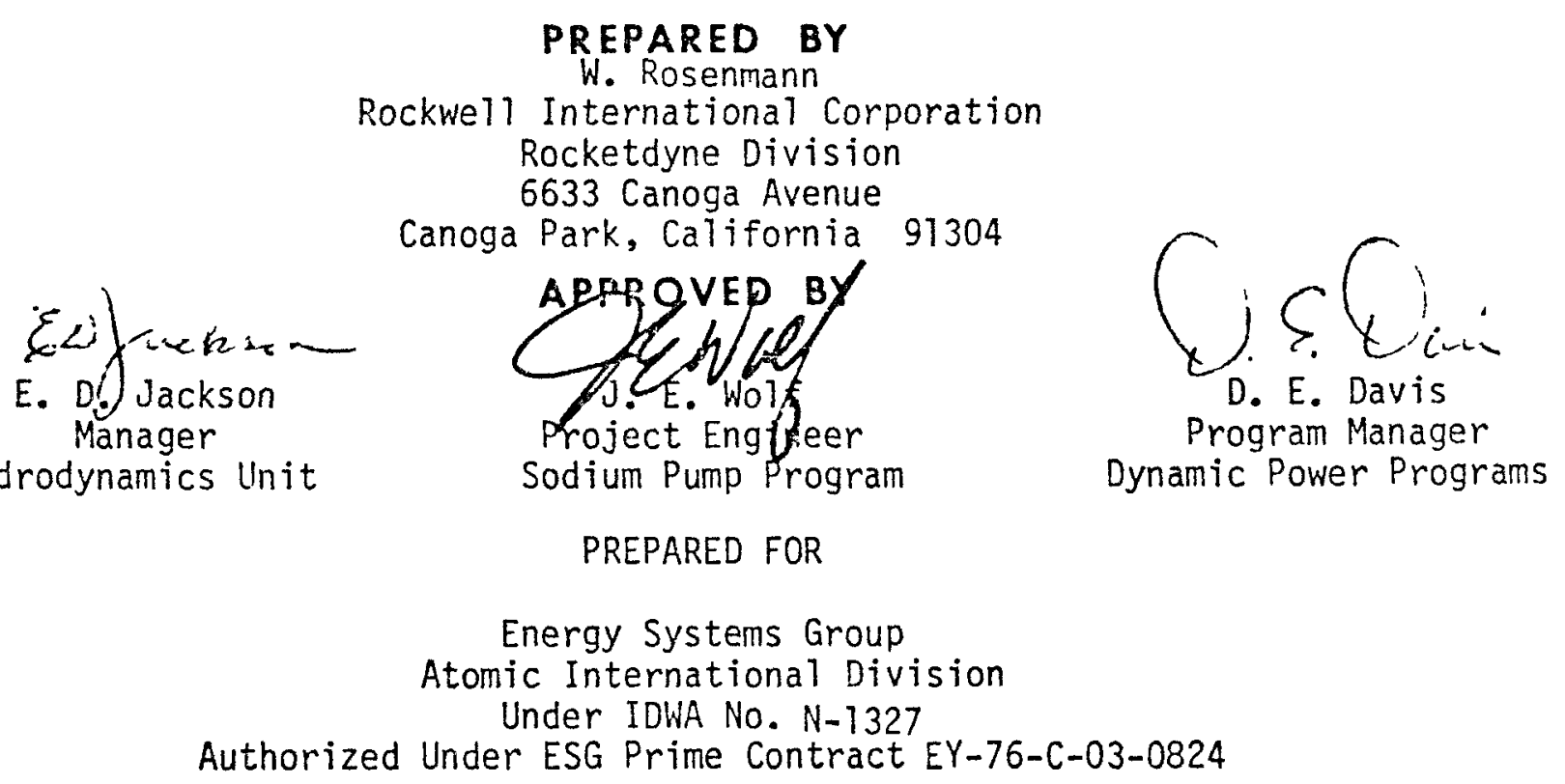


This "proprietary data" furnished under Contract EY-76-C-03-0824 with the Department of Energy may not be used by the Governotent or the Argonne National Laboratory for purposes of manufatture or be disclos or used outside the Government or the Laboratory for any purpose hout prior permission of the Contrador; except that such "propriatar data" mav ho diarlncort cnlelv hrevaluation purposes, participa ment of $\pi$ those bei order to Engineeri considere event a $F$ is used $t$ use Contr to object to tne specilic pump manuraccurer or speain employee of a pump mandfacturer proposed for such use) under the restriction that the "Proprietary data" be retained in confidence.

These restrictions do not 1 imit the Government's rights to use disclose any data obtained from another source without restriction. This legend shall be marked on any reproduction of this data in whole or in part. 
TABLE OF CONTENTS

$\begin{array}{ll}\text { INTRODUCTION } & 1 \\ \text { TEST ARTICLE } & 4 \\ \text { TEST FACILITY } & 6 \\ \text { TEST INSTRUMENTATION } & 11 \\ \text { TEST PROGRAM } & 15 \\ \text { TEST RESULTS } & 18 \\ \text { CONCLUSIOHS } & 60 \\ \text { REFEREICES } & 62\end{array}$


INTRODUCTION

The Intermediate-Size Inducer Pump (I.S.I.P.) was desinned to operate in the existing FFTP pump housing and to achieve the required pump head rise at the same speed and flow as the existing pump. The existing pump consists of four basic hydrodynamic elements:

1. In let [lbow

2. Centrifugal Impeller

3. Vaned Diffuser

4. Discharge Housing,

All of these elements except the centrifugal impeller were to be retained in an unmodified form for the I.S.I.P. design. The centrifugal impelier was to be replaced with a new design consisting of both an inducer and centrifugal impeller. The objective is to demonstrate the capability of designing an inducer pump for long life in sodium operation so that the advantages of the inducer pump can be realized in future sodium pump applications. These advantages consist primarily in the smaller envelope size and lower weight realized as a result of the better suction performance capability of the inducer. These advantages result in significant cost savings and ease of fabrication and handling for the very large pumps required in many of the reactor coolant loop systems.

Figure 1 shows a cross-section of the primary pump components. The most significant hydrodynamic challenge in the design is to achieve the long 

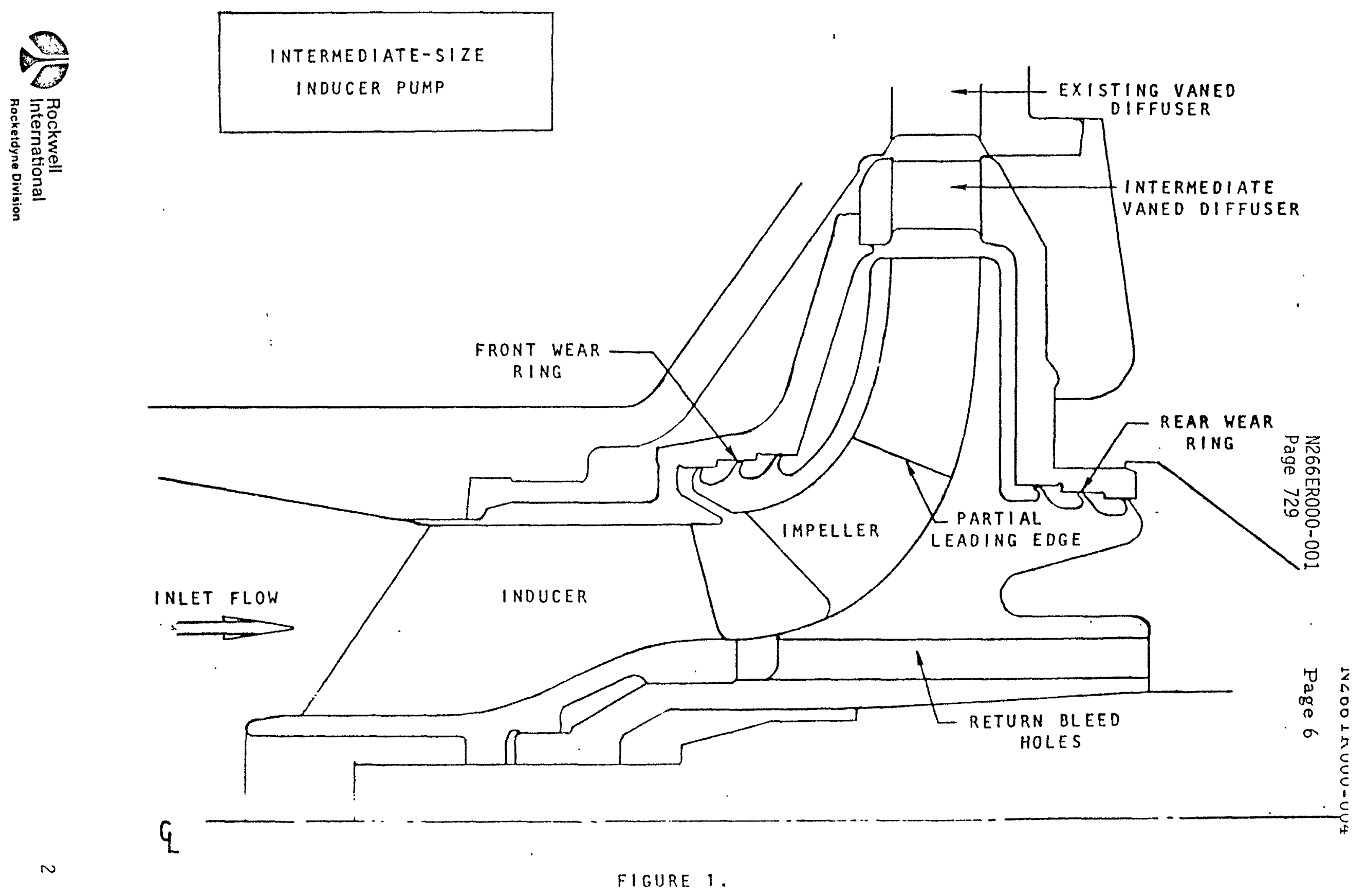
life in the inducer. To provide early confidence in the design before finalizing the fabrication and initiating testing of the full-size pump in sodium, a model of the inducer was fabricated for testing in the Rocketdyne water tunnel. The testing included both life and performance tests using a one-third scale model. The testing was successful and demonstrated both excellent performance and life characteristics for the Rocketdyne design. This report describes both the test program and test results. 


\section{TEST ARTICLE}

The inducer design was based on the same practices established and demonstrated by the successful waterjet inducer design concepts developed by Rocketdyne. The primary dimensions of both the full-size and water model of the inducer are given in Table 1. As can be seen, the model is approximately a one-third scale version of the full-size. The model inducer is defined by drawing number EWR 344240.

This test article was installed in the test adapter as shown in drawing number EWR 344200. The test adapter consisted of an inducer shaft supported on the test rolling element bearings and splined to an impeller assembly. The impeller assembly, which was driven by the facility gearbox, provided the head requirements to circulate the fluid through the system.

Two new tunnels for the inducer were fabricated. The first was eccentric with 0.007 inch offset of the tunnel inside diameter centerline from the inducer shaft centerline. Radial tip clearance ranged from a minimum of 0.007 inch to a maximum of 0.021 inch. This range represents the scaled worst case of the full size manufacturing tolerance eccentricity. The second tunnel was concentric with the inducer with a reduced radial tip clearance of 0.008 inch compared with the nominal model radial tip clearance of 0.016 inch in Table I. The eccentric tunnel, EWR 360711 , was fabricated from clear acrylic plastic, and the concentric tunnel, EWR 360739 was fabricated from aluminum alloy. 
TABLE 1. I.S.T.P. INDUCER FEATURES

\section{PARAIIETER}

No. of Blades

Tip Diameter, In.

Inlet Hub Diameter, In.

Disch. Hub Diameter, In.

Tip Radial Clearance, In.

Speed, RPM

Tip Speed, FPS

Design Flow, GPM

Inlet Flow Coefficient

Disch. Flow Coefficient
FULL-SIZE WATER-HODEL HARDWARE

4

18.53

6.626

11.358

0.050

1110

89.7

14,600

0.222

0.310
HARD:JARE

\section{4}

5.986

2.140

3.669

0.016

6322

165.1

2803

0.222

0.310 


\section{TEST FACILITY}

The testing was conducted at Rocketdyne's Pump Calibration Facility in Dept. 592. The pump was driven by a 1200 RPM, reversible, synchronous electric motor, which is rated at 4000 horsepower. The motor drives through a 4000 horsepower gearbox, which has two output shafts. One shaft is capable of producing speeds of 6322 and 8013 RPM. The other shaft is capable of producing speeds of 6322 and 10,029 RPM. The pump was run on the North powerhead (pump position No. 1) at 6322 RPM for this inducer test.

Figure 2 shows a schenlatic of the drive system and flow loop. An 8000 gallon water tank supplies water for the flow loop. This tank is rated at 150 psi with a vacuum capability of 28.5 inches of vacuum. The flow is measured by a turbine flow meter in the inlet line and regulated by a motor-operated throttle value in the discharge line, whereas, the inlet pressure is regulated by controlling the tank pressure.

The inlet ducting consists of 8 -inch schedule 40 steel piping, and the discharge loop is 4 -inch diameter steel piping. All metallic coupling joints were heavily greased to assure an air tight system. An orifice was installed in the inlet line to keep the tank pressure up during cavitation tests to further avoid air leaks. 


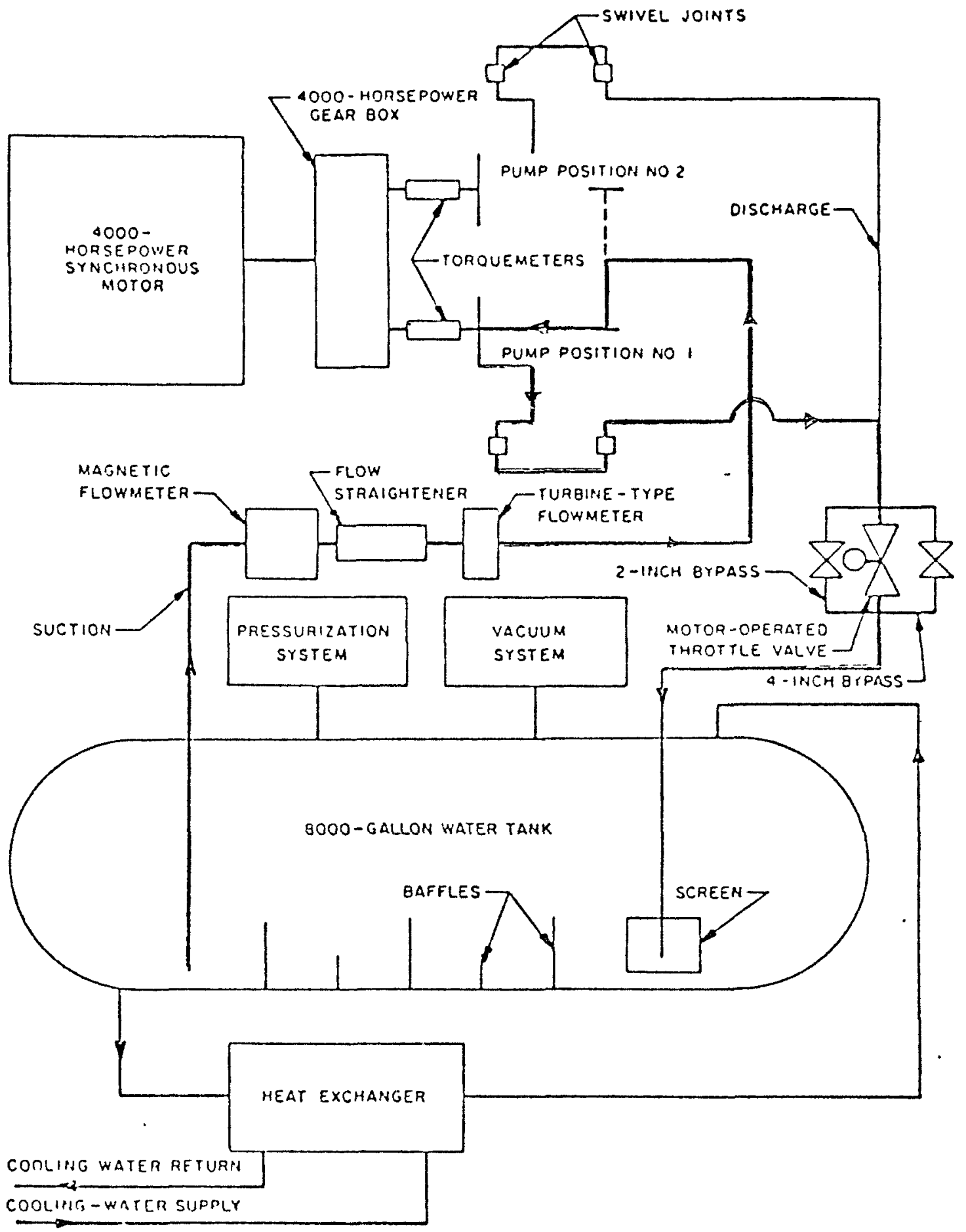

FIG. 2 Drive Svstem and Flow Loop Schenatic 
The inducer is mounted on its shaft which is supported by its own bearing system as shown in drawing number EWR 344200. The inducer shaft is connected to an impeller shaft by a quill shaft. The impeller is an 11-inch tip diameter centrifugal impeller previously designed and fabricated at Rocketdyne and used in the current program as a slave impeller to generate the required head to provide the design flow of the inducer. The impeller is far enough downstream of the inducer to permit instrumentation to be inserted between the two for measuring inducer performance without impeller interference. The test arrangement is designed to establish the inducer performance characteristics as an independent component. The only drawback of this facility arrangement is that the only facility torquemeter available is located between the impeller and the drive gearbox. Thus, there is no way to separate the drive torque of the inducer from the slave impeller, hence no way to determine the efficiency of the inducer. This is not a significant problem because the overall sodium pump efficiency is determined during sodium pump tests and is primarily driven by the centrifugal impeller and discharge system rather than the inducer.

The impeller housing and shaft system was mounted rigidly to a steel frame to assure perfect alignment with the driving motor and, thus, avoid possible oscillation of the system. Testing verified that both the alignment and quill shaft arrangement were satisfactory to prevent any significant rotor dynanic vibrations in either the inducer or impeller.

The inducer was enclosed in a plastic viewing tunnel, which allowed both

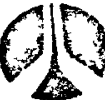


photographic and visual observation of the cavitation characteristics of the flow through the inducer. The test setup is shown in Fig. 3. 


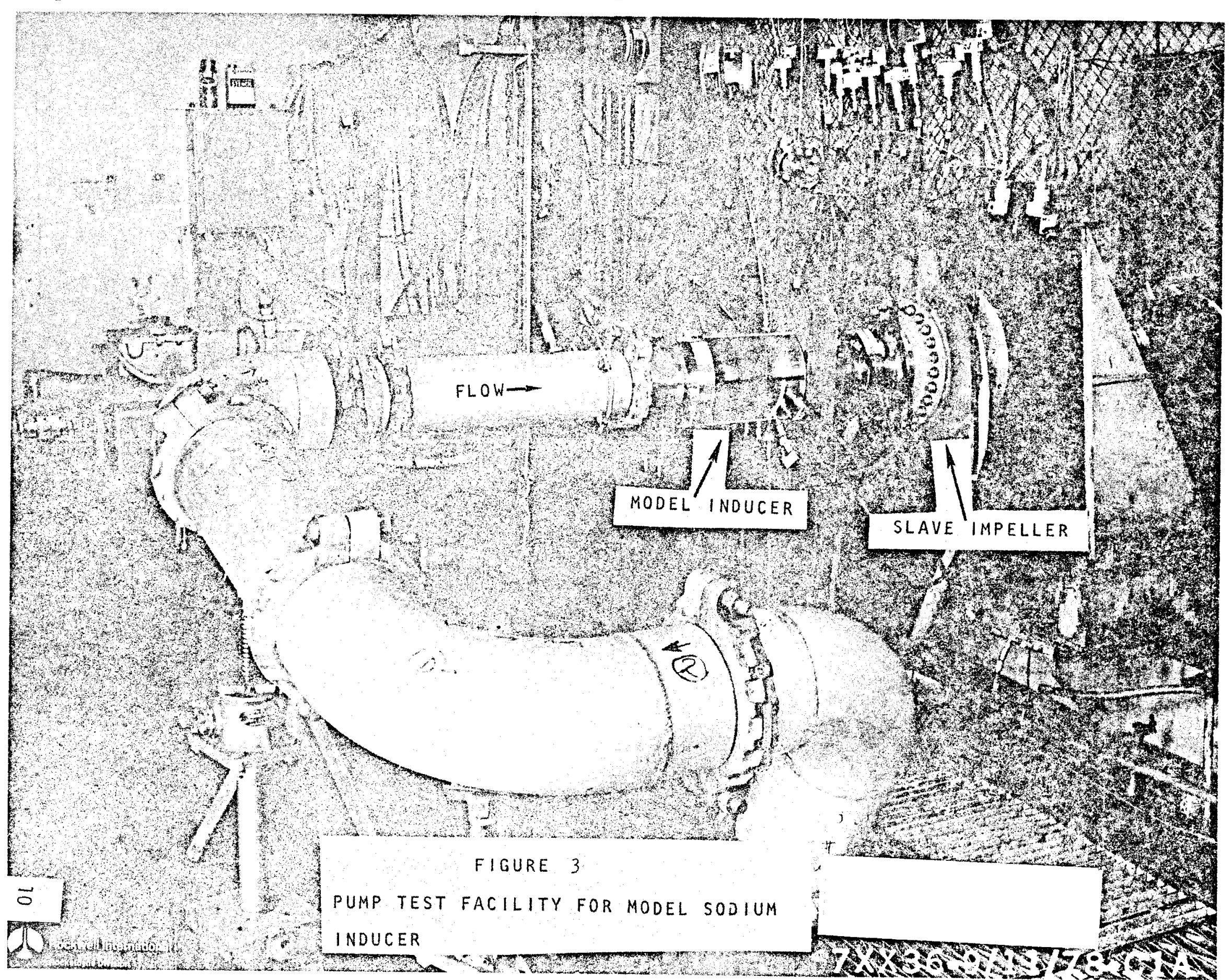




\section{TEST INSTRUMENTATION}

Table 2 presents a list of the instrumentation used during the testing. Figure 4 shows the pressure tap locations in the tester and facility. The inlet pressure consisted of a 4-hole piezometer ring located 30 inches upstream of the inducer to avoid interference effects due to the inducer tip backflow. Downstream of the inducer, two total pressure (Kiel) probes were used to measure the discharge pressure at the mid-blade height position. These probes are subject to clogging due to solid material in the water, and the use of two probes provides more assurance of getting good data during the tests. Yaw probe surveys were carried out to provide flow and pressure data as a function of radius and will be reported separately. There were also numerous static pressures recorded along the tip over the inducer and at the inducer discharge. These were all single point static pressures and provide an indication of the head distribution through the inducer. Drawing number EWR 344205 shows the location of these taps with the same identification keys as used in Table 2. They are also shown in Fig. 4.

Other instrumentation included the turbine flowmeter and an accelerometer fastened to the viewing section to detect excessive vibrations. The electric motor speed is fixed daring these tests. The torquemeter is omitted for this test series. Water temperature is measured in the inlet line to permit calculation of the water density and vapor pressure. The 

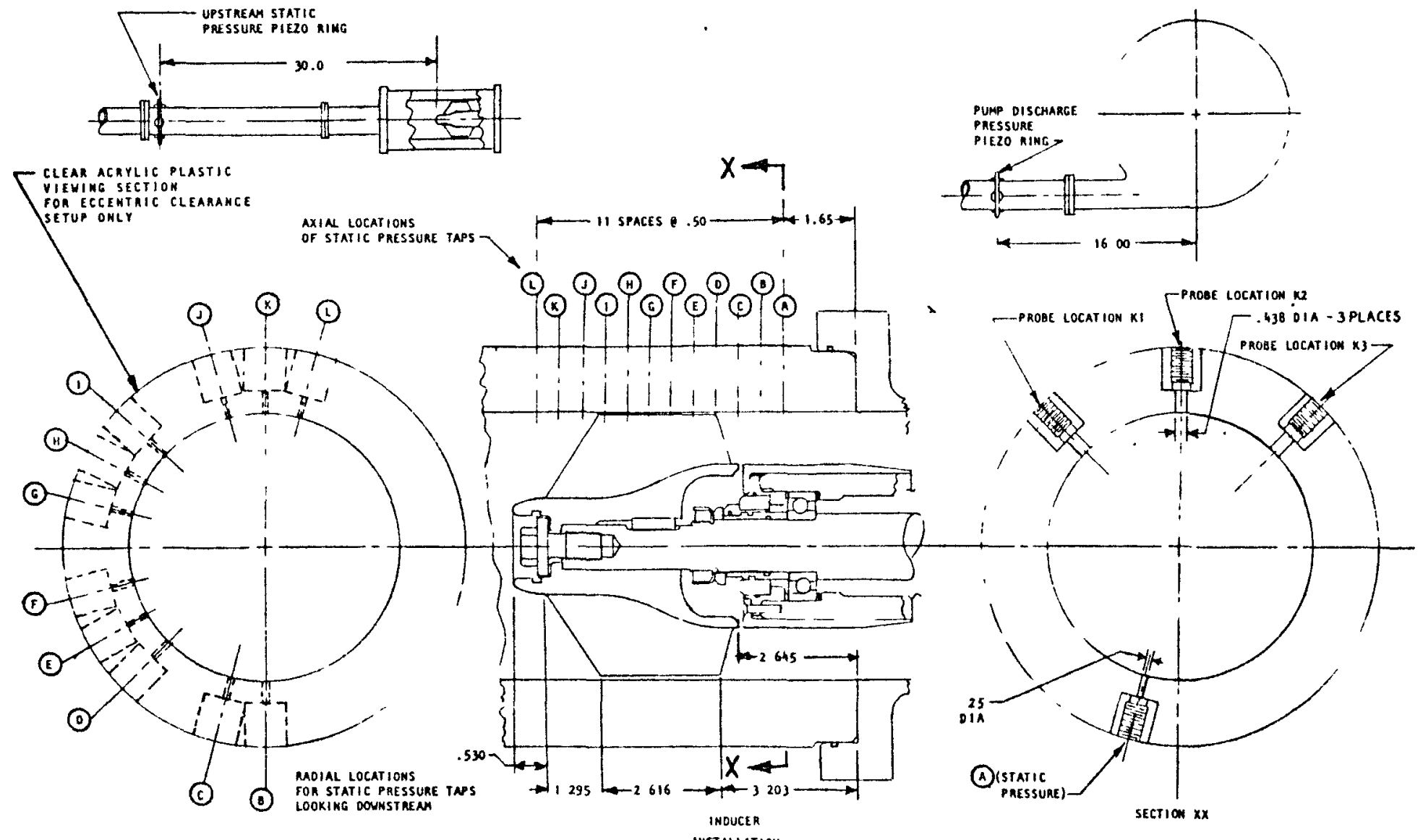
TABLE 2. INSTRUMENTATION

\begin{tabular}{|c|c|}
\hline & RANGE \\
\hline Inlet Static Pressure, Piezometer, PSIA & $0 \div 100$ \\
\hline Discharge Total Pressure, 41 Tunnel (A) PSIG & $0 \div 500$ \\
\hline Flowrate, GPM & $0 \div 4000$ \\
\hline Speed, RPM & 6322 \\
\hline Torquemeter, Ii LB & $0 \div 10,000$ \\
\hline Water Temperature, ${ }^{0} F$ & $40 \div 140$ \\
\hline Discharge Total Pressure $\# 2$ Tunnel (A) PSIG & $0 \div 500$ \\
\hline Pump Discharge Static Pressure, Pipe, PSIG & $0 \div 500$ \\
\hline Pump Delta Pressure, PSI & $0 \div 500$ \\
\hline Static Pressure, Tunnel (A), PSIG & $0 \div 100$ \\
\hline Static Pressure, Tunnel (C) PSIG & $0 \div 200$ \\
\hline Static Pressure, Tunnel (D) PSIG & $0 \div 200$ \\
\hline Static Pressure, Tunnel (E) PSIG & $0 \div 200$ \\
\hline Static Pressure, Tunnel (E) PSIG & $0 \div 200$ \\
\hline Static Pressure, Tunnel (a) PSIG & $0 \div 200$ \\
\hline Static Pressure, Tunnel (1) PSIG & $0 \div 200$ \\
\hline Static Pressure, Tunnel (J) PSIG & $0 \div 200$ \\
\hline
\end{tabular}

+ Circled letters refer to section locations on Drawing No. EWR 344205 
other measured pressures are used for facility diagnostics and conducting of the tests.

All of the data are recorded by a digital acquisition system (Autodata 9 by Accurex) on a "floppy disk" which is transmitted post-test to a digital computer. The data are reduced to provide all pertinent data and calculated parameters by a data reduction program written specifically for the Pump Test Facility. The data are then printed in tabular form, and if desired, selected CRT (cathode ray tube) graphic printouts are obtained.

In addition to the recorded data, photographic techniques were used with strobe-light stop-action cameras to record the cavitation patterns during certain tests. These photographic records were then spliced together to form an annotated presentation of the results. Still photographs were also used post-test to record the dye patterns after running life tests (to be described). 


\section{TEST PROGRAM}

The purpose of this test program was to conduct head-flow tests, cavitation tests, and dye tests for demonstrating the relative cavitation damage potential of the inducer at various radial tip clearance conditions.

Head-Flow Test

Head-flow tests were conducted with a constant inlet pressure of 65.0 psig which is sufficiently above the critical NPSH even at high flows to demonstrate non-cavitating inducer performance. Nine flowrates from 1962 GPM to 3644 GPM were run representing a variation from -30 to +30 percent about the design flow of 2803 rPM. Flow was varied by changing - the control settings on the automatic flow control valve. Data samples were recorded on the Autodata 9 system at each specific flow when stabilization had been achieved.

\section{Inducer Suction Performance}

Inlet pressure was set initially at 80 to $85 \mathrm{psia}$ and was allowed to decay continuously, while the flow was held constant, until the pump pressure rise decayed by 10 to 20 percent. The test sequence was performed at nine different flowrates ranging from 1962 to $3644 \mathrm{gpm}$. These latter extreme flow points represent \pm 30 percent deviation from the design flow of $2803 \mathrm{gpm}$. Data were continuously recorded on the Autodata system during the pressure 
decay. The purpose of these tests was to establish inducer suction performance with the modified tip clearance conditions.

Design Point Life Tests

After coating the inducer blades with a water-insoluble dye, twenty minute tests were performed at the design flow of 2803 GPM. With the eccentric tip clearance tunnel, three NPSH margins of 200, 100, and 50 percent above critical NPSH were used. With the concentric close tip clearance tunnel, the 200 and 100 percent $\mathrm{NPSH}^{\star}$ margins were used. Twenty operating data samples were acquired during these steady parameter runs every five minutes to maintain a record of compliance with specified operating conditions.

The dye erosion tests using "Magic Marker" dye has been proven, through extensive use at Rocketdyne, to be an excellent means of locating areas of potential cavitation damage during relatively short duration tests and thus reduce the need to conduct many costly, long duration runs which involve actual metal damage.

Cavitation sensitive coatings for water tests had been used previously by other researchers (Ref. 1) in connection with tests for liquid metal pumps. They used various types of acrylic coatings and even cadmium plating.

Off-Design Life Test

These tests were conducted in the same manner as the Design Point Life Tests 
described above. Nine more tests were conducted with the eccentric tip clearance setup, and six more tests were conducted with the reduced tip clearance setup. NPSH margins ranged from 20 to 200 percent. Data acquisition during these runs was identical to that used during Design Life Tests. 


\section{TEST RESULTS}

All of the data presented in this report are based on water tests. Long term experience at Rocketdyne has demonstrated that water tests give excellent predictability of pump performance with other liquids if proper conversion factors such as specific weight and vapor pressure are used to calculate the behavior with the other fluids.

Inducer Head-Flow Performance,

Figure 5 shows the head rise for the model inducer with two different tip clearances. The test data for the eccentric tip clearance setup were almost identical to the data presented in Fig. 4 of Ref. 2 in which the same inducer was tested with a concentric tip clearance of .016 inch. In the reduced tip clearance setup, the head rise was slightly higher at design flow and above design flow. Below design flow, the head rise was slightly lower with the reduced tip clearance. The reduced clearance will result in less tip clearance flow and would be expected to lower the tip clearance losses. This would result in slightly higher head and efficiency. No explanation can be given for this curve crossover. Some scattering of data for the head rise values was encountered during the test series. The values shown in this graph were extracted from $\mathrm{H}-\mathrm{Q}$ runs, high NPSH portions of cavitation runs, and life tests. Figure 6 presents the head-flow for the full-sized inducer using eccentric tip clearance. The performance calculation was based on model inducer data. The impeller has the capability 


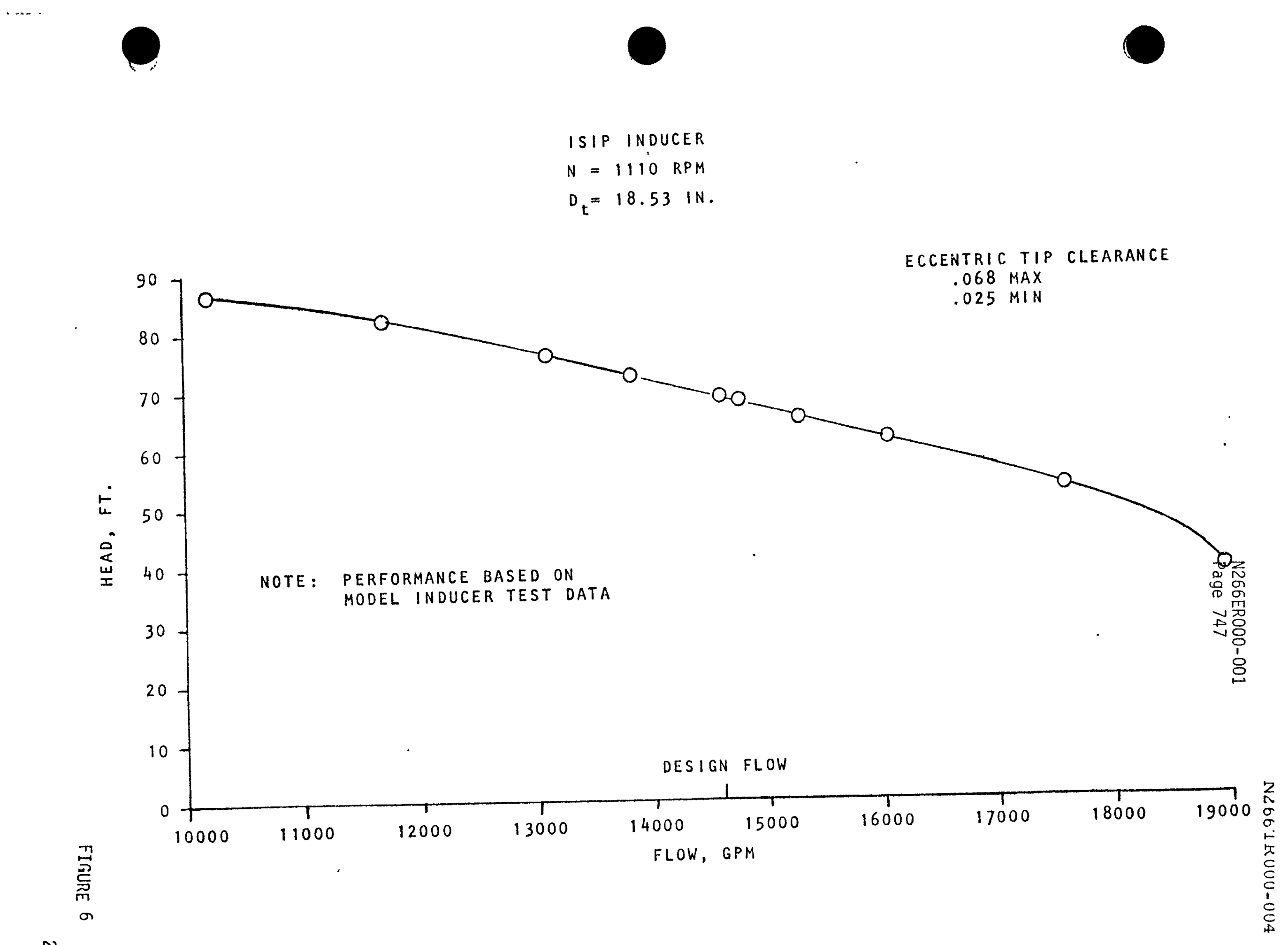


of functioning normally without serious cavitation problems with this inducer performance. Based on these tests, it is clear that neither the eccentricity nor the reduced clearance had any significant effect on the non-cavitating head rise of the inducer.

\section{Inducer Suction Performance}

The suction performance of the inducer using the eccentric tip clearance tunnel is shown in Fig. 7. The curve shows suction specific speed versus $Q / Q_{\text {Design }}$. The latter represents the ratio of actual flow divided by design flow. Two values of head fall-off were used to determine the critical NPSH from which the suction specific speed was calculated. The numerical difference between the two suction specific speed curves amounted to only about three percent. This indicates a sharp head loss near the critical NPSH which is characteristic of well designed inducers. This characteristic can also be seen on the CRT gräphic ptot in Fig. 8. The data shows a stahre head rise down to just above the critical NPSH and then a sharp head loss below that point.

For the ISIP inducer, the critical NPSH values were conservatively assumed to be at 15 percent head fall-off. At this operating point, the impeller usually compensates for most of the inducer head loss by increased head rise within the impeller. Figure 9 shows the suction specific speed versus flow ratio for concentric nomal tip clearance (from Ref. 2), eccentric normal tip clearance, and concentric reduced tip clearance.

At design flow and above, the three curves have only slight differences. At 70 percent to 90 percent of design flow deviations occurred between the 
MODEL INTERMEDIATE SODIUM

INDUCER PUMP (ISIP)

\section{RPM}

TIP DIA. $=5.986 \mathrm{INCH}$

$Q_{D E S I G N}=2803 \mathrm{GPM}$

ECCENTRIC TIP CLEARANCE: .021 MAX .007 MIN

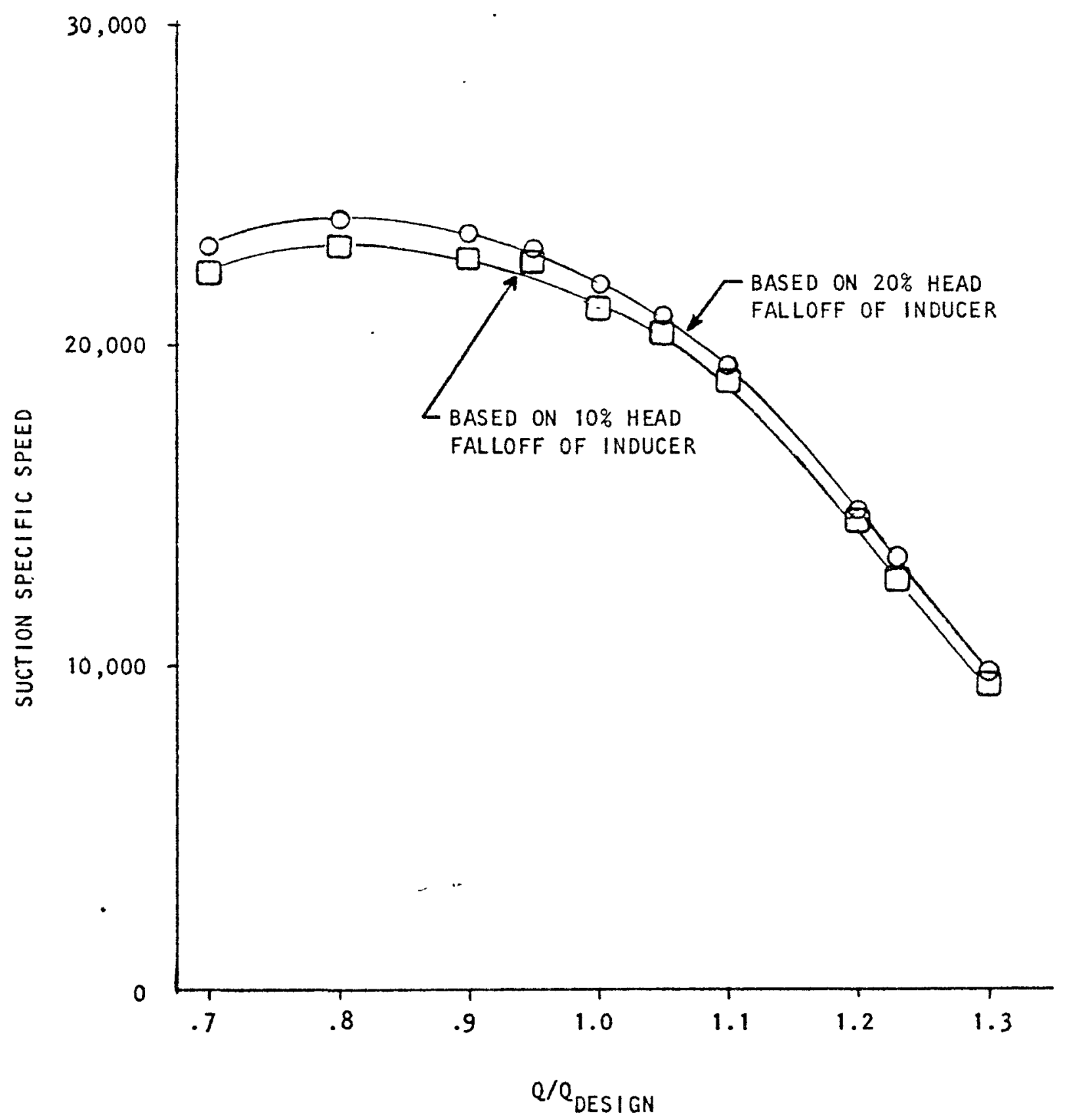

FIGURE 7 
(+) -2S IND HEAIPISE DE (FT)

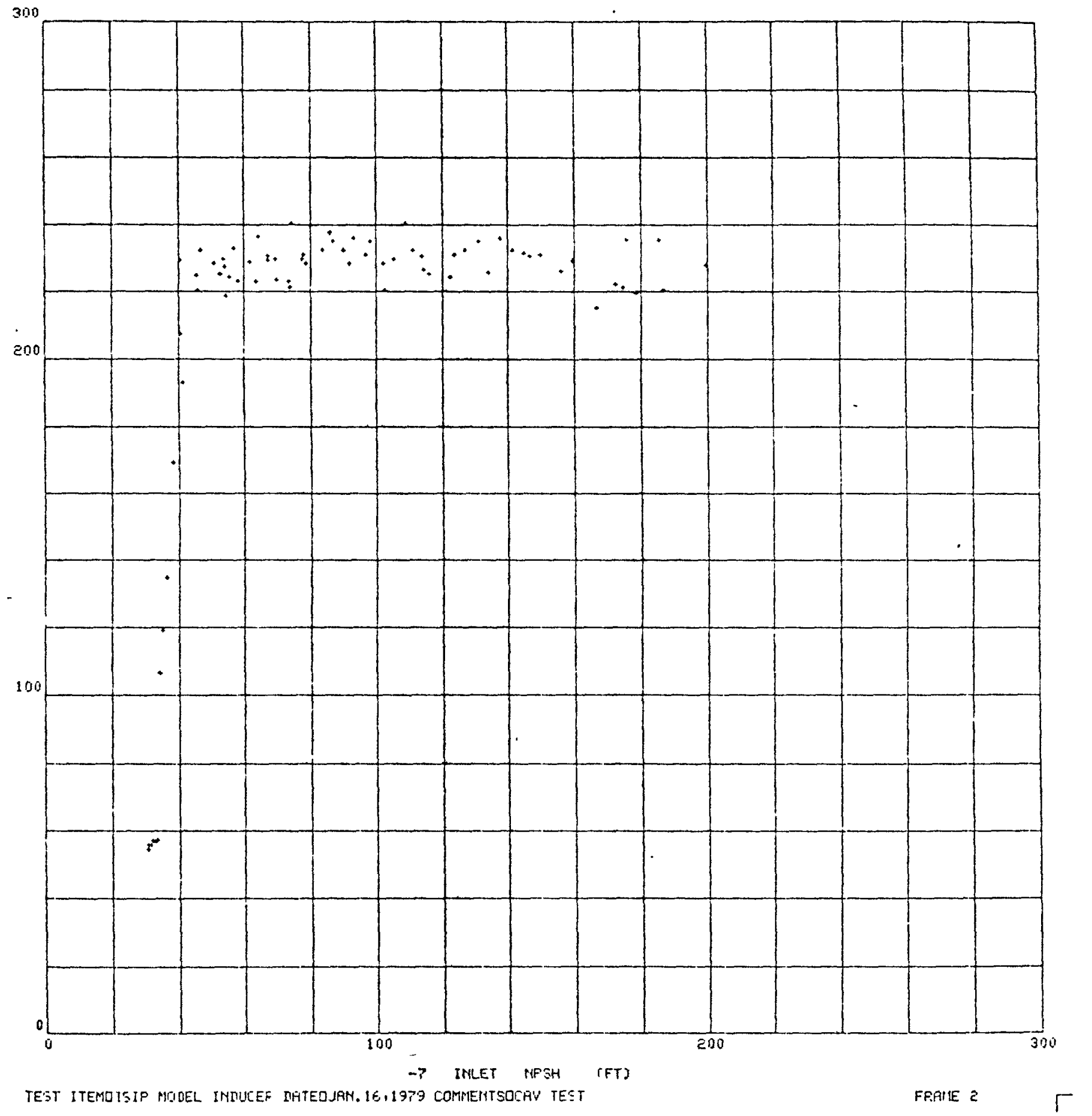

FIGURE 8. CRT GRAPHIC DISPLAY SHOMING HEAD RISE VS。 NPSH

TIP CLEARANCE ECCENTRIC MIN. .007 IN. - MAX .021 IN. FLOW: 100 PEPCEITT OF DESIGN FLOW 
ISIP MODEL INDUCER

WATER TEST RESULTS

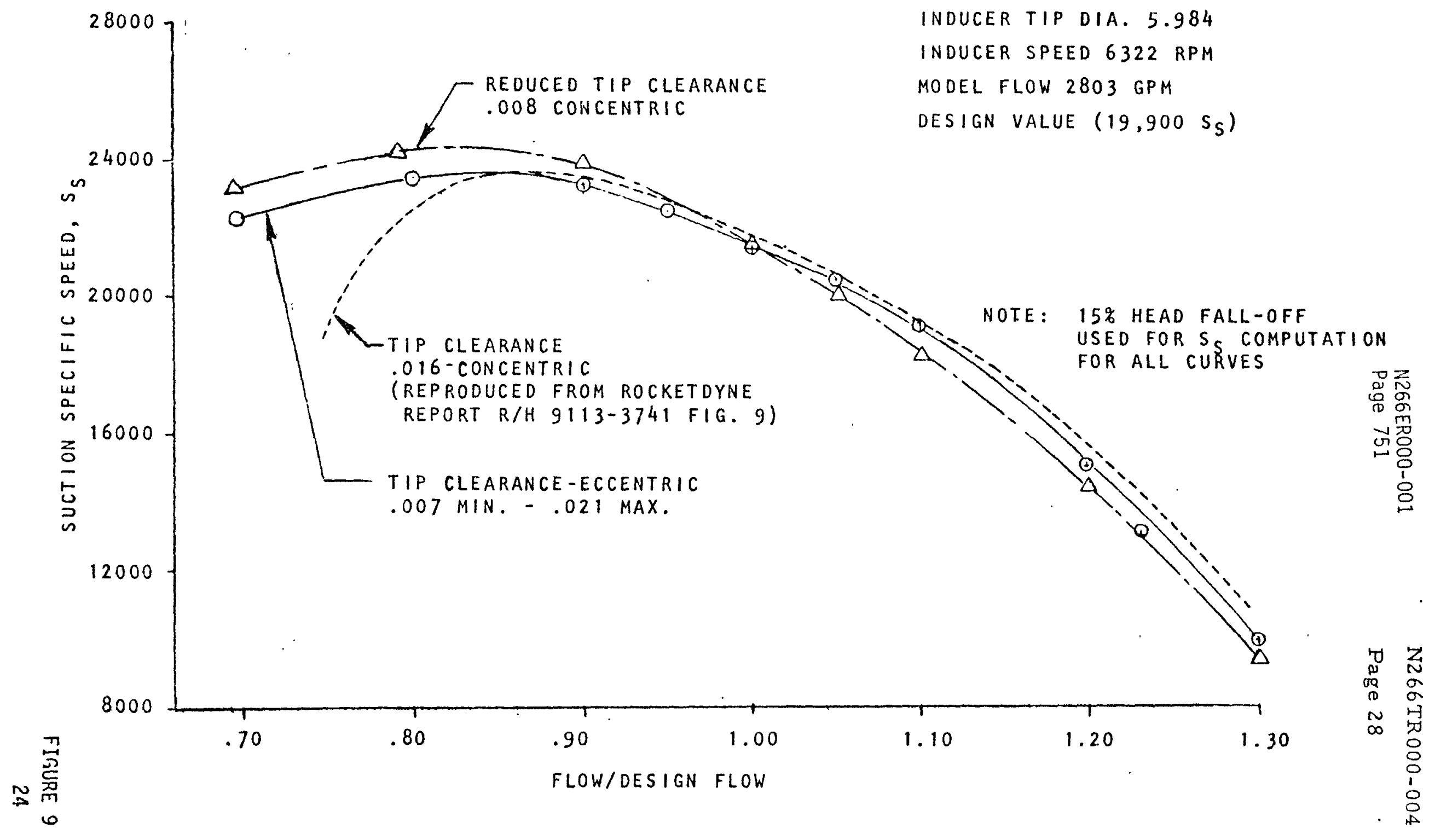


three curves. The eccentric ciearance setup exhibited somewhat better suction performance at the lower flows.

The reduced tip clearance setup also improved suction performance at flows below design flow. This resuit conforms with tests on other inducers.

At flows below approximately 85 percent of design flow there is an increase in tip leakage which flows opposite to the main flow direction and has an angular whirl velocity which is approximately one-half the inducer angular velocity. It mixes with the oncoming flow and imparts some angular velocity to it. This pre-whirl plus other flow disturbances usually cause a degradation in suction performance. Any tip clearance reduction which reduces this back flow improves the suction performance.

Inducer Internal Performance

In addition to the upstream piezo ring, static pressure tap, and the downstream kiel total pressure probe, the test instrumentation consisted of wall static pressure taps which were located at various axial and circumferential locations between the leading and trailing edges of the inducer as shown in Fig. 4. The data obtained from these pressures are presented in Fig. 10 and 11 .

Figure 10 shows data obtained during an $\mathrm{H}-\mathrm{Q}$ run. The inlet pressure was high enough to prevent cavitation head loss at all flows which were tested. At design flow, the measured head rise increased almost linearly from the 
ISIP MODEL INDUCER

PRESSURE TAP LOCATIOHS

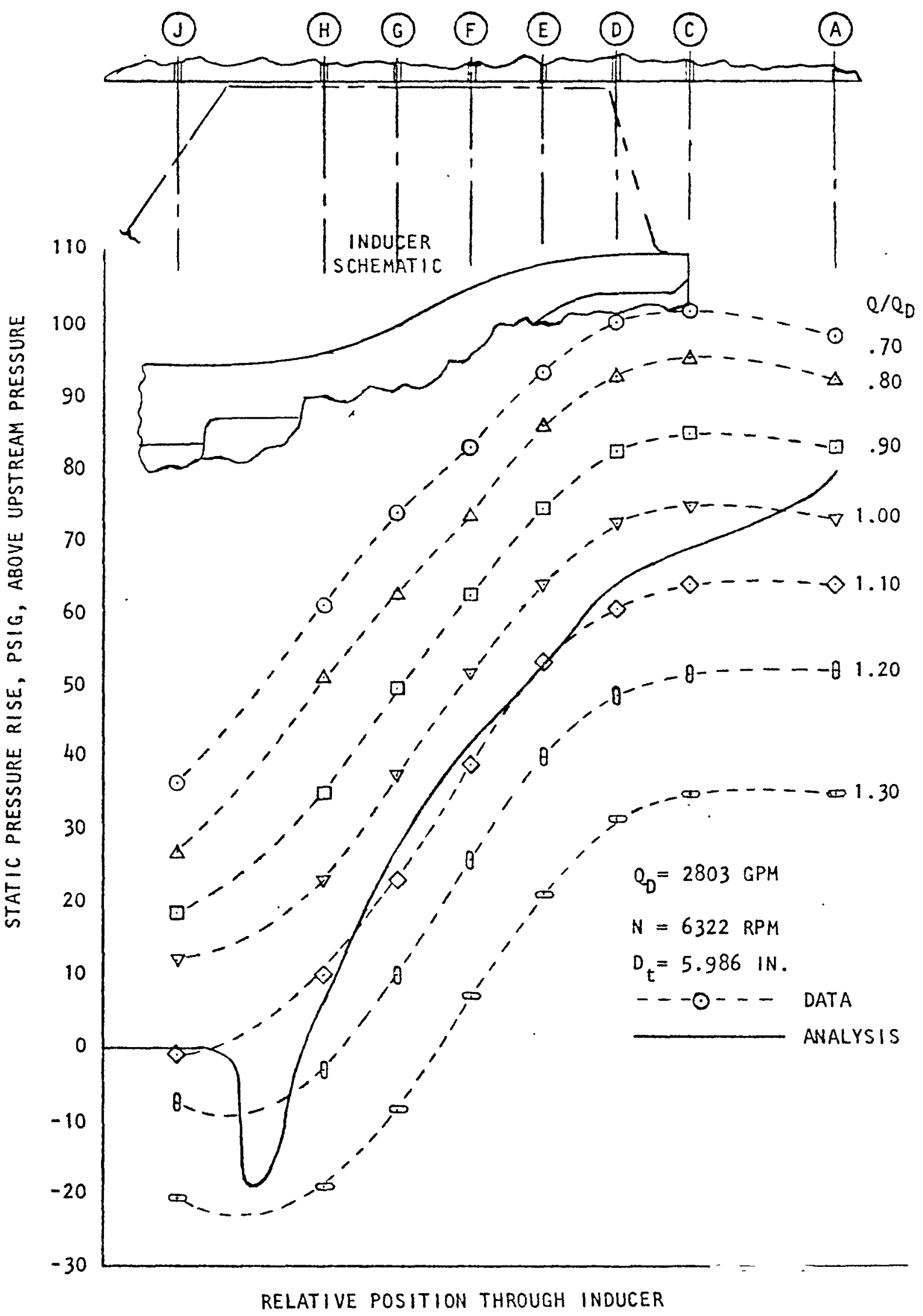


leading edge to within 0.50 inch of the trailing edge measured axially along the tip. Aft of this point the rate of pressure rise gradualty diminished to zero.

The performance was in full agreement with theoretical predictions based on a quasi-three-dimensional mathematical model. The negative pressure which occurs at station $J$ is due to hub blockage which causes a static pressure drop as compared to conditions which revait in front of the inducer.

It may also be noticed that the front part of the inducer (between the leading edge and station $H$ ) performs like a turbine at flows above $Q / Q_{\text {Design }}$ equals 1.10. A survey of the theoretical blade incidence angles leads to an expectation of zero or negative pressure rise at high flows in this area.

Figure 10 also shows predicted pressure rise at design flow based on auasithree-dimensional analysis.

The predicted data show a sharp pressure drop just aft of the leading edge. This curve dip is primarily due to the limitations of the math modeling analysis but is partially explained by a rapid rate of increase in blockage just aft of the leading edge without a corresponding change in blade angle. This dip could not be defined precisely by experimental data due to lack of a pressure tap at the affected axial location.

Figure 11 shows the data obtained during a cavitation run at design flow. 
STATIC PRESSURE RISE VS INLET NPSH

AS MEASURED ALONG VARIOUS AXIAL LOCATIONS

MODEL ISIP INDUCER - EXPERIMENTAL DATA

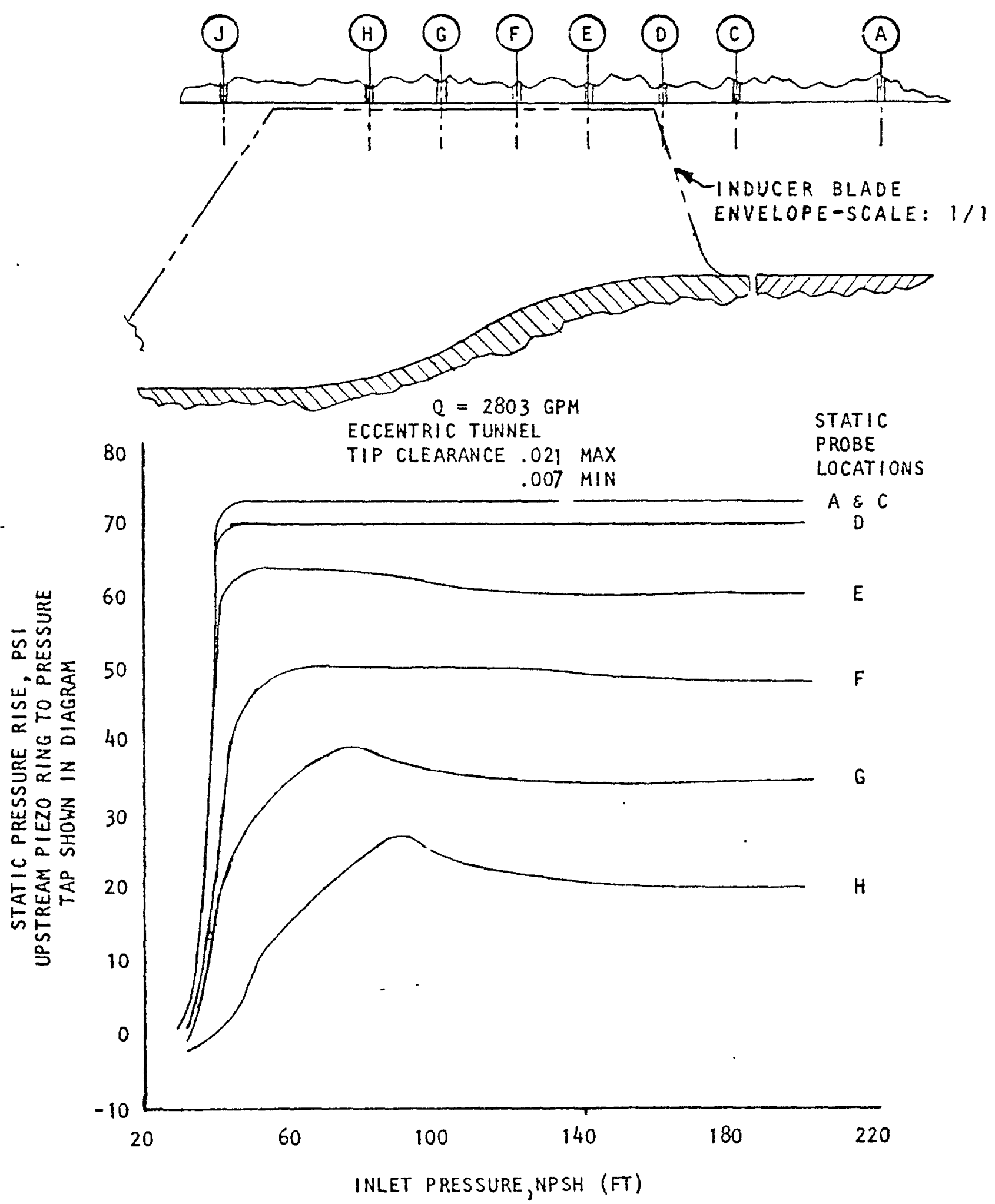

FIFIIRE 11 
It confirms performance predictions that; at certain operating conditions just above the critical NPSH the decreased head rise due to partial cavitation in the front part of the inducer is fully compensated by increased head rise in the aft part of the inducer. This phenomenon occurs in this test approximately between inlet NPSH values of between 45 and 60 feet. The reason for the rise in pressure above the non-cavitating pressure at stations $G$ and $H$ cannot be ascertained at this time. One possible reason is that localized increased pressure rise may occur just aft of the trailing boundary of the blade suction side cavity.

The most useful data shown in Figure 11 reveals that cavitation of sufficient magnitude to effect a shift in wall static pressures occurs at 120 feet of NPSH which is 200 percent above the critical NPSH of 40 feet at design flow.

An examination of the data at 80 percent of design flow shows that this pressure shift near the front part of the inducer also first occurs at approximately 200 percent above the critical NPSH.

Further examination of the data at 120 percent of design flow shows that this pressure shift between critical NPSH and 200 percent above critical NPSH virtually disappears since the forward part of the inducer has only a small head rise even in the non-cavitation operating regime.

\section{Motion Picture Test Data}

During the cavitation testing, photographic movies were taken to permit 


\section{Page 34}

observation of tip vortices and blade cavities as inlet pressure was being reduced. Tip vortices could easily be seen but blade suction side cavities were very difficult to observe due to turbulence. The pulse camera took approximately one picture for each five inducer revolutions. A pressure gage was mounted within the picture to provide direct correlation between inlet pressure and vortex generation. Figure 12 presents the ratio of the head divided by the non-cavitating head as a function of inlet pressure and NPSH with flags to indicate where the still photographs were taken. The photographs in this report include only those which were taken during the design flow run and are shown in Figures 13 through 16.

\section{Life Test Results}

Tests by other researches have shown that cavitation damage caused by collapsing vapor bubbles on the pump rotor surface is less in water than in sodium. The magnitude of the variation has been quoted at different levels ranging from two orders of magnitude (Ref. 3) to a factor of approximately 3.0 (Ref. 4). Part of this difference was compensated for in the water tests of the model by testing at a higher inducer tip speed. Laboratory measurements of the effect of tip speed have not been totally consistent, but the majority of the data appear to support the dependency of damage on the sixth power of the velocity. The model inducer was tested with a tip speed of 165.1 feet per second (fps) compared to 89.7 fps for the ful1size pump in sodium. Using the sixth-power relationship, this is equivalent to a damage rate 39 times faster due to the higher tip speed of the model. 


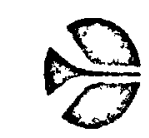

굼웅

畒

ำ ริ

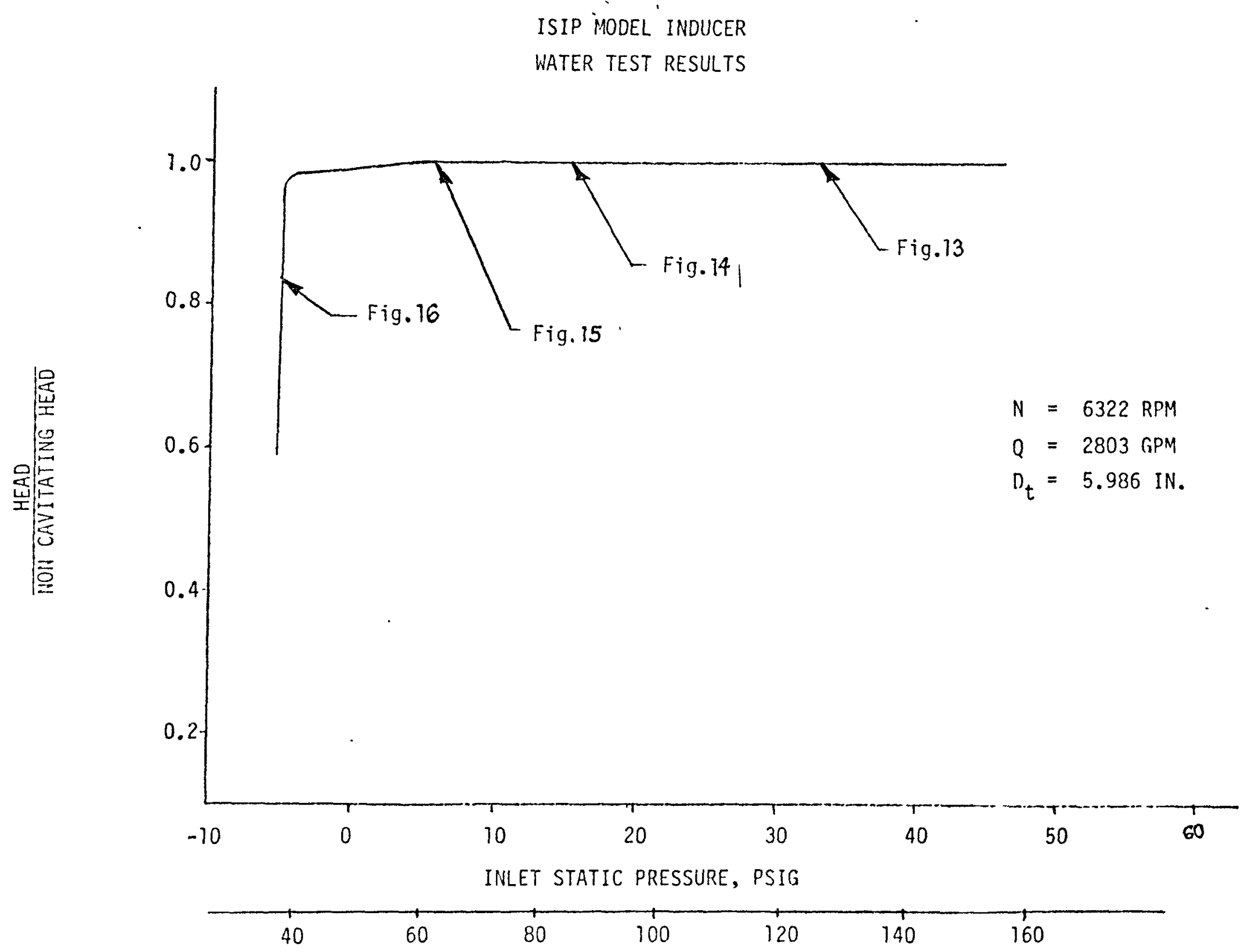


However, the advantage of performing life tests with dye coatings is that the test is not attempting to identify and/or match damage rates. No attempt is made to measure the extent of damage and scale the rate to predict rate of failure of the full-size hardware. The dye test is designed to identify any potential region of cavitation damage regardless of rate. It takes very little time for a cavity bubble collapsing on the blade to remove the dye. Therefore, for a long-life design, no dye removal would be expected, and the dye test would have to verify that condition. Rocketdyne's design approach is to design to eliminate any cavitation collapse on the inducer blades over the operating range.

Tables 3 and 4 present the various operating conditions tested with dye, indicating both the target and actual test conditions. The flow was varied from approximately 70 to 130 percent of design flow, and the NPSH margin was varied for some flows. There was no dye removal above 80 percent of design flow, substantiating the long-life design. features of this inducer. In fact, the I.S.I.P model inducer showed a greater flow range for no dye removal due to cavitation than any previous inducer tested to date. The dye tests would indicate that long life could be expected in the sodium testing for flows varying from 90 to 130 percent of design flow and over a significant NPSH range. This provides the very highest confidence in the sodium testing, paricularly considering the large difference in tip speeds between model and full-size.

The only way to document the results of the dye tests is through photographs of the blades post-test. Such photographs were made of each inducer 


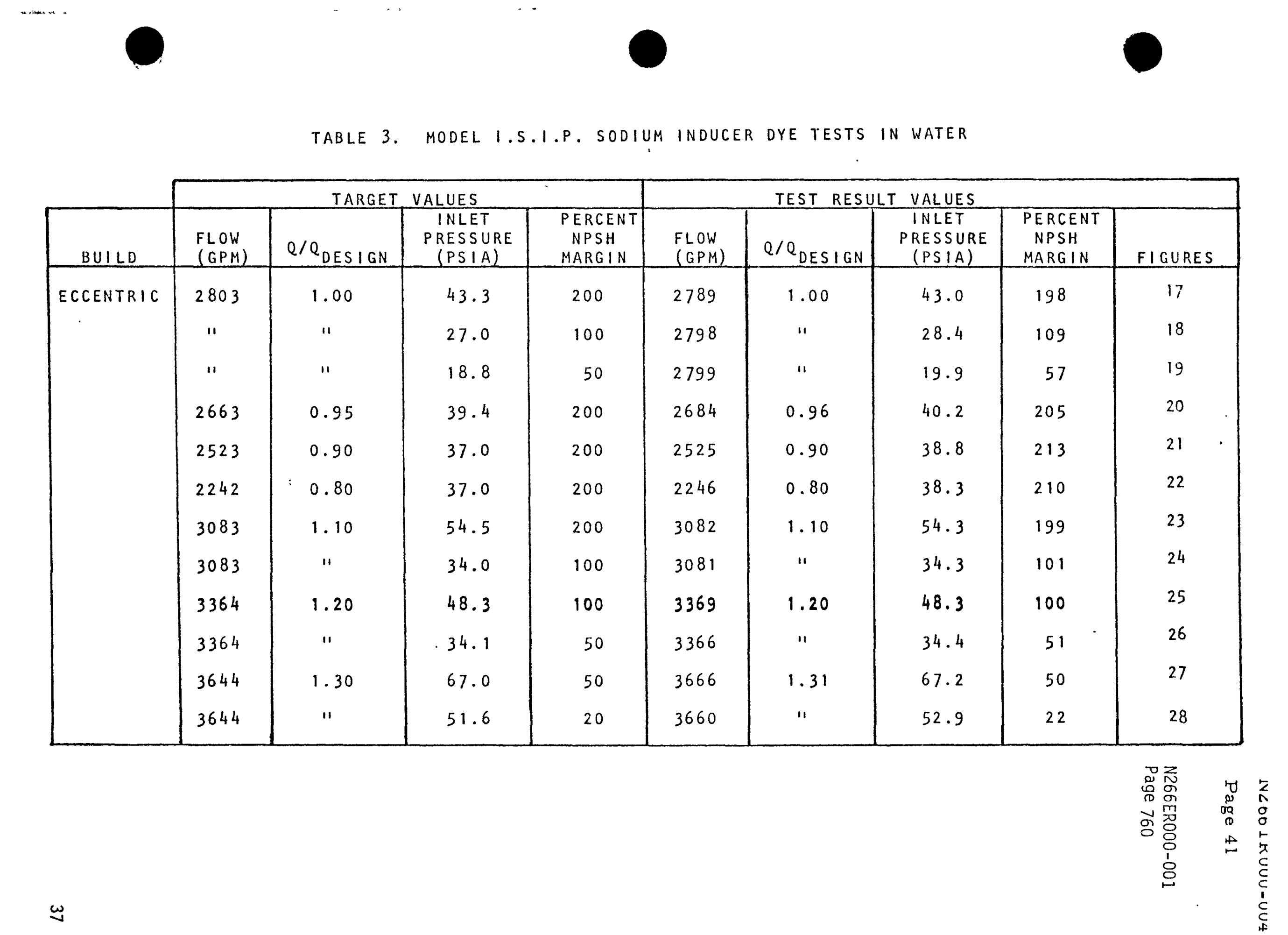


TABLE 4. MODEL, 1.S.I.P. SODIUM INDUCER DYE TESTS IN WATER

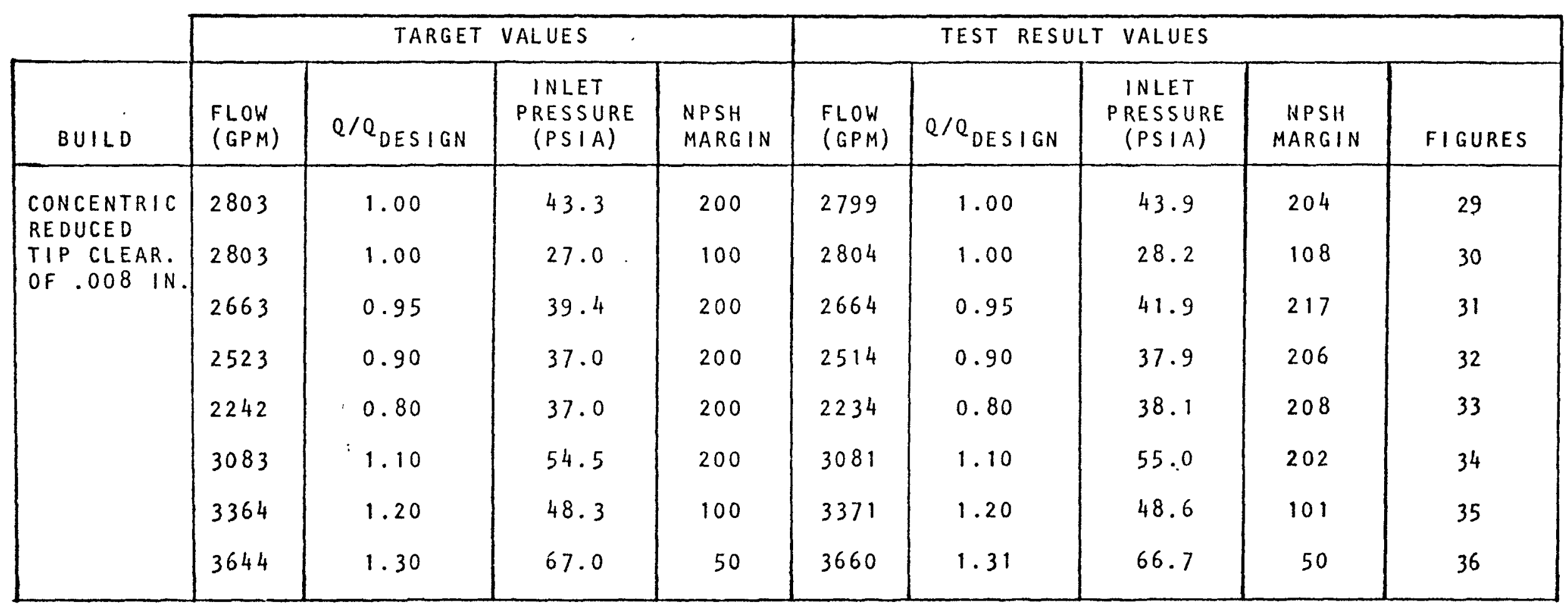


blade for each test (Table 3). The photographs are not ideal in that light. reflections and dye streaking that occurred when the blade was originally coated can appear as dye removal when no such removal was experienced. Nevertheless, it is instructive to include representative photographs to verify the results. Photographs were taken of each of the four blades of the inducer after each of the tests of Table 3. Reproductions of all of the photographs would be an unnecessary expense, but a representative photograph from each test is shown in Figures 17 through 37. A mirror was used behind the inducer to show the backside of the blades.

Many pictures have large white areas on the inducer. These white areas are due to light reflection of the photographers flash from the glossy inducer surface. The tips of the blades were not coated to prevent smearing of dye on the plastic tunnel. In many cases the inducer blades suffered accidental scratch marks due to foreign matter, such as scale, circulating within the water tunnel loop. These scratch marks are not to be confused with erosion due to cavitaion action. A typical effect of this scratch erosion may be seen in Figure 36.

In contrast a typical example of dye erosion due to cavitaion action may be seen in Figure 22. Cavitation erosion was expected to occur during this test since the flowrate was maintained at 70 percent of design flow. 


\section{CONCLUSION}

The test program discussed in the Rocketdyne report Ref. 2 revealed that the I.S.I.P. inducer has exceeded all design objectives if installed concentrically with the housing and using a scaled down concentric tip clearance. The test program in this report has revealed that if the model size inducer is mounted eccentrically by approximately 0.007 inch due to manufacturing tolerance buildup, the performance of the inducer will not degrade or be subject to increased cavitation action as demonstrated by the test data shown in this report.

This test program also consisted of an experimental setup in which the I.S.I.P. inducer tip clearance was reduced by approximately 50 percent to .008 inch and concentric. The resulting slight improvement in head rise performance could be considered negligible in the overall pump performance.

There was an improvement in suction performance at 70 percent to 80 percent of design flow. However in this operating regime blade dye removal occurred and the inducer should not be operated for extended periods in this flow range. Severe rubbing marks were discovered in the aluminum sleeve after disassembly of this close tip clearance setup. This does not necessarily signify that rubbing would also occur in the complete pump since the latter may have greater shaft rigidity. However, in the overall picture, it appears that the slight gain in inducer performance does not warrant the increased risk of inducer rubbing against the housing bore. The life tests for the reduced tip clearance installation showed virtually no difference 
in cavitation action on the inducer as compared to the normal tip clearance installation as evidenced by dye removal tests. 


\section{REFERENCES}

1. G. M. Wood, R. S. Kulp, J. V. Altieri, Jr., Pratt \& Whitney, "Aircraft-CANEL Symposium on Cavitation in Fluid Machinery", November 1965.

2. E. D. Jackson, Rockwell International, Rocketdyne Division, "Intermediate Sodium Inducer Pump Model Inducer Water Tunnel Test Report", R/H 9113-3741, 9 February 1979.

3. Y. S. Cha and R。L. Miller, "Comparative Studies of Cavitation Inception and Damage in Water and Sodium Using Venturis," Proceedings of Joint Symposium on Design and Operation of Fluid Machinery, Vol. II, June 1978 Symposium at Colorado State University, Fort Collins, Colo., sponsored by ASCE, IAHR/AIHR, ASME

4. Y. S. Cha and P. R. Huebotter, "Final Report and Design Guide for Cavitation-Free LMFBR Hydraulic Components" Technical Memorandum, ANL-CT-78-7, October 1977. 